Universidad de Lima

Facultad de Ingeniería Industrial

Carrera de Arquitectura

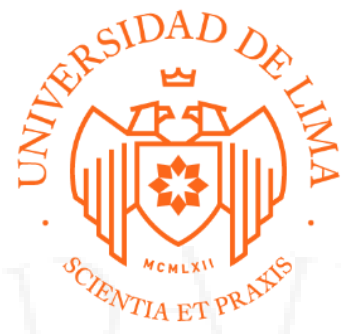

\title{
FÁBRICA CULTURAL
}

\section{RECICLAJE DE UNA FÁBRICA EN DESUSO EN EL BORDE DE LA BAHÍA DE CHIMBOTE}

Trabajo de suficiencia profesional para optar el Título Profesional de Arquitecto

Proyecto de Fin de Carrera

\section{Ximena De Olazábal Coz}

Código 20120412

\section{Alessandra Gudila Rodríguez Mercado \\ Código 20121116}

\author{
Asesor \\ Diego Franco Coto \\ Lima - Perú
}

Octubre de 2019 
(Hoja en blanco) 


\section{FÁBRICA CULTURAL}

RECICLAJE DE UNA FÁBRICA EN DESUSO EN EL BORDE DE LA BAHÍA DE CHIMBOTE 


\section{TABLA DE CONTENIDO}

CAPÍTULO I: GENERALIDADES .........................................3

1.1 Tema

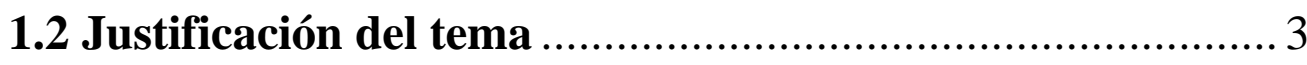

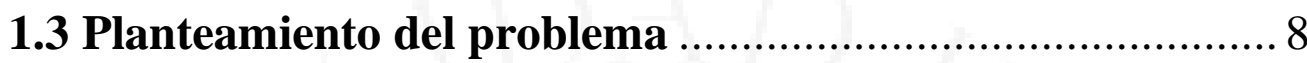

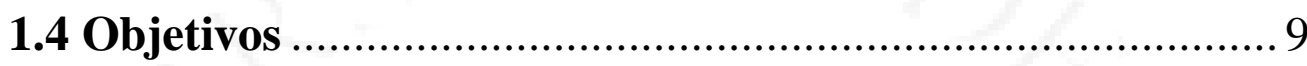

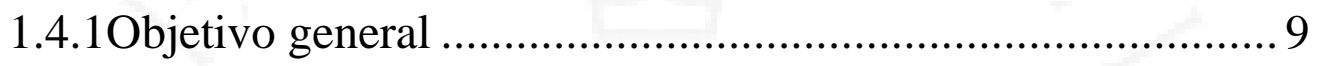

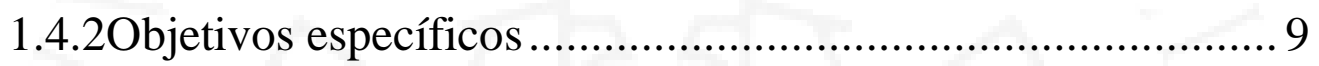

1.5 Supuesto básico de la investigación ..................................... 10

1.5.1Fábrica Cultural como equipamiento en sí ............................ 10

1.5.2Fábrica Cultural como regenerador urbano ........................... 10

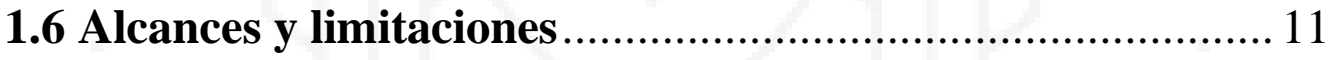

1.6.1 Alcances de la investigación ................................................ 11

1.6.2Limitaciones de la investigación .......................................... 12

1.6.3Alcances del proyecto ....................................................... 12

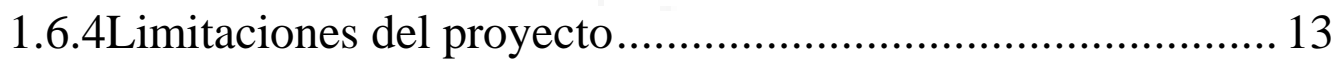

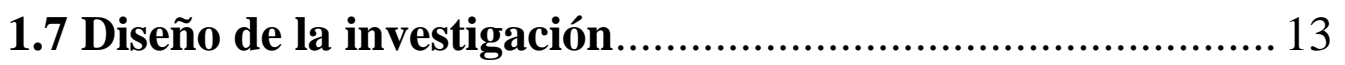

1.8 Metodología de la investigación ........................................ 14

1.8.1Forma de consulta de la información .................................... 14

1.8.2Forma de recopilación de la información............................... 14 
1.8.3Forma de análisis de la información

1.8.4Forma de presentación de la información .............................. 15

CAPÍTULO II: MARCO HISTÓRICO - REFERENCIAL..... 16

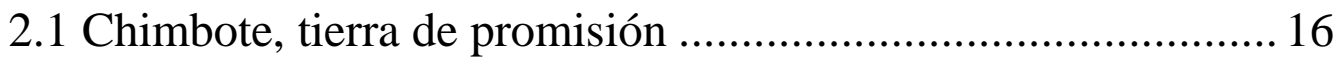

2.1.1Ubicación geográfica de Chimbote y la bahía El Ferrol ........ 16

2.1.2Del mar a la ciudad: Inicios como ciudad puerto .................. 20

2.1.3Aproximaciones a la planificación urbana de Chimbote ........32

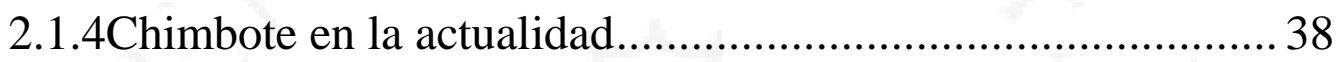

2.1.5Identidad chimbotana y manifestaciones culturales .............. 42

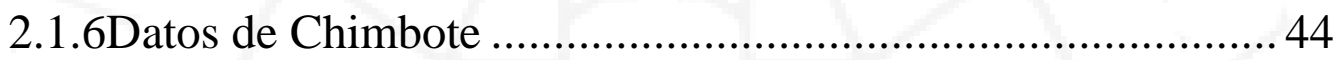

2.2 Centros Culturales en tres panoramas distintos .......................58

2.2.1Primeros espacios culturales en el mundo.............................58

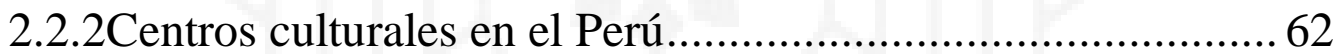

2.2.3Asociaciones y centros culturales en Chimbote ....................69

2.3 Regeneración de puertos y transformación de frentes costeros 71

2.4 De lo inactivo al nuevo uso: reciclaje arquitectónico ............... 78

2.4.1Reciclaje arquitectónico industrial ....................................... 79

2.5 Línea de tiempo de la historia y evolución de Chimbote, Centros Culturales y la reactivación de frentes costeros....................... 84

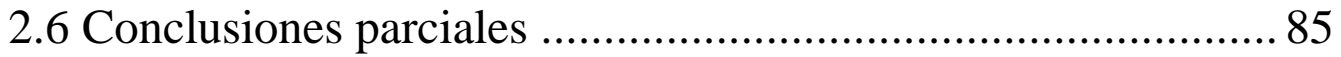

CAPÍTULO III: MARCO TEÓRICO..........................................8 87

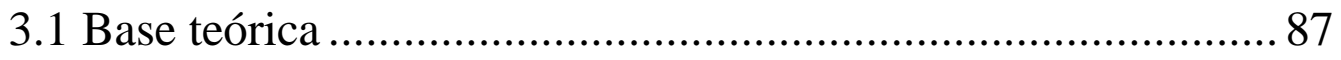




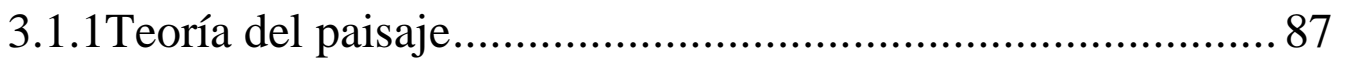

3.1.2Teoría del urbanismo a escala humana................................... 97

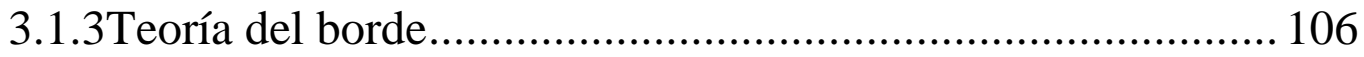

3.1.4Teoría de Regeneración Urbana............................................ 109

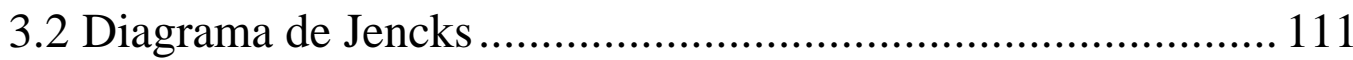

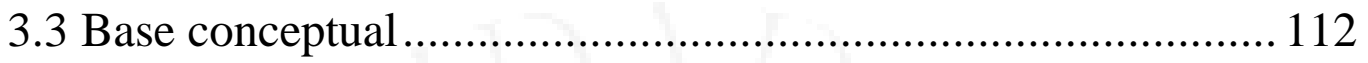

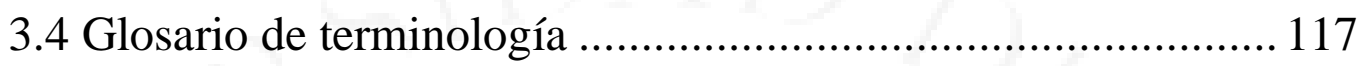

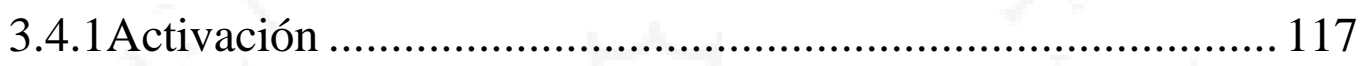

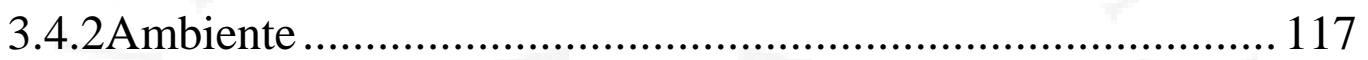

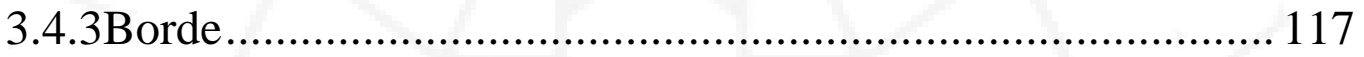

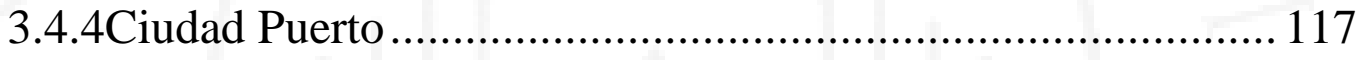

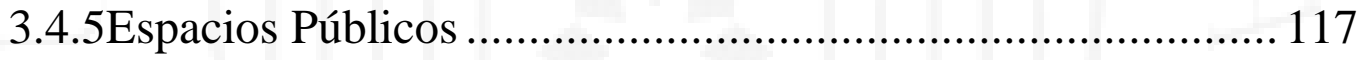

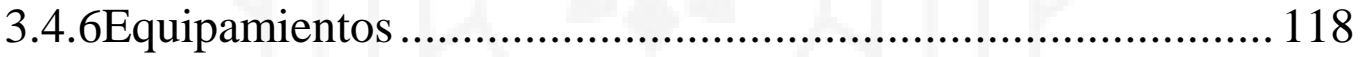

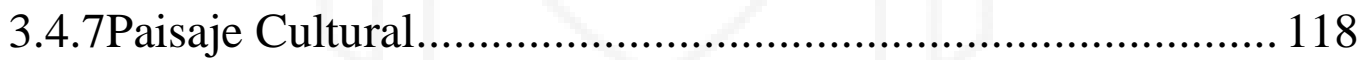

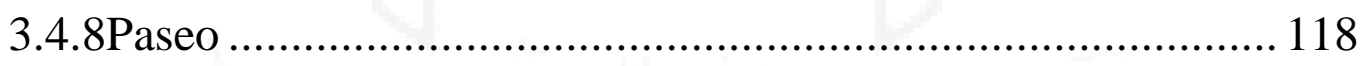

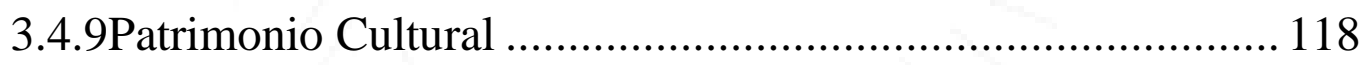

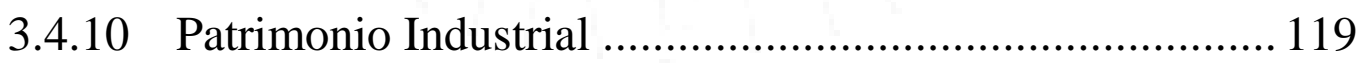

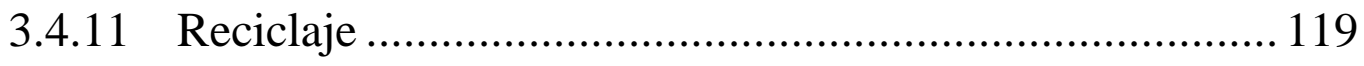

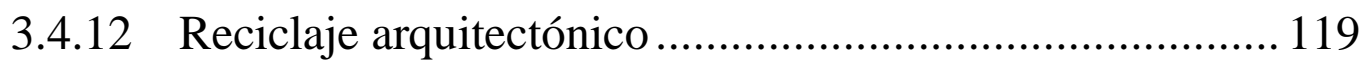

3.4.13 Reconversión portuaria …............................................... 119

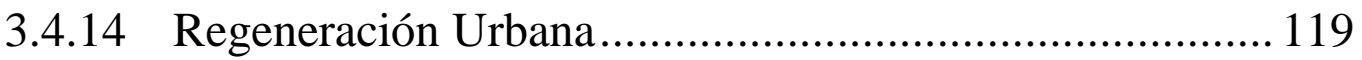

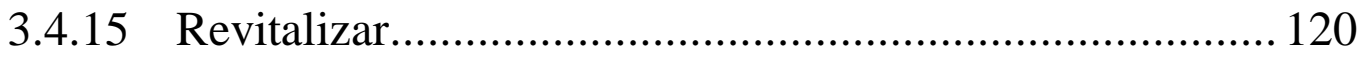




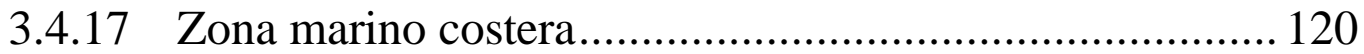

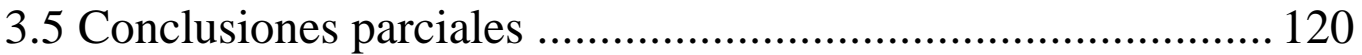

CAPÍTULO IV: MARCO NORMATIVO ...................................122

4.1 Estándares normativos Nacionales...................................... 122

4.1.1Reglamento Nacional de Edificaciones............................... 122

4.1.2Plan de Desarrollo Urbano de la Ciudad de Chimbote 2012-2022

4.1.4Proyecto de Ley de gestión sostenible e integrada de las zonas marino costeras del Perú y estable el marco para su protección, recuperación, mantenimiento y aprovechamiento sostenible

4.1.5Lineamiento de Políticas Integradas Marino Costeras........... 126

4.2 Estándares normativos Internacionales ................................. 126

4.2.1Agenda 2030 para el Desarrollo Sostenible ......................... 126

4.2.2Objetivo de Desarrollo Sostenible 11: Ciudades y comunidades sostenibles 126

4.2.3Guía de consulta: introducción a la gestión e infraestructura de un Centro Cultural Comunal....................................................... 127

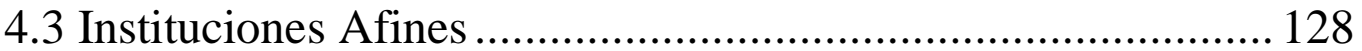

4.3.1Municipalidad Provincial del Santa (MPS) .......................... 128

4.3.2Ministerio del Ambiente ......................................................... 128

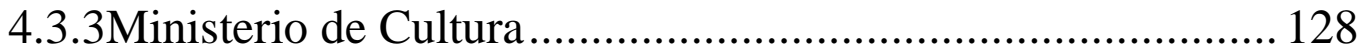


5.1 Referentes Análogos

5.1.1Kanal Centre Pompidou

5.1.2SESC Pompeia 148

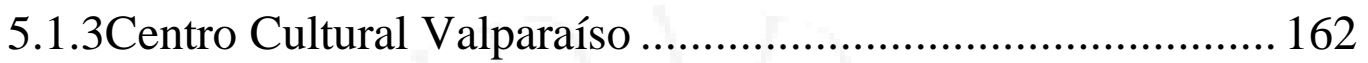

5.1.4Escuela de Artes Le Fresnoy............................................... 178

5.2 Referentes de Estrategias Proyectuales ................................. 190

5.2.1Biblioteca Regional Joaquín Legina y Archivo Regional de la Comunidad de Madrid 190

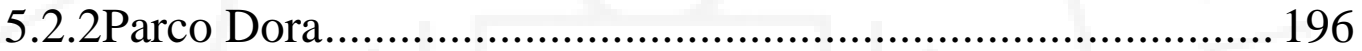

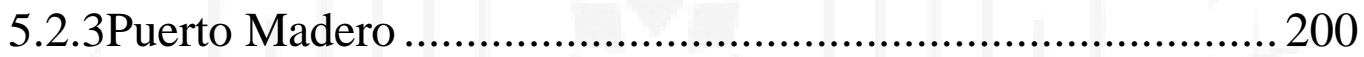

5.3 Resumen de referentes análogos ...........................................203

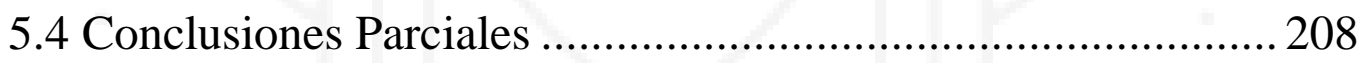

CAPÍTULO VI: MARCO CONTEXTUAL ................................ 210

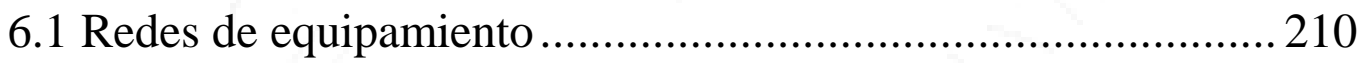

6.1.1Chimbote en relación a la provincia del Santa ..................... 210

6.1.2Redes de equipamiento en Chimbote ....................................211

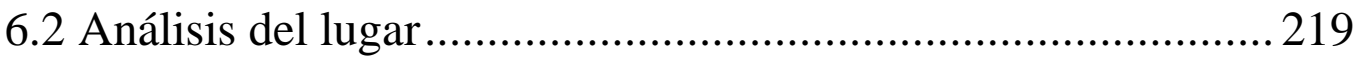

6.2.1Características de las construcciones de la zona....................219

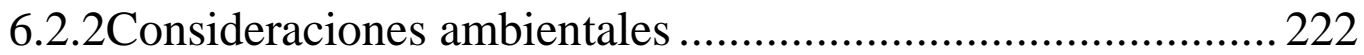

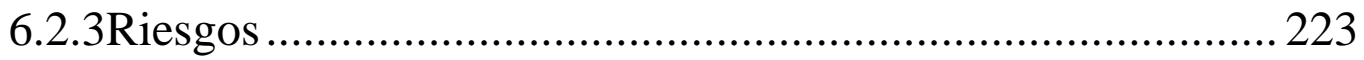


6.2.4Limitaciones normativas

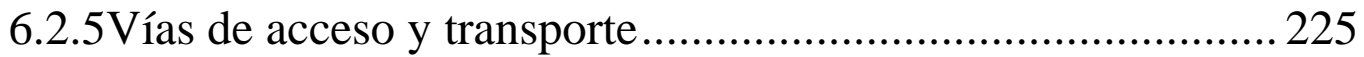

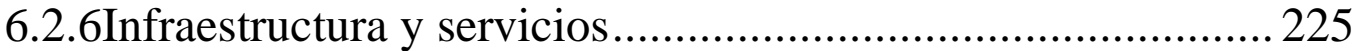

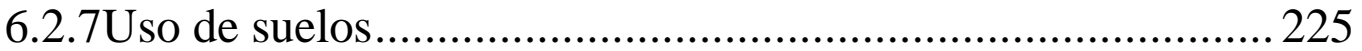

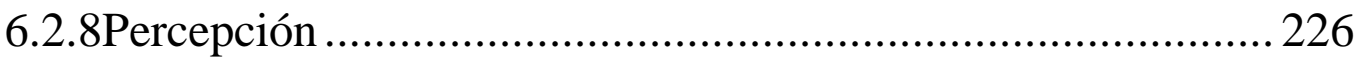

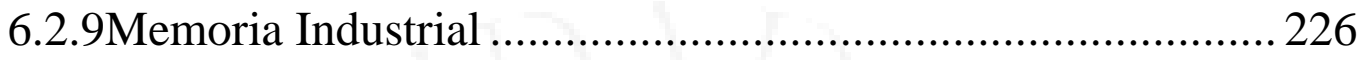

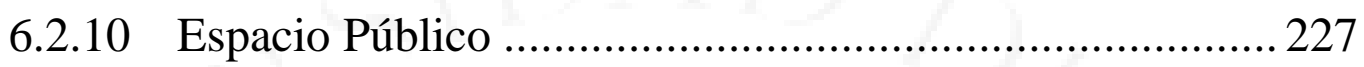

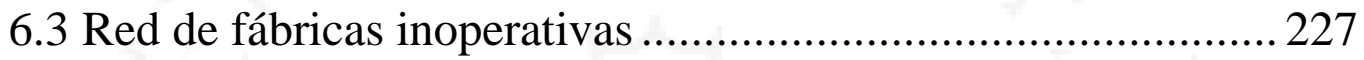

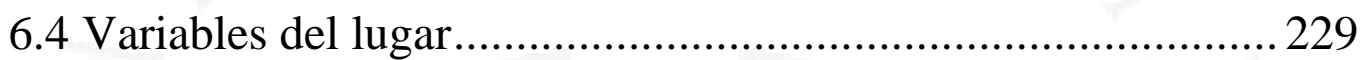

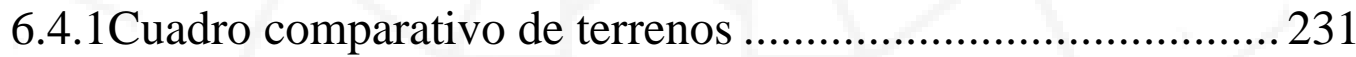

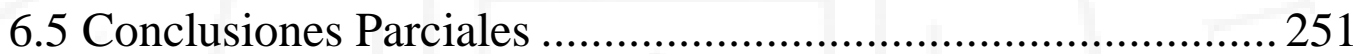

CAPÍTULO VII: CONCLUSIONES FINALES.........................253

CAPÍTULO VIII: PROYECTO FÁBRICA CULTURAL ........ 255

8.1 Fábrica de conserva y harina de pescado ...............................255

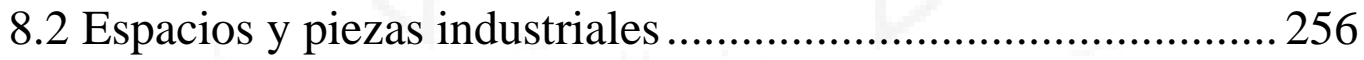

8.3 Proceso productivo de la fábrica ............................................. 261

8.4 Organización espacial de las preexistencias .............................265

8.5 Reciclaje como medio para revalorar y fortalecer la identidad

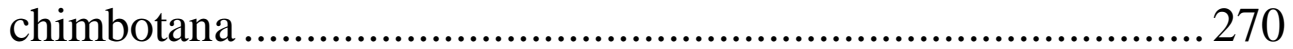

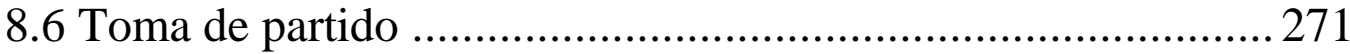

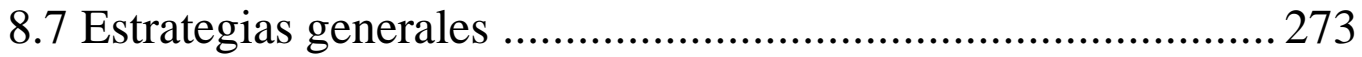

8.8 Estrategias específicas del proyecto ....................................278 


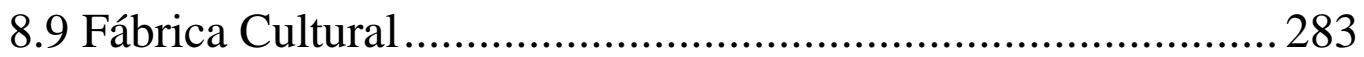

8.10 Sistema Fábrica Cultural......................................................283

8.11 Exploración espacial de galpones ......................................28 288

8.12 Exploración espacial de tanques .........................................289

8.13 Manual de ensamblaje .....................................................290

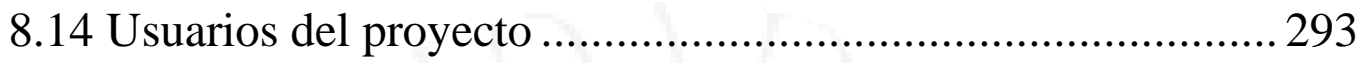

8.14.1 Encuestas a alumnos de la I.E N $88008 \ldots \ldots \ldots \ldots \ldots \ldots \ldots \ldots . . .294$

8.15 Programa arquitectónico ....................................................296

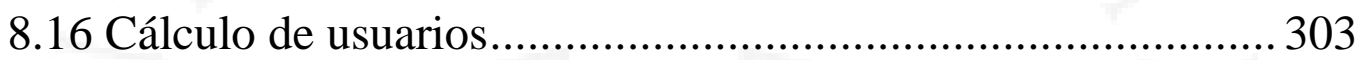

8.17 Programa con cabida distribuido en galpones ....................... 303

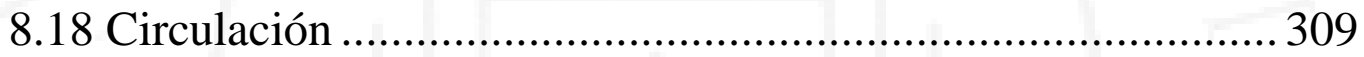

8.18.1 Circulación rápida y circulación lenta .............................310

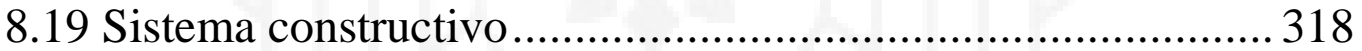

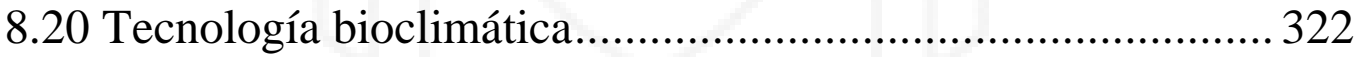

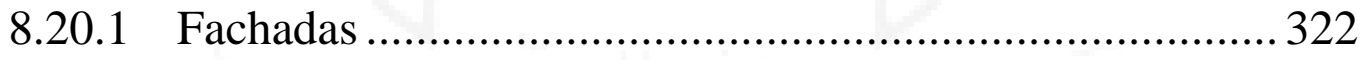

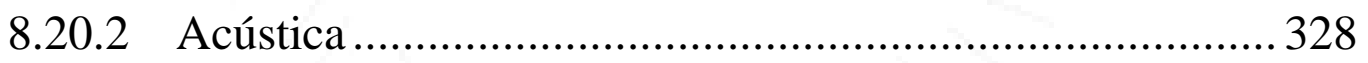

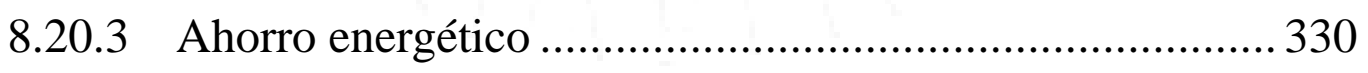

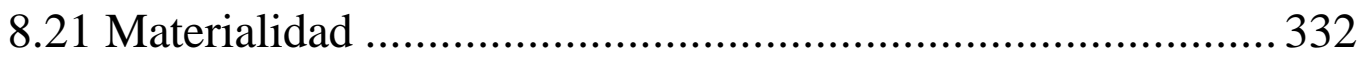

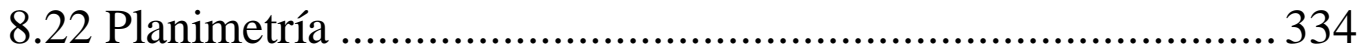

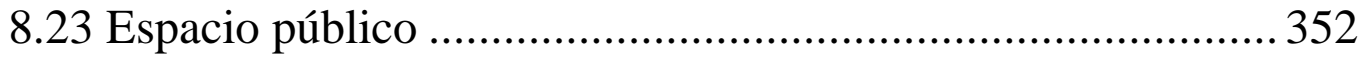

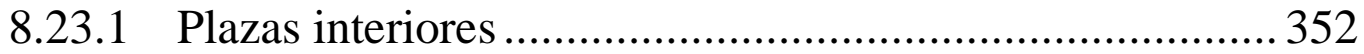

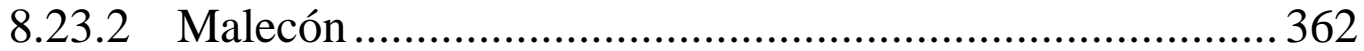


8.24 Relación del proyecto con el mar

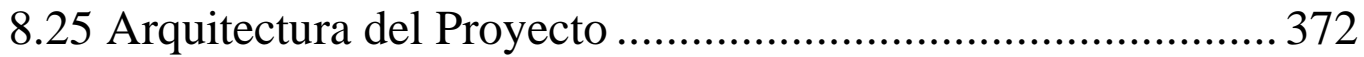

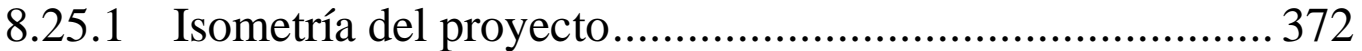

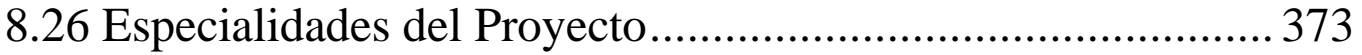

8.26.1 Memoria descriptiva de estructuras ............................... 373

8.26.2 Memoria descriptiva de Instalaciones Sanitarias ............. 374

8.26.3 Memoria descriptiva de Instalaciones Eléctricas ..............375

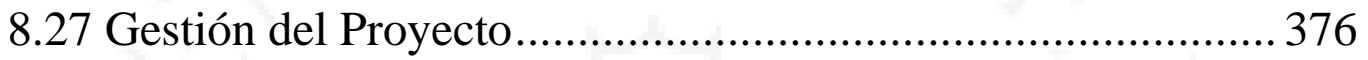

8.27.1 Sostenibilidad económica, social y ambiental ..................376

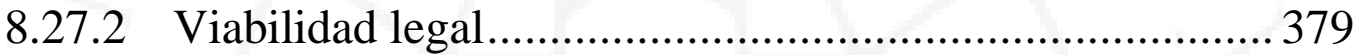

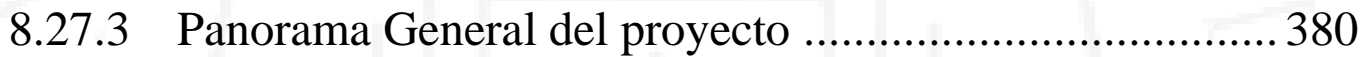

8.27.4 Gestión del tiempo del proyecto....................................... 383

8.27.5 Gestión económica - financiero ....................................... 384

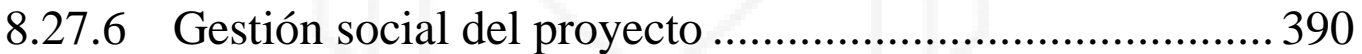

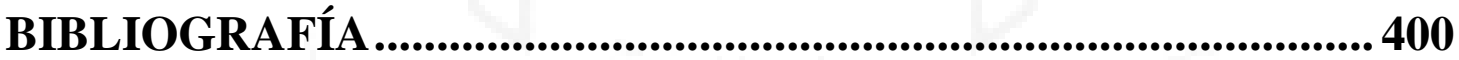




\section{ÍNDICE DE TABLAS}

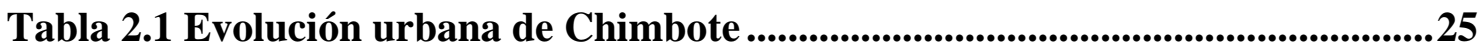

Tabla 2.2 Prognosis del desarrollo demográfico de Chimbote (1972 - 1990) ...........37

Tabla 2.3 Población de Chimbote y Nuevo Chimbote ................................................45

Tabla 2.4 Grupo de edades de la población de Chimbote .............................................46

Tabla 2.5 Crecimiento poblacional de Chimbote y Nuevo Chimbote ..........................46

Tabla 2.6 Población por sectores urbanos según números de viviendas ..................47

Tabla 2.7 PBI de Chimbote por sectores ...........................................................................49

Tabla 2.8 Ubicación de Chimbote dentro de los 20 distritos con mayor acumulación de basura ...................................................................................52

Tabla 2.9 Fuentes de acumulación de residuos sólidos...............................................56

Tabla 2.10 Lista de Centros Culturales por departamento, provincia y distrito en el Perú ..........................................................................................................................64

Tabla 6.1 Población total de la provincia del Santa ...............................................210

Tabla 8.1 Programa arquitectónico por áreas ...........................................................300

Tabla 8.2 Tabla de porcentaje de circulación por niveles...........................................311

Tabla 8.3 Tabla de porcentaje de circulaciones por niveles .................................311

Tabla 8.4 Presupuesto referencial del proyecto ......................................................386

Tabla 8.5 Recuperación de la inversión ........................................................................386

Tabla 8.6 Monto recuperado por año ................................................................387

Tabla 8.7 Cantidad de alumnos inscritos por talleres .............................................392 


\section{ÍNDICE DE ILUSTRACIONES}

Ilustración 1.1 Bahía de Chimbote alrededor de los años 60 - 70...............................4

Ilustración 1.2 Vista de la forma cóncava de la bahía desde el Cerro de la Paz........5

Ilustración 1.3 Relación de la ciudad con la bahía..................................................5

Ilustración 1.4 Paisaje pesquero de Chimbote ................................................................66

Ilustración 2.1 Ubicación de Chimbote a nivel nacional y departamental ................ 16

Ilustración 2.2 Ubicación de Chimbote con respecto a la provincia del Santa .......17

Ilustración 2.3 Límites geográficos de la ciudad de Chimbote .................................18

Ilustración 2.4 Características generales de la Bahía El Ferrol ...............................19

Ilustración 2.5 Vista del Hotel Chimú, hotel de turistas, desde la bahía El Ferrol 21

Ilustración 2.6 Calles de Chimbote en plena producción de las fábricas pesqueras

Ilustración 2.7 Vista de Chimbote en 1906 .......................................................................24

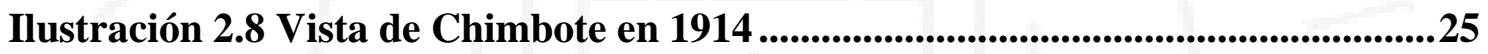

Ilustración 2.9 Tejido urbano de Chimbote en 1872 ..............................................26

Ilustración 2.10 Tejido urbano de Chimbote en 1930 ............................................27

Ilustración 2.11 Tejido urbano de Chimbote en 1950 ..........................................28

Ilustración 2.12 Tejido urbano de Chimbote en 1970 .................................................29

Ilustración 2.13 Tejido urbano de Chimbote en 1990 ..............................................30

Ilustración 2.14 Tejido urbano de Chimbote en 2010 ......................................................31

Ilustración 2.15 Plano de Chimbote propuesto por Meiggs en 1906 ...........................32

Ilustración 2.16 Plano de Chimbote propuesto por Meiggs en 1872 ...........................33

Ilustración 2.17 Vista del Plan Regulador de Sert y Wiener ....................................34

Ilustración 2.18 Propuesta de casa patio del Plan Regulador.....................................35

Ilustración 2.19 Elevación de la casa patio del Plan Regulador ...............................35

Ilustración 2.20 Vista aérea del Plan Regulador .......................................................35

Ilustración 2.21 Vista de la extensión de Chimbote .....................................................39

Ilustración 2.22 Vía Panamericana o Av. Meiggs en la zona de la Florida .............40

Ilustración 2.23 Vista de la Av. Bolognesi en el casco urbano de Chimbote ............40 
Ilustración 2.24 Vista de la Av. Pardo en el caso urbano de Chimbote .41

Ilustración 2.25 Edificios contemporáneos en el casco urbano .41

Ilustración 2.26 Procesión por la festividad de San Pedrito en la zona de la Caleta

Ilustración 2.27 Procesión de San Pedrito en su fiesta patronal ................................44

Ilustración 2.28 Chimbote, la 8va ciudad más poblada...........................................45

Ilustración 2.29 Grado de instrucción de la población..................................................48

Ilustración 2.30 PEA de Chimbote por sectores ................................................................448

Ilustración 2.31 Ciclo de extracción de anchoveta ...............................................................49

Ilustración 2.32 Principales puertos del Perú ....................................................................50

Ilustración 2.33 Uso de suelo en la Ciudad de Chimbote ...............................................51

Ilustración 2.34 Contaminación del agua de la bahía de Chimbote...........................53

Ilustración 2.35 Contaminación del aire en la ciudad de Chimbote ...........................53

Ilustración 2.36 Los habitantes transitan por el borde costero contaminado ..........53

Ilustración 2.37 Contaminación en la zona de la Florida en la bahía de Chimbote54

Ilustración 2.38 Acumulación de desmonte en el borde de la bahía .........................54

Ilustración 2.39 Mapa de puntos críticos de acumulación de basura en la bahía El

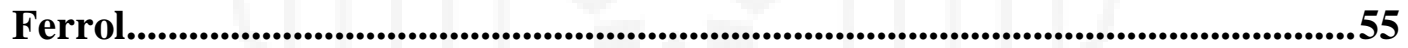

Ilustración 2.40 Mapa de delitos de la Comisaría del P.J La Libertad-Chimbote 2016

Ilustración 2.41 Organización espacial del ágora en Grecia....................................59

Ilustración 2.42 Centro Cultural Pompidou en París, Francia ..................................60

Ilustración 2.43 Centro Cultural Le Havre - Le Havre, Francia...............................61

Ilustración 2.44 Centro Cultural Barrial en Buenos Aires .........................................62

Ilustración 2.45 Casa de la Literatura Peruana en la antigua estación de Trenes de

Desamparados ........................................................................................................63

Ilustración 2.46 Centros Culturales en el Perú .....................................................................66

Ilustración 2.47 Centros Culturales por departamento ...........................................67

Ilustración 2.48 Habitantes por Centro Cultural en el Perú .......................................68

Ilustración 2.49 Centro Cultural Centenario en Chimbote ........................................... 70

Ilustración 2.50 Patio interior del Centro Cultural Centenario ................................71 
Ilustración 2.51 Megaproyectos de revitalización de zonas portuarias y costeras en desuso

Ilustración 2.52 Recuperación de Inner Harbour-Baltimore, Estados Unidos....... 76 Ilustración 2.53 Recuperación del Port Vell, Muelle de España-Barcelona, España

Ilustración 2.54 Recuperación de Puerto Madero-Buenos Aires, Argentina ........... 78

Ilustración 2.55 Mercado Les Halles-París, Francia .....................................................80

Ilustración 2.56 Centro Cultural Matucana 100-Santiago de Chile, Chile ...............81

Ilustración 2.57 Museo Tate Modern-Londres, Reino Unido ...................................82

Ilustración 2.58 CaixaFórum Barcelona en una antigua fábrica textil-Barcelona, España.

Ilustración 2.59 CaixaFórum Madrid en una antigua central eléctrica-Madrid, España..........................................................................................................................................83

Ilustración 3.1 Alentar o rechazar la oportunidad de ver y oír a otros ......................98

Ilustración 3.2 Conexión entre la actividad al aire libre y el estado de las condiciones para realizarlas...................................................................................................101

Ilustración 3.3 Resumen de la teoría del urbanismo a escala humana ...................103

Ilustración 3.4 Doce criterios de calidad en relación con el paisaje peatonal ........105

Ilustración 3.5 Abstracción de la teoría de paisaje ..........................................................112

Ilustración 3.6 Adaptación de la teoría de paisaje a la fábrica en desuso ..............113

Ilustración 3.7 Chimbote como paisaje cultural ................................................................113

Ilustración 3.8 Abstracción de la teoría de urbanismo social .................................114

Ilustración 3.9 Abstracción de la teoría de borde ................................................115

Ilustración 3.10 Interpretación de la teoría de borde a la relación entre la fábrica

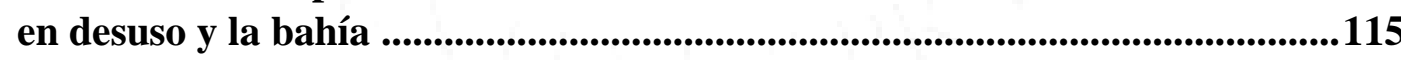

Ilustración 3.11 Funcionamiento de la fábrica en desuso como espacio de encuentro entre la ciudad y la bahía .....................................................116

Ilustración 3.12 Adaptación de la teoría de regeneración urbana al proyecto .....116

Ilustración 5.1 Vista exterior de la fachada icónica de Kanal Centre Pompidou.145

Ilustración 5.2 Vista de la relación de Kanal Centre Pompidou con el canal de

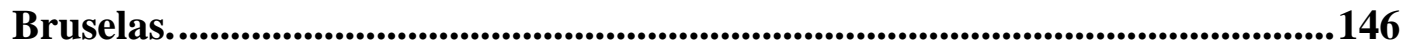

Ilustración 5.3 Interior del gran galón que contiene cajas de actividades en su interior. 
Ilustración 5.4 Nave central de circulación, sobre la que se desarrollan actividades.

Ilustración 5.5 Exposición de arte en el centro cultural Kanal.

Ilustración 5.6 Vista exterior de la relación entre lo existente y lo nuevo a través de

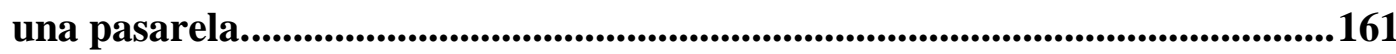

Ilustración 5.7 Vista interior del galpón reciclado con el nuevo uso cultural. .......161

Ilustración 5.8 Vista de la explanada central y la ex galería de reos. .....................176

Ilustración 5.9 Nuevo bloque que completa el borde..............................................177

Ilustración 5.10 Interior de la ex galería de reos que alberga talleres. ...................177

Ilustración 5.11 Vista de la cubierta que acoge todo el proyecto. ..............................189

Ilustración 5.12 Pasarelas que conectan los espacios interiores bajo la cubierta.189

Ilustración 5.13 vista antigua de la fábrica El Águila .................................................190

Ilustración 5.14 Fachadas de los nuevos edificios ......................................................194

Ilustración 5.15 Relación de los silos de cebada con los bloques antiguos...............195

Ilustración 5.16 Maqueta de los volúmenes que componen el proyecto ..................195

Ilustración 6.1 Población por edades en el distrito de Chimbote ..............................211

Ilustración 6.2 Usos de suelo en el distrito de Chimbote .......................................212

Ilustración 6.3 Mapa de equipamientos en el distrito de Chimbote.......................213

Ilustración 6.4 Radio de influencia del equipamiento educativo en el distrito de Chimbote

Ilustración 6.5 Radio de influencia del equipamiento cultural en el distrito de Chimbote

Ilustración 6.6 Embarcaciones en la bahía EI Ferrol ............................................216

Ilustración 6.7 Fábricas que operaban en la Bahía El Ferrol en el año 2004........217

Ilustración 6.8 Fábricas operativas e inoperativas en la bahía EI Ferrol en la actualidad

Ilustración 6.9 Número de fábricas operativas e inoperativas en la bahía El Ferrol

Ilustración 6.10 Número de lotes según el uso del suelo del sector 5

Ilustración 6.11 Mapa de equipamientos, uso de suelo y relación con la bahía en el sector 5

Ilustración 6.12 Área donde se concentra las fábricas en desuso en el sector 5....222

Ilustración 6.13 Mapa de riesgos en la bahía EI Ferrol. .224 
Ilustración 6.14 Red de fábricas inoperativas en la zona de Florida Baja 228

Ilustración 8.1 Ubicación de la fábrica elegida .255

Ilustración 8.2 Vista de la preexistencia en la fábrica CFG Investment desde el Jr. San Martín. .256

Ilustración 8.3 Vista de la fábrica CFG Investment desde el Malecón Grau .........256

Ilustración 8.4 Espacialidad del galpón .257

Ilustración 8.5 Tanques de almacenamiento .257

Ilustración 8.6 Tanques pequeños complementarios .258

Ilustración 8.7 Vista de la fábrica que se extiende a través del muelle hacia el mar 258

Ilustración 8.8 Vista aérea de la situación actual de la fábrica .259

Ilustración 8.9 Vista frontal de la fabrica. .260

Ilustración 8.10 Proceso de elaboración de conserva de pescado . .262

Ilustración 8.11 Piezas que alberga el galpón para la producción de conservas de harina de pescado.

Ilustración 8.12 Maquinaria utilizada para la elaboración de conserva al interior del galpón .263

Ilustración 8.13 Tanques utilizados para almacenamiento de aceite, petróleo y pana

Ilustración 8.14 Muro perimetral continuo característico de los lotes industriales

Ilustración 8.15 Área ocupada por los galpones dentro de la fábrica......................266

Ilustración 8.16 Área ocupada por las piezas industriales en el patio ....................266

Ilustración 8.17 Organización espacial de los elementos dentro de la fábrica CFG

Investment 267

Ilustración 8.18 Conexión con la bahía a través del muelle .267

Ilustración 8.19 Tanques pequeños de color verde ubicados en el patio .268

Ilustración 8.20 Vista de las piezas fabriles en el interior de la fábrica..................268

Ilustración 8.21 Relación entre las piezas encontradas en la fábrica......................269

Ilustración 8.22 Emplazamiento de los elementos fabriles en el terreno ................269

Ilustración 8.23 Piezas recicladas en la fábrica ........................................................2270

Ilustración 8.24 Espacios no reciclados de la fábrica .....................................................271

Ilustración 8.25 Isometría de piezas recicladas ....................................................271 
Ilustración 8.26 Variables relevantes en de la toma de partido del proyecto........2272

Ilustración 8.27 Estrategia de liberar el espacio invadido en el borde ...................273

Ilustración 8.28 Estrategia de proyectar un malecón peatonal ................................274

Ilustración 8.29 Estrategia de rodear el perímetro del terreno con programa.....275

Ilustración 8.30 Estrategia de configurar plazas entre bloques ...............................276

Ilustración 8.31 Estrategia de conectar los bloques a través de puentes .................277

Ilustración 8.32 Piezas fabriles características de la fábrica: galpón y tanque.....278

Ilustración 8.33 Pendiente natural del proyecto: $3 \%$..............................................279

Ilustración 8.34 Reinterpretación de la pendiente natural en plataformas............280

Ilustración 8.35 Trazado de ejes en el terreno para determinar la ubicación y orientación de las piezas ......................................................................................280

Ilustración 8.36 Organización espacial del proyecto ................................................281

Ilustración 8.37 Respuesta a la medianera del vecino colindante ..........................282

Ilustración 8.38 Vista aérea del muro ciego del terreno vecino..............................282

Ilustración 8.39 Gráfico de definición de fábrica cultural .......................................283

Ilustración 8.40 Galpón, espacio servido del sistema ............................................284

Ilustración 8.41Tanque, espacio servidor del sistema .............................................284

Ilustración 8.42 Puente, espacio conector horizontal del sistema.............................285

Ilustración 8.43 Ascensor y escaleras, elementos conectores verticales del sistema

Ilustración 8.44 Secuencia de organización de piezas en el sistema Fábrica Cultural. .286

Ilustración 8.45 Sistema fábrica cultural completo .287

Ilustración 8.46 Configuraciones generadas a partir de la exploración espacial del galpón

Ilustración 8.47 Configuraciones generadas a partir de la exploración espacial del tanque.

Ilustración 8.48 Espacio determinado por el tipo de programa. .290

Ilustración 8.49 Espacio determinado por la circulación exterior .291

Ilustración 8.50 Manual de ensamblaje del espacio interior del galpón .291

Ilustración 8.51 Vista interior de la biblioteca general, donde la circulación exterior se inserta en el galpón 
Ilustración 8.52 Ususarios directos e indirectos del proyecto

Ilustración 8.53 Resultados de las encuestas realizadas a los alumnos de primaria y secundaria de la I.E No 88008 - Manuel Peralta Hurtado, Florida Baja ......295

Ilustración 8.54 Distribución del programa en el proyecto ....................................297

Ilustración 8.55 Paquetes programáticos del proyecto..............................................298

Ilustración 8.56 Porcentaje de áreas del programa específico del proyecto...........299

Ilustración 8.57 Axonometría explotada por tipo de programa y por piezas del proyecto...................................................................................................................302

Ilustración 8.58 Distribución programática del galpón reciclado 01 ........................305

Ilustración 8.59 Distribución programática del galpón reciclado 02 ......................305

Ilustración 8.60 Vista interna del galpón reciclado, convertido en una sala de exposición...............................................................................................................306

Ilustración 8.61 Distribución programática del galpón biblioteca general ............307

Ilustración 8.62 Distribución programática del galpón biblioteca infantil ............307

Ilustración 8.63 Distribución programática galpón auditorio ..................................308

Ilustración 8.64 Distribución programática del galpón administrativo ..................308

Ilustración 8.65 Espacios servidos y servidores del proyecto .................................309

Ilustración 8.66 Vista de la circulación lenta del proyecto ........................................310

Ilustración 8.67 Vista de la circulación lenta del proyecto ...................................310

Ilustración 8.68 Elementos reciclados de la fábrica y empleados en el proyecto...312

Ilustración 8.69 Ubicación de los elementos reciclados ............................................313

Ilustración 8.70 Planta del primer nivel ...........................................................314

Ilustración 8.71 Planta del segundo y tercer nivel ...........................................................315

Ilustración 8.72 Planta del cuarto nivel .....................................................................316

Ilustración 8.73 Planta del quinto nivel ...................................................................................317

Ilustración 8.74 Estructura metálica principal del galpón ....................................318

Ilustración 8.75 Detalle constructivo isométrico del galpón .......................................319

Ilustración 8.76 Estructura metálica principal el tanque .....................................320

Ilustración 8.77 Detalle constructivo isométrico del tanque .....................................321

Ilustración 8.78 Diagrama del asoleamiento con respecto al proyecto ....................322

Ilustración 8.79 Diagrama de vientos con respecto al proyecto ..............................323 
Ilustración 8.80 Composición de la fachada del galpón ..........................................324

Ilustración 8.81 Detalle de estructura de la fachada ..............................................325

Ilustración 8.82 Detalle del techo del galpón ...............................................................326

Ilustración 8.83 Gráfico de calor al interior del galpón ............................................327

Ilustración 8.84 Gráfico de calor en el doble techo del galpón ..................................328

Ilustración 8.85 Detalle acústico del galpón .......................................................................329

Ilustración 8.86 Detalle del muro acústico al interior del galpón, dependiendo de su uso

Ilustración 8.87 Detalle de ubicación del panel solar empleado ..............................331

Ilustración 8.88 Panel solar empleado .........................................................................331

Ilustración 8.89 Materialidad empleada en el proyecto ...............................................333

Ilustración 8.90 Plano de Orientación........................................................................334

Ilustración 8.91 Planta Nivel +4.50m .............................................................335

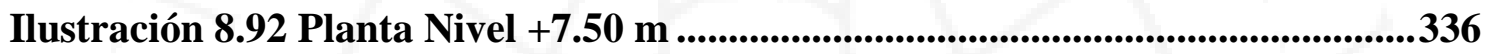

Ilustración 8.93 Planta Nivel +12.70 m ...........................................................337

Ilustración 8.94 Planta Nivel +16.05 m ......................................................................338

Ilustración 8.95 Planta de Techos...........................................................................339

Ilustración 8.96 Corte longitudinal fugado del proyecto con el muelle ...................340

Ilustración 8.97 Corte longitudinal fugado del proyecto.........................................341

Ilustración 8.98 Corte transversal fugado del proyecto ..........................................342

Ilustración 8.99 Secciones del proyecto....................................................................343

Ilustración 8.100 Secciones del proyecto....................................................................344

Ilustración 8.101 Secciones del proyecto...............................................................................345

Ilustración 8.102 Secciones del proyecto...........................................................346

Ilustración 8.103 Secciones del proyecto..............................................................347

Ilustración 8.104 Detalle constructivo del galpón biblioteca infantil .......................348

Ilustración 8.105 Detalle constructivo del galpón biblioteca general.......................349

Ilustración 8.106 Detalle constructivo del tanque ...............................................350

Ilustración 8.107 Detalle constructivo del puente .................................................351

Ilustración 8.108 Emplazamiento del espacio público interno ................................353

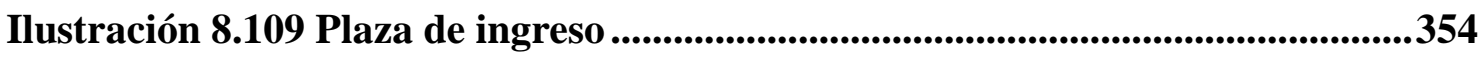


Ilustración 8.110 Vista de la plaza de ingreso a La Fábrica con preexistencias ...355

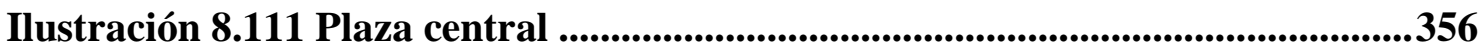

Ilustración 8.112 Vista nocturna de espectáculo en plaza central............................357

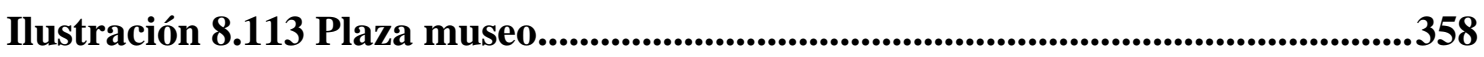

Ilustración 8.114 Plaza tanques ...............................................................................359

Ilustración 8.115 Vista de la plaza infantil como extensión del galpón biblioteca infantil .................................................................................................................

Ilustración 8.116 Vegetación utilizada en el proyecto. Izquierda: molle, centro: palmera datilera y derecha: penissetum, comúnmente conocida con cola de zorro..

Ilustración 8.117 Plantas trepadoras buganvillas .361

Ilustración 8.118 Rejilla medianera empleada como muro verde............................362

Ilustración 8.119 Gráfico del análisis del malecón 363

Ilustración 8.120 Diseño del malecón a partir de espacios de control, estar y circulación constante

Ilustración 8.121 Sinuosidad de la isla Blanca, inspiración para la forma de la cobertura del malecón

Ilustración 8.122 Vista del malecón y sus respectivos elementos de sombra. .366

Ilustración 8.123 Estructura de la cobertura de madera empleada en el malecón

Ilustración 8.124 Vista del muelle reciclado

Ilustración 8.125 Isometría explotada de las capas propuestas en el diseño del malecón 368

Ilustración 8.126 Mapa del sistema de inversión urbana ...........................................377

Ilustración 8.127 Mapa del sistema de inversión costera ..........................................377

Ilustración 8.128 Certificado literal de la fábrica...................................................379

Ilustración 8.129 Matriz de intersados ..........................................................382

Ilustración 8.130 Etapa 1 de la construcción del proyecto.......................................384

Ilustración 8.131 Etapa 2 de construcción del proyecto...........................................385

Ilustración 8.132 Etapas de construcción del proyecto .............................................385

Ilustración 8.133 Cronograma de recuperación de la inversión ...............................387

Ilustración 8.134 Vista aérea del proyecto Fábrica Cultural.......................................389

Ilustración 8.135 Marca La Fábrica ................................................................390 
Ilustración 8.136 Competencia de equipamiento cultural en Chimbote...................391

Ilustración 8.137 Participantes de los talleres por sexo..........................................392

Ilustración 8.138 Alumnos inscritos por edades ........................................................393 


\section{ÍNDICE DE ANEXOS}

Anexo 1: Fábricas en la bahía El Ferrol ..................................................................431

Anexo 2: Ordenanza 01-2009-MPS ...................................................................432

Anexo 3: Mapa de sistema de inversión provincial en la zona costera ..................433

Anexo 4: Mapa de sistema de inversión urbana 2012 - 2022 ...............................434

Anexo 5: Encuesta realizada a alumnos de primaria de la I.E $N^{0} 88008$..............435

Anexo 5: Encuesta realizada a alumnos de secundaria de la I.E N88008 ..........436 


\section{INTRODUCCIÓN}

La mayoría de ciudades industriales alrededor del mundo ha atravesado por una problemática similar: después de la explotación de su materia prima, han ido quedando en abandono y desuso, mostrándose como paisajes aislados sin acción alguna sobre las dinámicas urbanas de la ciudad. Por este motivo, se ha visto necesaria su transformación urbana, social y cultural. El deterioro del tejido urbano y las dinámicas en torno a estas han sido acentuadas por el abandono y olvido de los que ejercían el uso industrial, pero también por la actividad social, debido a que las personas han perdido el interés por hacer uso de los espacios industriales, aduciendo la alta percepción de inseguridad que estos generan. Viendo esta situación y el constante crecimiento de las ciudades, se ha optado por regenerar estas zonas, convirtiéndolas en una oportunidad de desarrollo y crecimiento.

Chimbote, ciudad puerto ubicada al norte del Perú, no es ajena a la inactividad de espacios industriales. Tras ordenarse el traslado de la industria pesada a la zona industrial, la Florida Baja, una zona centro de la ciudad ubicada frente a la bahía, cuenta con fábricas en desuso y grandes lotes inactivos rodeados de muros ciegos, los cuales se alzan como islas dentro del uso residencial. Estas fábricas forman parte de la historia de la ciudad y de la memoria colectiva de los chimbotanos, pues durante el boom pesquero de los años 60 , la ciudad se convirtió en el primer puerto exportador de harina de pescado. Sumado a ello, la ciudad presenta una barrera de basura y desmonte en el borde costero, dando la espalda a la bahía. Esto ha formando como consecuencia un paisaje desolado, un foco contaminante y le ha negado a los ciudadanos la posibilidad de contemplar el hermoso paisaje costero rodeado de islas.

La situación mencionada nos lleva a pensar en lo que el escritor José María Arguedas escribió sobre esta ciudad cuando vivía allí. Luego de analizar los distintos factores que esta presentaba, catalogó a Chimbote como "la ciudad que menos entiendo, pero que más me entusiasma".

En la actualidad, Chimbote también enfrenta un déficit de equipamientos culturales que no satisface la demanda social. La ciudad presenta una fuerte identidad marítima, donde sus actividades culturales, sociales y económicas han tenido como centro de su desarrollo 
la actividad pesquera. Sin embargo, los chimbotanos no cuentan con un espacio donde se puedan expresar y compartir las diversas manifestaciones culturales.

Hay, sin embargo, una estrecha relación en regenerar ciudades a través de equipamientos culturales, que generen espacios de encuentro y fortalezcan la identidad del lugar. Ante el déficit de equipamiento cultural en Chimbote, se ha visto necesario integrar ambos escenarios, interviniendo la fábrica en desuso en el borde de la bahía a través del reciclaje de las estructuras industriales. A su vez, insertando un programa cultural que cubra la demanda social insatisfecha, reforzando la identidad de la ciudad y brindando nuevas oportunidades a los chimbotanos, especialmente a la población predominante, los niños y jóvenes. 


\section{CAPÍTULO I: GENERALIDADES}

\subsection{Tema}

El distrito de Chimbote, ubicado en el departamento de Ancash, provincia del Santa al norte del Perú, empezó a tener renombre a nivel nacional e internacional a partir de la convergencia del desarrollo siderúrgico y el boom de la producción de harina de pescado, que generó el significativo crecimiento de la ciudad. (Moseley et al., 2006, p. 171) Durante el boom harinero, las fábricas se asentaron en el borde de la bahía siendo esta una ubicación estratégica para la producción, convirtiendo Chimbote en una ciudad puerto.

Actualmente la realidad de Chimbote es otra, las fábricas ubicadas en la zona centro de la ciudad próximas a la bahía han quedado en desuso debido a la Ordenanza $\mathrm{N}^{\circ}$ 001-2009-MPS establecida por la Municipalidad Provincial del Santa (MPS), desplazando el uso industrial a otra zona, dejando estos espacios como "vacíos urbanos" dentro de la zona residencial que degradan el frente costero de la ciudad.

La intención de esta investigación es lograr que a partir de la inserción de un nuevo uso a una de las fábricas inactivas que hoy representan un problema, se pueda generar un espacio cultural que potencie la identidad chimbotana. Equipamiento al que se le ha denominado "Fábrica Cultural" debido a que se encuentra dentro de un espacio anteriormente utilizado como fábrica, en el que predominan estructuras industriales y un pasado histórico con valor de identidad. Por su parte, lo cultural está definido por el programa que se va a desarrollar en el interior de los edificios. Estos ambientes vendrán acompañados de espacios públicos que complementen el desarrollo de las distintas actividades.

\subsection{Justificación del tema}

En el Perú, una de las actividades más importantes es la pesca, que siempre estuvo ligada a las ciudades puerto del país. Una de ellas es Chimbote, que en los años 50 y 60 se

\footnotetext{
${ }^{1}$ Los vacíos urbanos pueden definirse como:

Espacios vacíos o fragmentos de suelos en zonas degradadas de la ciudad consolidada, sin una función dentro de lo urbano, que están expectantes de un desarrollo incierto.

Espacios resultantes del crecimiento urbano en lugares donde antiguamente se desarrollaron polígonos industriales y retazos de infraestructuras o amplios desarrollos urbanísticos. (Berruete Martínez, 2017)
} 
transformó en la capital del acero peruano y el primer puerto pesquero exportador de harina de pescado del mundo. (Sulmontet al., 2006, p. 171) Ya desde los años 40, era visitada por turistas por ser una hermosísima caleta con una playa enorme de doradas arenas, con una extensión aproximada de 60 a 70 metros de ancho del mar al malecón. (Moseley et al., 2006, p. 227)

\section{Ilustración 1.1 Bahía de Chimbote alrededor de los años 60 - 70.}

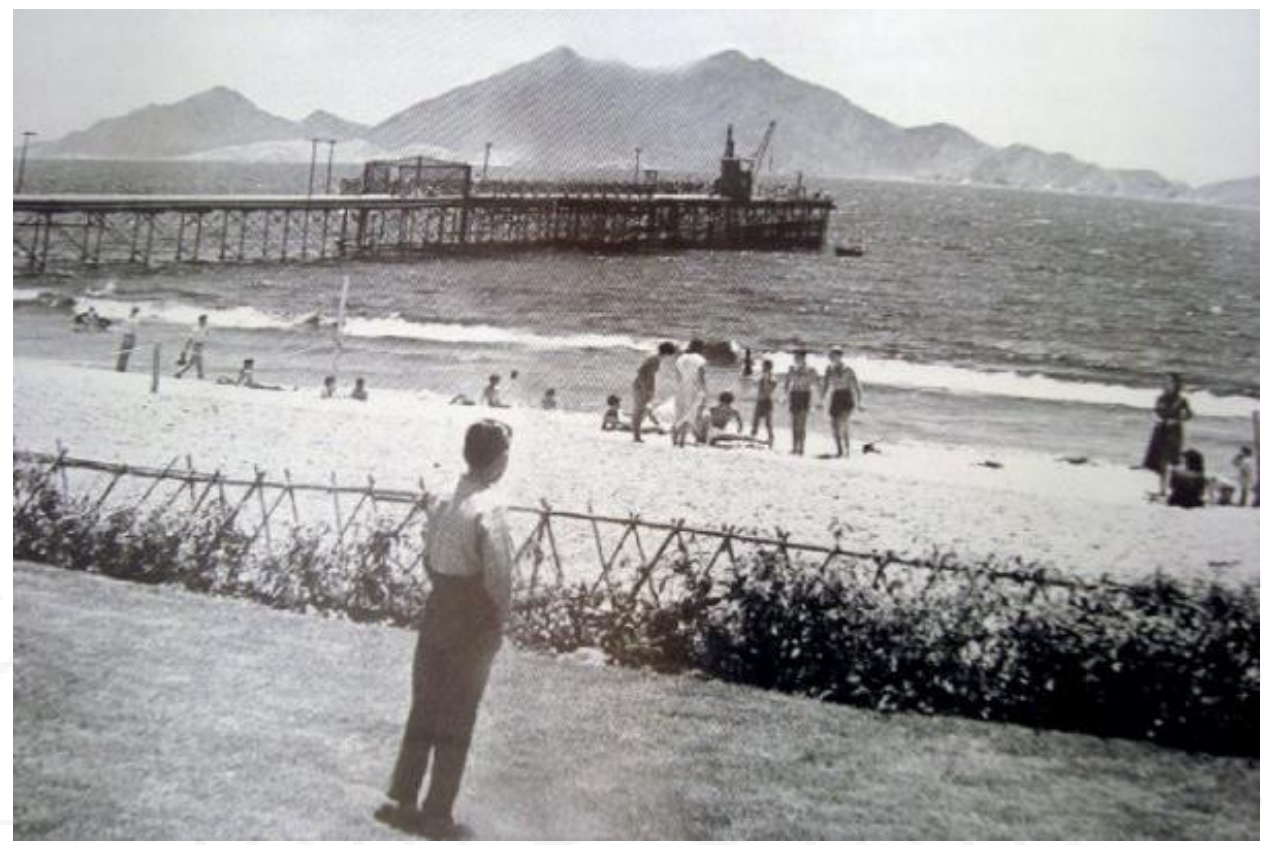

Fuente: (Icochea, 2007)

De haber sido una caleta de pescadores a convertirse en una ciudad en la que muchos visionarios percibieron un gran potencial de desarrollo industrial con aspiración de convertirse en "tierra de promisión”, como lo vaticinó Enrique Tovar y se expresa en la letra de su himno; en la actualidad, Chimbote presenta una bahía sumamente contaminada, donde el $75 \%$ de la contaminación es originado por aguas residuales pesqueras (PAT Santa, 2012) y a su vez, una contaminación del aire en la que el $44 \%$ es ocasionado por industrias. (Ministerio de la Producción, 2012)

El impresionante paisaje de Chimbote, dado por su forma cóncava, la presencia de las islas y el malecón que permitía una estrecha y articulada conexión entre la ciudad y la bahía y que generaba identidad en los chimbotanos, ha perdido protagonismo debido a que la ciudad ya no avizora hacia el mar, en parte ocasionado por la contaminación que ha reducido el espacio entre lo natural y lo construido, como también por la presencia de fábricas harineras y conserveras que han quedado en desuso en el borde. 
Ilustración 1.2 Vista de la forma cóncava de la bahía desde el Cerro de la Paz

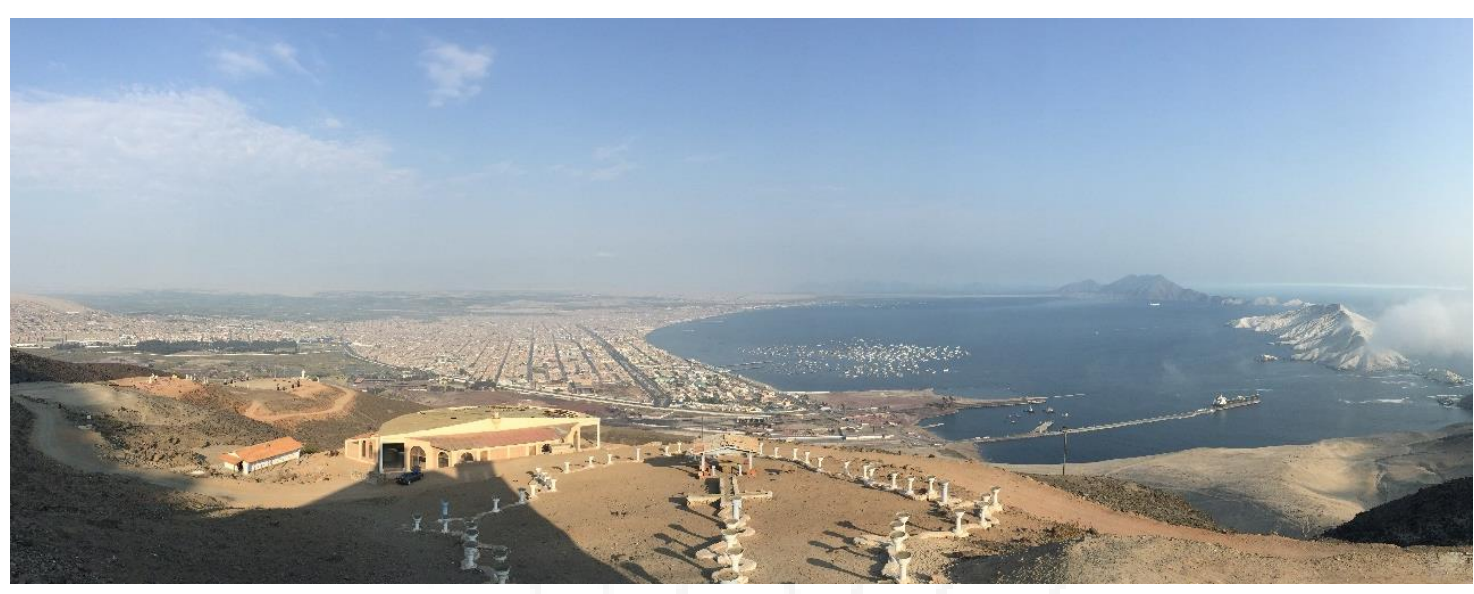

Fuente: Fotografía propia

Ilustración 1.3 Relación de la ciudad con la bahía

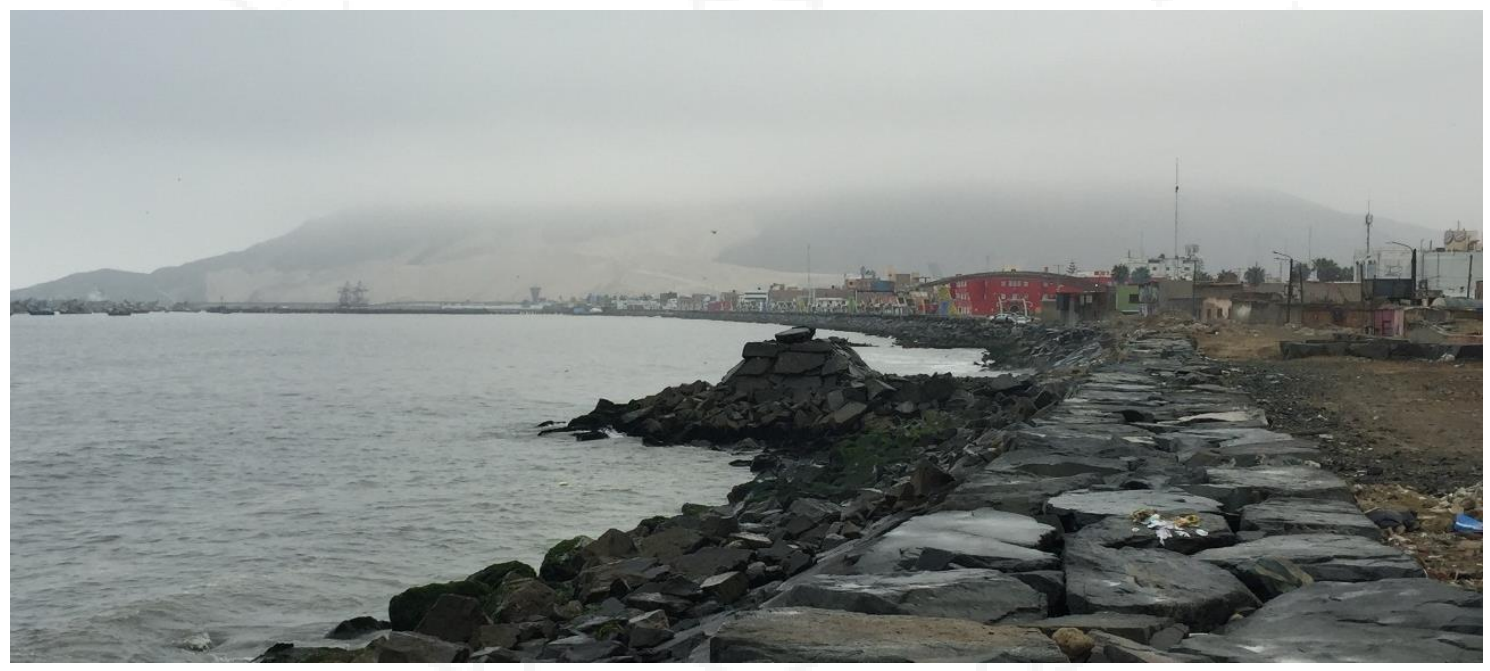

Fuente: Fotografía propia

Actualmente en la bahía El Ferrol se encuentran ubicadas 47 fábricas de harina y conserva de pescado, de las cuales 11 están inoperativas² (OEFA, 2016, pp. 19-35) e insertas en la zona residencial, lo que representa un "vacío" dentro del tejido urbano. La paralización de las fábricas de esta zona se debió a que en el año 2009, la Municipalidad Provincial del Santa (MPS) estableció la Ordenanza Municipal No 001-2009-MPS ${ }^{3}$, que fijaba la salida de las industrias pesadas con actividad molesta y peligrosa y su traslado a la zona industrial. Sin embargo, en el desarrollo urbano de una ciudad no se puede pasar drásticamente de una zonificación a otra, es necesario la presencia de elementos

\footnotetext{
${ }^{2}$ Ver Anexo $\mathrm{N}^{\mathrm{o}} 01$

${ }^{3}$ Ver Anexo $\mathrm{N}^{\circ} 02$
} 
intermedios (equipamientos) que presenten otros usos distintos al residencial e industrial, precisamente lo que requiere esta parte de la ciudad.

El paisaje productivo de Chimbote es el punto de partida de su identidad y del desarrollo de esta. Contar con un mar altamente diverso y rico en especies marinas, desencadenó que los empresarios pesqueros ubicaran sus fábricas al borde la bahía, atrayendo a pescadores que se asentaron junto con sus familias en esta ciudad. Con el paso del tiempo, los chimbotanos fueron desarrollando manifestaciones culturales como muestra de agradecimiento a la tierra que les brindó la materia prima de su sustento económico, siendo la más importante la fiesta de San Pedrito, Patrón de los pescadores, celebrada cada 29 de junio y que hoy es Patrimonio Cultural de la Nación declarada a través de la R.S. N 063-2018-VMPCIC-MC del Ministerio de Cultura ${ }^{4}$. No obstante, el patrimonio industrial de muchas ciudades costeras de nuestro país pasa casi desapercibido, aun cuando posee un enorme valor histórico e identitario, por lo que es indispensable reconocerlo y potenciarlo para forjar un vínculo entre la ciudad y la población.

\section{Ilustración 1.4 Paisaje pesquero de Chimbote}

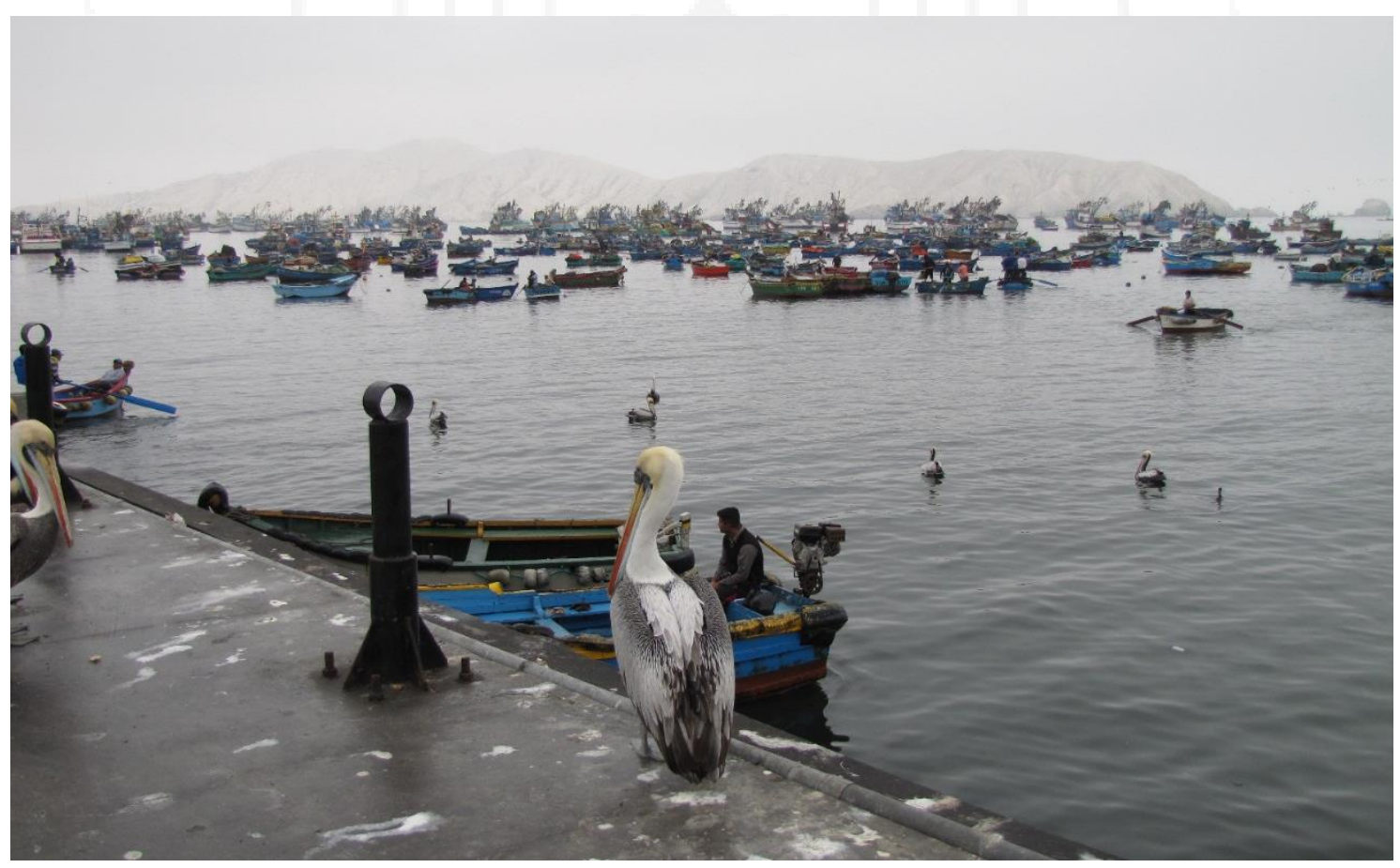

Fuente: Fotografía propia

\footnotetext{
${ }^{4}$ Ver Anexo $\mathrm{N}^{\circ} 03$
} 
El patrimonio industrial chimbotano materializado en el presente proyecto en las fábricas en desuso también forman parte de la cultura. Ámbito que en Chimbote ha sido descuidado y que no se ha desarrollado como equipamiento urbano, lo que se puede observar claramente en los usos de suelo establecidos en el PDU Santa 2012, donde existen 265 lotes de equipamiento educativo, 90 lotes para equipamiento de salud, 647 lotes para equipamiento de recreación y únicamente 1 lote para equipamiento cultural. Información que revelan un gran déficit pues solo existe un Centro Cultural ubicado en el distrito de Chimbote que abastece a $1.5 \%$ del total de la población.

La cifra anterior es alarmante ya que la población chimbotana mayoritaria se encuentra en el rango de edad entre los 10 - 19 años, formando un total de 61438 personas (INEI, 2007), es decir, el 20.09\% de la población. Niños y jóvenes que no gozan de espacios propicios donde puedan formarse cultural y educativamente. Adicionalmente, este déficit de equipamiento se ve reflejado en el grado de instrucción de la población ya que solo el 35\% llega a completar los estudios secundarios (INEI, 2007), conformándose con realizar trabajos temporales que no les brindan una estabilidad económica. Muchos de los varones se dedican a la pesca y las mujeres, a trabajar en fábricas como "mujeres fileteras $5 "$. En base a las características de la población, se propone desarrollar un proyecto que cuente con un programa que brinde herramientas necesarias para educar, culturizar y capacitar técnicamente para que la población pueda desempeñarse en otras actividades cuando el sector pesquero se encuentre en veda ${ }^{6}$.

Los argumentos expuestos en los párrafos anteriores justifican el desarrollo de un equipamiento cultural en la bahía de Chimbote, que permita conectar la ciudad con la bahía y revalorizar la identidad chimbotana a través del reciclaje de una fábrica en desuso. Este equipamiento a su vez servirá como modelo para aplicarse en las distintas infraestructuras abandonadas que se encuentran en las mismas condiciones a lo largo del litoral. Por tal motivo, se considera necesario intervenir en espacios inactivos con el objetivo de reestructurar el tejido urbano de la ciudad mediante un equipamiento que articule la zonificación industrial pasada y el actual uso residencial. Además, los espacios

\footnotetext{
${ }^{5}$ Mujeres Fileteras, denominadas así en el lenguaje criollo, son las personas de género femenino que trabajan en las fábricas de conservas de pescado limpiando y fileteando los pescados para que posteriormente sean procesados.

${ }^{6}$ Veda: periodo de tiempo en el que se prohíbe la caza y pesca de una especie para permitir el desarrollo de esta. (Péres Porto \& Merino, 2010)
} 
industriales inactivos cuentan con estructuras preexistentes que al activarlas acercarían el pasado histórico a la población joven de Chimbote.

\subsection{Planteamiento del problema}

En el Perú, el número de habitantes por centro cultural es de 272796 (Ministerio de Cultura, 2011, pág. 121) debido a que solo existen 108 centros culturales que abastecen a toda la población (Ministerio de Cultura, 2011, pág. 118). Indicador que refleja un bajo nivel de cultura en la población.

Chimbote no es ajeno a esta realidad ya que presenta solo tres centros culturales, de los que solo uno funciona como tal y abastece a esta ciudad y a todo el departamento de Ancash. Realidad que necesita ser revertida pues una sociedad sin cultura es una sociedad sin educación, que no se identifica con su lugar de origen y se desarraiga del pasado, además de inclinarse por la carencia de aspiraciones y progreso. (Rish Lerner, 2005, p. 22) La población más afectada por este déficit son los jóvenes, entre 10 y 19 años, quienes representan el $20.09 \%$ de la población total chimbotana. No obstante, es esta población la que presenta un grado de instrucción muy bajo, pues solo el $35 \%$ culmina los estudios secundarios y otro porcentaje menor (entre el 6 y 9\%) culminan estudios técnicos y/o universitarios, problemática que resalta el escaso desarrollo cultural de la población.

La cultura es un factor catalizador de conocimientos que además ejerce una regeneración urbana a través de un cambio social, económico y medioambiental del lugar. (Rish Lerner, 2005, p. 6) Acción que sería de gran impacto en la bahía de Chimbote, donde la mayor problemática radica en las fábricas inactivas que cuentan con un gran potencial histórico y valor industrial pero que por la falta de uso y por la disyuntiva entre su anterior uso industrial y la zonificación residencial actual, se perciben como islas inmersas dentro del tejido urbano que no permiten una conexión directa entre la ciudad y la bahía.

Además de ello, este frente costero industrial se encuentra rodeado de una acumulación de residuos que con el paso del tiempo han ido formando grandes montículos estableciéndose como una barrera física, que ha desencadenado una barrera psicológica en la población que percibe este borde como inseguro y ajeno a su realidad. Dificultad que ha sido superada en muchas ciudades industriales del mundo donde han 
visualizado el valor y la identidad industrial como un medio para regenerar y transformar por completo una ciudad, dotando a la población de equipamientos y espacios públicos.

¿En qué medida la inserción de una Fábrica Cultural dentro de una fábrica en desuso puede dotar de cultura e identidad en la población de Chimbote? ¿Proyectar en un vacío urbano ubicado en el borde de la bahía logrará recuperar la conexión perdida de la ciudad con la bahía?

\subsection{Objetivos}

\subsubsection{Objetivo general}

Idear el proyecto Fábrica cultural dentro de una fábrica en desuso, ubicada en el borde de la bahía de Chimbote, con la intención de desarrollar cultura que contribuya a acentuar la identidad chimbotana con el pasado industrial y con el paisaje marino - costero especialmente en la población más joven. Además, se busca que el equipamiento funcione como disipador ${ }^{7}$ del paso de lo industrial a lo residencial y que a su vez genere un borde blando de interacciones entre la ciudad y la bahía a través del diseño de espacio público.

\subsubsection{Objetivos específicos}

- Estudiar a la población del distrito para conocer el equipamiento existente y el necesario para su desarrollo.

- Investigar la historia y la evolución de Chimbote para entender la importancia de recuperar las fábricas en desuso y el vínculo entre ellas y la población.

- Integrar el anterior uso industrial de la fábrica con la zonificación residencial actual del entorno a través de la inserción de un equipamiento cultural que disipe el paso brusco de una zonificación a otra.

- Comprender y estudiar las teorías de paisaje - "terrain vagues", borde, urbanismo social e identidad y memoria colectiva, de manera que puedan aplicarse a la Fábrica Cultural a través de la relación edificio - paisaje. Estas

\footnotetext{
${ }^{7}$ Disipar: ir reduciendo de manera sutil y progresiva el paso de un estado a otro.
} 
teorías ayudarán a revalorizar las potencialidades con las que cuenta la bahía y lo que hoy se percibe como un problema, poder convertirlo en una oportunidad.

- Investigar y analizar referentes de casos análogos, es decir, edificios culturales ubicados dentro de estructuras recicladas, a nivel nacional y mundial para entender el funcionamiento de estos y a la vez analizar referentes no análogos, relacionados con variables como el paisaje, borde y espacio público que sirvan como estrategias proyectuales.

- Rescatar lo obsoleto en el proyecto con el fin de acentuar la identidad y memoria colectiva industrial en la población.

- Potencializar los elementos industriales presentes en la fábrica inactiva de manera que estos se integren con los nuevos elementos propuestos para que la arquitectura industrial sea valorada y se convierta en la imagen referente de la identidad chimbotana.

- Establecer la transformación del borde urbano a través del estudio de procesos de regeneración urbana en ciudades costeras y del patrimonio industrial que permita recuperar la conexión perdida con la bahía, reducir la percepción de inseguridad, generar nuevos espacios públicos atrayendo a la población hacia este espacio descuidado.

\subsection{Supuesto básico de la investigación}

\subsubsection{Fábrica Cultural como equipamiento en sí}

- Si se diseña una Fábrica Cultural dentro de una fábrica en desuso, que fomente la cultura y educación a través de talleres y capacitaciones, se contribuirá a reducir el déficit de equipamiento cultural en la ciudad, a tener una sociedad con mayor nivel de instrucción, además de convertir este espacio en un elemento de identidad por el valor industrial e histórico que tiene para Chimbote.

\subsubsection{Fábrica Cultural como regenerador urbano}

- Si se proyecta una Fábrica Cultural en la zona de la Florida Baja en el borde de la bahía, se logrará regenerar el tejido urbano pues se integrará 
adecuadamente el paso de zonificación industrial a residencial a través de un equipamiento, al mismo tiempo que generará un borde activo mediante el diseño de un espacio público en el frente costero que volcará la mirada de la ciudad a la bahía.

\subsection{Alcances y limitaciones}

\subsubsection{Alcances de la investigación}

- La presente investigación indagará sobre la historia y evolución de Chimbote, así como la aparición de centros culturales en el mundo, en el Perú y en Chimbote.

- Se realizará un levantamiento de información de la situación actual de las fábricas, en el que se cuantificará las fábricas en desuso y en uso en la bahía de Chimbote.

- Se realizará una línea de tiempo donde se contraste la historia de Chimbote con la regeneración de las ciudades con frentes costeros industriales en el mundo.

- Se investigará sobre las referencias y antecedentes relacionados al tema de reciclaje de fábricas en desuso y su papel en la regeneración de una zona.

- Se analizará tres proyectos de Centros Culturales que estén ubicados en espacios con preexistencias y donde se hayan reciclado estructuras, los cuales se tomarán como referentes para la determinación del programa y de la integración entre lo nuevo y lo existente, también se investigará tres proyectos que presenten contextos similares al proyecto, los cuales se tomarán como referentes de estrategias proyectuales.

- Se estudiarán variables como: presencia preexistencias, espacio público y borde costero para la determinación de la ubicación del proyecto.

- La idea proyectual se elaborará a través del concepto de adaptabilidad al paisaje costero y a una zona con antecedentes industriales. 


\subsubsection{Limitaciones de la investigación}

- No se cuenta con una base de datos digital de las fábricas en desuso y en uso en la bahía de Chimbote.

- Debido a que la Municipalidad Provincial del Santa no cuenta con expedientes de proyectos urbano y/o arquitectónicos ni de infraestructura vial realizados en la zona costera, se trabajará solo sobre la información del Plan de Desarrollo Urbano de la Ciudad de Chimbote 2012-2022 (PDU) y el Plan de Acondicionamiento Territorial de la Provincia del Santa 2012-2022 (PAT).

- La información estadística sobre la población estará basada en el Censo realizado en el 2007 en la Ciudad de Chimbote.

- No se cuenta con estadísticas del impacto del Centro Cultural Centenario en la población de Chimbote.

- Por la extensión del proyecto y por cuestión de tiempo, no se desarrollará un plan de reciclaje de fábricas en desuso ubicadas a lo largo de la bahía de Chimbote.

\subsubsection{Alcances del proyecto}

- Se desarrollará planos de anteproyecto de arquitectura y esquemas básicos de especialidades, así como el diseño del espacio público dentro del terreno y en el borde costero entre el proyecto y el mar, además de la intervención en el muelle existente.

- Se desarrollará un levantamiento de las fábricas inoperativas del sector a analizar que puedan ser consideradas como patrimonio industrial a fin de identificar todas las estructuras industriales con potencial de ser recicladas.

- Se conservará los elementos industriales existentes en las fábricas tales como: tanques, tijerales, entre otros.

- Se trabajará sobre los parámetros municipales correspondientes al terreno. Sin embargo, a pesar de que en este no se exige estacionamientos, en el proyecto sí se han desarrollado. 
- Se diseñará un proyecto que se recorra por completo de manera ininterrumpida a través de circulaciones lentas y rápidas que atraviesen todos los bloques presentes en el terreno.

- El proyecto liberará el espacio ocupado por un galpón preexistente en el borde de la bahía para dotar a la ciudad de un espacio público costero.

- Se realizará el levantamiento de los elementos existentes en el interior de la fábrica y se corroborará la distancia entre el terreno y el mar.

\subsubsection{Limitaciones del proyecto}

- Por la envergadura del proyecto no se desarrollará el espacio público ubicado en las calles colindantes.

- No se realizarán talleres de participación ciudadana. Sin embargo, se recopilará información a través de conversaciones con personas conocedoras del tema.

- Por ubicarse en el borde de la bahía, el terreno se encuentra en una zona con erosión y con alto riesgo de licuación.

- No se desarrollará estudios de impacto ambiental y vial del proyecto.

- El pre dimensionamiento de la cimentación (pilotes) se establecerá en términos generales porque no se realizará el estudio de suelos del terreno.

\subsection{Diseño de la investigación}

La investigación realizada es de tipo descriptiva. Se iniciará analizando la necesidad de proyectar una fábrica cultural en el borde costero de la bahía de Chimbote, a través del estudio tanto de la población como de los antiguos planes propuestos para la ciudad. Se estudiarán escritos e investigaciones de autores sobre temas relacionados con: el paisaje costero, "terrain vagues", borde, urbanismo social e identidad y memoria colectiva, términos que serán de gran ayuda para guiar la investigación de acuerdo con los objetivos planteados.

Con los datos obtenidos se realizarán estadísticas que permitan establecer patrones para guiar el diseño del proyecto.

Adicionalmente, se logrará que el futuro proyecto sea parte de lo proyectado por el Plan de Desarrollo Urbano desarrollo por la Municipalidad del Santa en el año 2012. 
Asimismo, el proyecto se basará en la O.M No 001-2009-MPS, donde se establece que las estructuras industriales de la zona la Florida Baja ya se han trasladado a la zona industrial, por lo cual estos edificios se encuentran actualmente en desuso.

La investigación estudiará 6 proyectos referentes, de los cuales 3 estarán relacionados al mismo tema de investigación, y otros 3 contarán con entornos similares en donde se desarrollará el proyecto. Esta labor permitirá contar con la mayor cantidad estrategias proyectuales para diseñar la Fábrica Cultural. Al mismo tiempo, se evidenciará la identidad marítima y se valorizará las estructuras industriales en el diseño de la Fábrica Cultural, a través de las conductas sociales y culturales de la población.

Por último, la investigación desarrollará una red de reciclaje de fábricas industriales, en la que se designará qué proyectos podrían realizarse en ellas, basado en la información del PDU Santa 2012. Así como, se demostrará la relevancia de implementar una Fábrica Cultural dentro de una fábrica en desuso. A nivel proyectual, se desarrollará la Fábrica Cultural que responda a las estrategias establecidas en la investigación.

\subsection{Metodología de la investigación}

\subsubsection{Forma de consulta de la información}

La información se consultará a través de buscadores científicos, repositorios de tesis a nivel nacional, hemerotecas virtuales y bibliotecas públicas y privadas

\subsubsection{Forma de recopilación de la información}

$\mathrm{Al}$ encontrarse el proyecto a desarrollar dentro de un panorama costero, es un área que también les compete a entidades oficiales del Estado, por lo que se recopilará información de: ministerios, organismos medioambientales y fiscalizadores y municipalidades. Adicionalmente también se recolectará información a través de libros, enciclopedias, planes desarrollados por la Municipalidad Provincial del Santa, Datos relacionados a vientos y marea pertenecientes a la Marina de Guerra, Tesis de distintos grados académicos, conversatorios con personas conocedoras del tema y asistencia a charlas del Colectivo Chimbote de pie.

\subsubsection{Forma de análisis de la información}

La información será recopilada, procesada, interpretada y sintetizada en esquemas, gráficos, líneas de tiempo, mapas mentales y cuadros comparativos, de manera que se logre sintetizar y resaltar los aspectos más importantes de esta investigación. 


\subsubsection{Forma de presentación de la información}

Inicialmente, la información será presentada a través de una monografía, la cual incluirá tablas, esquemas, y líneas de tiempo, además del texto que se desarrollará junto con la investigación, la cual incluirá imágenes, esquemas, gráficos y tablas. La segunda parte, estará representada en planos de anteproyecto, que incluirá tanto plantas como cortes, elevaciones y plano de detalles. Se elaborará además planos de especialidades para complementar el proyecto, así como vistas 3D y maquetas. 


\section{CAPÍTULO II: MARCO HISTÓRICO - REFERENCIAL}

\subsection{Chimbote, tierra de promisión}

\subsubsection{Ubicación geográfica de Chimbote y la bahía El Ferrol}

El Distrito de Chimbote, se encuentra a $425 \mathrm{~km}$. al norte del departamento de Lima. Pertenece al departamento de Ancash y a la provincia del Santa. Cuenta con una extensión total de 3500 ha expandidas en un área de $10 \mathrm{~km}$ de longitud y $5 \mathrm{~km}$ de anchura. Se encuentra delimitado por el cerro Chimbote al norte, el cerro Península al sur, al este con terrenos agrícolas y por el oeste con la bahía El Ferrol. La bahía presenta una forma particular, es cóncava de norte de sur y se encuentra semicerrada por el norte por la Isla Blanca y por el extremo sur por las Islas Ferrol del Norte, del Medio y del Sur.

\section{Ilustración 2.1 Ubicación de Chimbote a nivel nacional y departamental}
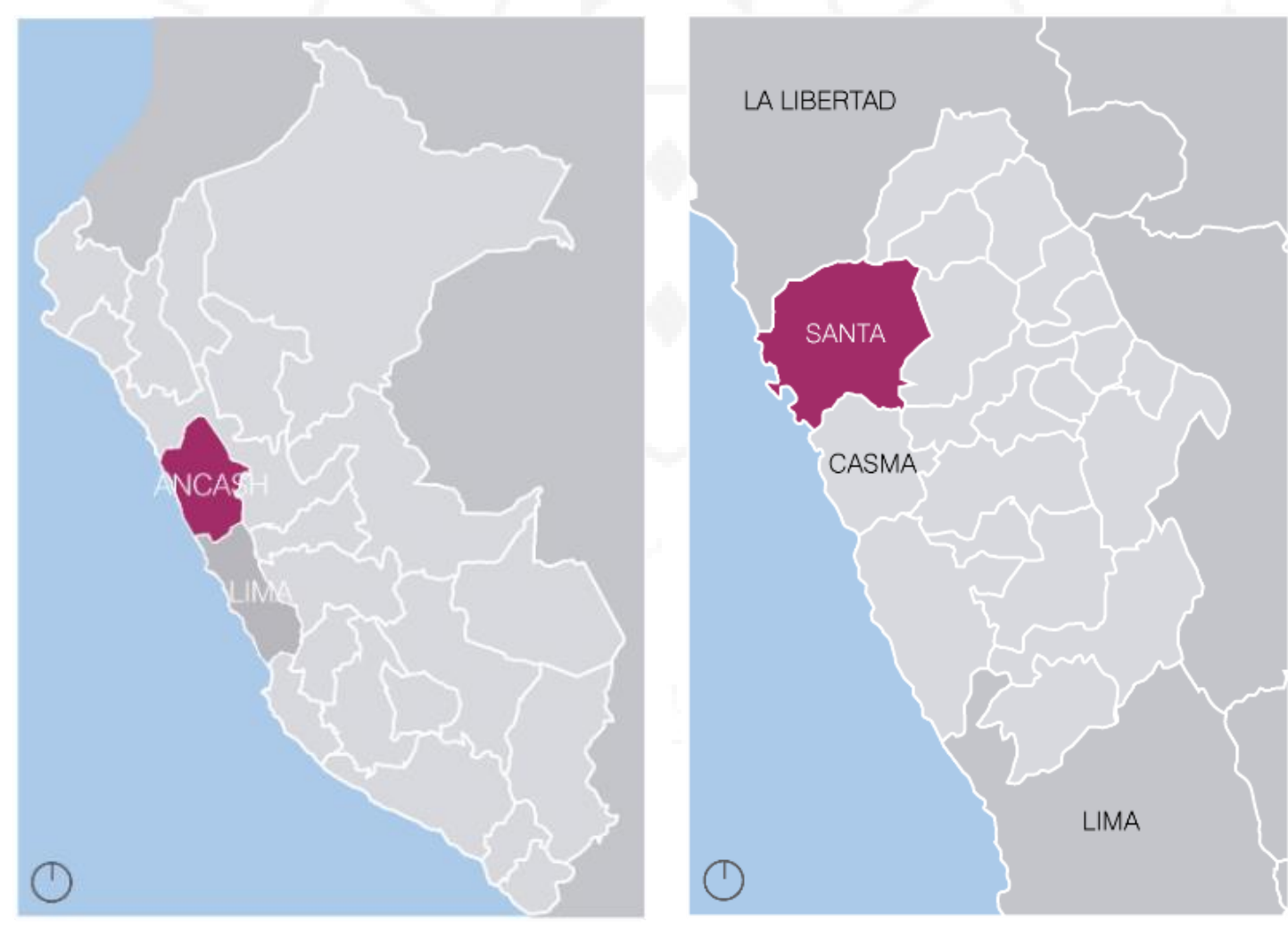

Fuente: PDU Chimbote 2012-2022. Elaboración propia 


\section{Ilustración 2.2 Ubicación de Chimbote con respecto a la provincia del Santa}

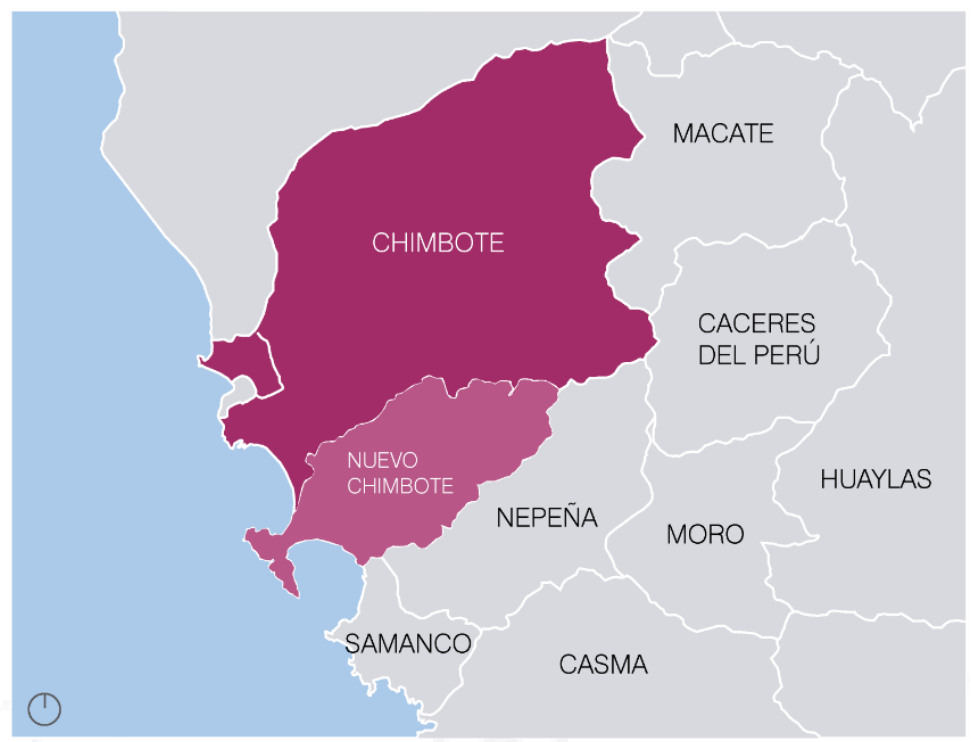

Fuente: PDU Chimbote 2012-2022. Elaboración propia

“... debido a la presencia de disposición de los factores orográficos, la comunicación entre las aguas de la bahía y el mar abierto se encuentra muy limitada, constituyéndose en el factor más importante para que el oleaje, en términos generales, al interior de la bahía sea moderado, y por otro lado que la renovación de las aguas sea lenta”. (Consejo Nacional del Ambiente del Perú, 2000, p. 16)

Con respecto a la organización de la ciudad, la mayor parte de esta se emplaza a lo largo de la bahía. Hacia el sur se encuentra la zona de Nuevo Chimbote, mientras que al este se encuentran las dunas y montañas. El pantanoso suelo dificultó el poblamiento del este de la ciudad en sus inicios, sin embargo, a la actualidad ya se encuentra urbanizado en su mayoría por viviendas.

La bahía el Ferrol tiene una longitud de siete millas y una anchura de cinco millas. Limita al sur con el Monte División y al norte con el cerro cónico de Chimbote. Dentro de ella se encuentran 3 islas llamadas Ferrol norte, Ferrol centro y la isla Blanca. Esta última es llamada así por su distintivo color blanco y es la más alta del conjunto, llegando a los 200 metros de elevación. 
Ilustración 2.3 Límites geográficos de la ciudad de Chimbote

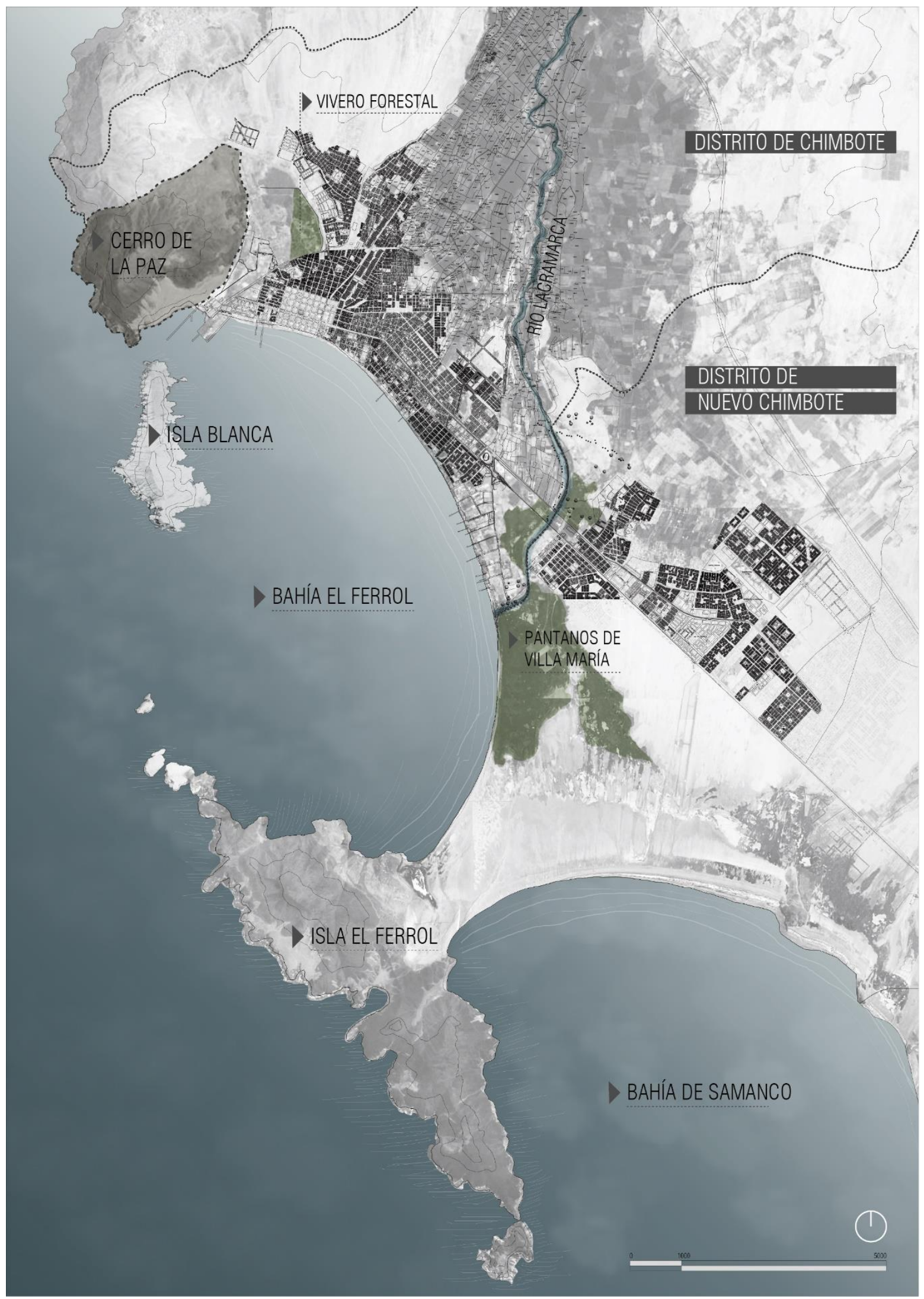

Fuente: PDU Chimbote 2012-2022. Elaboración propia 
Ilustración 2.4 Características generales de la Bahía El Ferrol

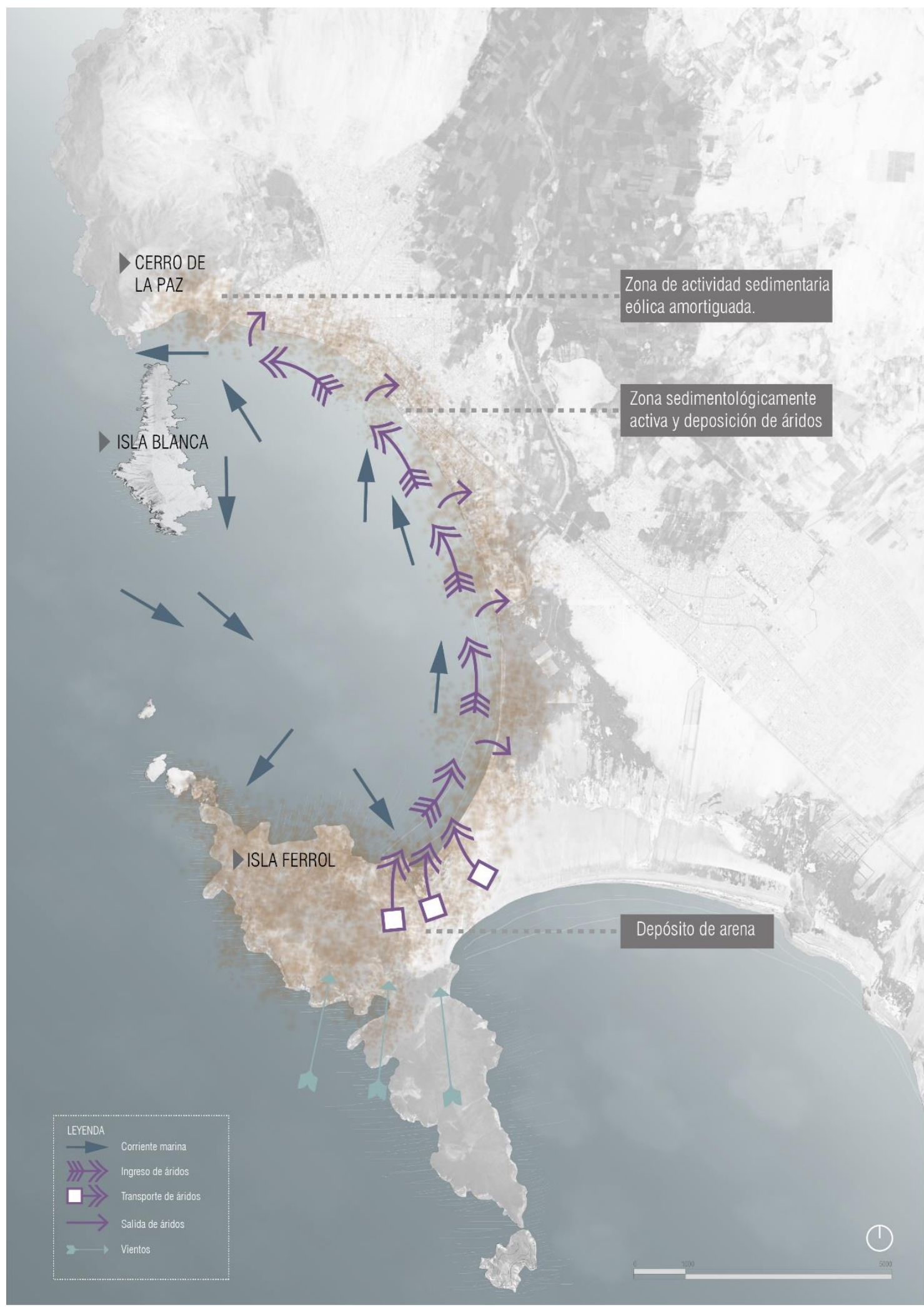

Fuente: Basado en Loayza, p.19. Elaboración propia 


\subsubsection{Del mar a la ciudad: Inicios como ciudad puerto}

Las primeras aproximaciones de la historia de Chimbote datan de la época Pre Inca, cuando las tierras se encontraban habitadas por la cultura Mochica, quienes representaron un importante rol en el desarrollo de los pueblos gracias a sus conocimientos sobre la pesca y agricultura. (PDU de la ciudad de Chimbote , 2012)

Al no existir un puente asentado sobre el río Santa, los pobladores ayudaban a cruzar a los viajeros por medio de caballos de totora. A esta actividad se le conocía como "chimbar" y a todos los que realizaban este oficio se les denominaba "chimbadores". Posteriormente se construyó un puente de totora que permitía cruzar el río Santa, donde pasaron luego las fuerzas libertadoras. En honor a los servicios prestados, Simón Bolívar decide llamar Chimbote a la ciudad. (PDU de la ciudad de Chimbote , 2012)

El primer poblador de Chimbote se remonta hacia el año 1760 y tenía oficio de pescador. Fueron los recursos marinos los que le permitieron no solo abastecerse, sino también suministrar a las comunidades cercanas. Este fácil y cómodo medio de subsistencia le permitió establecerse en Chimbote y empezar a formar una familia; los primeros pobladores chimbotanos. (Blass, 2003)

Las primeras divisiones de terrenos se dieron en agosto de 1870, cuando al señor Víctor Hurtado le fueron atribuidos gran cantidad de lotes que iban desde el mar hasta Río Seco. Poco después, Hurtado vendió estos terrenos a Juan Gilberto Meiggs, hermano de E. Meiggs, quién solicitaría la construcción del ferrocarril más adelante. En diciembre del siguiente año Meiggs solicita al gobierno el proyecto para empezar a formar una ciudad y un puerto que permita un intercambio comercial. El proceso duró un par de semanas hasta que finalmente el 27 de diciembre el presidente José Balta aprueba la propuesta argumentando además que la ciudad requería de edificios públicos y privados.

Debido al crecimiento acelerado de la población durante los siguientes años y a la falta de vías que imposibilitaban el transporte económico, se plantea el proyecto del futuro ferrocarril que logre conectar Chimbote con el resto de las regiones. La mayoría de departamentos ubicados en la parte central y sur del Perú ya contaban con ferrocarriles que lograban conectarlos.

Fue la construcción del ferrocarril de Chimbote a Recuay el 9 de diciembre de 1871, que permitió a Chimbote ser elevado a categoría de Puerto Mayor. Ocho largos 
años tardó la obra, y finalmente el 12 de febrero de 1872 se realizó la inauguración de dicho ferrocarril que por motivos económicos fue paralizado en el año 1875.

En 1872 también se construyó el primer muelle por Enrique Meiggs y se constató que Chimbote había adquirido la categoría de Puerto Mayor, por lo que surgió la relevancia de construir la aduana que permita organizar tanto las embarcaciones que ingresaban como las que salían del puerto. Este proyecto debía contener un almacén, oficinas e inclusive habitaciones para los empleados del puerto, es así como se aprobó esta obra e inició su construcción en mayo de 1872, posteriormente en julio empezaría el funcionamiento del muelle.

En 1879, Perú inicia la guerra con Chile, conflicto que había generado la destrucción de varias ciudades en el país y que no sería ajeno a Chimbote. En setiembre de 1880 las tropas chilenas llegaron a tierras chimbotanas en busca del coronel Andrés Avelino Cáceres, quien estaba al mando de las guerrillas peruanas que se dirigían al Callejón de Huaylas, por lo que debía tomar el ferrocarril en Chimbote. Lamentablemente, el invasor chileno Patricio Lynch dio la orden de incendiar el muelle y la aduana. Por este motivo, en abril de 1898 se convoca a un concurso para la construcción de un segundo muelle, quedando el diseño a cargo de Eduardo López de Romaña. La obra fue construida y culminó el 8 de julio de 1901. (Icochea, 2007) (Blass, 2003)

Ilustración 2.5 Vista del Hotel Chimú, hotel de turistas, desde la bahía El Ferrol

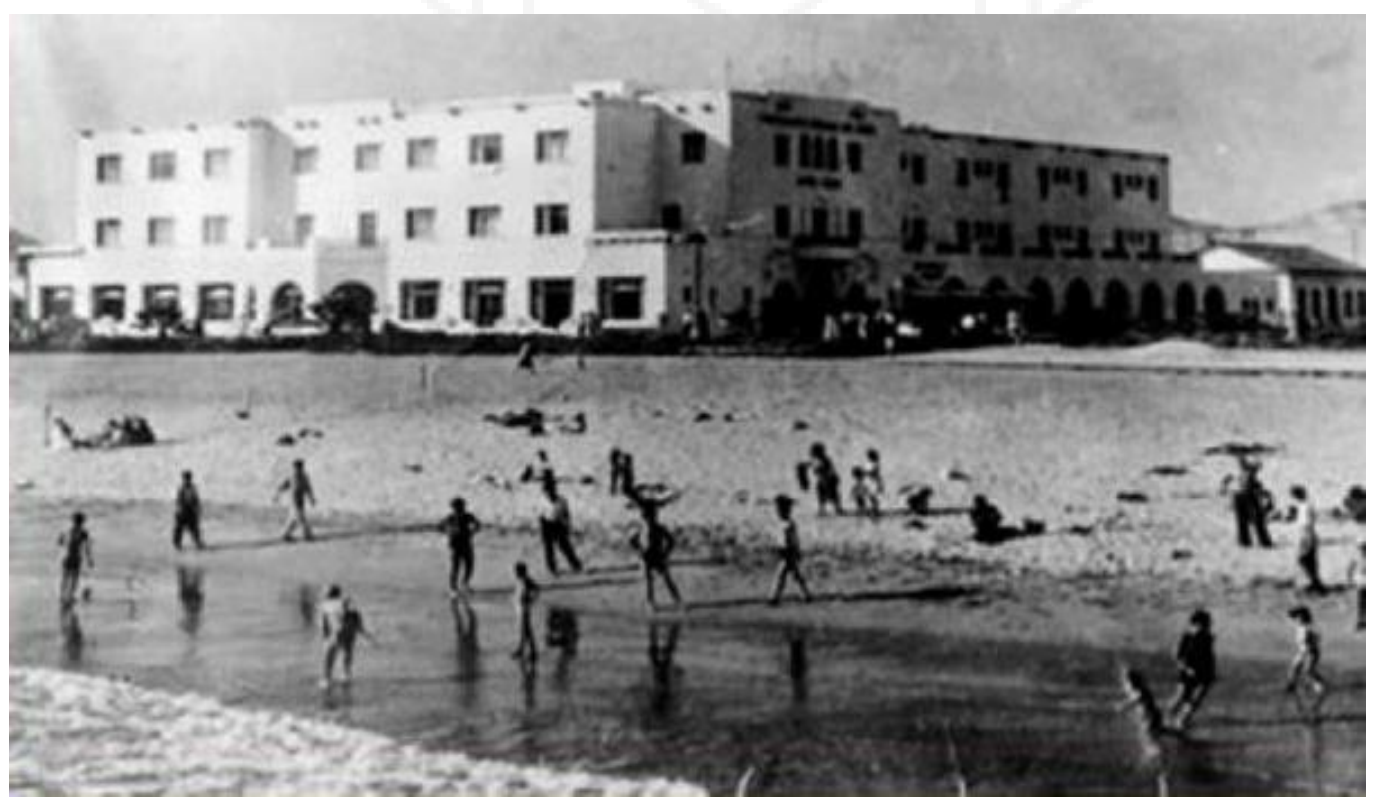

Fuente: Recuperado de www.chimboteenlaweb.com 
Es el 29 de octubre de 1895 que los diputados Fausto Valdevallano, Fidel Rodríguez, Belisario Rodríguez y Velis Huaylas solicitan que Chimbote se convierta en la capital del distrito del Santa. Este pedido fue debidamente sustentado mencionando que Chimbote ya contaba con una población más numerosa, además de contar con un mejor desarrollo comercial, una ubicación estratégica en cuanto a puerto pesquero y contar con un ferrocarril que permitía una conexión más estrecha con los pueblos vecinos.

El 27 de noviembre de ese mismo año, el congreso consideró aprobar la ley y elevar al pueblo de Chimbote como capital del distrito del Santa. El presidente Nicolás de Piérola promulga esta ley el 4 de diciembre de 1895.

En 1904 Meiggs fallece en Inglaterra, es debido a esto que los pobladores inician un proceso de adjudicación de terrenos, los cuales variaban entre 0.20 céntimos a S./ 1.00 el metro cuadrado. La única condición propuesta era que las viviendas debían iniciar su construcción en un plazo máximo de 6 meses. Si este proceso no se cumplía en su debido momento, el Estado debía proceder a la devolución del dinero.

El 4 de junio de 1943, el gobierno creó la Corporación Peruana del Santa, entidad encargada de desarrollar proyectos que logren explotar las riquezas del río Santa y sus afluentes, así como también construir obras públicas y administrarlas. Esta entidad también se encargó de desarrollar obras de beneficencia pública, como la construcción del hospital La Caleta, la arborización del vivero forestal, entre otros. (Blass, 2003) (Icochea, 2007)

Posteriormente en 1948, la cooperación decide encomendar a los Urbanistas Paul Wiener y Jose Luis Sert la realización de un estudio urbanístico de Chimbote a fin de reorganizar la ciudad para su futuro crecimiento, pues se estimaba que con la llegada de las industrias se generaría un crecimiento desordenado. Este plan no se concretó, por lo que fue necesario un segundo plan, el cual estuvo en manos de Ernesto Gastelumendi, quien proponía una zonificación industrial para las fábricas ligeras y pesadas, así como también una zona residencial y comercial. Lamentablemente, este también quedó archivado.

Entre los años 1945 y 1954 Chimbote experimenta un apogeo de la industria pesquera para el consumo humano. La primera fábrica instalada fue la pesquera Samanco, encargada de procesar grandes cantidades de bonito para generar conservas y exportarlas a Estados Unidos y Europa. Finalmente llegaron las fábricas de harina de pescado, las 
cuales se instalaron en el Barrio de Acero. Ya para el año 1964 existían 41 fábricas de harina de pescado y 7 de conservas. (Icochea, 2007) (Blass, 2003)

Alrededor de 1952 llegan a Chimbote los primeros empresarios pesqueros, quienes buscaban establecer plantas de harina de pescado en la zona costera. Ellos solicitan al alcalde Oscar Arciniega los permisos necesarios para llevar a cabo el desarrollo del proyecto. Sin embargo, este se niega, sustentando que la construcción de fábricas generaría contaminación, además de disminuir las actividades turísticas de la costa. Los empresarios al verse rechazados por la autoridad chimbotana se dirigen al Ministro del Interior Augusto Romero Lovo, quien les autoriza no solo la construcción de las fábricas en los terrenos costeros, sino que también envió un documento que destituía al alcalde chimbotano del poder. (Icochea, 2007) Es así como empiezan a instalarse las fábricas a lo largo de toda la bahía. Por otro lado, al no contar con un sistema de alcantarillado desarrollado empiezan a eliminar los efluentes al mar, iniciando así el ciclo de contaminación. La situación se agravó cuando la empresa siderúrgica Siderperú trajo abajo el "Cerro Colorado" generando que el agua del mar aumente su nivel y termine precipitándose hacia la población. Este suceso generó que el agua llegue hacia el malecón Grau por lo que los pobladores se vieron enfrentados a la necesidad de construir un enrocado que funcione como barrera hacia el mar. (Blass, 2003)

\section{Ilustración 2.6 Calles de Chimbote en plena producción de las fábricas pesqueras}
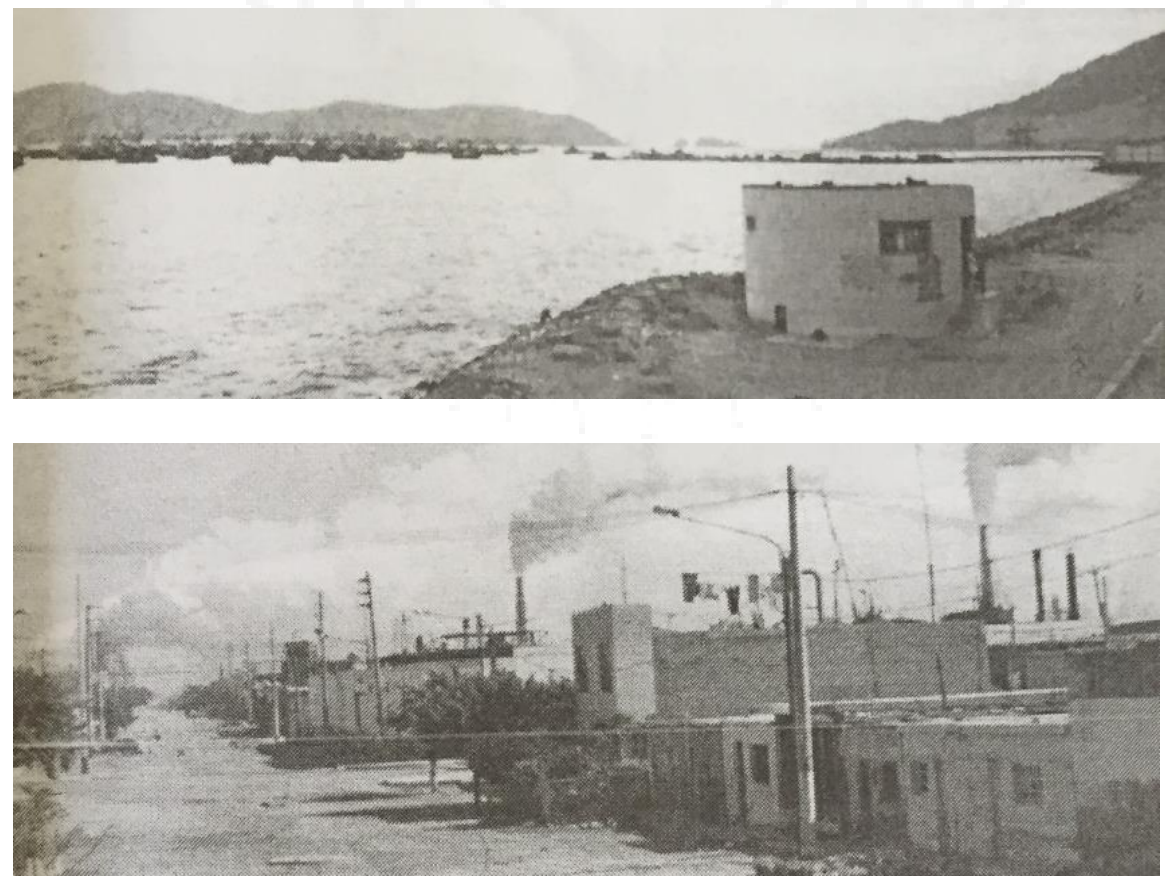

Fuente: Blass, p.40. 
Durante el gobierno de Velasco, alrededor de los años 70, se propone que, debido al constante crecimiento industrial, toda el área residencial y de equipamientos debía establecerse en el sur de Chimbote, específicamente en el distrito de Buenos Aires. No obstante, esta medida generó un escándalo a nivel nacional y fue rechazada por los pobladores, quienes sustentaban la imposibilidad de trasladar toda una ciudad hacia la zona sur. (Icochea, 2007)

Fue entonces cuando el gobierno decide establecer un plazo para la construcción del colector submarino, a fin de dirigir todos los desechos de la producción hacia la zona trasera de las islas del Ferrol, contrarrestando de este modo la contaminación que venía generándose en la bahía. Los dueños de las fábricas aceptaron construir este colector, no obstante, el día que vencía el plazo para la construcción de este se produce el gran sismo de 1970, que dejó la ciudad destruida y con proyectos más importantes por desarrollar.

Este gran sismo fue el factor desencadenante para que inicien los planes de ordenamiento de la ciudad. Este mismo año se da inicio a labores de reconstrucción y rehabilitación, que culminaron en el Plan Director de Chimbote, recibiendo ayuda además de las Organización de las Naciones Unidas (ONU).

\section{Ilustración 2.7 Vista de Chimbote en 1906}

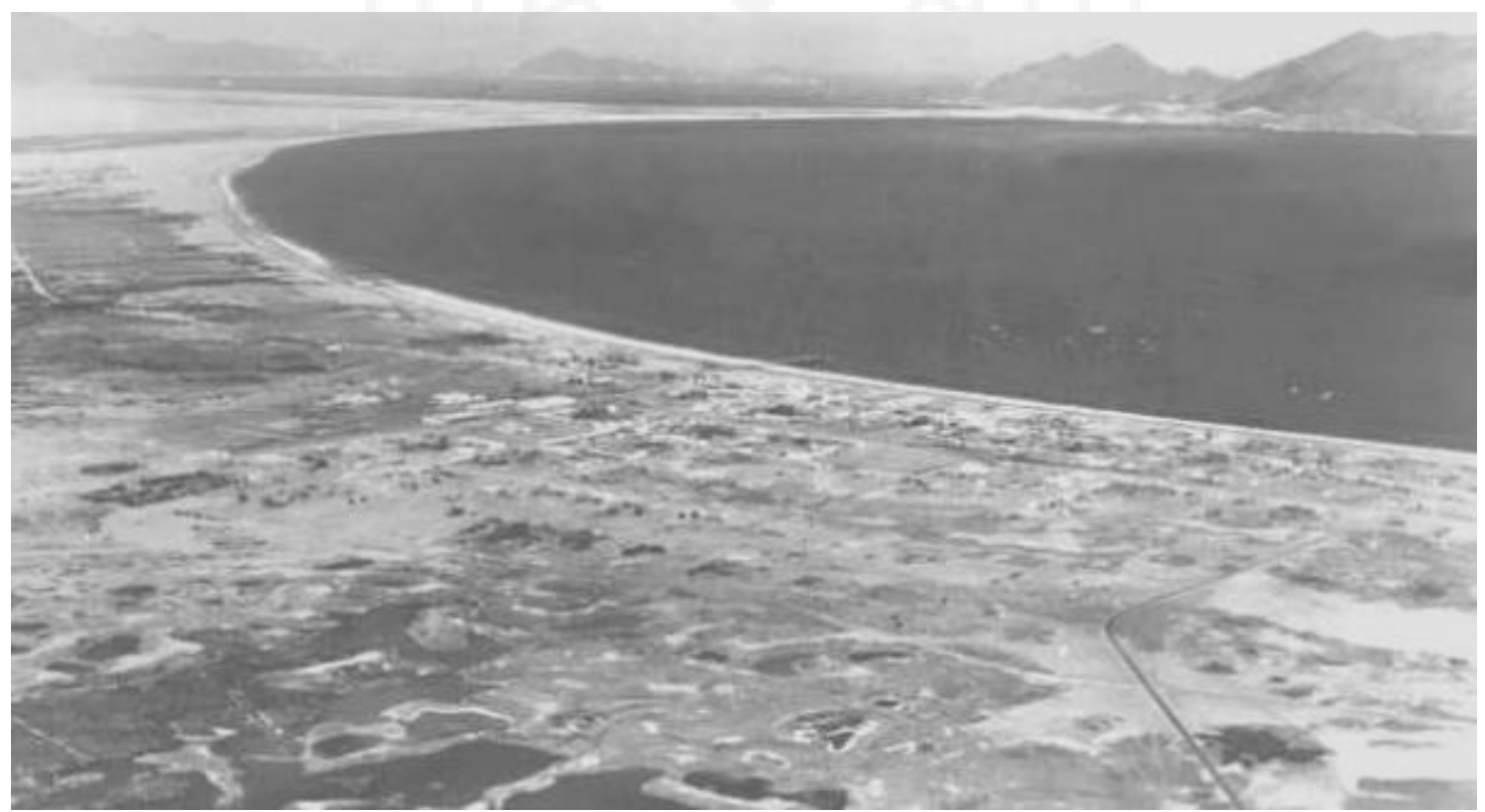

Fuente: PDU Chimbote 2012-2022, p. 
Ilustración 2.8 Vista de Chimbote en 1914

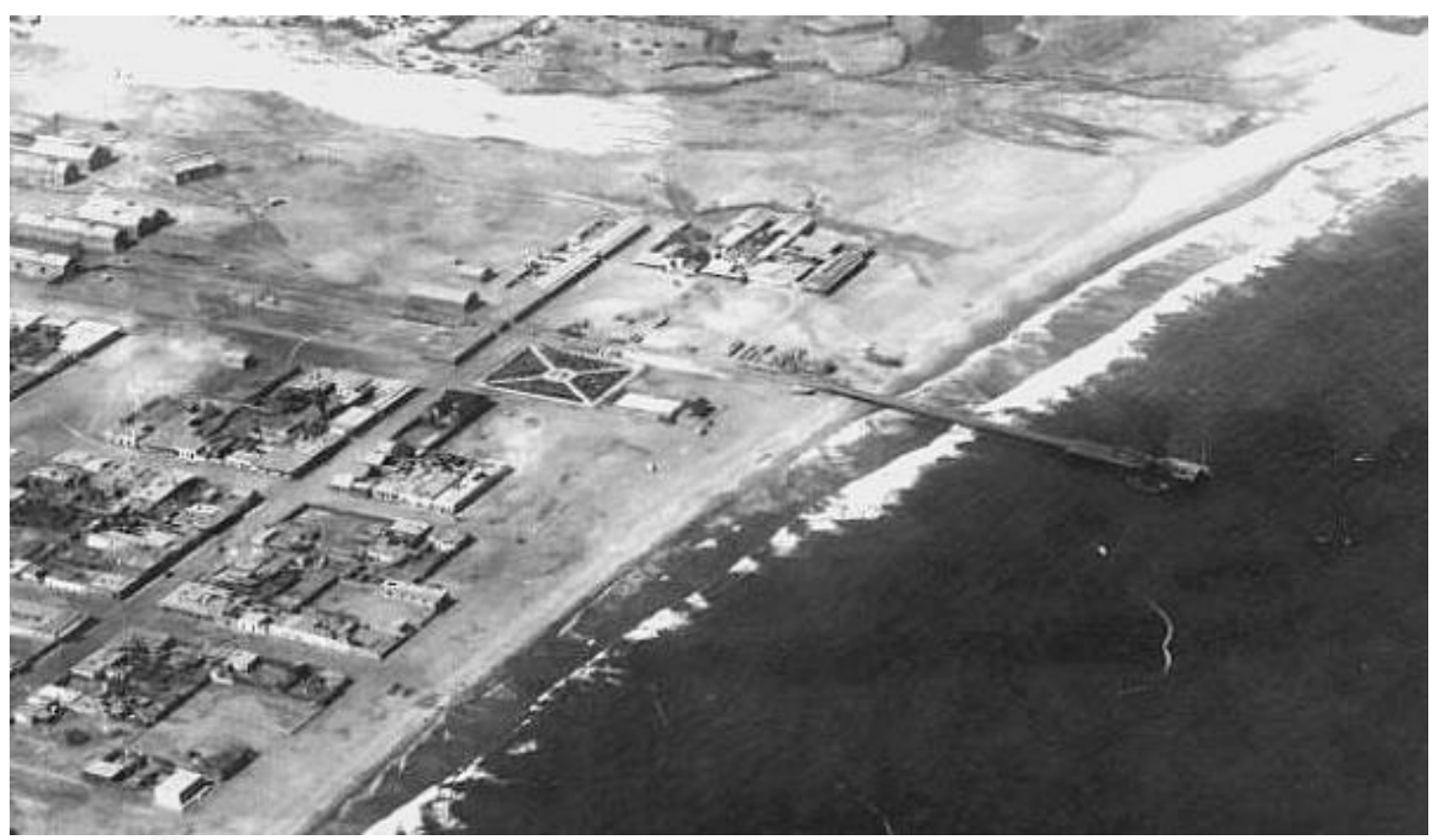

Fuente: PDU Chimbote 2012-2022, p.

En las siguientes imágenes se muestra el crecimiento de la ciudad de Chimbote a partir de la cuadrícula inicial establecida por Enrique Meiggs en 1872. En 1930, la ciudad creció alrededor de esta cuadrícula consolidando el centro de la ciudad. Hacia 1950, la ciudad ya se encontraba poblada hasta sus límites más cercanos; el cerro de la Juventud hacia el norte y el río Lacramarca por el sur, formando lo que hoy es el distrito de Chimbote. Posteriormente, la ciudad empieza a expandirse notablemente hacia el sur, es así como entre 1990 y 2010 ya se observa la extensión de Chimbote, lo que hoy está conformando el distrito de Nuevo Chimbote.

Tabla 2.1 Evolución urbana de Chimbote

\begin{tabular}{|c|c|c|c|c|}
\hline \multicolumn{5}{|c|}{ EVOLUCIÓN URBANA } \\
\hline AÑO & N HABITANTES & $\begin{array}{c}\text { ÁREA } \\
\text { URBANA(Ha) }\end{array}$ & $\begin{array}{c}\text { DENSIDAD } \\
\text { BRUTA }\end{array}$ & $\begin{array}{c}\text { TASA } \\
\text { CRECIMIENTO } \\
(\%)\end{array}$ \\
\hline 1930 & 4243 & 81.00 & 52 & \\
\hline 1950 & 40000 & 164.00 & 244 & 11.2 \\
\hline 1970 & 160000 & 2300.00 & 70 & 6.5 \\
\hline 1990 & 260000 & 3504.00 & 74 & 2.5 \\
\hline 2010 & 340000 & 5135.87 & 66 & 1.2 \\
\hline
\end{tabular}

Fuente: INEI Censo2007 
Ilustración 2.9 Tejido urbano de Chimbote en 1872

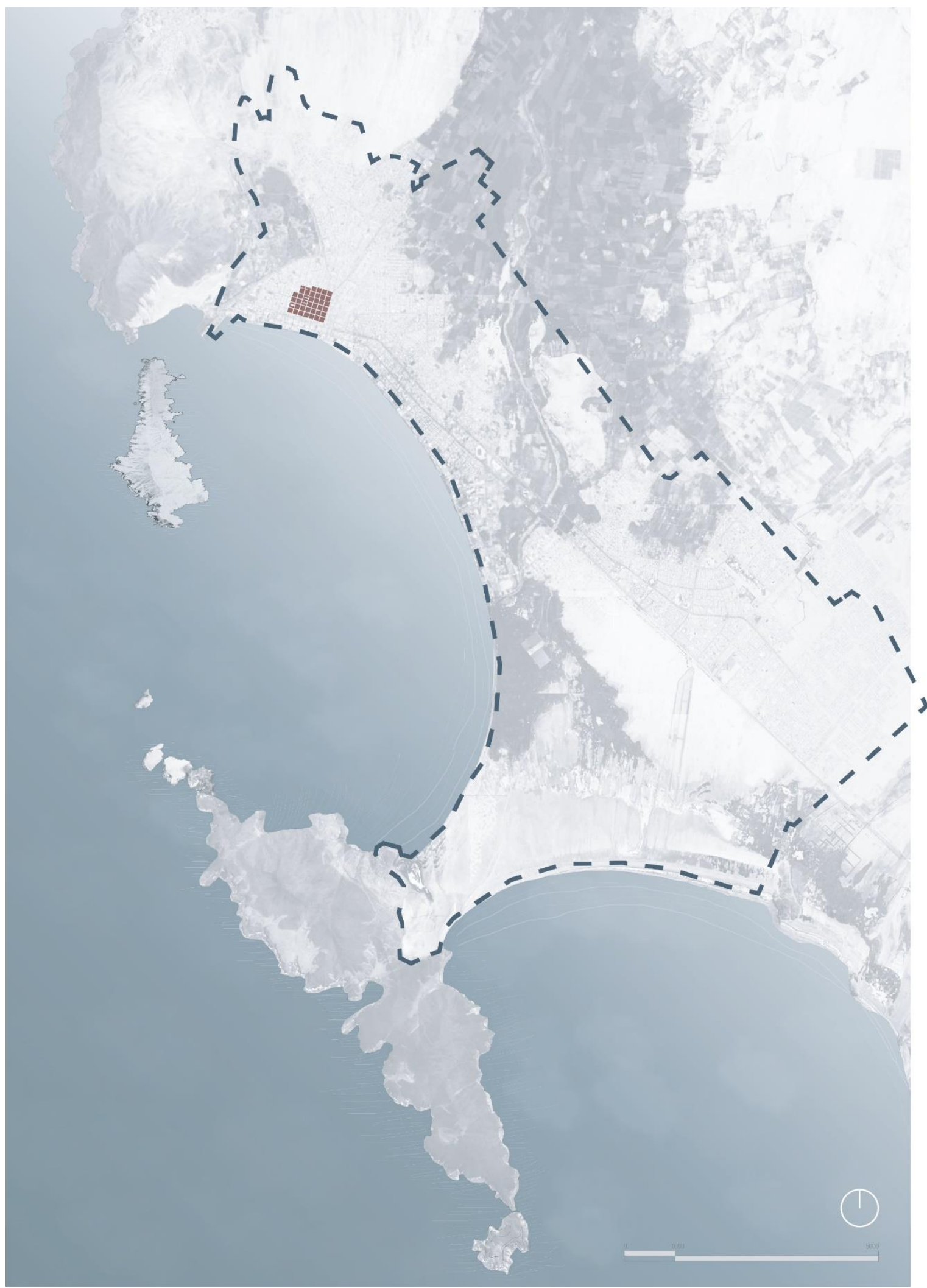

Fuente: PDU Chimbote 2012-2022, p. 
Ilustración 2.10 Tejido urbano de Chimbote en 1930

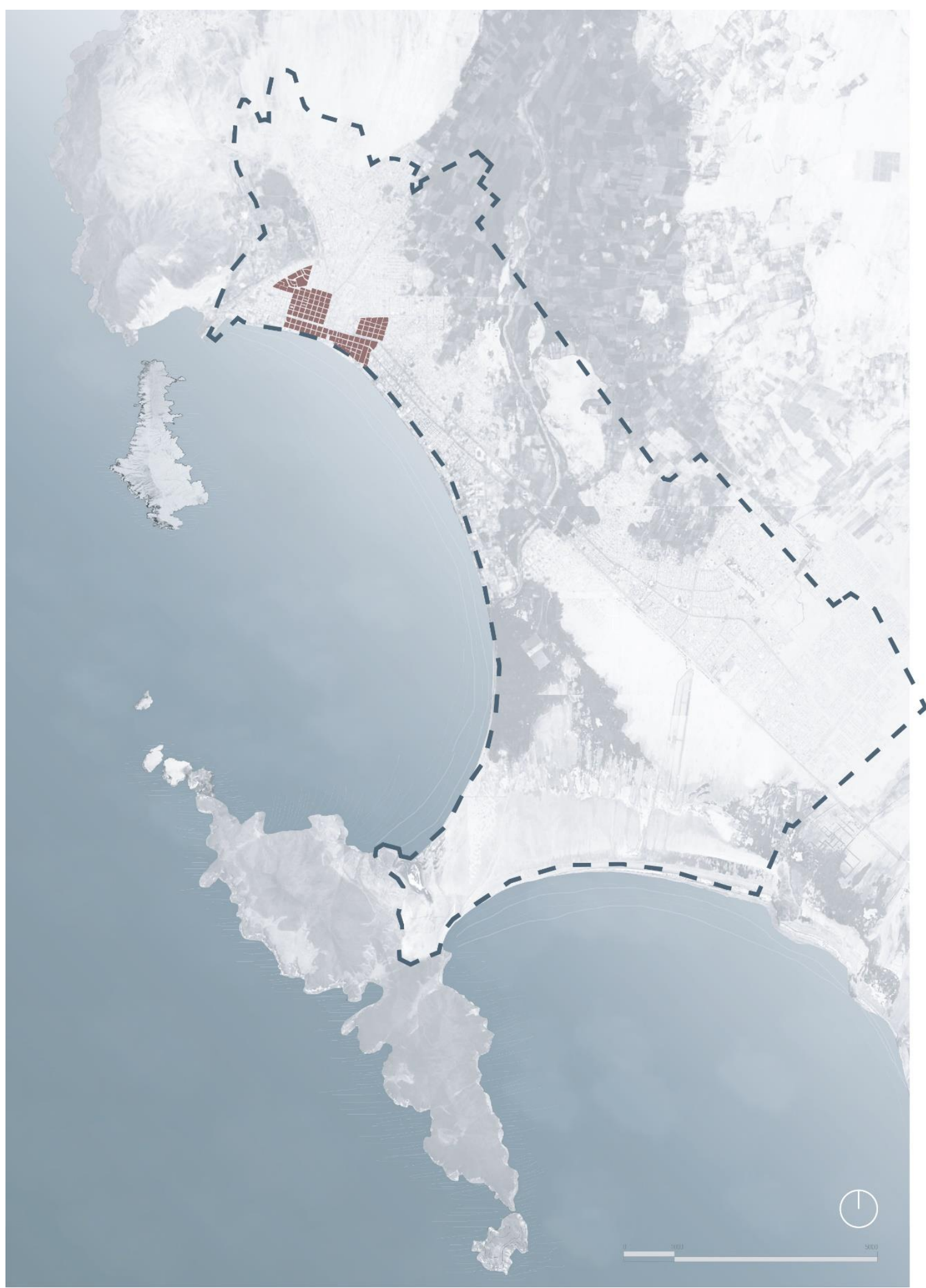

Fuente: PDU Chimbote 2012-2022, p. 
Ilustración 2.11 Tejido urbano de Chimbote en 1950

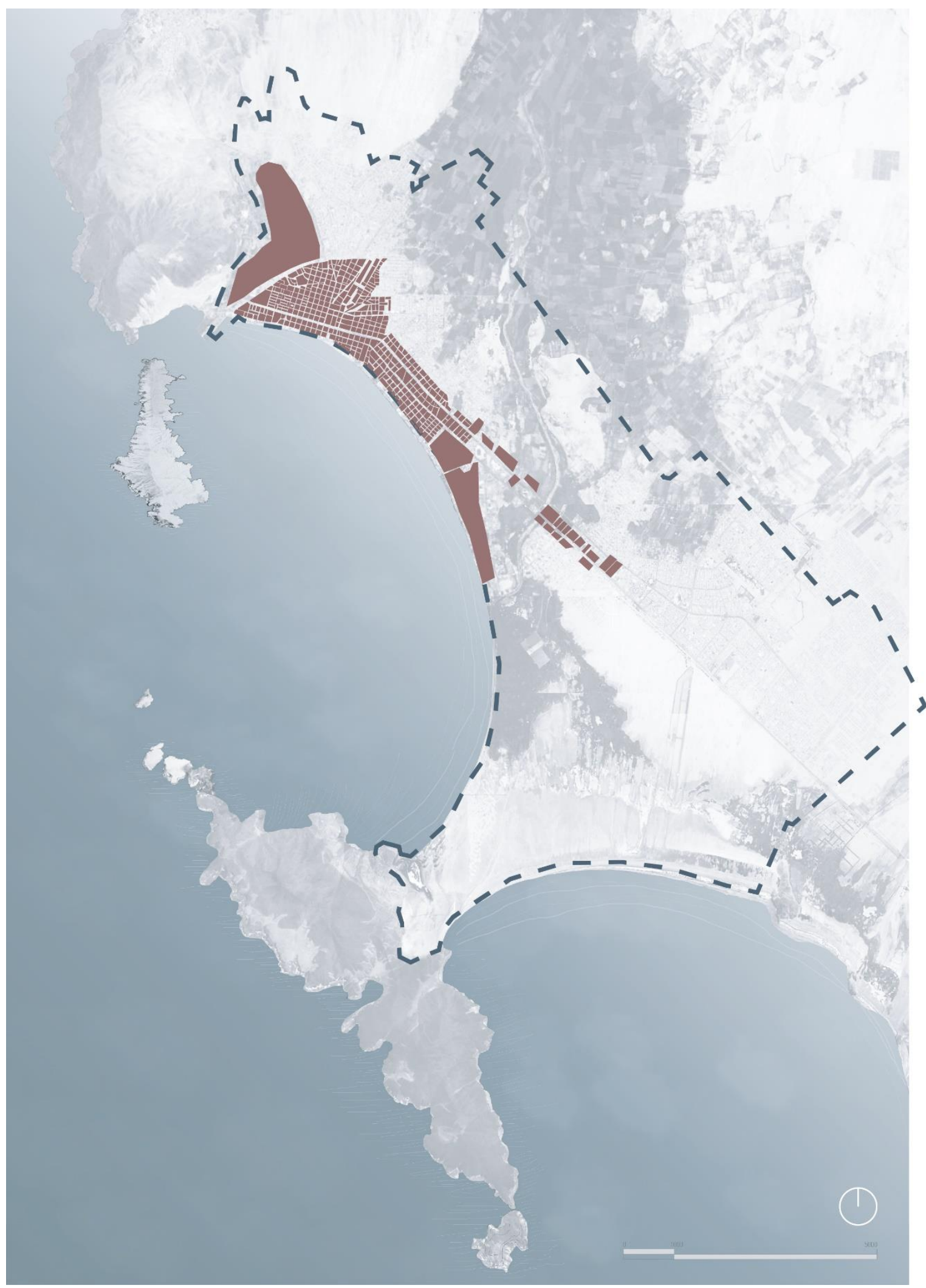

Fuente: PDU Chimbote 2012-2022, p. 
Ilustración 2.12 Tejido urbano de Chimbote en 1970

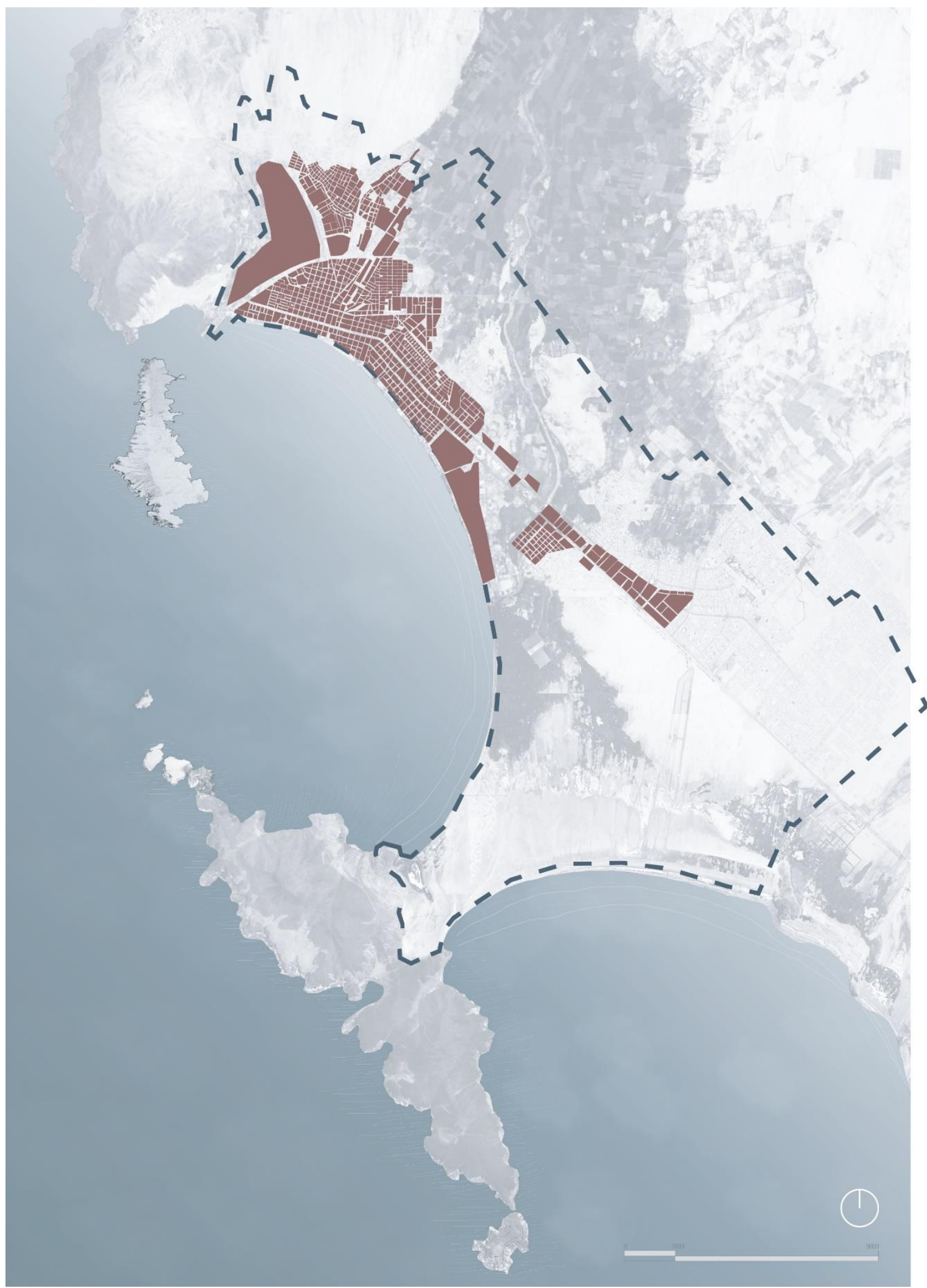

Fuente: PDU Chimbote 2012-2022, p. 
Ilustración 2.13 Tejido urbano de Chimbote en 1990

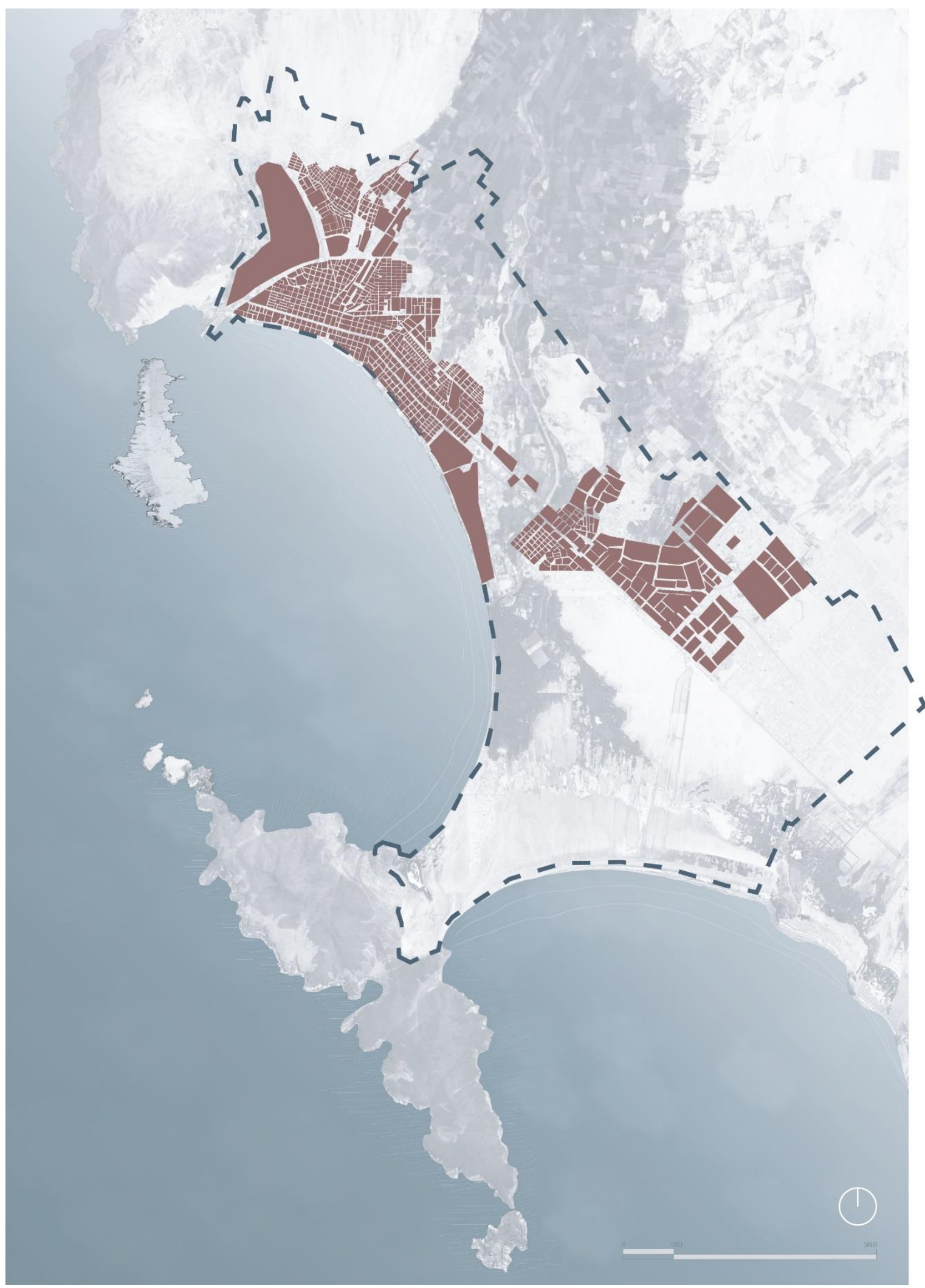

Fuente: PDU Chimbote 2012-2022, p. 
Ilustración 2.14 Tejido urbano de Chimbote en 2010

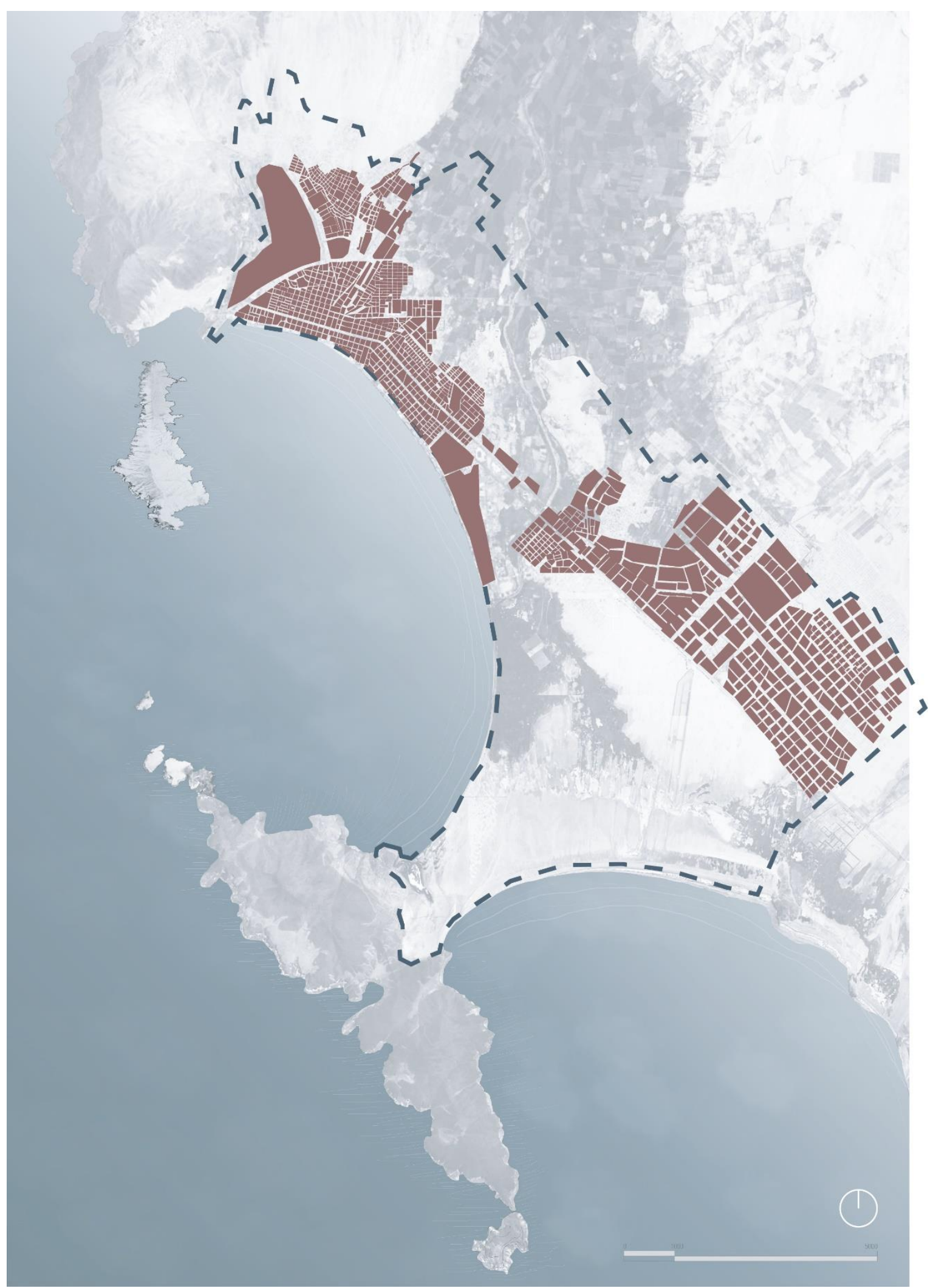

Fuente: PDU Chimbote 2012-2022, p. 


\subsubsection{Aproximaciones a la planificación urbana de Chimbote}

\section{Plan Regulador de Gilberto Meiggs}

En diciembre de 1871, Juan Gilberto Meiggs presentó al gobierno un plan de reordenamiento de la ciudad en respuesta al crecimiento desmedido que se estaba generando en los últimos años.

Este plan suponía la creación de sesenta manzanas de $10000 \mathrm{~m}^{2}$ cada una; diez manzanas de largo por 6 de ancho. La primera iniciaba donde hoy se encuentra el hotel Chimú. Además, se cedía al gobierno la manzana número 5, la cual vendría a ser destinada a la futura aduana. La treinta y uno se convertirían en el mercado, la mitad de la veintitrés para la oficina de correos y cuartel, la mitad de la treinta y cinco para la iglesia, y la cuarta parte de la veinticinco para la municipalidad. Hacia el lado derecho de las manzanas se estableció un gran terreno de $120000 \mathrm{~m}^{2}$ para la estación del ferrocarril. (Blass, 2003)

Cada manzana estaba conformada por 10 lotes, cada uno con dimensiones de 20 x 50 metros de ancho.

\section{Ilustración 2.15 Plano de Chimbote propuesto por Meiggs en 1906}

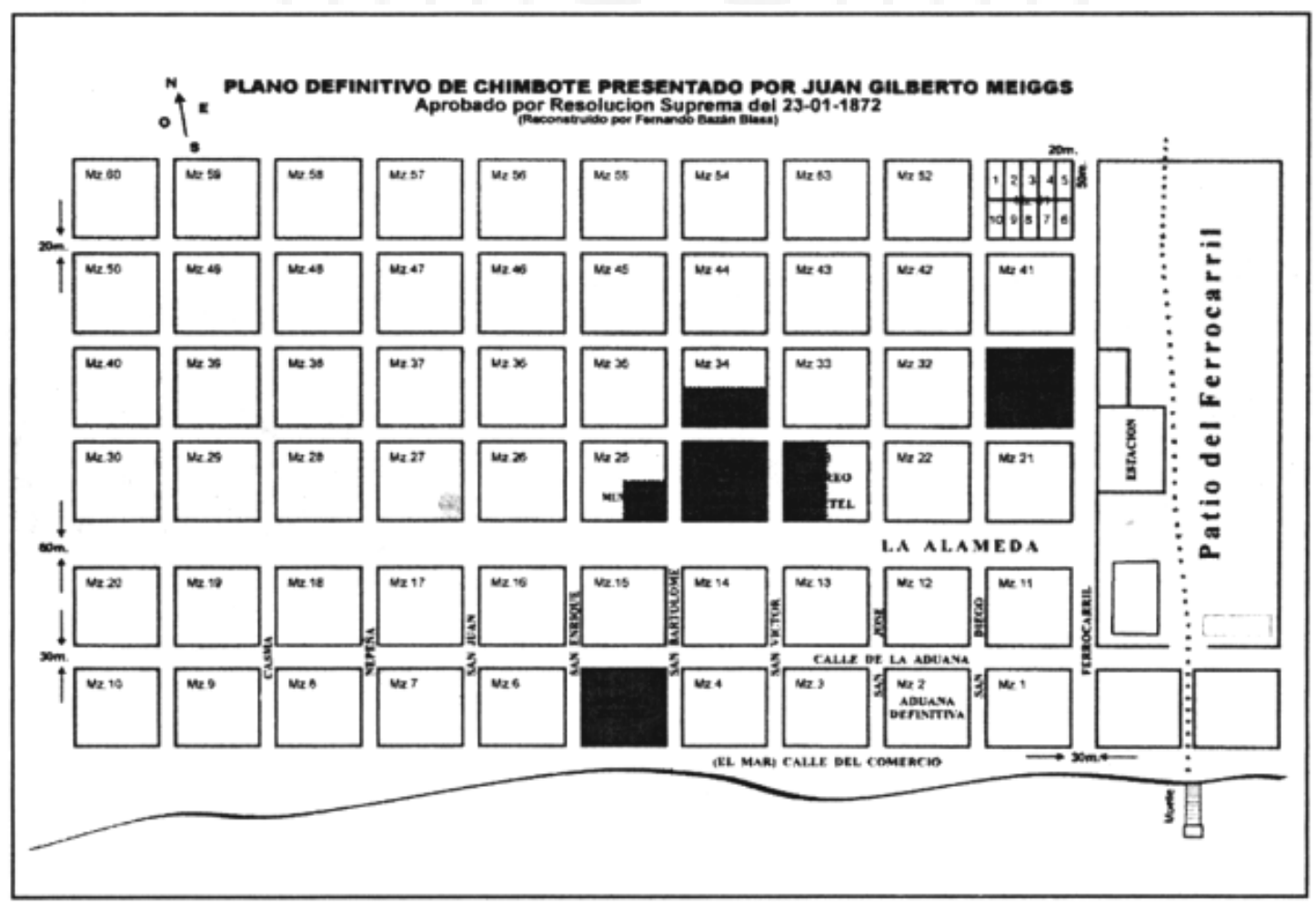

Fuente: 250 Año de Historias y Leyendas de Chimbote 


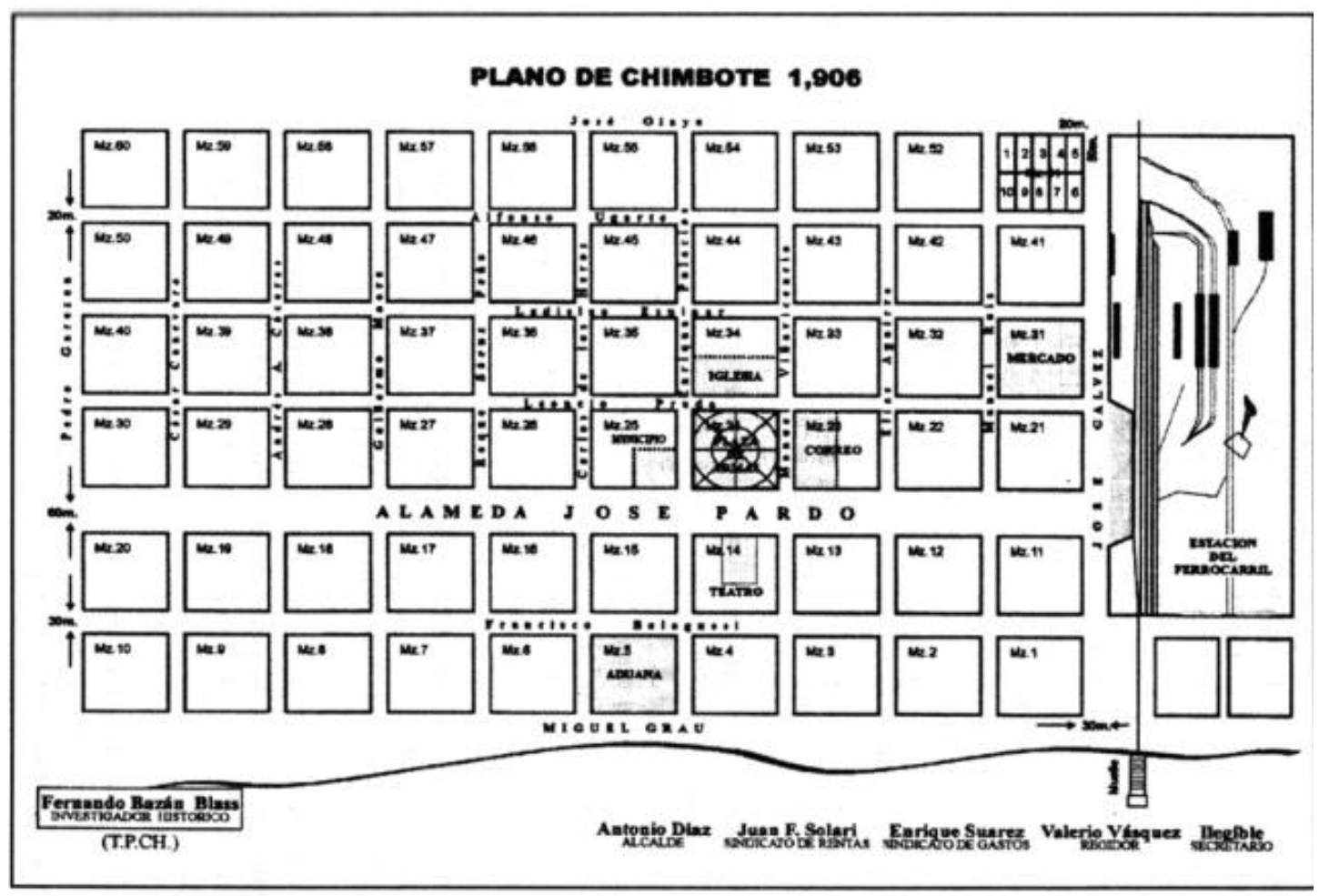

Fuente: 250 Año de Historias y Leyendas de Chimbote

\section{Plan Regulador de Chimbote- Sert y Wiener}

El principal objetivo tanto de Jose Luis Sert como de Paul Weiner, era crear una ciudad ordenada con equipamiento para los pobladores chimbotanos a fin de evitar un crecimiento desordenado de esta. Se preveía además que, con el crecimiento industrial, la población aumentaría notablemente. Sin embargo, al contar con una población que vivía de su principal actividad económica, la cual era la pesca, fue imprescindible partir por construir un puerto adecuado para sus trabajadores. (Aldo Facho, 2016)

El plan de Sert y Weiner principalmente proponía eliminar las chozas de barro presentes en el plan de Gilberto Meiggs y diseñar viviendas para una población de 12000 habitantes. Se propuso además reactivar los canales de irrigación existentes, con el objetivo de huertas que puedan alimentar los futuros parques de la ciudad. (Aldo Facho, 2016) El plan proponía sectorizar la ciudad en dos unidades residenciales de 6000 habitantes e incluía una amplia red vial con cuatro carriles para la pista panamericana.

Para el diseño del Centro Cívico se proyectó una gran plaza central con edificaciones que la rodeaban. La gran plaza tendría acceso tanto peatonal como vehicular y contenía equipamientos como una iglesia, un campanario, una biblioteca y un museo. 
Junto a la plaza también se proyectaron edificios comerciales rodeados de pequeños patios.

En referencia al diseño de las viviendas, estas fueron proyectadas para contar tanto con una, dos o tres plantas y un gran espacio central que permita a los usuarios desarrollar actividades al aire libre. (Borga, 2009) Se introdujo una nueva tipología de vivienda basada en la casa patio con estructuras de ladrillo, por lo que requerían menor conocimiento tecnológico y eran más factibles económicamente. Además, al contar con una población agricultora y ganadera, las viviendas eran provistas con espacios para guardar animales. (Borga, 2009) El conjunto de estas viviendas con patios representaban una modalidad de alta densidad y baja altura, lo cual se adaptaba al suelo árido de Chimbote.

Ilustración 2.17 Vista del Plan Regulador de Sert y Wiener

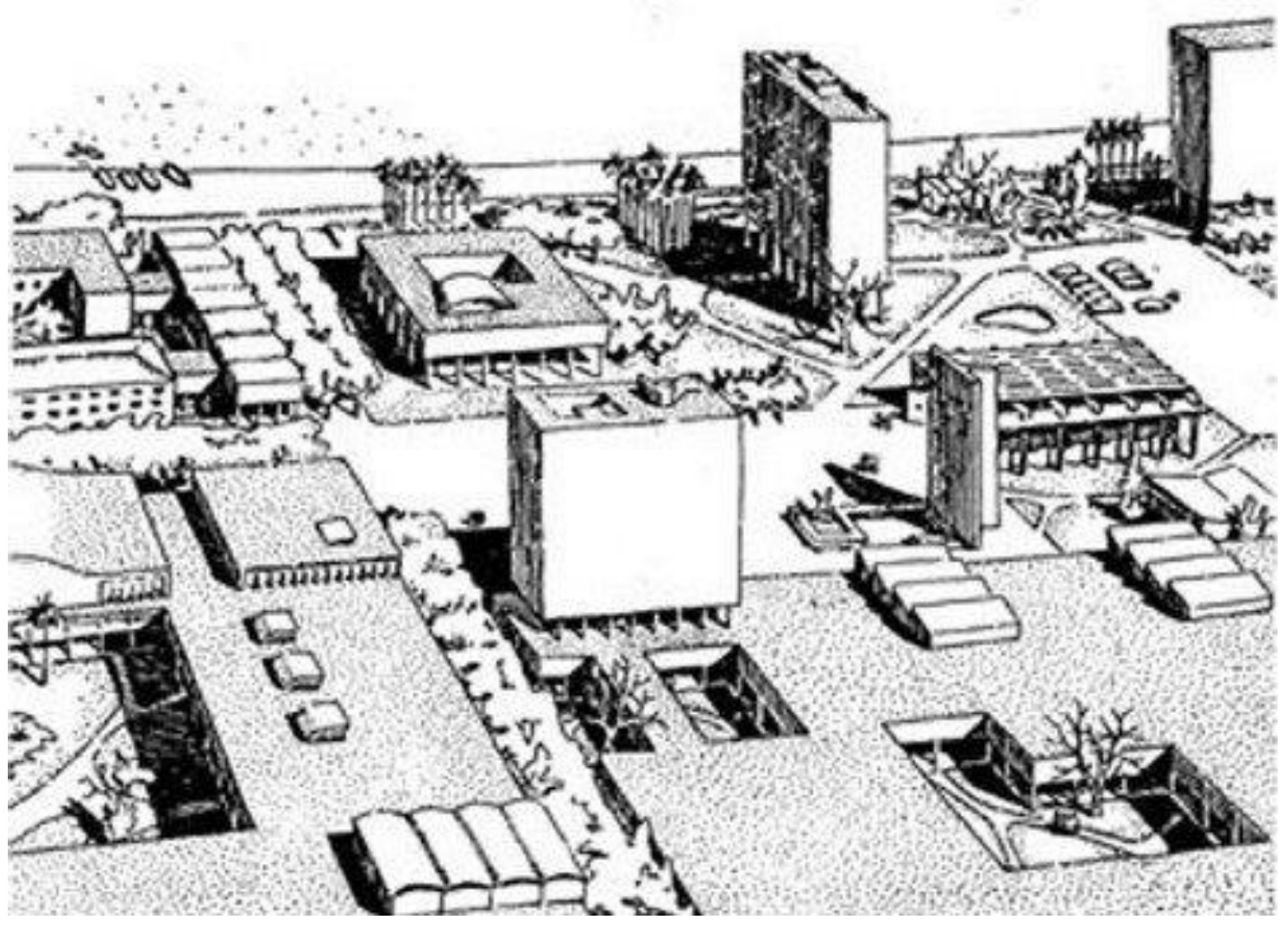

Fuente: Recuperado de www. habitar-arq.blogspot.com/2016/06/chimbote-entre-lautopia-y-la_8 
Ilustración 2.18 Propuesta de casa patio del Plan Regulador

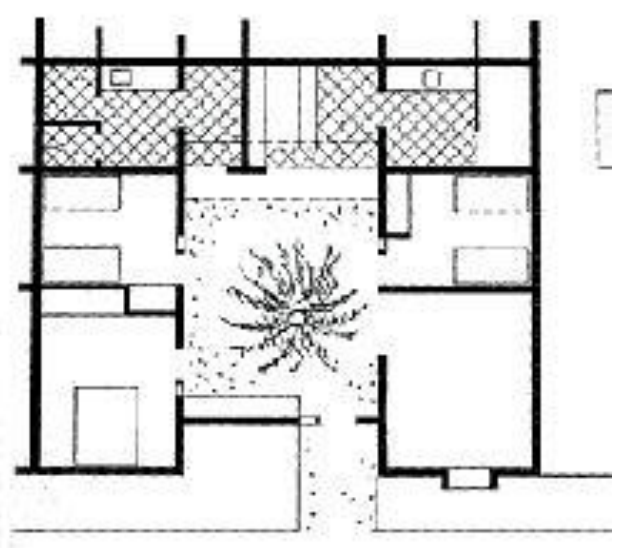

Fuente: Burga, 2009

Ilustración 2.19 Elevación de la casa patio del Plan Regulador

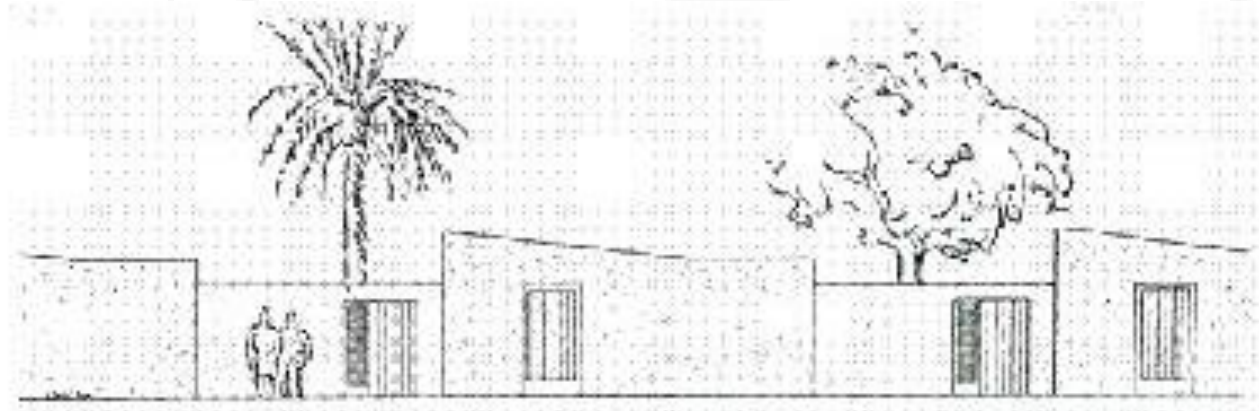

Fuente: Burga, 2009

Ilustración 2.20 Vista aérea del Plan Regulador

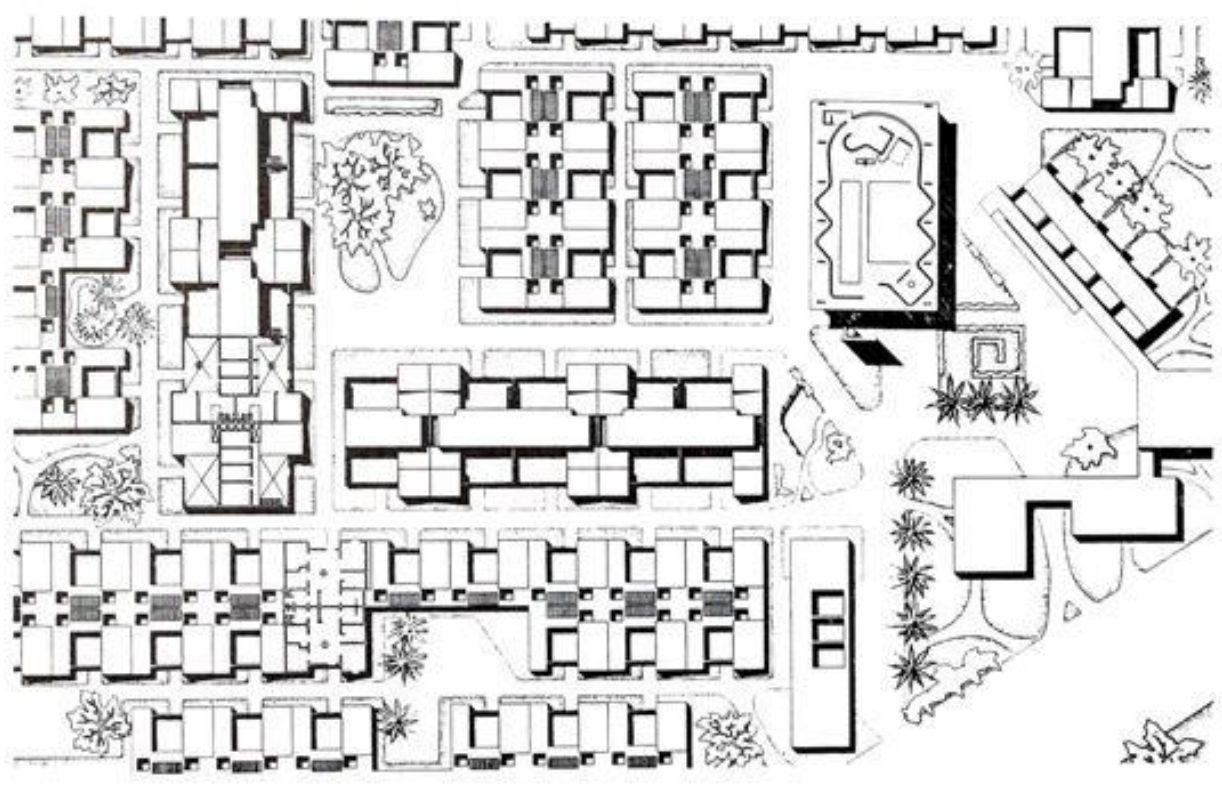

Fuente: Burga, 2009 
El plan desarrollado por Sert y Wiener fue abandonado, quedando como modelo teórico debido a que sus propuestas se alejaban de la realidad a través de edificios monumentales sumamente altos que el suelo de Chimbote no podría soportar.

\section{Plan de Gastelumendi}

Surge debido a que el plan director propuesto por Jose Luis Sert y Paul Wiener quedó obsoleto. Se buscaba un proyecto que se adapte a la realidad de Chimbote, sobre todo a la baja densidad que presentaba.

Hacia el año 1952 se contrata al arquitecto Ernesto Gastelumendi para que junto con la ONPU (Oficina Nacional de Planeamiento y Urbanismo) coordinen el nuevo plan director de Chimbote. Este plan proponía una zonificación industrial para las fábricas ligeras y pesadas, así como también una zona residencial y comercial. (Aldo Facho, 2016) (Blass, 2003) Este plan fue aprobado el 11 de junio de 1952, no obstante, no llegó a concretarse.

\section{Plan Director de Chimbote}

Se creó a raíz del terremoto de 1970, ya que era de suma emergencia la reconstrucción y desarrollo integral de la ciudad de Chimbote. Fue formulado en 1972 y su principal objetivo fue establecer las pautas para la expansión de la ciudad tanto a corto, mediano y largo plazo. Para el desarrollo de este plan se debió realizar un estudio de la realidad de la ciudad con el objetivo de entender su futuro crecimiento urbano y poblacional. (Ministerio de Vivienda, 2013) (PDU de la ciudad de Chimbote , 2012)

Este plan contiene la síntesis de los estudios y análisis de la problemática encontrada en Chimbote, así como también soluciones técnicas y de infraestructura. El plan a largo plazo establece el desarrollo hasta el año 1990.

El objetivo principal fue disminuir la sobrecarga en la zona del casco urbano, enfrentando la posibilidad de generar un nuevo sistema urbano que permita el adecuado desarrollo de la población. Por este motivo CRYRZA plantea el traslado de los pobladores hacia Nuevo Chimbote, ya que se consideraba una zona más segura ante el peligro de la licuación de suelos. (PDU de la ciudad de Chimbote , 2012) 
Tabla 2.2 Prognosis del desarrollo demográfico de Chimbote (1972 - 1990)

\begin{tabular}{|c|c|c|c|c|}
\hline AMBITO & 1972 & 1975 & 1980 & 1990 \\
\hline $\begin{array}{l}\text { Ciudad de } \\
\text { Chimbote }\end{array}$ & $159,000 \mathrm{Hab}$ & $235,000 \mathrm{Hab}$ & $335,000 \mathrm{Hab}$ & $640,000 \mathrm{Hab}$ \\
\hline
\end{tabular}

Fuente: Plan Director de Chimbote 1972 - 1990. Elaboración CRYRZA

\section{Plan de Organización de las Naciones Unidas}

Este plan fue creado en el año 1973 a raíz del terremoto de 1970 a través del Programa Nacional de Desarrollo Urbano. En este, se proponía reubicar a todas las fábricas y alejarlas de las zonas residenciales y principalmente de la bahía. Este proceso no se concretó completamente ya que muchas fábricas no se reubicaron y pasaron a formar parte del paisaje urbano. (Aldo Facho, 2016)

\section{Plan de INADUR 2000}

Se genera a manera de alternativa de prevención ante posibles desastres naturales, además de conseguir un reordenamiento de la ciudad frente a un desarrollo previo que requería actualización. Fue presentado en 1997 y buscaba actualizar el Plan Director de Chimbote propuesto por CRYRZA, teniendo en cuenta los cambios generados por el crecimiento urbano. El Plan de Usos de Suelos de Chimbote actualiza los cambios que se habían generado en la ciudad con el objetivo de realizar un adecuado desarrollo urbano.

Este plan consideraba continuar con el crecimiento lineal hacia el sur de la ciudad, siguiendo con los ejes viales longitudinales. La expansión urbana se proyectó en tres etapas; a corto, mediano y largo plazo. Sin embargo, el crecimiento de Chimbote se veía condicionado por los siguientes límites geográficos: Al norte por los Cerros Huamanchacata y Tambo Real, por el este con terrenos agrícolas, por el oeste con la bahía y por el sur con terrenos eriazos. Es debido a esto que la mayor expansión se dio hacia el sur, con el surgimiento de Nuevo Chimbote.

\section{Plan de Recuperación Ambiental de la bahía el Ferrol}

Creado en el año 2012 por el Ministerio del Medio Ambiente con la finalidad de incentivar el interés por detener la contaminación y deterioro de la bahía. 
El objetivo fue lograr la recuperación de las condiciones ambientales de la bahía a través de cuatro principales componentes: control de descargas de efluentes líquidos, control de la sedimentación y erosión, control de residuos sólidos y fortalecimiento institucional. ( Ministerio de Ambiente, 2012) Como principales objetivos se estableció recuperar la calidad del agua, sancionar el arrojo de residuos, recuperar la biodiversidad de la bahía, retirar las embarcaciones contaminantes y la calidad del fondo marino.

( Ministerio de Ambiente, 2012)

Se trabajó de la mano con la Ley General del Medio Ambiente, propuesta también en el año 2012, en ella se encargaba la aprobación del Plan de Recuperación Ambiental de la bahía El Ferrol ${ }^{8}$ y de tomar las medidas necesarias para que este plan se implemente.

\section{Plan de Desarrollo Urbano de la ciudad de Chimbote 2012-2021}

Este Plan surge en consecuencia de que los planes anteriores como el propuesto por CRYRZA no llegaban a tener la jerarquía de un Plan de Desarrollo Urbano. Se buscaba promover el desarrollo integral de la ciudad, pero siempre manteniendo concordancia con el Plan de Acondicionamiento Territorial. En él se establece:

- Un modelo de desarrollo urbano que permita fortalecer los niveles de eficacia territorial

- Lineamientos y estrategias de desarrollo urbano

- Clasificación de suelos para futuras intervenciones urbanísticas

- Un plan vial y de transporte

- Sectorización de equipamientos de recreación, seguridad, educación, salud, entre otros.

- Demanda de nuevas viviendas

- Los requerimientos de saneamiento ambiental (PDU de la ciudad de Chimbote , 2012)

\subsubsection{Chimbote en la actualidad}

La ciudad de Chimbote en la actualidad se observa como un territorio extenso de baja densidad que se prolonga hacia el sur bordeando la bahía. El perfil urbano de la ciudad

\footnotetext{
${ }^{8}$ Ver Anexo $\mathrm{N}^{\circ} 04$
} 
es longitudinal con muy pocos edificios altos, siendo estos de uso comercial y de equipamientos privados de educación y salud.

La ciudad de Chimbote cuenta con la conurbación de los distritos de Chimbote y Nuevo Chimbote, que están estrechamente ligados tanto territorial como socioculturalmente. Estos están conectados físicamente por dos vías de alto flujo vehicular; la Av. Meiggs o vía panamericana que soporta vehículos de carga pesada y la Av. Pardo de flujo vehicular liviano.

\section{Ilustración 2.21 Vista de la extensión de Chimbote}

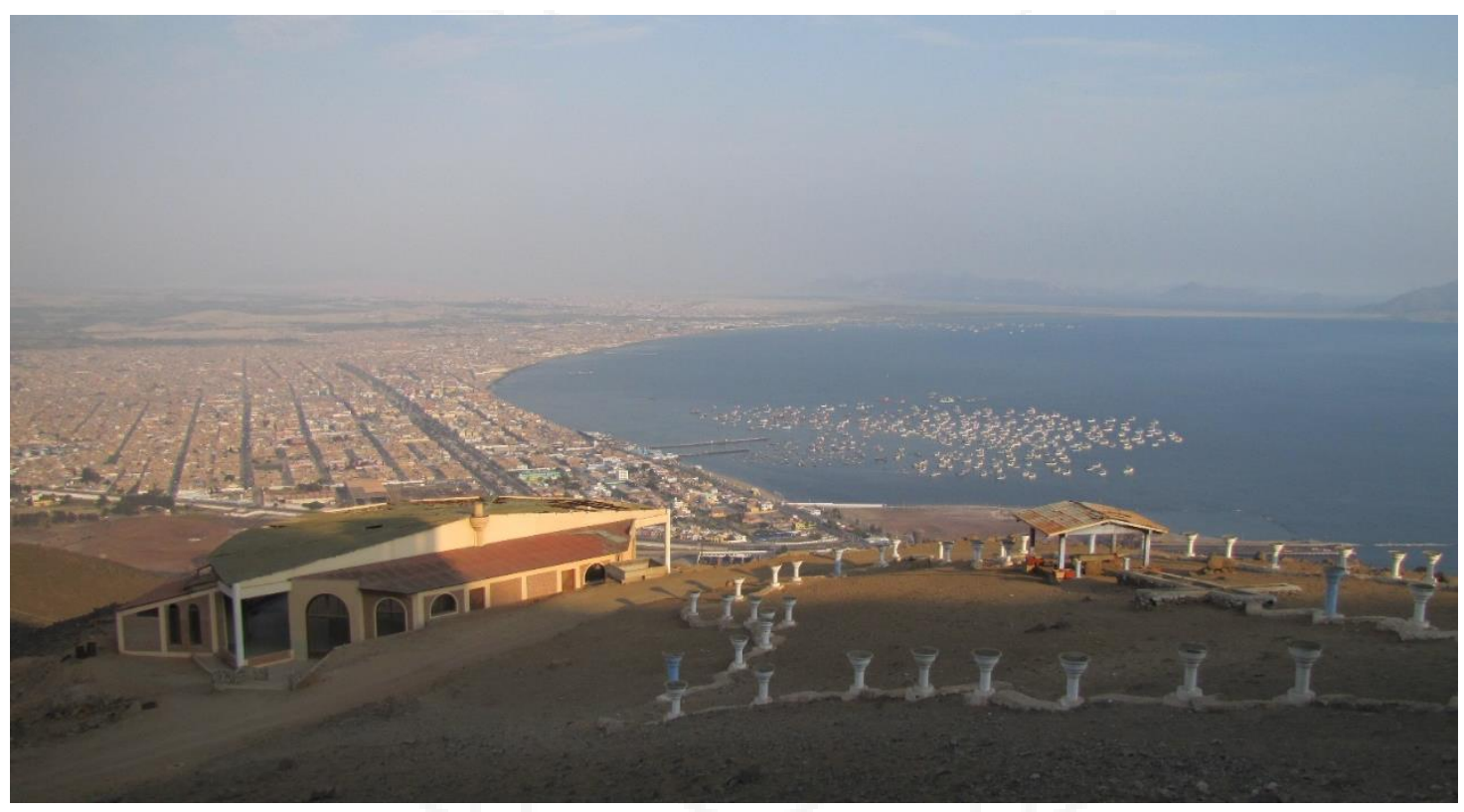

Fuente: Fotografía propia

El tejido urbano de Chimbote es en su mayoría ortogonal que sigue la convexidad de la bahía, en el que se puede identificar diversas zonas; hacia el norte se encuentra el casco urbano cuyo uso es comercial - residencial, y mantiene conexión directa con urbanizaciones, pueblos jóvenes y asentamientos humanos que lo rodean, cuyo uso es residencial. Esta zona evoluciona y se transforma constantemente por la misma intensidad comercial que desarrolla diariamente en su infraestructura y calles. En la zona centro, se encuentra un tejido residencial mezclado con tejido industrial cuyo uso ya no es ese pero la trama urbana aún refleja la escala de los grandes lotes rodeados de muros ciegos. En esta parte de la ciudad también se encuentran viviendas taller por la cercanía a los lotes industriales. En la zona sur de Chimbote se encuentra el puerto y cerca a este 
la zona del 27 de octubre, netamente industrial que finaliza en el río Lacramarca, que separa geográficamente Chimbote de Nuevo Chimbote.

El tejido de Nuevo Chimbote es más ortogonal y de mayor densidad que Chimbote, cuyo uso de suelo es mayormente residencial con tipología de viviendas como viviendas taller, vivienda comercio, que en los últimos años ha incluido la tipología de edificios multifamiliares y complejos residenciales.

Ilustración 2.22 Vía Panamericana o Av. Meiggs en la zona de la Florida

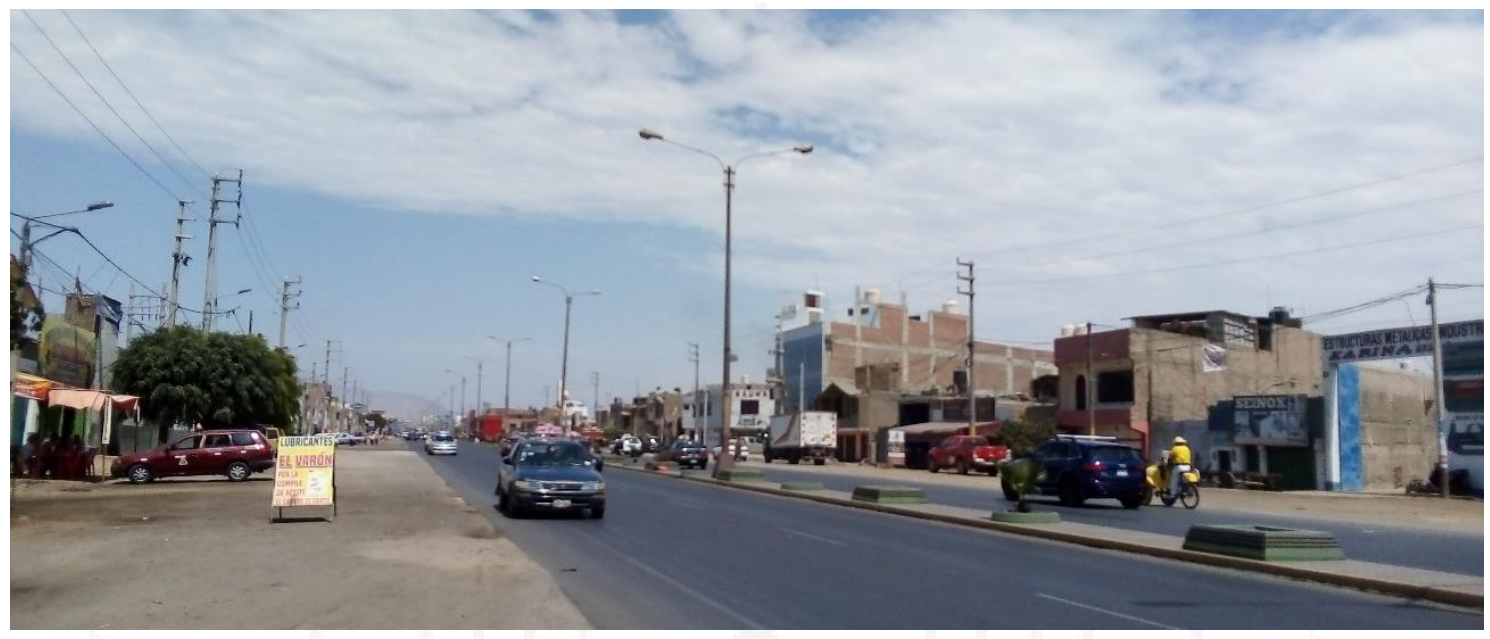

Fuente: Fotografía propia

Ilustración 2.23 Vista de la Av. Bolognesi en el casco urbano de Chimbote

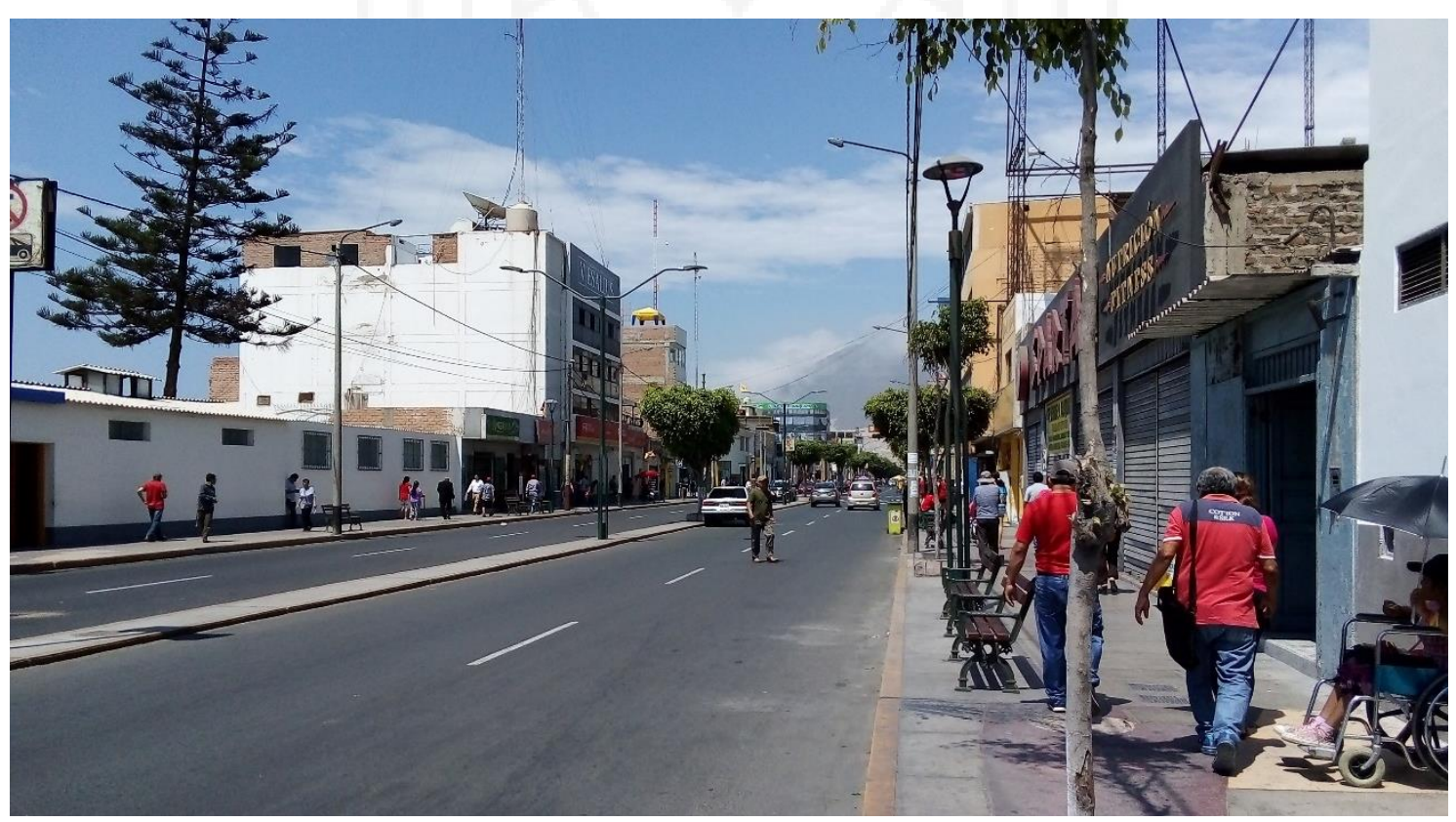

Fuente: Fotografía propia 
Ilustración 2.24 Vista de la Av. Pardo en el caso urbano de Chimbote

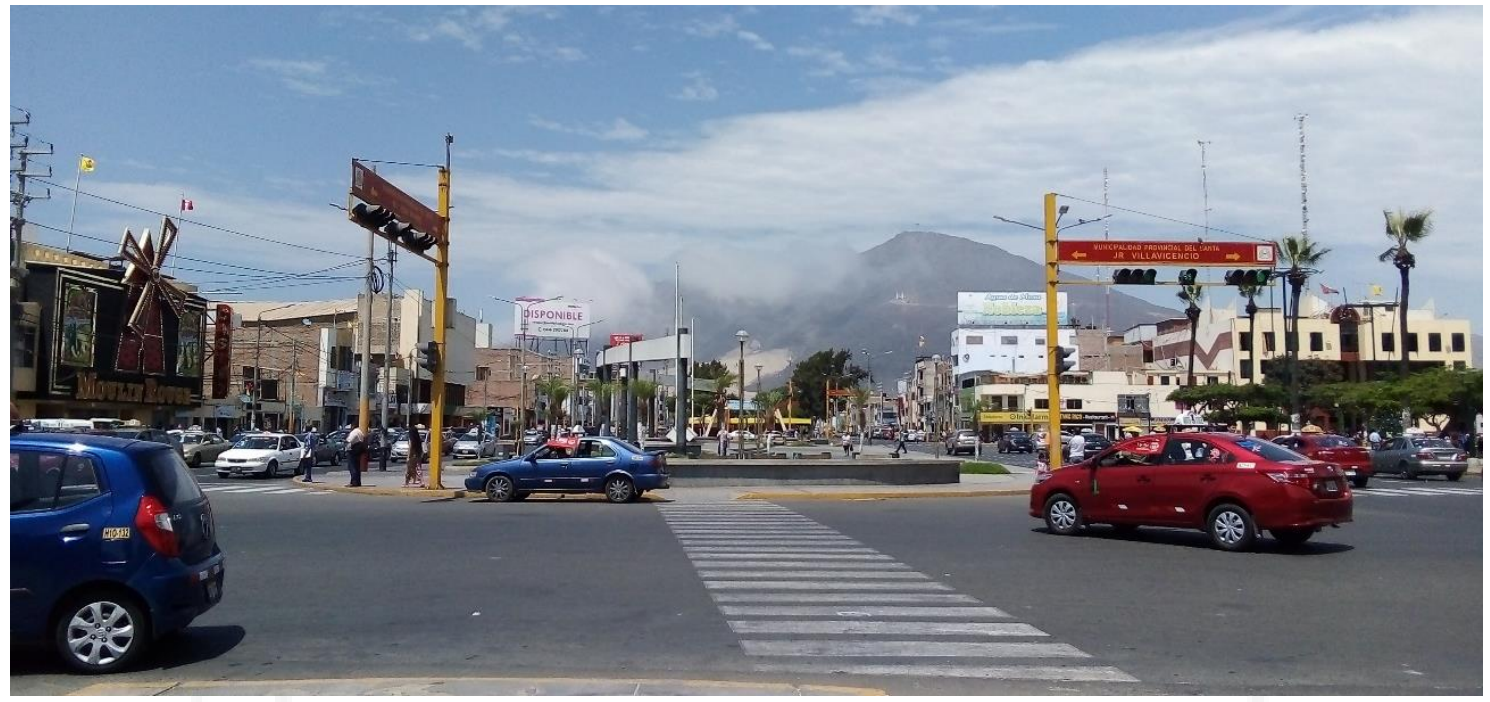

Fuente: Fotografía propia

Las edificaciones en Chimbote no presentan arquitectura característica del lugar tanto en forma como en materialidad, generalmente las construcciones son hechas de albañilería confinada con techos de losa aligerada y fachadas pintadas. Sin embargo, en los últimos años la ciudad se ha visto invadida de edificios con fachada de muro cortina que desentonan completamente con el común denominador de las construcciones.

Ilustración 2.25 Edificios contemporáneos en el casco urbano
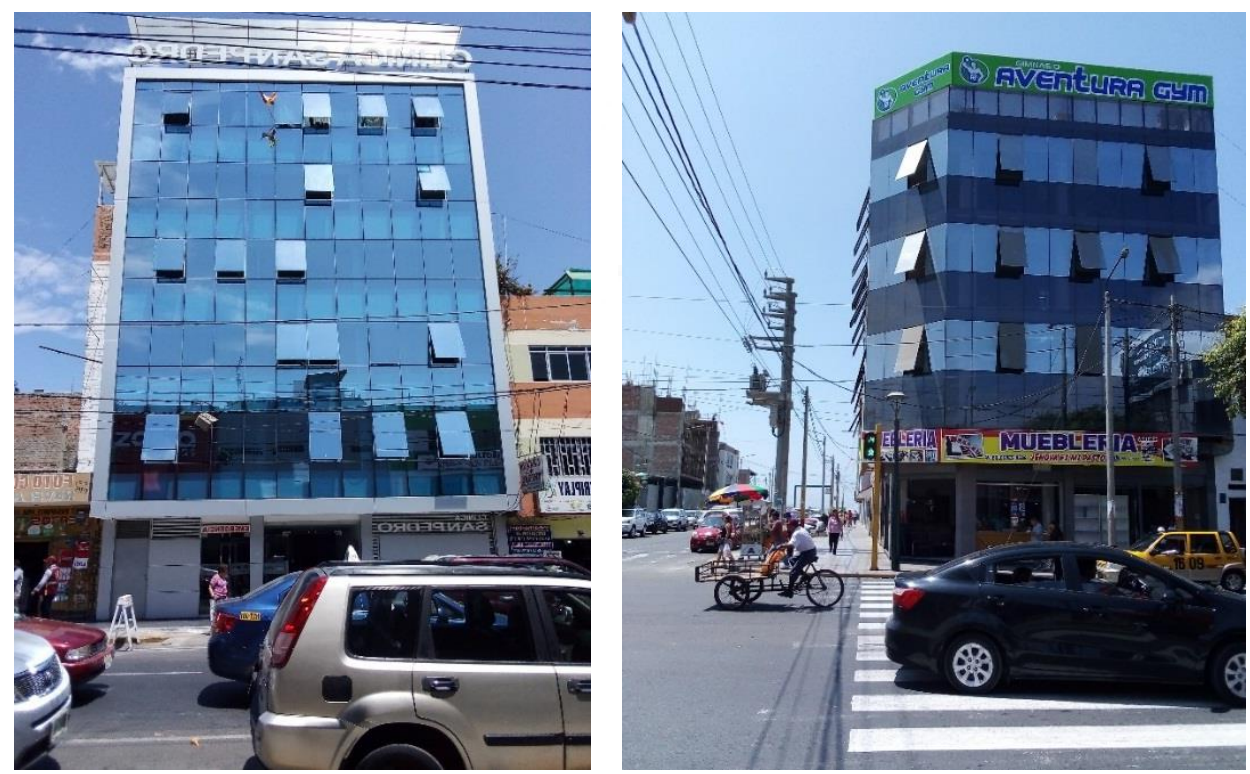

Fuente: Fotografía propia 
La presencia de espacios públicos en la ciudad es escasa. En las zonas de uso residencial se encuentran plazas de escala barrial, cuyo suelo es duro, con poca presencia de vegetación y mobiliario. La ciudad es rica en espacios naturales que deberían ser usados como espacios públicos de recreación; sin embargo, uno de ellos, el Vivero Forestal, se encuentra administrado por la Diócesis de Chimbote, que estableció el pago de una tarifa para hacer uso del espacio, y los Pantanos de Villa María que no presentan intervención alguna para ser visitados.

El transporte en ambos distritos está conformado por colectivos organizados que van de norte a sur y viceversa y por algunas custers y combis que vienen de otros distritos cercanos. Los colectivos inicialmente satisfacían la demanda de transporte de la población, sin embargo, conforme la demanda aumentaba, estos también, por lo que ahora las calles están abarrotadas de autos con poca capacidad de personas lo que lleva a la necesidad de que Chimbote cuente con un sistema de transporte masivo que reduzca la cantidad de autos que en la actualidad existen y evite llegar a los problemas de tráfico vehicular.

\subsubsection{Identidad chimbotana y manifestaciones culturales}

Chimbote es actualmente un centro de expresión de la diversidad cultural, donde sus manifestaciones artísticas se desarrollan mediante festividades religiosas, música, danza y gastronomía. La principal manifestación cultural es la fiesta de San Pedrito, que se celebra el 29 y 30 de junio, también conocida como la semana cívica de Chimbote. Esta fiesta ha sido declarada recientemente como Patrimonio de la Humanidad. Durante esta celebración se busca rendir culto al patrón de los pescadores y se celebra con actos religiosos, actividades deportivas y festivales de comida.

La festividad se inició como un culto popular de familias de pescadores y hoy ha pasado a ser uno de los símbolos integradores de toda la sociedad de Chimbote, en la que asisten instituciones y diversos sectores de la población. La imagen de San Pedrito, guía espiritual de los pobladores de Chimbote, se erige como uno de los elementos más fuertes de la identidad chimbotana y la región, sin haber perdido la huella de sus inicios como patrón de los pescadores.

El pedido para la declaratoria de Patrimonio Cultural de la Festividad de San Pedrito se presentó el 4 de julio de 2017 a iniciativa del padre Juan Roger Rodríguez, 
vicario de la Diócesis de Chimbote y ha sido en mayo de este año que esta festividad logró consolidarse como Patrimonio Cultural.

Ilustración 2.26 Procesión por la festividad de San Pedrito en la zona de la Caleta

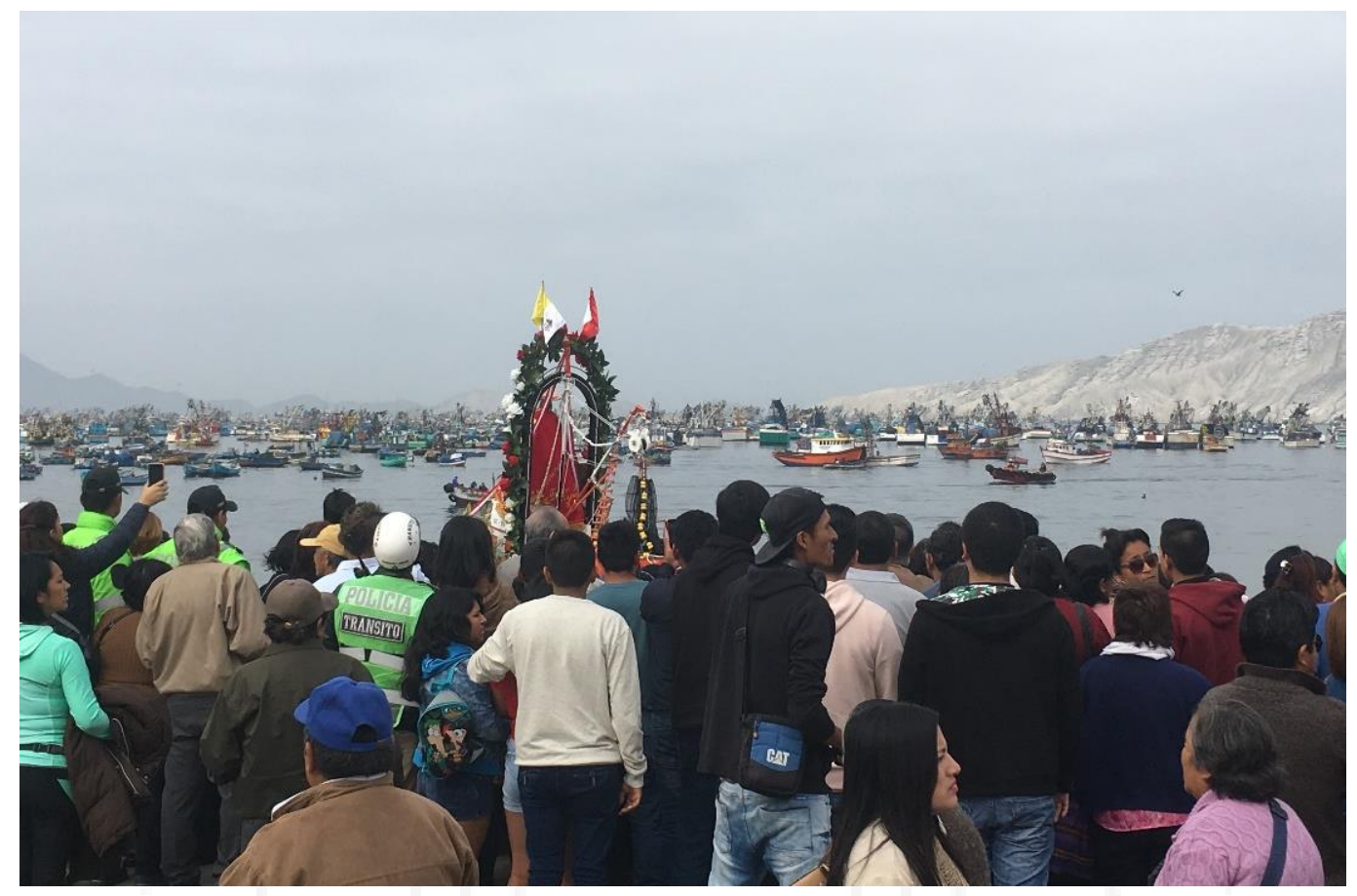

Fuente: Fotografía propia

El sentido de identidad en Chimbote es bastante fuerte, inclusive muchos de ellos le denominan "chimbotanismo", término que se refiere a una "expresión individual y colectiva de la conciencia social que se afirma y desarrolla en la identificación, afecto, respeto y cultivo de los elementos culturales populares que simbolizan a una comunidad diferenciándola de las demás. Este sentimiento se puede transmitir de generación en generación o a través de medios de comunicación social como la cultura y educación." (Velezmoro, 2012)

Sin embargo, uno de los principales obstáculos para fomentar la identidad cultural en Chimbote es la falta de espacios para difundir sus expresiones artísticas y formar nuevos valores. José Gutiérrez Blas, escritor y periodista chimbotano, hace referencia a la lucha de muchos intelectuales e instituciones privadas por promover estas actividades, a pesar del escaso apoyo que reciben de las entidades públicas. Para el escritor Víctor Unyén Velezmoro resulta alarmante que aún no se cuente con un teatro municipal, un museo o una escuela de arte, pese al crecimiento económico que ha experimentado el puerto. Sin 
embargo, destaca iniciativas privadas como la creación del Centro Cultural Centenario, que cuenta con una orquesta sinfónica integrada por niños y jóvenes.

"En este contexto propone la creación de una Dirección Regional de Cultura, que permita organizar más actividades artísticas. Otra alternativa es la adaptación de espacios antiguos y emblemáticos de la ciudad como centros culturales, que representen una fuente de educación invaluable para el desarrollo de una identidad en las nuevas generaciones chimbotanas" (Raymundo, 2014).

\section{Ilustración 2.27 Procesión de San Pedrito en su fiesta patronal}

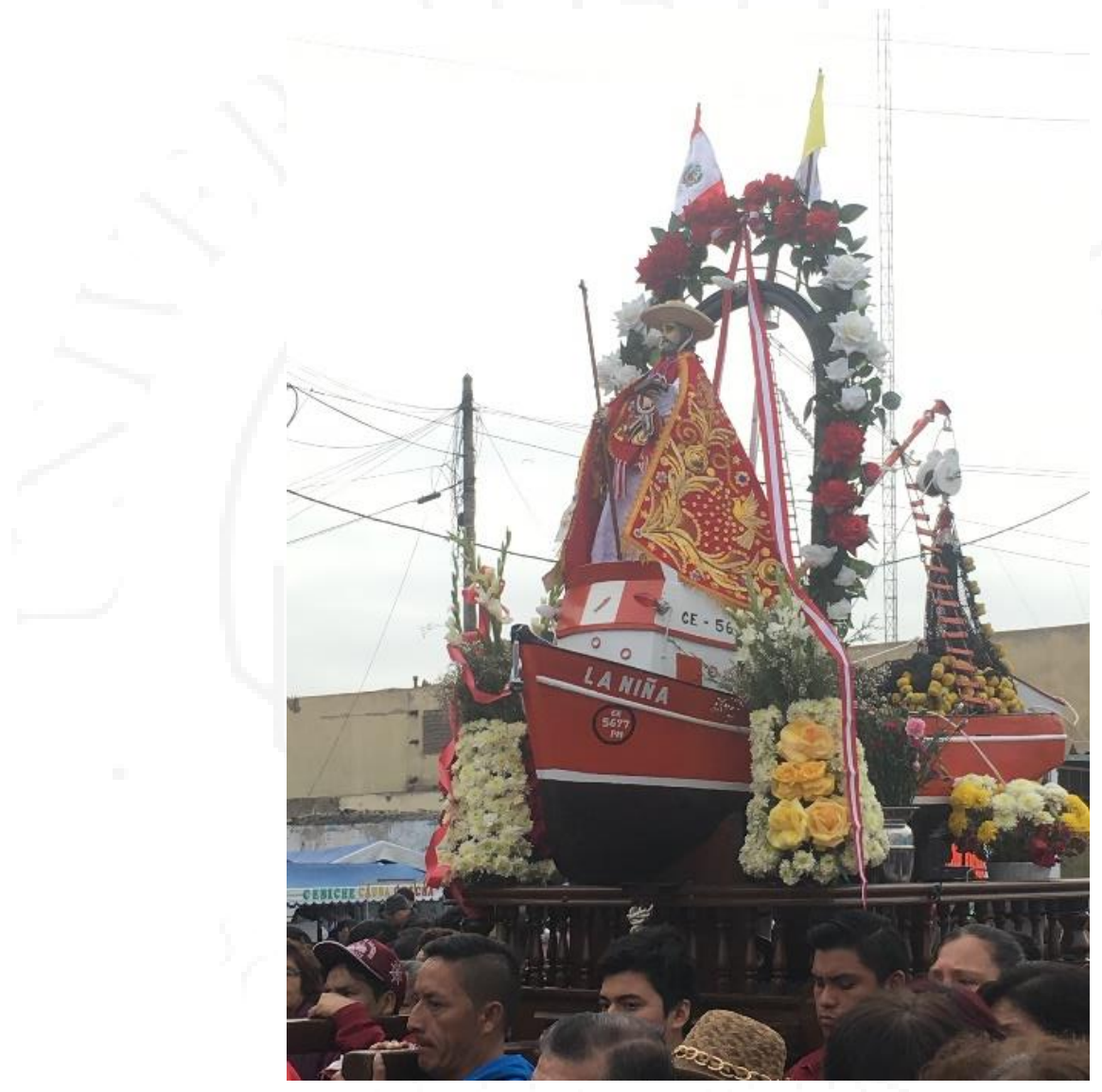

Fuente: Fotografía propia

\subsubsection{Datos de Chimbote}

Chimbote actualmente es un distrito en el que los ingresos económicos no provienen de una sola actividad, sin embargo, sí dependen directamente de la pesca pues la organización de la ciudad gira en torno a ella. 
a. Población

La ciudad de Chimbote, según el último censo de INEI del 2007, cuenta con una población de 328923 habitantes, perteneciendo a las 8 ciudades más pobladas del país. Además, cuenta con una predominante población joven de edades entre 10 a 19 años.

Ilustración 2.28 Chimbote, la 8va ciudad más poblada

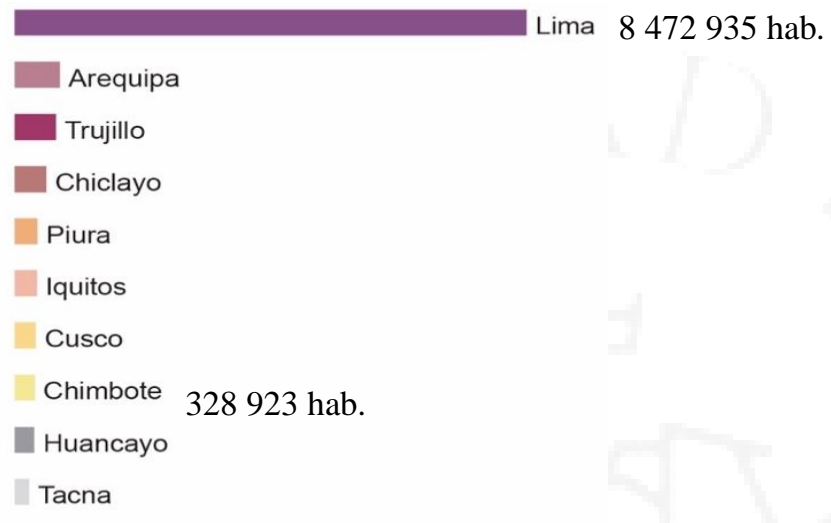

Fuente: INEI, Censo 2007. Elaboración propia

Tabla 2.3 Población de Chimbote y Nuevo Chimbote

\begin{tabular}{|l|l|l|}
\hline PROVINCIA & TOTAL DE HABITANTES & $\%$ \\
\hline Chimbote & 215817 & 54.44 \\
\hline Cáceres del Perú & 5062 & 1.28 \\
\hline Coishco & 14482 & 3.74 \\
\hline Macate & 3889 & 0.98 \\
\hline Moro & 7580 & 1.91 \\
\hline Nepeña & 13860 & 3.50 \\
\hline Samanco & 4218 & 1.06 \\
\hline Santa & 18010 & 4.54 \\
\hline Nuevo Chimbote & 113166 & 28.55 \\
\hline Provincia del Santa & 396434 & 100 \\
\hline
\end{tabular}

Fuente: PDU Chimbote 2012-2022 
Tabla 2.4 Grupo de edades de la población de Chimbote

\begin{tabular}{|l|r|}
\hline GRUPO DE EDADES & $N^{\circ}$ DE PERSONAS \\
\hline De 0 - 9 años & 52481 \\
\hline de 10 - 19 años & 51438 \\
\hline de 20 - 29 años & 47354 \\
\hline de 30 - 39 años & 36895 \\
\hline de 40 - 49 años & 24873 \\
\hline de 50 - 59 años & 17464 \\
\hline de 60 - 69 años & 9120 \\
\hline de 70 - 79 años & 3159 \\
\hline de 80 - 89 años & 666 \\
\hline de 90 - 99 años & 328923 \\
\hline TOTAL & \\
\hline
\end{tabular}

Fuente: INEI, Censo 2007. Elaboración propia

Con relación al crecimiento poblacional de Chimbote y Nuevo Chimbote se observa que, si bien el primero cuenta con una población mayor, en Nuevo Chimbote la población ha aumentado con mayor rapidez, lo cual se evidencia en la tasa de crecimiento. Este distrito que surgió a raíz del terremoto de 1970 se ha poblado de manera acelerada con respecto a Chimbote.

Tabla 2.5 Crecimiento poblacional de Chimbote y Nuevo Chimbote

\begin{tabular}{|c|c|c|c|c|c|}
\hline \multirow{2}{*}{ DISTRITO } & \multicolumn{3}{|c|}{ POBLACIÓN } & \multicolumn{2}{c|}{ TASA DE CRECIMIENTO } \\
\cline { 2 - 6 } & 1981 & 1993 & 2007 & $1981-1993$ & $1993-2007$ \\
\hline CHIMBOTE & 179895 & 221289 & 217817 & 1.7 & -0.343 \\
\hline $\begin{array}{c}\text { NUEVO } \\
\text { CHIMBOTE }\end{array}$ & 53163 & 65396 & 113166 & 1.9 & 2.795 \\
\hline
\end{tabular}

Fuente: INEI, Censo 2007. Elaboración propia 
Tabla 2.6 Población por sectores urbanos según números de viviendas

\begin{tabular}{|c|c|c|c|c|}
\hline \multirow{2}{*}{ DETALLE } & \multirow{2}{*}{ SECTORES URBANOS } & \multirow{2}{*}{$\begin{array}{c}N^{\circ} \mathrm{DE} \\
\text { VIVIENDAS }\end{array}$} & \multicolumn{2}{|c|}{ POBLACIÓN } \\
\hline & & & $\begin{array}{l}\mathrm{N}^{\circ} \\
\text { VIVIENDAS }\end{array}$ & $\%$ \\
\hline \multirow{8}{*}{ CHIMBOTE } & SECTOR 1 & 2052 & 10260 & 3 \\
\hline & SECTOR 2 & 1824 & 9120 & 2 \\
\hline & SECTOR 3 & 7828 & 39140 & 10 \\
\hline & & & & \\
\hline & SECTOR 4 & 4437 & 22185 & 6 \\
\hline & SECTOR 5 & 5828 & 29140 & 7 \\
\hline & SECTOR 6 & 14658 & 73290 & 19 \\
\hline & SECTOR 7 & 40 & 200 & 0.1 \\
\hline \multirow{3}{*}{ NUEVO CHIMBOTE } & SECTOR 8 & 8079 & 40395 & 10 \\
\hline & SECTOR 9 & 13445 & 67225 & 17 \\
\hline & SECTOR 10 & 20399 & 101995 & 26 \\
\hline \multicolumn{2}{|c|}{ CIUDAD CHIMBOTE } & 78590 & 392950 & 100 \\
\hline
\end{tabular}

Fuente: PDU Chimbote 2012-2022

Si se observa el mapa de la ciudad se puede constatar que esta se ha expandido hacia el sur, de modo que el distrito de Nuevo Chimbote ha crecido más que Chimbote, hasta el punto de convertirse casi en una sola mancha de ciudad. Asimismo, la información del mapa se puede reafirmar con la que aparece en la tabla anterior, pues Nuevo Chimbote presenta una mayor cantidad de viviendas debido a su acelerado crecimiento.

\section{b. Educación}

Aun cuando la población del distrito es joven, según datos del Censo 2007 realizado por INEI, más de la mitad de las personas que ingresan a cursar estudios superiores técnicos y universitarios, no los culminan, por lo que el porcentaje de población con secundaria completa aumenta. 
Ilustración 2.29 Grado de instrucción de la población

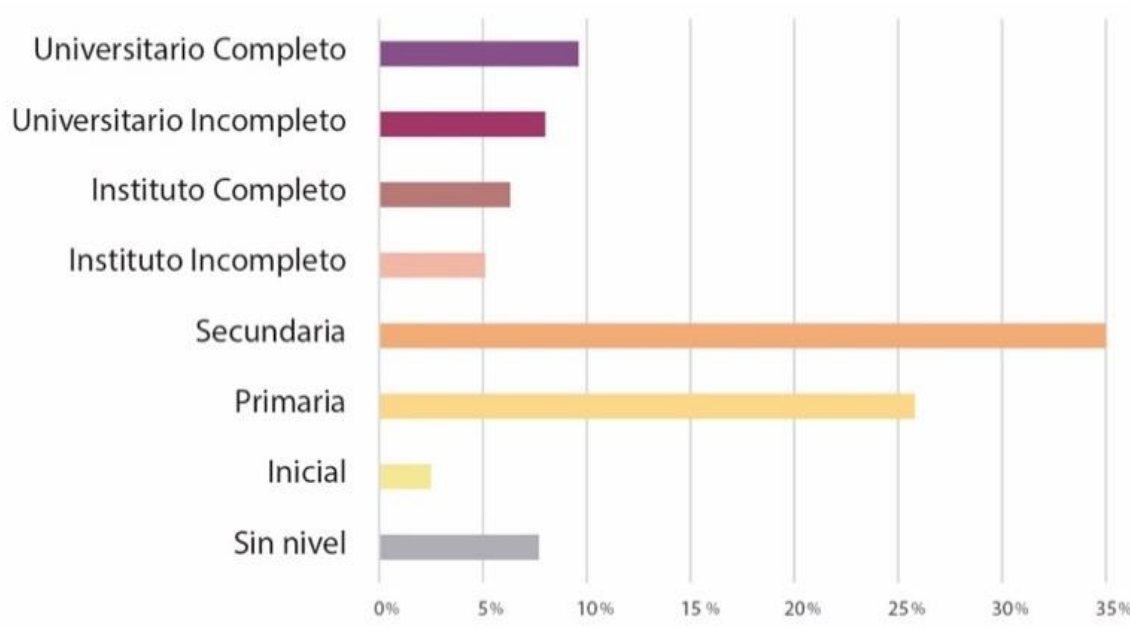

Fuente: INEI, Censo 2007. Elaboración propia

c. Economía

Una de las principales actividades económicas es la pesca, principalmente por la extracción de la anchoveta, por lo que el periodo de extracción es de 5 meses, quedando el resto del año como periodo de veda.

El censo del 2007 realizado por INEI, muestra que Chimbote tiene grandes ingresos de los sectores manufactura y agropecuario quedando un poco relegado el sector pesquero. Sin embargo, en la manufactura se realizan reparaciones o creación de piezas para embarcaciones lo que genera que esta área esté ligada directamente a la pesca.

Ilustración 2.30 PEA de Chimbote por sectores

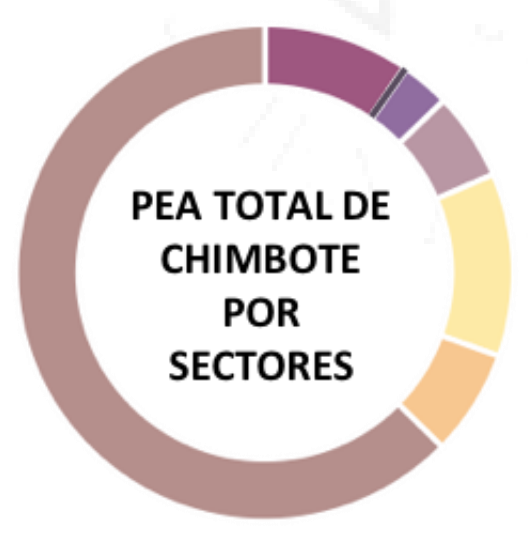
9.48\% Agropecuario
$0.18 \% \square$ Minero
$3.13 \%$ Pesquero
$5.73 \%$ Turismo
11.43\% $\square$ Manufactura
$6.92 \% \square$ Construcción
$62.62 \% \quad$ Servicios-comercio

Fuente: PVPP Santa, INEI - Censo 2007. Elaboración propia 
Tabla 2.7 PBI de Chimbote por sectores

\begin{tabular}{|l|l|}
\hline SECTOR & $\begin{array}{l}\% \text { PBI DEL } \\
\text { TOTAL }\end{array}$ \\
\hline Agricultura, caza y silvicultura & $6.8 \%$ \\
\hline Pesca & $3.7 \%$ \\
\hline Minería & $20.6 \%$ \\
\hline Manufactura & $18.4 \%$ \\
\hline Electricidad y agua & $3.6 \%$ \\
\hline Construcción & $5.1 \%$ \\
\hline Comercio & $6.5 \%$ \\
\hline Transportey comunicaciones & $7.3 \%$ \\
\hline Restaurantes y hoteles & $2.2 \%$ \\
\hline Servicios gubernamentales & $6.9 \%$ \\
\hline Otros servicios & $18.8 \%$ \\
\hline TOTAL & $100 \%$ \\
\hline
\end{tabular}

Fuente: INEI - Censo 2007. Elaboración propia

Ilustración 2.31 Ciclo de extracción de anchoveta
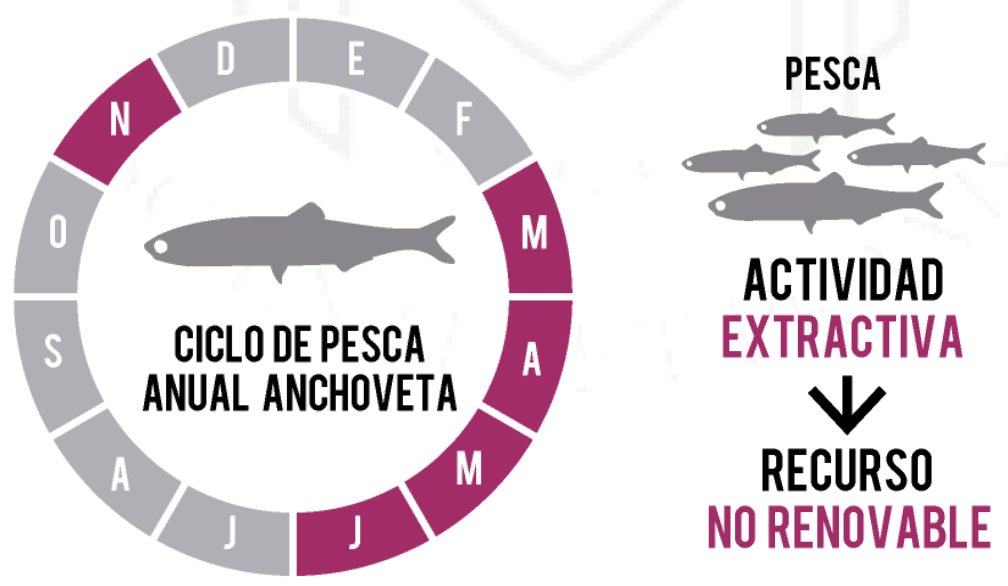

Período Extracción

Período de Veda

Fuente: Elaboración propia 
El gráfico anterior busca representar cómo la población se ha visto arraigada a la pesca desde los inicios de su historia, al aparecer como una caleta de pescadores que por medio de la extracción de especies marinas lograron desarrollarse económicamente y llegar a ser el principal puerto pesquero del mundo.

Ilustración 2.32 Principales puertos del Perú

(10) Carga en toneladas $\begin{aligned} & \text { Porcentaje } \\ & \text { metricas } 2010\end{aligned}$

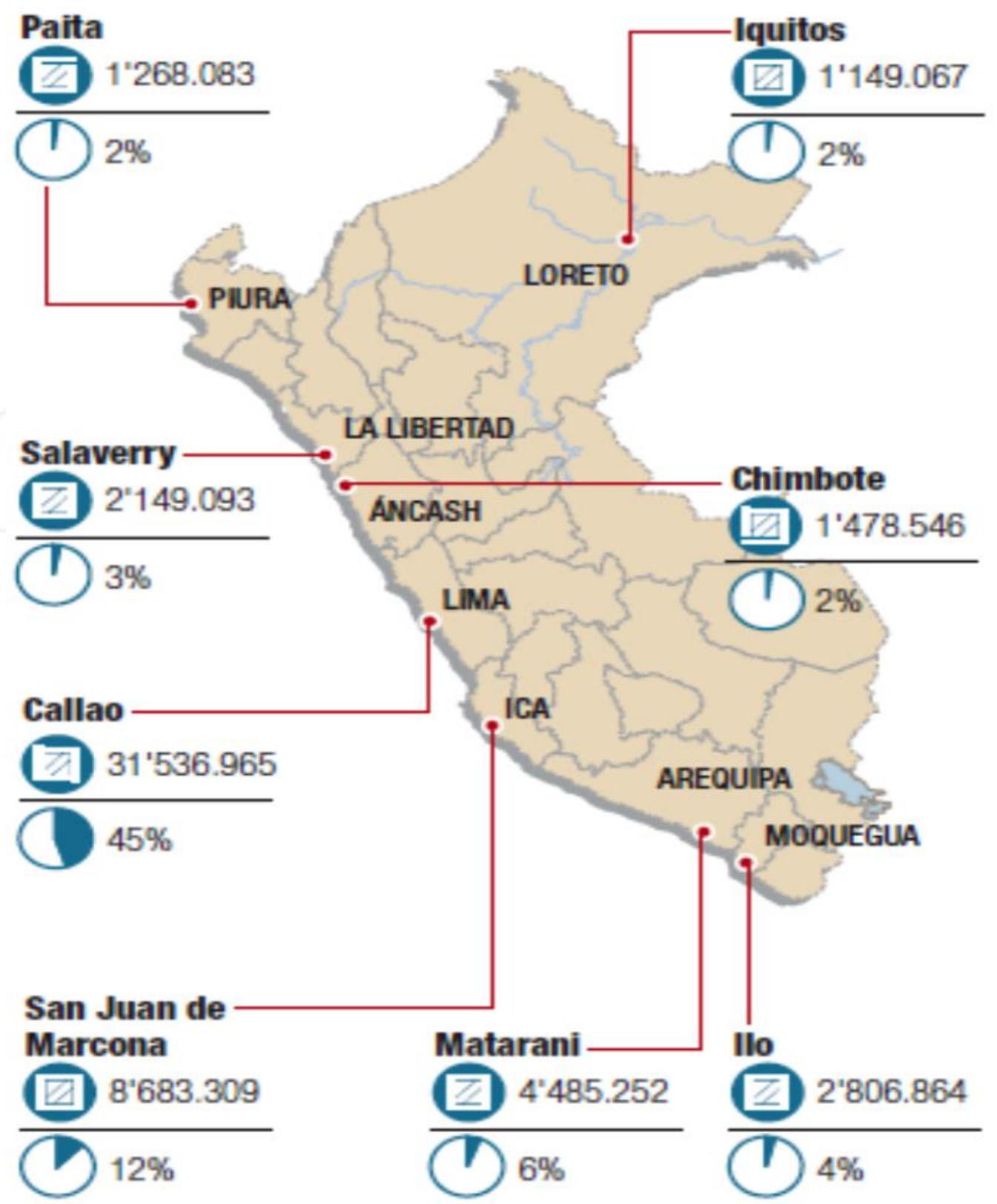

Fuente: Informe CENTRUM 2012. Diario El Comercio. 


\section{d. Estructura urbana}

El uso de suelo actual predominante en Chimbote es vivienda e industria. Siendo el equipamiento de salud, el menos ocupado y el equipamiento cultural que solo ocupa un lote y no se encuentra dentro del uso de suelo.

Ilustración 2.33 Uso de suelo en la Ciudad de Chimbote

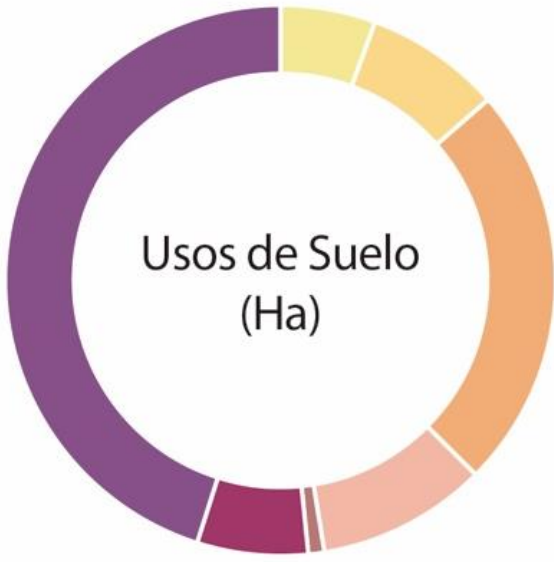

\begin{tabular}{|c|c|}
\hline $1258 \mathrm{Ha}$ & Vivienda \\
\hline $181.8 \mathrm{Ha}$ & Vacío \\
\hline $26.02 \mathrm{Ha}$ & Salud \\
\hline $278.7 \mathrm{Ha}$ & Parques y Recreación \\
\hline $666 \mathrm{Ha}$ & Industria \\
\hline $232.5 \mathrm{Ha}$ & Educación \\
\hline $155.8 \mathrm{Ha}$ & Comercio \\
\hline
\end{tabular}

Fuente: PDU Chimbote 2012-2022. Elaboración propia

Actualmente de las 47 fábricas operativas de Chimbote, solo 30 se encuentran conectadas al colector submarino, que fue construido por la asociación APROFERROL en el año 2012. A esta situación también se le debe sumar que de las 47 fábricas que se encuentran en la bahía, solo la tercera parte de ellas se encuentran operativas en una zonificación adecuada, a pesar de que en el 2009, la Municipalidad Provincial del Santa estableció la Ordenanza Municipal No 001-2009-MPS, en la que se señalaba que las industrias pesadas y molestosas que se encuentren dentro de la zona residencial, debían trasladarse a la zona para dichas industrias, molestosa y pesada ubicada en la zona del 27 de octubre?

"Hoy en día podríamos decir que la relación entre la ciudad y la bahía está fracturada. Las zonas residenciales ubicadas frente al mar carecen de espacios públicos; las playas no se usan por estar considerablemente contaminadas; muchas de las edificaciones industriales a través de una serie de regulaciones impulsadas por la administración pública han reducido los índices de contaminación del mar y los aires, iniciativa que produjo un cambio de funciones en algunas fábricas convirtiéndose en almacenes y otras

\footnotetext{
${ }^{9}$ Ver Anexo $\mathrm{N}^{\circ} 02$
} 
reemplazaron sus procesos industriales por actividades menos contaminantes (producción de conservas); proyecto que tuvo éxito pero de ninguna manera se mejoró la calidad urbana de la zona en relación a estas edificaciones.” (Aldo Facho, 2016)

\section{e. Contaminación}

Según la información presentada por el PDU Santa 2012, se encuentra dentro de los 20 distritos con mayor acumulación de basura del Perú. Así también, según el PAT Santa 2012, cuenta con gran contaminación del agua producto de las aguas residuales pesqueras, siderúrgicas y domésticas; y contaminación del aire debido a las industrias, a los automóviles y a las industrias económicas de menor escala.

Tabla 2.8 Ubicación de Chimbote dentro de los 20 distritos con mayor acumulación de basura

\begin{tabular}{|c|l|c|}
\hline$N^{\circ}$ & \multicolumn{1}{|c|}{ DISTRITO } & TONEL / DIA \\
\hline 1 & San Juan de Lurigancho & 970,32 \\
\hline 2 & San Martín de Porres & 625,93 \\
\hline 3 & Comas & 525,93 \\
\hline 4 & Ate & 516,64 \\
\hline 5 & Callao & 449,16 \\
\hline 6 & Villa el Salvador & 412,33 \\
\hline 7 & Villa María del Triunfo & 408,75 \\
\hline 8 & San Juan de Miraflores & 391,65 \\
\hline 9 & Los Olivos & 343,59 \\
\hline 10 & Lima & 323,45 \\
\hline 11 & Tujillo & 318,41 \\
\hline 12 & Santiago de Surco & 312,76 \\
\hline 13 & Chorrillos & 309,94 \\
\hline 14 & Ventanilla & 300,13 \\
\hline 15 & Chiclayo & 281,66 \\
\hline 16 & Piura & 275,27 \\
\hline 17 & Puente Piedra & 252,29 \\
\hline 18 & Juliaca & 234,05 \\
\hline 19 & Independencia & 224,26 \\
\hline 20 & Chimbote & 224,08 \\
\hline
\end{tabular}

Fuente: PDU Chimbote 2012-2022 
Ilustración 2.34 Contaminación del agua de la bahía de Chimbote

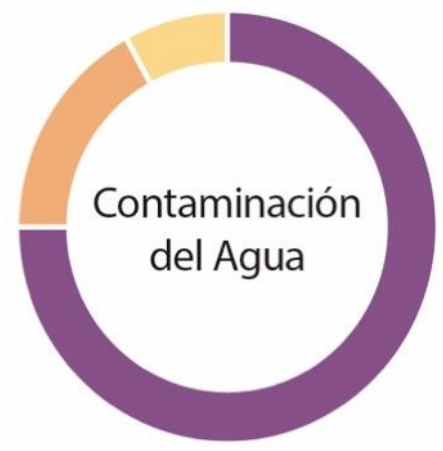

$75 \%$

Aguas Residuales Pesqueras

$17 \%$ Aguas Residuales Domésticas

$8 \%$ Aguas Residuales Siderúrgicas

Fuente: PAT Santa 2012-2022. Elaboración propia

Ilustración 2.35 Contaminación del aire en la ciudad de Chimbote

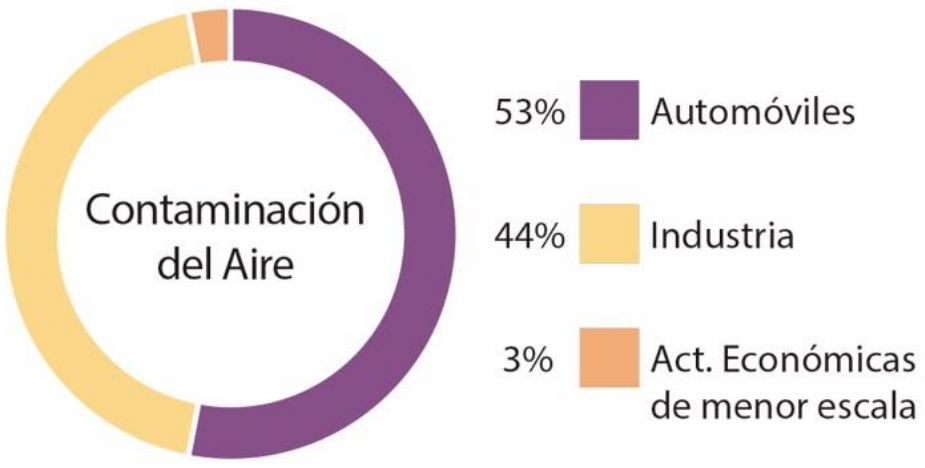

Fuente: PAT Santa 2012-2022. Elaboración propia

Ilustración 2.36 Los habitantes transitan por el borde costero contaminado

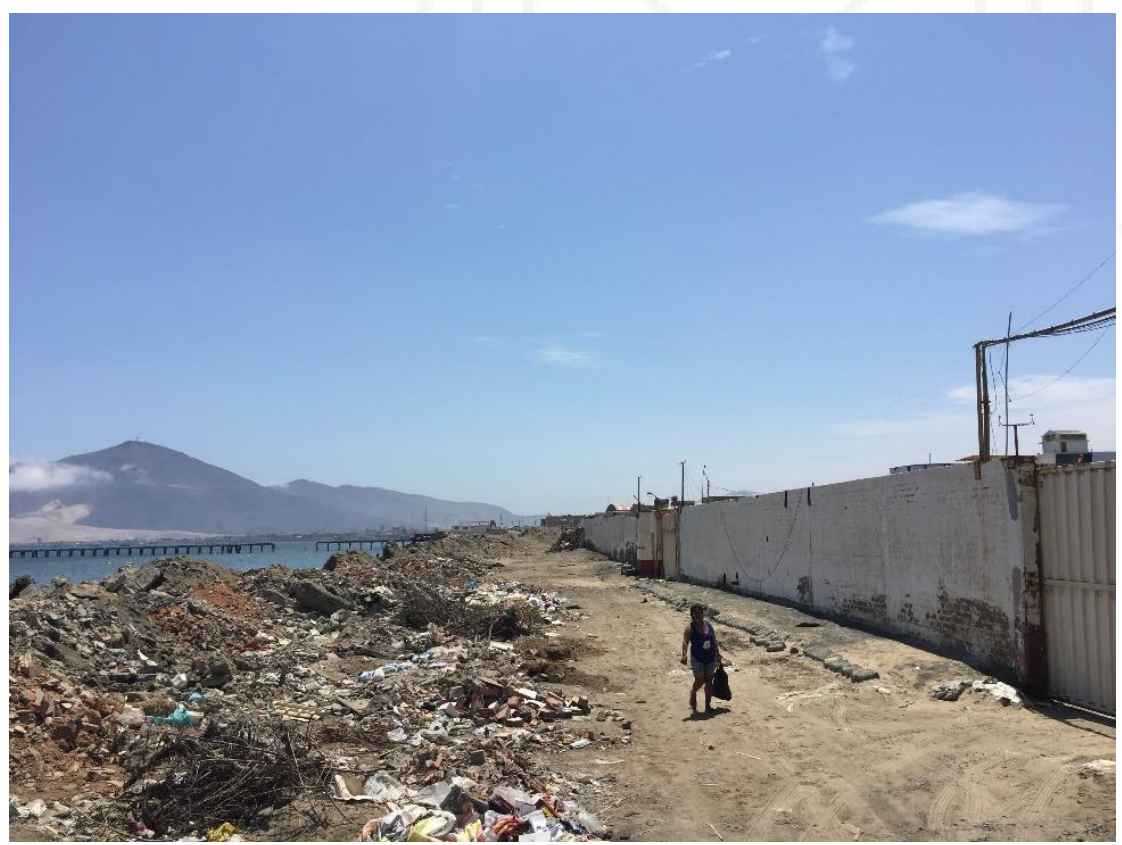

Fuente: Fotografía propia 
Ilustración 2.37 Contaminación en la zona de la Florida en la bahía de Chimbote

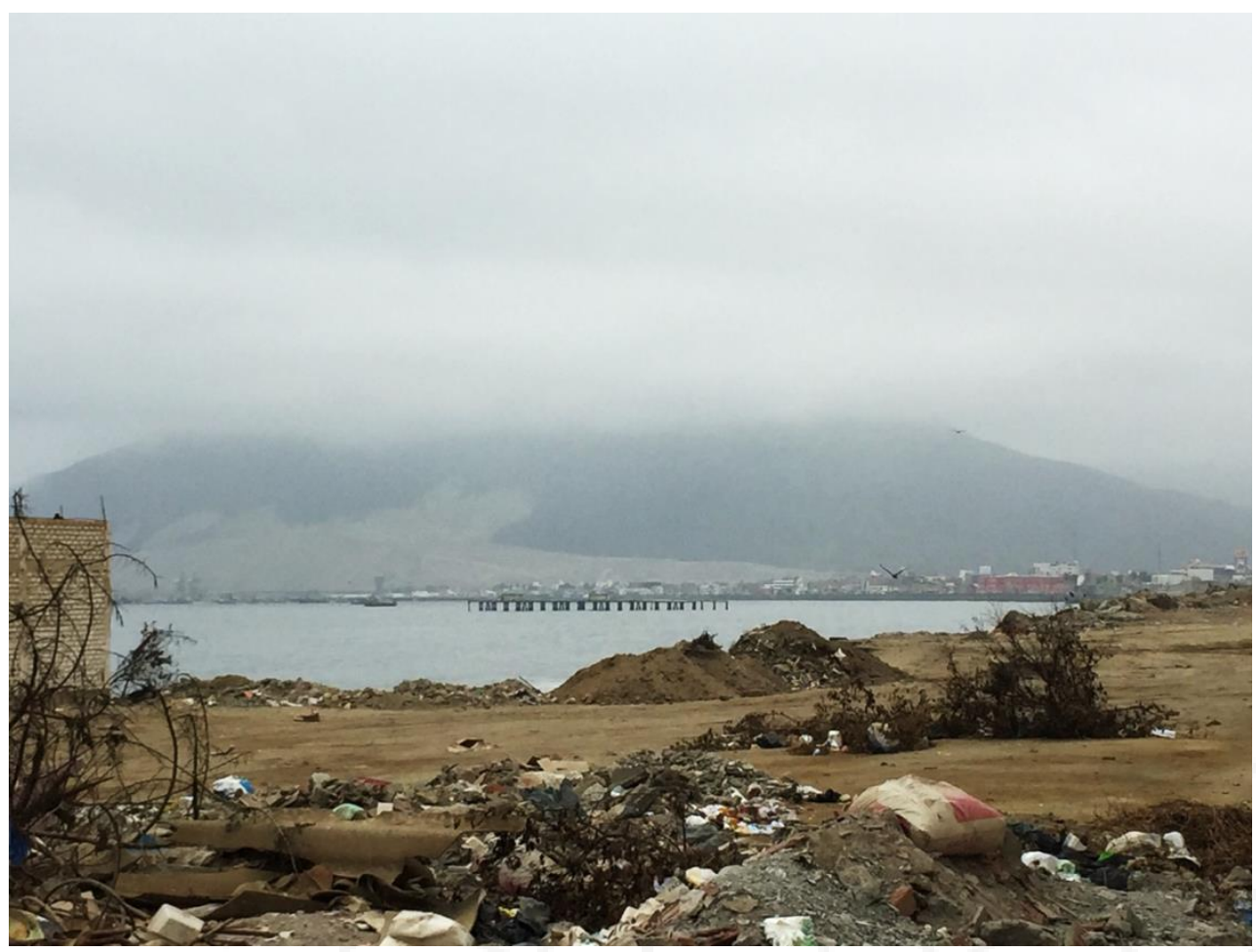

Fuente: Fotografía propia

Ilustración 2.38 Acumulación de desmonte en el borde de la bahía

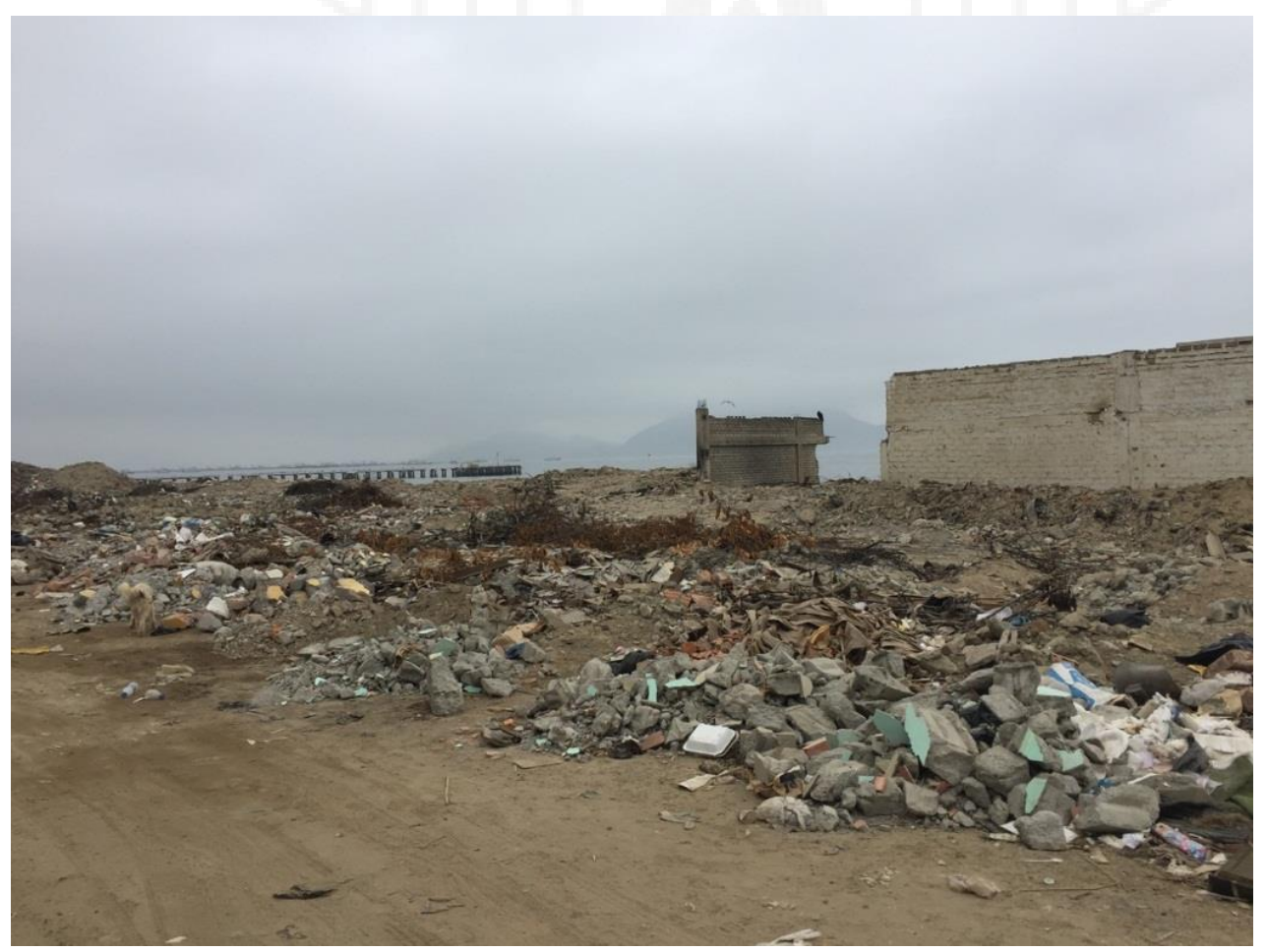

Fuente: Fotografía propia 
Ilustración 2.39 Mapa de puntos críticos de acumulación de basura en la bahía El Ferrol

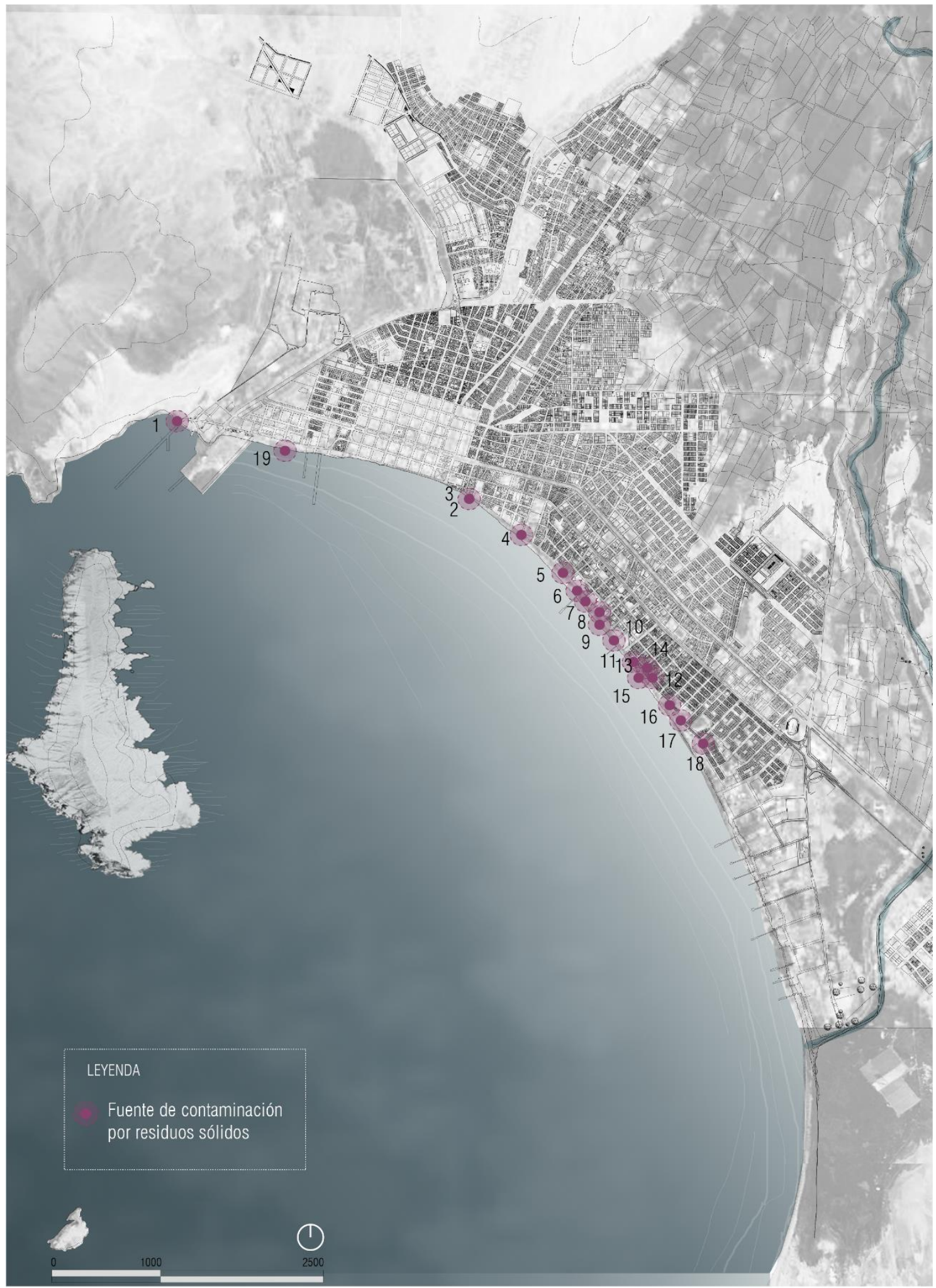

Fuente: Ministerio del Ambiente (SIGMINAM) 
Tabla 2.9 Fuentes de acumulación de residuos sólidos

\begin{tabular}{|c|c|c|c|c|}
\hline \multicolumn{5}{|c|}{ FUENTES DE CONTAMINACIÓN POR ACUMULACIÓN DE RESIDUOS SÓLIDOS } \\
\hline NOMBRE & REFERENCIA & ACUMULADO & DISPERSO & COMPACTADO \\
\hline Punto $\mathrm{n}^{01}$ & Cercano a SiderPeru & & $\mathbf{X}$ & \\
\hline Punto $n^{0} 2$ & Antes de Dren $n^{0} 1$ & & $\mathbf{x}$ & $\mathbf{x}$ \\
\hline Punto n03 & Después de Dren n01 & & $\mathbf{X}$ & \\
\hline Punto $n^{0} 4$ & Antes de Dren $n^{0} 3$ & $\mathbf{x}$ & $\mathbf{x}$ & $\mathbf{x}$ \\
\hline Punto $\mathrm{n}^{05}$ & Cercano a Dren n4 & & $\mathbf{x}$ & \\
\hline Punto $n^{0} 6$ & Cercano a Tasa (norte) & & $\mathbf{x}$ & \\
\hline Punto $n^{0} 7$ & Cercano a Dren n5 & $\mathbf{x}$ & & $\mathbf{x}$ \\
\hline Punto $n^{0} 8$ & Cercano a Rigel S.A. & $\mathbf{x}$ & & $\mathbf{x}$ \\
\hline Punto nog & Cercano a Marpesa S.A. & $\mathbf{x}$ & & $\mathbf{x}$ \\
\hline Punto $n^{010}$ & Cercano a Dren n ${ }^{\circ} 6$ & $\mathbf{x}$ & & $\mathbf{x}$ \\
\hline Punto $n^{011}$ & $\begin{array}{l}\text { Después CFG } \\
\text { Investment (conservera) }\end{array}$ & $\mathbf{X}$ & $\mathbf{X}$ & \\
\hline Punto $\mathrm{n}^{012}$ & $\begin{array}{l}\text { Antes CFG } \\
\text { Investment (harinera) }\end{array}$ & & $\mathbf{X}$ & $\mathbf{X}$ \\
\hline Punto $n^{013}$ & $\begin{array}{l}\text { Después de CFG } \\
\text { Investment (harinera) }\end{array}$ & & $\mathbf{X}$ & $\mathbf{X}$ \\
\hline Punto $n^{014}$ & Antes de Sedachimbote $n^{0} 6$ & $\mathbf{x}$ & & $\mathbf{X}$ \\
\hline Punto $n^{015}$ & Cercano a Sedachimbote $n^{0} 6$ & $\mathbf{x}$ & & \\
\hline Punto $\mathrm{n}^{016}$ & Cefcano a Sedachimbote $n^{07}$ & $\mathbf{X}$ & & \\
\hline Punto $\mathrm{n}^{017}$ & Antes de Sedachimbote n8 & & $\mathbf{x}$ & \\
\hline Punto $n^{018}$ & Cercano de Pesquera Gamma & & & $\mathbf{X}$ \\
\hline Punto $n^{019}$ & Malecón frente al hosp. La Caleta & & $\mathbf{x}$ & \\
\hline
\end{tabular}

Fuente: Ministerio del Ambiente (SIGMINAM). Elaboración propia

Actualmente, la ciudad no se encuentra entre las más peligrosas del país, pero presenta áreas donde se cometen delitos que al observarse en el siguiente mapa, coincide con la zona donde se ubican las fábricas en desuso y con poca actividad en las calles que las rodean. 
Ilustración 2.40 Mapa de delitos de la Comisaría del P.J La Libertad-Chimbote 2016

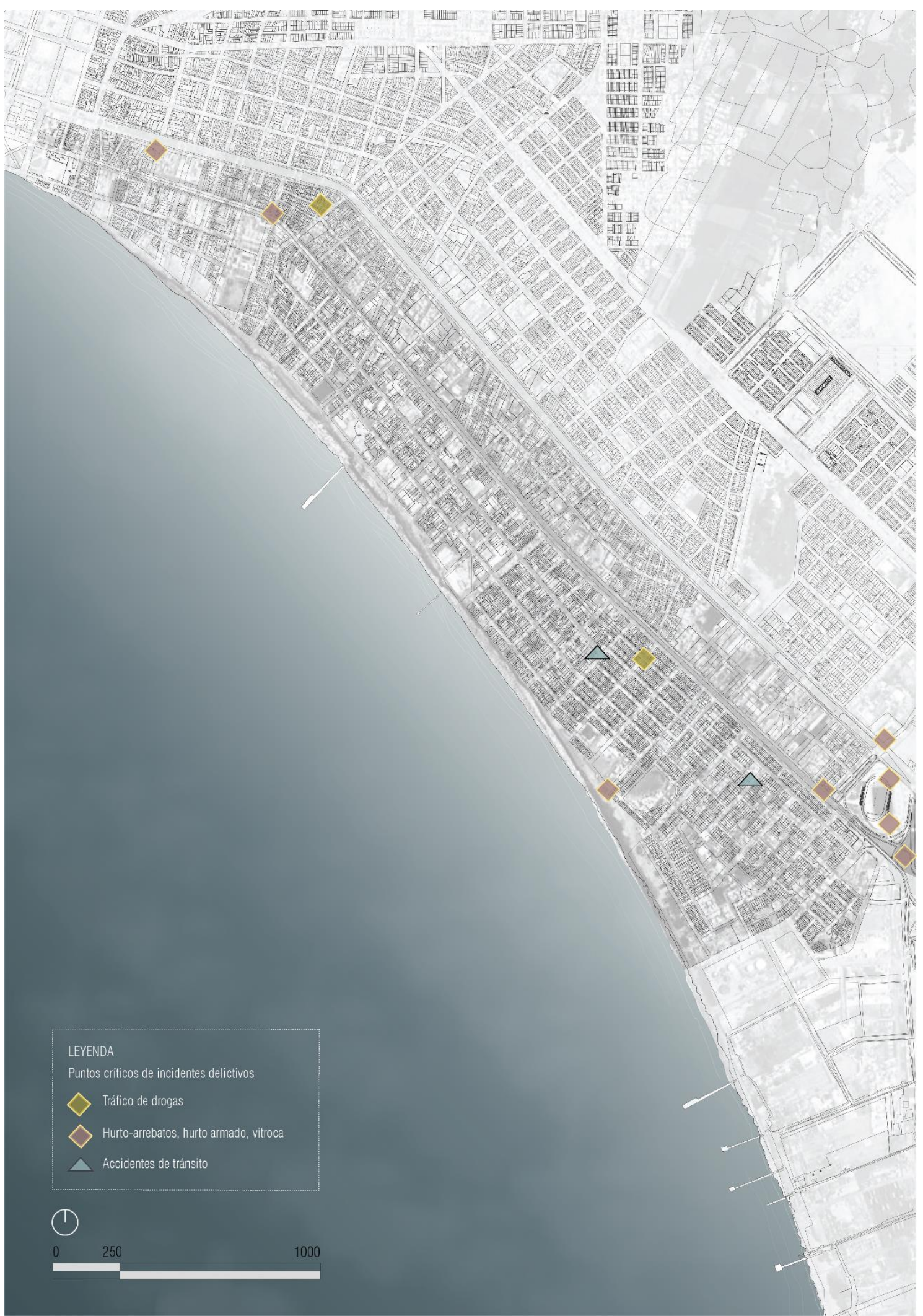

Fuente: CODISEC Chimbote 


\subsection{Centros Culturales en tres panoramas distintos}

\subsubsection{Primeros espacios culturales en el mundo}

Los seres humanos por naturaleza son sociales, se sienten a gusto al estar rodeados de sus pares para compartir momentos, experiencias y aprender junto a ellos. Por ejemplo, en la antigüedad, la vida social de la civilización griega se desarrollaba en el espacio público y en los edificios que lo rodeaban, elementos urbanos que enriquecían el desarrollo de la ciudad. Así crearon el ágora que se convirtió en el espacio público indispensable usado para expresar libremente las ideas, realizar todo tipo de intercambios y sobre todo para estar informados. Según Wycherley (1962) “era el lugar de reunión permanente de todos los ciudadanos, el escenario cotidiano de la vida social”. (de Tomás Medina, 2018, p. 52) El ágora era delimitado espacialmente por las stoas que se encontraban alrededor, estas eran espacios más cubiertos y funcionaban como la extensión del ágora manteniendo el carácter público. La stoa "servía para sesiones de justicia, asambleas del Consejo de la Ciudad y banquetes oficiales, a la vez que era el lugar donde se daban a conocer noticias públicas. Fue también espacio de encuentro de pensadores y estudiosos que, rodeados de alumnos, recorrían sus naves”. (Harris Diez, 2011, p. 71)

Del mismo modo que la civilización griega, la romana y la medieval cristiana desarrollaron espacios de intercambio social como el foro y las plazas dentro de la ciudad, cada una con una característica distinta debido a los hechos que sucedieron en determinado momento. De acuerdo con lo relatado en los antecedentes históricos, los espacios de intercambio fueron inicialmente espacios abiertos, de acceso totalmente público y gratuito, espacios que podrían considerarse como los orígenes de los Centros Culturales. 
Ilustración 2.41 Organización espacial del ágora en Grecia

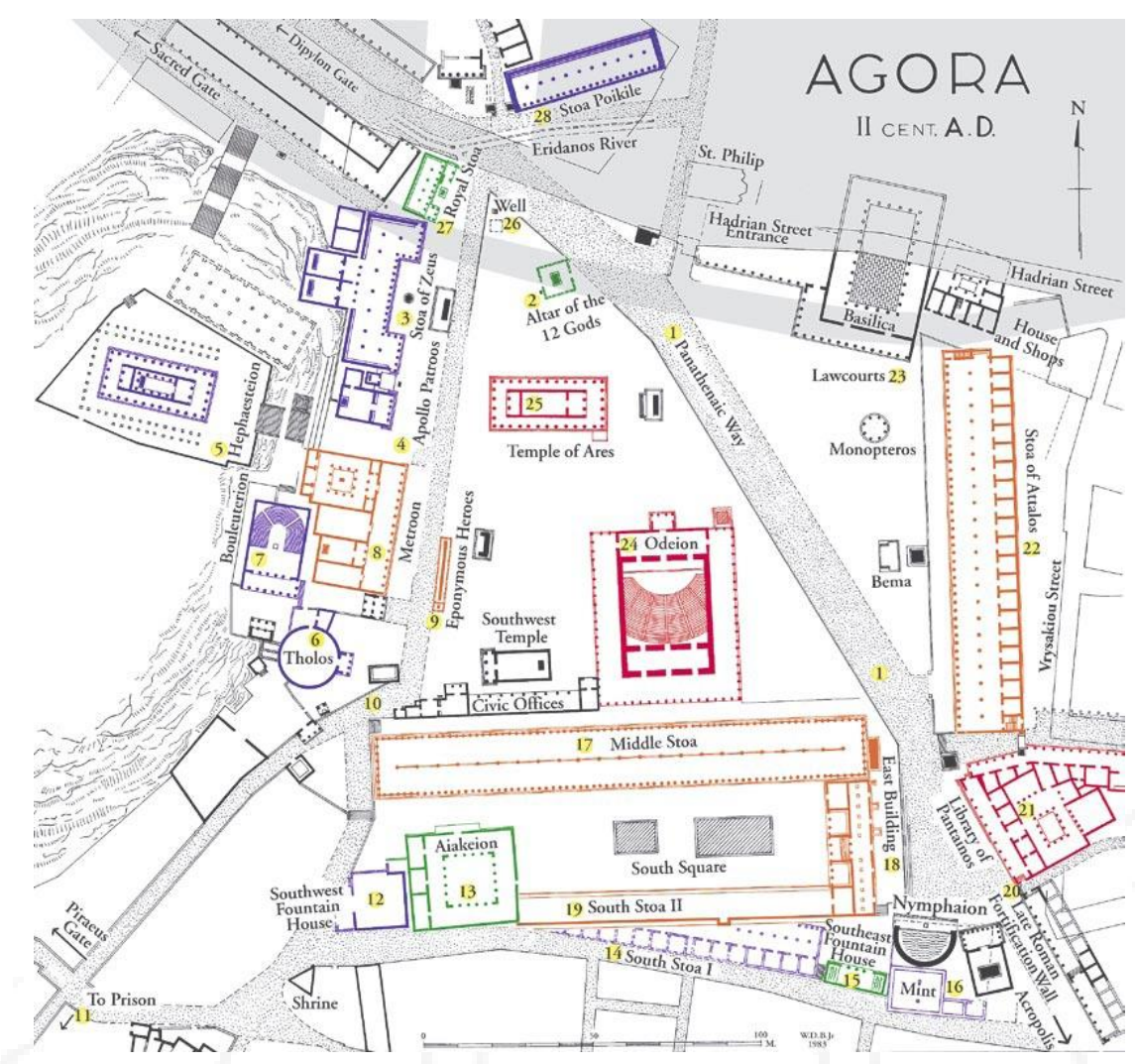

Fuente: Recuperado de www.arquiscopio.com/archivo/2016/04/24/agora-de-atenas

Más tarde, en el siglo XIX recién empezaron a formarse los Centros Culturales. En Inglaterra se crearon los primeros Centros de Cultura, llamados Centros de Arte que presentaban un carácter socio cultural establecido por las políticas culturales de países europeos. Sin embargo, fue recién a finales de 1950 que en Francia se establecieron las bases para la creación de los equipamientos culturales o lo que ahora se entiende como Centros Culturales. (Texeira Coelho, 1986, p. 165)

Después de la segunda guerra mundial, en Francia en 1959 se nombró a André Malraux como Ministro de Asuntos Culturales, quien estableció su plan de trabajo bajo tres lineamientos: democratización, difusión y creación, para lo que se debía desarrollar una política de cultura que sea verídica y tenga duración. Además, introdujo los proyectos culturales dentro de las políticas estatales, lo que generó que en los años próximos se empezaron a crear edificios culturales, así en 1967 se creó un Centro Nacional de Arte Contemporáneo y más tarde, un Consejo regional que se encargara del desarrollo del arte en cada región. (Antoine, 2011) 
Posteriormente, Francia desarrolló el proyecto de creación de "Casas de la Cultura", con las que se buscaba poner la cultura al alcance de toda la población, además de cumplir tres lineamientos base: animación, libertad y polivalencia. La primera se entiende como la acción de fomentar la participación de la población en actividades artísticas; la segunda, como la independencia frente al Estado, pues si bien es parte de este, el equipamiento cuenta con sus propias funciones y reglas y finalmente el tercero es entendido como la variedad de actividades con las que debe contar el equipamiento de modo que el público tenga muchas opciones para escoger. Las Casas de la cultura fueron las antecesoras de los Centros Culturales de hoy.

Dentro de los principales Centros Culturales construidos en Francia, se encuentran el Centro Cultural Georges Pompidou, inaugurado en 1977 como parte de una reforma urbana en centro de París y el Centro cultural Le Havre en la ciudad del mismo nombre, inaugurado en 1982 para reconstruir el edificio destruido después de la segunda guerra mundial.

\section{Ilustración 2.42 Centro Cultural Pompidou en París, Francia}

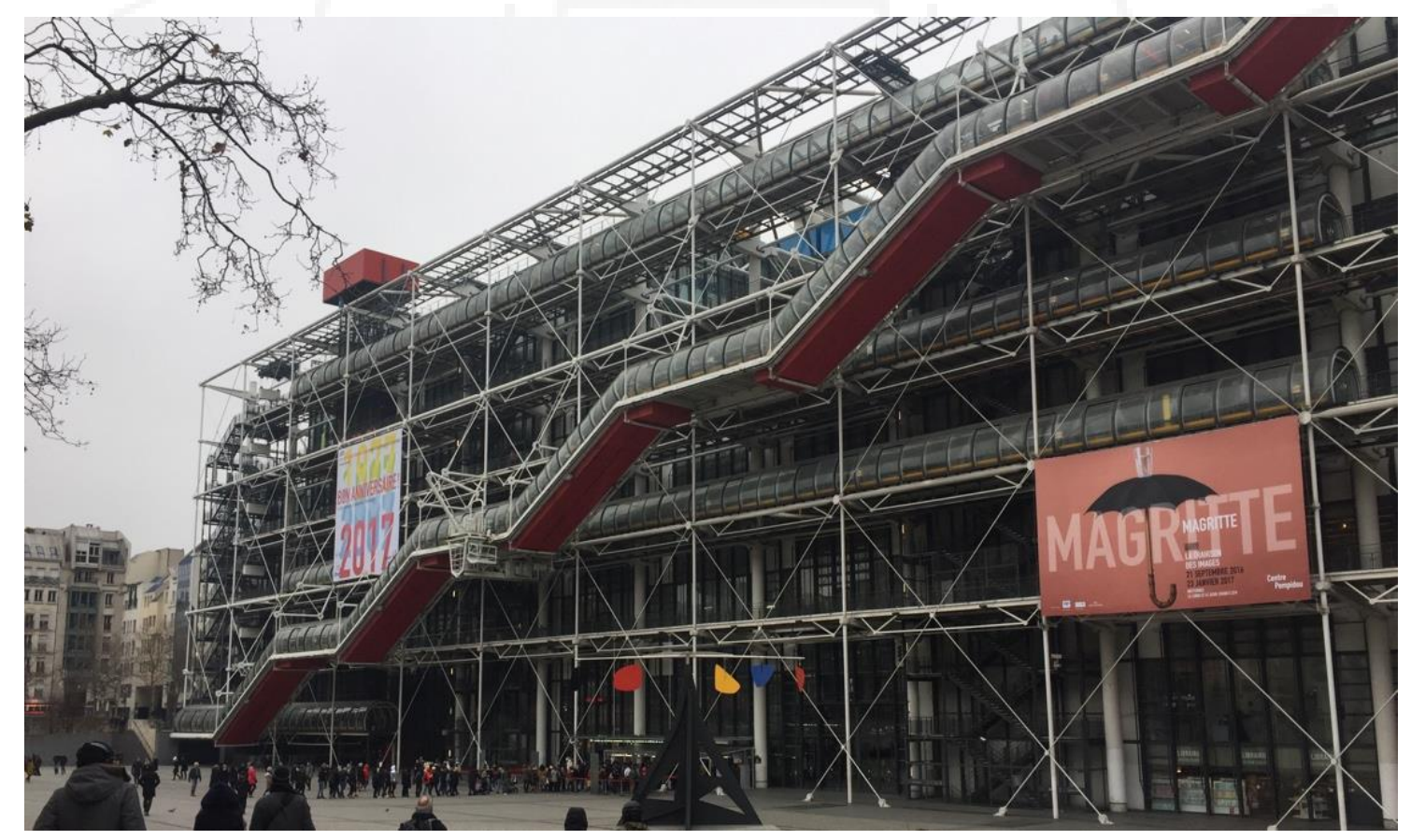

Fuente: Fotografía propia 


\section{Ilustración 2.43 Centro Cultural Le Havre - Le Havre, Francia}

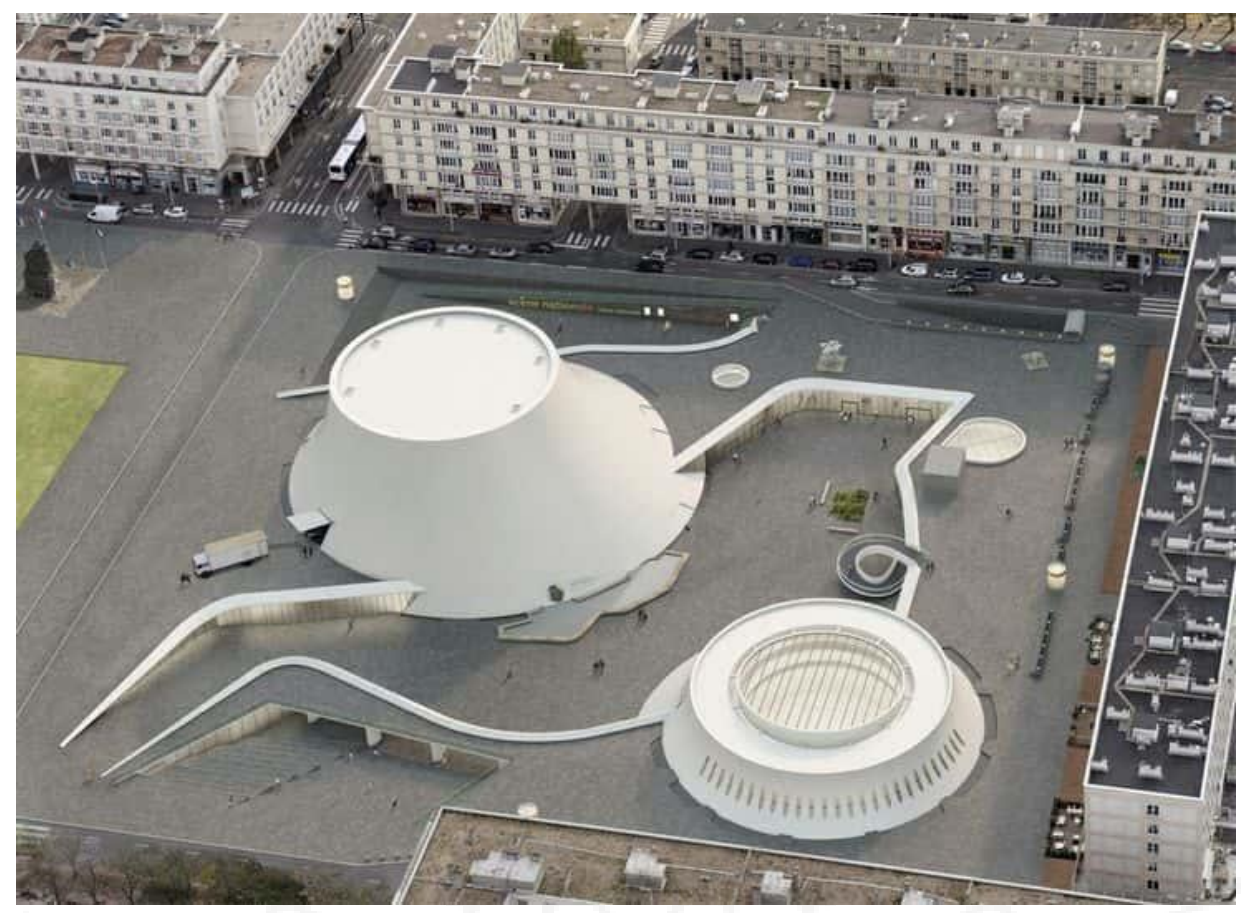

Fuente: Recuperado de www.espacioaretha.com

Por otro lado, la creación de Centros Culturales en Sudamérica no es reciente. En 1984 en Buenos Aires - Argentina se desarrolló el Programa Cultural en Barrios instalando cinco Centros Culturales Barriales, con la finalidad de fortalecer las relaciones socioculturales y promover el uso del espacio público. Este proyecto fue parte de una política pública que buscaba intervenir en todos los barrios de Buenos Aires a través de la difusión de 1200 talleres y cursos gratuitos (País Andade, 2006, p. 178) para promover las actividades artísticas, la identidad y recuperar la memoria del lugar, además de distribuir todo este programa por toda la ciudad estableciendo distintas sedes que ayuden a formar a la mayor cantidad de personas posible. "Por ese motivo, la cultura se convierte en una herramienta fundamental para la transformación personal y social, revirtiendo el proceso de fragmentación para convertirlo en uno de inclusión social y de solidaridad". (Arantes, 1993)

El proyecto fue creciendo paulatinamente hasta el año 2001 que se consolidó con 50 Centros Culturales que ofrecen diversas actividades que permiten formar a la población en distintas áreas, además de generar un espacio de encuentro e intercambio. Los centros culturales barriales tuvieron una relación directamente proporcional entre la cantidad de centros y el prestigio de estos, por tal razón empezaron a consolidarse como 
espacios de posibilidades y de formación de jóvenes, lo que permitía que estos sean tomados por el mercado laboral y empiecen a tener un ingreso monetario, convirtiéndose ya en artistas u obreros que forman parte de la población económicamente activa. (País Andade, 2006, p. 183)

Ilustración 2.44 Centro Cultural Barrial en Buenos Aires

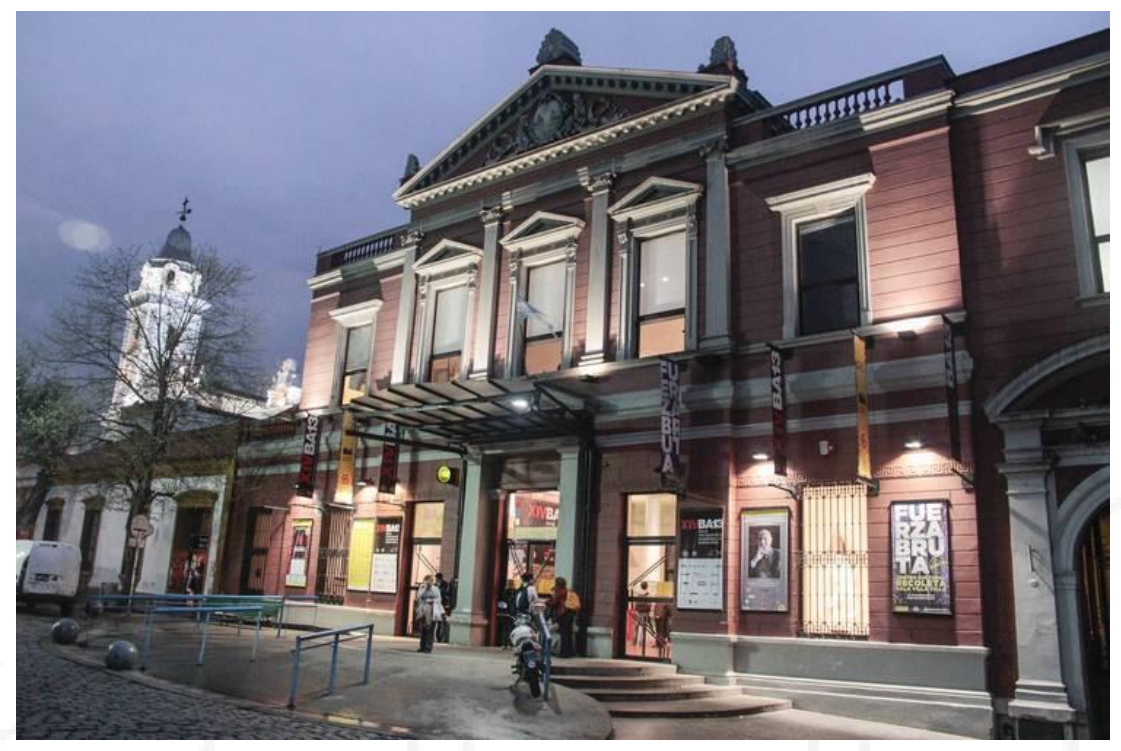

Fuente: Recuperado de www.buenavibra.com

\subsubsection{Centros culturales en el Perú}

En primer término, en el Perú no se establecieron directamente los Centros culturales, sino que primero se crearon equipamientos culturales con una función específica. Es así como en 1821, después de la proclamación de la independencia del país, San Martín estableció la creación de la Biblioteca Nacional del Perú. Posteriormente, en 1938 se creó la Orquesta Sinfónica Nacional del Perú, y en 1987 se fundó el Consejo Nacional de Danza del Perú, con lo que se completó la trilogía artística cultural del país, fomentando las artes y la cultura en la capital y en todo el país. (Díaz Sánchez, s.f.)

A partir de ello, empezaron a surgir los Centros Culturales, distintos entre sí de acuerdo con el tipo de gestión y su procedencia pública o privada. En 1949 se fundó el Centro Peruano Americano en Trujillo al norte del país, como parte del intercambio cultural entre Perú y Estados Unidos y se inauguró en 1979, del mismo modo lo hizo la Asociación Cultural Peruano Británica, creando su Centro Cultural en 1987 en Lima. Posteriormente, los sucedieron los Centros Culturales universitarios, formados con la finalidad de extender y complementar la educación y cultura impartida en estos centros 
de estudios. Entre ellos se encuentran el de la Pontificia Universidad Católica del Perú creado en 1994, el de la Universidad Mayor de San Marcos creado en 1995 en la antigua casona del Parque Universitario, el Centro Cultural y Académico Honorio Delgado de la Universidad Cayetano Heredia, el Centro Cultural Folklórico de la Universidad Nacional de Ingeniería - FOLKUNI. También se unieron a esta iniciativa las universidades del interior del país, entre las que destacan el Centro Cultural de la Universidad Nacional San Cristóbal de Huamanga en Ayacucho, el Centro Cultural Universitario de la Universidad Nacional de Trujillo y el Instituto de Cultura de la Universidad Nacional de Piura y el Centro Cultura de la Universidad San Agustín de Arequipa. Seguidamente, en 1996 se creó el Centro Cultural de la Escuela Nacional Superior Autónoma de Bellas de Artes del Perú para difundir las manifestaciones artísticas y como espacio de exposición para mostrar lo realizado por sus estudiantes. En el mismo año, también se fundó el Centro Cultural de España en Lima de la Agencia Española de Cooperación Internacional y Desarrollo (AECID), para fortalecer la cultura entre Perú y España. (Ministerio de Cultura, 2011, pp. 112-113)

Años más tarde, uno de los primeros edificios históricos en ser reciclado arquitectónicamente fue la antigua Estación de Trenes de Desamparados, donde se inauguró la Casa de la literatura peruana en el 2003. Proyecto que buscaba generar un nuevo atractivo en este edificio patrimonial de modo que se integre a la nueva ruta turística del Centro Histórico.

\section{Ilustración 2.45 Casa de la Literatura Peruana en la antigua estación de Trenes de Desamparados}

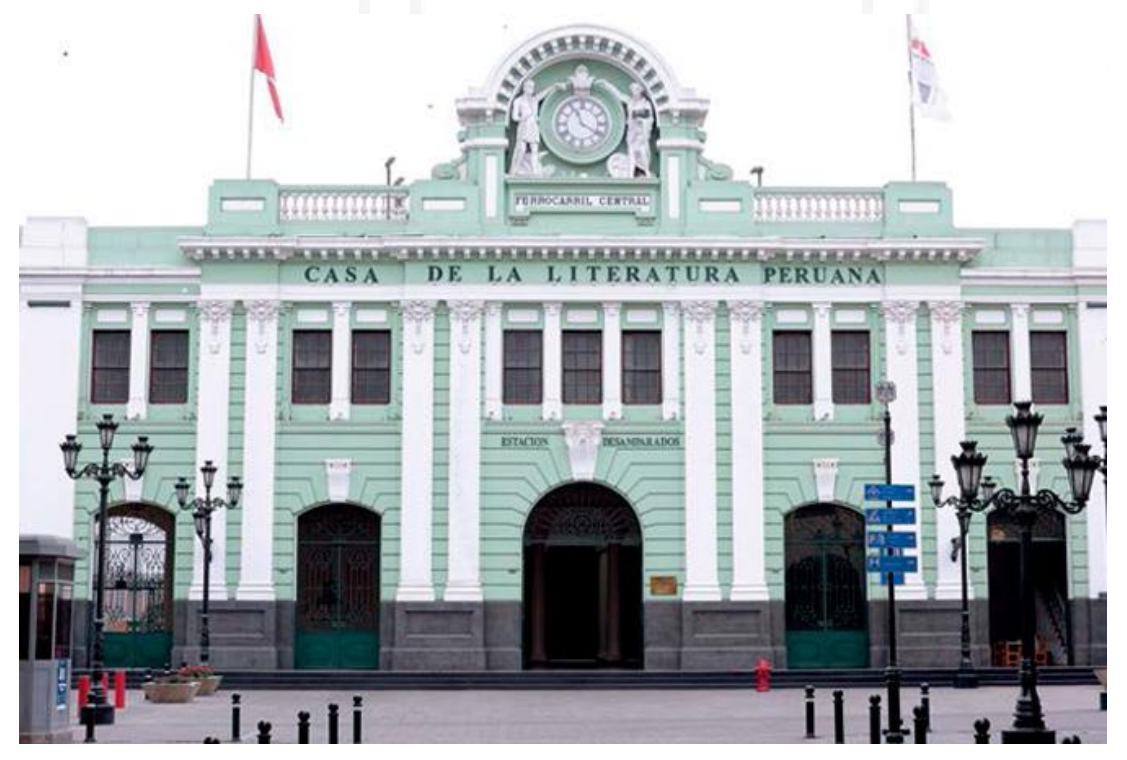

Fuente: Recuperado de www.lacasadelaliteratura.gob.pe 
Tabla 2.10 Lista de Centros Culturales por departamento, provincia y distrito en el Perú

\begin{tabular}{|c|c|c|c|}
\hline Centro Cultural & Departamento & Provincia & Distrito \\
\hline Centro Cultural Centenario & Ancash & Santa & Chimbote \\
\hline Centro Cultural Semblanza - Perú & Arequipa & Arequipa & Alto Selva Alegre \\
\hline Alianza Francesa Arequipa & Arequipa & Arequipa & Arequipa \\
\hline Centro Cultural Nitay Gouranga & Arequipa & Arequipa & Arequipa \\
\hline Centro Cultural Peruano Norteamericano de Arequipa & Arequipa & Arequipa & Arequipa \\
\hline Centro Cultural UNSA & Arequipa & Arequipa & Arequipa \\
\hline Instituto Cultural Ítalo Peruano - Arequipa & Arequipa & Arequipa & Arequipa \\
\hline Instituto Cultural Peruano Alemán & Arequipa & Arequipa & Arequipa \\
\hline Asociación Cultural Arlequín Teatro & Arequipa & Arequipa & Yanahuara \\
\hline Centro Cultural de Universidad de Huamanga & Ayacucho & Huamanga & Ayacucho \\
\hline Centro de Información y Cultura Yanacocha & Cajamarca & Cajamarca & Cajamarca \\
\hline Centro Cultural Juvenil Alejandro Miro Quesada Garland & Callao & Callao & Callao \\
\hline Casa de la Cultura David Juan Ferriz Olivares Sede Cusco & Cusco & Cusco & Cusco \\
\hline Casa de Cultura san Blas & Cusco & Cusco & Cusco \\
\hline Casa de la Cultura Túpac Inca Yupanqui & Cusco & Cusco & Cusco \\
\hline Centro Qosqo de Arte Nativo, Música y Danzas Folklóricas & Cusco & Cusco & Cusco \\
\hline Centro Tinku & Cusco & Cusco & Cusco \\
\hline Qosqo Wasinchis: Casa de la Cultura Solidaria & Cusco & Cusco & Cusco \\
\hline Taki Casa de Cultura & Cusco & Cusco & Cusco \\
\hline Alianza Francesa Cusco & Cusco & Cusco & Wanchaq \\
\hline Instituto Cultural Peruano Norteamericano - Cusco & Cusco & Cusco & Wanchaq \\
\hline Centro Cultural de Bellas Artes PaxArs & Huánuco & Huánuco & Huánuco \\
\hline Casa de la Cultura Juan Parra del Riego & Junín & Huancayo & ElTambo \\
\hline Centro Cultural Continental & Junín & Huancayo & Huancayo \\
\hline Instituto Cultural Peruano Norteamericano - Región Centro & Junín & Huancayo & Huancayo \\
\hline Instituto de la Juventud y la Cultura & Junín & Huancayo & Huancayo \\
\hline Centro Cultural Fortunato Cárdenas & Junín & Tarma & Tarma \\
\hline Alianza Francesa Trujillo & La Libertad & Trujillo & Trujillo \\
\hline Centro Cultural Haya de La Torre & La Libertad & Trujillo & Trujillo \\
\hline El Cultural, Centro Peruano Americano & La Libertad & Trujillo & Trujillo \\
\hline Alianza Francesa - Chiclayo & Lambayeque & Chiclayo & Chiclayo \\
\hline Instituto Cultural Peruano Norteamericano Chiclayo & Lambayeque & Chiclayo & Chiclayo \\
\hline Centro Cultural Rímac & Lima & Cañete & Asia \\
\hline Centro de Arte, de Títeres y Cultura Antarita & Lima & Huaura & Huacho \\
\hline Agárrate Catalina & Lima & Lima & Barranco \\
\hline Asociación Cultural Filarmonía & Lima & Lima & Barranco \\
\hline Asociación Cultural Folclórica Don Porfirio & Lima & Lima & Barranco \\
\hline Asociación Cultural Túpac & Lima & Lima & Barranco \\
\hline Casa Cultural Mocha Graña & Lima & Lima & Barranco \\
\hline Enana Blanca & Lima & Lima & Barranco \\
\hline Evidencia & Lima & Lima & Barranco \\
\hline Centro Cultural Aduni & Lima & Lima & Breña \\
\hline Centro Cultural Artístico Grecia - Sede Lucyana & Lima & Lima & Carabayllo \\
\hline Centro Cultural Artístico Grecia - Sede El Álamo & Lima & Lima & Comas \\
\hline Centro Cultural Artístico Grecia - Sede Retablo & Lima & Lima & Comas \\
\hline Centro Cultural Waytay & Lima & Lima & ElAgustino \\
\hline Aranwa Asociación Cultural & Lima & Lima & Jesús María \\
\hline Centro Cultural Al Andalus & Lima & Lima & Jesús María \\
\hline Centro Cultural Municipal & Lima & Lima & Jesús María \\
\hline Centro Cultural Peruano Japonés & Lima & Lima & Jesús María \\
\hline Instituto Goethe de Lima & Lima & Lima & Jesús María \\
\hline Asociación Cultural Brisas del Titicaca & Lima & Lima & Lima \\
\hline Asociación de Artistas Aficionados & Lima & Lima & Lima \\
\hline
\end{tabular}




\begin{tabular}{|c|c|c|c|}
\hline $\begin{array}{l}\text { Centro Cultural } \\
\text { Asociación Museo de Arte de Lima }\end{array}$ & $\begin{array}{l}\text { Departamento } \\
\text { Lima }\end{array}$ & $\begin{array}{l}\text { Provincia } \\
\text { Lima }\end{array}$ & $\begin{array}{l}\text { Distrito } \\
\text { Lima }\end{array}$ \\
\hline Centro Cultural Alberto Quintanilla & Lima & Lima & Lima \\
\hline Centro Cultural de España & Lima & Lima & Lima \\
\hline Centro Cultural de la Escuela de Bellas Artes & Lima & Lima & Lima \\
\hline Centro Cultural de la Universidad Mayor de San Marcos & Lima & Lima & Lima \\
\hline Centro Cultural Federico Villarreal & Lima & Lima & Lima \\
\hline Centro Cultural Inca Garcilaso & Lima & Lima & Lima \\
\hline Centro Cultural Inca Garcilaso de la Vega & Lima & Lima & Lima \\
\hline Centro Cultural José Pío Aza & Lima & Lima & Lima \\
\hline Centro Cultural Teatro de Cámara & Lima & Lima & Lima \\
\hline $\begin{array}{l}\text { Centro de Investigación, Documentación, Educación, } \\
\text { Asesoría y Servicios - IDEAS }\end{array}$ & Lima & Lima & Lima \\
\hline Centro Fundación Telefónica & Lima & Lima & Lima \\
\hline Club de la Unión & Lima & Lima & Lima \\
\hline Instituto Italiano de Cultura de Lima & Lima & Lima & Lima \\
\hline La Casa Ida & Lima & Lima & Lima \\
\hline Sociedad Bíblica Peruana & Lima & Lima & Lima \\
\hline Centro Cultural Arkabas & Lima & Lima & Lince \\
\hline La Casa de la Cultura de Lince & Lima & Lima & Lince \\
\hline Casa Cultural Vallecito & Lima & Lima & Los Olivos \\
\hline Asociación Cultural El Galpón. Espacio & Lima & Lima & Magdalena del Mar \\
\hline Grupo Cultural Yuyachkani & Lima & Lima & Magdalena del Mar \\
\hline Asociación Rafael Larco Hoyle & Lima & Lima & Magdalena Vieja \\
\hline Alianza Francesa & Lima & Lima & Miraflores \\
\hline Campo Abierto - Club de Arte y Cultura & Lima & Lima & Miraflores \\
\hline Centro Cultural CcoriWasi & Lima & Lima & Miraflores \\
\hline Centro Cultural El Olivar & Lima & Lima & Miraflores \\
\hline Centro Cultural Peruano Británico & Lima & Lima & Miraflores \\
\hline Centro Cultural Ricardo Palma & Lima & Lima & Miraflores \\
\hline Centro Cultural Universidad Cientifica del Sur & Lima & Lima & Miraflones \\
\hline Centro Cultural y Académico Casa Honorio Delgado & Lima & Lima & Miraflores \\
\hline Instituto Cultural Peruano Norteamericano - Lima & Lima & Lima & Miraflores \\
\hline La Tarumba & Lima & Lima & Miraflores \\
\hline Sociedad Filarmónica de Lima & Lima & Lima & Miraflores \\
\hline Centro Cultural Folklórico de la UNI & Lima & Lima & Rímac \\
\hline AFS del Perú Programas Interculturales & Lima & Lima & San Isidro \\
\hline Centro Cultural Cafae - SE José María Arguedas & Lima & Lima & San Isidro \\
\hline Centro Cultural de la Pontificia Universidad Católica del Perú & Lima & Lima & San Isidro \\
\hline Instituto Libertad y Democracia & Lima & Lima & San Isidro \\
\hline $\begin{array}{l}\text { Asociación Civil SINACOOP.PNP } \\
\text { Amigos de la Policía Nacional del Perú }\end{array}$ & Lima & Lima & Santiago de Surco \\
\hline Centro Cultural del Parque de la Amistad & Lima & Lima & Santiago de Surco \\
\hline Arena y Esteras & Lima & Lima & Villa El Salvador \\
\hline Casa Infantil Juvenil de Arte y Cultura - CIJAC & Lima & Lima & Villa El Salvador \\
\hline Casa Teatro Vichama & Lima & Lima & Villa El Salvador \\
\hline Alianza Francesa lquitos & Loreto & Maynas & lquitos \\
\hline Centro cultural de la Universidad cientifica del Perú & Loreto & Maynas & lquitos \\
\hline Centro Cultural Infantil Irapay & Loreto & Maynas & lquitos \\
\hline Centro de Estudios Teológicos de la Amazonía (Asociación CETA) & Loreto & Maynas & lquitos \\
\hline Instituto de Cultura - UNP & Piura & Plura & Castilla \\
\hline Alianza Francesa Piura & Piura & Plura & Piura \\
\hline Centro Cultural Tercera Orilla & Piura & Plura & Piura \\
\hline Instituto Cultural Peruano Norteamericano - Piura & Piura & Plura & Piura \\
\hline Instituto Americano de Arte Puno & Puno & Puno & Puno \\
\hline Casa de la Cultura David Juan Ferriz Olivares - Filial Tarapoto & San Martín & San Martín & Tarapoto \\
\hline Centro Cultural Resistencia & San Martín & San Martín & Tarapoto \\
\hline Centro Cultural Peruano Norteamericano - Filial Tacna & Tacna & Tacna & Tacna \\
\hline
\end{tabular}

Fuente: Ministerio de Cultura, 2011, pp. 114-115 


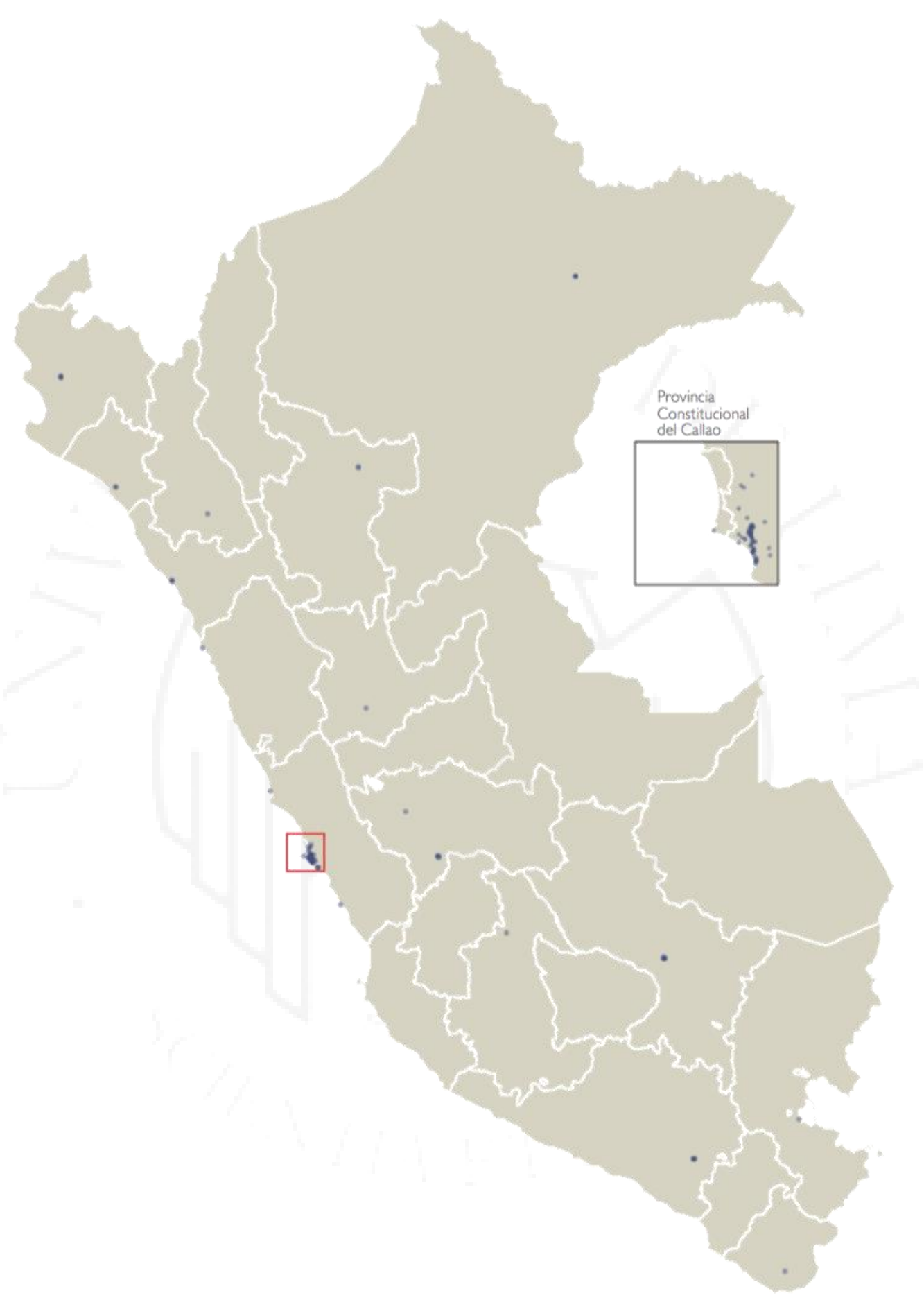

Fuente: Ministerio de Cultura, 2011, p. 117. Sistema de información general de las Américas. 
Ilustración 2.47 Centros Culturales por departamento

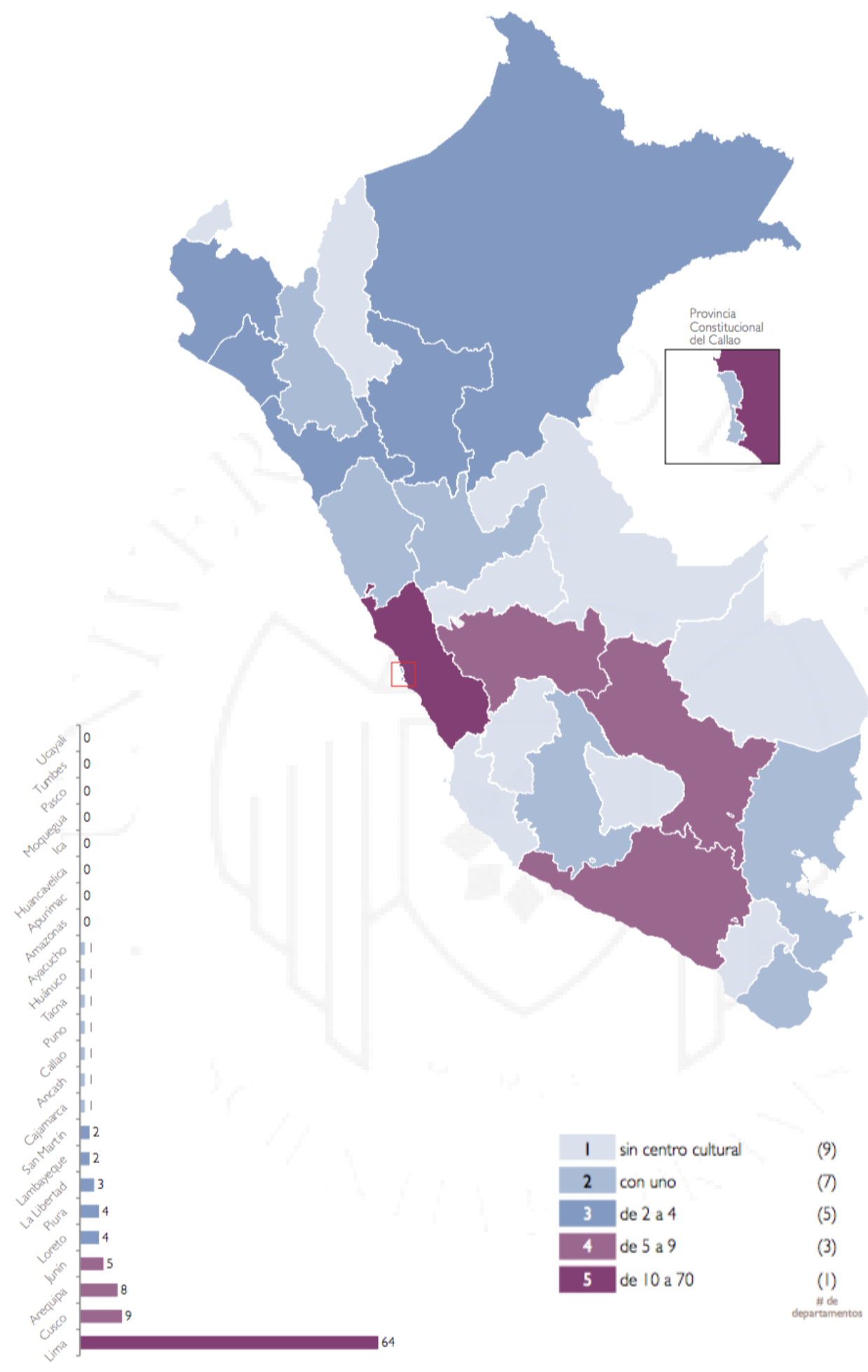

Fuente: Ministerio de Cultura, 2011, p. 118. 


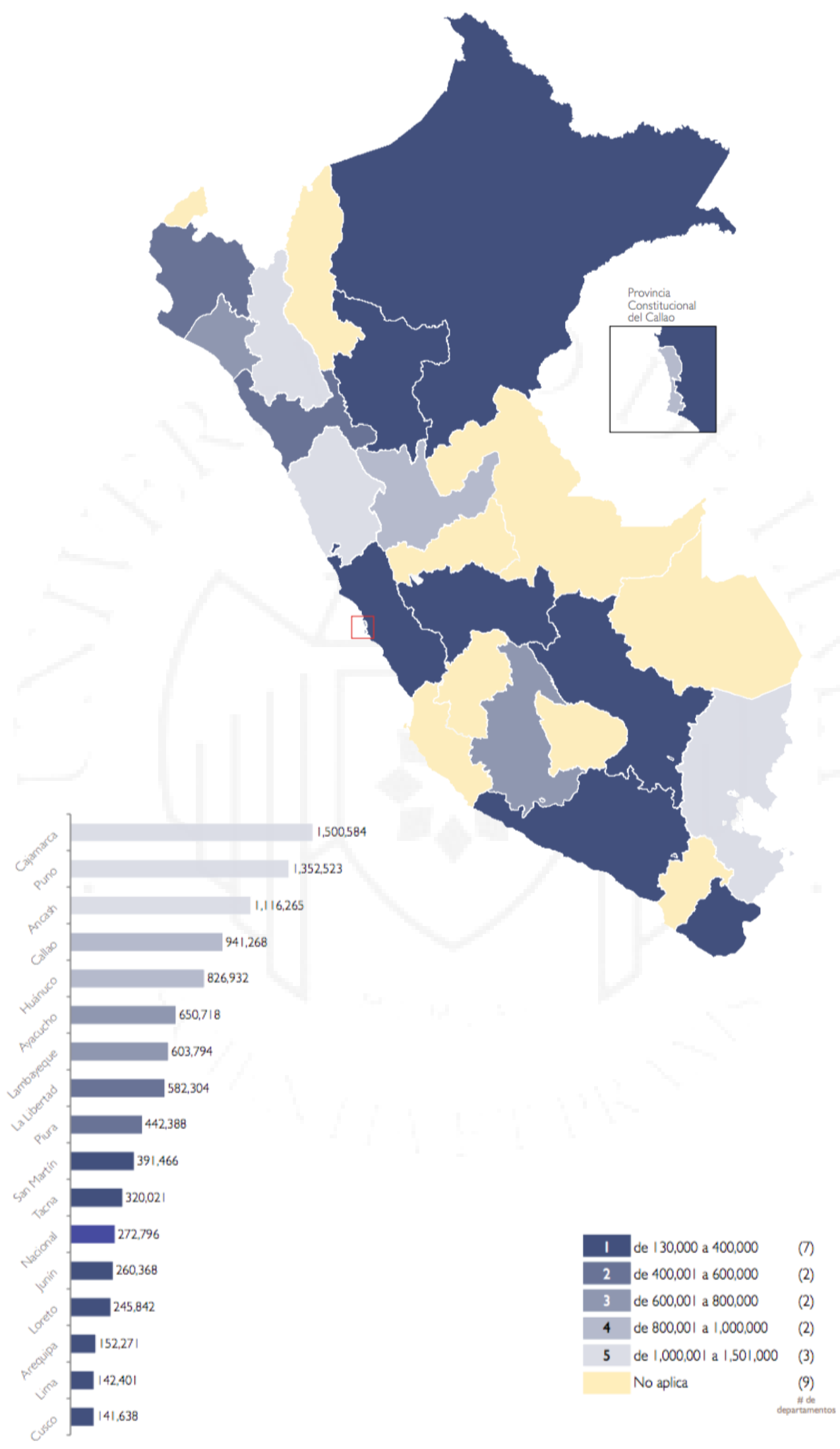

Fuente: Ministerio de Cultura, 2011, p. 119 


\subsubsection{Asociaciones y centros culturales en Chimbote}

El paisaje de Chimbote, su bahía, las islas y valles incentivaron a la población chimbotana a formar grupos y asociaciones que fomentaran la cultura poética, literaria, musical y teatral. Los gestores de este tipo de agrupaciones eran jóvenes chimbotanos cuyo ímpetu era sentar una base cultural en su ciudad pesquera ya que había recibido una variada influencia de culturas de los habitantes de pueblos cercanos que habían migrado a la ciudad.

Uno de los primeros espacios culturales fue el Centro Cultural Filarmónico fundado en 1936 en el centro de la ciudad con la finalidad de realizar diversos eventos sociales y artísticos para los chimbotanos. (Arroyo Icochea, 2007, p. 26) Posterior a este se fundaron los clubes sociales como Rotary Club de Chimbote, Club de leones y Club Social Chimbote. En 1968 se funda la Asociación Cultural Wha Yoi, que nace como resultado de deseo de ilustres personalidades y de jóvenes descendientes chinos que buscaban crear un espacio donde se fomente la cultura y deporte. (Unyén Velezmoro, 2016, p. 91) Años más tarde, empiezan a nacer grupos poéticos y literarios, que en sus poemas y cuentos reflejaban el aprecio que sentían por la ciudad que los había visto nacer y que había calado hondo en sus vidas. Entre ellos se encontraban: Asociación Cultural Peruano Soviética, Club Alfonso Ugarte, Grupo Literario Isla Blanca, Movimiento Cultural Bellamar, Frente Artístico Literario "Trincheras", Círculo Cultural Ferrol, Círculo Literario Ardiente Sombra, La Casa del Poeta Peruano (CADELPO), Sociedad Internacional de Arte y Cultura (SIAG). (Unyén Velezmoro, 2016, pp. 235-326)

En 1971, un grupo de profesionales creó la Inspección de Cultura de la Municipalidad Provincial del Santa, cuya finalidad era gestionar equipamientos culturales para la ciudad, entre las labores que realizó este grupo se destacan: la conformación de la comisión gestora de la Universidad Nacional del Santa, la creación del Instituto Nacional de Cultura (INC) en 1982 y la creación de la Biblioteca Inca Garcilaso de la Vega en el centro cívico del distrito de Nuevo Chimbote en 1977 en cooperación con el Organismo de Desarrollo de la Zona Afectada (ORDEZA) y el Ministerio de Educación y Ciencia de España, quien donó libros. La creación de la sede del INC en Chimbote trajo consigo la creación de Talleres Experimentales de Formación Artística (TEFAS) gestionada y promovida por el maestro Víctor Unyén Velezmoro, en los que se impartían clases de danza, pintura, artesanía, escultura, música y teatro. Para 
el desarrollo de los talleres se consiguió un terreno de $2500 \mathrm{~m}^{2}$ en el ex patio del ferrocarril, en el que se acondicionó el espacio mientras se desarrollaba el proyecto del Centro Cultural en este terreno; sin embargo, el proyecto quedó en nada y en este espacio hoy funciona la Galería Bahía Plaza Center. (Unyén Velezmoro, 2016)

Años más tarde y en ocasión de celebrar el centenario de la ciudad, en el 2006 se creó el Centro Cultural Centenario, el único que hasta hoy funciona como tal. Su creación se debió como principal motivación de la Municipalidad Provincial del Santa a la que se sumó la colaboración del estado, el sector privado y la sociedad civil. Como promotor de la iniciativa, la municipalidad donó el terreno de $4000 \mathrm{~m}^{2}$ en la zona urbana de la ciudad que hoy se encuentra inscrito como Asociación Centenario de Chimbote ante los registros públicos. En su interior alberga una biblioteca con sala infantil, letras y ciencias; hemeroteca, telecentro, galería de arte, cine club y sala multiusos. Además, se realizan conferencias, conversatorios y talleres diversos abiertos al público en general. (Cultura, s.f.)

\section{Ilustración 2.49 Centro Cultural Centenario en Chimbote}

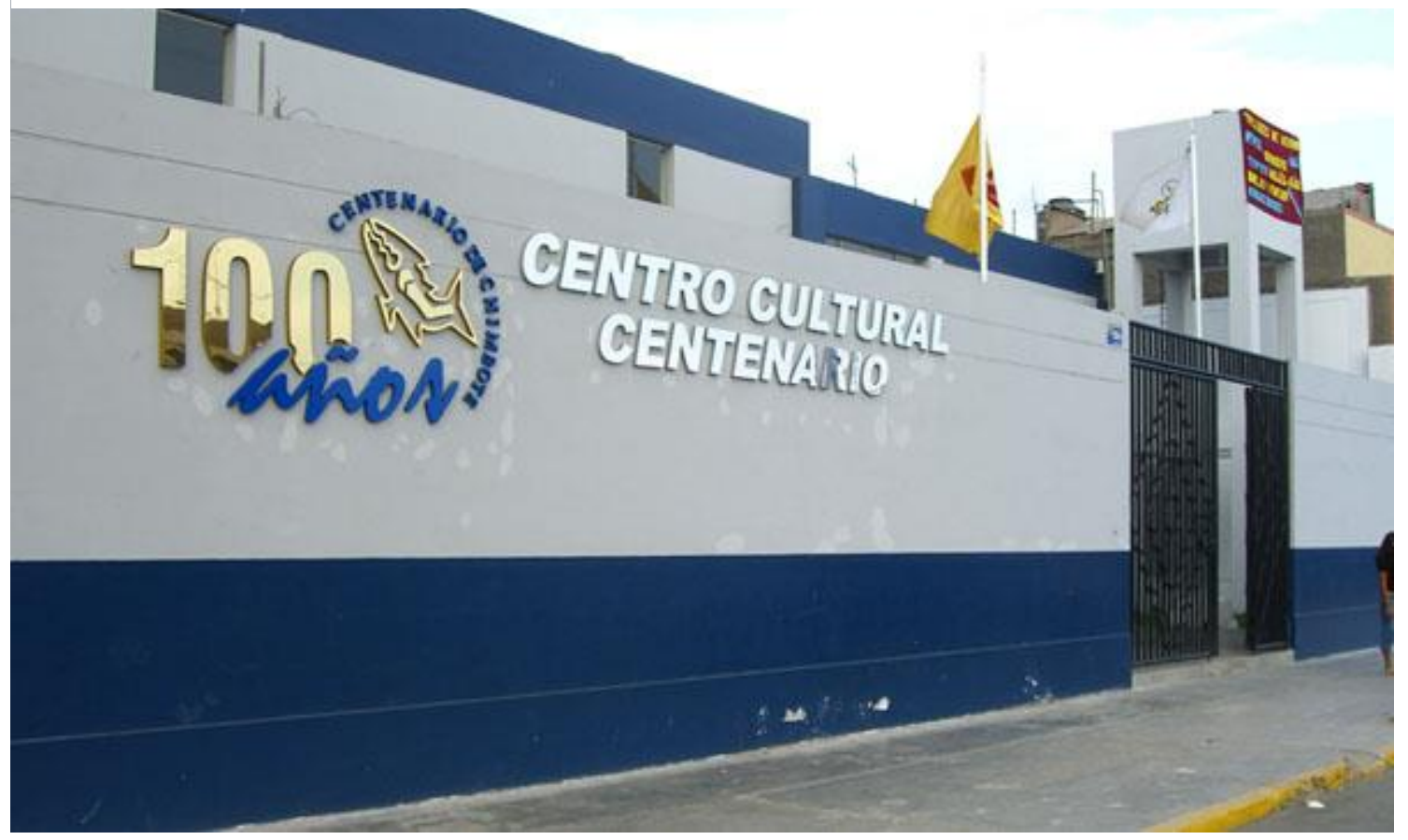

Fuente: Recuperado de www.centroculturalcentenario.org 
Ilustración 2.50 Patio interior del Centro Cultural Centenario

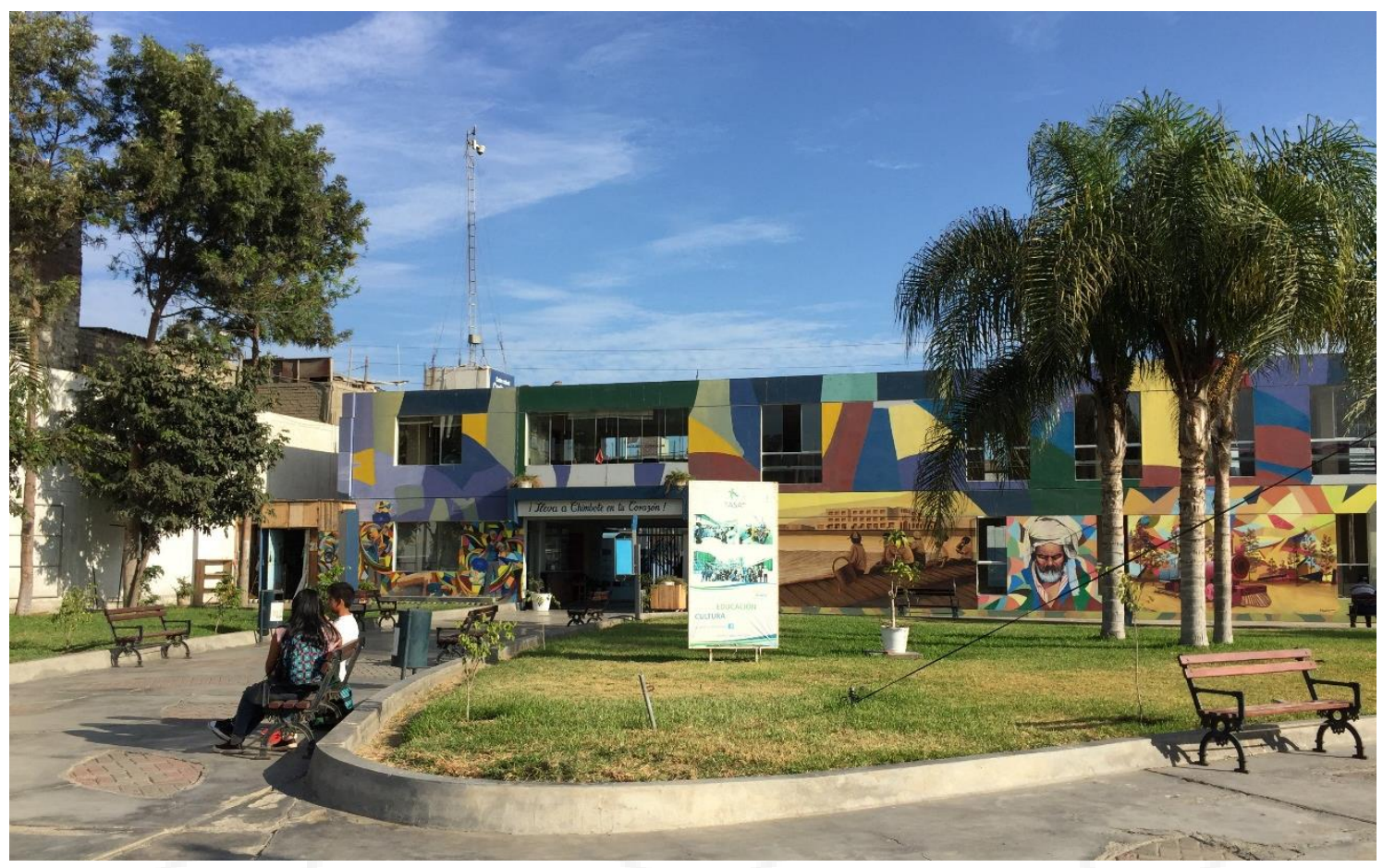

Fuente: Fotografía propia

A pesar de que la ciudad cuenta con un Centro Cultural, no se escapa de tener una crítica situación y desarrollo cultural, pues de acuerdo a la información plasmada en el Atlas de Infraestructura y Patrimonio Cultural de las Américas - Perú (2011), este equipamiento es el único en el departamento de Ancash que abastecer a toda la población que hay en este. (p. 118)

\subsection{Regeneración de puertos y transformación de frentes costeros}

Históricamente, los puertos se han presentado como elementos urbanos y territoriales de primer orden por la riqueza de las relaciones que se han tejido, y que tienen lugar, en sus entornos urbanos y territoriales. (Grindlay Moreno, 2008, p. 54) Eran espacios de intercambio de mercancías, creadores de productos industriales y puntos de confluencia de diversas personas y culturas. Albergaban tanto a inversionistas, a la masa trabajadora como a los visitantes. Las ciudades en las que se encontraban los puertos estaban en la mira de todo el mundo debido al gran desarrollo económico que se había suscitado.

Inicialmente, a mediados del siglo XVIII, los puertos y las ciudades estaban estrechamente ligados entre sí, muchos de ellos se encontraban en el centro de la ciudad 
donde se habían establecido debido al gran potencial extractivo con el que contaba. Posteriormente, la revolución industrial marcó un hito en la industria pues con ella se originaron diversos cambios, como la evolución del transporte marítimo y la modernización de las estructuras y procesos industriales, lo que desencadenó que las industrias empezaran a expandirse porque necesitaban mayor área de trabajo y maniobra. A finales de los años 60, se desencadenó un cambio inesperado en la estructura del comercio marítimo y de la economía portuaria, generando una disociación entre ciudad y puerto que conllevaría a la degradación de este último. (Schubert, 2004, p. 18)

"Los procesos de cambio tecnológico en la industria y el transporte marítimo en la segunda mitad del siglo XX, que han implicado la obsolescencia de muchas instalaciones portuarias, han propiciado el fenómeno de la recuperación de zonas portuarias obsoletas para usos urbanos, fundamentalmente recreativos y de equipamientos colectivos, que conllevan una recuperación del espacio público de la ciudad para el ciudadano, provocando mejoras en la calidad urbana que genera un aumento en la calidad de vida y beneficios sociales”. (Bierre \& García-Almirall, 2011, p. 639)

De acuerdo con los sucesos acontecidos en los puertos es que se empieza a hacer regeneración urbana en estos, ya que es un mecanismo que invierte un proceso de decadencia económica, demográfica y social a través de una intervención, que en muchos casos viene marcada por una fuerte acción pública. (ONU, 2016, p. 5) Se genera mediante la modernización de las infraestructuras y, en algunos casos, a través de modificaciones en el uso del suelo.

Los beneficios obtenidos de este proceso contribuyen al aumento de la productividad, la creación de empleo, la atracción de la inversión, el aumento de la accesibilidad a la vivienda, la capitalización de infraestructuras existentes, reducción de la delincuencia, la revitalización de infraestructuras en desuso, conservación de edificios históricos y la reducción de la contaminación atmosférica. (ONU, 2016)

Asimismo, el espacio público empieza a tener un valor importante dentro de las regeneraciones urbanas ya que funciona como elemento catalizador. Se ha comprobado que dinámicas urbanas negativas han sido desplazadas con éxito introduciendo mejoras en el espacio público y los equipamientos. Los espacios públicos contribuyen a la conformación de los sentidos individuales y necesarios de "lugar" que identifican a los 
usuarios con un territorio y de "pertenencia" que supone cuando dichos lugares se ligan a la memoria y las emociones. (Sabaté Bel, Paisajes culturales. El patrimonio como recurso básico para un nuevo modelo de desarrollo)

Los factores que inciden en el proceso de regeneración en las ciudades son:

- La integración de la perspectiva de género: Debe existir una igualdad de oportunidades entre la población, un espacio público que genere equilibrio entre la vida privada y pública, y unos equipamientos a favor de la igualdad.

- El fortalecimiento de las centralidades periféricas: Se busca favorecer la aparición de nuevas centralidades periféricas donde se fomente la actividad económica.

- El desarrollo de la economía local: Se busca potenciar espacios especializados de actividad económica y polígonos empresariales.

- Equipamientos como factor de cohesión: Ya que representan una gran oportunidad para generar espacios de encuentro donde se facilite la participación y se desarrolle una identidad común.

- Espacios en desuso: El uso de espacios obsoletos permite identificar áreas de oportunidad, que puedan ser activados para resolver demandas vecinales. (Sabaté Bel, De la preservación del patrimonio a la ordenación del paisaje, 2005) (ONU, 2016)

En este proceso también se asumen retos como la eficacia en la reducción de la huella ecológica, la mayor desigualdad social y territorial, el envejecimiento y la multiculturalidad, la necesidad de intervenir en las periferias frente al centro, entre otros. (ONU, 2016, p. 17)

La recuperación de los frentes costeros o waterfronts empezó a ser continuo en las ciudades puerto, porque se empezó ver en estos espacios olvidados, una oportunidad de desarrollo social, ambiental, urbano y sobre todo económico. El mar que en un inicio fue la base de su desarrollo industrial, ahora sería tomado como base para su regeneración urbana que desencadenaría la transformación total de la ciudad, en la que su mayor característica es su frente costero y su puerto. 
En cada regeneración o revitalización de zonas portuarias y costeras, se engloban diferentes procesos y planteamientos, como la planificación portuaria y el planeamiento urbano. El primer enfoque busca tratar medidas de desarrollo del puerto, en otras palabras, ve directamente la reorganización y reubicación de servicios portuarios, Mientras que el enfoque del planeamiento urbano se centra en variaciones del aprovechamiento de la zona, es decir, de cambiar usos anteriormente relacionados con el puerto por usos vinculados a actividades terciarias, de recreación y vivienda. (Schubert, 2004, pp. 16-17)

De acuerdo a Fagence (como se citó en Bierre \& García-Almirall, 2011), el objetivo de estas transformaciones ha sido la apertura la mar, dando libre acceso a los ciudadanos, con la exigencia de mejorar la imagen de zonas que previamente estaban en desuso, lo que a su vez comporta una activación económica que otorga nuevas oportunidades. (p. 640)

Las ciudades que hoy presentan puertos con transformaciones sumamente positivas y que se han convertido en grandes atracciones turísticas, ha sido gracias al desarrollo de megaproyectos que han convertido el tejido industrial en espacios beneficios para el crecimiento de la ciudad. Si bien, los proyectos de reconversión portuaria tienen muchas similitudes, cada uno tiene identidad debido a que cada ciudad puerto presenta sus propias condiciones geográficas, históricas, económicas, ambientales, sociales y culturales, que enriquecen aún más los proyectos. En muchos casos, además de recuperar los frentes costeros, también se han reciclado edificios y estructuras industriales que se encuentra dentro del puerto o cercanos a este para contribuir a revalorar el patrimonio industrial de las ciudades. 
Ilustración 2.51 Megaproyectos de revitalización de zonas portuarias y costeras en desuso

\begin{tabular}{|c|c|c|}
\hline Ciudad & Proyecto & Dimension (ha) \\
\hline Vancouver & Granville Island & 17 \\
\hline Bilbao & Abandoibarra & 35 \\
\hline Baltimore & Inner Harbor & 35 \\
\hline Toronto & Harbourfront & 36 \\
\hline New York & Battery Park City & 37 \\
\hline Barcelona & Port Vell & 54 \\
\hline Sydney & $\begin{array}{l}\text { Darling Harbour } \\
\text { Rocks }\end{array}$ & $\begin{array}{l}59 \\
21 \\
\end{array}$ \\
\hline Oslo & Aker Brygge & 64 \\
\hline Rotterdam & Kop van Zuid & 124 \\
\hline Hamburgo & $\begin{array}{c}\text { Hafen-City } \\
\text { Harburg Binnenhafen }\end{array}$ & $\begin{array}{l}155 \\
172 \\
\end{array}$ \\
\hline Amberes & "Kleine Insel" Eilandje & 170 \\
\hline Tokio & Teleport Town & 186 \\
\hline Melbourne & $\begin{array}{c}\text { Victoria Harbour } \\
\text { Southgate }\end{array}$ & $\begin{array}{c}220 \\
3 \\
\end{array}$ \\
\hline Bremen & $\begin{array}{c}\text { Áreas portuarias antiguas a la } \\
\text { derecha del Weser }\end{array}$ & 288 \\
\hline Amsterdam & Eastern Docklands & 313 \\
\hline Singapur & Marina Bay & 370 \\
\hline London & Docklands & 2.224 \\
\hline Shanghai & $\begin{array}{c}\text { Pudong } \\
\text { Lujiazui-Huamu }\end{array}$ & $\begin{array}{l}52.000 \\
2.800\end{array}$ \\
\hline
\end{tabular}

Fuente: (Schubert, 2004, p. 17)

Se han desarrollado proyectos con la finalidad de fortalecer y aumentar la economía, reorganizar el espacio urbano, dotar de espacio público, generar nuevos usos y recuperar el paisaje y patrimonio industrial de las ciudades. Entre los proyectos pioneros y de impacto positivo en las ciudades portuarias se encuentran:

a. Inner Harbour, Baltimore - Estados Unidos

Puerto que después de la segunda guerra mundial quedó en decadencia por no haber redireccionado a tiempo su industrial. Se encuentra en la costa este de Estados Unidos. El proyecto se empezó a desarrollar en 1963 y se culminó en 1980. Es el primero en ser "puerto nuevo". El principal objetivo del proyecto era convertir a Baltimore en una ciudad con nuevos atractivos, por ello cuenta con un malecón de diez metros y medio de ancho; un acuario, dos hoteles, uno pequeño y otro grande, torres de oficinas, museo de ciencias, parque, condominio de viviendas, restaurantes y conjuntos de negocios. 
Por ser el pionero tuvo aciertos y desaciertos. Desarrolló una adecuada conexión con la ciudad, pero no supo manejar la escala equilibrada entre los conjuntos de viviendas frente al mar y el puerto. (Gutiérrez \& Talesnik, 2002, pp. 7-8)

Ilustración 2.52 Recuperación de Inner Harbour-Baltimore, Estados Unidos

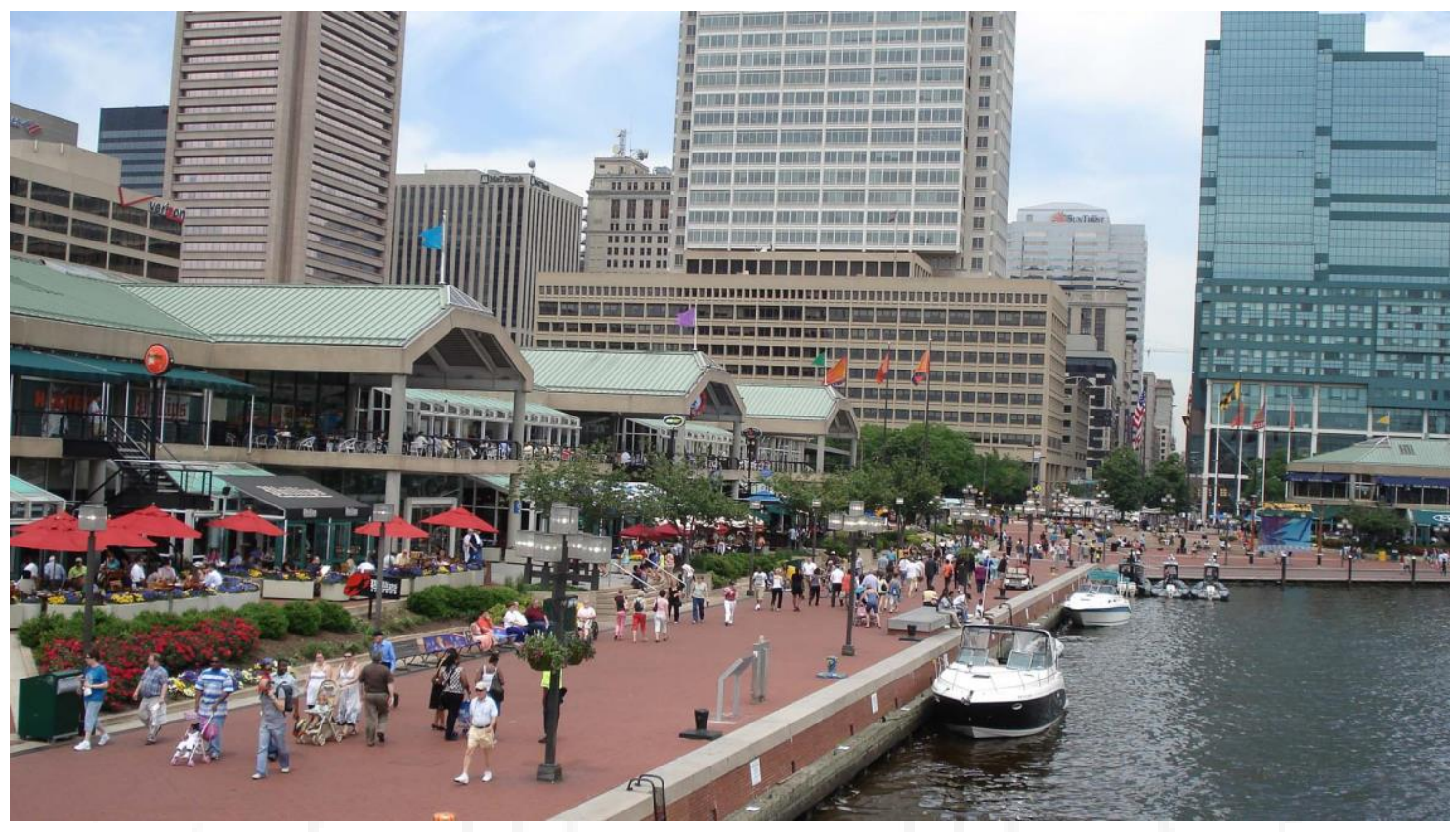

Fuente: Recuperado de eskipaper.com/baltimore-2.html\#gal_post_65624_baltimore2.jpg

b. Muelle de España, Barcelona - España

Es la continuidad de las Ramblas, también conocido como la Rambla de Mar. Después del auge de Barcelona con el Puerto Olímpico en las olimpiadas de 1992, el puerto autónomo de Barcelona decidió desarrollar un proyecto que contara con frente de diversiones, por ello cuenta con un centro comercial, un acuario y un complejo de cines. Lamentablemente el proyecto no ha sabido aprovechar el lugar privilegiado en el que se encuentra y ha desarrollado una conexión nula con el agua. Este espacio es más visitado por turistas que por los residentes. 
Ilustración 2.53 Recuperación del Port Vell, Muelle de España-Barcelona, España

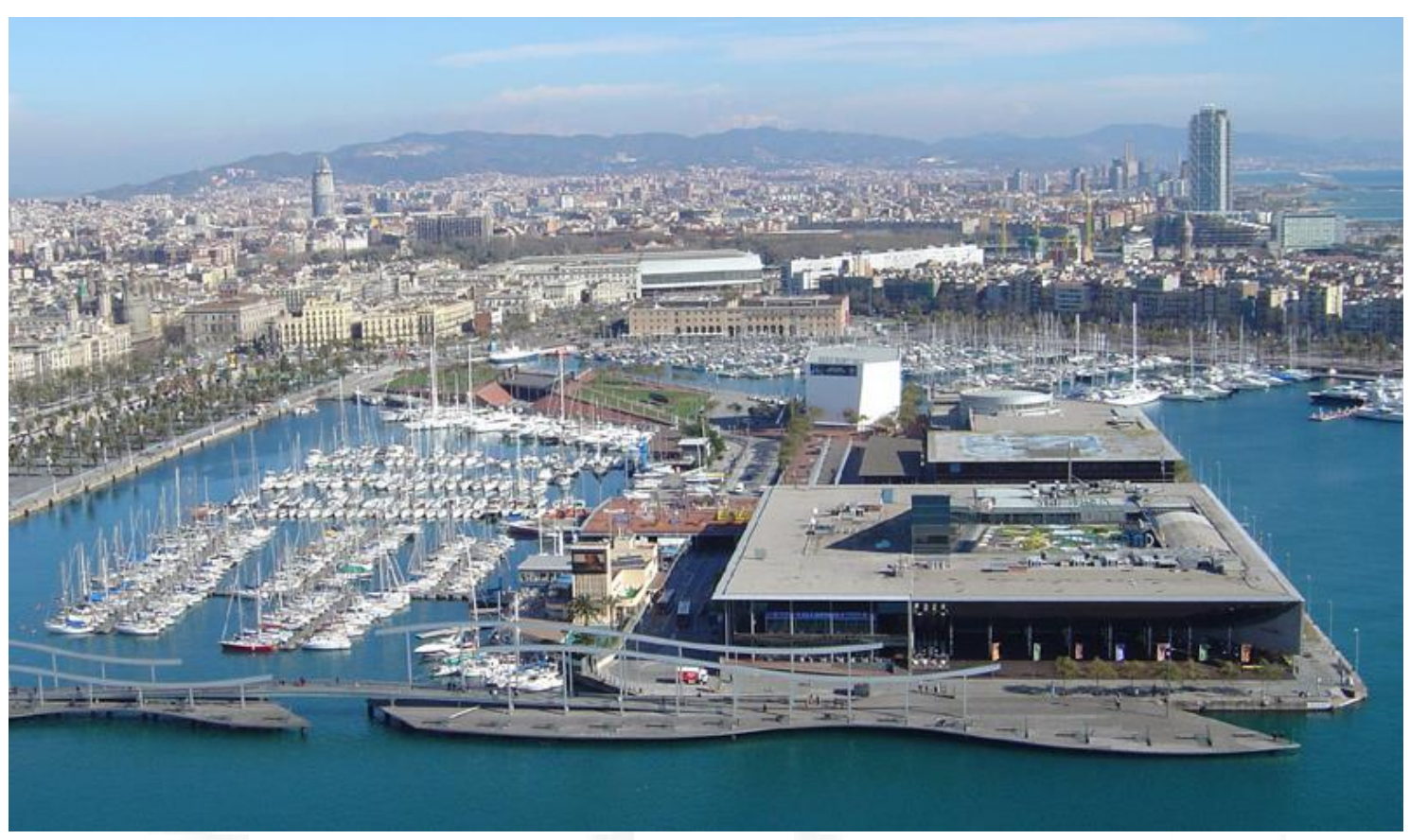

Fuente: Recuperado de www.portdebarcelona.cat/es/web/port-del-ciudada/espacios

c. Puerto Madero, Buenos Aires - Argentina

Es uno de los primeros proyectos de esta envergadura en realizarse en Sudamérica. Puerto Madero se encontraba abandonado por lo que en 1920 se pensó en un proyecto para convertirlo en un parque público. Puerto Madero tiene una superficie de 170 hectáreas, de las cuales se ha recuperado la zona oeste que comprende 93 hectáreas. La notoriedad de este proyecto se debe a que se integran a un gran paseo público que incrementa la cantidad de espacios públicos en Buenos Aires. Además, cuenta con un área cultural y de recreación, hotel, parque, oficinas, restaurantes, condominios de viviendas y parte de un campo universitario. Lo singular de Puerto Madero es que ha sido un proyecto autofinanciado debido a que se han vendido los terrenos y se ha reinvertido lo obtenido en infraestructura. (Gutiérrez \& Talesnik, 2002, pp. 12-13) 


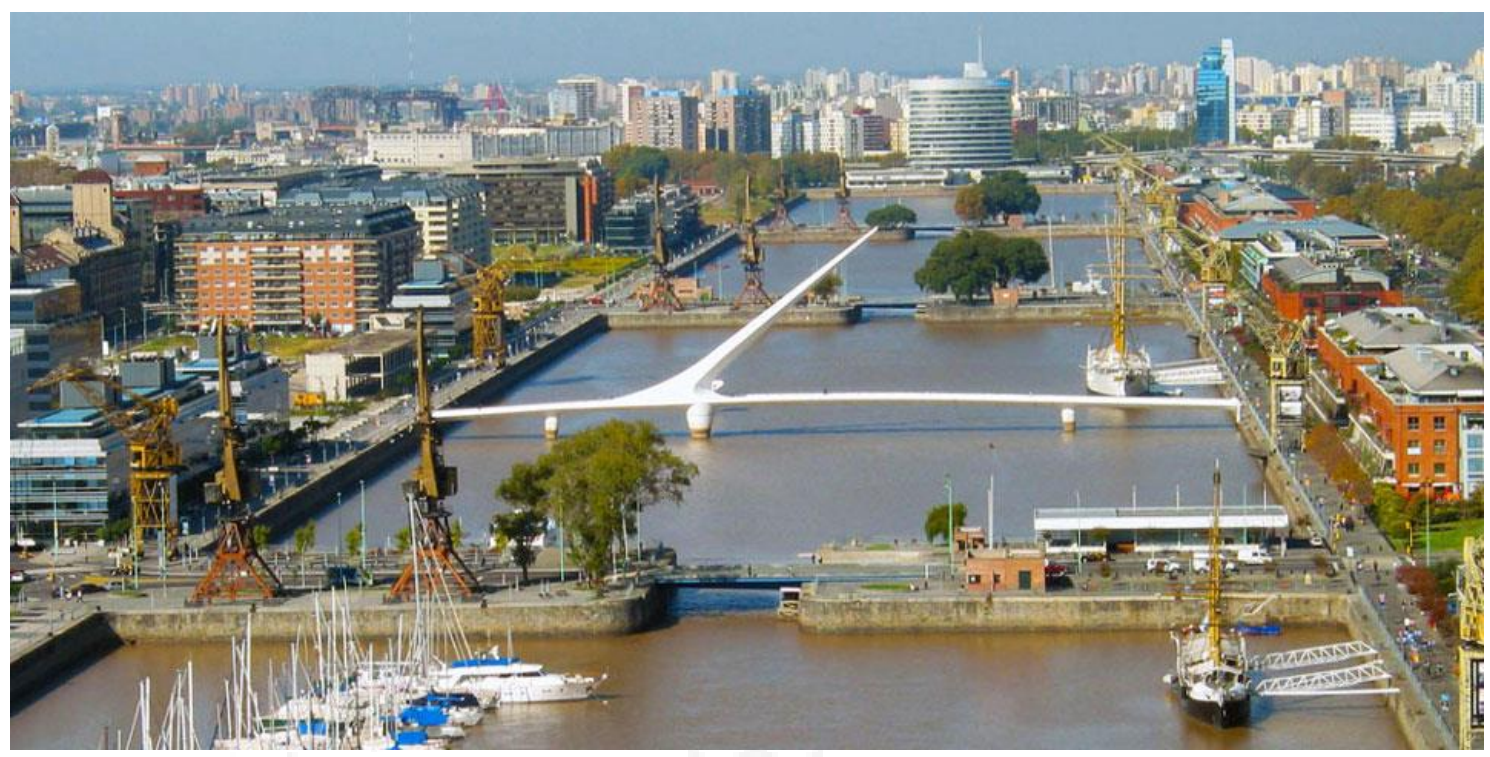

Fuente: Recuperado de www.portdebarcelona.cat/es/web/port-del-ciudada/espacios

\subsection{De lo inactivo al nuevo uso: reciclaje arquitectónico}

"Reciclar, más que rehabilitar o reconstruir. Reciclar es: iniciar un nuevo ciclo a partir de lo viejo”. (Valero Ramos \& Chacón Linares, Crecer por dentro, estrategias del reciclaje urbano para el tercer milenio, 2009, p. 532)

Aun cuando el uso del término reciclaje arquitectónico es reciente, sus orígenes se remontan a la antigüedad, cuando aún no existían teorías ni movimientos que avalen este término, pero ya a los edificios se les daba otro uso de acuerdo a las necesidades que las circunstancias exigían, como el Partenón que en el siglo VI d.C debido al dominio romano y a la implantación del cristianismo, pasó a convertirse en una iglesia cristiana. O como el actual museo de Louvre, que antiguamente fue creado como una fortaleza para cuidarse de los posibles ataques que vinieran del oeste de París, después quedó olvidado por parte de los reyes, lo que ocasionó que mucha gente de diversas clases sociales pasara a ocupar el edificio, ante esta situación se propuso reciclar y utilizarlo como museo público, siendo la inauguración de este en 1793. (Calleja Molina, 2013, pp. 42-43,56-58)

Según la RAE ${ }^{10}$, "reciclar" significa someter un material usado a un proceso para que se pueda volver a utilizar. Expresión que está en auge, debido a la concientización de la población por volver a utilizar todas las cosas para lograr la sostenibilidad del planeta. Del mismo modo se está tomando conciencia en la arquitectura, debido a que cada vez

\footnotetext{
${ }^{10}$ RAE: Real Academia Española
} 
las ciudades se urbanizan aceleradamente, lo que ha desencadenado que exista un agotamiento del suelo (Martínez Monedero, 2012, p. 25) y se empiece a volcar la mirada en edificios antiguos con algún valor arquitectónico, histórico o industrial, que en su debido momento fueron hitos en la ciudad donde se construyeron y que hoy en día están descuidados y en muchos casos abandonados.

"El reciclaje (...) surge de un planteamiento (...) mucho más ambicioso y exigente que la simple rehabilitación entendida de manera convencional. El reciclaje supone iniciar un nuevo ciclo de vida a partir de lo viejo, sin conformarse con meras actuaciones centradas exclusivamente en solventar problemas inmediatos y aspectos parciales y epidémicos, ni tampoco embalsamar lo que ya está muerto, como sería prolongar a toda costa situaciones insostenibles, ya sea por el grado de deterioro constructivo-estructural o por un inaceptable planteamiento inicial”. (Valero Ramos, 2010, p. 3)

\subsubsection{Reciclaje arquitectónico industrial}

"Reciclar o morir. La máxima que rige estos tiempos modernos ha calado hondo entre los grandes arquitectos. Antiguos edificios industriales están siendo sometidos a revolucionarios lavados de cara para vincularlos a usos muy diferentes a los de antaño”. (García Page, 2003) El reciclaje arquitectónico ha sido una forma novedosa de proyectar arquitectura en las últimas décadas.

Los espacios y piezas industriales empezaron a ser tomados en cuentan a partir de la desaparición de piezas en Les Halles en París, obra arquitectónica hecha de hierro por Victor Baltard entre 1852 y 1870, que posteriormente fue demolida entre 1971 y 1973. (Hernández Martínez, 2008, p. 29) Este hecho generó que los profesionales y diversas instituciones levantaran su voz en protesta por la desaparición de las obras arquitectónicas industriales que cuentan con un valor único que los hace parte del patrimonio industrial de cada ciudad. Como muestra de que se estaba tomando acciones para protegerlas, se empezó a darles reconocimiento internacionalmente mediante la declaración como Patrimonio Mundial. Una de las primeras obras en ser declarada fue la Siderurgia de Völklingen en Alemania en 1995, años más tarde en 1998 se declaró la línea de ferrocarril de Semmering en Austria. (Hernández Martínez, 2008, pp. 29-30) 


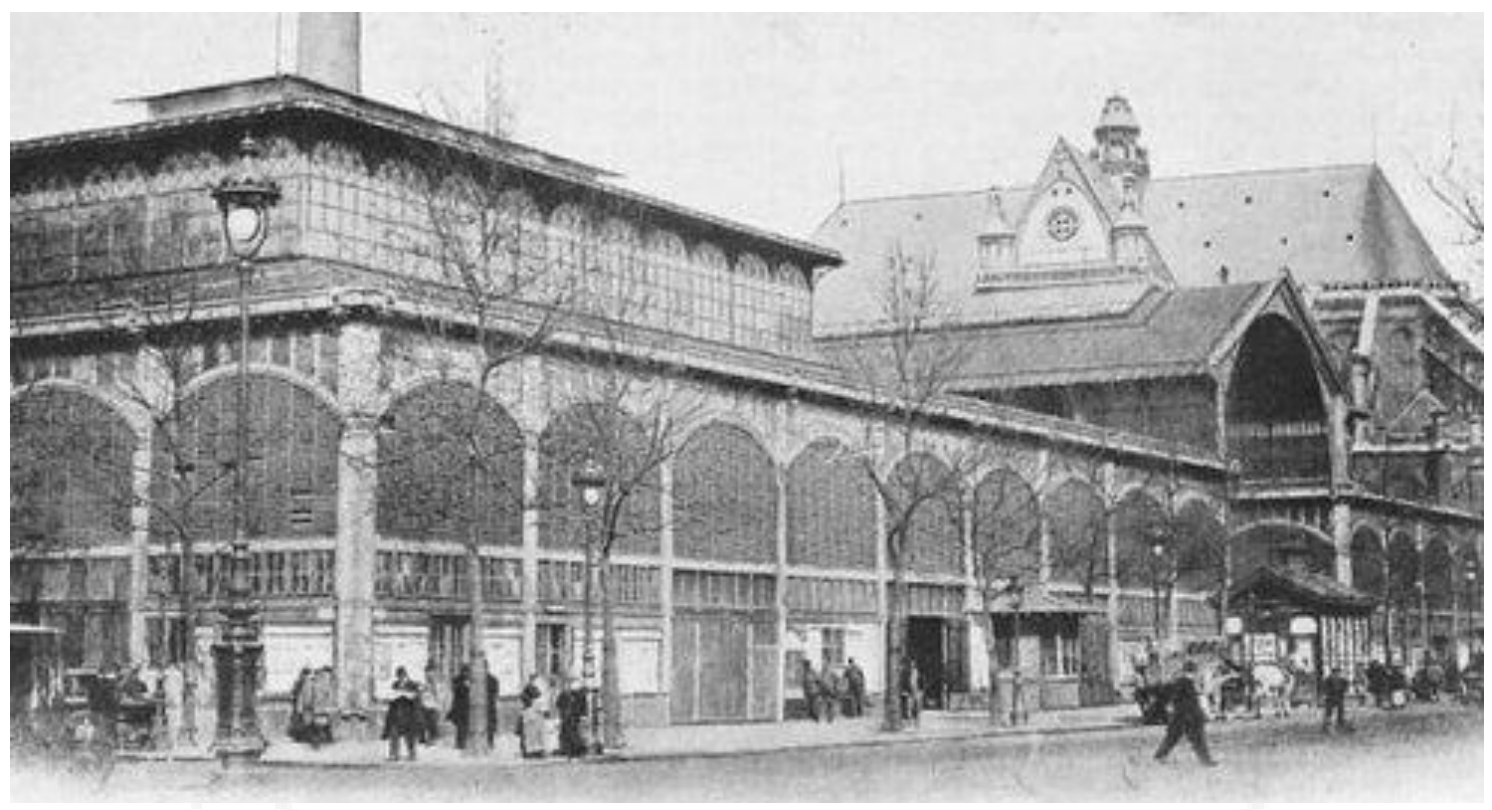

Fuente: Recuperado de paris1900.lartnouveau.com/cartes_postales_anciennes/les_ halles_de_paris.htm

De esta manera, las obras de arquitectura industrial fueron atrayendo las miradas de los arquitectos y de la instituciones públicas y privadas que veían en ellas gran potencial para desarrollar nuevos espacios que albergaran distintas actividades según las necesidades de la población en determinado momento pero que sobre todo mantuviese la memoria colectiva del lugar, de lo que algún día significó para el espacio donde se encuentran.

El gran desafío de los arquitectos al trabajar en un proyecto que alberga edificios industriales está en conectar adecuadamente el nuevo uso que se le quiere dar al edificio con el que presentaba anteriormente, que se ve determinado en la tipología y la escala del espacio interior. Es por ello que se han desarrollado diversas formas de intervención, que en su mayoría se han realizado en antiguas fábricas, almacenes, estaciones de ferrocarriles, centrales eléctricas y mataderos municipales para convertirse en museos o centros culturales con un programa acorde a lo que requiere la ciudad. Existe dos formas intervención bien marcadas, la primera es realizar una nueva obra que se mimetice con lo existente, con intervenciones mínimas en su interior y la segunda y totalmente contraria a la anterior, es proyectar arquitectura nueva que contraste con lo existente y que capte más la atención de los visitantes. 
El centro cultural Matucana 100 en Santiago de Chile, funciona en un antiguo almacén de ferrocarril, edificio industrial que data de 1909 y que lleva por nombre la vía y número en la que se ubica. Este proyecto que no solo es una intervención puntual, sino que es parte del eje de desarrollo cultural de la capital chilena, se puso en marcha por la celebración del bicentenario de la independencia de Chile. Aprovechando que el espacio se asocia a las personas que participaron en la Guerra del Pacífico y a la resistencia de la dictadura de Pinochet, se ha realizado una intervención muy sutil, que aprovecha la espacialidad de sus naves y que busca respetar el valor histórico que tiene para los chilenos. Las intervenciones interiores han sido mínimas como la implementación de graderías y telones que permitan el desarrollo de los talleres. Este proyecto es considerado una de las primeras intervenciones de reciclaje arquitectónico en Sudamérica. Con una intervención muy parecida se encuentra el Museo Tate Modern en Londres, ubicado en una antigua central eléctrica al borde del río Támesis, obra que data de 1940 y que es parte de la regeneración urbana del río. Los arquitectos encargados de su reconversión: Herzog y De Meuron propusieron una intervención mínima y suave, donde lo preexistente tenga mayor protagonismo, por ello mantuvieron los espacios más característicos como grandes naves y halls, y fieles a su estilo de proyección les dotaron de luz realzándolos, además de adaptar la arquitectura al diseño de la museología que se quería plasmar allí. El proyecto también se integra adecuadamente a su entorno a través de una plataforma que funciona como una plaza que conecta ambos extremos del río a través de un puente.

\section{Ilustración 2.56 Centro Cultural Matucana 100-Santiago de Chile, Chile}

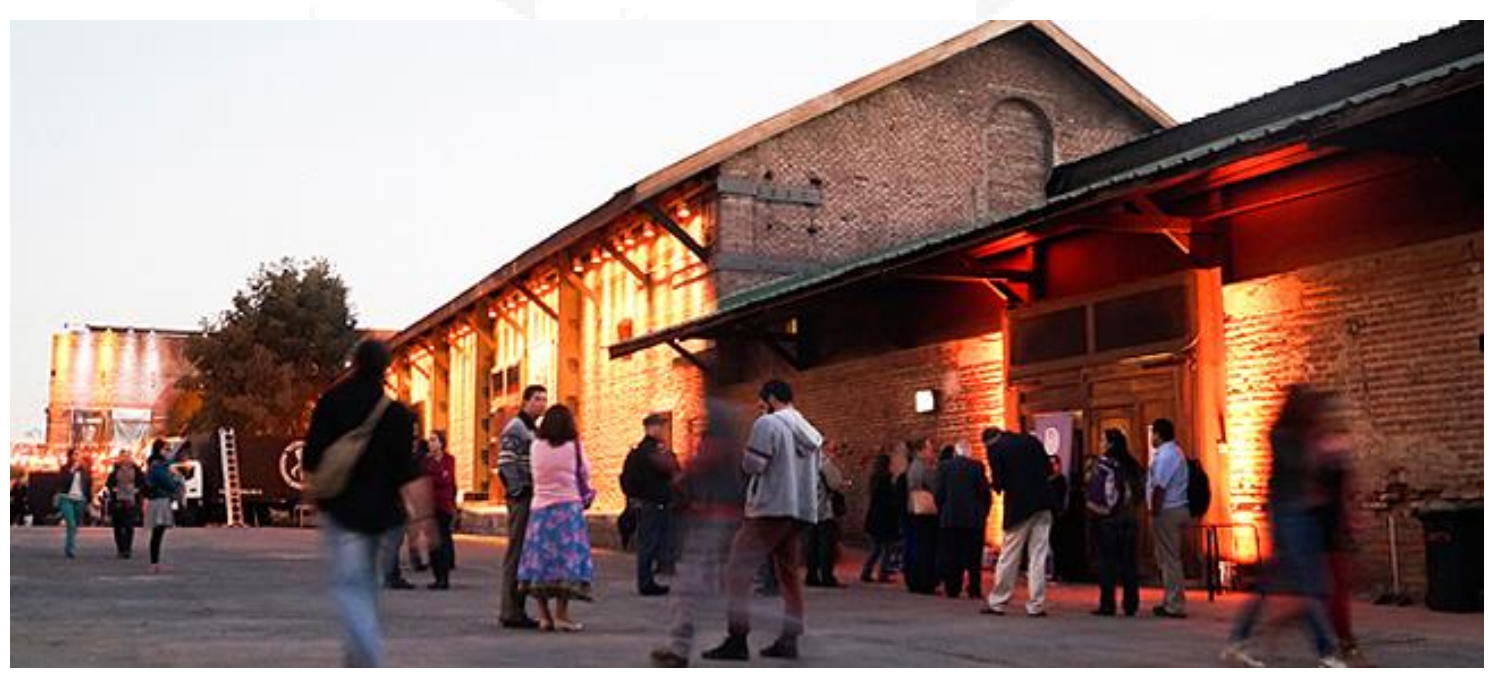

Fuente: Recuperado de www.cnnchile.com/economia/presupuesto-2019-centros-culturales-desantiago_20181011/ 


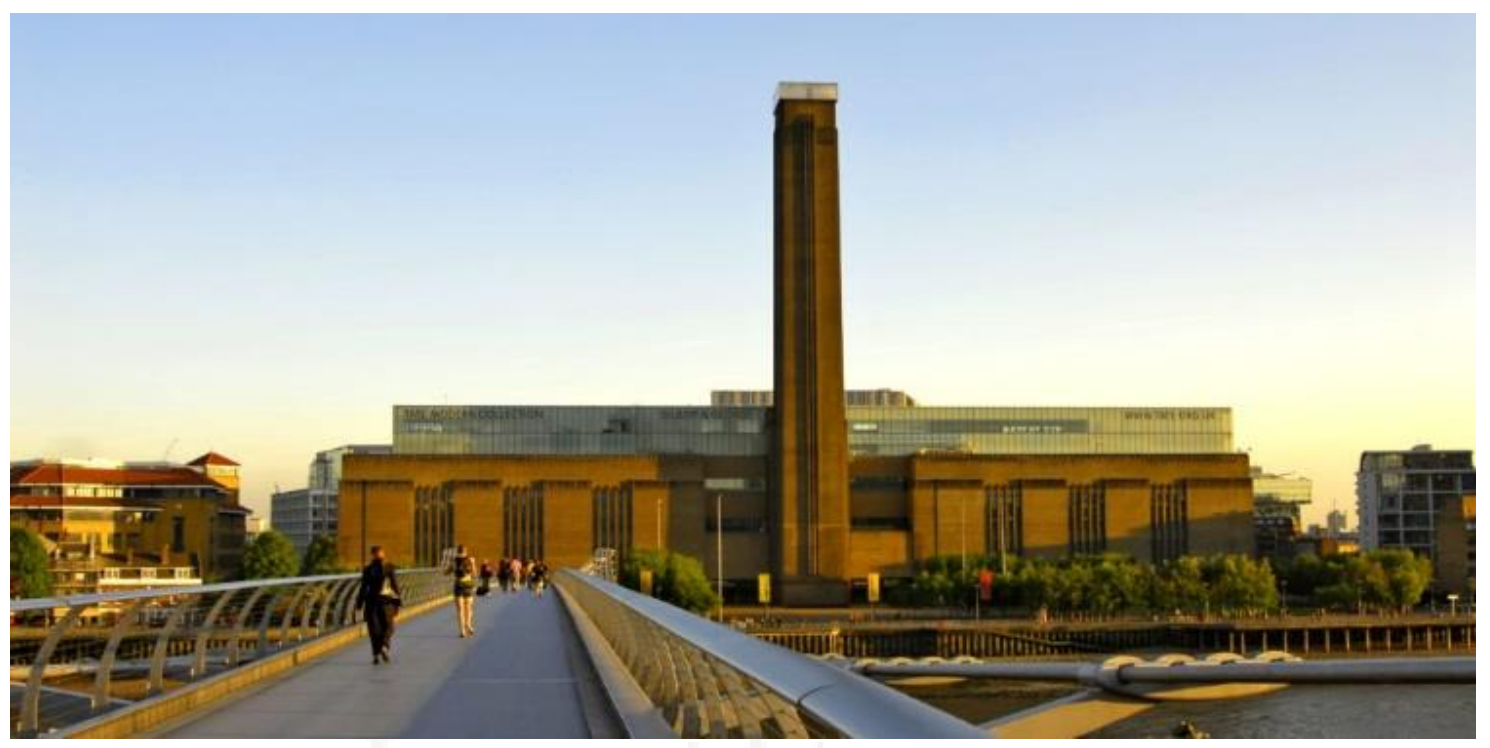

Fuente: Recuperado de londresando.com/tate-modern/

Por otro lado, se ha realizado una intervención drástica donde la nueva arquitectura y lo antiguo contrastan fuertemente, ello se puede observar en la transformación de la antigua Fábrica Textil Casarramona en Barcelona que en 1998 se convirtió en el CaixaFórum. Un espacio cultural de $2500 \mathrm{~m} 2$ que alberga salas de exposiciones, mediateca, biblioteca, auditorio y una tienda. En el proyecto se puede diferenciar claramente que la nueva arquitectura ubicada en el ingreso al espacio tiene características muy distintas a lo preexistente, tanto por el material empleado como por la forma. El arquitecto Arata Isozaki, decidió diseñara una especie de árboles de acero para que captaran la atención al ingresar a dicho edificio. Sin embargo, la intervención realizada al interior por el arquitecto Roberto Luna ha sido muy sobria, manteniendo la amplitud y claridad delos espacios. La mayor intervención realizada allí podría decirse que ha sido la ampliación de la fábrica hacia el sótano donde se ha colocado gran cantidad del programa que se requería. (Hernández Martínez, 2008, pp. 49-50)

El CaixaFórum de Barcelona no es el único de este tipo, la misma casa bancaria ha desarrollado otro proyecto cultural en Madrid en una antigua central eléctrica, donde los arquitectos intervencionistas han sido Herzog y De Meuron. La intervención más resaltante en el CaixaFórum Madrid es la creación de una nueva fachada sobre la preexistente, desde el exterior se observa el contraste entre los ladrillos preexistentes y el metal de la actualidad. 
Ilustración 2.58 CaixaFórum Barcelona en una antigua fábrica textil-Barcelona, España

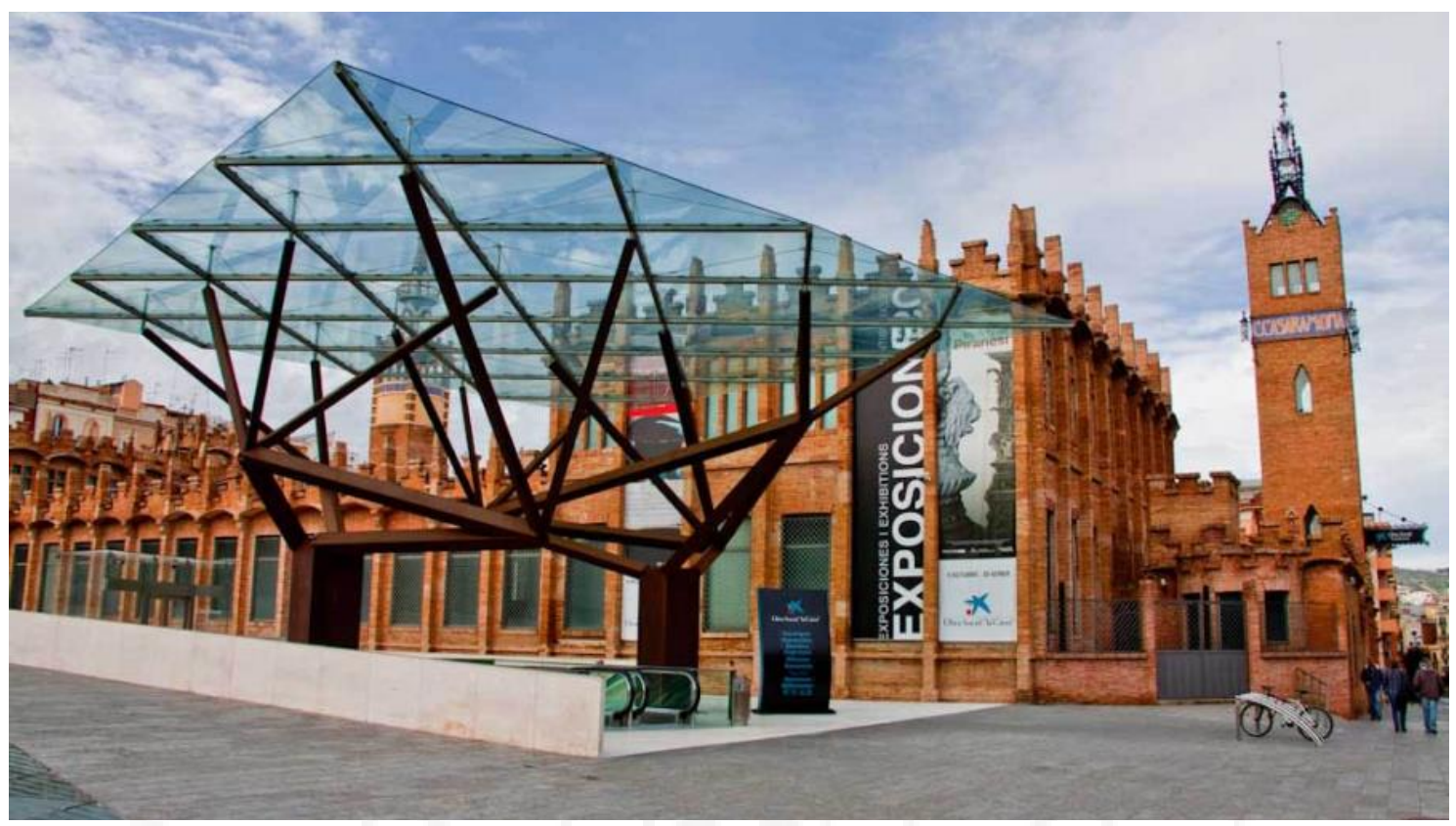

Fuente: Recuperado de www.winsiderbarcelona.com/es/items/item/60

Ilustración 2.59 CaixaFórum Madrid en una antigua central eléctrica-Madrid, España

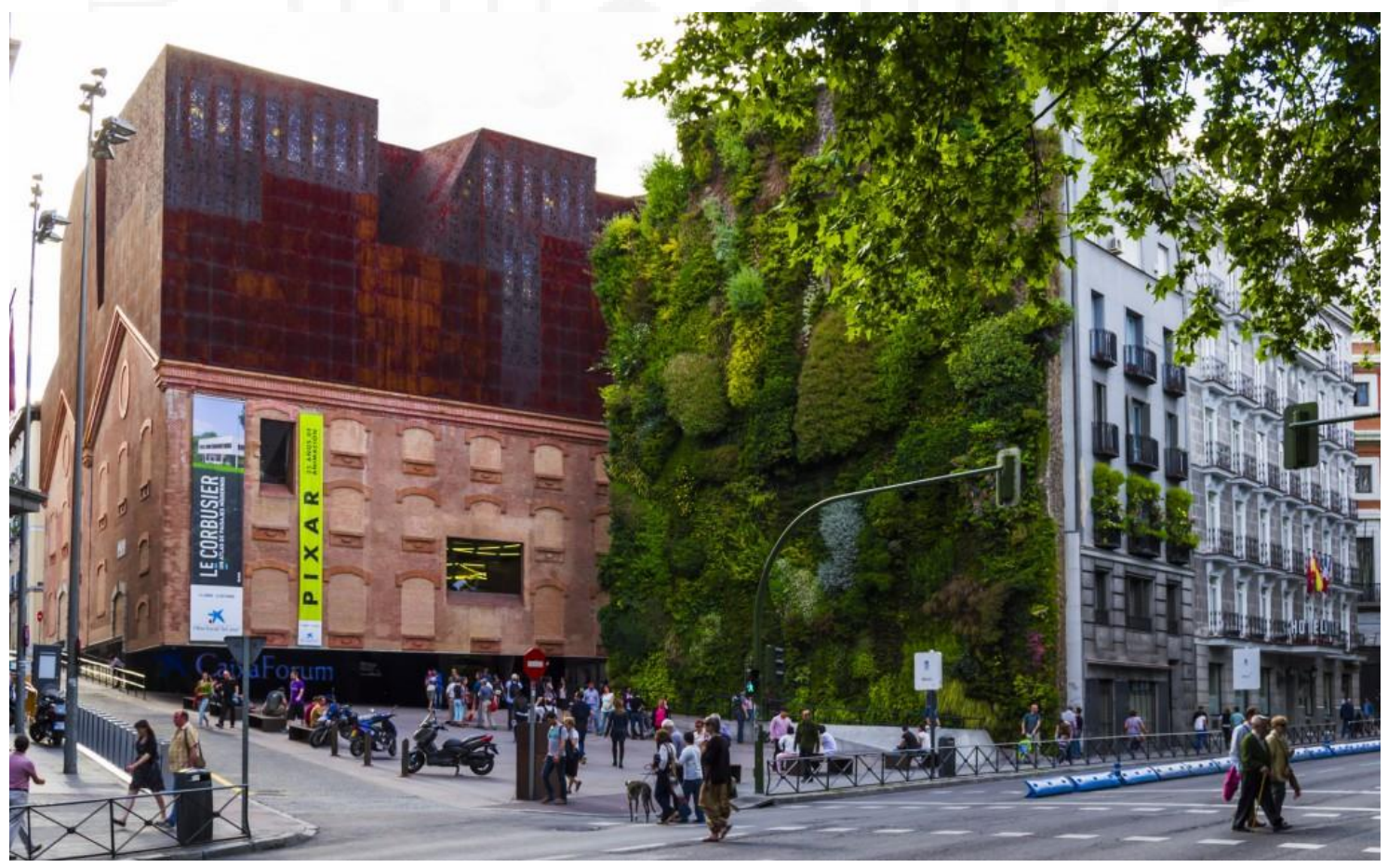

Fuente: Recuperado de arquigeek.blogspot.com/2014/06/caixaforum-madrid-mucho-mas-queun.html 
2.5 Línea de tiempo de la historia y evolución de Chimbote, Centros Culturales y la reactivación de frentes costeros

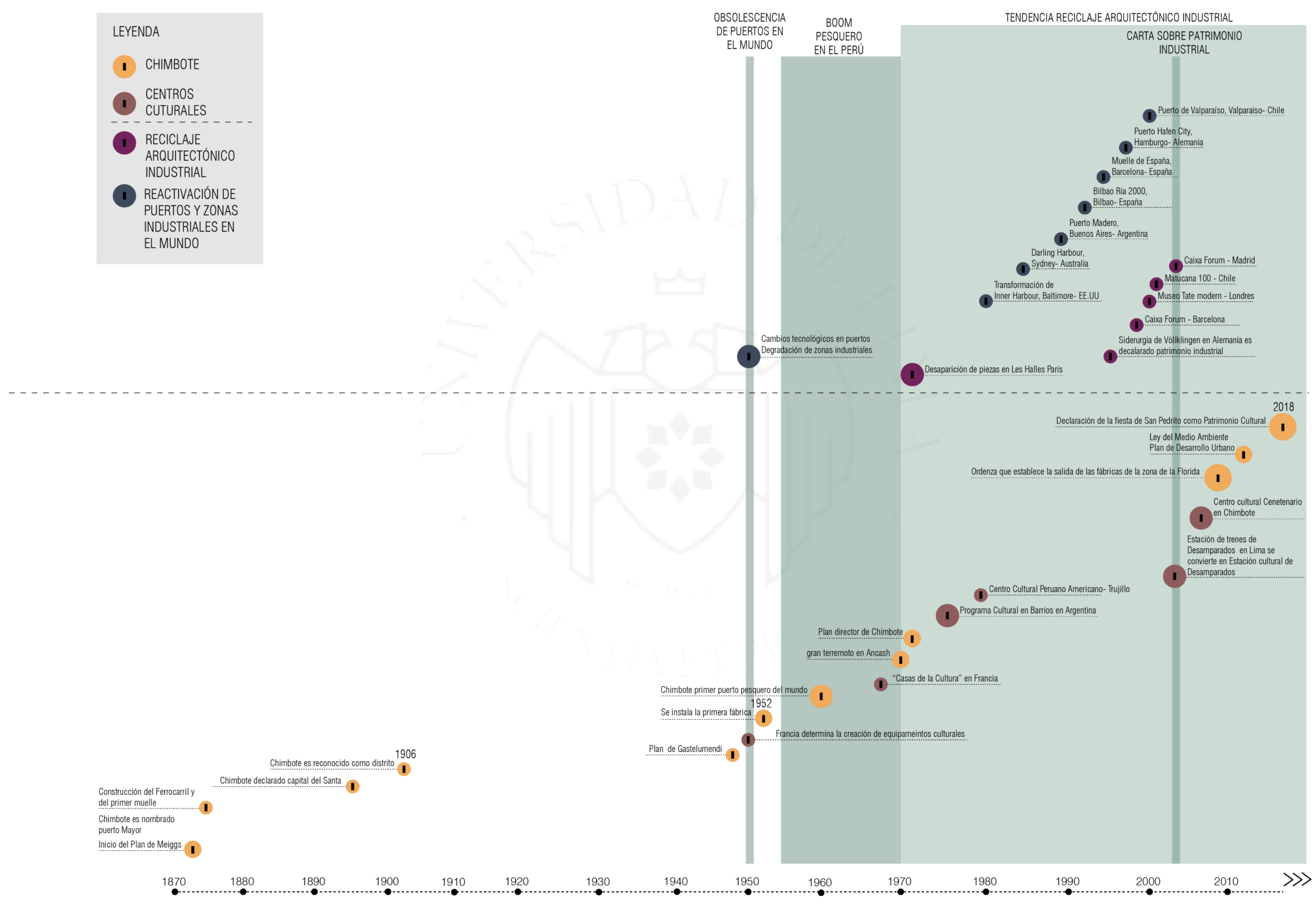




\subsection{Conclusiones parciales}

Chimbote es una ciudad puerto, en cuya historia se puede notar que inicialmente se asentó la industria relacionada a la pesca y posteriormente se consolidó la ciudad. Es un puerto con características geográficas singulares que son la potencialidad de la bahía, pues debido a ellas, antes que la bahía fuera contaminada, Chimbote no solo era conocido por ser puerto sino también por contar con hermosas playas en las que se podía gozar de un paseo al borde del mar. La industria de harina de pescado que por los años 60 fue el factor desencadenante de la bonaza económica de Chimbote, lamentablemente ha sido una de las causantes del deterioro y abandono de la bahía. Un punto neurálgico y a la vez con un gran potencial olvidado de la bahía es la ex zona industrial de la Florida, en la que hoy se encuentran las fábricas de conserva y harina de pescado en desuso que son percibidas por la población como espacios inseguros sin valor alguno y al no tener un uso que se complemente con la zonificación residencial de la zona ha contribuido a convertir el borde marítimo en un basurero, en la que la población le ha dado la espalda a la bahía y ha perdido la conexión con el mar, elemento que un día fue la base para el desarrollo pesquero de la ciudad.

Resulta inconcebible que aunque los espacios de intercambio cultural se encuentren presentes desde la antigüedad y que haya ido evolucionando de acuerdo al crecimiento de la población y a sus necesidades, en el Perú no se gestione el desarrollo de centros culturales públicos, especialmente en las provincias donde si se tiene suerte se cuenta con un centro cultural por departamento. Chimbote solo cuenta con un espacio cultural donde mostrar y compartir las diversas manifestaciones culturales. Es por ello que viendo el valioso bagaje cultural estrechamente relacionado con la pesca de Chimbote, se ha considerado adecuado, dotarle de un uso cultural a una fábrica inactiva, pues este espacio presenta un valor inmaterial, carga consigo la memoria colectiva industrial que se ve representada en sus estructuras.

Reciclar estructuras industriales para insertarle un nuevo uso, es una forma de proyectar reciente. Sin embargo, ya muchas ciudades en el mundo han aprovechado el potencial de sus espacios industriales que en algún momento consideraron obsoletos para dotarles de actividad y generar a través de ellos nuevas dinámicas sociales, ambientales y económicas que tengan un 
impacto positivo en la calidad de vida de la población. Además, para Chimbote desarrollar un proyecto de este tipo, teniendo como medio el reciclaje arquitectónico contribuye a revalorar la identidad chimbotana que se considera esta presente no solo en la fiesta de San Pedrito y en sus diversidad gastronómica sino también en las antiguas fábricas productoras de conservas y harina de pescado, pues en ellas se llevaba a cabo los procesos más importantes que generaban gran porcentaje de la economía chimbotana y donde además se encontraba empleada gran cantidad de chimbotanos a parte de los que ya trabajaban en alta mar.

Con la intervención en un solo punto se estaría realizando una acción minúscula para que los frentes marítimos industriales se activen completamente, es por ello que muchas ciudades portuarias alrededor del mundo se han visto en la necesidad de intervenir todo su frente marítimo, regenerando toda la extensión de sus puertos y zonas industriales obsoletas, lo que ha contribuido a mejorar significativamente el desarrollo de la ciudad, la calidad de vida de las personas y a revalorar el patrimonio industrial con el que cuentan. Se considera que la bahía El Ferrol necesita una intervención integral de gran magnitud en toda su extensión, tomando como centro articulador la ex zona industrial que podría convertirse en un gran atractivo turístico pero sobre todo en un gran barrio cultural, que albergue diversos equipamientos, que tanto necesita la ciudad. Sin embargo, para la presente tesis por la magnitud que implicaría realizar un proyecto como este y por cuestión de tiempo solo se ha desarrollado la intervención en una fábrica en específico y su espacio público colindante con el mar. 


\section{CAPÍTULO III: MARCO TEÓRICO}

\subsection{Base teórica}

\subsubsection{Teoría del paisaje}

Entendemos por paisaje al espacio abierto, al aire libre rodeado de naturaleza, donde se puede observar toda la creación en su estado natural que por lo general se muestra en obras de arte como pinturas. Sin embargo, paisaje es un término con un significado más profundo que integra también la intervención del ser humano y la reacción de este ante lo que ve.

En el libro El Paisaje, génesis de un concepto; Javier Maderuelo (2006) expresa:

"El paisaje no es un mero lugar físico, sino el conjunto de una serie de ideas, sensaciones y sentimientos que elaboramos a partir del lugar y sus elementos constituyentes". (p. 38) No existe paisaje si no es observado, contemplado e interpretado emocionalmente; es decir, es parte de todo lo acumulado culturalmente por una persona. Paisaje es el resultado de todas las piezas del gran equipaje cultural que lleva cada persona consigo misma, pues ninguna podría interpretar un paisaje de la misma manera que otra ya que cada una ha sido influenciada por variables culturales, emocionales y cognitivas de manera distinta.

\subsubsection{Paisaje como construcción social}

Como anteriormente se mencionó, paisaje no representa solamente algo tangible sino también está compuesto por una serie de elementos intangibles como: sentimientos, costumbres y vivencias de cada una de las personas que se ven resumidas en su cultura y que son producto de la transformación social de cada una. Los paisajes están cargados de historia y experiencias, generados y transformados principalmente por el ser humano que con solo observar puede capturar el momento o la situación y convertirlo en su paisaje.

Los paisajes son parte de la memoria colectiva de los lugares y de los ciudadanos. Muchas personas cuando vuelcan la mirada al pasado, lo primero que recuerdan son paisajes, escenarios en los que han estado presente y que ante los ojos parecieran ser invisibles, pero que han sido absorbidos e interiorizados como parte de su cultura y con los que se identifican. 
"El paisaje es hoy y ayer, presente y pasado, a simple vista; entra en la categoría de lo casi visible, aunque siempre presente: son las herencias históricas, las continuidades, permanencias, los estratos superpuestos de restos de antiguos paisajes”. (Nogué, 2007-2009, p. 20)

Si el paisaje se encuentra estrechamente ligado a las personas, la ciudad que es producto de la acción humana, también es considerada paisaje, que por su acelerado crecimiento y transformación ha paso a convertirse en un paisaje urbano, donde lo construido ocupa un porcentaje mayor que lo natural. El desarrollo de las ciudades ha conllevado a que se construya en demasía, en muchos casos sin planificación ni orden por lo que hay zonas en la ciudad que funcionan como verdaderos organismos vivos y otras que han quedado relegadas con vacíos que en algún momento tuvieron un determinado uso, pero que ahora son una carga para el completo desarrollo de estas.

“... Abundan en ellas los espacios vacíos, desocupados, aparentemente libres; espacios que aparecen como tierras de nadie, territorios sin rumbo y sin personalidad; espacios indeterminados, de límites imprecisos, de usos inciertos, expectantes, en ocasiones híbridos entre lo que han dejado de ser y lo que no se sabe si serán. Son los terrain vagues, extraños lugares que parecen condenados aun exilio desde el que contemplan, impasibles, los dinámicos circuitos de producción y consumo de los que han sido apartados y a los que algunos, no todos verán algún día”. (Nogué, 2007-2009, p. 21)

\subsubsection{Terrain Vagues}

El término fue introducido por Man Ray, un artista de la modernidad que empezó a fotografiar espacios desolados y abandonados que para él guardaban historia y valor para la zona, por lo que los empezó a considerar como espacios con condiciones favorables para desarrollar algún proyecto nuevo.

No obstante, el término recién fue introducido como parte del urbanismo y la arquitectura en 1995 por Ignasi Solà-Morales, arquitecto catalán, quien definió Terrain -Vague como lugares obsoletos, aparentemente dejados en el olvido, donde predomina la memoria del 
pasado sobre el presente y presenta una completa relación nula con la actividad de la ciudad, pero que a su vez deben ser tomados como espacios potenciales, promisorios, espacios de múltiples posibilidades, en los cuales debe intervenir para realizar una reactivación de la zona que rodea estos espacios.

Igualmente, define el término desde sus raíces, terrain vague, es una expresión francesa; terrain se refiere netamente al carácter urbano, a los suelos edificables de la ciudad, que a su vez es una porción de tierra que espera ser aprovechada. Por otro lado, vague tiene dos orígenes, germánico y latino, el primero está relacionado con el movimiento, la oscilación y la inestabilidad, mientras que el segundo se refiere a lo vacío, inocupado y no ganado. En resumen, es necesario entender la relación entre la actividad y la ausencia de uso y el sentido de libertad para explotar el potencial que pueden tener los terrain vague, los que desde el punto de vista económico se encuentran en: áreas industriales, puertos, lugares contaminados, estaciones de ferrocarril y zonas residenciales inseguras. (Solà-Morales, 2009, pp. 125-126)

Los terrain vagues en la actualidad se han convertido en islas interiores que se encuentran fuera de la dinámica urbana, donde la gente ya no se reúne, porque sienten que estos lugares no han sido vencidos por la arquitectura sino más bien los perciben como espacios inseguros, lejos de su radio de actividad urbana. La labor de los profesionales ahora es rescatar el valor que tienen y convertirlos en espacios productivos y regeneradores de esta parte muerta de la ciudad.

"Cuando la arquitectura y el diseño urbano intervienen en un espacio vacío (terrain vague) lo transforma radicalmente, cambia la falta de interés en el lugar destierro por ciudadanía y pretende disolver lo obsoleto en realismo de la eficacia. (Solà-Morales, 2009, p. 130)

Para fines de la presente investigación, las fábricas en desuso ubicadas en el borde la bahía de Chimbote, se han considerado como vacíos urbanos, es decir, terrain vagues debido a las características similares que presentan de acuerdo a las definiciones antes mencionadas. Son vacíos que han quedado aislados de la ciudad producto del cambio de zonificación industrial a residencial. Las fábricas inactivas forman parte del paisaje chimbotano, ellas cargan 
el peso de un pasado histórico lleno de historias y experiencias industriales, que tuvieron el mayor pico de producción durante el boom de la pesca.

\subsubsection{Paisaje cultural y paisaje industrial}

Los paisajes llevan consigo un valor indestructible por lo que deberían perdurar y mantenerse en el tiempo. Es por ello que para inmortalizarlos, protegerlos y reconocer el valor excepcional con el que cuentan, UNESCO determinó declararlos patrimonio natural o cultural del mundo. Hecho que se llevó acabo en 1972 en la Convención del Patrimonio Mundial en París ${ }^{11}$. Sin embargo, fue recién en 1992 que se decidió complementar lo tratado con una Guía Operativa para la implementación de dicha convención donde se incluyó el término paisaje cultural.

En la definición de Sauer (como se citó en University of Ferrara \& UNESCO’s World Hetritage Centre, 2002) sobre el paisaje cultural se expresa:

"El paisaje cultural se forma a partir del paisaje natural a través de un grupo de cultura. La cultura es el agente y el medio lo natural, que al unificarse da como resultado el paisaje cultural". (p. 17)

Los paisajes culturales se han desarrollado a lo largo de la historia sobre una base natural innata en los territorios, que al ser transformados y humanizados han adquirido cierta connotación que los ha hecho característicos de cada lugar y en donde se han desarrollado diversas manifestaciones relacionadas con su contexto. Es así como "el paisaje cultural es una realidad compleja, integrada por componentes naturales y culturales, tangibles e intangibles, cuya combinación configura el carácter que lo identifica como tal, por ello debe abordarse desde diferentes perspectivas". (Trachana, 2000, p. 1)

Un paisaje cultural entonces es una porción de territorio relacionado a un hecho histórico que contiene valores estéticos y culturales. Estos espacios narran una historia, atraen turismo e inversiones, generan actividades y puestos de trabajo, pero fundamentalmente

\footnotetext{
${ }^{11}$ La Convención sobre la Protección del Patrimonio Mundial, Natural y Cultural celebrada en París fue aprobada en 1972 por la UNESCO. Asienta sus bases en la Carta de Venecia en 1964, donde se trató sobre la conservación y la restauración de monumentos y sitios históricos.
} 
refuerzan la autoestima de la comunidad. (Sabaté Bel, De la preservación del patrimonio a la ordenación del paisaje, 2005)

El diseño de un parque patrimonial implica generar un proyecto que no solo garantice la conservación de espacios patrimoniales, sino que produzca una reactivación tanto económica como de todos aquellos espacios obsoletos. Los espacios en desuso pueden entenderse como además como oportunidades para trabajar en una nueva imagen y conformar una base adecuada de desarrollo.

Estos espacios deben contribuir a promover la educación, el ocio y el desarrollo económico, a partir de la cooperación entre administraciones, quienes garantizan la conservación de los bienes culturales. La organizada gestión de recursos es uno de los factores clave para su desarrollo económico, pues atrae turismo e inversiones, genera actividades y puestos de trabajo, pero fundamentalmente porque refuerza la autoestima de la comunidad.

Para un correcto desarrollo de los paisajes culturales se debe tomar en cuenta los siguientes puntos:

- En cada territorio se debe buscar una interpretación.

- Dicha interpretación resulta fundamental para relacionar entre sí los recursos, para situar al usuario respecto a un tiempo determinado de la historia. Cada lugar debe tener su propia identidad, pero al tiempo debe contribuir a la narración general.

- Manejar la gestión de recursos mediante un ente gestor capaz de consolidad las iniciativas existentes, y que integre agentes locales y administradores. (Sabaté Bel, De la preservación del patrimonio a la ordenación del paisaje, 2005)

Para narrar una historia resulta imprescindible documentarla de manera rigurosa. Los propios residentes constituyen recursos naturales muy importantes, ya que ellos los principales agentes interesados en valorizar su patrimonio. Tan pronto se refuerza su autoestima, dejan de sentirse parte de un territorio en crisis para empezar a construir un futuro sobre aquellos recursos patrimoniales. Las campañas de educación, programas de divulgación y celebración de eventos singulares funcionan como programa de concientización de sus pobladores, de 
manera que cada vez se pueda apreciar más los valores de su cultura. (Calderón Calderón \& Ruiz-Valdepeñas, 2007)

En la medida en que funcionamos a partir de percepciones, se debe dotar a los paisajes culturales de una imagen clara y recordable. Es de suma importancia la interpretación de un logotipo en una cultura que permita generar una imagen o ícono del patrimonio.

El revalorizar los recursos patrimoniales propios puede suponer un modelo económicamente más viable, ambientalmente más sostenible y atento a la identidad de cada territorio (...). (Sabaté Bel, Paisajes culturales. El patrimonio como recurso básico para un nuevo modelo de desarrollo, p. 8)

Las diferentes perspectivas que presenta un paisaje cultural podría decirse que están definidas por las actividades que se realizaron en ellos o por elementos sumamente característicos que seguramente marcaron su posterior desarrollo. De acuerdo a ello, se puede encontrar paisajes culturales urbanos, rurales, arqueológicos e industriales. Visto que Chimbote es un puerto en el que en determinado momento se convirtió en una ciudad industrial por la presencia de gran cantidad de fábricas en la bahía, se ha hecho énfasis en el paisaje industrial.

La inmensa parte del territorio en el mundo está ocupada por construcciones destinadas a la explotación, la transformación, la producción y el transporte de recursos, lo que ha marcado aún más la condición industrial en los territorios. (Trachana, 2011, pp. 193-194) La denominación de paisaje industrial implica así una calificación cualitativa, en otras palabras, importa su condición histórica, funcional y cultural, pues no solo contempla lo construido sino también todo aquello que no es visible pero que está inmerso y que acompaña lo material. En 1975, Borsi definía al paisaje industrial como "el paisaje resultante de una actividad reflexiva y sistemática del hombre en el paisaje natural o agrícola con el objetivo de desarrollar actividades industriales". (Loures, 2008, p. 24)

La formación de un paisaje industrial no se da únicamente por la presencia de un elemento aislado y único sino que es un conglomerado de estos elementos lo que hace característico al territorio, formando de esta manera un sistema común de la industrial del paisaje que los alberga. 
Lalana y Santos (como se citó en Trachana, 2011) comentan que por ejemplo, una fábrica no es solo una construcción social sino también una forma de organización del trabajo y de la relación social concreta, donde se lleva a cabo un determinado proceso de producción, donde se aplica un concreto sistema tecnológico y a través del cual se establece una serie de relaciones funcionales y visuales con el medio físico o la ciudad. (p. 195)

Debido a ello, al intervenir en un espacio de este tipo se debe estudiar el paisaje completo junto con su entorno, tanto en los aspectos histórico, social, económico, cultural y urbano pues la presencia de espacios industriales no es una situación aislada de la ciudad sino que es parte del todo, pues si bien el área industrial se encontraba alejada del centro de la ciudad, estas mantenían una relación muy directa de abastecimiento, logrando desarrollar un paisaje integrado urbano-industrial. Por tal motivo, de acuerdo con lo expresado por Álvarez, Aguilar y Ortega (como se citó en Trachana, 2011) un proyecto de intervención nunca debe contemplar aisladamente un determinado hito fabril sino en el contexto de un paisaje industrial, dentro de la entera estructura histórica del territorio, en el conjunto de elementos que constituyen esta estructura y se destinan a un mismo fin productivo. (p. 195)

\subsubsection{Paisaje convertido en patrimonio}

El valor testimonial y la memoria colectiva social, urbana, laboral e industrial, invisible en los paisajes necesitan ser salvaguardados para transmitirlos a las generaciones del futuro de modo que ellos también puedan experimentar del paisaje en el que encuentran y ser conscientes que sus paisajes presentes y nuevos se basarán en los paisajes pasados.

Paisaje y patrimonio se encuentran estrechamente ligados "son nociones que comparten, en su esencia, la relación entre objeto y sujeto, entre la realidad material de los hechos artísticos, históricos y geográficos, y sus representaciones culturales y simbólicas. Se desenvuelven, pues, en un mismo terreno de simultaneidad de ideas y sentimientos". (Maderuelo, y otros, 2010, p. 33)

La definición de patrimonio está ligada a la idea de herencia o legado de bienes propios, un conjunto de valores asignados y de recursos disponibles. (Ludeña Urquizo, 1998, p. 98) Bajo esta concepción, se puede entender patrimonio cultural como la herencia cultural de un 
lugar y como patrimonio industrial a la herencia industrial que deriva de la herencia cultural de un mismo lugar. En otras palabras, si una población basa su cultura en un determinado aspecto como en el caso de Chimbote que todas sus manifestaciones culturales giran en torno a la pesca y a la industria, la población encontrará en estas actividades elementos de valor con los que se identifique.

Para el patrimonio industrial el mayor documento regulador es la Carta de Nizhny Tagil sobre patrimonio industrial ${ }^{12}$ del 2003. En ella se define patrimonio industrial como el espacio que albergaba el desarrollo de una actividad industrial y en el que aún se encuentran restos característicos como: edificios, maquinarias, talleres, molinos, almacenes y depósitos, que poseen un valor social, histórico, arquitectónico y tecnológico. (TICCIH, 2003, parr.6)

El reconocimiento del patrimonio industrial en un territorio es una oportunidad para mejorar el desarrollo urbano y sobre todo para valorar el pasado y la memoria del lugar. Los ciudadanos de muchos lugares no son conscientes del valor con el que cuentan dentro de su jurisdicción y convierten estos ambientes fabriles en zonas del olvido llenos de basura y contaminación, aislados de la dinámica comercial y social lo que contribuye a deteriorar el tejido urbano y a perder la conexión de la gente con el espacio. En los territorios con paisaje y patrimonio industrial no se busca revalorar solo el aspecto arquitectónico, sino rescatar la riqueza de su tipología espacial de gran escala su funcionalidad y las relaciones desarrolladas con el resto del territorio.

La condición de ciudad puerto industrial de Chimbote es su ADN, rasgo que no se puede negar ni disolver sino que es justamente lo que lo hace único y diferente de otras ciudades de la costa peruana.

"Por su patrimonio las ciudades portuarias son fascinantes, ..., tienen un ambiente específico y una fuerte tensión: ubicadas en emplazamientos naturales al borde del agua, con una poderosa presencia de elementos tierra, agua, viento, sol; donde destacan las instalaciones físicas para el trasbordo de mercaderías y de las industrias relacionadas, barcos, muelles, trailes,

\footnotetext{
${ }^{12}$ Carta de Nizhny Tagil sobre Patrimonio Industrial llevada a cabo en Rusia en el 2003. Organizada por el Comité Internacional para la Conservación del Patrimonio Industrial, conocido por sus siglas en inglés como TICCIH.
} 
almacenes, oficinas, grúas, contenedores, depósitos de gas; donde destaca también una forma urbana y un espíritu estrechamente relacionado con el entorno acuático y con industria portuaria, vistas costeras, arquitectura representativa, barriadas populares, playas urbanas, espacios públicos con vida intensa, infraestructuras llamativas, amplias zonas industriales, población internacional, espíritu marítimo, condición cambiante”. (Diedrich, 2010, pp. 61-62)

El patrimonio es la relación que mantiene un territorio con el pasado, es el recuerdo tangible de la historia y que tiene la capacidad de generar un desarrollo tanto económico como cultural. Debido a que interpreta la memoria de un lugar, debe vincularse al territorio donde se ha producido, de manera que se refuerce la identidad. Para entender un patrimonio industrial se debe considerar no solo el edificio, sino todos los elementos necesarios para su propia existencia.

La regeneración de patrimonio da lugar a la creación de nuevas centralidades y a la generación de focos de oportunidad que permiten revalorizar la ciudad. Este proceso viene acompañado de mejoras en los equipamientos, infraestructuras y creación de áreas verdes. Es así como la ciudad pasa a ser ciudad cultural y contribuyen a detener el proceso de deterioro, abandono y de la ciudad, convirtiendo ocio y consumo en el motor del crecimiento urbano.

"Un territorio puede ser reconocido como un espacio cultural, es decir, con valores relevantes desde el punto de vista histórico y social como ejemplo de construcción singularizada del patrimonio cultural, no depende sólo de su valor intrínseco, ni de su reconocimiento objetivo experto, sino de su aceptación social. Es esta la que lo convierte en un recurso cultural.” (Calderón Calderón \& Ruiz-Valdepeñas, 2007, pág. 57)

A partir del siglo XX el patrimonio industrial pasó de percibirse como una ruina a entenderse como un objeto con potencial de ser conservado y puesto en valor. Hoy en día esta revalorización se promueve a partir de espacios para el ocio, entretenimiento y cultura, ya que son atractivos para el usuario y capaces de generar nuevas identidades. Sin embargo, existen muchos motivos por los cuales se puede generar una pérdida de patrimonio, como la falta de conciencia de valor patrimonial, una inadecuada gestión protectora, cambio de usos de suelo, y preferencia por recuperar equipamientos socialmente más valorados. 
Adicionalmente, el patrimonio industrial se enfrenta a tres enemigos para evitar su desaparición: la frágil memoria industrial que identifica a la fábrica con experiencias negativas (trabajo excesivo, ruido, contaminación, peligro, falta de conciencia empresarial, muerte), las construcciones que no resaltan por su belleza arquitectónica o estética y por consiguiente tienen una valoración artística o cultural negativa y el costo elevado de transformación del edificio, que abre paso a plantear otro tipo de equipamiento debido al alto valor del suelo.

Por este motivo, para que un proyecto de regeneración de patrimonio tenga éxito se deben definir con claridad los objetivos básicos de la intervención, iniciando con impulsar la participación urbana, para luego desarrollar mecanismos de protección de los recursos patrimoniales, que relacionen la historia del lugar con los usuarios, y desarrolle un programa de revitalización económica que utilice el patrimonio para atraer turistas y fuentes de financiación diversas, usando como medio un hilo conductor, que usualmente es el pasado histórico (Sabaté Bel, De la preservación del patrimonio a la ordenación del paisaje, 2005)

El área por intervenir debe contar con problemas urbanos como el deterioro de la vivienda, deterioro medioambiental, sobreexplotación del sector turístico, mala calidad de vida, etc. Lo importante es que el área urbana demuestre una carencia, para que se reconozcan como espacios con urgencia de ser intervenidos. Pero también debe tener potencialidades tanto en el patrimonio arquitectónico como en el cultural que fomenten competitividad en el territorio con otras áreas. El capital patrimonial es esencial para la propuesta porque a partir del desarrollo se hace posible plantear un plan de rehabilitación. (Aguero, 2014)

Se debe apuntar a un área urbana cuyo patrimonio urbano y arquitectónico sean la base de la identidad cultural de la población, de tal forma que por medio de la conservación patrimonial se logren reconstruir los espacios que tienen un gran significado cultural, tradiciones e identidad. Debe existir una identificación por parte de la población con respecto al patrimonio, principalmente para que la propuesta tome peso desde la organización y urgencia social del problema. Es necesario que existan organizaciones sociales para la protección del patrimonio, para difundir la historia y las tradiciones locales. (Aguero, 2014) 
Los paisajes culturales y parques patrimoniales están teniendo una importante influencia en el desarrollo económico. Se busca incluir naturaleza y cultura como parte de un concepto único: patrimonio. Y los paisajes culturales pueden constituir un medio para alcanzar el objetivo a través de la construcción de entornos más diversos y cargados de identidad. Paisaje y territorio no como soporte, sino como factor básico de cualquier transformación. Los paisajes culturales desarrollan un papel relevante, porque constituyen la expresión de la memoria, de la identidad de una región, identidad asimismo como proyecto abierto que se puede ir enriqueciendo sucesivamente. (Sabaté Bel, De la preservación del patrimonio a la ordenación del paisaje, 2005) (Calderón Calderón \& Ruiz-Valdepeñas, 2007)

\subsubsection{Teoría del urbanismo a escala humana}

\subsubsection{Los espacios públicos y su adecuado diseño}

Los espacios públicos o bien llamados espacios de encuentro y reunión son aquellos espacios de uso colectivo que permiten un contacto natural entre los distintos usuarios que hacen uso de ellos. Le atribuyen una mejor calidad de vida a la población, desarrollando una relación entre el usuario y el entorno y diseñando ambientes donde se pueda entender y aceptar "al otro". Estos espacios se desarrollan en armonía con la naturaleza y propician convivencia social e identidad con el lugar. Identidad debido a que los usuarios se sienten satisfechos e identificados con este espacio, por lo que deciden utilizarlo con frecuencia llegando a convertirse como parte de su rutina diaria.

Deben ser cómodos y llamar la atención de los usuarios de manera que estos tengan ganas de volver a utilizarlos. Además de generar contacto entre sus usuarios, estos espacios deben ser capaces de generar estímulos, los cuales se obtienen mediante la experiencia de estar con otras personas, quienes permiten recibir estímulos externos y variaciones sensoriales. El objetivo es crear condiciones para que se den actividades tanto de día como de noche, al igual que para todas las estaciones del año.

Con un buen planteamiento del espacio los usuarios estarán siempre dispuestos a volver a él. Sin embargo, para que pueda existir interacción las personas necesitan verse y oírse, por ello se requiere: vistas sin obstáculos, distancias cortas, baja velocidad de movimiento y 
mantener a todos en un mismo nivel. Además, para que un espacio sea adecuado se requiere que el usuario: pueda caminar libremente dentro de él, pueda estar de pie sin estorbar al resto y pueda sentarse a descansar o pasar el tiempo. Este último punto es fundamental ya que las largas estancias son las que permiten la interacción con otras personas.

Según Jan Gehl: “Un espacio público es bueno cuando en él ocurren muchas actividades no indispensables, cuando la gente sale al espacio público como un fin en sí mismo, a disfrutarlo" (Gehl, 2004, p. 7) Estos espacios son capaces de generar identidad con los usuarios, la cual puede adoptar una función integradora de la ciudad hacia el exterior, ya que el ser humano no existe si no convive con otros ciudadanos. (Diego Sánchez Gonzalez, 2014)

Ilustración 3.1 Alentar o rechazar la oportunidad de ver y oír a otros

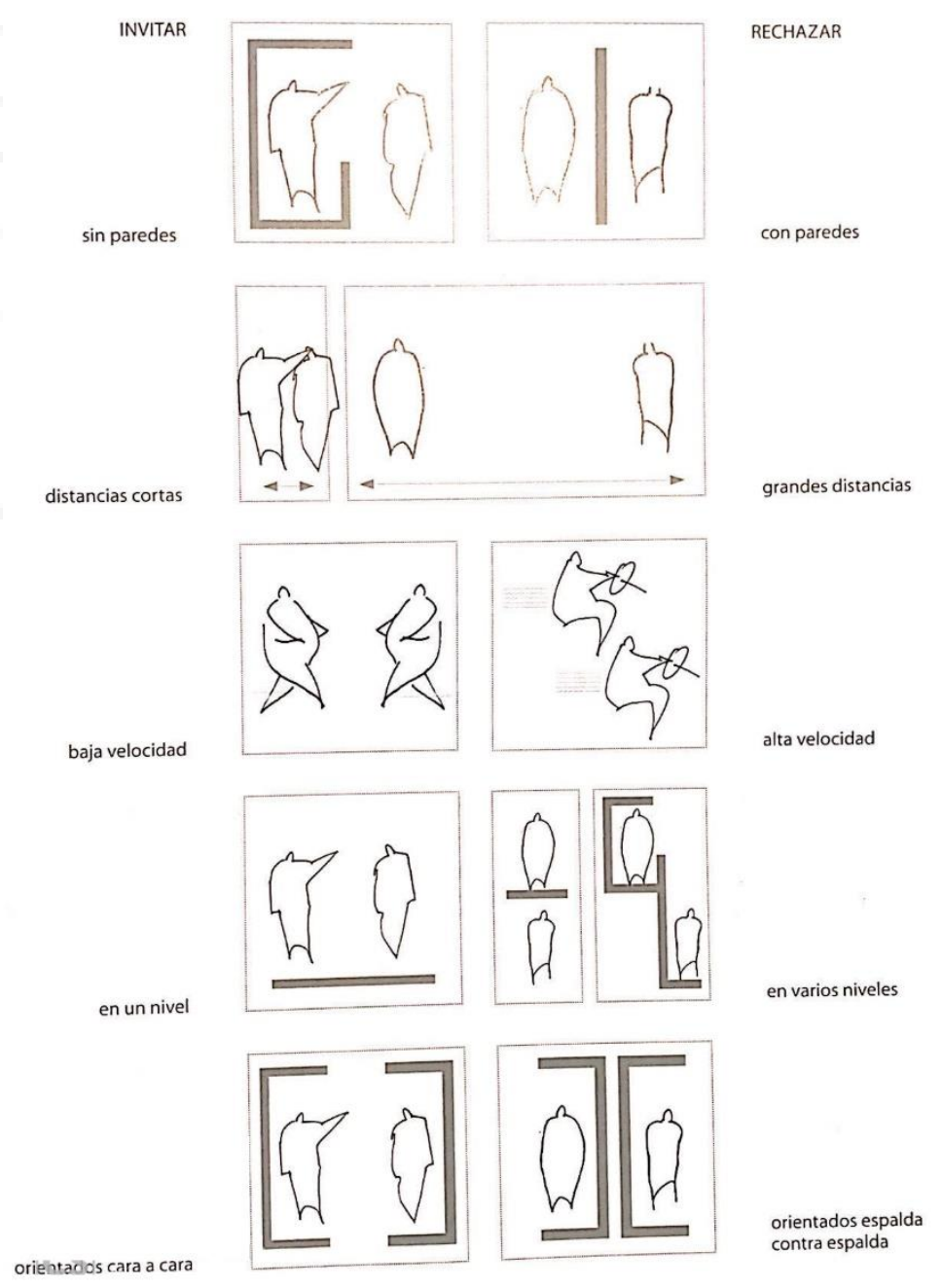

Fuente: Ciudades para la Gente, Jan Gehl, p. 237 
Una de las principales características del espacio público es su capacidad de generar permanencia, de atraer a la gente y su vida urbana. Sin embargo, no es sencillo obtener un espacio público efectivo. Algunas de las principales causas del fracaso de estos son la escala inadecuada, invasión de vehículos motorizados, poca versatilidad, contaminación, falta de confort, degradación física e incapacidad de generar sentido de pertenencia. Los principales problemas para configurar un espacio público también están relacionados con la indefinición de los límites, ya que son estos los que brindan sentido de seguridad a los futuros usuarios.

Víctor Neves supone que la pérdida de espacios públicos se debe al crecimiento de la ciudad, cuando esta llega a ocupar los vacíos urbanos. Debido a esto supone que quizá estos vacíos deberían tener una identidad, simbolismo y significado que los vinculen y arraiguen a los usuarios de manera que no puedan ser reemplazos por alguna otra edificación. Sin espacio público de todos y para todos no hay ciudadanía, sin ciudadanía no hay ciudad, sin ciudad no hay democracia. (Diego Sánchez Gonzalez, 2014). Para el fortalecimiento de la identidad es indispensable de la participación ciudadana y la planificación urbana. Este fortalecimiento de la ciudad genera que se desarrollen espacios con mayor calidad. (Diego Sánchez Gonzalez, 2014)

Hoy en día es lamentable como se viene generando una degradación de los espacios públicos. Otra causa importante es la aparición del automóvil, elemento que comparte tanto el espacio público con el hombre, y siendo muchas veces quien monopoliza el espacio. Es por medio de la convivencia entre los usuarios y automóviles que se percibe una ciudad cada vez más contaminada y peligrosa, fragmentada. Sin embargo, los efectos destructivos de los automóviles no son una causa sino más bien un síntoma de nuestra incompetencia para construir ciudades. (Jacobs, 2011, pág. 33)

Los vacíos urbanos permiten considerar como se puede entender una ciudad y además descubrir estrategias para diseñarla. La ciudad se diseña desde el punto de vista de materia edificada como de vacíos. En la mayoría de los casos los arquitectos se encargan de diseñar la ciudad a partir de lo edificado, y el espacio es "lo que queda", lo que "está entre". El espacio 
vacío es el negativo, el espacio que se amolda y adquiere forma con el objetivo de construir un lugar con identidad.

\subsubsection{El valor agregado de pertenencia, la identidad}

Existe una relación directa entre el sentido de pertenencia de un sujeto con el espacio vital. A este sentimiento se le llama identidad, sentimiento de pertenencia al territorio en el cual vivimos y donde se desarrolla una interacción social. Son los espacios públicos los encargados de generar lazos sociales, acogiendo a usuarios de diferentes grupos y generando entre ellos un sentimiento de pertenencia, o bien llamado identidad.

La ciudad es el factor determinante de la identidad para la sociedad. Conservar y fortalecer la identidad es un aspecto fundamental en los habitantes ya que les permiten sentir que son parte de un todo, lo que aporta un gran valor a sus vidas. Vivir con identidad nos permite dar sentido a la vida y así permite sentirnos relacionados con el entorno natural que nos rodea. Al sumar la identidad de varios usuarios se puede obtener un gran valor cultural, el cual puede ser percibido tanto por los habitantes como por los turistas.

Construir una memoria y protegerla es una garantía para la consolidación de las identidades, es por esto que muchas ciudades se basan en imágenes o estereotipos que permitan representarlas y le brinden un poco de personalidad al entorno habitado. La creación de esta imagen desempeña un papel muy importante en el proceso de planificación urbana, y para ello es indispensable la participación ciudadana, de manera que se consolide la idea de patrimonio.

La identidad se puede definir también a través del paisaje natural, donde el ser humano percibe lo que lo rodea y los estímulos a los que está expuesto. El fomento de una fuerte identidad cultural es un requisito previo para la creación de comunidades sostenibles.

La pérdida de esa identidad humana ha sido parte fundamental de lo que nos ha llevado a la violencia y a la crueldad que se han manifestado en las últimas décadas. Es fundamental mantener la identidad de una ciudad, ya que la lejanía y ausencia de esta es la que impulsa la intolerancia y violencia. 


\subsubsection{Actividades públicas}

Según Jan Gehl, las actividades desarrolladas al aire libre se pueden categorizar en tres grupos; las actividades necesarias, las actividades opcionales y las actividades sociales. Las actividades necesarias son todas aquellas obligatorias, como salir al colegio o al trabajo. Las actividades opcionales son aquellas realizadas si lo permite el tiempo o el lugar o si existen las ganas de hacerlas, como dar un paseo en bicicleta, salir a tomar un helado. Y las actividades sociales son todas aquellas que dependen de otras personas en los espacios públicos, es decir, cuando las personas se relacionan para charlar o compartir experiencias en plena calle o en un parque. Tanto las actividades opcionales como las actividades sociales solo se realizan si las condiciones externas son favorables.

Es indispensable contar con un entorno favorable de manera que este permita realizar distintos tipos de actividades para una población variada. Estas actividades son posibles cuando se ofrecen el máximo número de ventajas y el mínimo de inconvenientes. (Gehl, La humanización del espacio urbano, 2004, pág. 185) Cuanto se presente una mayor diversidad de usos y usuarios dentro de las calles, los usuarios generarán vida y espacios públicos activos, en lugar de espacios vacíos. "Una calle muy frecuentada tiene posibilidades de ser una calle segura. Una calle poco concurrida es probablemente una calle insegura.” (Jacobs, 2011, pág. 61)

Ilustración 3.2 Conexión entre la actividad al aire libre y el estado de las condiciones para realizarlas

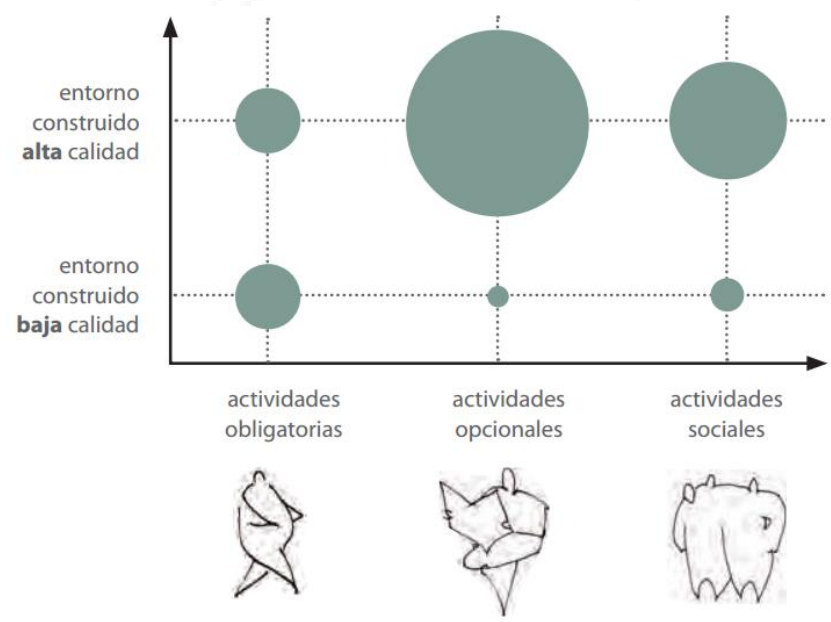

Fuente: Ciudades para la gente, Jan Gehl, p. 21 
El primer requisito para que se generen actividades públicas es estar dentro de un mismo espacio, encontrarse, ya que de esta manera es posible establecer relaciones de manera cómoda. Una ciudad donde se generan interacciones entre sus habitantes es considerada una ciudad viva, ya que son ricas en experiencias. Es este mismo movimiento de personas que permite atraer a más personas. "La gente se siente atraída por la gente” afirma Jan Gehl (Gehl, 2004, pág. 31), es por esto que si se tiene la opción de caminar por una calle animada o una calle desértica, el usuario siempre tomará la primera opción.

\subsubsection{Descubriendo espacios mediante el caminar}

La actividad de caminar también proporciona una posibilidad de estar presente en el entorno público. Además, por medio del andar se han desarrollado las más importantes relaciones que el hombre ha establecido con el territorio. (Careri, 2013)

La actividad de caminar es fundamental ya que permite describir y modifica los espacios que presenta la naturaleza y que muchas veces pasan desapercibidos, por medio del andar estos son capaces de cobrar sentido. Por este motivo es fundamental un adecuado diseño de rutas peatonales.

La circulación peatonal es muy sensible al pavimento y a las condiciones de la superficie, además las personas suelen evitar los pavimentos mojados y resbaladizos siempre que se pueda. La distancia aceptable para recorrer a pie es de 400 a 500 metros como máximo, siempre buscando tomar el camino más corto. Es de suma importancia generar que en los desplazamientos se siga la ruta más corta entre los destinos naturales de una zona, así como también se deben diseñar las conexiones individuales dentro del trazado.

Para el eficiente diseño de las rutas peatonales es indispensable alternar las calles con plazas, ya que estas generarán el efecto de acortar las distancias. Por otro lado, las diferencias de nivel representan un gran problema para los peatones, quienes deciden siempre que sea posible evitarlas. También son preferibles las rampas en situaciones donde se deba tanto subir o bajar. 
Si bien estar de pie dentro de los espacios públicos es importante, lo que es indispensable es permanecer dentro de ese espacio. Las principales zonas donde permanecen los peatones son en los bordes de los espacios o en los espacios de transición, donde tengan siempre un paisaje agradable que observar. Si los espacios se encuentran vacíos o si las fachadas no poseen detalles interesantes, entonces resultará difícil encontrar lugares donde se pueda permanecer parado.

Por otro lado es de suma importancia la disponibilidad de espacios para permanecer sentado, ya que para mejorar la calidad del entorno es indispensable generar más y mejores espacios para sentarse. Estos asientos deben tener respaldar, y estar orientados para obtener una agradable vista al paisaje que lo rodea, además de considerar otros factores como el sol y el viento, por lo que es indispensable generar una cubierta que permita dar sombra a estos espacios.

\section{Ilustración 3.3 Resumen de la teoría del urbanismo a escala humana}

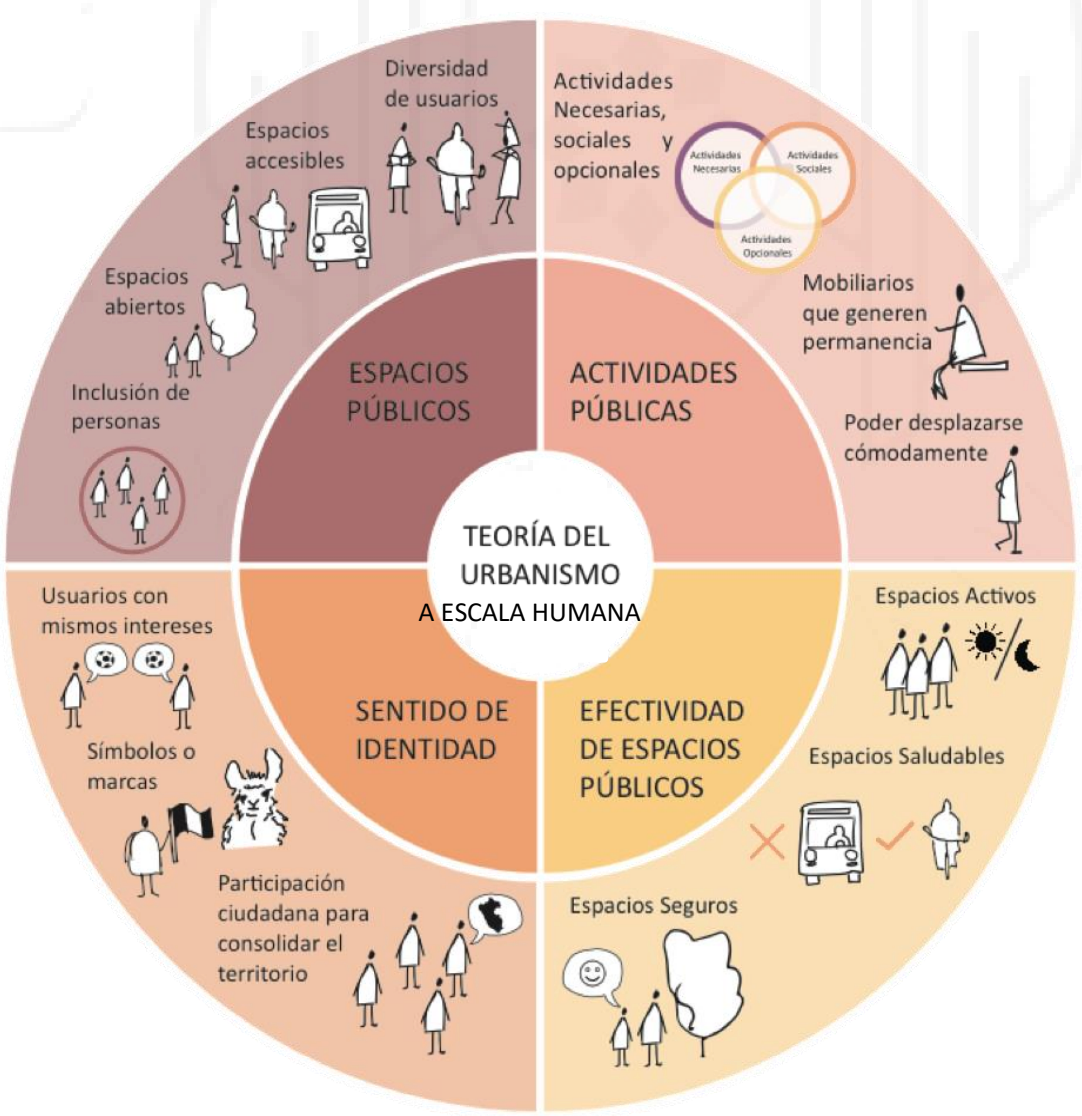

Fuente: Elaboración propia 


\subsubsection{Espacios vitales, seguros y sostenibles}

"Lograr que la gente se sienta segura es crucial si queremos que abrace el espacio urbano. Por lo general, son las personas las que hacen que una ciudad sea más segura y atractiva, tanto en términos de seguridad real como percibida." (Gehl, 2010, pág. 91). Para generar un espacio agradable también se debe considerar la protección ante el mal tiempo, generando confort exterior y oportunidades de permanecer en la calle. “...Cualquier estímulo que lleve a la gente a caminar, a andar en bicicleta o a permanecer en el espacio urbano contribuirá a aumentar la sensación de seguridad.” (Gehl, 2010, pág. 101)

El atributo clave de un distrito urbano logrado es que cualquier persona pueda sentirse segura en la calle en medio de desconocidos y no amenazada por ellos. Si queremos conservar una sociedad capaz de mantener alejados los problemas sociales, lo primero que debe hacerse es fortalecer cualquier potencia de las que ya existen en las ciudades que tenemos y que funcione a la hora de conservar la seguridad y la civilización. (Jacobs, 2011, p. 56)

Para que una calle pueda convertirse en un lugar seguro deben cumplirse tres cualidades; generarse una demarcación entre lo que es público y privado, deben haber siempre ojos que miren constantemente a la calle y la acera debe tener usuarios casi constantemente. Un factor básico para aumentar el flujo de personas en una calle es la colocación de tiendas y equipamientos públicos a lo largo de la calle. Sería recomendable que estos establecimientos sean de diferentes usos para que atraigan así a diferentes usuarios. (Jacobs, 2011, p. 61)

La presencia de otras personas nos señala a que lugares vale la pena ir. Un espacio se convierte significativo cuando es popular y capaz de atraer a gente hacia él. Por tanto, la ciudad vital requiere de actividades recreativas, espacio para el tránsito peatonal y oportunidades de formar parte de la vida urbana.

Los espacios públicos también deben consolidarse como sostenibles, por esto el objetivo es generar que los grupos sociales tengan las mismas oportunidades de acceso a espacios públicos y a un desplazamiento dentro de ellos. Esta igualdad de oportunidades viene 
acompañada con el derecho de las personas a utilizar el transporte público, ya que la gente que carece de un medio de transporte debe poder acceder a un buen sistema de movilidad ofrecido por la ciudad.

"Se debe establecer niveles óptimos de infraestructura, pero lo más importante de todo, se debe trabajar para estimular a todos a que caminen y anden en bicicleta como parte de la rutina diaria. Alentar y estimular son las palabras clave, y lograr calidad espacial urbana en la pequeña escala- a la altura de los ojos- es crucial.” (Gehl, 2010, p. 115)

Ilustración 3.4 Doce criterios de calidad en relación con el paisaje peatonal

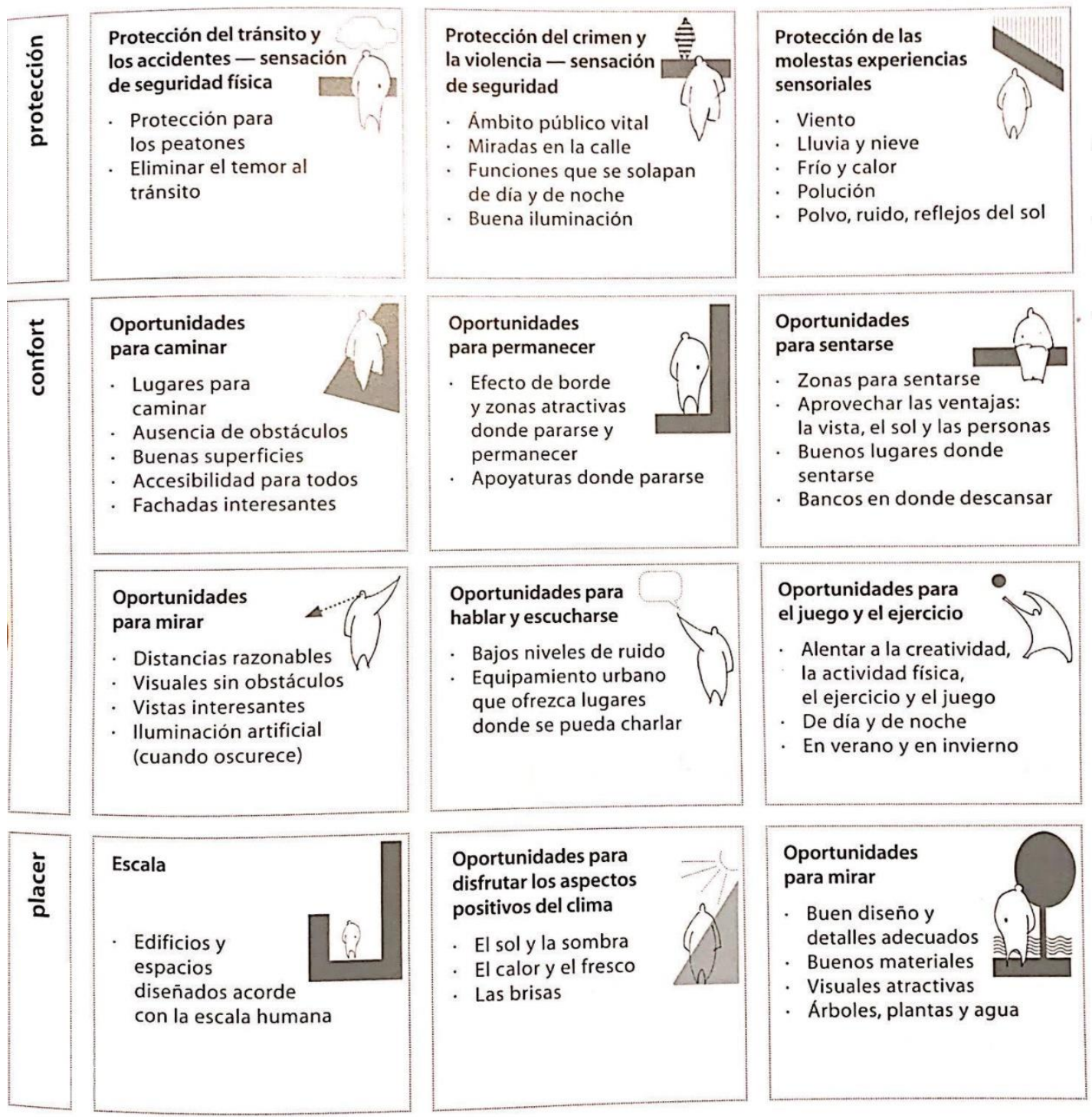

Fuente: Ciudades para la gente, Jan Gehl, p. 23 


\subsubsection{Teoría del borde}

En un espacio urbano, existen diversos elementos visibles en los que se puede basar la experiencia de una persona. Elementos tangibles que determinan las características de las ciudades y las hacen singulares entre sí. Según Lynch (2008) estos elementos pueden definirse como: sendas, bordes, hitos, nodos y barrios. Un borde es un elemento continuo, “... que puede ser más que una barrera dominante, tan solo si se permite que pase a través de él una penetración visual o de movimiento; si, por así decirlo, se le estructura en cierta profundidad con las regiones laterales. Entonces se convierte en una junta y deja de ser una barrera". (p. 123)

Los bordes que pueden ser fácilmente visualizados según la teoría de Lynch son los geográficos, como el punto de contraste o unión entre la tierra y el mar. De contraste porque son elementos distintos y de unión, porque se encuentran sobre el mismo lienzo de la naturaleza. Estos espacios desde cierta distancia pueden capturar la mirada de las personas. Desde este punto de vista, se podría considerar a los bordes como espacios de gran potencial a los que si se les agrega visibilidad y legibilidad sumada con la que cuentan naturalmente, pueden convertirse en espacios atractivos que aumenten el valor identitario de las ciudades.

Por otro lado, Steven Holl en su libro Edge of the city (1991) se refiere a borde como “... región filosófica donde se superponen paisaje natural y urbano, coexistiendo sin elección ni expectativas. Estas zonas llaman a visiones o proyectos que definan una nueva frontera entre lo urbano y lo rural". (p. 9) Para Holl, los bordes se han visto interrumpidos y han pasado a ser desapercibidos por el enorme crecimiento de lo urbano sobre lo natural y su escasa conexión entre ambos.

Los bordes no son solo espacios determinados naturalmente por la geografía sino también han sido construidos por el hombre. Como en la edad media en la que las murallas conformaban el borde de las ciudades. Hoy esas murallas han evolucionado y sean convertido en edificios pero aún siguen ejerciendo la labor de barrera. Richard Sennett en su artículo La ciudad abierta (2013), se muestra de acuerdo con la urbanista Jane Jacobs en generar sistemas 
abiertos en las ciudades, donde se promueva la participación social, espacios que permitan la total integración de las personas. (p. 29)

"Los bordes ofrecen a las ciudades su identidad y singularidad, y en muchas, estos están siendo perdidos por el amorfo y privatizado desarrollo de las ciudades actuales" (Zarza, 2001, p. 7). Con el crecimiento acelerado y desmedido de las ciudades, es muy difícil leer claramente sus bordes. Se ha obviado la marca de agua con la que contaba el gran lienzo y se ha escrito sobre este sin tener consideración alguna de lo que allí existía inicialmente, lo que ha generado que los territorios dejen de tener sus condiciones geográficas como características resaltantes. Este medio de yuxtaposición entre dos espacios, puede convertirse en un lugar de transición y tensión entre lo nuevo y lo viejo, entre lo estable y lo dinámico y en él se puede construir a muchas escalas, desde las territoriales a las urbanísticas, desde las arquitectónicas a las de las piezas, edificaciones, habitaciones, parcelas y caminos. (Zarza, 2001, p. 8)

La vida urbana de una ciudad en gran medida está influenciada por el adecuado manejo y tratamiento de los bordes, pues son los umbrales donde el interior y el exterior entran en contacto, y permite el encuentro de los edificios con la ciudad. Los bordes urbanos limitan el campo visual y definen los espacios individuales, contribuyendo a enriquecer la experiencia del usuario y ayudando a tomar conciencia que el espacio es un lugar propio. Es así como en una ciudad que presenta discontinuidad en algunos puntos de su territorio, puede regenerarse e impulsarse a través de bordes atractivos, que son el lugar propicio para que las actividades que antes se desarrollaban en un espacio cerrado, puedan integrarse con el exterior, generando así buen lugar para estar dentro del espacio urbano.

Según Jan Gehl en su libro Ciudades para la gente (2010), los bordes se pueden subdividir en dos categorías: borde blando y duro. El primero representa un escenario que tiene mucho por ver y tocar, donde sobran los motivos para pasear y detenerse a mirar, por ello tienen un impacto significativo en la vitalidad de la ciudad y en el grado de atracción que tendrá un espacio urbano. En contraposición, se encuentra el borde duro, donde hay pocas oportunidades de entrar en contacto con experiencias significativas, por ende las personas no tienen motivo alguno para circular por estas zonas. Contar con bordes activos y vitales es el factor más 
importante cuando se trata de lograr un espacio urbano atractivo y vital. Cuando estos funcionan bien, ayudan a retroalimentar el círculo de la vida urbana. (p. 88)

Indicar de modo claro los límites territoriales resulta ser esencial cuando se refiere al contacto entre personas y la protección de la esfera privada. Construir zonas de transición que garanticen un paso gradual del espacio público al privado significa que las oportunidades de contacto entre las personas aumentan. Estos espacios de transición deben configurarse de tal manera que se entienda dónde acaba uno y dónde empieza el otro. (Gehl, 2010, p. 90)

Para el presente caso de estudio, es indispensable indagar sobre el borde costero, específicamente de ciudad - puerto, pues si bien Chimbote es una ciudad que pertenece a la región costa, también ha ejercido y ejerce hasta la actualidad la condición de puerto, lo que condiciona de manera distinta su borde a si tan solo fuera una ciudad costera.

Los bordes costeros de ciudades - puerto de muchas ciudades del mundo han pasado por diversas etapas, que han estado determinadas por los diferentes eventos históricos. Como se mencionó anteriormente en el marco histórico - referencial, en ellas se pueden apreciar dos escenarios muy marcados que han influido enormemente en su desarrollo urbano. El primero, es el periodo industrial, tiempo del apogeo de las industrias y de mayor producción, lo que atrajo la mirada de otras ciudades, de inversionistas y de la masa trabajadora. El segundo escenario, es el post industrial, en el que la industria decayó, generando un desbalance económico en estas ciudades.

Inicialmente, durante el boom industrial, el borde costero fue ocupado en toda su extensión por las diversas industrias que buscaban asentarse y generar ingresos en esas ciudades, claramente les importaba más las divisas que obtendrían que los impactos negativos que podrían ocasionar en el territorio en el que se encontraban, pues se asentaron allí como pudieron y quisieron. Sin embargo, fue recién en el periodo post industrial donde se pudo reconocer que el borde costero había sido agredido enormemente, pues debido a la caída de las industrias, muchas se fueron retirando del lugar que ocupaban, dejando así los puertos y zonas industriales totalmente deterioradas en el aspecto territorial, ambiental, urbano y social. 
Es justamente el borde costero industrial lo que identifica a las ciudades - puerto, por lo que es un punto importante tomarlo en cuenta para la revitalización y regeneración de las ciudades, de modo que se voltee la mirada de la ciudad hacia el mar.

\subsubsection{Teoría de Regeneración Urbana}

Regeneración urbana es un término amplio que conlleva a pensar en diversos aspectos que intervienen en la ciudad, pues al ser esta un organismo complejo, es necesario entenderla como tal. Roberts, director del comité de Buenas Prácticas de la Asociación Británica para la Regeneración Urbana define el término así (como se citó en Iraegui Cuentas, 2014):

Una actuación integrada y exhaustiva que conduzca a la resolución de problemas urbanos, buscando una solución perdurable en ámbitos económicos, físicos, sociales y ambientales del área sujeta a la transformación. (pp. 12-13)

Por lo tanto, se entiende como regeneración urbana a un proceso complejo de intervención en la ciudad cuyo énfasis e impacto no es solo físicamente sino que tienen que tomarse en cuenta diversos aspectos que influyen en la mejora de un área concreta de la ciudad, como aspectos mediambientales, económicos, sociales y culturales.

"Desde el punto de vista espacial, las intervenciones de regeneración tienen como objetivo reintegrar un área con fuertes deficiencias o en demostrada decadencia al resto de la ciudad, mejorando la conectividad tanto en las escalas de barrio como de ciudad en su conjunto". (ONU, 2016)

Dentro del proceso de regeneración urbana, una de las formas de alcanzar mayor impacto es con la inclusión y desarrollo de equipamientos en zonas vulnerables y potenciales para transformar una zona en específico. Los equipamientos actúan como el nexo o impulso para que una zona con problemas de inserción de diversos tejidos urbanos pueda funcionar como un sistema integrado, en donde exista reciprocidad en la función social y urbana. En otras palabras, para que las diversas intervenciones hechas en la ciudad puedan dialogar pacíficamente y los mayores beneficiados sean los habitantes debido a las dinámicas urbanas que los equipamientos generan. 
"Los equipamientos, entendidos como nodos que articulan los tejidos urbanos, representan una gran oportunidad para generar espacios de encuentro donde se facilite la participación y se desarrolle una identidad común, fomentando la economía local, genere espacios de identidad del barrio, de apoyo a la población más desfavorecida y de integración de la perspectiva de género"

La regeración urbana es también un proceso que se encuentra estrechamente ligado a las políticas urbanas debido a todo el proceso que conlleva realizarla, es decir, que se les atribuye como tarea a realizar por parte de las autoridades. Sin embargo, es labor de todos los ciudadanos exigir e impulsar que las autoridades se inclinen por desarrollar este tipo de intervenciones que contribuyen en gran medida a la ciudad.

\subsubsection{Regeneración urbana a través de la cultura}

Rish Lerner (2005) en su artículo El valor de la cultura en los procesos de desarrollo sustentable, desarrolla cómo la cultura puede llegar a impactar en el desarrollo positivo de las ciudades. El impacto está reflejado en tres tipos de regeneraciones. La primera, dada por la regeneración medioambiental, a través del reciclaje y recuperación de espacios abandonados o en desuso que fomenten el sentimiento de orgullo e identidad por un espacio en el que se desarrollen actividades que promuevan y faciliten una relación positiva entre el trabajo - vida y tengan un efecto positivo en la calidad de vida de la gente. Seguida de la regeneración económica que fomente la inversión en áreas estratégicas para promover el empleo y estimule al desarrollo y a la formación de profesionistas con los conocimientos exigidos por la sociedad. Asimismo, el proyecto cultural se convertirá en un atractivo turístico tanto para la población local como para visitantes externos, lo que tendrá un impacto en los inmuebles aledaños, aumentando el valor de las propiedades residenciales y comerciales, permitiendo el crecimiento económico de la zona y de la ciudad. Finalmente, la cultura permite una regeneración social, transformando de forma positiva la percepción del entorno, contribuyendo a que los habitantes de la zona se identifiquen con su zona y con lo que ella cuenta, logrando que se reduzca la deserción escolar y el comportamiento ofensivo, se estimule el alcance de mayores logros educativos y además se fomente un cambio de imagen y reputación del lugar. (pp. 83 - 84) 
3.2 Diagrama de Jencks

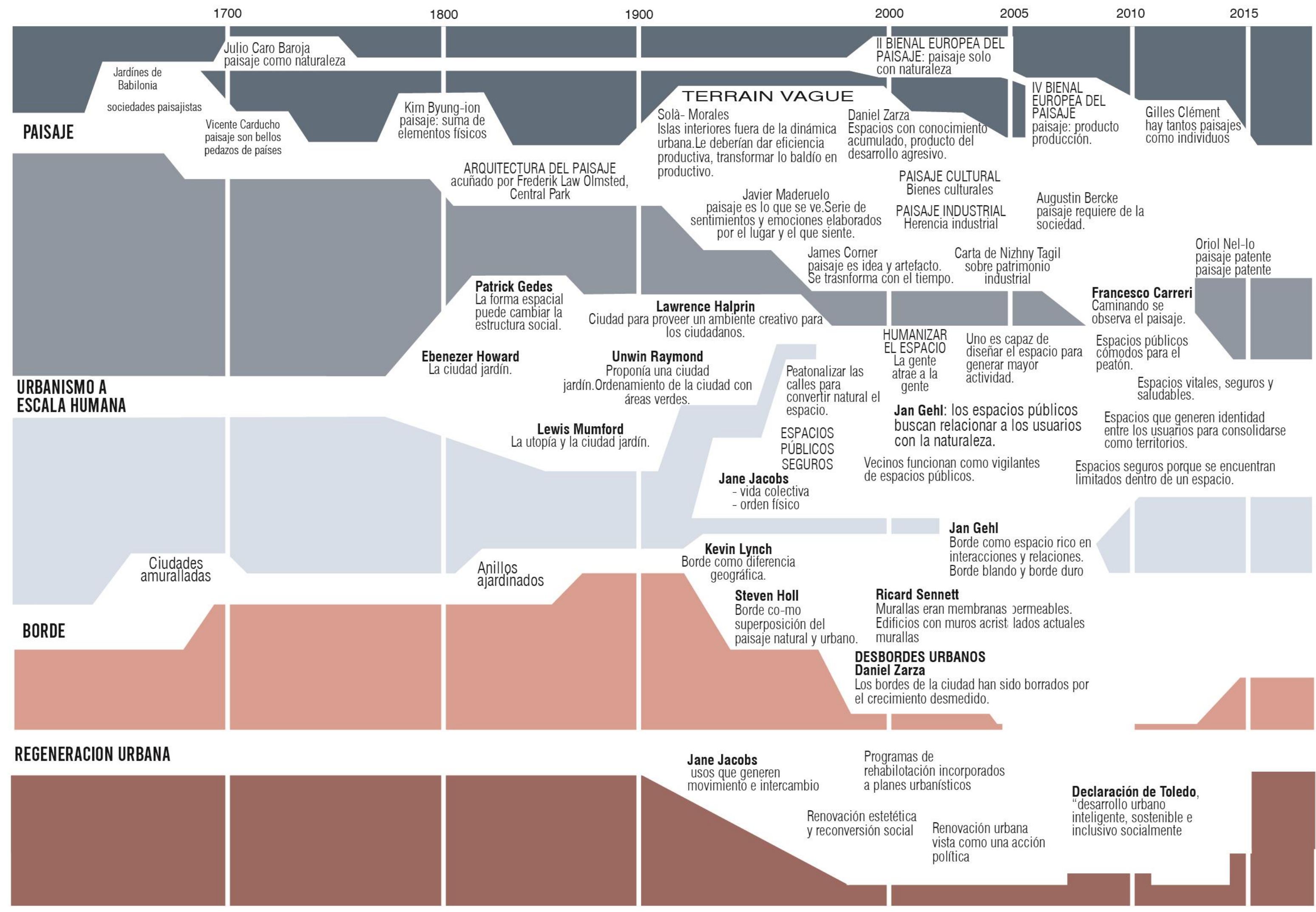




\subsection{Base conceptual}

Las teorías anteriormente estudiadas, han sido explicadas por varios autores, pero todos con un mismo fin. Se ha decido resumir las teorías en conceptos que ayuden a situarlas en el proyecto a desarrollarse.

\section{Paisaje}

En base a esta teoría como concepto de proyecto, se ha determinado potencialización y adaptabilidad. El primer concepto se refiere a que la fábrica en desuso es un espacio atractivo en el que se puede desarrollar un equipamiento debido a toda la riqueza histórica e industrial con la que cuenta.

Por otro lado, se ha tomado en cuenta la adaptabilidad porque el proyecto deberá tener la capacidad de adecuarse al paisaje de la ciudad y al perfil urbano del entorno, de modo que la intervención no resulte un elemento aislado, sino que genere un nexo entre la ciudad y su entorno medioambiental, atrayendo la mirada de los residentes hacia este espacio olvidado.

Ilustración 3.5 Abstracción de la teoría de paisaje

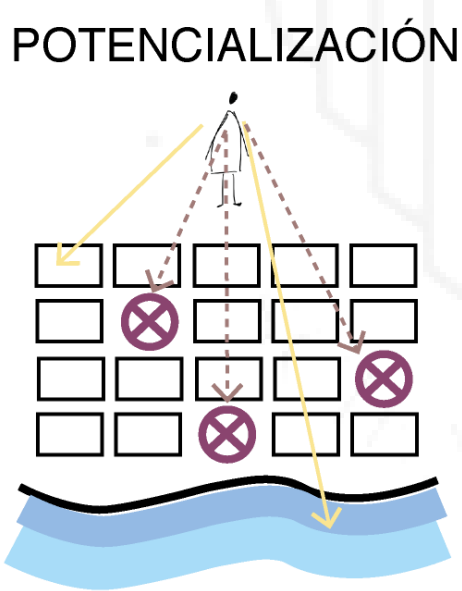

Potenciar los terrain vague, convirtiéndolos en parte del paisaje de las personas.
ADAPTABILIDAD

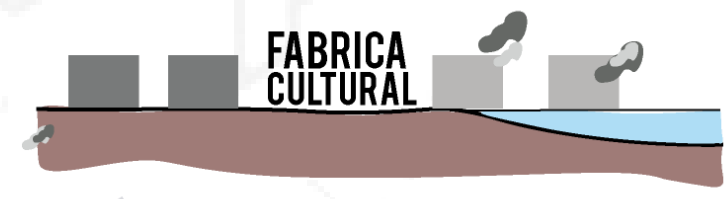

\section{1}

Antes

Después

Fuente: Elaboración propia 
Ilustración 3.6 Adaptación de la teoría de paisaje a la fábrica en desuso

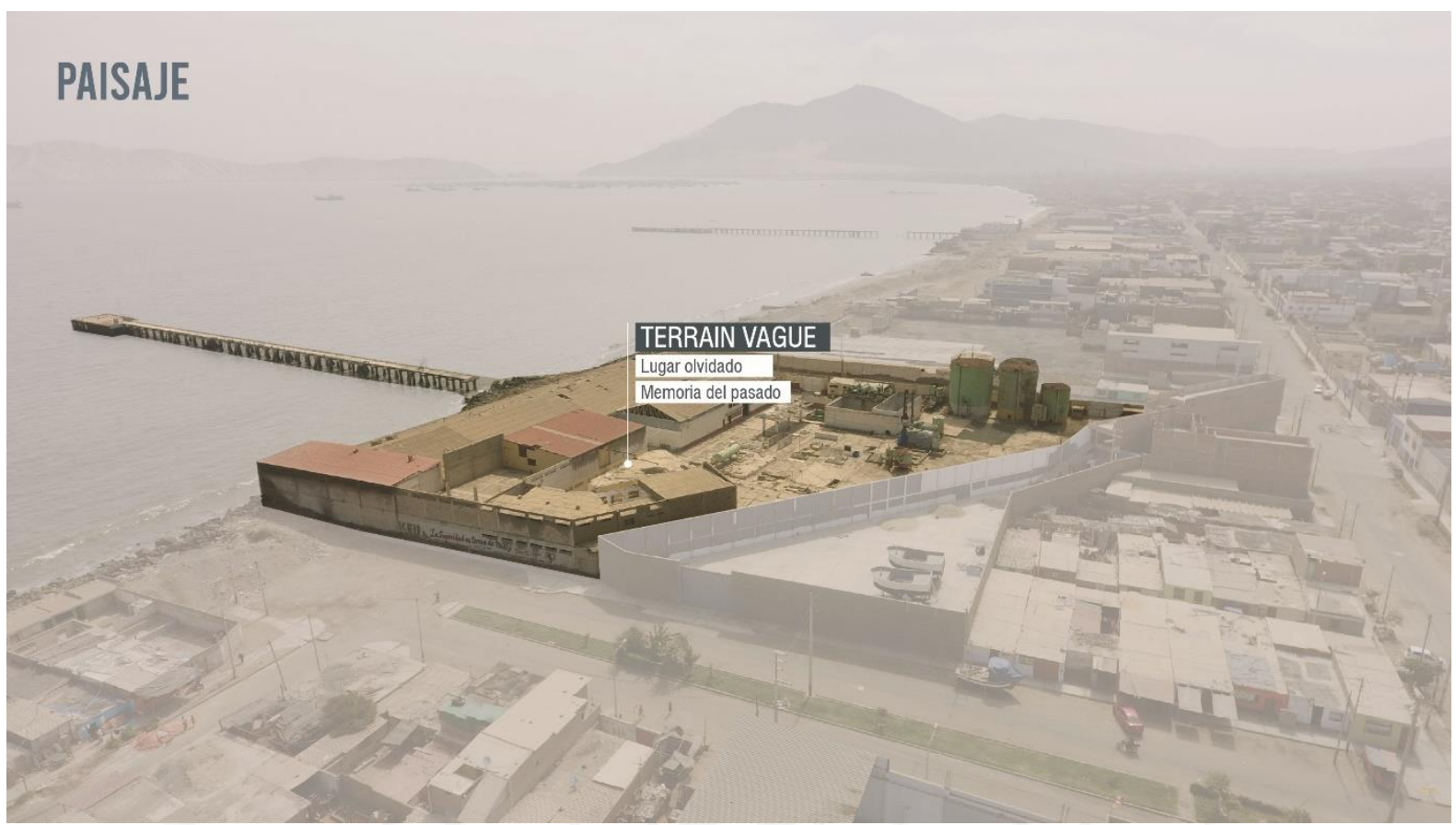

Fuente: Elaboración propia

\section{Ilustración 3.7 Chimbote como paisaje cultural}

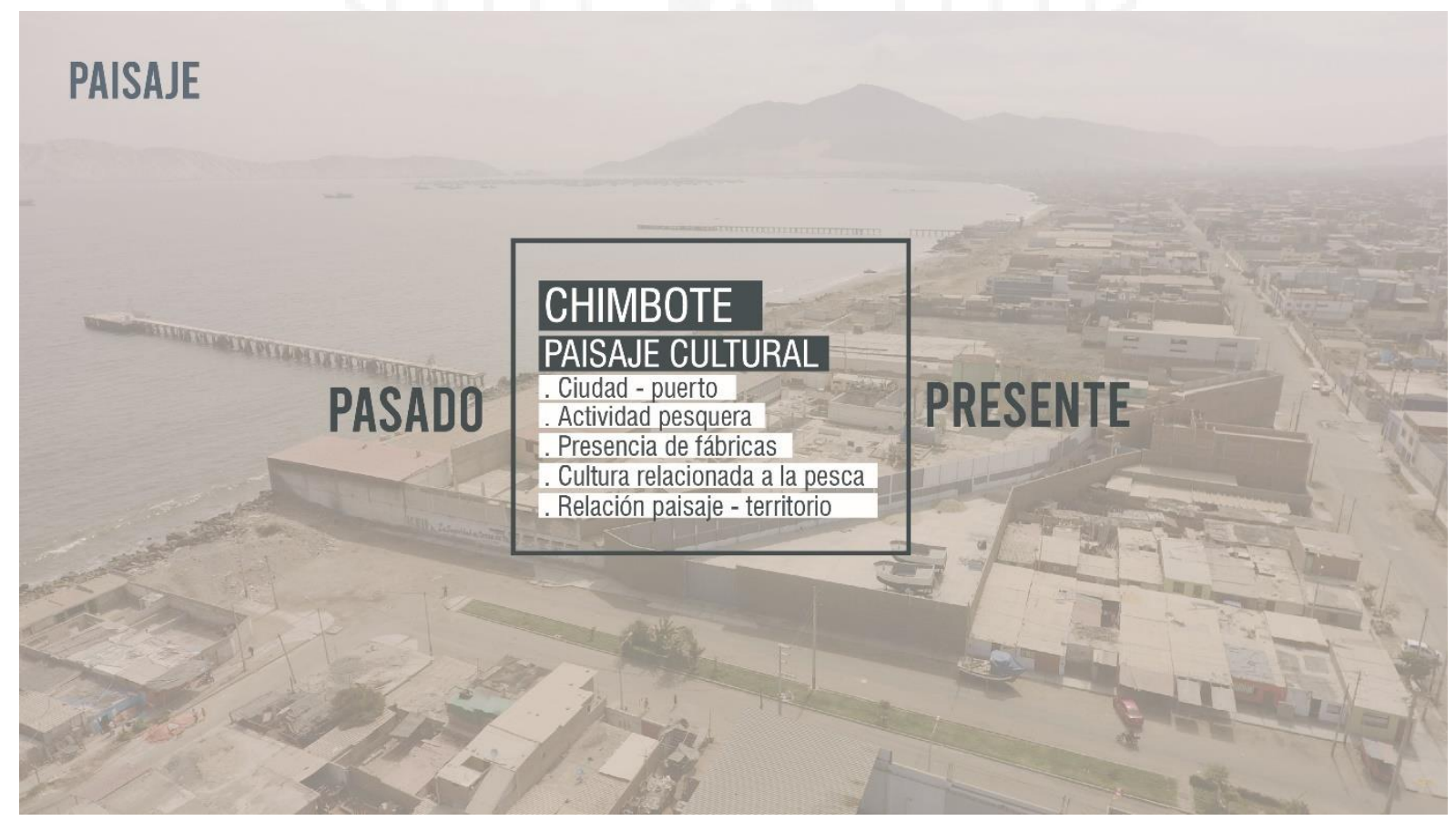

Fuente: Elaboración propia 


\section{Urbanismo a escala humana}

Con respecto a esta teoría, se ha determinado el concepto inclusión, que se define como la aceptación de todo tipo de elementos y usuarios dentro de un mismo espacio, con el objetivo de que a través de la interacción social se genere vitalidad en la intervención. Esta inclusión está dada no solo en el área exterior que es hacia donde está orientada la teoría, sino que también se empleará en el interior de la intervención donde se busca que el dinamismo del espacio público también se inserte al programa específico del proyecto. La inclusión no solo está orientada a los usuarios sino también a los visitantes quienes acudirán al espacio solo si se sienten identificados con este, para ello este debería contar con símbolos o marcas que sean parte de su cultura.

\section{Ilustración 3.8 Abstracción de la teoría de urbanismo social}

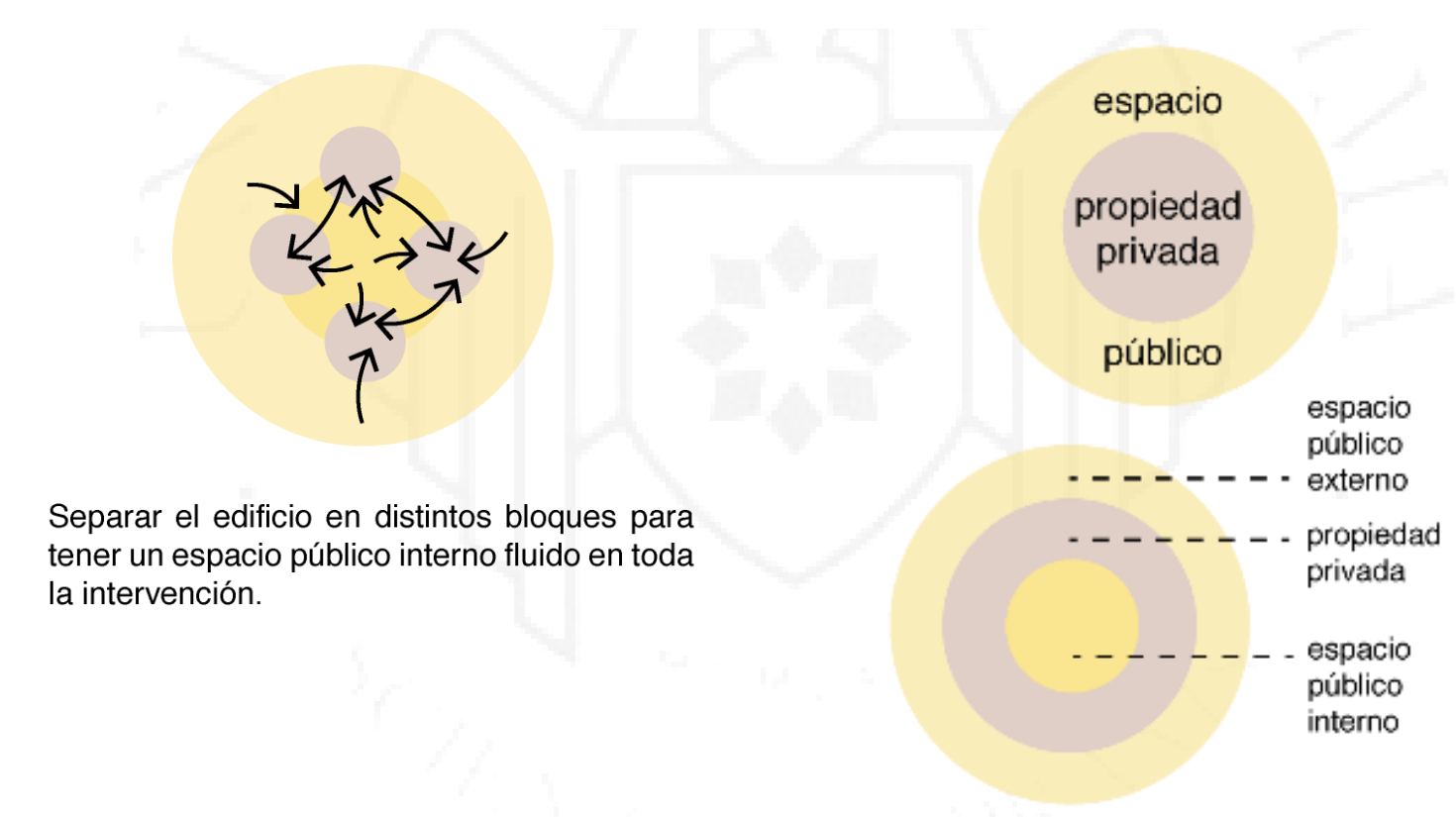

Fuente: Elaboración propia

\section{Borde}

En base a esta teoría como concepto de proyecto, se ha determinado transición y permeabilidad. El primer concepto se refiere al cambio de un elemento a otro de manera sensible y pausada, generando un espacio de confluencia de actividades, que nace de la riqueza histórica e identidad que el borde presenta. El término de permeabilidad hace referencia al paso de un espacio a otro sin cambios drásticos ya que se concibe como un espacio fluido entre lo 
natural y lo urbano, donde pueda llevarse a cabo diversas actividades. Por este motivo, el proyecto buscará abrirse hacia el entorno a través de bordes difusos y no cerrarse en una forma sólida.

Ilustración 3.9 Abstracción de la teoría de borde

TRANSICIÓN

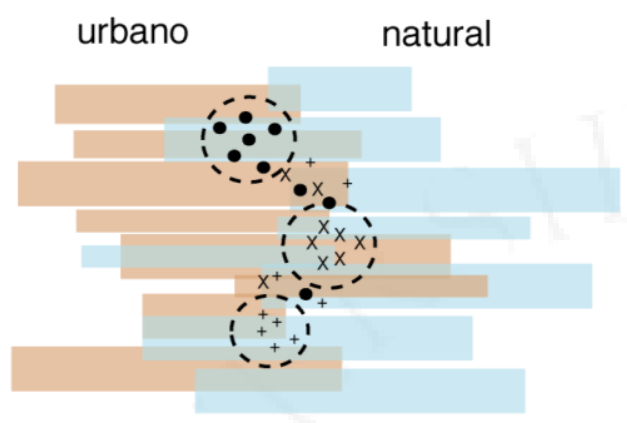

Suavizar el borde y convertirlo en un borde blando, donde conflutan muchas actividades.

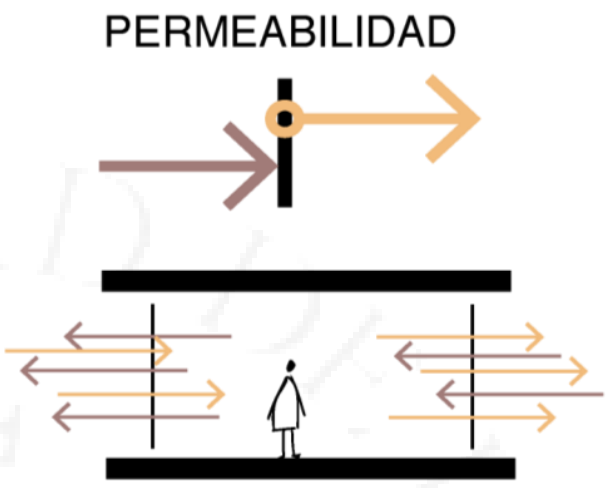

Fluidez del espacio interno y externo.

Fuente: Elaboración propia

Ilustración 3.10 Interpretación de la teoría de borde a la relación entre la fábrica en desuso y la bahía

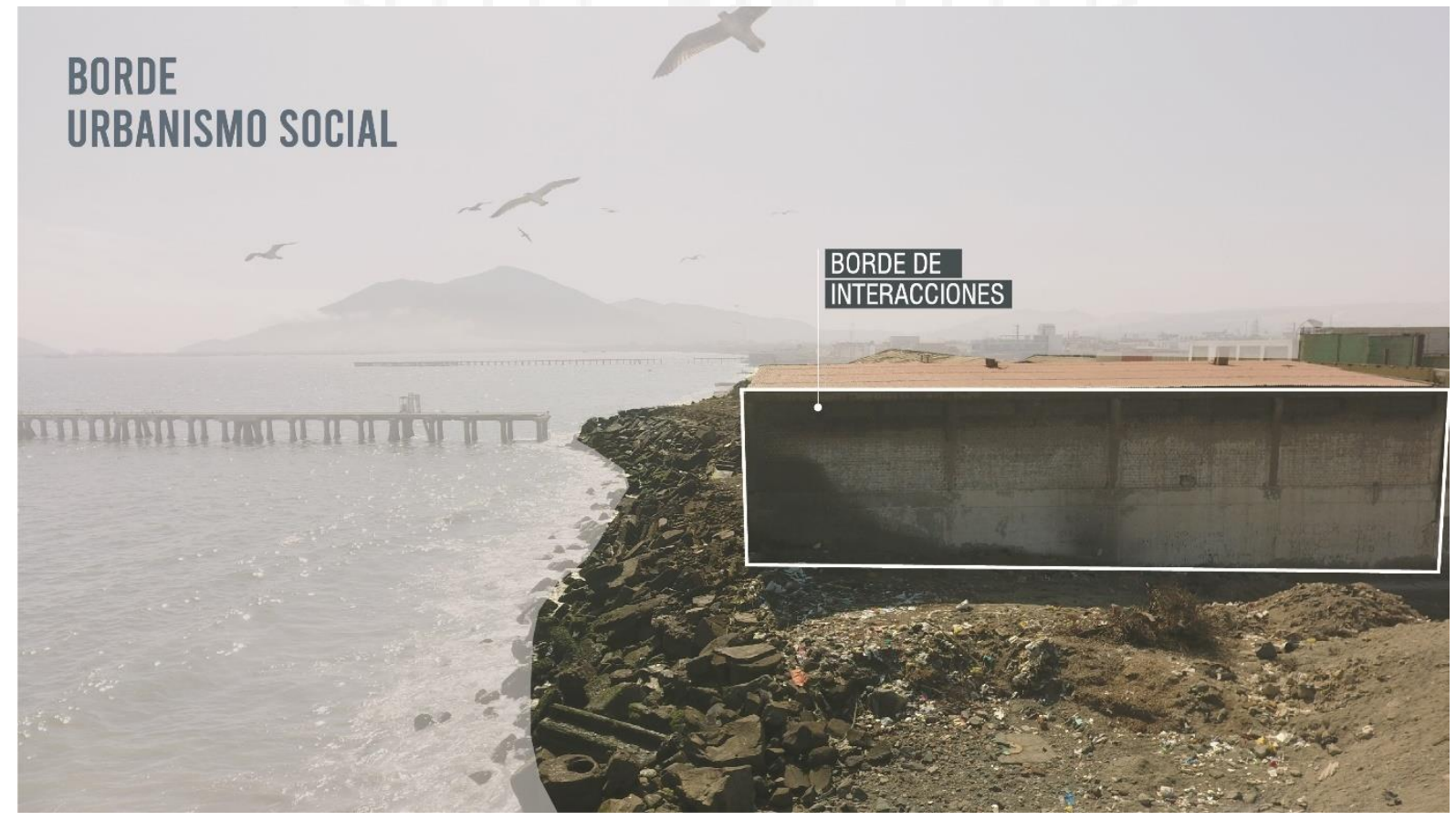

Fuente: Elaboración propia 
Ilustración 3.11 Funcionamiento de la fábrica en desuso como espacio de encuentro entre la ciudad y la bahía

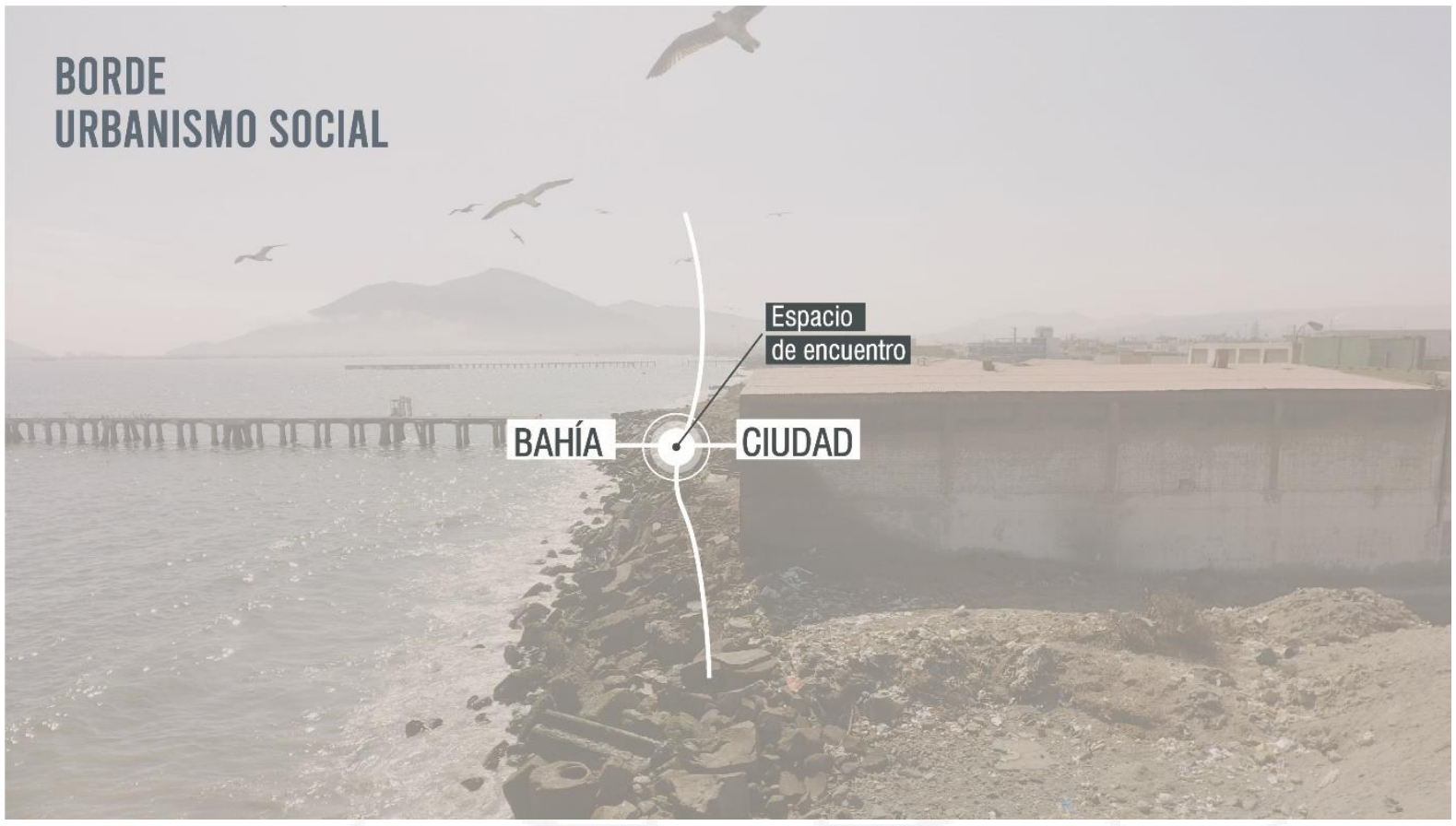

Fuente: Elaboración propia

Ilustración 3.12 Adaptación de la teoría de regeneración urbana al proyecto

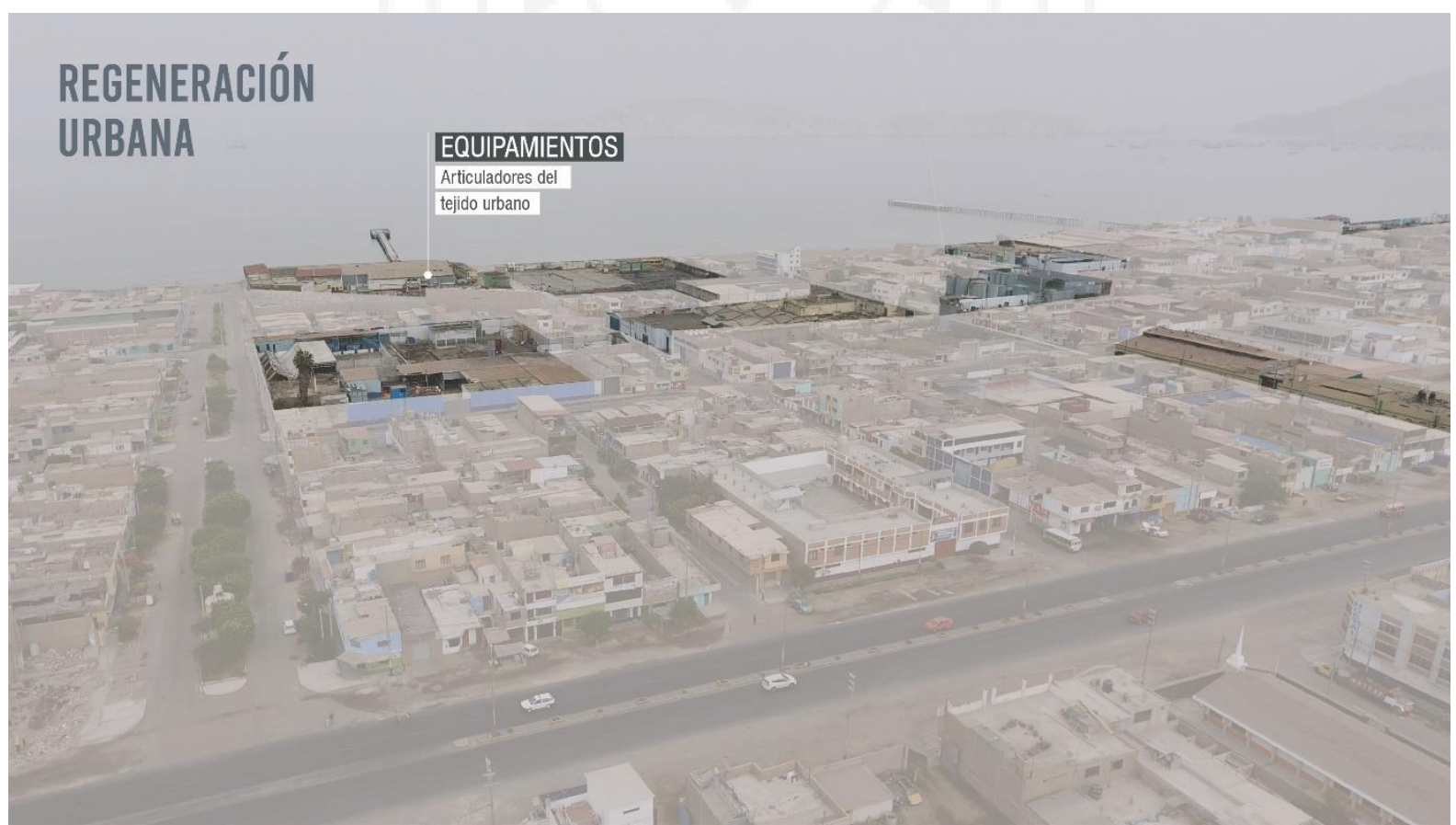

Fuente: Elaboración propia 


\subsection{Glosario de terminología}

\subsubsection{Activación}

El territorio se activa con la presencia de la arquitectura; la arquitectura se activa mediante el uso (...). (Gausa, 2001). (...)Impulsor de valores sociales urbanos (...) (Turrado). Habilitar un espacio por medio de actividades. (Certas, 1998)

\subsubsection{Ambiente}

Lugar en el que es propio descubrir orden y desorden, vacío y caos. (...) (Gausa, 2001). Conjunto de situaciones o atmósfera de un lugar o medio. (Diccionario de arquitectura y construcción, 2012). Espacio abierto propicio para el desarrollo de factores naturales (...) (Kuramoto, 2005)

\subsubsection{Borde}

Diferencias naturales entre dos lugares. Se dividen en bordes fuertes, que logran ser percibidos visualmente y bordes fragmentarios, que solo pueden ser visualizados en algunos puntos. (Lynch, 2008, págs. 79,80,82) Región filosófica donde se superponen paisaje natural y urbano. Definen una nueva frontera entre lo urbano y lo rural. (Gutiérrez \& Talesnik, 2002, pág. 9) Son elementos que funcionan como barreras. (Sennett, La ciudad abierta, pág. 29) Espacios de transición que permiten entender donde inicia y donde termina un espacio. (Gehl, Ciudades para la gente, 2010)

\subsubsection{Ciudad Puerto}

Ciudad que se ha desarrollado en función de su actividad portuaria y de la actividad económica surgida del intercambio y del comercio marítimo. (Bierre \& García-Almirall, 2011, p. 640)

\subsubsection{Espacios Públicos}

Sistema de espacios e instalaciones asociadas, destinados a parques, jardines, áreas de ocio, expansión y recreo de la población (Glosario de términos urbanísicos). Territorio de la ciudad donde cualquier persona tiene derecho a estar y circular libremente. (UNAM). Espacios libres constituidos por plazas, plazuelas y otros, que se producen como resultado del ensanche de las 
vías de circulación (...). (Municipalidad de la Habana, 1994). Espacio de uso colectivo, disperso, indeterminado y con equilibrio inestable. (Gausa, 2001)

\subsubsection{Equipamientos}

Sistema de construcciones, instalaciones y espacios asociados que se destinen a la prestación de servicios básicos a la comunidad (...) (Glosario de términos urbanísicos). Instalaciones de servicio generalmente vinculadas a sectores residenciales o barrios por la frecuencia diaria de su utilización. (Municipalidad de la Habana, 1994). Conjunto de edificaciones y espacios, predominantemente de uso público, en los que se realizan actividades complementarias a las de habitación y trabajo (...). (Estudio de regeneración urbana, 1976)

\subsubsection{Paisaje Cultural}

Bienes culturales de valor excepcional que representan obras conjuntas del hombre y la naturaleza. Ilustran la evolución de la sociedad humana y sus asentamientos a lo largo del tiempo, condicionados por las limitaciones y/o oportunidades físicas que presenta su entorno natural y por las sucesivas fuerzas sociales, económicas y culturales, tanto externas como internas. (Centro del Patrimonio Mundial de la UNESCO, 2005, p. 48)

\subsubsection{Paseo}

Espacio público de forma longitudinal concebido como sitio de circulación y esparcimiento. (Municipalidad de la Habana, 1994). Espacio público de forma longitudinal concebido como sitio de circulación y esparcimiento, que puede contar con vegetación y/o mobiliario urbano (...). (Municipalidad de la Habana, 1994). Zona destinada a andar y pasear, en especial en espacios públicos para disfrute y esparcimiento. (Ching, 1998)

\subsubsection{Patrimonio Cultural}

"El patrimonio cultural es una síntesis simbólica de referentes identitarios pero, sobre todo, una construcción social, un acto de legitimación y, como tal, constitutivamente objeto de invención o de activación selectiva y reflexiva, a cargo de agentes como el poder político y la sociedad civil, son objeto de mostrar y ensalzar una imagen del "nosotros", de la identidad de una comunidad.” (Martínez, 2007, p. 58) 


\subsubsection{Patrimonio Industrial}

En ella se define patrimonio industrial como el espacio que albergaba el desarrollo de una actividad industrial y en el que aún se encuentran restos característicos como: edificios, maquinarias, talleres, molinos, almacenes y depósitos, que poseen un valor social, histórico, arquitectónico y tecnológico. (TICCIH, 2003, parr.6)

\subsubsection{Reciclaje}

Someter un material usado a un proceso para que se pueda volver a utilizar. (Molina) Significa modificar la capacidad propia del edificio para poder cumplir nuevas funciones, sin por ello alterar la esencia y el patrimonio histórico que conllevan. (Genovés, 2014). Transformación de los residuos, para su fin inicial o para otros fines. (Izazaga, 2014)

\subsubsection{Reciclaje arquitectónico}

Según la definición de Chacón (como se citó en Martínez Monedero, 2012), es someter a un proceso un edificio ya usado para que pueda volver a utilizarse, conservando o modificando su anterior uso e iniciando de este modo un nuevo ciclo de vida. (p. 32)

\subsubsection{Reconversión portuaria}

Consiste en la liberación de las fachadas marítimas de los puertos para generar una apertura de las ciudades al mar, construyendo nuevas áreas de centralidad urbana que apartan la actividad industrial portuaria y dan cabida a nuevas actividades de ocio, comerciales, terciarias, turísticas y culturales. (Bierre \& García-Almirall, 2011, pp. 639-640)

\subsubsection{Regeneración Urbana}

Proceso que (...) constituye al desarrollo de las funciones, así como al mejoramiento de las condiciones del medio ambiente. (Estudio de regeneración urbana, 1976). Intervención dirigida a recuperar y/o mejorar la capacidad de uso de un conjunto urbano (...) (Municipalidad de la Habana, 1994). Recuperación de espacios mediante intervenciones (...) (Pozo, 2012) 


\subsubsection{Revitalizar}

Dinamizar, mejorar y humanizar el ecosistema urbano (aspectos físicos y sociales) para que la vida fluya a través de él. Es decir, conseguir un soporte urbano dotado de energía e impulso para el desarrollo de la vida en toda su complejidad. (Glosario de términos urbanísicos). Instrumento y el recurso potencial para revertir los efectos del deterioro - físico, social y económico - de los centros de ciudad y de otras partes importantes de la misma. (Taracena, 2013)

\subsubsection{Urbanización}

Conjunto de las vías públicas, servicios urbanos y espacios libres públicos previstos en el instrumento de planeamiento urbanístico (...). (Glosario de términos urbanísicos). Núcleo de población con características de asentamiento urbano, morfológicamente diferenciado por su viario y edificación (...) (Alicante) Proceso que concentra a la población y las actividades en las ciudades (...) (Fernardi, 2009)

\subsubsection{Zona marino costera}

Espacio geomorfológico a uno y otro lado de la orilla del mar en el que se produce la interacción entre la parte marina y la parte terrestre a través de los sistemas ecológicos y de recursos complejos formados por componentes bióticos y abióticos que coexisten e interactúan con las comunidades humanas y las actividades socioeconómicas pertinentes. (Proyecto de Ley 197/2016-CR, 2016)

\subsection{Conclusiones parciales}

El paisaje es y constituye la cultura de una sociedad, ha sido esta la que ha plasmado conocimientos, emociones y sentimientos sobre un territorio, creando así los paisajes culturales, que por su valor intangible han pasado a convertirse en patrimonio, mereciendo ser valorado y sostenido en el tiempo. De acuerdo con la teoría estudiada los paisajes son verdaderamente un producto social que ha quedado como herencia de generación en generación y que es lo que ha permitido acentuar la identidad de la población con la ciudad y difundirla ante el resto del mundo. 
Inmerso en los paisajes industriales se han encontrado espacios olvidados producto del crecimiento de las ciudades y la transformación de la industria. De acuerdo con lo estudiado sobre terrain vagues, estos espacios son sumamente valiosos para el desarrollo y regeneración de las ciudades debido a la ubicación en la que se encuentran y a la herencia histórica que existe sobre ellos.

Las ciudades necesitan espacios para la gente, que sean usados tanto por los residentes como por visitantes y que permanezcan en ellos para que activen las áreas urbanamente degradadas e inseguras. Conforme con la teoría de urbanismo social es importante dotar de actividad a los espacios públicos para vincular a las personas con los espacios, que se apropien de ellos y por ende tiendan a identificarse, contribuyendo así que la calle esté activa todo el día y se perciba como un espacio inclusivo, seguro y atractivo.

En los bordes urbanos existe una yuxtaposición de lo natural y lo construido que ha generado la fragmentación de las ciudades con su entorno, convirtiendo esta parte del territorio en un espacio inactivo aun cuando posee un gran valor geográfico y paisajístico. En concordancia con lo investigado en la teoría del borde, estos deben ser espacios de encuentro, de concentración de actividad, bordes suaves que capten la atención de los ciudadanos y se sientan atraídos hacia este. 


\section{CAPÍTULO IV: MARCO NORMATIVO}

\subsection{Estándares normativos Nacionales}

\subsubsection{Reglamento Nacional de Edificaciones}

A 010. Consideraciones Generales de Diseño

Del artículo 1 al artículo 17

Del artículo 19 al artículo 27,29

Del artículo 32 al artículo 41

Artículos 43, 44, 46, 47, 48 y 51

Del artículo 57 al artículo 61, 62

Del artículo 65 al artículo 69

A 070. Comercio

Del artículo 1 al artículo 16

Artículos 21, 22, 23, 29, 30, 31, 33, 35 у 36

A 090. Servicios comunales

Del artículo 8 al artículo 17

A 120. Accesibilidad para personas con discapacidad

Artículos 2, 4

Del artículo 5 al artículo 9

Artículos 10, 15 y 16

A 130. Requisitos de Seguridad

Del artículo 3 al artículo 6, 8

Del artículo 10 al artículo 17 
Artículos 20, 22, 23, 25, 26, 27 y 40

\subsubsection{Plan de Desarrollo Urbano de la Ciudad de Chimbote 2012-2022}

Capítulo II.-Localización y marco regional

2.1 Ámbito Territorial

2.3 Rol y función urbano regional

Capítulo III.-Diagnóstico Urbano

3.1 Diagnóstico demográfico

3.2 Diagnóstico social

3.3 Diagnóstico económico-productivo

3.4 Diagnóstico físico-espacial

3.5 Diagnóstico físico-ambiental

3.6 Diagnóstico de la gestión urbana

3.7 Síntesis y caracterización del diagnóstico urbano

Capítulo IV.-Propuesta del Plan de Desarrollo Urbano

4.1 Visión

4.2 Modelo de desarrollo sostenible

4.3 Objetivos estratégicos

4.4 Propuestas específicas de desarrollo urbano

Capítulo V.-Propuesta específicas de Desarrollo Urbano

5.3 Propuesta vial

5.4 Propuesta de zonificación

5.5 Infraestructura de servicios básicos 
5.6 Propuesta de equipamiento urbano

Capítulo VII.-Sistema de Inversión Urbana

7.1 Listado de Proyectos Estratégicos de Inversión Identificados

7.2 Priorización de proyectos

7.3 Proyectos Estratégicos de Inversión Prioritarios

7.4 Fichas de proyectos priorizados

\subsubsection{Ley $\mathbf{N}^{\circ}$ 28611- Ley General del Ambiente}

\section{Título preliminar}

Artículo I.- Del derecho y deber fundamental

Toda persona tiene el derecho irrenunciable a vivir en un ambiente saludable, equilibrado y adecuado para el pleno desarrollo de la vida, y el deber de contribuir a una efectiva gestión ambiental y de proteger el ambiente, así como sus componentes, asegurando particularmente la salud de las personas en forma individual y colectiva, la conservación de la diversidad biológica, el aprovechamiento sostenible de los recursos naturales y el desarrollo sostenible del país. (Ley N²8611, 2005)

\section{Título I.- Política nacional del ambiente y gestión ambiental}

\section{Capítulo 3.- Gestión Ambiental}

Artículo 20.- De los objetivos de la planificación y el ordenamiento territorial

La planificación y el ordenamiento territorial tienen por finalidad complementar la planificación económica, social y ambiental con la dimensión territorial, racionalizar las intervenciones sobre el territorio y orientar su conservación y aprovechamiento sostenible. Tiene los siguientes objetivos:

a. Orientar la formulación, aprobación y aplicación de políticas nacionales, sectoriales, regionales y locales en materia de gestión ambiental y uso sostenible de los recursos naturales y la ocupación ordenada del territorio, en concordancia con las características 
y potencialidades de los ecosistemas, la conservación del ambiente, la preservación del patrimonio cultural y el bienestar de la población. (...) (Ley $\left.\mathrm{N}^{\circ} 28611,2005\right)$

Artículo 69.- De la relación entre cultura y ambiente

La relación entre los seres humanos y el ambiente en el cual viven constituye parte de la cultura de los pueblos. Las autoridades públicas alientan aquellas expresiones culturales que contribuyan a la conservación y protección del ambiente y desincentivan aquellas contrarias a tales fines. (Ley $\left.\mathrm{N}^{\circ} 28611,2005\right)$

\section{Título II.- De los sujetos de la gestión ambiental}

Capítulo 3.- Población y Ambiente

Artículo 69.- De la relación entre cultura y ambiente

La relación entre los seres humanos y el ambiente en el cual viven constituye parte de la cultura de los pueblos. Las autoridades públicas alientan aquellas expresiones culturales que contribuyan a la conservación y protección del ambiente y desincentivan aquellas contrarias a tales fines. (Ley $\left.\mathrm{N}^{\circ} 28611,2005\right)$

\subsubsection{Proyecto de Ley de gestión sostenible e integrada de las zonas marino costeras del Perú y estable el marco para su protección, recuperación, mantenimiento y aprovechamiento sostenible}

Artículo 3. Principios rectores de la gestión sostenible e integrada de las zonas marino costeras Son principios rectores para la gestión sostenible e integrada de zonas marino costeras:

3.2 Enfoque ecosistémico para el desarrollo sostenible. La gestión integrada de la tierra, el agua y los recursos vivos, promueve la conservación y el uso sostenible de una forma equitativa y permite armonizar las dimensiones económica, social y ambiental para satisfacer las necesidades actuales y futuras de los seres vivos como base para el desarrollo sostenible.

3.3 Sostenibilidad. Las dimensiones económica, social y ambiental deben armonizar con la satisfacción de las necesidades actuales y futuras de la persona. (Proyecto de Ley 678/2016CR, 2016) 


\subsubsection{Lineamiento de Políticas Integradas Marino Costeras}

Lineamiento estratégico 7

Promover la participación social en el manejo integrado de las zonas marino costeras. Acciones priorizadas:

e) Revalorar y respetar los aspectos culturales y turísticos vinculados con las zonas marino costeras, con el fin de generar ingresos económicos a través del turismo. (Resolución Ministerial Nº189-2015-MINAM, 2015)

\subsection{Estándares normativos Internacionales}

\subsubsection{Agenda 2030 para el Desarrollo Sostenible}

"La Agenda 2030 es una agenda transformadora, que pone la igualdad y dignidad de las personas en el centro y llama a cambiar nuestro estilo de desarrollo, respetando el medio ambiente. Es un compromiso universal adquirido tanto por países desarrollados como en desarrollo, en el marco de una alianza mundial reforzada, que toma en cuenta los medios de implementación para realizar el cambio y la prevención de desastres por eventos naturales extremos, así como la mitigación y adaptación al cambio climático. Incluye 17 Objetivos y 169 metas, presenta una visión ambiciosa del desarrollo sostenible e integra sus dimensiones económica, social y ambiental”. (CEPAL, 2016, p. 7)

\subsubsection{Objetivo de Desarrollo Sostenible 11: Ciudades y comunidades sostenibles}

"Las ciudades son hervideros de ideas, comercio, cultura, ciencia, productividad, desarrollo social y mucho más. En el mejor de los casos, las ciudades han permitido a las personas progresar social y económicamente. Ahora bien, son muchos los problemas que existen para mantener ciudades de manera que se sigan creando empleos y prosperidad sin ejercer presión sobre la tierra y los recursos. Los problemas comunes de las ciudades son la congestión, la falta de fondos para prestar servicios básicos, la escasez de vivienda adecuada y el deterioro de la infraestructura". (CEPAL, 2016, pp. 29-30)

Metas del Objetivo 11: 
11.4 Redoblar los esfuerzos para proteger y salvaguardar el patrimonio cultural y natural del mundo.

11.7 De aquí a 2030, proporcionar acceso universal a zonas verdes y espacios públicos seguros, inclusivos y accesibles, en particular para las mujeres y los niños, las personas de edad y las personas con discapacidad.

\subsubsection{Guía de consulta: introducción a la gestión e infraestructura de un Centro Cultural Comunal}

IV. Misión de un Centro Cultural

1. Centro Cultural como casa común

Un centro cultural tiene la misión de actuar como:

- Espacio democrático para la participación política y civil.

- Plataforma para la formación, creación y difusión del quehacer artístico-cultural.

- Vehículo de referencia identitaria de una comunidad.

- Soporte para la articulación urbanística.

- Elemento para la integración social y la vertebración de la comunidad.

En resumen, un centro cultural debe servir de casa común, ya sea como contenedor pasivo de colectivos y entidades, o bien como contenedor activo de iniciativas y proyectos artísticoculturales, contribuyendo de manera significativa a la construcción del tejido social y al fortalecimiento de la sociedad civil.

2. Cualidades de un Centro Cultural

Singularidad.- Un centro cultural debe ser único y distinguirse de los demás, ya sea por sus características arquitectónicas, su programación y/o su modelo de gestión.

Conectividad.- Un centro cultural debe estar en constante conexión con el resto de los espacios culturales existentes en el territorio más próximo.

Adaptabilidad.- Un centro cultural debe adaptarse a las transformaciones y entregarse al cambio sin abandonar su misión. (Consejo Nacional de la Cultura y las Artes, 2011, pp. 18-19) 


\subsection{Instituciones Afines}

\subsubsection{Municipalidad Provincial del Santa (MPS)}

Institución encargada de velar por el cumplimento del PAT Santa y PDU de la ciudad de Chimbote 2012-2022. Así como de la efectividad de la O.M Nº 001-2009-MPS.

\subsubsection{Ministerio del Ambiente}

Institución encargada de velar por el cumplimiento de la Ley del Medio Ambiente 2012 y El Plan de Recuperación Ambiental de la bahía El Ferrol.

\subsubsection{Ministerio de Cultura}

Institución encargada de fomentar, preservar y difundir la cultura.

\subsection{Conclusiones Parciales}

De acuerdo a lo investigado en a las normas con respecto al Centro Cultural, el país no cuenta con normas que estén directamente relacionadas al diseño de estos. Es por este motivo que se ha recurrido a tomar en cuenta las normativas establecidas en el Reglamento Nacional de edificaciones con respecto a los servicios comunales, las normas de diseño, las normas de comercio, de discapacitados y de seguridad y evacuación.

Sin embargo, se hace necesario el empleo de normativa que se encuentre relacionado con el ámbito cultural, de modo que se ha recurrido a tomar en cuenta la Guía de diseño establecida por Chile para la creación de Centros Culturales, donde se establecen normas, pautas y lineamientos que todo centro cultural debe seguir si desea ser insertado en la sociedad.

Es sumamente lamentable que Perú no cuenta con una normativa específica para este ámbito pues tan importante como la creación de centros educativos o deportivos, ya que en los últimos años se ha incrementado la aparición de centros cultural o comunitarios, los cuales albergan a distintos tipos de personas que realizan diversas actividades, y para las cuales se debería saber qué tipo de espacio es el más adecuado para su buen funcionamiento. 


\section{CAPÍTULO V: MARCO OPERATIVO}

\subsection{Referentes Análogos}

\subsubsection{Kanal Centre Pompidou}

\subsubsection{Datos Generales}

Se encuentra ubicada en Bruselas - Bélgica, en una antigua fábrica de garaje de Citroën. El desarrollo del proyecto nació como parte del concurso para la conversión de la antigua fábrica por un nuevo centro cultural en el 2017, convirtiéndolo así en el centro de arte más grande de Europa. Kanal Centre Pompidou reúne espacios públicos dedicados a la cultura, la educación y el ocio (G de Juan, 2018, parr. 1).

Diseñado y proyectado por los arquitectos noAarchitecten, EM2N y Sergison Bates Architects.

KANNAL CENTRE POMPIDOU
ARQUITECTOS
NOAARCHITECTEN / EM2N /
SERGISON BALES
AÑO
2017 - 2022
UBICACIÓN
BRUSELAS, BÉLGICA

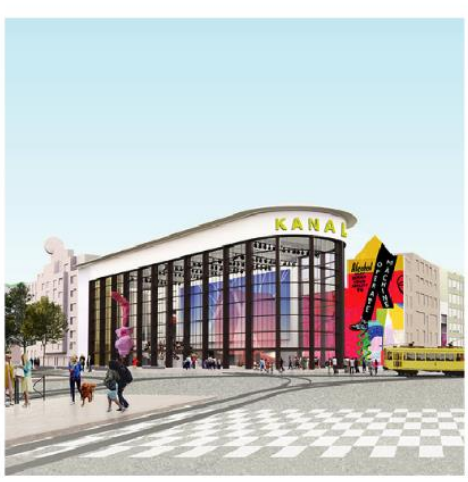

http://oma.eu/projects/kanal

\subsubsection{Historia}

La antigua fábrica Citroën de propiedad de André Citroën, fue adquirida por el mismo en 1930 en Bruselas para desarrollar, ensamblar y comercializar automóviles. Sin embargo, ya para el 2015 la fábrica se encontraba en desuso, por lo que la Corporación de desarrollo urbano de Bruselas decidió comprarla. En el 2017, la fábrica pasó a manos del Gobierno Regional de Bruselas, quien en el siguiente año decidió lanzar a concurso el desarrollo del proyecto de reconversión de la fábrica. 


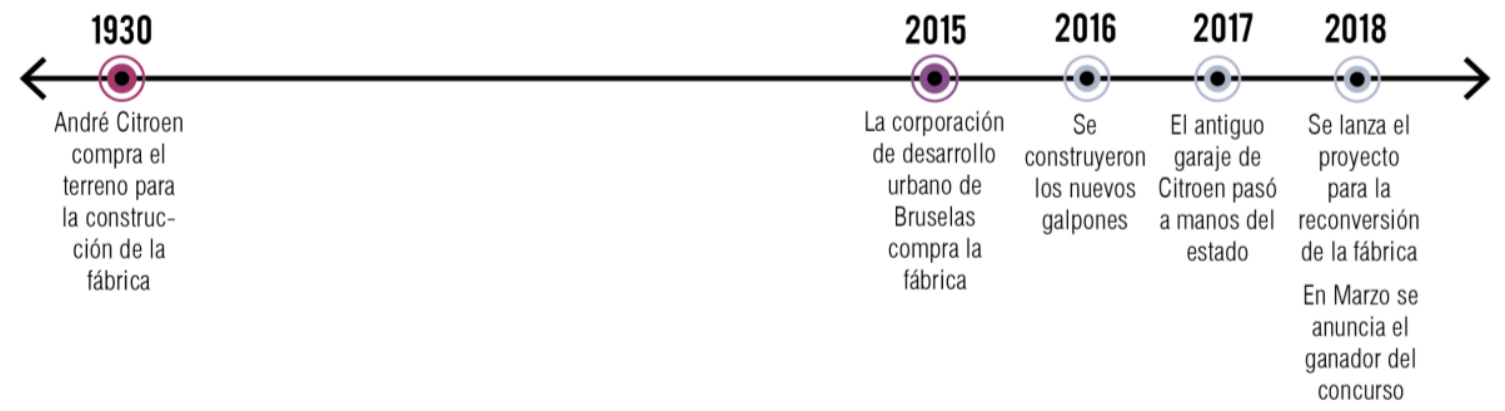

\subsubsection{Ubicación}

La fábrica se encuentra Bélgica, en el centro de la ciudad de Bruselas. Emplazada frente al Canal de Bruselas en el barrio de Molenbeek.

Plano de localización y ubicación
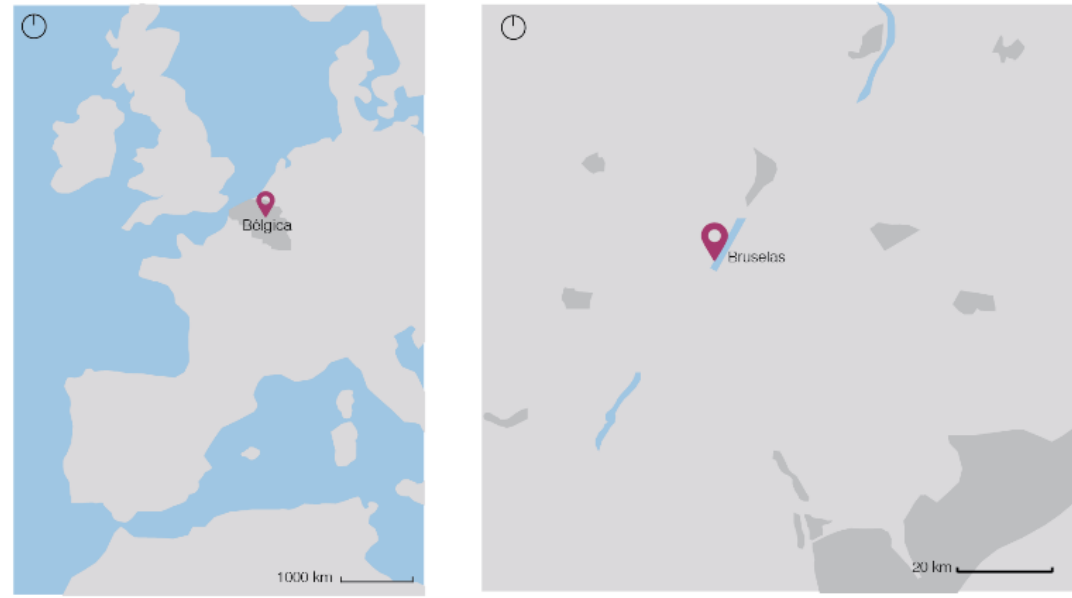

Relación con el entorno

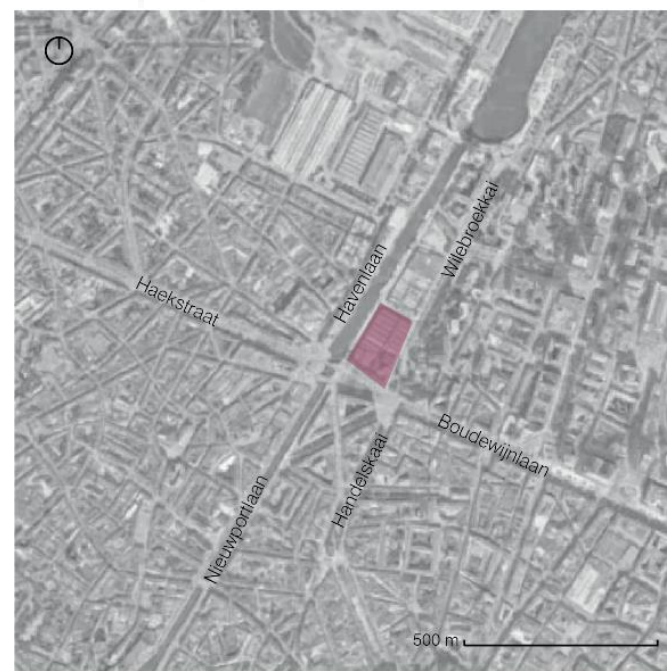




\subsubsection{Toma de partido}

La propuesta realizada por el equipo de arquitectos, fue felicitada y destacada por el jurado "por la capacidad del edificio tanto para integrarse con su entorno como para aprovechar y revitalizar las cualidades arquitectónicas de la construcción original” (RBA Revistas S.L., s.f., parr. 2).

La idea principal del proyecto es desvestir la estructura de la fábrica en desuso para seguidamente insertar tres volúmenes con los usos fundamentales de la institución. El primero será sede del museo; el segundo albergará a la Fundación CIVA, un centro de arquitectura de la ciudad de Bruselas; y, finalmente, el tercer volumen conformará una serie de espacios públicos (Revista de arte de México, s.f., parr. 2).

El edificio vidriado, ícono de la arquitectura industrial de los años 30, se vaciará para albergar una gran sala de exposiciones que acogerá instalaciones temporales y conciertos en la planta baja y un restaurante en el tercer nivel. La fachada tiene un friso superior perimetral, que llevará una pantalla digital con anuncios culturales.

En el interior, se abre una amplia y larga calle que dirige a tres grandes espacios de actividades. "Esta sectorización permite a los arquitectos un mejor control de las condiciones climáticas en los diferentes espacios, además libera las fachadas y las hace permeables a su entorno para que reflejen la dinámica vida cultural del museo hacia el exterior" (RBA Revistas S.L., s.f., parr. 5). Además de ello, los espacios de exposiciones están organizados en cuatro niveles, lo que permite que los espacios sean flexibles y se adapten a los requerimientos de arte. 
1. Mantener y resaltar los elementos icónicos de la arquitectura existente de la antigua fábrica Citroën, patrimonio industrial de Bruselas.

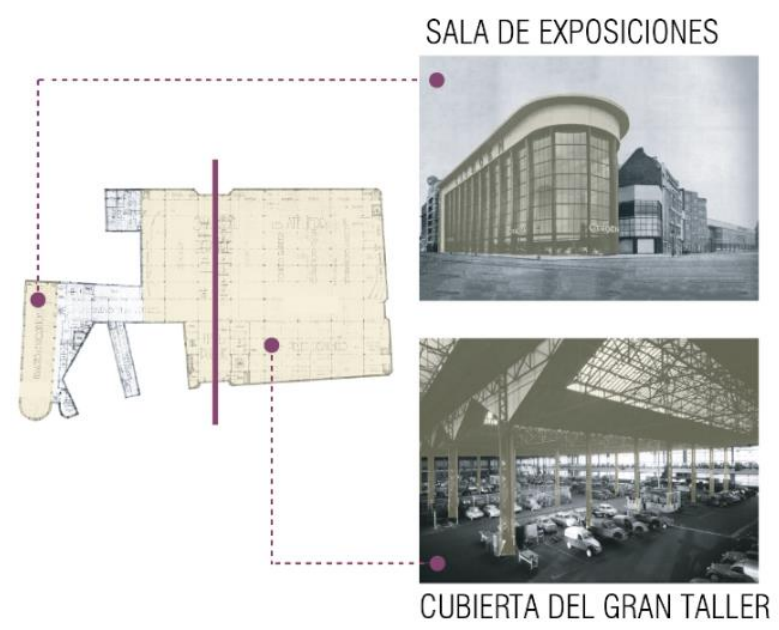

2. Generar volúmenes al interior para atraer al público del exterior. "Cajas dentro de la caja (gran taller)".
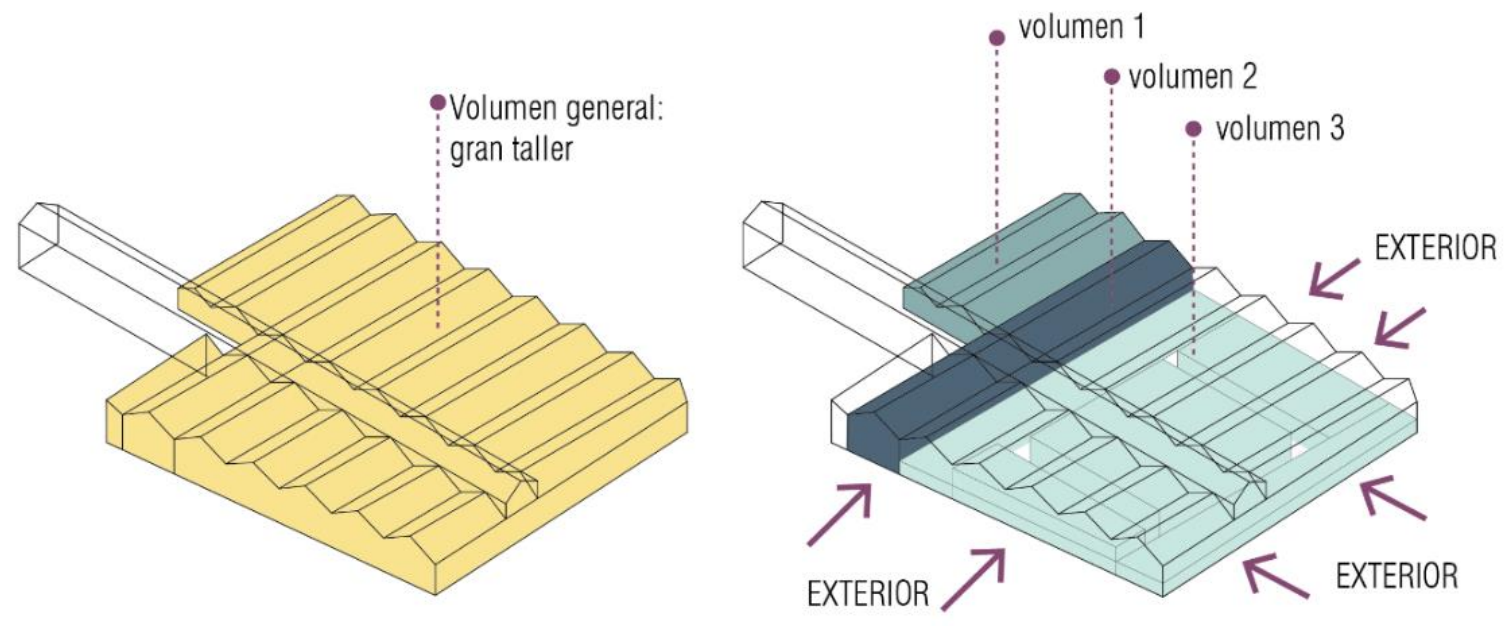

3. Abrir el edificio a la ciudad, para tener un espacio de intercambio, abierto a todos, de modo que se libere el interior. 

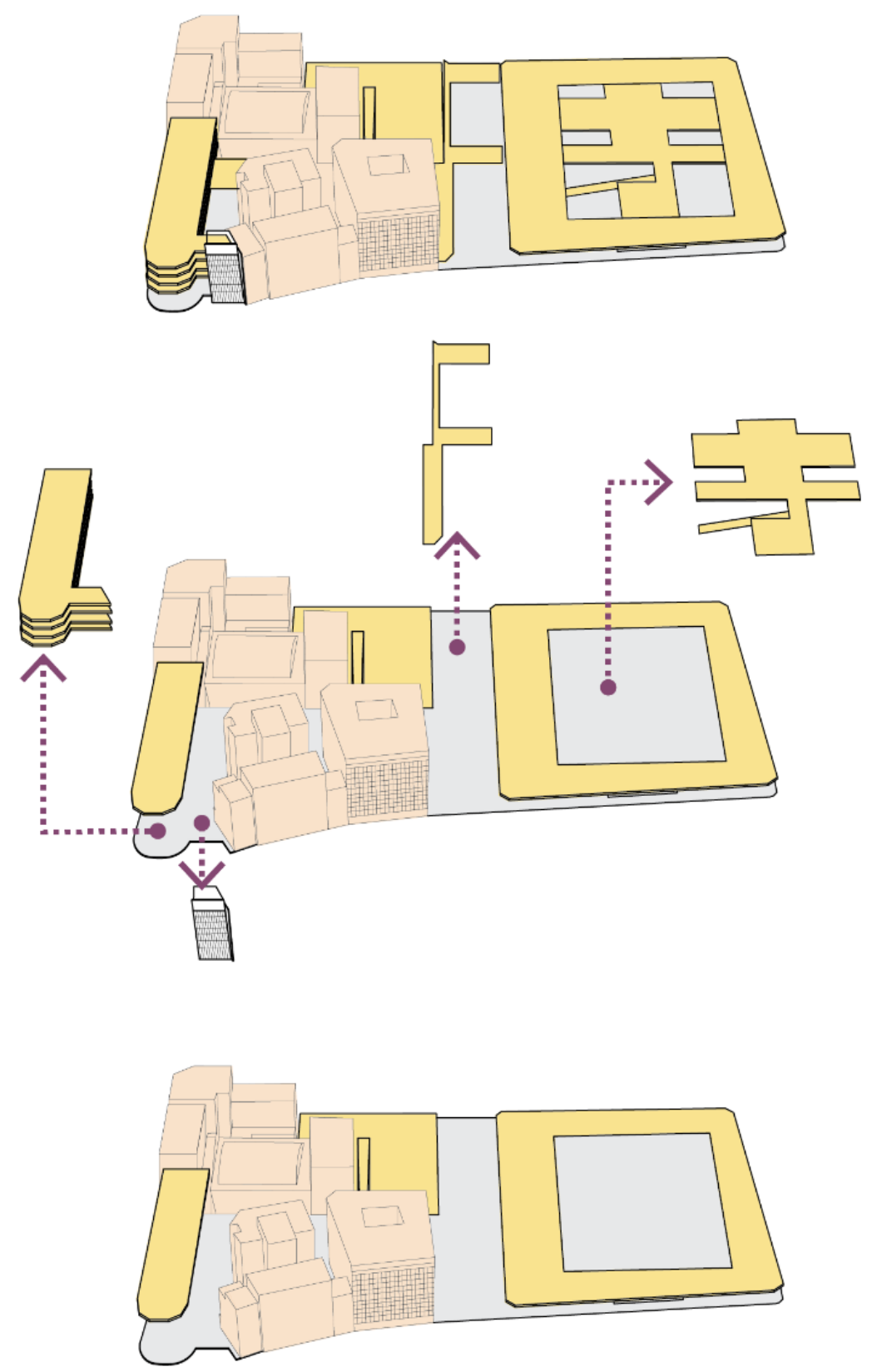

Bloques existentes de la fábrica

Entorno

Terreno 
4. Integrar con el contexto urbano, a través de aberturas y transparencia en las fachadas. Además de la inserción de actividades orientadas hacia los ejes circundantes: Canal y Parque Maximillen.

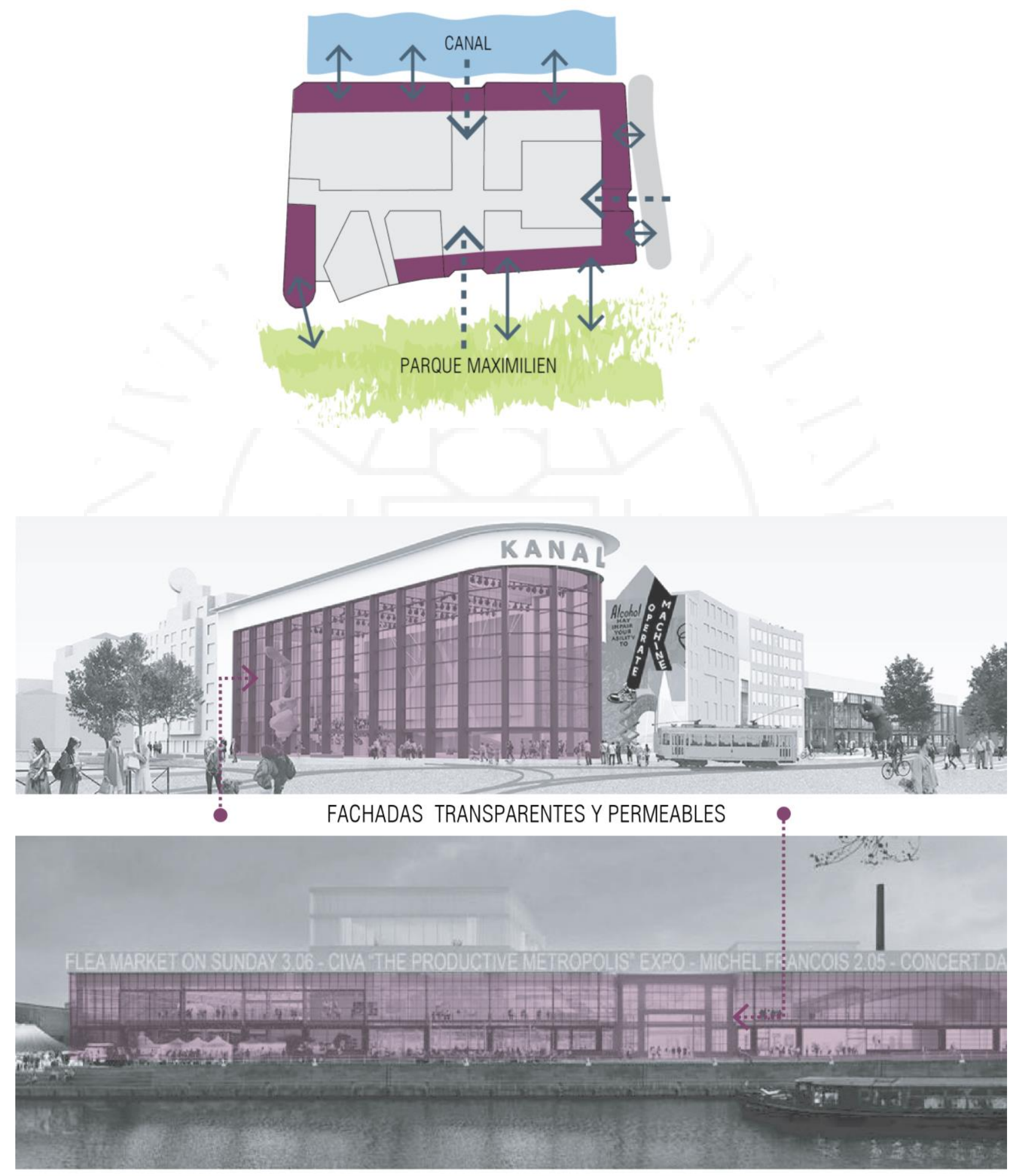




\subsubsection{Análisis vial}

Kanal Centre Pompidou se encuentra en una zona muy céntrica y de fácil llegada a ella debido a los paraderos de buses cercanos y a la estación de metro Yser.

\section{Vías}

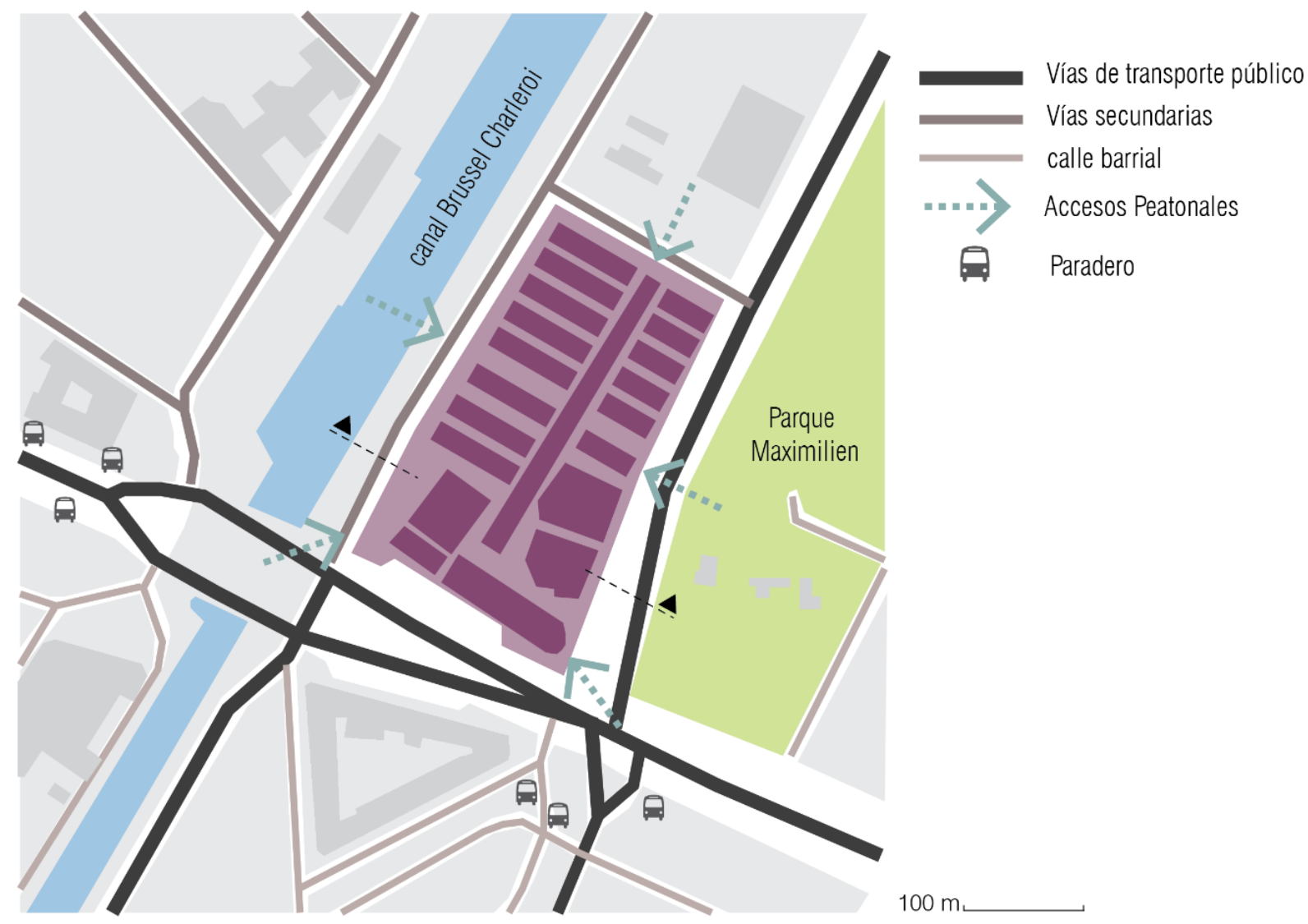

Sección vial

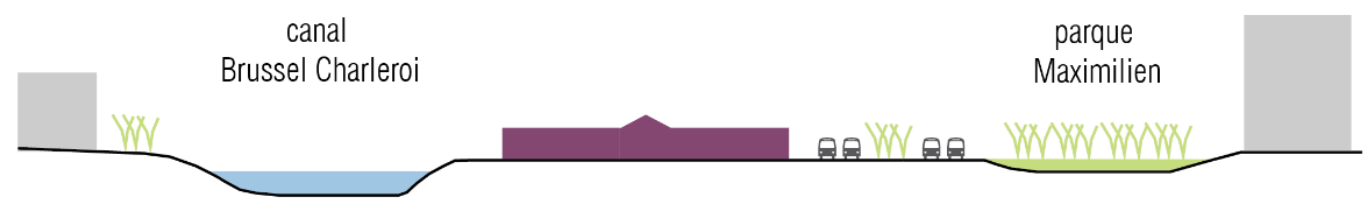




\subsubsection{Programa}

El proyecto cultural tiene está situado en un terreno de $39000 \mathrm{~m} 2$, con un área construida aproximada de $25000 \mathrm{~m} 2$, divididas en área cultural, área de ocio, de servicios y circulación.

El programa ha sido organizado y adaptado de acuerdo a los espacios con los que ya contaba la antigua fábrica, sobre todo aprovechando las grandes luces que permite contar con una gran flexibilidad espacial.

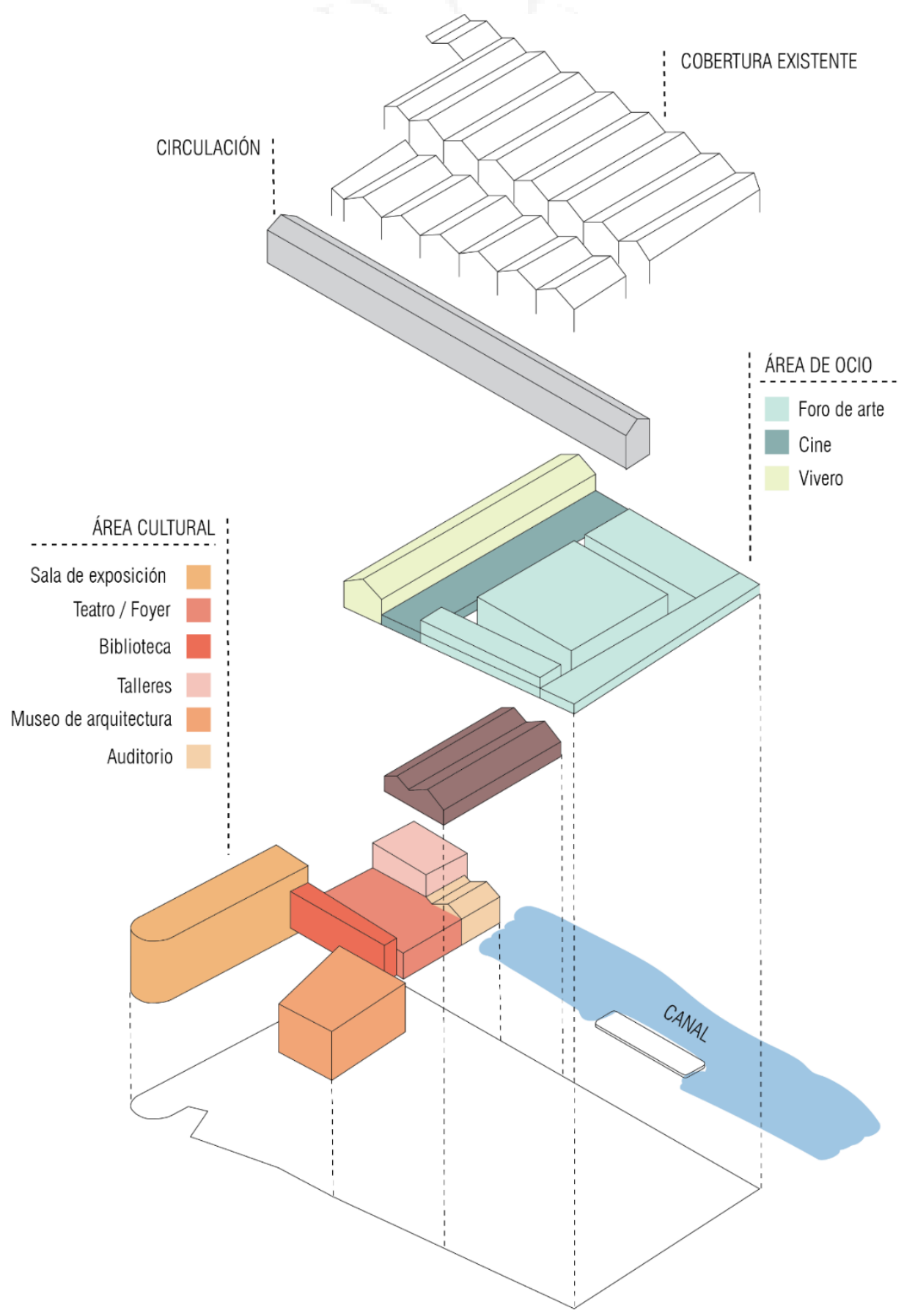




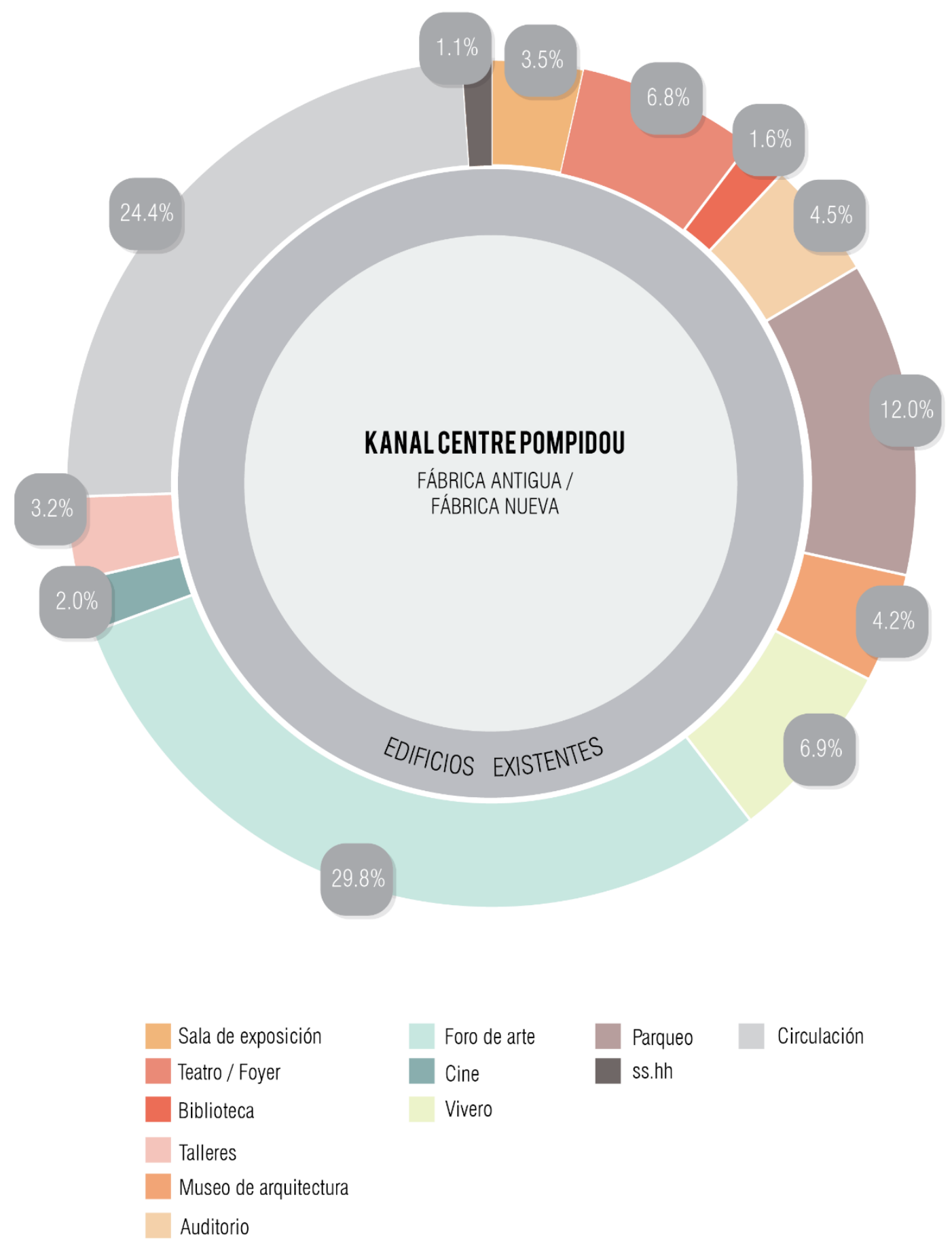




\subsubsection{Organigrama funcional}
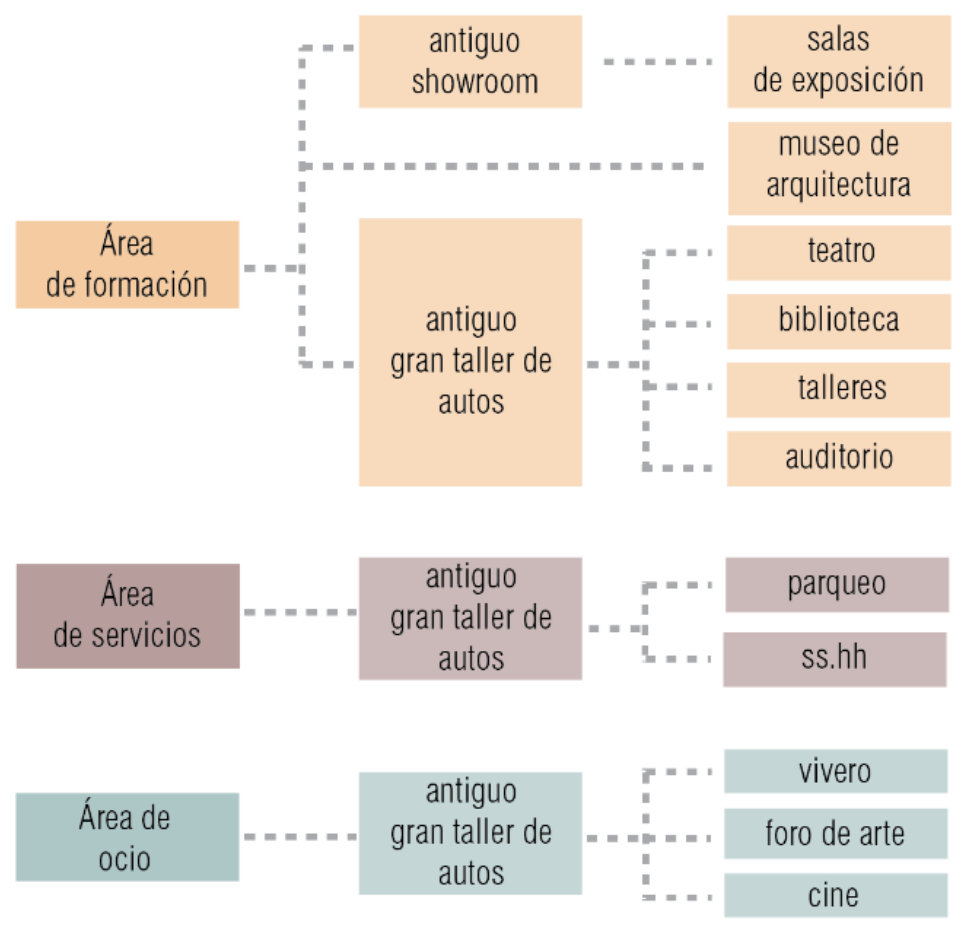

\subsubsection{Relaciones espaciales}

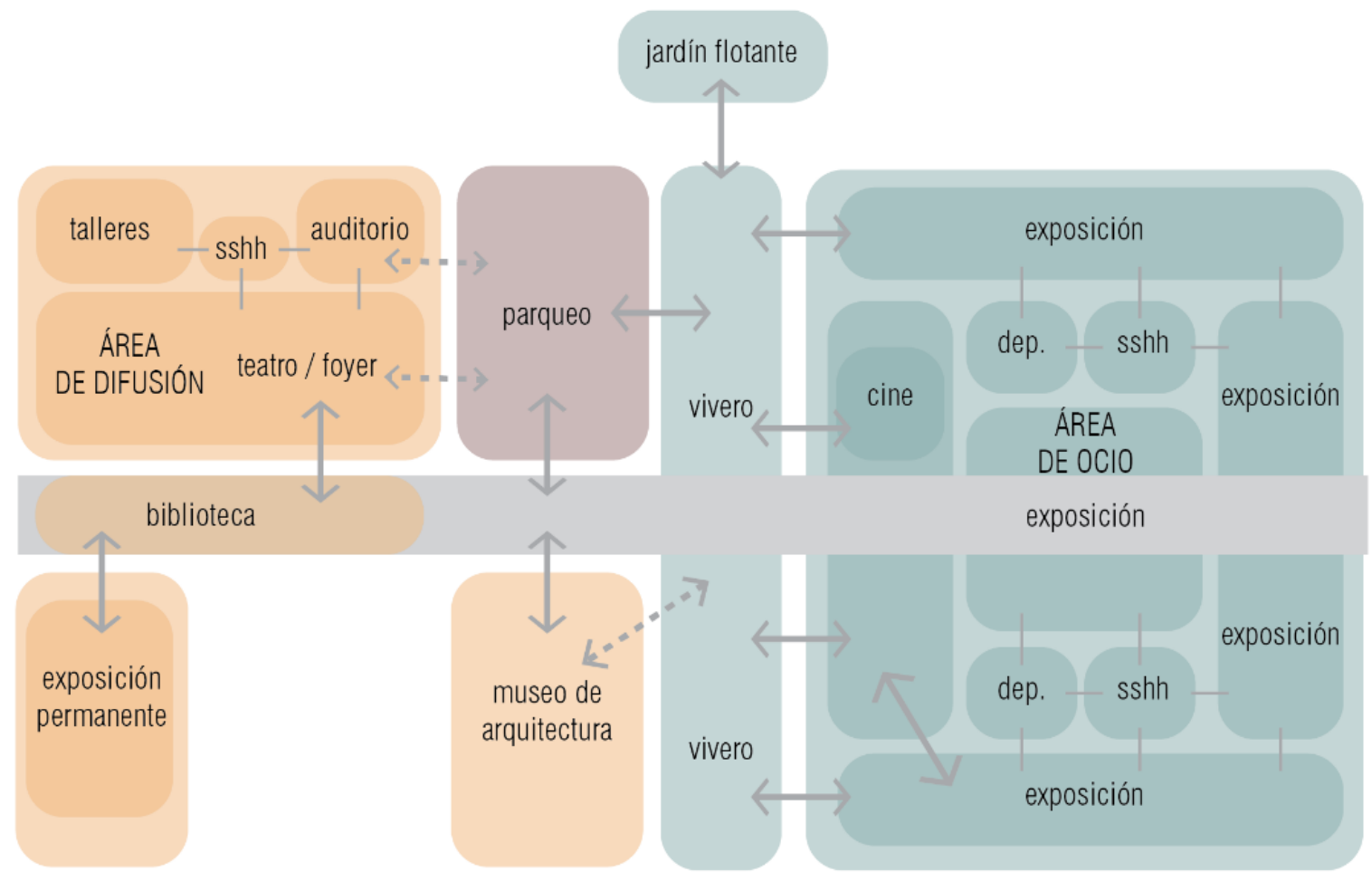




\subsubsection{Distribución espacial}

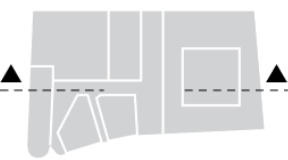

\section{FÁBRICA \\ ANTIGUA}
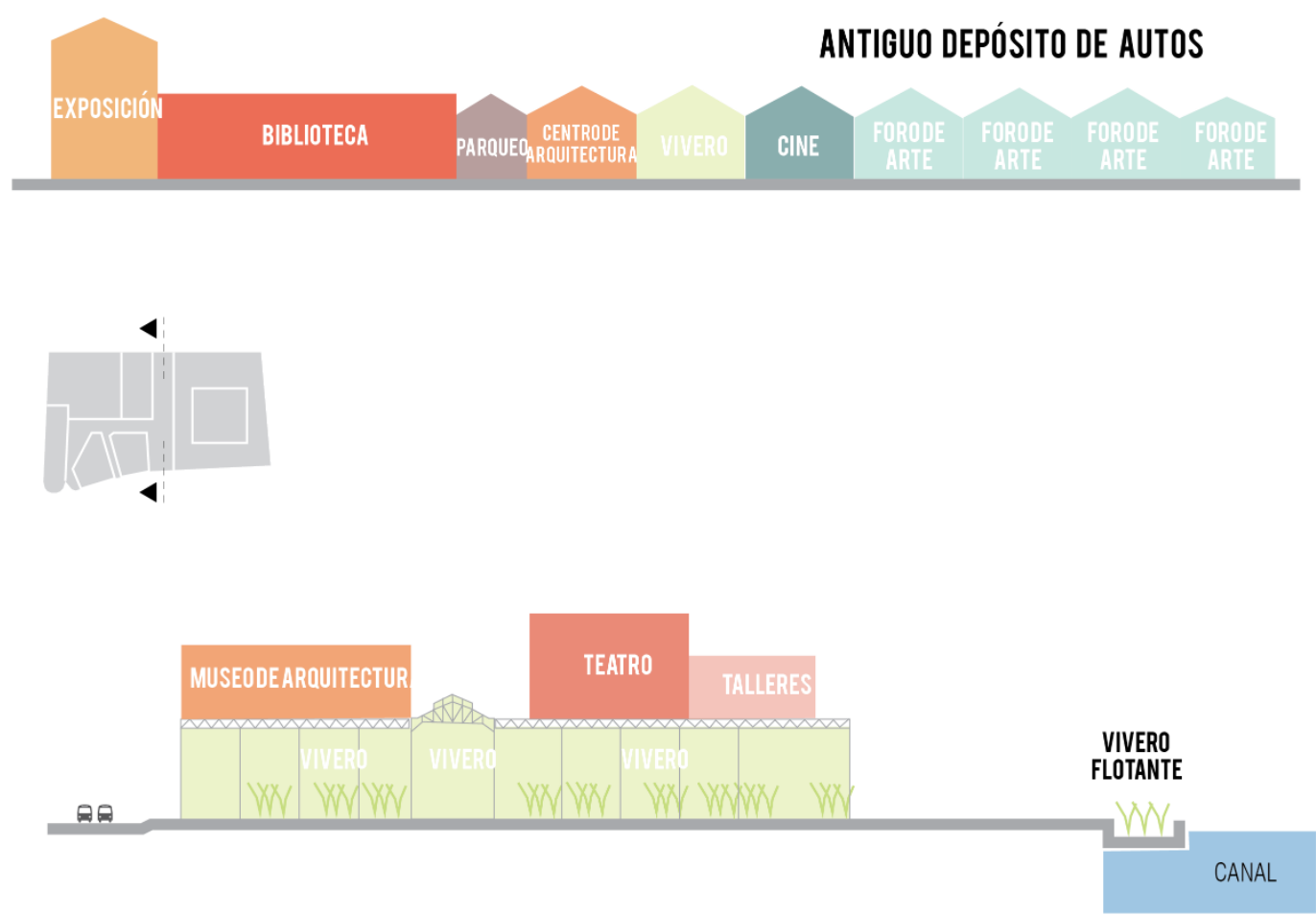

5.1.1.10 Cuadro de áreas

Terreno 3.9 ha

\begin{tabular}{|c|c|c|c|}
\hline ÁREA & ESPACIO & METRAJE & TOTAL \\
\hline \multirow{6}{*}{$\begin{array}{c}\text { ÁREA } \\
\text { CULTURAL }\end{array}$} & sala de exposición & 875 m2 & \multirow{6}{*}{$5951 \mathrm{~m} 2$} \\
\hline & teatro & 1704 m2 & \\
\hline & auditorio & $411 \mathrm{~m} 2$ & \\
\hline & biblioteca & 1130 m2 & \\
\hline & museo de arquitectura & $1040 \mathrm{~m} 2$ & \\
\hline & talleres & $791 \mathrm{~m} 2$ & \\
\hline \multirow{2}{*}{$\begin{array}{c}\text { ÁREA } \\
\text { DE SERVICIOS }\end{array}$} & parqueo & $3000 \mathrm{~m} 2$ & \multirow{2}{*}{$3275 \mathrm{~m} 2$} \\
\hline & sshh & $275 \mathrm{~m} 2$ & \\
\hline \multirow{3}{*}{$\begin{array}{c}\text { ÁREA DE } \\
\text { OCIO }\end{array}$} & vivero & $1740 \mathrm{~m} 2$ & \multirow{3}{*}{$9684 \mathrm{~m} 2$} \\
\hline & foro de arte & $7440 \mathrm{~m} 2$ & \\
\hline & cine & $504 \mathrm{~m} 2$ & \\
\hline \multirow[t]{2}{*}{ CIRCULACIÓN } & circulación & $6100 \mathrm{~m} 2$ & $6100 \mathrm{~m} 2$ \\
\hline & & & $25010 \mathrm{~m} 2$ \\
\hline
\end{tabular}


5.1.1.11 Tipología espacial

1. Una calle interior une dos bloques existentes.

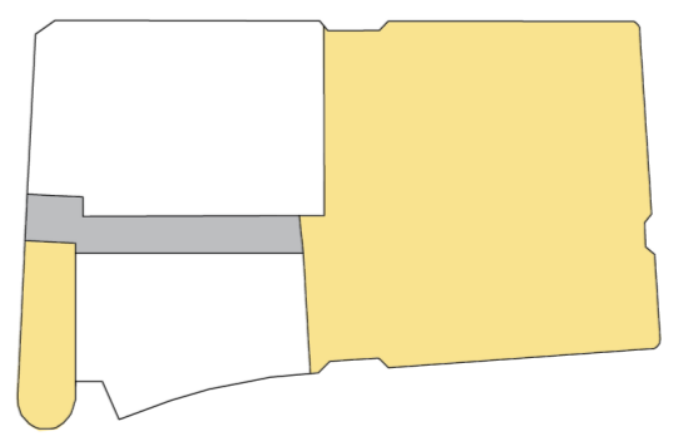

2. Se estableció dos ejes transversales entre sí que conecten el interior con el exterior.

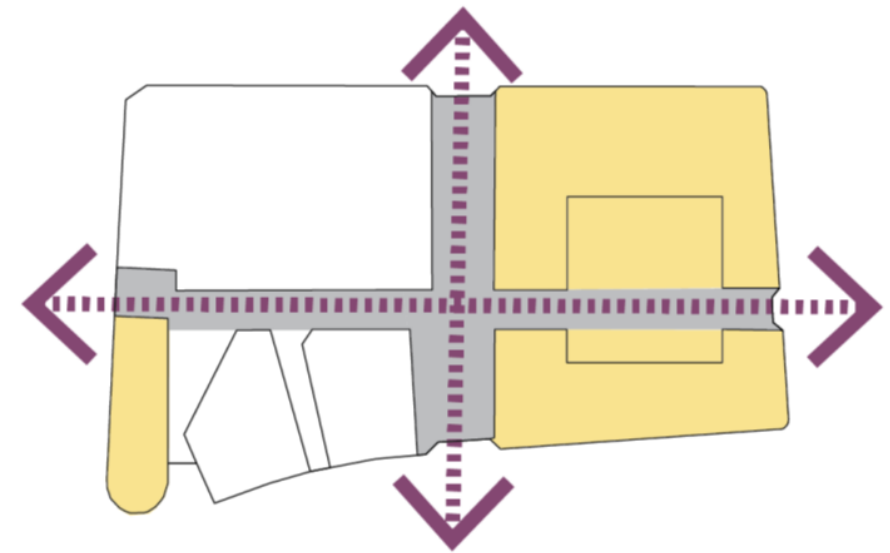

3. El programa se ha colocado alrededor de los dos ejes.

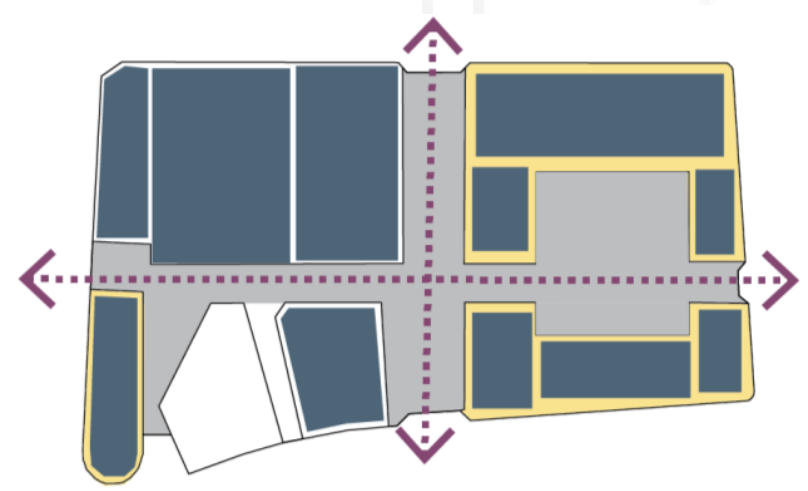

bloques existentes

nuevos espacios

circulación

$\langle\cdots$ eje interior 


\subsubsection{Relación público - privado}

PLANTA PRIMER NIVEL
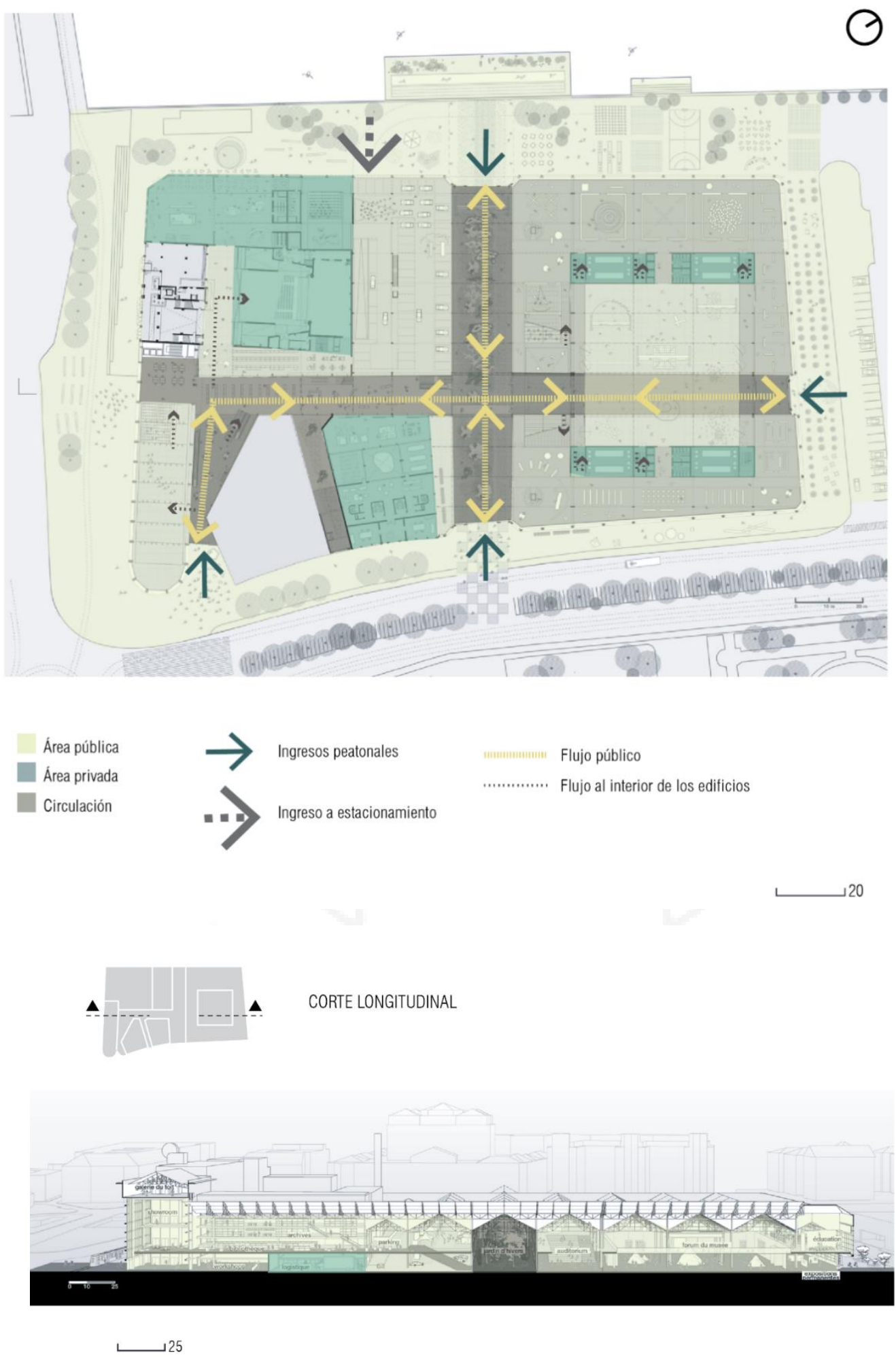
Área pública
Área privada
Circulación 


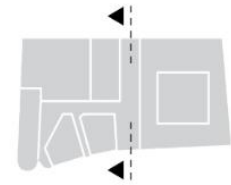

CORTE TRANSVERSAL
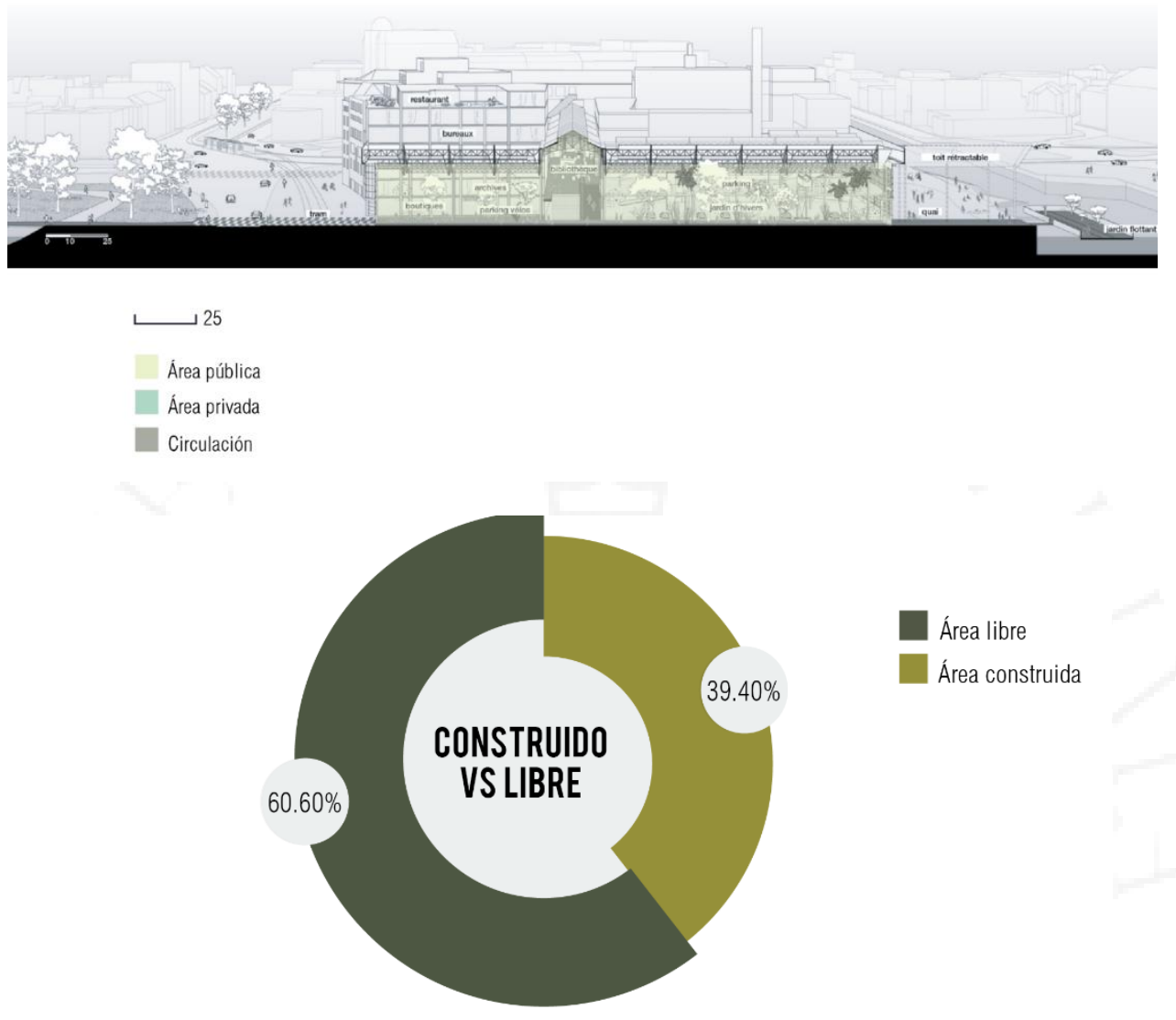

Área pública

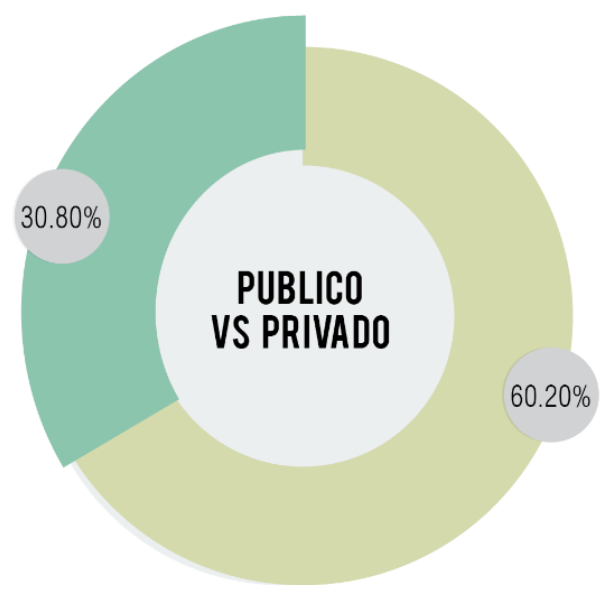




\subsubsection{Tecnología estructural}

Kanal Centre Pompidou ha mantenido la materialidad metálica icónica del edificio Citroën y la ha potenciado a través del perfecto ensamblaje entre forma y función.

La estructura tiene columnas y vigas de estructura metálica que soportan tijerales del mismo material. Sobre la estructura principal, le han adosado cerramientos interiores para delimitar los espacios.
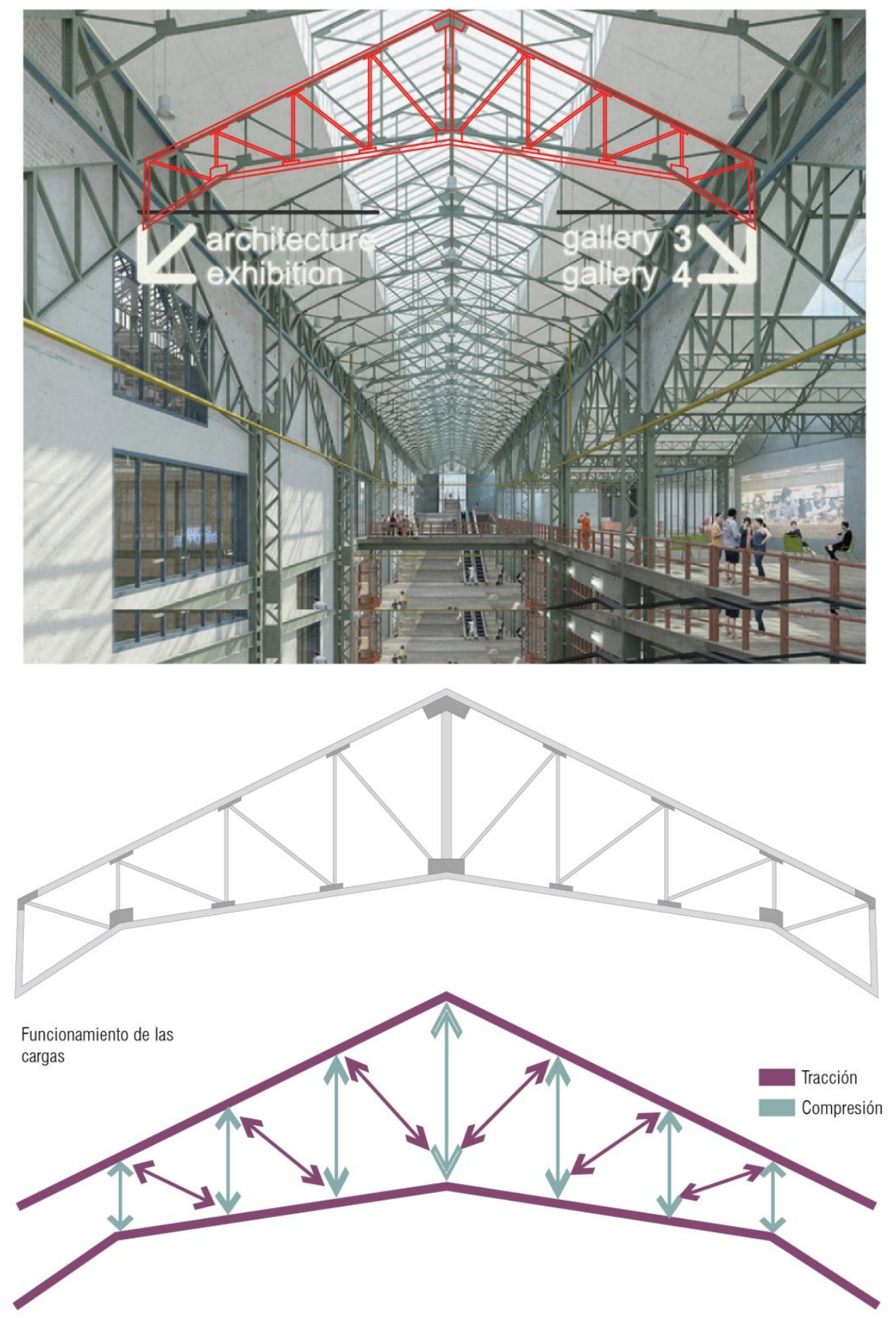

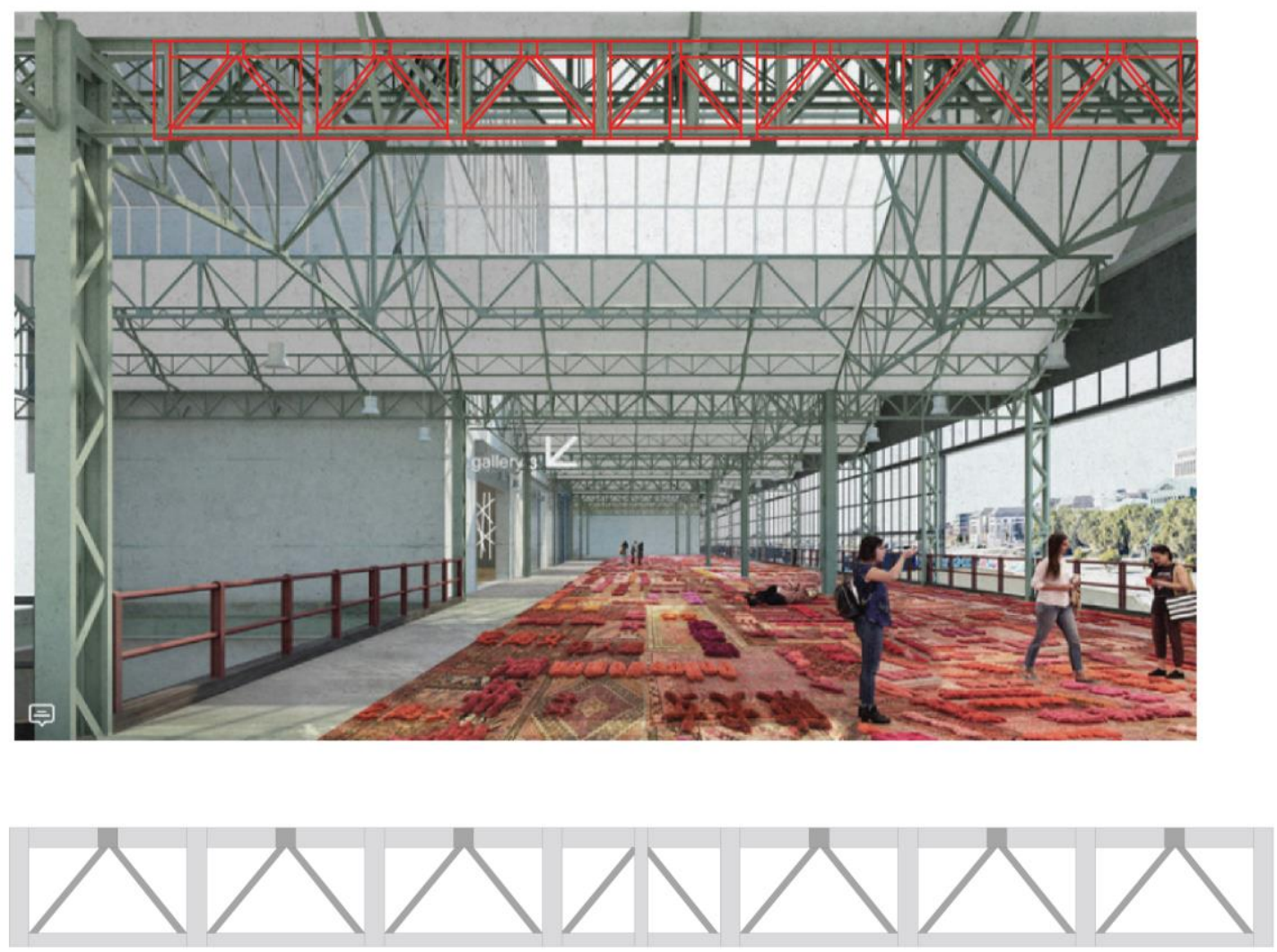

Funcionamiento de las cargas

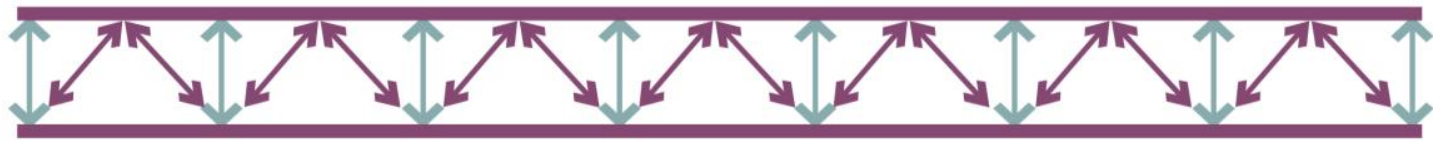

Tracción

Compresión

\subsubsection{Impacto social}

El proyecto se convertirá en un gran referente y punto de atracción cultural tanto para los habitantes y visitantes de Bruselas como para toda Europa, por la oferta cultural que alberga en su interior. 


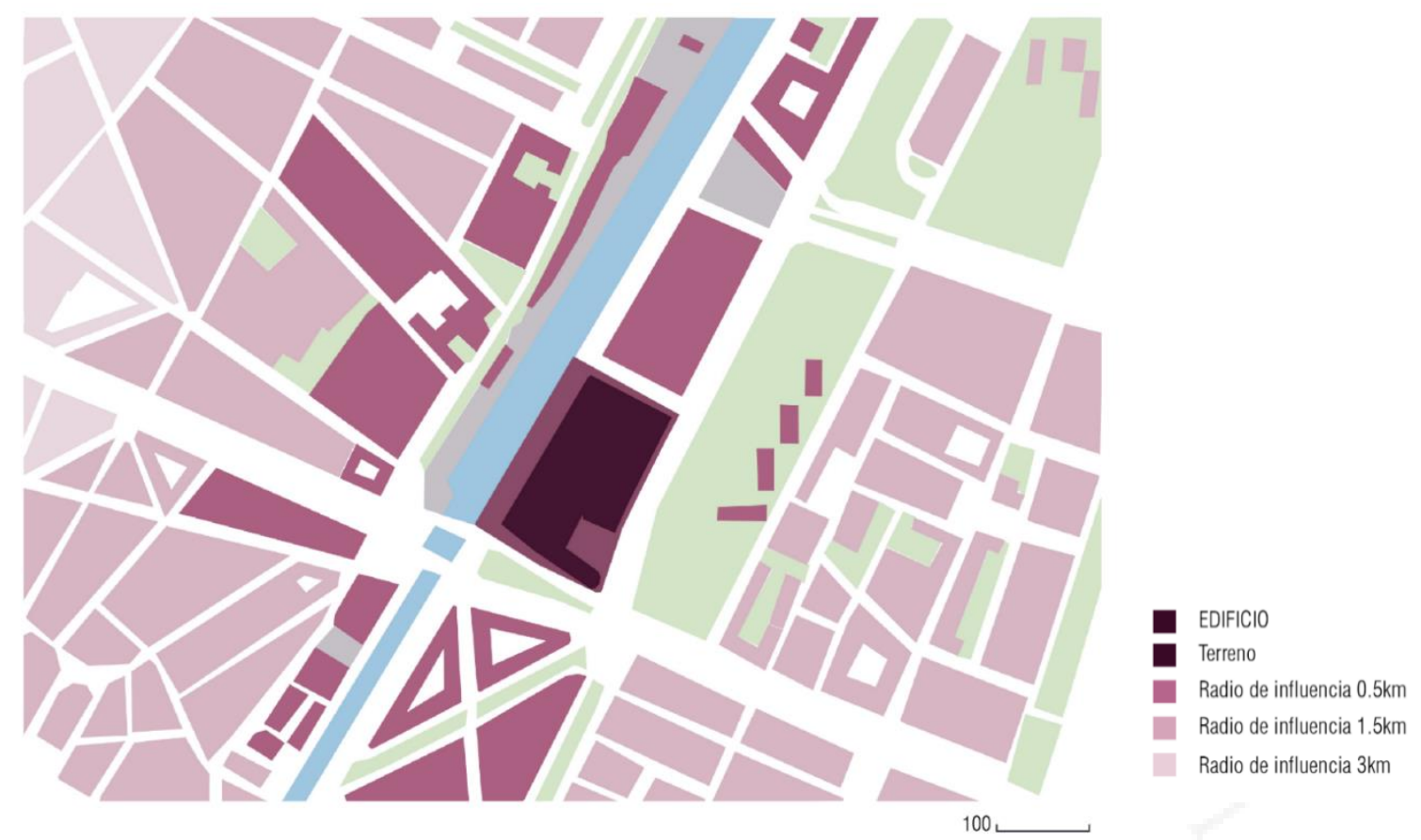

5.1.1.15 Galería de fotos

Ilustración 5.1 Vista exterior de la fachada icónica de Kanal Centre Pompidou

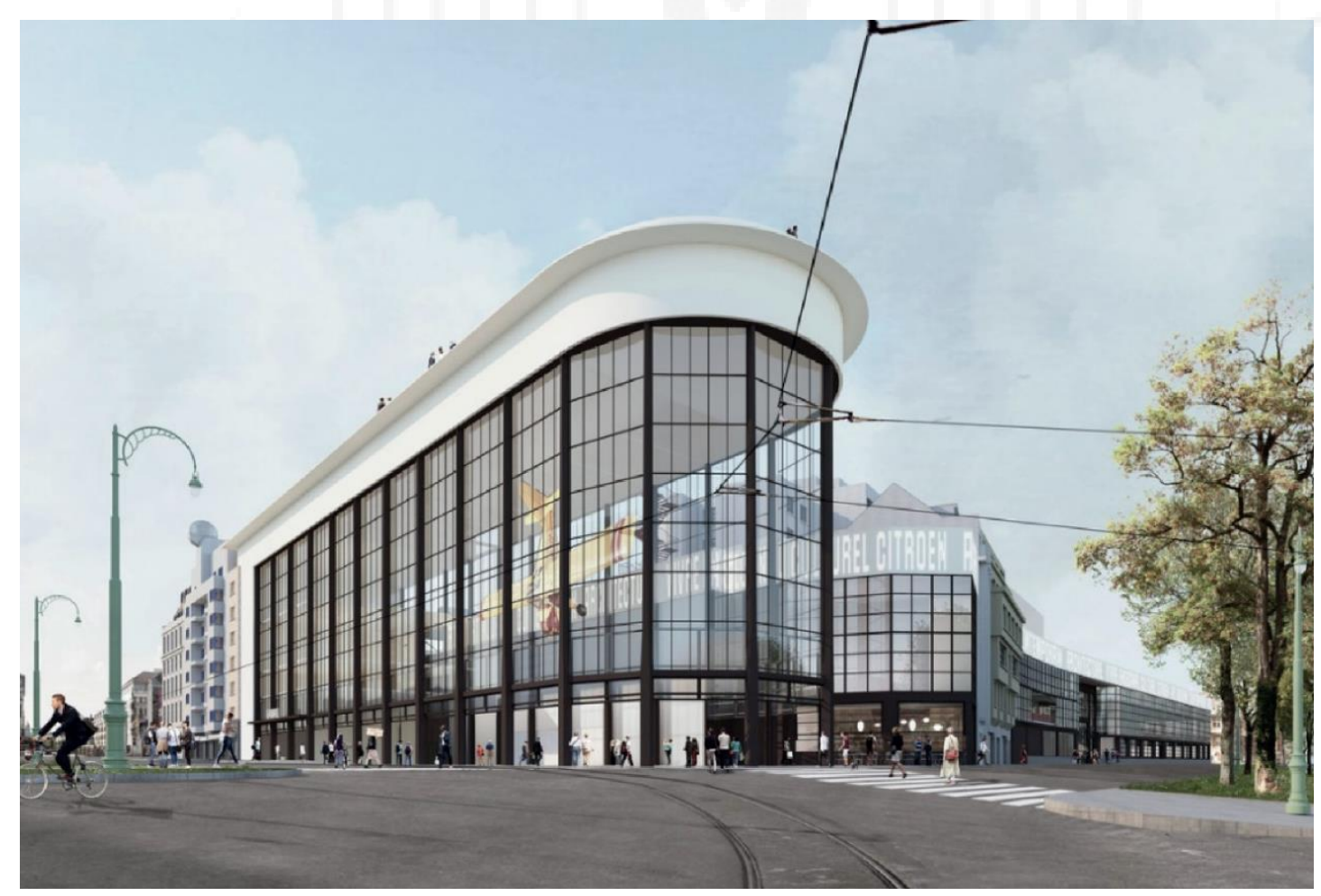

Fuente: Recuperado de www.archdaily.com 
Ilustración 5.2 Vista de la relación de Kanal Centre Pompidou con el canal de Bruselas.

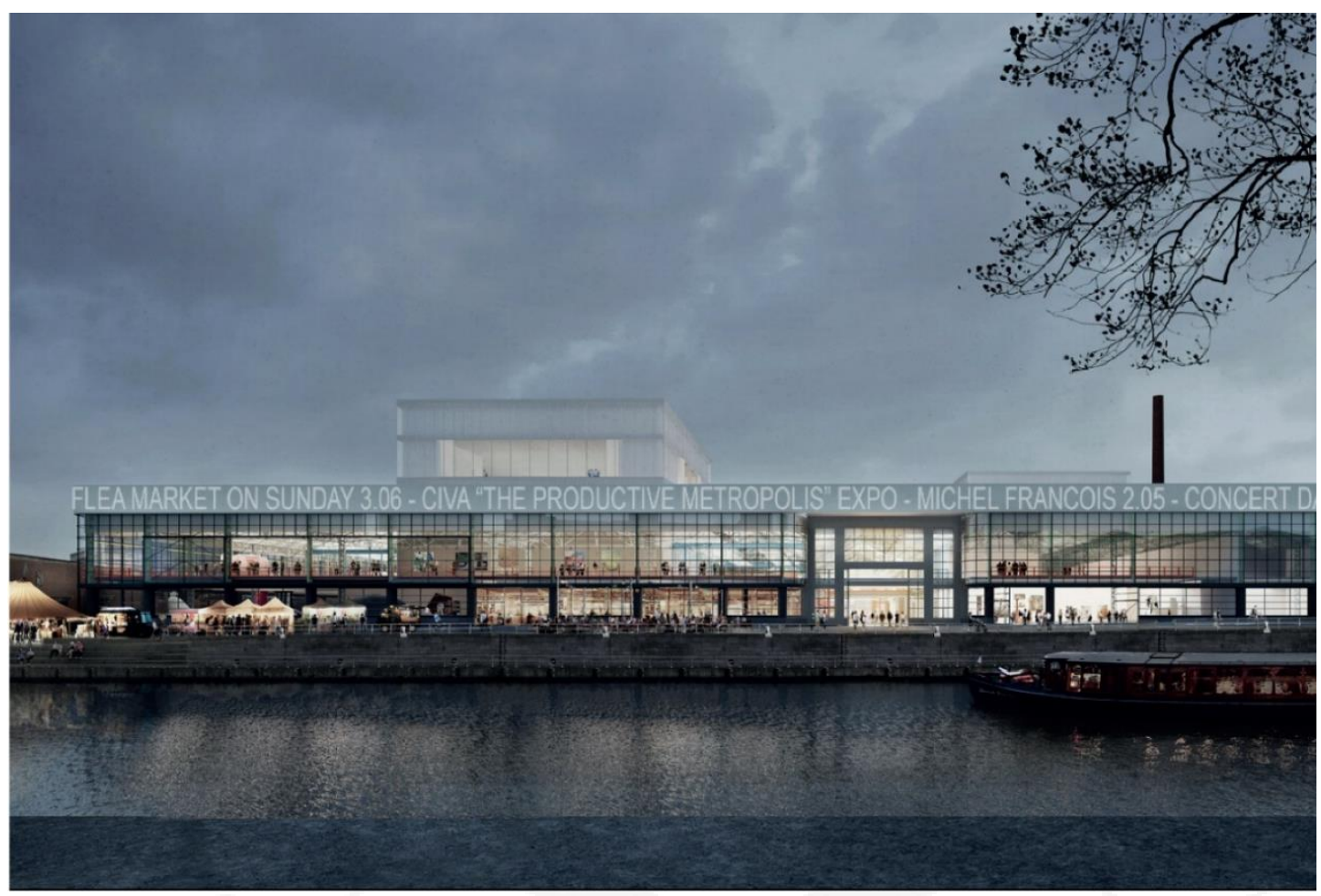

Fuente: Recuperado de www.archdaily.com

Ilustración 5.3 Interior del gran galón que contiene cajas de actividades en su interior.

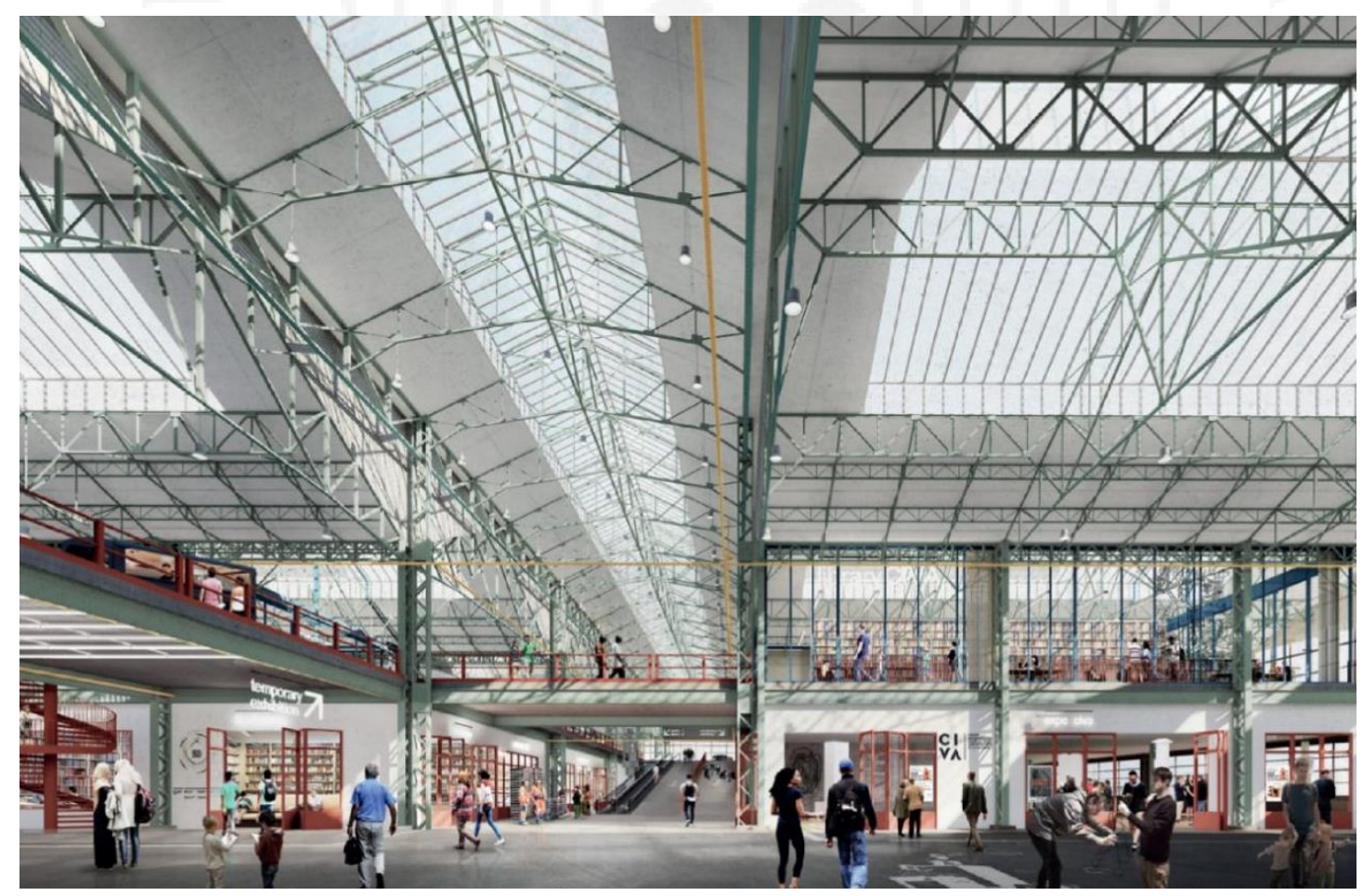

Fuente: Recuperado de www.archdaily.com 
Ilustración 5.4 Nave central de circulación, sobre la que se desarrollan actividades.

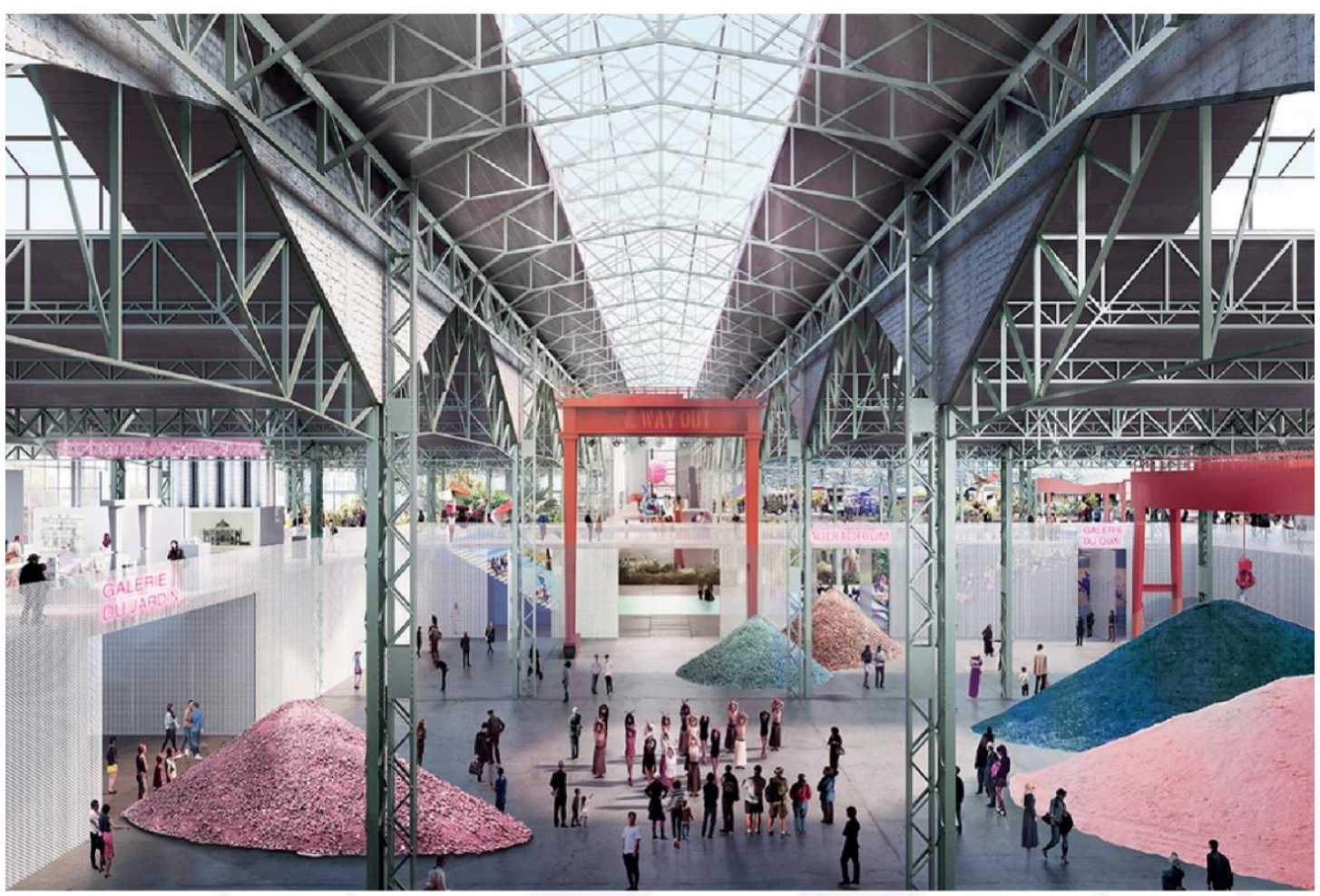

Fuente: Recuperado de www.archdaily.com

Ilustración 5.5 Exposición de arte en el centro cultural Kanal.

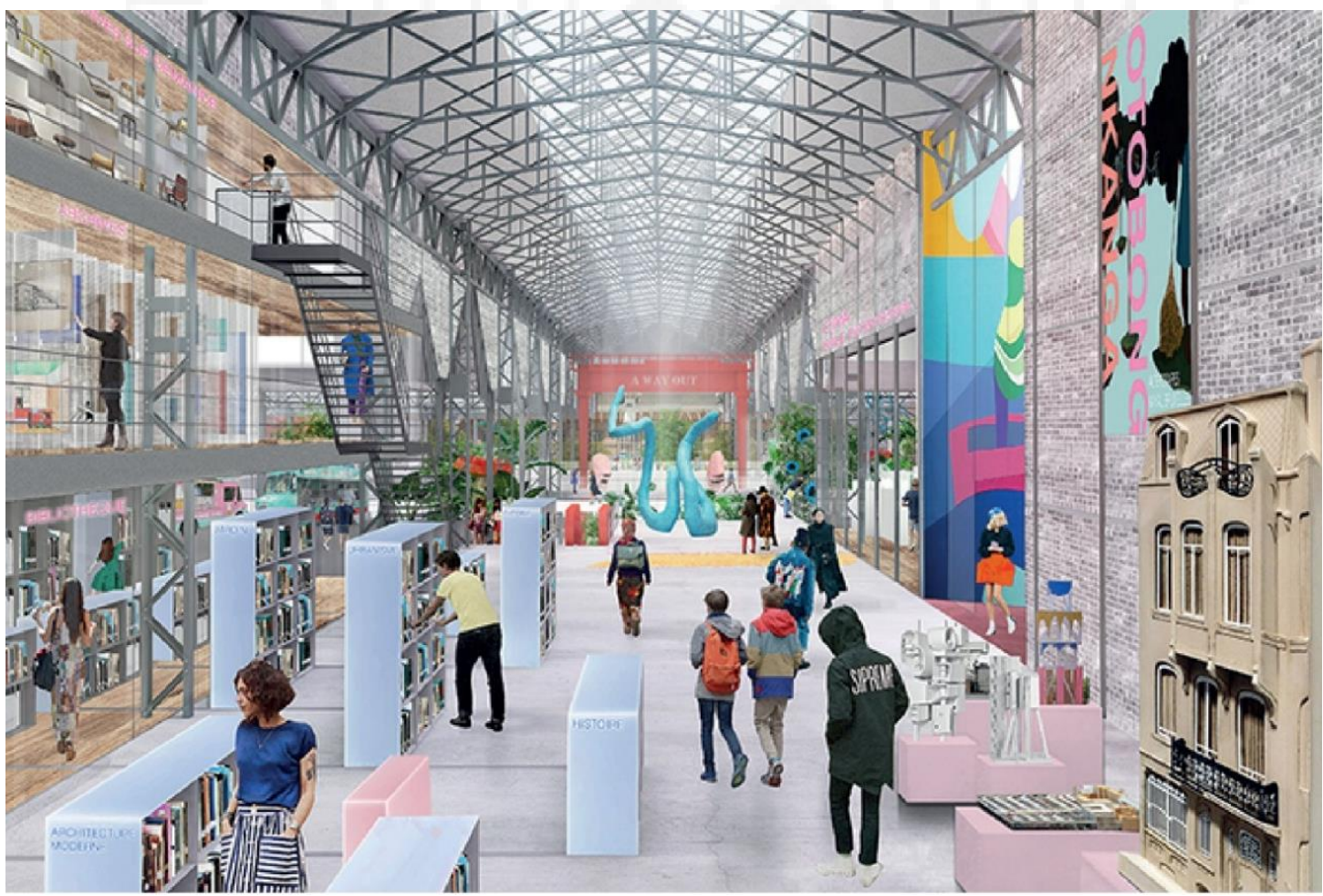

Fuente: Recuperado de www.archdaily.com 


\subsubsection{SESC Pompeia}

\subsubsection{Datos Generales}

Sesc Pompeia es un centro cultural ubicado en una antigua fábrica de tambores en el barrio de Pompeia en Sao Paulo, Brasil. El proyecto estuvo a cargo de la arquitecta italo brasileña Lina Bo Bardi, quien fue convocada para diseñar una sede del Servicio Social de Comercio (SESC) en 1976 y en 1982 se inaugura el centro cultural.

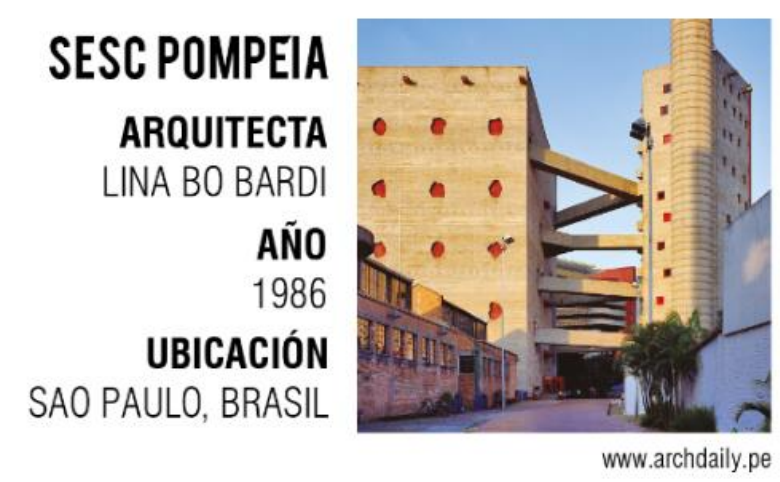

\subsubsection{Historia}

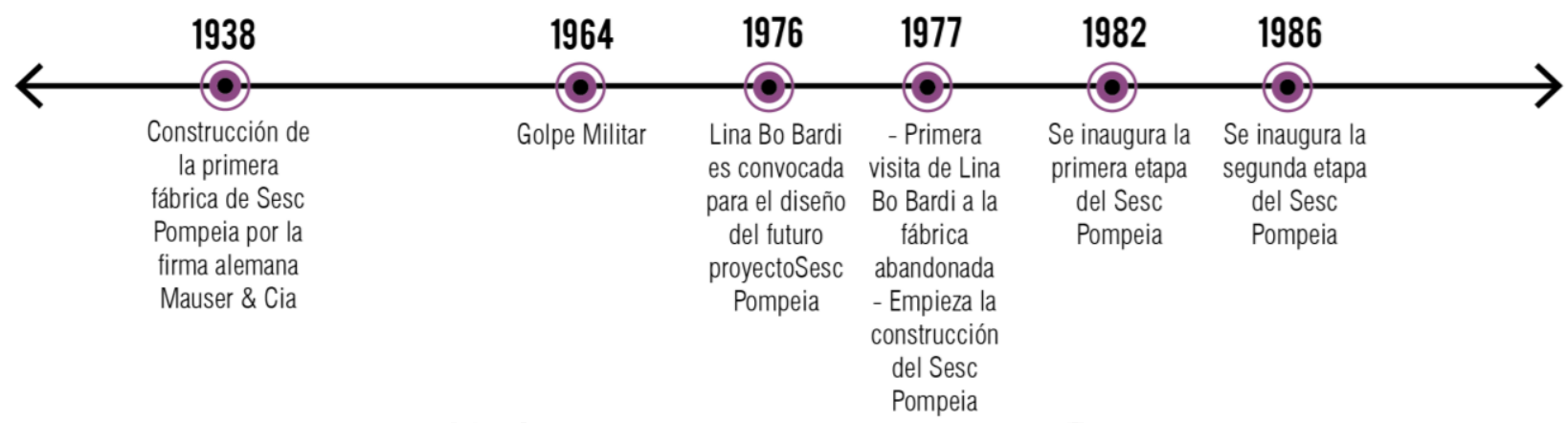

5.1.2.3 Ubicación

Se encuentra en el barrio de Pompeia de Sau Paulo, en Brasil. 
Plano de localización y ubicación
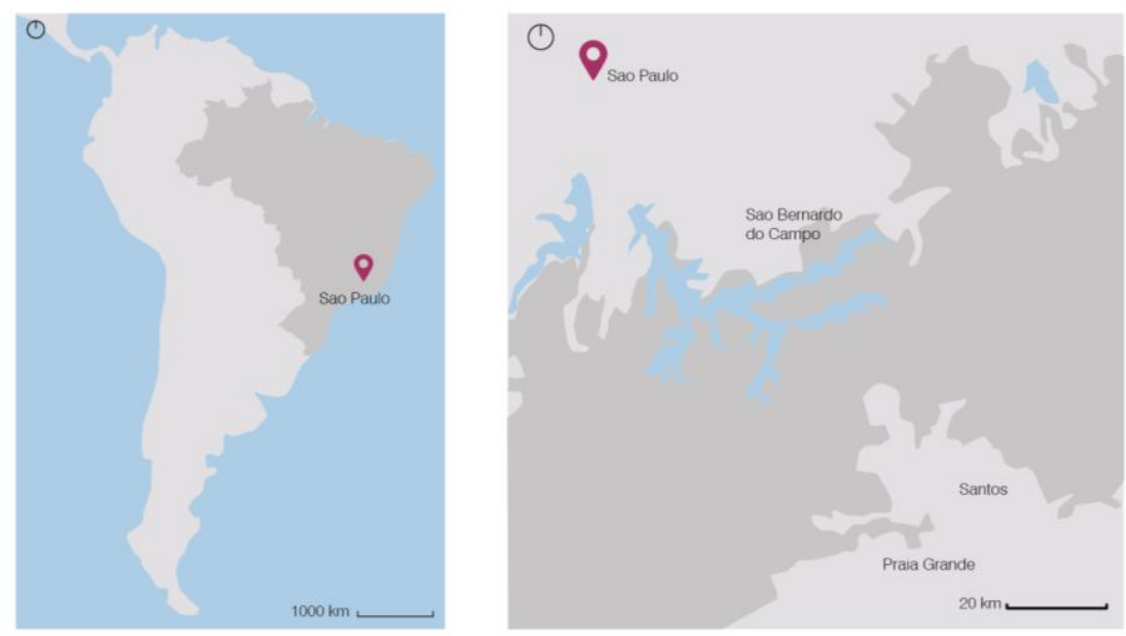

Relación con el entorno

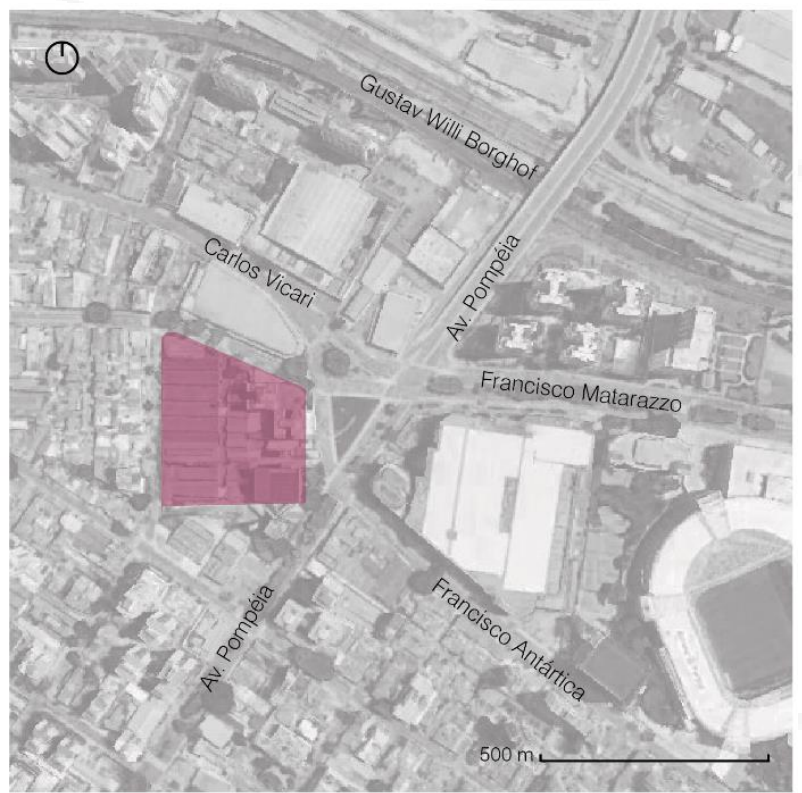

\subsubsection{Toma de partido}

Lina Bo Bardi, de acuerdo al encargo que le solicitaron, decidió conservar el edificio de ladrillo preexistente de la fábrica, que podría haber sido demolido y lo complementó con dos volúmenes de concreto expuesto, unidos con puentes del mismo material (Duque, 2011, parr. 2).

Lo existente, que son los antiguos galpones con lo nuevo, los edificios de concreto, se encuentran integrados a través de una calle como extensión de la actividad cultural que se desarrolla en el interior de los espacios. 
1. El proyecto nace de dos intensiones. La primera es la reactivación del edificio y la segunda, la repercusión en el contexto urbano.

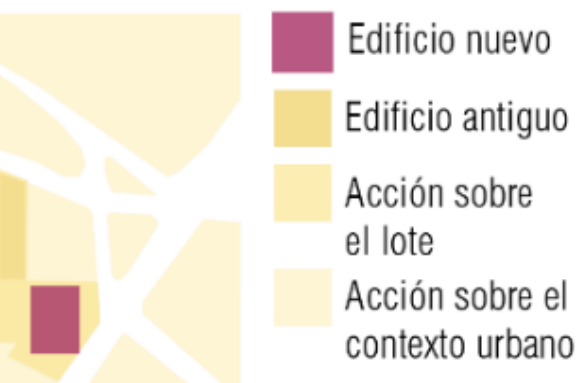

2. El proyecto nace de dos intensiones. La primera es la reactivación del edificio y la segunda, la repercusión en el contexto urbano.

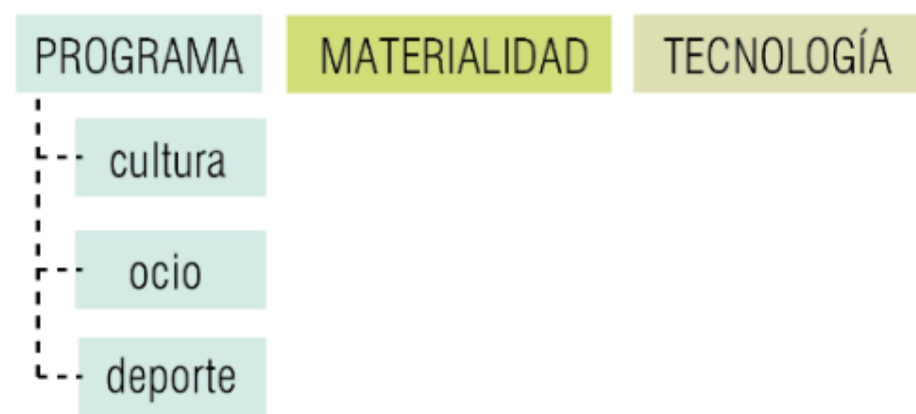

3. De acuerdo, al entorno, Lina decidió mantener el edificio antiguo y complementarlo con uno nuevo.

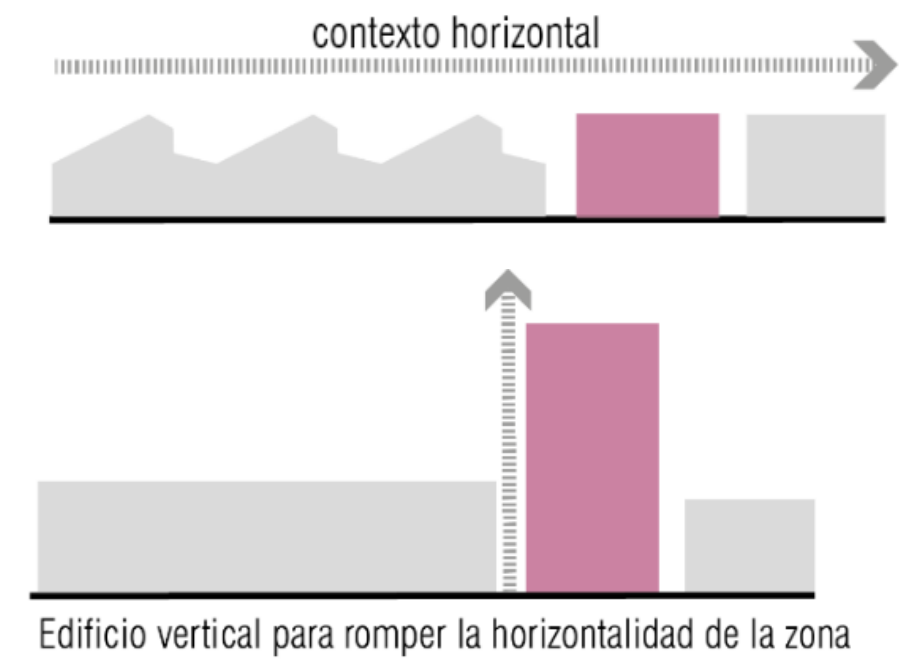


4. Mantener la austeridad expresiva, de los edificios existentes.
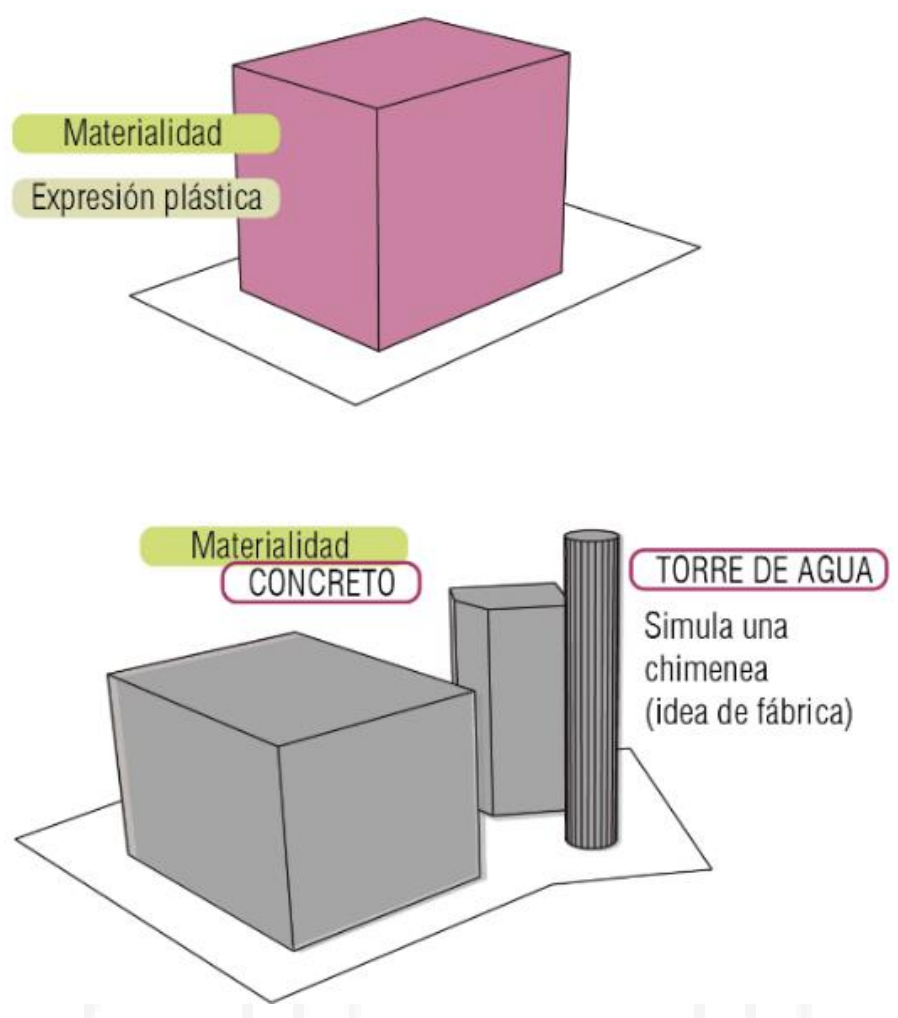

5. Aprovechar los ejes públicos dentro del terreno para emplazar el nuevo edificio.

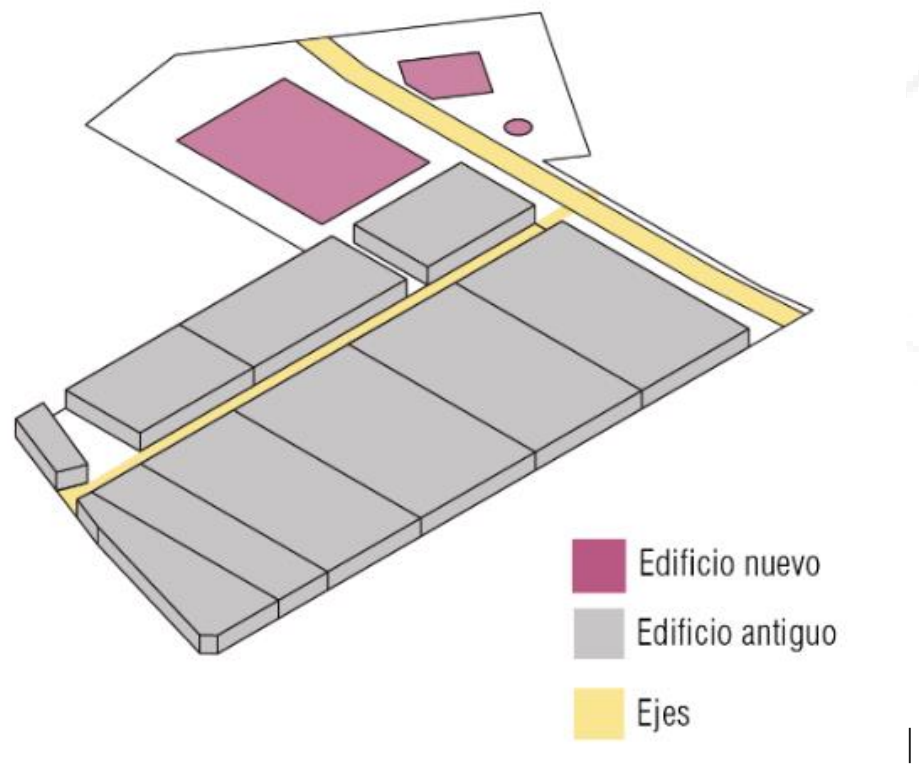




\subsubsection{Análisis vial}

Vías
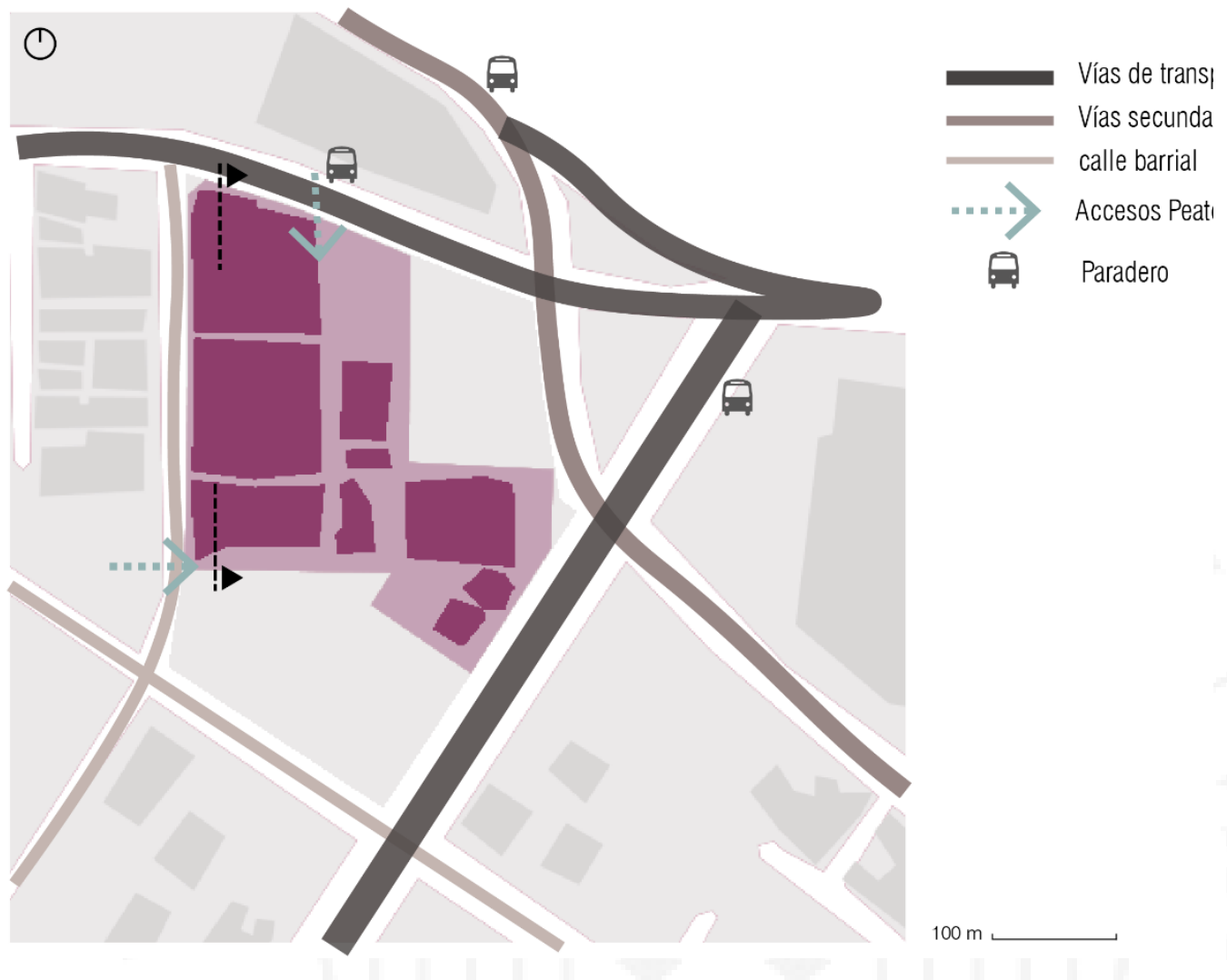

Relación con el entorno

$100 \mathrm{~m}$

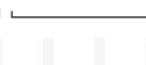

FÁBRICAS ANTIGUAS

VIVIENDA

NUEVO

EDIFICIO

FABRICASANTIGUAS 


\subsubsection{Programa}

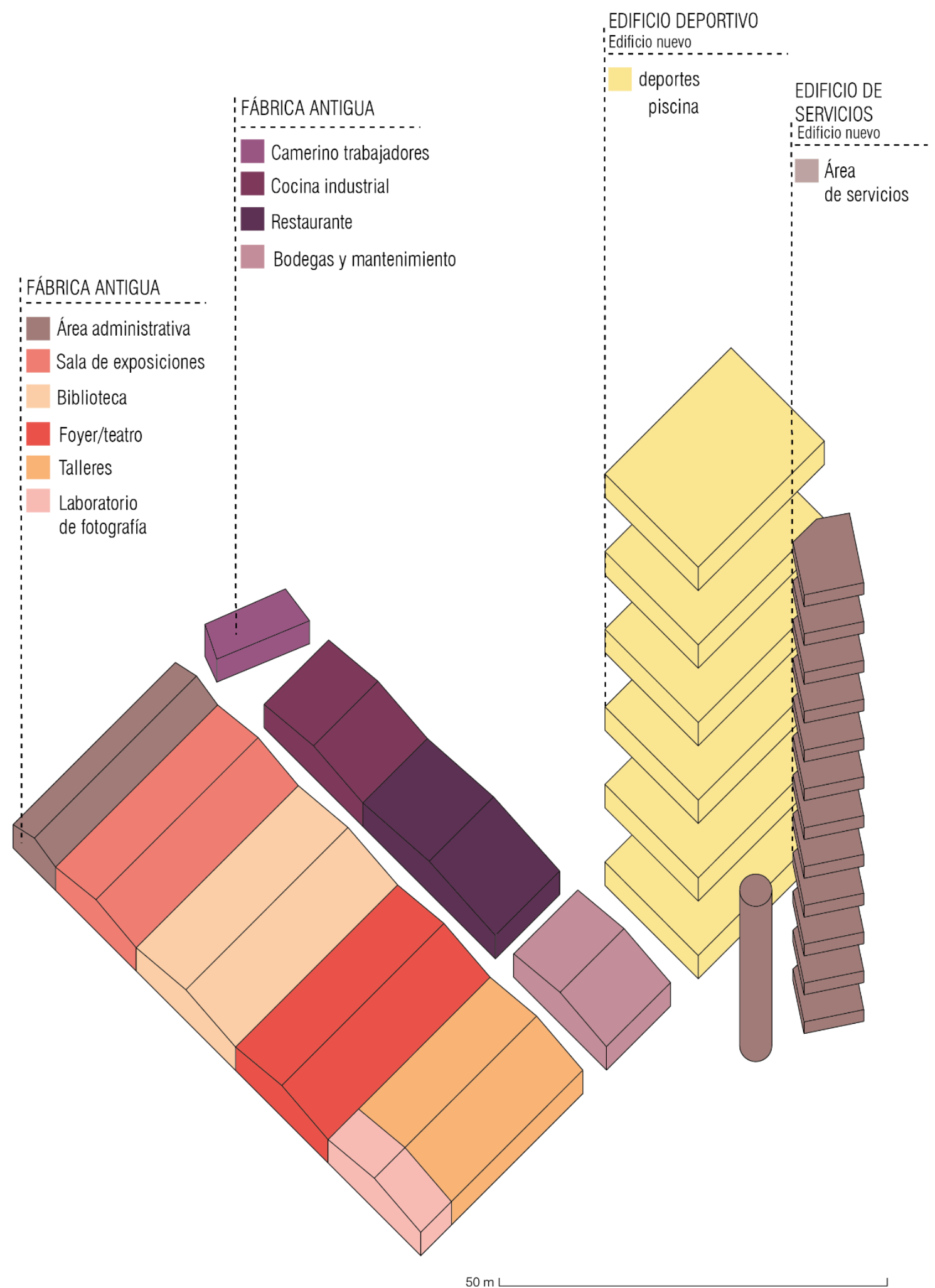




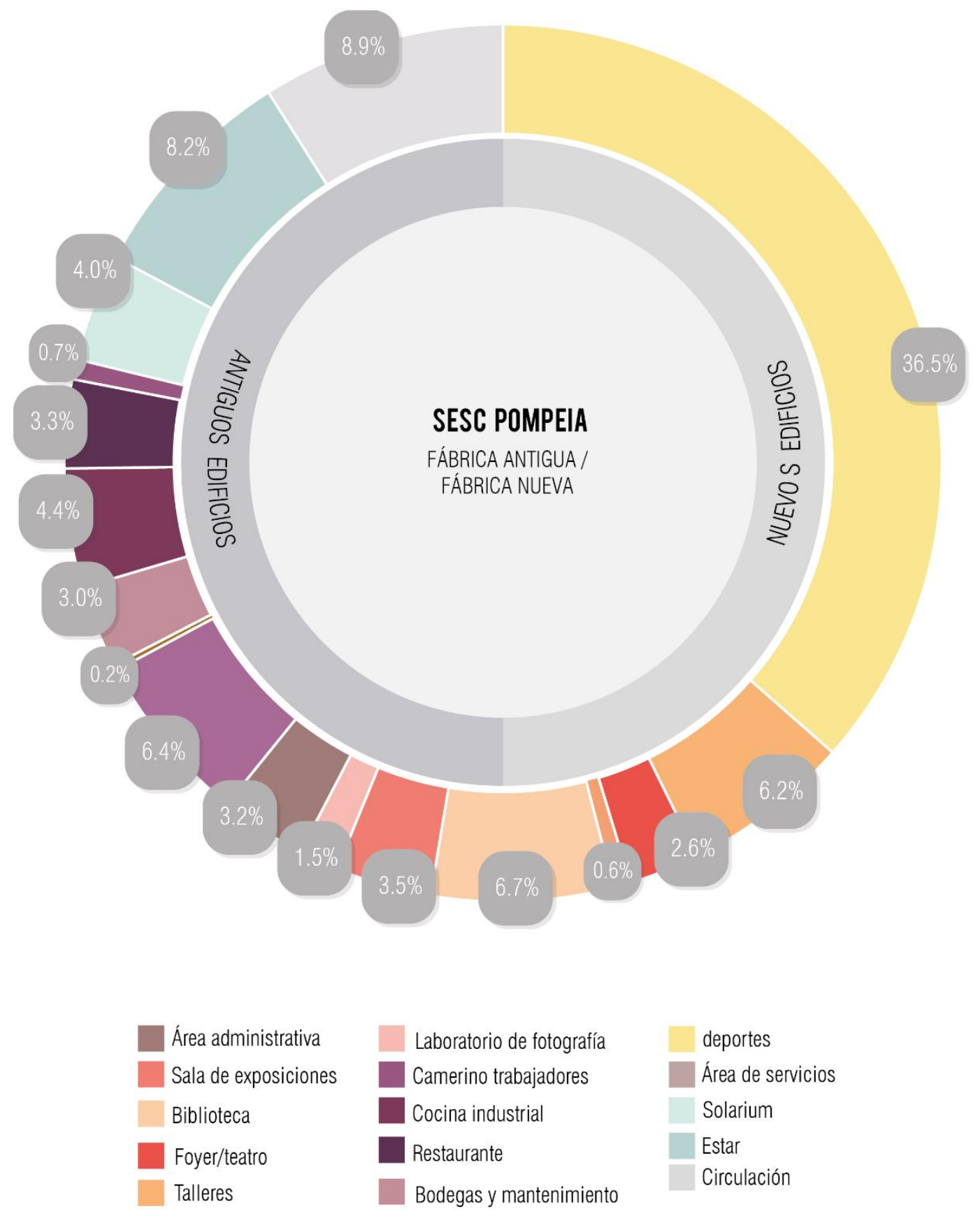




\subsubsection{Organización funcional}

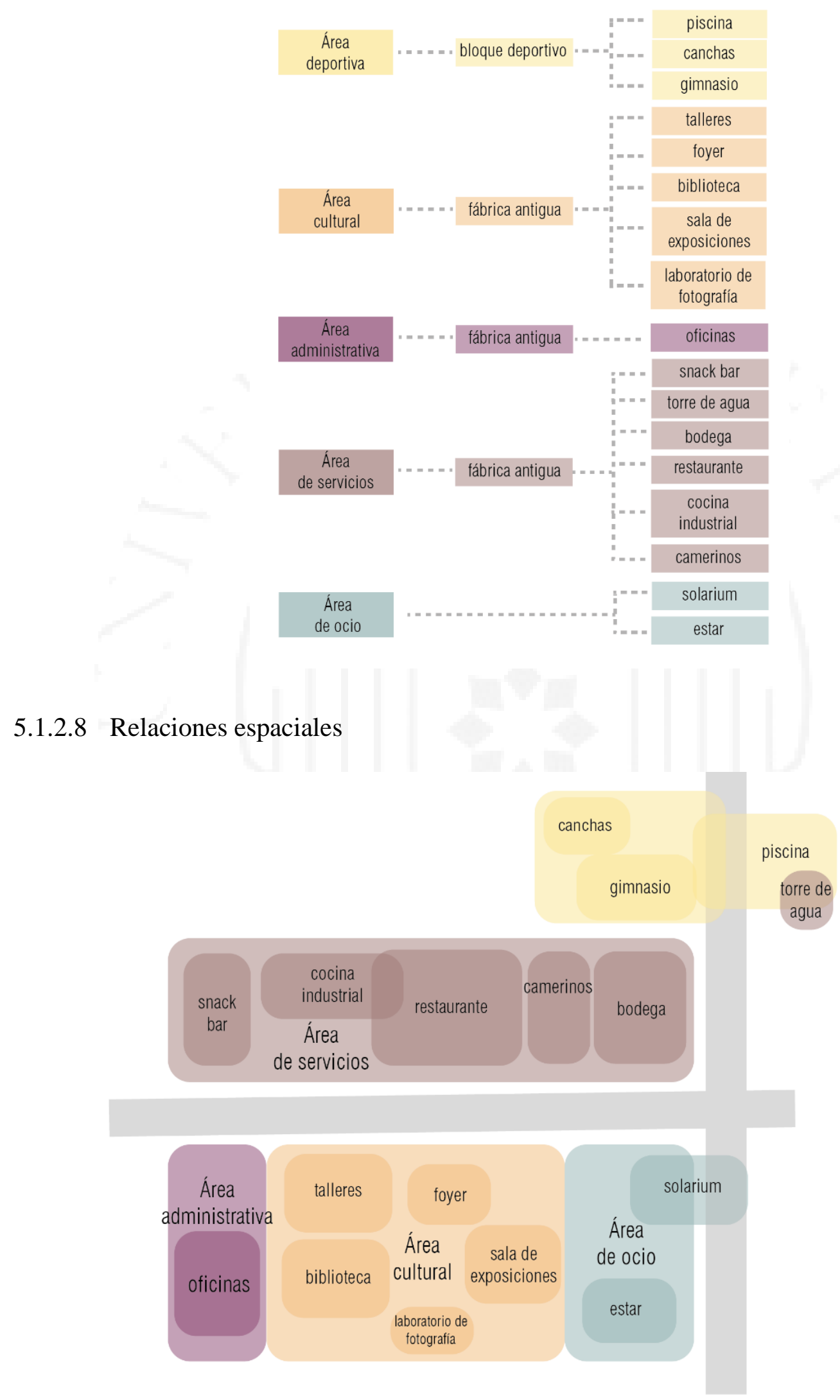




\subsubsection{Distribución espacial}
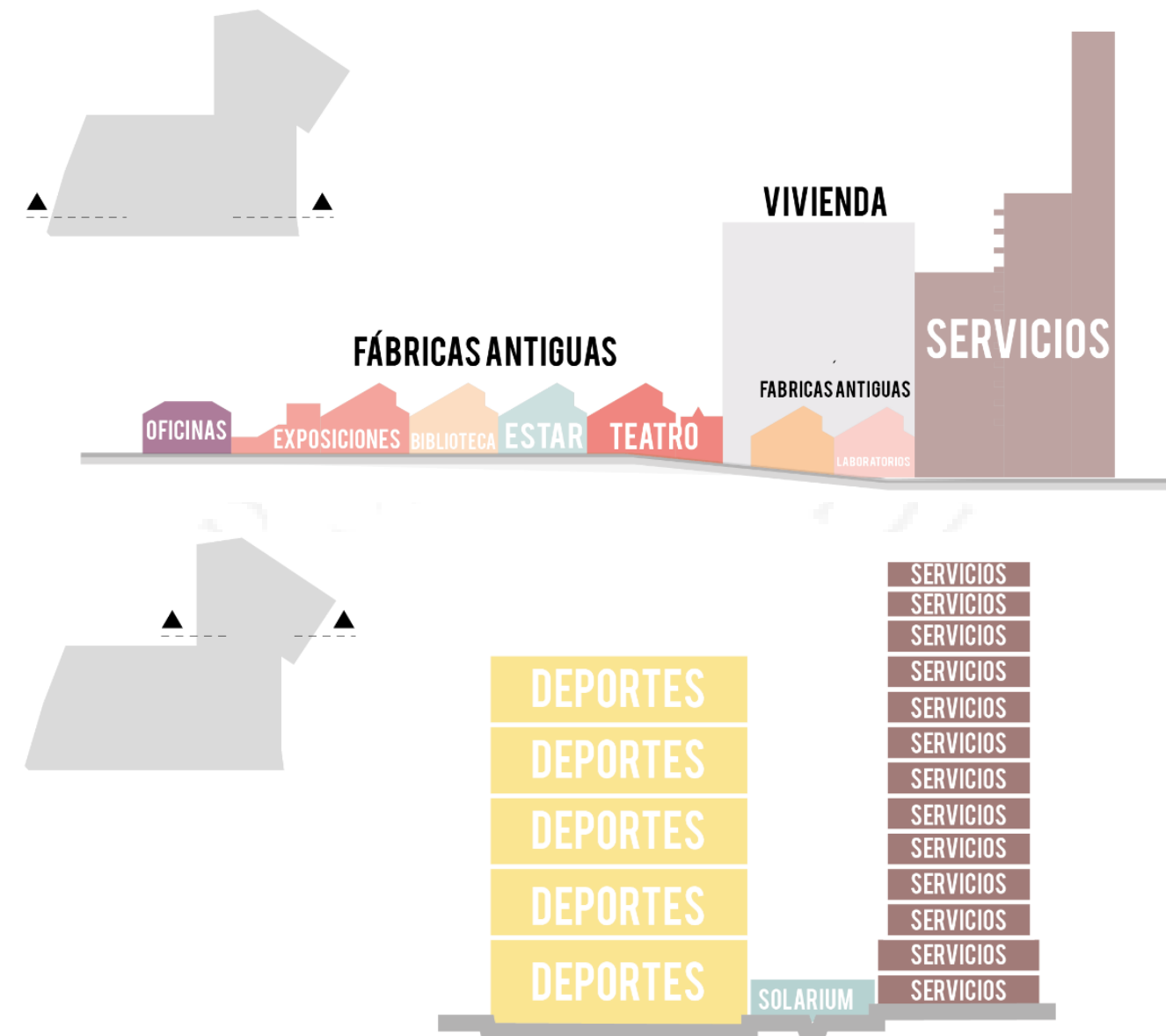

5.1.2.10 Cuadro de área

\begin{tabular}{|c|c|c|c|}
\hline ÁREA & ESPACIO & METRAJE & TOTAL \\
\hline $\begin{array}{c}\text { ÁREA } \\
\text { DEPORTIVA }\end{array}$ & bloque deportivo & $9457 \mathrm{~m} 2$ & $9457 \mathrm{~m} 2$ \\
\hline $\begin{array}{c}\text { ÁREA } \\
\text { CULTURAL }\end{array}$ & \begin{tabular}{|c|} 
talleres \\
teatro \\
foyer \\
biblioteca \\
sala exposiciones \\
laboratorio de fotografía \\
\end{tabular} & $\begin{array}{r}1615 \mathrm{~m} 2 \\
677 \mathrm{~m} 2 \\
162 \mathrm{~m} 2 \\
1737 \mathrm{~m} 2 \\
917 \mathrm{~m} 2 \\
379 \mathrm{~m} 2\end{array}$ & $5489 \mathrm{~m} 2$ \\
\hline $\begin{array}{c}\text { ÁREA } \\
\text { ADMINISTRATIVA }\end{array}$ & oficinas administrativas & $825 \mathrm{~m} 2$ & $825.1 \mathrm{~m} 2$ \\
\hline $\begin{array}{c}\text { ÁREA } \\
\text { DE SERVICIOS }\end{array}$ & $\begin{array}{c}\text { snack bar } \\
\text { torre de agua } \\
\text { bodega } \\
\text { restaurante } \\
\text { cocina industrial } \\
\text { camerinos }\end{array}$ & $\begin{array}{r}273 \mathrm{~m} 2 \\
53 \mathrm{~m} 2 \\
788 \mathrm{~m} 2 \\
2704 \mathrm{~m} 2 \\
845 \mathrm{~m} 2 \\
191 \mathrm{~m} 2\end{array}$ & $3290 \mathrm{~m} 2$ \\
\hline $\begin{array}{c}\text { ÁREA DE } \\
\text { OCIO }\end{array}$ & $\begin{array}{c}\text { solarium } \\
\text { estar }\end{array}$ & $\begin{array}{l}1027 \mathrm{~m} 2 \\
2141 \mathrm{~m} 2\end{array}$ & $3168.84 \mathrm{~m} 2$ \\
\hline \multirow[t]{2}{*}{$\begin{array}{c}\text { ÁREA DE } \\
\text { CIRCULACIÓN }\end{array}$} & $\begin{array}{c}\text { solarium } \\
\text { estar }\end{array}$ & $\begin{array}{l}1027 \mathrm{~m} 2 \\
2141 \mathrm{~m} 2\end{array}$ & $3168.84 \mathrm{~m} 2$ \\
\hline & & & $14337 \mathrm{~m} 2$ \\
\hline
\end{tabular}


5.1.2.11 Tipología espacial

1. Proyecto por adición.

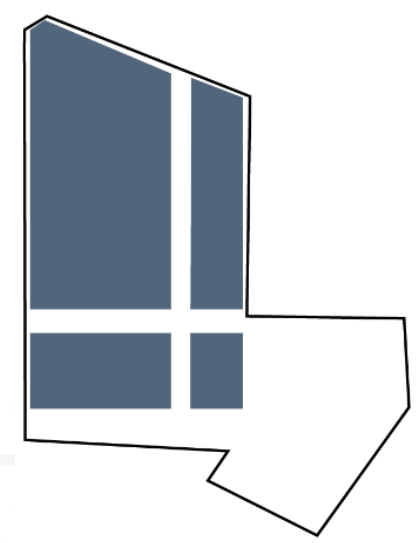

2. Agregar, teniendo como referencia los ejes existentes y creando un nuevo eje.

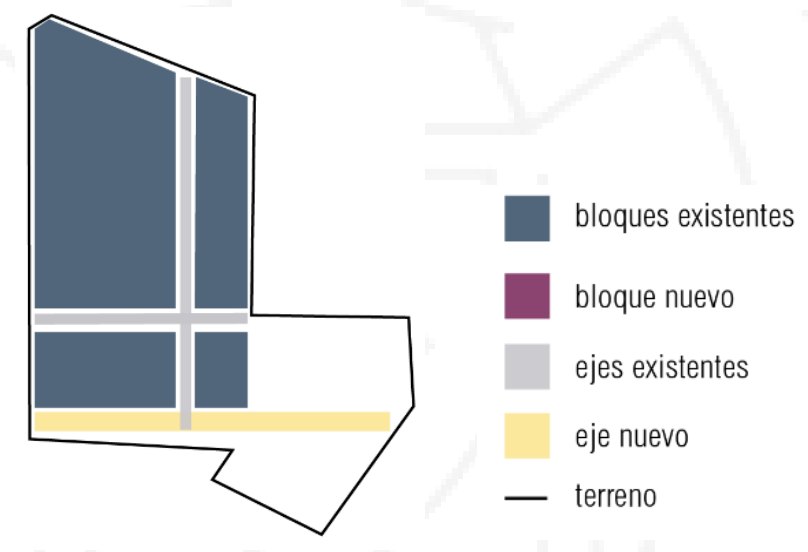

3. Agregar un bloque nuevo.

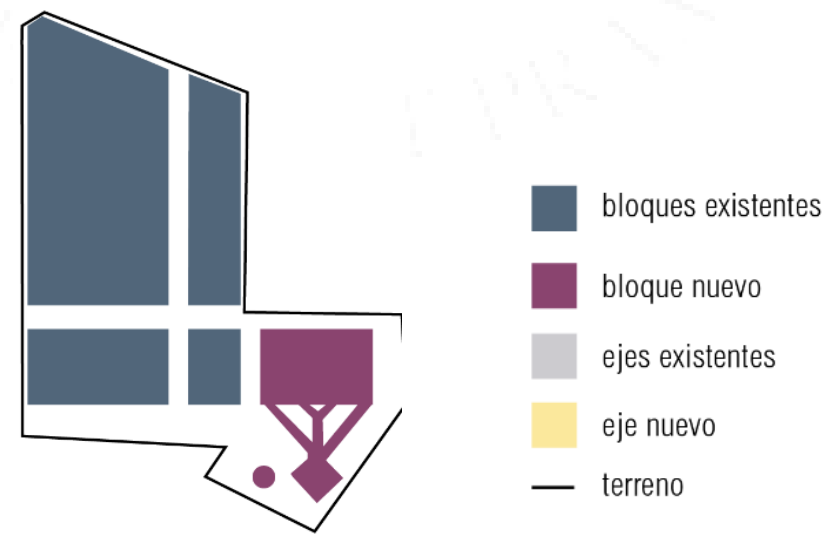




\subsubsection{Relación público - privado}

PLANTA GENERAL

$\Theta$

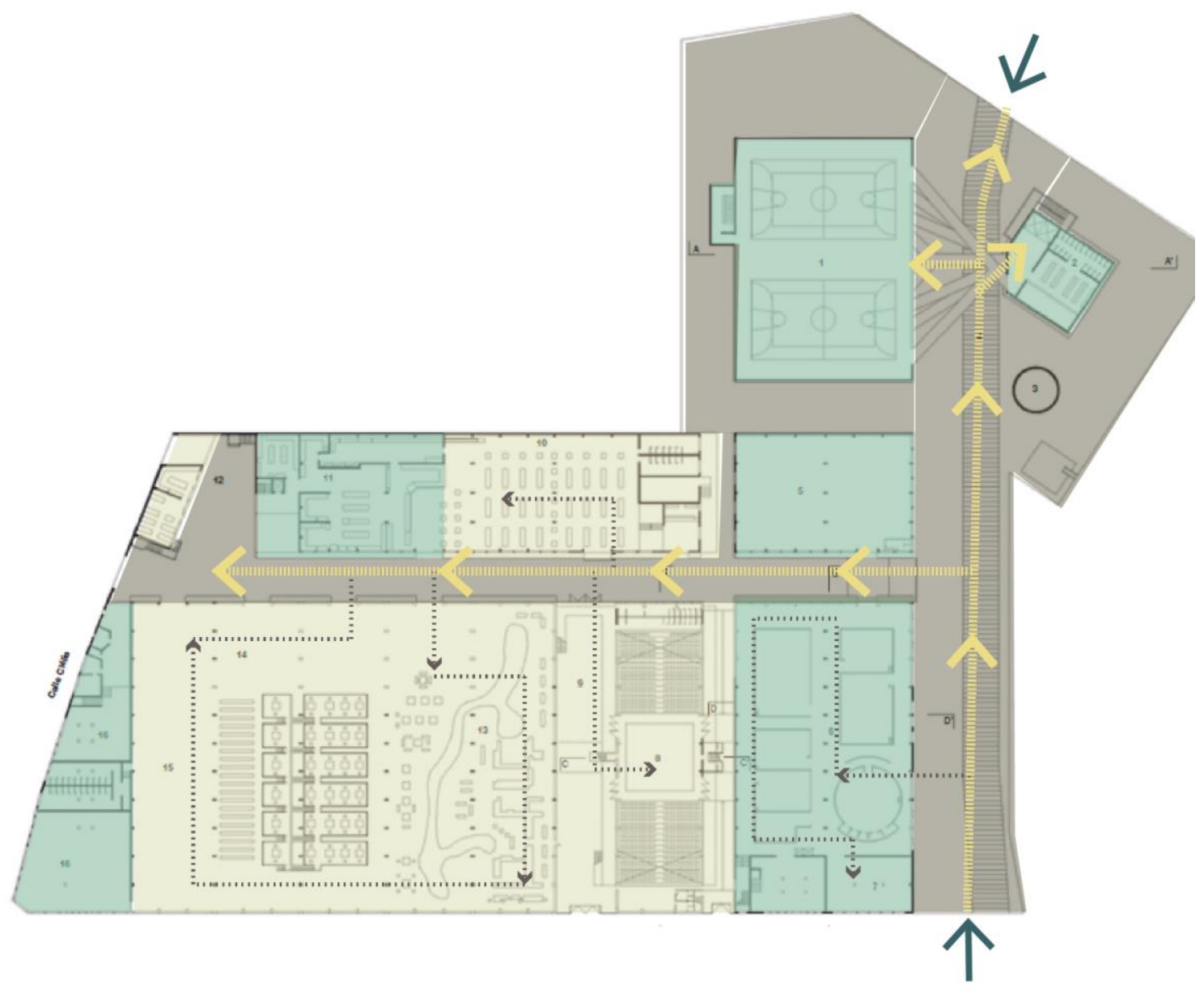

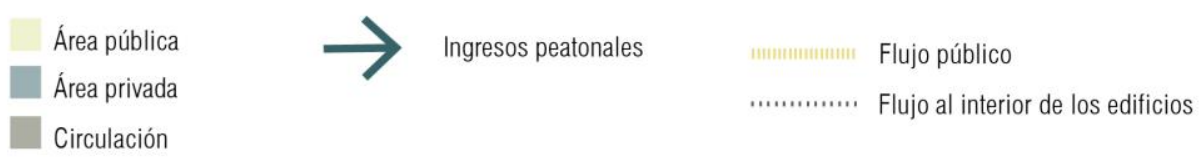




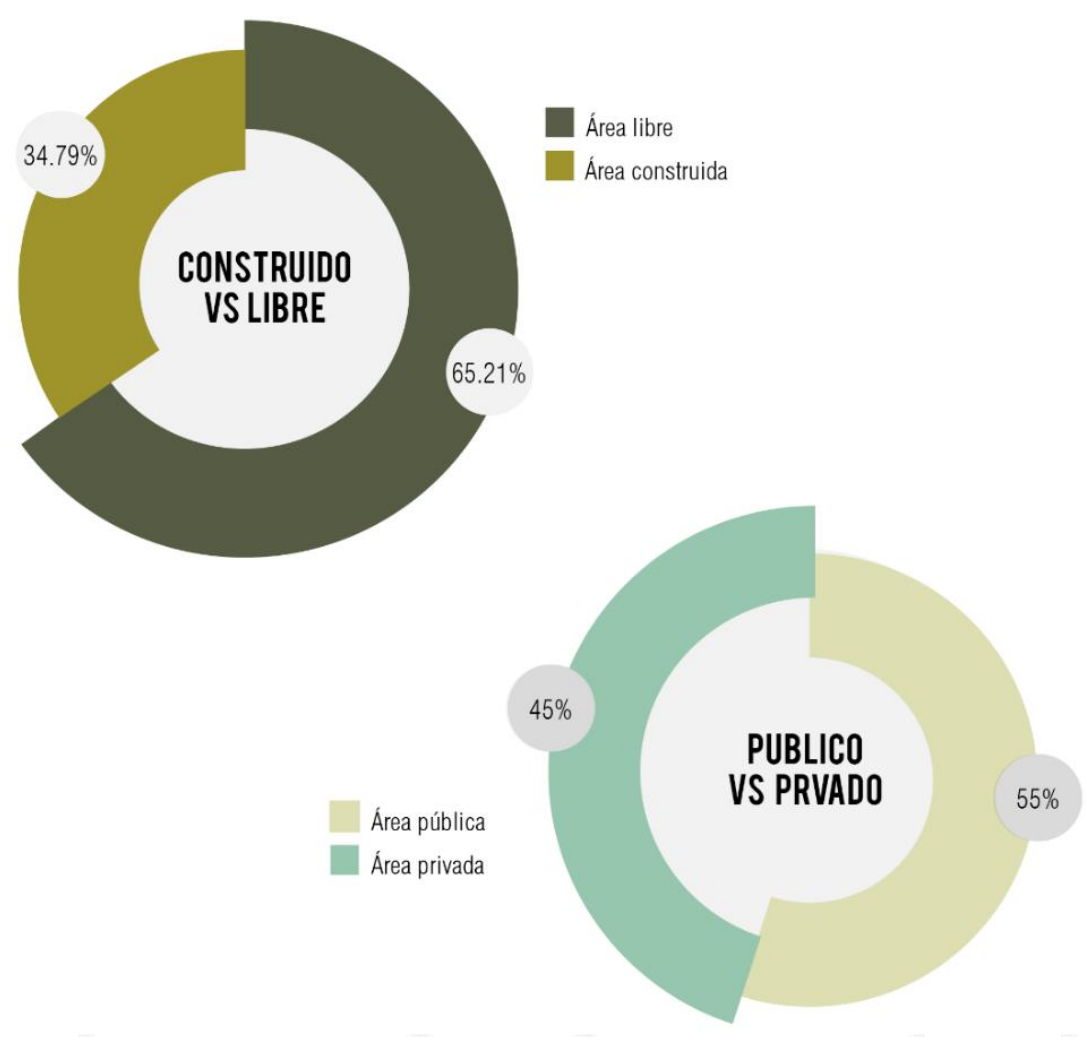

5.1.2.13 Tecnología estructural

Si bien el proyecto es conocido por sus impresionantes volúmenes de concreto con perforaciones. La arquitecta también hizo un gran uso de los techos de los galpones, permitiendo el paso de la luz que resaltaba la materialidad fabril y brutalista del interior de los galpones.

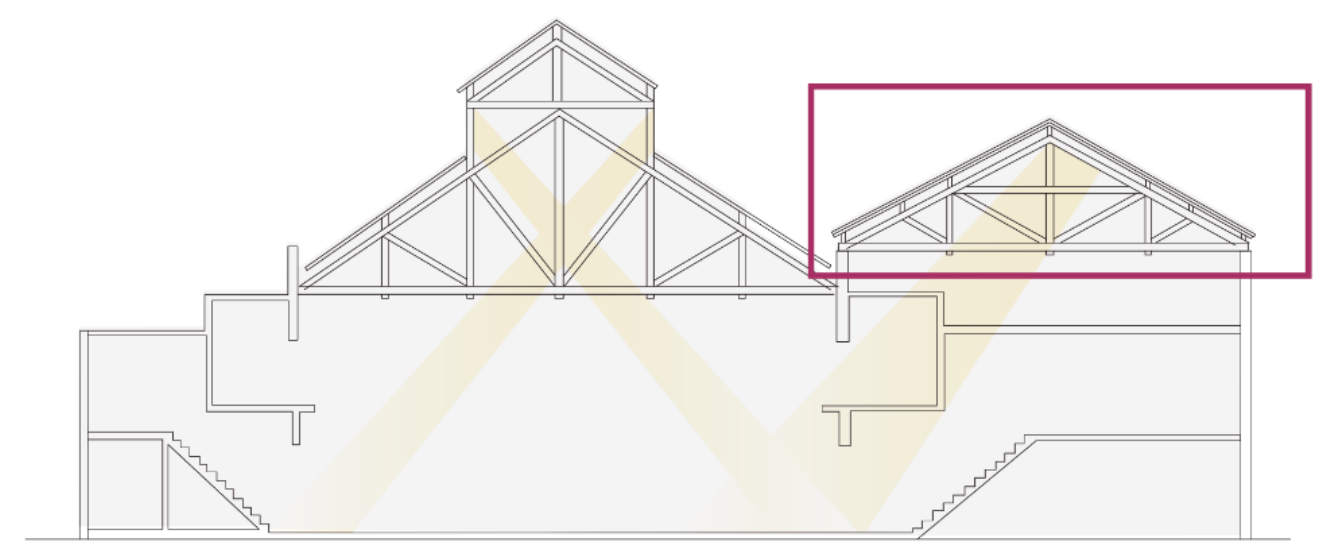




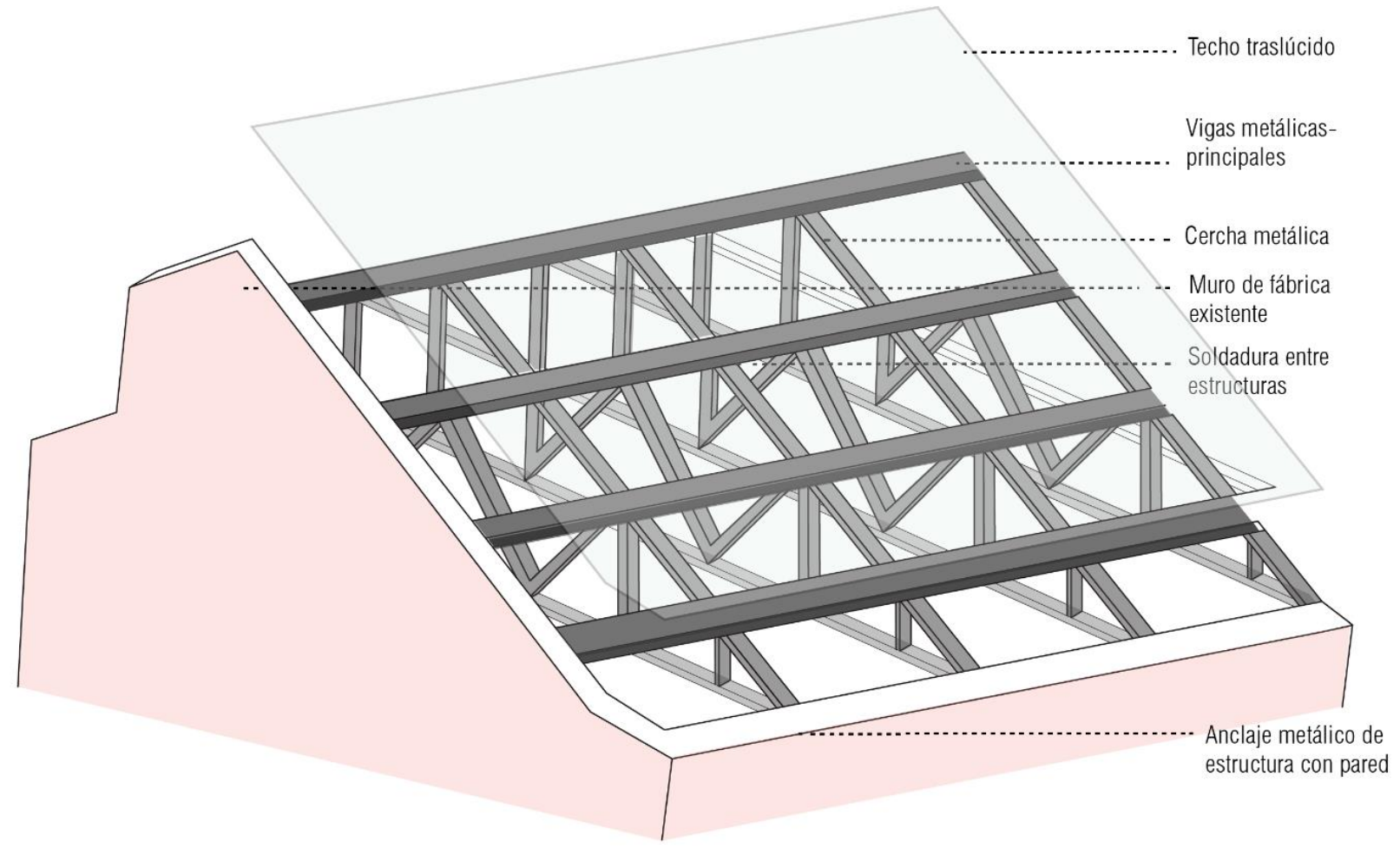

\subsubsection{Impacto Social}

En palabras de la arquitecta, "el proyecto es monumental, siendo aprovechado por niños, jóvenes y familias enteras como forma de ocio. Todo esto debe continuar, con toda esta alegría" (Duque, 2011, parr. 3).

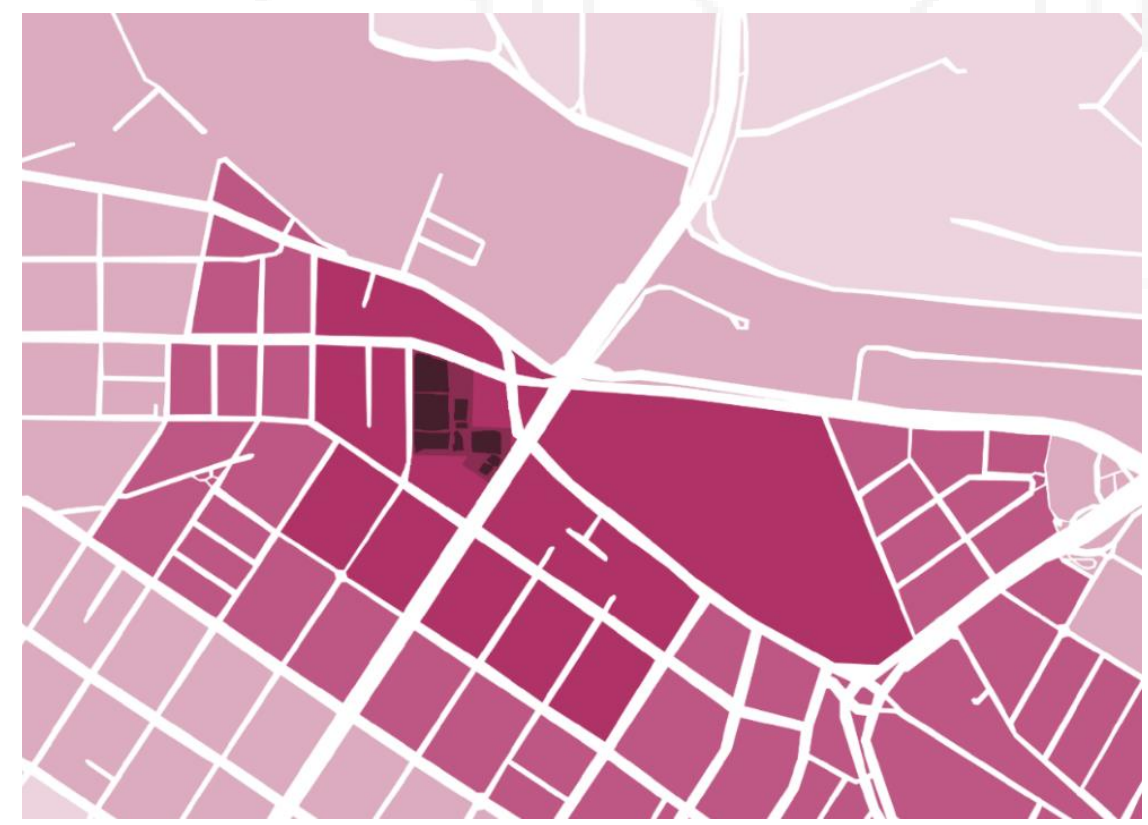




\subsubsection{Galería de fotos}

Ilustración 5.6 Vista exterior de la relación entre lo existente y lo nuevo a través de una pasarela.

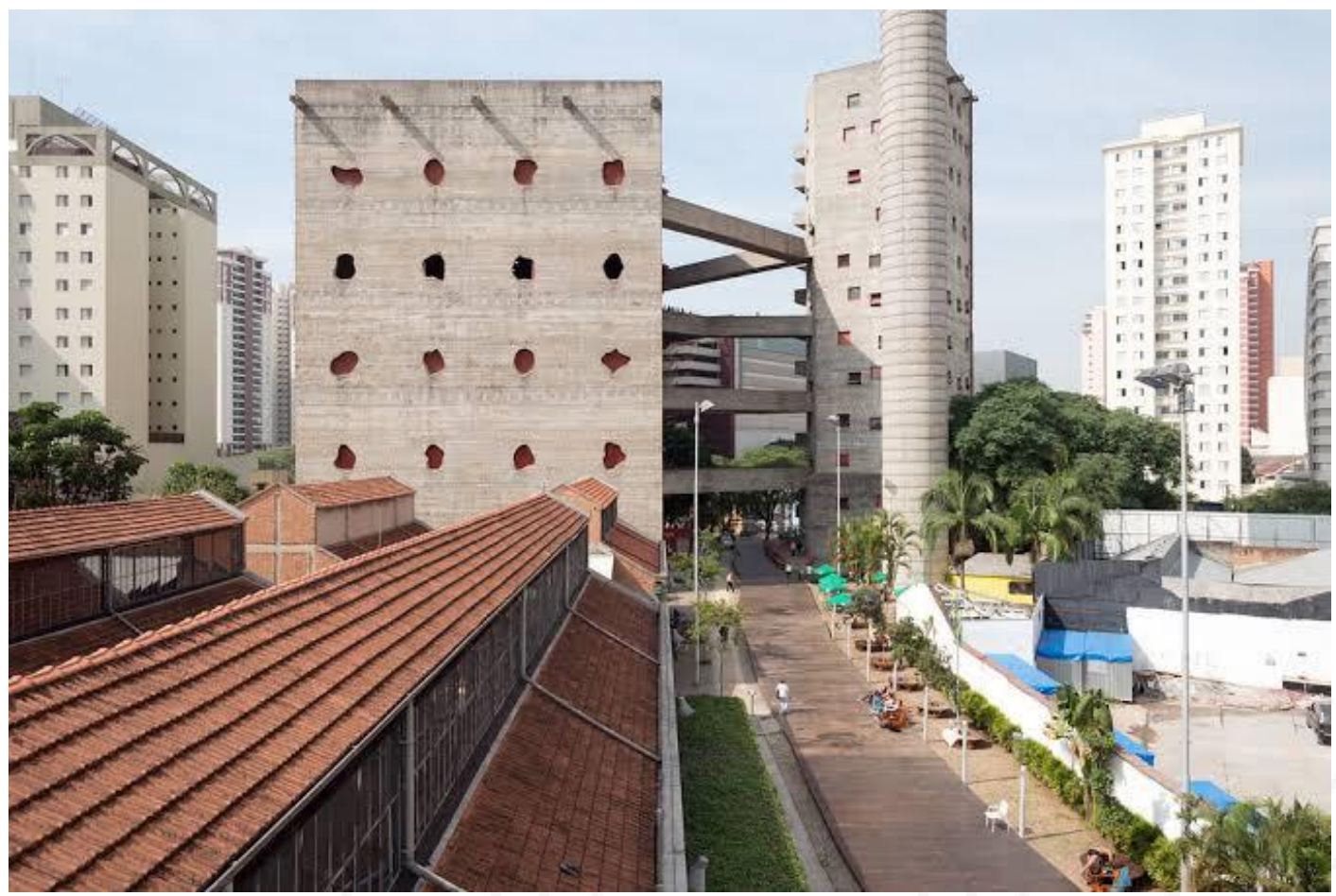

Fuente: Recuperado de www.archdaily.com

Ilustración 5.7 Vista interior del galpón reciclado con el nuevo uso cultural.

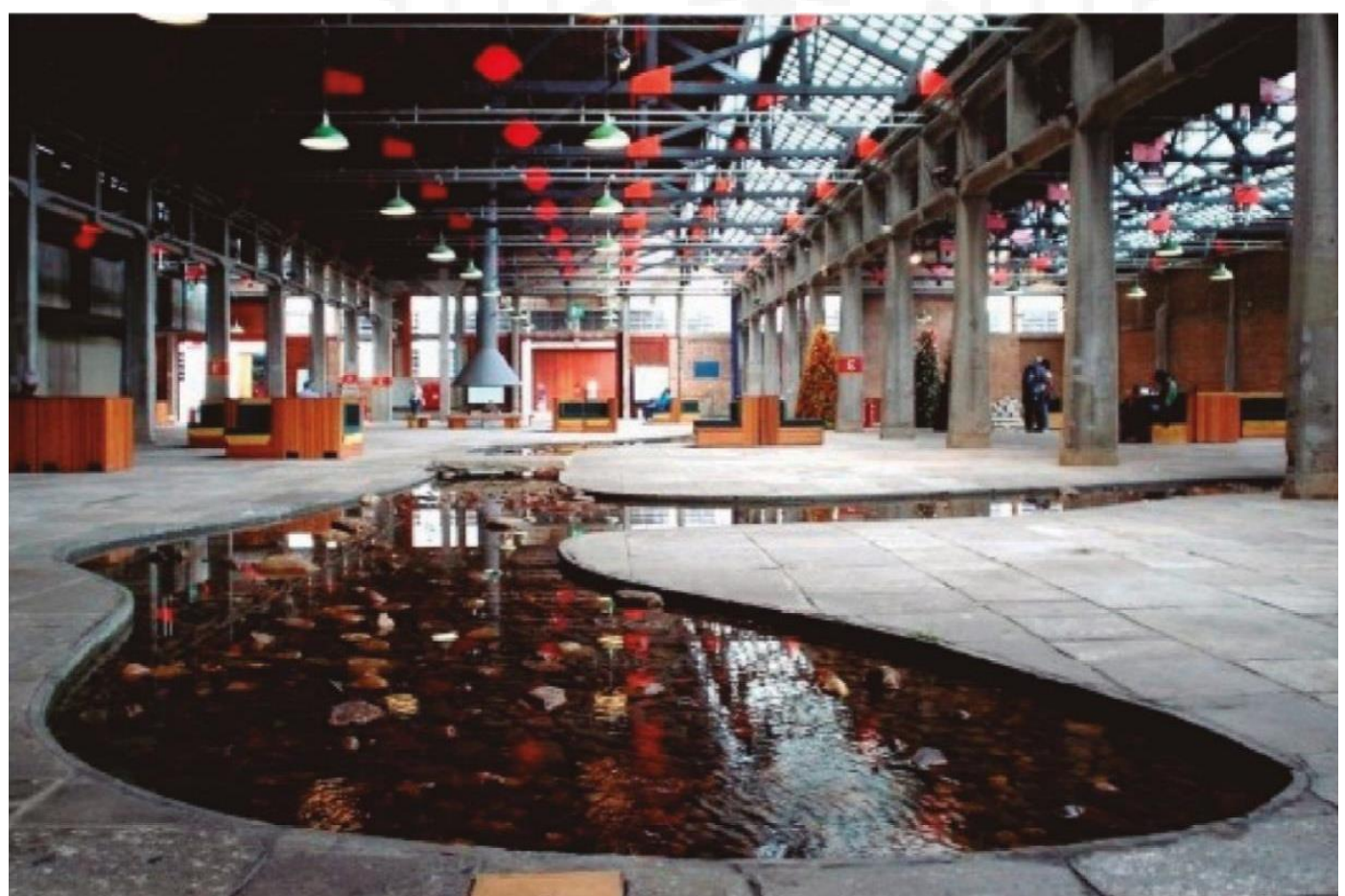

Fuente: Recuperado de www.archdaily.com 


\subsubsection{Centro Cultural Valparaíso}

\subsubsection{Datos Generales}

El Parque Cultural Valparaíso, se encuentra sobre el terreno de la ex cárcel, alzándose como un proyecto cuya lectura es diferente a la que proyectaba el anterior uso, un espacio hermético y recluido. Hoy, es un espacio de encuentro e integración para Valparaíso.

Desarrollado por los arquitectos de la firma HLPS, quienes tuvieron que responder a la premisa de cómo hacer del encierro un espacio integrador (Vial, 2012, parr. 2).

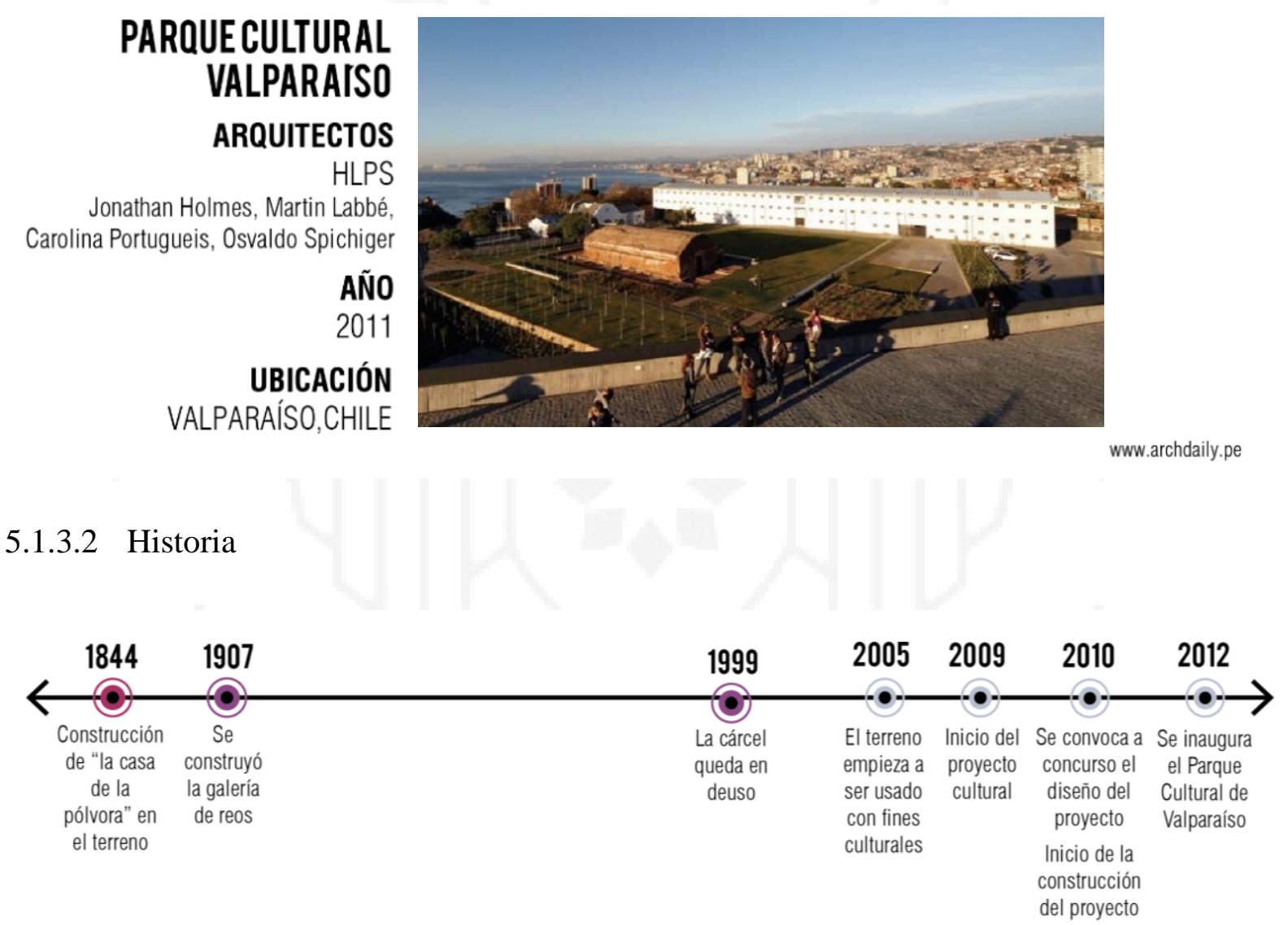

\subsubsection{Ubicación}

El proyecto se ubica en la parte alta de Valparaíso en Chile, lo que permite tener una gran vista del paisaje de la ciudad.

Plano de localización y ubicación 

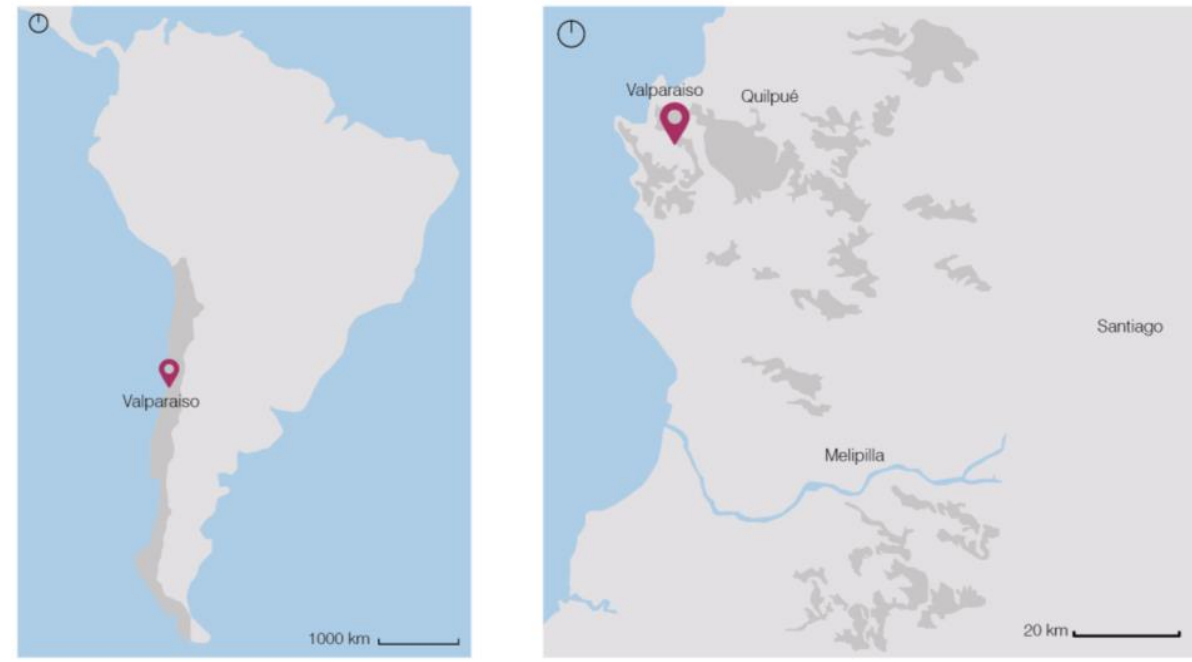

Relación con el entorno

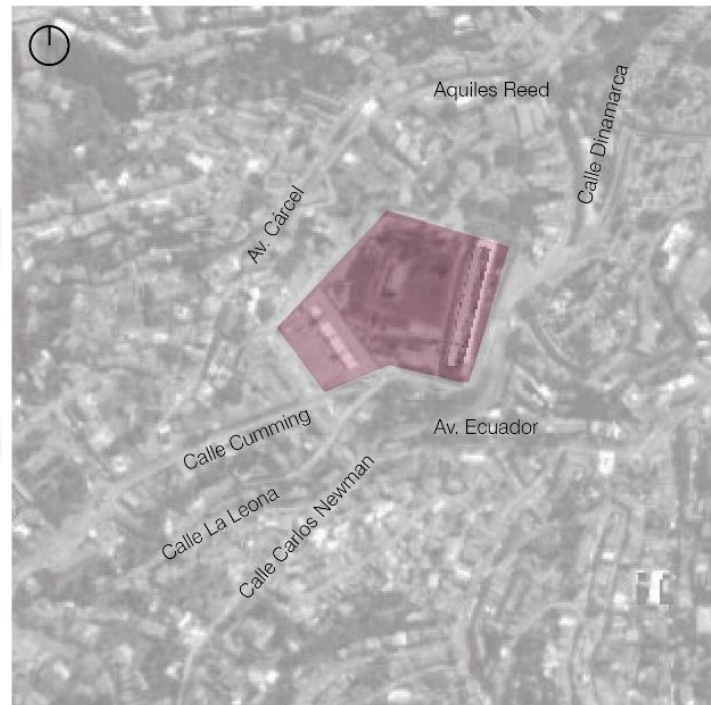

5.1.3.4 Toma de partido

Desde el punto de vista arquitectónico, el proyecto sienta sus bases en tres espacios de diferentes ambientes a partir de la re-significación de la Galería de Reos como arquitectura de reciclaje, la consolidación del parque como arquitectura paisajista y la incorporación de una nueva fachada como arquitectura contemporánea (Ministerio de las Culturas, las Artes y el Patrimonio, s.f., parr. 3). 
La extensa horizontalidad del lugar fue aprovechado por los arquitectos, quienes a su vez decidieron reciclar y poner en valor la galería de reos, el edificio de acceso y el antiguo polvorín español, todo ello rodeado por el característico muro perimetral de la cárcel.

1. La idea propuesta en contraposición de la vocación de la ex cárcel, el hermetismo.
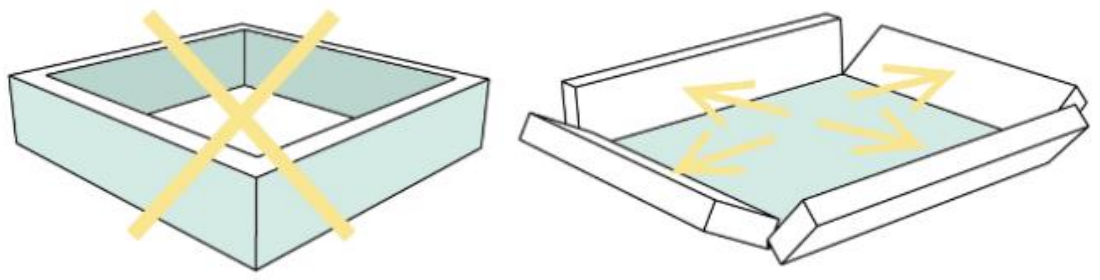

2. Reactivar el espacio público para generar integración socio - cultural. Aprovechar la topografía del terreno, para generar una plataforma.

3. Crear tres situaciones.

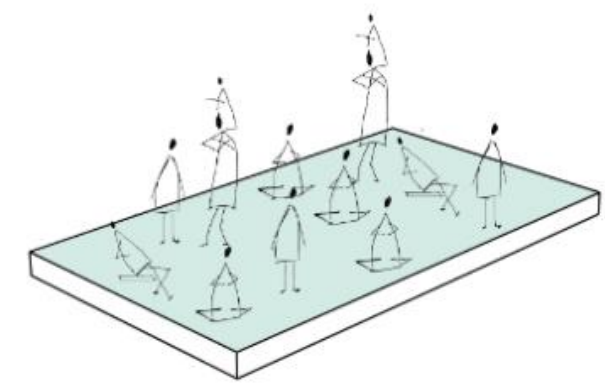

creación de un plano urbano

(explanada para el barrio)

creación de un paseo público

(explanada intermedia)

corte horizontal del muro

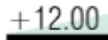

(consolidación del patio central)

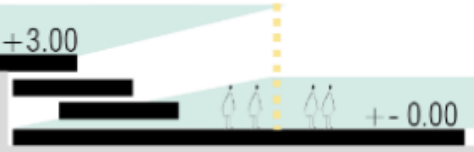


4. Mantener ambientes de la antigua cárcel.

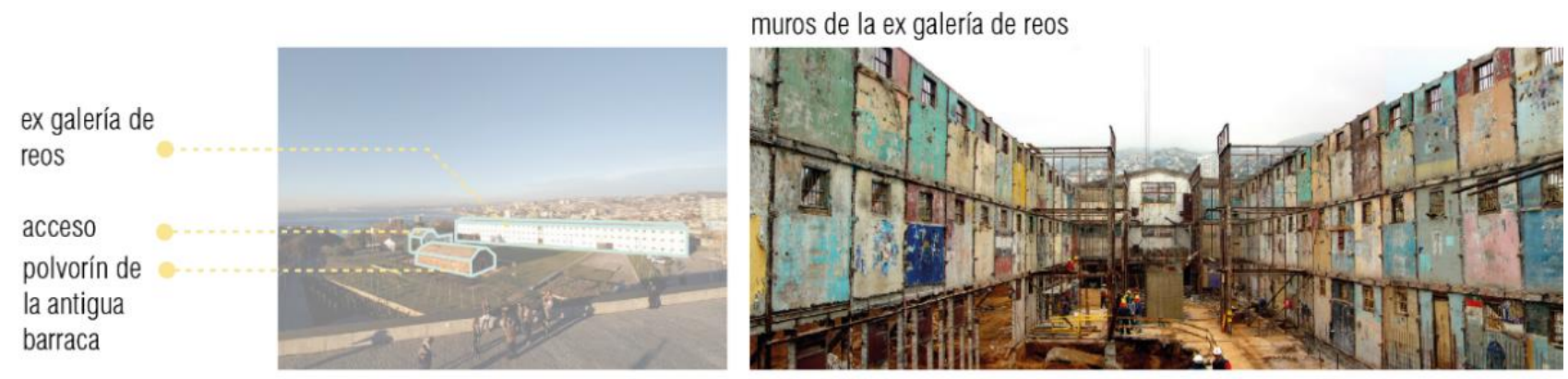

5.1.3.5 Análisis vial

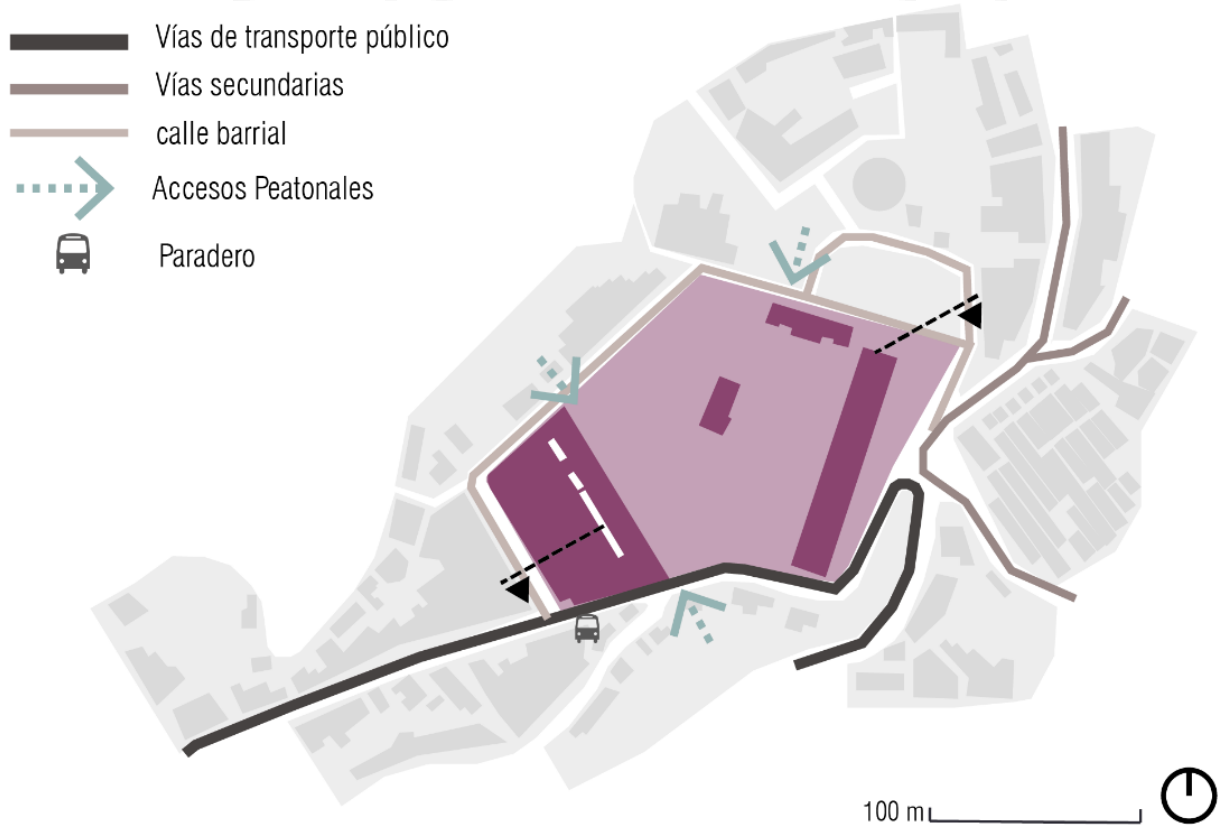

Relación con el entorno

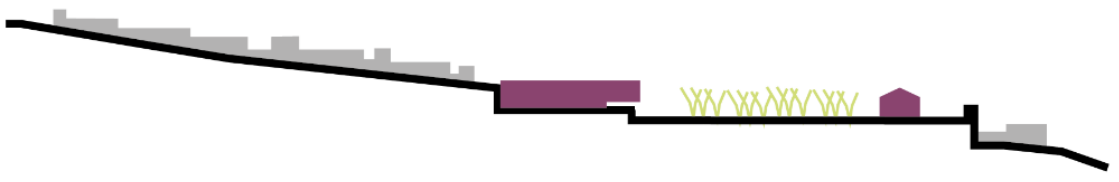

$100 \mathrm{~m}$ 


\subsubsection{Programa}

Los arquitectos aprovecharon la pendiente de los cerros de Valparaíso, colocando el edificio adicionado hacia la parte más alta por su relación directa a nivel con la calle. En el volumen, se insertó el programa de difusión, como teatro y salas de exposiciones, por la rápida accesibilidad. Paralelamente, en la galería de reos, se ubicaron los talleres y aulas de práctica. Este bloque tiene una característica especial, pues mantiene las paredes con las texturas y colores de cómo era en la cárcel, revalorando la memoria colectiva del espacio y transmitiéndola a la nuevos usuarios del mismo.

La plaza, si bien no contiene programa establecido, cumple un papel importante en todo el conjunto, pues funciona como la extensión de la actividad de ambos bloques extremos, así como de ser un espacio integrador y conector para los habitantes de Valparaíso.

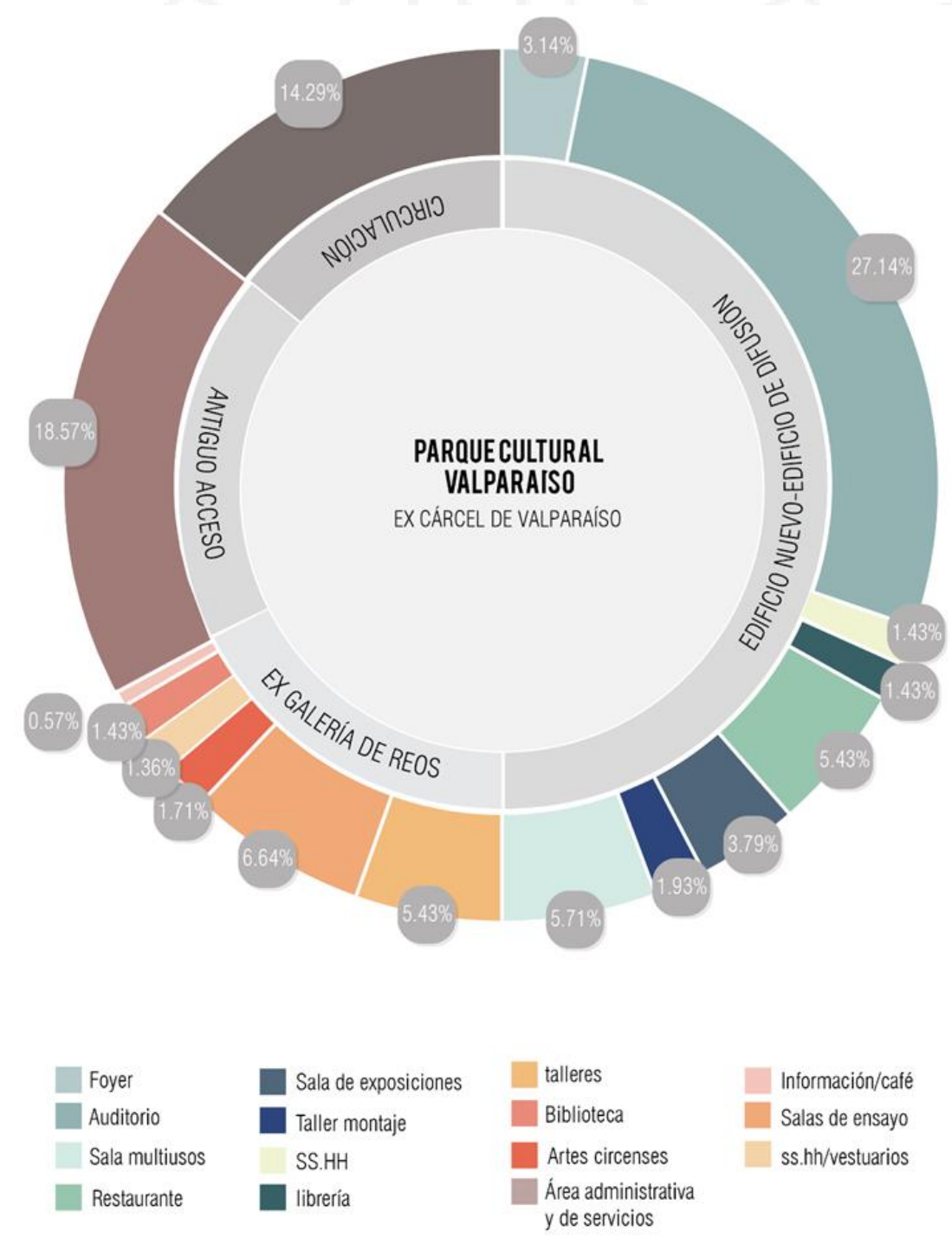




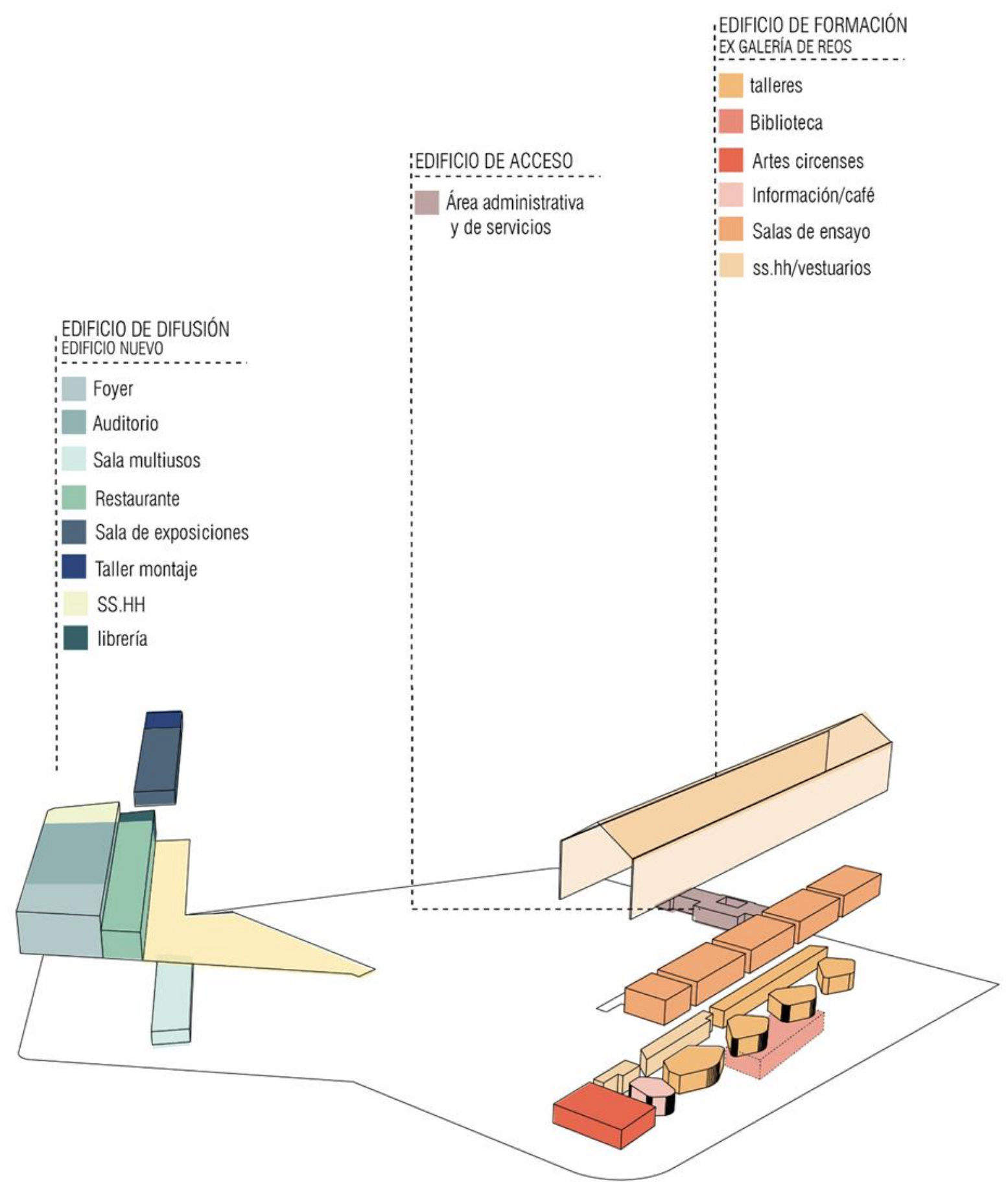




\subsubsection{Organización funcional}

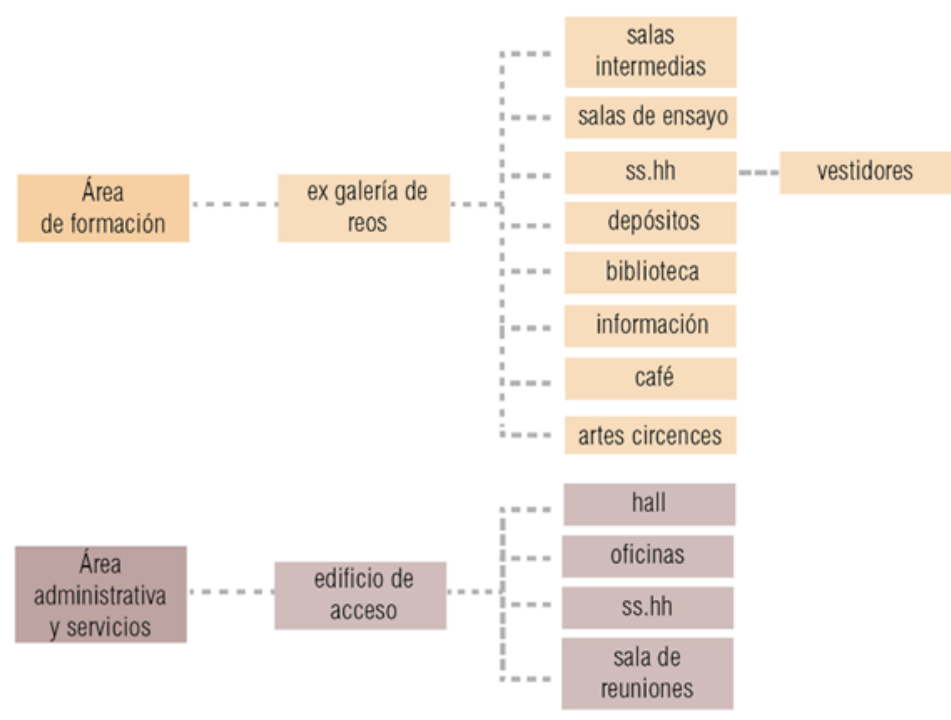

\subsubsection{Relaciones espaciales}

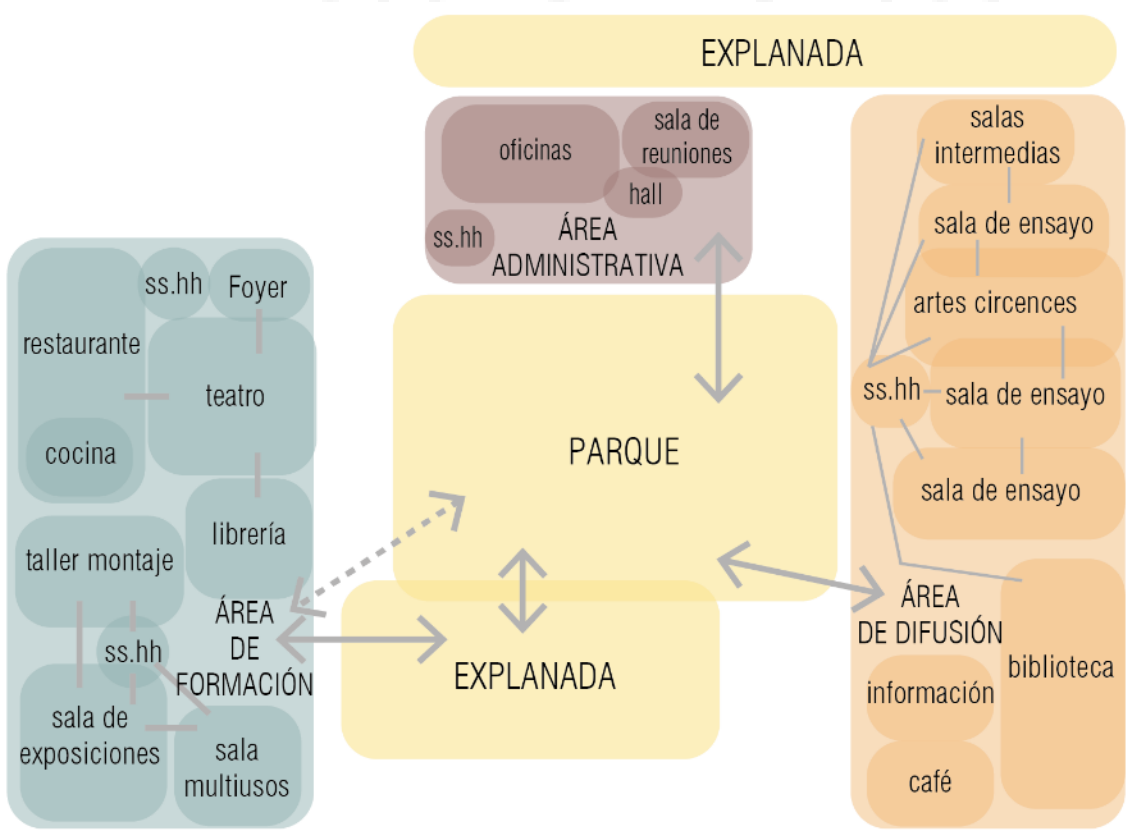




\subsubsection{Distribución espacial}
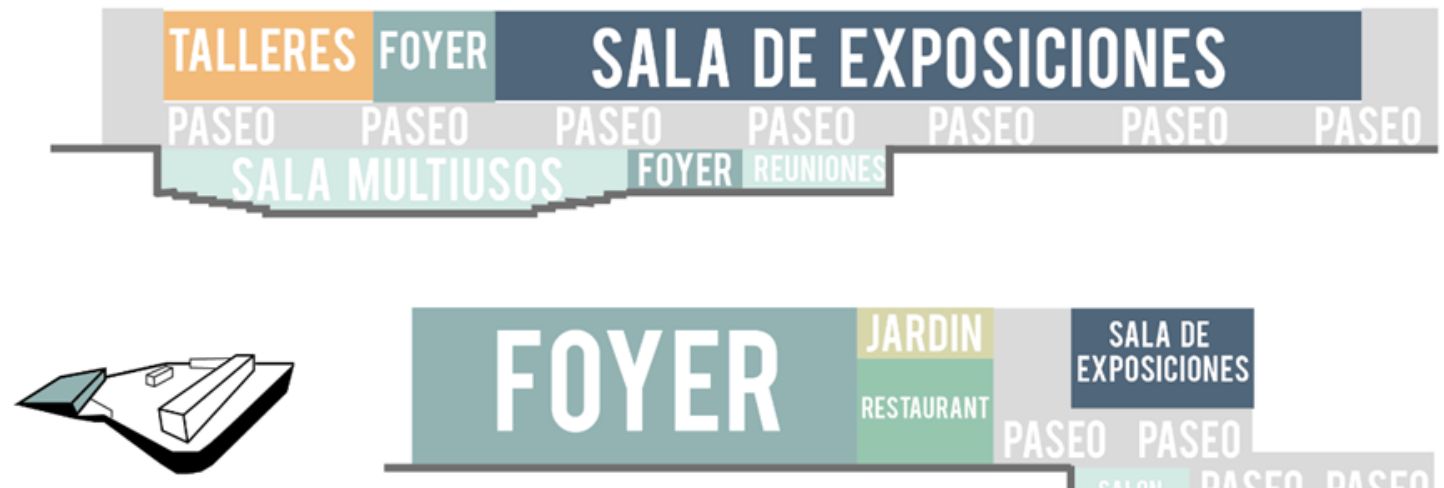

SALA DE
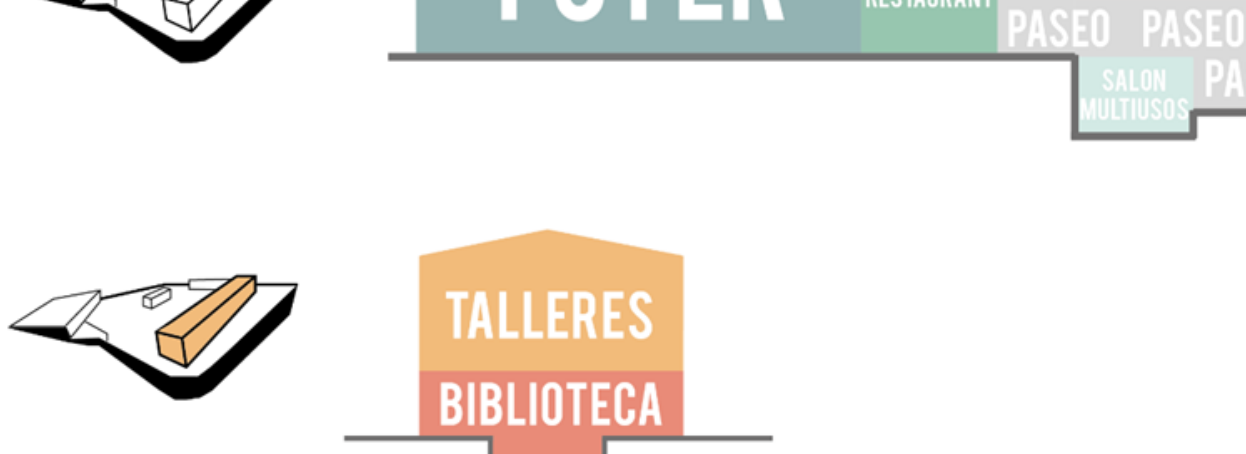

5.1.3.10 Cuadro de áreas

Terreno 2.1 ha

\begin{tabular}{|c|c|c|c|}
\hline ÁREA & ESPACIO & METRAJE & TOTAL \\
\hline \multirow{7}{*}{$\begin{array}{l}\text { ÁREA DE } \\
\text { FORMACIÓN }\end{array}$} & talleres & $380 \mathrm{~m} 2$ & \multirow{7}{*}{$1200 \mathrm{~m} 2$} \\
\hline & salas de ensayo & $465 \mathrm{~m} 2$ & \\
\hline & artes circenses & $120 \mathrm{~m} 2$ & \\
\hline & ss.hh/vestidores & $70 \mathrm{~m} 2$ & \\
\hline & biblioteca & $100 \mathrm{~m} 2$ & \\
\hline & información/café & $40 \mathrm{~m} 2$ & \\
\hline & depósitos & $25 \mathrm{~m} 2$ & \\
\hline \multirow{4}{*}{$\begin{array}{c}\text { ÁREA } \\
\text { ADMINISTRATIVA } \\
\text { Y SERVICIOS }\end{array}$} & hall & $40 \mathrm{~m} 2$ & \multirow{4}{*}{$1300 \mathrm{~m} 2$} \\
\hline & oficinas & $1145 \mathrm{~m} 2$ & \\
\hline & ss.hh & $15 \mathrm{~m} 2$ & \\
\hline & salas de reuniones & $100 \mathrm{~m} 2$ & \\
\hline \multirow{9}{*}{$\begin{array}{l}\text { ÁREA DE } \\
\text { DIFUSIÓN }\end{array}$} & auditorio & $1900 \mathrm{~m} 2$ & \multirow{9}{*}{$3500 \mathrm{~m} 2$} \\
\hline & foyer & $220 \mathrm{~m} 2$ & \\
\hline & ss.hh & $20 \mathrm{~m} 2$ & \\
\hline & ss.hh públicos/ depósitos & $80 \mathrm{~m} 2$ & \\
\hline & sala de exposiciones & $265 \mathrm{~m} 2$ & \\
\hline & taller montaje & $135 \mathrm{~m} 2$ & \\
\hline & sala multiusos & $400 \mathrm{~m} 2$ & \\
\hline & libreria/tienda & $100 \mathrm{~m} 2$ & \\
\hline & restaurante & $380 \mathrm{~m} 2$ & \\
\hline \multirow{3}{*}{ CIRCULACIÓN } & c. horizontal & $900 \mathrm{~m} 2$ & \multirow{3}{*}{$\begin{array}{r}1000 \mathrm{~m} 2 \\
7000 \mathrm{~m} 2\end{array}$} \\
\hline & c. vertical & $100 \mathrm{~m} 2$ & \\
\hline & & & \\
\hline
\end{tabular}




\subsubsection{Tipología espacial}

1. Presenta bloques antiguos disgregados.

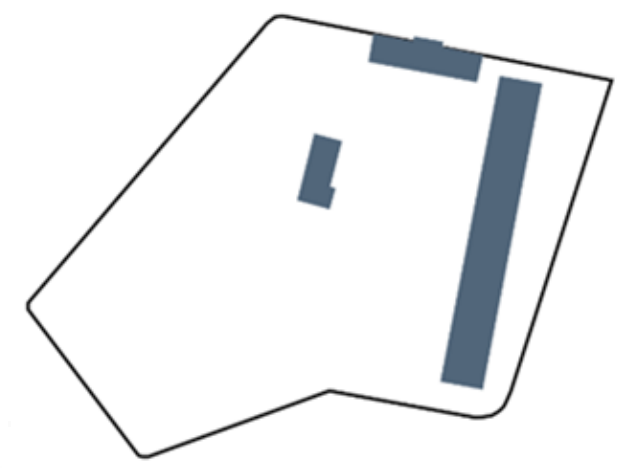

2. Ante la situación de los bloques disgregados, que se encuentran rodeando el borde en tres frentes, se completa el frente restante con un nuevo bloque.

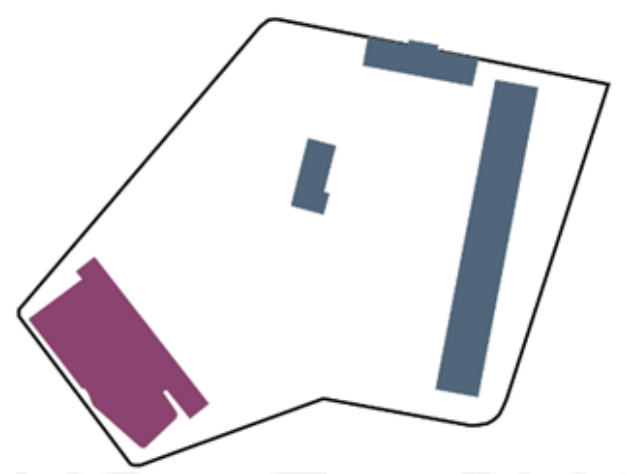

3. Se coloca el programa alrededor de los espacios públicos (plataformas) entre los bloques disgregados.

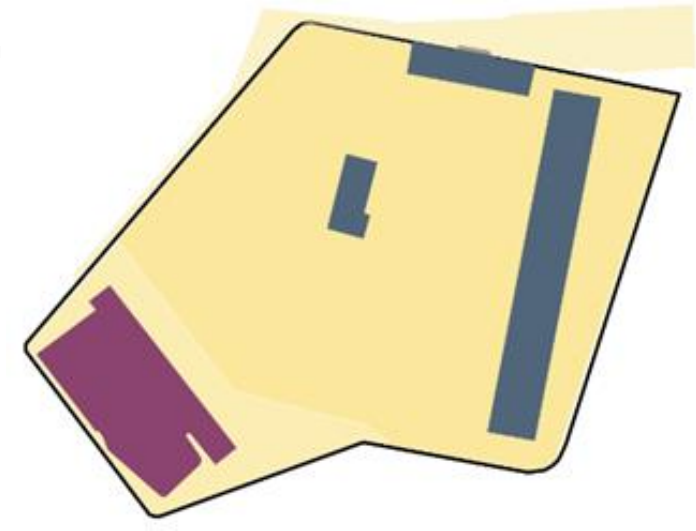

bloques existentes

bloque nuevo

espacio público

- terreno 


\subsubsection{Relación público - privado}

PLANTA GENERAL

(1)

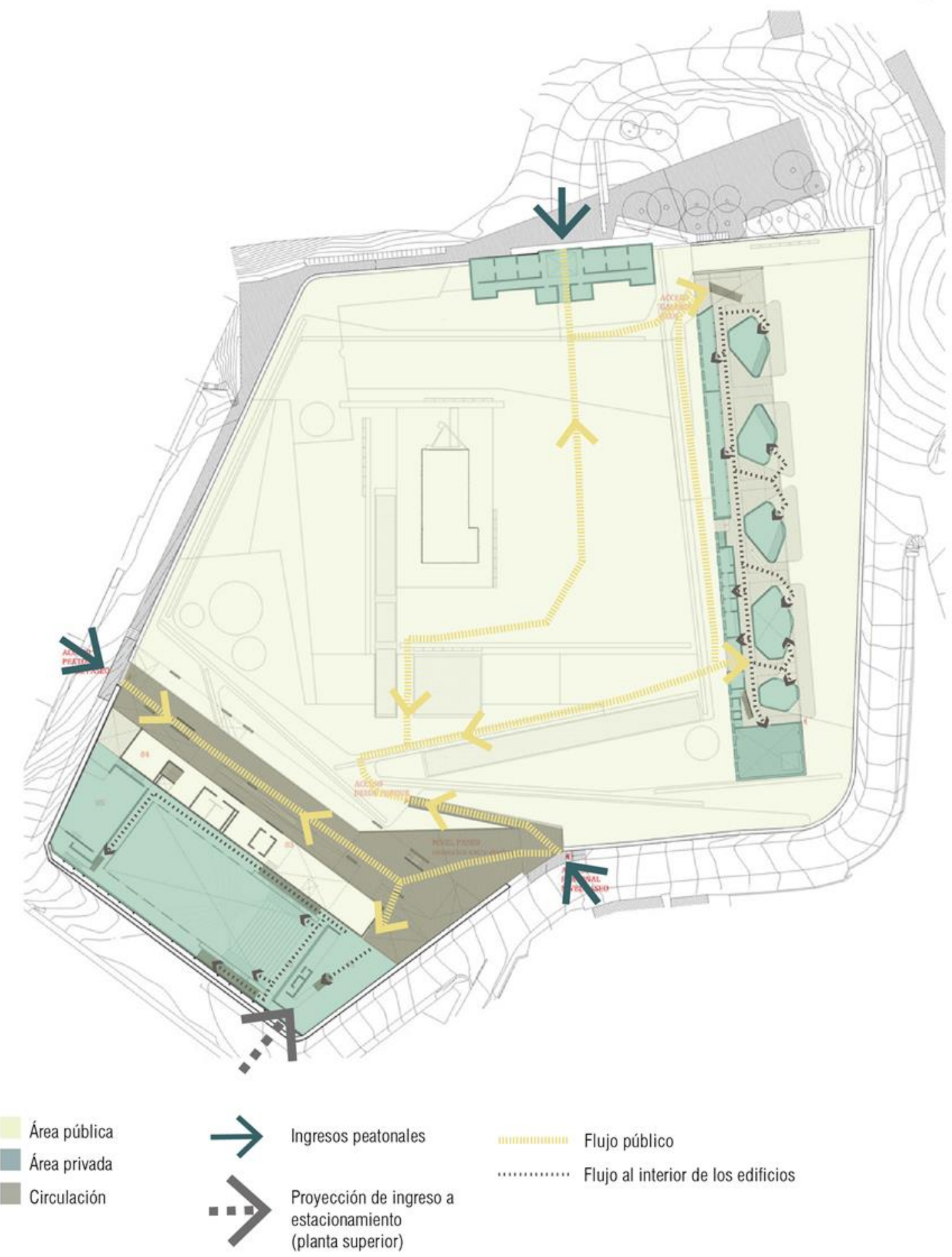




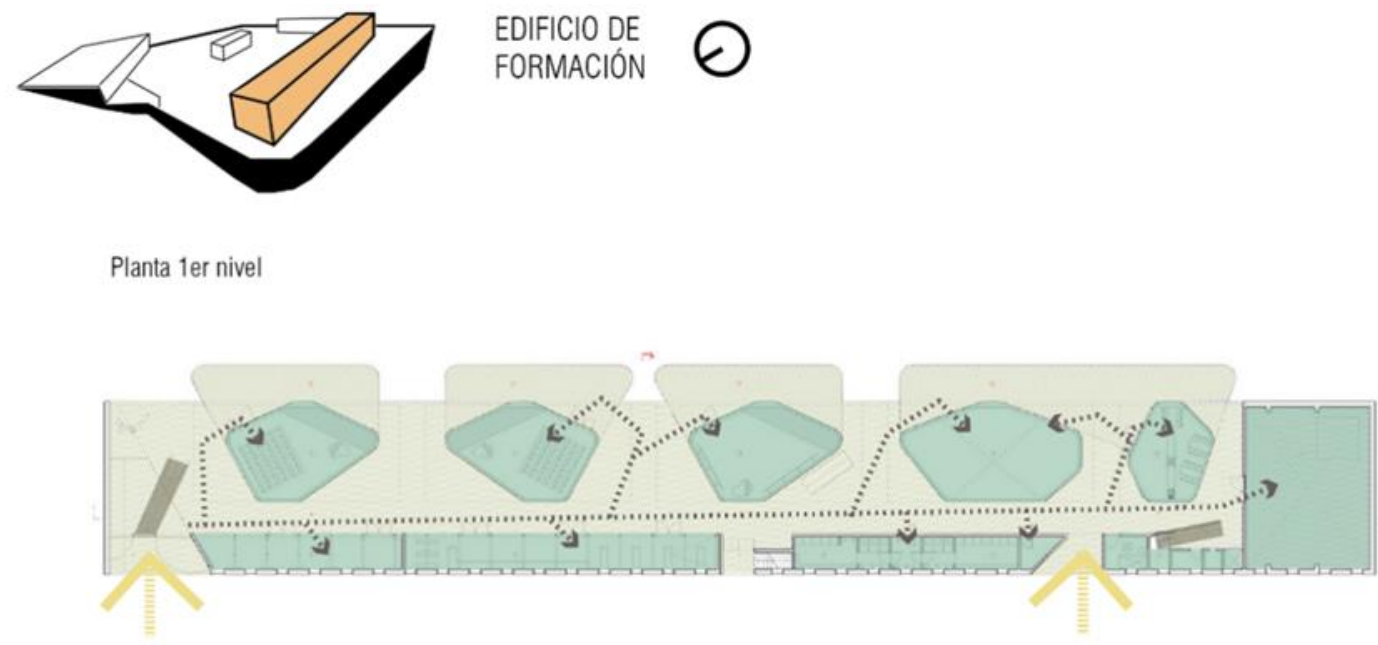

Planta 2do nivel
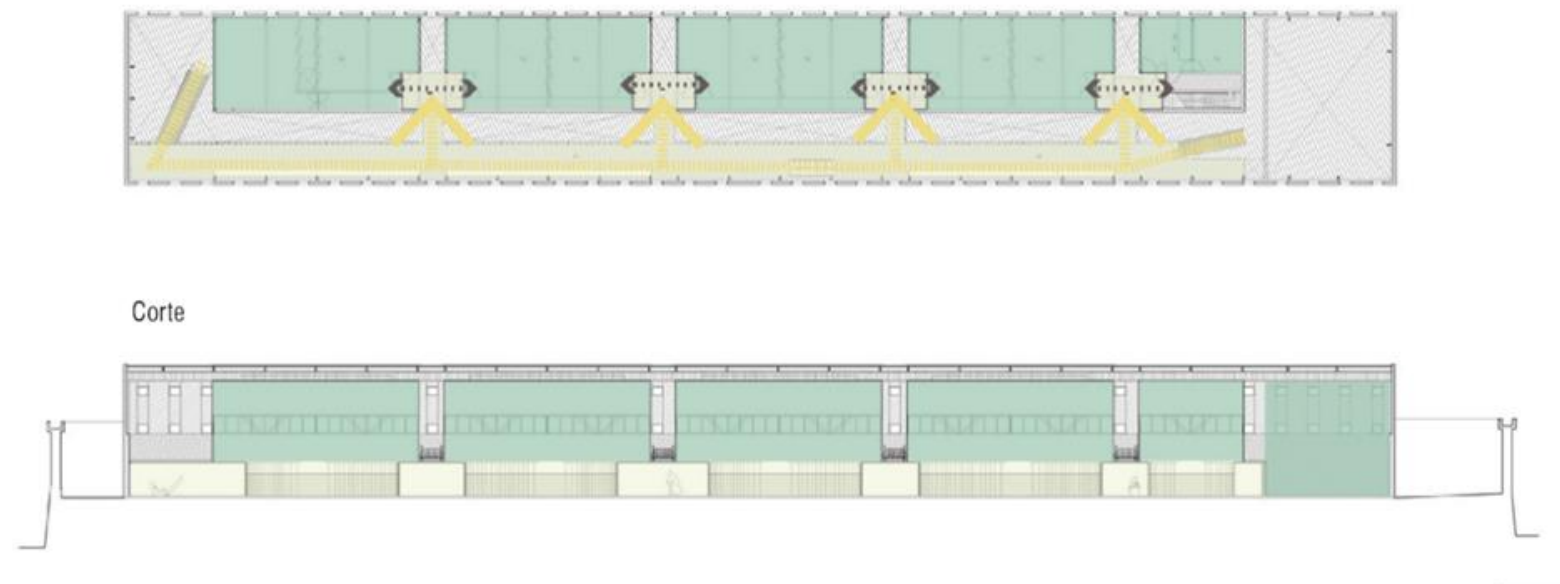

Área pública

Área privada

Circulación
Flujo público

Flujo al interior de los edificios 


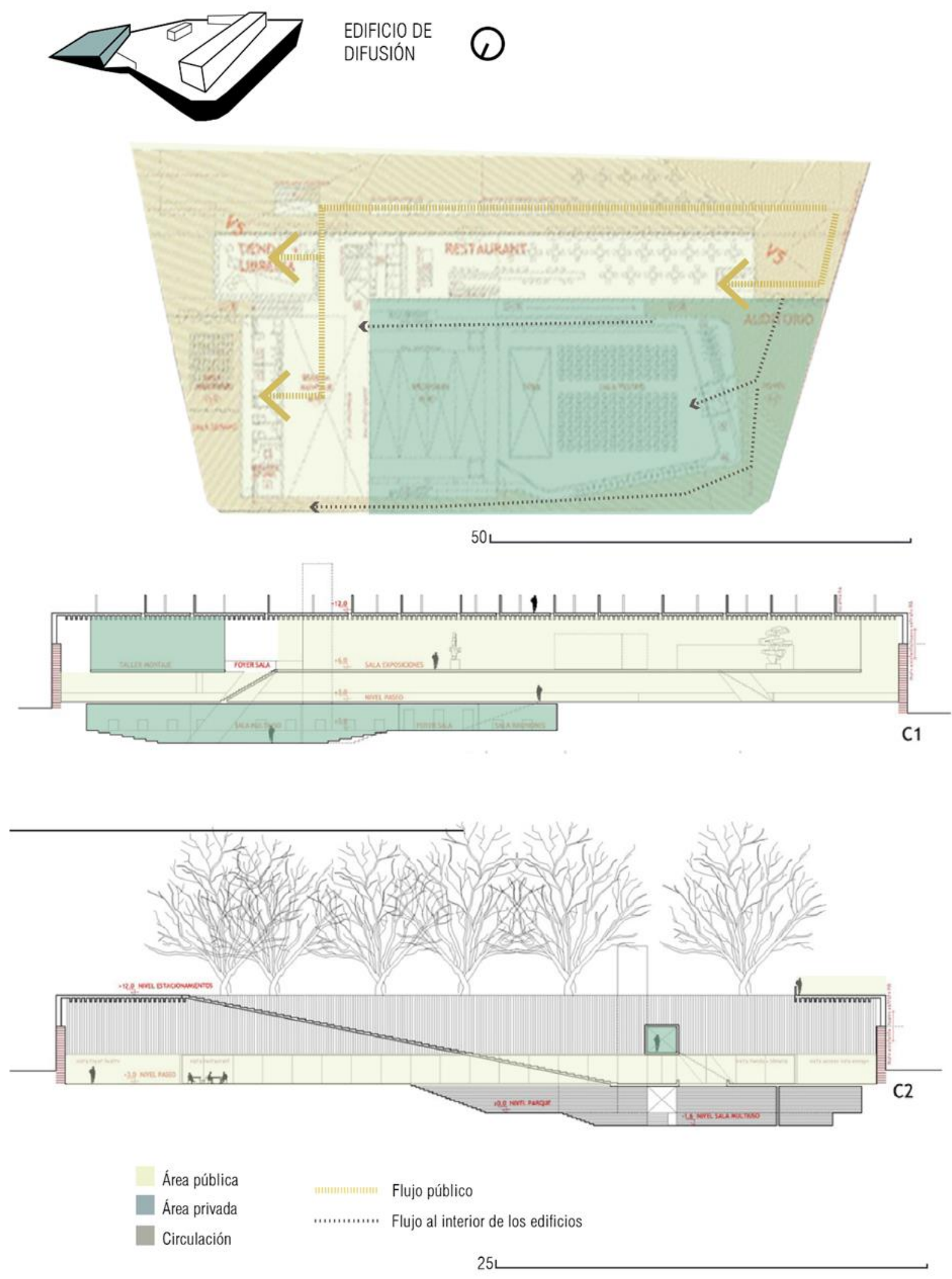




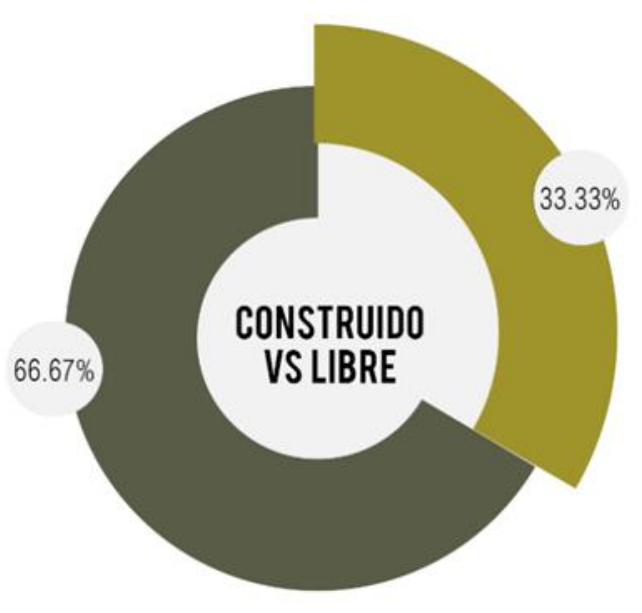

Área libre

Área construida

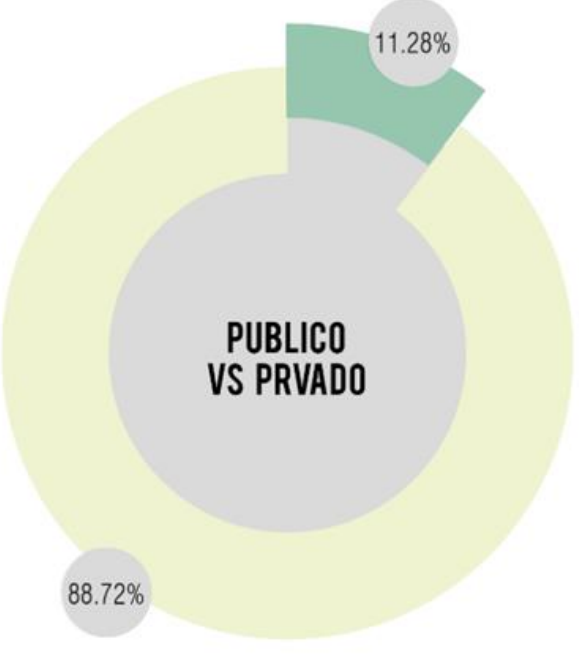

Área pública

Área privada

\subsubsection{Tecnología estructural}

La galería de reos de la ex cárcel, ha mantenido su estructura de concreto. Sin embargo, los proyectistas han decidido adosar una estructura metálica moderna para reforzar la estructura preexistente.

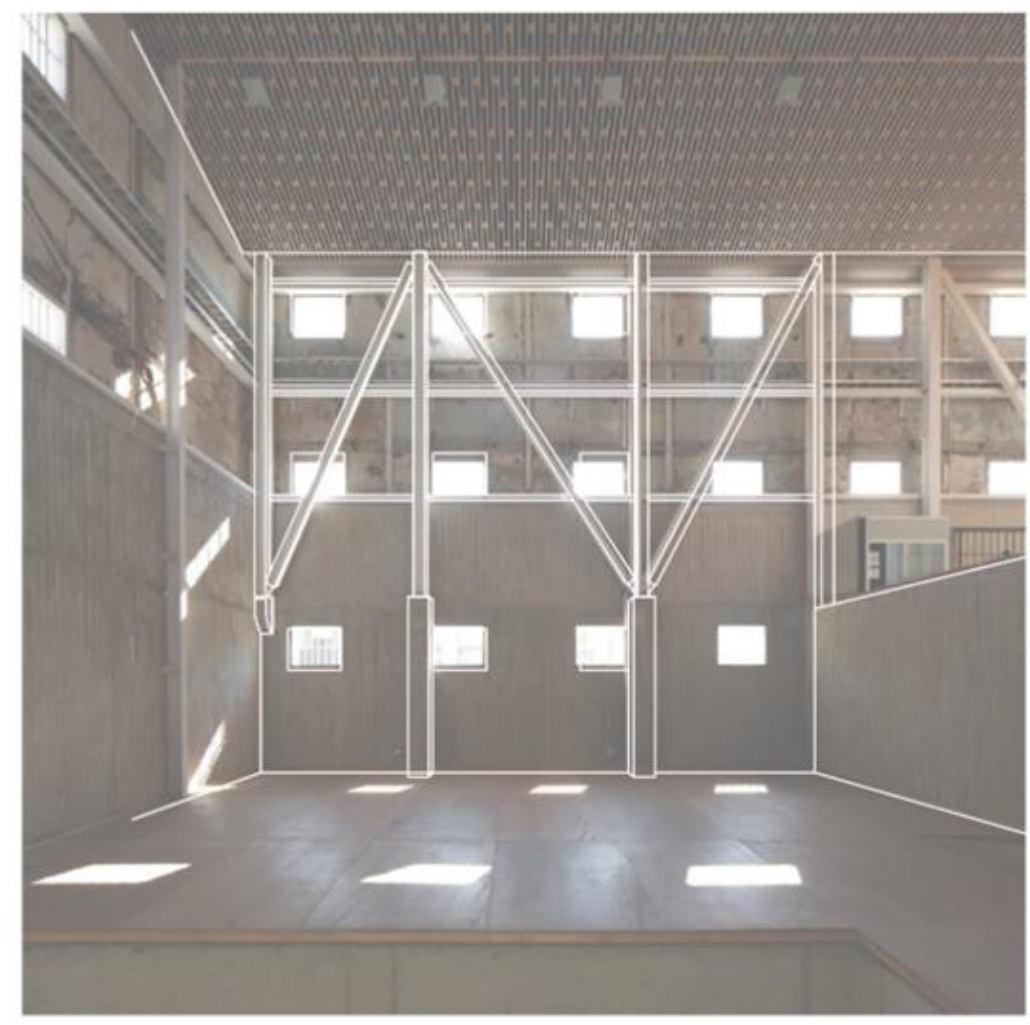



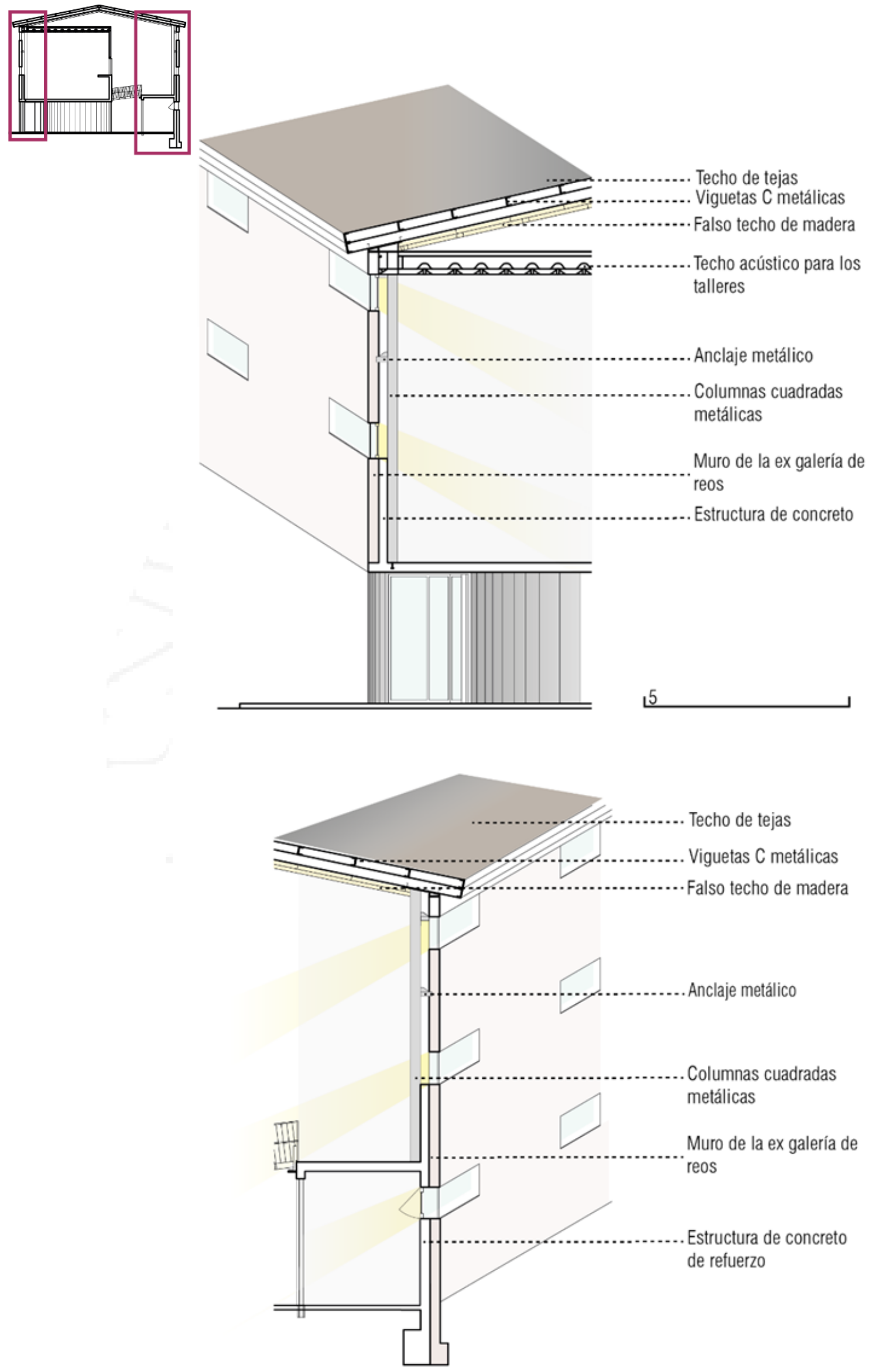


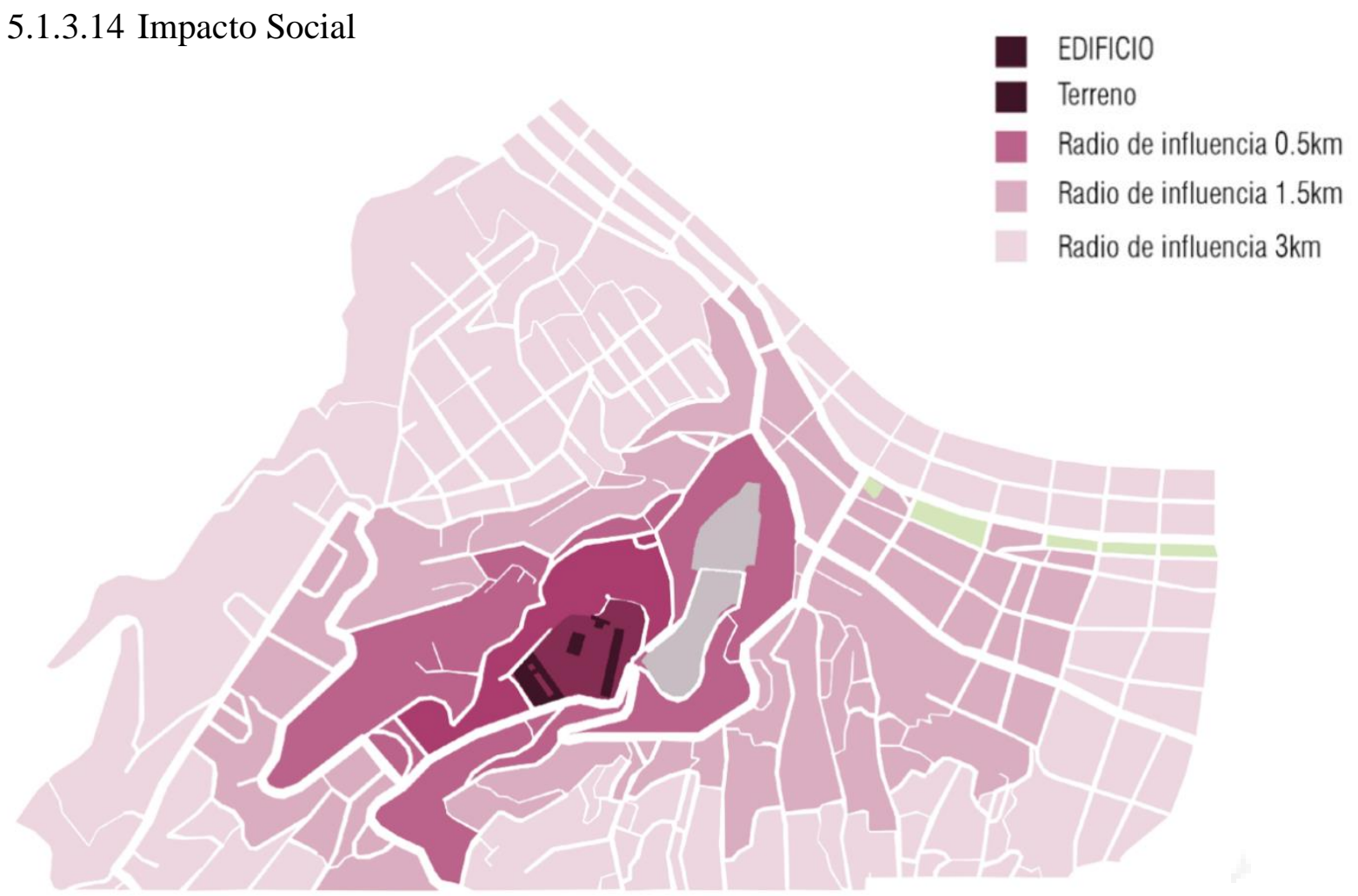

5.1.3.15 Galería de fotos

Ilustración 5.8 Vista de la explanada central y la ex galería de reos.

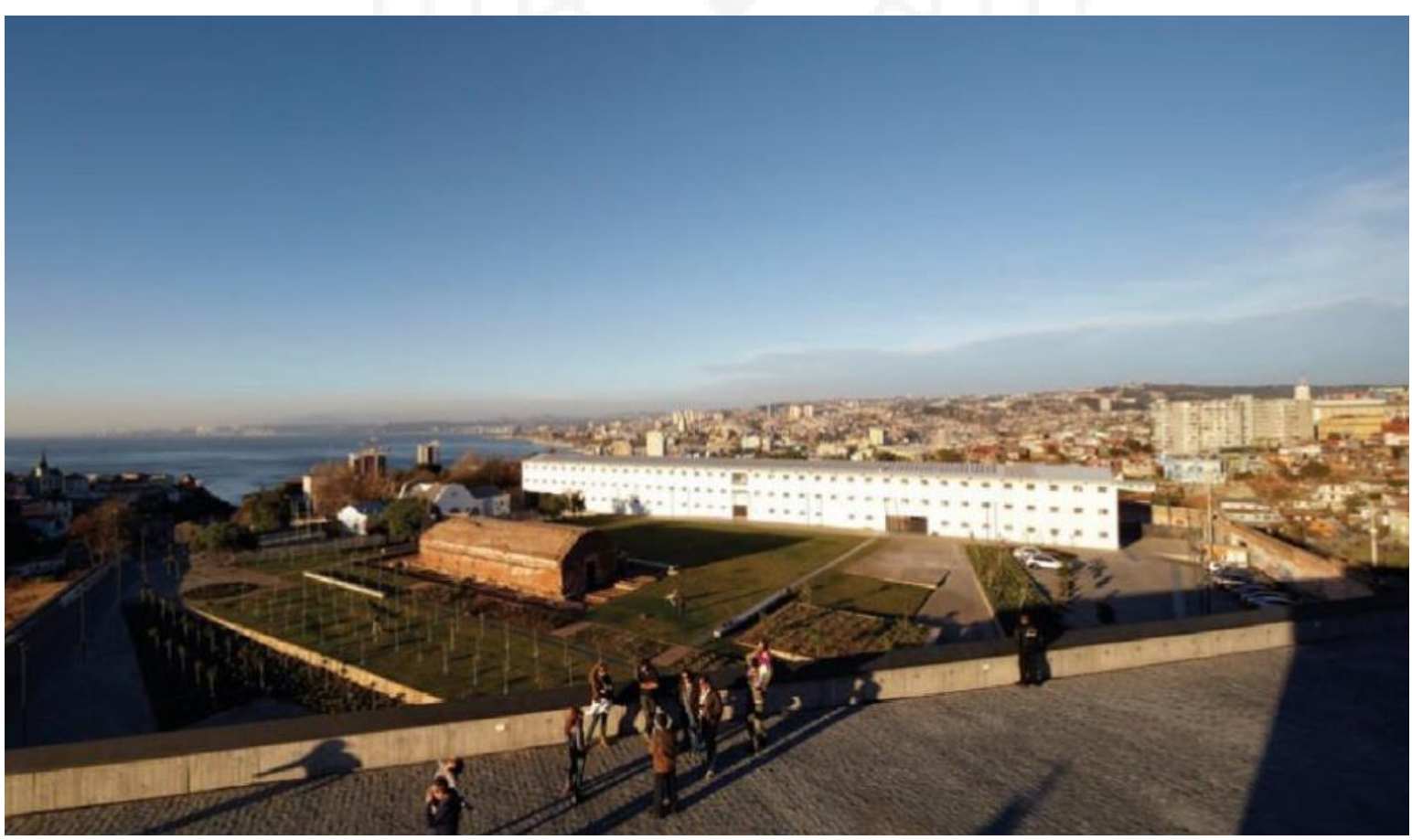

Fuente: Recuperado de www.archdaily.com 
Ilustración 5.9 Nuevo bloque que completa el borde

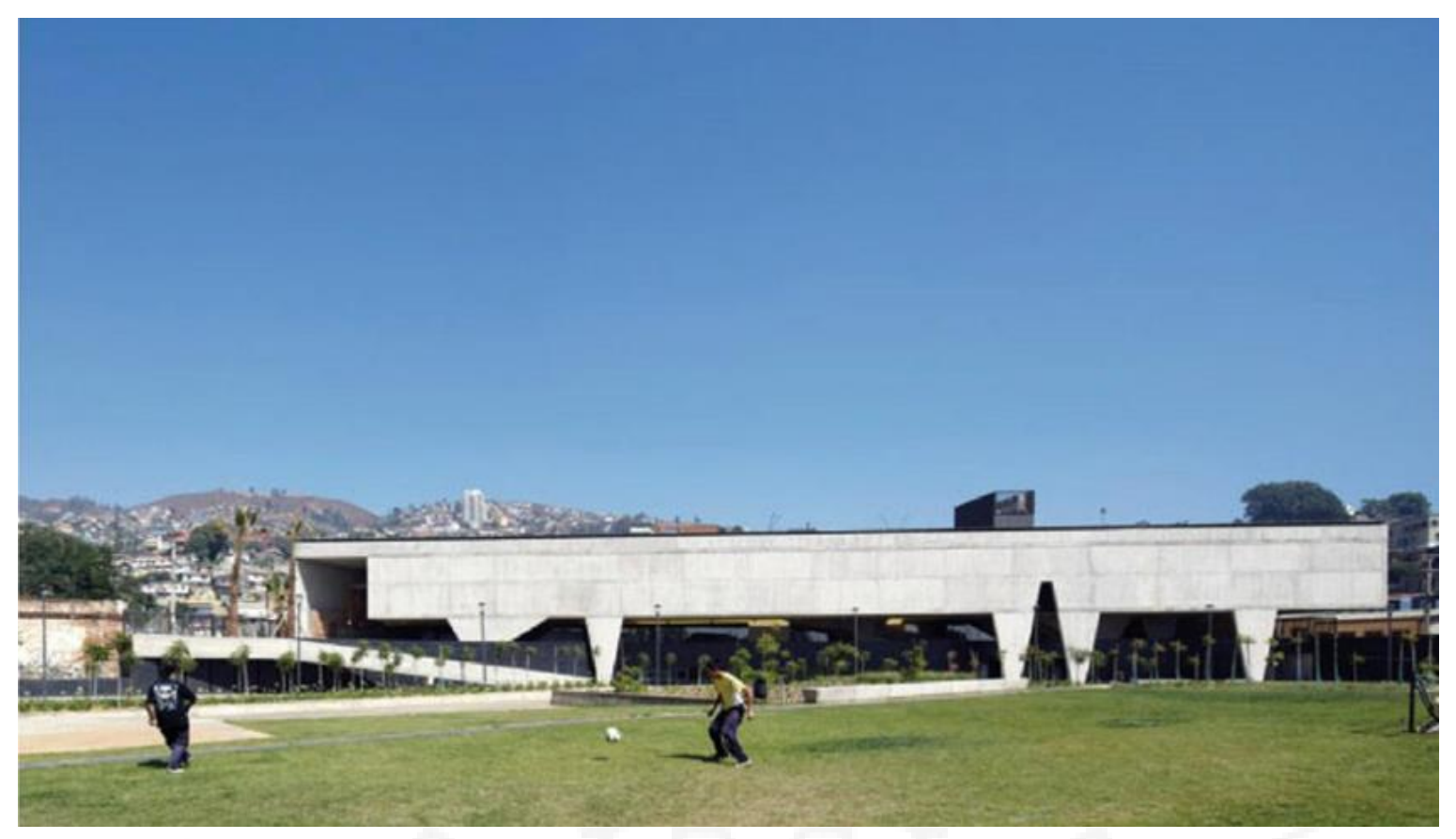

Fuente: Recuperado de www.archdaily.com

Ilustración 5.10 Interior de la ex galería de reos que alberga talleres.

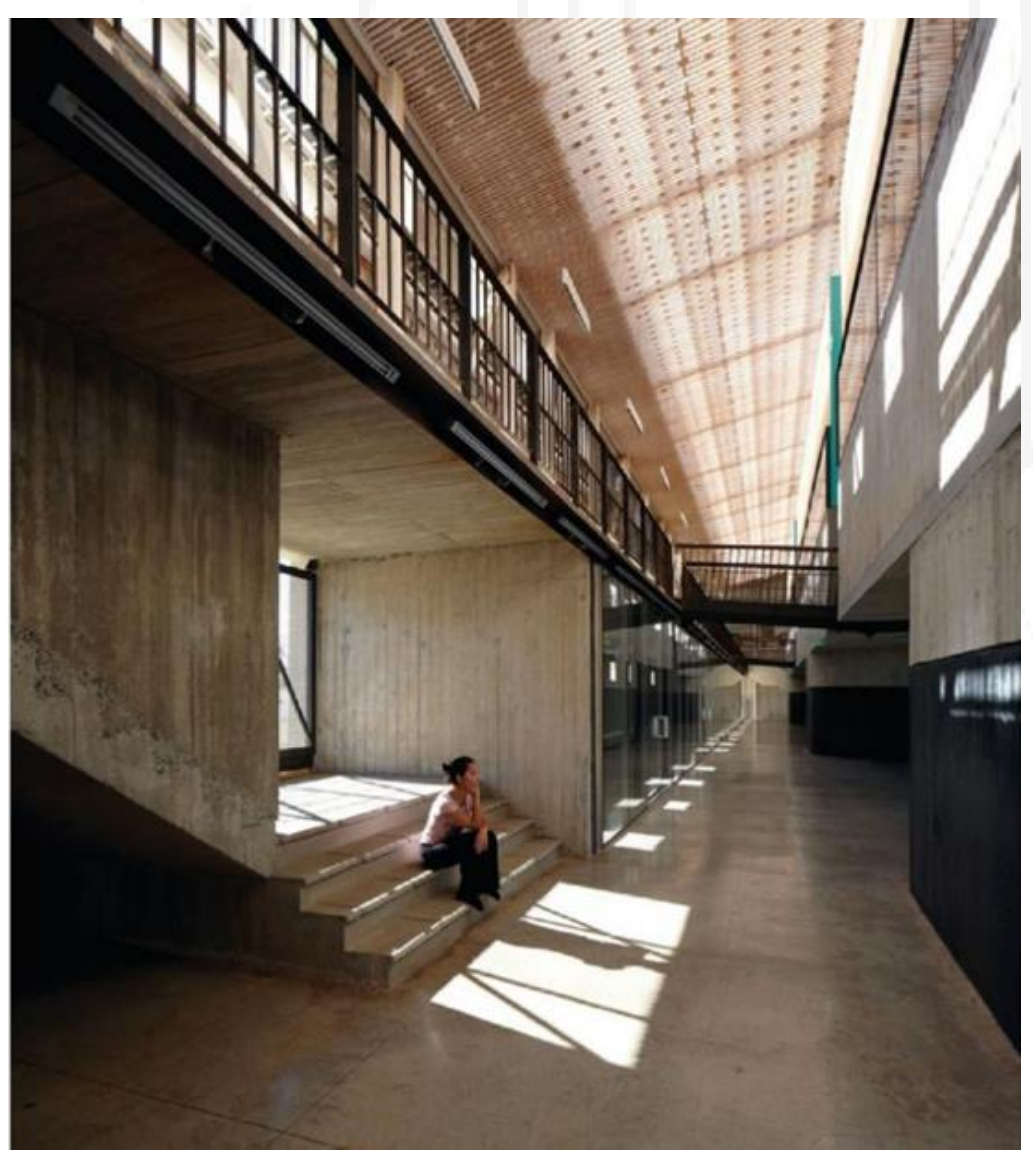

Fuente: Recuperado de www.archdaily.com 


\subsubsection{Escuela de Artes Le Fresnoy}

\subsubsection{Datos Generales}

La escuela de artes Le Fresnoy, es un complejo de arte, que alberga escuela, un estudio de cine, dos cines y laboratorios de investigación y producción de sonido, imagen, video y cine. Fue proyectado por el arquitecto Bernad Tschumi sobre sitios con edificios abandonados, en Tourcoing - Francia.

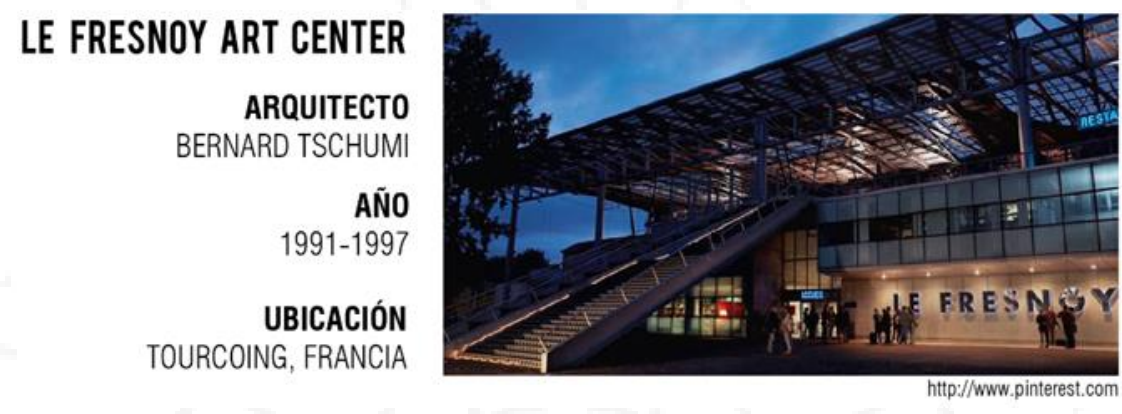

5.1.4.2 Historia

Boom de la

tecnología

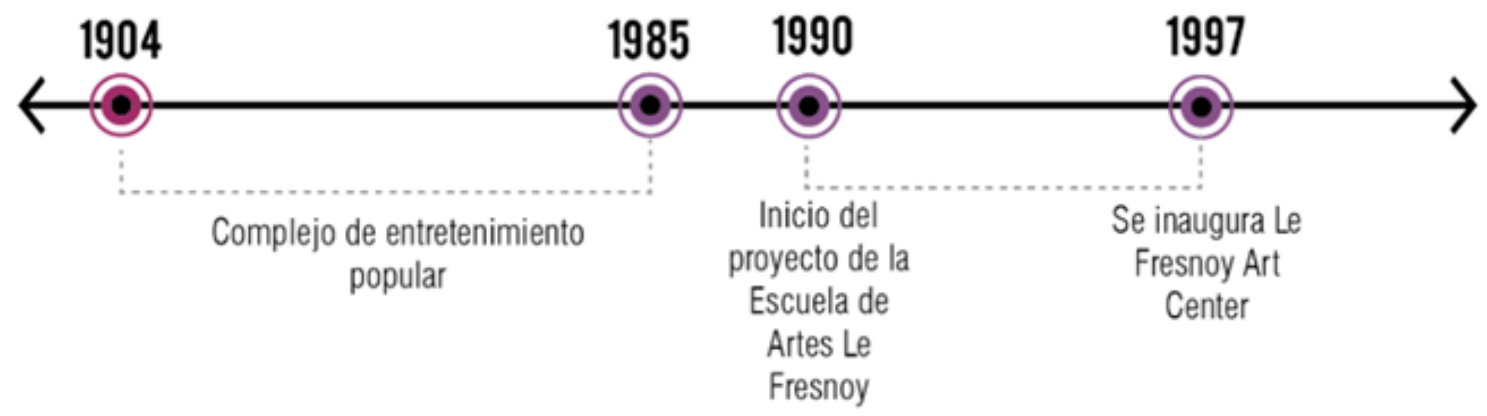

\subsubsection{Ubicación}

Le Fresnoy, se emplaza en uno de los lugares más alejados del corazón de la ciudad. Con una dinámica de rehabilitación y regeneración urbana, tan propia de nuestro contexto, reactiva un antiguo complejo recreativo que ocupaba un área degradada, dentro de un tejido residencial de densidad baja, al cual engancha a toda la estructura cultural urbana, incorporándolo al movimiento social de la ciudad (ETSA Sevilla, 2014, parr. 7). 
Plano de localización y ubicación
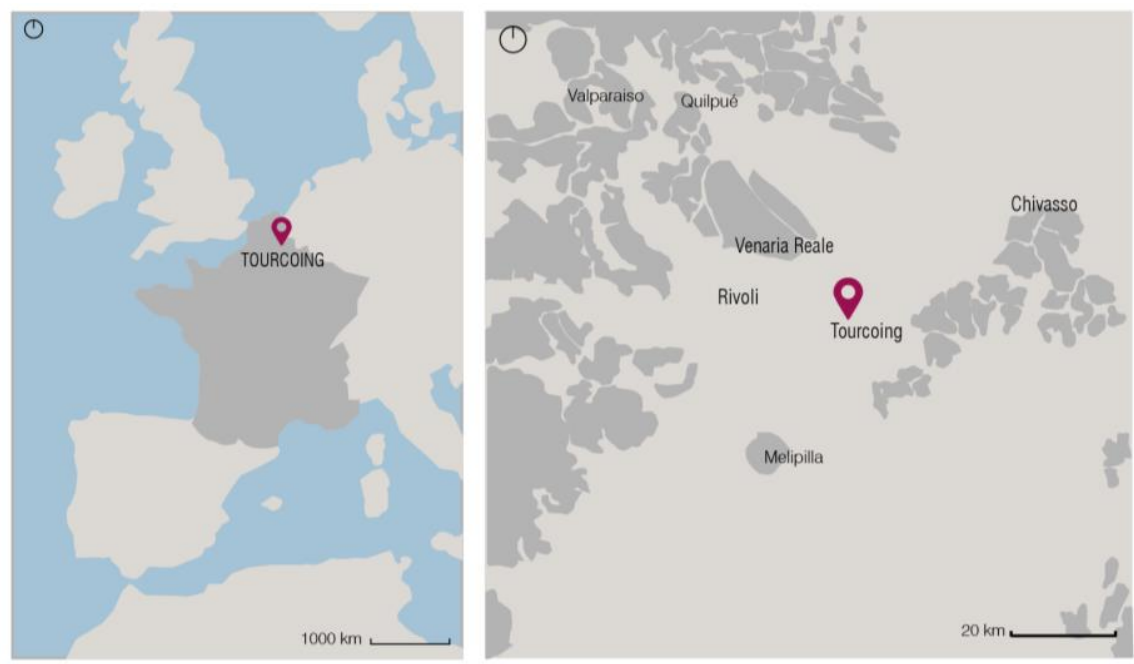

Relación con el entorno

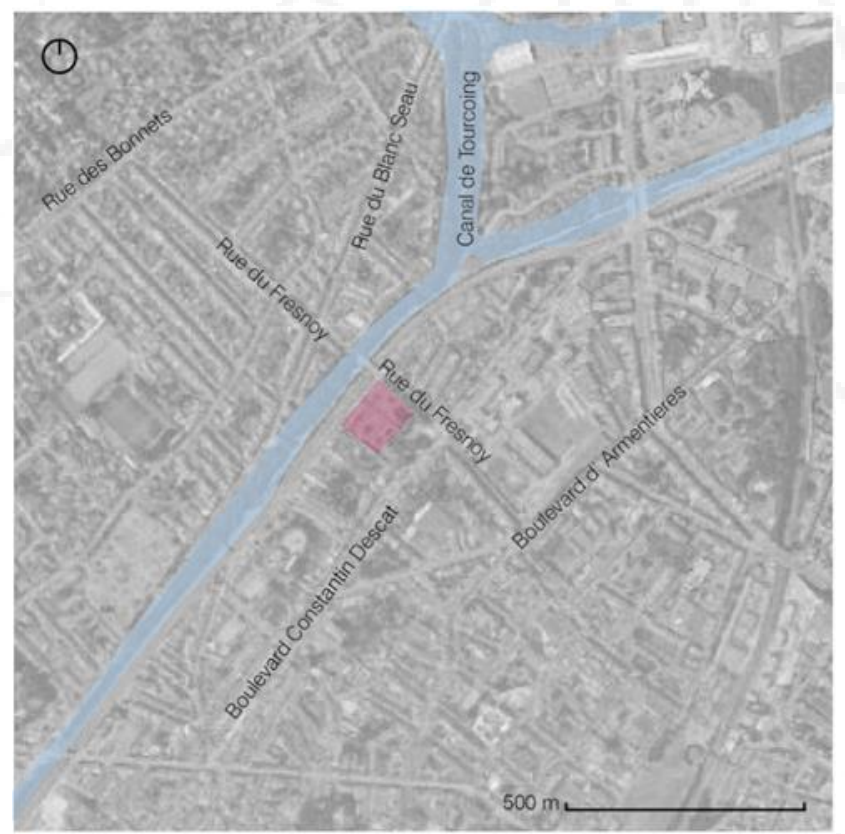

\subsubsection{Toma de partido}

Bernard Tschumi decidió mantener las estructuras existentes, protegiéndolas con una cubierta metálica que se sitúa sobre todo el proyecto. El proyecto parece una cinta, la cubierta parte del suelo para envolver la fachada oeste, permitiendo delimitar lo existente de lo nuevo. Al interior de ella, se puede observar como el espacio está conformado por una sucesión de cajas que a su vez albergan espacios más pequeños. 
La gran cubierta es una pieza clave para el desarrollo de todo el proyecto, especialmente a nivel estructural, debido a que forma el espacio intermedio entre las cubiertas, donde se encuentran las pasarelas, elementos de conexión horizontal (ETSA Sevilla, 2014, parr. 9).

1. Nace de dos intenciones: la reactivación del edificio y la repercusión en el contexto urbano.

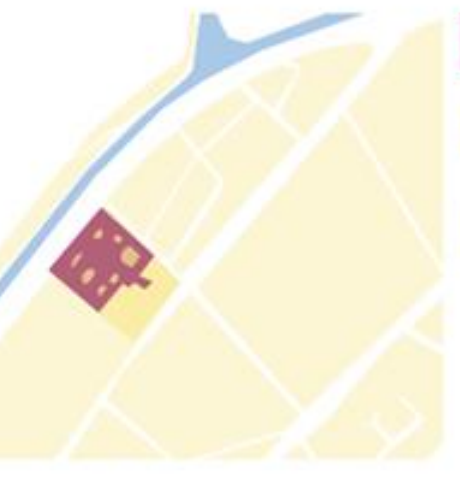

Edificio Antiguo

Acción sobre

el lote

Acción sobre el

contexto urbano

2. Visión conjunta de:

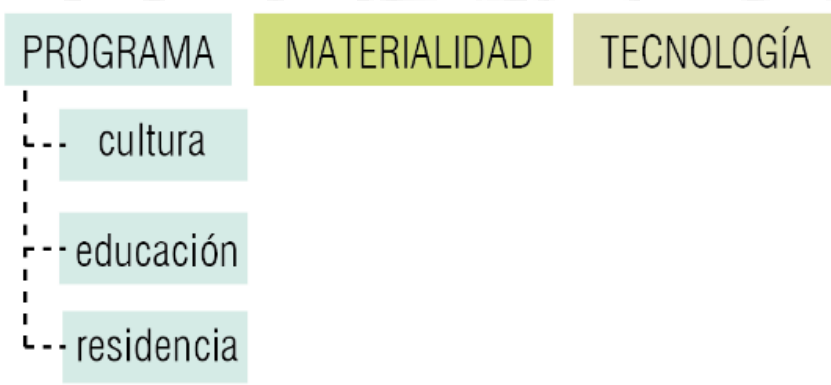

3. Prescindir de las naves más deterioradas, protegiendo lo más excepcional para generar una gran cubierta de metal gris.

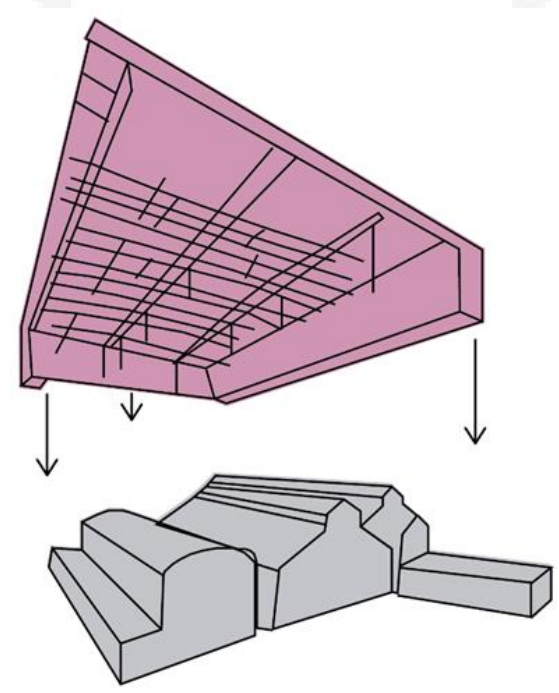


4. La cubierta juega un papel conceptual y estructural, que a su vez genera un espacio intermedio y conexiones horizontales a través de pasarelas.

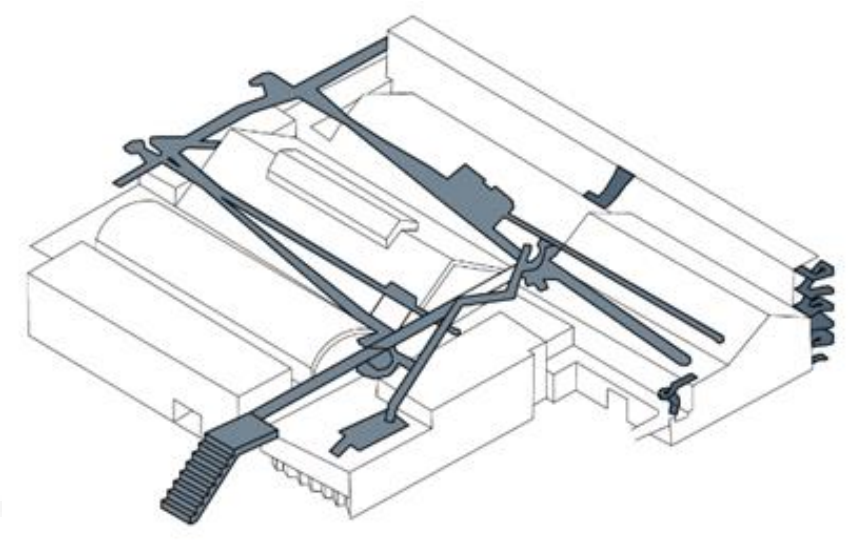

\subsubsection{Análisis vial}

\section{Vías}

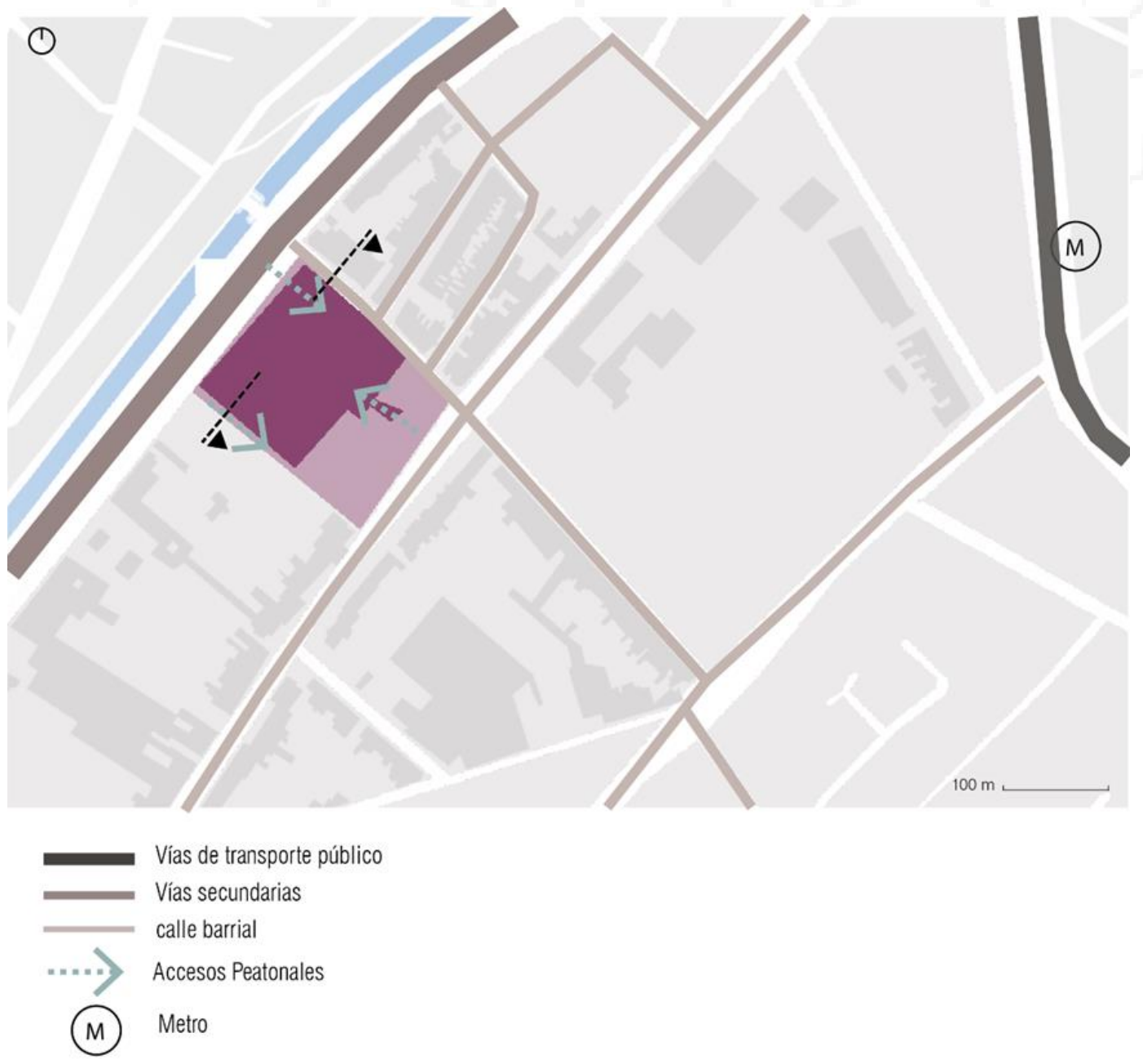


Relación con el entorno

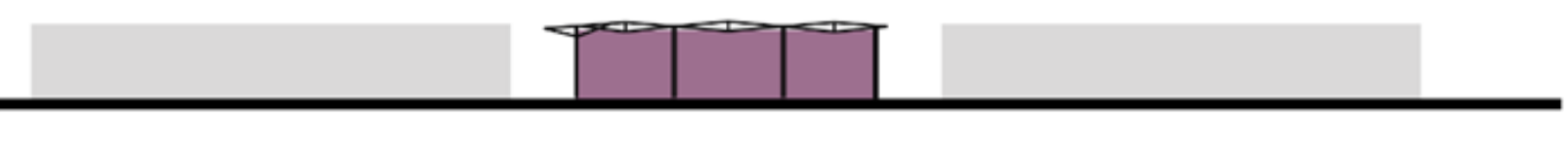

$100 \mathrm{~m}$

\subsubsection{Programa}

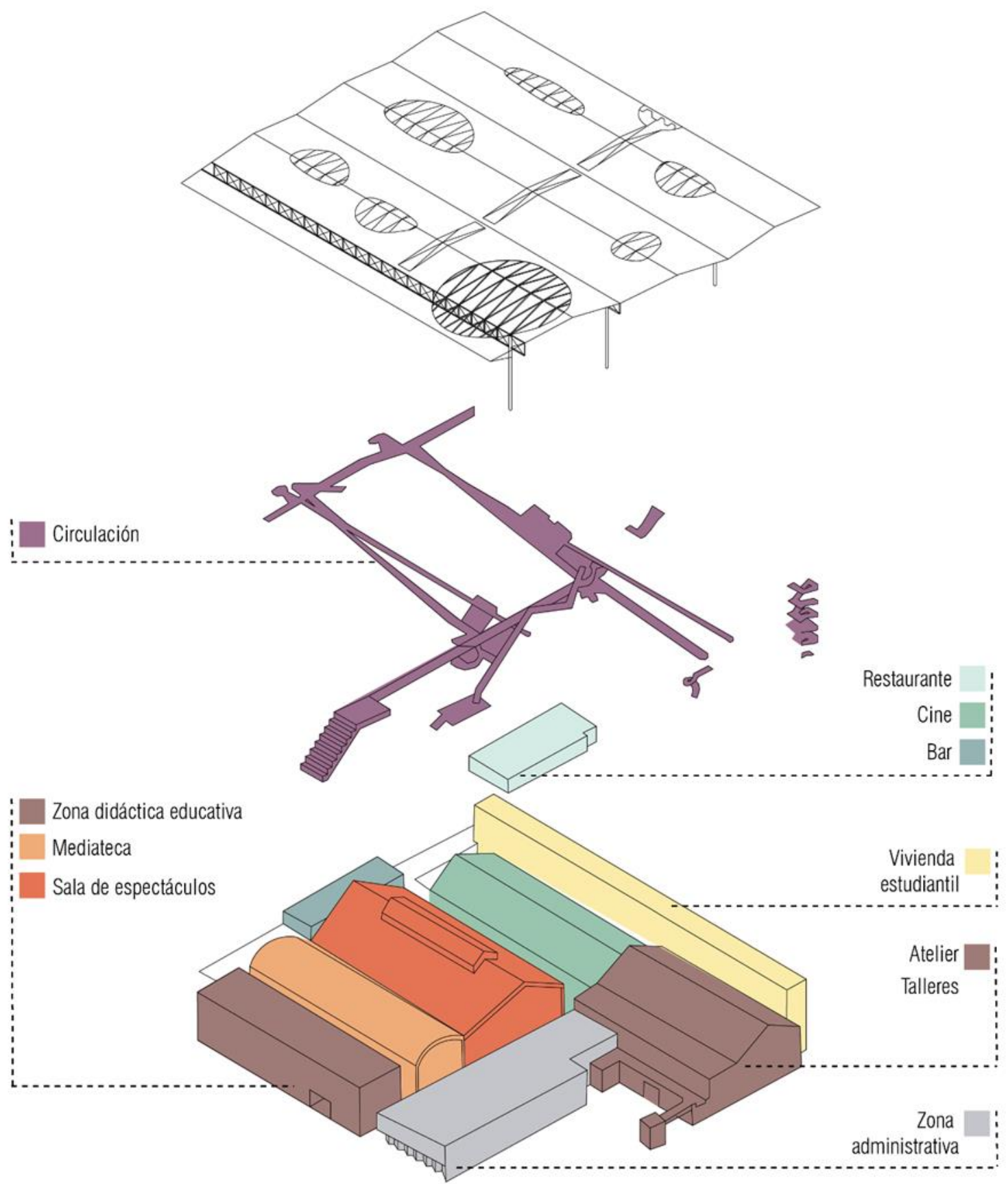

$50 \mathrm{~m}$ 


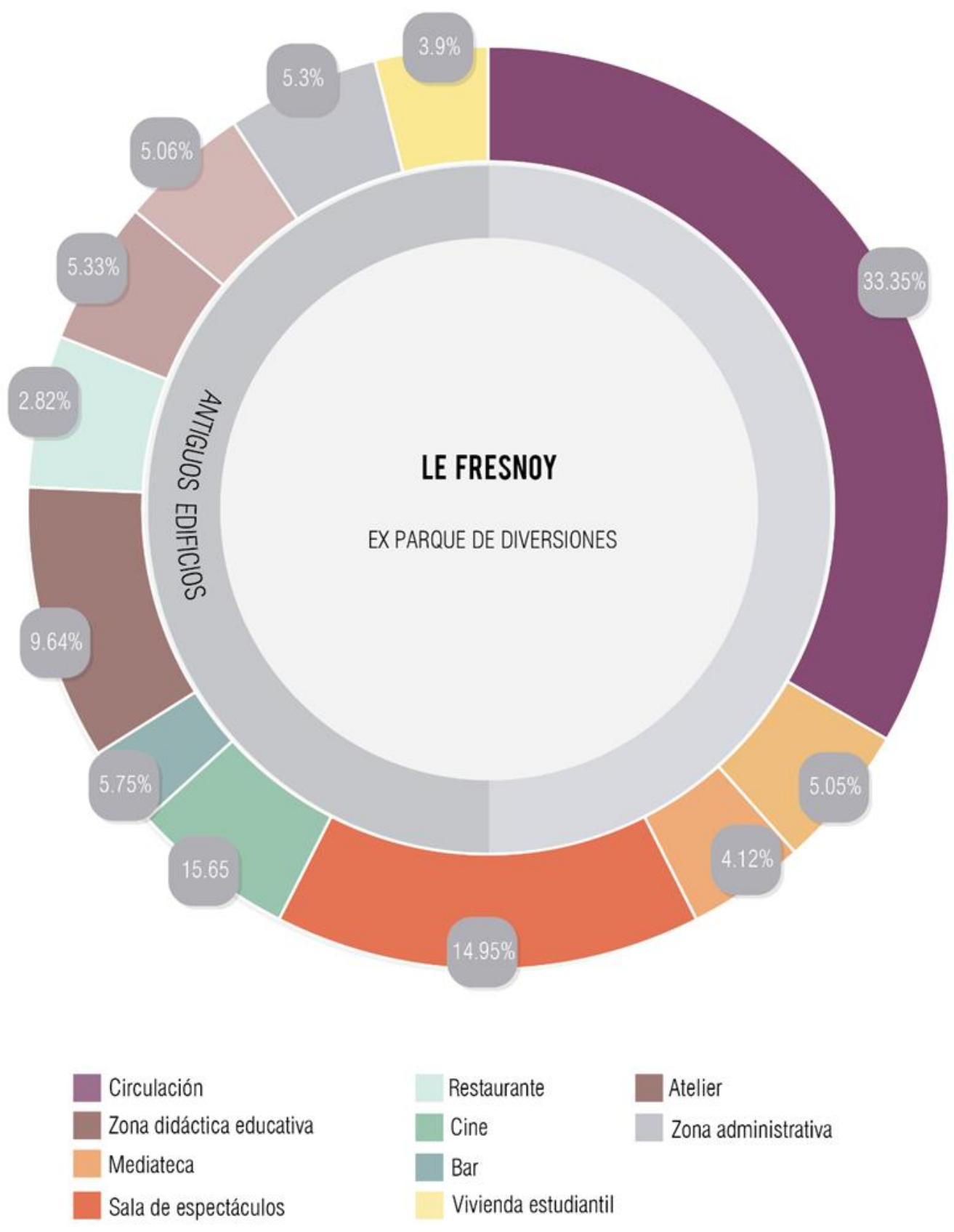




\subsubsection{Organización funcional}
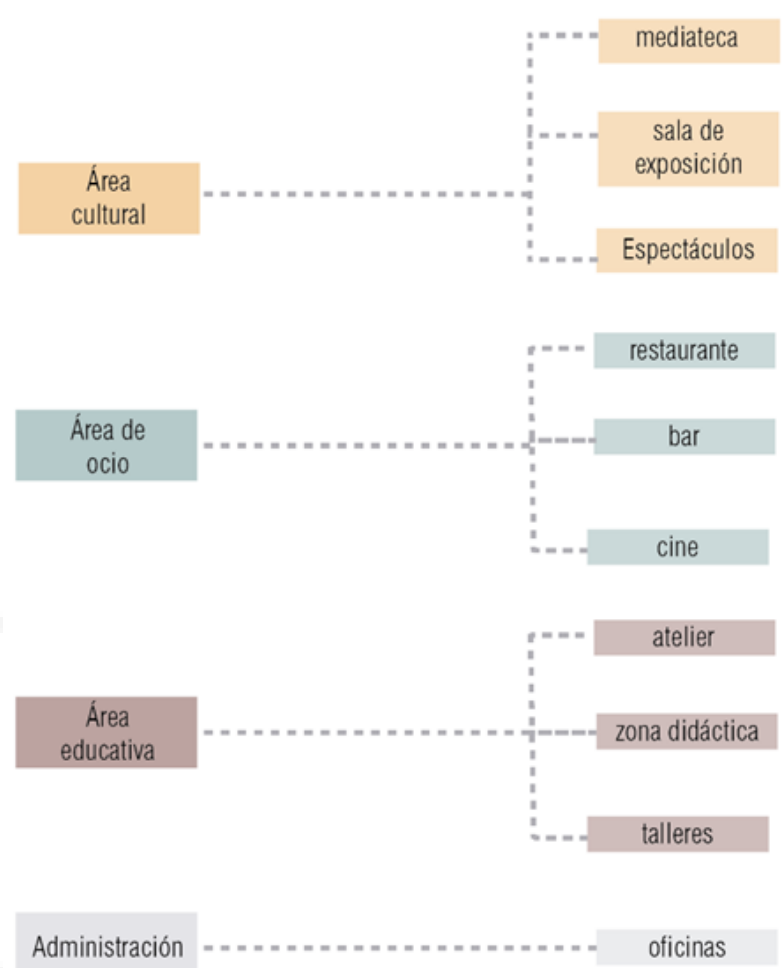

Viviendas

Estudiantiles

viviendas

\subsubsection{Relaciones espaciales}

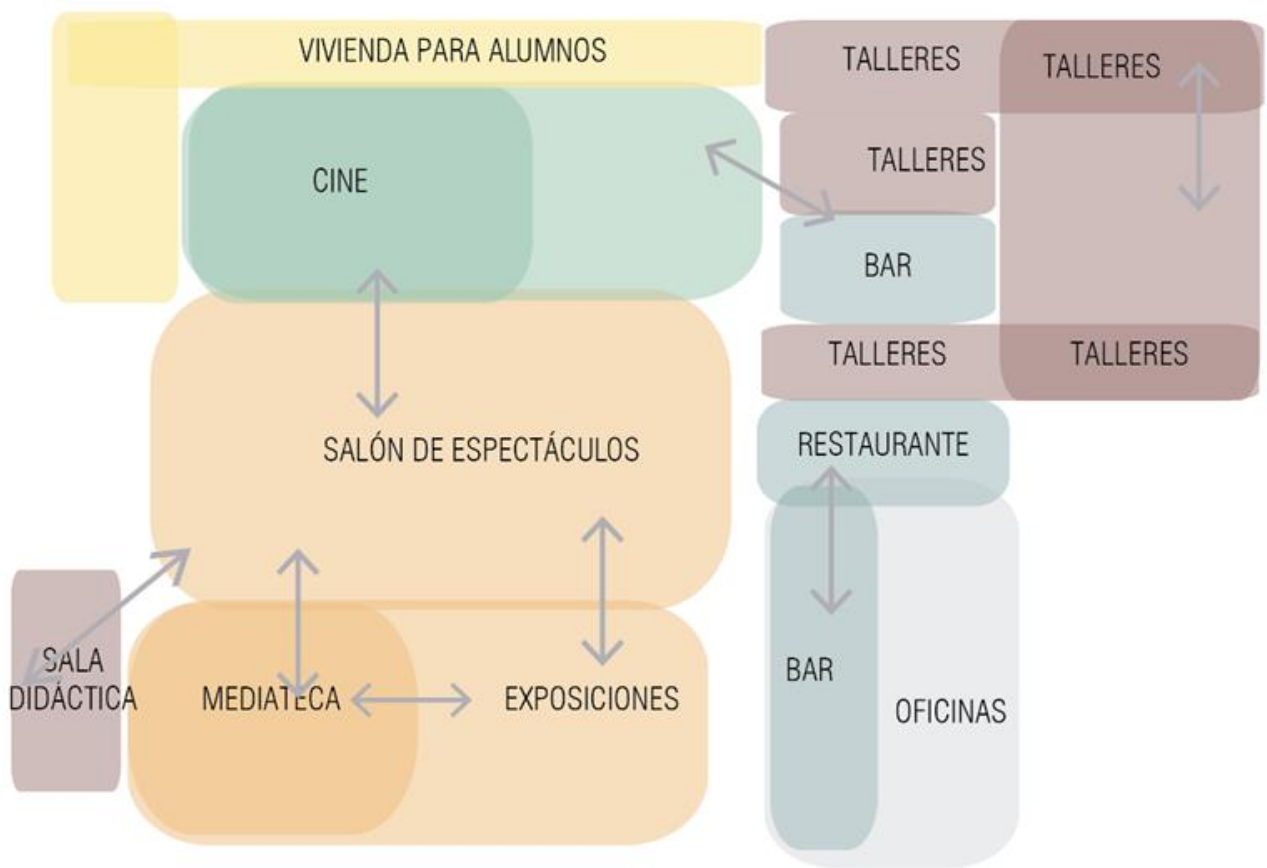




\subsubsection{Distribución espacial}

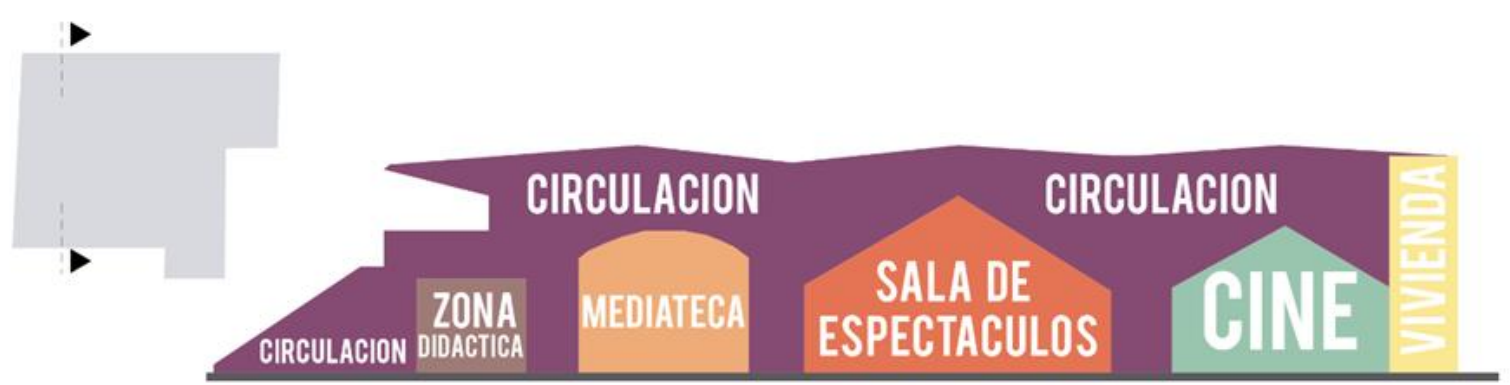

5.1.4.10 Cuadro de áreas

\begin{tabular}{|c|c|c|c|}
\hline ÁREA & ESPACIO & METRAJE & TOTAL \\
\hline CIRCULACIÓN & Circulación & $3557 \mathrm{~m} 2$ & $3557 \mathrm{~m} 2$ \\
\hline \multirow{3}{*}{$\begin{array}{c}\text { ÁREA } \\
\text { CULTURAL }\end{array}$} & mediateca & $538.97 \mathrm{~m} 2$ & \multirow{3}{*}{$2575.18 \mathrm{~m} 2$} \\
\hline & exposición & $1145 \mathrm{~m} 2$ & \\
\hline & espectáculos & $1028.14 \mathrm{~m} 2$ & \\
\hline \multirow{3}{*}{$\begin{array}{c}\text { ÁREA } \\
\text { de ocio }\end{array}$} & bar / restaurante & $614 m 2$ & \multirow{3}{*}{$2575.18 \mathrm{~m} 2$} \\
\hline & bar & $301 \mathrm{~m} 2$ & \\
\hline & cine & $1028.14 \mathrm{~m} 2$ & \\
\hline \multirow{3}{*}{$\begin{array}{c}\text { ÁREA } \\
\text { EDUCATIVA }\end{array}$} & atelier & $568.40 \mathrm{~m} 2$ & \multirow{3}{*}{$1596.19 \mathrm{~m} 2$} \\
\hline & zona didáctica & $540.3 \mathrm{~m} 2$ & \\
\hline & talleres & $488 \mathrm{~m} 2$ & \\
\hline ADMINISTRACIÓN & oficinas & $570 \mathrm{~m} 2$ & $570 \mathrm{~m} 2$ \\
\hline \multirow[t]{2}{*}{ VIVIENDA EST. } & viviendas & $422.8 \mathrm{~m} 2$ & $422.8 \mathrm{~m} 2$ \\
\hline & & & $10665 \mathrm{~m} 2$ \\
\hline
\end{tabular}

\subsubsection{Tipología espacial}

1. Es un proyecto por agregación.

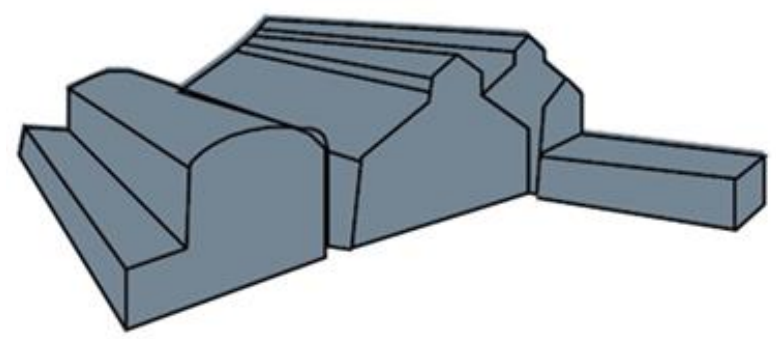

bloques existentes 
2. Al antiguo parque de Tourcoing se le agregó una cubierta.

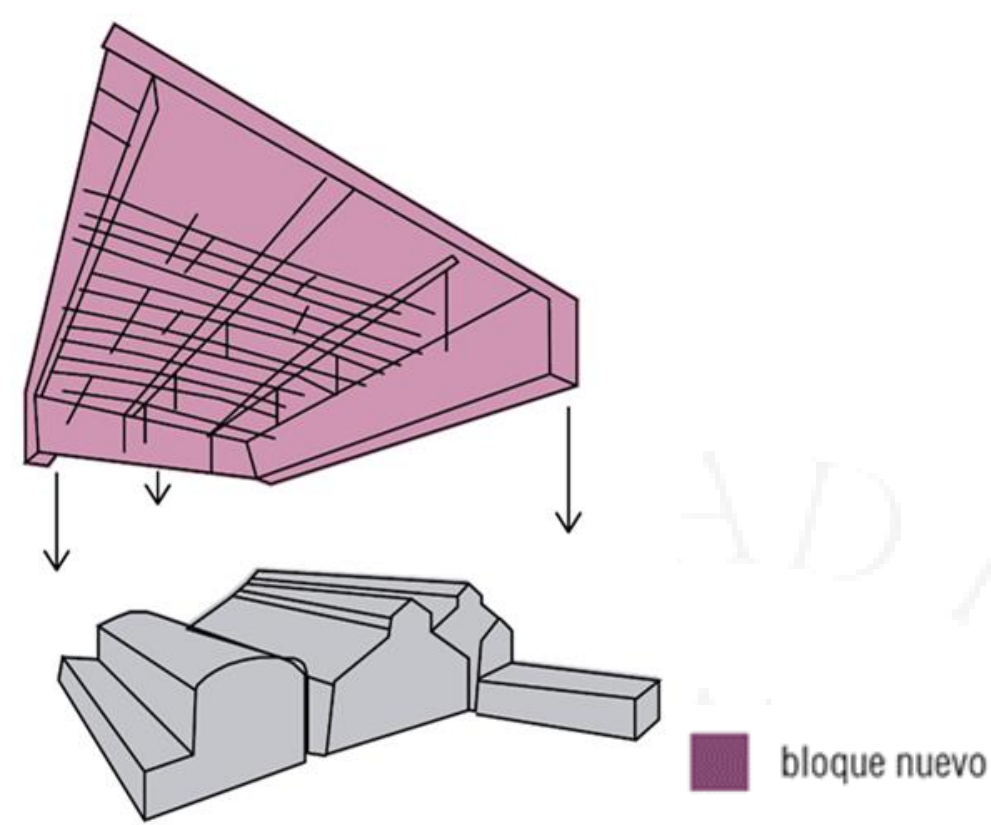

5.1.4.12 Relación público - privado

Planta general

(1)

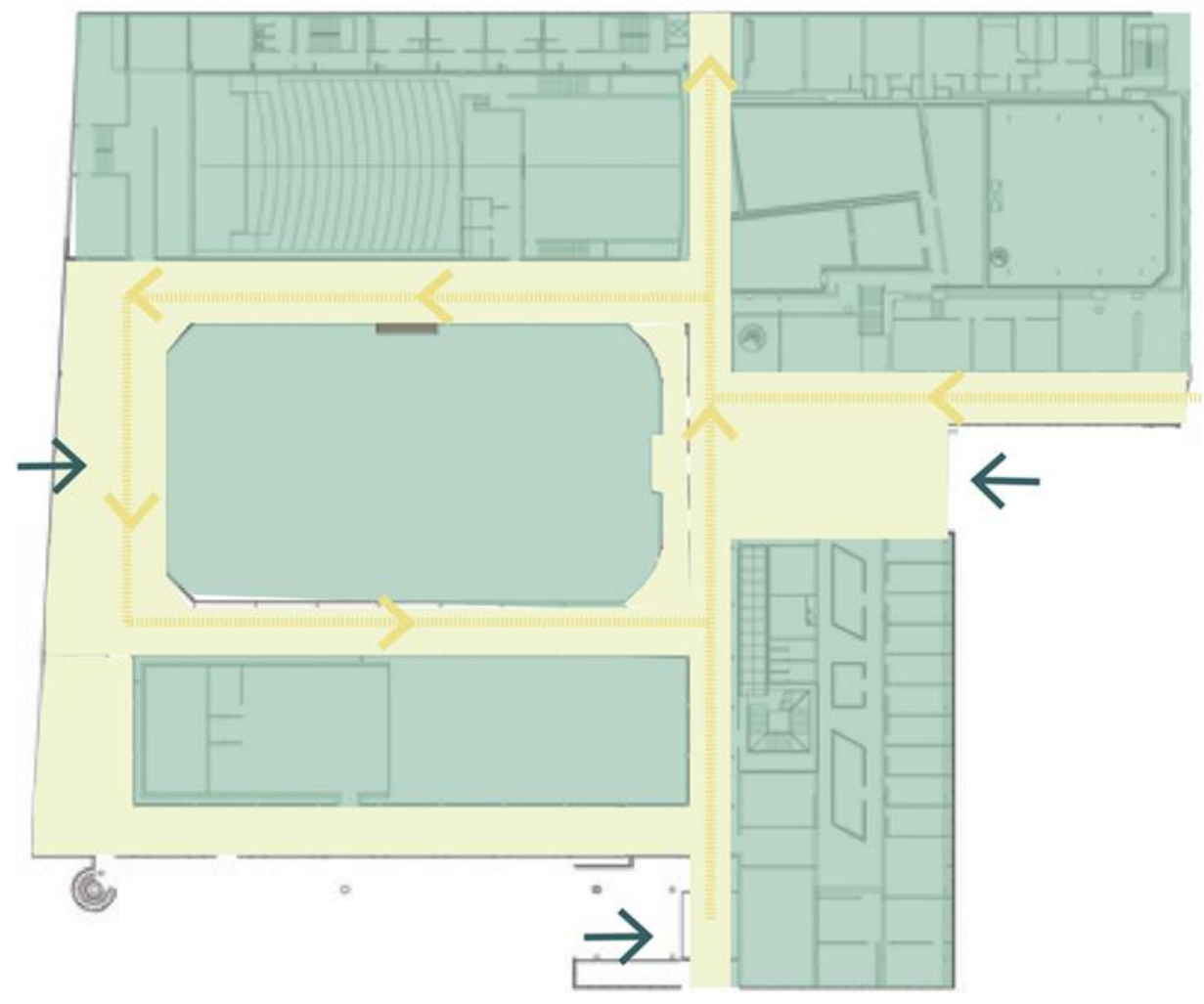




Área pública
Área privada
Circulación

$100 \mathrm{~m}$
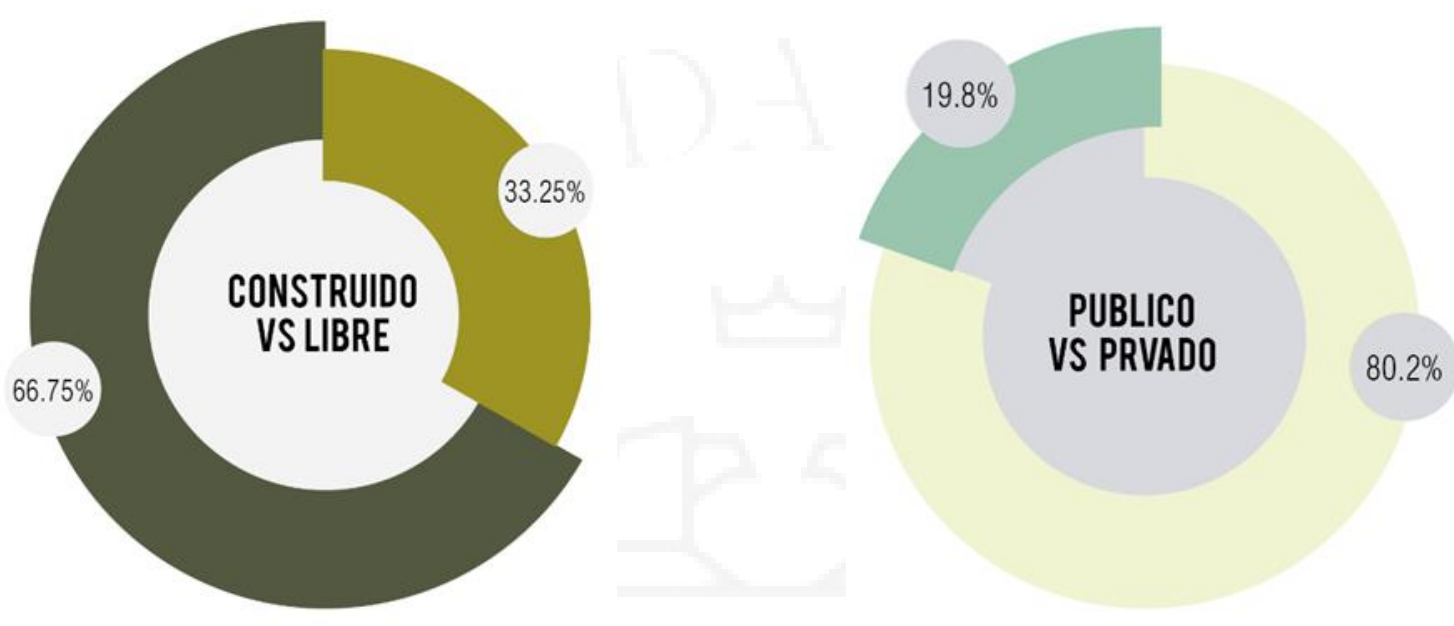

Área libre

Área construida

\section{Área pública}

Área privada

\subsubsection{Tecnología estructural}

La cubierta del proyecto compuesta por cerchas, estuvo alineada a lo tecnológico de los años 90, convirtiéndola en una estructura interesante de analizar, por su función programática, funcional y estructural, pues de esta se desprenden las pasarelas que conectan los espacios, permitiendo aprovechar el espacio al máximo espacio interior de cada caja.

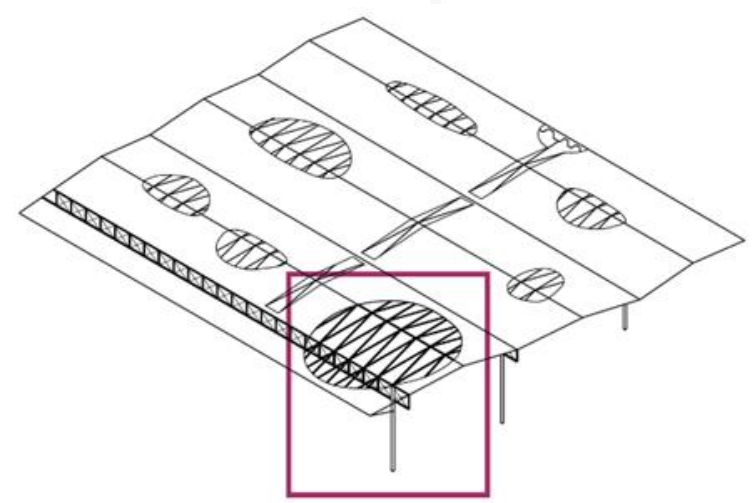




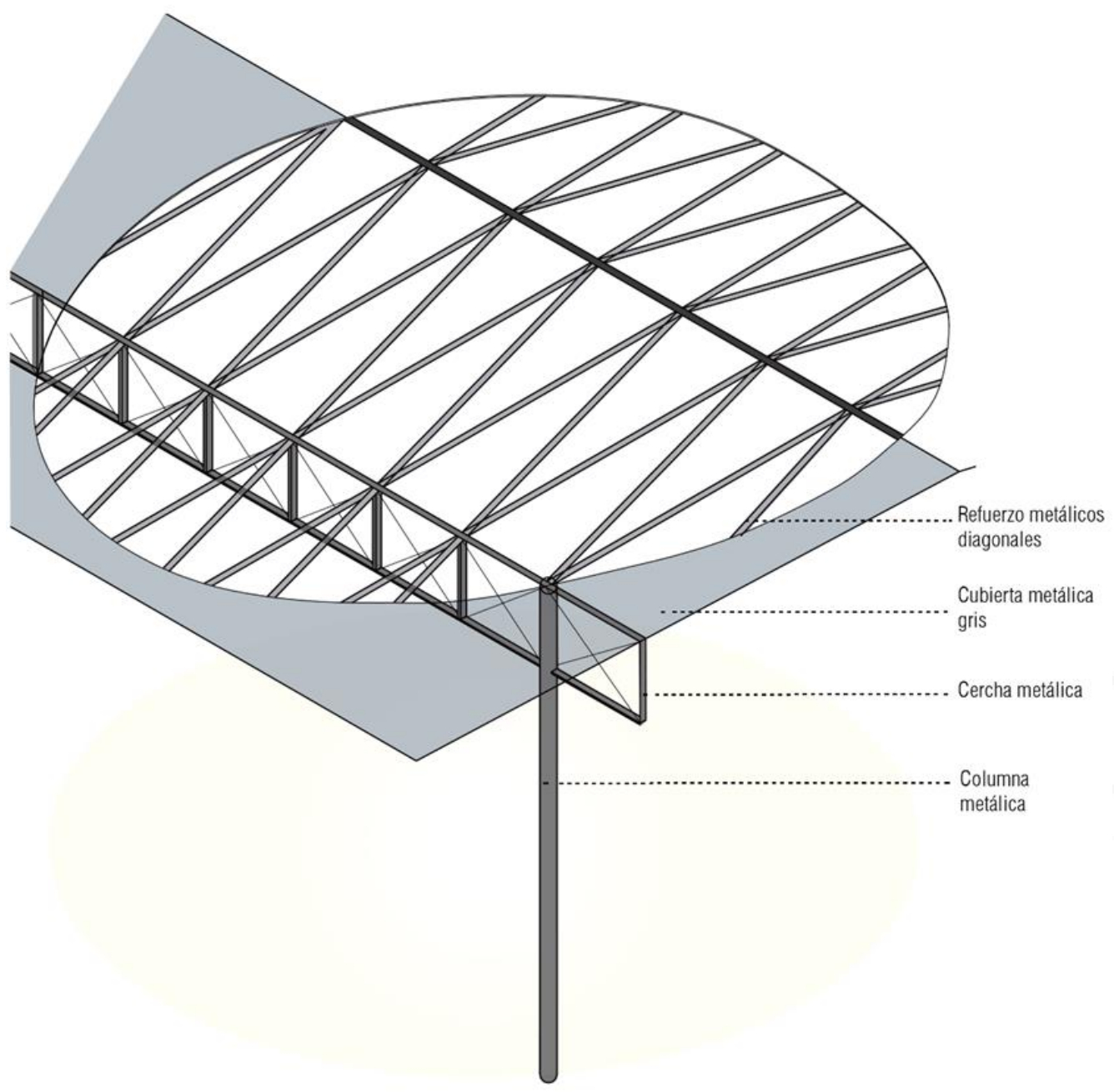

5.1.4.14 Impacto social

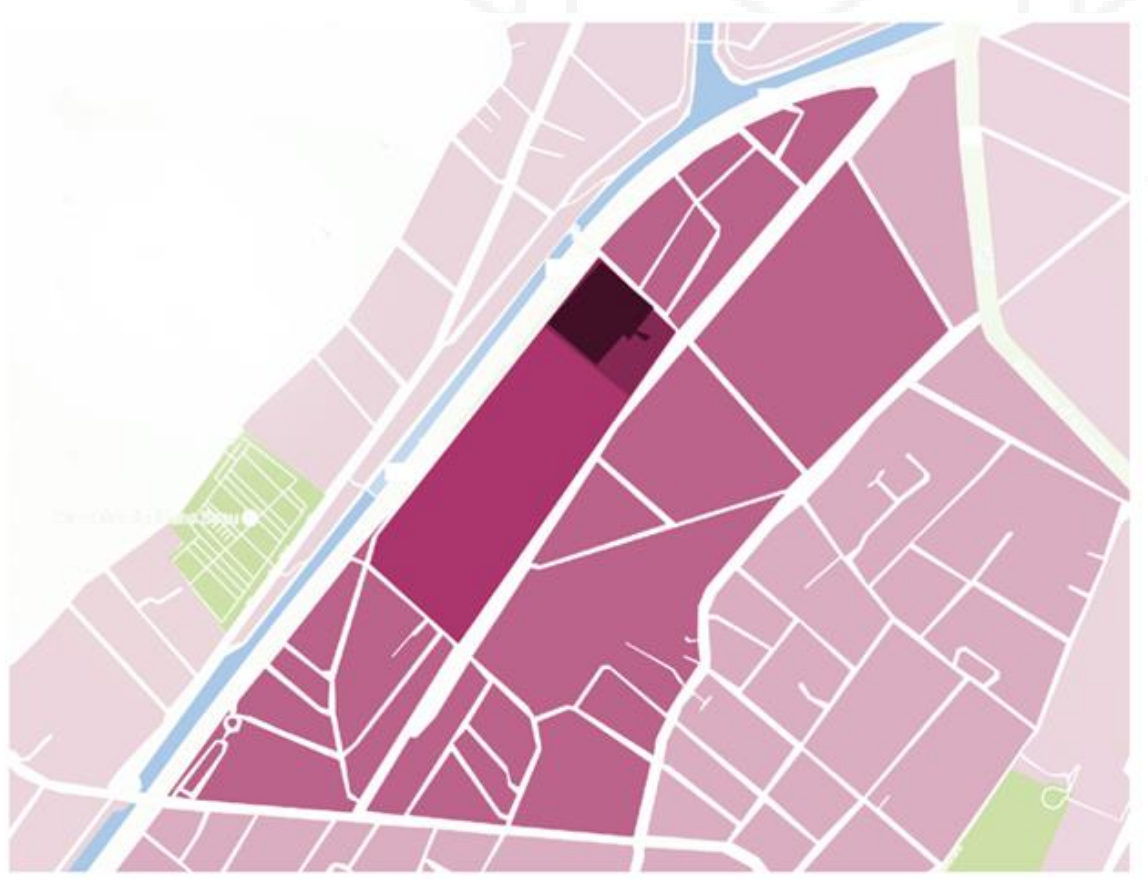

EDIFICIO

Terreno

Radio de influencia $0.5 \mathrm{~km}$

Radio de influencia $1.5 \mathrm{~km}$

Radio de influencia $3 \mathrm{~km}$ 


\subsubsection{Galería de fotos}

Ilustración 5.11 Vista de la cubierta que acoge todo el proyecto.

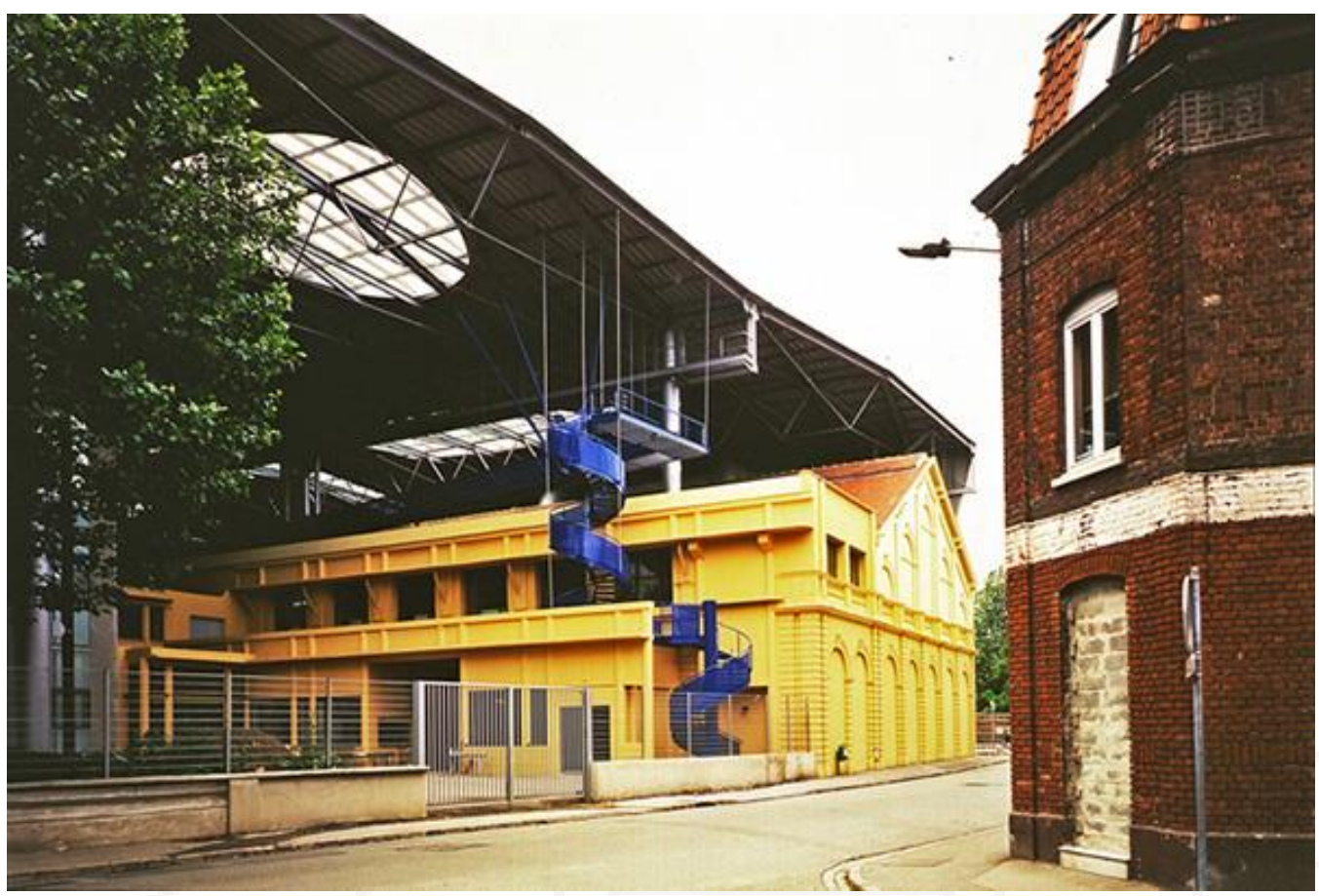

Fuente: Recuperado de www. proyectos4etsa.wordpress.com

Ilustración 5.12 Pasarelas que conectan los espacios interiores bajo la cubierta.

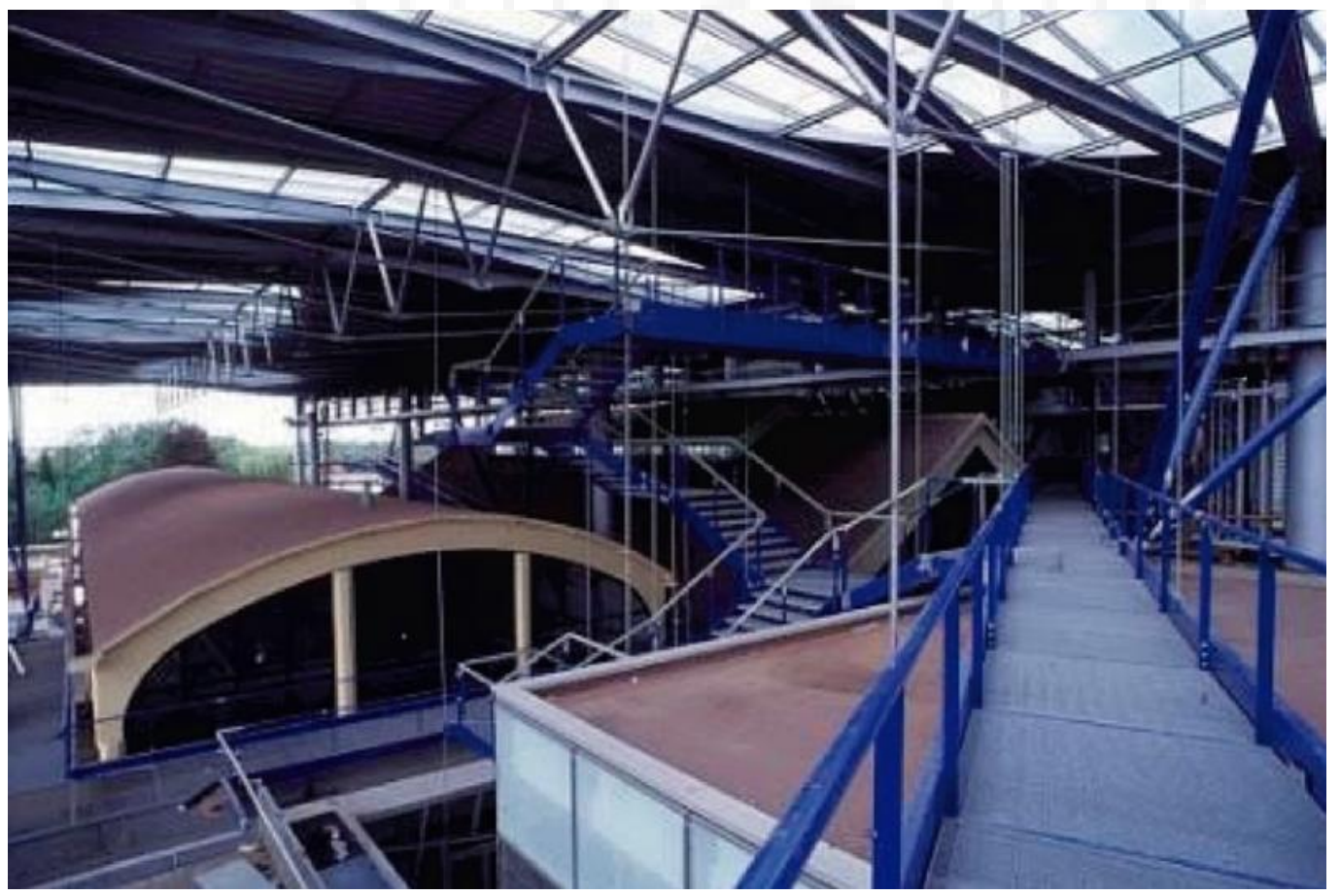

Fuente: Recuperado de www. proyectos4etsa.wordpress.com 


\subsection{Referentes de Estrategias Proyectuales}

\subsubsection{Biblioteca Regional Joaquín Legina y Archivo Regional de la Comunidad de}

\section{Madrid}

En la Antigua Fábrica de Cervezas El Águila hoy funciona la Biblioteca Regional Joaquín Leguina y el Archivo Regional de la Comunidad de Madrid.

La recuperación de esta antigua fábrica se debió a que en el año 1994, la Dirección General de Patrimonio Cultural de la Comunidad de Madrid, realizó una convocatoria para reutilizar este edificio y convertirla en un centro documental para la conservación, preservación y difusión del patrimonio histórico documental (Sánchez Mustieles, 2014, parr. 7) .

\section{BIBLIOTECAREGIONALDE JOAQUINLEGUINA ARCHIVO REGIONAL DE LA COMUNIDADDEMADRID ANTIGUA FÁBRICA DE CERVEZA EL ÁGUILA \\ ARQUITECTOS LUIS MORENO MANSILLA Y EMILIO TUÑON \\ AÑO \\ 1996 - 2002 \\ UBICACIÓN MADRID, ESPAÑA}

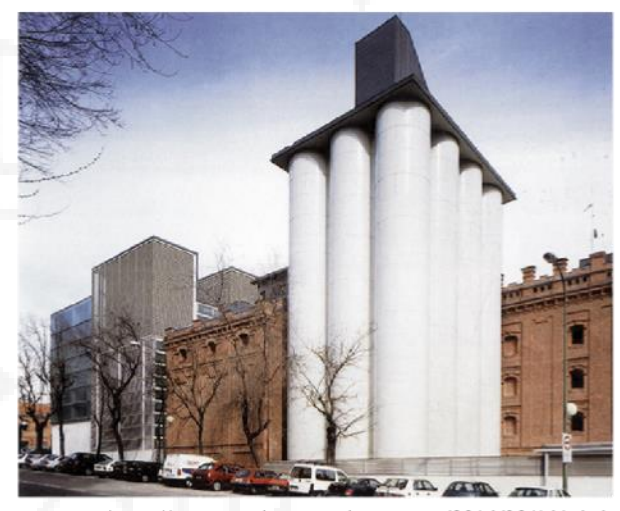

Ilustración 5.13 vista antigua de la fábrica El Águila

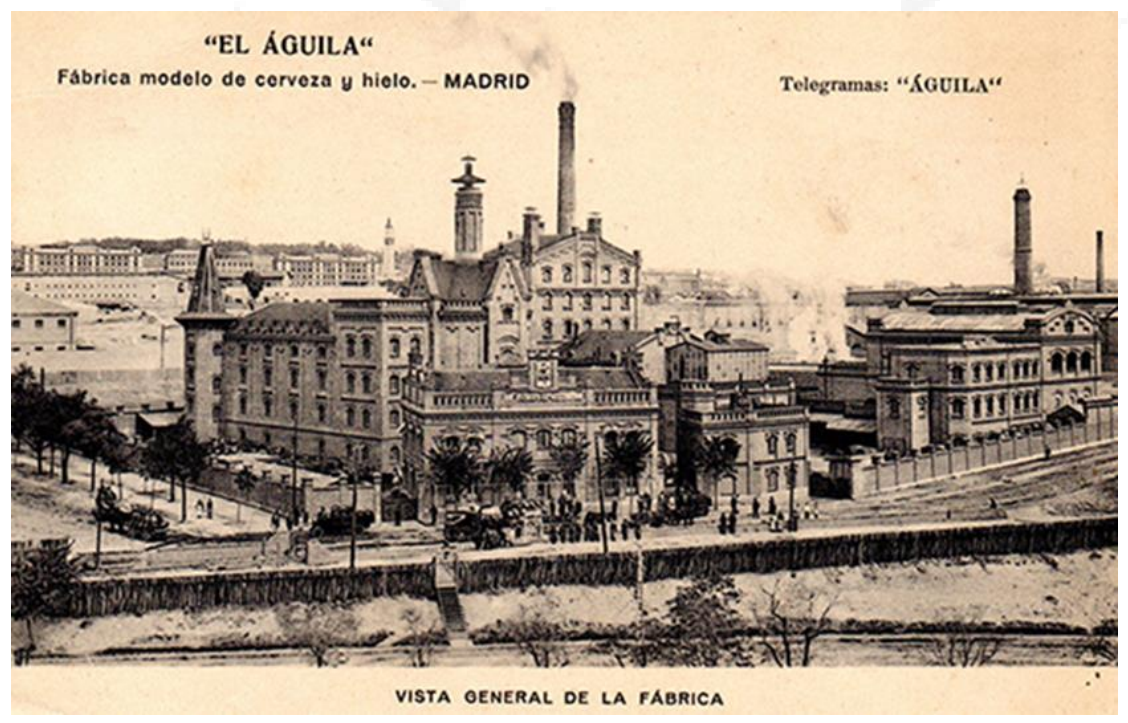

Fuente: Recuperado de www. proyectos4etsa.wordpress.com 
La construcción inicial de la fábrica data de 1900, por lo que arquitectónicamente es considerada un hito y referente de la arquitectura industrial española.

Mansilla y Tuñón, fueron los arquitectos ganadores de la propuesta. Ellos propusieron recuperar la antigua fábrica a través del reciclaje de algunos espacios y piezas como los edificios iniciales de 1900, la maltearía con horno y chimenea, el pabellón administrativo, la heladería y el pabellón de fermentación, los silos de cebada y las líneas de las calles interiores. Además, se adicionó una nueva arquitectura, nuevos edificios para mantener el perfil urbano y no alterar la imagen de la manzana (ETSA Sevilla, 2014, parr. 8).

La idea de tener edificios nuevos y antiguos era componer una fachada que combinara ambos tipos de edificios, es así que se demolió la fachada norte y oeste, y se mantuvo la fachada sur y este, por tratarse de los edificios más antiguos, representativos y de mayor calidad.

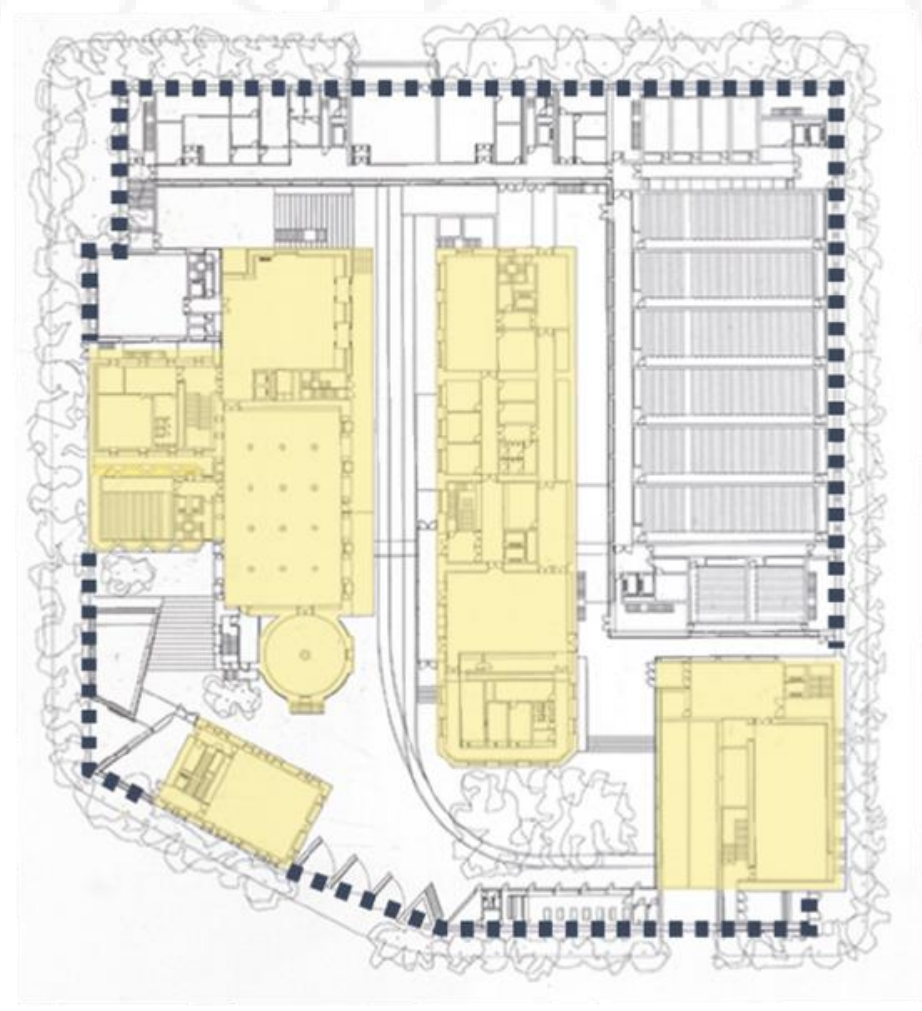

edificios existentes y

rehabilitados

- " - fachadas nuevas 

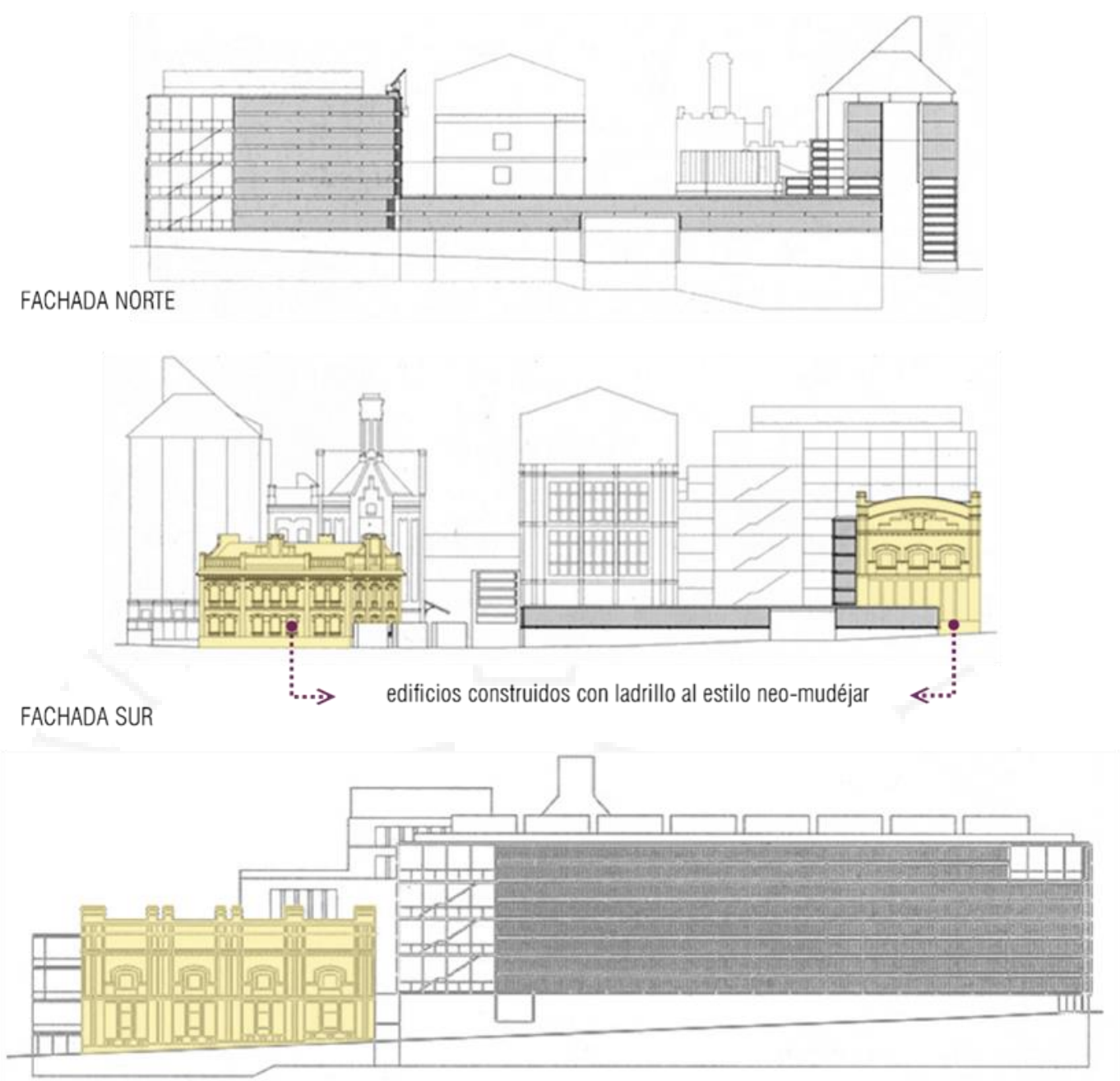

FACHADA ESTE

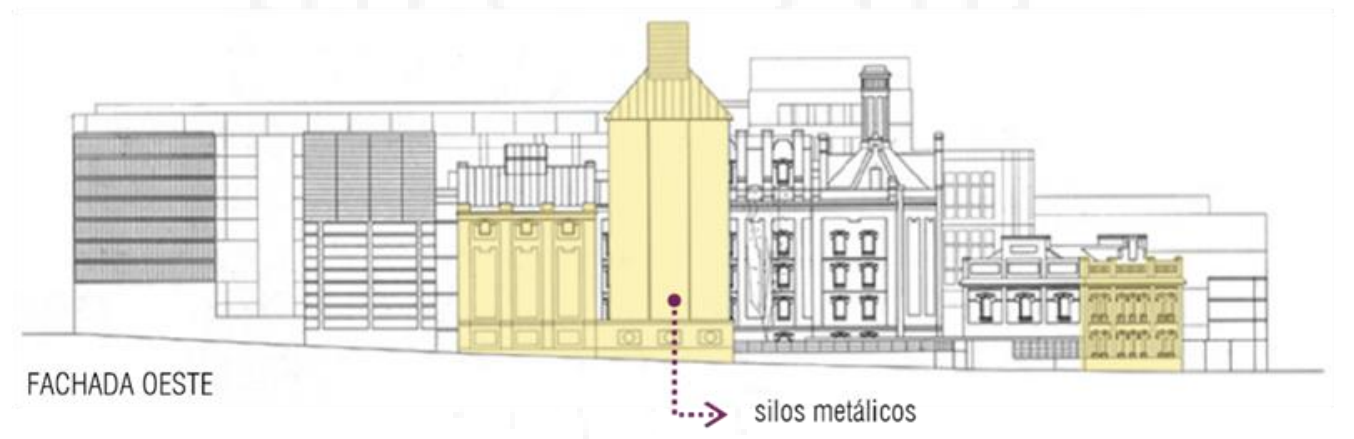

edificios existentes 
La visión de Mansilla y Tuñón, era desarrollar un proyecto que tuviera una visión tecnológica, que el programa converse y encaje con los espacios recuperados y se tenga una materialidad novedosa y funcional en los nuevos edificios.

Ahora bien, la lógica de desarrollo del proyecto estuvo guiada a partir de tres reflexiones determinadas por los proyectistas. La primera era valorar los espacios intermedios, es decir, todos aquellos espacios que han sido formados a partir de adosar algún elemento a otro ya existente. La segunda, valorar la condición intersticial de las piezas, sobre todo de aquellas que formaban un espacio en los vacíos; y, finalmente, trabajar con sistemas constructivos y de relación y no con piezas sueltas que actúan de forma independiente.

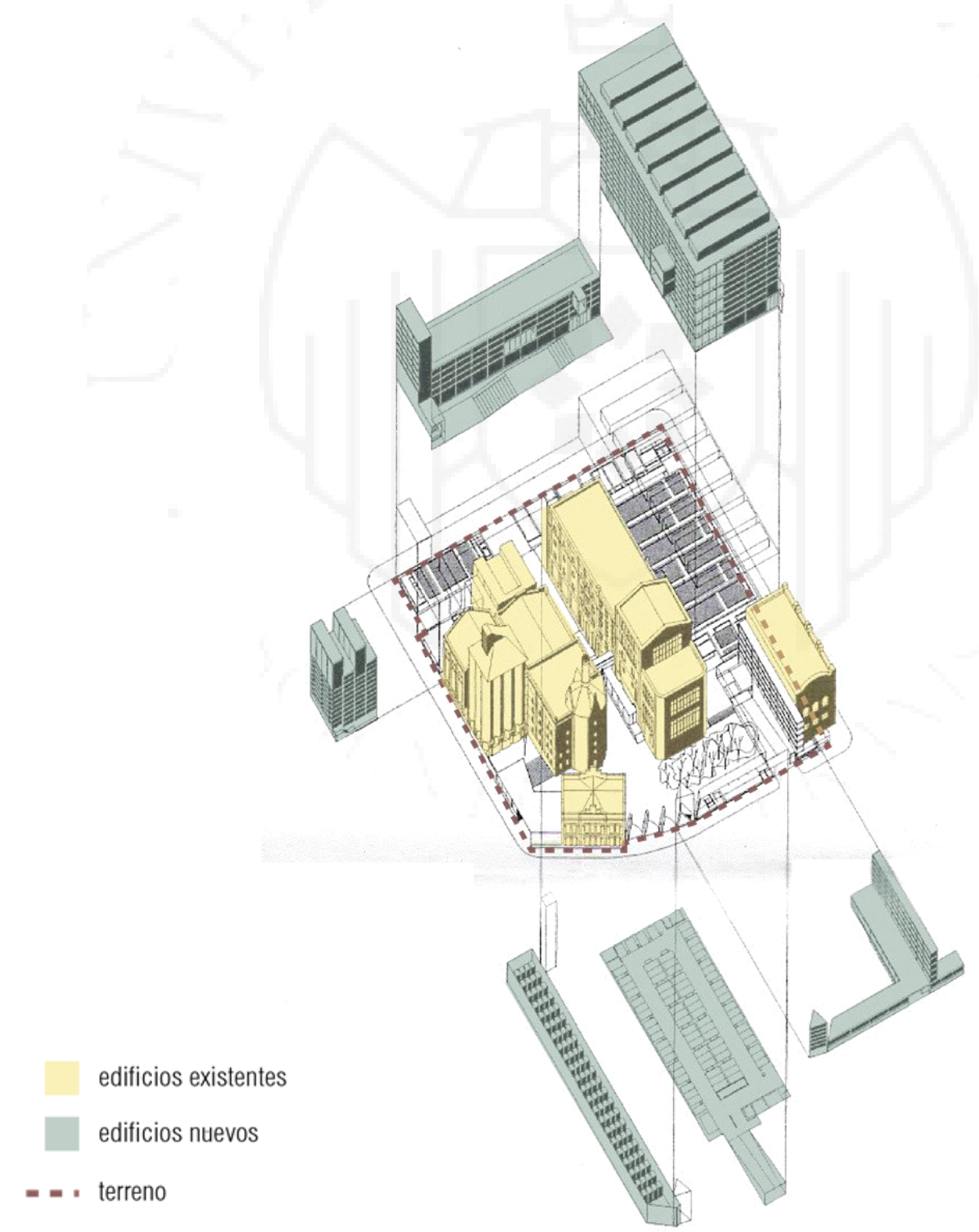


Espacios intermedios entre edificios existentes y nuevos
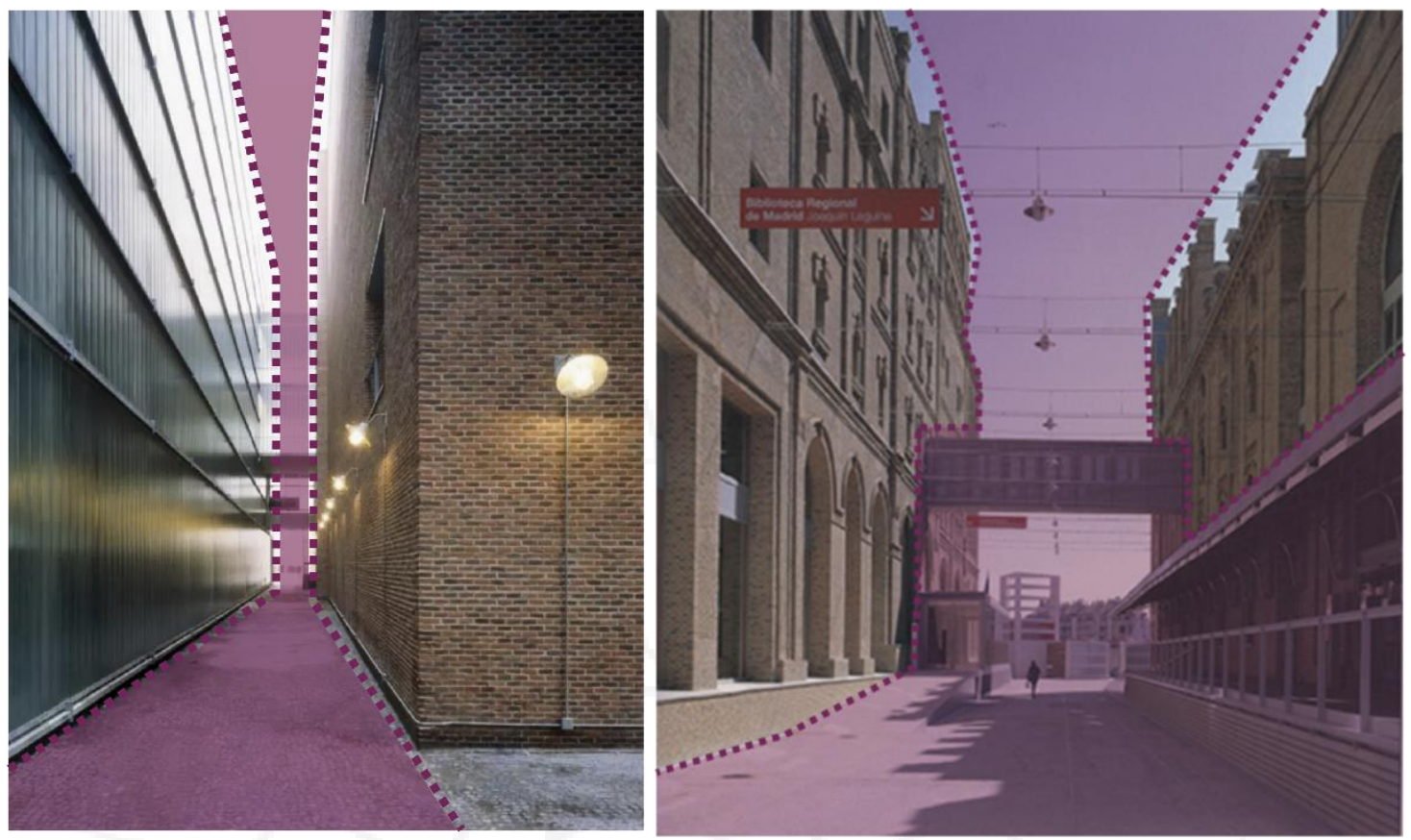

Por otro lado, es importante destacar que las fachadas de los nuevos edificios han sido diseñadas como si fuera una operación quirúrgica, de manera minuciosa, para no alterar el imaginario de la fábrica, pero si lograr que la nueva arquitectura se diferencie de las anteriormente construidas y que respondían a otra época y contexto.

\section{Ilustración 5.14 Fachadas de los nuevos edificios}
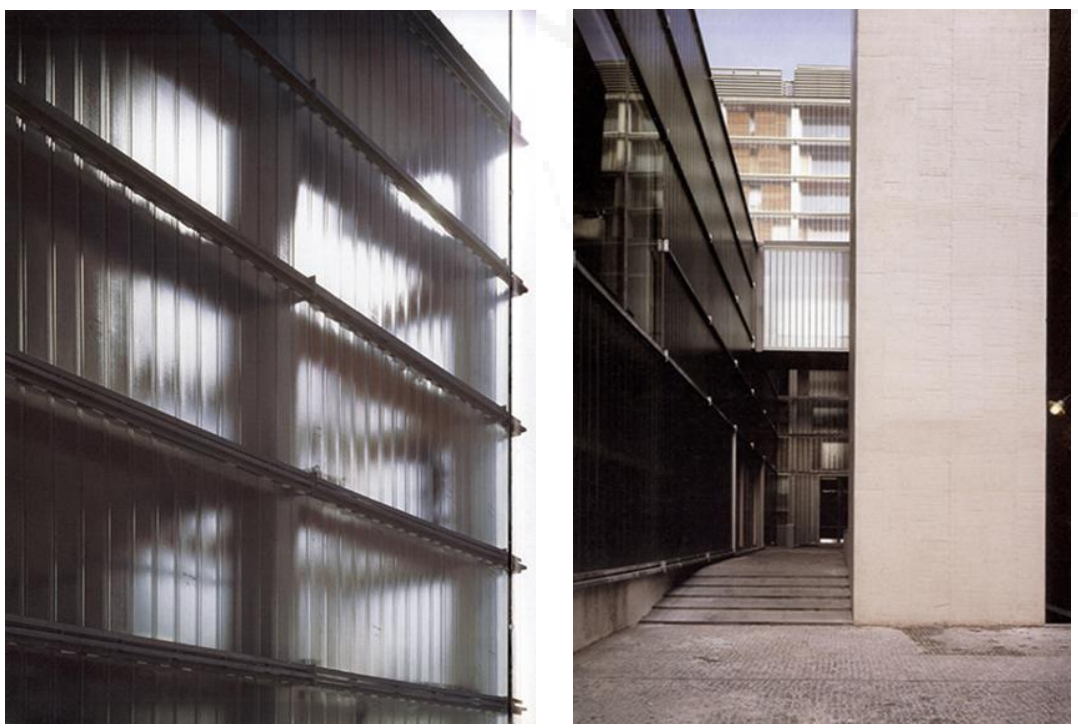

Fuente: Recuperado de www. proyectos4etsa.wordpress.com 
Ilustración 5.15 Relación de los silos de cebada con los bloques antiguos

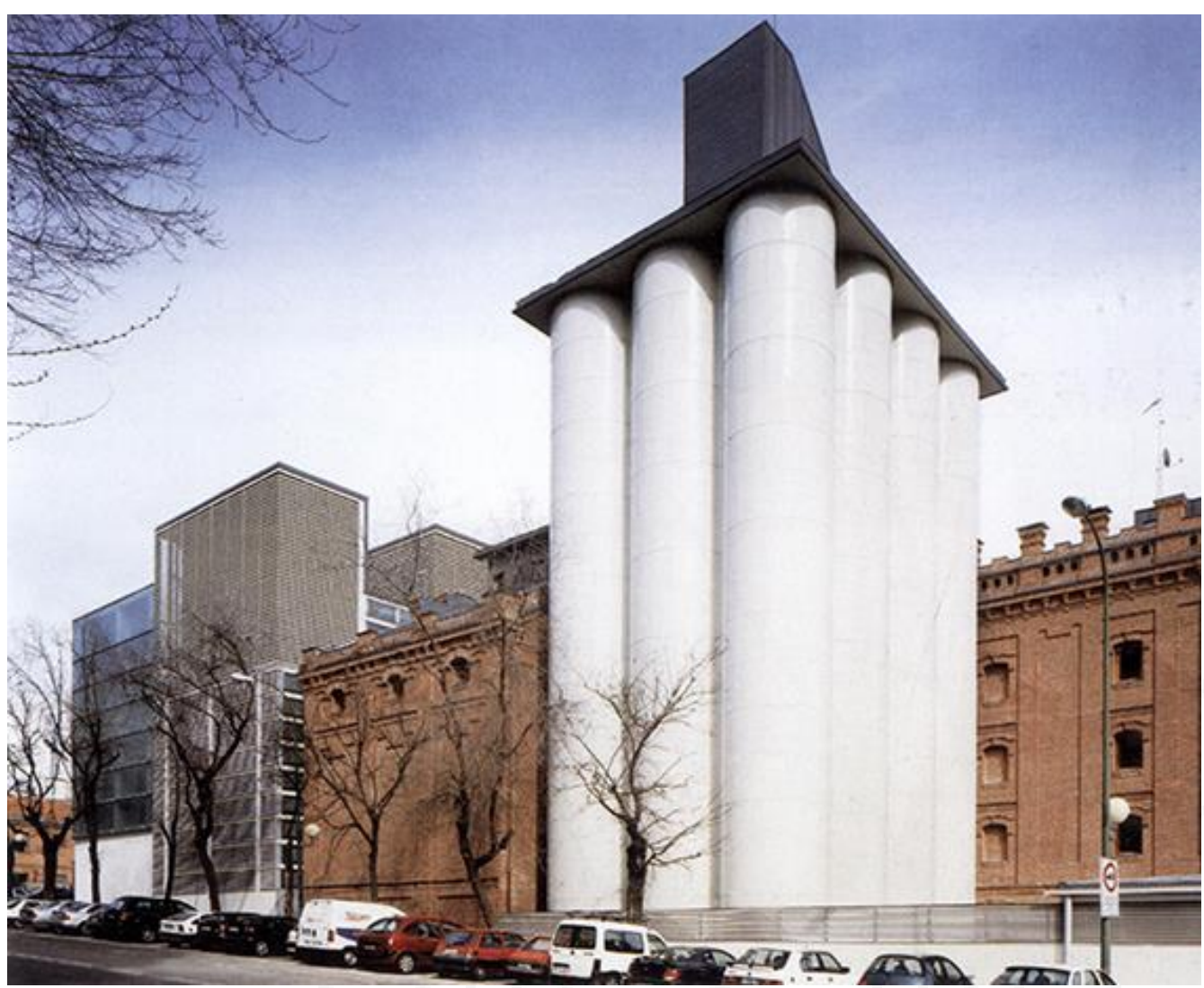

Fuente: Recuperado de www. proyectos4etsa.wordpress.com

Ilustración 5.16 Maqueta de los volúmenes que componen el proyecto

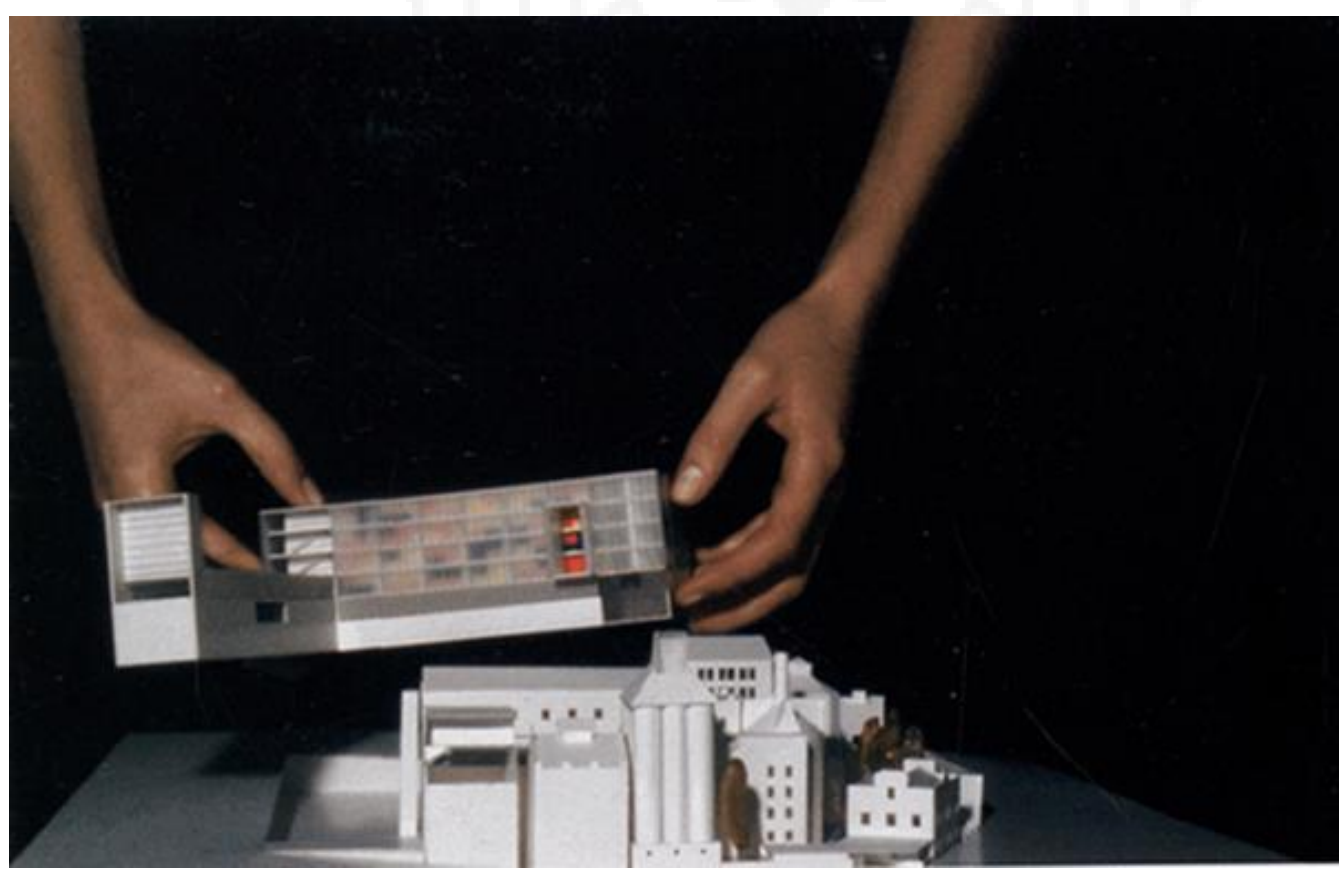

Fuente: Recuperado de www. proyectos4etsa.wordpress.com 


\subsubsection{Parco Dora}

Parco Dora es un parque post industrial ubicado en Turín, Italia y ocupando una extensión de 37 hectáreas. Este parque se encuentra ubicado en la antigua fábrica de llantas Michellin y de la fábrica Fiat. Este proyecto fue diseñado por el estudio alemán Latz \& Partners y tomó 8 años hasta su inauguración

Plano de localización y ubicación
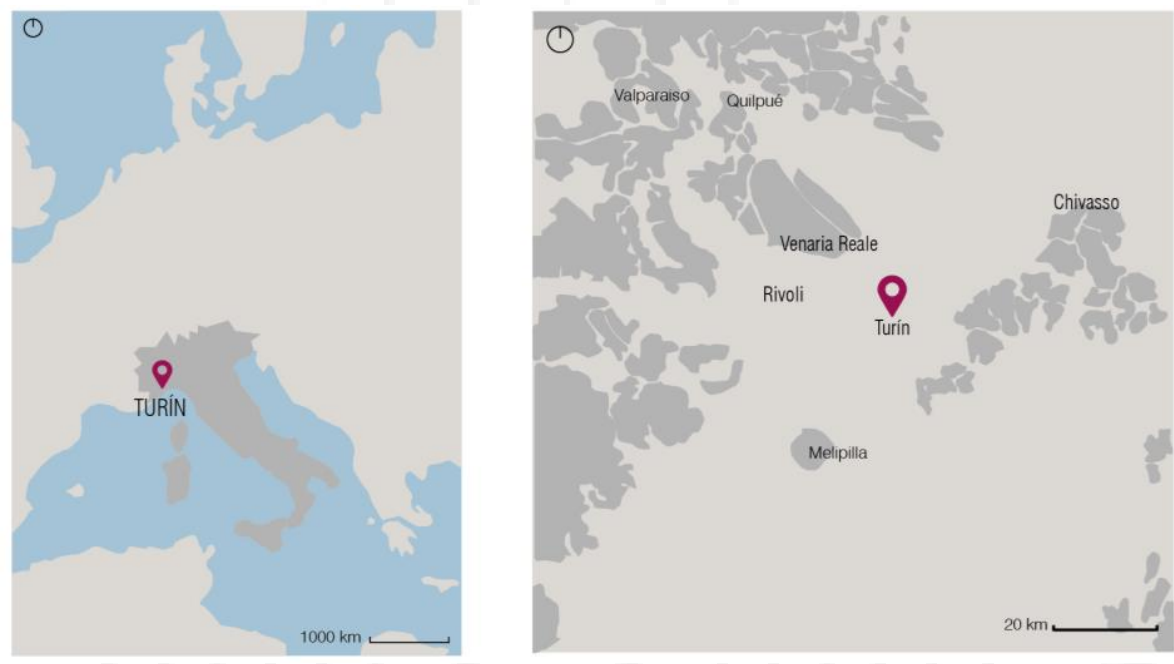

Relación con el entorno

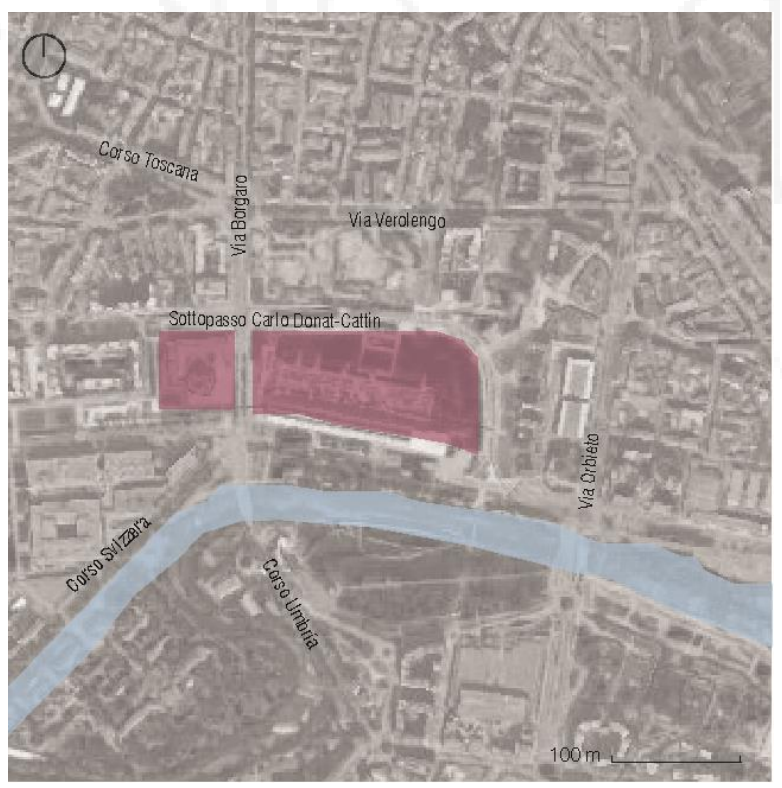


El parque Dora fue proyectado debido a que Turín había sido electa como la sede de los Juegos Olímpicos de invierno. Por este motivo se quería un gran espacio verde que genere un respiro a esta nueva área de equipamientos. Este parque debía acompañar al Río Dora y a la vez rehabilitarlo.

Hoy en día el parque Dora conforma una de las obras más importantes de transformación urbana y funciona como un gran pulmón verde.

Como toma de partido se contaba con cuatro influencias externas al proyecto; el contexto social, el contexto físico, la infraestructura existente y el legado histórico de las fábricas. Se contaba entonces con un eje antiguo representado por las fábricas, al cual se añadiría un nuevo eje representado por el parque, para configurar el gran complejo de parque Dora. Además, se buscó siempre trabajar en base a los elementos preexistentes del espacio, como estructuras metálicas y pasarelas, de manera que se pueda repotenciar la identidad y el carácter del espacio. El proyecto genera un delicado manejo del paisaje, pues se inserta y logra establecer una agradable comunicación con los materiales ya existentes del espacio.

1. Temas que han influenciado dentro del proyecto.

CONTEXTO SOCIAL CONTEXTO FISICO INFRA. EXISTENTE HISTORIA

2. Ordenar los conceptos en base al área social.

EJE VIEJO (FÁBRICA)
EJE NUEVO (PARQUE)
PARCO DORA

Se buscó siempre trabajar al lado del río, de manera que el proyecto siga la forma natural del cauce del río, resaltando de este modo su carácter protagonista.

Como idea de emplazamiento inicialmente se generó un gran eje lineal que seguía la forma del río, luego se pudo notas la existencia de objetos industriales a lo largo de este gran eje, por lo que se optó por mantenerlas. Estos objetos se acompañarían de nuevos elementos que repliquen la arquitectura industrial, de manera que evoquen la monumentalidad del espacio. 
3. Revalorar la identidad y el carácter del espacio a través de la materialidad y elementos industriales.
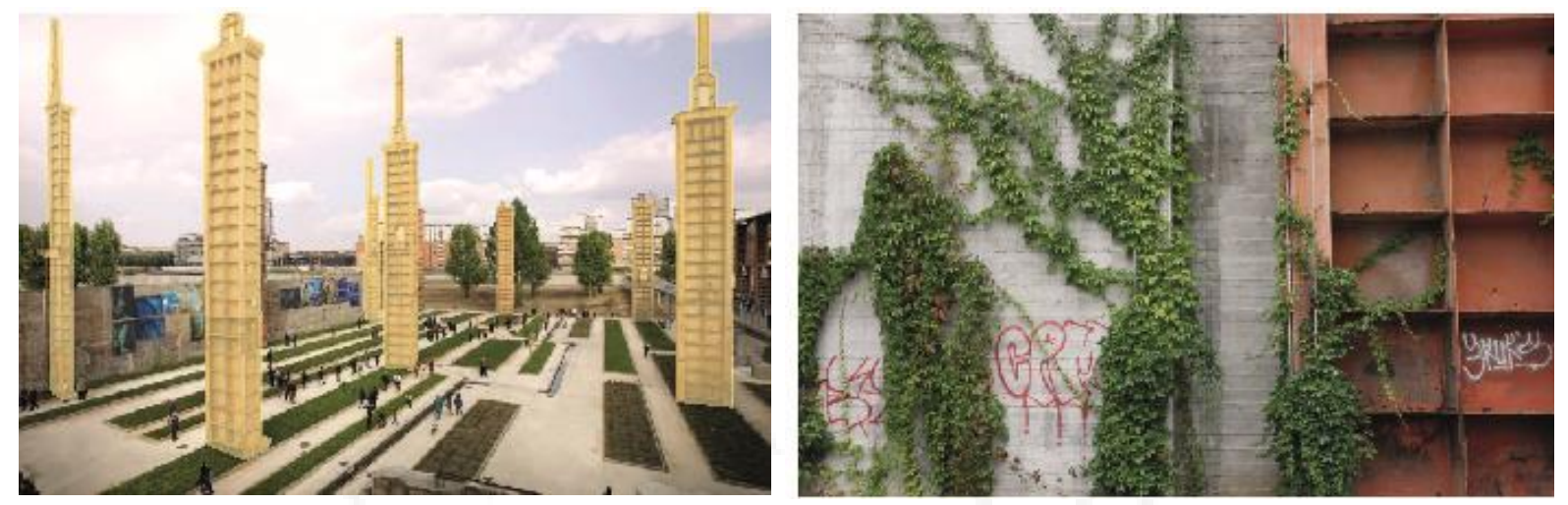

Síntesis del pasado dentro de un nuevo paisaje.

4. Metamorfosis de las viejas estructuras en busca de un nuevo lenguaje.

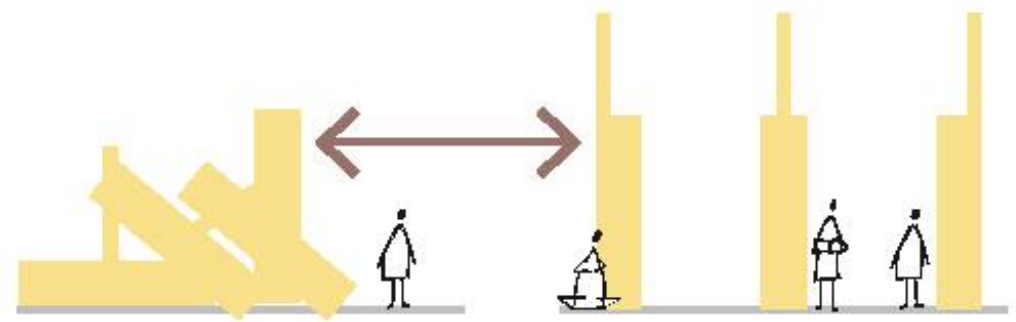

5. Integración de la ciudad con el paisaje.
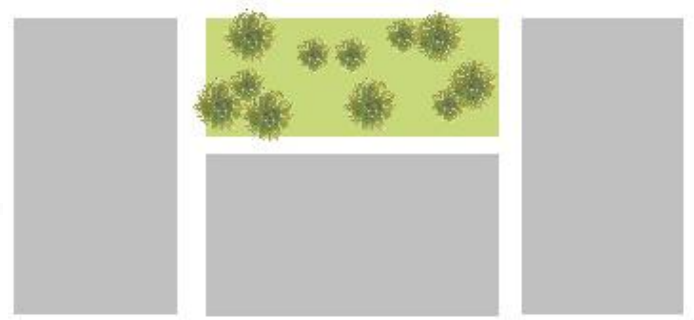

6. Colocar al río como elemento protagonista, aprovechando que la ciudad gire en torno a él.

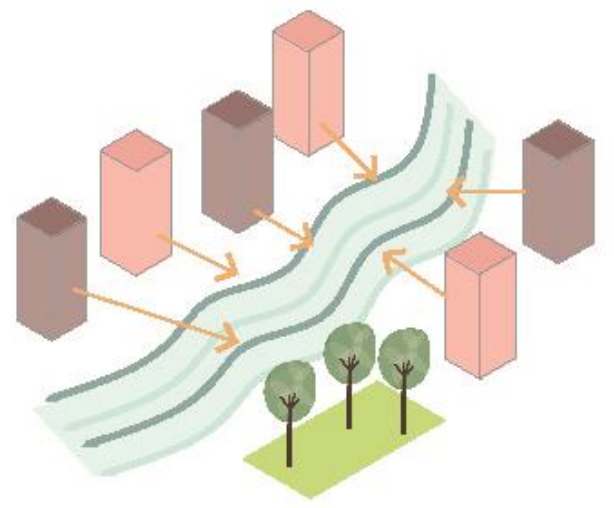


7. Mantenimiento de elementos existentes del lugar.

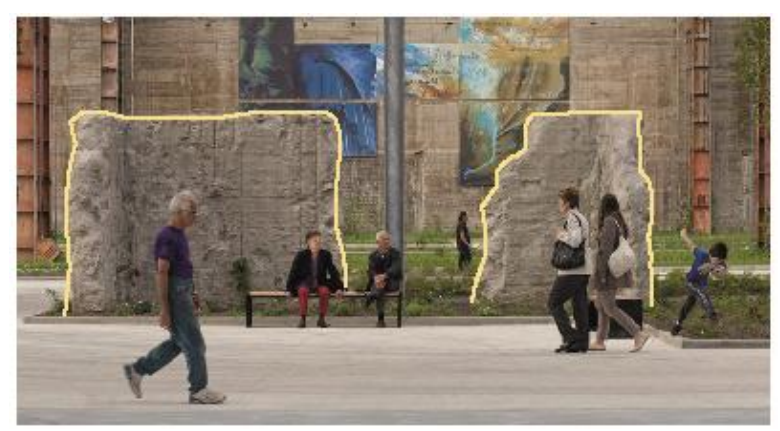

El emplazamiento del proyecto está determinado por el trazado de un eje, alrededor del cual se encuentran los elementos industriales.

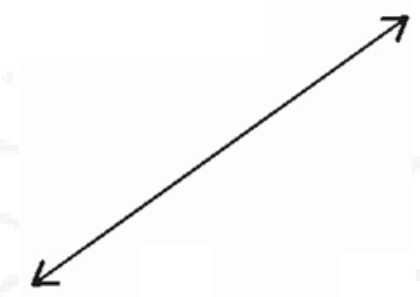

Trazado de un eje

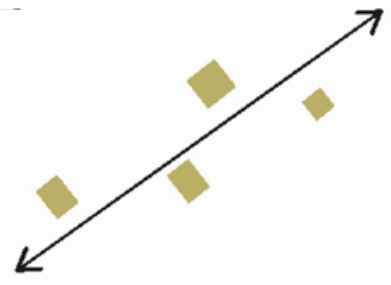

Mantener antiguos

elementos industriales

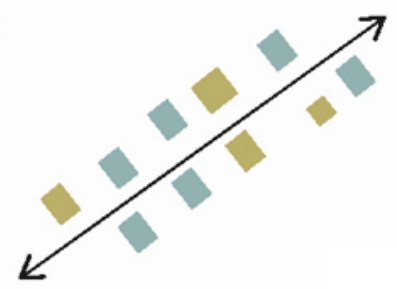

Colocar elementos mediante una repetición formal

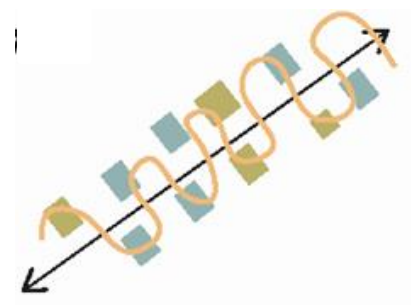

Unificar los elementos mediante una pasarela 


\subsubsection{Puerto Madero}

El primer plan de intervención en Puerto Madero se generó en el año 1887. Para ese entonces se le conocía como el nuevo barrio de Buenos Aires. Con esta renovación se fortaleció el carácter de puerto que tenía, abriendo paso a la entrada y salida d grandes embarcaciones al canal.

La vida útil de este proyecto no duró más de 20 años, pues los diques no fueron diseñados para la gran capacidad de buques que estaba albergando, por este motivo el puerto empieza a decaer desde los años 30 hasta los 90. Es en este momento cuando se propone una reconstrucción edilicia de toda el área.

El nuevo plan de regeneración urbana de Puerto Madero si bien buscaba rediseñar gran parte del área urbana, uno de sus objetivos principales fue reestablecer el diálogo que antes se mantenía con el río La Plata, y que actualmente se había perdido.

Toma de partido

1. Recuperar el diálogo entre la ciudad y el río La Plata.

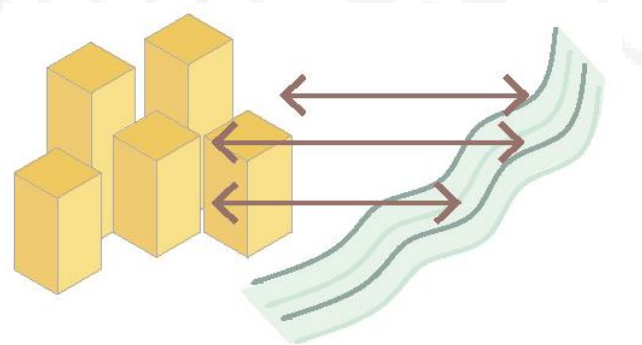

Ciudad que solo conversaba con sus edificios

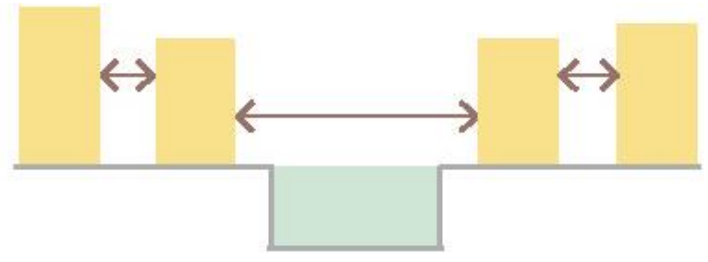


Ciudad con distintos niveles de diálogo

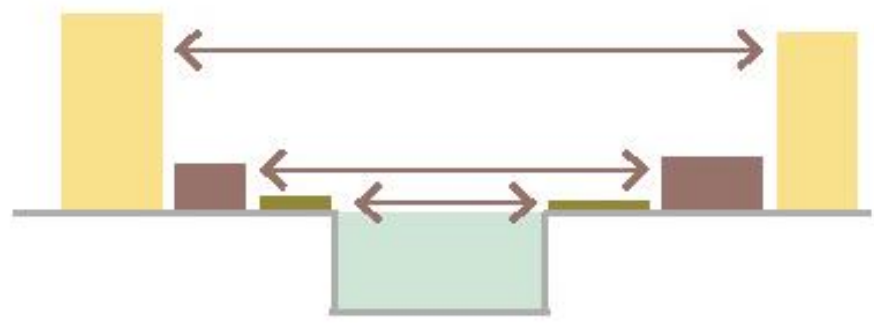

Es por este motivo que el río funciona como el principal escenario. Como emplazamiento se generó énfasis en el río la Plata como un largo elemento longitudinal ubicado en el eje central del proyecto, a continuación, se acompañó el borde de estos diques con grandes parques y plazas. Buscando que estos parques se mantuviesen siempre activos se instalaron tiendas comerciales y paseos alrededor, de manera que aumente la vitalidad del espacio. Grandes torres de vivienda se colocaron alternadas con equipamientos culturales y comerciales, esto espacios también se encontraban acompañados de colchones verdes.

2. Reforzamiento de la centralidad alrededor de la casa rosada.

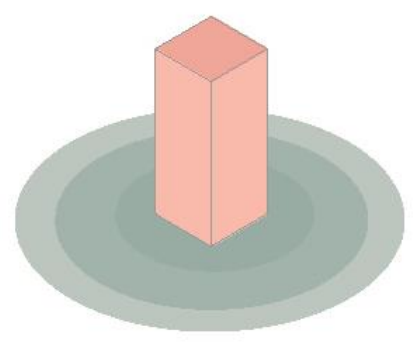

Poder evocativo

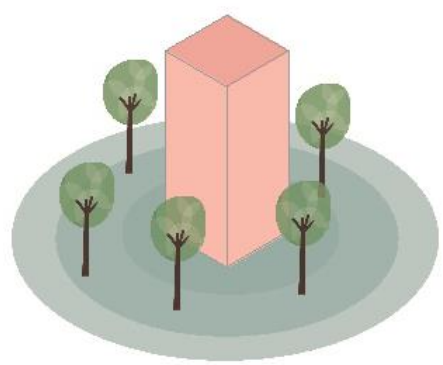

Acompañamiento con espacio público

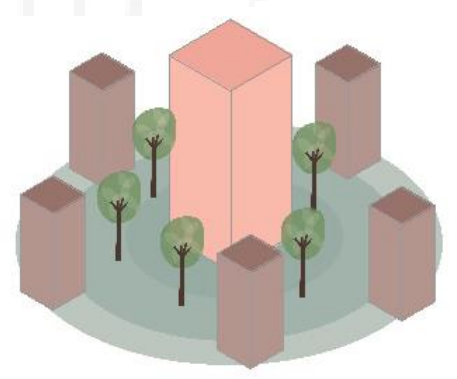

Red de equipamientos, vivienda y espacios públicos

3. Metamorfosis del espacio público degradado.

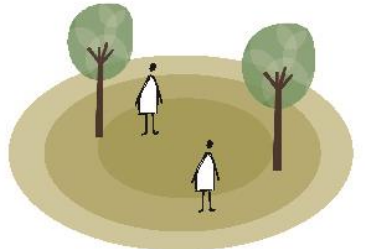

Espacios públicos degradados y en desuso

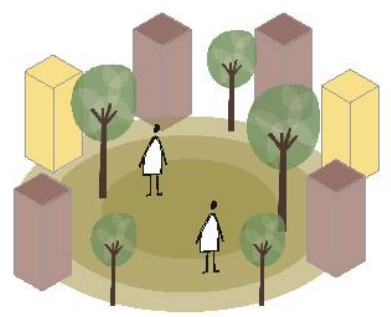

Acompañamiento con equipamientos comerciales

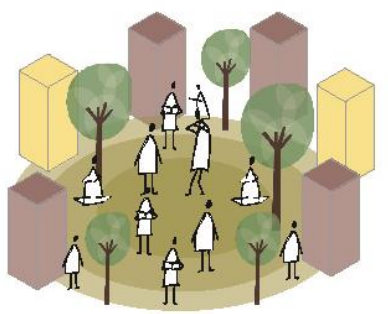

Reactivación de espacios públicos 
Estrategias de emplazamiento
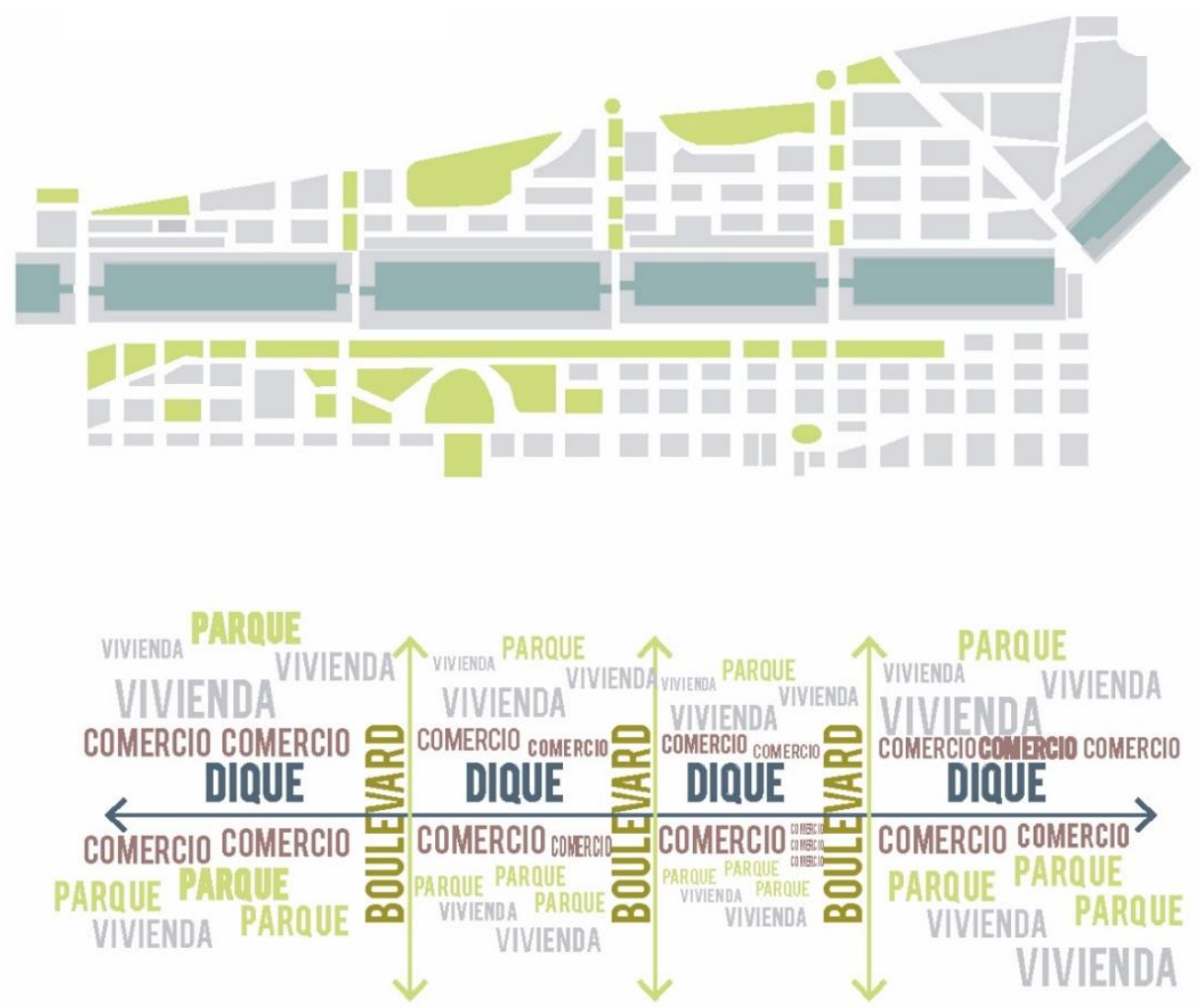

Este proyecto además gira alrededor de un equipamiento de gran envergadura, la casa rosada, espacio habitado por el presidente. 


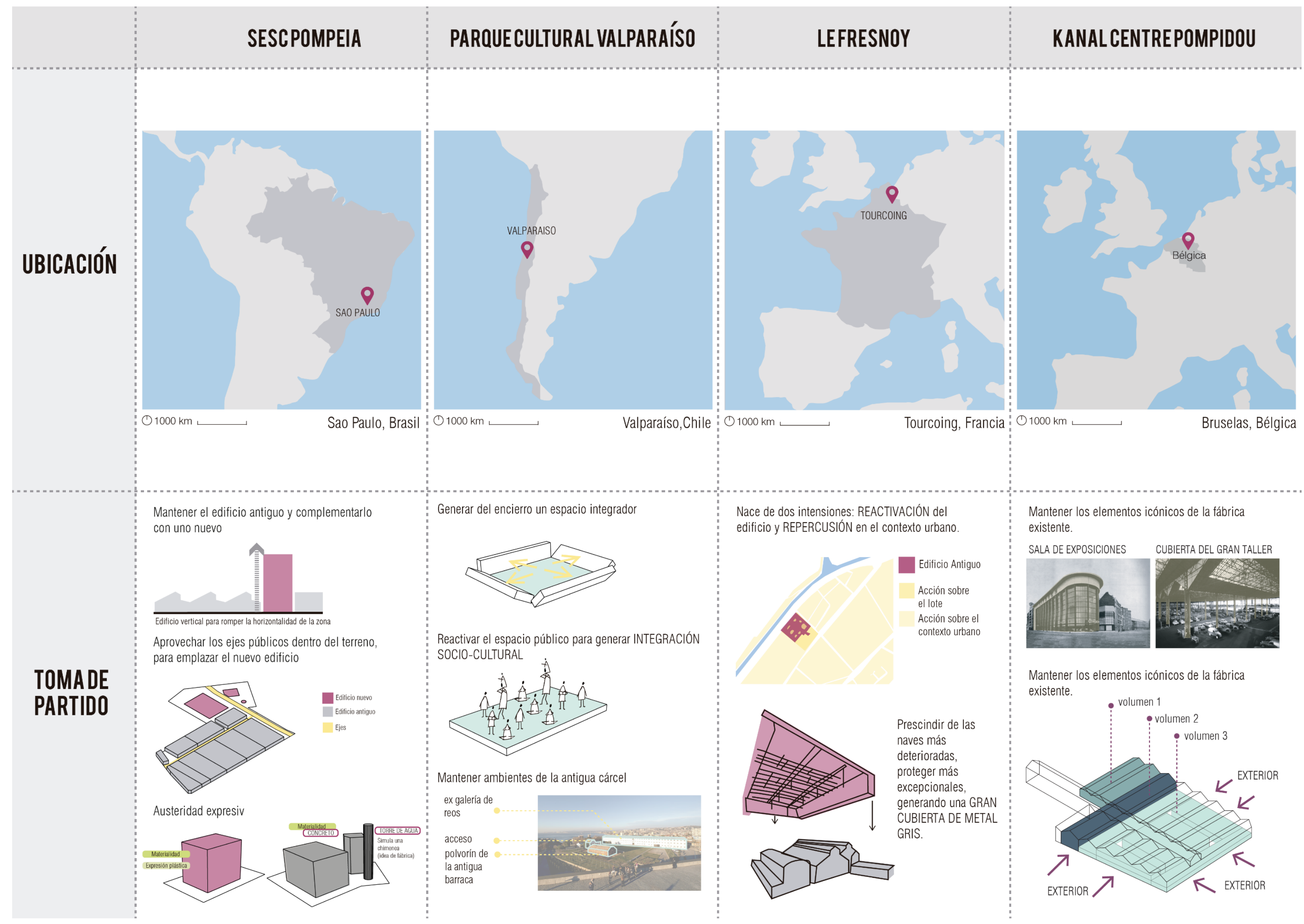




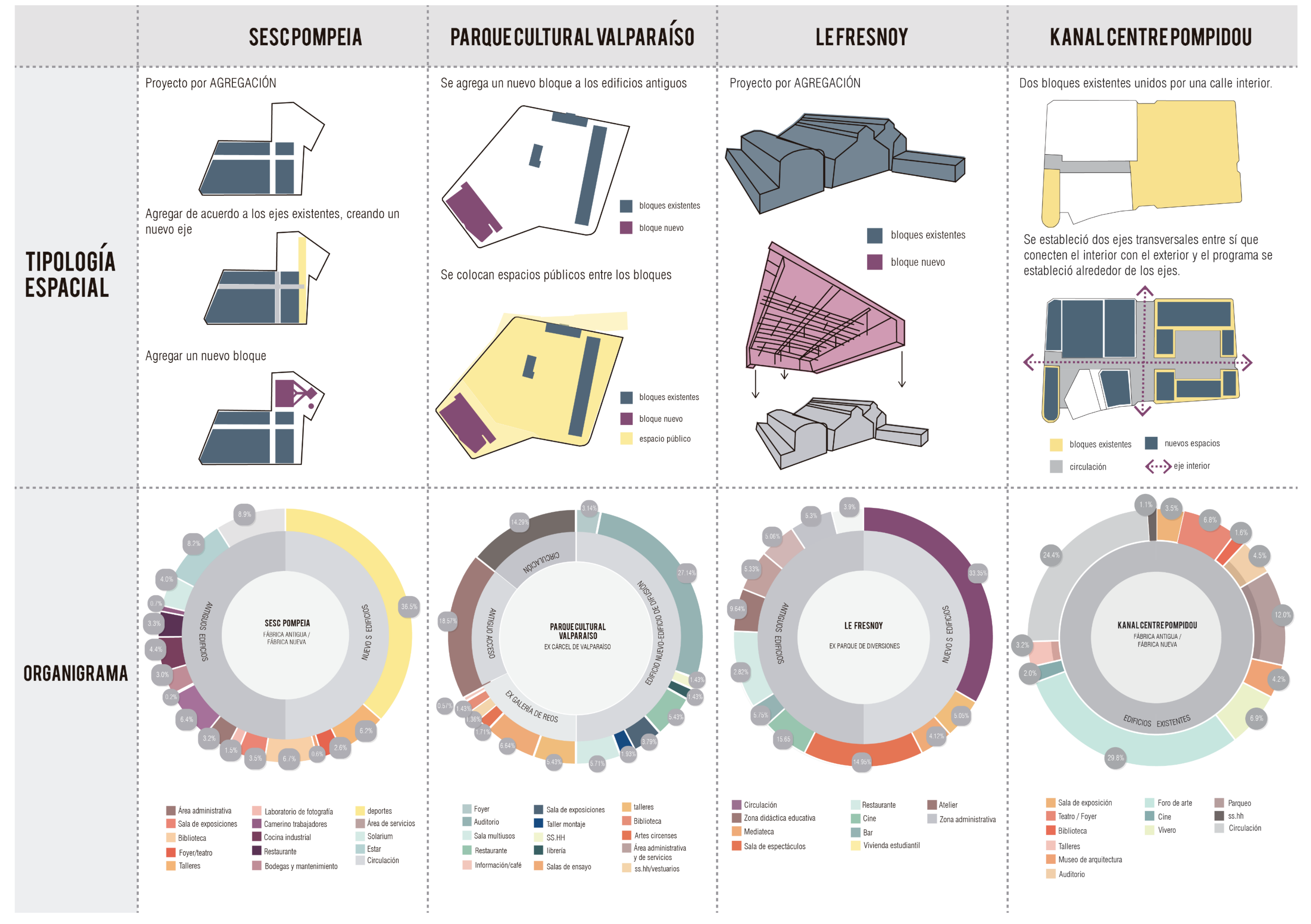




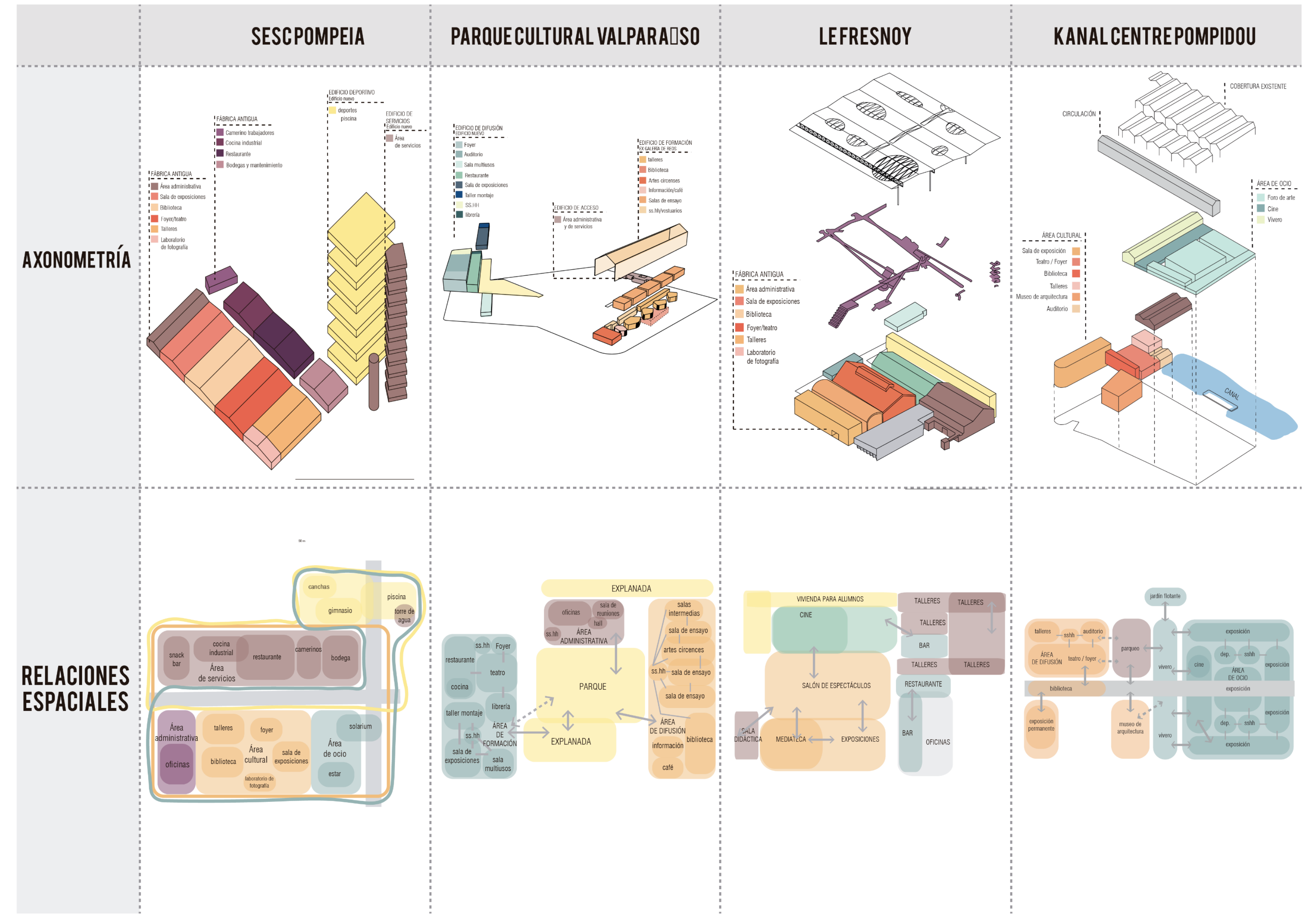




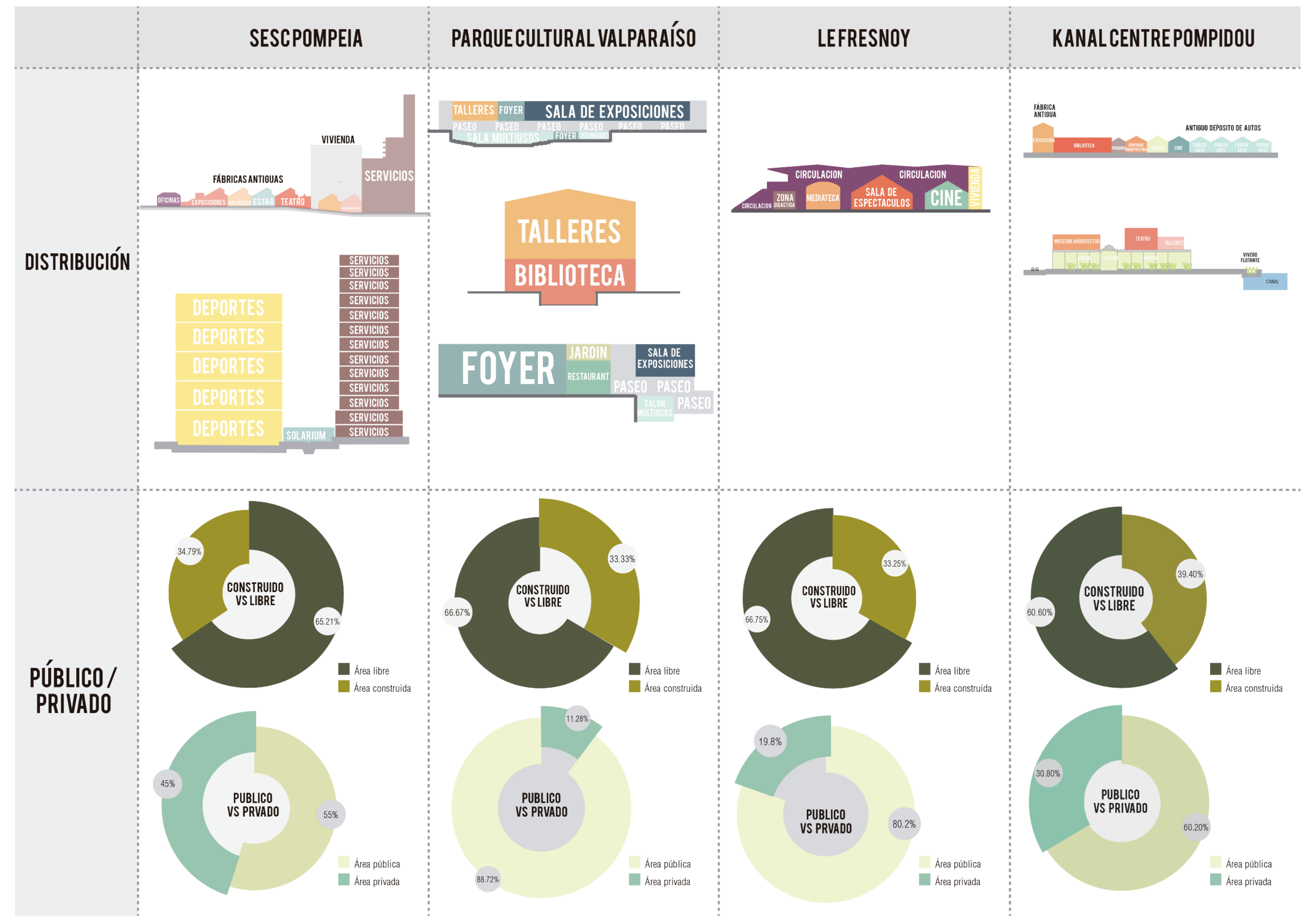




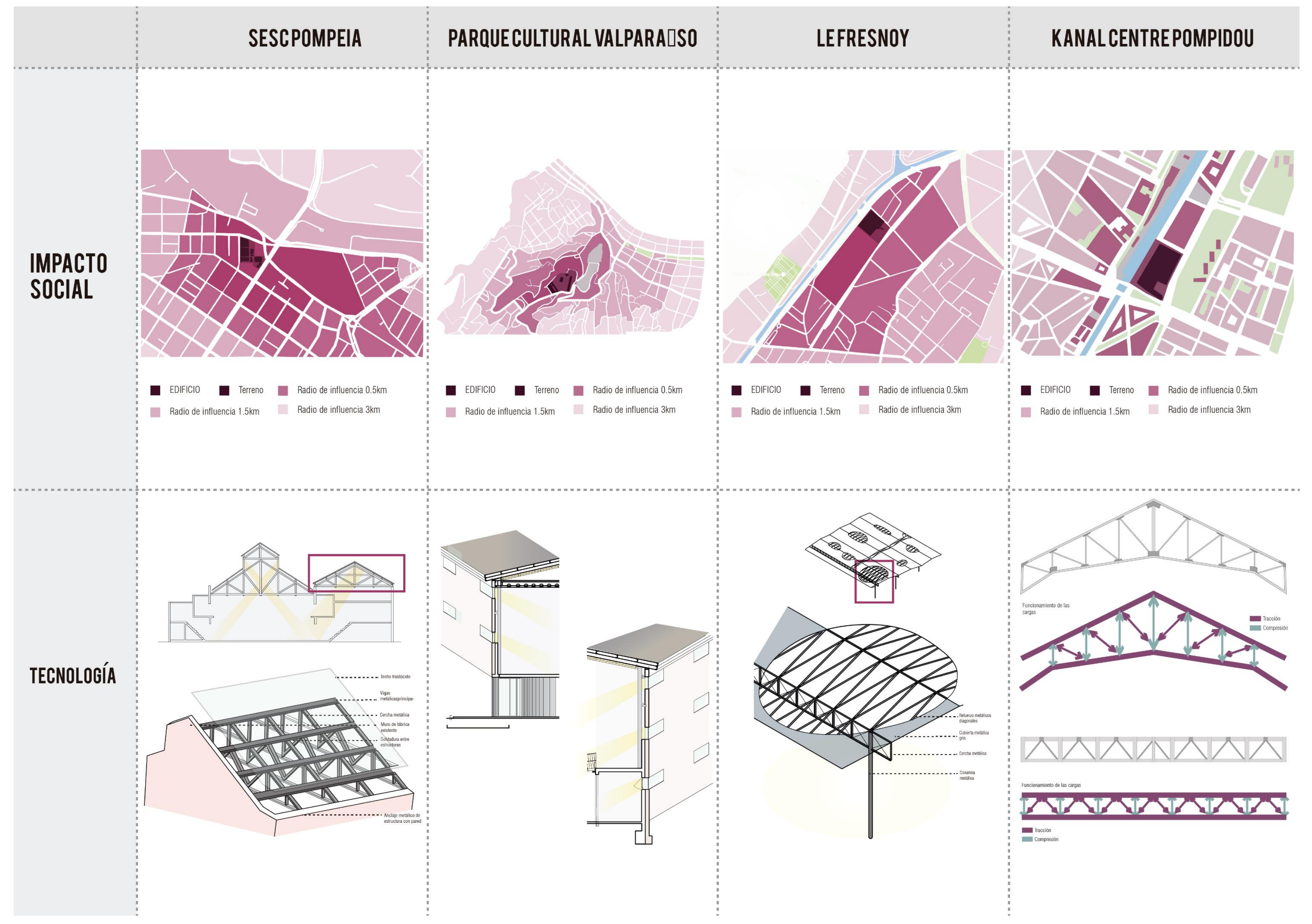




\subsection{Conclusiones Parciales}

Los referentes análogos analizados fueron escogidos principalmente por la función cultural que desempeñan y por ser equipamientos que cuentan con preexistencia, es decir, han reciclado edificios que se encuentran dentro de ellos. Además, el programa con el que cuentan y sus relaciones programáticas servirían de guía para el desarrollo de la fábrica cultural. Las intenciones por las que se desarrollaron estos proyectos tienen dos tipos de alcance, uno puntual para el mismo proyecto y otro a una escala mayor que permite la regeneración de la zona.

$\mathrm{Al}$ ser edificios con infraestructura reciclada comparten tomas de partido y estrategias de diseño pues los arquitectos encargados han agregado volúmenes o elementos que complementen los edificios existentes en el mismo lote. Es así como Kanal Centre Pompidou, SESC Pompeia, el Parque Cultural de Valparaíso y la Escuela de Artes Le Fresnoy tienen una intención, pero cada uno responde a ella de con una forma distinta debido al contexto en el que se encuentran.

De acuerdo a los casos análogos analizados, se puede concluir que al ser proyectos emplazados en edificios ya existentes, se comportan como rompecabezas en las que las piezas delimitan el espacio pero a la vez forman una composición de llenos y vacíos que ayuda a engranar adecuadamente lo existente con lo nuevo. En muchos casos, se busca introducir el espacio público al interior del programa de modo que el edificio logre ser más público que privado, lo que genera que la gente se identifique más con estos espacios y a la vez permite que el equipamiento sea accesible para los usuarios y visitantes.

Dentro de los referentes de estrategias proyectuales se analizaron aquellos relacionados con los temas de borde costero, el reciclaje de fábricas y planes de regeneración de bordes costeros. Dentro de ellos se encuentran: la reconstrucción de Puerto Madero, el desarrollo del Parco Dora y la antigua fábrica de cerveza El Águila. Con respecto a los dos primeros referentes, ambos inciden en que el paisaje debe trabajar de la mano con el espacio público de manera que este logre funcionar como un espacio vital. Ambas propuestas hacen hincapié en el reciclaje de elementos que cuenten con valor histórico y cultural y contribuyan a revalorar 
el pasado industrial. El tercer referente ha sido analizado por la materialidad que emplea en los nuevos edificios, generando el reconocimiento de las piezas nuevas sobre las existentes. 


\section{CAPÍTULO VI: MARCO CONTEXTUAL}

\subsection{Redes de equipamiento}

\subsubsection{Chimbote en relación a la provincia del Santa}

La capital de la provincia del Santa es el distrito de Chimbote, el cual tiene la mayor extensión territorial, por lo que concentra la mayor cantidad de población. Asimismo, Chimbote es el distrito que cuenta con el más importante patrimonio cultural industrial de toda la provincia pues fue aquí donde se ubicaron las primeras fábricas industriales en el boom pesquero de los años sesenta.

Este patrimonio está ligado directamente a la más grande manifestación cultural con la que cuenta la ciudad, la fiesta de San Pedrito, reflejo del carácter pesquero e industrial que tiene la ciudad.

Tabla 6.1 Población total de la provincia del Santa

\begin{tabular}{l|l|l}
\hline PROVINCIA & TOTAL DE HABITANTES & $\%$ \\
\hline Chimbote & 215817 & 54.44 \\
\hline Cáceres del Perú & 5062 & 1.28 \\
\hline Coishco & 14482 & 3.74 \\
\hline Macate & 3889 & 0.98 \\
\hline Moro & 7580 & 1.91 \\
\hline Nepeña & 13860 & 3.50 \\
\hline Samanco & 4218 & 1.06 \\
\hline Santa & 18010 & 4.54 \\
\hline Nuevo Chimbot & 113166 & 28.55 \\
\hline Provincia del Santa & 396434 & 100 \\
\hline
\end{tabular}

Fuente: PDU Santa 2012 


\subsubsection{Redes de equipamiento en Chimbote}

Chimbote es una ciudad que cuenta con población joven, de acuerdo con el Censo realizado por INEI en el 2007, el mayor porcentaje de población se encuentra en el grupo de 10 a 19 años que representa $20.09 \%$ de la población total, seguido de los grupos de 0 a 9 y de 20 a 39 que representan el $17.16 \%$ y el $17.11 \%$ respectivamente. Asimismo, es un distrito que presenta equipamientos educativos, de salud, recreación activa y pasiva y además tiene áreas con patrimonio cultural. Sin embargo, solo cuenta con un equipamiento cultural que no puede atender a toda la población con la que cuenta la ciudad. Se hace necesaria la existencia de estos espacios para que toda la población joven pueda realizar actividades extracurriculares, complementen la educación que reciben en el colegio y en el futuro se conviertan en jóvenes que contribuyan a la sociedad.

\section{Ilustración 6.1 Población por edades en el distrito de Chimbote}

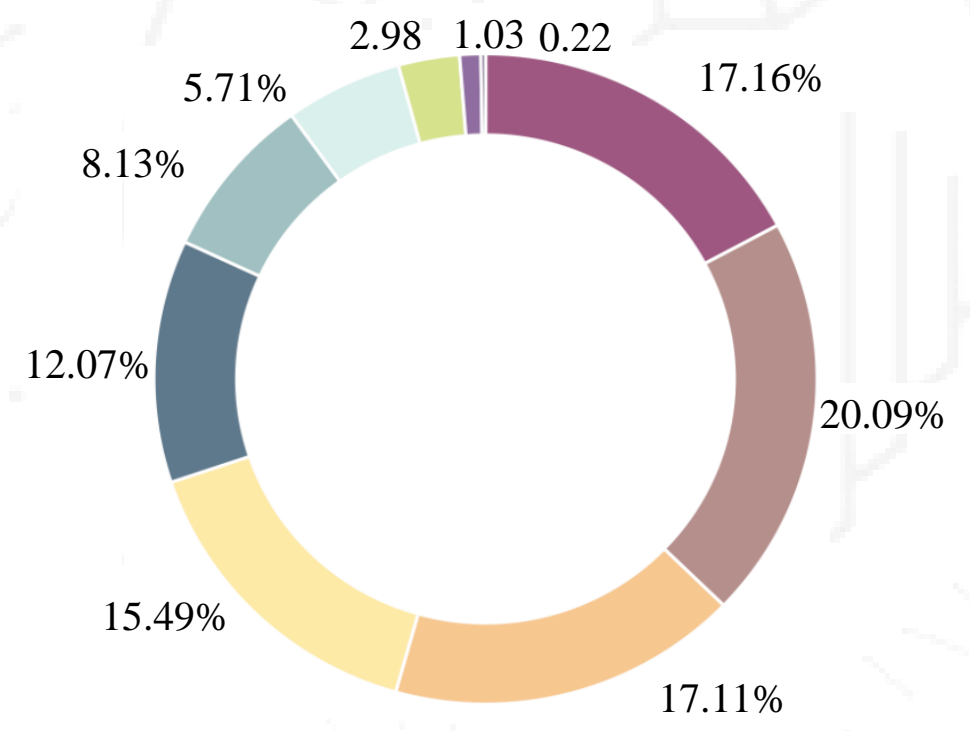

Fuente: PDU Santa 2012 
Ilustración 6.2 Usos de suelo en el distrito de Chimbote

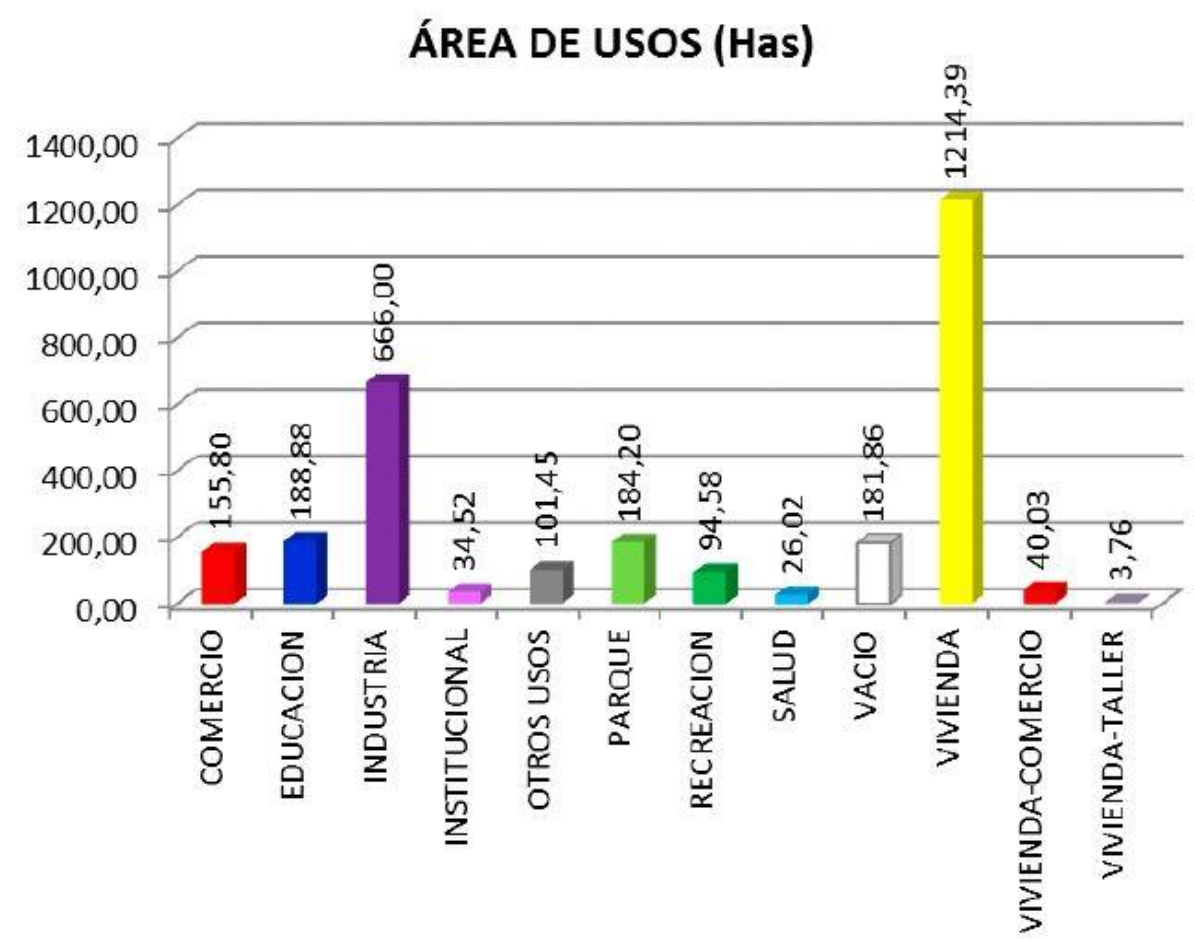

Fuente: PDU Santa 2012, Plano N ${ }^{\circ} 28$ 
Ilustración 6.3 Mapa de equipamientos en el distrito de Chimbote

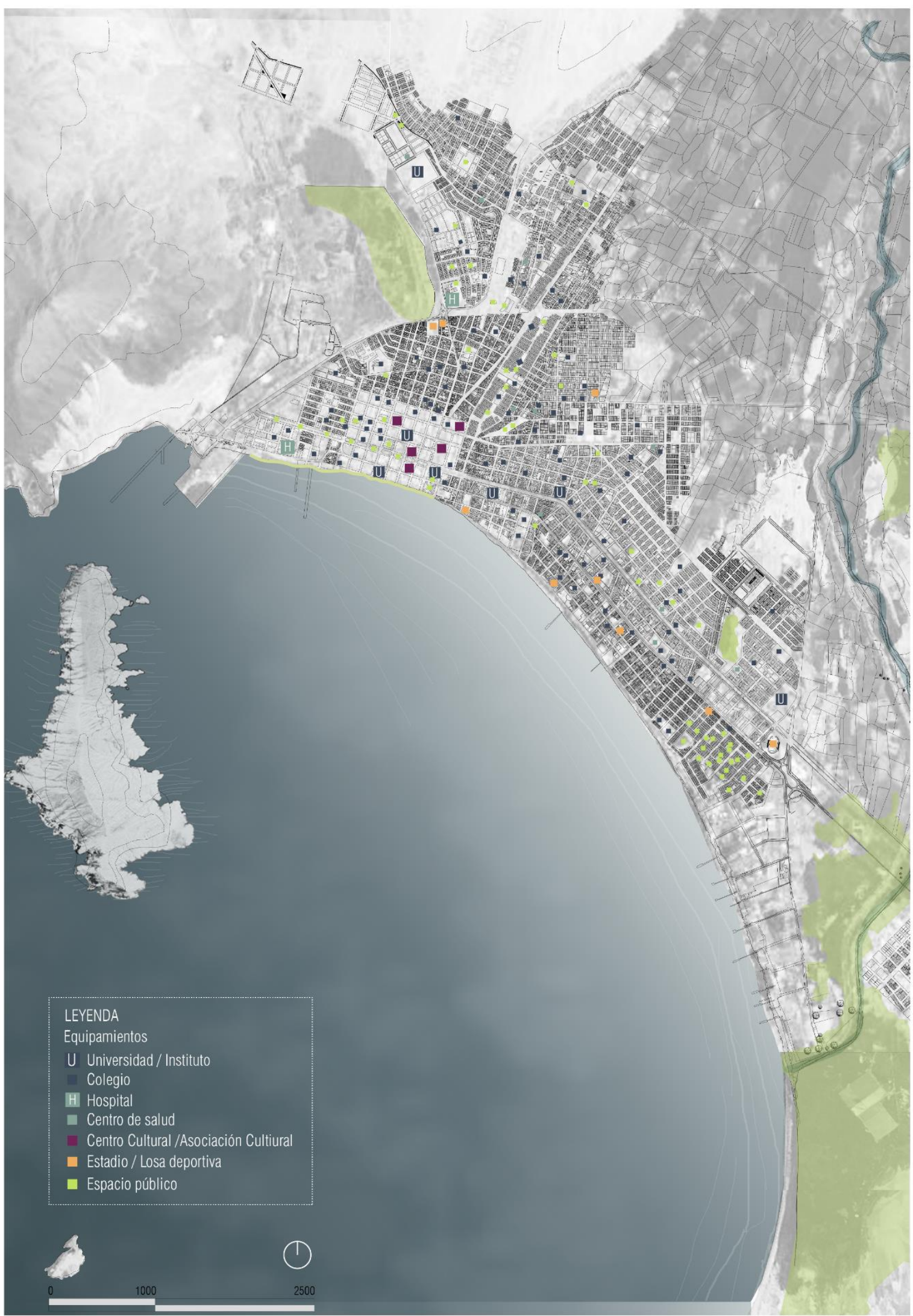

Fuente: PDU Santa 2012. Elaboración propia 
Ilustración 6.4 Radio de influencia del equipamiento educativo en el distrito de Chimbote

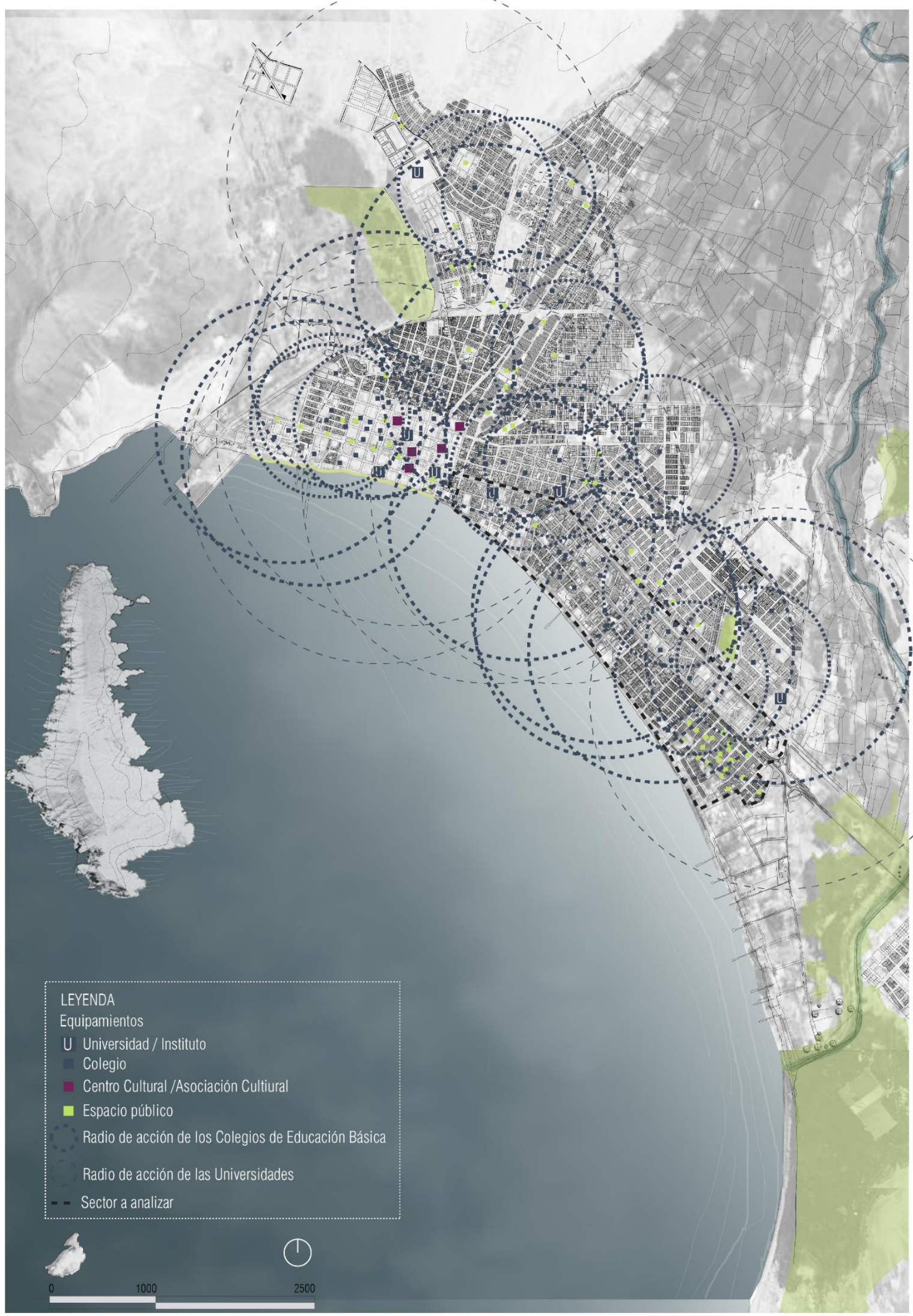

Fuente: PDU Santa 2012. Elaboración propia 
Ilustración 6.5 Radio de influencia del equipamiento cultural en el distrito de Chimbote

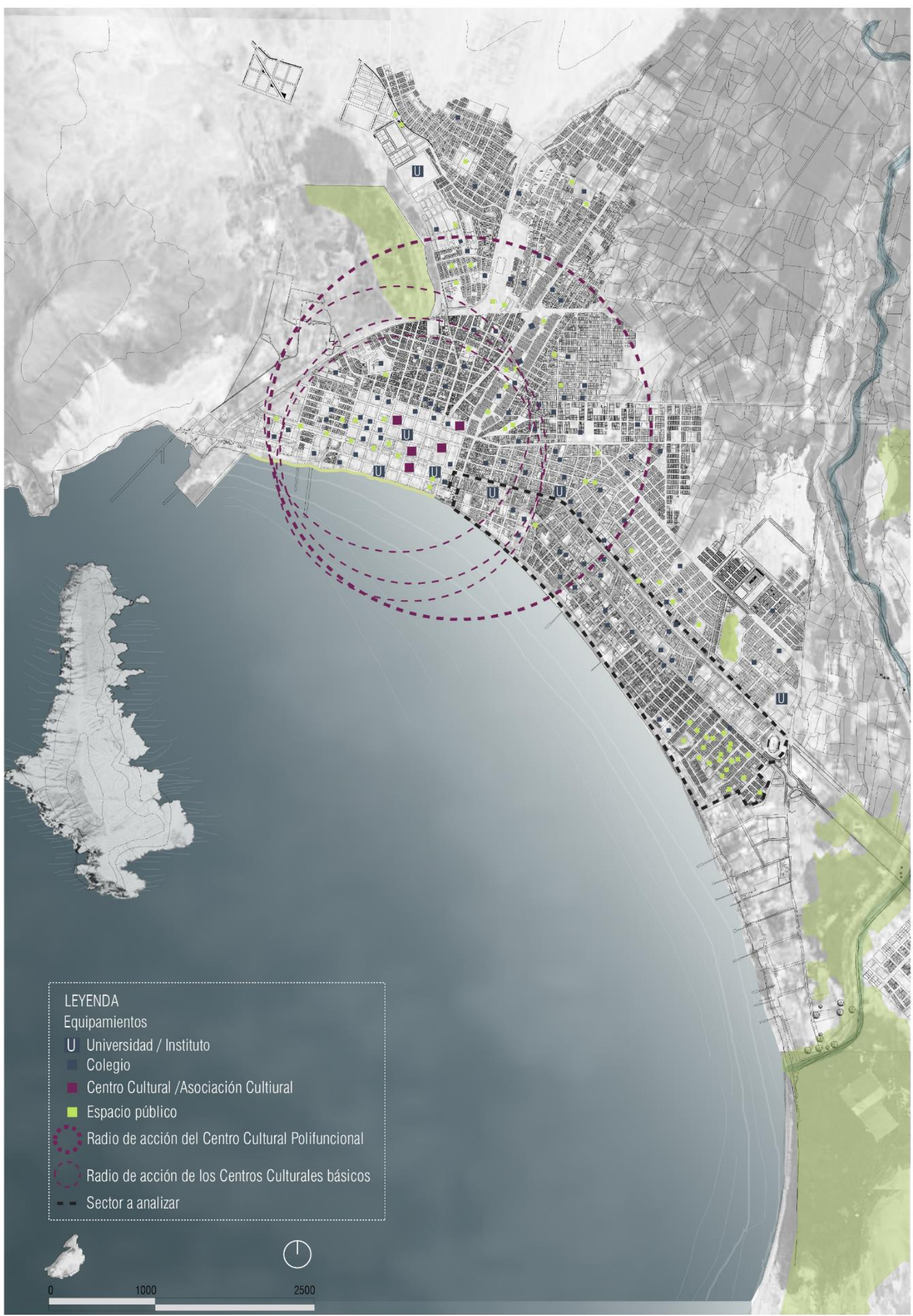

Fuente: PDU Santa 2012. Elaboración propia 
Luego de observar la red de equipamientos existentes de Chimbote, se ha hallado déficit de equipamientos culturales pues en la actualidad solo existe un Centro Cultural en el distrito de Chimbote, incapaz de atender a toda la población de Chimbote. De igual manera, en el distrito de Nuevo Chimbote no existe ningún equipamiento que presente estas características. Sin embargo, en ambos distritos se puede observar que existe gran cantidad de colegios, información que si se complementa con la cantidad de población por edades, demuestra que existe gran población estudiantil, necesitada de equipamiento público donde pueda desarrollar actividades después del horario escolar y a su vez complemente los conocimientos obtenidos.

Del mismo modo, se observa que los demás equipamientos están concentrados en la parte norte de la ciudad (centro de Chimbote) como en la parte sur (centro de Nuevo Chimbote), por lo que el sector 5 de la ciudad es el que presenta menor cantidad de equipamientos, aun cuando en este sector se encuentran ubicadas las primeras fábricas que se establecieron en Chimbote y que actualmente se encuentran en desuso, pues a través de la O.M No 001-2009MPS, se estableció que debían cambiar de ubicación por encontrarse en una zona residencial. Además, según el PDU Santa 2012 la bahía El Ferrol se encuentra dentro del patrimonio cultural de la ciudad, por lo que se tendría una doble razón de recuperar estos espacios industriales en desuso, principalmente porque cuentan con un valioso pasado histórico cultural industrial y segundo porque recuperando estos espacios también se incentivará a recuperar y reactivar la bahía de Chimbote que actualmente se encuentra en una situación deplorable y totalmente contaminada.

\section{Ilustración 6.6 Embarcaciones en la bahía El Ferrol}

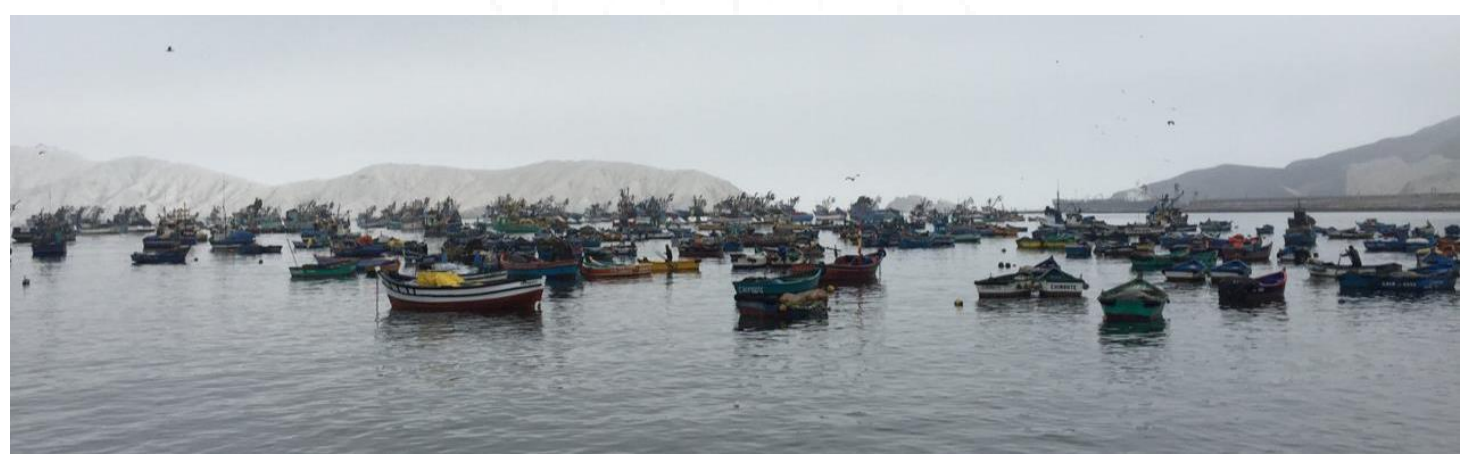

Fuente: Fotografía propia 
Ilustración 6.7 Fábricas que operaban en la Bahía El Ferrol en el año 2004

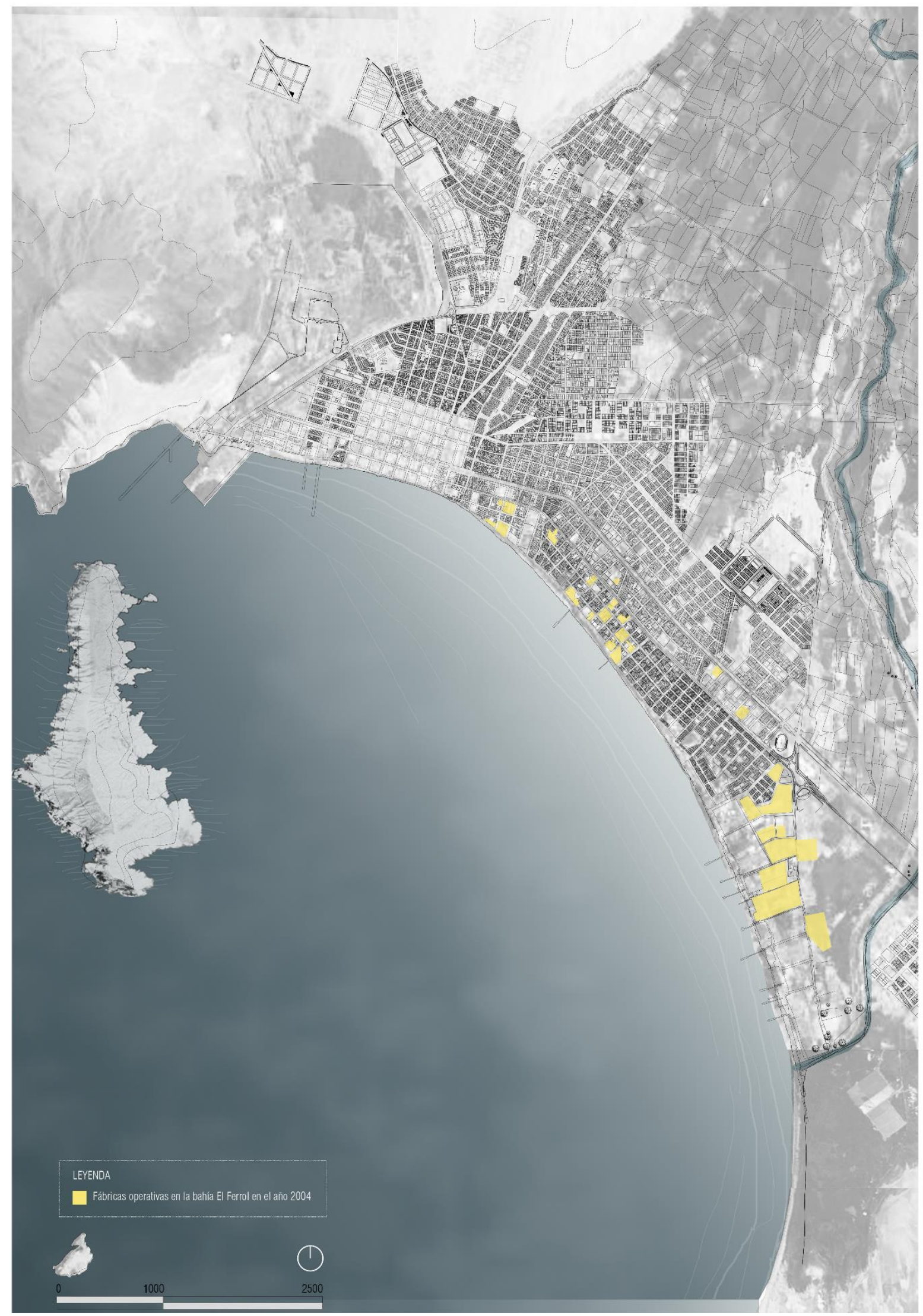

Fuente: Plan de Recuperación Ambiental de la Bahía El Ferrol, 2004. Elaboración propia 
Ilustración 6.8 Fábricas operativas e inoperativas en la bahía El Ferrol en la actualidad

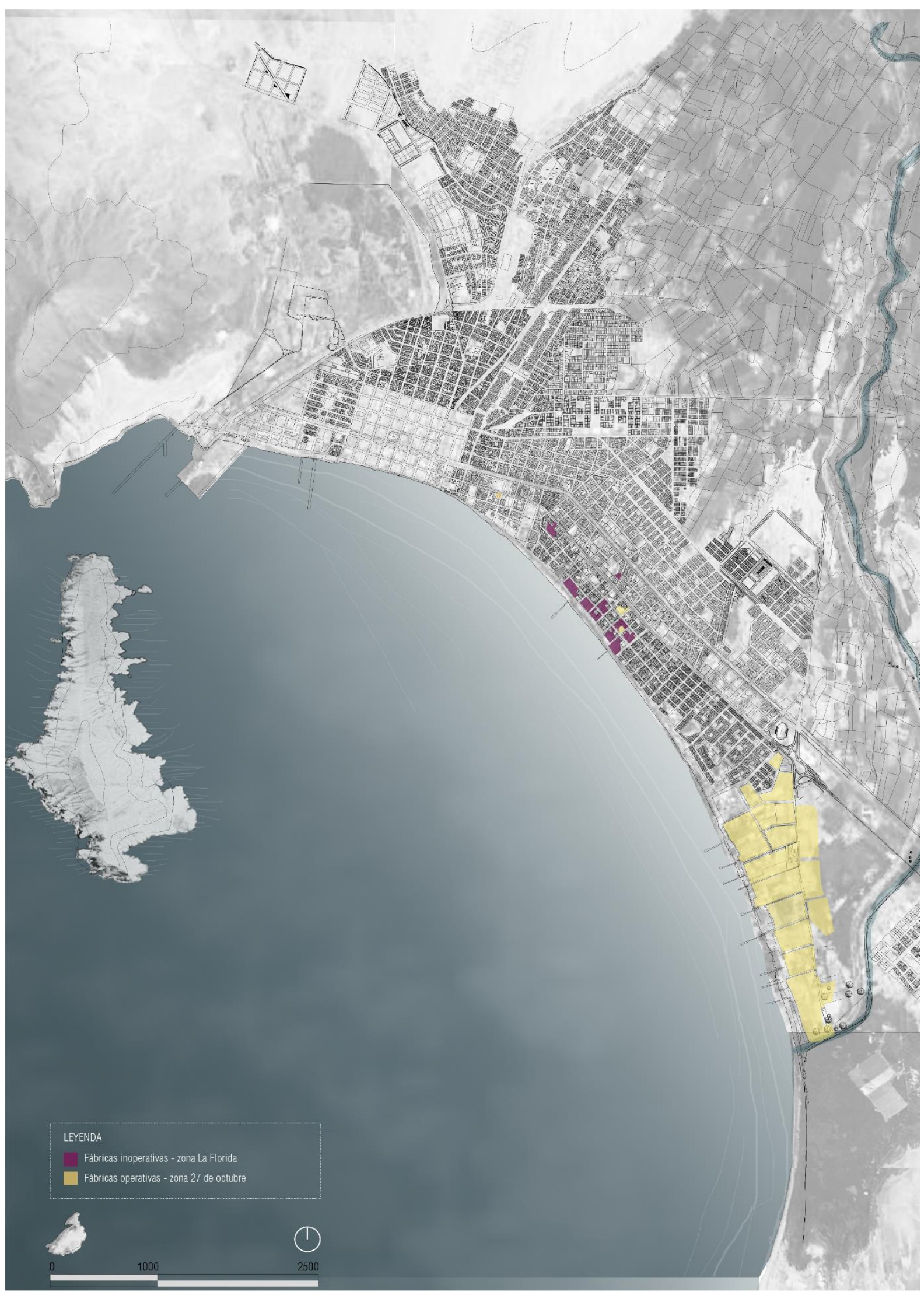

Fuente: Informe OEFA 2016. Elaboración propia 
Ilustración 6.9 Número de fábricas operativas e inoperativas en la bahía EI Ferrol

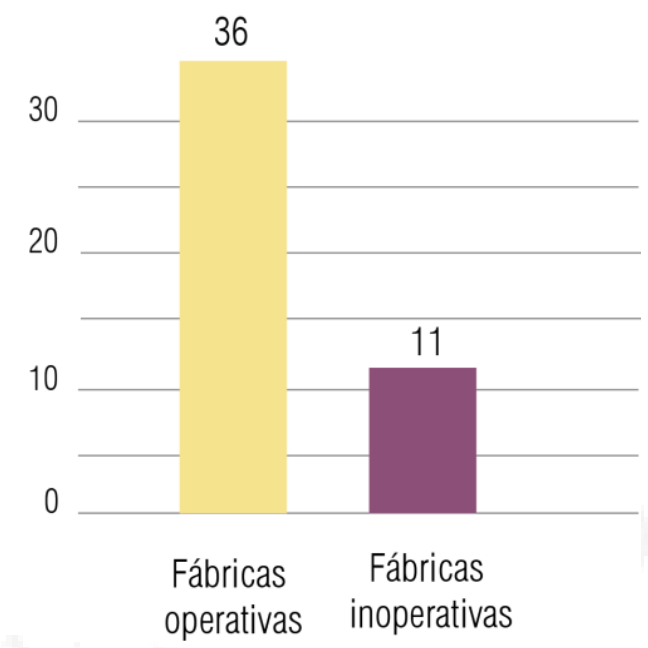

Fuente: Informe OEFA 2016. Elaboración propia

\subsection{Análisis del lugar}

\subsubsection{Características de las construcciones de la zona}

El sector 5 comprende cinco barrios: Miraflores Bajo, Miraflores I zona, Miraflores Alto, Miraflores Alto III zona, Florida Baja y Florida Baja. Es un área con zonificación mixta, donde el mayor porcentaje, $85.66 \%$ corresponde a viviendas, seguido de porcentaje pertenecientes a comercio, vivienda -comercio e industria. Asimismo, es un área de densidad media pues predominan las viviendas con estas características, es decir, albergan entre 165 a 1300 habitantes por hectárea. Estas viviendas ocupan un total de 5585 lotes. 


\section{NÚMERO DE LOTES}

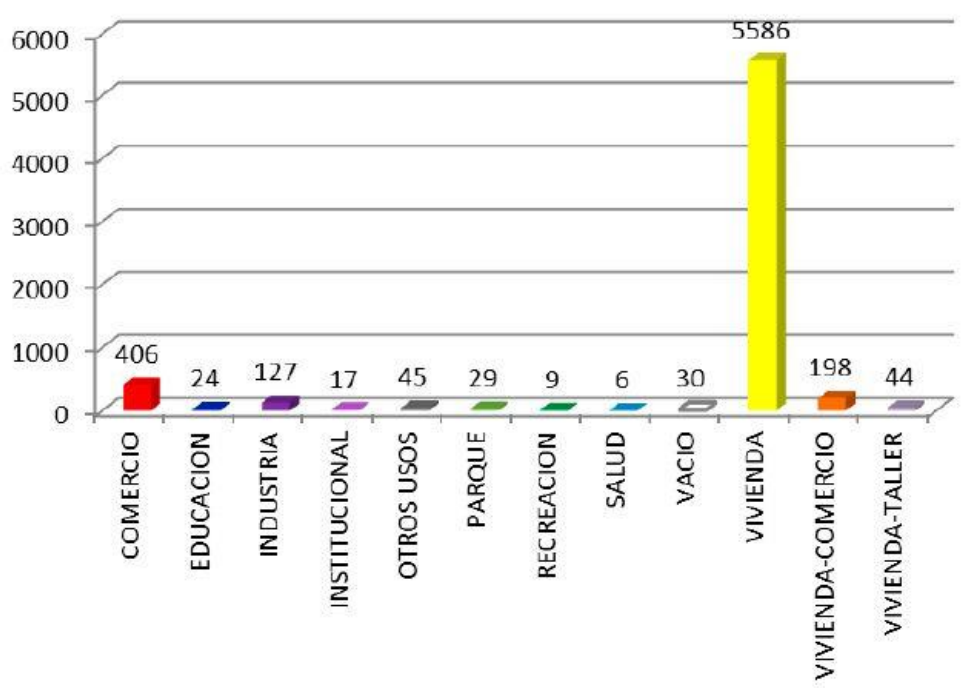

Fuente: PDU Santa 2012. Elaboración propia

El sector 5 es un área que presenta edificaciones bajas en altura, predominan las construcciones de un piso que representan el $57.14 \%$ de los lotes y las de dos pisos representan el $36.51 \%$. El material de las construcciones es en su mayoría es ladrillo que conforman el $97.49 \%$, pero también existen edificaciones de adobe, madera y material recuperable. (PDU de la ciudad de Chimbote , 2012)

Existe una cantidad significativa de colegios de niveles inicial, primaria y secundaria, que se encuentran muy cercanos a lotes industriales. Lotes que no todos son fábricas, sino que también son usados como almacenes, frigoríficos y servicios complementarios de las fábricas, por lo que presentan las mismas características en su fachada, muro ciego y un portón de gran altura. Al mismo tiempo se puede observar en el siguiente mapa que los espacios públicos se encuentran concentrados en la parte sur del sector, que por su tejido urbano puede reconocerse el uso residencial y la escala barrial de las plazas.

Todas las calles de los sectores perpendiculares a la bahía no cuentan con una conexión visual directa del mar sino que esta se encuentra interrumpida por una barrera continua de desmonte y basura, lo que conlleva a que las personas no se acerquen a la bahía sino que se limiten a observar el paisaje del montículo hacia el cielo. 
Ilustración 6.11 Mapa de equipamientos, uso de suelo y relación con la bahía en el sector 5

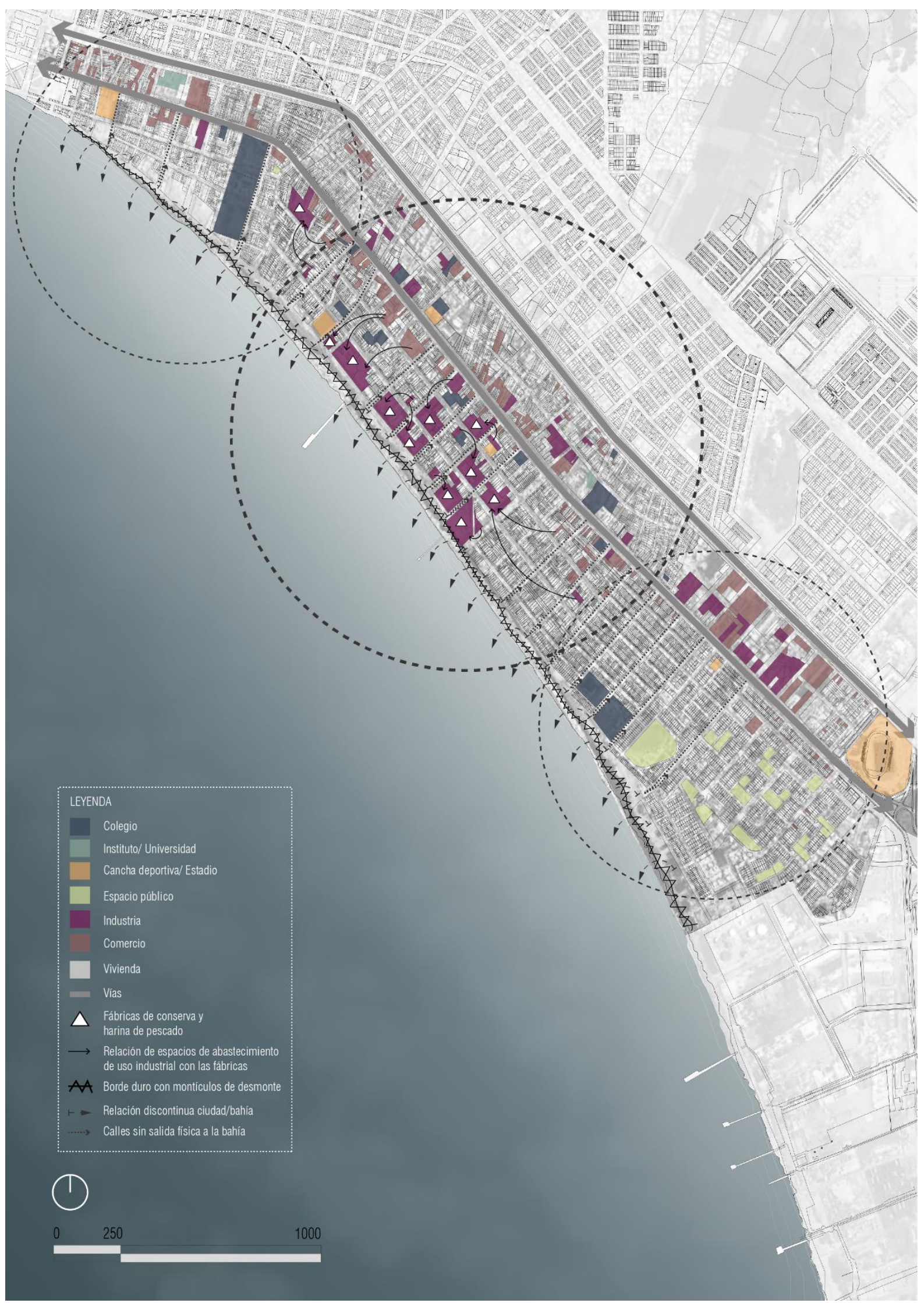

Fuente: Elaboración propia 


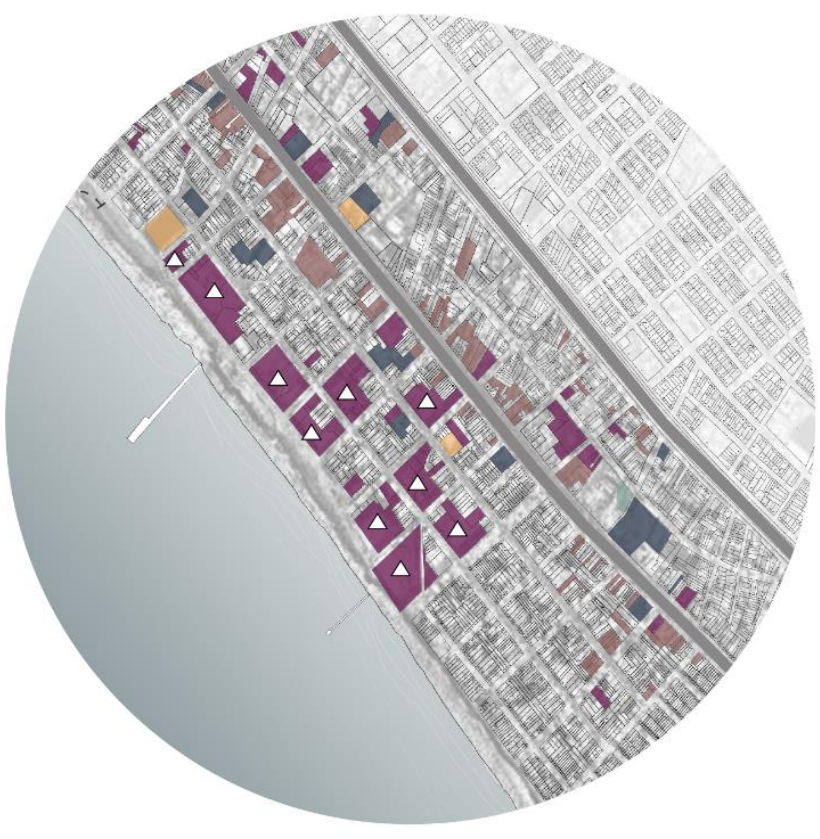

Fuente: Elaboración propia

\subsubsection{Consideraciones ambientales}

Chimbote es una ciudad que presenta un clima desértico con precipitaciones casi nulas, pero a su vez es húmedo debido a su condición portuaria. La humedad relativa que presenta oscila entre el 80 y $90 \%$. Asimismo, su temperatura puede llegar hasta $28^{\circ}$ en verano y $14^{\circ}$ en invierno, por lo que el clima es mayormente templado.

Con respecto al asoleamiento, Chimbote presenta una latitud de $9^{\circ}$, muy cercana a la línea ecuatorial permitiendo que la ciudad presente mayor cantidad de horas de sol al día en verano, y en invierno presenta una disminución de estas. De igual manera, sucede con las sombras, debido a la latitud, estas no son alargadas y la diferencia de ellas entre las estaciones del año no son significativas.

Los vientos en Chimbote son notables, lo más predominantes y fuertes son los de otoño, los cuales provienen del sur-oeste con una velocidad de $40 \mathrm{~m} / \mathrm{s}$. Seguido de estos se encuentran los de verano, que vienen del sur-este con una velocidad entre $32-15 \mathrm{~m} / \mathrm{s}$. 


\subsubsection{Riesgos}

Los lotes que funcionaban como fábricas en el sector 5 hasta antes de la aparición de la O.M No 001-2009-MPS, presentaban una zonificación industrial. Pero, después de este documento tuvieron que trasladarse a la zona industrial por lo que los locales han quedado en desuso y con el PDU Santa 2012 se les ha cambiado de zonificación de modo que se realice una regeneración urbana de la zona.

Debido a que esta zona era en gran medida industrial, no se ha tenido en cuenta el estado de la bahía, sino que como era un espacio que nadie visitaba le han dado la espalda a esta, generando un borde sumamente contaminado, lleno de residuos sólidos, que fomentan la contaminación de agua que ya presenta la bahía debido a que los efluentes de fábricas pesqueras, de la siderurgia y de los desagües domésticos son vertidos al mar.

El tipo de suelo que presenta el sector es un suelo no estable, pues la napa freática se encuentra muy cercana al exterior, aproximadamente a $5 \mathrm{~m}$ y con suelo estable a $10 \mathrm{~m}$ de profundidad.

Ahora bien, en cuanto a la vulnerabilidad ante desastres naturales, según el mapa de peligros y plan de usos de suelo de la ciudad de Chimbote elaborado por Instituto Nacional de Desarrollo Urbano (INADUR) en febrero 2000, el sector 5 es un sector peligroso, pues presenta mayor incidencia de peligros con afectación destructiva, moderada probabilidad de licuación de tsunami, inundación por colapso de drenes y arenamiento de anteplaya. 


\section{Ilustración 6.13 Mapa de riesgos en la bahía EI Ferrol}

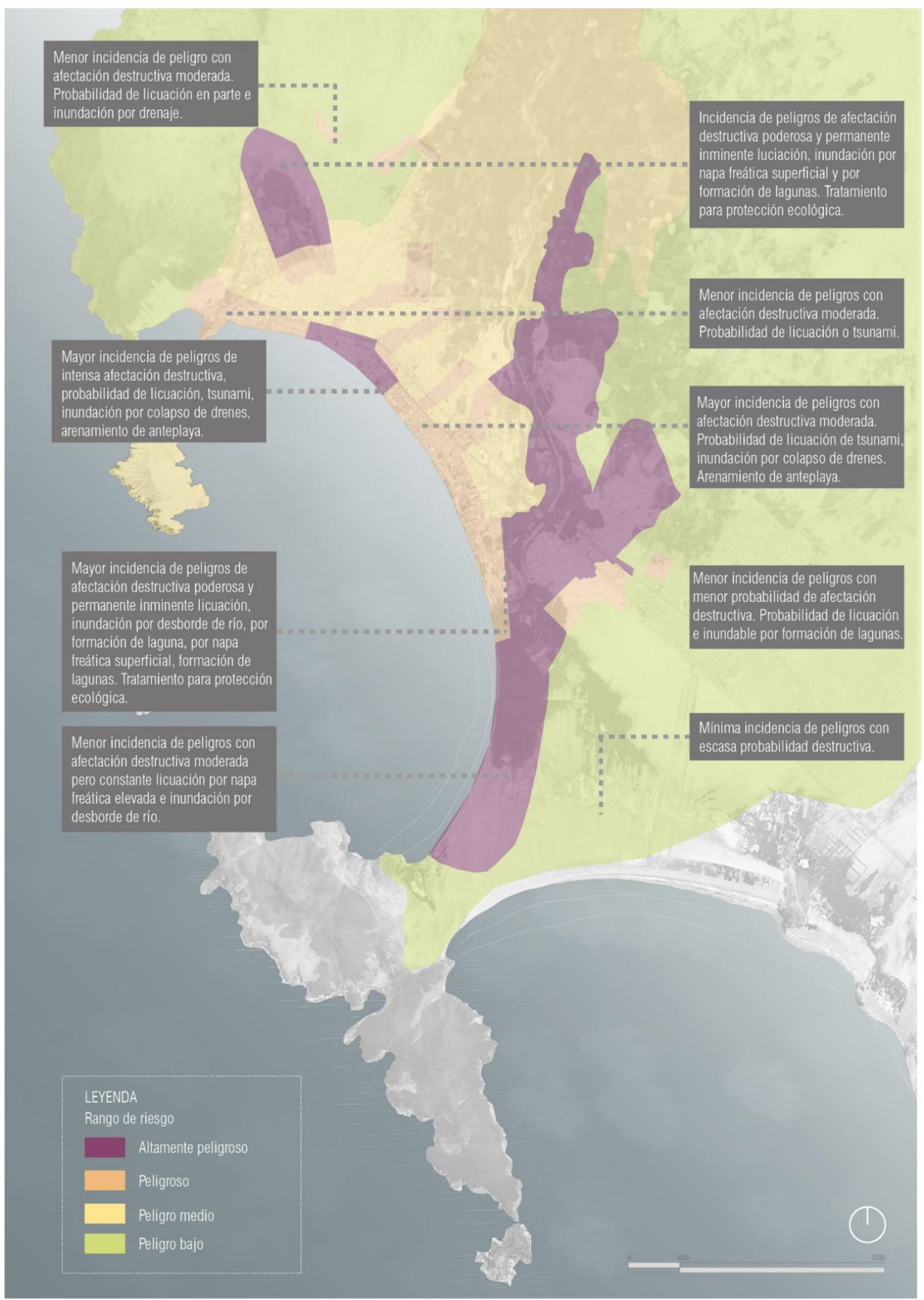

Fuente: INADUR, 2000. Elaboración propia 


\subsubsection{Limitaciones normativas}

El Ministerio de Cultura no presenta normativas relacionadas directamente con la creación de centros culturales. Sin embargo, si existen normativas para preservar el patrimonio cultural, que se tendrá en cuenta en algunos ámbitos pues las fábricas en desuso no son edificaciones que pertenecen a esta categoría, sino que presentan un legado histórico cultural que es parte de la identidad de la población.

\subsubsection{Vías de acceso y transporte}

El sector 5 se encuentra flanqueado por una la Av. Meiggs que a su vez es la Panamericana Norte y por el borde del mar. El principal acceso a este sector es esta avenida donde existe un gran flujo de vehículos tanto pesados como ligeros y un menor flujo de peatones en el sentido de la vía, sino que más bien estos se desplazan en el sentido transversal a la vía debido a que al otro lado se encuentra una mayor variedad de comercio, además de equipamientos educativos y de salud. En las vías transversales a la Av. Meiggs, existe un menor flujo vehicular y de peatones, debido a que es una zona más residencial.

El transporte de la ciudad se caracteriza por tener autos colectivos como transporte público, este tipo predomina sobre los buses, los cuales son escasos en la ciudad. Además, existe una cantidad significativa de autos privados.

\subsubsection{Infraestructura y servicios}

El sector 5, cuenta con servicios de agua, desagüe, alumbrado público. Sin embargo, presenta un déficit en el servicio de recolección de residuos, especialmente en el borde costero, debido a que existe una gran acumulación de residuos sólidos que degradan las visuales y las condiciones de habitabilidad. En cuanto a infraestructura, el sector presenta vías pavimentadas, pero la vía aledaña al borde costero, se encuentra sin asfaltar.

\subsubsection{Uso de suelos}

El sector 5 presenta el $85.66 \%$ del uso de suelo ocupado por vivienda, 5586 lotes. Sin embrago, la zona presenta un uso mixto, pues existen otros usos como comercio con el $6.23 \%$ de los 
lotes, vivienda-comercio con el 3.04\%, industria con el 1.95\%, recreación $0.69 \%$ y otros usos con menor porcentajes.

\subsubsection{Percepción}

Al encontrarse la zona central de la extensión de la bahía El Ferrol, cuenta con una potente visual de toda la bahía, desde donde se puede observar hacia el extremo norte, la majestuosidad y belleza de la isla blanca y hacia el extremo sur, los islotes de El Ferrol.

Las visuales de la zona son muy potentes, sin embargo, son muy difíciles de apreciar debido a la gran barrera visual en el borde de la bahía generada por la acumulación de desmontes y basura, que a su vez generan mal olor y animales molestos como moscas e insectos. Esto genera que cada vez sean menos las personas que se acerquen al borde costero y la ciudad continúe dándole la espalda al mar. Además de estos montículos de basura y desmonte acumulados, la zona costera ha sido invadida por viviendas de escasos recursos, y en muchos casos estructuras improvisadas con plásticos y maderas con la finalidad de servir de viviendas a personas de escasos recursos. Estas viviendas precarias han llegado inclusive a interrumpir algunas vías de circulación, así como también bloquear la conexión entre las calles y el borde costero. Si bien los montículos de basura emanan un olor bastante desagradable, a esto se le suma un olor inclusive más potente y molesto generado por las tuberías de desagüe de viviendas y fábricas que desembocan en el mar, las cuales incrementan la contaminación de la bahía. El olor a pescado tan característico de la zona aún permanece, sin embargo, ha ido disminuyendo a partir del traslado de las fábricas de industria pesada a la zona industrial del 27 de octubre. Es una bahía sumamente contaminada, tanto en el agua, aire, como en la acumulación de residuos, y que necesita con suma urgencia una intervención.

\subsubsection{Memoria Industrial}

Las fábricas en desuso de este sector presentan un valor importante de memoria industrial, pues estos espacios cuentan con elementos hitos como tanques de aceite, tijerales, hangares que hacen referencia a un pasado histórico industrial que la población sabe que existe pero no le otorgan el valor suficiente que deberían tener como legado de la historia de Chimbote. 


\subsubsection{Espacio Público}

En esta área existen espacios públicos en mal estado como: alamedas, losas deportivas y plazas, que pueden complementar para contribuir a la recuperación de los espacios industriales en desuso, que ayudaría a generar un proyecto completo de equipamiento y espacio público.

\subsection{Red de fábricas inoperativas}

Tras analizar el sector 5, que comprende la zona de la Florida Baja, en donde se encuentran las 11 fábricas en desuso, se ha visto necesario relacionarlas entre sí formando una red de activación de fábricas inoperativas, que permitan ver estos espacios fabriles como unidades de intervención y como oportunidad de transformación y regeneración de la zona. En este sentido, se propone activar los 11 puntos, para que a partir de ellos se genere actividad en las calles transversales que finalizan en el mar. Cada fábrica albergará un nuevo uso, que dependerá del análisis que resulte de cada punto específico. La inserción del nuevo programa permitirá que los habitantes de la zona se identifiquen con ella, avivando su interés por mejorar el lugar donde viven, por ende volverán la mirada hacia el mar, que como efecto colateral de la activación de las calles de menor escala, activarán el malecón, el mayor espacio público que necesita la ciudad de Chimbote, como respuesta a un cambio social, cultural y ambiental.

Para fines de la presente tesis, se ha escogido una de las fábricas en desuso para ser desarrollada. Su selección está basada en el análisis contextual de la zona y su nuevo uso en la demanda cultural que presenta la ciudad. 
Ilustración 6.14 Red de fábricas inoperativas en la zona de Florida Baja

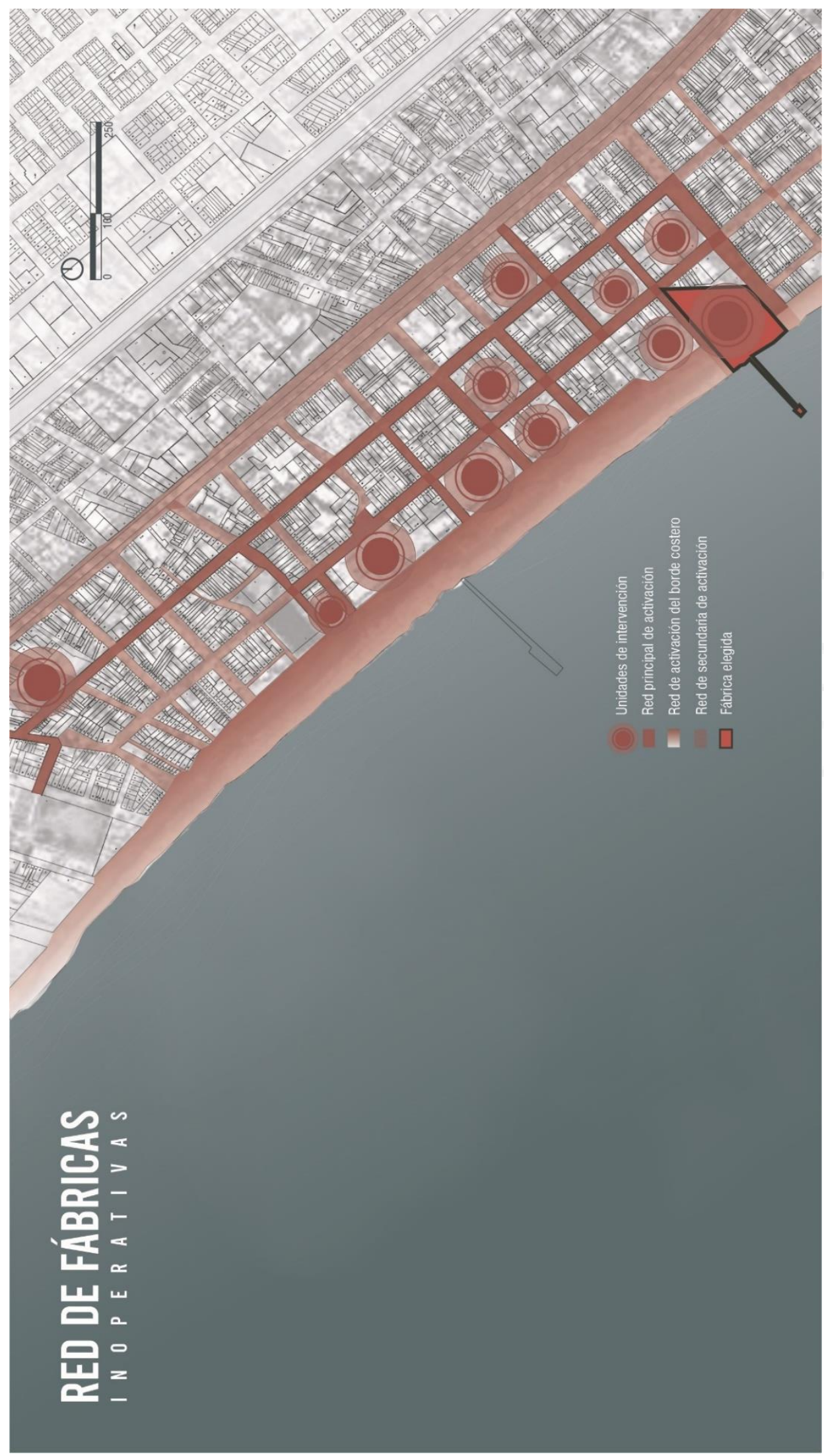

Fuente: Elaboración propia 


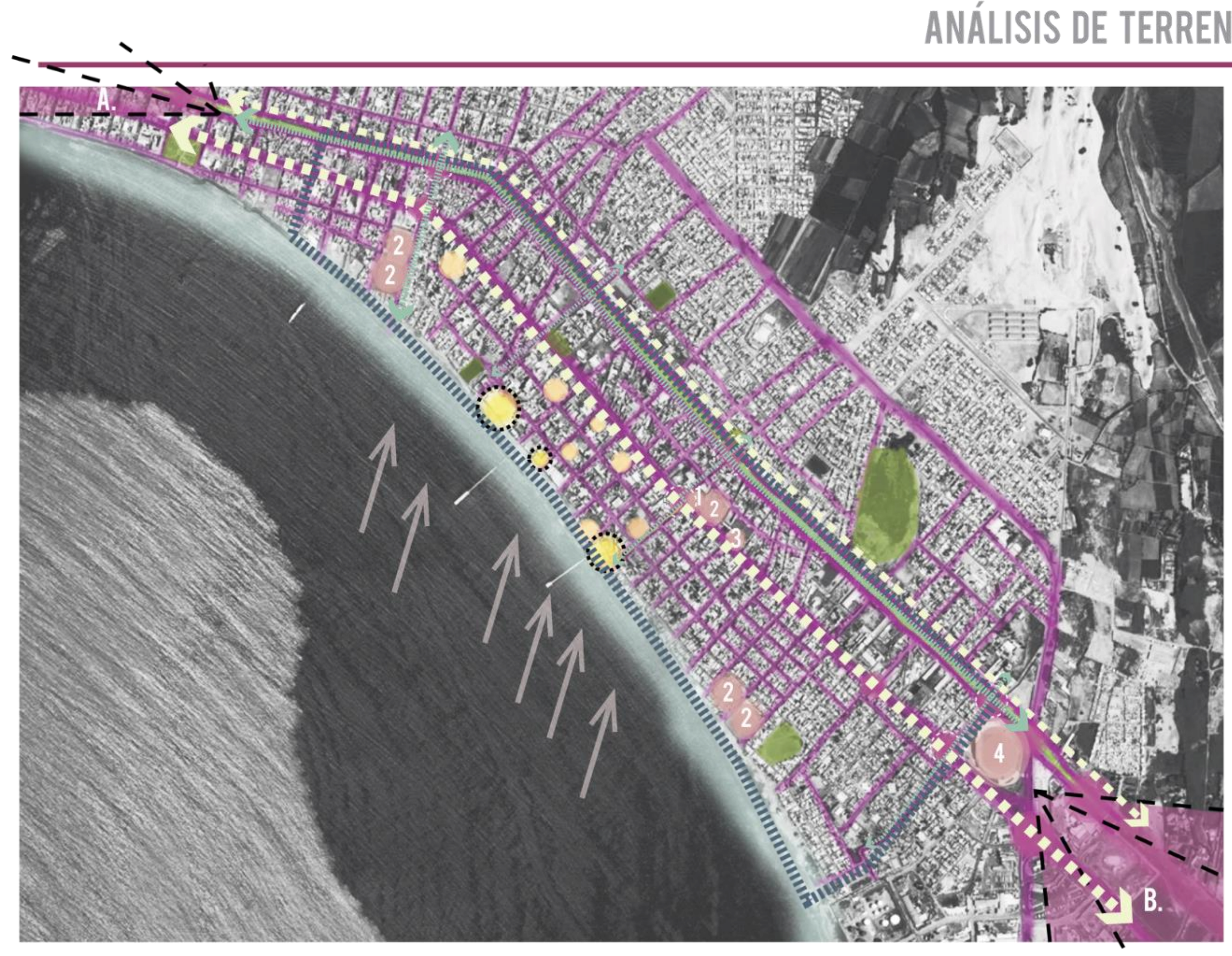

\author{
Fábricas en desuso \\ seleccioandas \\ Fábricas en desuso no \\ seleccioandas \\ Equipamientos \\ 1. Salud \\ 2.Educación \\ 3. Deportivo \\ Áreas recreativas \\ Puntos de acumulación de \\ residuos sólidos \\ Borde \\ IIIIIIII Sector 5 \\ Sendas \\ Vías secundarias \\ 6 Nodo \\ мимимим Flujo peatonal \\ Flujo vehicular \\ Vientos de otoño (so) \\ A. Hacia Chimbote
}

B. Hacia Nuevo Chimbote 500 


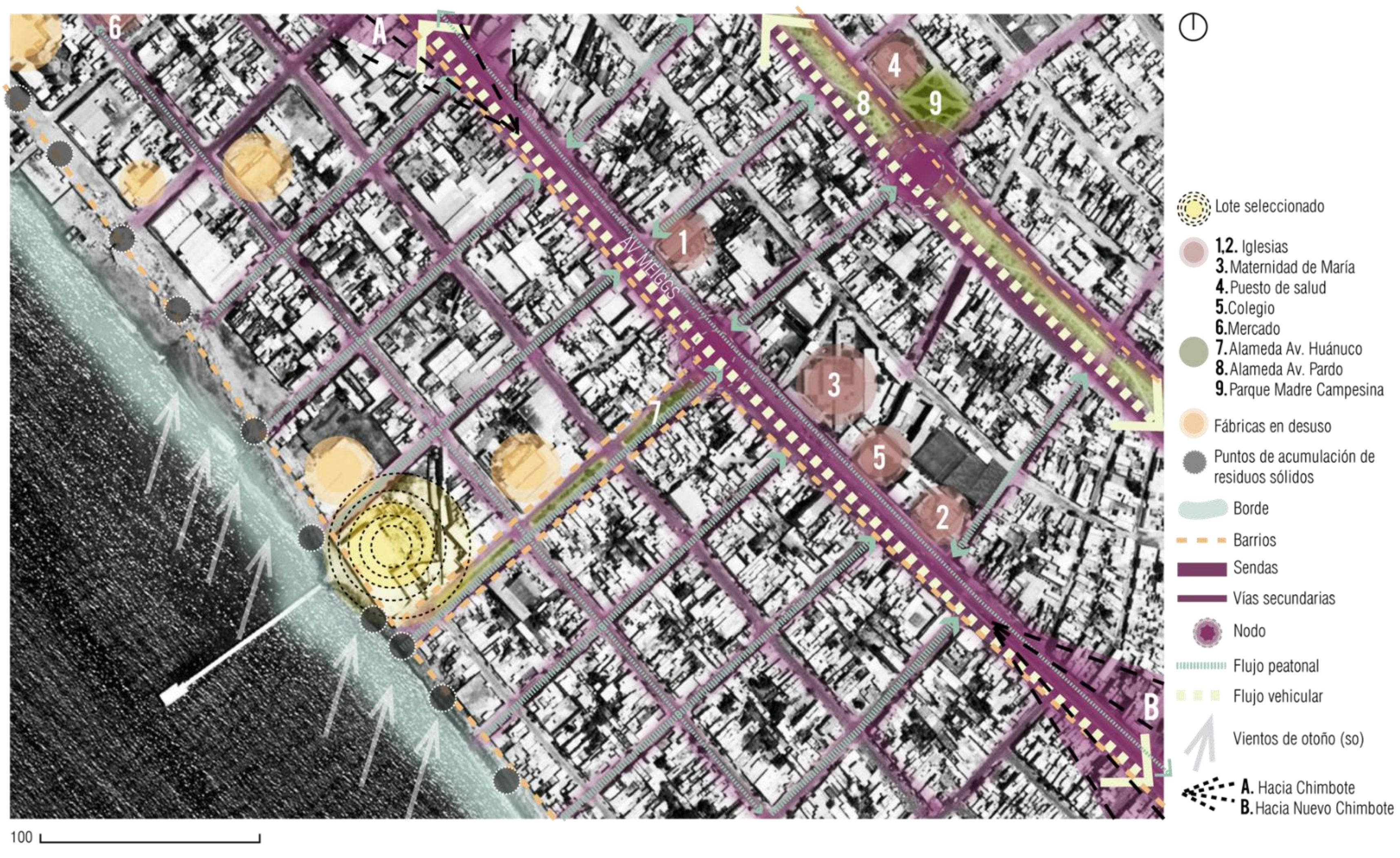




\begin{tabular}{|c|c|c|c|c|c|c|c|c|c|c|c|c|c|c|c|c|}
\hline ÍTEM 1 & & ÍTEM 2 & CRITERI0 1 & CRITERIO 2 & CRITERIO 3 & CRITERIO 4 & CRITERIO 5 & CRITERIO 6 & CRITERI0 7 & CRITERIO 8 & CRITERIO 9 & CRITERIO 10 & CRITERIO 11 & \multicolumn{2}{|c|}{ CRITERIO 12} & $T$ \\
\hline IN & DISTRITO & $\begin{array}{c}\text { IMAGEN } \\
\text { REFERENCIAL }\end{array}$ & $\begin{array}{c}\text { Construcciones } \\
\text { de la zona }\end{array}$ & $\begin{array}{l}\text { Consideraciones } \\
\text { Ambientales }\end{array}$ & Riesgos & $\begin{array}{l}\text { Limitaciones } \\
\text { Normativas }\end{array}$ & Vías de Acceso & \begin{tabular}{|c|} 
Infraestructura \\
y Servicios
\end{tabular} & Usos de Suelos & Morfología & Paisaje & $\begin{array}{l}\text { Memoria } \\
\text { Industrial }\end{array}$ & Accesos & \multicolumn{2}{|l|}{$\begin{array}{l}\text { Urbanismo } \\
\text { Social }\end{array}$} & \\
\hline & Chimbote & & \begin{tabular}{|c|} 
Entorno inmedia- \\
to. Viviendas de \\
densidad media \\
y estructuras \\
industriales
\end{tabular} & $\begin{array}{c}\text { Clima: Desértico } \\
\text { con precipitacio- } \\
\text { nes nulas, } \\
\text { húmedo. } \\
\text { Vientos: Predo- } \\
\text { minantes del sur } \\
\text { - oeste }\end{array}$ & \begin{tabular}{|l} 
Vulnerabilidad \\
peligroso. Con \\
riesgo de \\
licuación en caso \\
de tsunami, \\
inundación por \\
colapso de \\
drenes y arena- \\
miento
\end{tabular} & $\begin{array}{c}\text { Terreno Privado } \\
\text { de la empresa } \\
\text { CFG }\end{array}$ & $\begin{array}{l}\text { Cercanía a las av. } \\
\text { Meiggs, Av. } \\
\text { Huánuco y Av. } \\
\text { San Martín. } \\
\text { Acceso por el } \\
\text { Borde Costero se } \\
\text { encuentra } \\
\text { restringido }\end{array}$ & \begin{tabular}{|c|} 
Si cuenta con \\
agua, alcantarilla- \\
do, pavimento \\
(solo en calles \\
laterales), \\
alumbrado y \\
recolección de \\
basura
\end{tabular} & $\begin{array}{c}\text { Zonificación: } \\
\text { Comercio Zonal. } \\
\text { Acceso a } \\
\text { Parámetros }\end{array}$ & \begin{tabular}{|c} 
Forma del terreno \\
asimétrica. \\
Proporciones \\
ligeramente \\
trapezoidales. \\
Ubicado al borde \\
del mar.
\end{tabular} & \begin{tabular}{|c|} 
Visuales: Bahía e \\
Isla Blanca. \\
Contaminación \\
ambiental por \\
acumulación de \\
residuos sólidos
\end{tabular} & $\begin{array}{c}\text { Presenta } 5 \\
\text { tanques de } \\
\text { almacenamiento } \\
\text { de aceite y } \\
\text { estructuras con } \\
\text { tijerales. }\end{array}$ & $\begin{array}{l}\text { Cuenta con } \\
\text { acceso por } 3 \\
\text { frentes }\end{array}$ & \multicolumn{2}{|c|}{$\begin{array}{l}\text { Alameda en la } \\
\text { Avenida Huánuco }\end{array}$} & 29 \\
\hline & & & \begin{tabular}{|l|l|l|l|}
1 & 2 & 3 & 4 \\
\end{tabular} & \begin{tabular}{|l|l|l|l|}
1 & 2 & 3 & 4 \\
\end{tabular} & \begin{tabular}{|l|l|l|l|}
1 & 2 & 3 & 4 \\
\end{tabular} & \begin{tabular}{|l|l|l|l|}
1 & 2 & 3 & 4 \\
\end{tabular} & \begin{tabular}{|l|l|l|l|}
1 & 2 & 3 & 4 \\
\end{tabular} & \begin{tabular}{|l|l|l|l|}
1 & 2 & 3 & 4 \\
\end{tabular} & \begin{tabular}{|l|l|l|l}
1 & 2 & 3 & 4 \\
\end{tabular} & \begin{tabular}{|l|l|l|}
2 & 3 & 4 \\
\end{tabular} & \begin{tabular}{|l|l|l|l|}
1 & 2 & 3 & 4 \\
\end{tabular} & \begin{tabular}{l|l|l|}
1 & 2 & 3 \\
\end{tabular} & \begin{tabular}{|l|l|l|l|}
1 & 2 & 3 & 4 \\
\end{tabular} & \begin{tabular}{|l|l|l|}
1 & 2 & 3 \\
\end{tabular} & 4 & \\
\hline & Chimbote & & $\begin{array}{l}\text { Entorno inmedia- } \\
\text { to. Viviendas de } \\
\text { densidad media } \\
\text { y estructuras } \\
\text { industriales }\end{array}$ & $\begin{array}{c}\text { Clima: Desértico } \\
\text { con precipitacio-- } \\
\text { nes nulas, } \\
\text { húmedo. } \\
\text { Vientos: Predo- } \\
\text { minantes del sur } \\
\text { - oeste }\end{array}$ & \begin{tabular}{|c|} 
Vulnerabilidad \\
con riesgo de \\
licuación en caso \\
de tsunami, \\
inundación por \\
colapso de \\
drenes y arena- \\
miento.
\end{tabular} & $\begin{array}{l}\text { Terreno Privado } \\
\text { de la empresa } \\
\text { RIGEL }\end{array}$ & \begin{tabular}{|c|} 
Cercanía a las av. \\
Meiggs, Av. \\
Cajamarca y \\
Borde Costero
\end{tabular} & \begin{tabular}{|c|} 
Si cuenta con \\
agua, alcantarilla- \\
do, pavimento \\
(solo en calles \\
laterales), \\
alumbrado y \\
recolección de \\
basura \\
\end{tabular} & \begin{tabular}{|c|} 
Zonificación: \\
Zona de \\
Tratamiento \\
Especial
\end{tabular} & \begin{tabular}{|l} 
Forma del terreno \\
irregular. \\
Proporciones \\
ligeramente \\
alargadas. \\
Ubicado al borde \\
del mar.
\end{tabular} & $\begin{array}{c}\text { Visuales: Vista } \\
\text { directa a fábricas. } \\
\text { Contaminación } \\
\text { ambiental por } \\
\text { acumulación de } \\
\text { residuos sólidos. }\end{array}$ & $\begin{array}{c}\text { Presenta } 2 \\
\text { tanques media- } \\
\text { nos }\end{array}$ & $\begin{array}{c}\text { Cuenta con } \\
\text { acceso por } 2 \\
\text { frentes }\end{array}$ & \multicolumn{2}{|c|}{$\begin{array}{c}\text { No presenta } \\
\text { espacios } \\
\text { públicos }\end{array}$} & 25 \\
\hline & & & \begin{tabular}{|l|l|l|l|}
1 & 2 & 3 & 4 \\
\end{tabular} & \begin{tabular}{|l|l|l|l|}
1 & 2 & 3 & 4 \\
\end{tabular} & \begin{tabular}{|l|l|l|l|}
1 & 2 & 3 & 4 \\
\end{tabular} & \begin{tabular}{|l|l|l|l|}
1 & 2 & 3 & 4 \\
\end{tabular} & \begin{tabular}{|l|l|}
1 & 2 \\
\end{tabular} & \begin{tabular}{|l|l|l|l|}
1 & 2 & 3 & 4 \\
\end{tabular} & \begin{tabular}{|l|l|l|l|}
1 & 2 & 3 & 4 \\
\end{tabular} & \begin{tabular}{|l|l|l|l|}
1 & 2 & 3 & 4 \\
\end{tabular} & \begin{tabular}{|l|l|l|l|}
1 & 2 & 3 & 4 \\
\end{tabular} & \begin{tabular}{|l|l|l|l|}
1 & 2 & 3 & 4 \\
\end{tabular} & \begin{tabular}{|l|l|l|}
2 & 3 & 4 \\
\end{tabular} & \begin{tabular}{|l|l|}
2 & 3 \\
\end{tabular} & 4 & \\
\hline & Chimbote & & $\begin{array}{c}\text { Entorno inmedia- } \\
\text { to. Viviendas de } \\
\text { densidad media } \\
\text { y estructuras } \\
\text { industriales }\end{array}$ & $\begin{array}{l}\text { Clima: Desértico } \\
\text { con precipitacio- } \\
\text { nes nulas, } \\
\text { húmedo. } \\
\text { Vientos: Predo- } \\
\text { minantes del sur } \\
\text { - oeste }\end{array}$ & \begin{tabular}{|} 
Vulnerabilidad \\
con riesgo de \\
licuación en caso \\
de tsunami, \\
inundación por \\
colapso de \\
drenes y arena- \\
miento.
\end{tabular} & $\begin{array}{c}\text { Terreno Privado } \\
\text { de la empresa } \\
\text { TASA }\end{array}$ & $\begin{array}{l}\text { Cercanía a las av. } \\
\text { Huancavelica, } \\
\text { Tacna, Junín y } \\
\text { Borde Costero }\end{array}$ & \begin{tabular}{|c|} 
Si cuenta con \\
agua, alcantarilla- \\
do, pavimento \\
(solo en calles \\
laterales), \\
alumbrado y \\
recolección de \\
basura
\end{tabular} & $\begin{array}{l}\text { Zonificación: } \\
\text { Zona de } \\
\text { Tratamiento } \\
\text { Especial }\end{array}$ & $\begin{array}{l}\text { Forma del terreno } \\
\text { irregular. } \\
\text { Proporciones } \\
\text { ligeramente } \\
\text { alargadas. } \\
\text { Ubicado al borde } \\
\text { del mar. }\end{array}$ & $\begin{array}{c}\text { Visuales: Bahía e } \\
\text { Isla Blanca. } \\
\text { Contaminación } \\
\text { ambiental por } \\
\text { acumulación de } \\
\text { residuos sólidos }\end{array}$ & $\begin{array}{l}\text { No presenta } \\
\text { tanques }\end{array}$ & $\begin{array}{l}\text { Cuenta con } \\
\text { acceso por } 4 \\
\text { frentes }\end{array}$ & $\begin{array}{l}\text { No present } \\
\text { espacios } \\
\text { públicos }\end{array}$ & & 27 \\
\hline & & & \begin{tabular}{|l|l|l|l|}
1 & 2 & 3 & 4 \\
\end{tabular} & \begin{tabular}{|l|l|l|l|}
1 & 2 & 3 & 4 \\
\end{tabular} & \begin{tabular}{|l|l|l|}
2 & 3 & 4 \\
\end{tabular} & \begin{tabular}{|l|l|l|l|}
1 & 2 & 3 & 4 \\
\end{tabular} & \begin{tabular}{|l|l|}
1 & 2 \\
\end{tabular} & \begin{tabular}{|l|l|l|l|}
1 & 2 & 3 & 4 \\
\end{tabular} & \begin{tabular}{|l|l|l|l|}
1 & 2 & 3 & 4 \\
\end{tabular} & \begin{tabular}{|l|l|}
1 & 2 \\
\end{tabular} & \begin{tabular}{|l|l|l|l|}
1 & 2 & 3 & 4 \\
\end{tabular} & \begin{tabular}{l|l|l|}
2 & 3 & 4 \\
\end{tabular} & \begin{tabular}{|l|l|l|}
1 & 2 & 3 \\
\end{tabular} & \begin{tabular}{|l|l|}
2 & 3 \\
\end{tabular} & 4 & \\
\hline
\end{tabular}




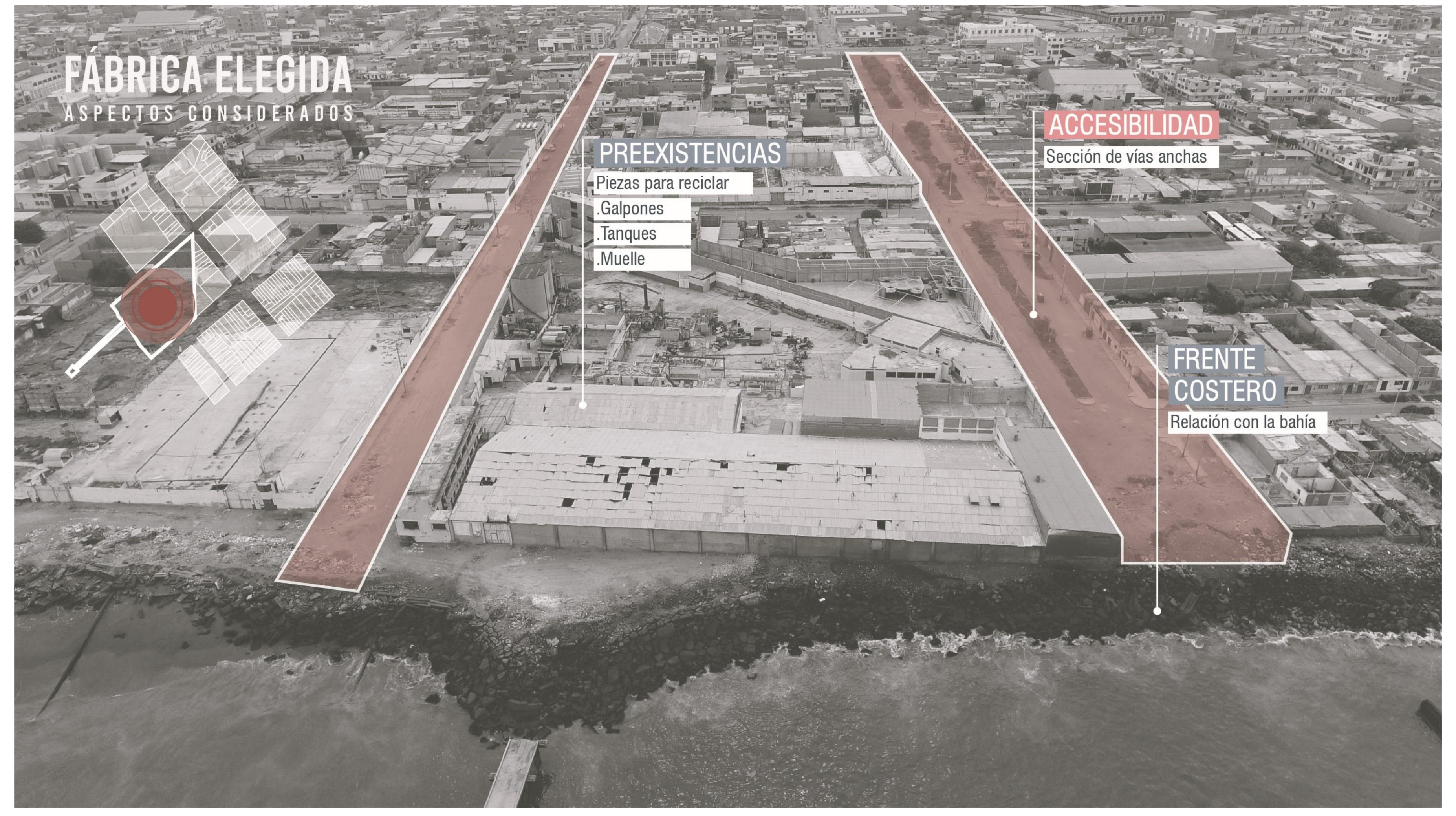




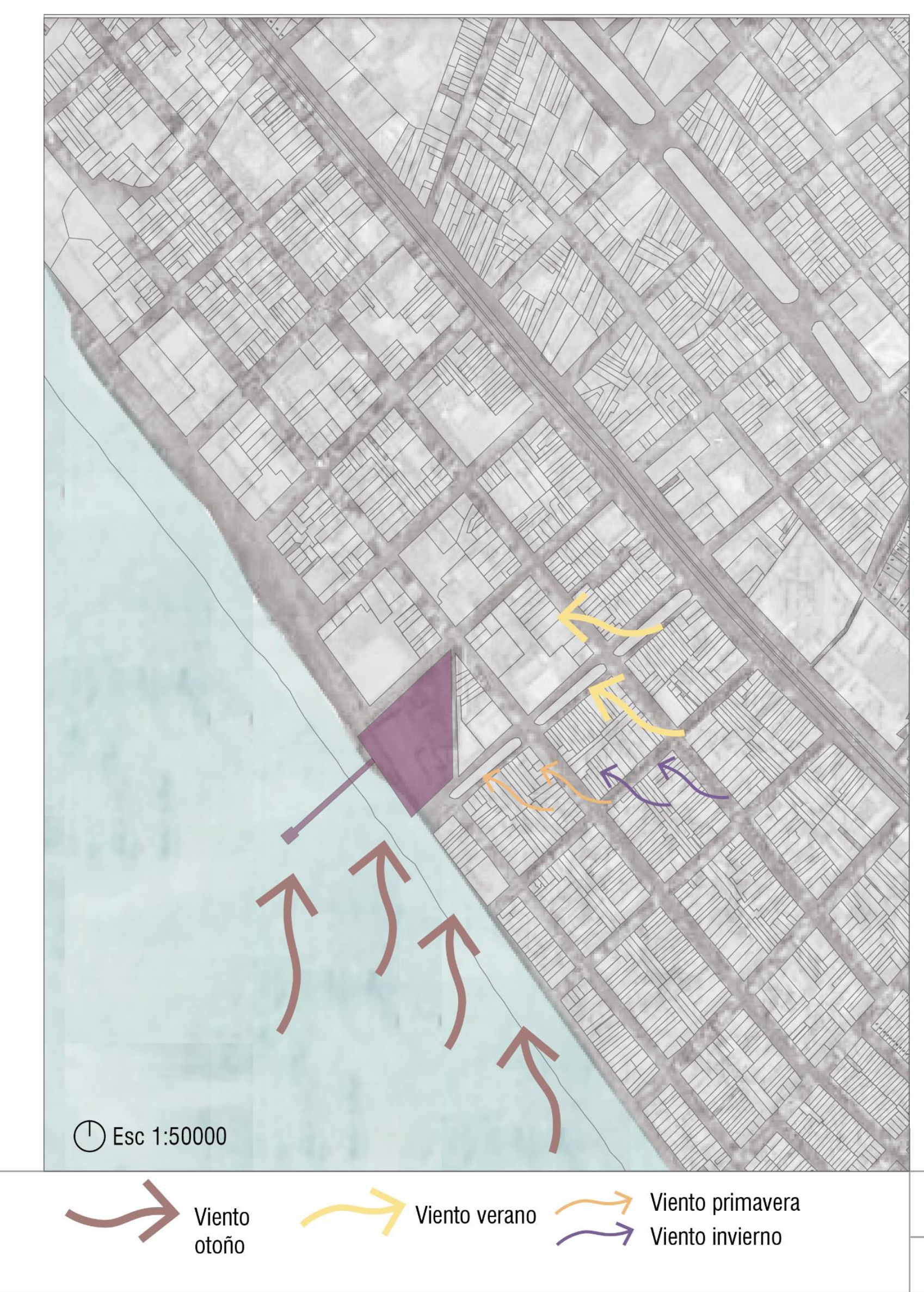

\section{CONDICIONES MEDIOAMBIENTALES \\ Latitud: $9^{\circ} 05^{\circ} 07^{\prime \prime S} \quad$ Longitud: $78^{\circ} 34^{\prime} 41^{\prime \prime} 0$}

Asoleamiento

\section{Vientos}

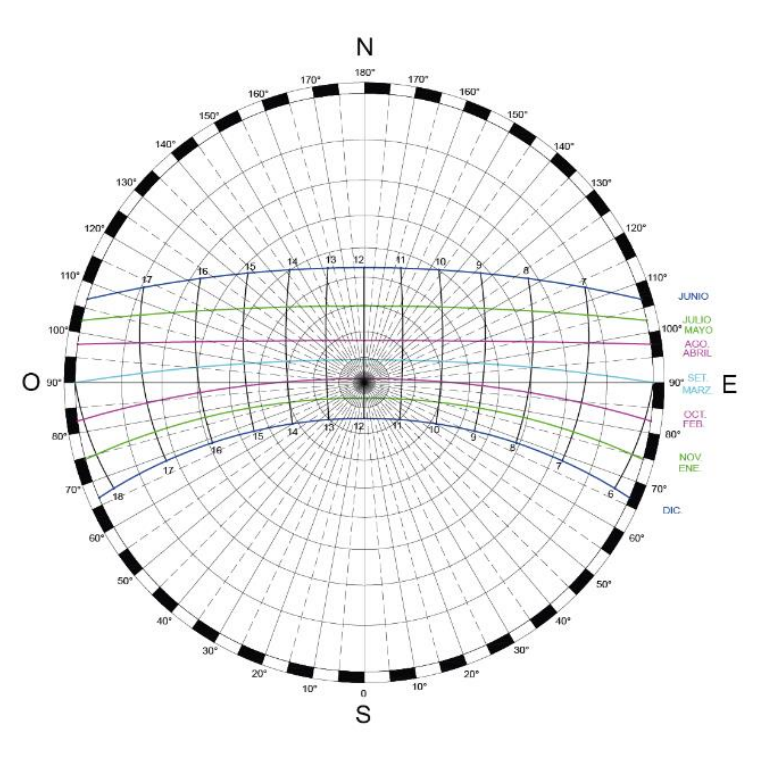

Otoño (marzo)

Primavera (setiembre)

NWW N NNE ${ }^{N E}$

WNW ENE

SWW

Invierno (junio)

SSW SS SSE

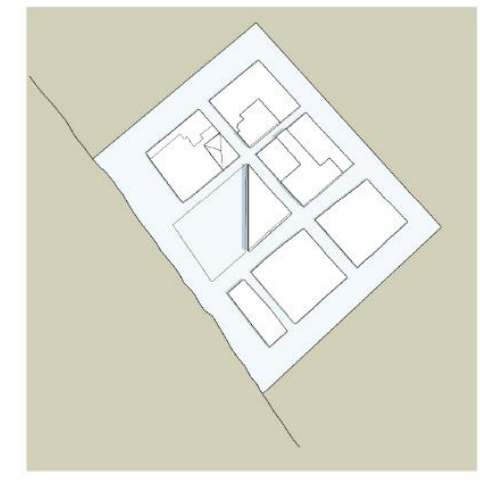

Solsticio de verano

8:30 a.m

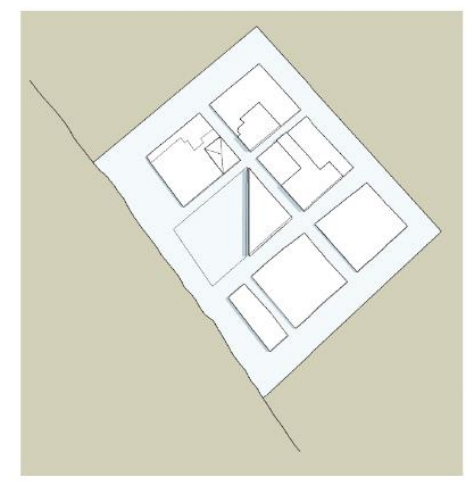

Equinoccio
8:30 a.m

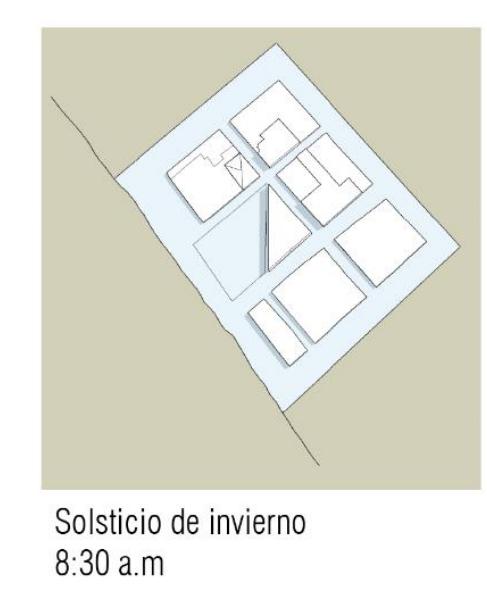

Topografía

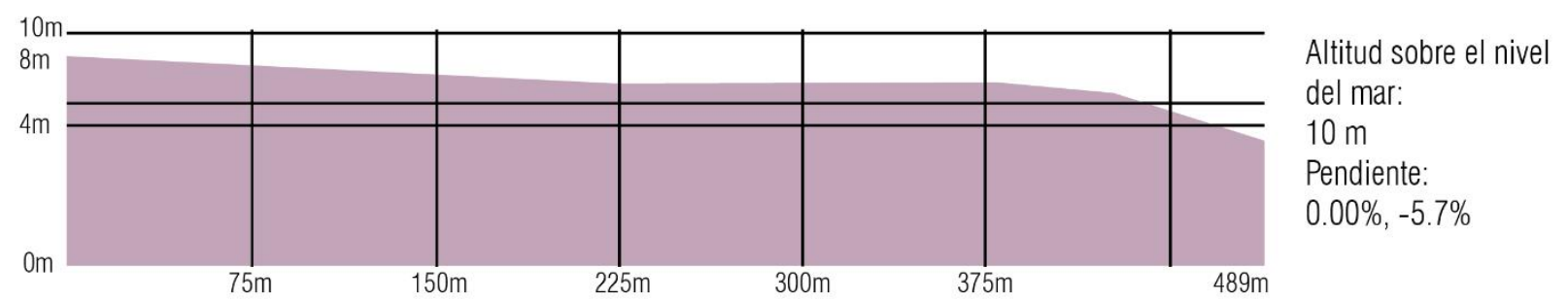

\begin{tabular}{c|c|} 
FABRICA CULTURAL DE CHIMBOTE & \multirow{2}{\text{MedianteelreciclajedeunafábricaendesusoenelbordedelabahíadeChimbote}}{} \\
\cline { 1 - 2 } Ximena de Olazábal Coz & Alessandra Rodriguez Mercado
\end{tabular}




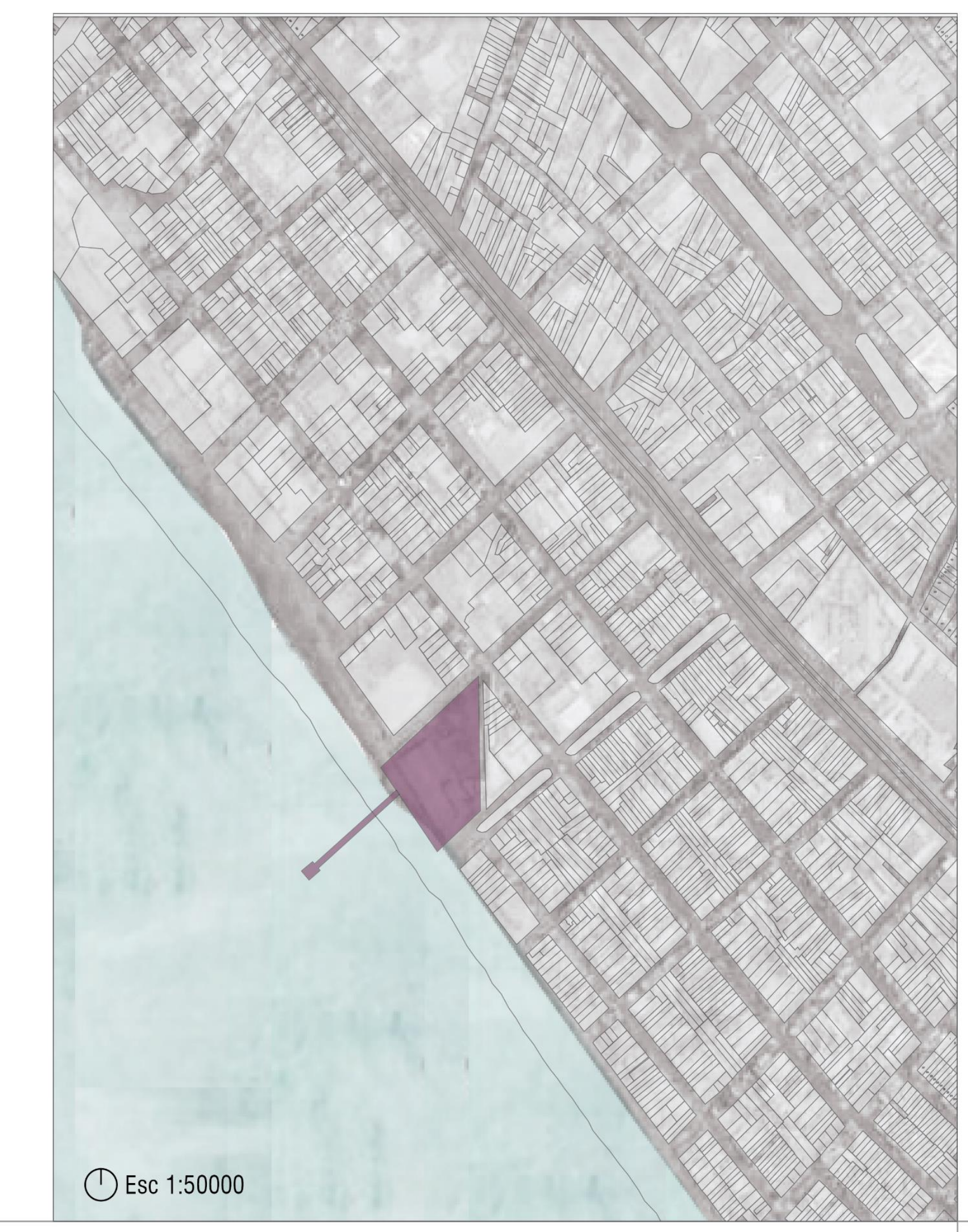

1. CONDICIONES MEDIOAMBIENTALES BAHÍA ELFERROL
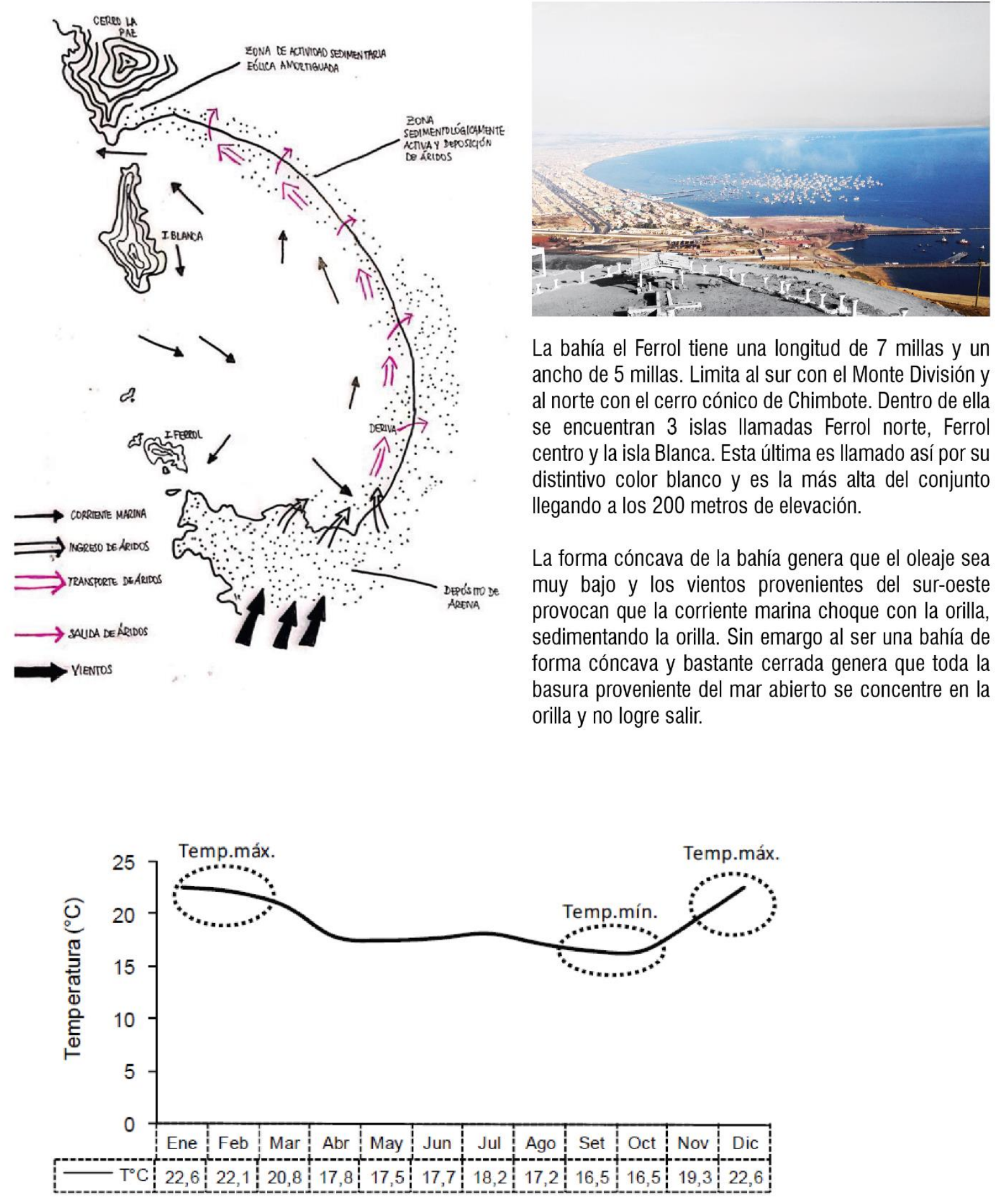

\begin{tabular}{c|c|c|} 
FABRICA CULTURAL DE CHIMBOTE & \multirow{2}{*}{ Mediante el reciclaje de una tábrica en desuso en el borde de la bahía de Chimbote } \\
\cline { 1 - 1 } Ximena de Olazábal Coz $\quad$ Alessandra Rodriguez Mercado &
\end{tabular}




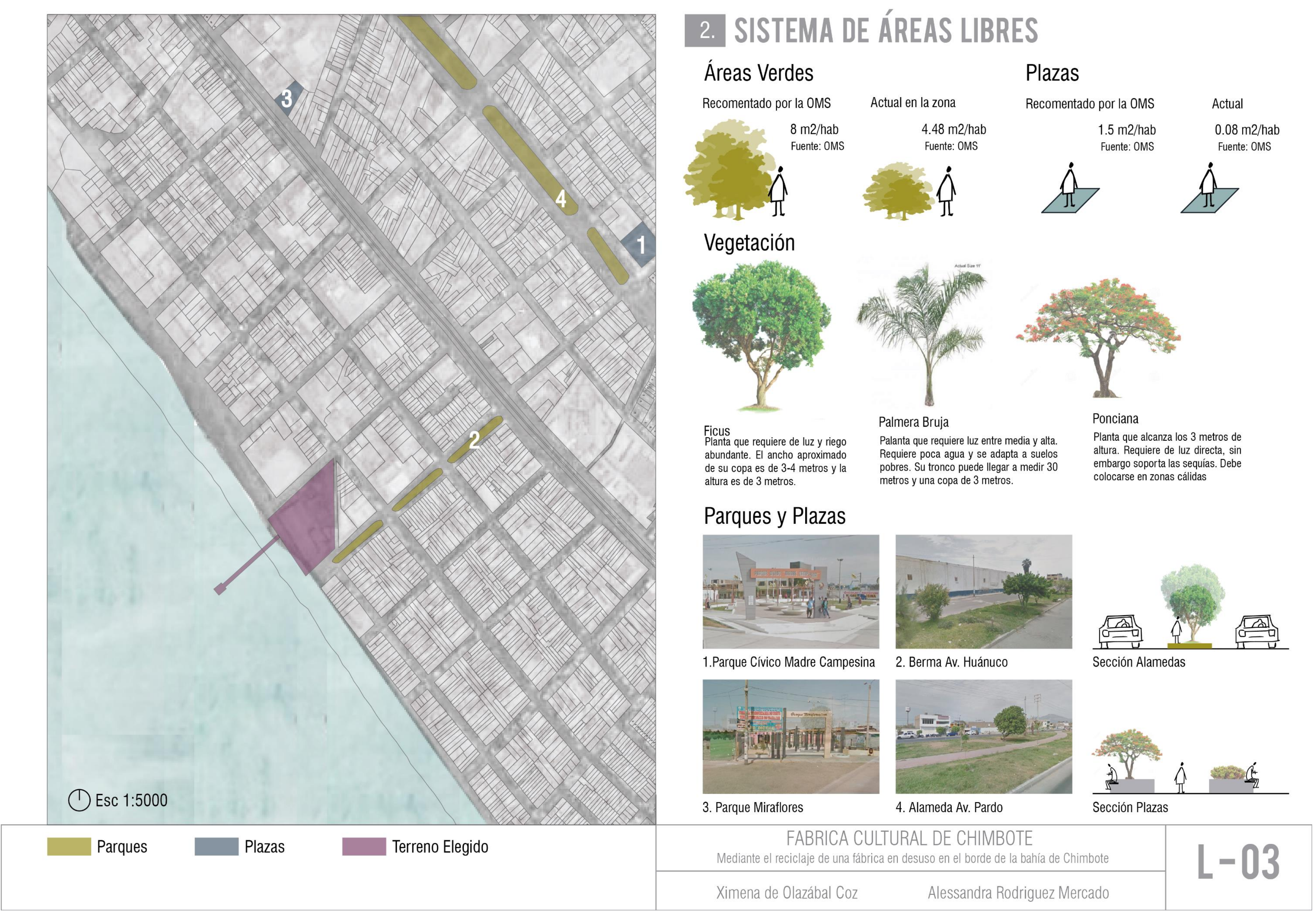




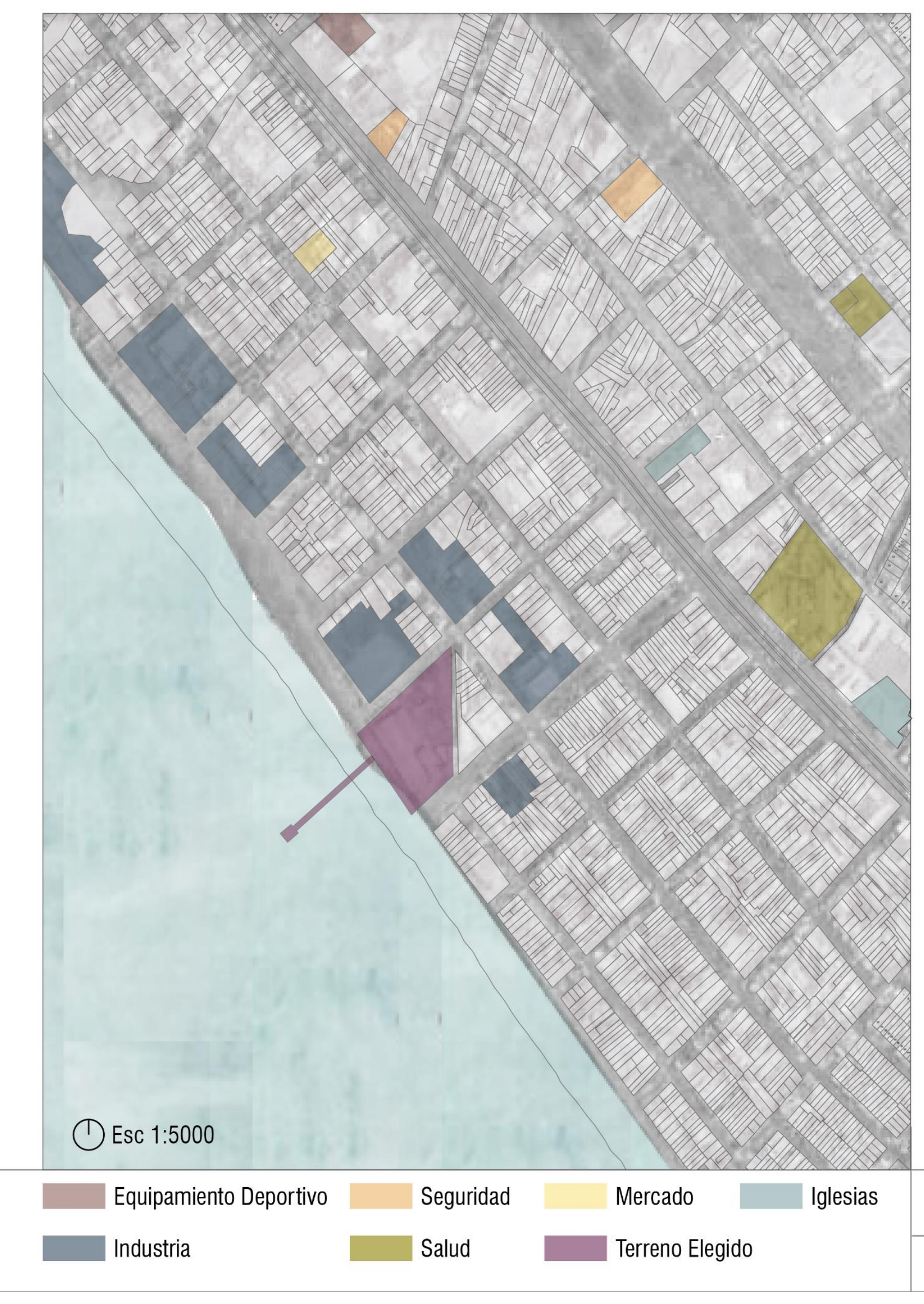

\section{ENTORNO LUGARES DE INTERÉS}

Los equipamientos aledaños al terreno elegido son de carácter industrial, las cuales funcionaban como fábricas conserveras. Ellas representan el patrimonio industrial de la ciudad. Sin embargo, actualmente son espacios en desuso.El terreno también cuenta con equipamientos cercanos de otro tipo como Centros de Salud, colegios, comisaría, mercado y losas deportivas.
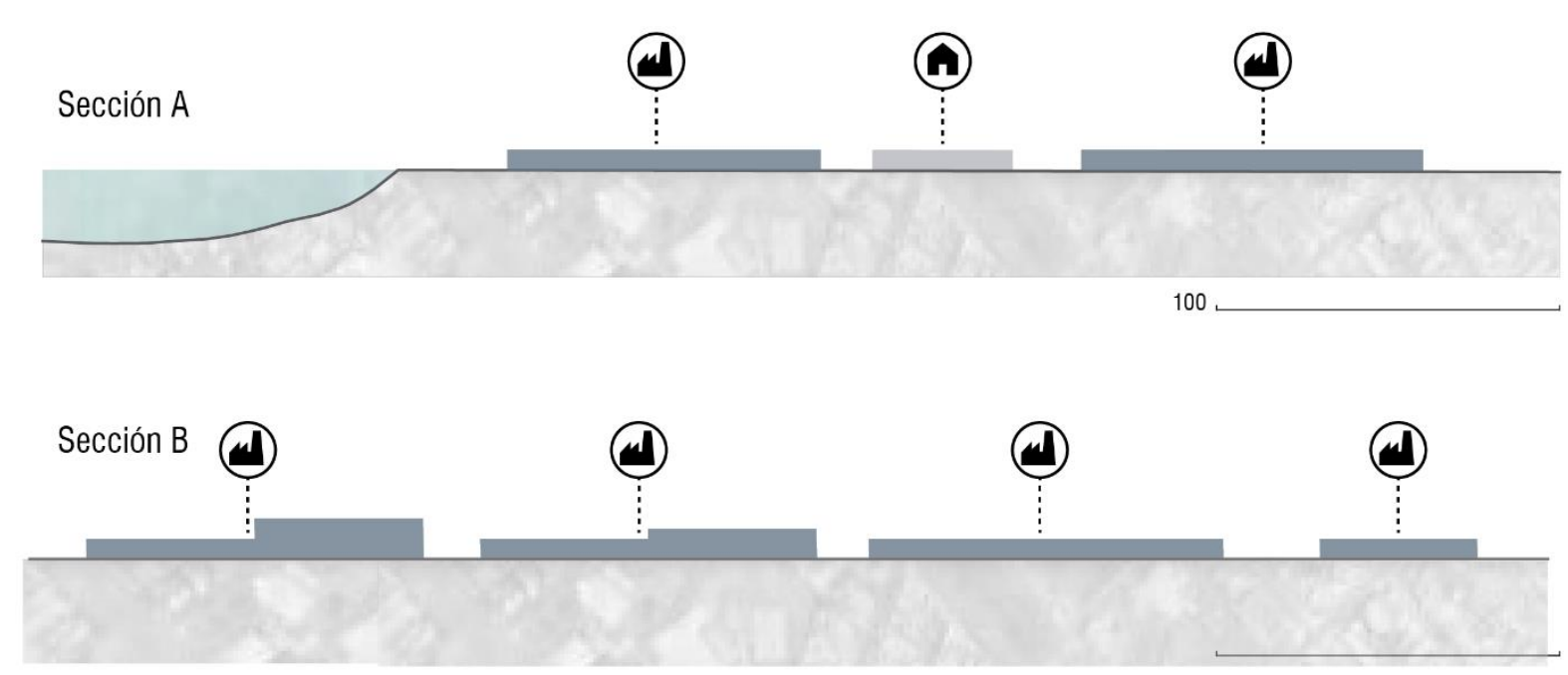

100

\section{Posible Patrimonio industrial}
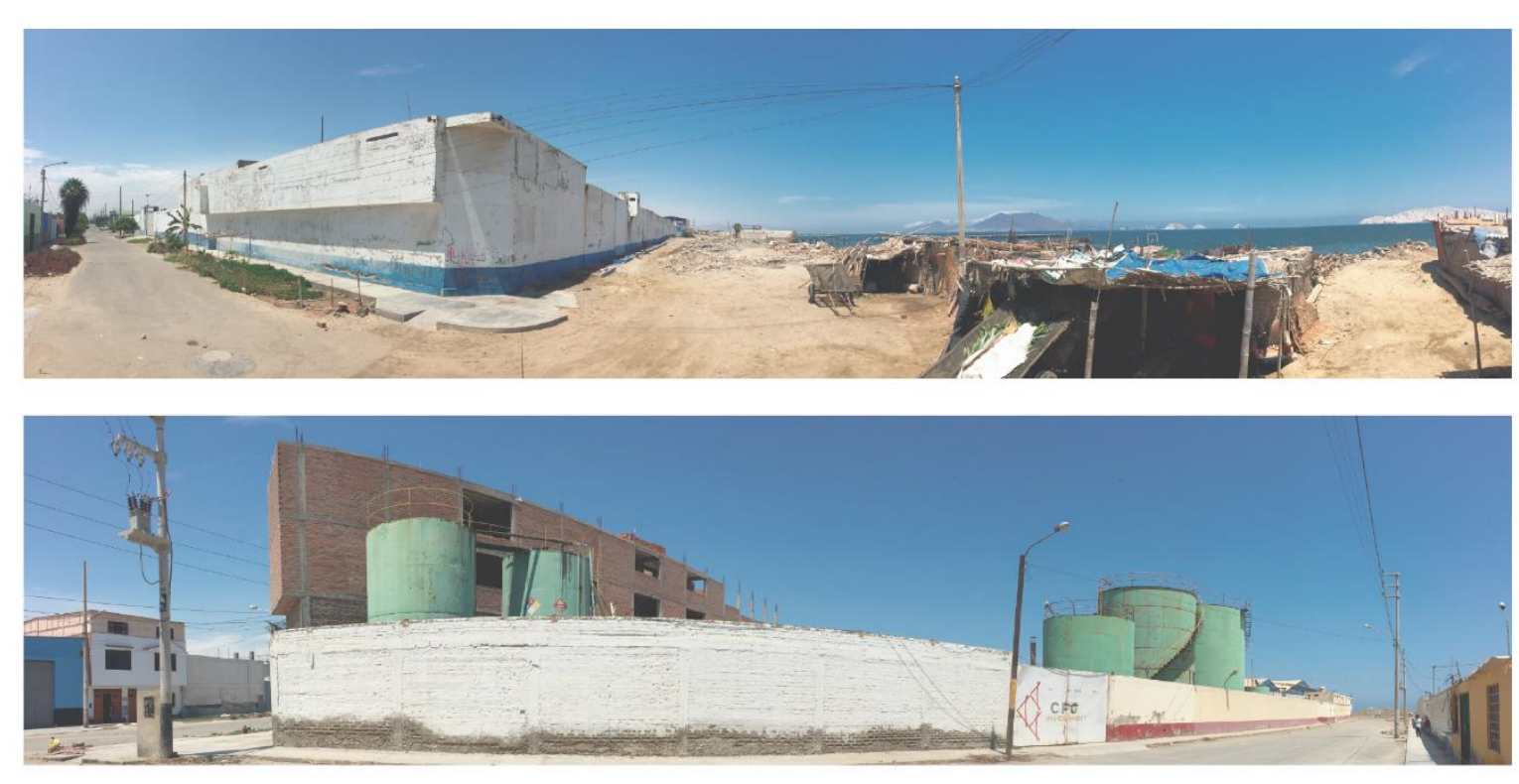

\begin{tabular}{c|c|c|} 
FABRICA CULTURAL DE CHIMBOTE & \\
Mediante el reciclaje de una fábrica en desuso en el borde de la bahía de Chimbote & \\
\cline { 1 - 2 } Ximena de Olazábal Coz $\quad$ Alessandra Rodriguez Mercado &
\end{tabular}




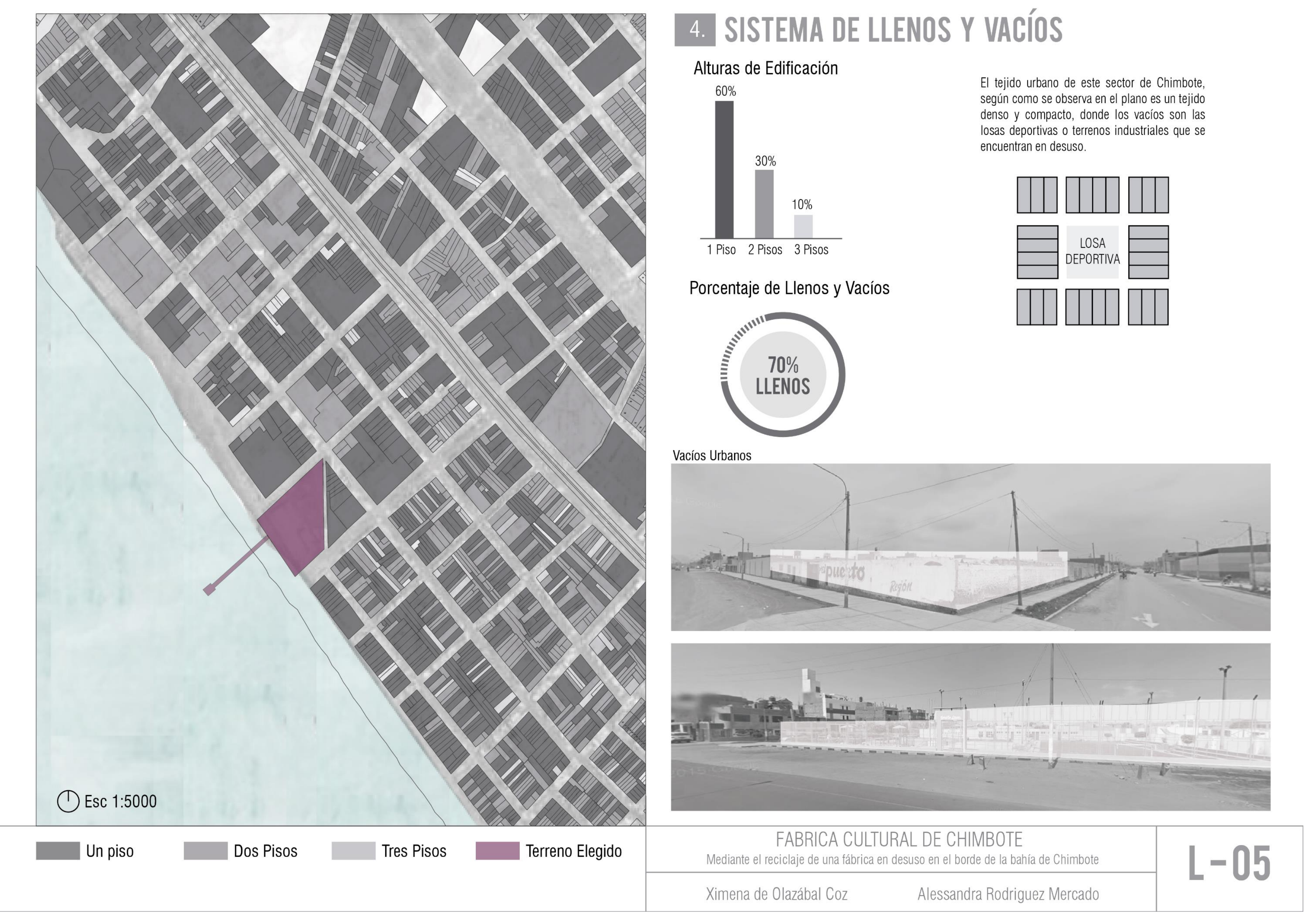




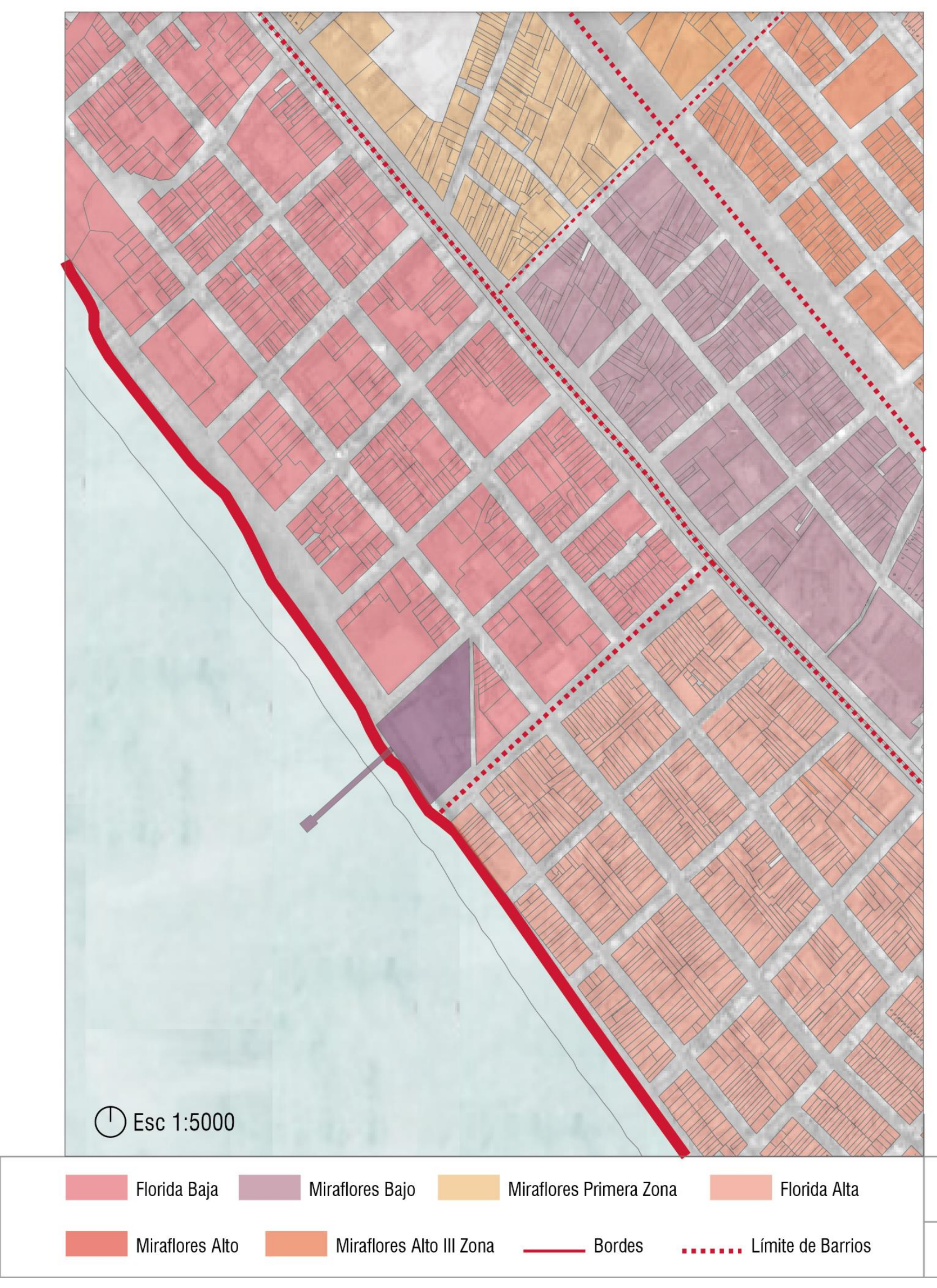

\section{BORDES Y BARRIOS}

\section{Bordes}

El borde se encuentra delimitado por el mar, el cual no solo representa un borde geográfico, sino también ambiental, pues este espacio se encuentra rodeado de desmonte y basura, convirtiéndose además en un borde duro. Por este motivo los usuarios no desean acercase a la bahía, sino alejarse de ella.
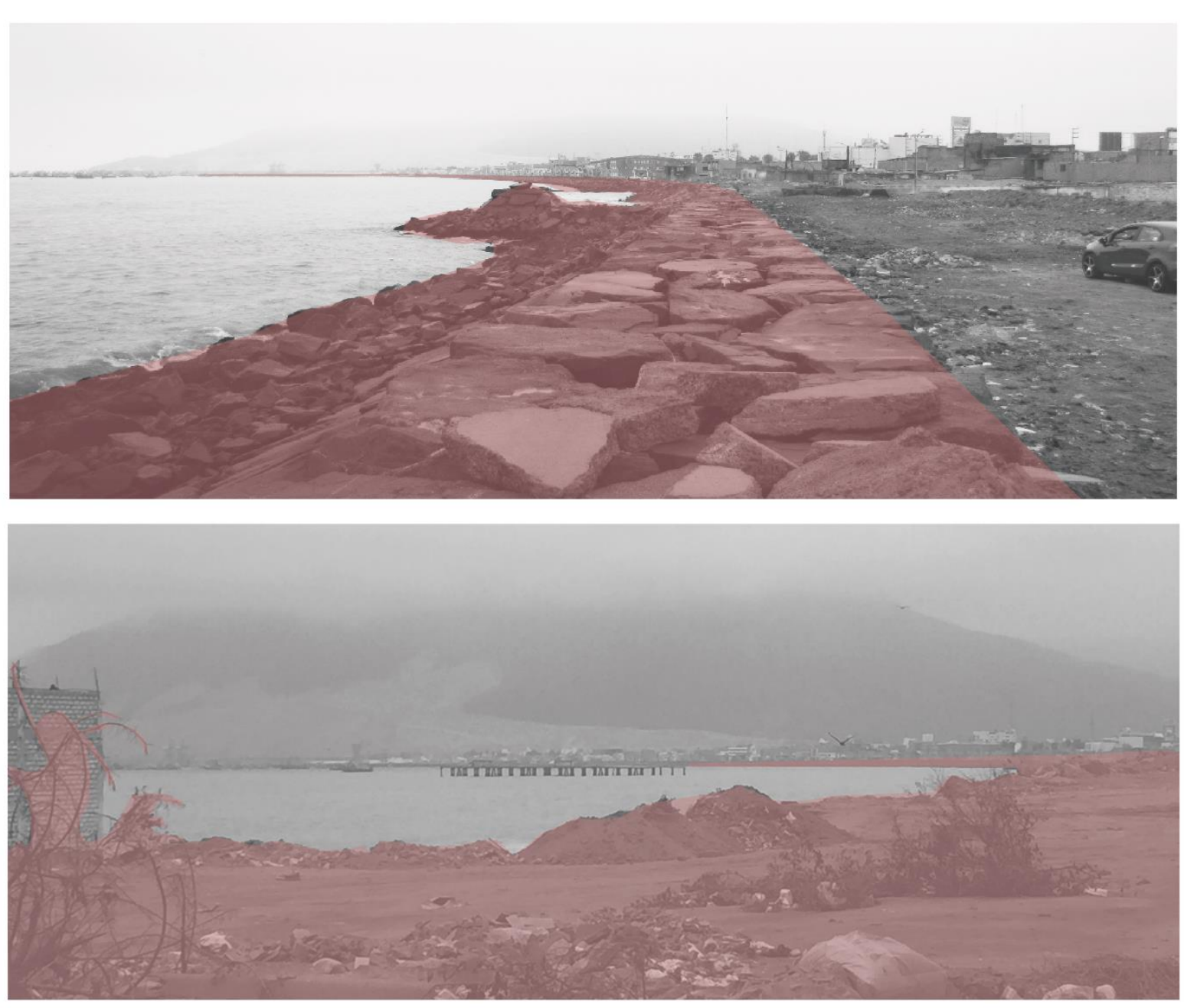

Corte esquemático

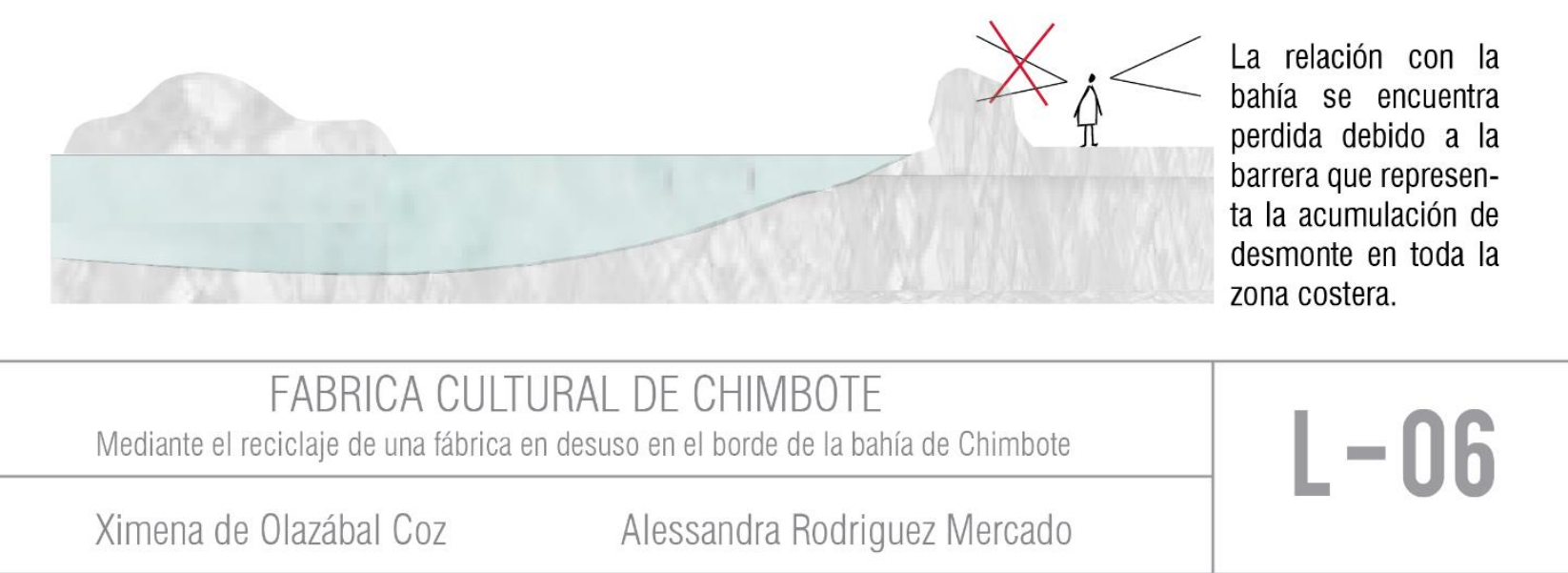




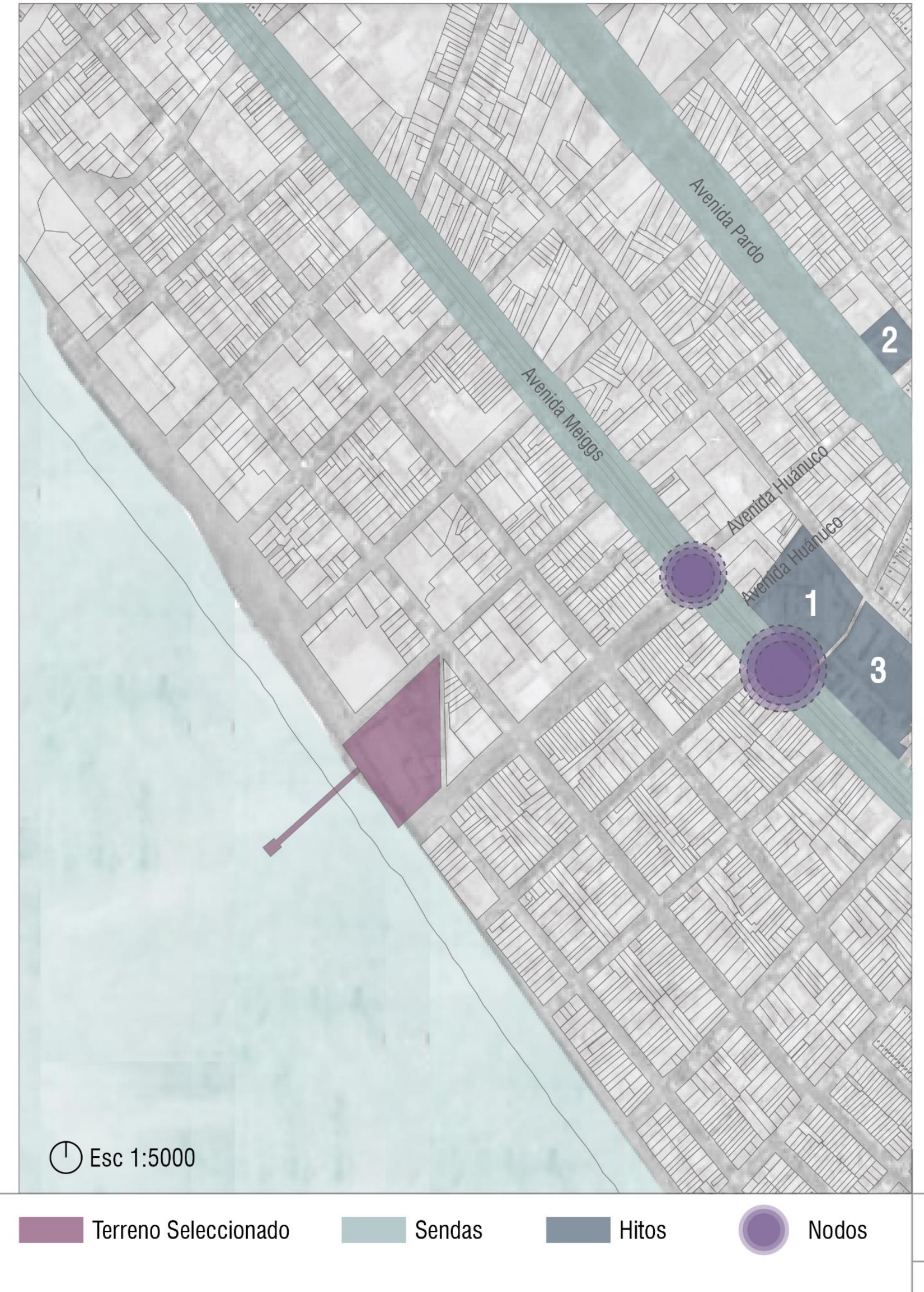

\section{HITOS, NODOS Y SENDAS}

\section{Sendas}

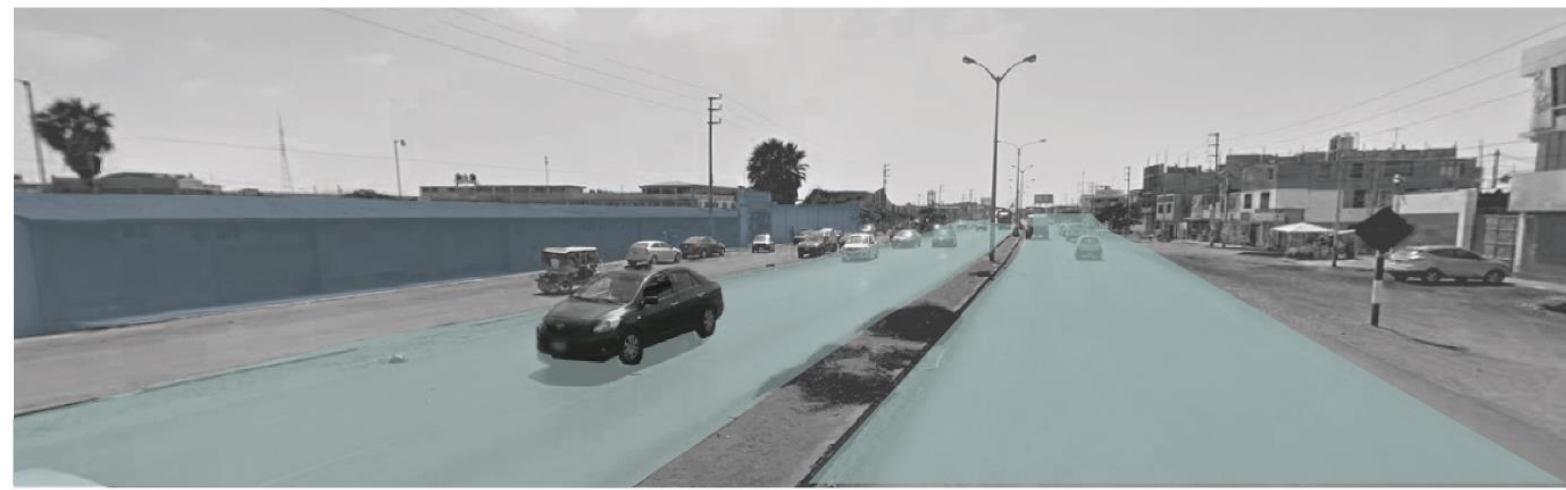

Cruce de Avenidas Meiggs y Huánuco

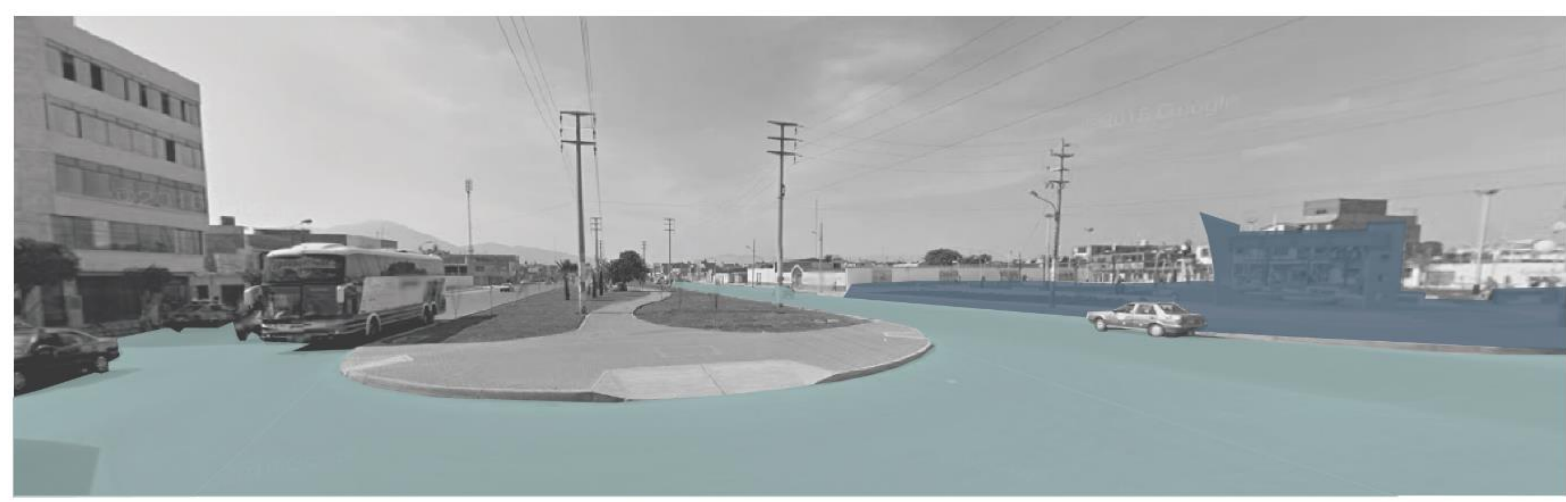

Cruce de Avenidas Pardo y Huánuco

Hitos

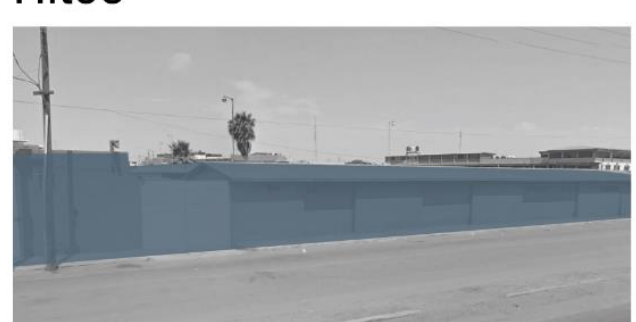

1. Maternidad de María

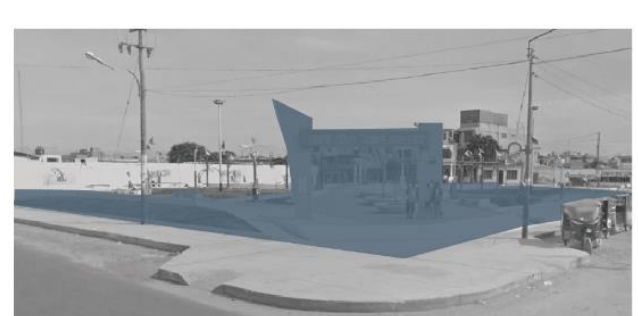

Las principales sendas son La Av. Pardo y la Av. Meiggs debido en sentido constante flujo vehicular en sentido longitudinal y peatonal en sentido transversal. La Avenida Meiggs además forma parte de la Panameri-
cana Norte, recibiendo transporte de cargas mayores provenientes de diferentes provincias.

Si bien en Chimbote no se distinguen construcciones de gran altura, sus hitos se encuentran dterminados por instituciones con un gran pasado histórico, y por plazas y parques, tales como la Plaza Madre Campesina.

El principal nodo de la zona se encuentra en el cruce de la Avenida Huánuco y Enrique Meiggs ya que los flujos tanto vehiculares y peatonales se intersectan en este punto. Este nodo también se debe la cercanía con la Maternidad de María y al colegio Mundo Mejor.

2. Plaza Madre Campesina

\begin{tabular}{l|l} 
FABRICA CULTURAL DE CHIMBOTE & \\
Mediante el reciclaje de una fábrica en desuso en el borde de la bahía de Chimbote & \\
Ximena de Olazábal Coz & Alessandra Rodriguez Mercado
\end{tabular}




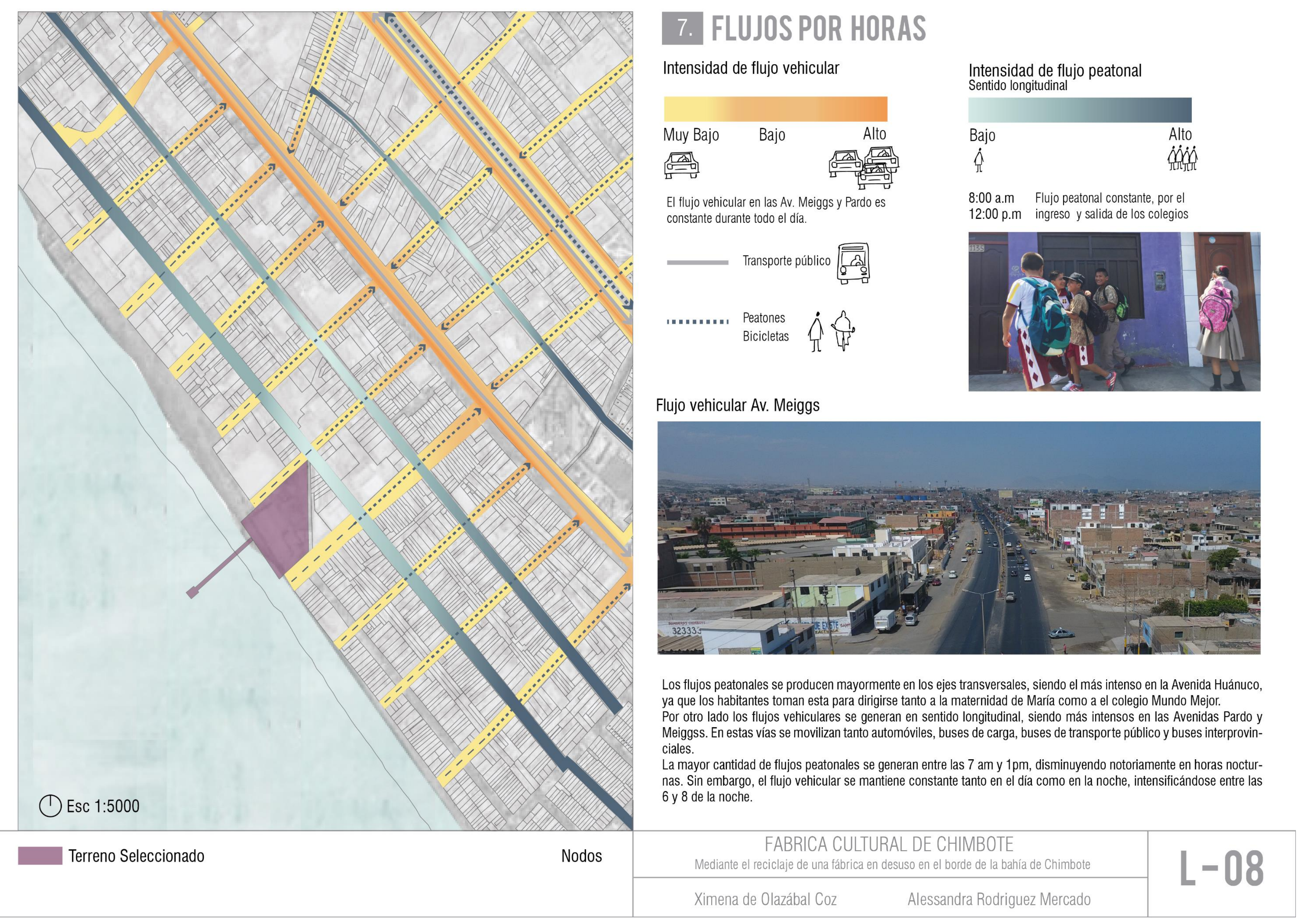




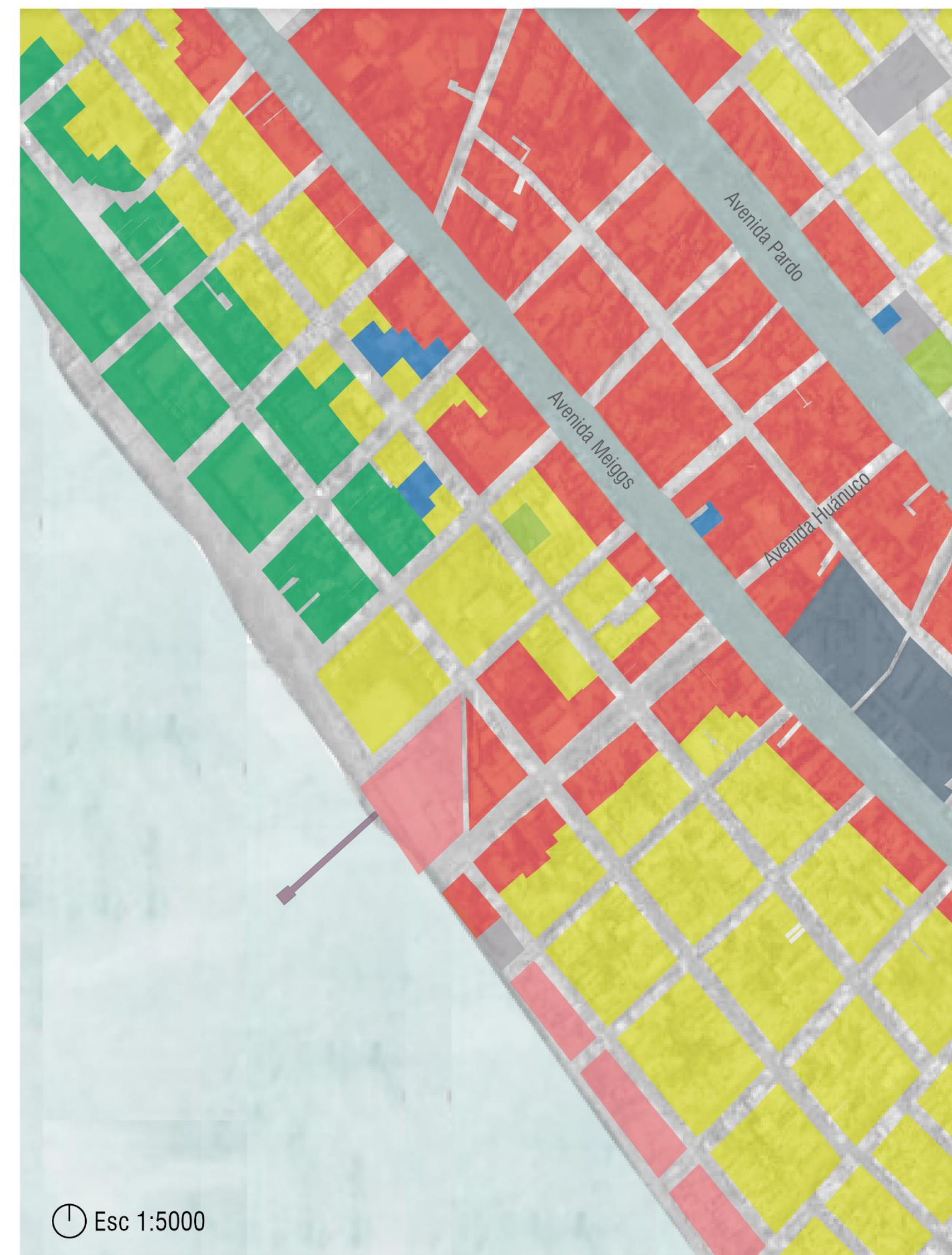

Comercio Zonal Residencial Densidad Baja Comercio Especializado Zona de Tratamiento Especial
Zona de Recreación

\section{ZONIFICACION}

Comercio Especializado Esta zona abarca comercio especializado para el ámbito industrial, como almacenes, fábricas de hielo, talleres de soldadura, además de hospedajes y farmacias.
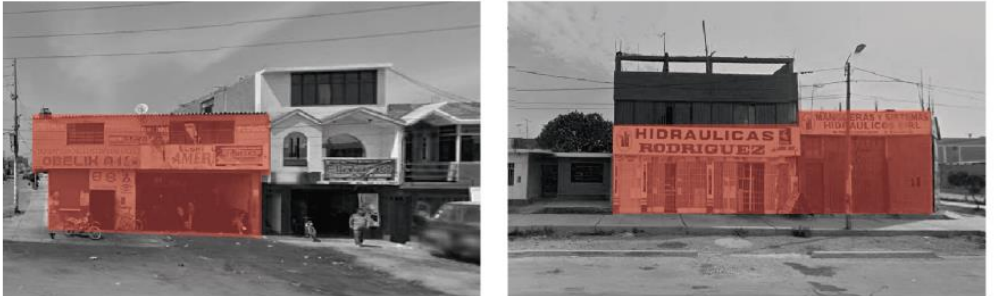

Residencial Baja Altura

Esta zona abarca viviendas de tanto un nivel como dos niveles. Algunas viviendas son de tipologi vivienda / taller o vivienda / comercio.
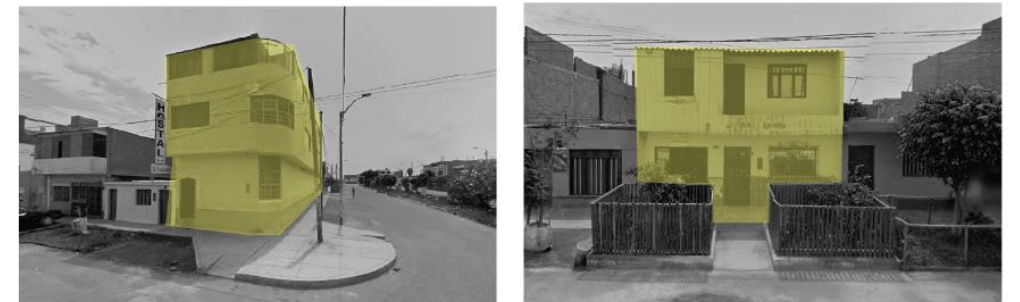

Zona de Tratamiento Especial Esta zona abarca zonas caracterizadas por una crítica ubicación con respecto a riesgos físicos 0 de servicios públicos, por lo que exigen ser renovadas.
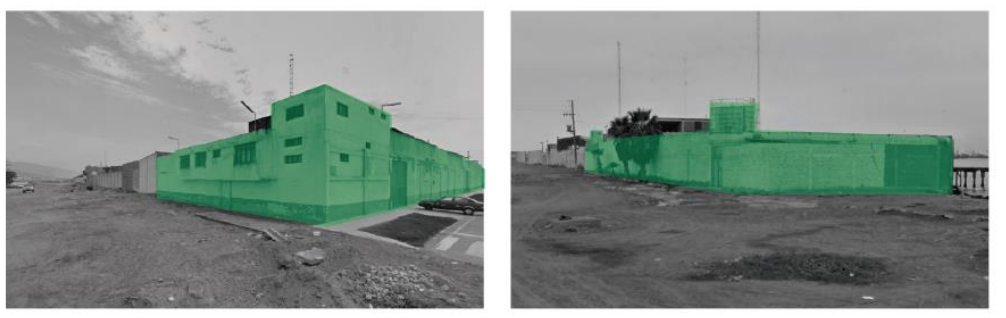

\section{Zona de Recreación}

Esta zona abarca espacios destinados tanto a recreación activa como pasiva y a servicios complementarios de uso publico.
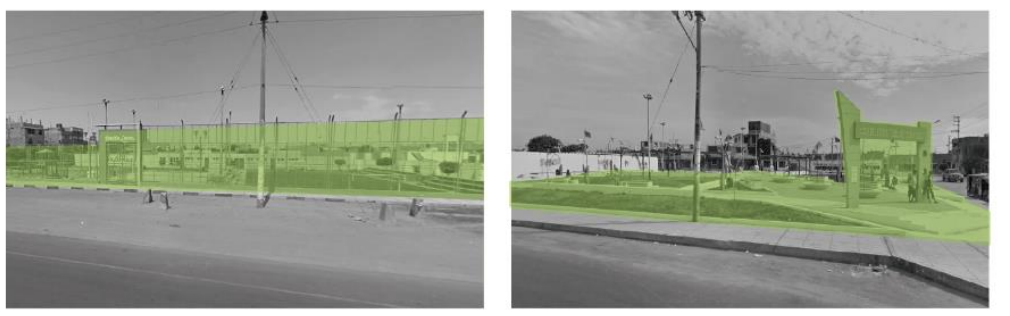

Educación Básica

Esta zona abarca equipamientos dstinados a educación inicial, primaria y secundaria. Deben seguir las
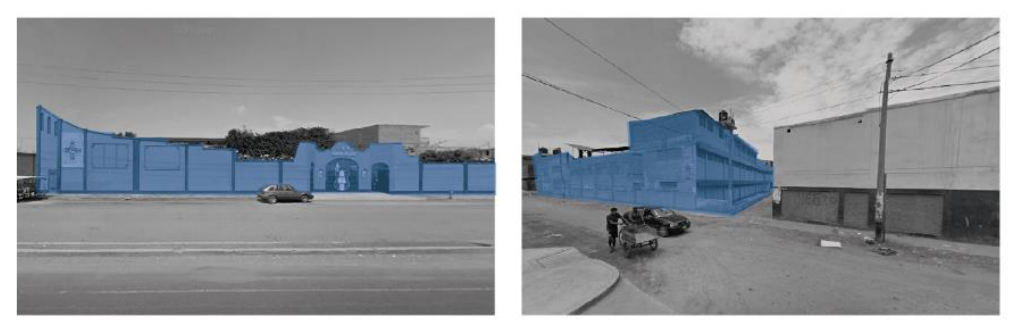

\begin{tabular}{|c|c|}
\hline FABRICA CULTURAL DE CHIMBOTE & \\
Mediante el reciclaje de una fábrica en desuso en el borde de la bahía de Chimbote & \\
\cline { 1 - 2 } Ximena de Olazábal Coz $\quad$ Alessandra Rodriguez Mercado & \\
\hline
\end{tabular}




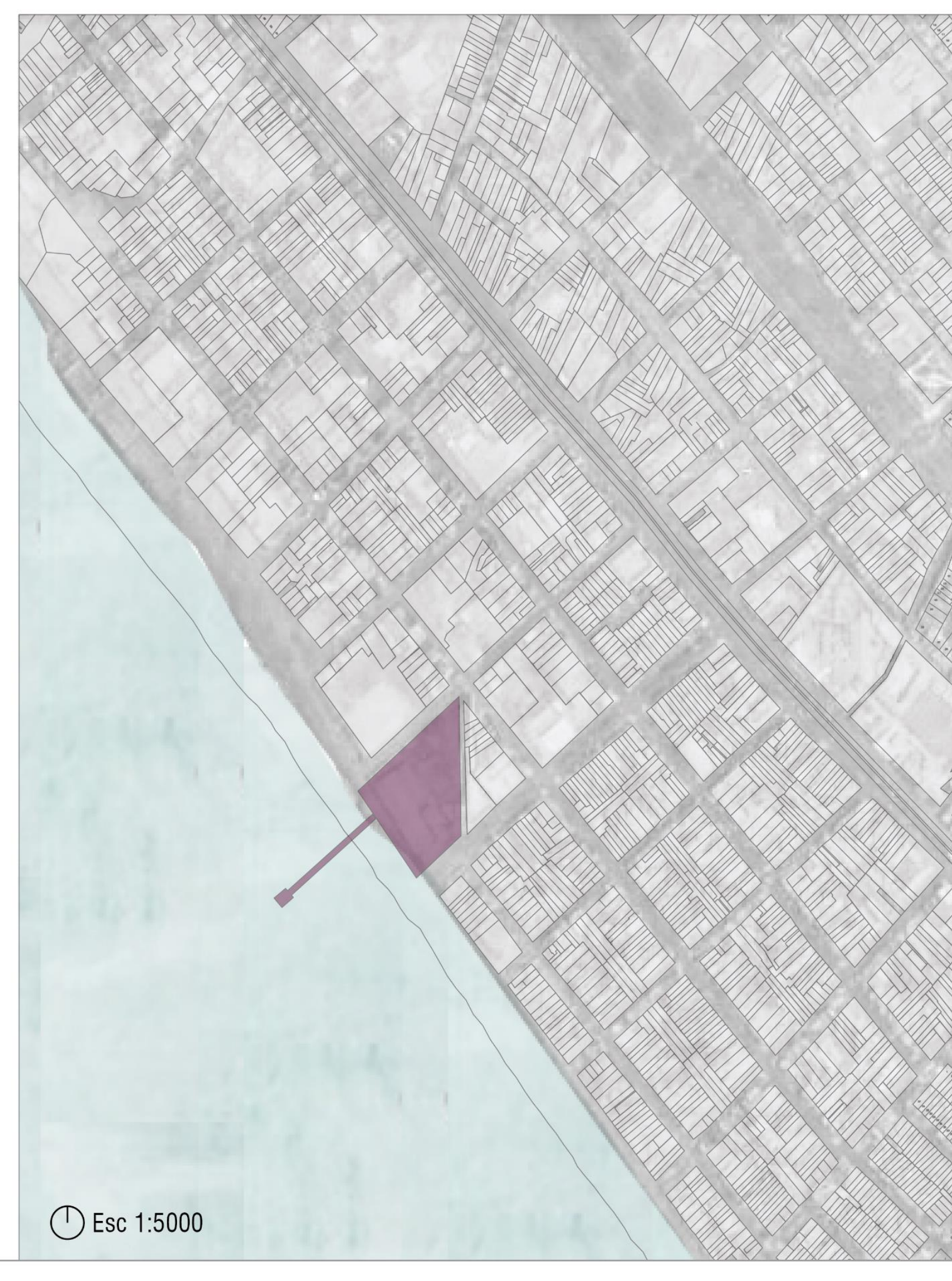

\section{PARÁMETROS DEL LOTE}

\section{Zona de Comercio Zonal}

Zona caracterizada por el comercio urbano de productos, bienes y servicios. Caracterizado por establecimientos de comercio de bienes de consumo, tienda de artículos diversos, oficinas, etc.

Nivel de Servicio Debe servir a una población entre 10000 y 30000 habitantes

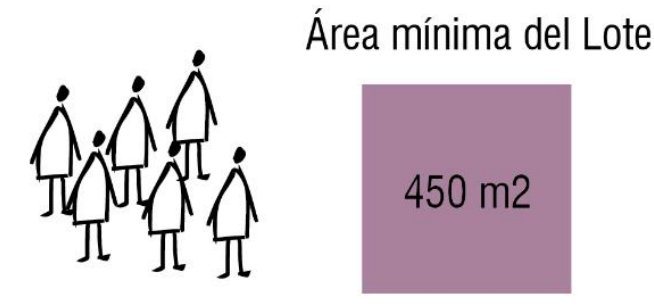

Altura máxima

Usos Permitidos

\begin{tabular}{|l|c|}
\hline \multicolumn{1}{|c|}{ Uso } & 1 Estacionamiento por cada \\
\hline Cine, teatros, Locales de espectáculo & 50 butacas \\
\hline Locales culturales, clubes institucionales y similares & $100 \mathrm{~m} 2$ de área techada total \\
\hline Locales deportivos o Coliseos & 10 espectadores \\
\hline Academias & $100 \mathrm{~m} 2$ de área techada total \\
\hline Colegios y Nidos & $100 \mathrm{~m} 2$ de área techada total \\
\hline Restaurantes & $50 \mathrm{~m} 2$ de área techada total \\
\hline Salas de Baile y discotecas & $100 \mathrm{~m} 2$ de área techada total \\
\hline Universidades & $300 \mathrm{~m} 2$ de área techada total \\
\hline Hospitales, Clínicas y Sanatorios & $500 \mathrm{~m} 2$ de área techada total \\
\hline Policlínicos, Postas Sanitarias y Emergencias & $100 \mathrm{~m} 2$ de área techada total \\
\hline Centros Médicos y Laboratorios & $40 \mathrm{~m} 2$ de área techada total \\
\hline Consultorios individuales & $40 \mathrm{~m} 2$ de área techada total \\
\hline Hoteles y hostales & $25 \%$ del número total de dormitorios \\
\hline
\end{tabular}

Estacionamientos

\section{1 estaciona-}

miento

cada $75 \mathrm{~m} 2$ de

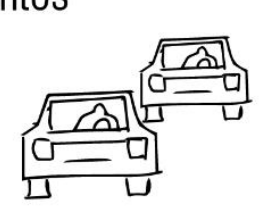

Área Libre

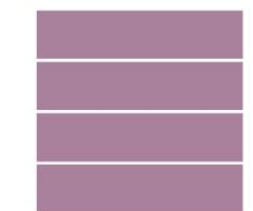

4 niveles

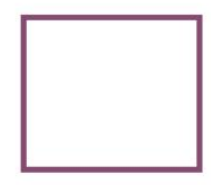

No es necesaria

en caso de uso

completam
comercial

Fuente: PDU 2012

\begin{tabular}{|c|c|} 
FABRICA CULTURAL DE CHIMBOTE & \\
Mediante el reciclaje de una fábrica en desuso en el borde de la bahía de Chimbote & \\
\cline { 1 - 2 } Ximena de Olazábal Coz Alessandra Rodriguez Mercado &
\end{tabular}




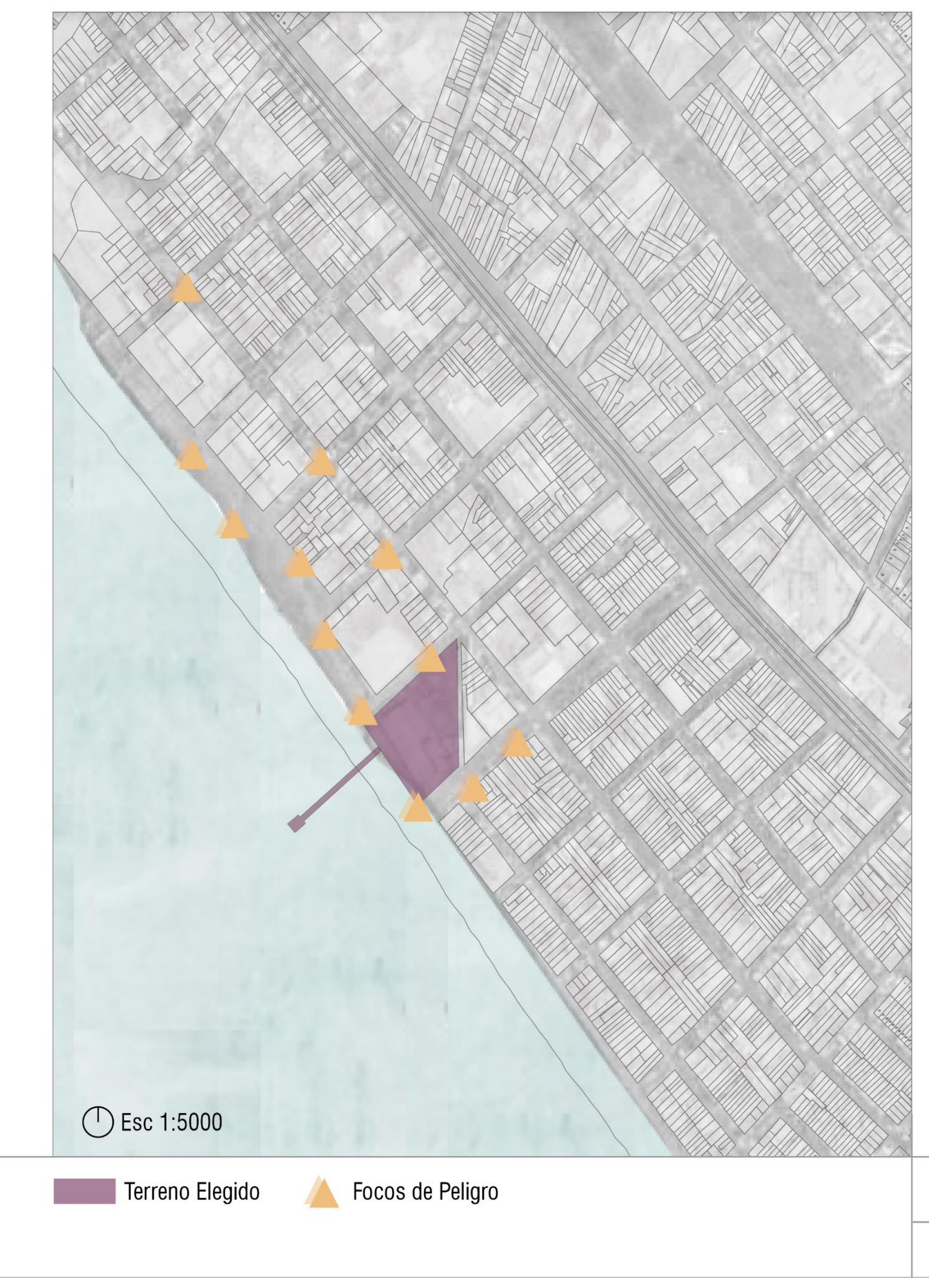

\section{PERCEPCIÓN}

Espacialidad Sensorial

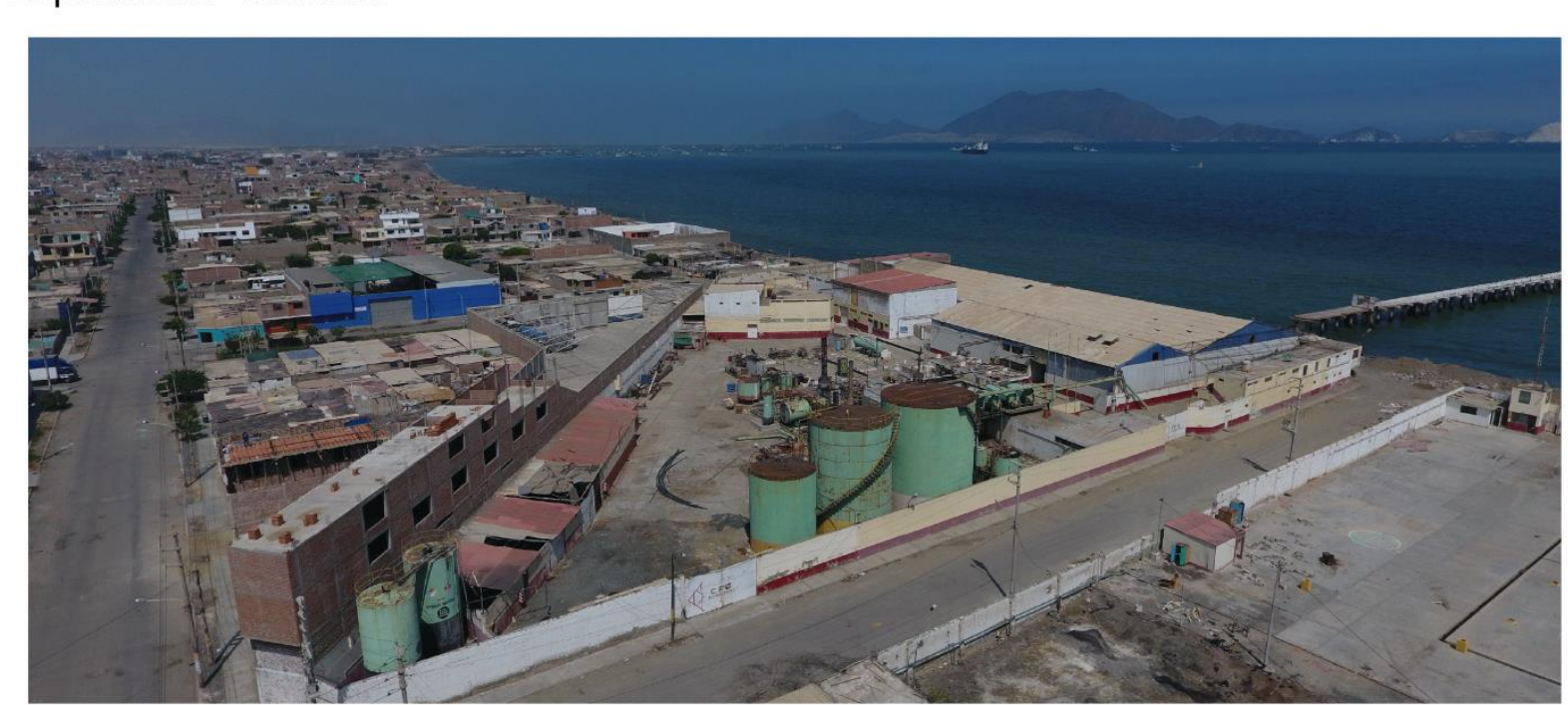

Estructuras industriales que generan una sensaci[on

monumentalidad en los

espacios. Además de

recordar el legado
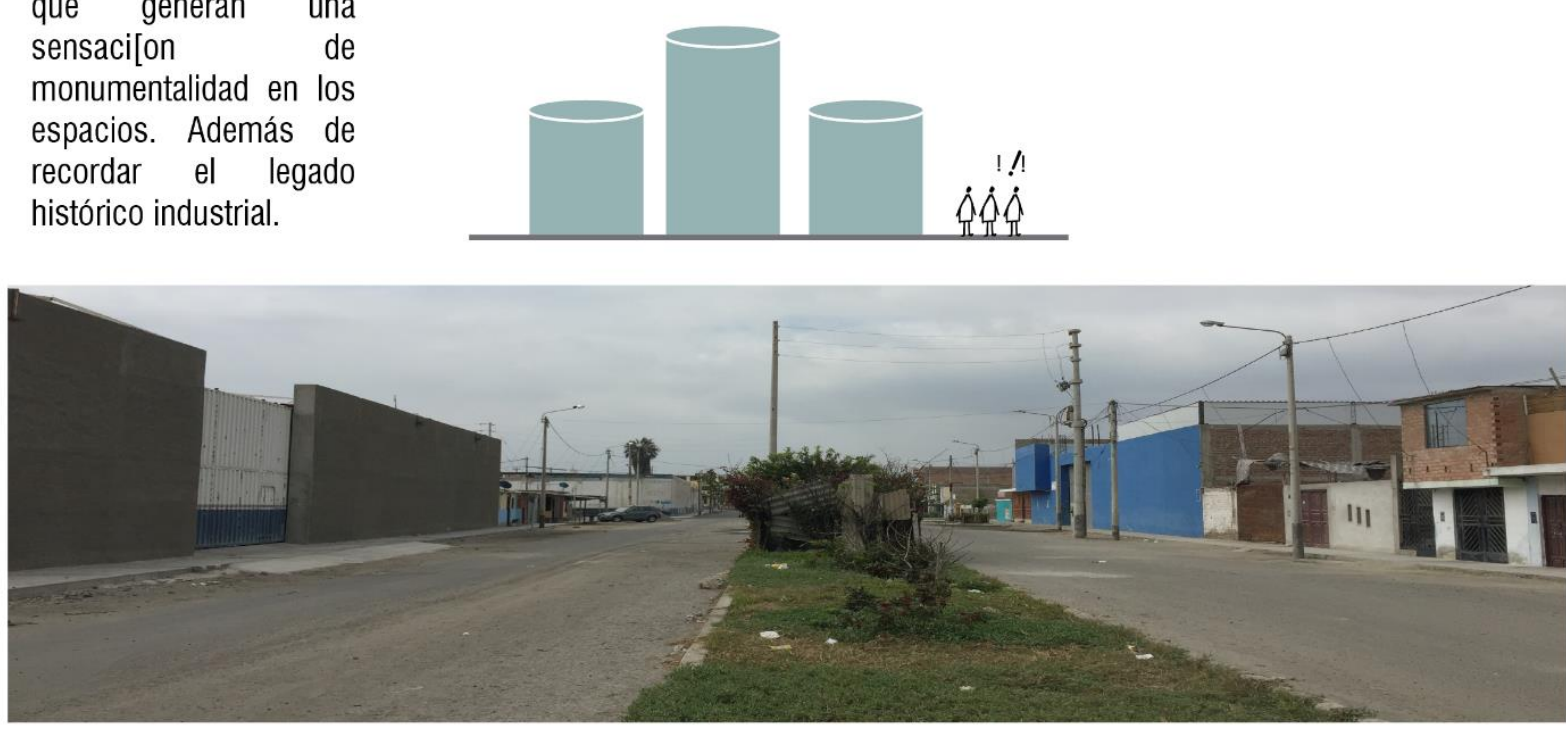

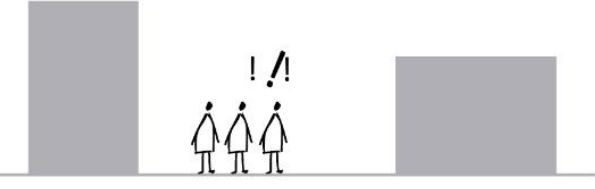

Terreno que se percibe como un borde duro y hostil debido a la gran cantidad de muros ciegos.
Dentro del terreno, gran cantidad de elementos representativos tales como tanques y estructuras con tijerales aluden a un pasado histórico industrial bastante prominente.

Se puede percibir además alrededor del terreno un alto grado de inseguridad debido a la gran cantidad de muros ciegos que se encuentran rodeando todo el terreno, asimismo la falta dealumbrado público y tratamiento de pistas y veredas incrementan esta percepción.

\begin{tabular}{c|c|c|} 
FABRICA CULTURAL DE CHIMBOTE & \\
Mediante el reciclaje de una fábrica en desuso en el borde de la bahía de Chimbote & \\
\cline { 1 - 2 } Ximena de Olazábal Coz Alessandra Rodriguez Mercado &
\end{tabular}




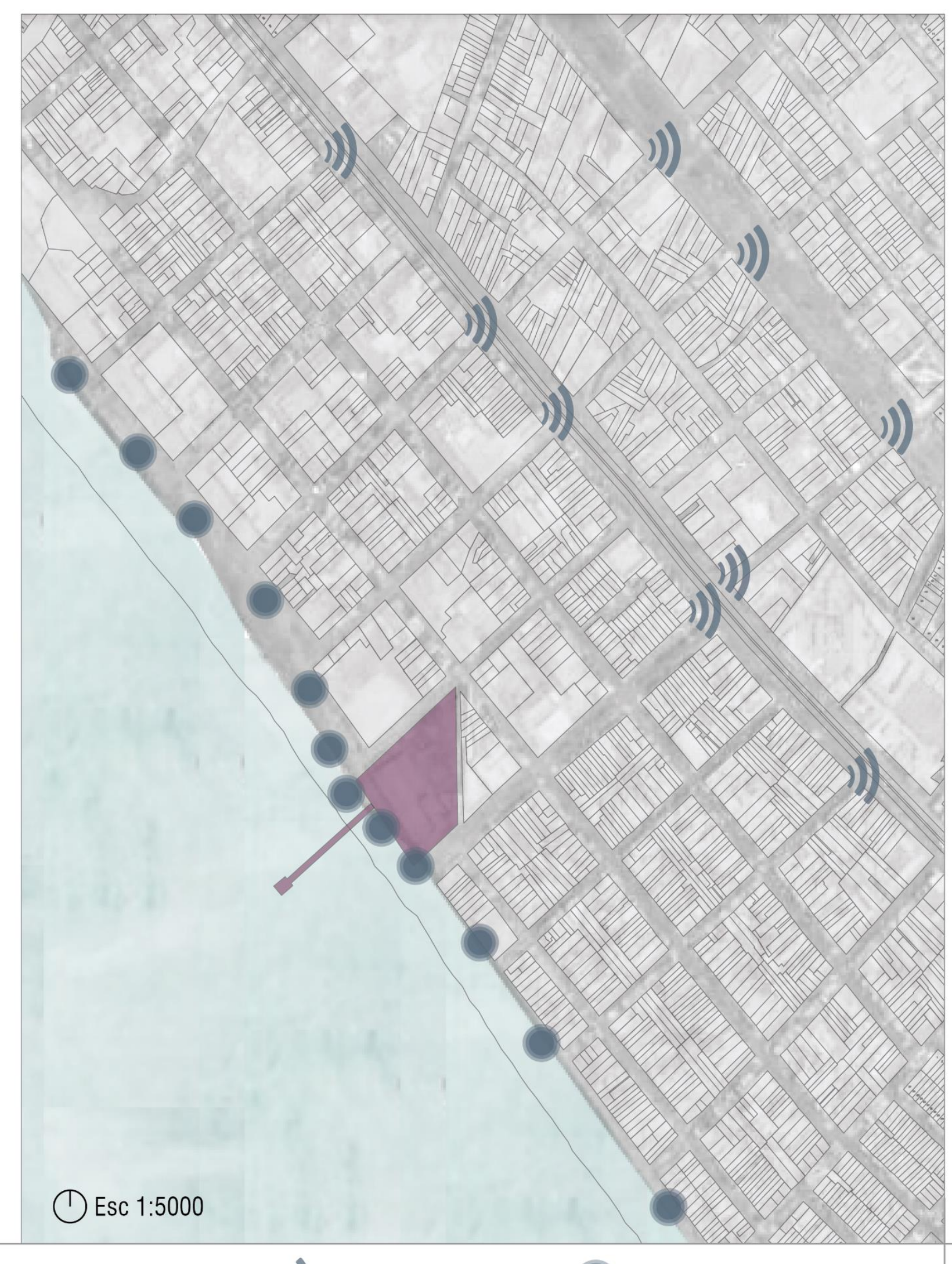

\section{PERCEPCIÓN}

Contaminación
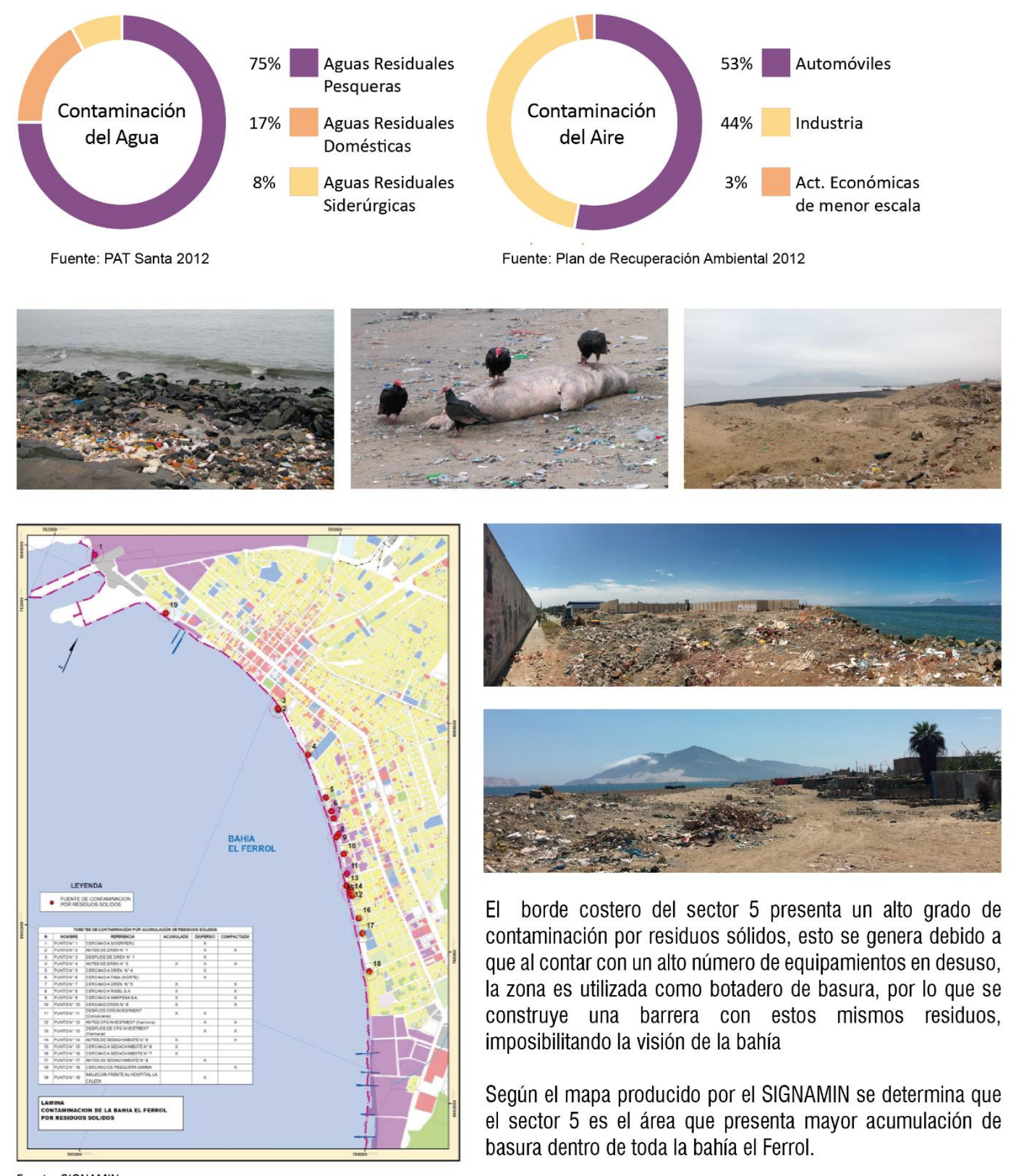

El borde costero del sector 5 presenta un alto grado de contaminación por residuos sólidos, esto se genera debido a que al contar con un alto número de equipamientos en desuso, la zona es utilizada como botadero de basura, por lo que se construye una barrera con estos mismos residuos, imposibilitando la visión de la bahía

Fuente: SIGNAMIN

Segun el mapa producido por el SIGNAMIN se determina que el sector 5 es el área que presenta mayor acumulación de basura dentro de toda la bahía el Ferrol.

\begin{tabular}{|c|}
\hline FABRICA CULTURAL DE CHIMBOTE \\
\hline Mediante el reciclaje de una fábrica en desuso en el borde de la bahía de Chimbote \\
\hline Ximena de Olazábal Coz $\quad$ Alessandra Rodriguez Mercado \\
\hline
\end{tabular}

$$
\mathrm{L}-12
$$




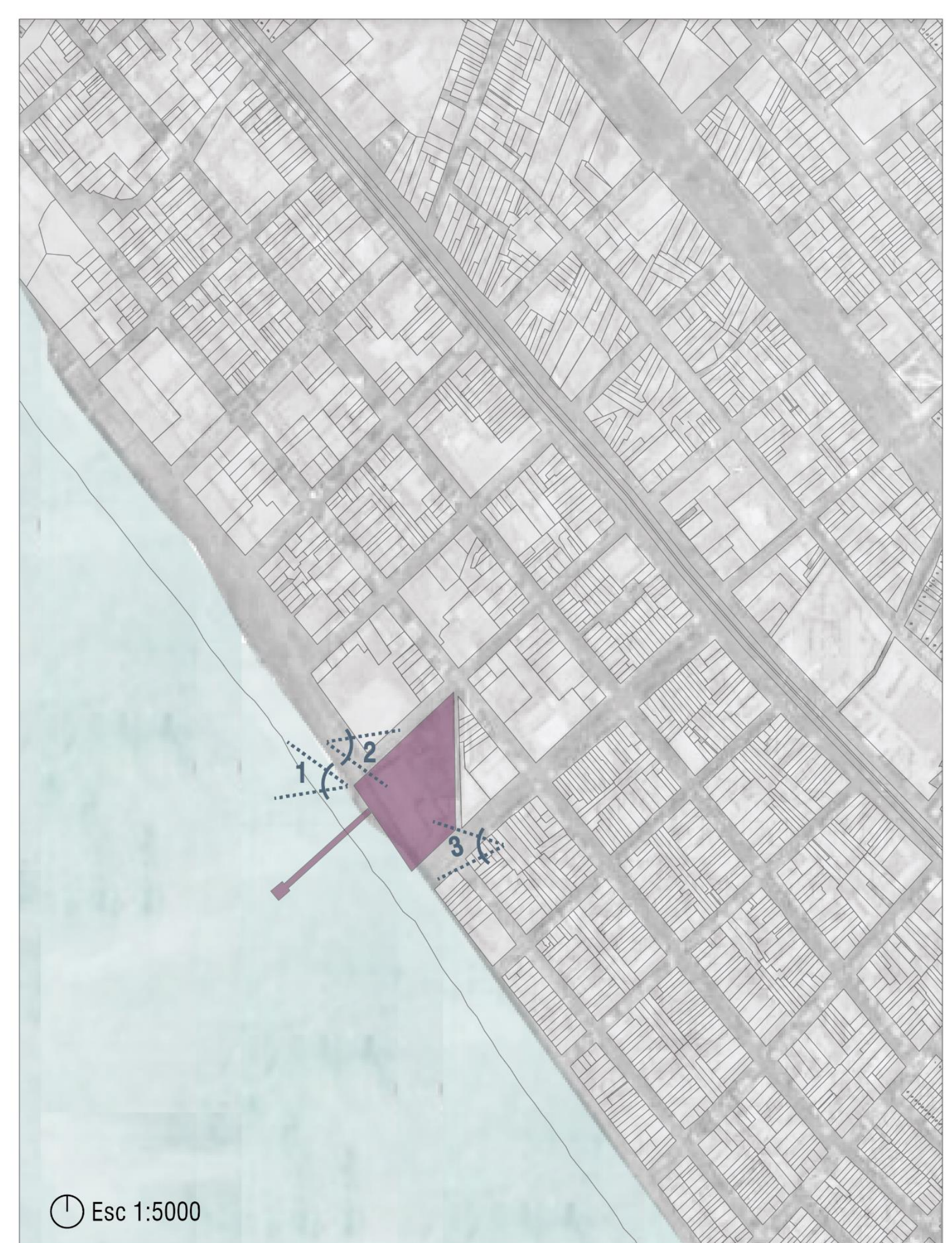

Terreno Elegido
10. PERCEPCIÓN Visuales, Espacialidad, Sensorial. Contaminación

Visuales
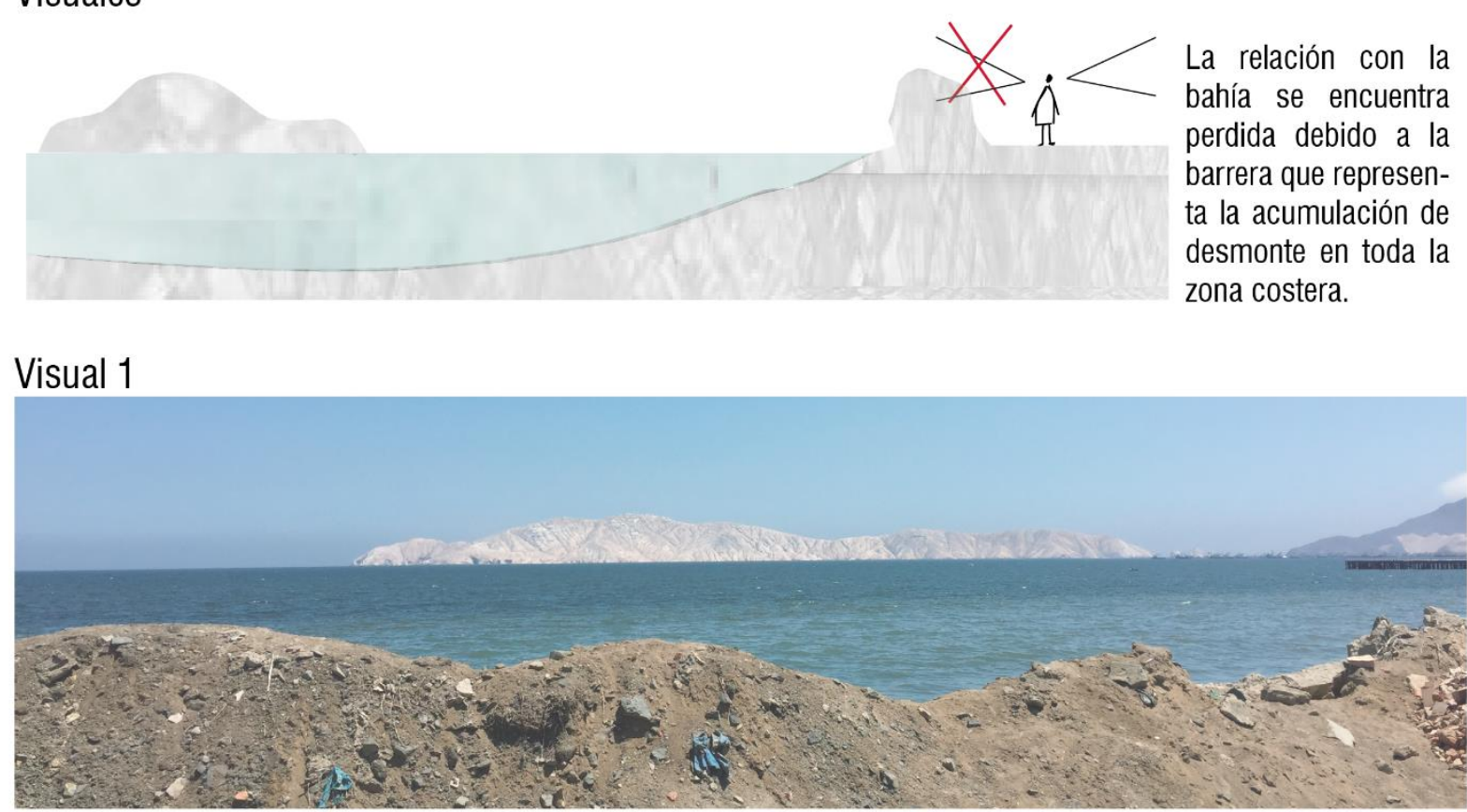

Visual 2

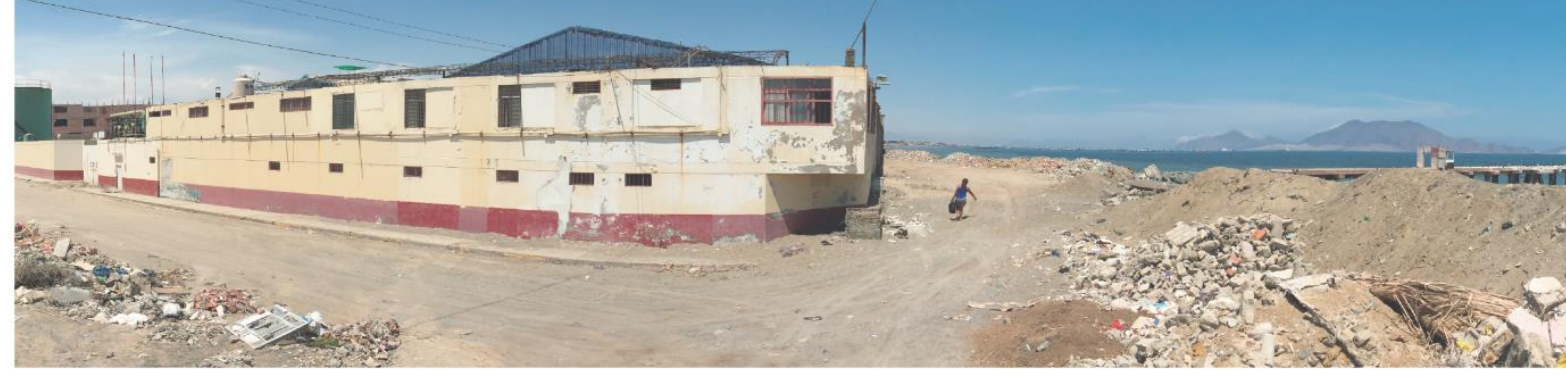

Visual 3

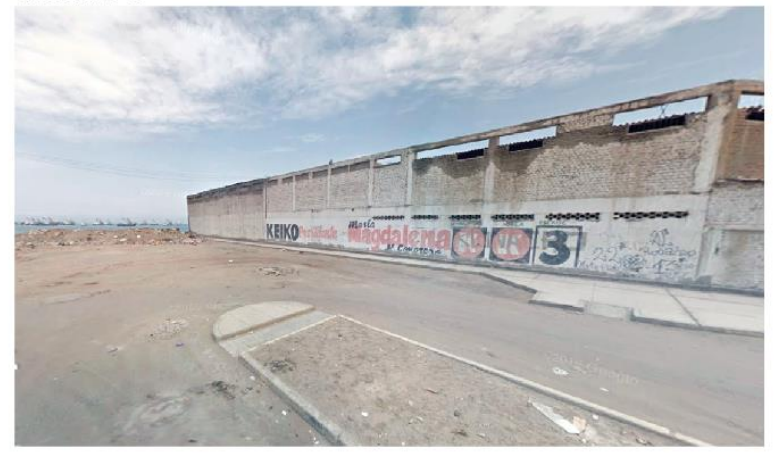

El terreno cuenta con un paisaje agradable hacia la isla blanca, sin embargo la barrera generada por la
contaminación corta esta visual generando un borde muy marcado.

Por otro lado las visuales alrededor del terreno no presentan atracción alguna ya que están conformadas por fábricas y estructuras industriales en desuso.

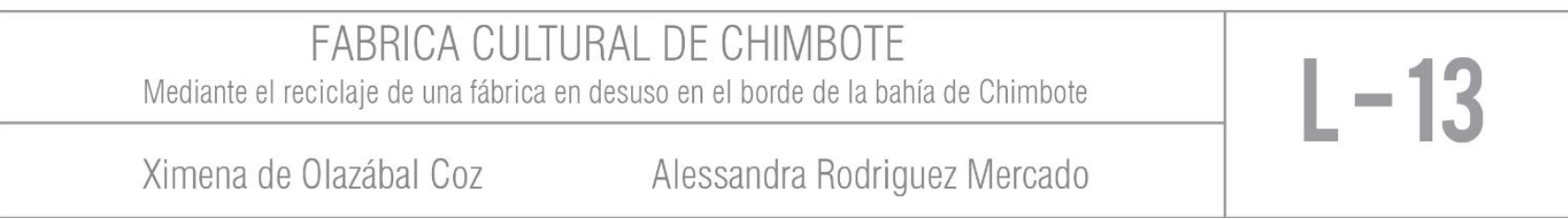




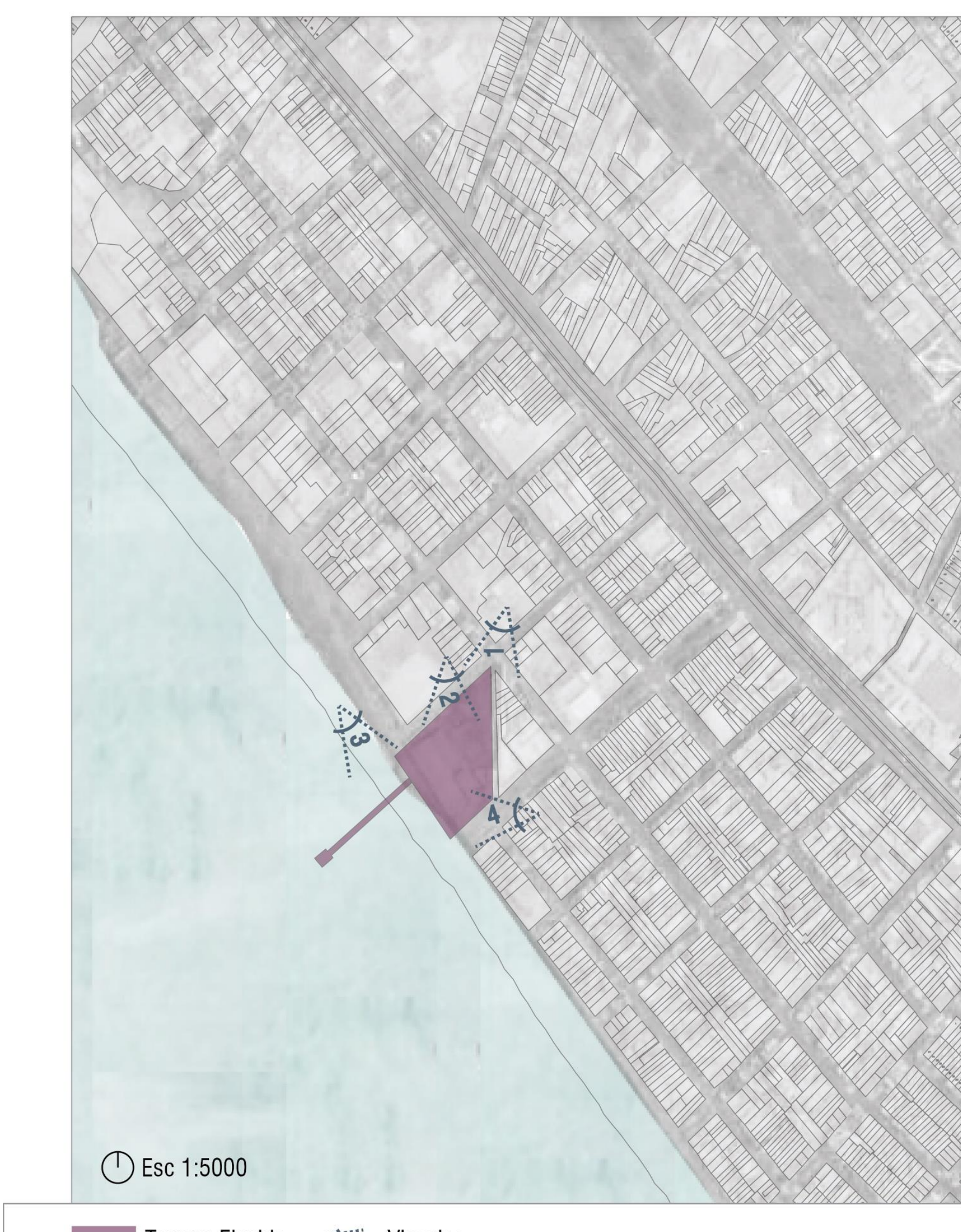

\section{REGISTRO FOTOGRÁFICO}

Visual 1

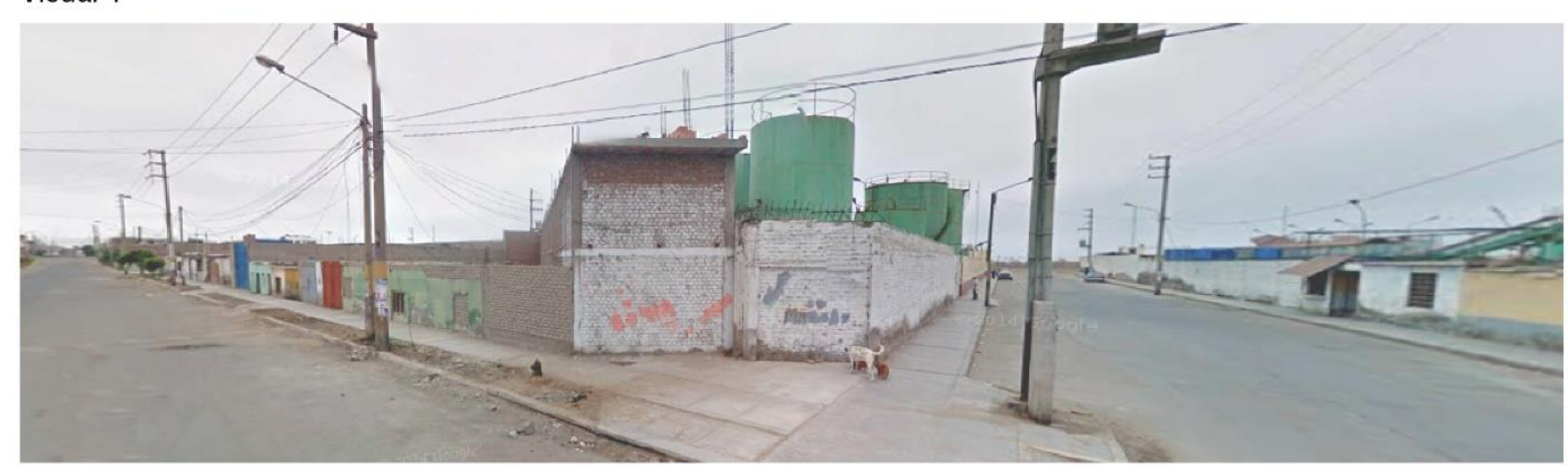

Visual 2

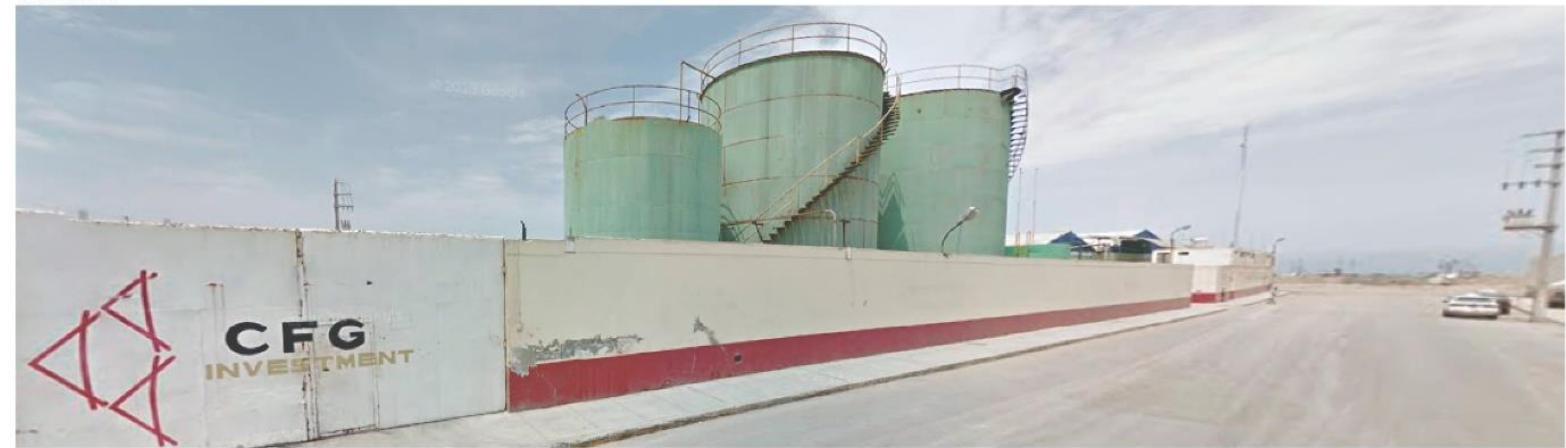

Visual 3

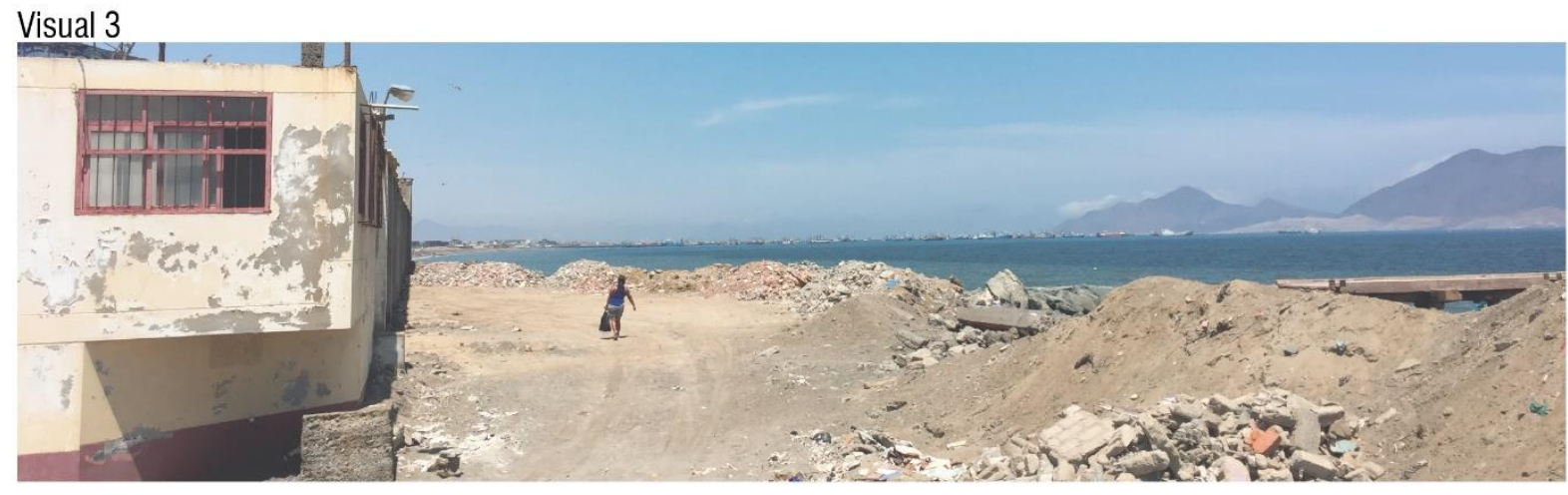

Visual 4

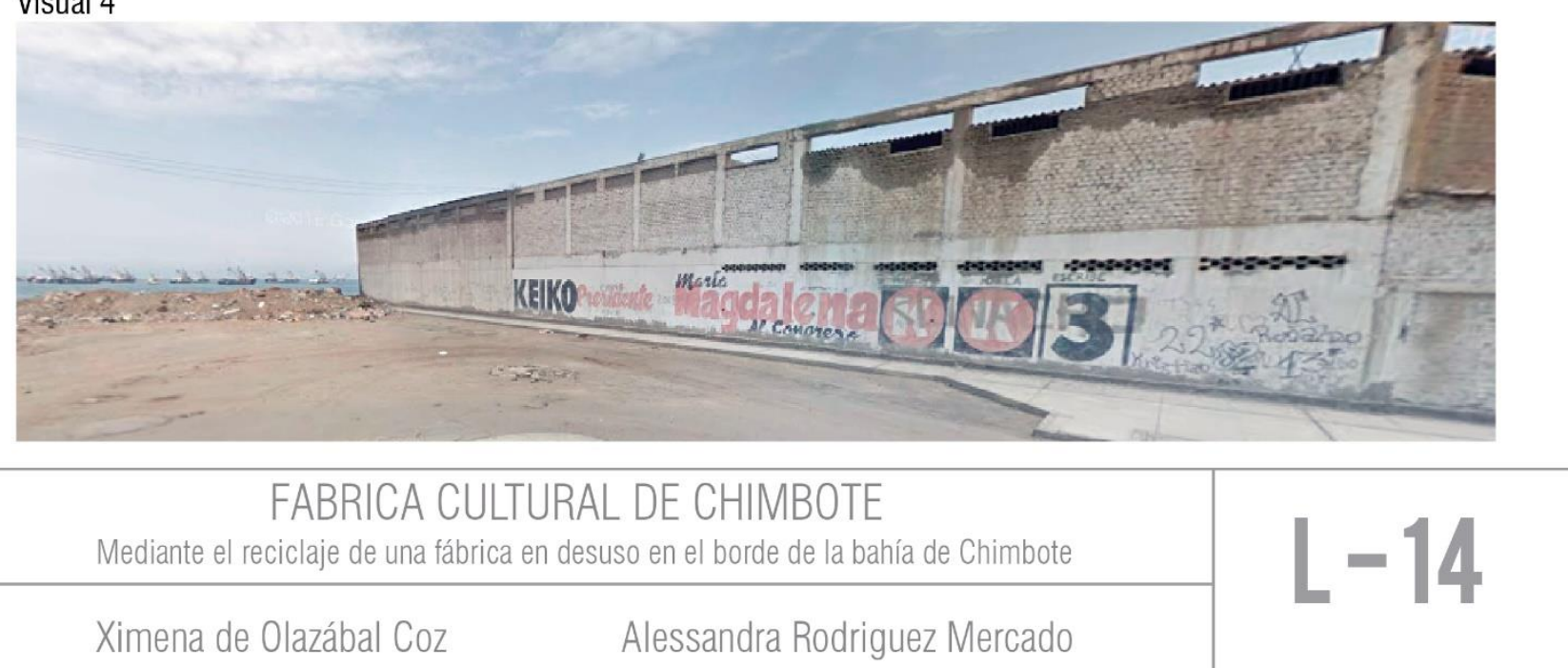




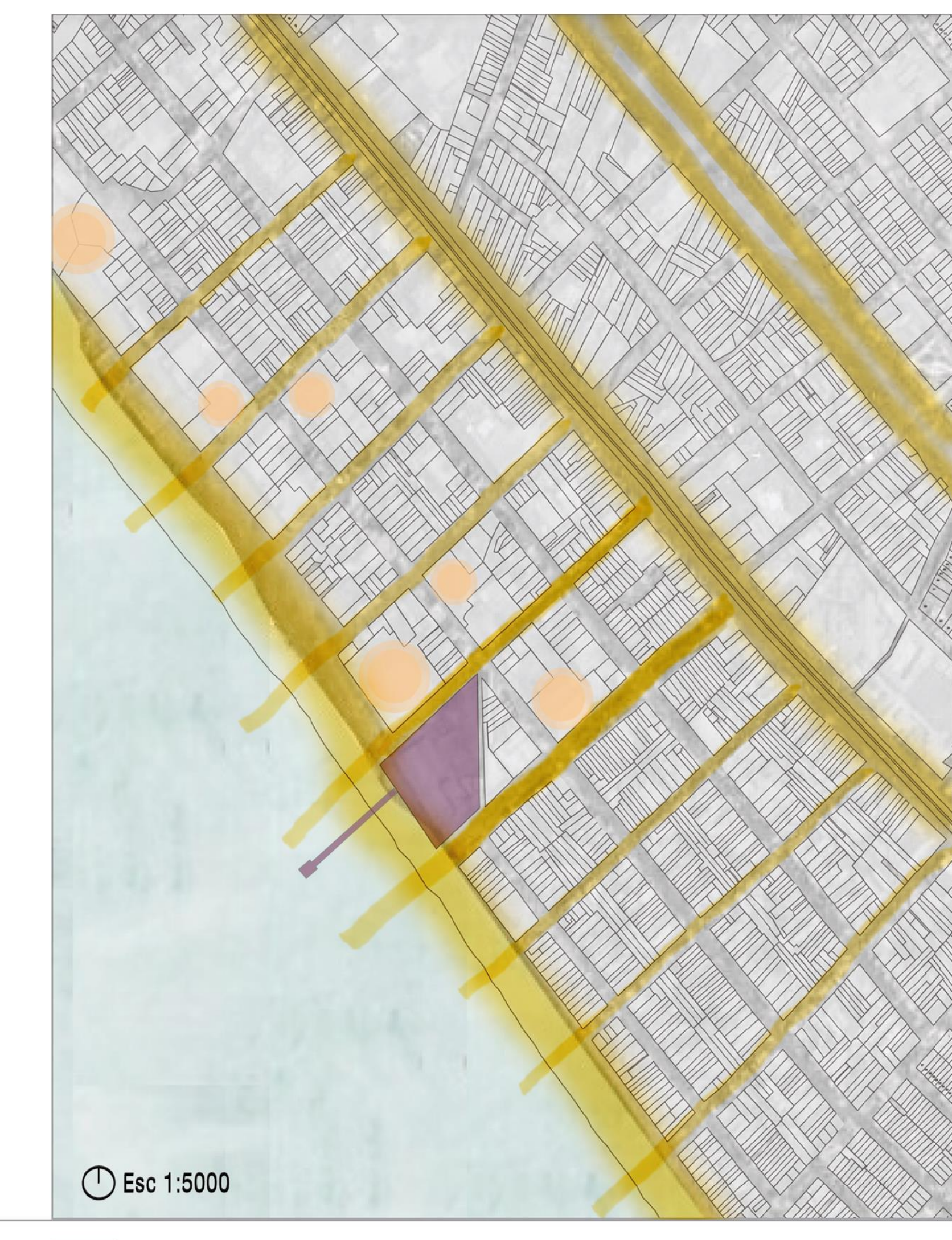

12. POTENCIALIDADES Y LIMITACIONES

Situación Actual

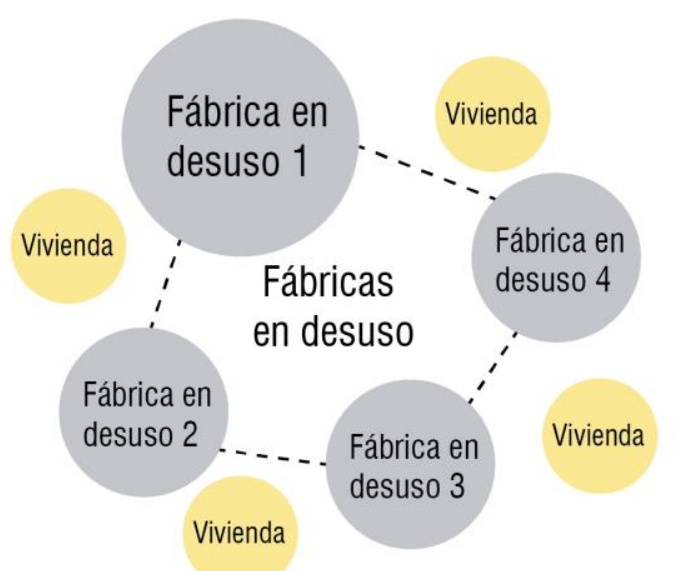

Potencialidades

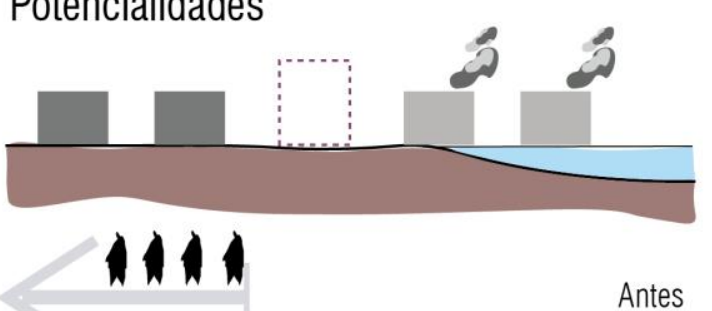

Limitaciones
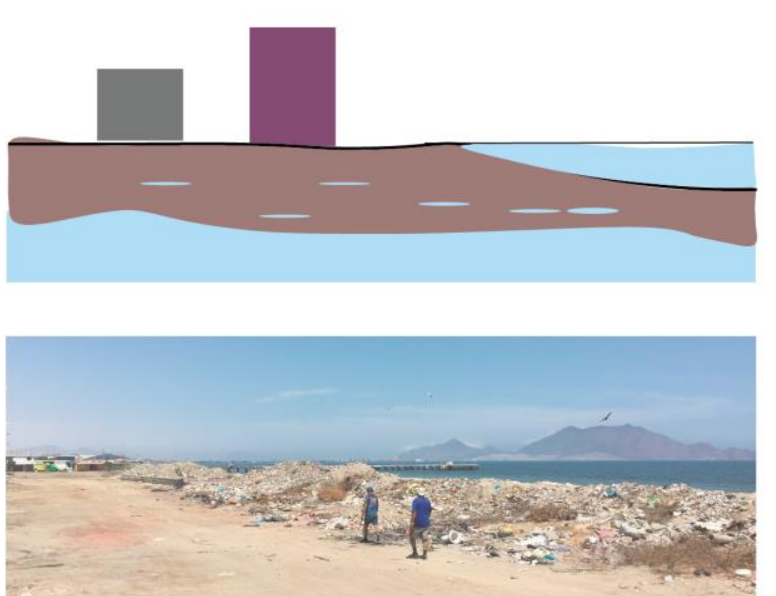

En relación a potencialidades del terreno, al encontrarse dentro de un entorno con varias fábricas en desuso, se presenta una posibilidad de reactivarlas a través de diferentes usos, permitiendo además la conformación de una red conectada de equipamientos, las cuales reactivarían a las viviendas aledañas. Además al colocar equipamientos públicos en la zona costera generaría un foco de atracción de usuarios, constribuyendo a recuperar la relación perdida de los usuarios con la bahía.

Como principal limitación se identifica que el suelo de erreno no es tan adcuado debido a que la napa freatica se encuentra en un nivel alto, impidiendo excavaciones mayores a 5 metros por debajo del suelo. Esta situación puede agravarse con desastres naturales como tsunamis. 


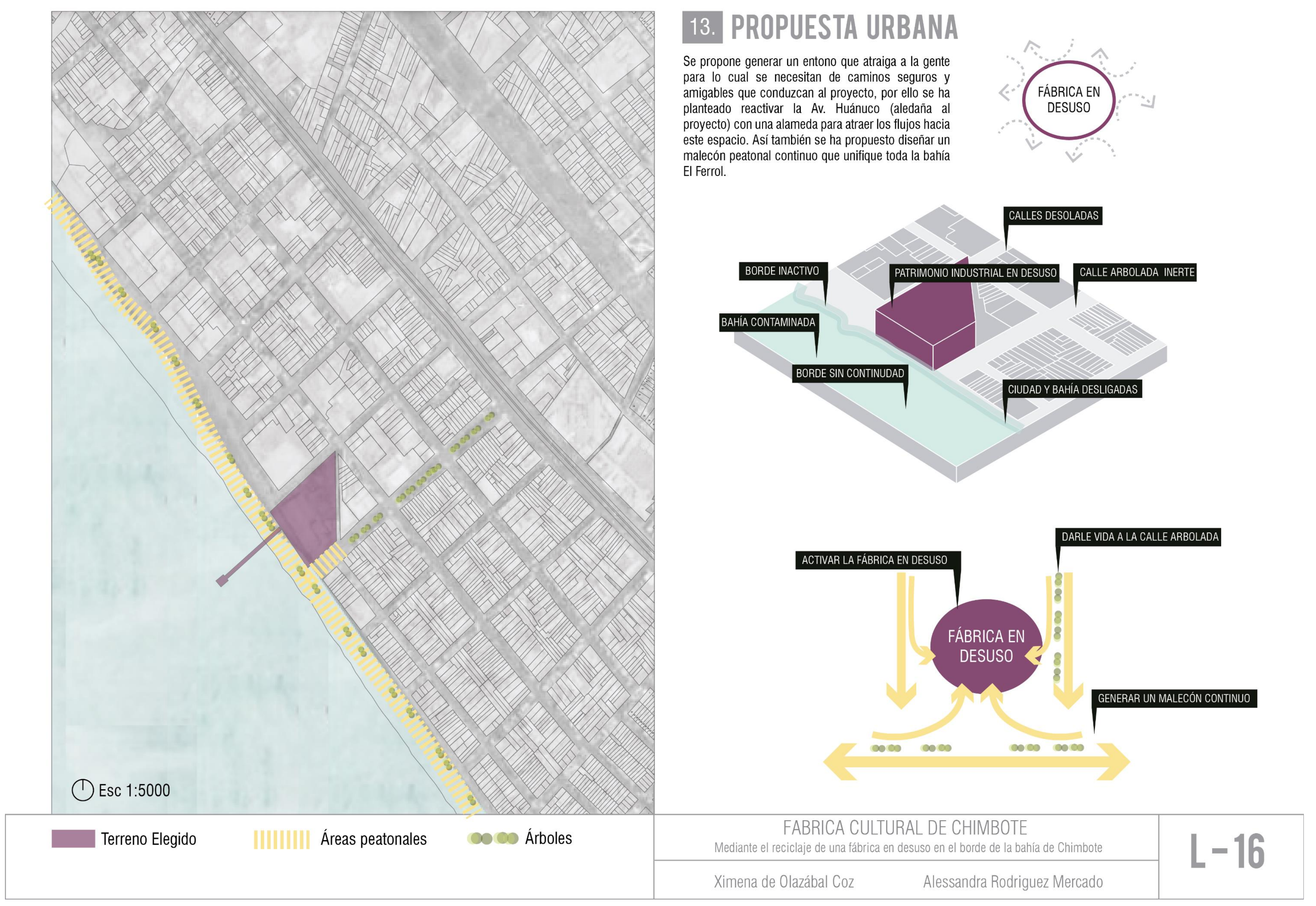




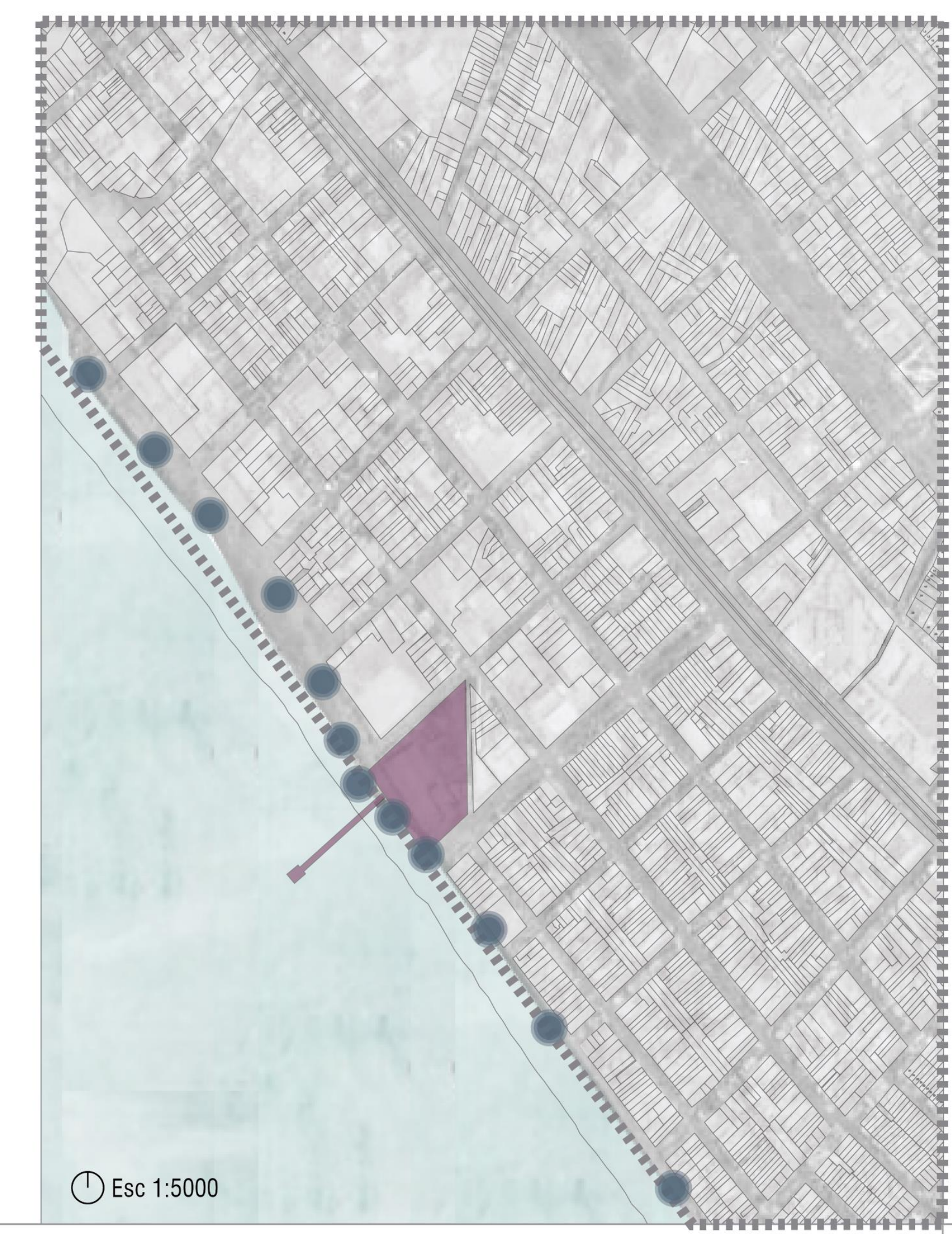

Terreno Elegido

"un. Paisaje urbano

\section{PAISAJE}

Paisaje contaminado

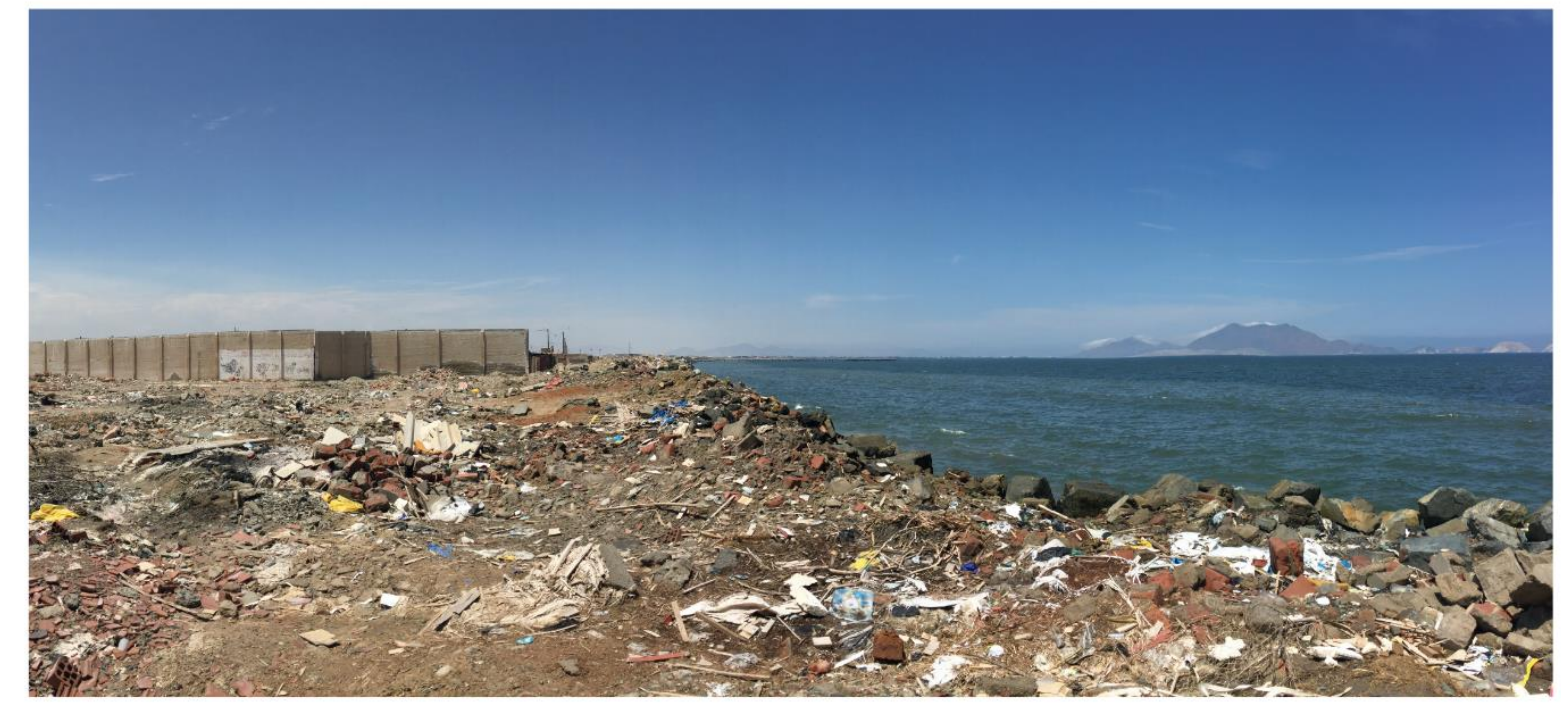

Paisaje urbano

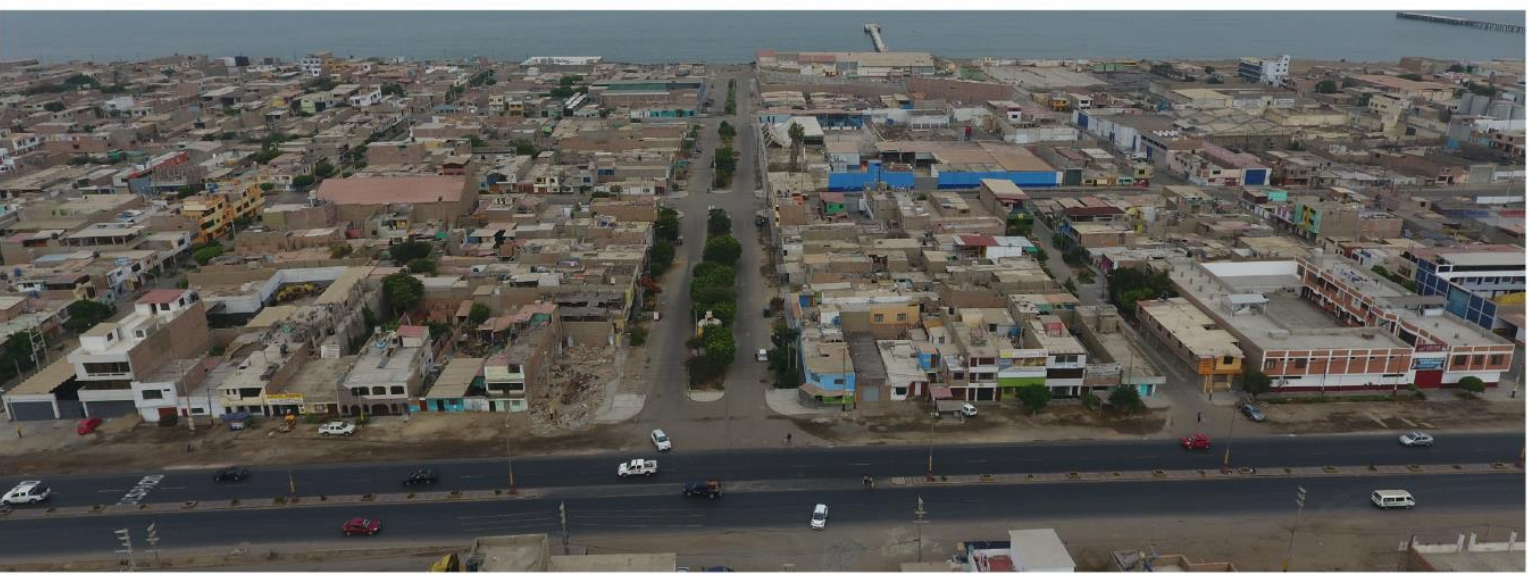

Tejido urbano de densidad baja

Tipología de viviendas
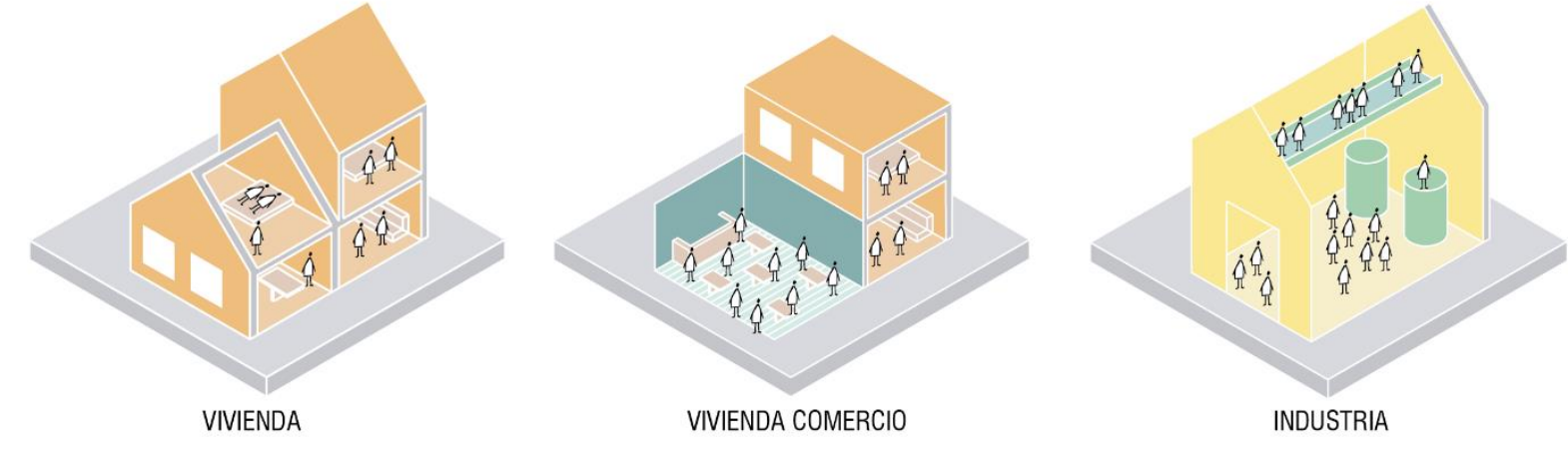

$\mathrm{L}=17$ 
15. MEMORIA COLECTIVA

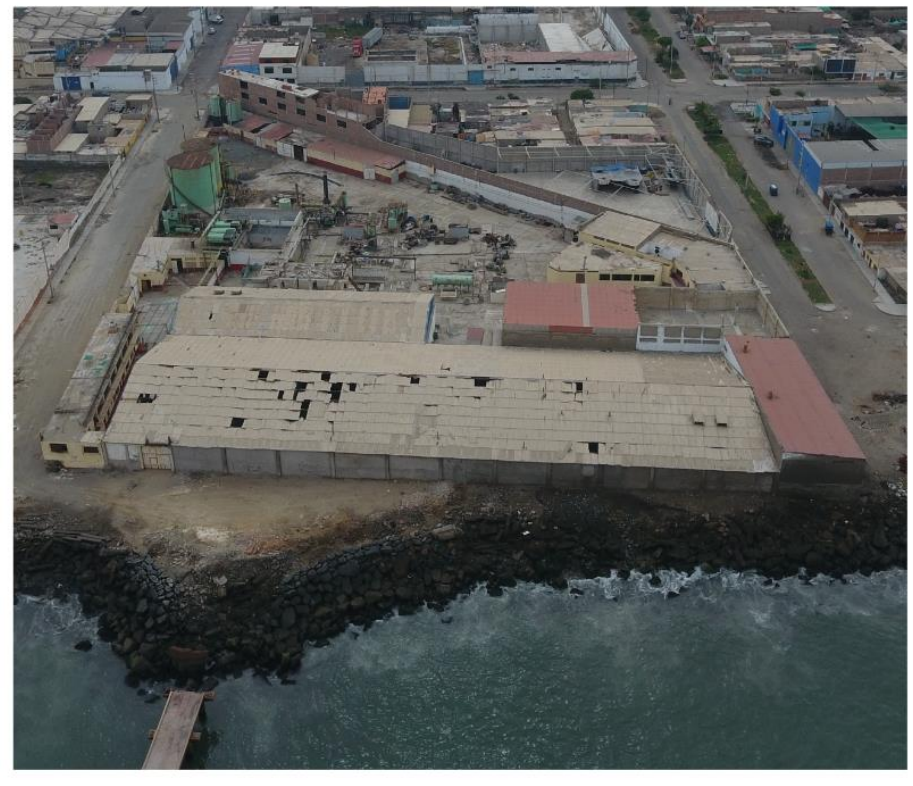

Los elementos industriales presentes dentro de la fábrica en desuso son parte de la memoria colectiva de la población chimbotana pues establecieron las fábricas pesqueras de harina y conservas de pescado y a partir de ello nació la ciudad. Por este motivo se busca mantener todos aquellos elementos que ayuden a generar identidad en la población, quienes saben que la industria pesquera es parte de su cultura pero no le dan la debida importancia.

\section{SÍMBOLOS DE CHIMBOTE}

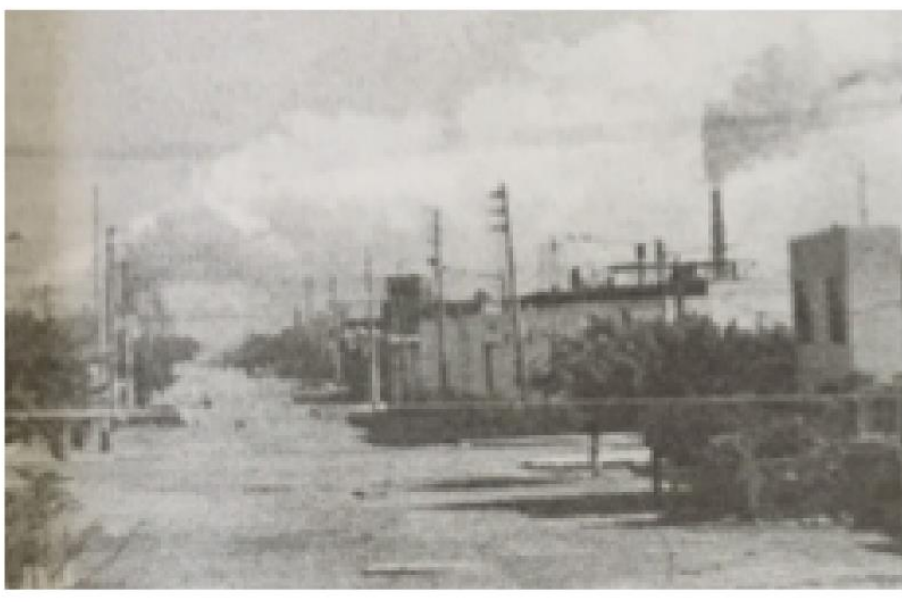

HUMOY Los chimbotanos consideran estas dos MAL OLOR económica de la ciudad
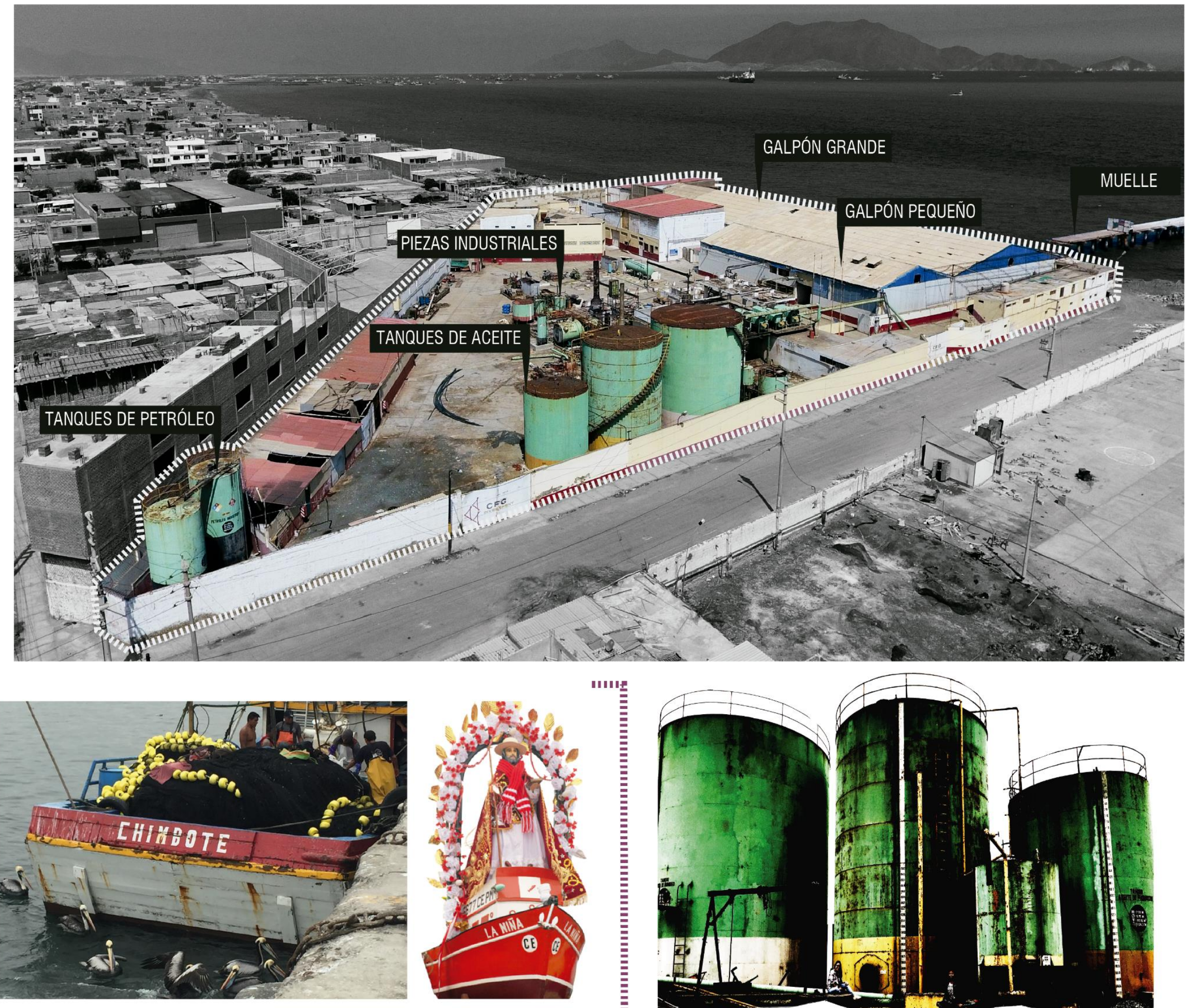

San Pedrito es considerado el patrón de los pescadores y et santo más venerado de Chimbote, a ello se debe que todos los años se festeja la fiesta de

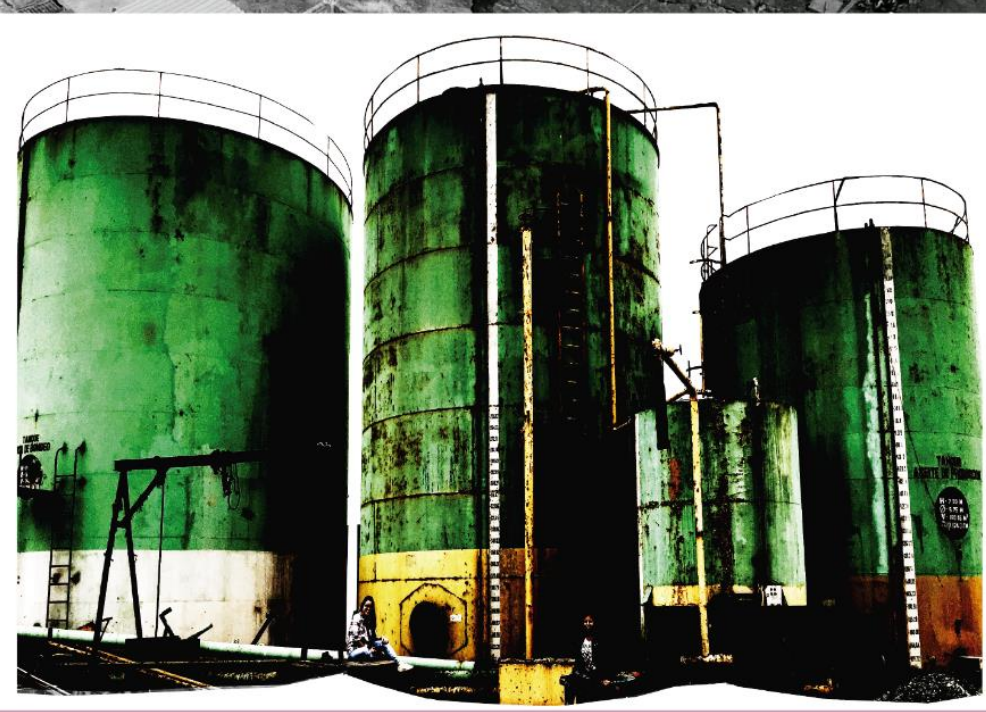

FÁBRICAS EN DESUSO ELEMENTOS INDUSTRIALES POTENCIADORES 


\subsection{Conclusiones Parciales}

De acuerdo con el análisis de redes de equipamientos existentes en la ciudad de Chimbote, se puede concluir que existe un alto déficit de equipamientos culturales, pues actualmente el distrito de Chimbote solo cuenta con un centro cultural que solo abastece a una parte de la población, aproximadamente a 5000 personas; mientras que el distrito de Nuevo Chimbote no cuenta con ninguno de este tipo. Es por ello que se considera necesario el incremento de equipamientos culturales, propuesta que también responde a la gran cantidad de población joven comprendida entre 10 y 19 años representando el 20.09\% del total. Este grupo de edad, se encuentra en su mayoría cursando la educación básica, primaria y secundaria, por lo que requieren de equipamientos que complementen sus estudios, es decir, que puedan realizar actividades extracurriculares que ayuden a desarrollar mejor sus competencias.

La elección de la zona de desarrollo del proyecto se debe a que, si la ciudad necesita de equipamientos culturales que mejor lugar que crearlos en una zona que cuenta con un pasado histórico cultural relacionado a la industria y a la pesca. Es por ello que se ha considerado el sector 5 de la ciudad como una zona con gran potencial, especialmente el barrio de la Florida Baja, debido a que esta zona presenta fábricas que actualmente se encuentran en desuso y que no están siendo parte de la dinámica urbana, sino por el contrario están contribuyendo a degradar el paisaje. Asimismo, para que estos espacios funcionen deben formar parte de una red de equipamientos que se instalen dentro de estructuras industriales en desuso. Al encontrase estos espacios muy cerca unos a otros, sería excesivo tener una gran cantidad de equipamiento netamente cultural en una misma zona por lo que se propondría una red de equipamiento de diferentes ámbitos que alberguen dentro de ellos un área destinada al desarrollo de la cultura, así se tendría una variedad de equipamientos sin descuidar el área cultural que es lo que más se necesita en la ciudad.

La zona a intervenir cuenta con un alto déficit de áreas verdes y espacios públicos, además de encontrarse en un sector con altos índices de contaminación e inseguridad, por lo que se busca que el proyecto pueda funcionar como un nuevo espacio público que integre a la 
población no solo con el proyecto, sino también con el paisaje que lo acompaña y de esta manera se pueda regenerar el paisaje urbano de Chimbote, dándole una imagen positiva.

La población de Chimbote le ha dado la espalda a la bahía, olvidándose que ésta siempre les ha provisto de los medios necesarios para subsistir. La relación directa que existía entre ambos se ha fragmentado debido al descuido que se le ha dado y que actualmente representa una barrera entre lo urbano y lo natural. Debido a esta razón, es que se ha buscado un terreno que se encuentre ubicado en el borde costero de manera que sirva como herramienta que ayude a recuperar el borde y a su vez genere un espacio de interacción. Al encontrarse en la zona central de la bahía representa un fácil alcance tanto para los pobladores de Chimbote como para los de Nuevo Chimbote, así como también la accesibilidad por medio del futuro malecón. Además, el terreno cuenta con 3 frentes, los cuales poseen un alto potencial de ser aprovechados, para permitir el acceso de los usuarios y la interacción con los vecinos. Si bien el terreno se encuentra dentro de una ex zona industrial y con un alto valor histórico, la escasa valoración e interés de la población por estas estructuras ha generado que hoy se encuentren deteriorados, dejando el sector con una gran cantidad de vacíos urbanos y fomentando la percepción de inseguridad. Por este motivo se espera que a través de la intervención de la antigua fábrica CFG y la puesta en valor de cada una de las piezas industriales encontradas dentro de ella se pueda regenerar el suelo por medio de la inserción de un programa cultural, de manera que se pueda generar un impacto positivo que sirva como punto de partida para un posible cambio de la imagen de la zona.

La sede de la fábrica CFG fue elegida para proyectarse como futura fábrica cultural debido a la calidad y variedad de piezas preexistentes tales como tanques, tijerales y grandes espacios industriales, ya que estos elementos son hitos y hacen alusión directa a la historia industrial. Estos elementos tienen la capacidad de ser revitalizados para fomentar vínculos con el pasado histórico industrial, permitiendo así que los usuarios puedan identificarse con ellas y reforzar la identidad de Chimbote. Se espera que a través de la inserción de un proyecto de carácter cultural se puedan reforzar los nexos entre el pasado histórico de la población, así como también se estima que el proyecto pueda generar un crecimiento económico de la zona a través de la creación de nuevos puestos de trabajo y aumento del turismo. 


\section{CAPÍTULO VII: CONCLUSIONES FINALES}

Chimbote es una ciudad - puerto, cuyo territorio ha estado ligado desde sus inicios al mar, convirtiendo el malecón como el principal espacio público de la ciudad, donde los habitantes gozaban de las playas y los visitantes llegaban a contemplar la bahía. Sin embargo, en la actualidad la ciudad ha perdido esta estrecha relación con el mar, la población ha dejado de mirar hacia este pues no existe una conexión visual directa debido a la presencia de una barrera de basura y desmonte que bordea todo el litoral generando que la ciudad olvide este espacio que es la razón de ser de Chimbote pues todas las actividades giran en torno al mar y a la pesca. Sumado a ello, la inactividad de las fábricas ubicadas en el borde de la bahía ha acentuado la degradación de esta parte de la ciudad, ya que el marcado tejido industrial de la zona no se ha engranado con el tejido residencial por lo que la gran cantidad de muros ciegos y la poca actividad en las calles de la zona de la Florida Baja han aumentado la percepción de inseguridad y la delincuencia. Es por ello que, resulta indispensable la regeneración de esta zona y del frente costero a través del reciclaje de las fábricas en desuso en equipamientos que contribuyan a activar la zona y volver la mirada de la ciudad y de los habitantes hacia el mar.

El paisaje de Chimbote está marcado por la bahía y la industria, lo que lo ha convertido en un paisaje industrial en el que sus habitantes han desarrollado una cultura en torno a la pesca y a todo lo que gira alrededor a ella como historia, gastronomía, fiestas religiosas, convirtiéndolo así en paisaje cultural. Tipo de paisaje con el que aún no se ha asociado Chimbote por lo no se ha puesto en valor las estructuras industriales que han formado parte de la historia de la ciudad y que si se revaloran y se convierten en patrimonio industrial contribuirían a la regeneración de la ciudad, impulsarían el territorio a desarrollarse económicamente y reforzarían la identidad y memoria colectiva de la población generando así un vínculo entre los habitantes y los espacios fabriles.

La cultura e identidad chimbotana están sentadas sobre la base de su paisaje. En la ciudad se han gestado diversas manifestaciones culturales, sin embargo, no existen espacios que las alberguen y donde se fomente actividades educativas, culturales y artísticas. Resulta 
incoherente que ante una gran cantidad de población joven con necesidad de recibir educación y cultura exista una escasez de equipamientos culturales en la ciudad, ante ello se infiere que al dotar de uso cultural a uno de los espacios fabriles inactivos ubicado frente a la bahía se podrá contribuir a la regeneración de la ciudad y a la transformación del frente costero, ya que la cultura fortalece la identidad de los habitantes desarrollando un vínculo participativo en la ciudad.

Si bien el desarrollo de un equipamiento cultural en un espacio con identidad y memoria colectiva a través del reciclaje de una fábrica en desuso contribuirá a la regeneración de la zona de la Florida Baja y la transformación del frente costero, se considera que por la magnitud del proceso de regeneración que necesita esta zona es necesario desarrollar un sistema de reciclaje de estructuras industriales que alberguen equipamientos de diverso tipo de acuerdo a la necesidad de la población, de manera que se teja los usos de suelo de la zona y se tenga un mayor radio de influencia en la ciudad. 


\section{CAPÍTULO VIII: PROYECTO FÁBRICA CULTURAL}

\subsection{Fábrica de conserva y harina de pescado}

El terreno en el que se encuentra ubicado el proyecto fue asentado por primera vez ante los registros públicos en el año 1962 de propiedad de privados. En 1968, el terreno pasa a manos de la Compañía Pesquera La Florida S.A, quien construye la fábrica productora de conserva y harina de pescado, desde ese momento empezó el desarrollo productivo de la fábrica hasta el año 2009 en la que se puso en marcha la Ord. $\mathrm{N}^{\circ}$ 001-2009-MPS, por lo que la industria pesada tuvo que cesar sus funciones en esta zona. Hoy en día, la fábrica es de propiedad de la empresa pesquera CFG Investment S.A.C., y esporádicamente se aprovecha como depósito las otras fábricas de esta compañía.

Ilustración 8.1 Ubicación de la fábrica elegida

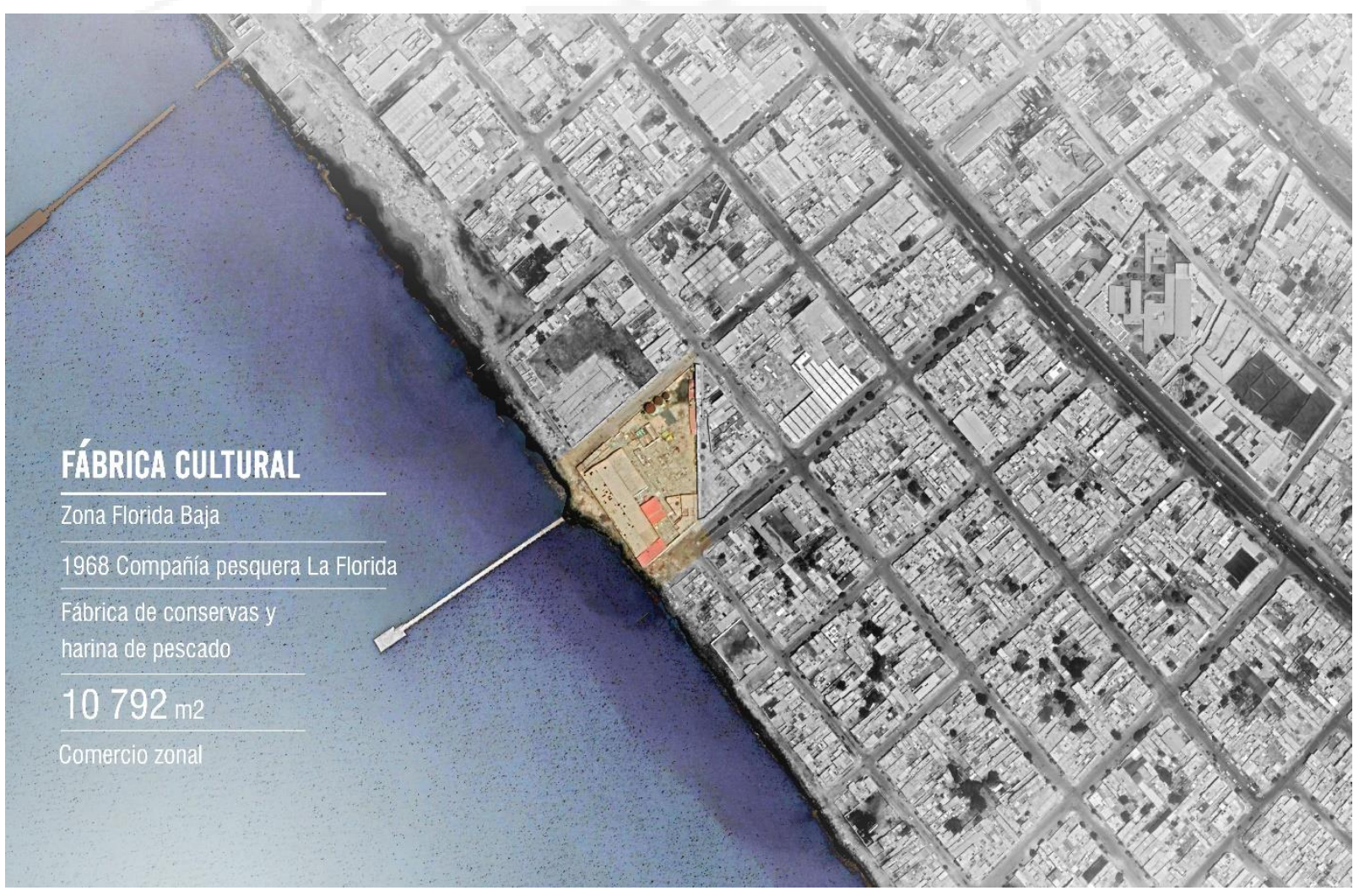

Fuente: Elaboración propia 
Ilustración 8.2 Vista de la preexistencia en la fábrica CFG Investment desde el Jr. San Martín

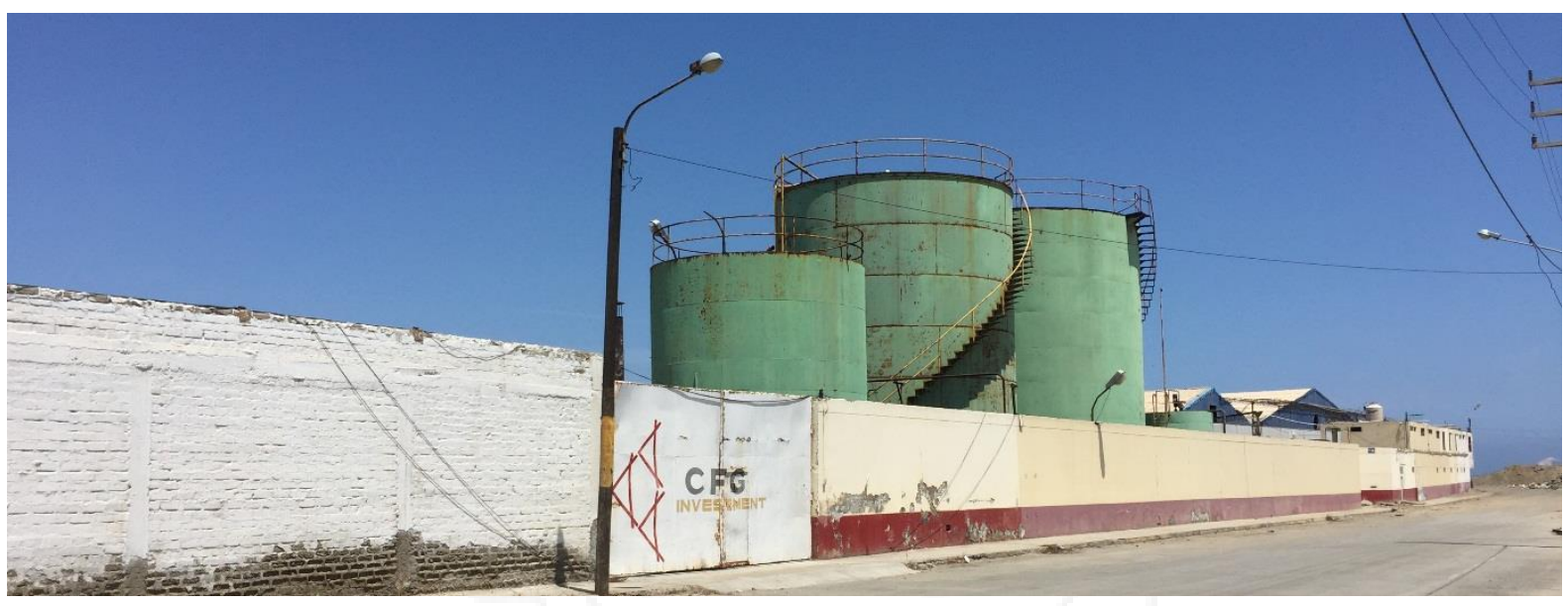

Fuente: Fotografía propia

Ilustración 8.3 Vista de la fábrica CFG Investment desde el Malecón Grau

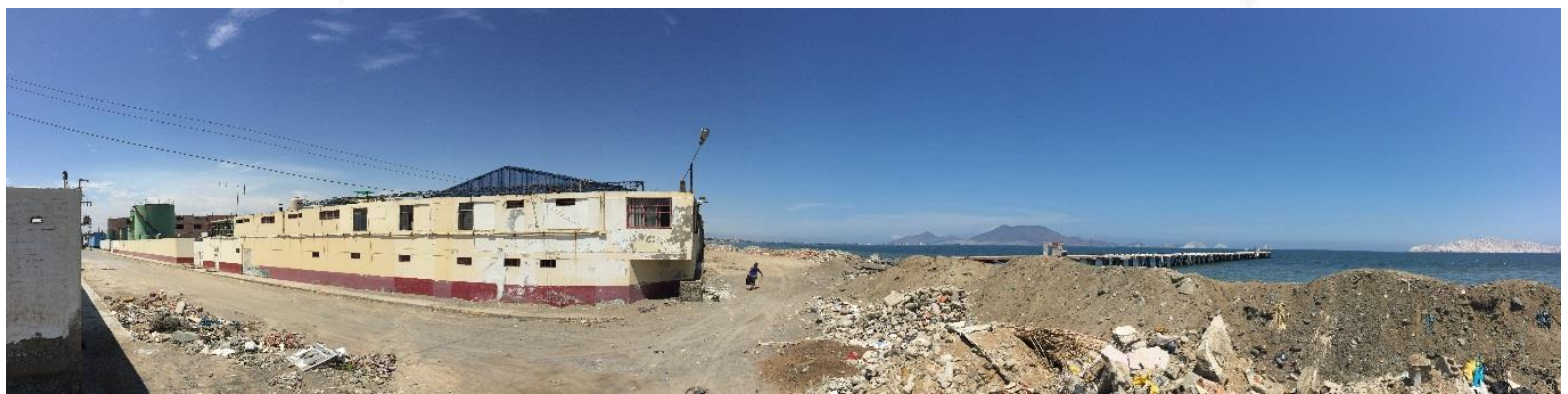

Fuente: Fotografía propia

\subsection{Espacios y piezas industriales}

La fábrica elegida se caracteriza por albergar en su interior preexistencias, piezas que hacen referencia a la principal actividad extractiva de Chimbote, la pesca. Entre las piezas halladas y analizadas, se encuentran galpones, tanques, tanques pequeños y el muelle.

Los galpones se ubican en el sentido longitudinal, completando uno de los frentes de la fábrica, lo que hace que desde fuera sean vistos como un espacio cerrado, sin relación alguna con el exterior. Sin embargo, el valor de los galpones radica en su riqueza espacial, en la gran luz con la que cuentan. Son espacios flexibles, multifuncionales, adaptables a cualquier situación y actividad. Sumado a ello, la altura significativa que tienen permite usar el espacio tanto longitudinal como verticalmente, hallando así m3 de espacio por usar. Ciertamente, presenta esta espacialidad gracias a la estructura que lo cubre, presenta estructuras de concreto 
como basamento sobre las que se sostienen cerchas metálicas que conforman la liviana cubierta del galpón.

\section{Ilustración 8.4 Espacialidad del galpón}
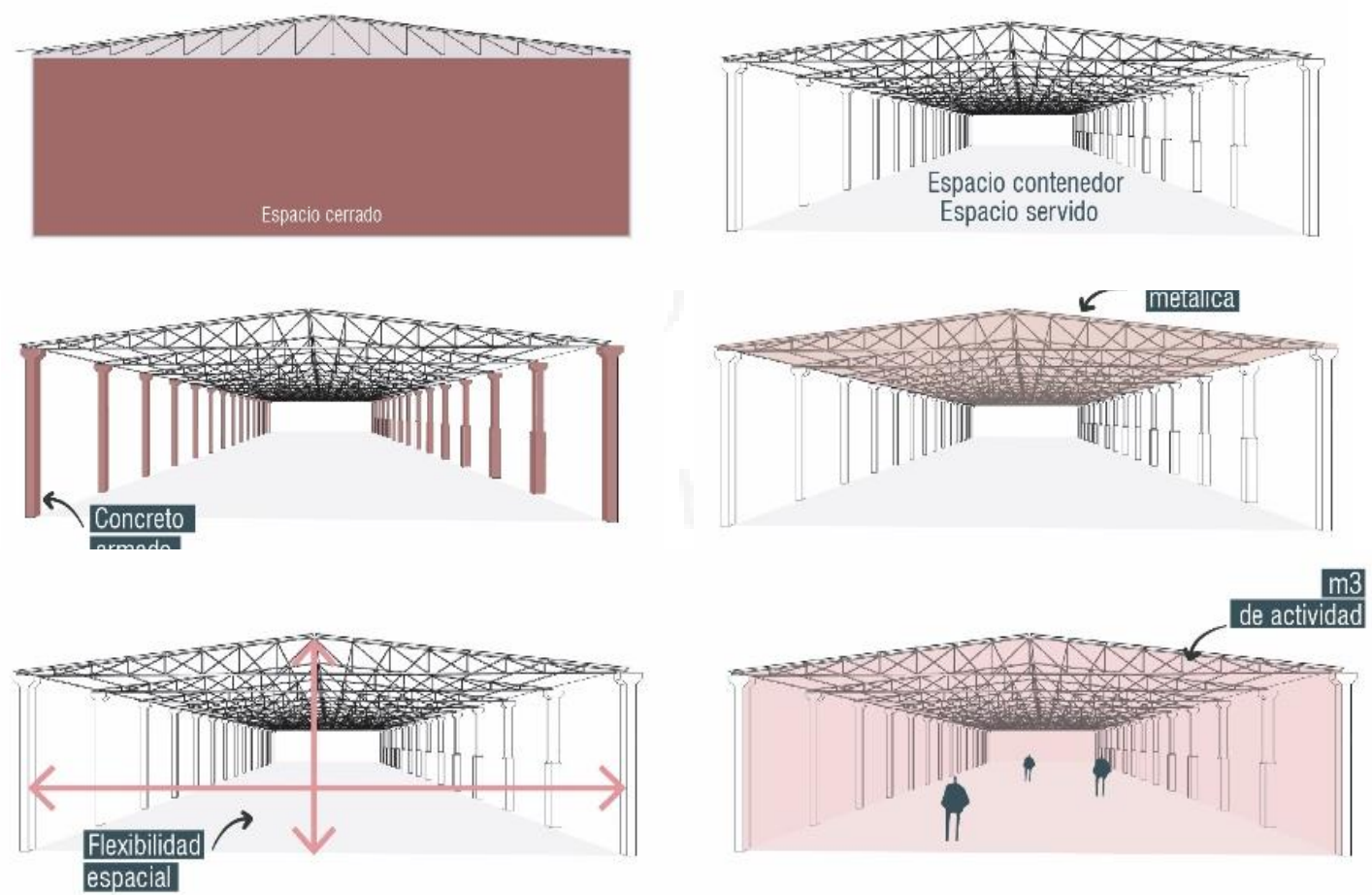

Fuente: Elaboración propia

Los tanques son elementos que acompañan y alimentan la actividad que se da al interior de los galpones. Están hechos de planchas de lata y son de gran tamaño porque almacenan grandes volúmenes de líquidos como agua de bombeo, agua de producción, petróleo y aceite.

Ilustración 8.5 Tanques de almacenamiento

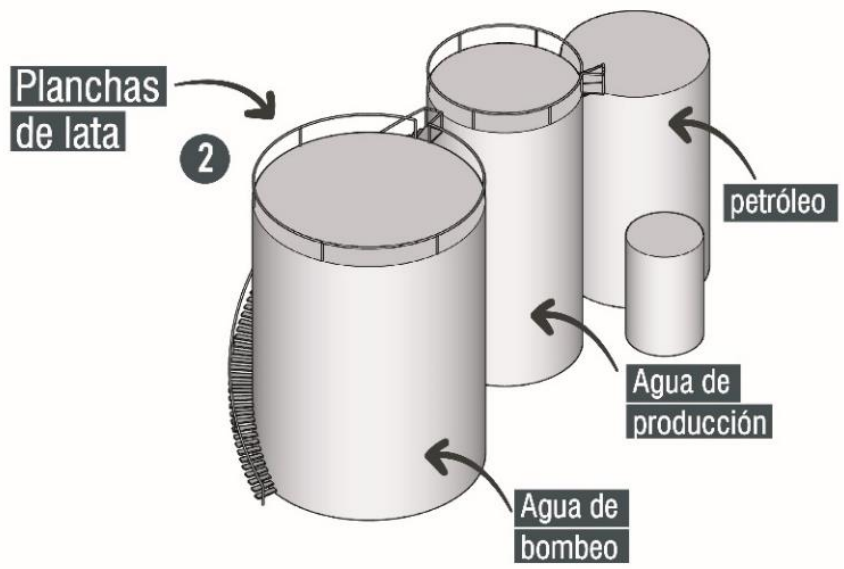

Fuente: Elaboración propia 
Los tanques pequeños son piezas que complementan la función de los tanques principales. Hay de diferentes tipos y tamaños y pueden encontrar de manera horizontal y vertical, siempre con relación a los tanques grandes.

\section{Ilustración 8.6 Tanques pequeños complementarios}

Fuente: Elaboración propia

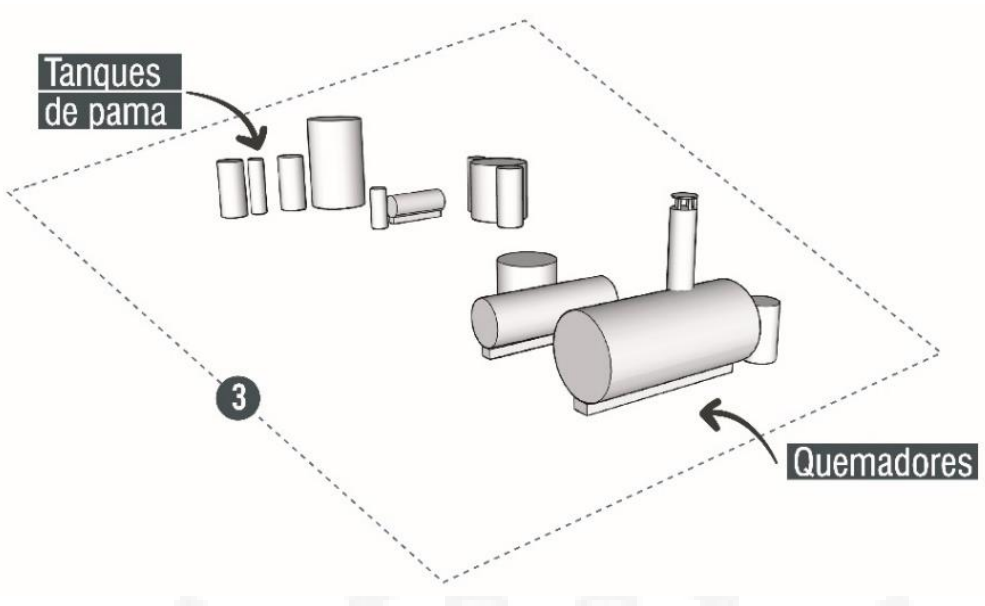

Entre las piezas también se encuentra el muelle, actualmente está separado de la bahía por el desuso y falta de mantenimiento, no obstante, es la conexión más directa de la fábrica con la bahía. Es un muelle de madera asentado sobre pilotes de concreto, cuya longitud es de 120 metros de largo.

Ilustración 8.7 Vista de la fábrica que se extiende a través del muelle hacia el mar

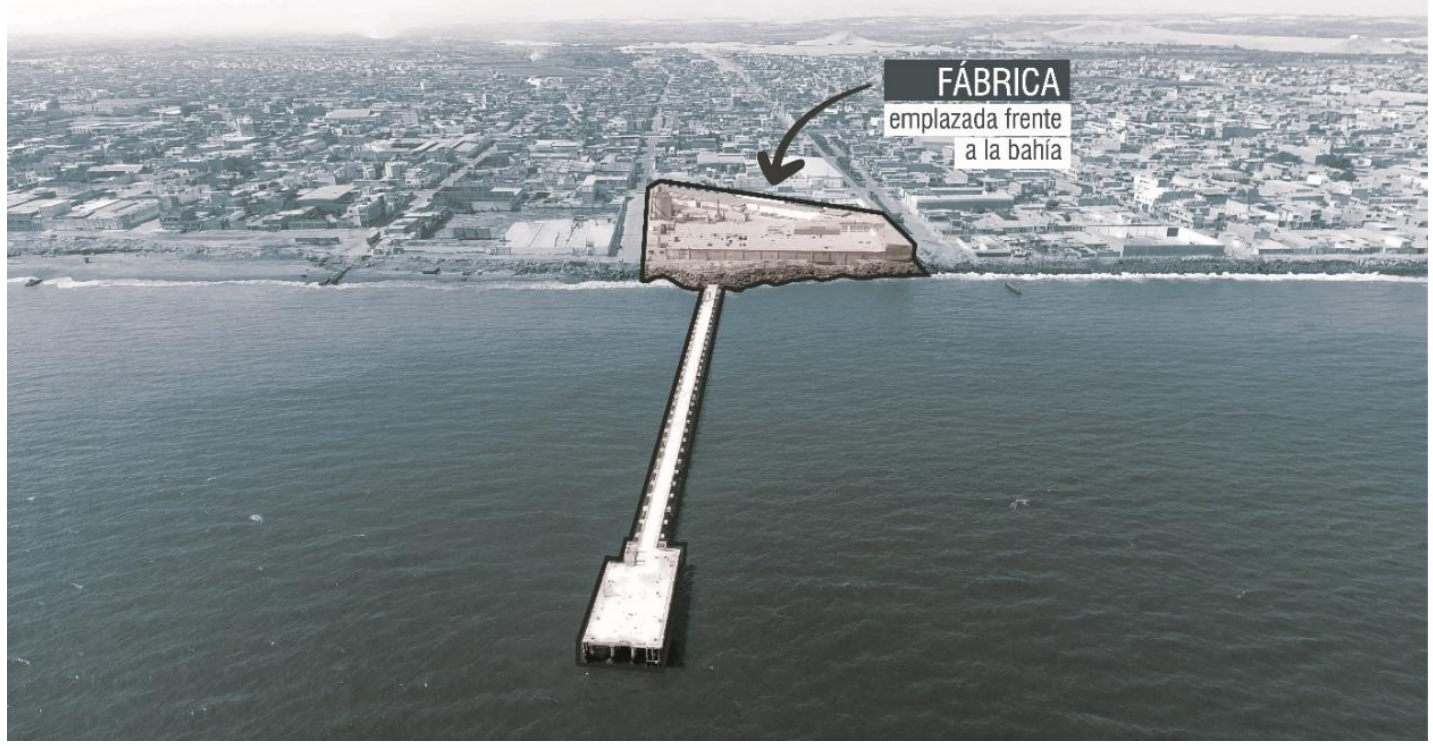

Fuente: Elaboración propia 
Ilustración 8.8 Vista aérea de la situación actual de la fábrica

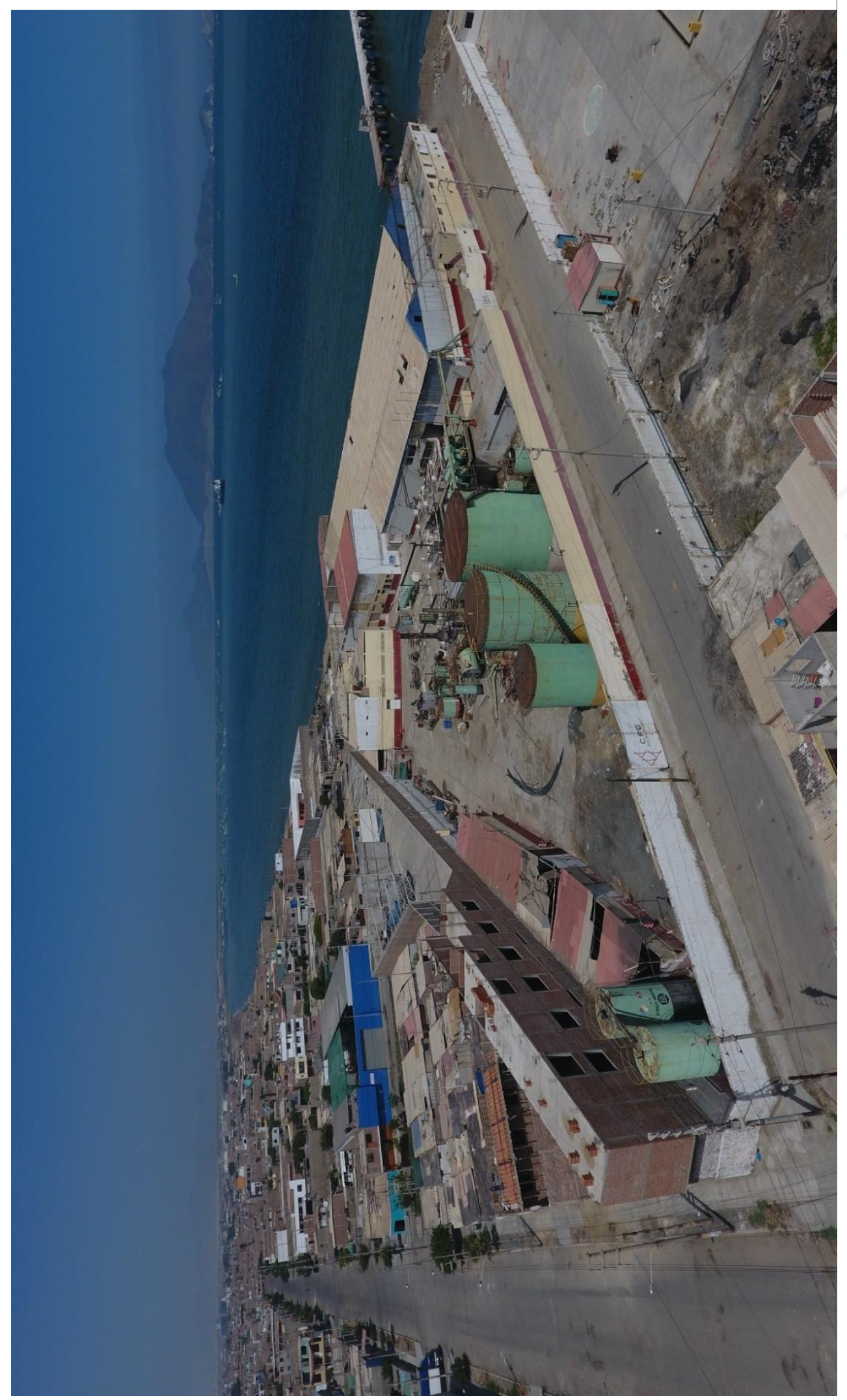

Fuente: Fotografía propia 


\section{Ilustración 8.9 Vista frontal de la fabrica}

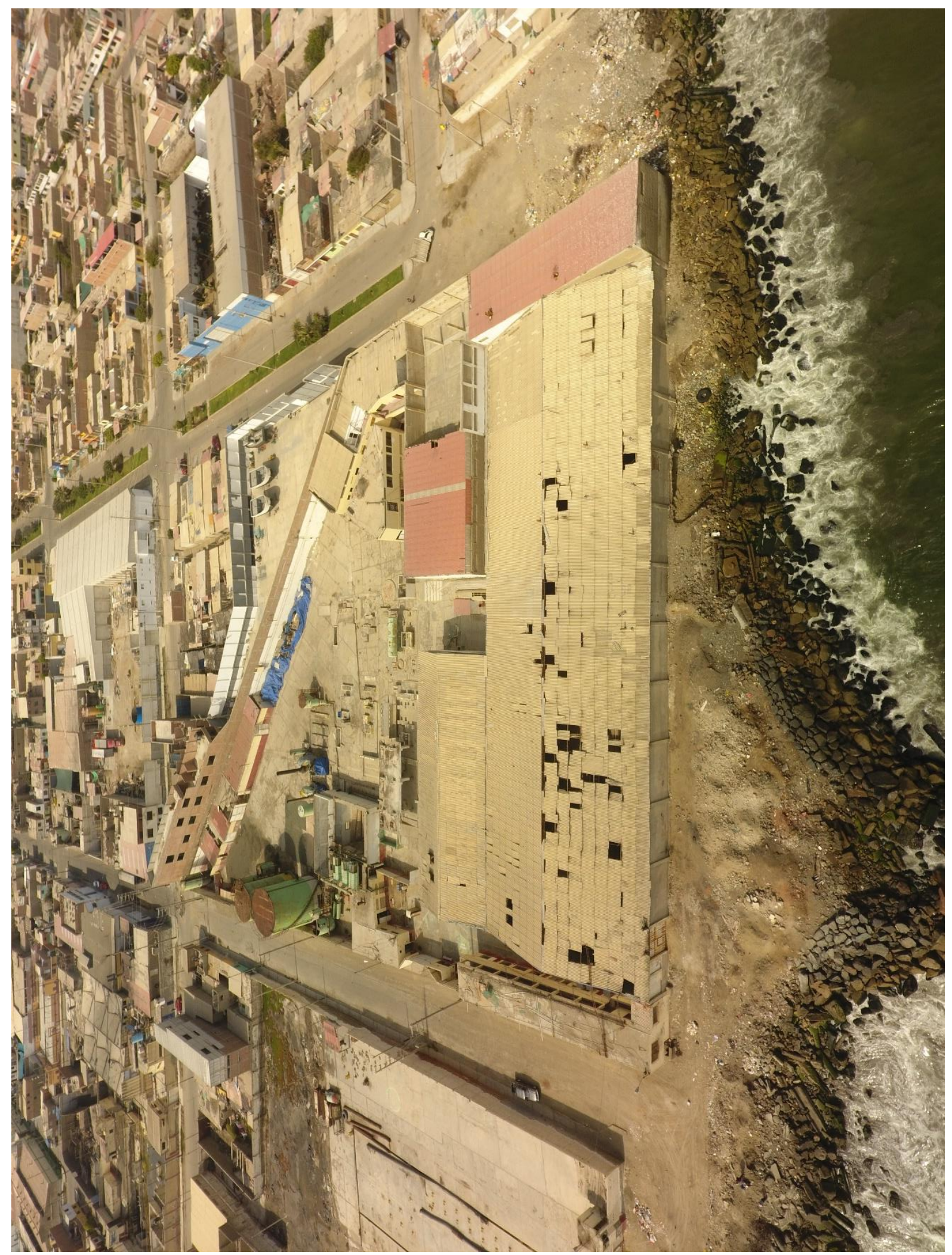

Fuente: Fotografía propia 


\subsection{Proceso productivo de la fábrica}

El proceso productivo empieza cuando el barco descarga el pescado en una chata ${ }^{13}$. Esta cuenta con unas bombas que impulsan el pescado mediante tuberías de 20 pulgadas de diámetro para que la pesca llegue a la zona de descarga de la fábrica. El pescado es recibido por una máquina desaguadora que separa que el agua del pescado, luego es pesado en una balanza para saber cuánto es la carga que hizo la embarcación, todo ello controlado por los trabajadores de la fábrica y por un encargado de la embarcación. Desde este momento empieza netamente el proceso de producción de la conserva de pescado, el pescado pesado pasa a unas pozas donde se almacenan para luego ser transportado por unas fajas. Alrededor de ellas se encuentran señoras, llamadas comúnmente mujeres fileteras, que separan el pescado en canastillas y las ordenan de acuerdo con el tamaño de la especie, que es supervisado por ingenieros químicos y biólogos. Seguido de ellos, las canastillas son introducidas en unos cocinadores para que el pescado se cueza a una temperatura ente 85 a $90^{\circ} \mathrm{C}$, después el producto es ubicado en mesas donde las mujeres fileteras limpian el pescado, le quitan la cabeza, la cola, las vísceras y la carne negra, el pescado seleccionado pasa a otras mesas para ser envasados en tarros que mediante fajas transportadoras son llevados a la máquina selladora donde se les coloque tapa y fecha de vencimiento a las conservas. Nuevamente las latas selladas son transportadas en canastillas a los autoclaves (cocinadores) donde por última vez se cocina el pescado a misma temperatura anterior. Finalmente, a los carros con las canastillas que contienen las latas se les rocía agua y es etiquetado por el área de producto terminado.

La maquinaria empleada para la producción de conserva de pescado se ha encontrado intacta dentro de los galpones de la fábrica. Entre las piezas pueden apreciarse las canastillas, las mesas y los cocinadores.

\footnotetext{
${ }^{13}$ Chata, embarcación flotante.
} 
Ilustración 8.10 Proceso de elaboración de conserva de pescado
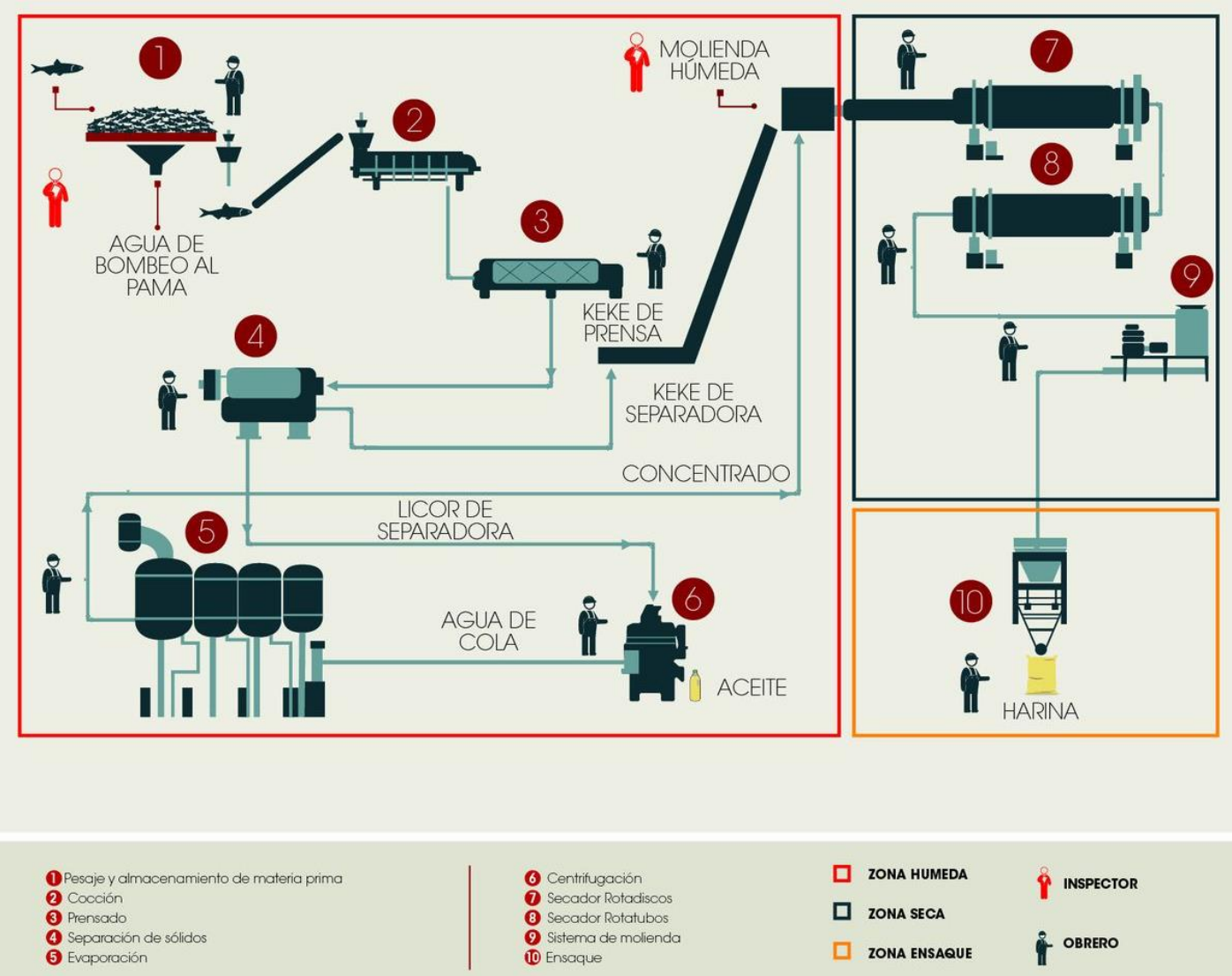

Fuente: Recuperada de www.snp.org.pe

Ilustración 8.11 Piezas que alberga el galpón para la producción de conservas de harina de pescado

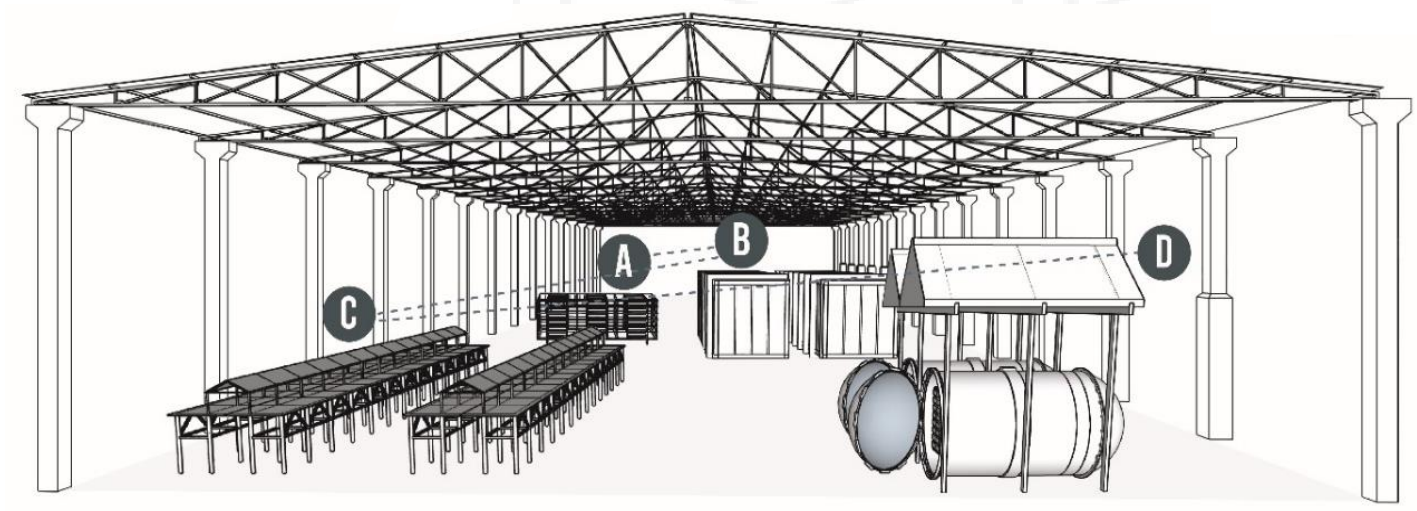

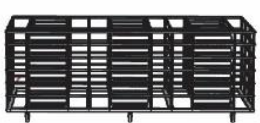

1. Canastillas

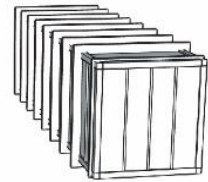

2. Cocinador

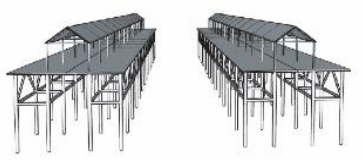

3. Mesas para limpiar

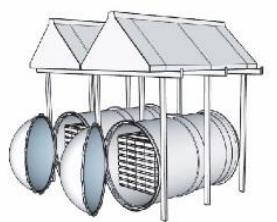

4. Autoclaves

Fuente: Elaboración propia 
Ilustración 8.12 Maquinaria utilizada para la elaboración de conserva al interior del galpón
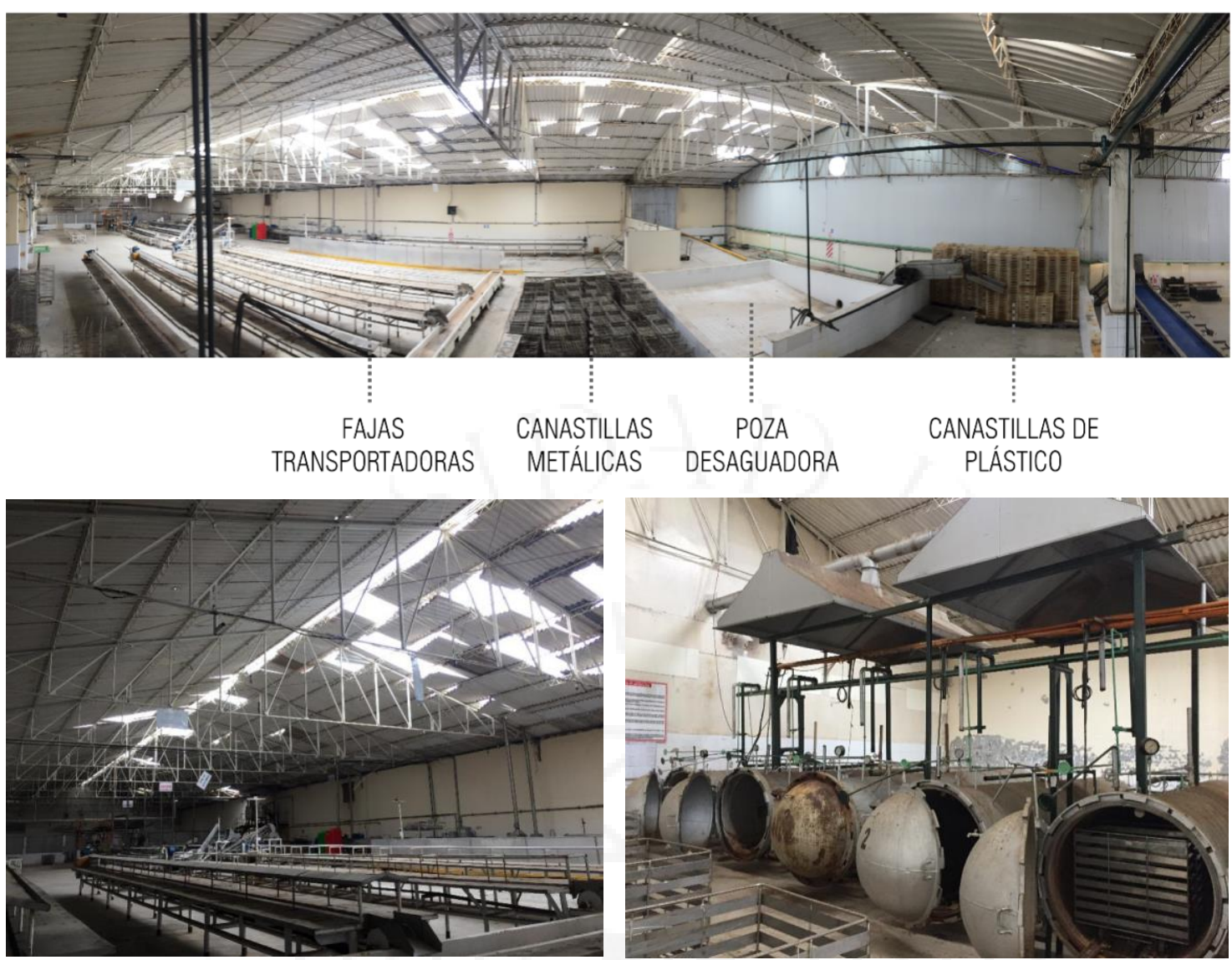

Fuente: Fotografía propia

Paralelamente a este proceso, se produce el aceite y harina de pescado, el agua que es separada por la máquina desaguadora, pasa a ser almacenada a los tanques de PAMA (área de recuperación secundaria), este líquido no contiene únicamente agua sino también está mezclado con la sangre de pescado, a ello en el sector pesquero se le llama sanguaza. Seguidamente el líquido pasa a otro tanque llamado crosta, que separa la sangre del aceite, para procesarlo. El trasportador celda YAP es una poza que trabaja con burbujas de aire que recibe el aceite para separar la grasa que es espuma, quedando así el aceite en la parte baja y el agua en la parte superior, obteniéndose así el aceite de pescado. 
Ilustración 8.13 Tanques utilizados para almacenamiento de aceite, petróleo y pana
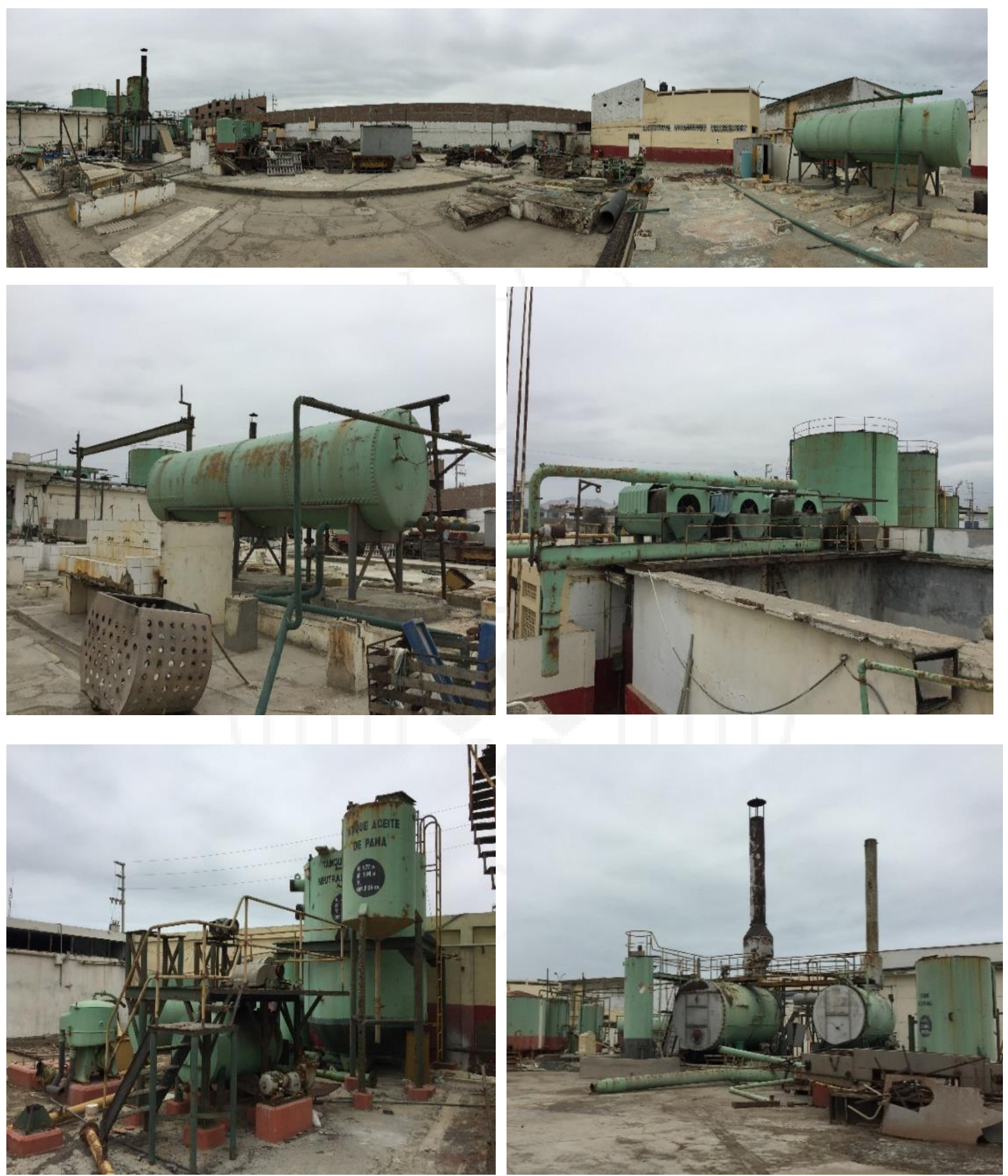

Fuente: Fotografía propia. 
Si se analizan los espacios y elementos industriales desde el punto de vista funcional, se puede tener como resultado que los galpones cumplen la función de espacios servidos mientras que los tanques son espacios servidores. Los galpones son cobertores que albergan actividad, mientras que los tanques almacenan sustancias, que en muchos casos abastecen al galpón. Ambas piezas funcionan como parte de un sistema en la que una necesita de la otra para completar su proceso de producción.

\subsection{Organización espacial de las preexistencias}

La organización espacial de la fábrica es singular y característica de espacios industriales que van colocando la maquinaria de mayor tamaño y volumen en los bordes siguiendo la forma del terreno para luego habitar el centro de este con máquinas y piezas más livianas y que ocupan menos espacio sin orden alguno. En el caso de esta fábrica se podría inferir que el primer frente al que se enfrentaron espacialmente fue la cara con la bahía, colocando dos galpones en el sentido longitudinal para luego ir entrando al centro del espacio hasta limitar con las viviendas posteriores.

\section{Ilustración 8.14 Muro perimetral continuo característico de los lotes industriales}

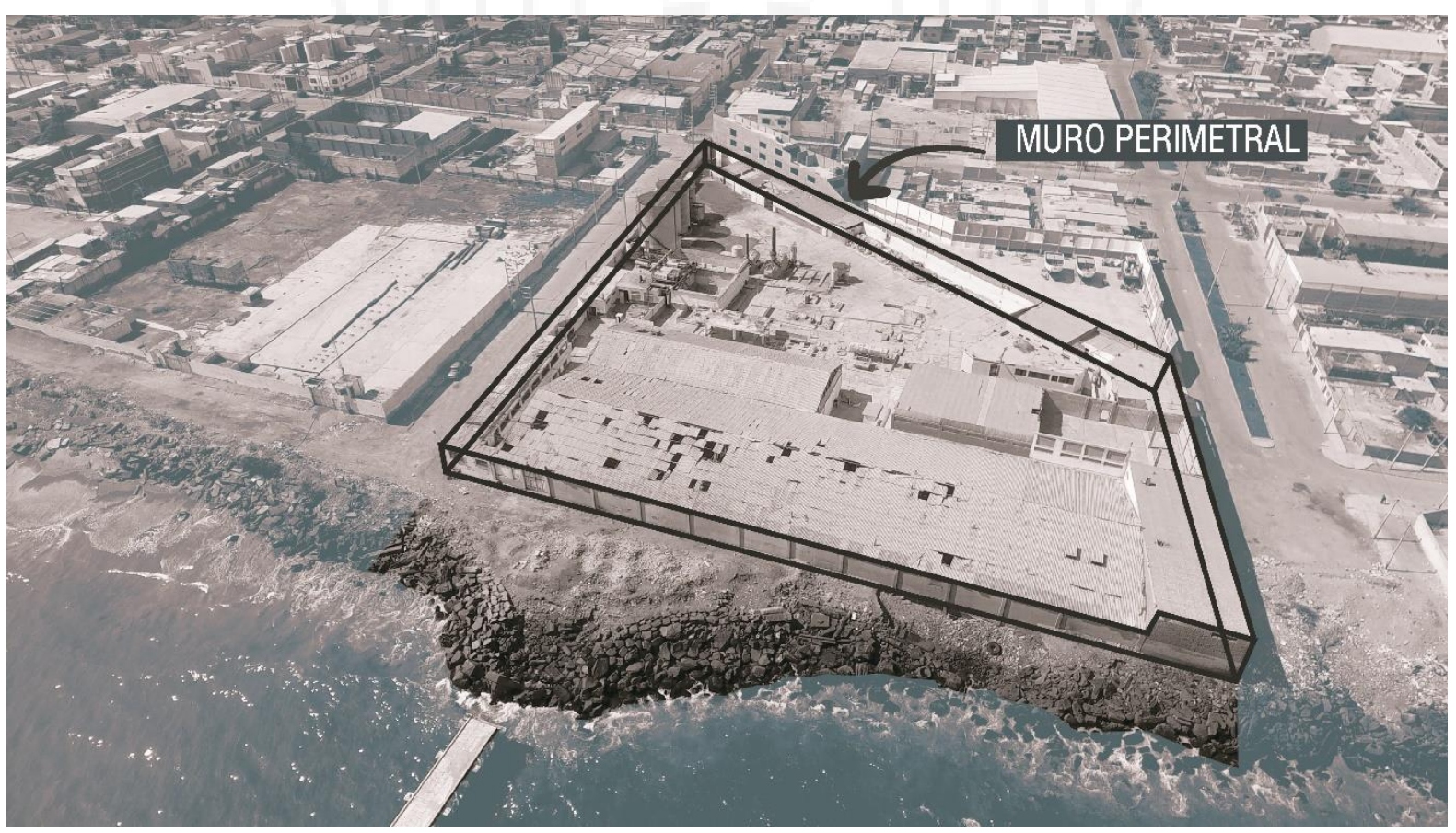

Fuente: Fotografía propia. 
Ilustración 8.15 Área ocupada por los galpones dentro de la fábrica

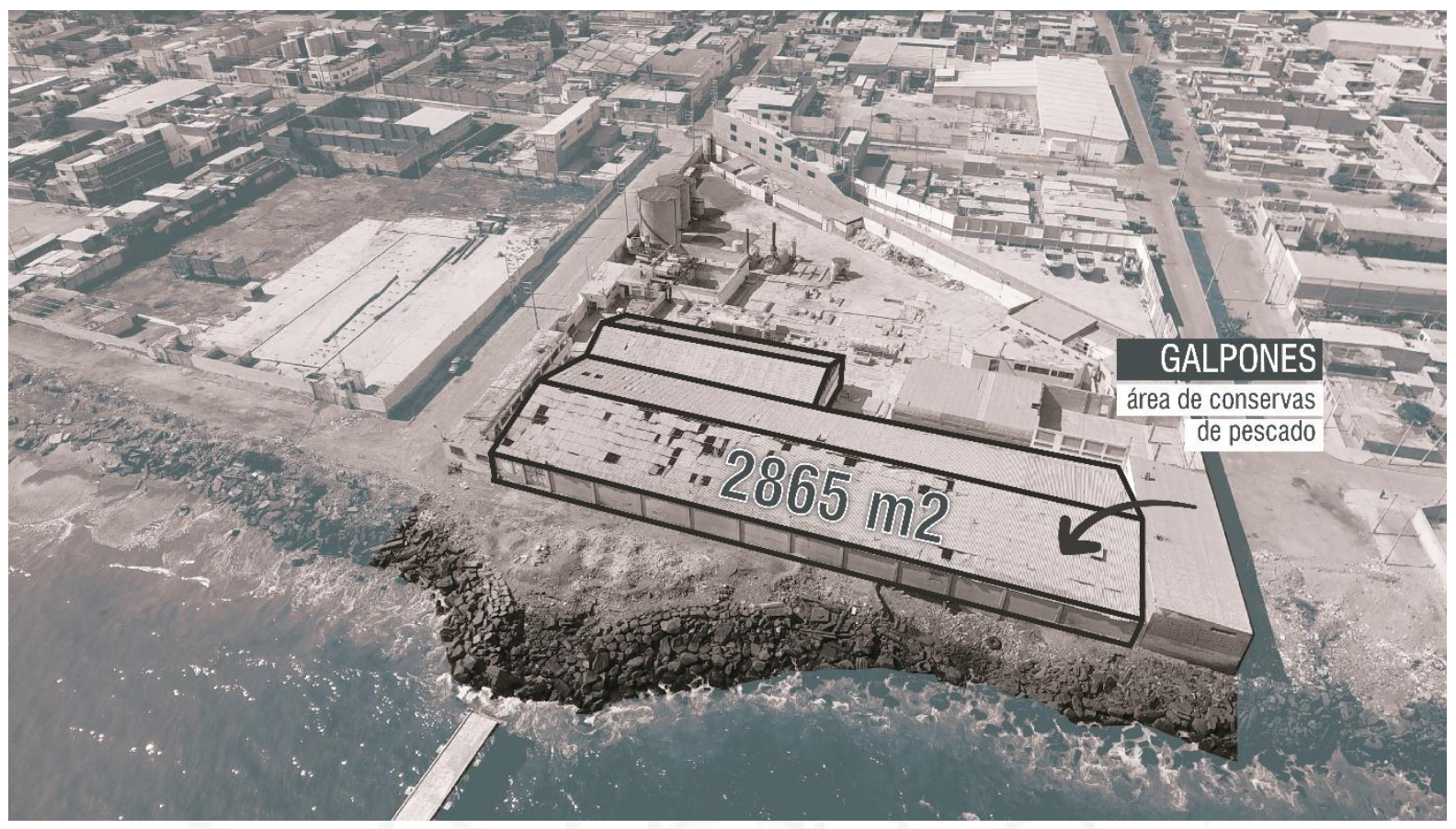

Fuente: Fotografía propia.

Ilustración 8.16 Área ocupada por las piezas industriales en el patio

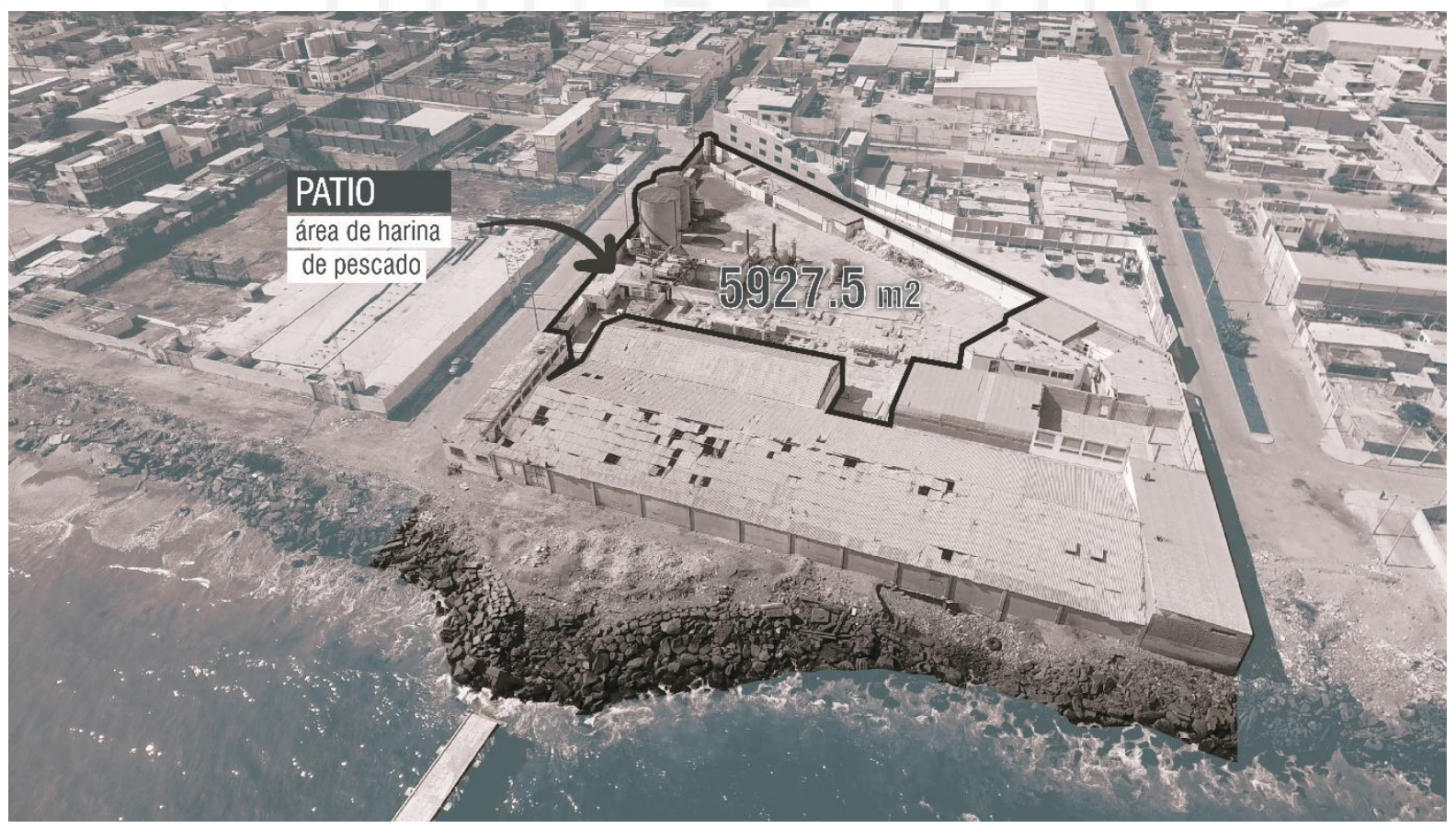

Fuente: Fotografía propia. 
La ubicación de los galpones y tanques responden a la actividad que se realizaba en esta fábrica. En el interior de la fábrica se puede observar claramente dos espacios diferenciados, hacia el lado derecho, los espacios cerrados representados en dos galpones y cercanos al borde del mar, y hacia el otro extremo, el patio que alberga diversos elementos industriales en su mayoría tanques cuyo color predominante es el verde industrial. A su vez, se observa el mar que se erige como la proyección de la fábrica hacia la bahía.

\section{Ilustración 8.17 Organización espacial de los elementos dentro de la fábrica CFG Investment}

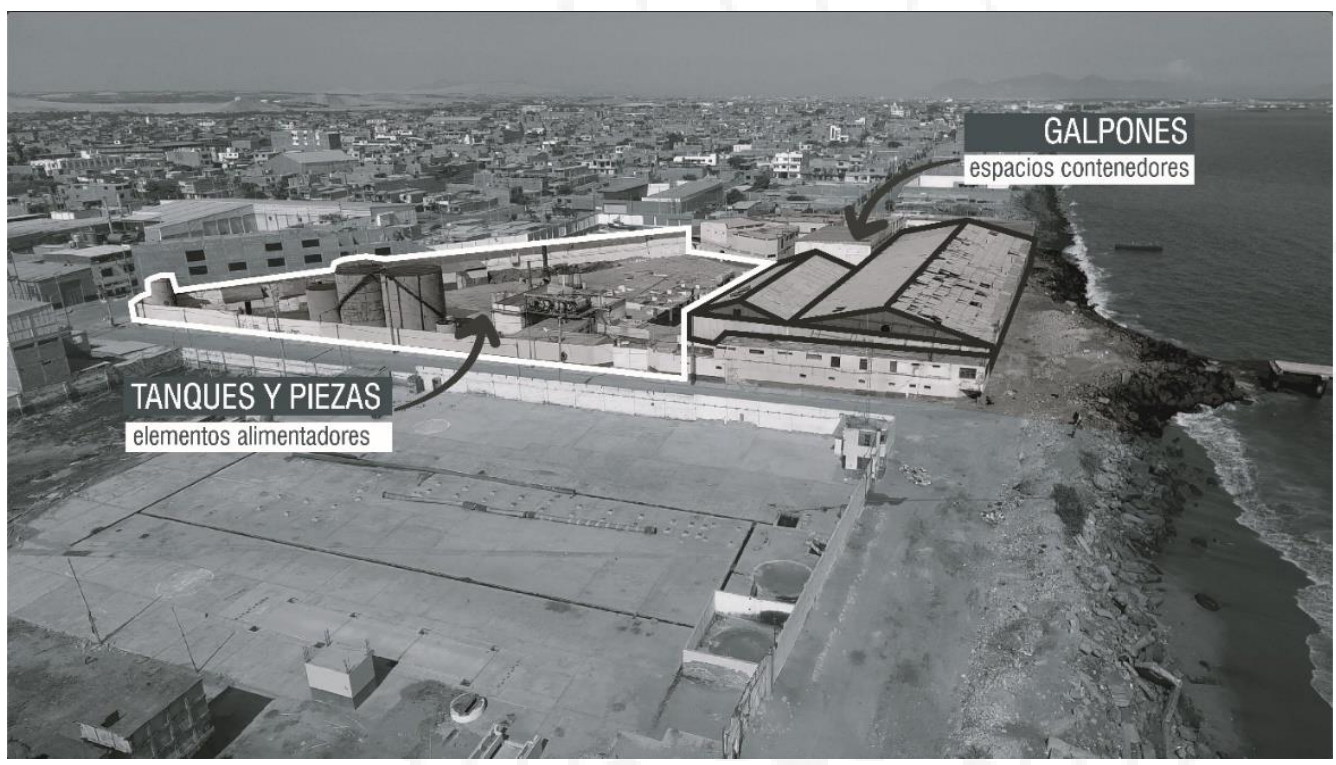

Fuente: Fotografía propia

\section{Ilustración 8.18 Conexión con la bahía a través del muelle}

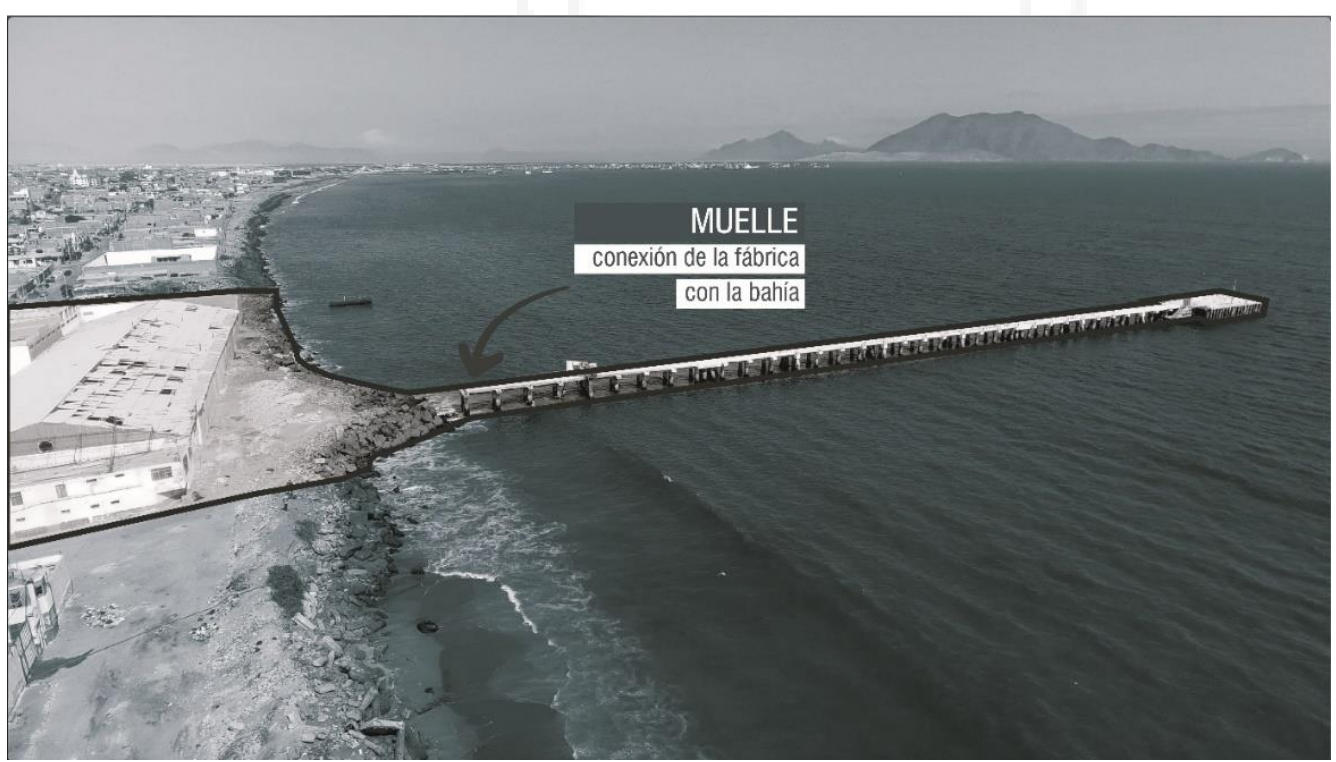

Fuente: Fotografía propia 
El amplio patio interior con piezas pequeñas y de mediano volumen permiten contar con un espacio moldeable en el que se pueda tener una variada disposición de piezas a fin de obtener mayor área útil en el espacio. Asimismo, los tanques de gran tamaño y volumen ubicados en el borde del terreno proporcionan valor industrial al terreno ya que se erigen como grandes hitos fabriles de la zona.

Ilustración 8.19 Tanques pequeños de color verde ubicados en el patio

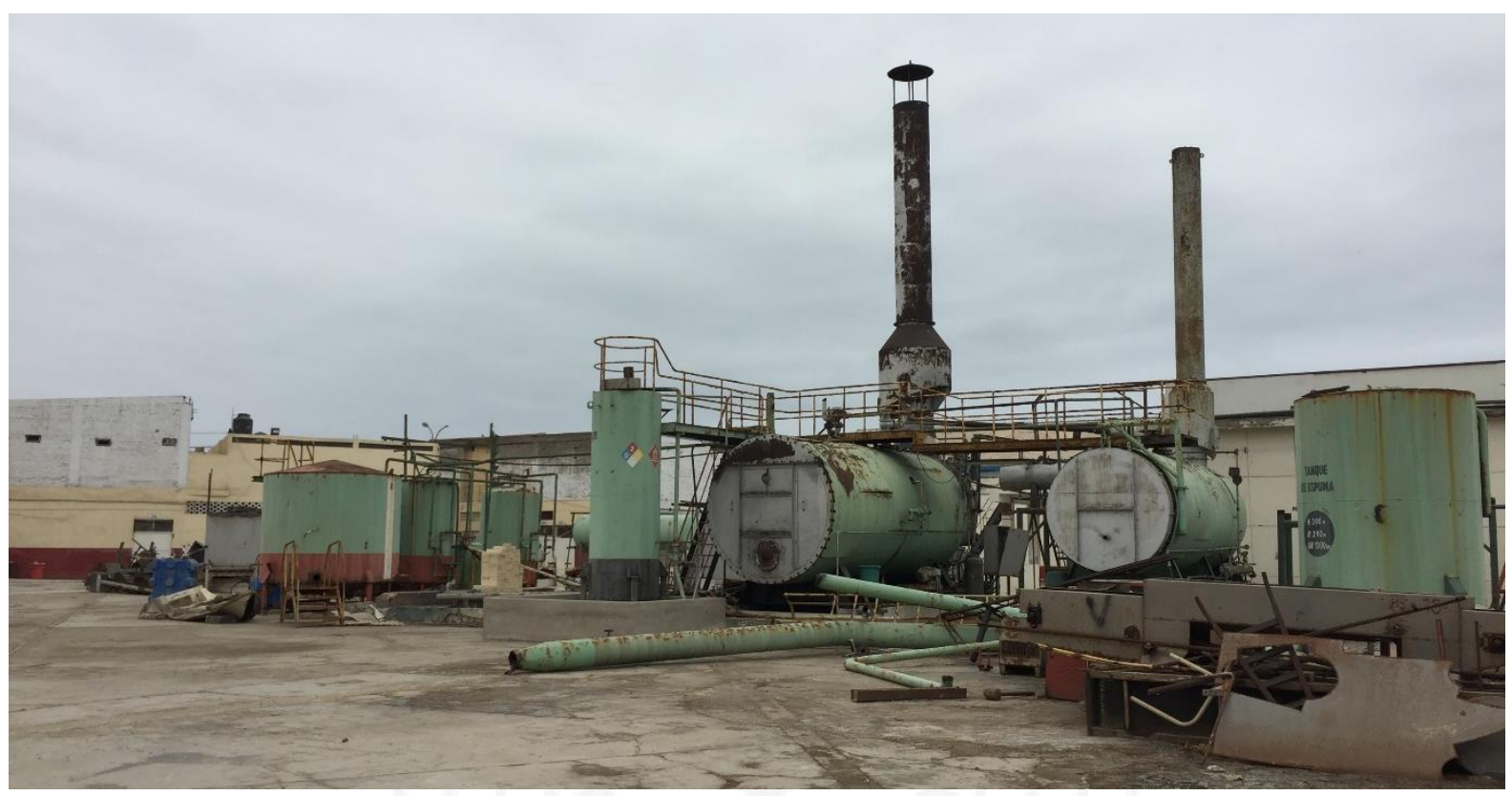

Fuente: Fotografía propia

Ilustración 8.20 Vista de las piezas fabriles en el interior de la fábrica

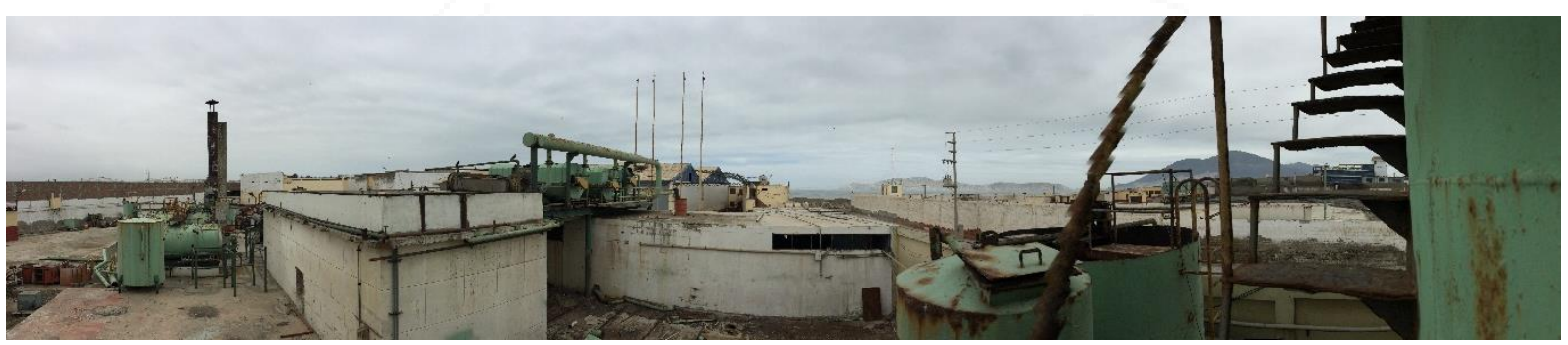

Fuente: Fotografía propia 
Ilustración 8.21 Relación entre las piezas encontradas en la fábrica

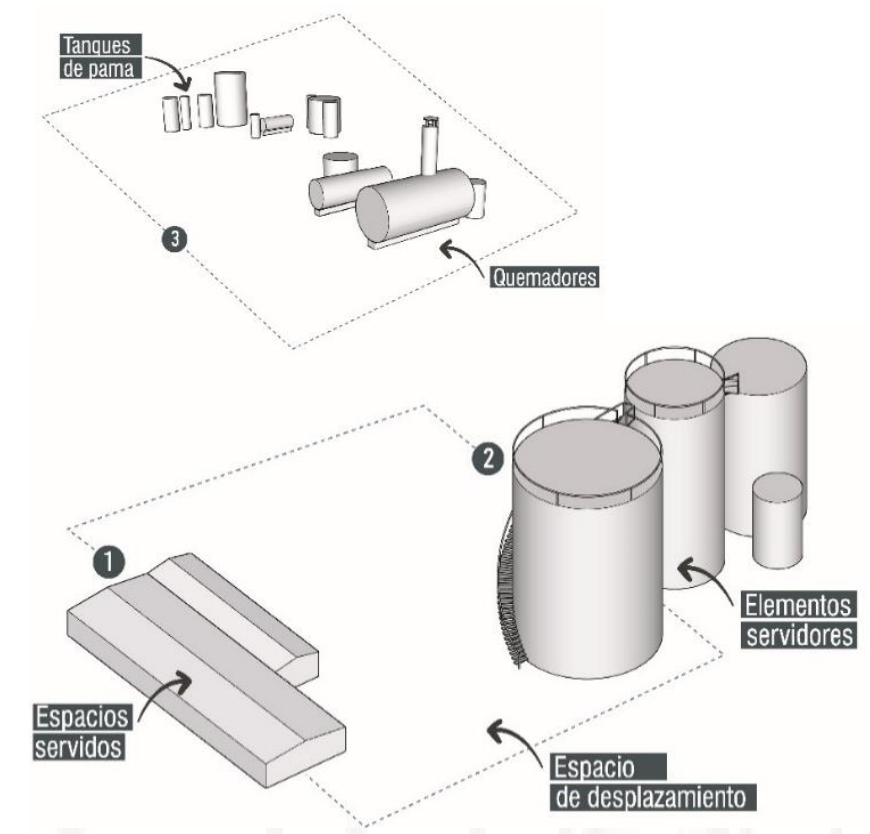

Fuente: Fotografía propia

Ilustración 8.22 Emplazamiento de los elementos fabriles en el terreno

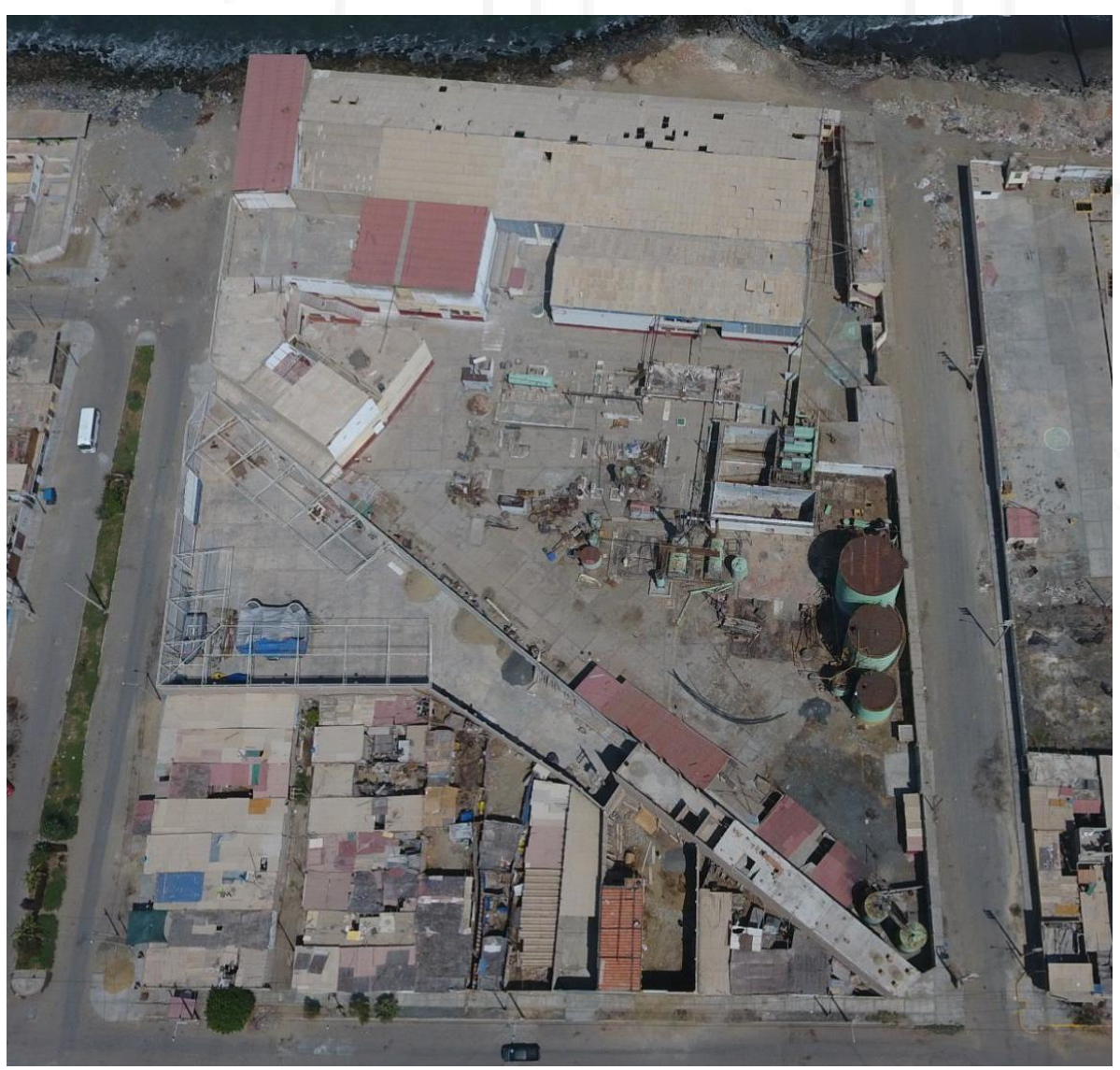

Fuente: Fotografía propia 


\subsection{Reciclaje como medio para revalorar y fortalecer la identidad chimbotana}

De acuerdo con Kenneth Powell, cuando reciclamos un edificio estamos recuperando un legado histórico, memoria e identidad, creando un fuerte nexo entre lo que fue y lo que será.

Se ha reciclado espacios y piezas de la fábrica en desuso para el proyecto Fábrica cultural por su valor histórico - social de la cultura e imaginario chimbotano, de ser una ciudad puerto exportadora de harina de pescado; por su valor arquitectónico espacial, por su gran flexibilidad y por la función que cumplían dentro de la actividad industrial de producción de conserva y harina de pescado.

En esa misma línea, se tomado el reciclaje como herramienta para no condenar al olvido lo que significó la presencia de fábrica en la zona, porque es necesario entender el pasado, dialogar con él y proyectar un presente que represente una oportunidad para las generaciones de hoy y de mañana.

El reciclaje en el proyecto está dado de dos formas. La primera, a través del reciclaje del espacio por su forma y función, representado en el galpón, el tanque y el muelle; la segunda forma es el reciclaje de piezas industriales emplazadas en los espacios públicos para reforzar la identidad y memoria colectiva del lugar.

\section{Ilustración 8.23 Piezas recicladas en la fábrica}

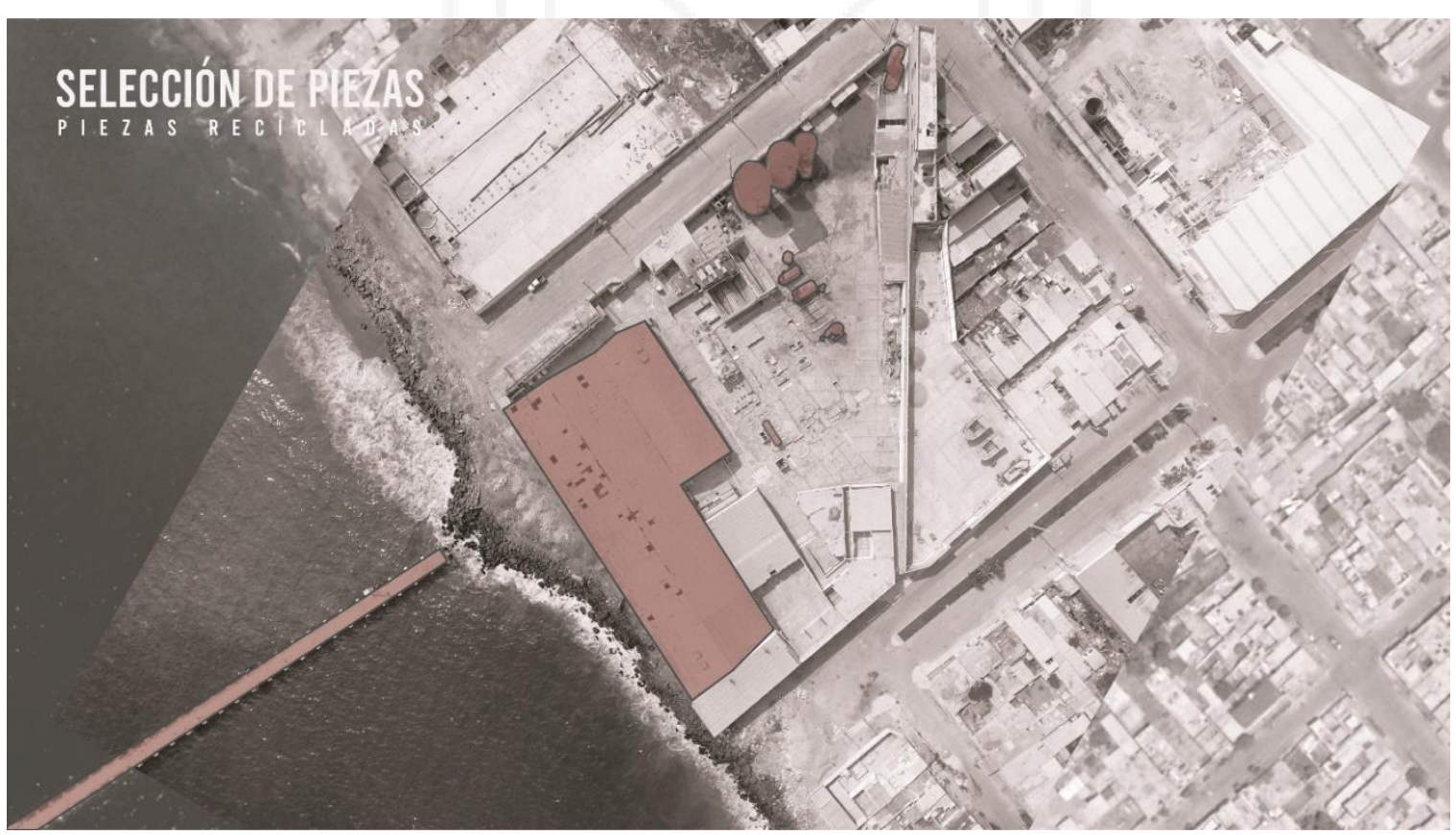

Fuente: Elaboración propia 
Ilustración 8.24 Espacios no reciclados de la fábrica

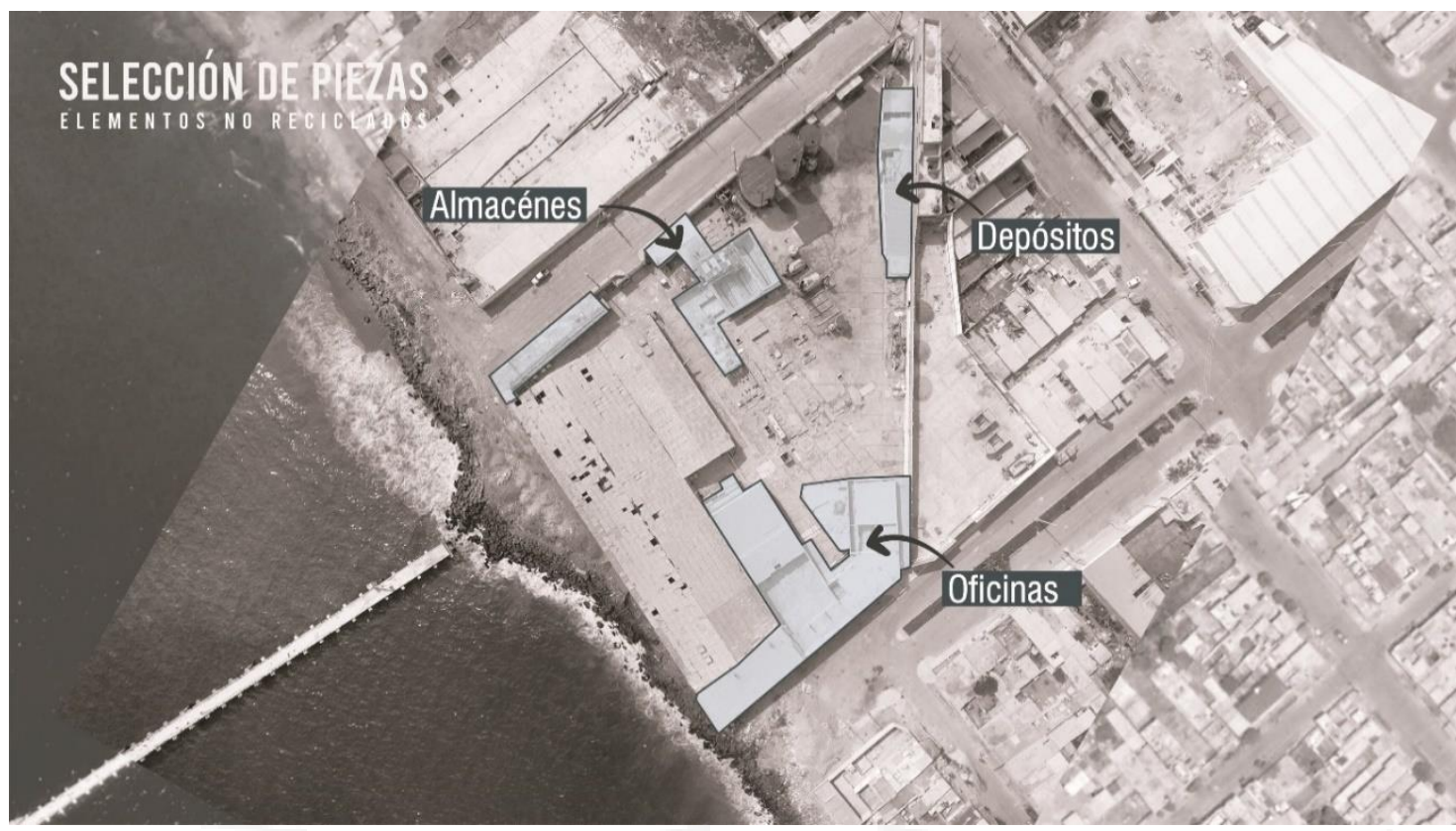

Fuente: Elaboración propia

Ilustración 8.25 Isometría de piezas recicladas

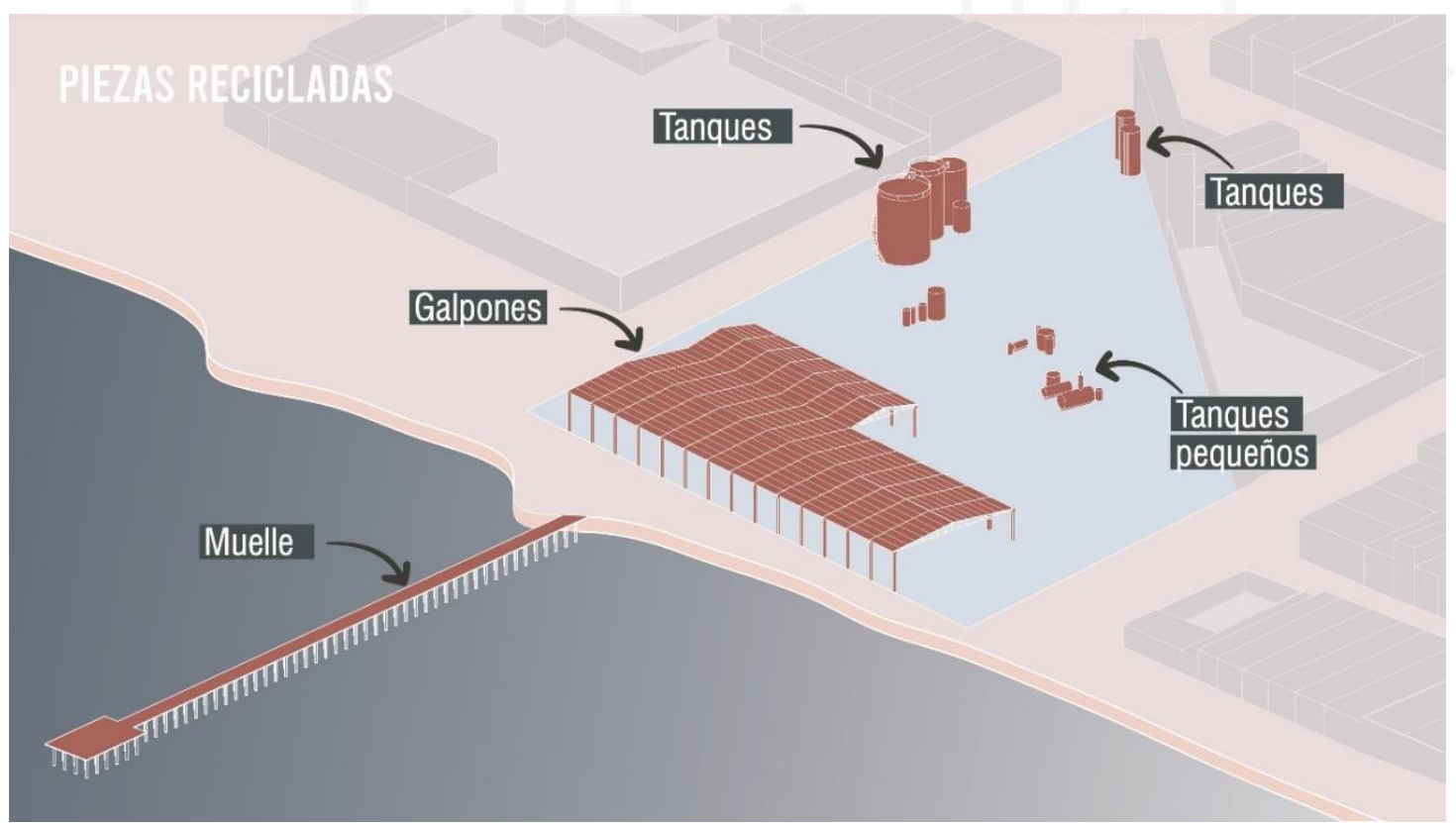

Fuente: Elaboración propia

\subsection{Toma de partido}

El proyecto se encuentra inserto en un espacio donde existen diversas variables que este debe afrontar. La toma de partido nace principalmente como respuesta a la variable físico espacial, 


\section{la fábrica cultural funcionará como un disipador del paso del tejido industrial a}

residencial, es decir, buscará ocupar el "vacío" generado por el desuso de las fábricas en la zona, siendo el nexo entre estos dos usos opuestos que al no integrarse adecuadamente dificultan el desarrollo urbano

Para lograr que el proyecto funcione como tal, este debe atraer a los usuarios a través de un programa que les genere interés, que según la investigación y necesidades de la población debe ser de carácter cultural. Además, mediante el reciclaje de estructuras industriales de la fábrica el proyecto repotenciará su valor histórico para fortalecer la identidad chimbotana que se encuentra estrechamente relacionada a la pesca.

Finalmente, al encontrarse al borde de la bahía, el proyecto contribuirá a lograr un borde activo, reduciendo la falta de interés hacia la bahía y volcando la mirada de la ciudad hacia el paisaje cultural y natural con el que cuenta.

Ilustración 8.26 Variables relevantes en de la toma de partido del proyecto

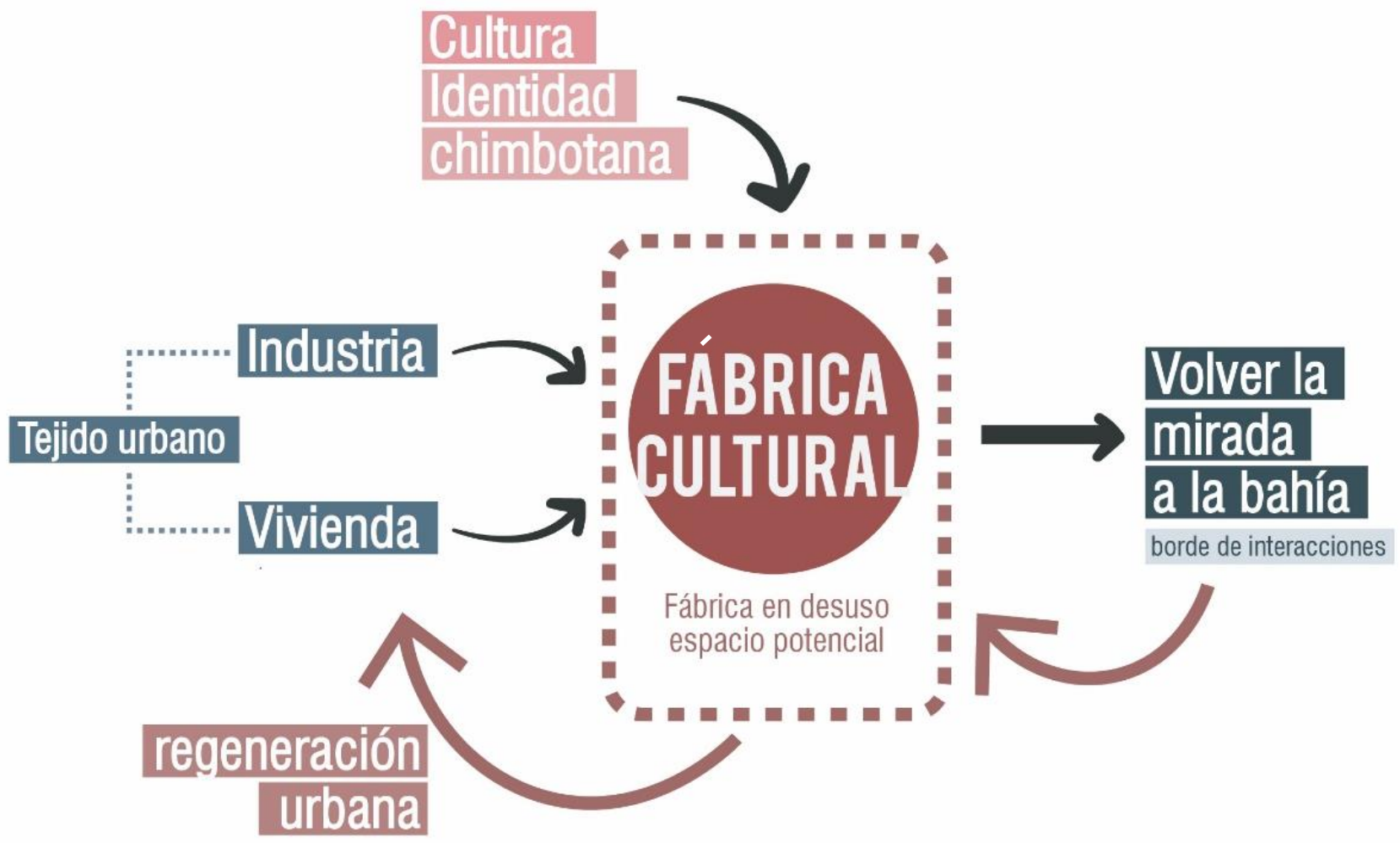

Fuente: Elaboración propia 


\subsection{Estrategias generales}

Para el diseño formal del proyecto se plantearon estrategias que respondan tanto al paisaje urbano como natural, así como también a las variables internas del terreno (fábrica en desuso).

1. Partiendo del reciclaje de las piezas industriales, la fábrica contaba con un gran galpón que invadía el borde costero, motivo por el cual se decidió liberar el área invadida de manera que se pueda establecer una conexión directa entre el proyecto y la bahía, manteniendo a su vez la huella del edificio liberado.

Ilustración 8.27 Estrategia de liberar el espacio invadido en el borde

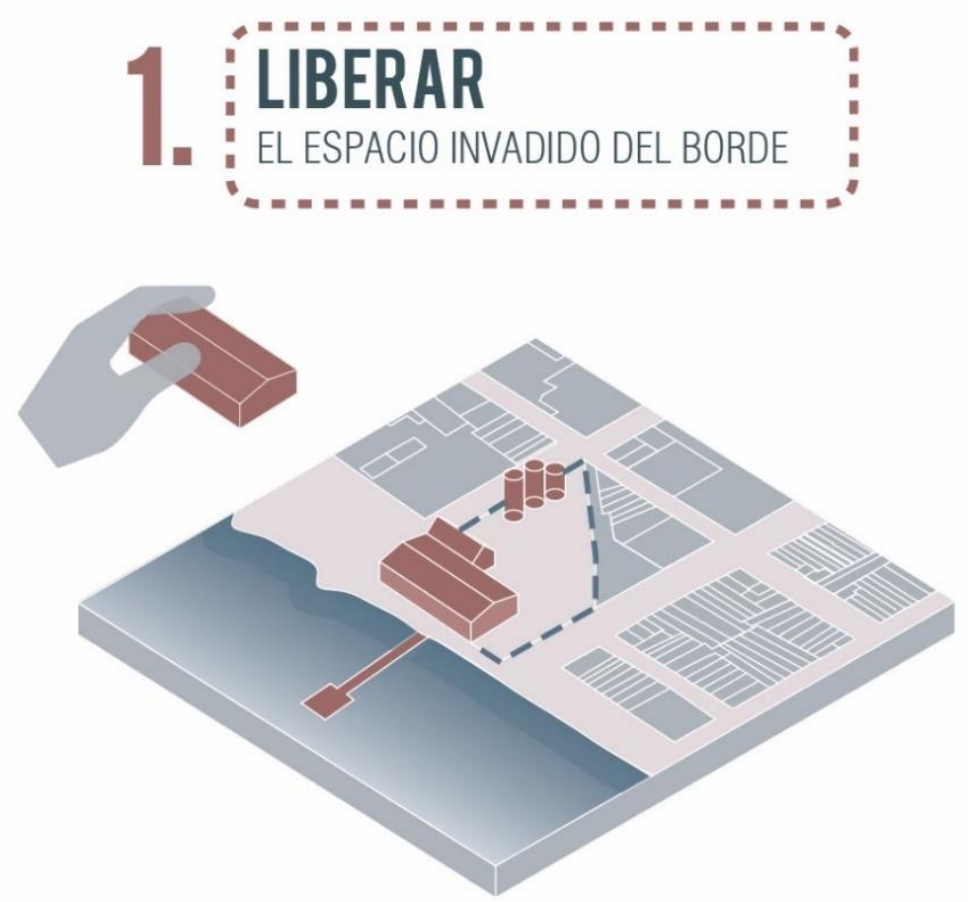

Fuente: Elaboración propia 
2. Con el objetivo de generar una continuidad a lo largo de toda del borde costero se optó por proyectar un malecón peatonal aprovechando el espacio liberado en la estrategia anterior. De esta manera se logrará transformar el borde duro actual por un borde blando de interacciones y atraer a los usuarios al proyecto.

\section{Ilustración 8.28 Estrategia de proyectar un malecón peatonal}
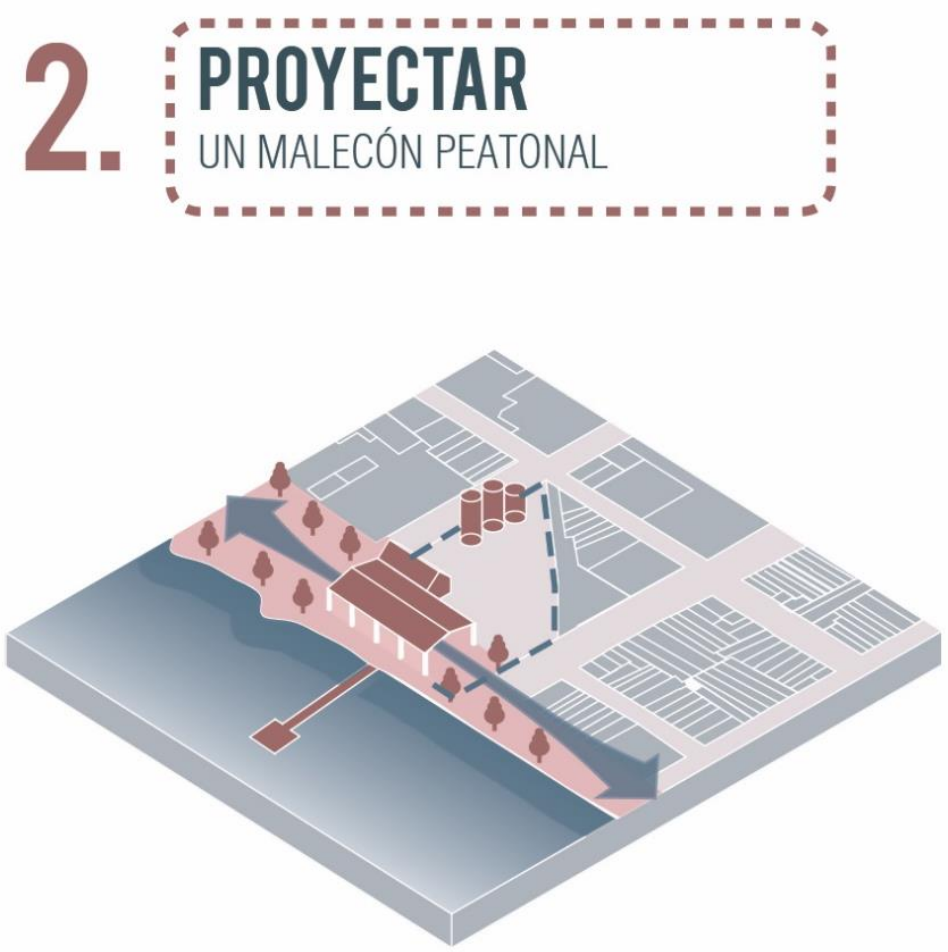

Fuente: Elaboración propia 
3. Con la finalidad de delimitar el terreno de una manera activa y amigable con el entorno se optó por fragmentar el proyecto en piezas y colocar estas rodeando el perímetro del terreno. De esta manera el proyecto también busca interactuar con los vecinos y reactivar las calles aledañas.

Ilustración 8.29 Estrategia de rodear el perímetro del terreno con programa
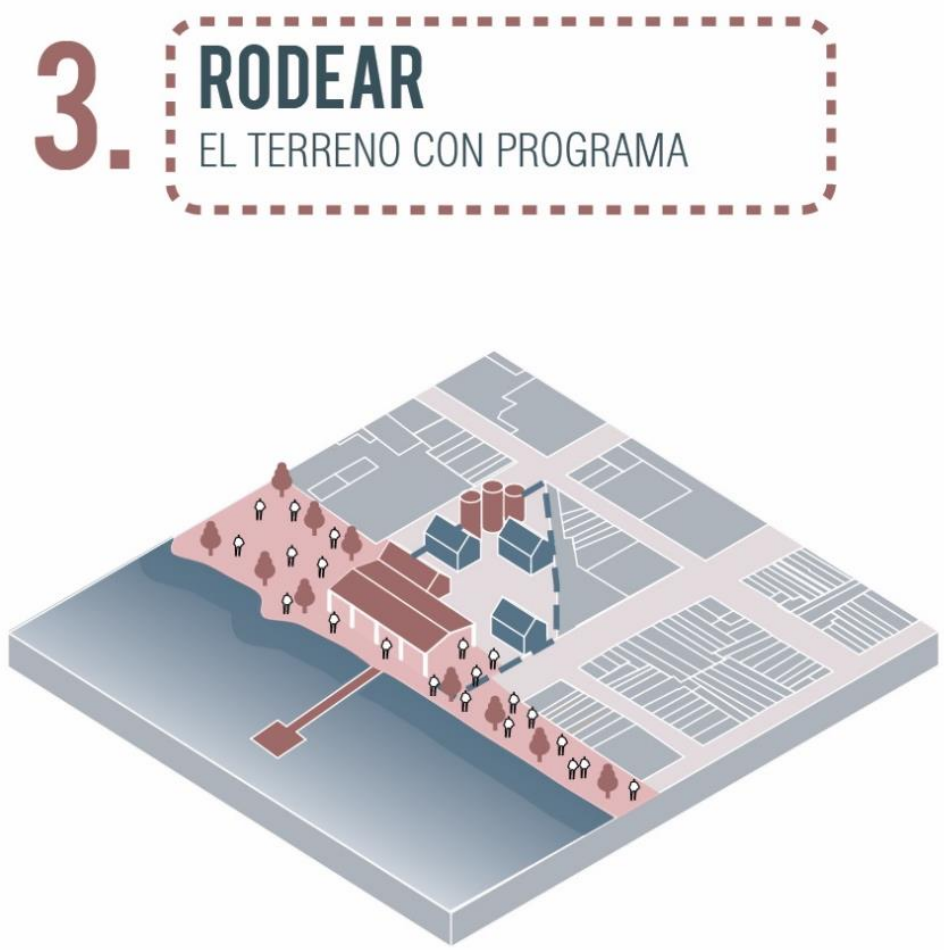

Fuente: Elaboración propia 
4. Con la finalidad de responder ante las condiciones climáticas de Chimbote y aprovechando que el proyecto se fragmentó en diferentes piezas, se configuraron plazas internas entre los bloques, de manera que el proyecto pueda recibir una mejor ventilación y se logren disipar los vientos provenientes del sur- oeste. Además, estas plazas también permitirán que el proyecto cuente con una adecuada iluminación en cada una de sus fachadas.

Ilustración 8.30 Estrategia de configurar plazas entre bloques

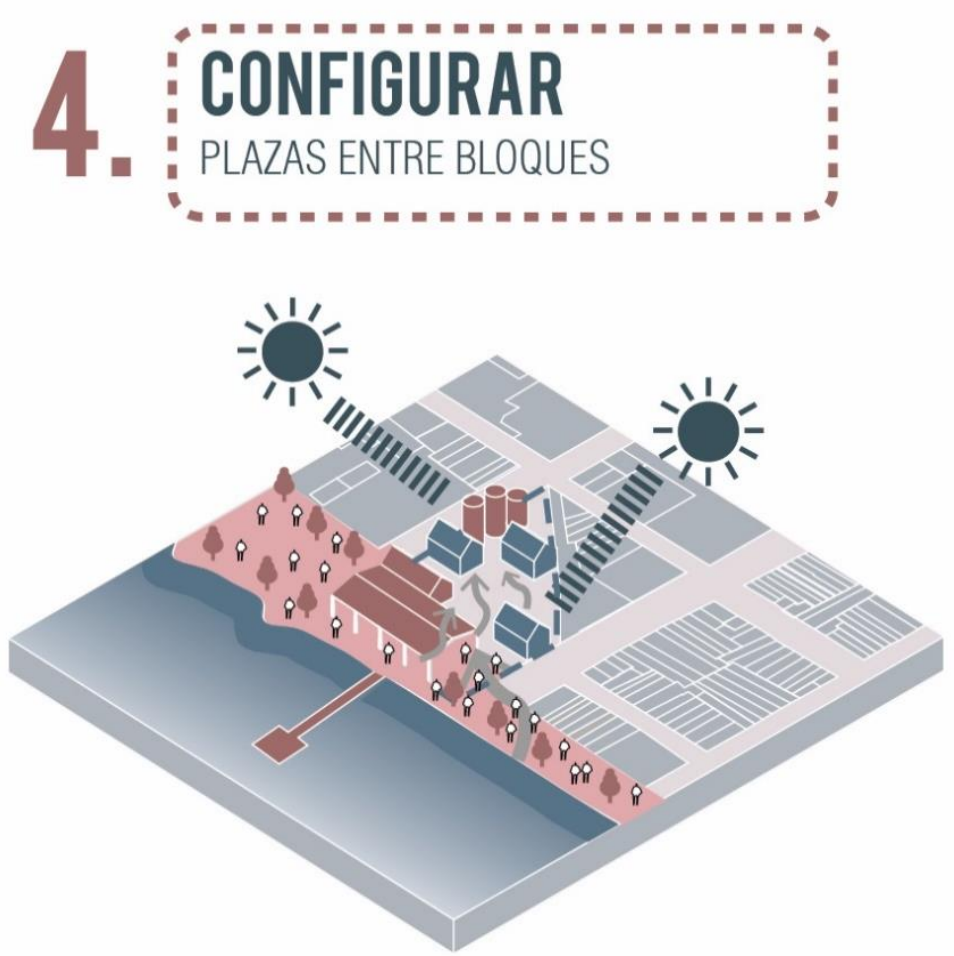

Fuente: Elaboración propia 
5. Uno de los objetivos principales es que el proyecto funcione como un recorrido que no solo permita disfrutar de los espacios interiores, sino también apreciar el paisaje que lo rodea. Por este motivo se colocaron pasarelas aéreas que permitan conectar cada uno de los bloques (tanques y galpones).

Ilustración 8.31 Estrategia de conectar los bloques a través de puentes
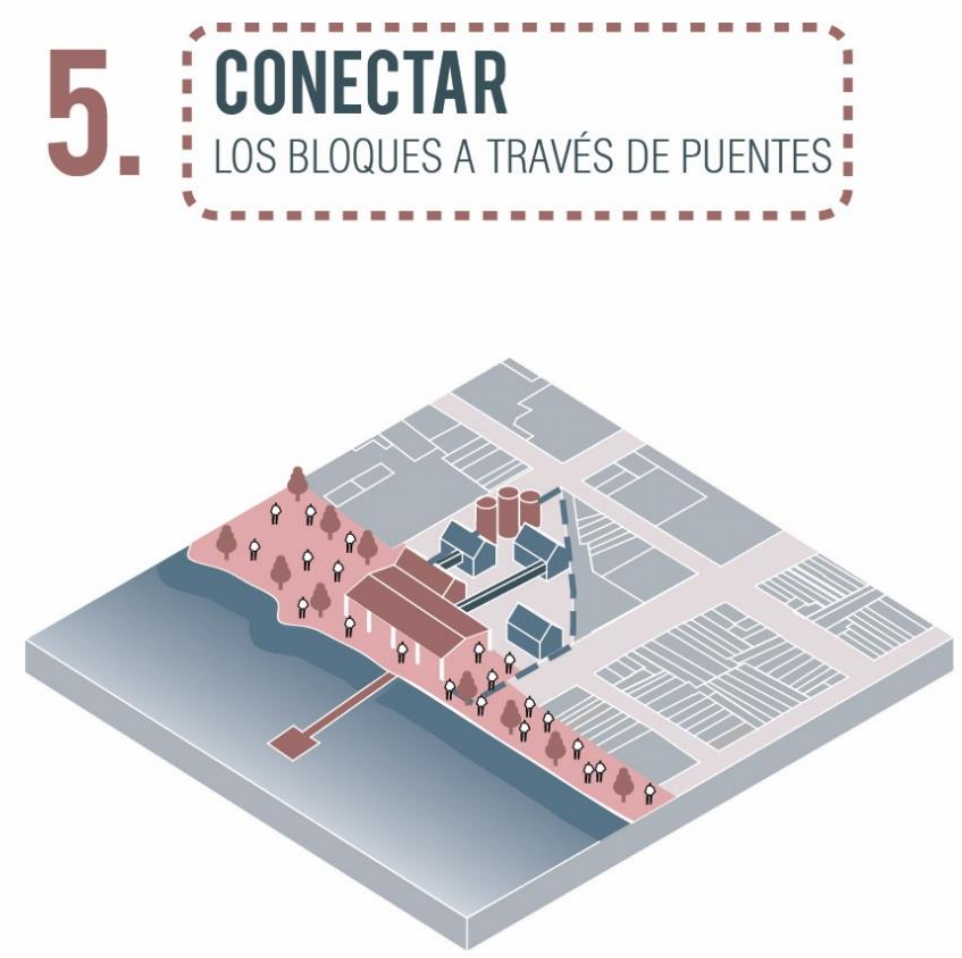

Fuente: Elaboración propia 


\subsection{Estrategias específicas del proyecto}

1. Identificación de las piezas existentes

Dentro de las prexistencias del terreno, se puede reconocer dos piezas predominantes: el galpón y el tanque. De acuerdo con la función que desarrollaba cada uno, se ha determinado que el galpón es un espacio que actúa como espacio servido y cobertor, donde se puede desarrollar diversas actividades por tener una gran luz que determina su flexibilidad espacial. Por otro lado, el tanque cumple el rol de espacio servidor y contenedor, en él se almacenan elementos con los que se abastece a la actividad que se realiza dentro de los galpones.

\section{Ilustración 8.32 Piezas fabriles características de la fábrica: galpón y tanque}

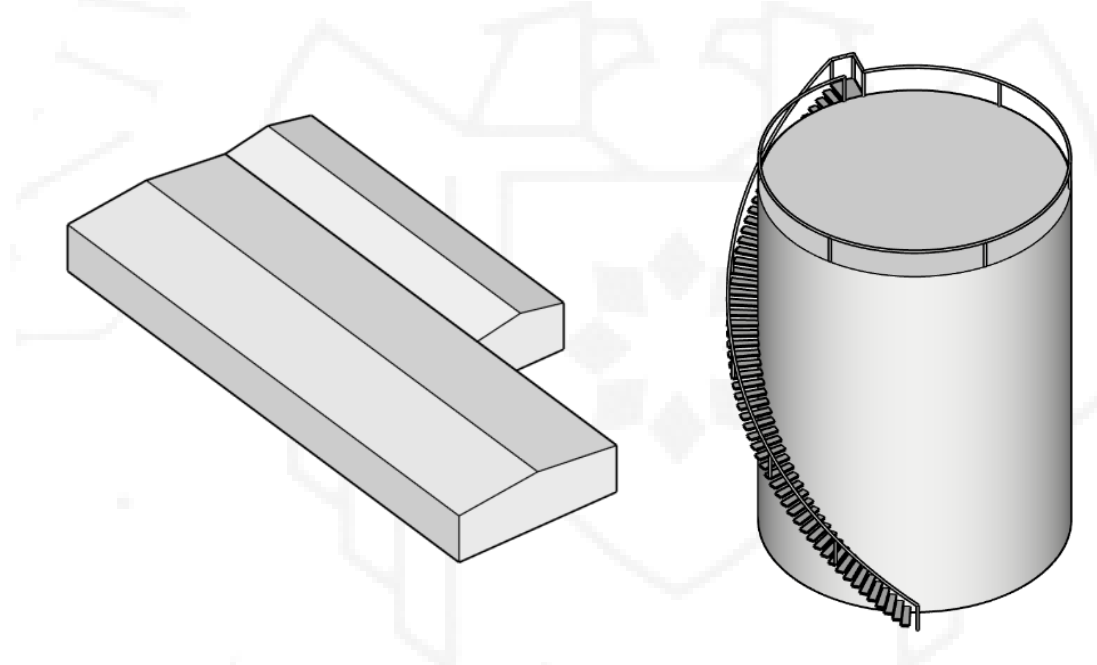

Fuente: Elaboración propia

Si bien el terreno cuenta con una vasta diversidad de elementos industriales, también cuenta con construcciones de concreto, que contienen programa como oficinas y que se encuentran bloqueando los accesos al proyecto, reconociéndose además como piezas excedentes que fueron colocadas posteriormente y que no guardan relación con las piezas industriales. Por este motivo no se optó por reciclarlas. Las piezas recicladas fueron dos galpones que actúan como la fachada de ingreso a la fábrica desde el malecón, tres tanques de $10 \mathrm{~m}$ de diámetro ubicados en el perímetro lateral izquierdo que almacenan aceite de pescado y dos tanques de petróleo de $5 \mathrm{~m}$ de diámetro ubicados en el lindero 
posterior, estos elementos se han mantenido en su lugar debido a su tamaño y por su ubicación estratégica para conformar los límites del proyecto. Adicionalmente se han reciclado otros elementos industriales ubicados en el patio que son de menor tamaño por lo que se ha creído conveniente reubicarlos dentro del proyecto y fomentar identidad a través de ellos, así como también el muelle, que funcionará como elemento conector con el paisaje.

2. Entender la topografía natural del proyecto

$\mathrm{Al}$ reconocer el terreno y evaluar su topografía, existe una pendiente de 4.50 metros, que al interior de la fábrica es percibida sutilmente, pero que puede ser aprovechada como capas para el proyecto. Por ello se ha resuelto esta diferencia a través de plataformas que van subiendo 1.5 metros, consiguiendo tener cuatro niveles distintos, que van acompañados de preexistencias recicladas.

\section{Ilustración 8.33 Pendiente natural del proyecto: 3\%}

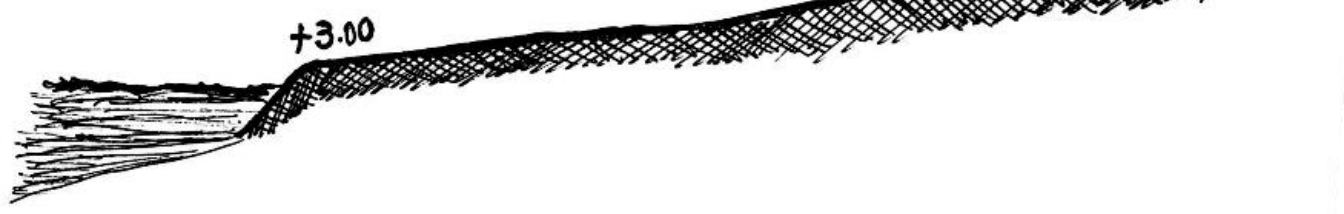

Fuente: Elaboración propia 
Ilustración 8.34 Reinterpretación de la pendiente natural en plataformas

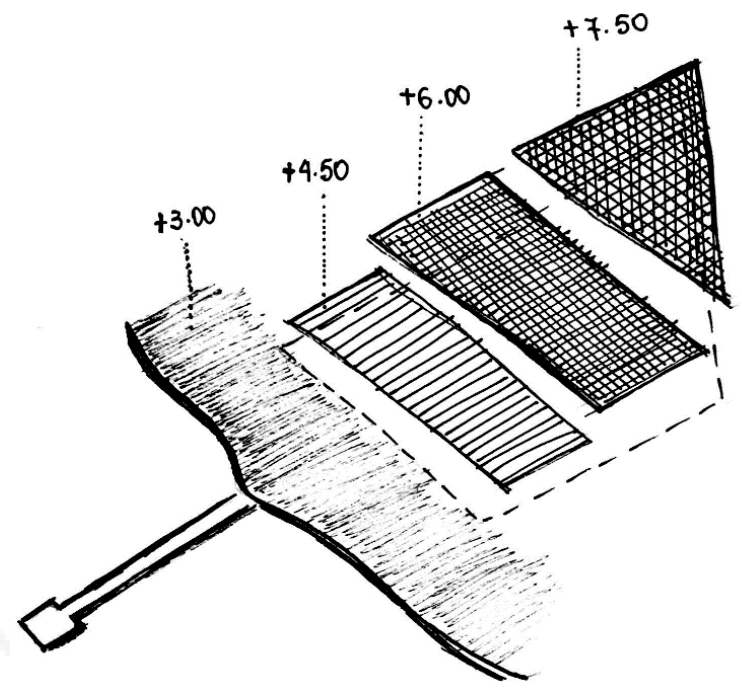

Fuente: Elaboración propia

3. Ubicación y orientación de las piezas

A partir de la identificación de las preexistencias, se ha hecho mayor énfasis en los galpones debido a su ubicación cercana al borde, se ha tomado en cuenta su orientación para emplazar del proyecto, a partir de ellos se trazaron ejes paralelos con la misma luz de 15 metros que existe en los galpones, consiguiendo una cuadrícula que permite tener una mayor organización en el terreno.

Ilustración 8.35 Trazado de ejes en el terreno para determinar la ubicación y orientación de las piezas

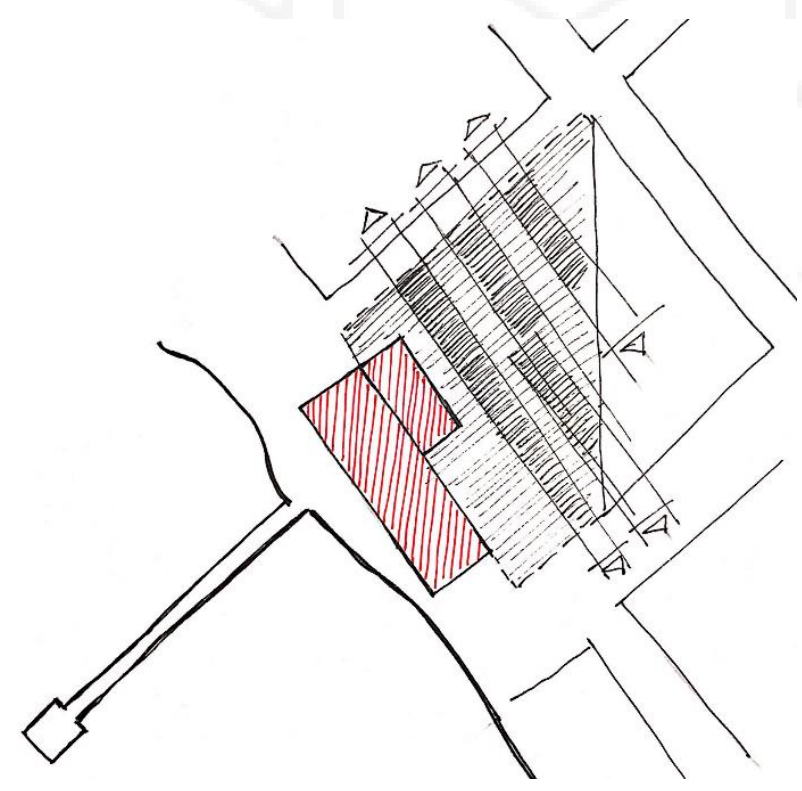

Fuente: Elaboración propia 
Sobre la base de los elementos predominantes en el terreno, espacio servido y servidor se ha sobrepuesto la cuadrícula desarrollada, para determinar la ubicación de los nuevos edificios que conformaran el proyecto, teniendo en cuenta que los tanques acompañaran a los galpones, puesto que ambos conforman el sistema de la fábrica cultural.

\section{Ilustración 8.36 Organización espacial del proyecto}

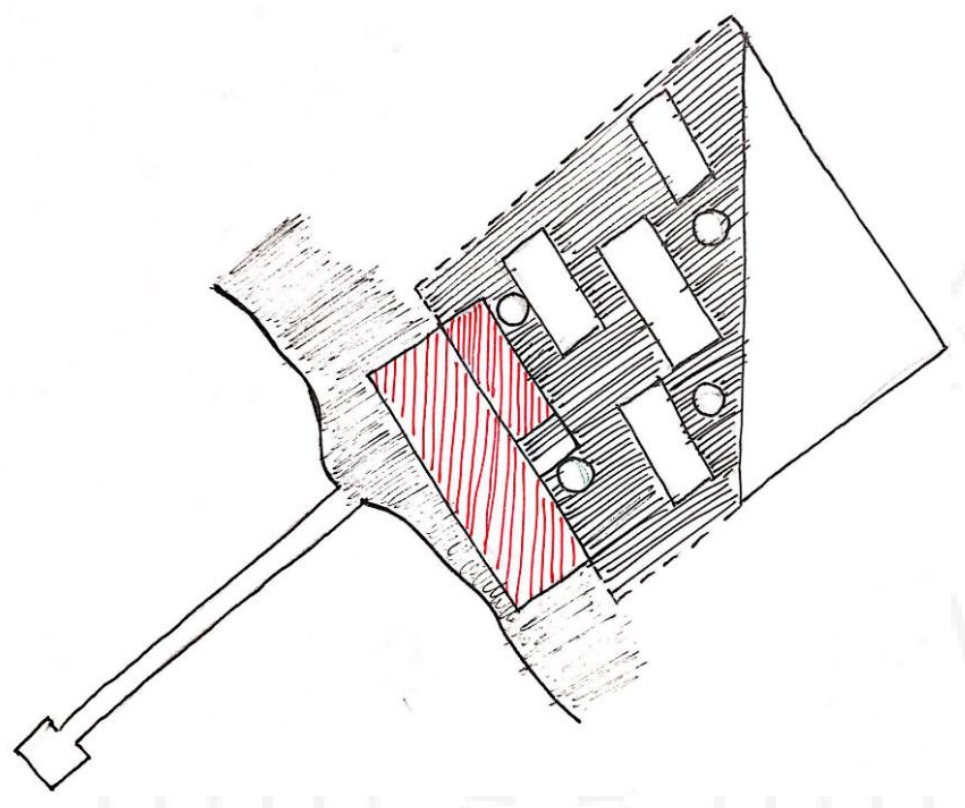

Fuente: Elaboración propia

4. Relación con el entorno

Si bien el terreno cuenta con cuatro frentes, el posterior es un pasaje que ha sido absorbido por la fábrica y que está delimitado por una medianera perteneciente al vecino, este es un muro ciego de 12 metros de altura. En vista que el muro medianero es percibido como de una escala mayor a la fábrica, se ha aprovechado esta verticalidad para generar un límite ligero, formado por piezas en el que se pueda insertar vegetación al terreno y disolver la impresión de que la fábrica está siendo invadida por el vecino. 
Ilustración 8.37 Respuesta a la medianera del vecino colindante

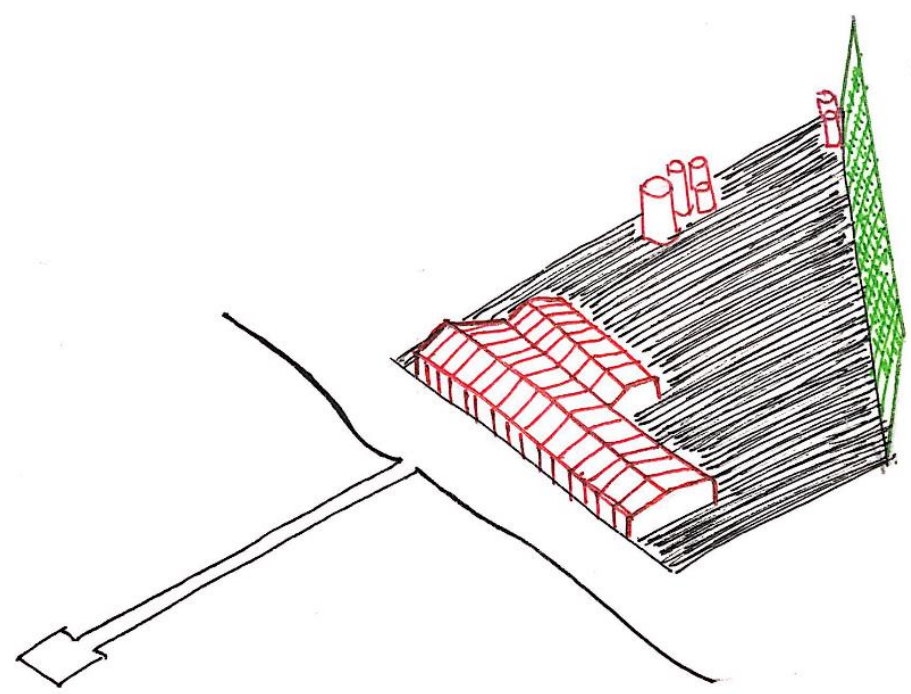

Fuente: Elaboración propia

Ilustración 8.38 Vista aérea del muro ciego del terreno vecino

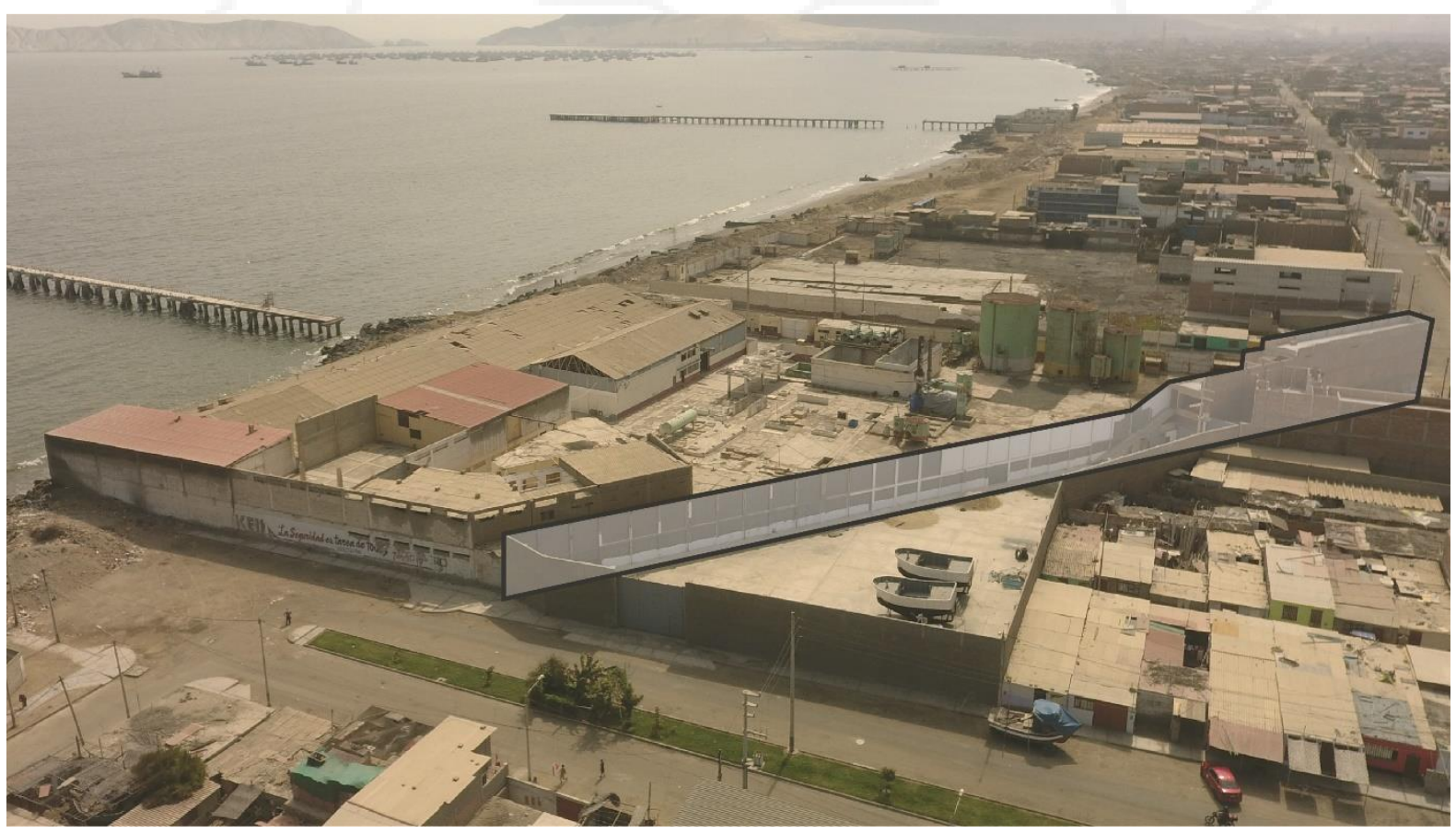

Fuente: Fotografía propia 


\subsection{Fábrica Cultural}

El proyecto ha sido denominado Fábrica Cultural, debido a que para las proyectistas fábrica es un espacio industrial que alberga piezas en su interior en donde se transforma materia prima en un producto final. Por otro lado, cultura son todas las manifestaciones que reflejan la identidad de un lugar y generan un vínculo entre las personas y el territorio.

En ese sentido, han unido ambas palabras debido a que el proyecto se encuentra sobre un lugar con pasado histórico que refleja parte del imaginario chimbotano al que se le ha insertado un nuevo uso, carácter cultural para crear así el proyecto Fábrica cultural como el espacio de carácter industrial en el que se desarrollan actividades culturales relacionadas al territorio en el

\section{Ilustración 8.39 Gráfico de definición de fábrica cultural}
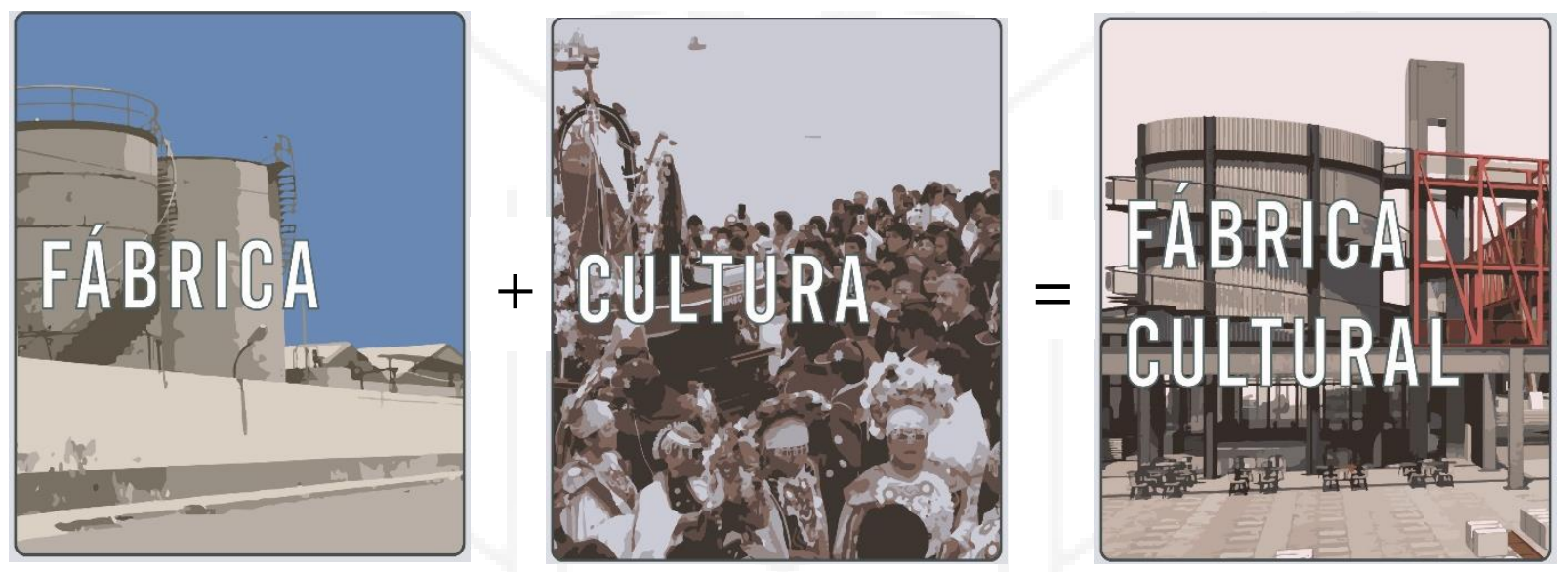

Fuente: Elaboración propia

\subsection{Sistema Fábrica Cultural}

La fábrica cultural funciona como un sistema, ya que es la sincronización y adaptación de las piezas que funciona como un circuito. Este sistema está conformado por los espacios servidos, los cuales contienen actividad (galpones), que están acompañados de los espacios servidores y alimentadores (tanques). Ambas piezas se encuentran conectadas entre sí por circulaciones horizontales (puentes aéreos), además de las circulaciones verticales (ascensores y escaleras independientes de cada tanque). 
Ilustración 8.40 Galpón, espacio servido del sistema

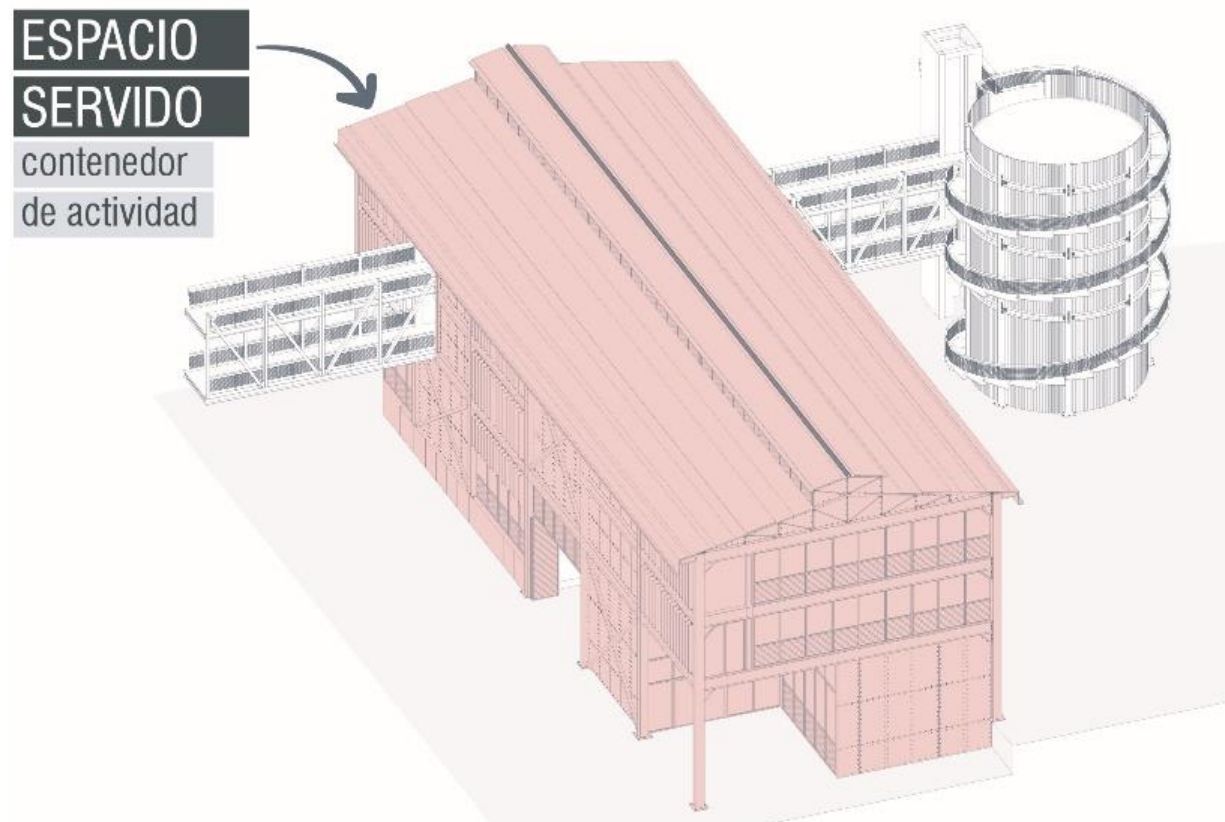

Fuente: Elaboración propia

Ilustración 8.41Tanque, espacio servidor del sistema

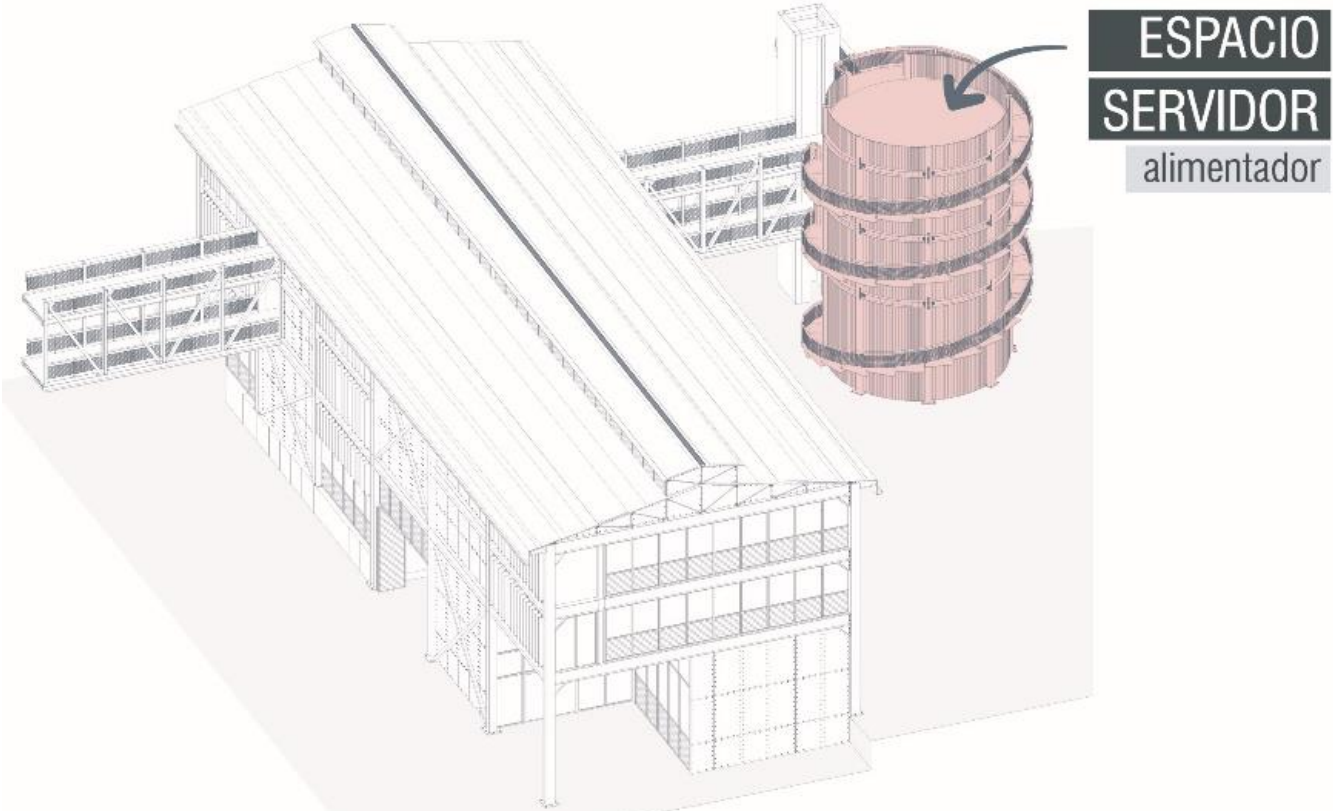

Fuente: Elaboración propia 
Ilustración 8.42 Puente, espacio conector horizontal del sistema

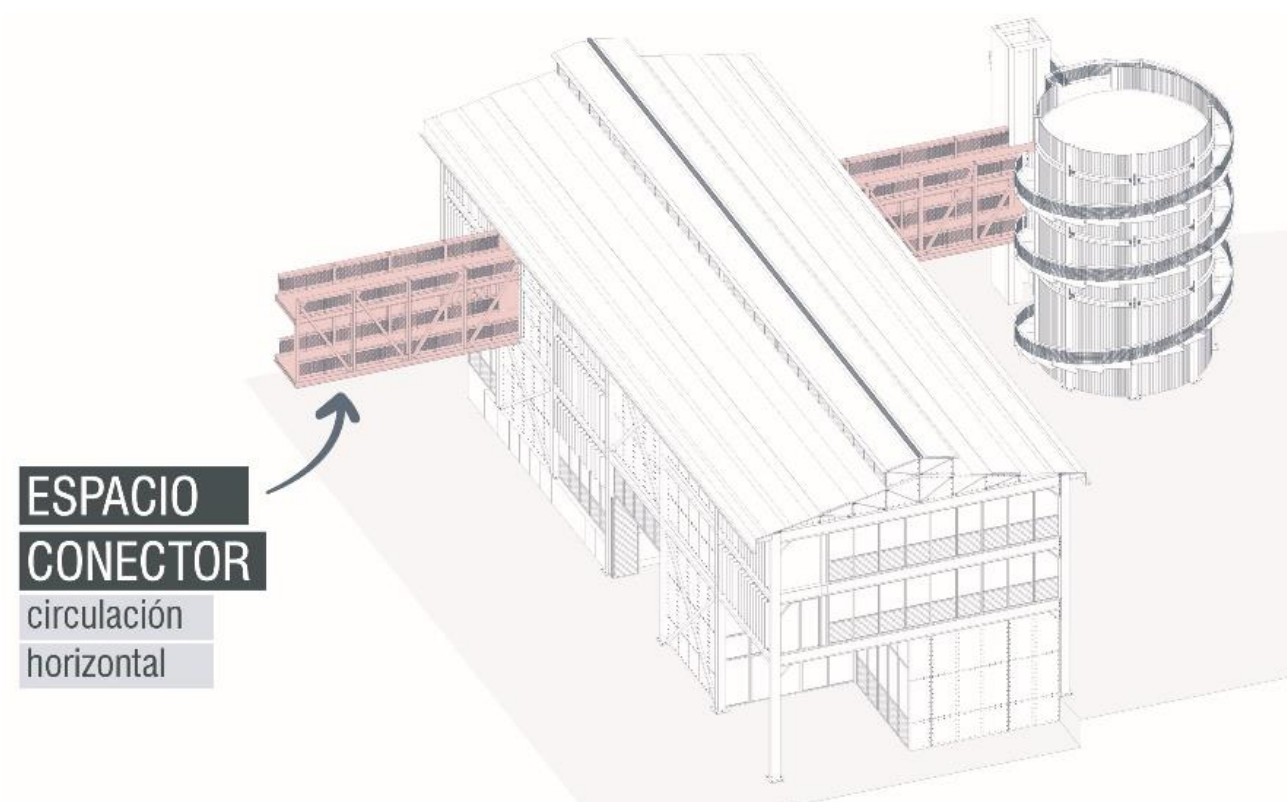

Fuente: Elaboración propia

Ilustración 8.43 Ascensor y escaleras, elementos conectores verticales del sistema

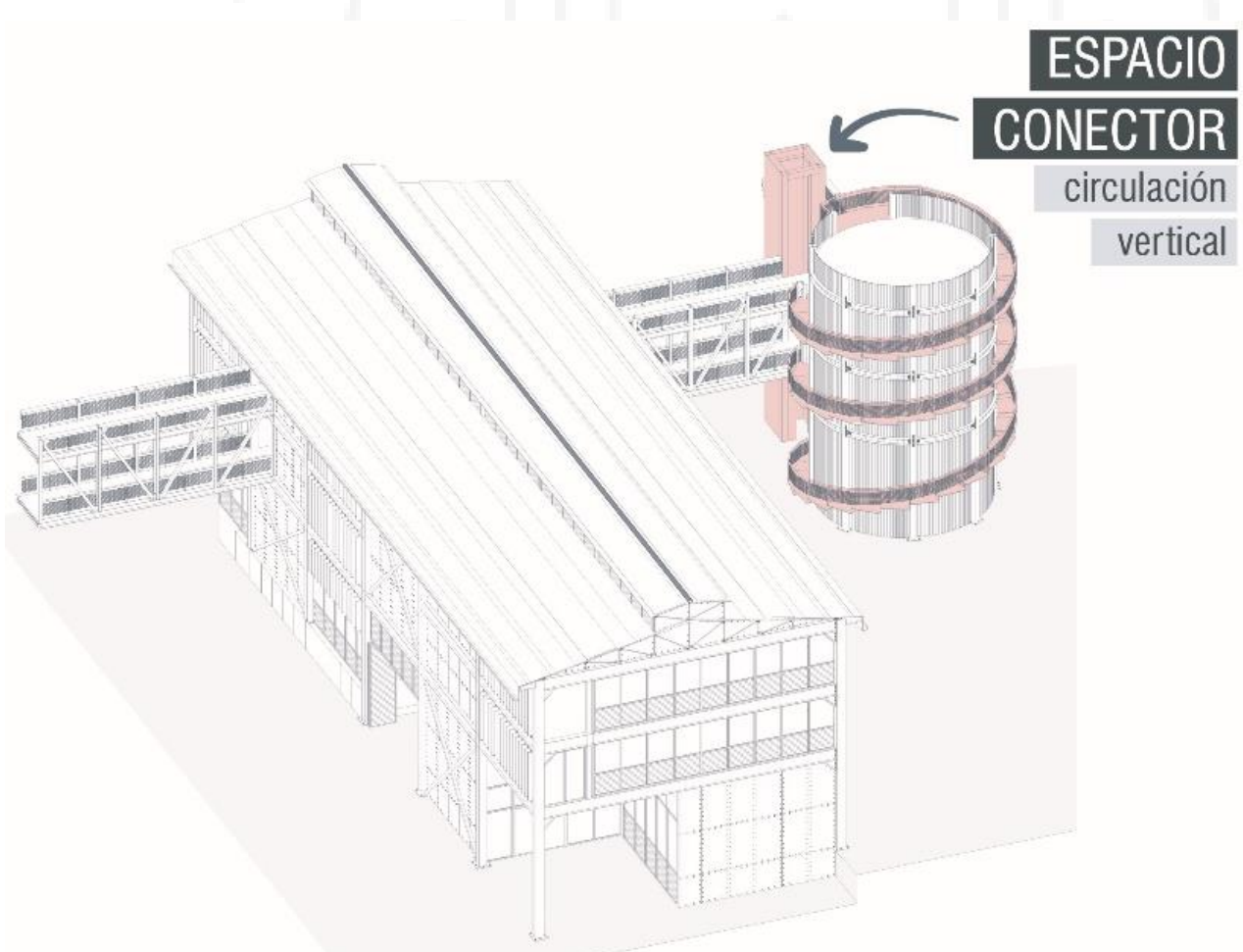

Fuente: Elaboración propia 
Como se puede apreciar en el siguiente gráfico, para la configuraricón del sistema primero se emplazaron los galpones contenedores de actividad (espacios servidos) según la ubicación previamente mencionada en las estrategias específicas. A continuación, estos espacios servidores se acompañaron por sus respectivos tanques (espacios servidores). Posteriormente, se conectaron los espacios servidos y servidores a través de puentes aéreos (espacios conectores horizontales). Finalmente, el circuito terminaría con elementos conectores verticales, reperesentados en los ascensores y las escaleras que envuelve cada tanque, de modo que todo el proyecto estaría conectado de manera horizontal y vertical eprmitiendo el acceso de cualquier persona a todos los espacios.

\section{Ilustración 8.44 Secuencia de organización de piezas en el sistema Fábrica Cultural}

1.

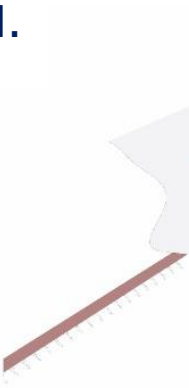

3.
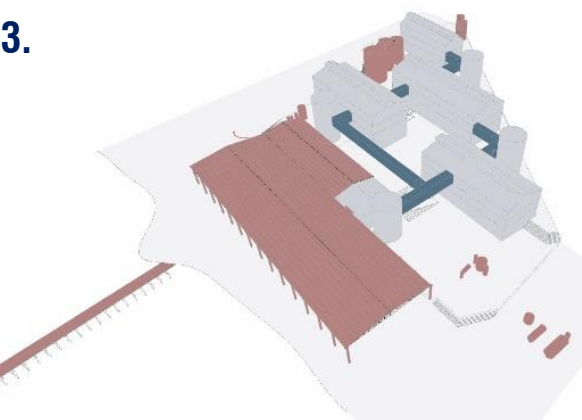

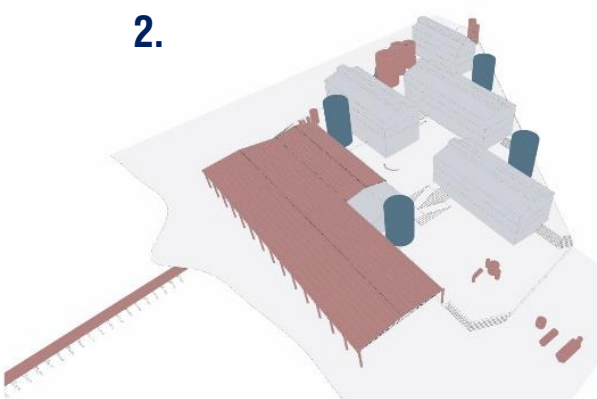

4.

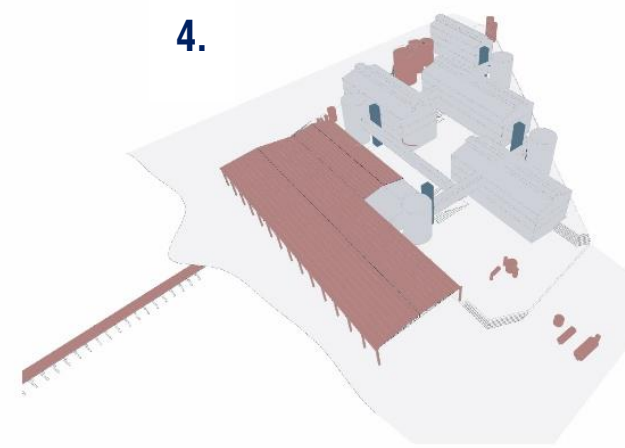

Fuente: Elaboración propia 
Ilustración 8.45 Sistema fábrica cultural completo
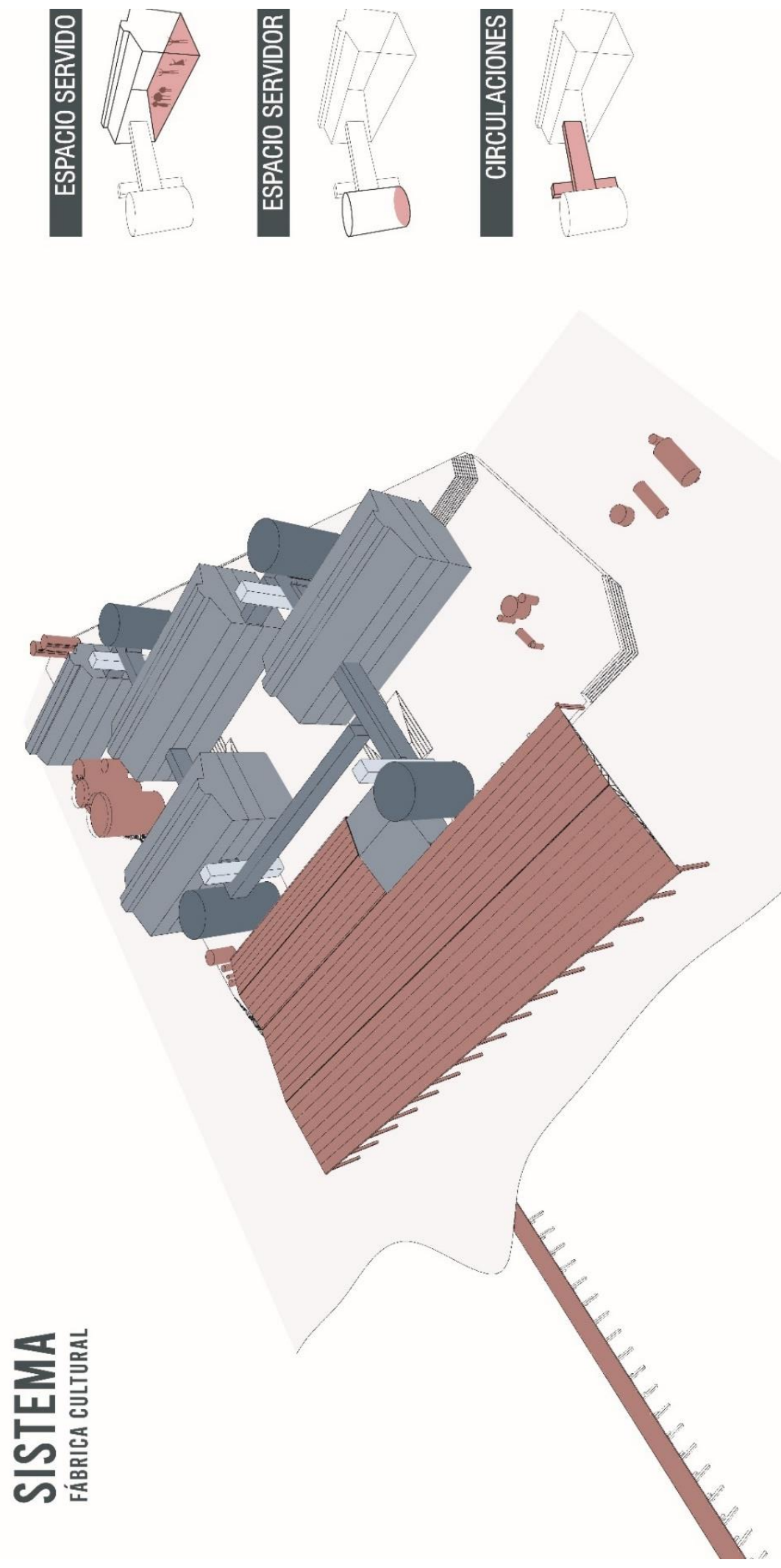

Fuente: Elaboración propia 


\subsection{Exploración espacial de galpones}

Una vez identificadas las piezas que conformarían el sistema, se exploraron los espacios de modo que se obtenga la forma adecuada de manejar el vacío interior, además de poder generar distintas relaciones espaciales a través de este. La primera exploración fue el espacio incluido, donde los espacios se encuentran en diferentes niveles dentro de un gran galpón contenedor. La siguiente exploración espacial fue la de espacio escalonado, donde a través de una sucesión de espacios en distintos niveles se podría configurar el espacio. Asimismo, se logró tener espacios contiguos, donde estos se encontraban en el mismo nivel separados por vacíos y conectados entre sí por puentes. Se probó también con el espacio alrededor de otro, donde se extraía la pieza central del espacio para configurar un vacío y generar que el programa rodee a este. Otra exploración fue la de dobles alturas, donde a través de un mismo espacio se podría recorrer distintos niveles. Finalmente, la exploración de nodos y conexiones, donde los espacios se concentraban a ambos extremos del galpón y eran conectados por puentes.

\section{Ilustración 8.46 Configuraciones generadas a partir de la exploración espacial del galpón}
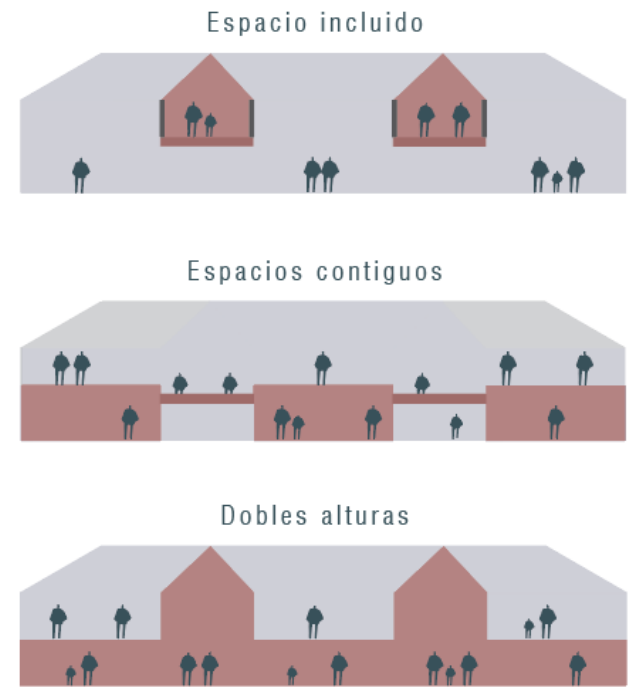
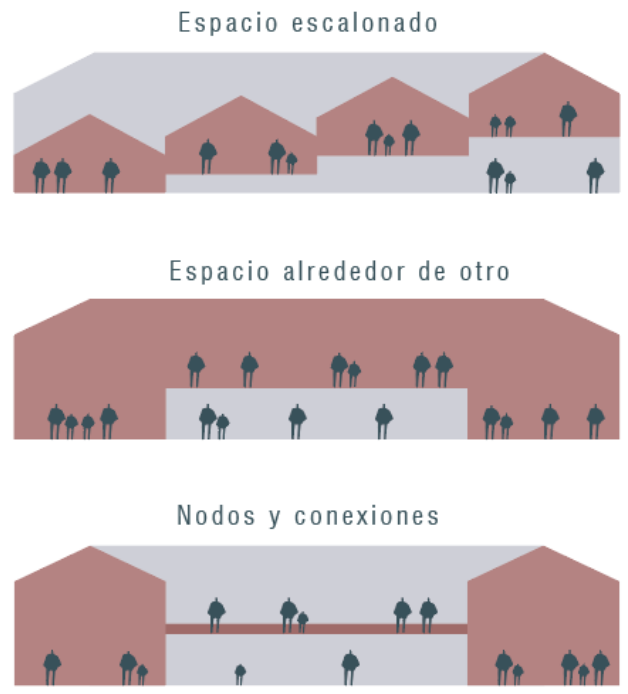

Fuente: Elaboración propia 


\subsection{Exploración espacial de tanques}

El tanque cuenta con una geometría circular singular, por lo que también se realizó un estudio de esta pieza para analizar la mejor manera de distribuir el espacio dentro de este. La primera exploración fue la de espiral, donde todo el espacio se configuró de manera espiralada rodeando el espacio. Seguidamente, se exploró colocando mezanines, donde la circulación de ubicó en la parte central del tanque y el espacio se distribuyó de manera escalonada alrededor de esta circulación. Así también, se probó colocando espiral y programa, es decir, se ubicó la circulación de manera espiralada rodeando el programa que se ubicó en la parte central del proyecto. La siguiente exploración fue la de circulación interna, donde la circulación se ubicó en la parte central y el programa en forma de anillos alrededor de este. Otra prueba se obtuvo al distribuir el espacio en niveles escalonados y que a través de este mismo espacio que vaya ascendiendo. Finalmente, la circulación externa, donde el espacio se ubicaba en la parte central del tanque y la circulación rodeaba este a manera de anillos.

\section{Ilustración 8.47 Configuraciones generadas a partir de la exploración espacial del tanque}

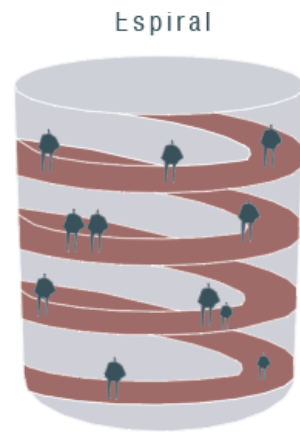

Circulación interna

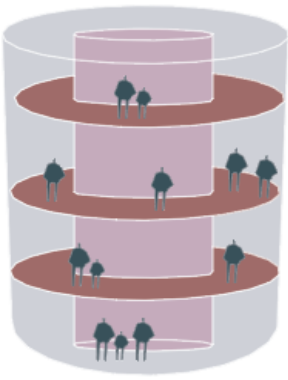

Mezanines

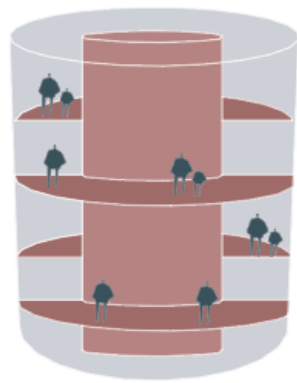

Escalonamiento

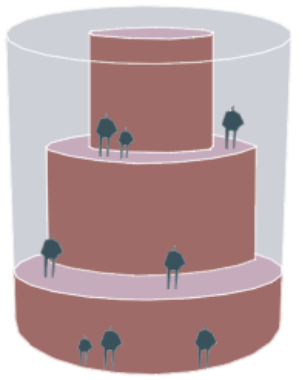

Espiral y programa

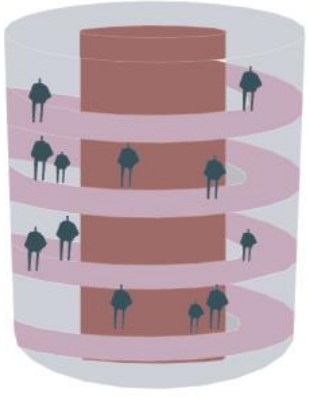

Circulación externa

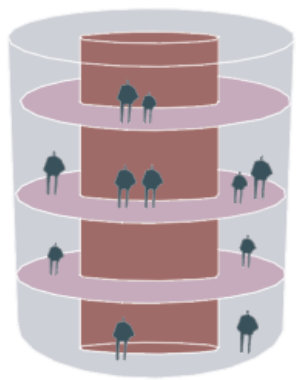

Fuente: Elaboración propia 


\subsection{Manual de ensamblaje}

A partir de la exploración espacial, se empezaron a configurar los espacios teniendo en cuenta las variables a las que responderían cada uno de ellos, dependiendo del galpón en el que se encontraran. De esta forma, se estableció un manual de ensamblaje, a manera de analogía en la que se establecieran las variables que determinan la organización espacial en el interior de los galpones. Cada galpón presenta una estructura metálica organizada por crujías de la misma media, lo que permite contar con espacios libres con luces grandes.

En el manual se establecen tres variables generales. La primera es el tipo de espacio a desarrollar, que esta determinado por el programa que va a contener, en otras palabras, dependerá de la actividad que se realice como espacio de lectura, aulas, auditorio, talleres, aulas de ensayo, para determinar cuántos módulos se necesitaran en el sentido horizontal como vertical.

\section{Ilustración 8.48 Espacio determinado por el tipo de programa}

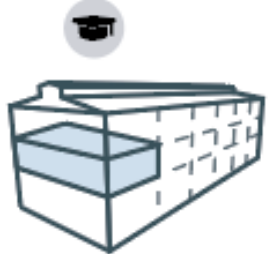

Una crujía

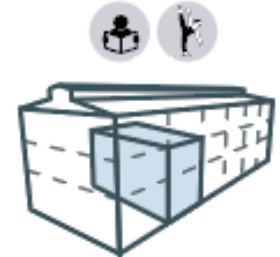

Doble altura

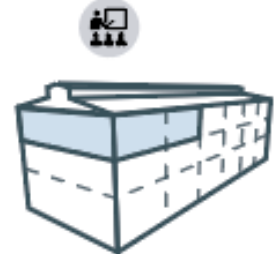

Doble crujía

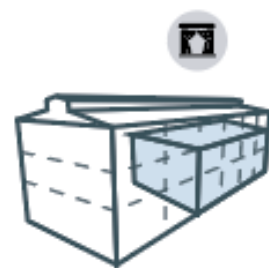

Cuádruple crujía

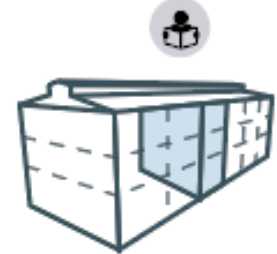

Triple altura

Fuente: Elaboración propia

Posterior a ello, cada galpón recibe una circulación exterior que al atravesarlo influye en la configuración del espacio interior. Cuando el puente corta el galpón en el sentido longitudinal, los espacios laterales pueden determinarse a partir de explorar con las alturas o se puede extender como una gran plataforma. Del mismo modo, cuando el puente llega al galpón por el sentido transversal, el espacio interior se organizará respondiendo a este nuevo ingreso, de modo que el usuario sienta que el espacio lo recibe. 


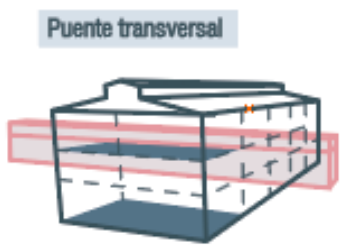

Puente - doble altura

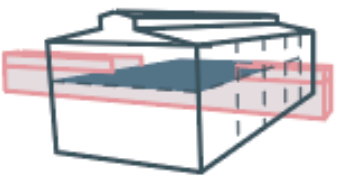

Puente - explanada

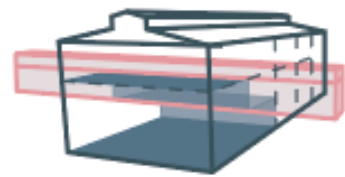

Puente - doble y simpler
Puente lateral

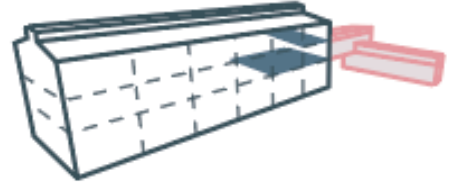

Puente - recibo

Fuente: Elaboración propia

Por último, la tercera variable es la circulación interior, cuya tarea es la más importante pues organiza y determina el espacio, la labor de esta circulación es conectar el exterior con la actividad interior, generando espacios acogedores, que reciban a los usuarios y les transmitan la sensación de permanecer en el espacio y desplazarse por todo el galpón de manera horizontal y vertical.

Ilustración 8.50 Manual de ensamblaje del espacio interior del galpón

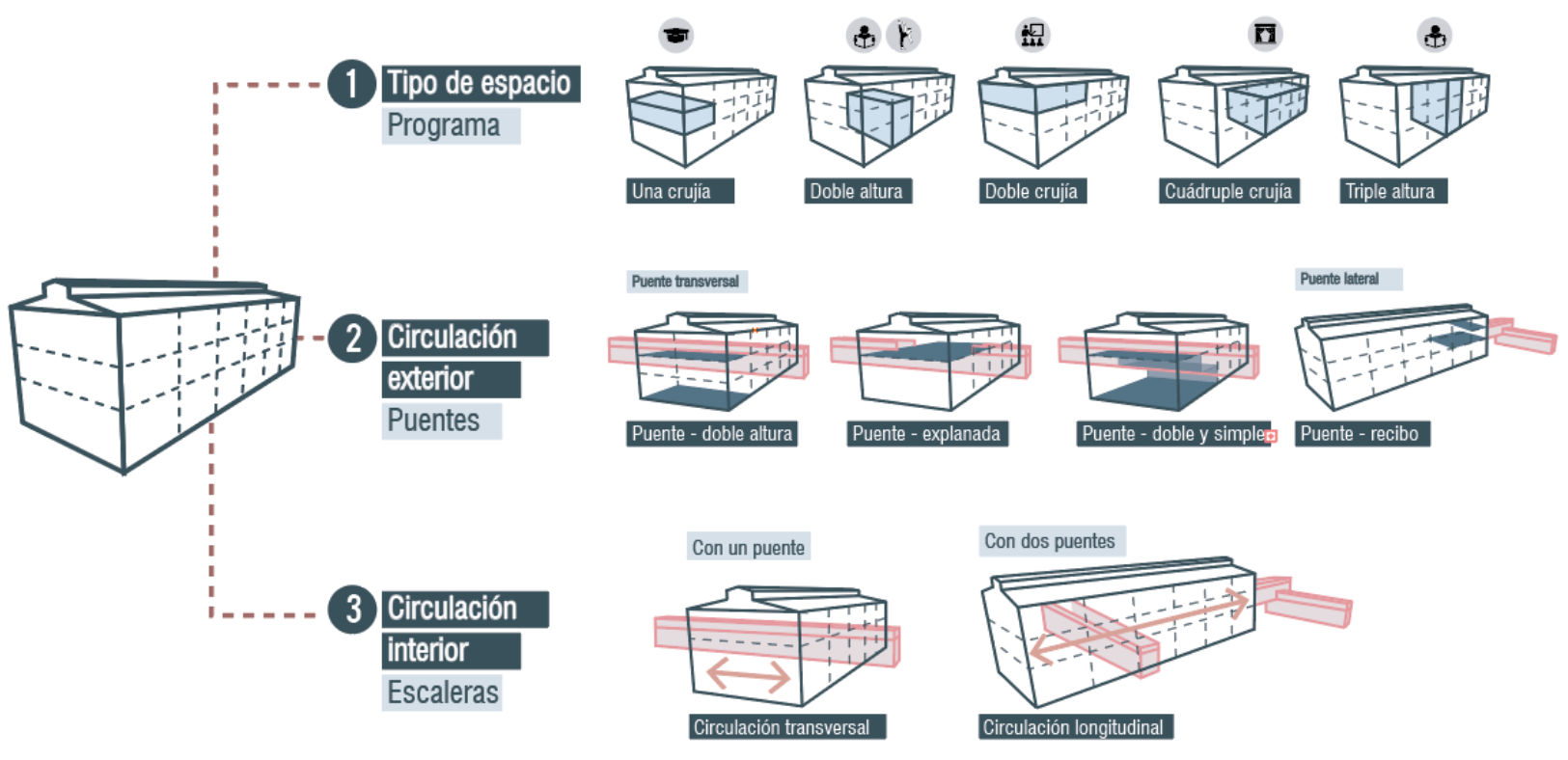

Fuente: Elaboración propia 
Ilustración 8.51 Vista interior de la biblioteca general, donde la circulación exterior se inserta en el galpón

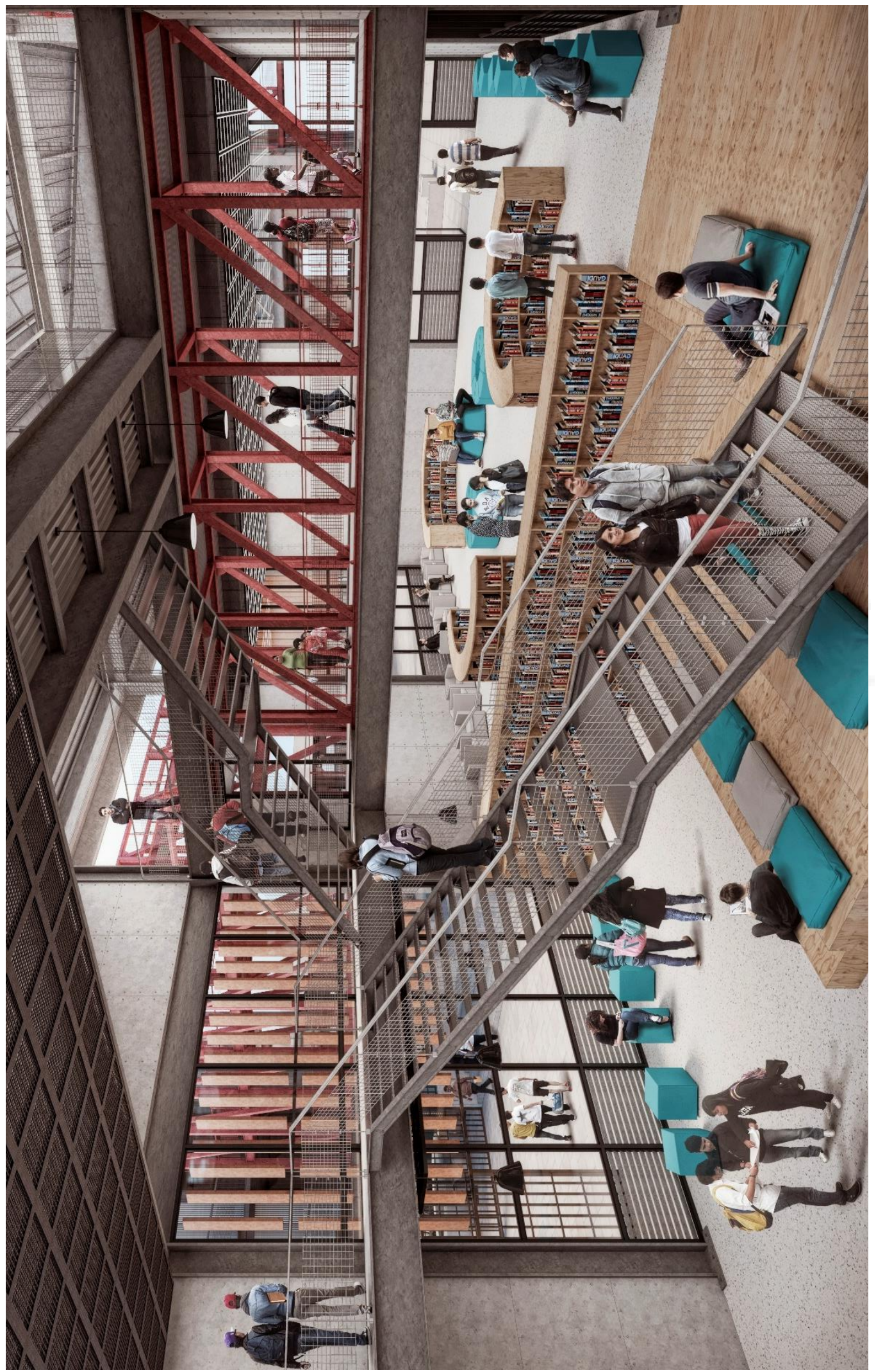

Fuente: Elaboración propia 


\subsection{Usuarios del proyecto}

La fábrica cultural está orientada principalmente a una población joven; niños y adolescentes entre los 10 y 19 años que se encuentran cursando el colegio y la universidad.

Para el proyecto se identificaron dos categorías; los usuarios directos e indirectos. Los usuarios directos son todas aquellas personas para quienes principalmente ha sido diseñado el proyecto, por hacer uso de constantemente. Por otro lado, los usuarios indirectos no buscan llegar al proyecto, sino que generalmente son atraídos a través de los usuarios directos y su presencia es esporádica.

Asimismo, los usuarios directos se subdividen en usuarios permanentes y temporales. Dentro de la primera categoría se encuentran los niños y adolescentes que le darán un constante uso al proyecto, mientras que, en la segunda, se encuentra la población dedicada a laborar en el sector pesquero, ya que su presencia en el proyecto dependerá de la temporada de pesca. Si bien esta categoría se asemeja a los usuarios indirectos por su falta de continuidad en el proyecto, estos no lo son, pues el proyecto tiene un considerable impacto en los usuarios directos temporales ya que a través de los talleres de capacitación que se brindarán dentro del proyecto se buscará generar mayores oportunidades y desarrollar nuevas capacidades en ellos para que logren in sentarse en nuevos campos laborales, y no solo tener a la pesca como principal campo de acción.

En relación a los usuarios indirectos como se mencionó previamente son todos aquellos usuarios que no tienen un interés directo al proyecto pero que, de alguna manera, ya sea porque fueron guiados por terceros o que el proyecto se encontraba cercano a ellos, llegan al proyecto. Dentro de esta categoría se encuentran las madres de familia que acompañan a sus hijos a la fábrica cultural, las personas mayores que viven por la zona, los trabajadores de la zona, los vecinos y los turistas; que vendrán atraídos por el impacto y presencia del proyecto a la ciudad. 

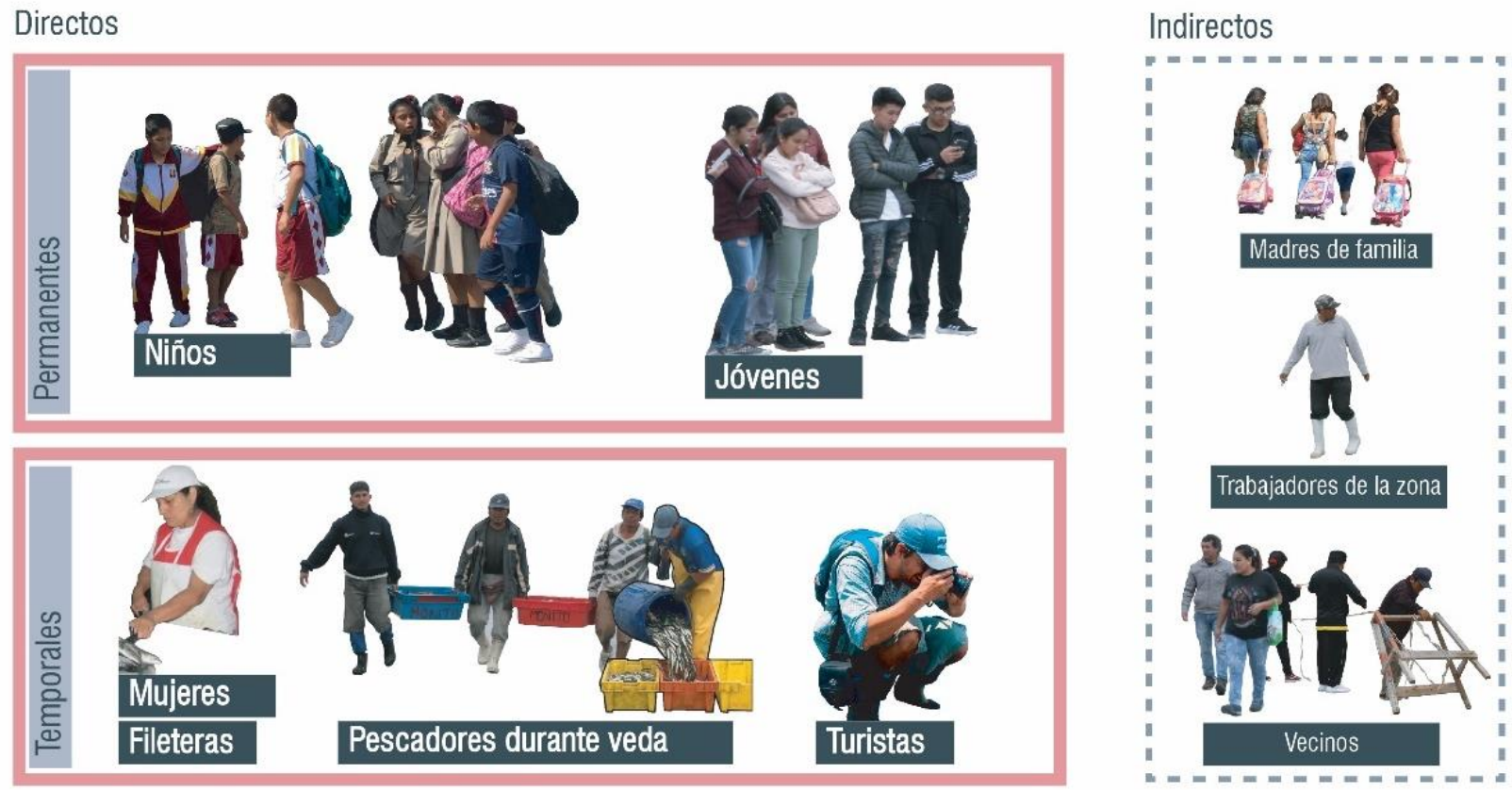

Fuente: Elaboración propia

\subsubsection{Encuestas a alumnos de la I.E $\mathbf{N}^{\circ} 88008$}

Para establecer el programa del proyecto, se realizaron encuestas en la I.E N ${ }^{\circ} 88008$ - Manuel Peralta Hurtado, ubicado en la zona de la Florida Baja, muy cercano a la fábrica cultural.

Tras desarrollar la encuesta con alumnos de nivel primaria y secundaria, con una muestra de 100 alumnos entre ambos niveles, se obtuvo que, para los alumnos del nivel primario, Chimbote representa es el lugar donde nacieron; mientras que para los del nivel secundario, representa un lugar de pesca, trabajo y fábricas. Además, el 50. 8\% no se acerca a ver el mar; sin embargo, reconoce el malecón como un espacio de paseo y diversión.

Por otro lado, para los niños de primaria, las fábricas son malas porque se consideran como punto de contaminación para la ciudad; mientras que el $29 \%$ de los alumnos de secundaria considera que las fábricas son buenas para Chimbote porque representan una fuente de trabajo para las personas, lo que a su vez hace que el $66 \%$ reconozca a las fábricas como parte importante de la historia de la ciudad. 
Por último, al 85\% del total de alumnos les gustaría tener un espacio público frente al mar y un equipamiento donde se desarrollen actividades. El $70 \%$ prefiere desarrollar actividades culturales mientras que el $15 \%$, actividades deportivas.

Ilustración 8.53 Resultados de las encuestas realizadas a los alumnos de primaria y secundaria de la I.E No 88008 - Manuel Peralta Hurtado, Florida Baja
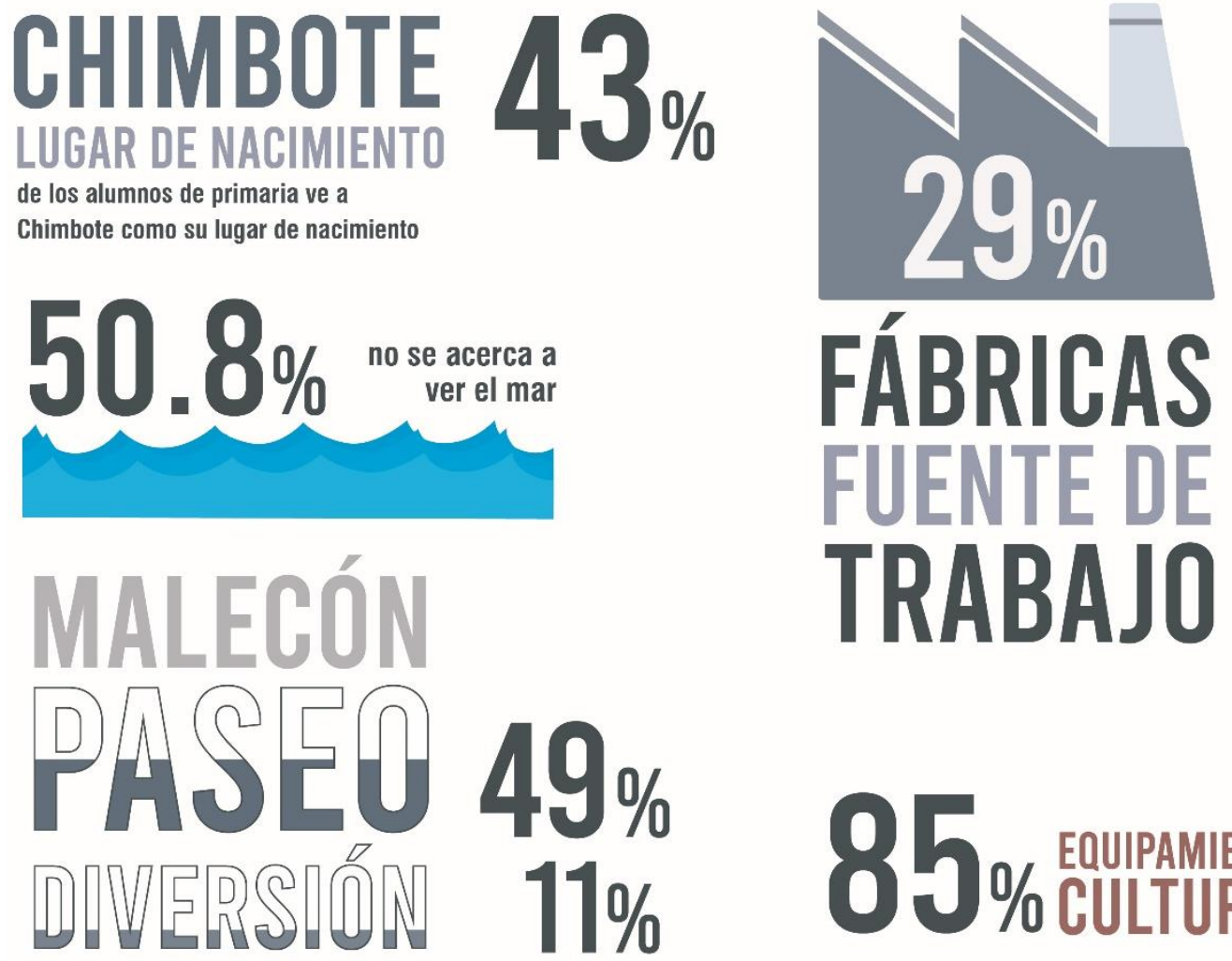

el $49 \%$ vel malecón como un lugar de paseo y el $11 \%$ como lugar de diversión

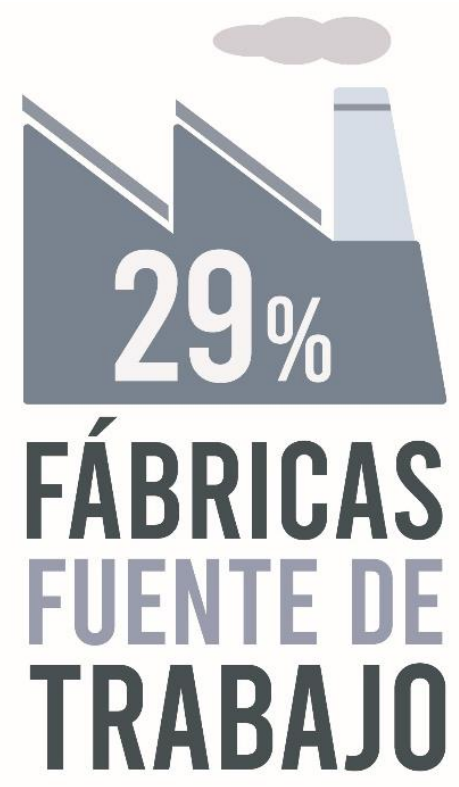

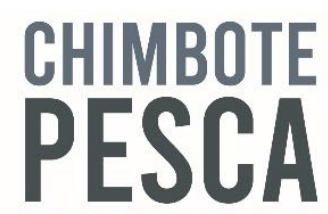

TRABAJO FÁBRICAS

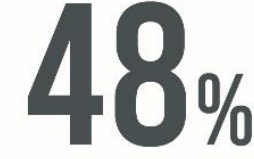

de los alumnos de secundaria considera a Chimbote un lugar de pesca, trabajo y tábricas

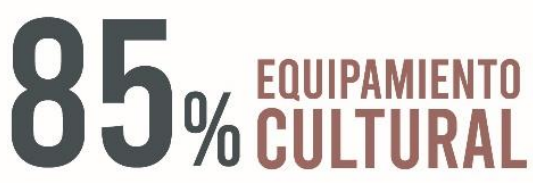

desea tener desarrollar actividades culturales y tener espacio público frente al mar

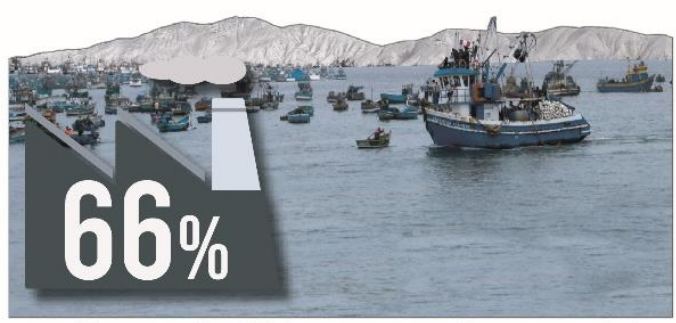

considera que las fábricas son parte importante de la historia de Chimbote

Fuente: Elaboración propia 


\subsection{Programa arquitectónico}

De acuerdo con el análisis contextual, se determinó que Chimbote presenta un déficit de equipamiento cultural, contando con un solo centro cultural el cual no llega a abastecer a toda la población. Por este motivo se determinó que la fábrica reciclada debía abarcar un programa que sea cultural en su mayoría.

Además, se realizaron encuestas a niños y jóvenes (usuarios directos) para consultarles qué tipo de actividades les gustaría desarrollar y con esta información poder generar un programa que responda a sus ellos. Estas necesidades, la ubicación del proyecto y las condiciones del entorno permitieron generar además un programa específico para el proyecto, el cual está conformado por los siguientes espacios: sala de exposición historia de Chimbote, sala de exposición historia de la fábrica, taller de concientización ambiental, taller de manualidades en redes, taller de manualidades en totora, taller de reciclaje, taller de emprendimiento e industrias creativas, taller de gestión, taller de capacitación y emprendimiento.

Por otro lado, también se tomaron como base los referentes de proyectos de carácter cultural y con presencia de preexistencias, quienes dieron una idea de los ratios y la organización espacial que debía tener este programa dentro del espacio.

El programa arquitectónico dentro de la Fábrica Cultural se encuentra dividido en 4 categorías; entre ellas un programa cultural, comercial, administrativo y de difusión. El 30.78\% del área total del proyecto está compuesta por los servicios, seguido por el programa de cultural, ocupando un $25.60 \%$ del área total, seguido del programa de difusión, el cual ocupa un $22.59 \%$, seguido por el programa de comercio, el cual ocupa un $4.88 \%$ y finalmente el programa administrativo, la cual ocupa un $2.4 \%$ del área total del proyecto. 


\section{Ilustración 8.54 Distribución del programa en el proyecto}

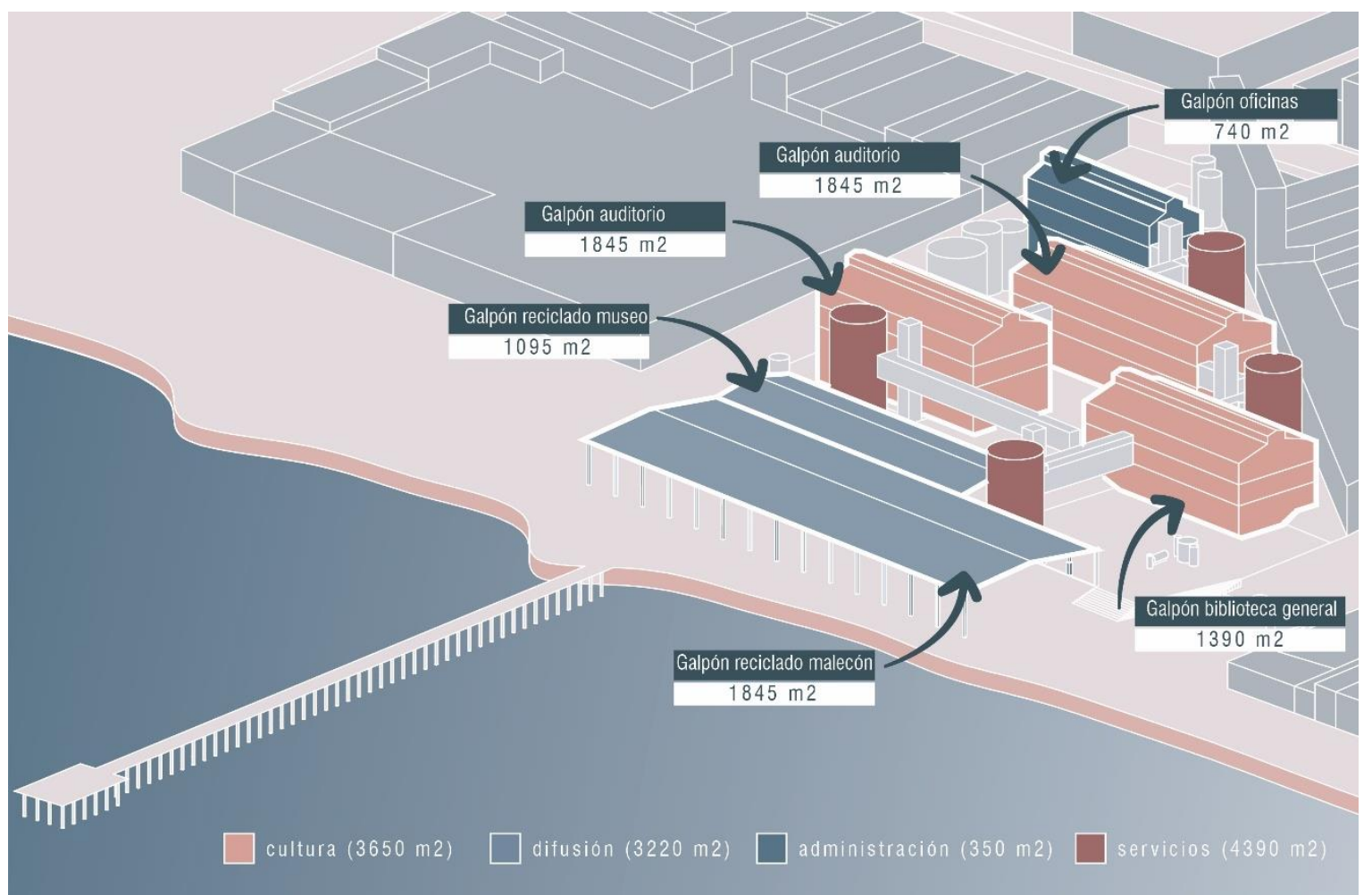

Fuente: Elaboración propia

Este programa comprende un $42 \%$ de área construida, mientras que el $58 \%$ es comprendido por área libre.

El programa cultural está compuesto por talleres de pintura, talleres de dibujo, talleres de escultura, talleres de manualidades, talleres de danza, talleres de música, talleres de canto, talleres de teatro, talleres de oratoria, talleres de reciclaje, talleres textiles, talleres de jardinería, talleres de juegos de mesa, cine, biblioteca, biblioteca infantil, aulas educativas y servicios.

El programa de difusión está conformado por salas de exposición permanente, aulas educativas, salas de exposición, un auditorio y servicios.

El programa comercial está compuesto por una cafetería, un bar y servicios.

Y finalmente el programa administrativo está compuesto por una oficina de secretaría, una oficina de dirección, una oficina de contabilidad, una oficina de promoción, salas de reunión, un tópico y servicios. 
Ilustración 8.55 Paquetes programáticos del proyecto

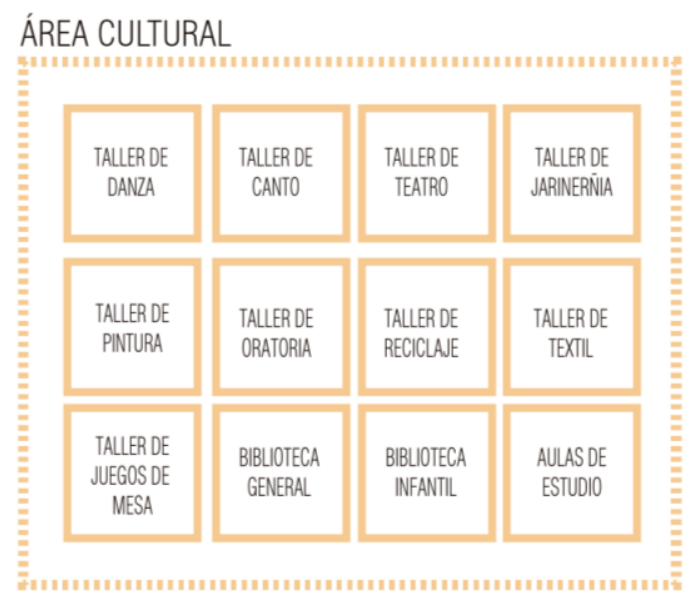

ÁREA COMERCIAL

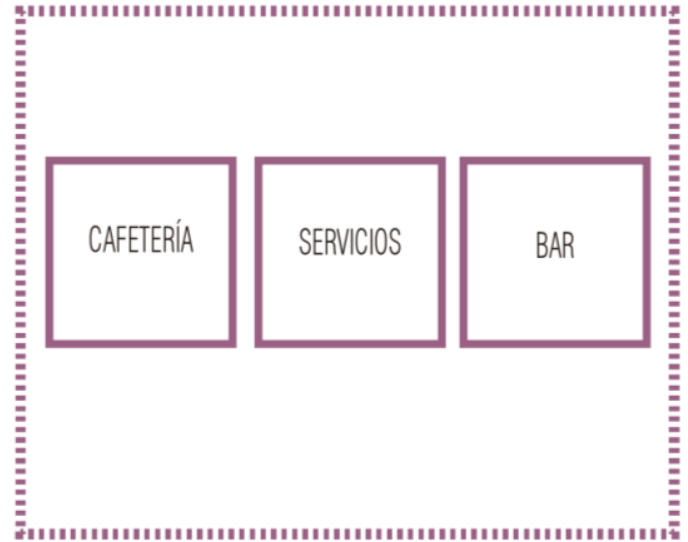

ÁREA DE DIFUSIÓN

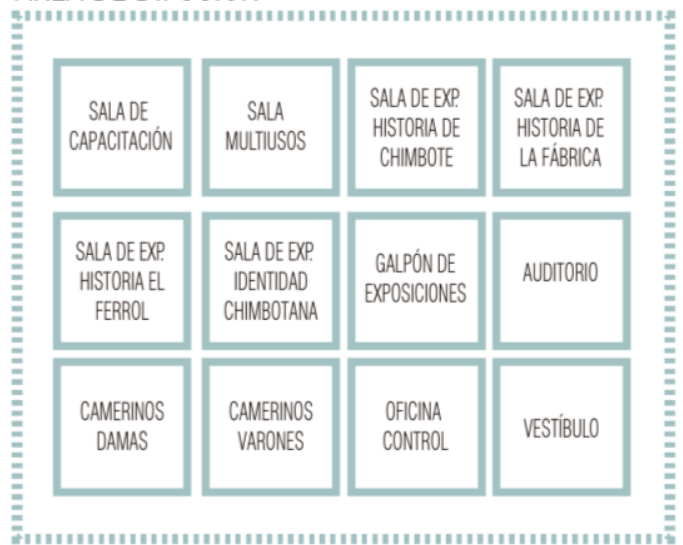

ÁREA ADMINISTRATIVA

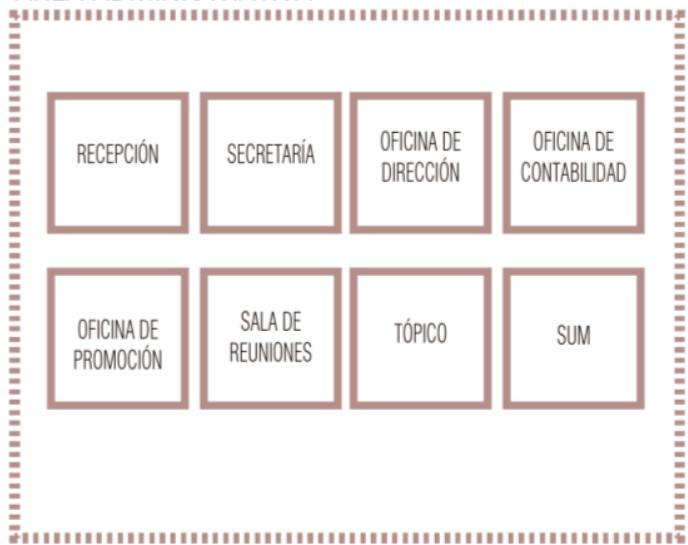

Fuente: Elaboración propia 
Ilustración 8.56 Porcentaje de áreas del programa específico del proyecto

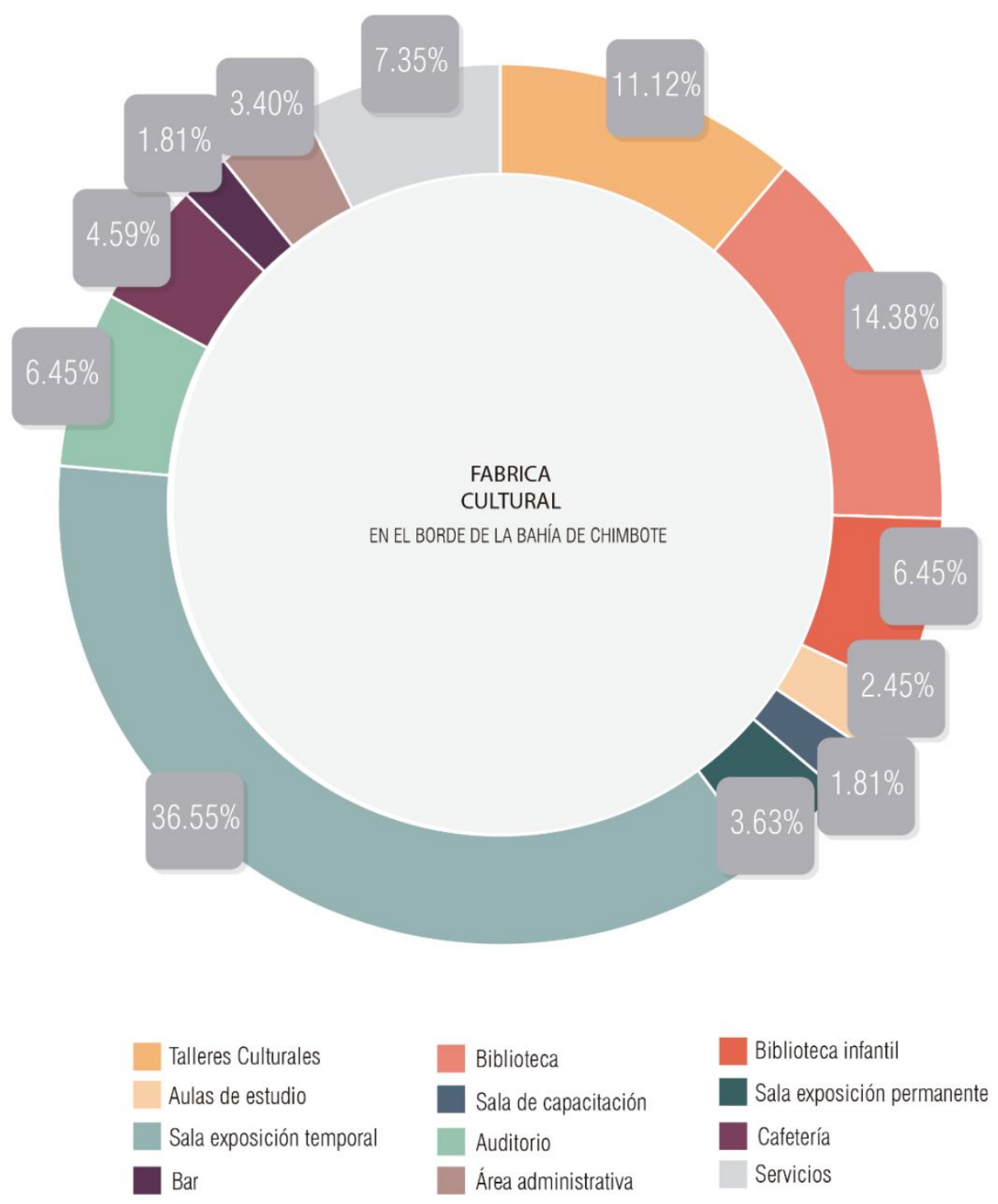

Fuente: Elaboración propia 

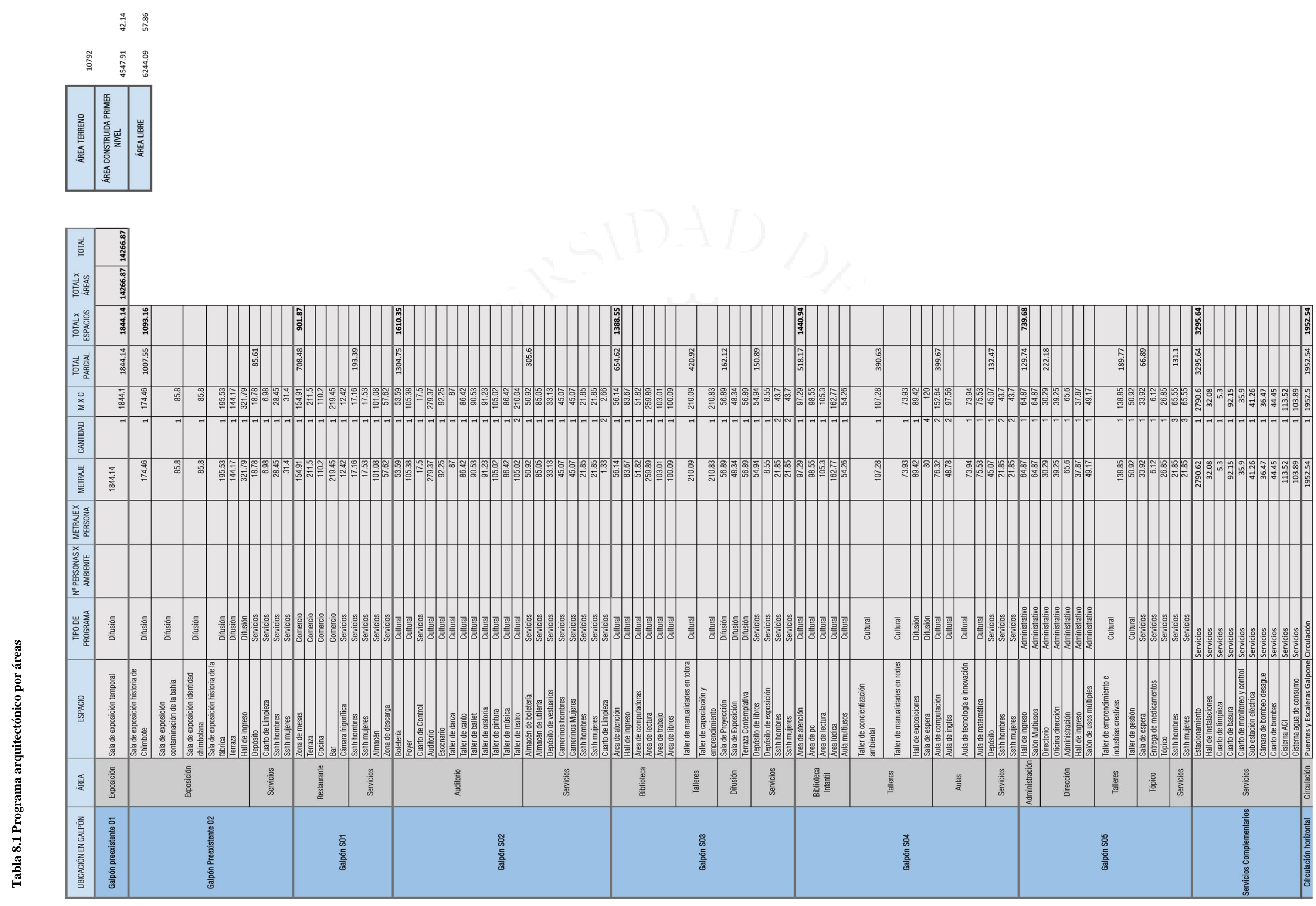
Si bien el programa está conformado por equipamientos de diferentes categorías, todos estos se encuentran relacionados de manera directa, secundaria, e indirecta. Los programas con mayor presencia son todas las salas de exposición y concientización de Chimbote, ya que el proyecto busca a la vez generar una respuesta ante el impacto negativo que está presentando Chimbote el día de hoy. A su vez, estas salas de concientización se relacionan con el programa cultural de manera directa por medio de talleres, tales como el taller de manualidades y reciclaje.

Dentro del ambiente de difusión también se presenta una relación con los equipamientos comerciales como la gran cafetería que busca abastecer no solo a los usuarios internos del proyecto sino también a los visitantes. 
Ilustración 8.57 Axonometría explotada por tipo de programa y por piezas del proyecto
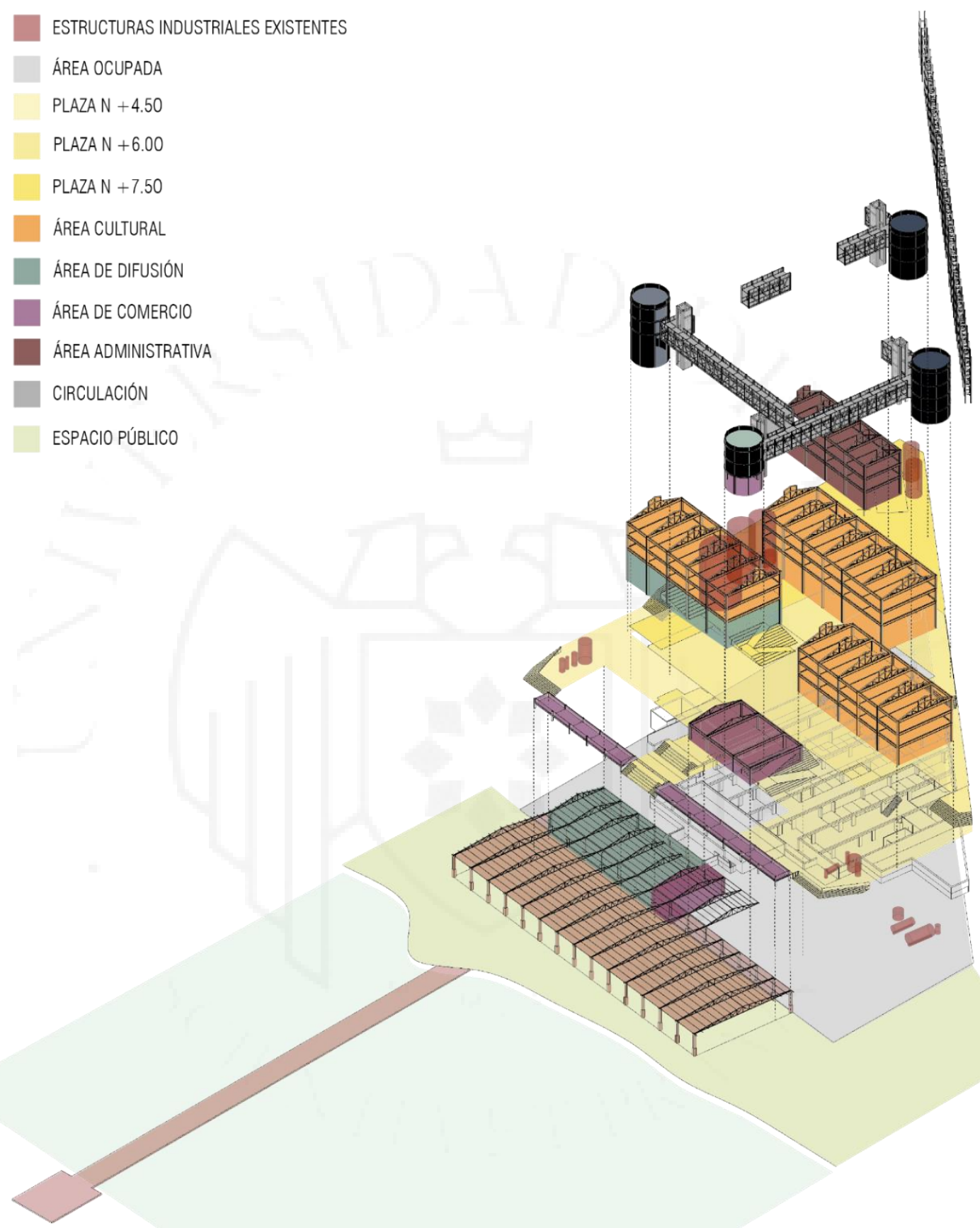

Fuente: Elaboración propia 


\subsection{Cálculo de usuarios}

En relación con el cuadro de áreas, en el $42 \%$ de área construida, la cantidad de usuarios que alberga el proyecto es 4000 personas en los espacios internos del proyecto. Esta cifra no contempla a los usuarios que puede usar el espacio público.

\subsection{Programa con cabida distribuido en galpones}

Galpón preexistente 01:

- Programa cultural

- Programa de difusión (1844.14 m2)

- Programa comercial

- Programa administrativo

- Programa de servicios

Galpón preexistente 02:

- Programa cultural

- Programa de difusión (1007.55 m2)

- Programa comercial

- Programa administrativo

- Programa de servicios (85.61 m2)

Galpón S01 (Galpón bar):

- Programa cultural

- Programa de difusión

- Programa comercial (696.06 m2)

- Programa administrativo

- Programa de servicios (205.81 m2)

Galpón S02 (Galpón Auditorio):

- Programa cultural (1287 m2)

- Programa de diffusion

- Programa commercial

- Programa administrativo

- Programa de servicios (323.10 m2)

Galpón S03 (Galpón Biblioteca general):

- Programa cultural (1075.54 m2)

- Programa de diffusion (162.12 m2)

- Programa commercial 
- Programa administrativo

- Programa de servicios (150.89 m2)

Galpón S04 (Galpón Biblioteca infantil):

- Programa cultural (1099.05 m2)

- Programa de diffusion (209.42 m2)

- Programa commercial

- Programa administrativo

- Programa de servicios (132.47 m2)

Galpón S05 (Galpón Oficinas):

- Programa cultural (189.77 m2)

- Programa de diffusion

- Programa commercial

- Programa administrative (351.92 m2)

- Programa de servicios (197.99 m2) 
Ilustración 8.58 Distribución programática del galpón reciclado 01

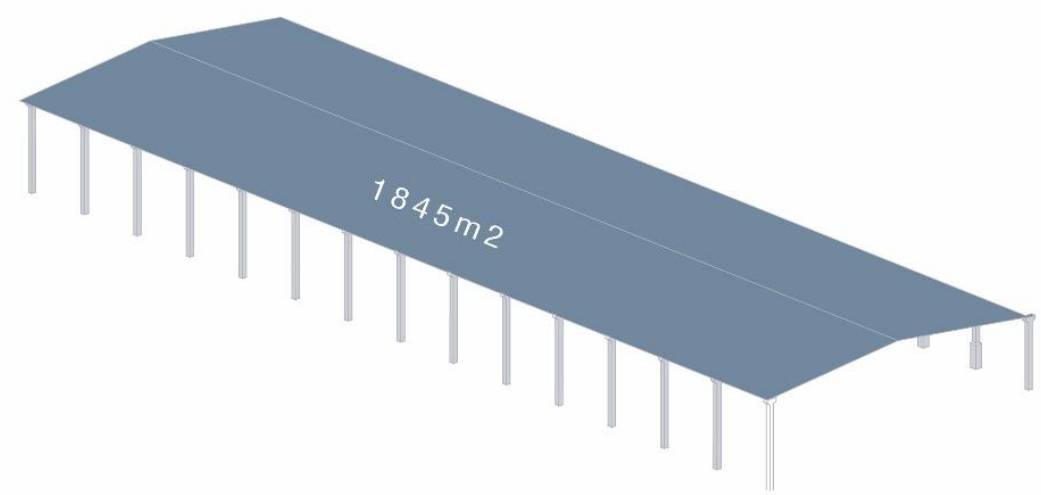

Fuente: Elaboración propia

Ilustración 8.59 Distribución programática del galpón reciclado 02

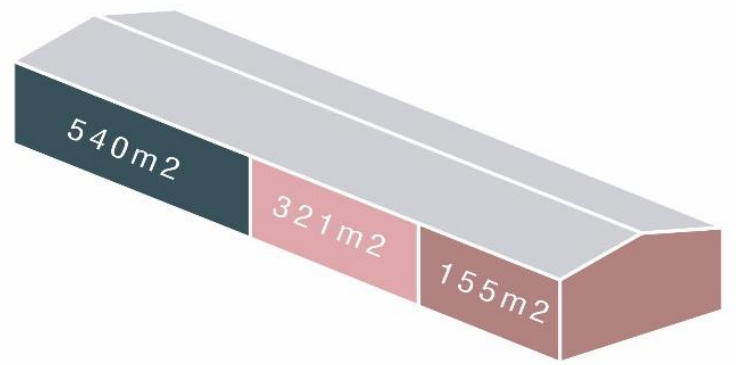

Fuente: Elaboración propia 
Ilustración 8.60 Vista interna del galpón reciclado, convertido en una sala de exposición

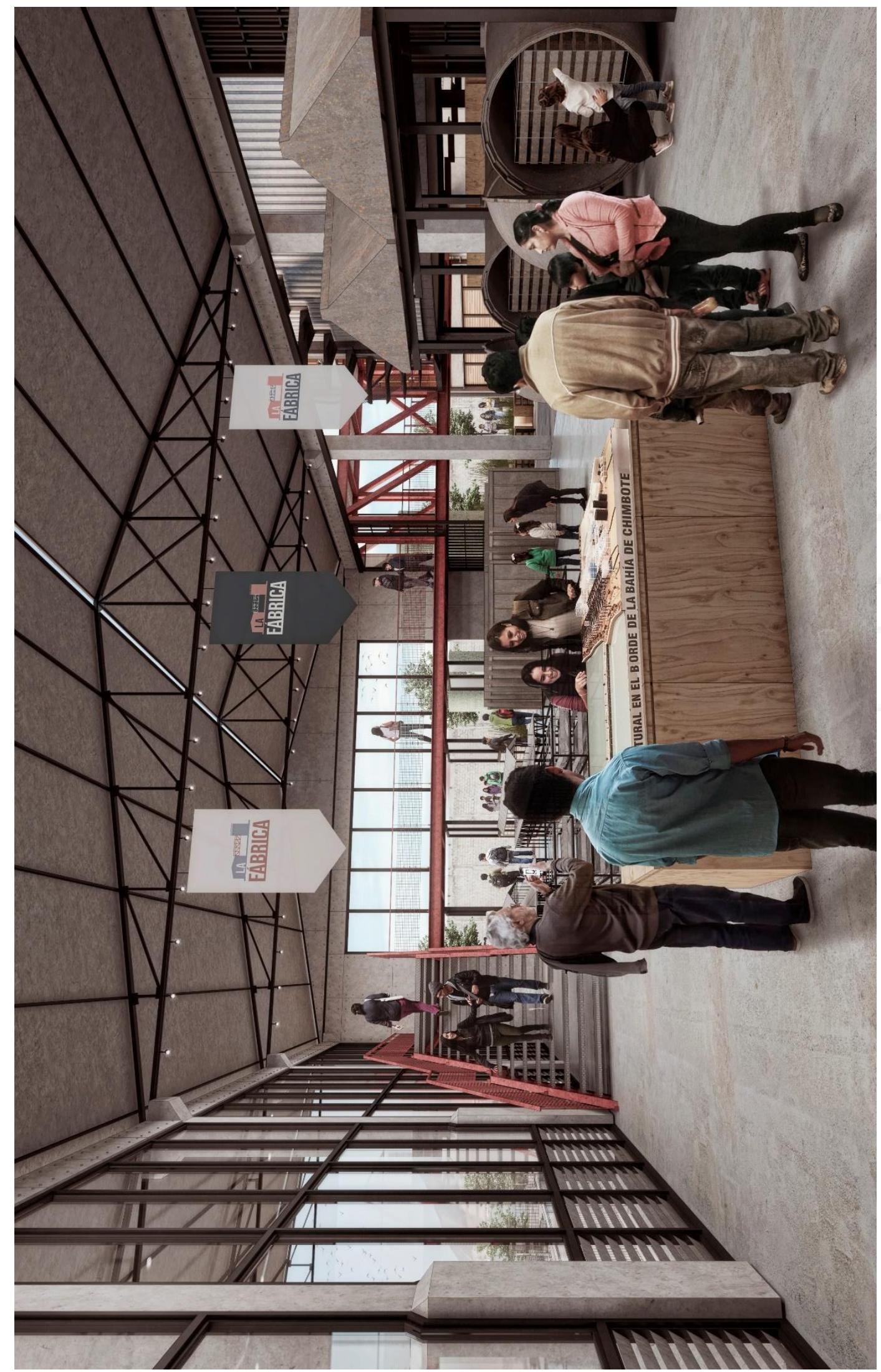

Fuente: Elaboración propia 
Ilustración 8.61 Distribución programática del galpón biblioteca general
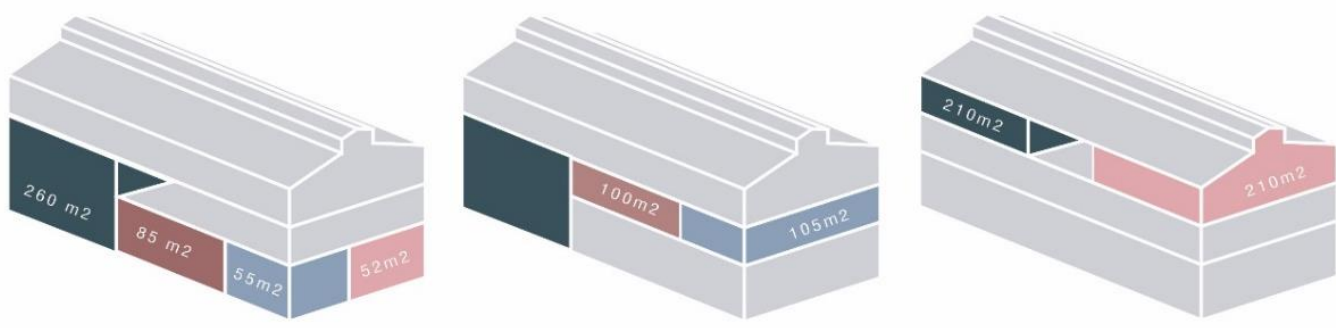

PLANTA PRIMER NIVEL

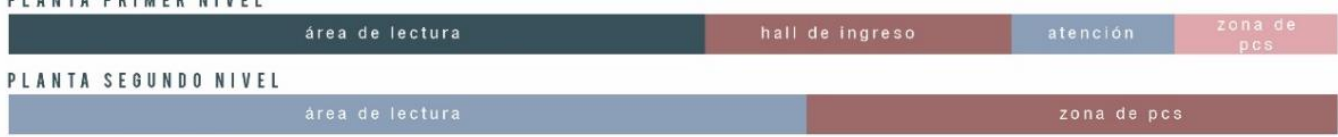

PLANTA TERCER NIVEL

taller de manualidades en totora

Ilustración 8.62 Distribución programática del galpón biblioteca infantil
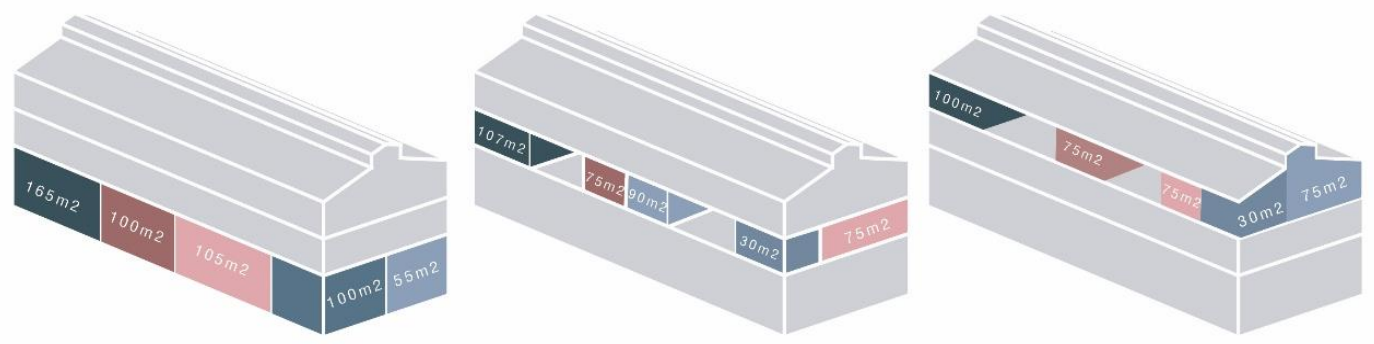

\begin{tabular}{|c|c|c|c|c|}
\hline área lúdica & área de $p c$ & área de lectura & atención & $\begin{array}{c}\text { salón } \\
\text { multiusos }\end{array}$ \\
\hline $\begin{array}{l}\text { LANTA SEGUNDO N IVEL } \\
\text { aula de concientización ambiental }\end{array}$ & $\begin{array}{c}\text { taller de manualidades } \\
\text { en redes }\end{array}$ & hall de exhibicion & aula de cómputo & $\begin{array}{l}\text { sala de } \\
\text { espera }\end{array}$ \\
\hline aula de ingés & $\begin{array}{l}\text { taller de tecnología } \\
\text { e innovación }\end{array}$ & aula de computación & aula de matemática & $\begin{array}{l}\text { sala de } \\
\text { espera }\end{array}$ \\
\hline
\end{tabular}

Fuente: Elaboración propia 


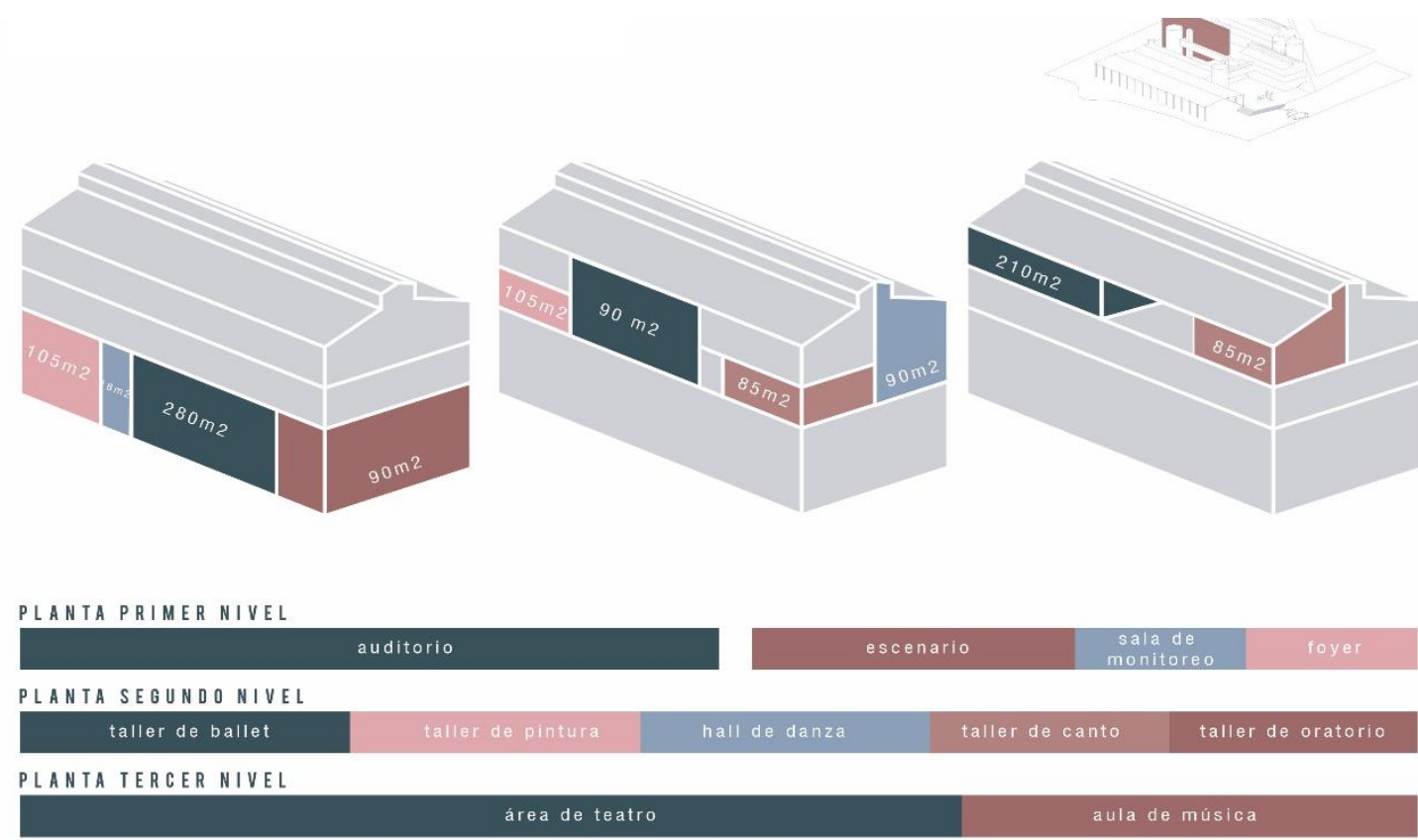

Fuente: Elaboración propia

Ilustración 8.64 Distribución programática del galpón administrativo
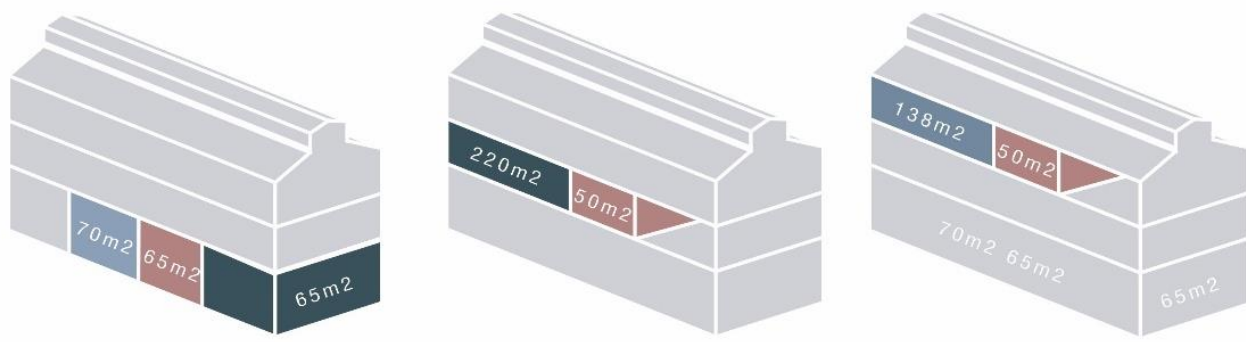

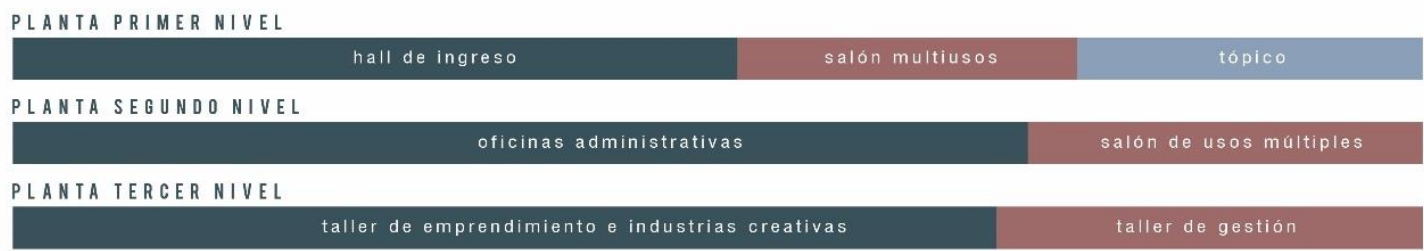

Fuente: elaboración propia 


\subsection{Circulación}

La circulación es un aspecto fundamental del proyecto, ya que al ser un programa compuesto por piezas (cinco galpones que cumplen el rol de espacios servidos y cuatro tanques que cumplen el rol de espacios servidores), estos espacios deben estar articulados de manera que el proyecto funcione como un sistema. Por este motivo se tomó la decisión de colocar puentes aéreos de logren vincular el proyecto en todos sus niveles.

No hay necesidad de que el usuario requiera bajar al primer nivel para poder acceder al resto de espacios, sino que por medio de las pasarelas aéreas se podrá dirigir a cualquier ambiente del proyecto.

\section{Ilustración 8.65 Espacios servidos y servidores del proyecto}

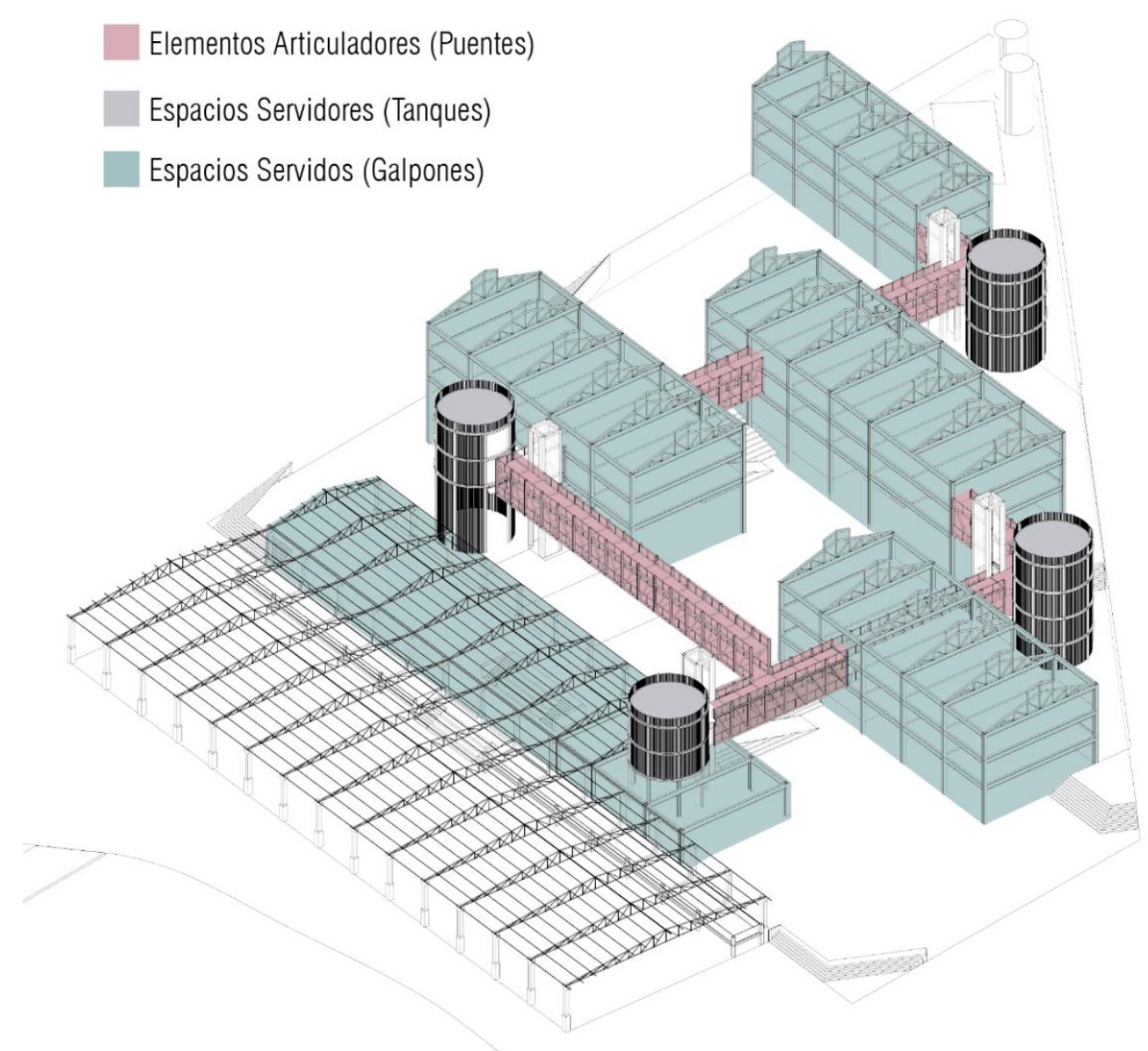

Fuente: Elaboración propia 


\subsubsection{Circulación rápida y circulación lenta}

El proyecto está compuesto por dos tipos de circulación; la primera es la llamada circulación rápida y se refiere a aquella que permite al usuario llegar a los diferentes espacios de manera directa. Dentro de este tipo de circulación se consideran tanto las escaleras internas de cada galpón, así como también los cuatro ascensores que se encuentran distribuidos en el proyecto.

\section{Ilustración 8.66 Vista de la circulación lenta del proyecto}

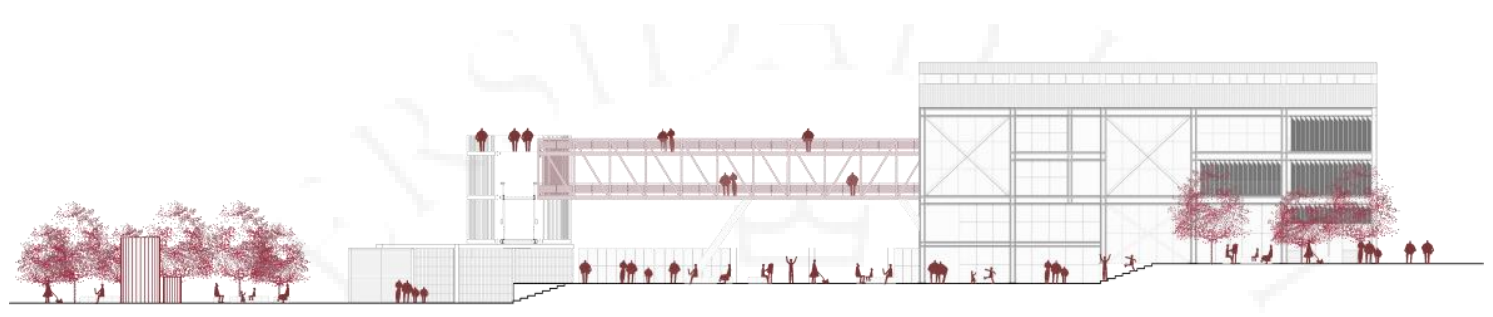

Fuente: Elaboración propia

El segundo tipo de circulación es la llamada circulación lenta y se refiere a aquella que permite al usuario llegar a los diferentes espacios a manera de recorrido. Este tipo de circulación representa un mayor porcentaje dentro del proyecto ya que el objetivo es que no solo se pueda acceder a los espacios, sino que también mediante este recorrido se pueda apreciar tanto la arquitectura del proyecto, así como también el paisaje que lo rodea.

Ilustración 8.67 Vista de la circulación lenta del proyecto

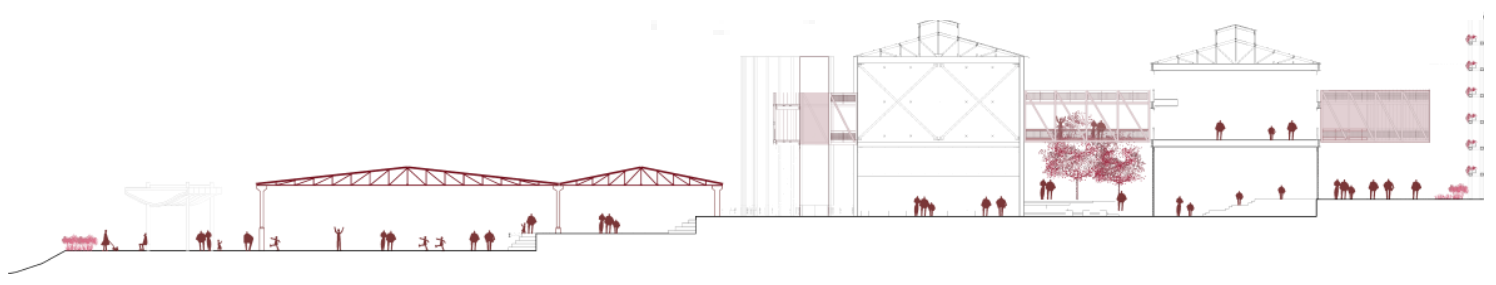

Fuente: Elaboración propia 
En relación a la circulación distribuida en cada planta, los niveles con mayor porcentaje de circulación son el tercero y el cuarto, ya que en estas plantas inicia el recorrido de los puentes aéreos alrededor de todo el proyecto. El nivel con menor porcentaje de circulación es el primero, ya que se encuentran considerados los espacios ubicados en el sótano, que solo cuentan con escaleras (circulación rápida). El porcentaje total de circulación del proyecto es de $16,67 \%$ que representa $1952.54 \mathrm{~m} 2$ del proyecto.

Tabla 8.2 Tabla de porcentaje de circulación por niveles

\begin{tabular}{|l|c|}
\hline NIVELES & \% CIRCULACIÓN \\
\hline Primer Nivel $(+4.50)$ & $3.27 \%$ \\
\hline Segundo Nivel $(+7.50)$ & $11.83 \%$ \\
\hline Tercer Nivel $(+9.35)$ & $24.85 \%$ \\
\hline Cuarto Nivel $(+12.70)$ & $25.88 \%$ \\
\hline Quinto Nivel $(+16.05)$ & $17.33 \%$ \\
\hline Circulación Total & $16.67 \%$ \\
\hline
\end{tabular}

Fuente: Elaboración propia

La siguiente tabla describe el porcentaje de circulación tanto lenta como rápida por cada nivel del proyecto. Como se puede apreciar a continuación, el porcentaje de circulación rápida es bastante bajo en comparación con la circulación lenta, que representa un alto porcentaje del proyecto. Esto se debe a que el proyecto se presenta a manera de recorrido y no como espacios de paso

Tabla 8.3 Tabla de porcentaje de circulaciones por niveles

\begin{tabular}{|c|c|c|c|c|c|}
\hline NIVELES & CIRCULACIÓN RÁPIDA & $\%$ & CIRCULACIÓN LENTA & $\%$ & TOTAL \\
\hline Primer Nivel (+4.50) & $242.68 \mathrm{~m} 2$ & $100 \%$ & -- & -- & $242.68 \mathrm{~m} 2$ \\
\hline Segundo Nivel $(+7.50)$ & $19.65 \mathrm{~m} 2$ & $5.26 \%$ & $353.76 \mathrm{~m} 2$ & $94.74 \mathrm{~m} 2$ & $373.41 \mathrm{~m} 2$ \\
\hline Tercer Nivel $(+9.35)$ & $26.10 \mathrm{~m} 2$ & $13.59 \%$ & $166.02 \mathrm{~m} 2$ & $86.41 \mathrm{~m} 2$ & $192.12 \mathrm{~m} 2$ \\
\hline Cuarto Nivel $(+12.70)$ & $52.33 \mathrm{~m} 2$ & $7.71 \%$ & $626.36 \mathrm{~m} 2$ & $92.29 \mathrm{~m} 2$ & $678.69 \mathrm{~m} 2$ \\
\hline Quinto Nivel (+16.05) & $8.75 \mathrm{~m} 2$ & $1.88 \%$ & $456.89 \mathrm{~m} 2$ & $98.12 \mathrm{~m} 2$ & $465.64 \mathrm{~m} 2$ \\
\hline \multicolumn{5}{|l|}{ Circulación Total } & $1952.54 \mathrm{~m} 2$ \\
\hline
\end{tabular}

Fuente: Elaboración propia 
Ilustración 8.68 Elementos reciclados de la fábrica y empleados en el proyecto

De
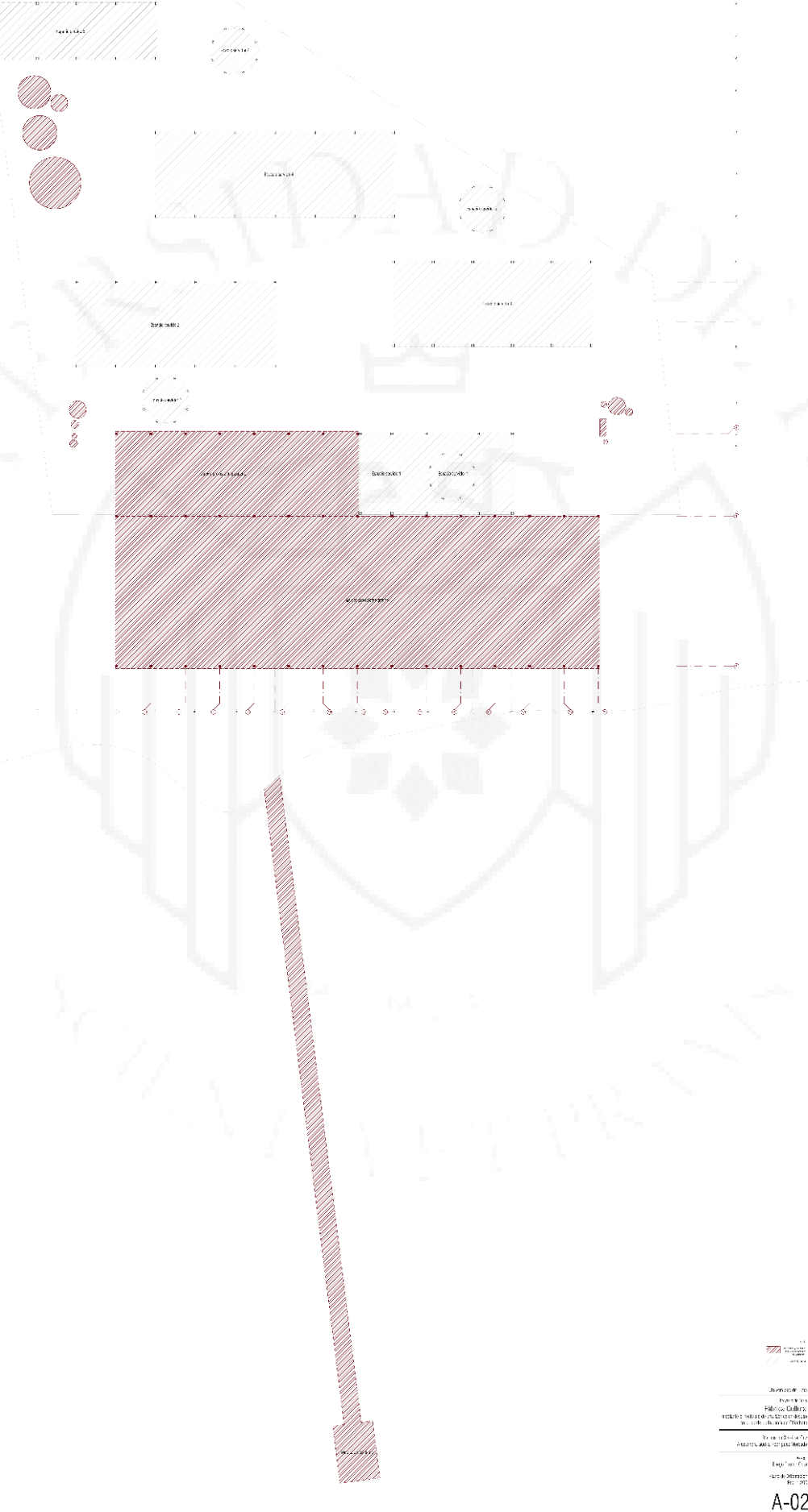

Fuente: Elaboración propia 
Para el entendimiento de las piezas y su ubicación en el espacio se adjunta el plano a continuación. Las piezas sombreadas en color rojo son aquellas que fueron recicladas, y las nuevas piezas que se encuentran sombreadas en color gris.

\section{Ilustración 8.69 Ubicación de los elementos reciclados}

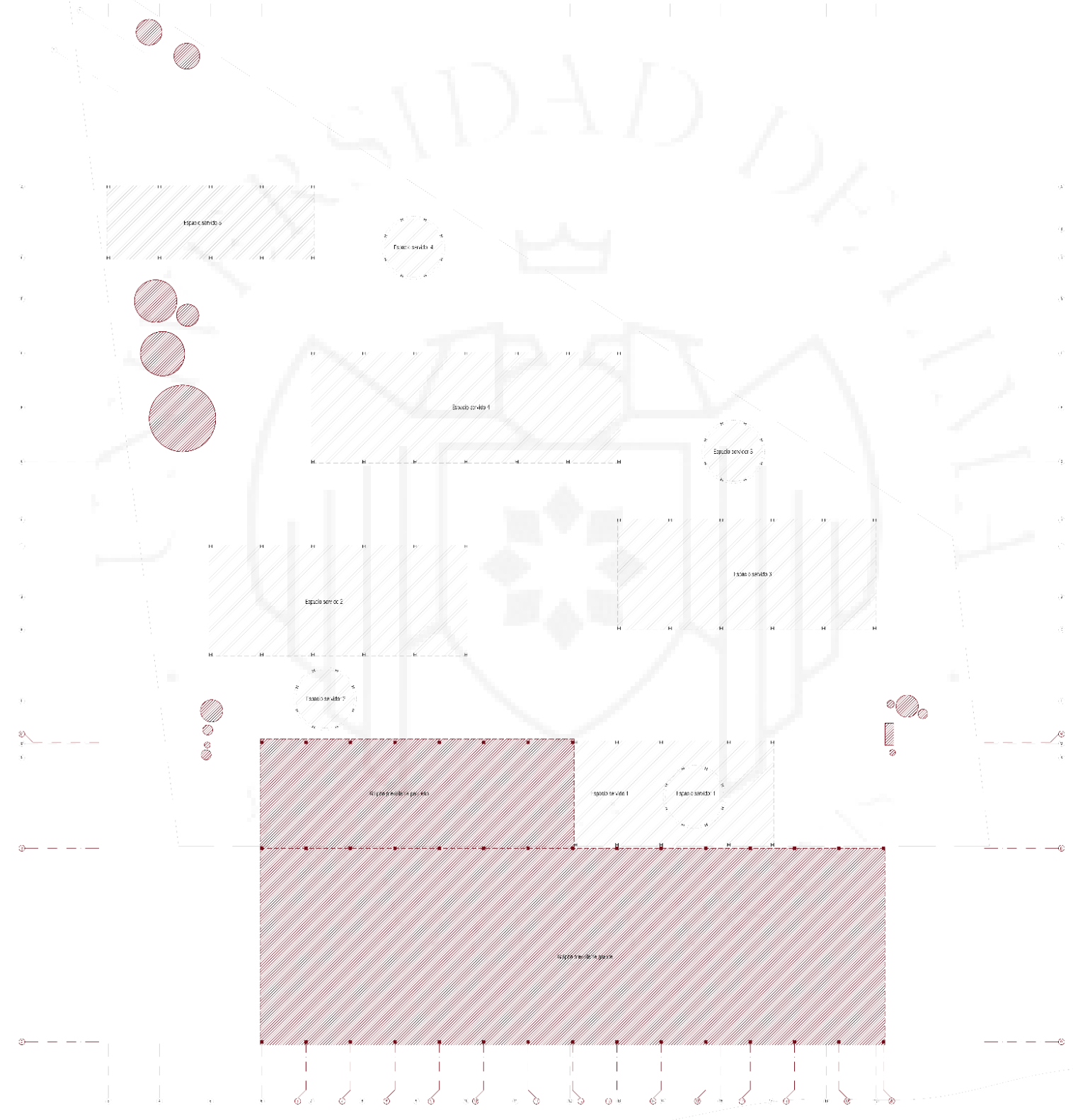

Fuente: Elaboración propia 
Ilustración 8.70 Planta del primer nivel

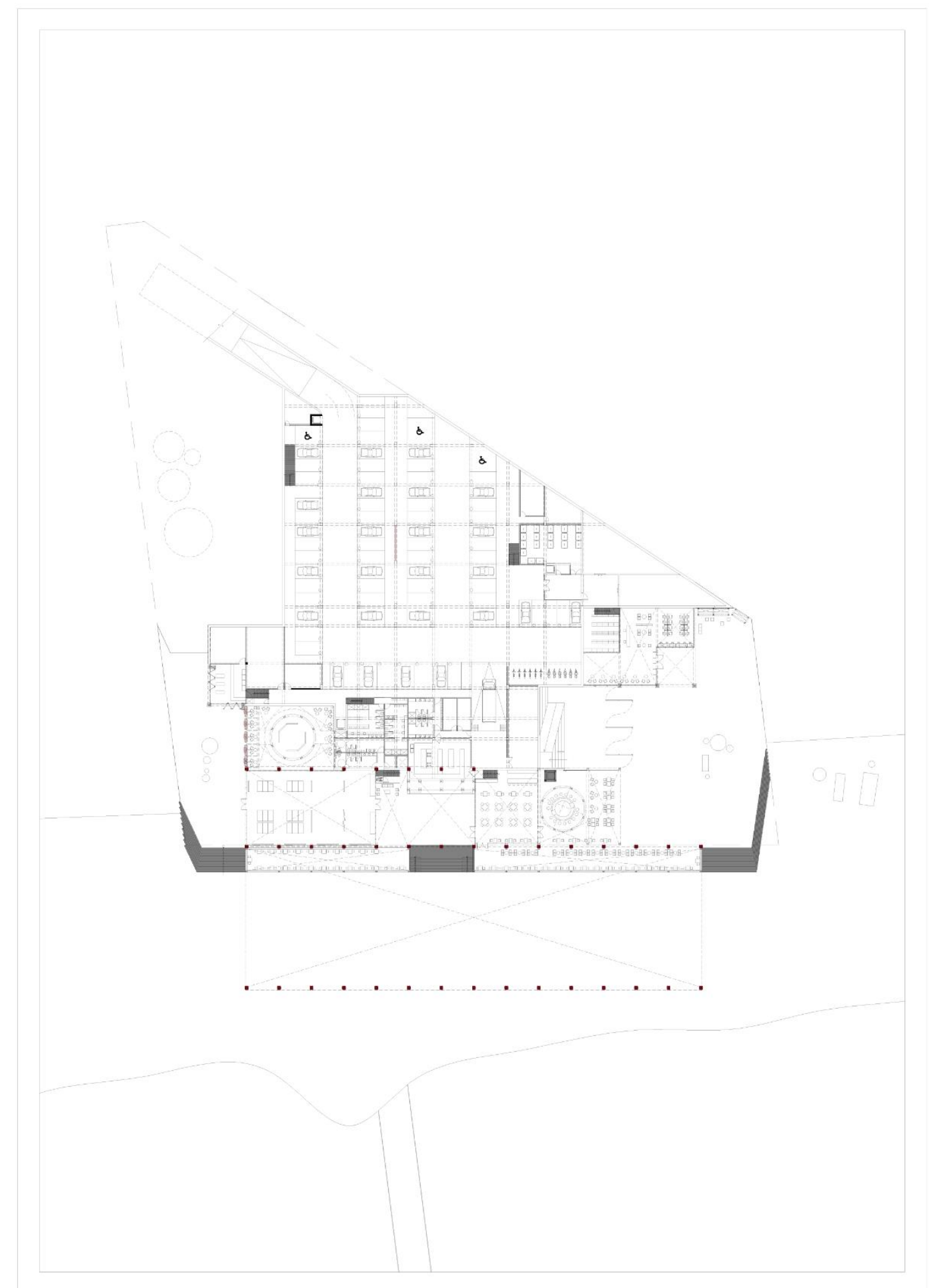

Fuente: Elaboración propia 


\section{Ilustración 8.71 Planta del segundo y tercer nivel}

Planta Segundo Nivel (+7.50)

Planta Tercer Nivel (+9.35)

Circulación Rápida (13.59\%)

Circulación Lenta (86.41\%)

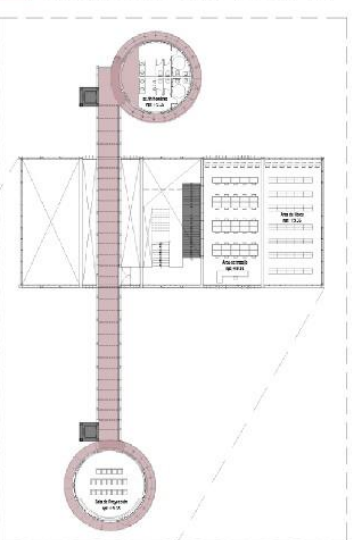

Circulación Rápida (13.59\%)

Circulación Lenta $(86.41 \%)$

Fuente: Elaboración propia 
Ilustración 8.72 Planta del cuarto nivel

Planta Cuarto Nivel (+12.70)

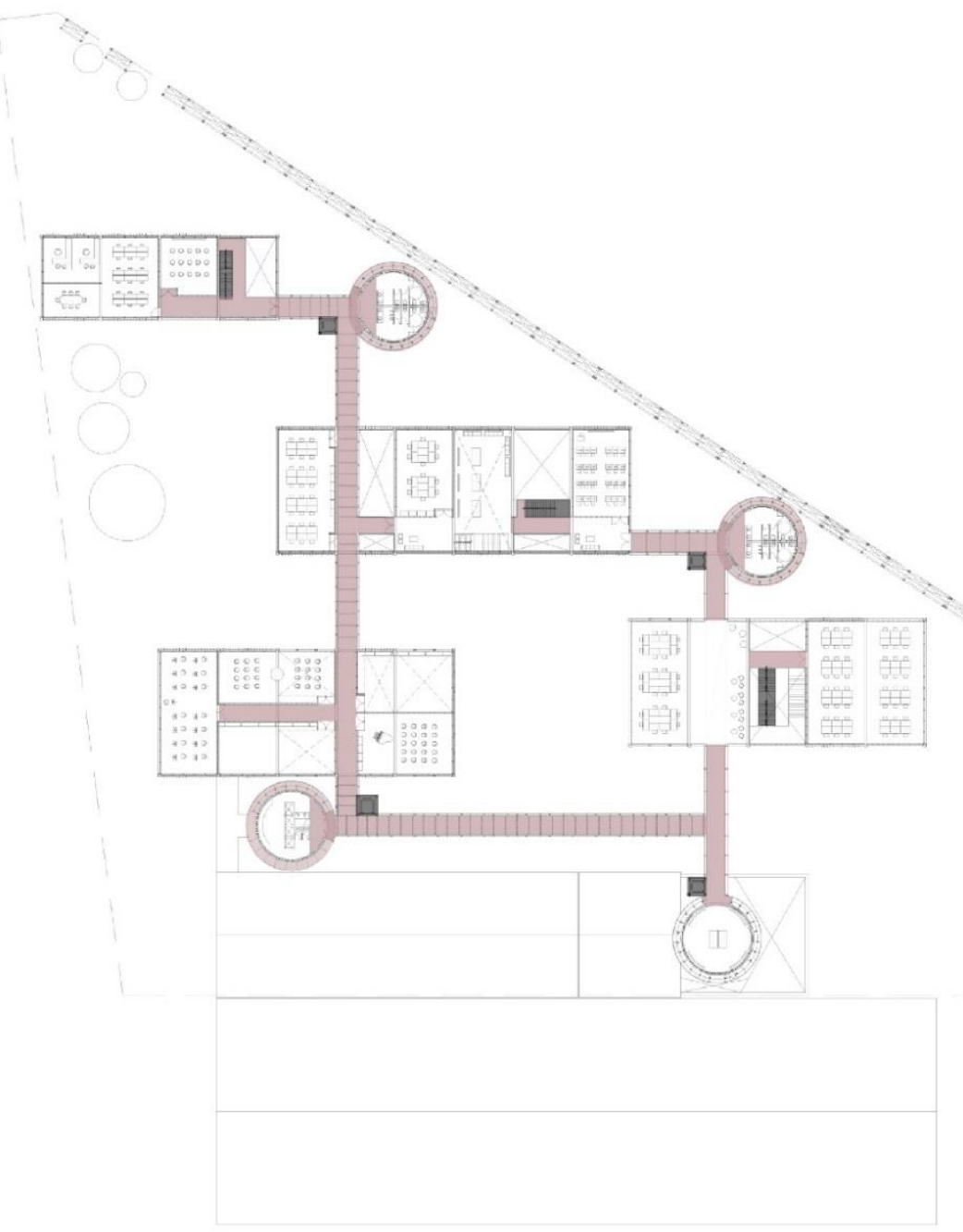

Circulación Rápida (7.71\%)

Circulación Lenta (92.29\%)

Fuente: Elaboración propia 


\section{Ilustración 8.73 Planta del quinto nivel}

Planta Quinto Nivel (+16.05)

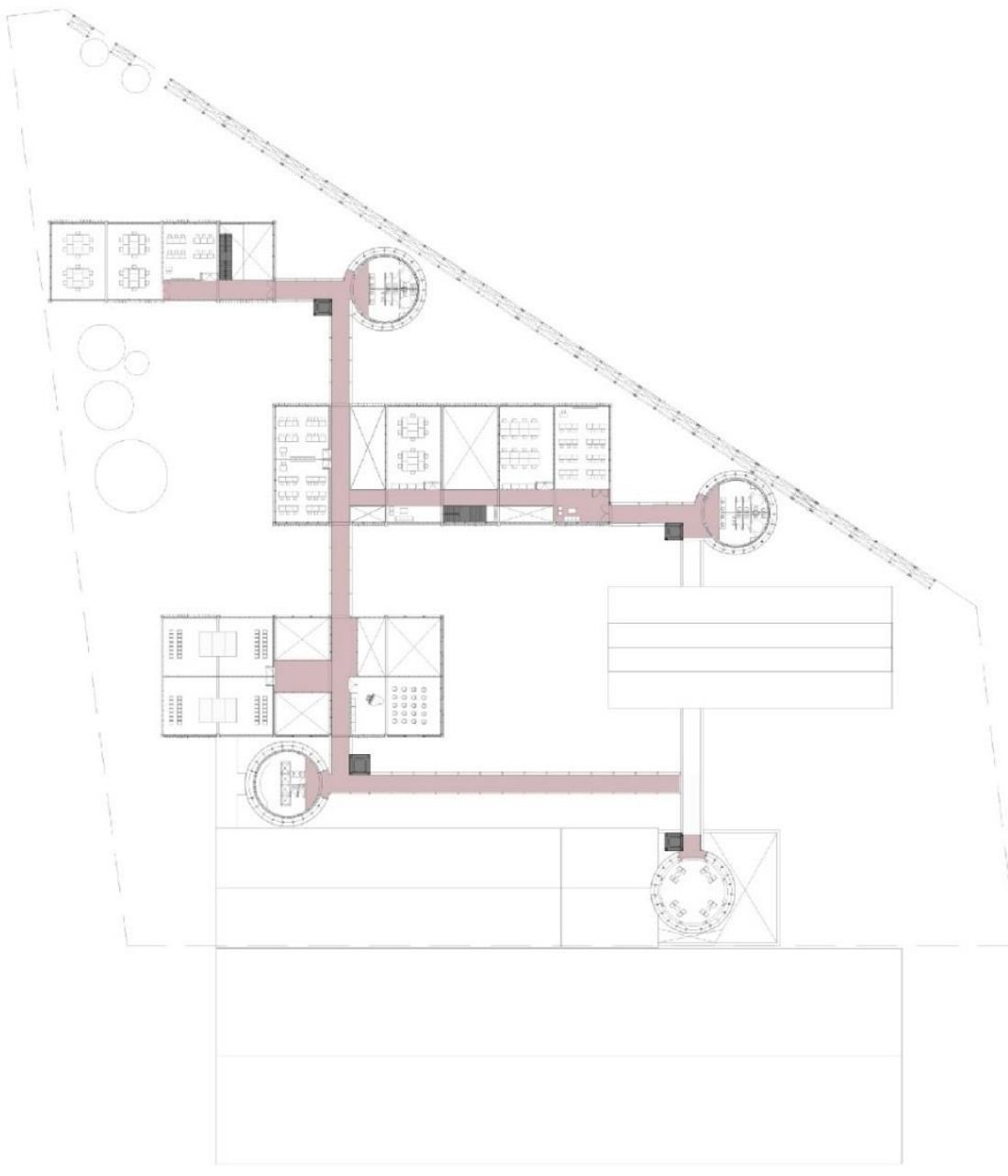

Circulación Rápida (1.88\%)

Circulación Lenta (98.12\%)

Fuente: Elaboración propia 


\subsection{Sistema constructivo}

El sistema constructivo de los galpones está conformado por un conjunto de piezas que al ensamblarse logran dar como resultado la composición final. Cada galpón está constituido por una estructura completamente metálica la cual se amarra a la estructura de concreto armado proveniente de los sótanos. Está compuesto por un sistema de vigas y columnas metálicas que conforman el soporte vertical del espacio; sobre estos elementos se apoyan losas colaborantes y viguetas metálicas que permiten adosar cada paño del proyecto. La estructura interna de los galpones está compuesta por tabiquería de superboard, la cual tiene una resistencia a la humedad bastante alta. Además, toda la carpintería tanto interna como externa del proyecto es metálica con celosías metálicas operables que permiten una adecuada ventilación de los espacios. La cubierta de los galpones también está compuesta por una serie de tijerales metálicos estructurados entre sí para poder sostener las planchas de zinc que se encuentran sobre ellos. Se optó por colocar estas planchas ya que son elementos sumamente resistentes ante la corrosión y agentes atmosféricos.

\section{Ilustración 8.74 Estructura metálica principal del galpón}

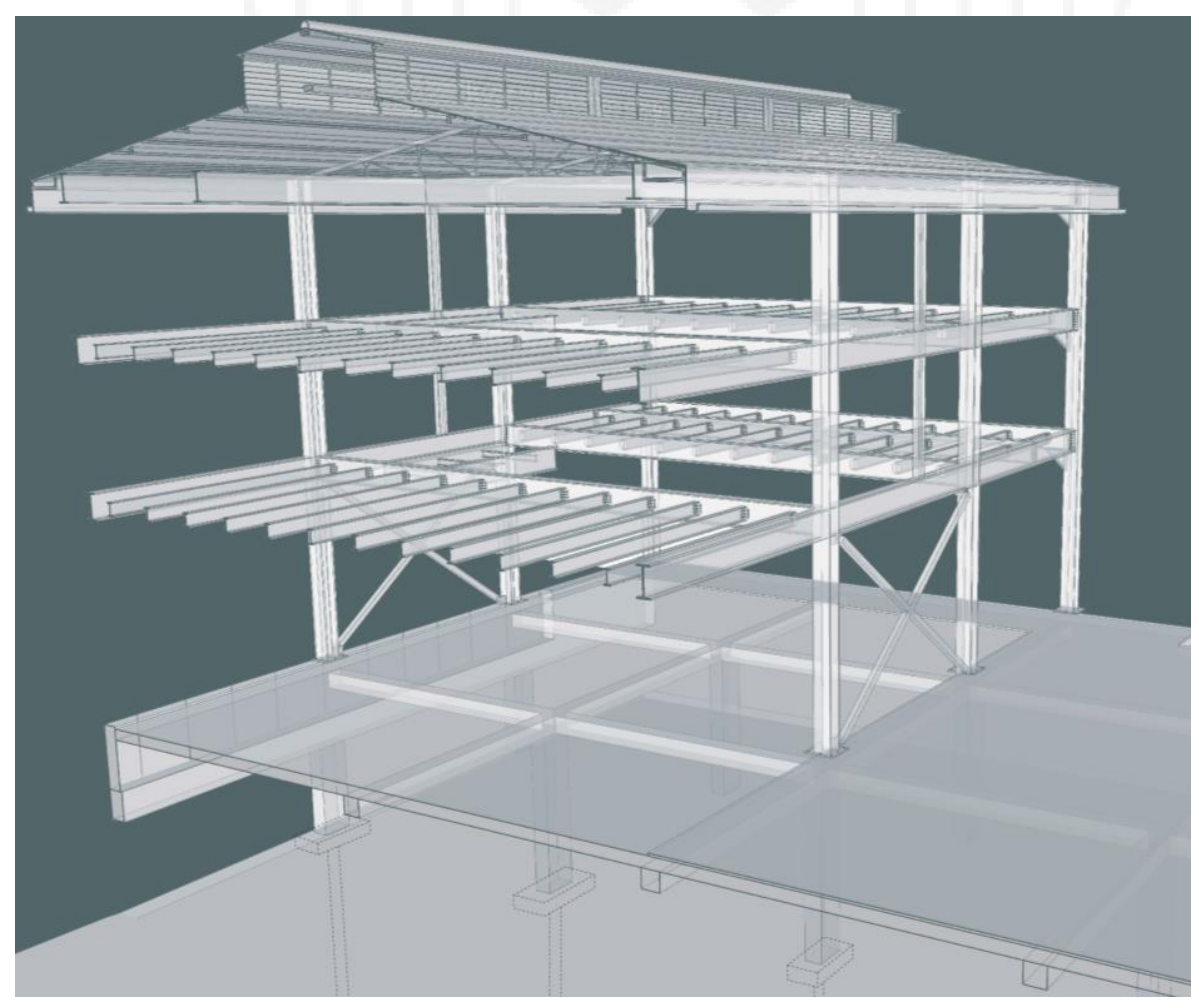

Fuente: Elaboración propia 


\section{Ilustración 8.75 Detalle constructivo isométrico del galpón}

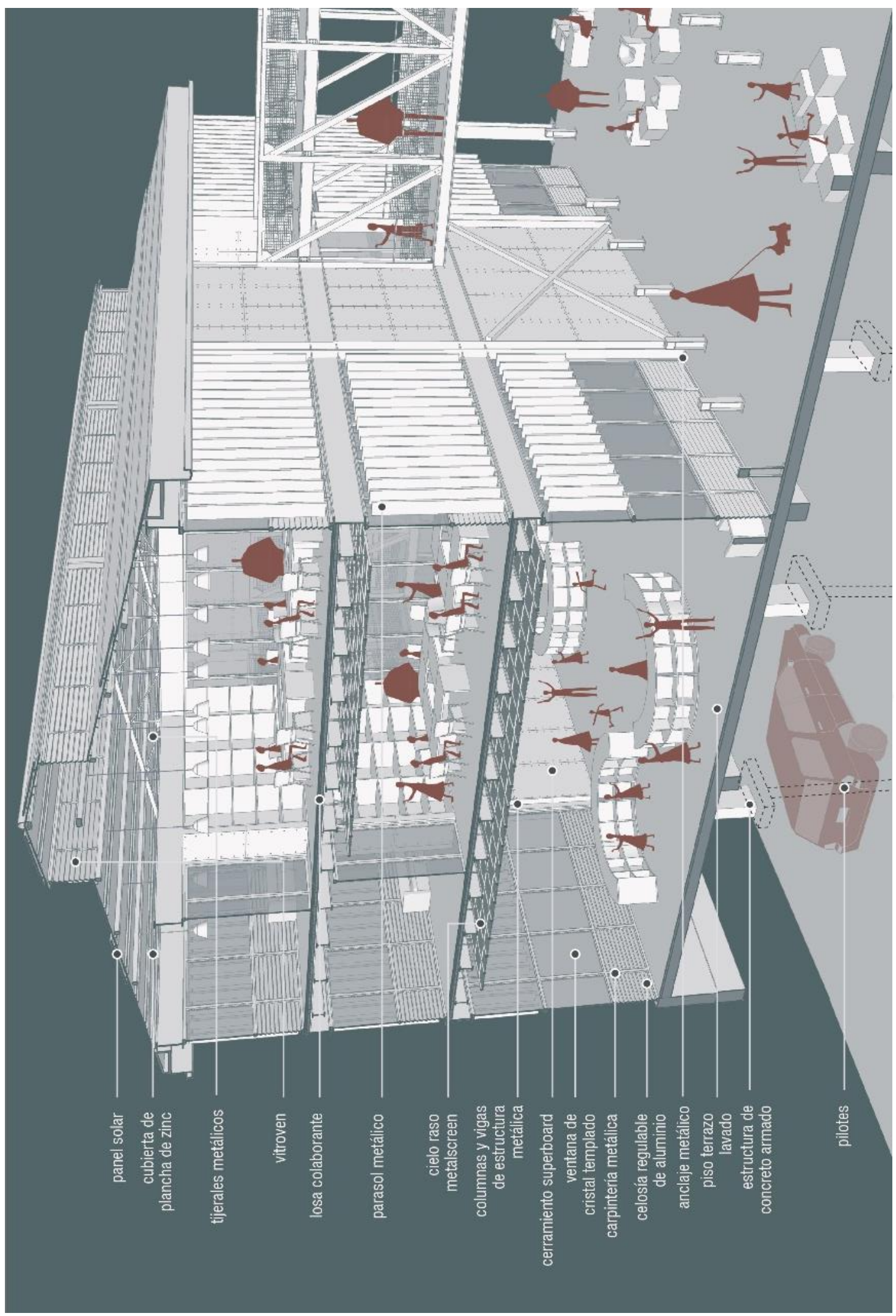

Fuente: Elaboración propia 
Los tanques al ser elementos servidores que contienen espacios sanitarios como baños y camerinos debían tener una estructura que responda a estos requisitos.El sistema constructivo también se encuentra compuesto por una estructura metálica de vigas y columnas, reforzadas por viguetas metálicas sobre las que se apoyan losas colaborantes. Todas las divisiones internas están conformadas por tabiques de superboard sanitario.

\section{Ilustración 8.76 Estructura metálica principal el tanque}

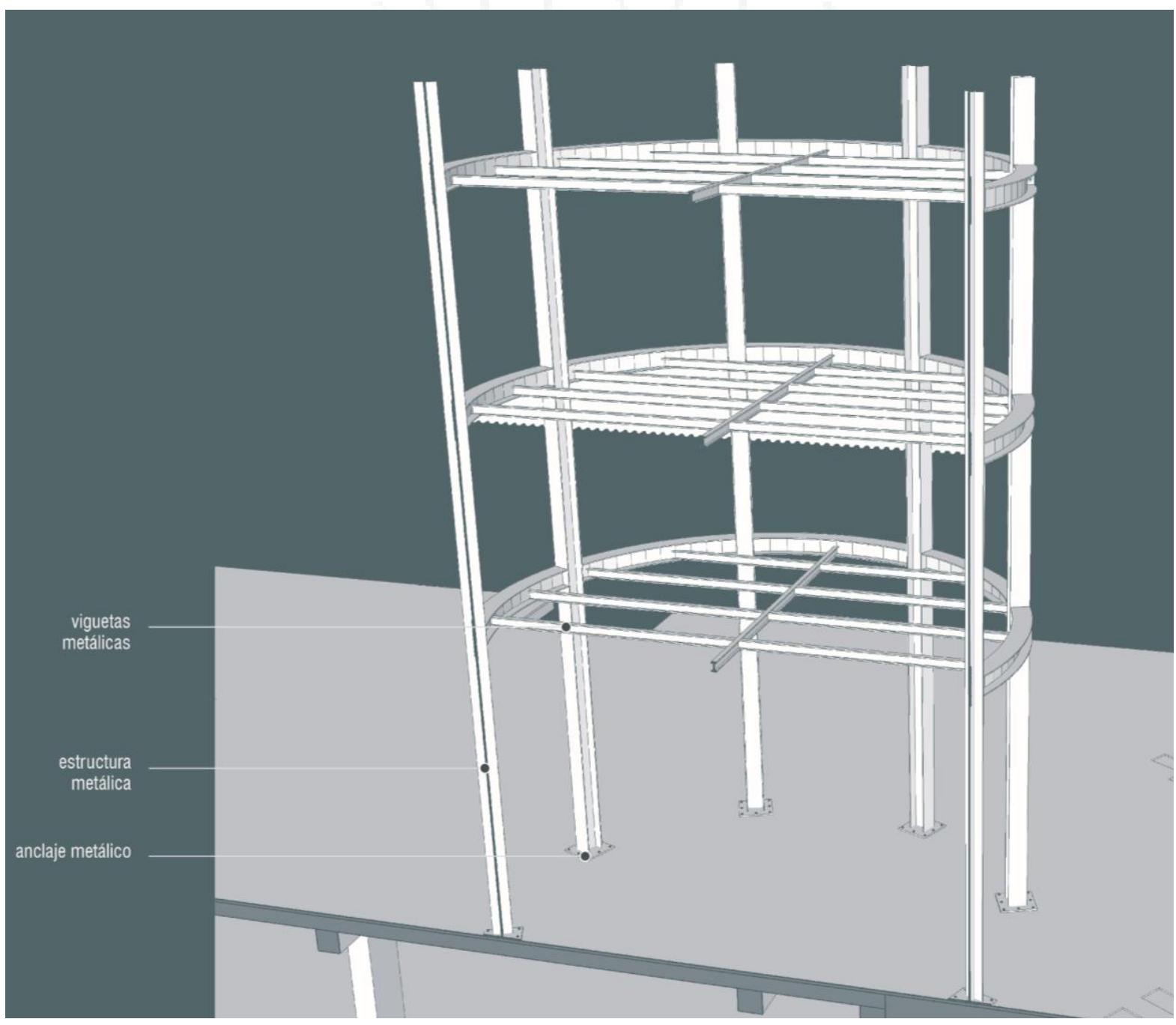

Fuente: Elaboración propia 
Ilustración 8.77 Detalle constructivo isométrico del tanque

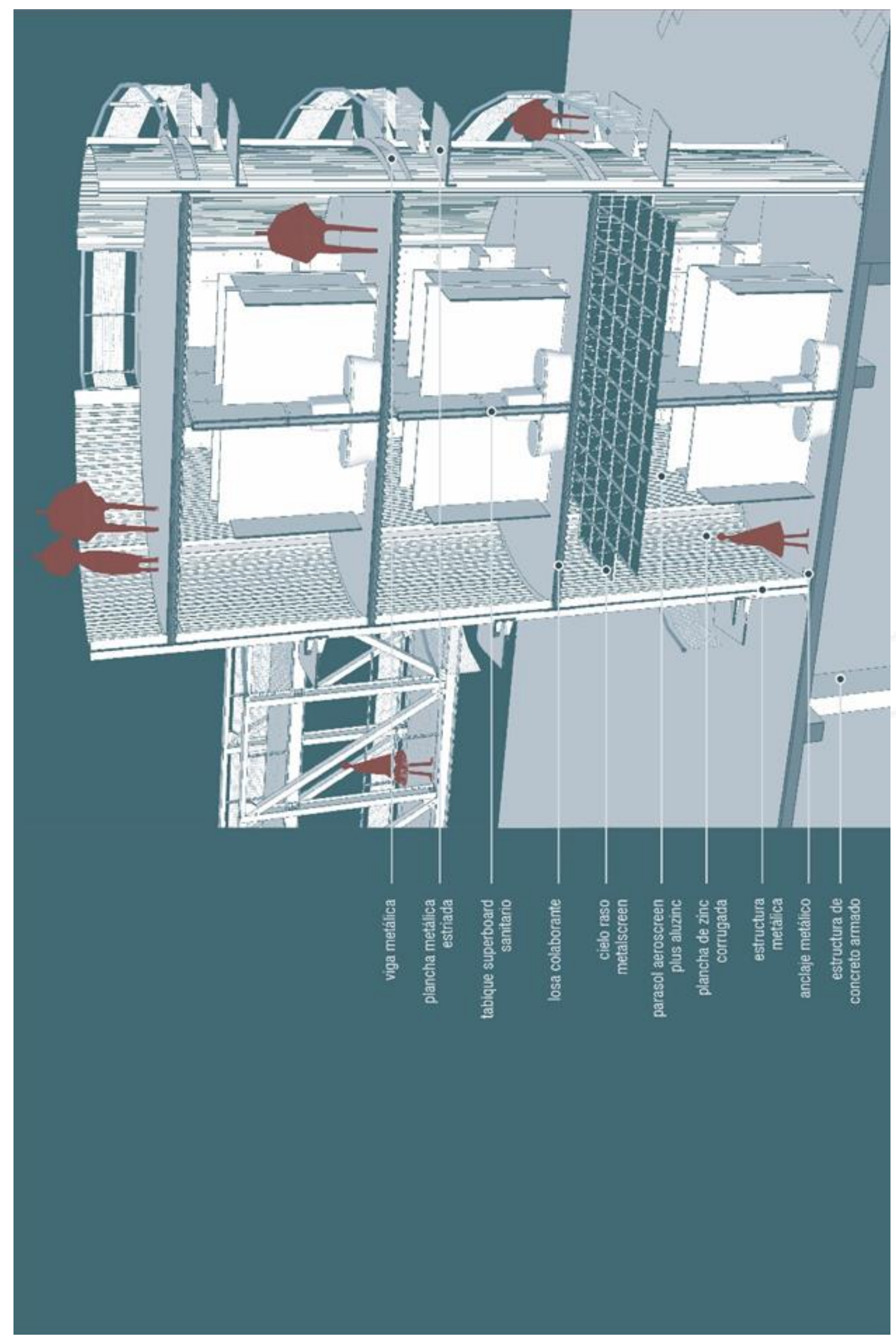

Fuente: Elaboración propia 


\subsection{Tecnología bioclimática}

Para el correcto diseño de espacios fue necesario realizar un análisis sobre las condiciones climáticas que tendría que afrontar el proyecto. Con respecto a la tecnología del proyecto es importante señalar la ubicación en la que este se encuentra situado. Al encontrarse en un frente costero se presentaron distintos factores medio ambientales sobre los que el proyecto debía adaptarse y responder ante ellos como son: asoleamiento, viento y brisa marina y precipitaciones.

\subsubsection{Fachadas}

Los galpones se encuentran orientados de acuerdo a la dirección de los galpones preexistentes para obtener una mejor organización espacial en el terreno. De acuerdo al análisis bioclimático de asoleamientos, las caras longitudinales recibirían mayor cantidad de luz solar causando que el confort dentro de los espacios no sea el mejor para los usuarios. Es por ello que, para proteger las fachadas afectadas, se decidió colocar parasoles aeroscreen plus de acero corten que acompañan las ventanas de cristal templado, que además presentan celosías regulables de aluminio en la parte inferior para permitir el ingreso de aire proveniente del sur oeste a los espacios.

\section{Ilustración 8.78 Diagrama del asoleamiento con respecto al proyecto}

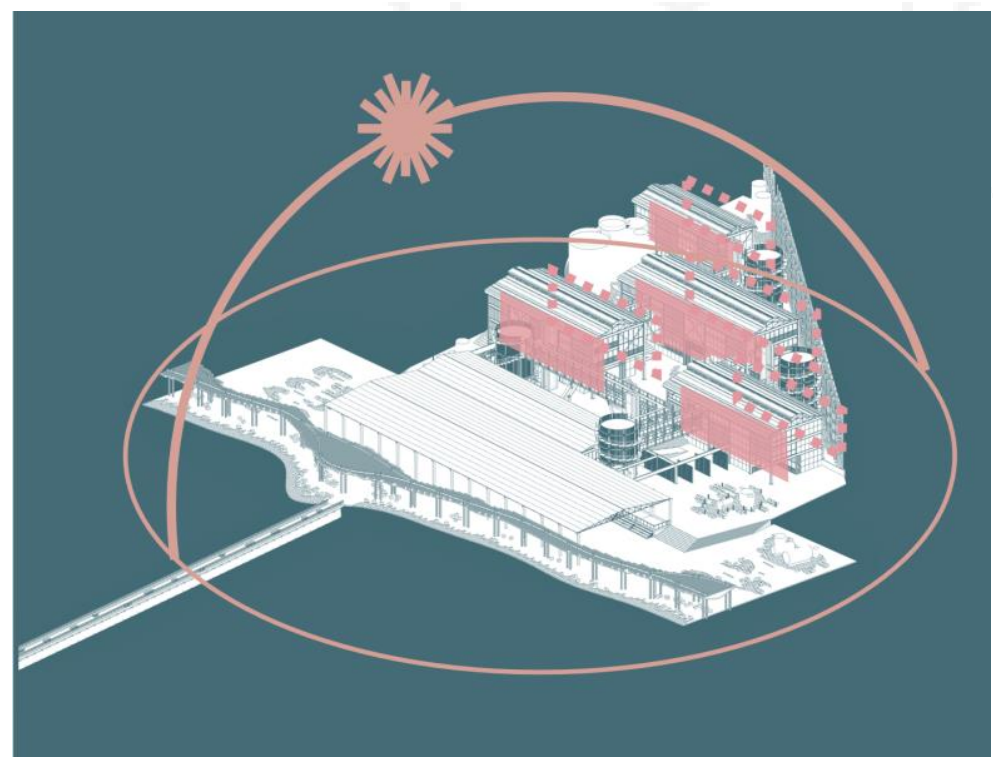

Fuente: Elaboración propia 
El diseño de las fachadas de los galpones no solo responde al asoleamiento del entorno, sino también a los vientos provenientes del Sur- Oeste. El proyecto además aprovechó esta orientación de los vientos para que con una adecuada ubicación de vanos se pueda lograr una ventilación cruzada dentro de los ambientes y con esto eliminar la necesidad de aparatos de aire acondicionado, reduciendo el consumo energético del edificio.

La cubierta además funciona como elemento de ventilación a través de la celosía operable de aluminio con la que cuenta en la parte superior y que permite el ingreso del aire frío, el cual a su vez permitirá expulsar el aire caliente interno de cada galpón.

Otra estrategia utilizada para responder ante los vientos del sur-oeste fue que el proyecto se diseñará por piezas o galpones independientes, de manera que a través de las plazas que existan entre ellos se puedan canalizar las corrientes de viento.

La inclinación de la cobertura también responde a las condiciones medioambientales ya que en el año 2017 Chimbote se vio afectado por la corriente del niño, por lo que se decidió diseñar cubiertas inclinadas que se desemboquen en canaletas en ambos extremos para poder filtrar el agua de las precipitaciones.

\section{Ilustración 8.79 Diagrama de vientos con respecto al proyecto}

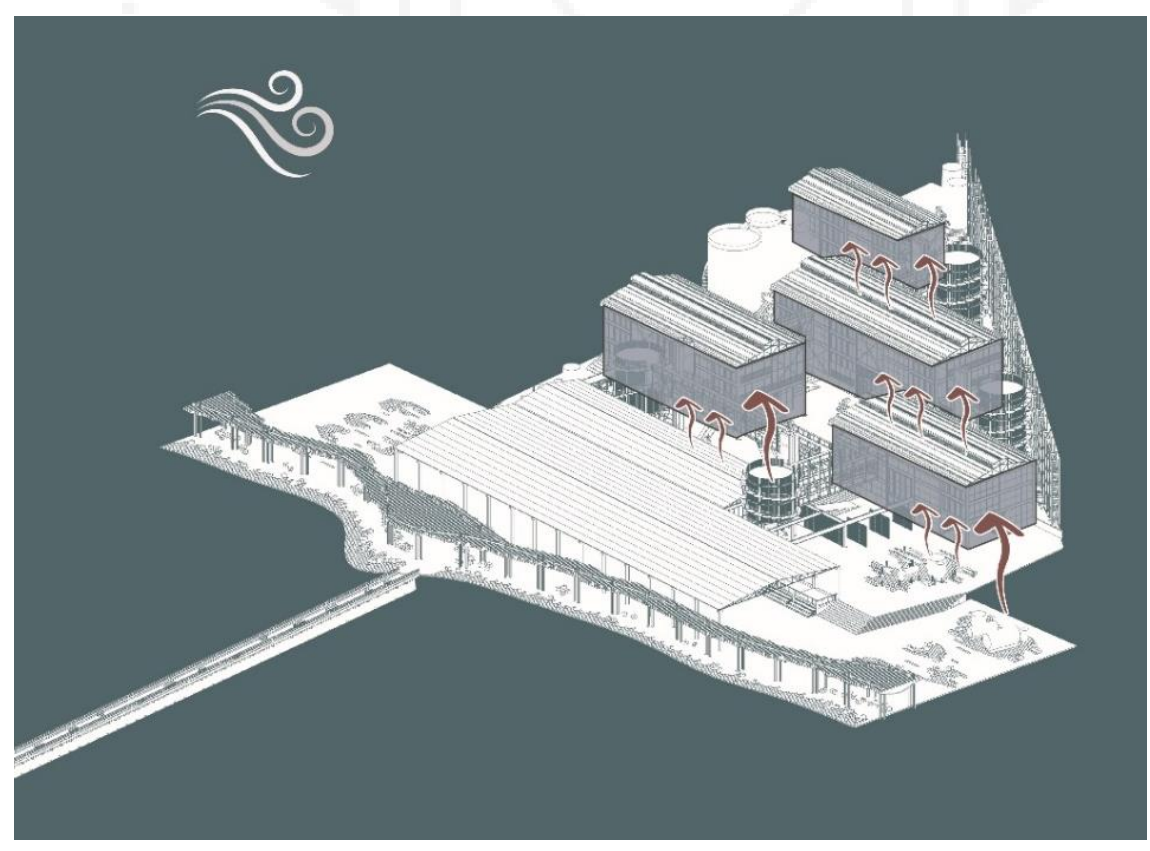

Fuente: Elaboración propia 
El proyecto está compuesto por una doble fachada, en la que la capa externa está conformada por parasoles fijos verticales de plancha metálica de 1" de espesor y $30 \mathrm{~cm}$ de fondo, que evitan que los rayos solares ingresen al proyecto.

La capa interna de la fachada está compuesta por 2 módulos; el módulo superior está compuesto por un paño de vidrio templado fijo y en la parte inferior un módulo de celosía operable de aluminio, que permitirá el ingreso de ventilación a los espacios.

\section{Ilustración 8.80 Composición de la fachada del galpón}

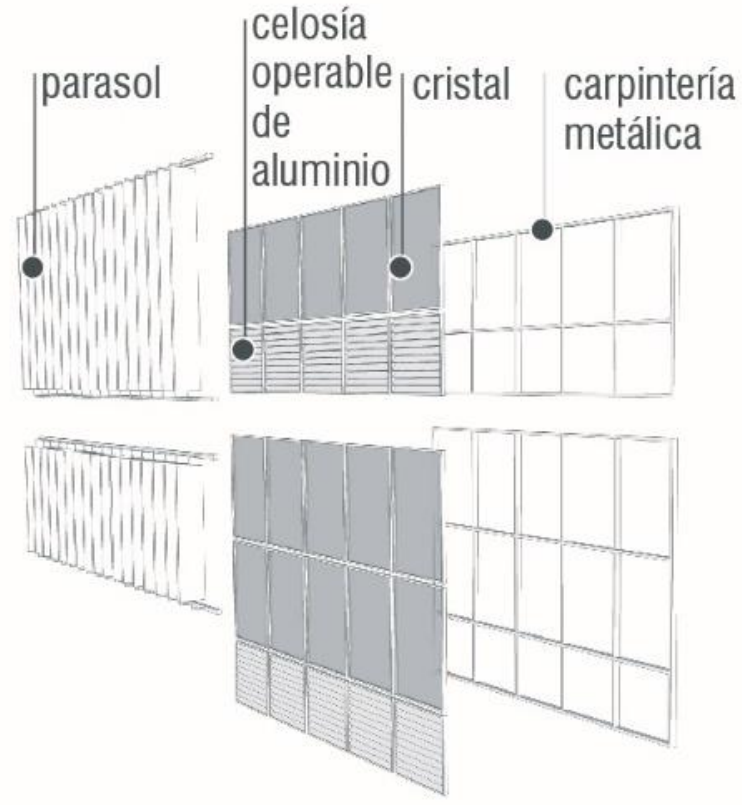

Fuente: Elaboración propia

En la siguiente sección se puede apreciar los elementos que componen la fachada, donde la capa externa está compuesta por los parasoles fijos, las dimensiones en cuanto a altura de estos son variable, ya que en muchos casos los vanos poseen doble altura, como es el caso de la sección que se aprecia a continuación. En este caso la fachada contiene dos parasoles, uno debajo del otro y ambos, fijos. En el caso de la fachada interna también al ser doble altura se duplicaron los módulos tanto de celosías operables de aluminio, así como también del cristal templado. 


\section{Ilustración 8.81 Detalle de estructura de la fachada}

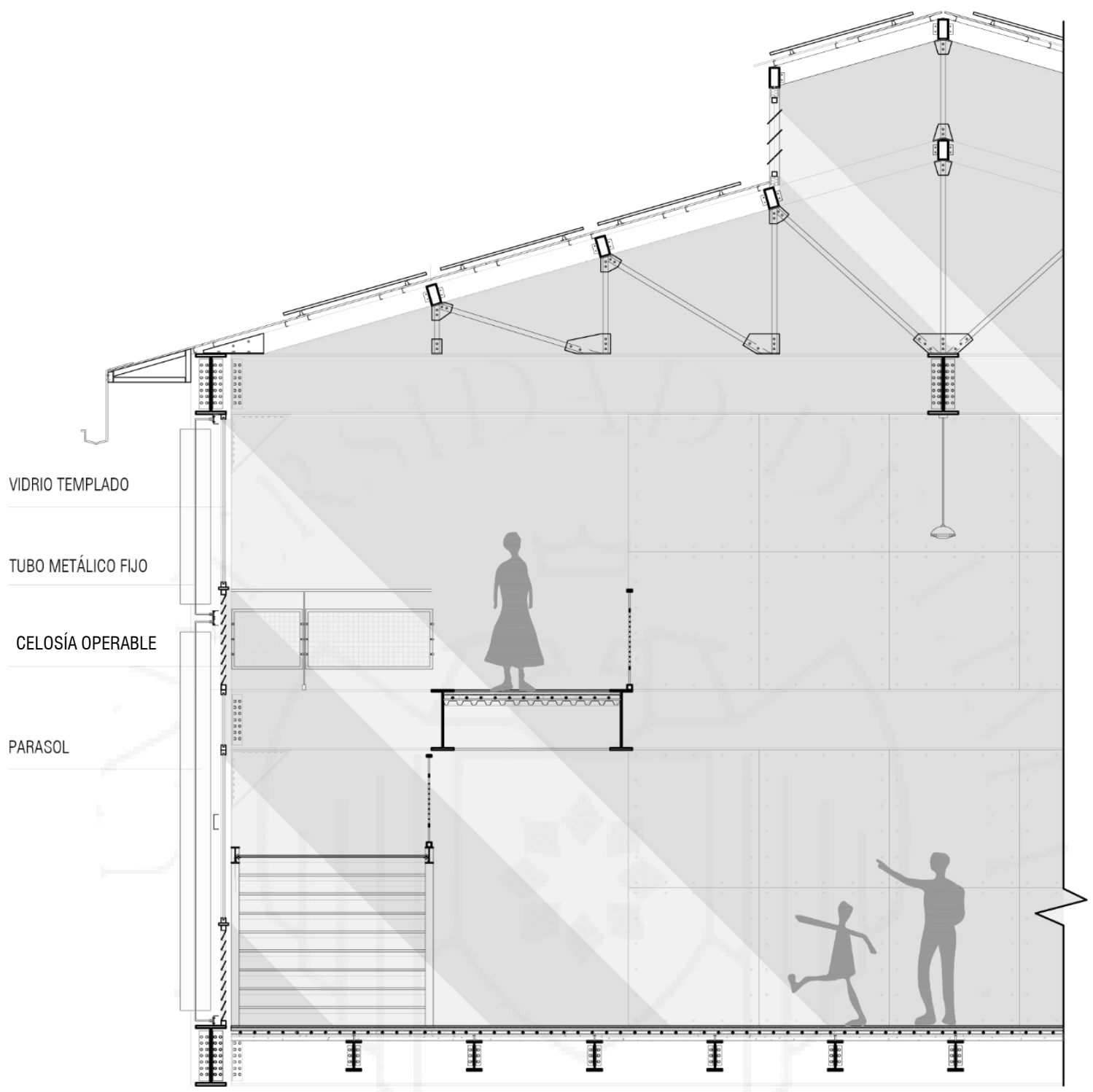

Fuente: Elaboración propia

En la siguiente imagen se aprecian los techos inclinados que desembocan en una canaleta curva de PVC de 8", además se decidió colocar una cobertura metálica acanalada, de manera que las precipitaciones se puedan deslizar por la cobertura con mayor facilidad. 


\section{Ilustración 8.82 Detalle del techo del galpón}

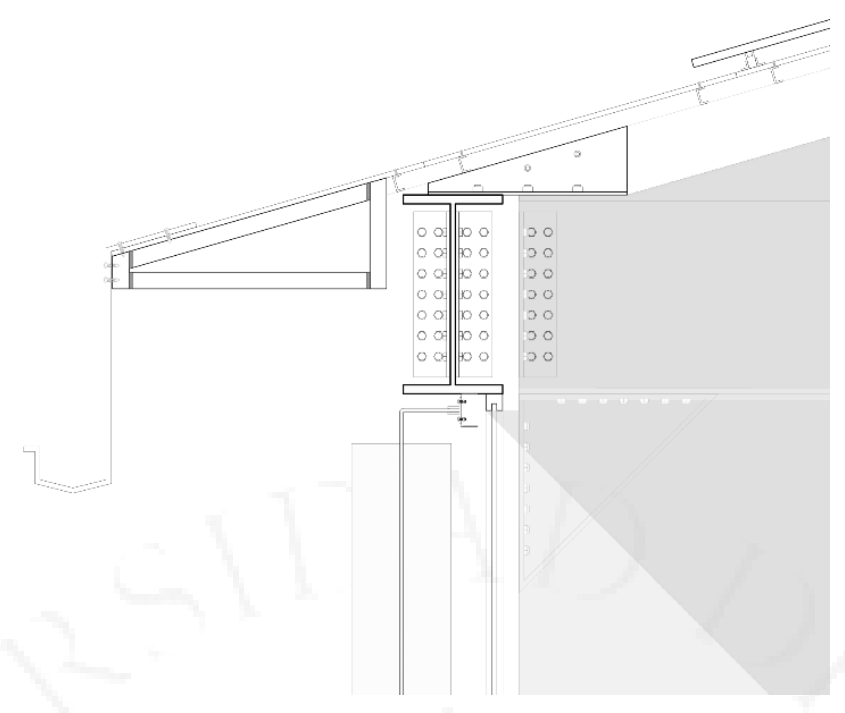

Fuente: Elaboración propia

El siguiente gráfico representa la temperatura interna del galpón y cómo el proyecto ha sido diseñado para mantener un confort térmico en los espacios interiores. Se ha considerado colocar celosías operables de aluminio en la parte inferior de los vanos, de manera que el aire ingrese en dirección de abajo hacia arriba y logre refrescar los espacios y eliminar el aire caliente por medio de la cubertura.

Las coberturas inclinadas son los elementos con temperatura más alta debido al contacto directo con el sol, transmitiendo esta temperatura hacia el resto de espacios. Por este motivo, el propósito de colocar las celosías operables en la parte inferior fue también con el objetivo de que la corriente de aire frío que ingrese a los galpones pueda empujar el aire caliente que se encuentra dentro de los espacios y salga con mayor facilidad por los vanos que se encuentran en los niveles superiores del proyecto. 


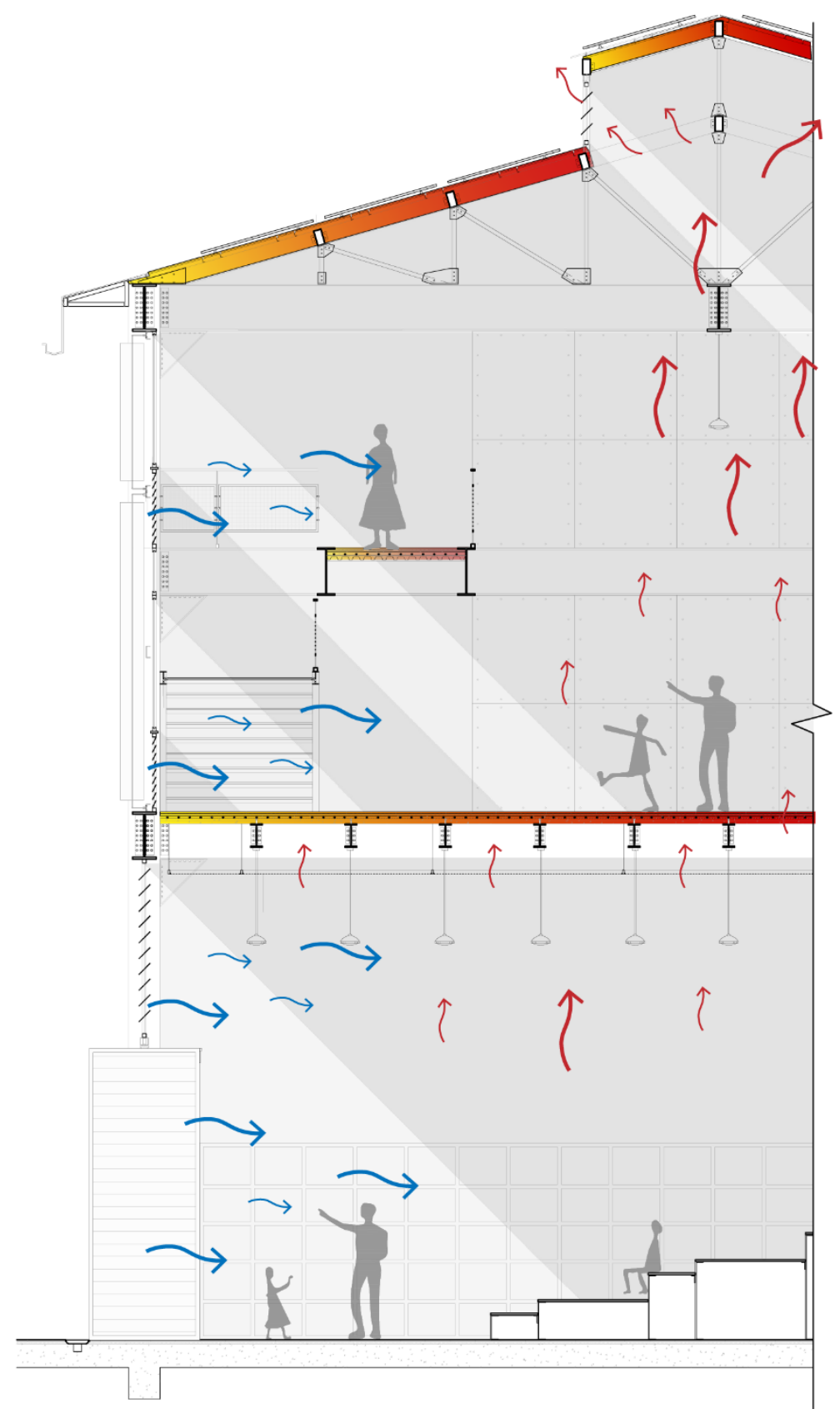

Fuente: Elaboración propia

El aire caliente dentro de los espacios tiende a elevarse, por lo que las losas también representan uno de los elementos dentro del espacio con mayor temperatura. El aire frío que ingrese al proyecto logrará empujar este calor almacenado, llevándolo al techo superior, el cual tiene una dimensión menor al resto del galpón. Esta dimensión fue pensada para que todo el 
calor que se encuentre almacenado en esa área pueda salir del galpón por presión, presentándose así el "Efecto Venturi”, ya que al disminuir la sección el aire caliente aumentará su velocidad al momento de salir.

\section{Ilustración 8.84 Gráfico de calor en el doble techo del galpón}

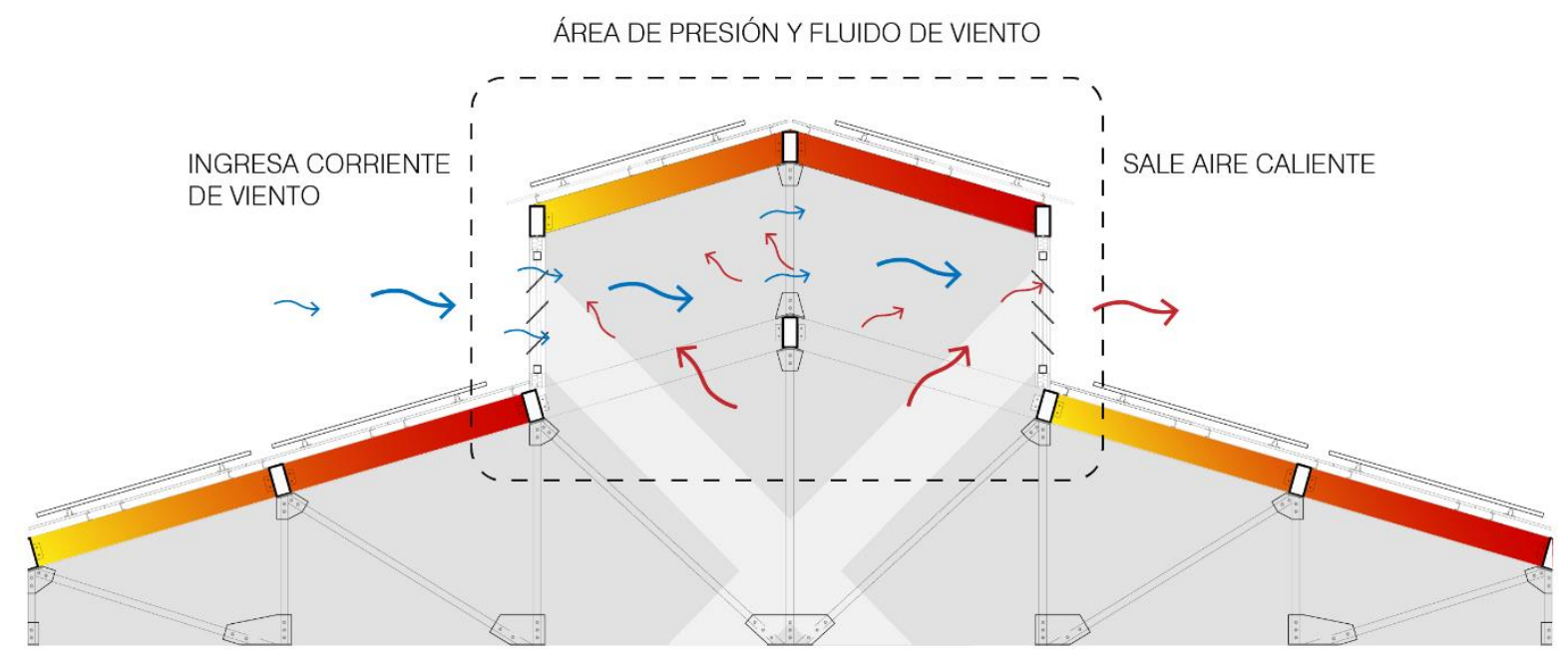

Fuente: Elaboración propia

\subsubsection{Acústica}

El diseño de los espacios internos también contempló el impacto que puede generar el ruido en el confort de los usuarios, es por esto que para aquellos espacios que tienen actividad con altos decibeles, tales como el auditorio principal, talleres de canto, talleres de baile, talleres de oratoria y entre otros, se optó por diseñar un recubrimiento que permita aislar el sonido tanto en el interior, como en el exterior del galpón. 


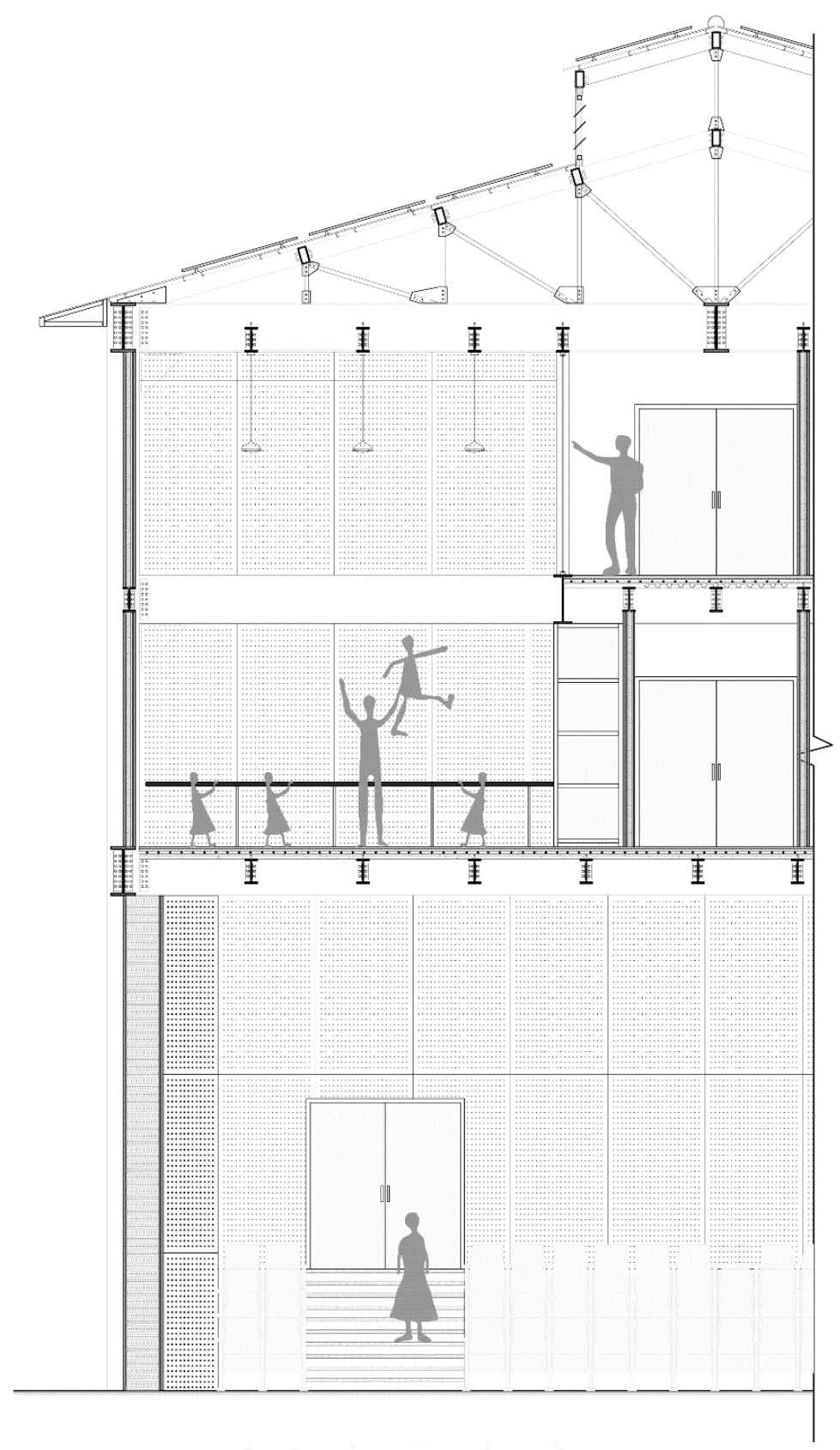

Fuente: Elaboración propia

Para ello se consideró colocar tabiquería aislante conformada por paneles perforados acústicos de madera, de dimensión 2.40 x 1.20 m, hacia ambos lados del tabique, que irán colocados adicionalmente al panel de fibrocemento con el que ya se contaba. Ambas piezas se unirán por una capa de tarrajeo. El interior del tabique también cuenta con un recubrimiento de fibra de vidrio para disminuir el impacto del ruido. La sección se puede apreciar a continuación. 
Los tabiques tienen dimensión rectangular, como se puede apreciar en el detalle previo, y están conformados por agujeros redondos de $8 \mathrm{~mm}$ de diámetro, los cuales se encuentran entre sí con una separación de 16 mm entre ellos.

Ilustración 8.86 Detalle del muro acústico al interior del galpón, dependiendo de su uso

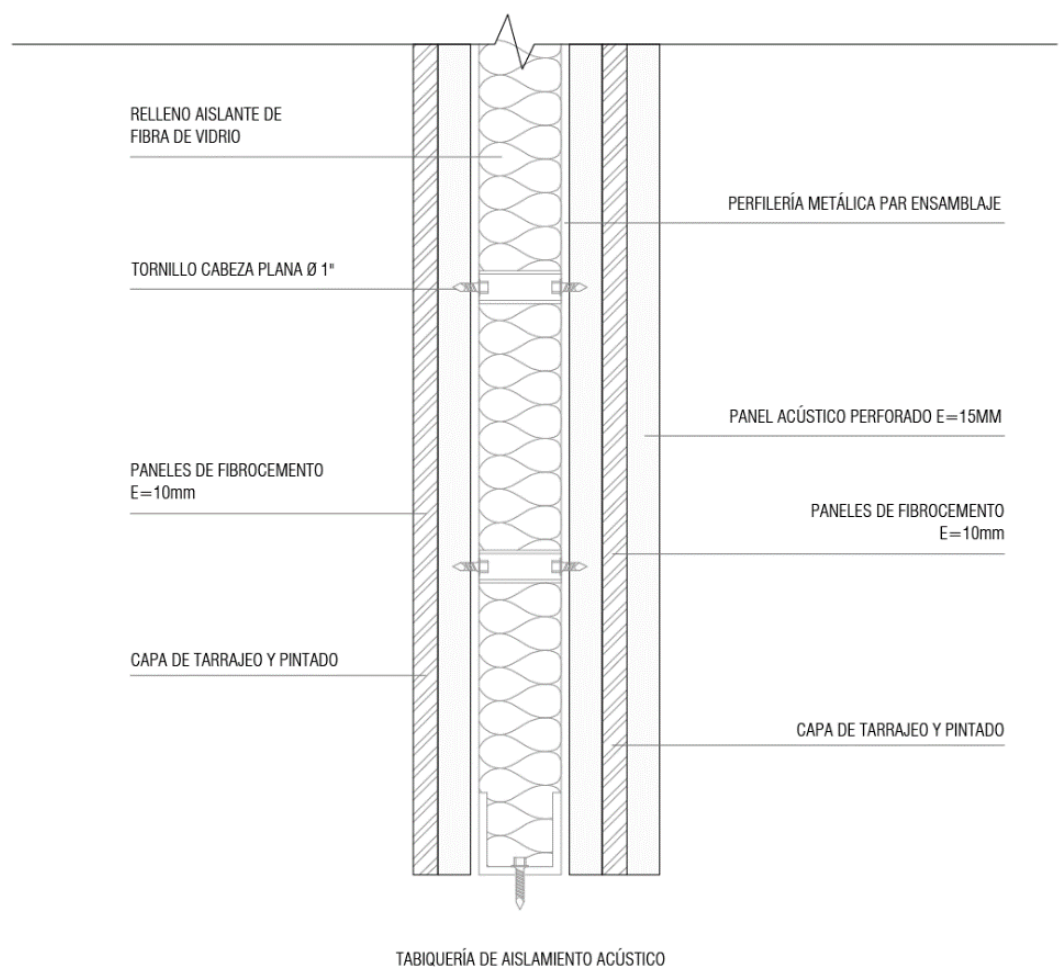

Fuente: Elaboración propia

\subsubsection{Ahorro energético}

Con el objetivo de aprovechar la gran superficie en las cubiertas inclinadas de los galpones y disminuir el consumo energético dentro de cada galpón se optó por colocar paneles solares fotovoltaicos de manera que se pueda captar la energía de los rayos solares y aprovecharla para la iluminación interna de los galpones. 
Los paneles solares fotovoltaicos tienen una dimensión de 1148 x $66 \mathrm{~cm}$, por lo que aproximadamente un galpón tiene capacidad para 140 paneles solares. La distribución se puede apreciar a continuación en la planta de techos.

\section{Ilustración 8.87 Detalle de ubicación del panel solar empleado}

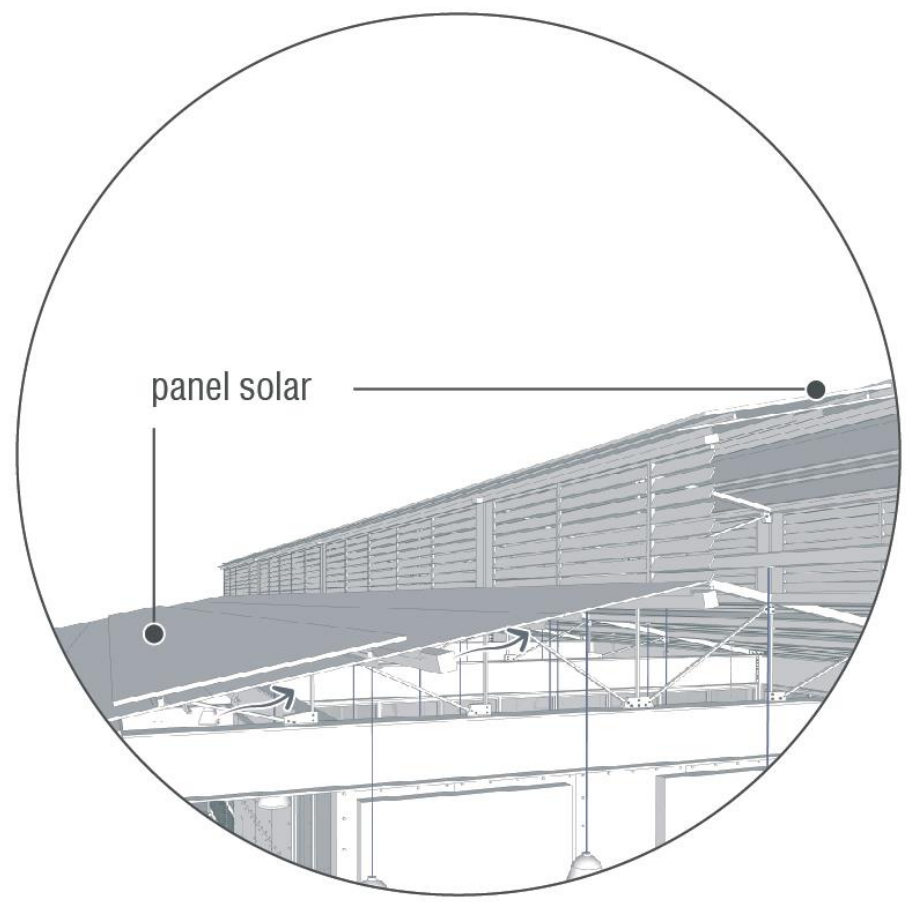

Fuente: Elaboración propia

\section{Ilustración 8.88 Panel solar empleado}

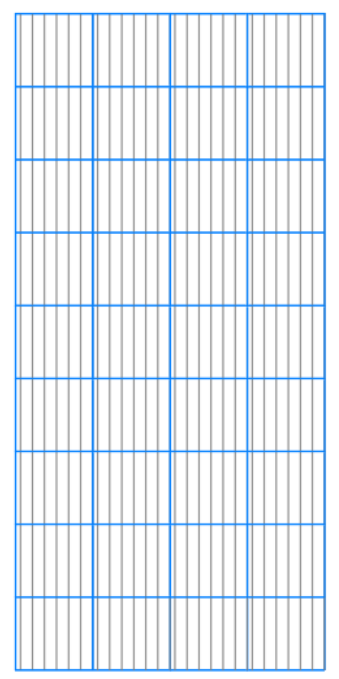

Fuente: Elaboración propia 


\subsection{Materialidad}

Uno de los objetivos del proyecto es repotenciar la identidad y memoria colectiva de la ciudad, por ello está ubicado en una fábrica y se han reciclado estructuras y piezas industriales, sumado a todo ello también se ha continuado con la apariencia a través de los materiales empleados. En la estructura se ha optado por columnas y vigas metálicas y losa colaborante, lo que permite tener un módulo base que al unir varios forman los galpones, tanques y puentes. En las fachadas, se ha empleado materiales distintos de acuerdo con el espacio que alberga cada pieza.

En la fachada de los galpones, se tiene fachadas traslúcidas compuestas por ventanas de vidrio templado, celosías operables de aluminio y parasoles de acero corten; y en las fachadas opacas compuestas por muros cubiertos de fibrocemento superboard, que cuando forman paños de doble altura se encuentran arriostradas por una estructura metálica en equis.

De la misma manera, los tanques presentan una estructura de vigas y columnas metálicas, fachada opaca compuesta por planchas de zinc doblada y una fachada que permite la iluminación y ventilación formada por una serie de láminas metálicas colocadas de manera diagonal.

La materialidad empleada en el proyecto ha sido pensada para responder a los efectos atmosféricos de la brisa marina, por lo que en su mayoría se ha empleado materiales metálicos con zinc permitiendo que el metal se vuelva más activo y esté conectado eléctricamente para controlar la corrosión a través de la protección catódica. Así también, se ha pensado en revestirlos de un aislamiento eléctrico como resina que complemente la labor del zinc en la estructura metálica empleada. 


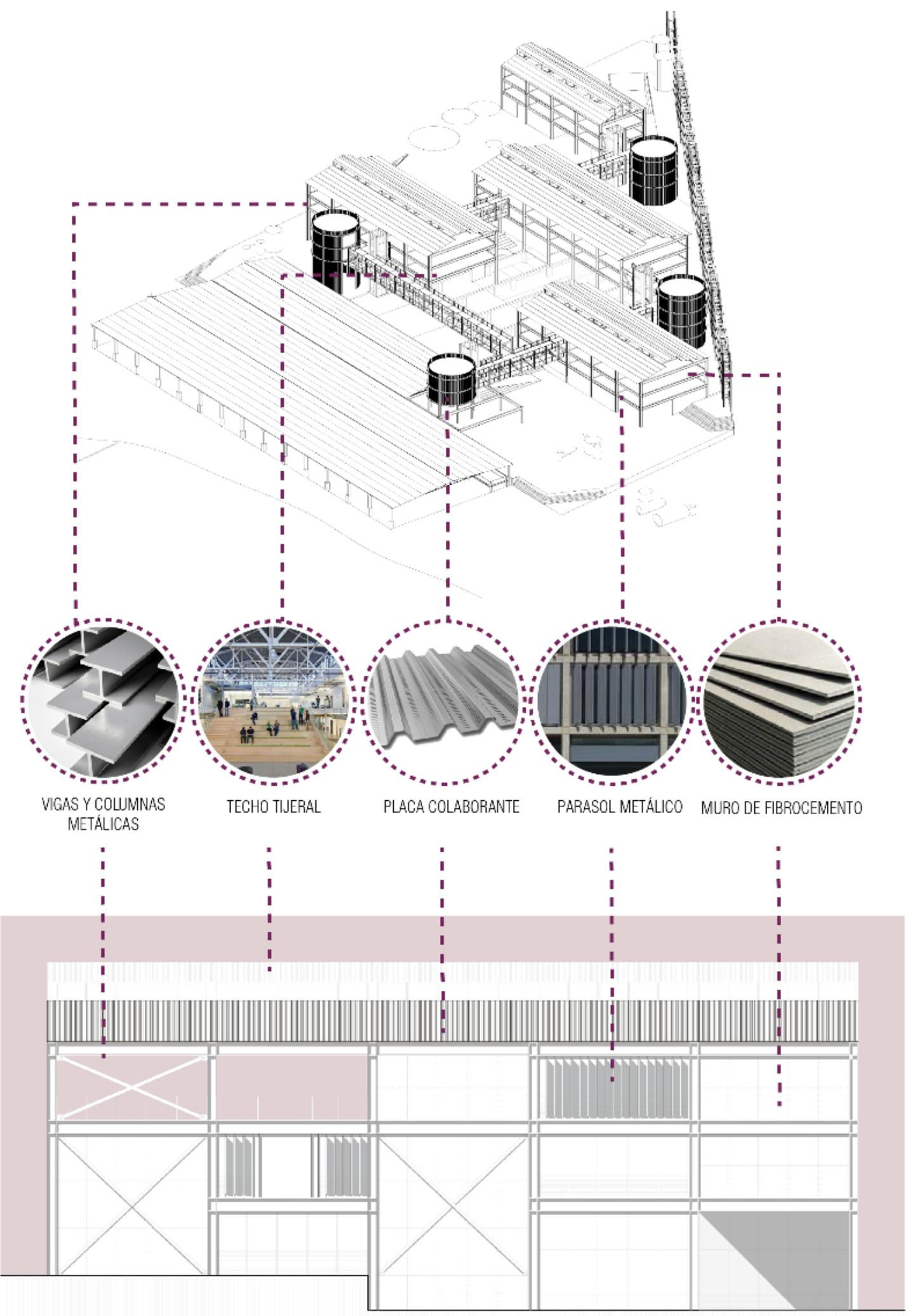

Fuente: Elaboración propi 


\subsection{Planimetría}

Ilustración 8.90 Plano de Orientación
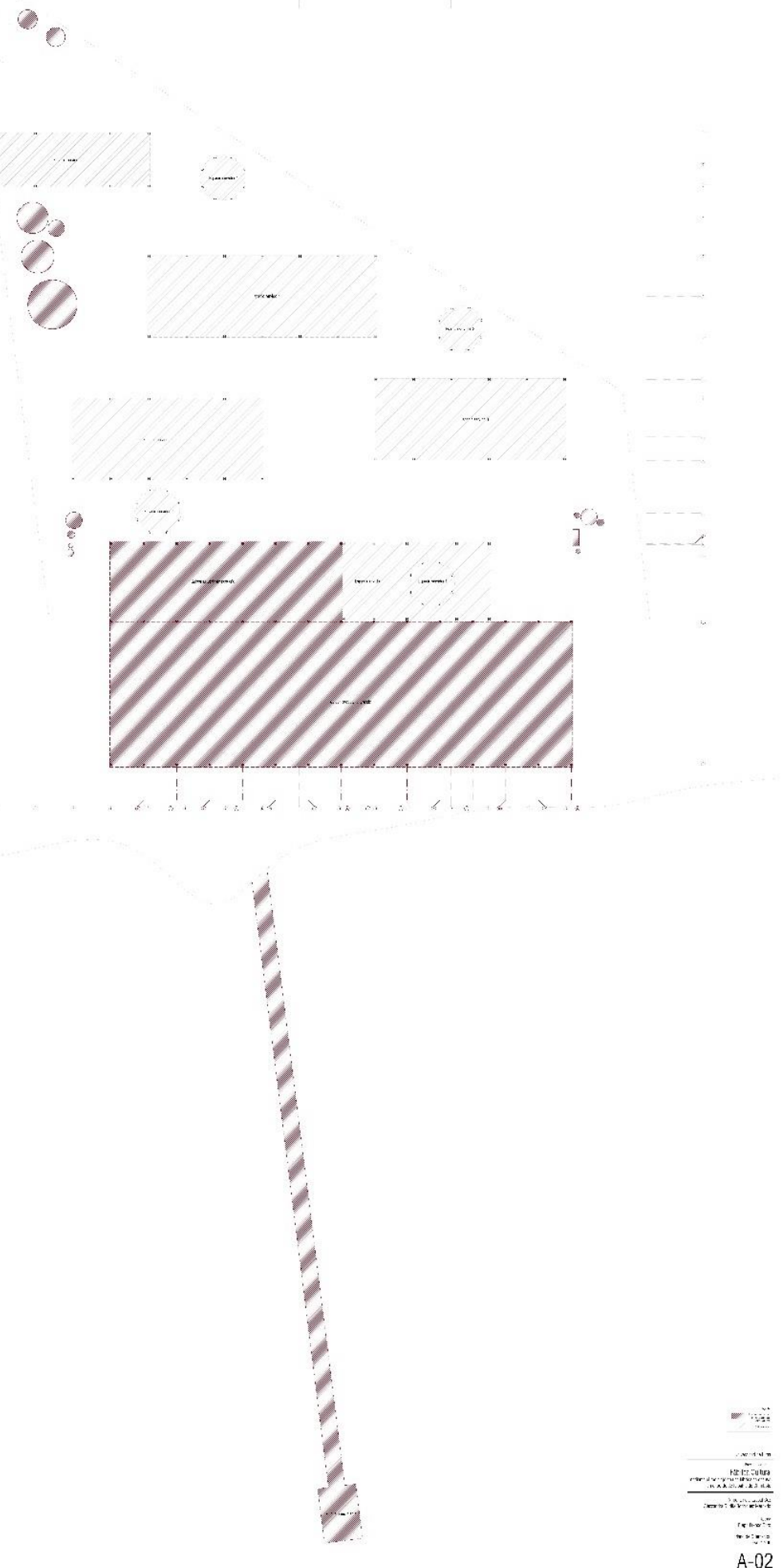

Fuente: Elaboración propia 
Ilustración 8.91 Planta Nivel +4.50m

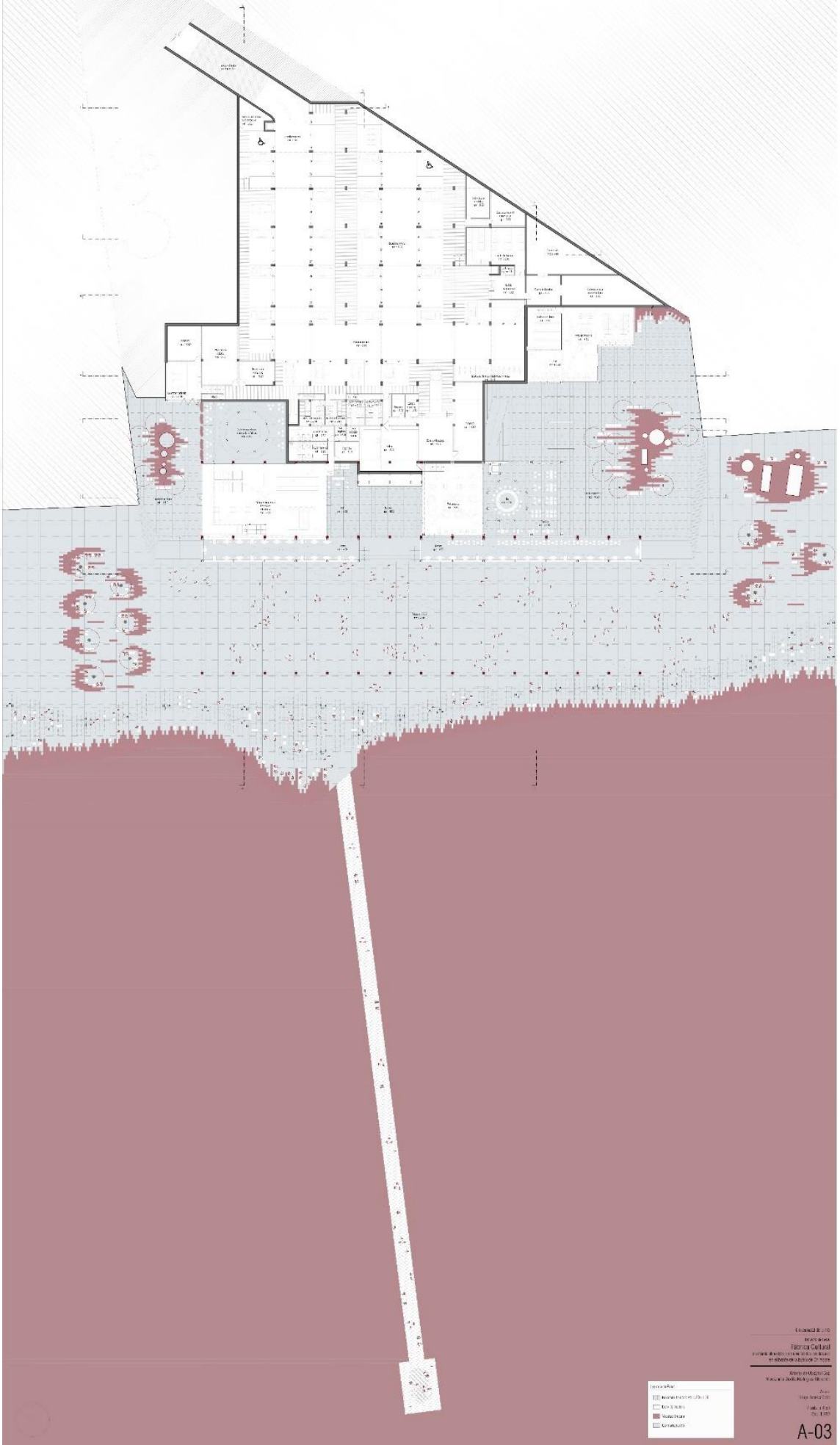

Fuente: Elaboración propia 
Ilustración 8.92 Planta Nivel +7.50 m

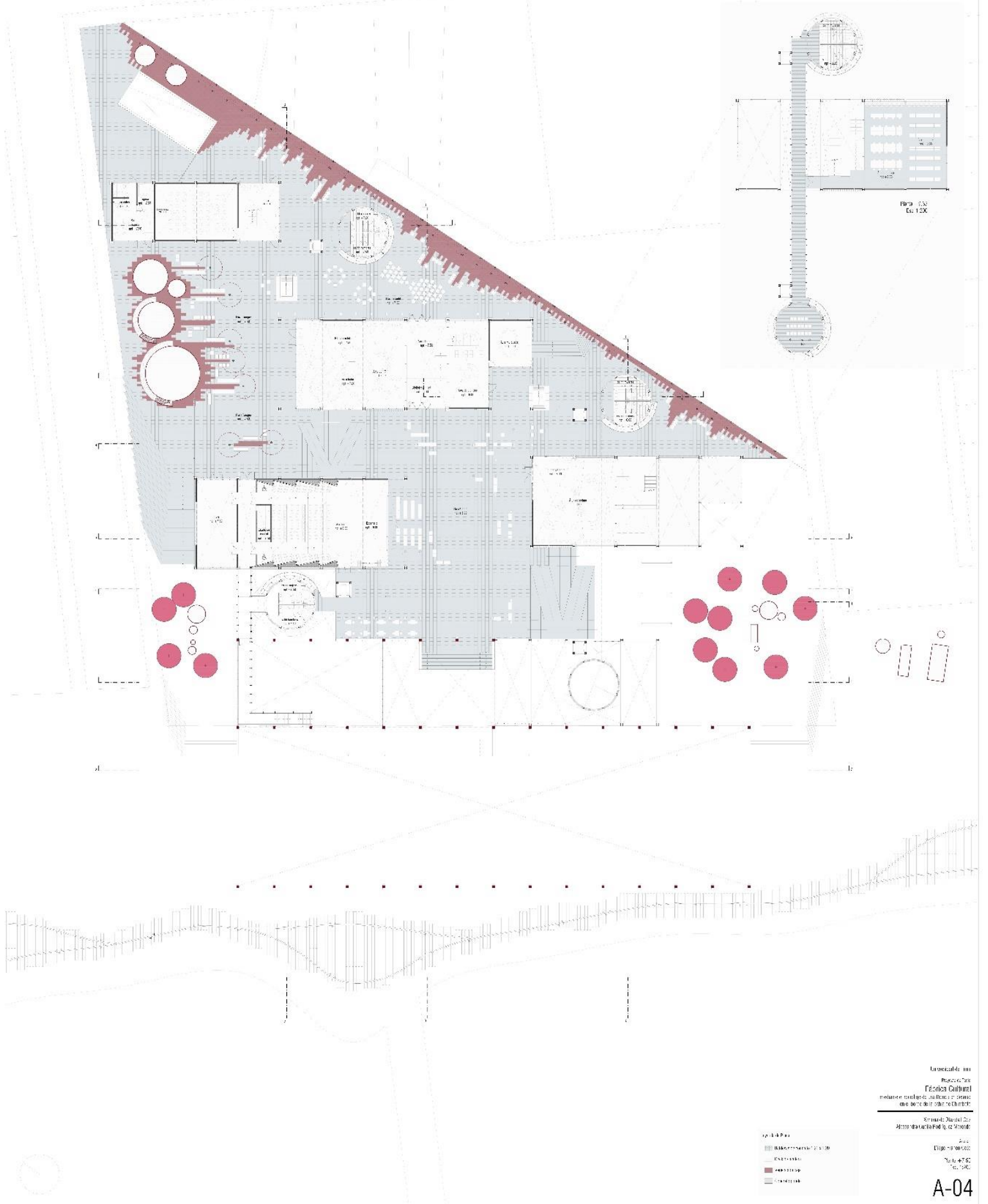

Fuente: Elaboración propia 
Ilustración 8.93 Planta Nivel +12.70 m
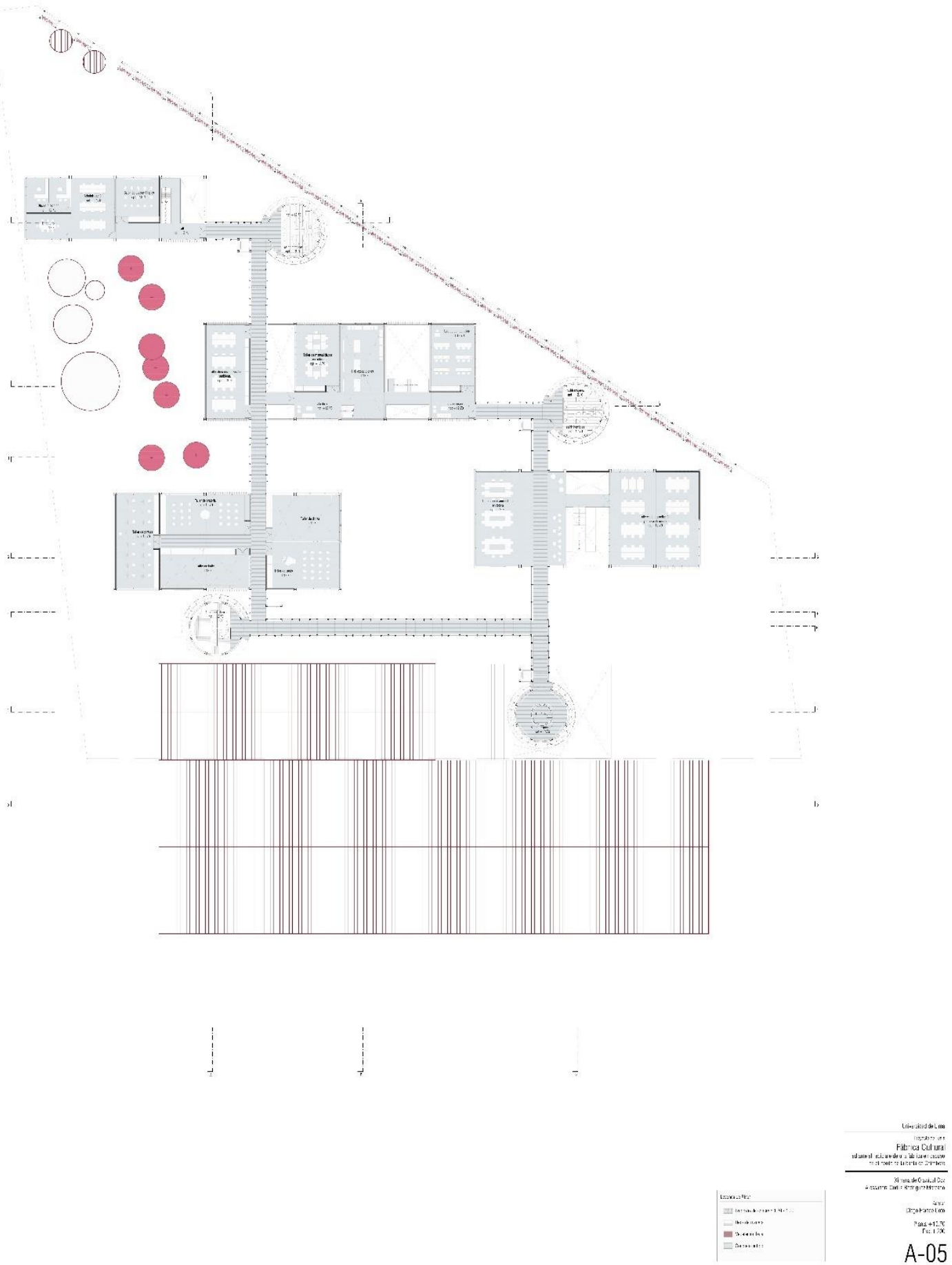

Fuente: Elaboración propia 
Ilustración 8.94 Planta Nivel +16.05 m

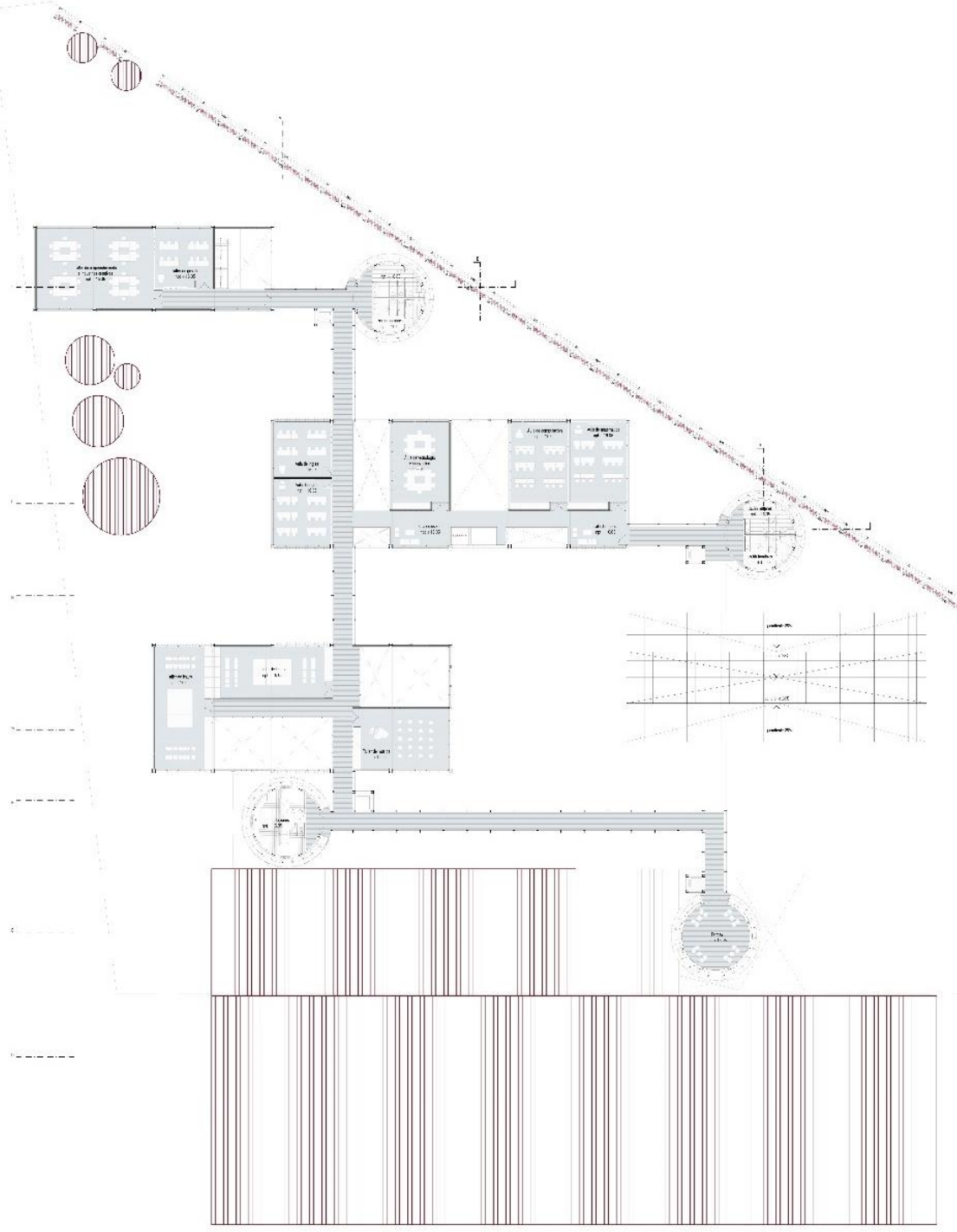

Fuente: Elaboración propia 
Ilustración 8.95 Planta de Techos

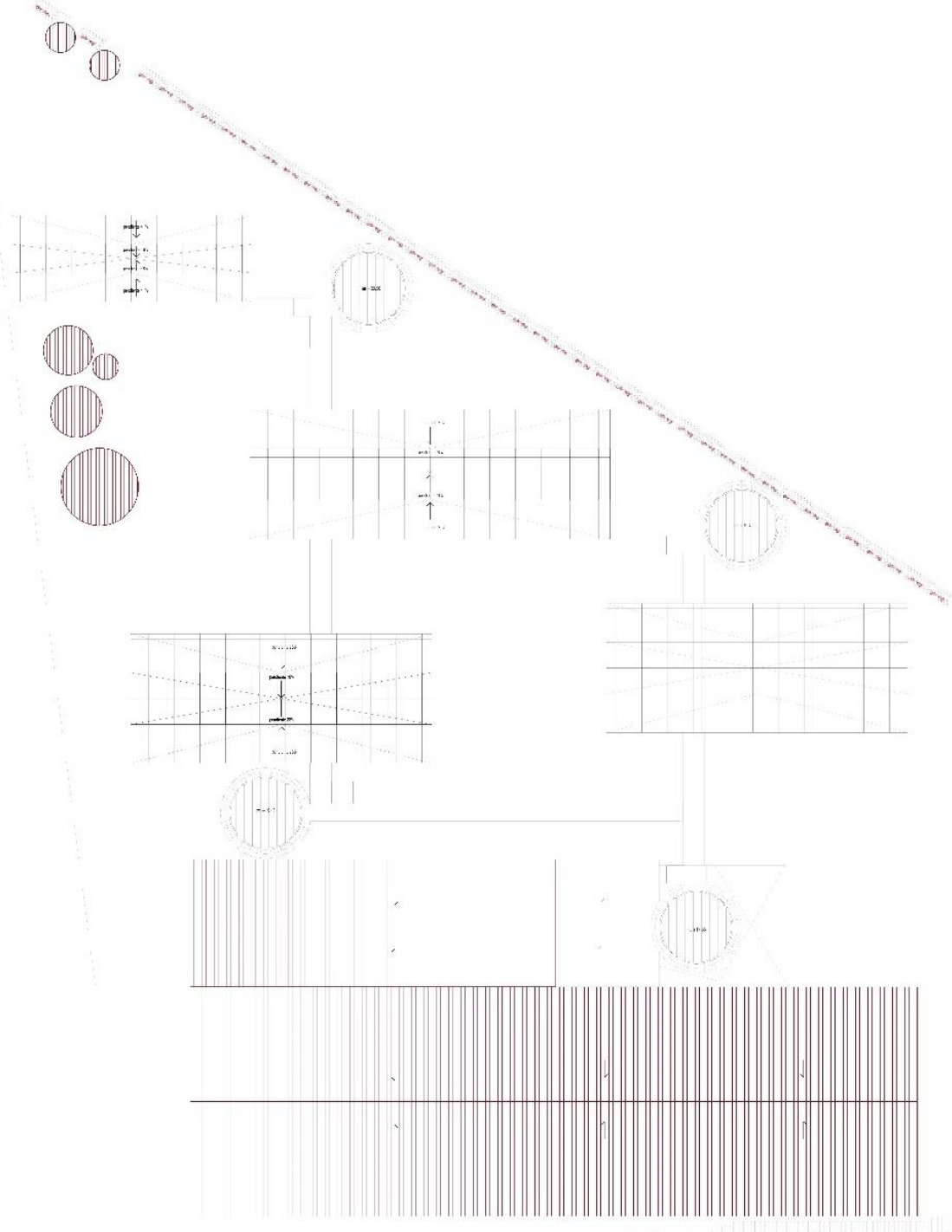

Fuente: Elaboración propia 
Ilustración 8.96 Corte longitudinal fugado del proyecto con el muelle

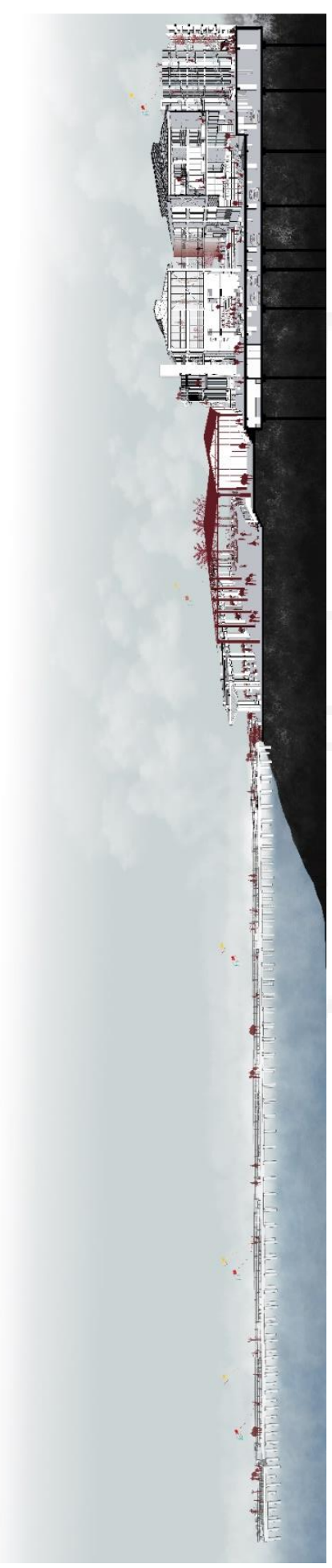

Fuente: Elaboración propia 
Ilustración 8.97 Corte longitudinal fugado del proyecto

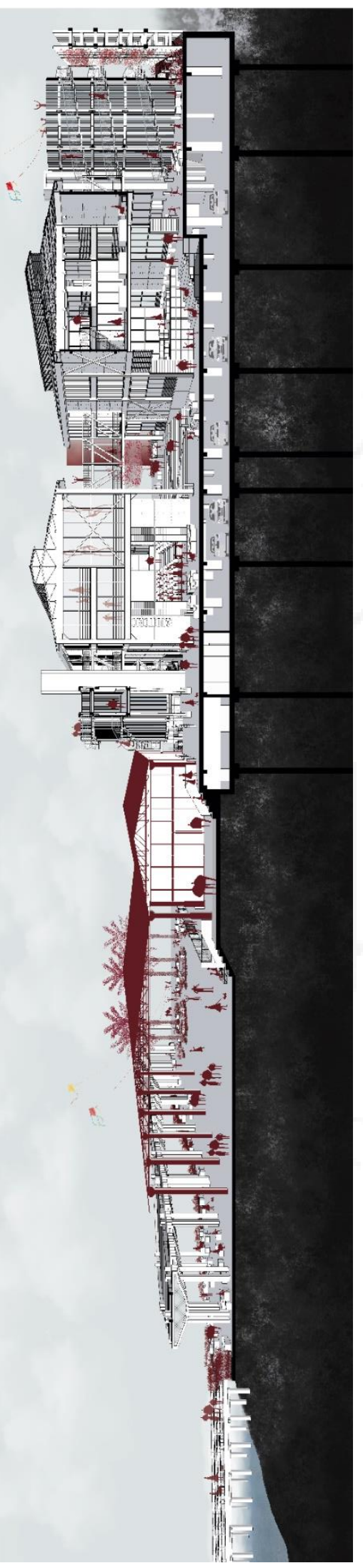

Fuente: Elaboración propia 
Ilustración 8.98 Corte transversal fugado del proyecto

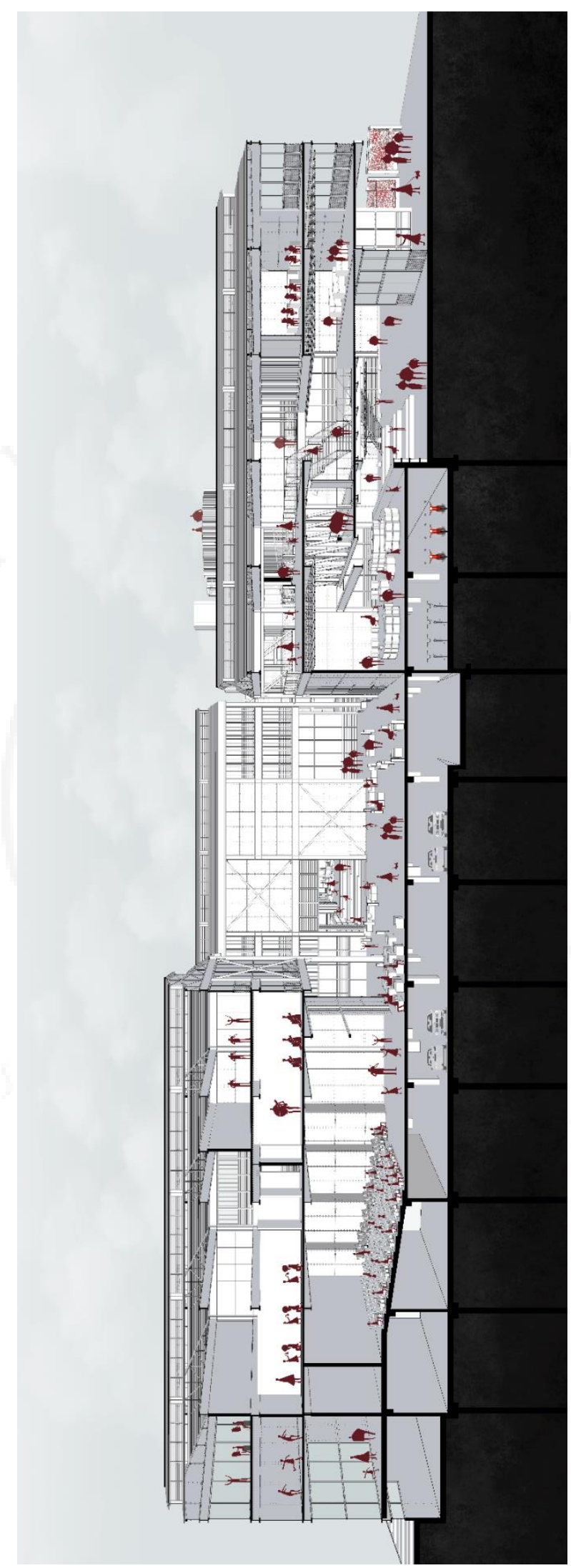

Fuente: Elaboración propia 
Ilustración 8.99 Secciones del proyecto
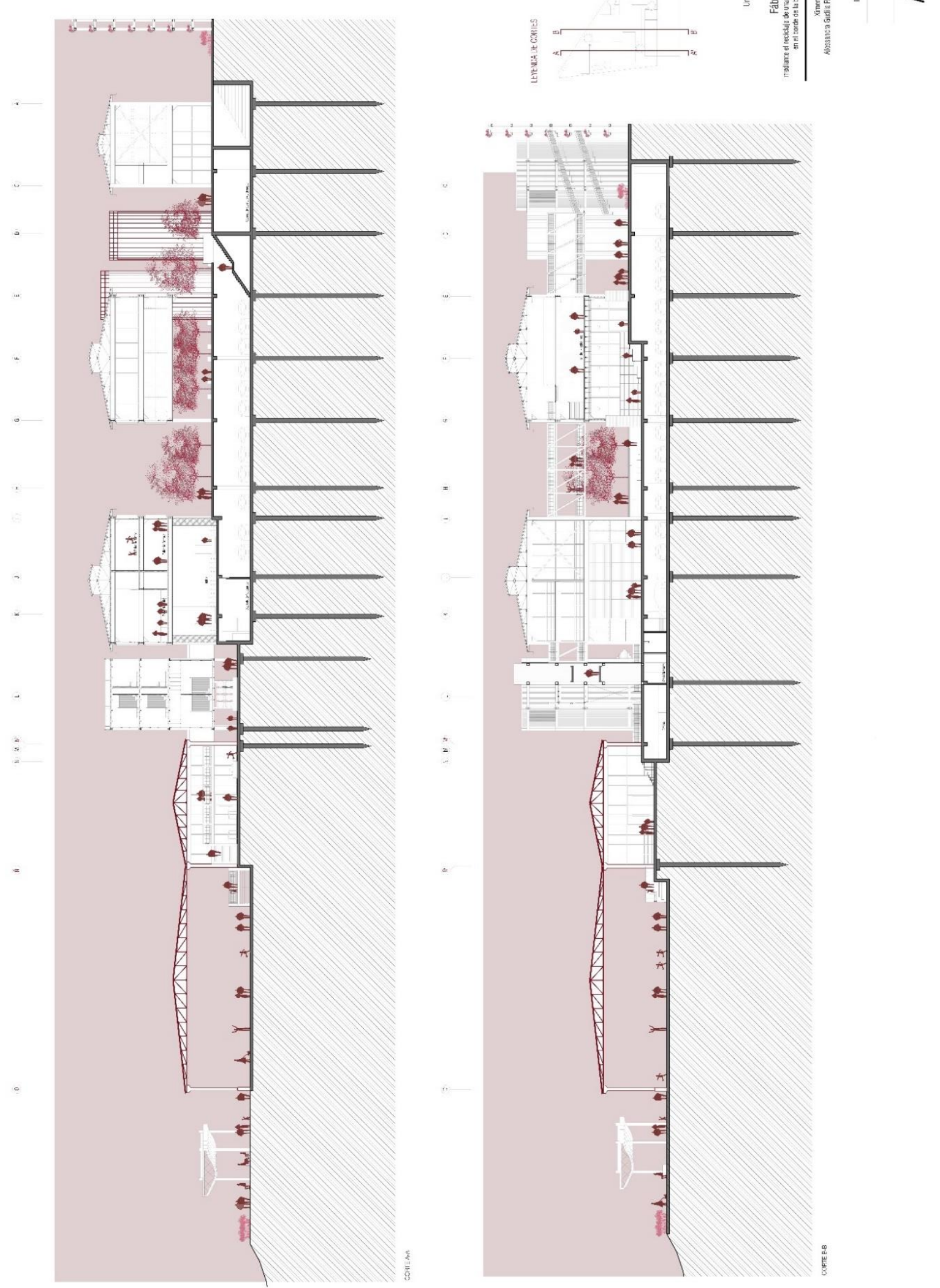

Fuente: Elaboración propia 
Ilustración 8.100 Secciones del proyecto
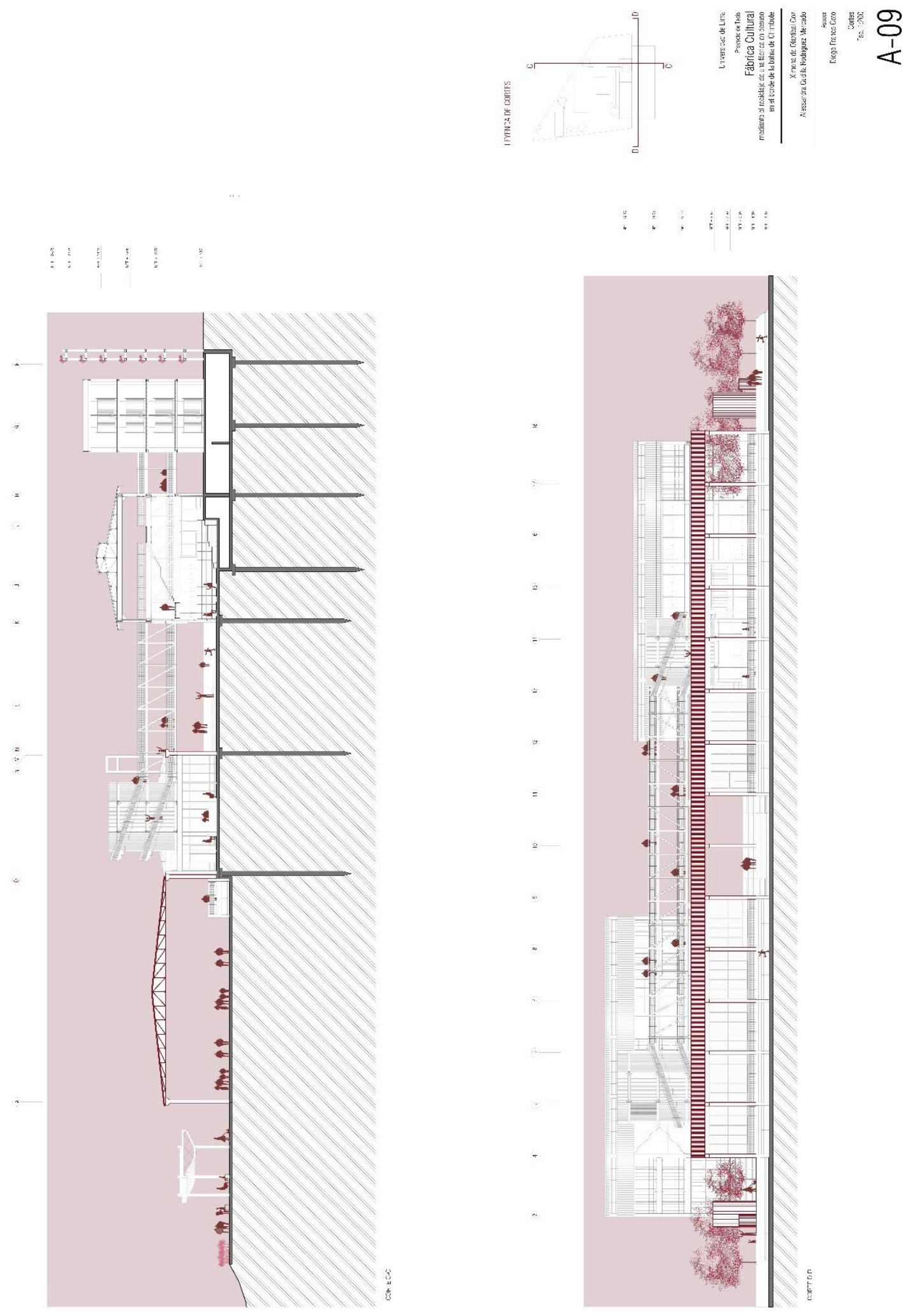

Fuente: Elaboración propia 
Ilustración 8.101 Secciones del proyecto
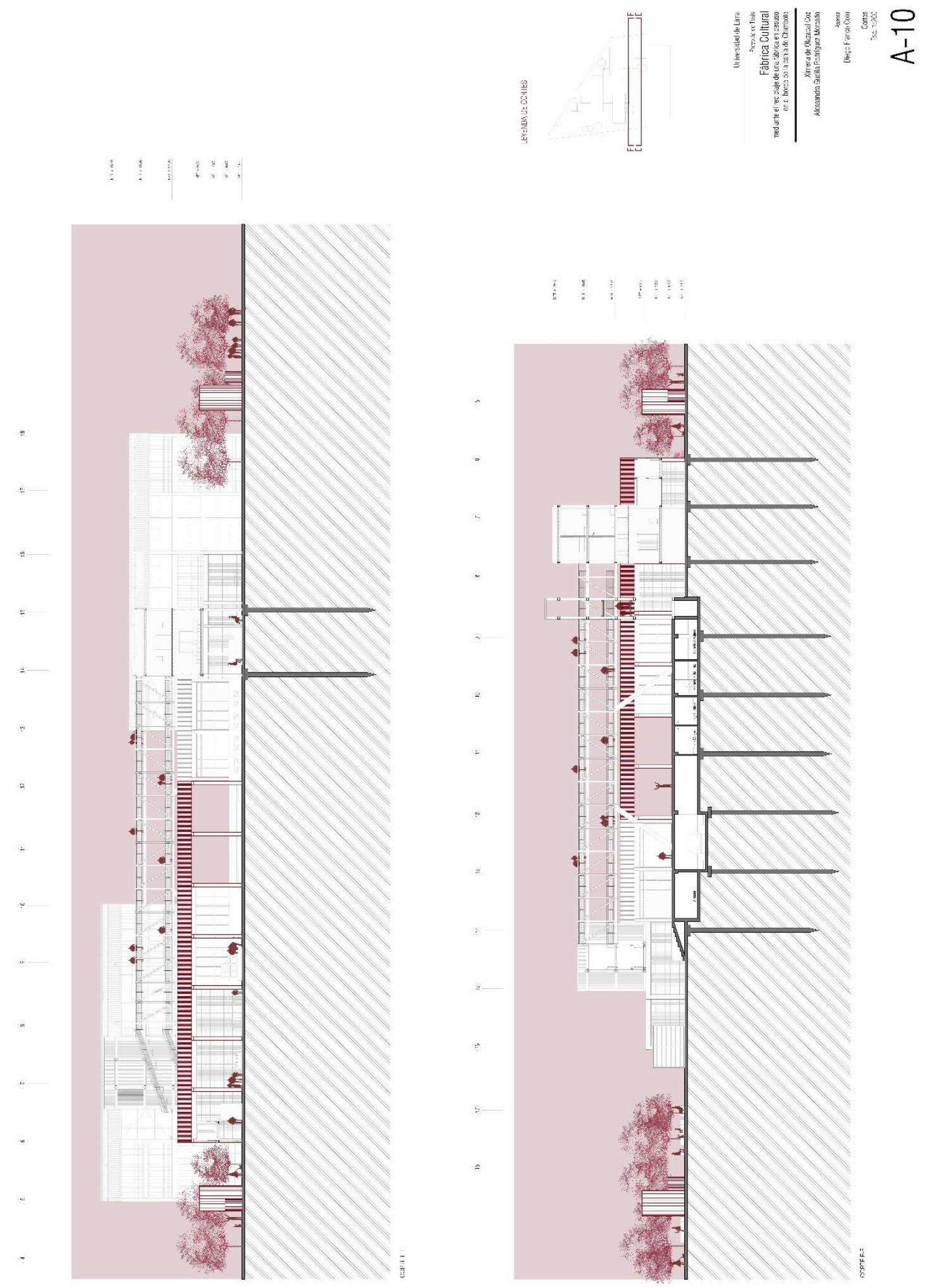

Fuente: Elaboración propia 
Ilustración 8.102 Secciones del proyecto
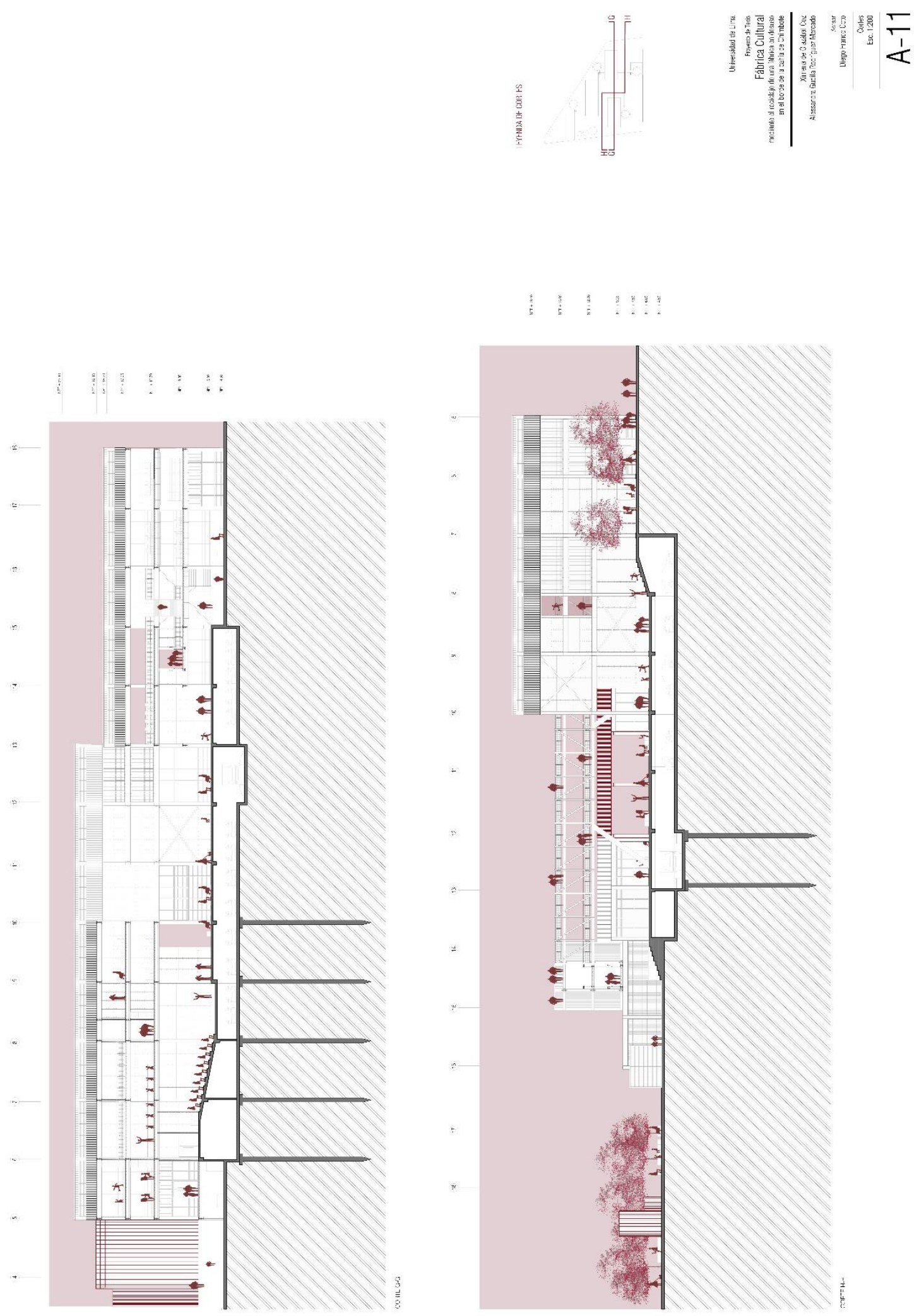

Fuente: Elaboración propia 
Ilustración 8.103 Secciones del proyecto
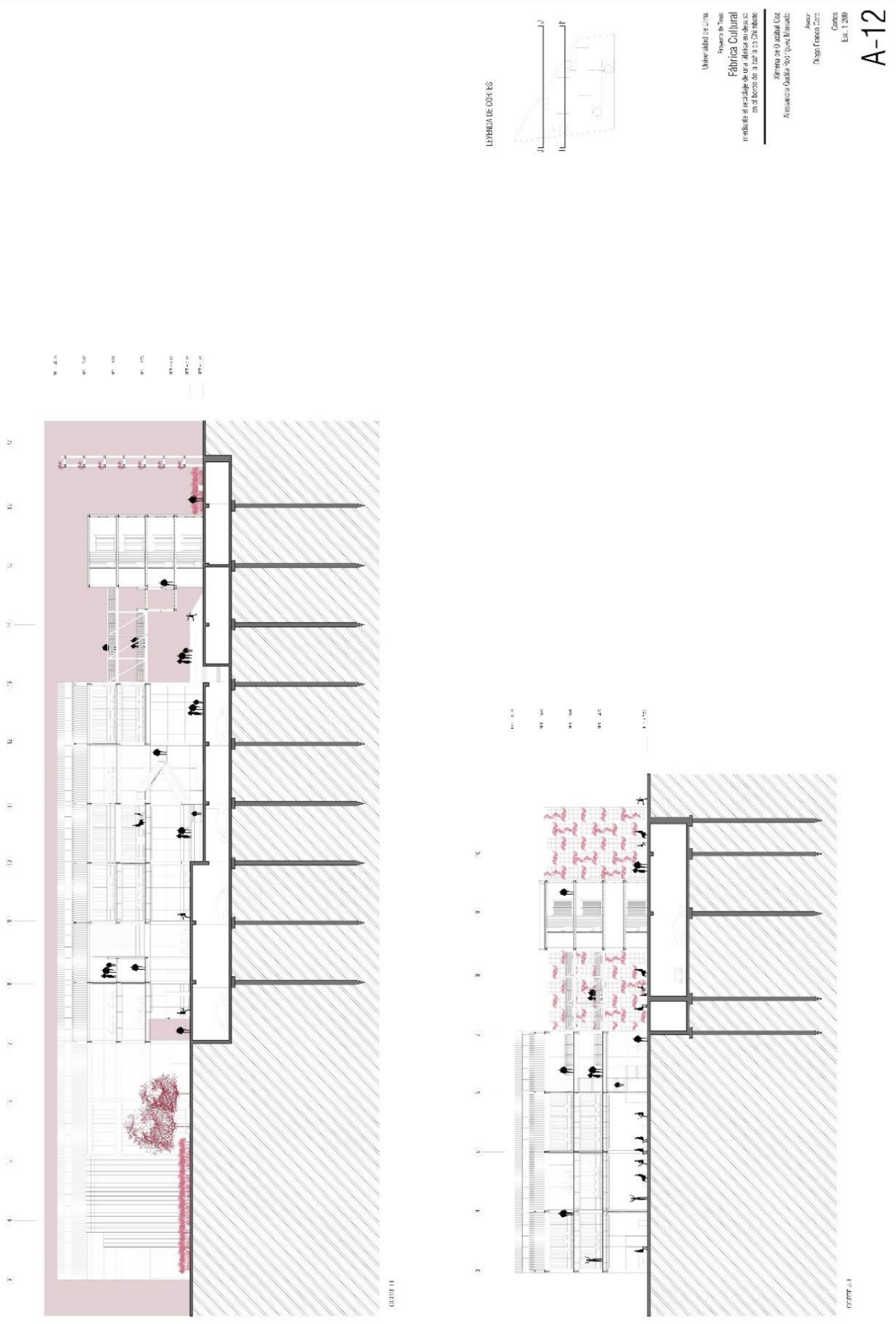

Fuente: Elaboración propia 
Ilustración 8.104 Detalle constructivo del galpón biblioteca infantil
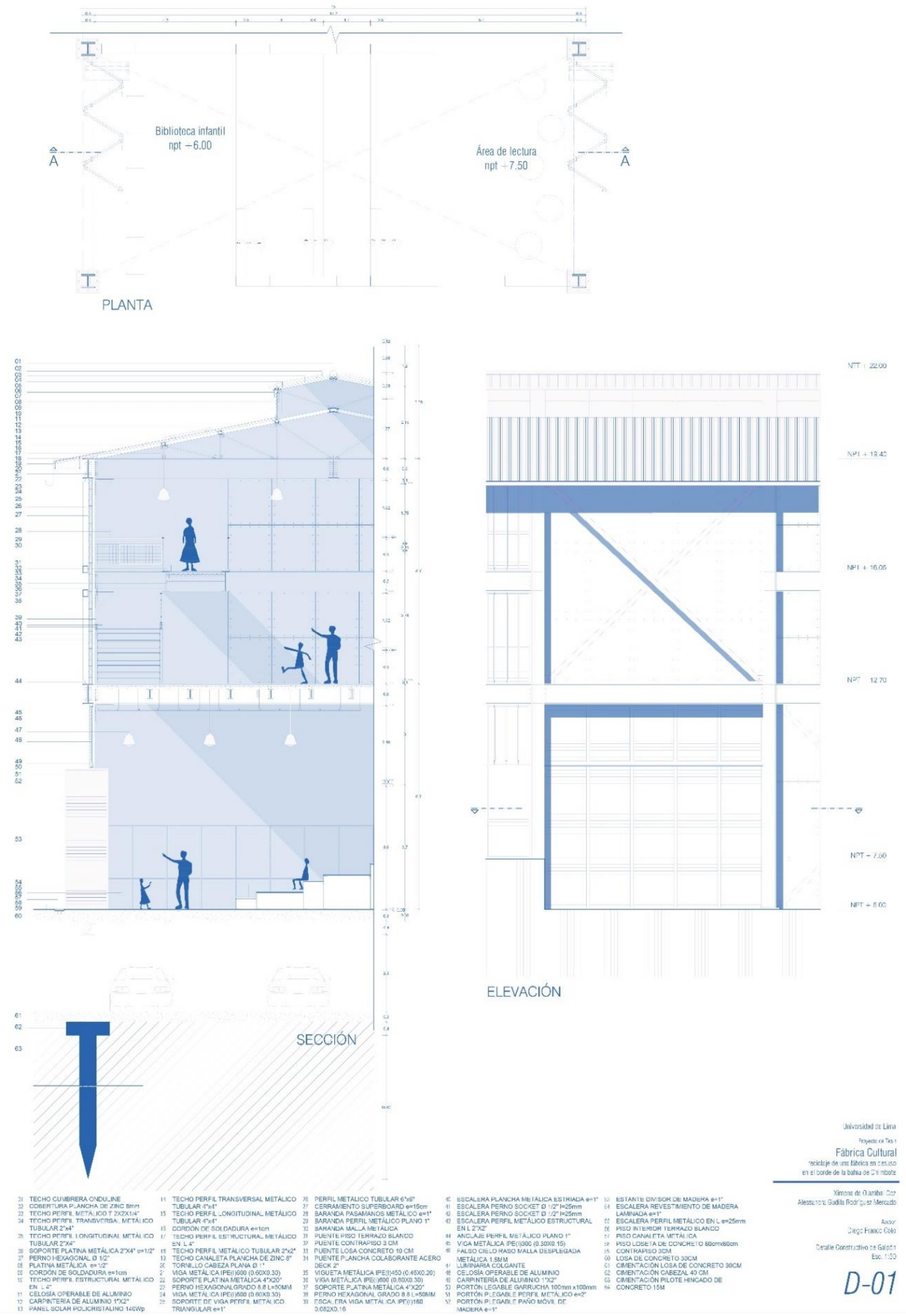

Fuente: Elaboración propia 
Ilustración 8.105 Detalle constructivo del galpón biblioteca general
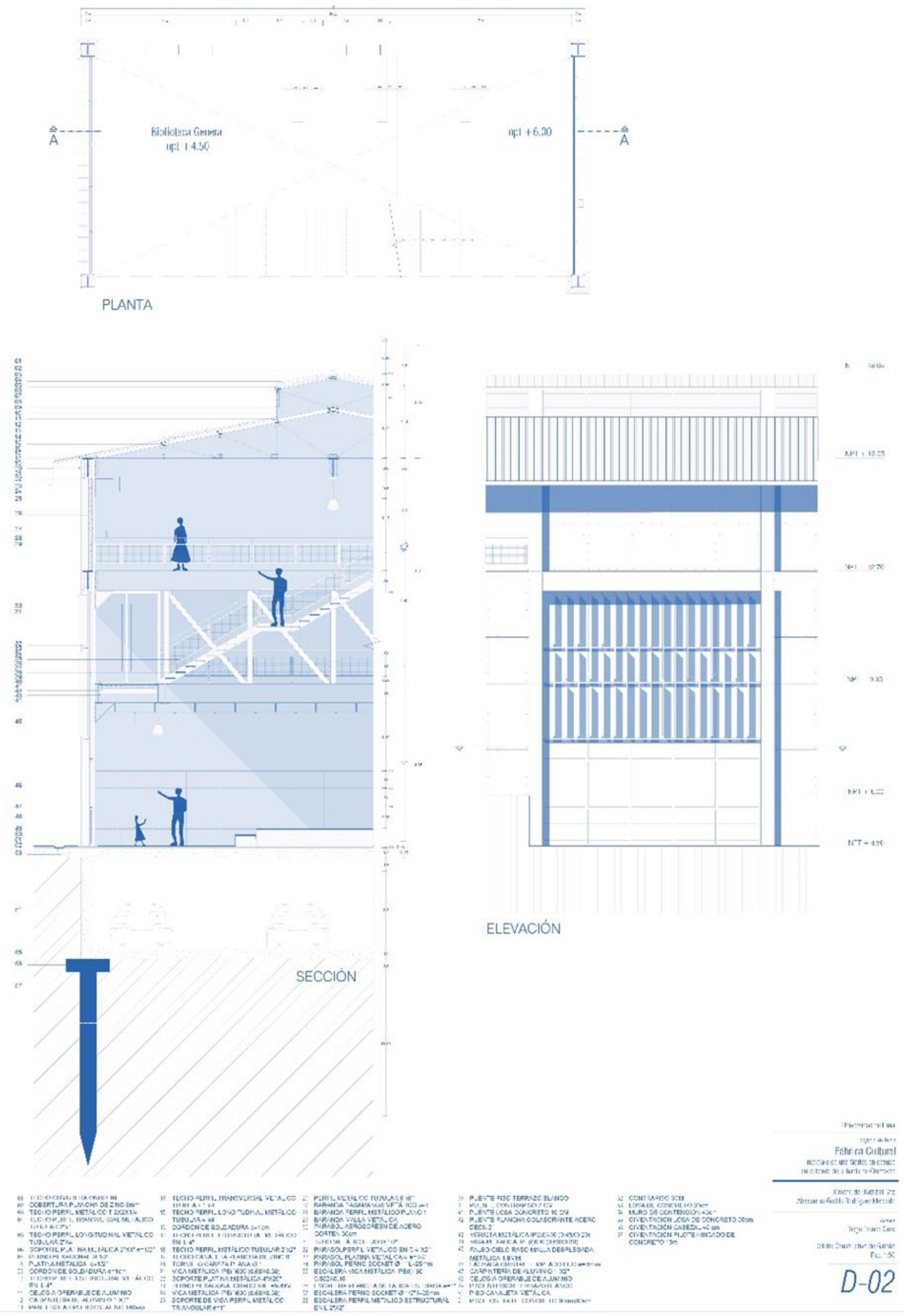

Fuente: Elaboración propia 
Ilustración 8.106 Detalle constructivo del tanque
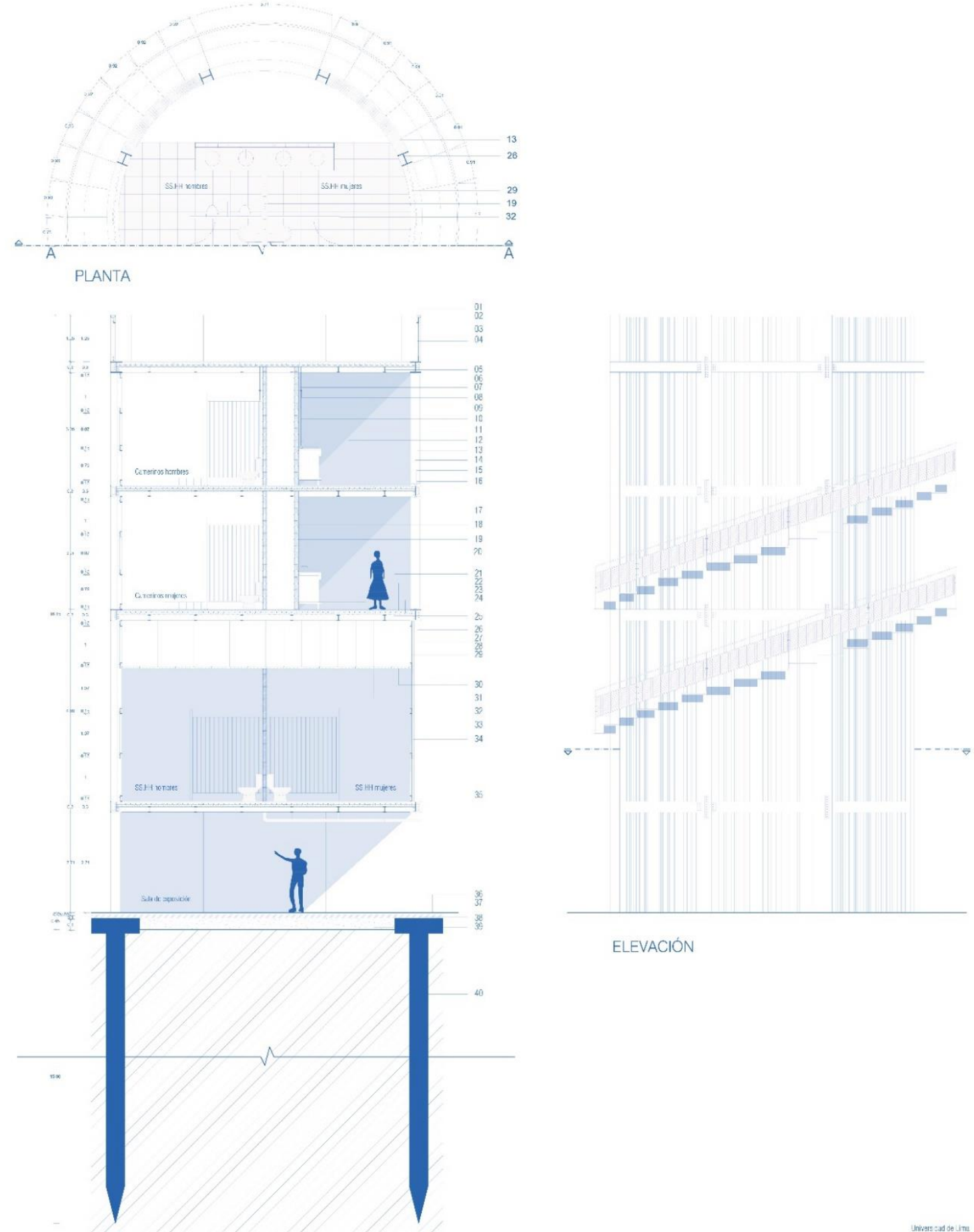

SECCIÓN

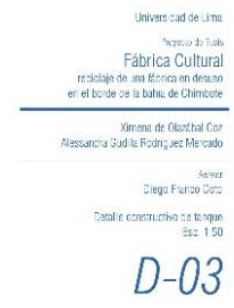

Fuente: Elaboración propia 
Ilustración 8.107 Detalle constructivo del puente
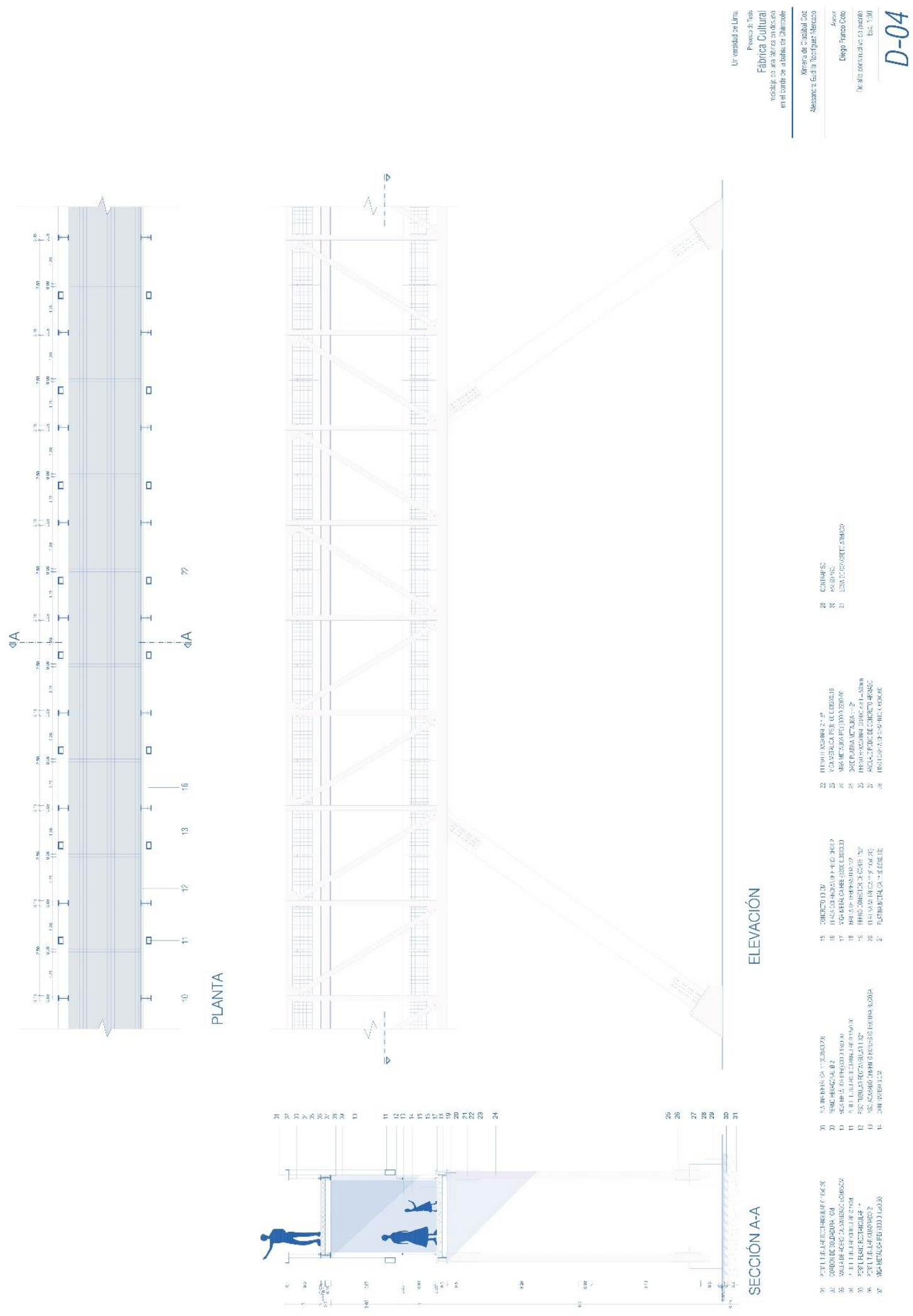

Fuente: Elaboración propia 


\subsection{Espacio público}

En el proyecto se ha desarrollado un espacio público continuo, que desde el exterior se perciba que la calle se inserta en la fábrica cultural. Por tal motivo, los ingresos al proyecto son plazas que delimitan el terreno y que acompañan el recorrido entre los edificios que conforman el proyecto. En la fábrica cultural se aprecia dos escalas de espacio público, el primero es el distrital, conformado por el malecón y por otro lado se cuenta con plazas barriales al interior.

\subsubsection{Plazas interiores}

Las plazas interiores responden a la secuencia de niveles que existen en el proyecto. Estas están acompañadas de una serie de escaleras-rampa que permiten recorrer el espacio de extremo a extremo, desde el nivel más bajo (+3.00) hasta el más alto $(+7.50)$.

El emplazamiento de las plazas se debió a que se deseaba proyectar el espacio del interior de los galpones hacia el exterior, de modo que cuando los galpones se encontrarán abierto se tuviera un gran espacio fluido.

Se pensó además en 5 elementos que debían acompañar cada plaza del proyecto. El primer elemento es un piso adecuado, se optó por colocar baldosas de concreto ya que es un piso cómodo para transitar, además que con diferentes formatos se pueden determinar pisos tanto para transitar como también para generar permanencia. El segundo elemento es el mobiliario; se plantearon bancas fijas e individuales de concreto para fomentar la permanencia de los usuarios. El tercer elemento es la vegetación; se proponen colas de zorro ya que son herbáceas con alta resistencia al viento y al calor, además de requerir poco riego. El cuarto elemento es la sombra; para acondicionar las plazas internas se optó por colocar árboles Molle, ya que se adaptan a cualquier tipo de suelo y son árboles altamente resistentes a la salinidad, además de ofrecer una excelente sombra. Finalmente, como valor agregado del proyecto se decidió establecer un quinto elemento que debía contener toda plaza interna del proyecto; las preexistencias materializadas en tanques y piezas recicladas de la antigua fábrica que permitirán potenciar la identidad industrial del proyecto y generar un sentimiento de pertinencia entre los usuarios y el espacio. 
Ilustración 8.108 Emplazamiento del espacio público interno

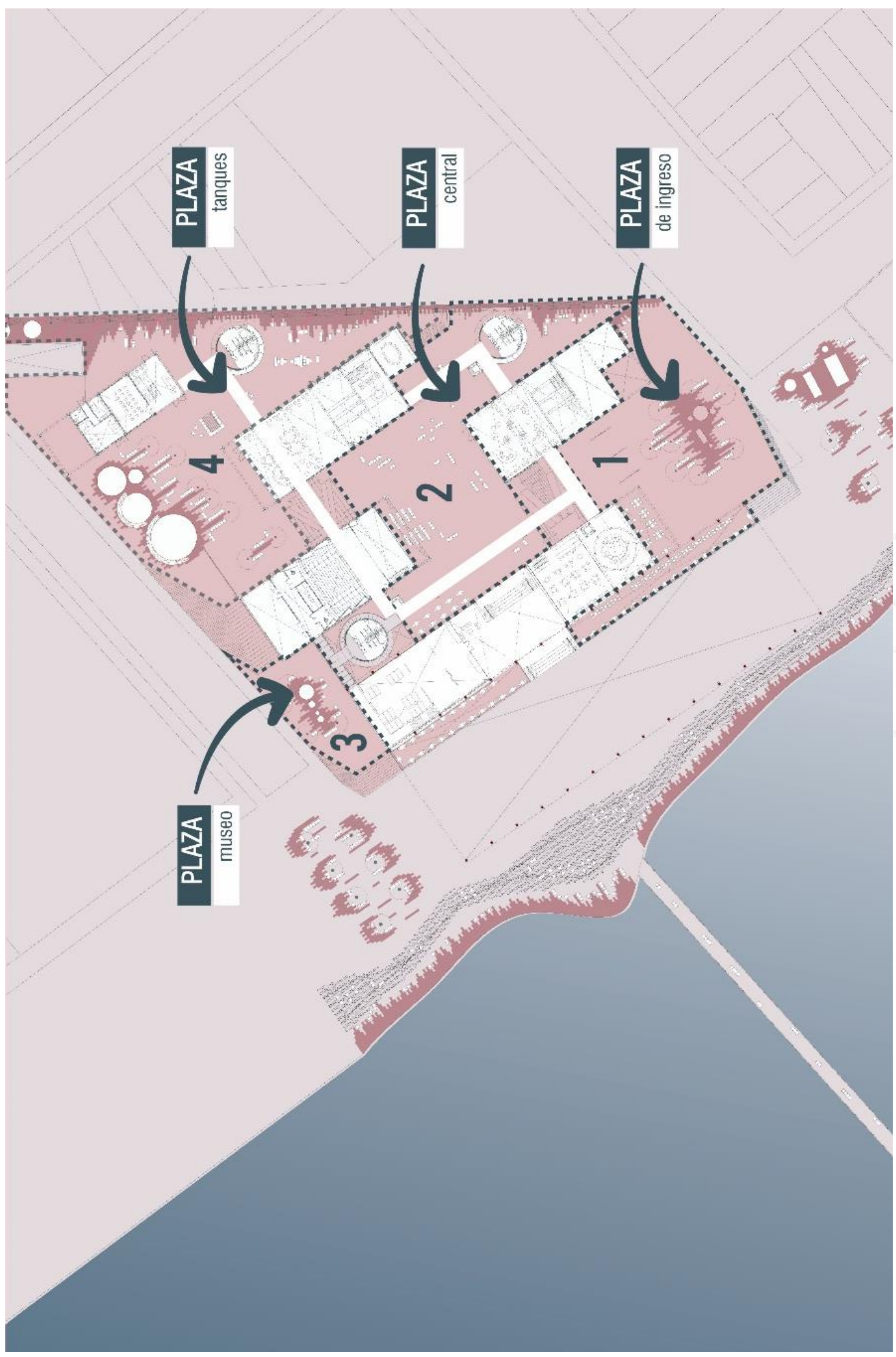

Fuente: Elaboración propia 
La primera plaza es la plaza de ingreso, la cual se encuentra en la cota más baja del proyecto $(+3.00 \mathrm{~m})$. Esta plaza tiene una amplia dimensión ya que albergará a una gran cantidad de usuarios por ser el principal acceso. Funciona también como punto de incidencia de los distintos flujos tanto de ingreso como de salida al proyecto, además de conectarse con el malecón. Esta plaza se encuentra acompañando al galpón de la biblioteca general y al restaurante/ bar. Como mobiliario cuenta con bancas de concreto para fomentar permanencia en este espacio, además de que estas bancas se encuentran acompañadas por árboles Molle para brindar sombra y colas de zorro como vegetación baja que complementan el paisaje costero. Esta plaza también cuenta con tanques reciclados para generar identidad desde que uno accede al proyecto.

\section{Ilustración 8.109 Plaza de ingreso}

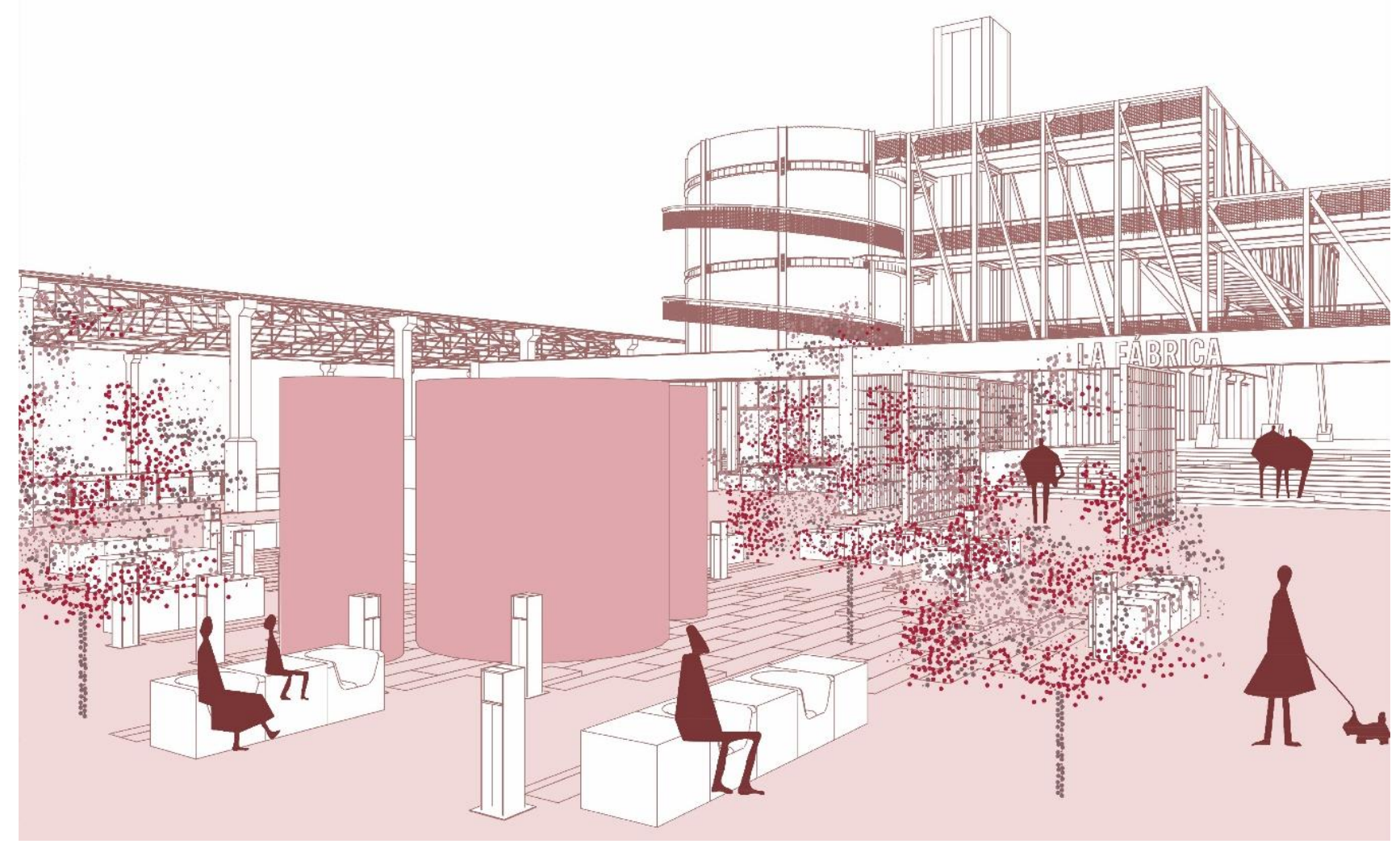

Fuente: Elaboración propia 
Ilustración 8.110 Vista de la plaza de ingreso a La Fábrica con preexistencias

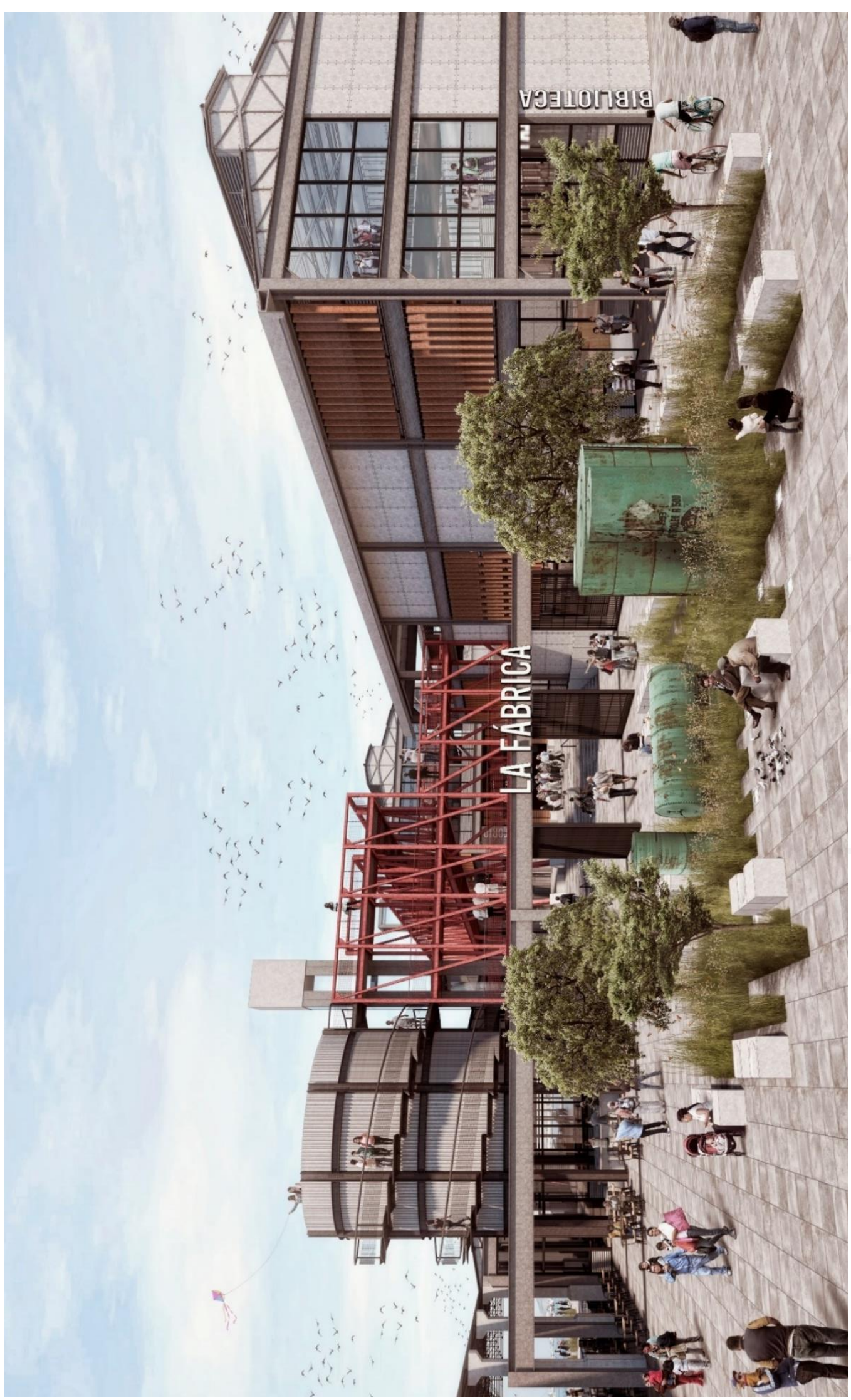

Fuente: Elaboración propia 
La segunda plaza es la plaza central, ubicada en el nivel $+4.50 \mathrm{~m}$ se encuentra contenida por rodeada galpones y será un gran punto de influencia de usuarios y de constante actividad. Alrededor de ella se encuentran el galpón del auditorio, la biblioteca general, la biblioteca infantil y el galpón de museo.Esta plaza pretende funcionar como extensión del espacio de los galpones que la rodean, como por ejemplo el caso del auditorio, de manera que se conforme todo un espectáculo dentro de esta plaza. Debido a que esta plaza albergará distintas actividades el mobiliario se encuentra disperso en ella, motivo por el cual tampoco cuenta con vegetación baja. Esta plaza no cuenta con árboles ya que recbirá sombra de los galpones que la rodean.

\section{Ilustración 8.111 Plaza central}

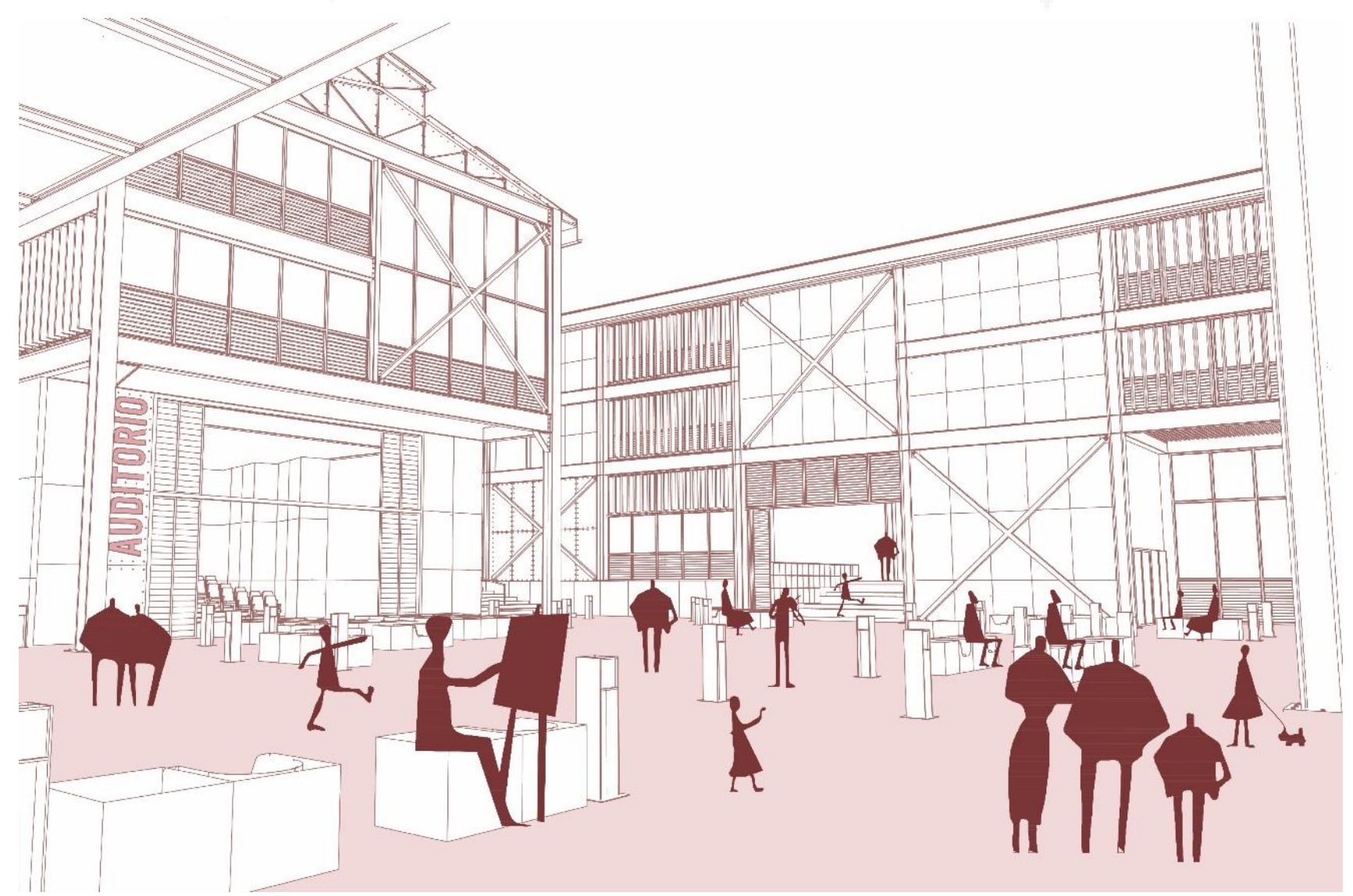

Fuente: Elaboración propia 
Ilustración 8.112 Vista nocturna de espectáculo en plaza central

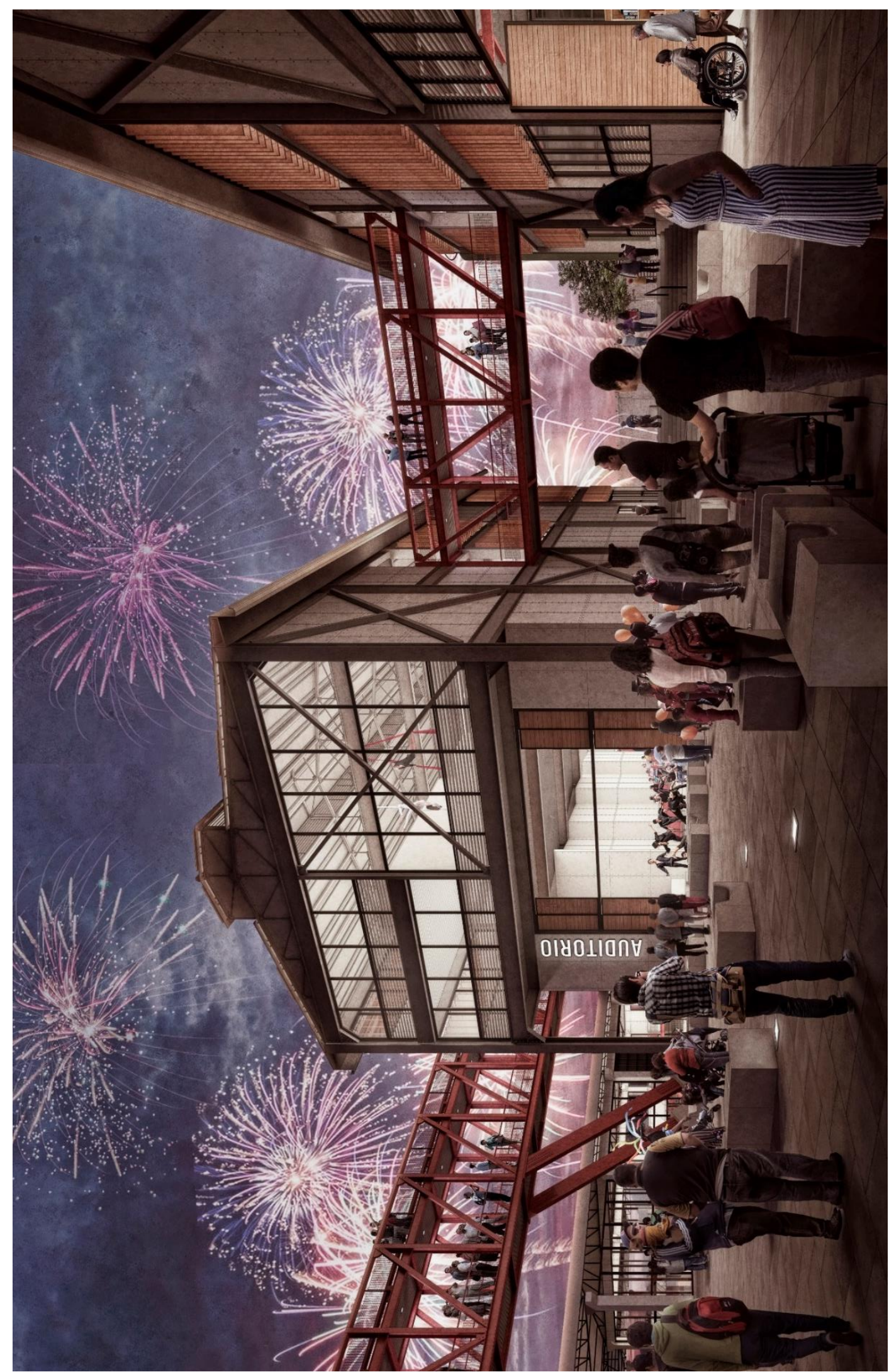

Fuente: Elaboración propia 
La plaza del museo funciona como una antesala al galpón reciclado del museo.Tiene una escala menor al resto de plazas ya que los flujos de personas que recibe no son tan intensos como los anteiores. Este espacio también funciona como un área de reposo o espera para las funciones en el auditorio por su cercanía a la boletería. Esta plaza también cuenta con mobiliario de bancas de concreto, acompañados por Molles como elementos de sombra y también con preexistencias para generar un sentimiento de pertinencia con los usuarios.

\section{Ilustración 8.113 Plaza museo}

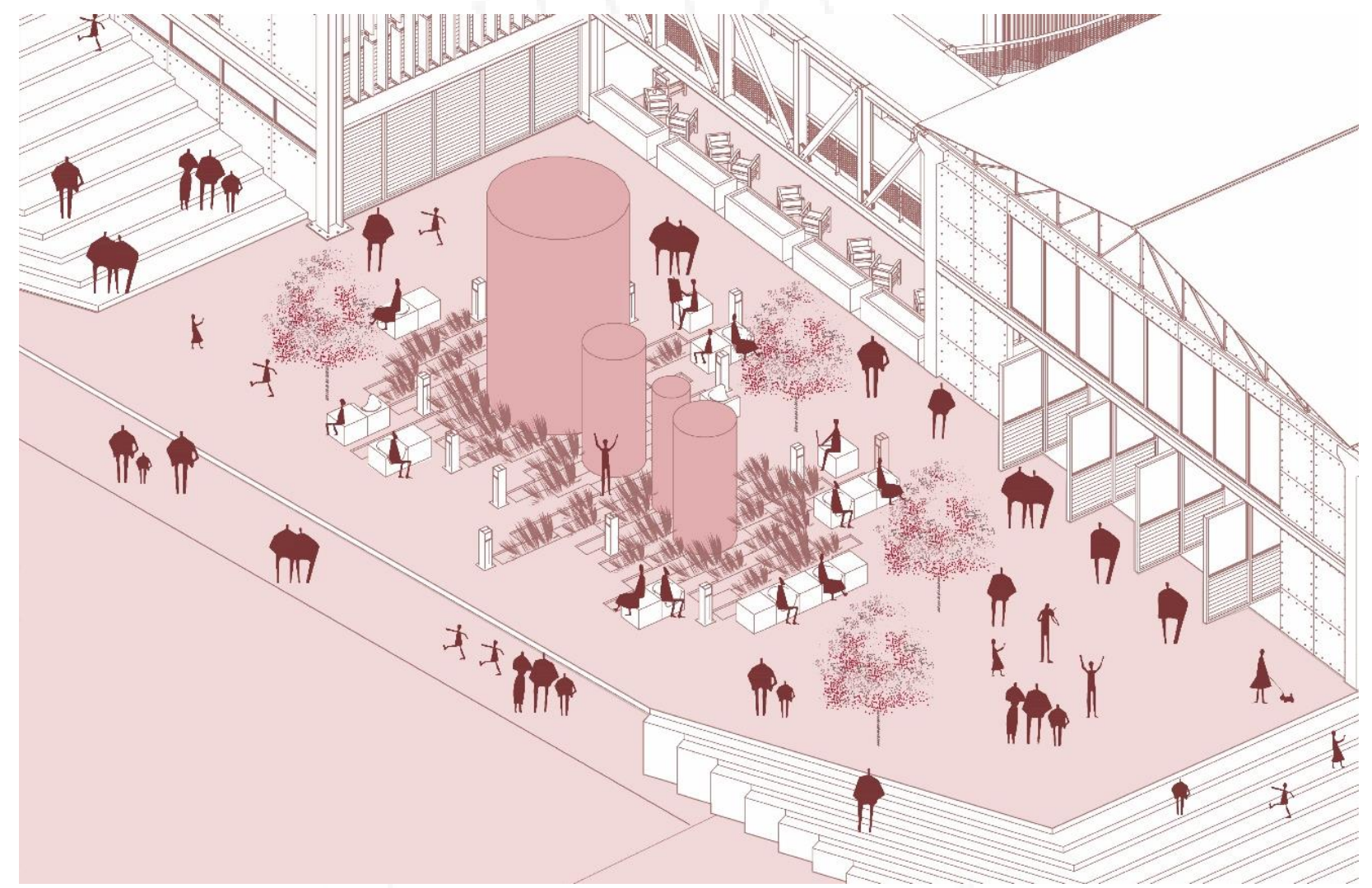

Fuente: Elaboración propia 
La plaza tanques se encuentra ubicada en la cota más alta del proyecto $(+7.50)$, por lo que también funciona como acceso secundario al proyecto. Esta plaza funciona como la extensión del espacio interior de los galpones además de contener los grandes tanques recicados de la antigua fábrica. Esta plaza por su gran escala funciona también como un espacio de contemplación a estas piezas, a las cuales se puede acceder a la parte más alta a través de una escalera. Estos tanques también ayudan a delimitar el terreno de la fábrica y de esta manera evitar los muros ciegos. Dentro de la plaza tanques también se encuentra contenida la plaza infantil, la cual funciona como extensión de la biblioteca infantil y se buscó generar un espacio seguro para los niños, a través de la delimitación de este espacio por las piezas que lo rodean (tanque, galpón, puente y rejilla).

\section{Ilustración 8.114 Plaza tanques}

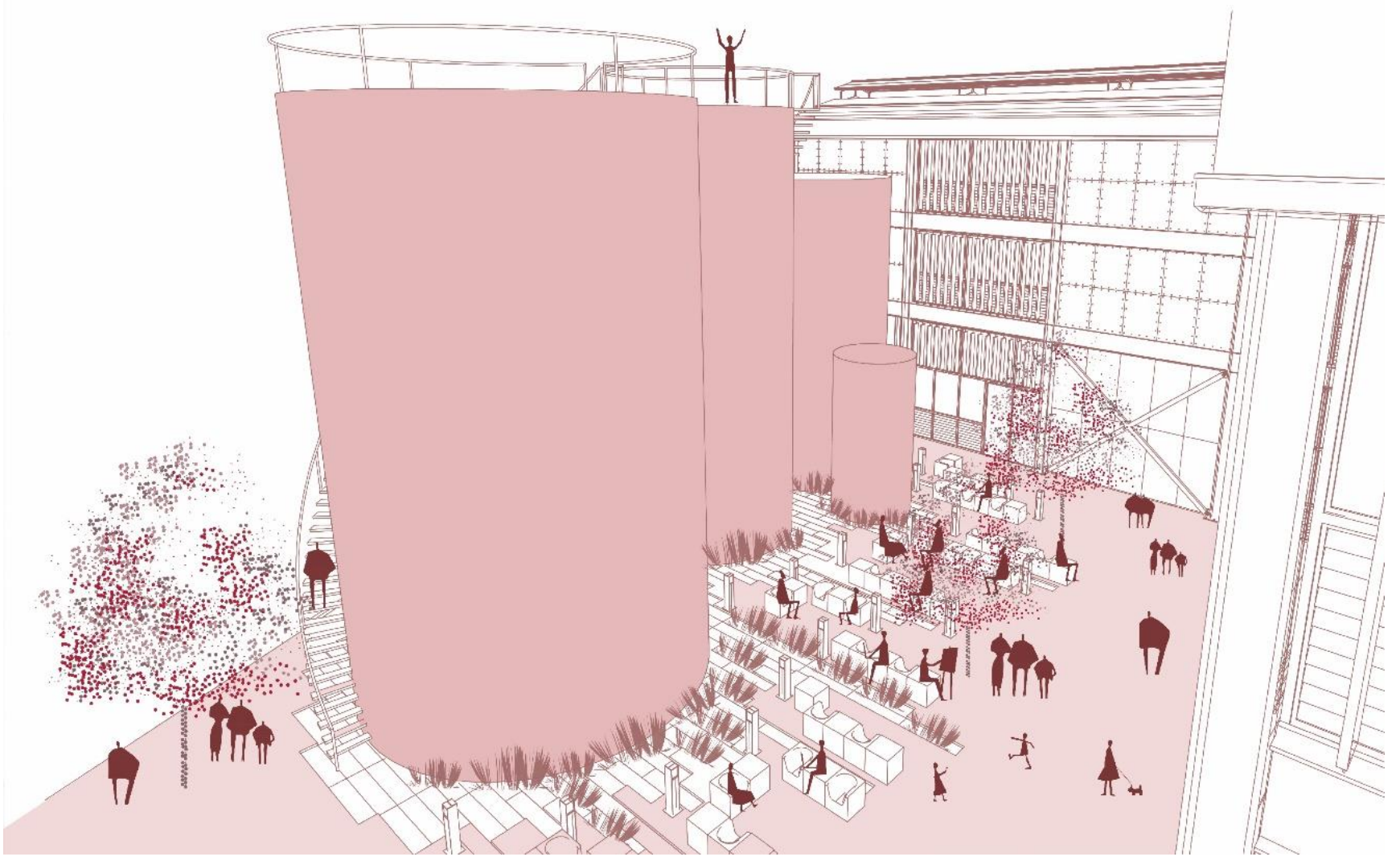

Fuente: Elaboración propia 
Ilustración 8.115 Vista de la plaza infantil como extensión del galpón biblioteca infantil

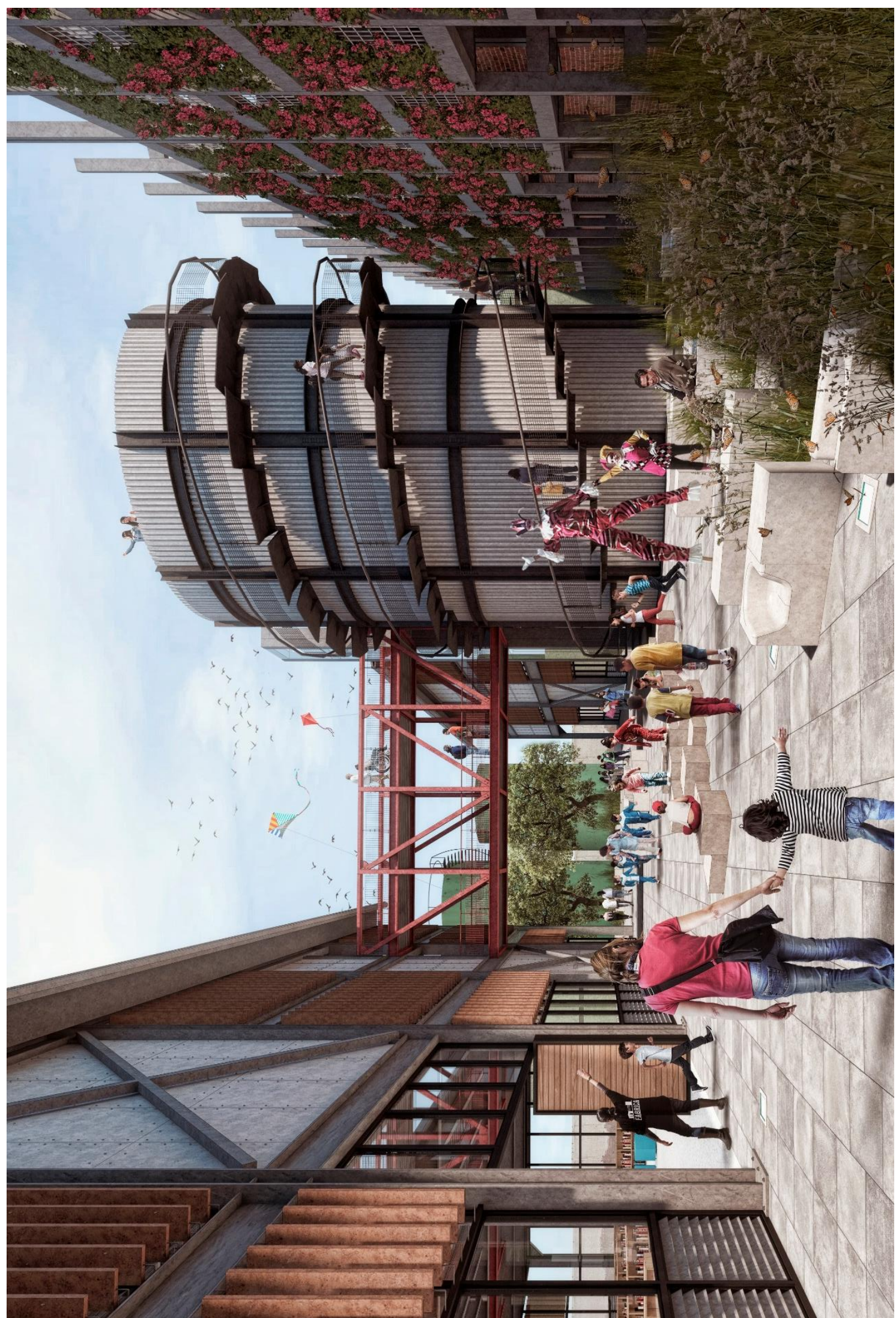

Fuente: Elaboración propia 
Ilustración 8.116 Vegetación utilizada en el proyecto. Izquierda: molle, centro: palmera datilera y derecha: penissetum, comúnmente conocida con cola de zorro..
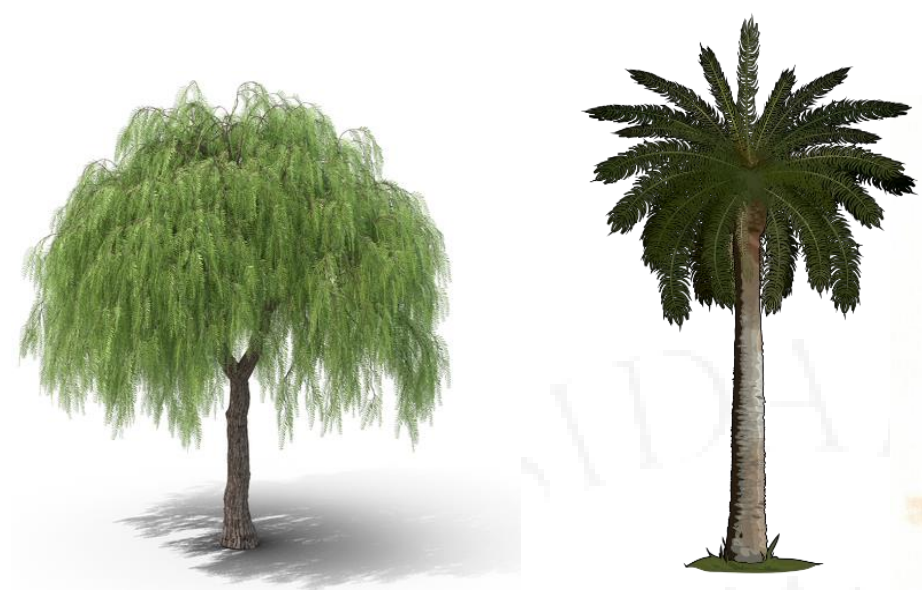

Fuente: Recuperado de www.pinterest.com

Entre los galpones y la medianera, que se encuentran en línea diagonal, se ha diseñado plazas de forma triangular que están unidas a través de una rejilla medianera vertical. Esta soporta maceteros, donde crecen trepadoras, buganvillas, que ascienden por la rejilla, generando una atmósfera contenida, de menor escala y permite que el proyecto afronte el muro medianero del vecino a través de un jardín vertical de carácter industrial.

\section{Ilustración 8.117 Plantas trepadoras buganvillas}

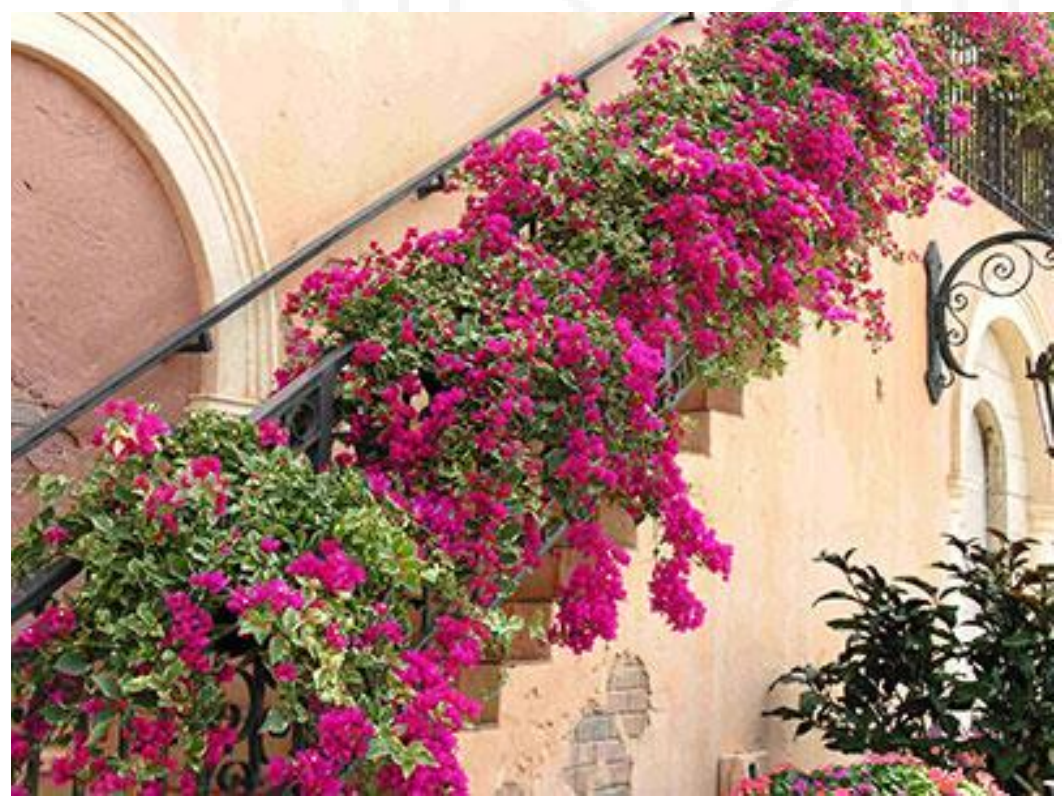

Fuente: Recuperado de gardeningsolutions.ifas.ufl.edu 


\section{Ilustración 8.118 Rejilla medianera empleada como muro verde}
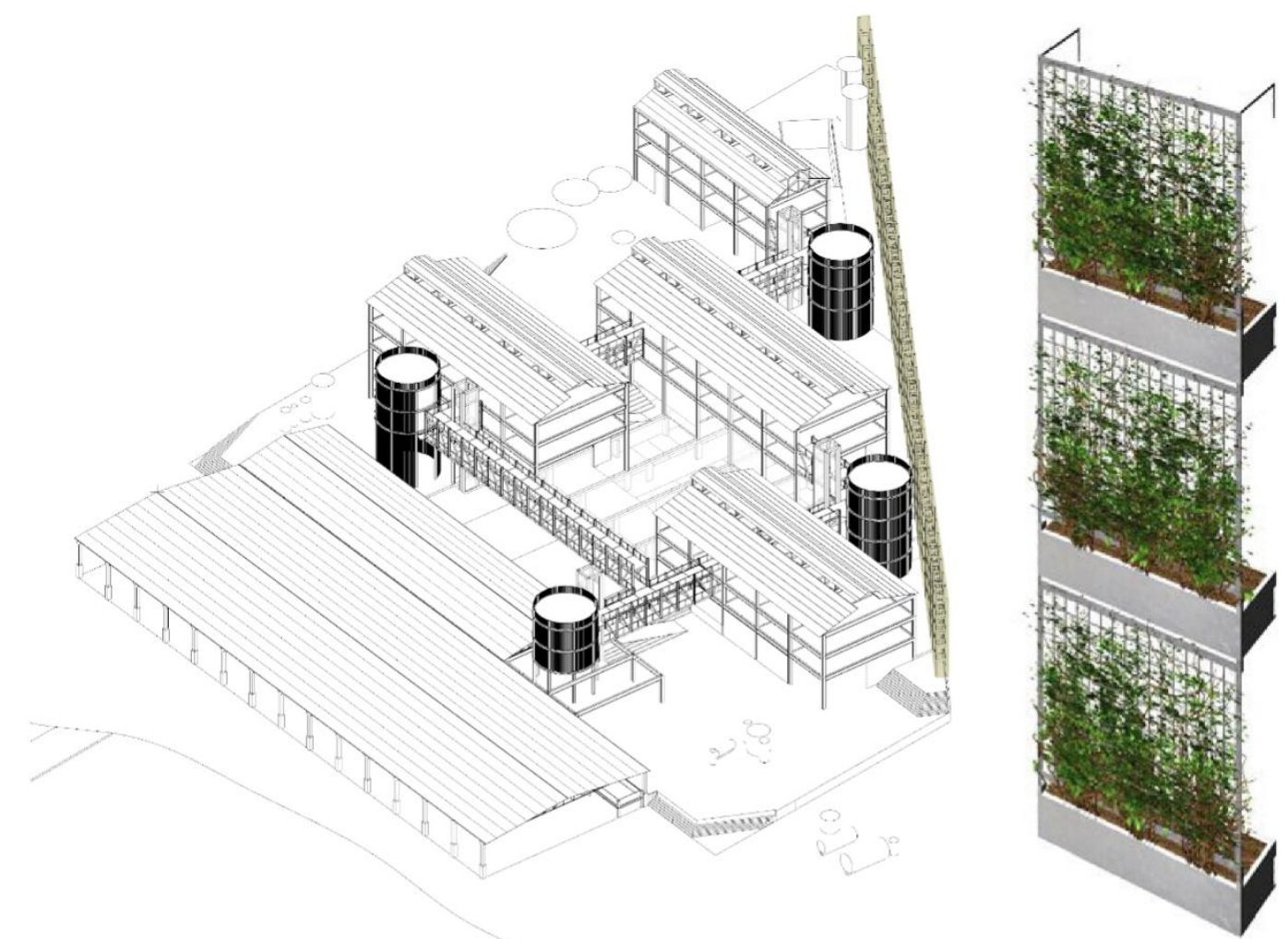

Fuente: Elaboración propia

\subsubsection{Malecón}

La fábrica cultural está ubicada de cara a la bahía; sin embargo, el espacio público entre la ciudad y el borde marino que debería ser el espacio público característico de Chimbote por ser una ciudad - puerto, que contribuya a mejorar la calidad de vida de la población y que conecte el centro de la ciudad con el resto de zonas, actualmente se presenta como un espacio abandonado lleno de basura y desmonte, que la población usa como basurero y al que le ha dado la espalda, contaminándolo cada día más. Por esta situación y porque el mayor frente del proyecto es la bahía con un magnífico paisaje en el que se puede observar las diversas islas, se ha diseñado el malecón, como un patrón que puede replicarse a lo largo de toda la extensión de la bahía.

Para el diseño del malecón se partió por estudiar los flujos de la zona. Un flujo constante e intenso se presenta longitudinalmente en el malecón, mientras que transversalmente se intersecta con otros tres, provenientes de la Av. Huánuco, la plaza central y la calle San Martín, 
generando tres importantes nodos. El diseño del malecón además debía estar protegido por elementos de sombra, por lo que se decidió trazas tres ejes, el primero como una circulación constante y que permita transitar debajo del galpón reciclado, el segundo eje como un espacio de estar y permanencia, protegido por un elemento de sombra y acompañado por mobiliario, y finalmente un espacio de control frente al mar, protegido por la vegetación baja cola de zorro.

La vegetación también fue un aspecto a tomar en cuenta para el diseño del malecón. De acuerdo a las especies recomendables para sobrevivir ante el clima de Chimbote y por contar con un suelo alto en salinidad se optó por colocar cola de zorro como vegetación baja del proyecto, la cual se ubicará en el borde costero funcionando como colchón verde. En relación a la vegetación alta se optó por colocar palmeras como elementos de sombra que acompañen las áreas de mayor concentración de usuarios.

\section{Ilustración 8.119 Gráfico del análisis del malecón}

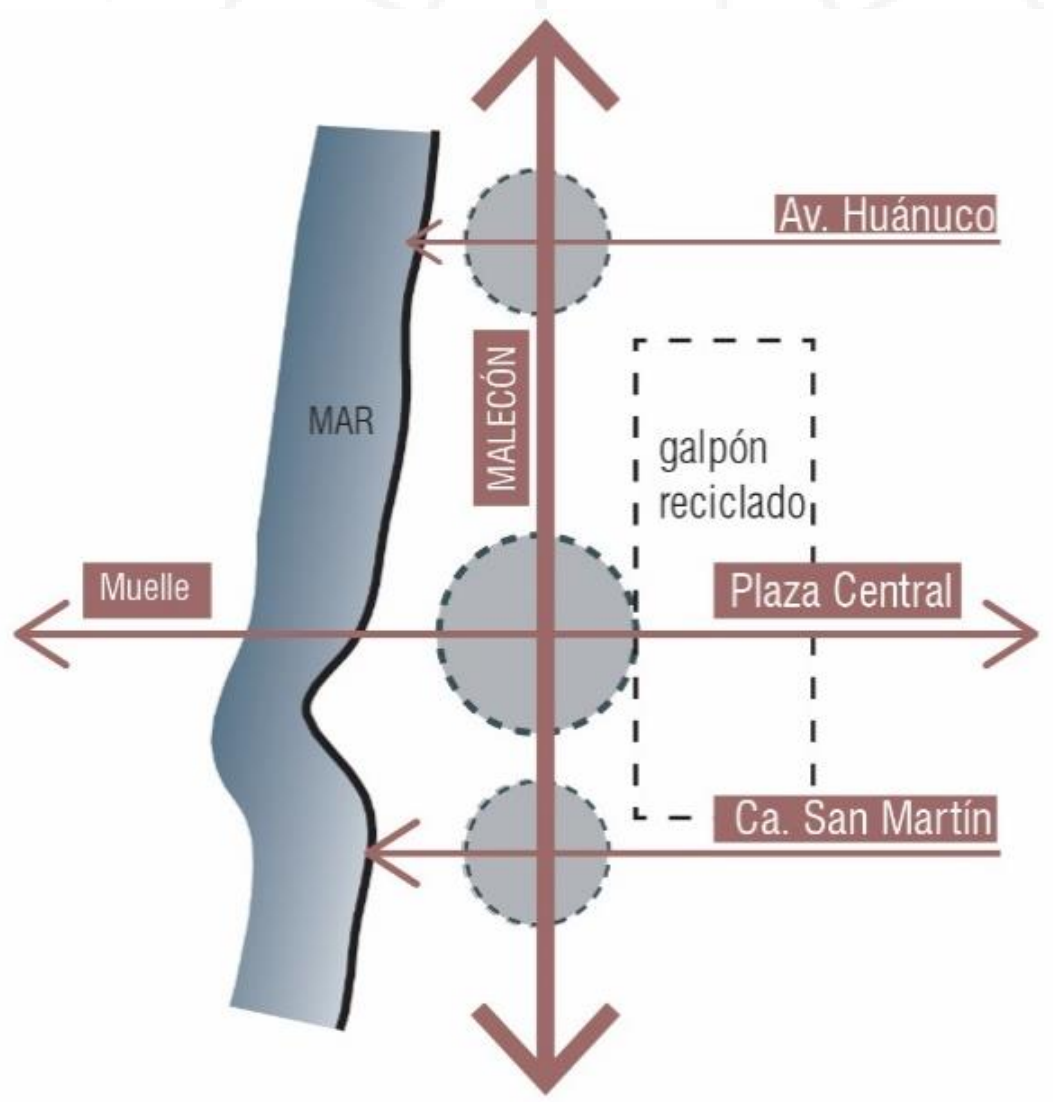

Fuente: Elaboración propia 
Ilustración 8.120 Diseño del malecón a partir de espacios de control, estar y circulación constante

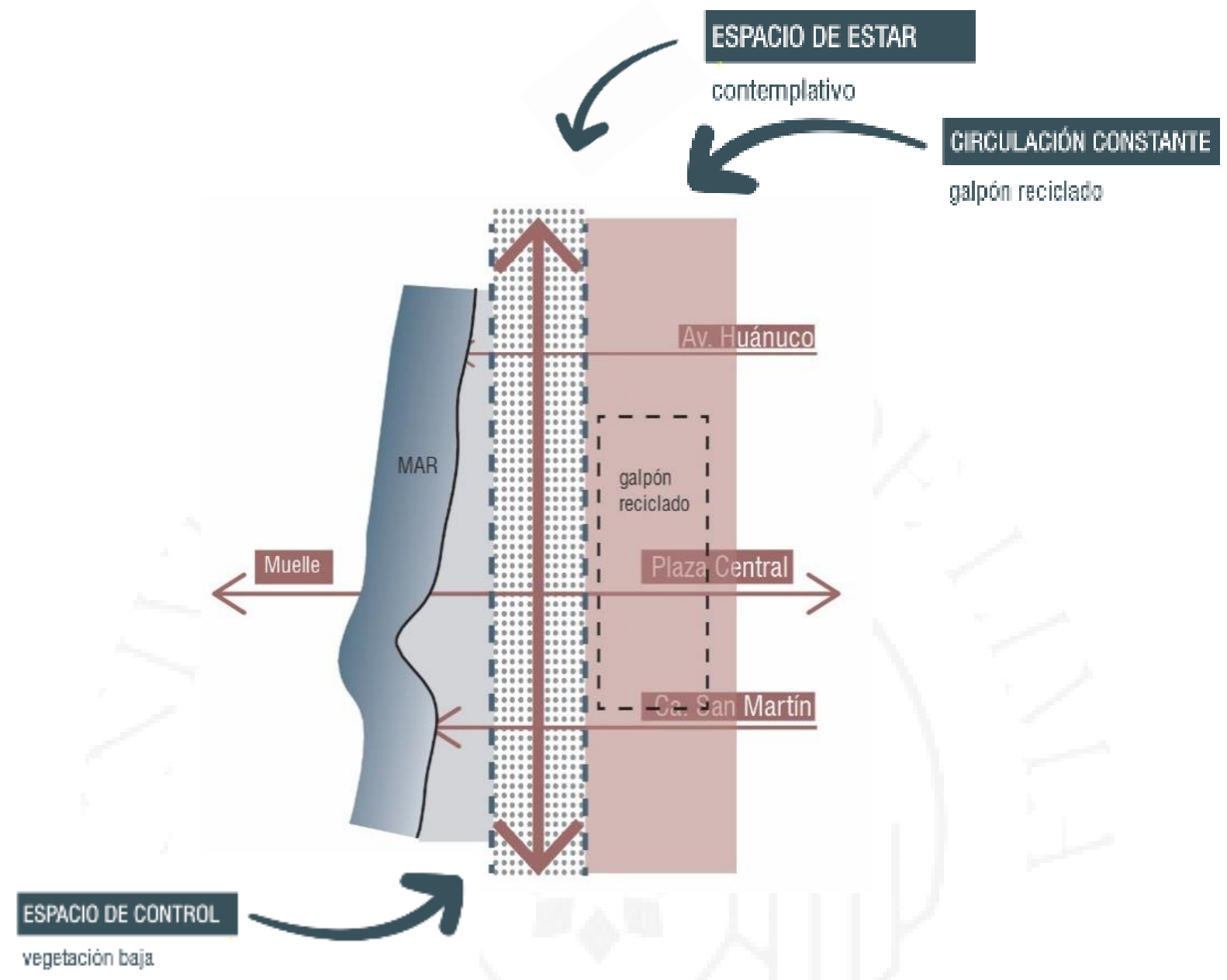

Fuente: Elaboración propia

- Pavimento: Se colocarán losetas de concreto de 1.20 x 1.20, tamaño que consideramos adecuado para un espacio de alto flujo peatonal. Para el pavimento del muelle se optó por reciclar y mejorar el piso de madera existente.

- Mobiliario: El mobiliario se encuentra conformado por 150 bancas a lo largo del malecón y 48 bancas que acompañan al muelle y que permiten convertirlo en un espacio de contemplación.

- Sombra: Como elementos de sombra se encuentran las palmeras y se ha propuesto una estructura/cobertura de madera que genere sombra en toda la extensión. La forma de la estructura surgió a partir de completar el vacío dejado por la Isla Blanca que se tiene como fondo dentro del paisaje de la ciudad, ella está compuesta por una serie de 
módulos que en su interior lleva malla desplegada para permitir el paso del viento. Todo este conjunto está soportado por columnas de madera, colocadas cada $7 \mathrm{~m}$ y unidas en la parte superior por una viga que cumple la función de cordón del que cuelgan los módulos. Se desarrolló un diseño sutil ya que se buscaba que la cobertura no opaque la presencia del galpón existente.

- Intensidad de uso: Como intensidad de uso se consideran aquellos puntos con mayor incidencia de usuarios. Este criterio permitió identificar los espacios propicios para ubicar el mobiliario, de manera que acompañe aquellos espacios con gran afluencia de personas y necesidad de espacios de reposo.

Como se puede apreciar en el gráfico a continuación, el elemento de sombra nace de la abstracción de la sinuosidad de la Isla blanca, elemento característico del paisaje costero de Chimbote. Se buscó además que este elemento sea una estructura más orgánica y sensible con el entorno.

Ilustración 8.121 Sinuosidad de la isla Blanca, inspiración para la forma de la cobertura del malecón

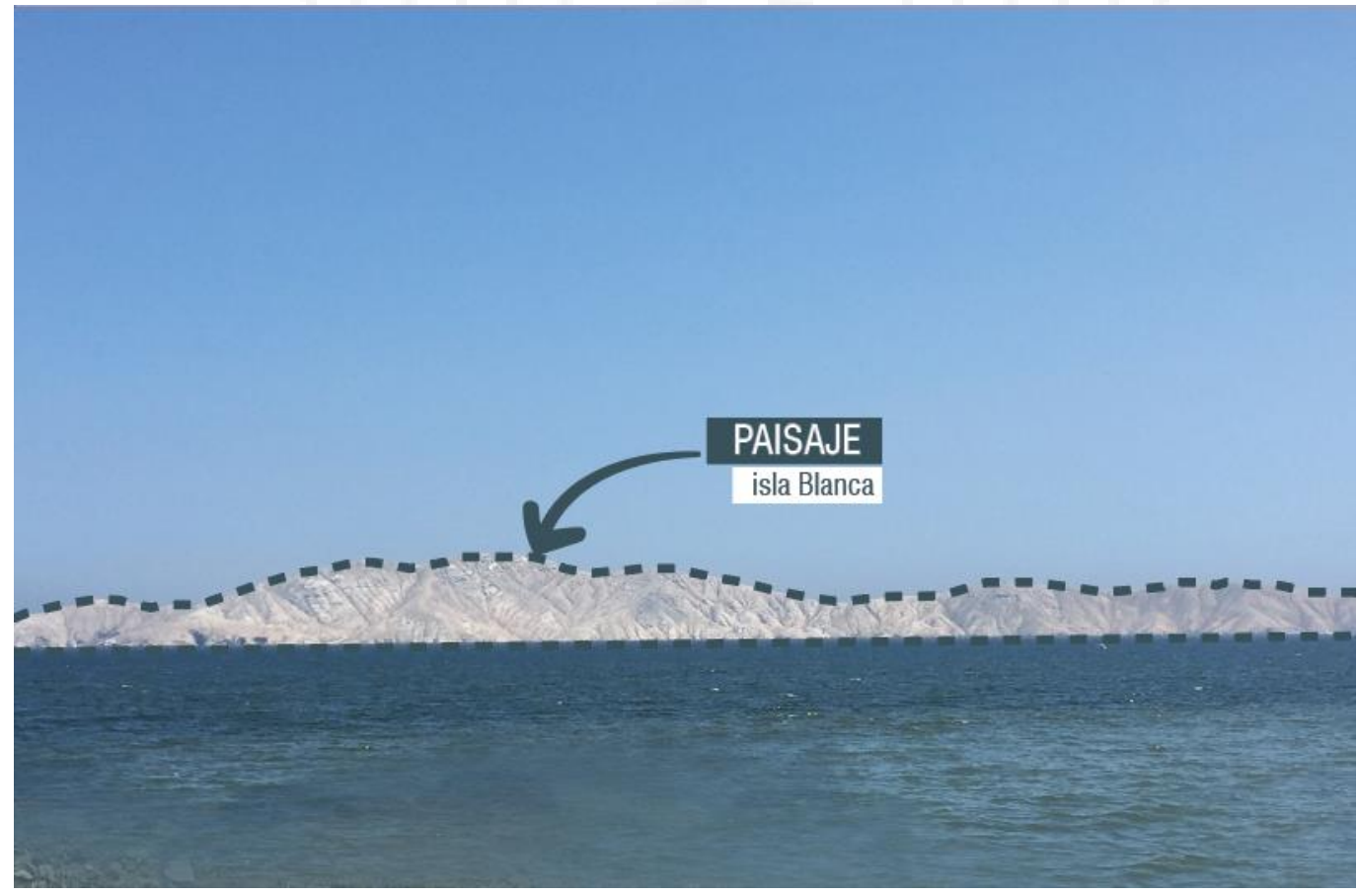

Fuente: Elaboración propia 
Ilustración 8.122 Vista del malecón y sus respectivos elementos de sombra

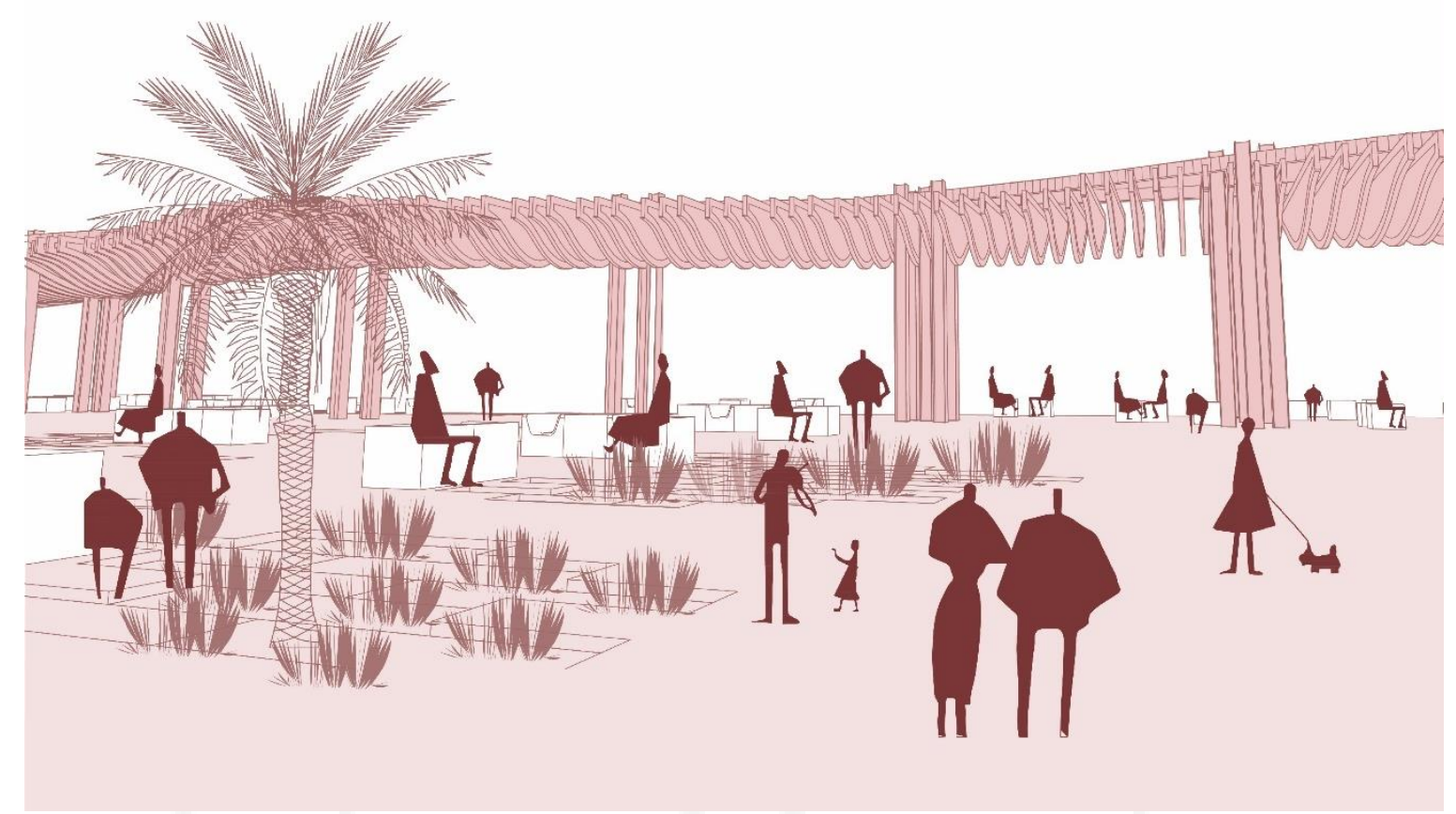

Fuente: Elaboración propia

Ilustración 8.123 Estructura de la cobertura de madera empleada en el malecón

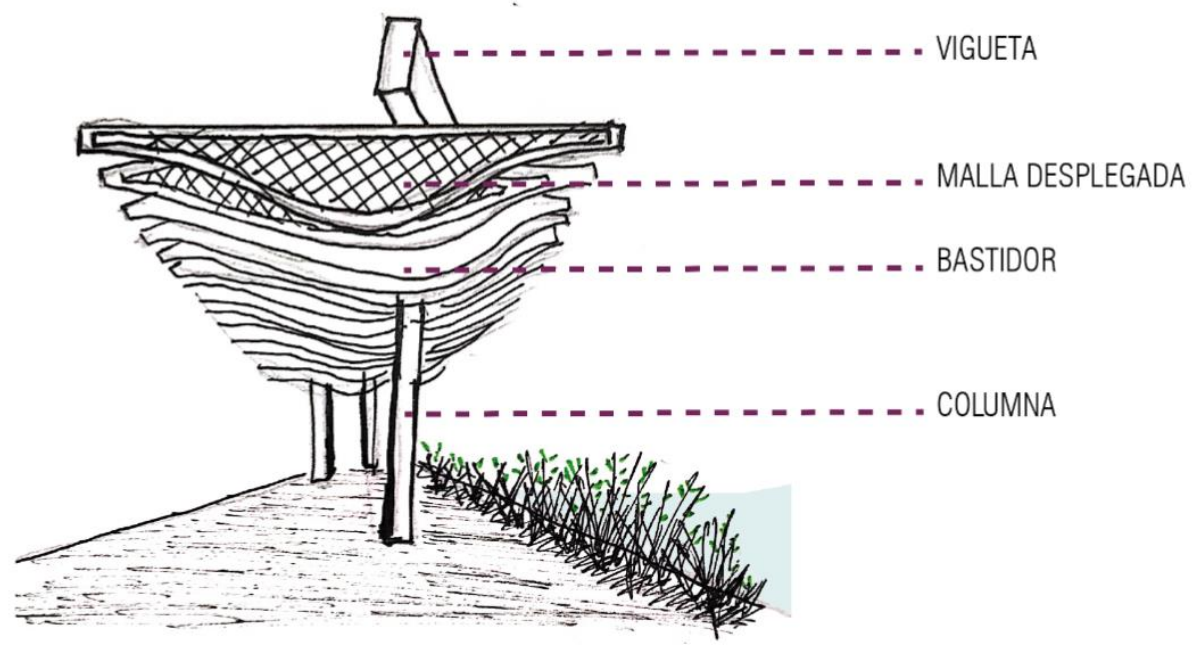

Fuente: Elaboración propia 
Otro importante elemento del espacio público es el antiguo muelle, reciclado por ser el elemento que permite la principal conexión con el mar. Se optó por reciclar su actual estructura, así como también conservar sus dimensiones y materialidad para no modificar el estado en el cual fue encontrado. Este muelle se conservará como elemento contemplativo y no para aparcar embarcaciones, de manera que establezca una relación más sensible con el paisaje.

Ilustración 8.124 Vista del muelle reciclado

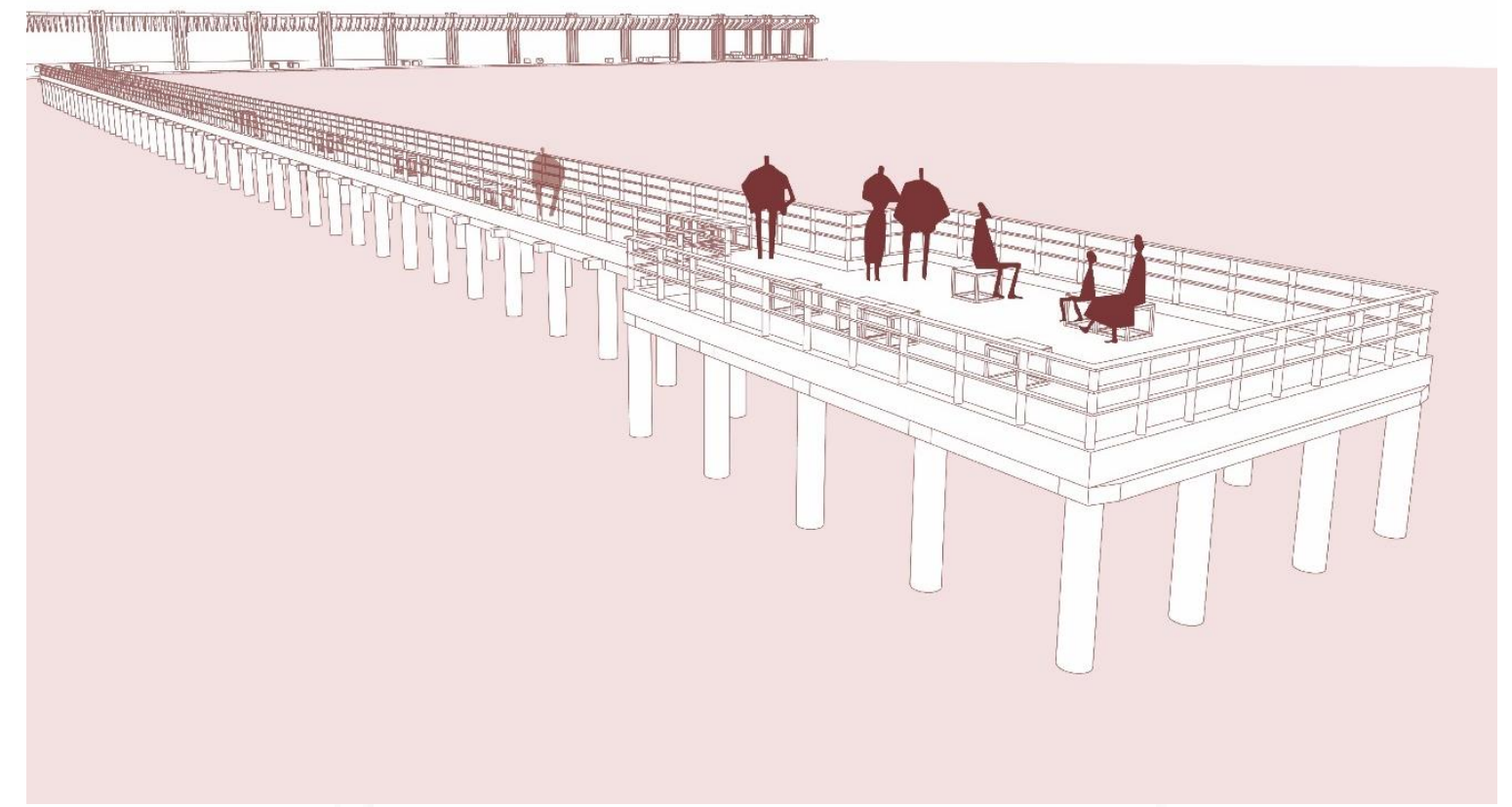

Fuente: Elaboración propia 


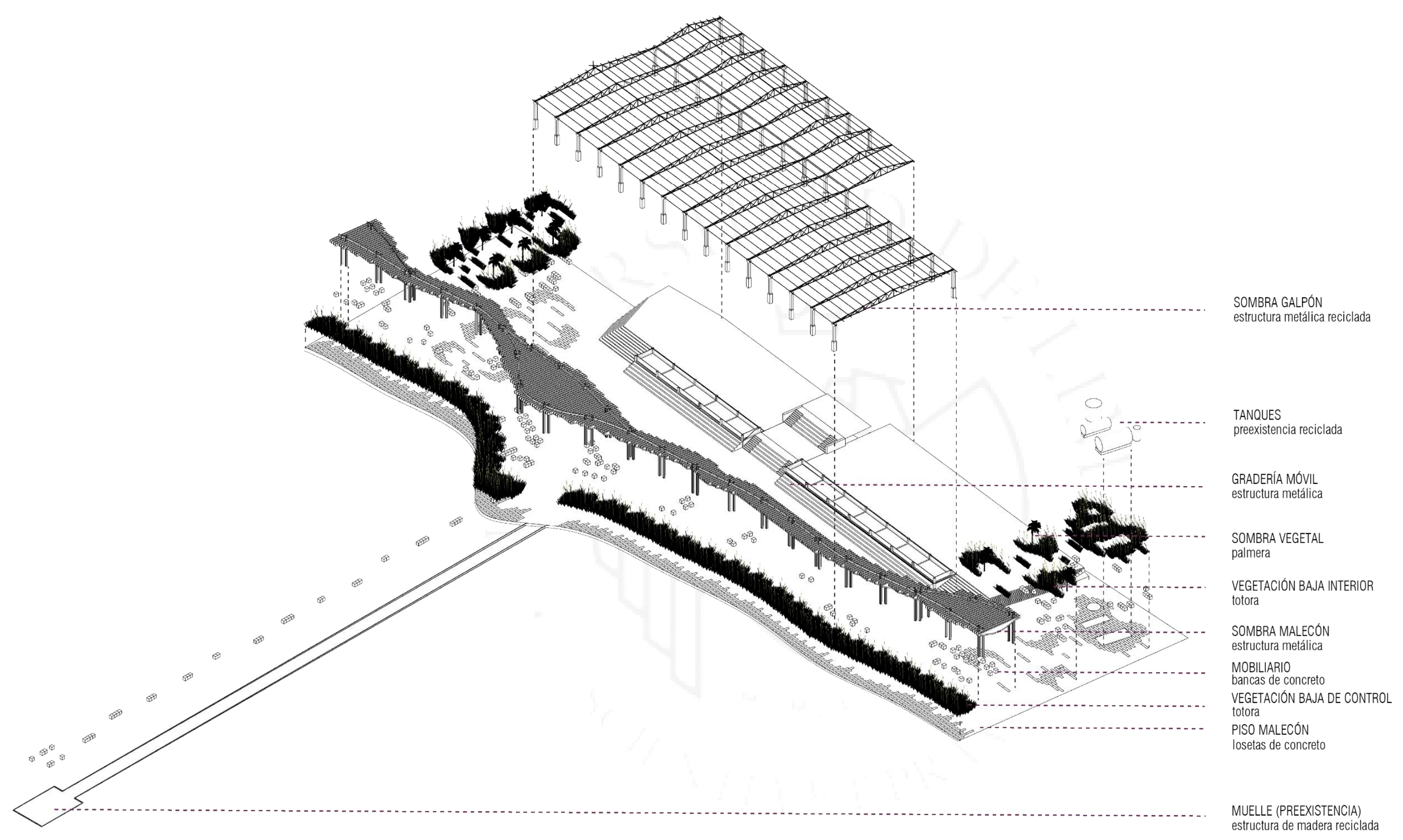




\subsection{Relación del proyecto con el mar}

1. Si bien el terreno se encuentra frente al mar, el espacio que había sido destinado para ser el malecón se había convertido en un botadero y acumulación de basura, generando una gran barrera donde se le da la espalda al mar, por este motivo se decidió trabajar también en este espacio y diseñar el futuro malecón, ya que nos servirá como herramienta para recuperar la conexión perdida con la bahía y tener una relación directa con el mar.

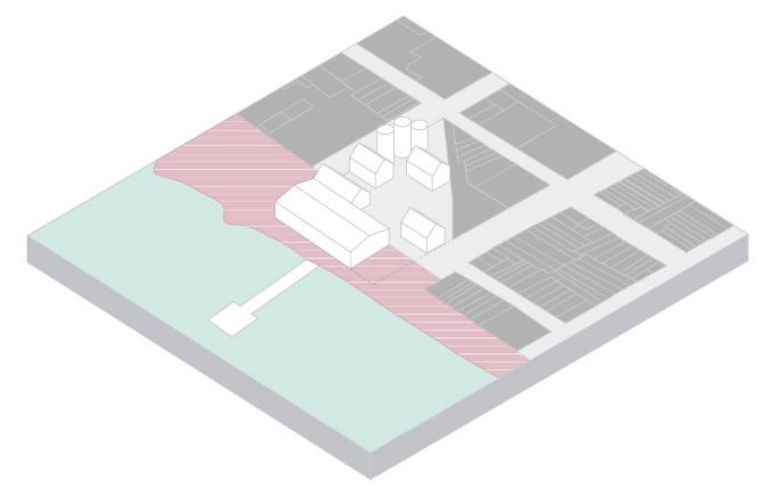

2. Además de reciclar los galpones y tanques de la antigua fábrica, se optó también por recuperar el antiguo muelle, de manera que este elemento funcione como remate del proyecto y los usuarios puedan tener un mayor contacto con el mar. Asimismo, se proyectó un gran eje de recorrido que parta desde el muelle y atraviese todo el proyecto, generando aberturas entre los galpones permitiendo la conexión tanto de las piezas, como de las plazas con el entorno.

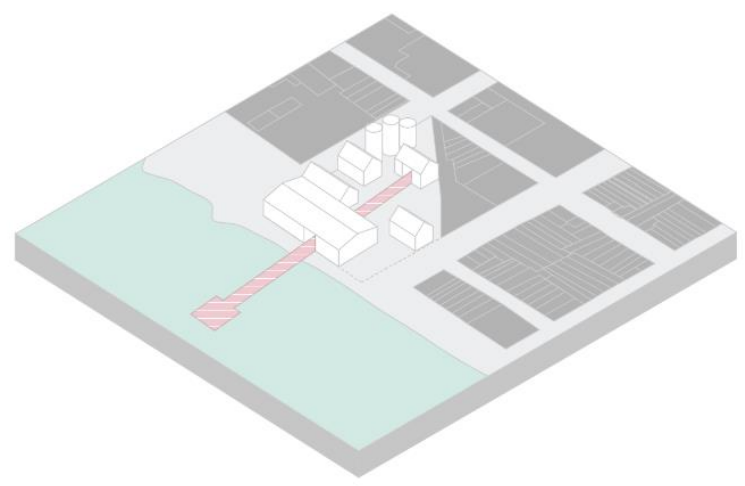

3. Se optó por liberar el gran galpón que se encontraba frente al malecón Grau conservando solo su estructura, de manera que funcione como una gran cobertura y elemento que brinde sombra a los usuarios. El espacio fue liberado además para permitir un flujo directo y constante de usuarios en el malecón y aprovechar las visuales hacia la bahía. Esta cobertura 
al funcionar como un gran espacio flexible puede albergar tanto ferias, exposiciones, desfiles y diferentes presentaciones artísticas de los talleres que se brinden en la fábrica, es por esto que se ha pensado en adherir graderías para que los espectadores puedan apreciar las funciones, así como también el paisaje costero.

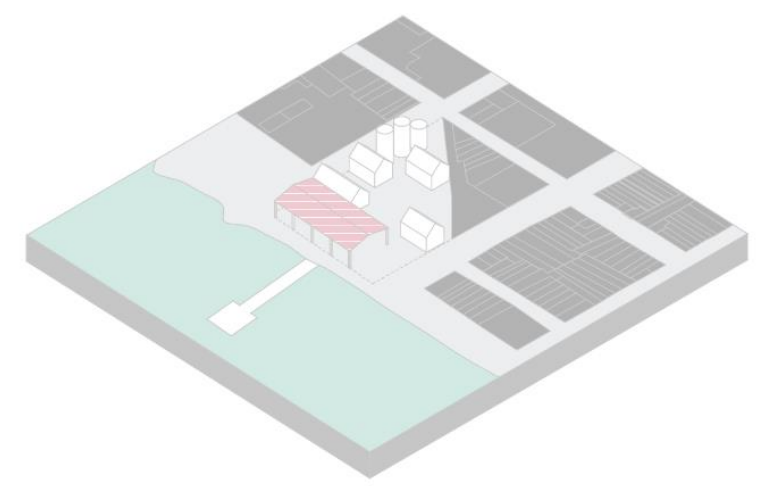

4. Si bien el proyecto se encuentra en un terreno con pendiente, se aprovechó la inclinación de este para generar plataformas escalonadas y de esta forma cada uno de los galpones pueda tener distintas visuales hacia la bahía y ninguno logre bloquear al que se encuentre detrás del otro.

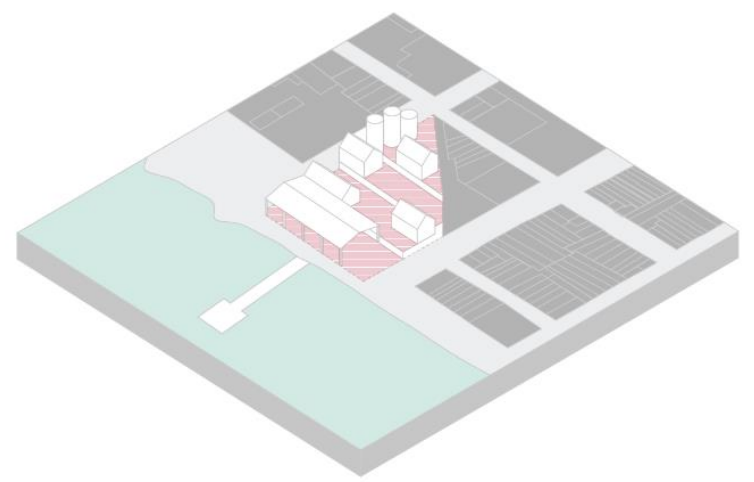

5. Con el objetivo de aprovechar las visuales se decidió ubicar la cafetería en el galpón más cercano al malecón, de manera que se genere un espacio agradable y con diversas visuales hacia la bahía, además de diseñarse una terraza abierta donde se colocaron mesas para los comensales y que de esta forma los usuarios puedan también tener relación con las futuras

6. Al contar con un terreno acompañado por un paisaje tan rico se pensó que tanto los espacios exteriores como interiores debían aprovecharse y mantener una relación con la bahía, por lo que de acuerdo al programa y con el objetivo de fomentar mayor creatividad en los talleres se decidió acompañar con fachadas traslúcidas. Si bien no toda la fachada podría 
ser transparente porque se debía proteger ante la radiación solar, se buscó que los talleres más creativos sean los espacios abiertos y aquellos talleres que requieran de mayor concentración y enfoque sean los opacos. 


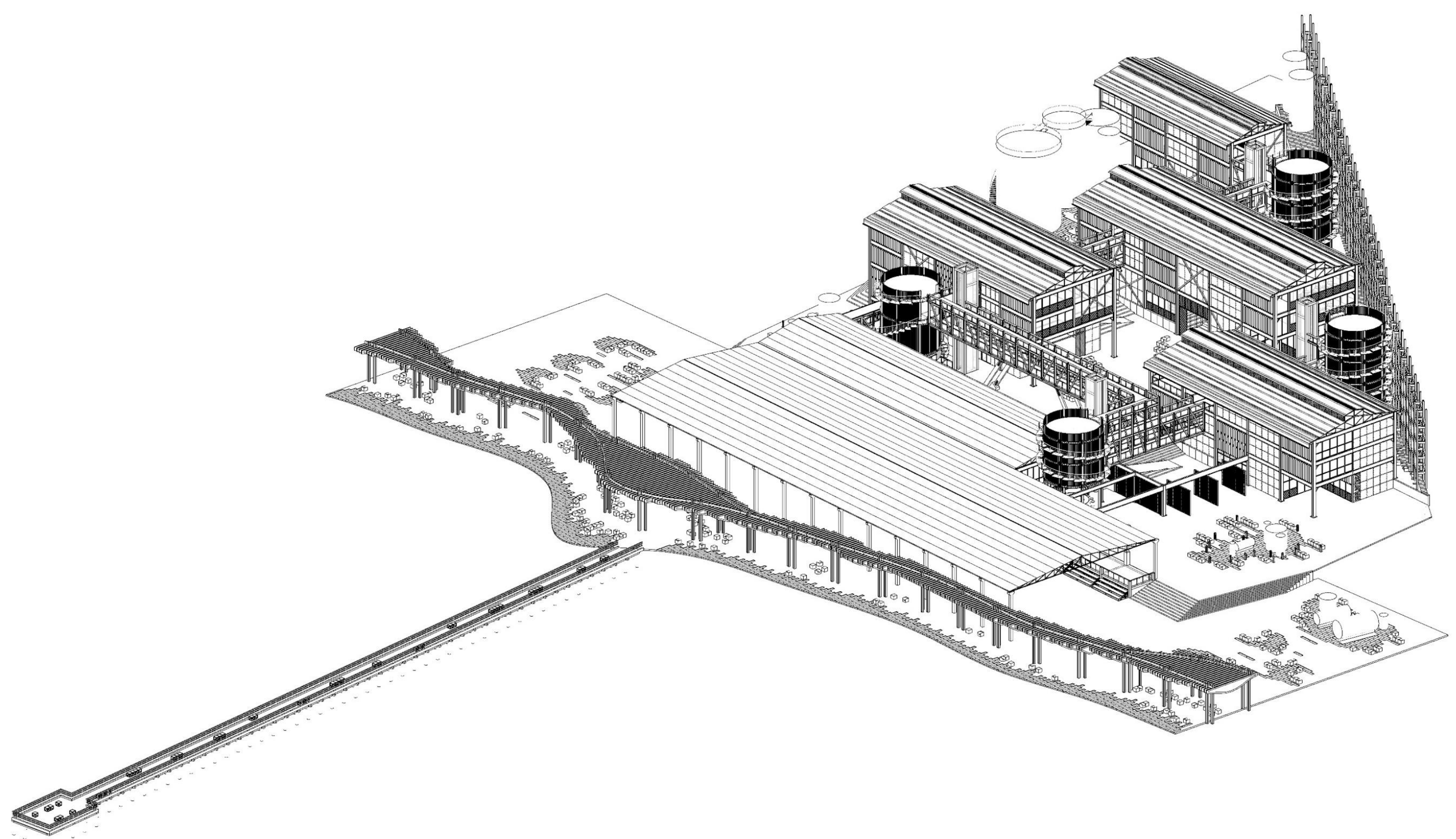

Fuente: Elaboración propia 


\subsection{Especialidades del Proyecto}

\subsubsection{Memoria descriptiva de estructuras}

El diseño de la estructura del proyecto se ha realizado sobre lo establecido en la Norma Técnica de Edificación E-030 de Diseño Sismo Resistente perteneciente al Reglamento Nacional de Edificaciones.

Suelo del terreno

El suelo del terreno presenta la napa freática en promedio a poca profundidad entre $0.70 \mathrm{y}$ 1.40m, Lo que lo convierte en un suelo vulnerable y con riesgo de licuación.

Cimentación del proyecto

Debido al tipo de suelo que existe donde el estrato superior es arenoso de granos finos y el suelo firme y de gravas se encuentra recién a $10 \mathrm{~m}$ de profundidad, se ha diseñado una cimentación mediante pilotes hincados de concreto armado de $15 \mathrm{~m}$ de profundidad con cabezal de concreto armado en la parte superior.

Estructura del proyecto

El proyecto presenta cuatro niveles distintos que van ascendiendo desde el mar hacia las vías más cercanas. Por ello se ha aprovechado la diferencia de niveles para colocar un sótano en la parte posterior del proyecto, este está compuesto por columnas y vigas de concreto armado que en algunos casos van desde el +3.00 hasta el +6.00 y en otros hasta el +7.50 , dependiendo de los niveles que se encuentren en la parte superior.

Cada columna de concreto de 0.40 x $0.80 \mathrm{~cm}$ está cimentada en dos pilotes de $50 \mathrm{~cm}$ de diámetro, que de acuerdo a la ubicación de los nuevos edificios que se encuentran en el exterior van unidas a través de cabezales.

A partir del nivel +4.50 al +7.50 se ha levantado los nuevos edificios, cuya estructura es metálica y compuesta de columnas y vigas tipo Heb e Ipe. Las dos piezas, tanto galpón como tanque, están estructuradas de forma modular, de modo que la sumatoria de estos conforman los edificios.

Losa de los edificios 
La losa del primer nivel (sótano +3.00) es losa de concreto armado y en algunos casos donde no se apoyan las piezas es losa aligerada.

En los niveles superiores, el galpón y el tanque cuentan con losa colaborante que está apoyada sobre viguetas metálicas y tienen una luz de $6.50 \mathrm{~m}$.

Las losas de los tanques están confinadas por una viga metálica I circular que en su interior carga las viguetas y sobre ella se encuentra la losa colaborante.

Techo de los galpones

Los galpones tienen dos techos a dos aguas. El principal está formado por tijerales de perfiles tubulares que se apoyan sobre las columnas y las vigas. Entre tijerales están unidos por perfiles tubulares transversales, que a su vez sobre ellos se han colocado perfiles T que funcionan como viguetas para soportar el techo de planchas de zinc con con el que está cubierto el galpón.

\subsubsection{Memoria descriptiva de Instalaciones Sanitarias}

Abastecimiento de Agua

El abastecimiento de agua es a través de una conexión domiciliaria de agua potable de la red pública, la cual va a una cisterna de agua de consumo de $77 \mathrm{~m} 2$ y a su vez hay una derivación a la cisterna de agua contra incendios de $100 \mathrm{~m} 2$.

Descripción del sistema de agua potable

La distribución de las redes de agua se realiza iniciando por el sótano, donde se abastece a los servicios higiénicos tanto del teatro, como de la cocina. Las redes suben por medio de montantes y se distribuyen en los 3 tanques que cumplen la función de espacios servidores. De los 3 tanques que contienen servicios higiénicos, 2 de ellos presentan la misma distribución, por lo que sus 4 plantas son similares. El cuarto tanque presenta una distribución distinta en sus dos últimas plantas, ya que contiene camerinos con duchas.

\section{Distribución de Agua Caliente}

Son 6 los servicios higiénicos que cuentan con camerinos y duchas, por lo que estos son los únicos del proyecto abastecidos con agua caliente. El primer ambiente es el que contiene los servicios higiénicos de hombres y mujeres para los actores del teatro. Se optó por colocar un calentador de agua compartido para ambos espacios. El siguiente ambiente abastecido con agua 
caliente son los baños para el personal de cocina. Al contar solo con una ducha en cada baño se optó por colocar un calentador de agua compartido. El último ambiente abastecido con agua caliente son los camerinos de hombres y mujeres que se encuentran en el tercer y cuarto piso del tanque del teatro. Al contar con 4 duchas en cada nivel se optó por que cada baño cuente con un calentador independiente.

Descripción del sistema de Desagüe

Las redes de desagüe descienden de los 3 tanques a través de montantes de 4 " y 2" hacia el nivel del sótano, donde estas se conectan hacia las redes principales por medio de cajas de registro de 30 x $60 \mathrm{~cm}$, todas descendiendo por pendientes de 1". Estas cajas llegan hacia la cámara de bombeo que se encuentra en el sótano, para finalmente dirigirse al colector.

Descripción del sistema de Agua contra Incendio

El sistema de redes de agua contra incendio parte de una cisterna de almacenamiento de agua de $100 \mathrm{~m} 2$, la cual recibe agua de la red pública y la deriva directamente hacia un gabinete de agua contra incendio. Este gabinete reparte agua por todo el sótano hacia los rociadores que se encuentran en cada estacionamiento y pistas. Todas las tuberías de agua contra incendio tienen un espesor de 1 ".

\subsubsection{Memoria descriptiva de Instalaciones Eléctricas}

Al ser un proyecto conformado por bloques independientes se optó por que cada galpón funcione de manera independiente, es por ello que cada uno cuenta con tableros generales en cada planta, para una mejor distribución de la energía eléctrica.

Tablero General y Tableros de Distribución

El proyecto cuenta tanto con un tablero general como con tableros de distribución. Estos tableros de distribución se encuentran ubicados en cada planta de los diferentes galpones, mientras que el tablero general se encuentra en el sótano de estacionamientos.

El punto de partida de la red inicia en los medidores de luz, que se encuentran ubicados en el muro que acompaña la rampa vehicular. A partir de estos medidores la red eléctrica se distribuye por todo el sótano por medio de cuatro tableros generales, el primero ubicado en el pasadizo anexo a los depósitos de vestuarios, el segundo en el cuarto de limpieza entre los 
servicios higiénicos del museo, el tercero dentro del almacén de conserva de la cocina y finalmente el cuarto en el depósito de libros de la biblioteca.

En relación a la planta del segundo nivel (+7.50) las redes independientes parten de los tableros generales de cada galpón, en el caso del galpón de oficinas este se encuentra dentro del tópico, en el caso del galpón de la biblioteca infantil este se encuentra en el aula multiusos, en el caso del galpón del auditorio, este se encuentra en el cuarto de monitoreo y control, y en el caso de la biblioteca general, el tablero se encuentra dentro del depósito de libros, como ya se mencionó previamente.

Con relación a la planta del tercer nivel $(+12.70)$ el galpón de oficinas es alimentado por un tablero que se encuentra en el área del kitchenette de las oficinas, en el galpón de la biblioteca infantil el tablero general se encuentra en la sala de espera, y finalmente en el galpón del auditorio el tablero general se encuentra dentro de uno de los talleres de teatro.

Para una adecuada regulación de la energía eléctrica dentro del proyecto se colocó una subestación eléctrica en la planta del sótano.

\subsection{Gestión del Proyecto}

\subsubsection{Sostenibilidad económica, social y ambiental}

La bahía el Ferrol está proyectada a convertirse en el futuro eje turístico para la ciudad de Chimbote de acuerdo con el Plan de Desarrollo Urbano 2012-2022 (PDU) y al Plan de Acondicionamiento Territorial de la Municipalidad del Santa 2012-2022 (PAT). En ambos documentos, se plantean intervenciones a desarrollar con el objetivo de potenciar el uso del suelo urbano y fortalecer la economía de la ciudad, lo que traerá como efecto colateral, el turismo.

En el sistema de inversión territorial del $\mathrm{PAT}^{14}$, la mayor cantidad de proyectos a atender se encuentran en la zona costera, siendo parte de ellos la construcción e implementación de un centro cultural en la ciudad de Chimbote. Adicionalmente, en el sistema de inversión urbana del PDU ${ }^{15}$, se observa dentro de los proyectos la reconversión urbana y habilitación turística de la zona donde se encuentran las fábricas en desuso.

\footnotetext{
${ }^{14}$ Ver anexo $\mathrm{n}^{\mathrm{o}} 3$

15 Ver anexo n ${ }^{\circ} 4$
} 
Ilustración 8.126 Mapa del sistema de inversión urbana

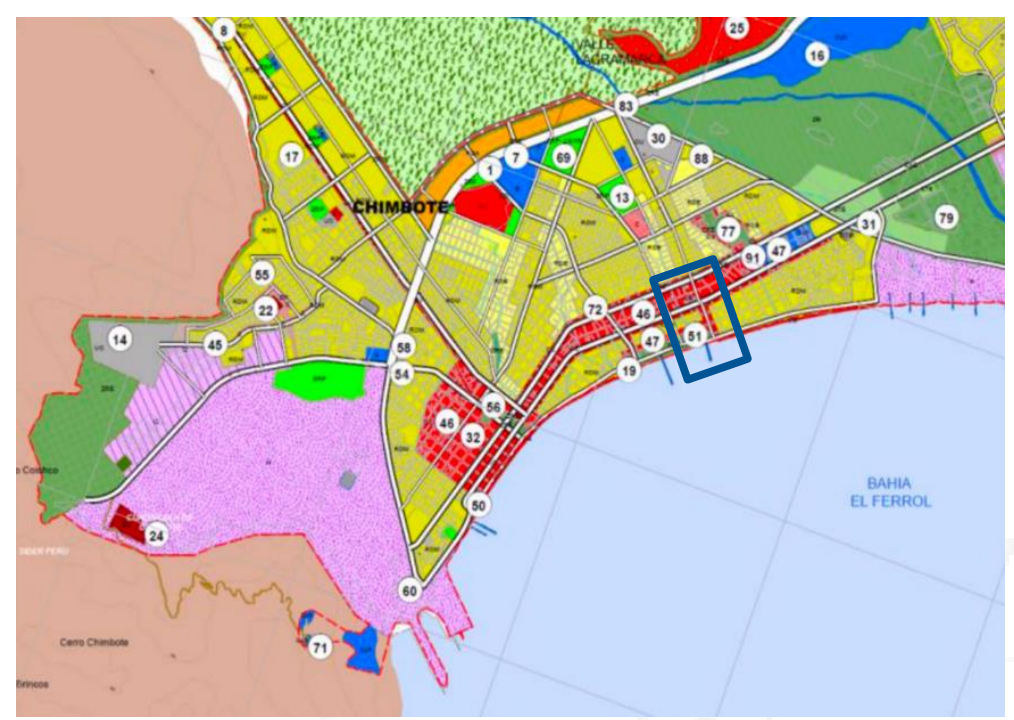

Fuente: PDU Chimbote 2012-2022.

Ilustración 8.127 Mapa del sistema de inversión costera

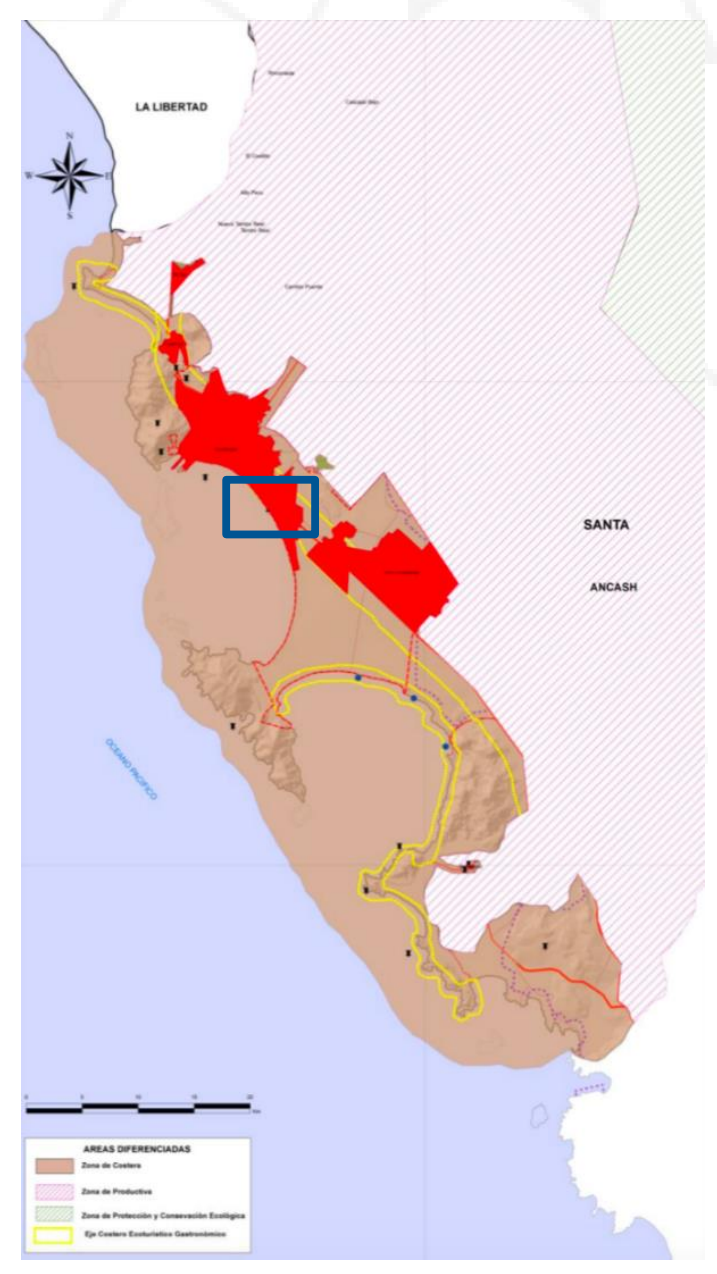

Fuente: PAT Santa 2012. 
Luego de observar y traslapar la información de ambos mapas, conllevar a determinar que si los proyectos planteados se integraran en un solo proyecto como se ha desarrollado en la presente tesis, el impacto y beneficio sería mayor, debido a que concentraría y respondería a las necesidades que se han encontrado para determinar el planteamiento de los proyectos elaborados en ambos planes.

Ambos planes hacen hincapié de plantear proyectos en la zona centro del borde costero de la ciudad, donde precisamente se encuentran las fábricas en desuso que ya no forman parte de la dinámica urbana de la ciudad. Es por ello, que se considera importante no solo intervenir en un punto, sino que la regeneración y transformación de la ex zona industrial será posible a través de una red de intervención de las 11 fábricas inoperativas que se encuentran en la zona, según el informe de OEFA del año 2016, información que ha sido corroborada en el presente año para el desarrollo de este documento.

La Fábrica Cultural será el primer proyecto por desarrollarse de la red de intervención de las fábricas inoperativas que buscarán convertir la relación de la ciudad con la bahía, volviendo la mirada al mar e insertando un futuro eje de actividad. La actuación de la red permitirá transformar urbanamente el área, aumentar el valor del terreno, mejorar la calidad de vida de los habitantes y a su vez atraer la inversión privada que incentivará el turismo en la zona. Evidentemente, el proyecto impactará en todo el borde costero a través de la conversión de la actual barrera compuesta por desmonte y basura para activarlo y convertirse en un malecón que conecte los 11 kilómetros que existe a lo largo de la bahía, contribuyendo de esta manera al beneficio ambiental y de salubridad para todas las personas que viven actualmente frente a esta realidad.

Del mismo modo, el proyecto contribuirá a satisfacer la demanda social insatisfecha causada por el déficit de equipamientos culturales en la ciudad de Chimbote. La inserción de este equipamiento en la fábrica en desuso le otorgará a la población un espacio donde desarrollar actividades culturales que complemente su nivel educativo y les otorgue herramientas para poder crecer e insertarse a la oferta laboral de la ciudad. Asimismo, al situar el equipamiento en un lugar con historia y memoria colectiva permitirá revalorar y fortalecer la identidad chimbotana, entendiendo el pasado y proyectando un presente que represente una oportunidad para las generaciones de hoy y del futuro.

De esta manera se sustenta la viabilidad social, económica y ambiental del proyecto. 


\subsubsection{Viabilidad legal}

Según los registros públicos, el terreno donde se encuentra el proyecto fue asentado por primera vez en el año 1962 como propiedad de privados. En 1968, el terreno pasa a manos de la Compañía Pesquera La Florida S.A, quien construye la fábrica productora de conserva y harina de pescado, desde ese momento empezó el desarrollo productivo de la fábrica hasta el año 2009 en la que se puso en marcha la Ord. $\mathrm{N}^{\circ}$ 001-2009-MPS, por lo que la industria pesada tuvo que cesar sus funciones. Hoy en día, la fábrica es de propiedad de la empresa pesquera CFG Investment S.A.C., y esporádicamente se aprovecha como depósito las otras fábricas de esta compañía.

Ilustración 8.128 Certificado literal de la fábrica

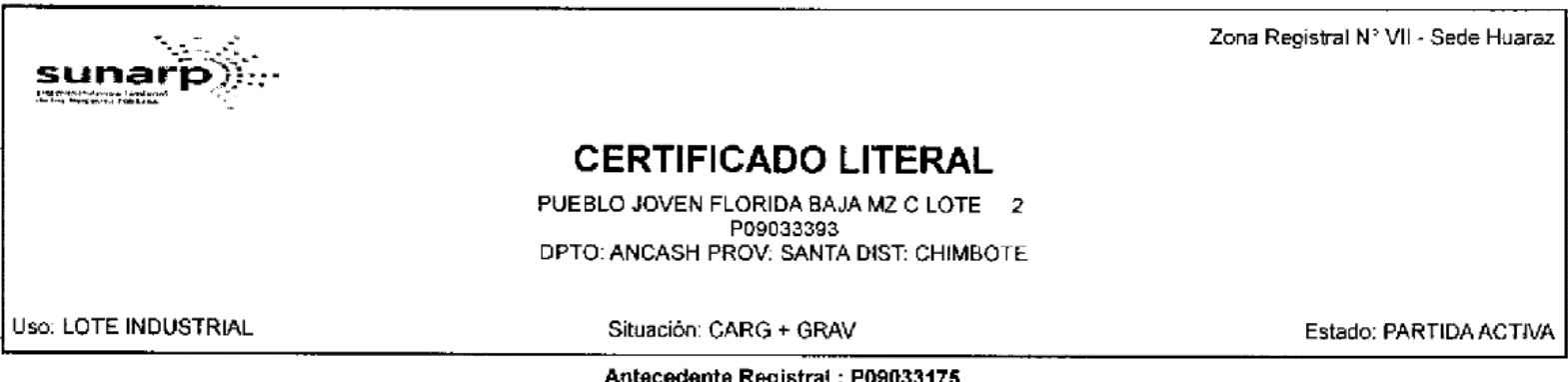

Asiento 00001

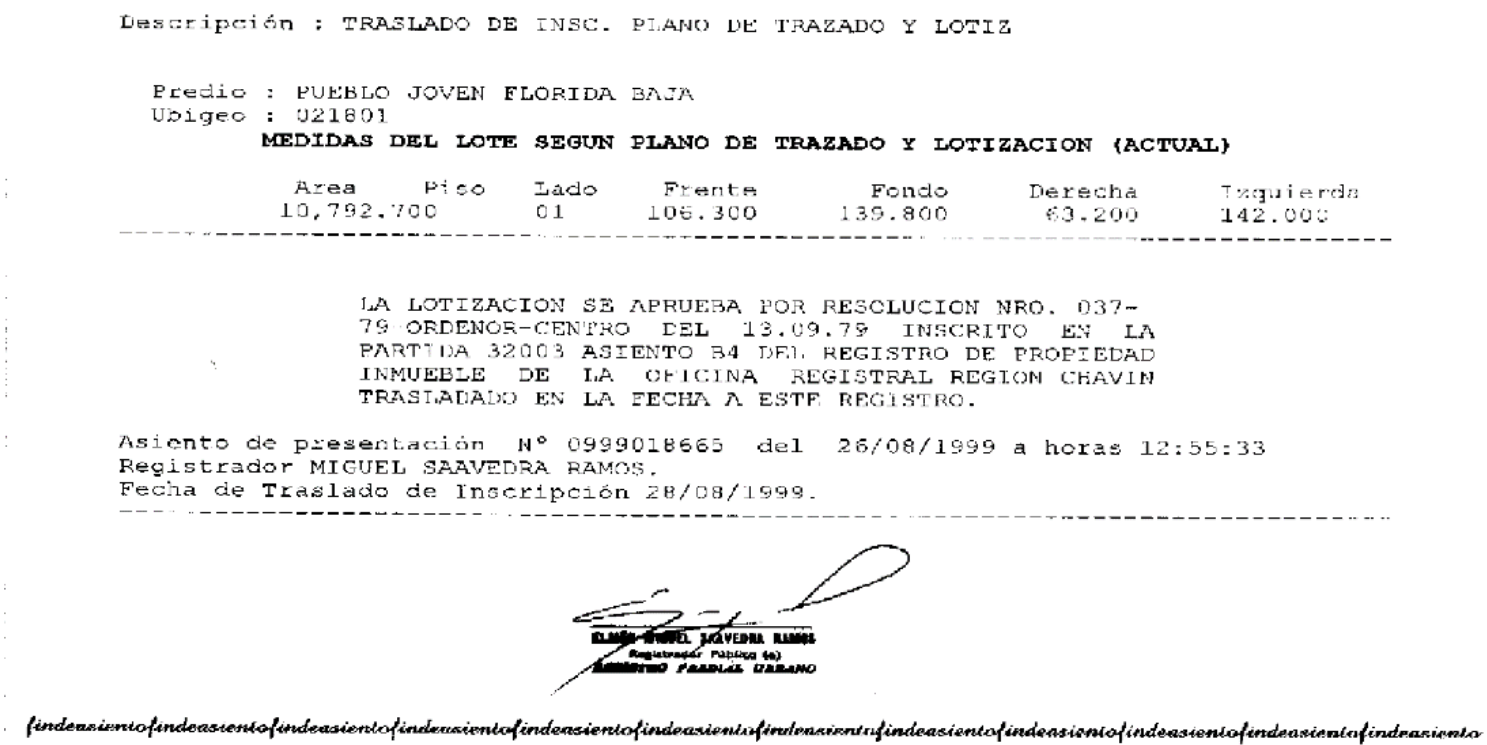

Fuente: SUNARP, 2017. 


\subsubsection{Panorama General del proyecto}

\subsubsection{FODA del terreno y del proyecto}

\begin{tabular}{|c|c|c|c|c|}
\hline & FORTALEZAS & DEBILIDADES & OPORTUNIDADES & AMENAZAS \\
\hline \multirow{3}{*}{$\begin{array}{l}\text { SUB SISTEMA } \\
\text { FÍSICO } \\
\text { TERRITORIAL }\end{array}$} & $\begin{array}{l}\text { Contar con elementos y } \\
\text { estructuras industriales } \\
\text { (preexistencias) }\end{array}$ & $\begin{array}{l}\text { Elevado costo por el } \\
\text { mantenimiento de las } \\
\text { estructuras. }\end{array}$ & $\begin{array}{l}\text { Posibilidad de revalorar la } \\
\text { memoria colectiva e identidad de } \\
\text { Chimbote y ser tomada en cuenta } \\
\text { como patrimonio industrial de la } \\
\text { ciudad. }\end{array}$ & $\begin{array}{l}\text { Corrosión de las estructuras } \\
\text { industriales por acción de la } \\
\text { brisa marina }\end{array}$ \\
\hline & $\begin{array}{l}\text { De acuerdo a la ordenanza xx- } \\
\text { 2009-MPS, la zona de la Florida } \\
\text { ha dejado de ser una zona } \\
\text { industrial }\end{array}$ & $\begin{array}{l}\text { El terreno actualmente es } \\
\text { utilizado como depósito de la } \\
\text { empresa pesquera CFG. }\end{array}$ & $\begin{array}{l}\text { Contar con fábricas en desuso } \\
\text { alrededor del terreno, donde se } \\
\text { puedan desarrollar } \\
\text { equipamientos complementarios }\end{array}$ & $\begin{array}{l}\text { Calles desoladas por la } \\
\text { presencia de muros } \\
\text { perimétricos ciegos de las } \\
\text { antiguas fábricas }\end{array}$ \\
\hline & $\begin{array}{l}\text { Zonificación actual - Comercio } \\
\text { zonal }\end{array}$ & $\begin{array}{l}\text { Contar con lotes vecinos de } \\
\text { zonificación residencial baja } \\
\text { en la misma manzana }\end{array}$ & $\begin{array}{l}\text { Posibilidad de desarrollar un } \\
\text { proyecto de uso compatible con } \\
\text { la zonificación actual. }\end{array}$ & $\begin{array}{l}\text { Modificaciones en la } \\
\text { zonificación en consecuencia } \\
\text { del cambio de gestión. }\end{array}$ \\
\hline \multirow[b]{2}{*}{$\begin{array}{l}\text { SUB SISTEMA } \\
\text { MEDIO AMBIENTAL }\end{array}$} & $\begin{array}{l}\text { Ubicación en el borde de la } \\
\text { bahía. }\end{array}$ & $\begin{array}{l}\text { Vulnerabilidad del suelo. } \\
\text { Terreno con riesgo de } \\
\text { licuación y napa freática a } 5 \\
\text { metros de profundidad }\end{array}$ & $\begin{array}{l}\text { Contar con un borde marítimo } \\
\text { recuperado que conecte la } \\
\text { ciudad con la bahía. }\end{array}$ & Riesgo de Tsunami \\
\hline & $\begin{array}{l}\text { Cercanía con el paisaje marino } \\
\text { costero y paisaje industrial }\end{array}$ & $\begin{array}{l}\text { Acumulación de basura en el } \\
\text { frente marítimo que genera } \\
\text { una barrera física. } \\
\text { Contaminación del agua por } \\
\text { el desemboque de los } \\
\text { efluentes industriales y } \\
\text { domésticos }\end{array}$ & $\begin{array}{l}\text { Aprovechar las visuales hacia la } \\
\text { bahía, Isla Blanca e Islas El Ferrol }\end{array}$ & Erosión del borde costero \\
\hline \multirow{2}{*}{$\begin{array}{l}\text { SUB SISTEMA DE } \\
\text { MOVILIDAD }\end{array}$} & $\begin{array}{l}\text { Colindancia con ejes de } \\
\text { movilidad de jerarquía nacional } \\
\text { (Av. Meiggs - Actual } \\
\text { Panamericana) }\end{array}$ & $\begin{array}{l}\text { La vía que se encuentra en el } \\
\text { borde marítimo está sin } \\
\text { asfalto y con gran cantidad de } \\
\text { acumulación de desmonte y } \\
\text { basura. }\end{array}$ & $\begin{array}{l}\text { Fácil acceso de los usuarios al } \\
\text { terreno }\end{array}$ & $\begin{array}{l}\text { Alto nivel de ruido por el flujo } \\
\text { de vehículos pesados. }\end{array}$ \\
\hline & $\begin{array}{l}\text { Bajo flujo vehicular en las } \\
\text { calles colindantes }\end{array}$ & $\begin{array}{l}\text { Bajo flujo peatonal, } \\
\text { especialmente en el borde } \\
\text { marítimo. }\end{array}$ & $\begin{array}{l}\text { Desarrollar espacios públicos en } \\
\text { el borde costero que no se vean } \\
\text { interrumpidos por los autos. }\end{array}$ & $\begin{array}{l}\text { Percepción de inseguridad } \\
\text { por la escasa iluminación y } \\
\text { actividad en los espacios } \\
\text { públicos }\end{array}$ \\
\hline $\begin{array}{l}\text { SUB SISTEMA } \\
\text { EQUIPAMENTAL }\end{array}$ & $\begin{array}{l}\text { Presencia aledaña de } \\
\text { equipamientos educativos y de } \\
\text { salud. }\end{array}$ & $\begin{array}{l}\text { Déficit de equipamiento } \\
\text { cultural cercano y carencia } \\
\text { de espacios públicos }\end{array}$ & $\begin{array}{l}\text { Desarrollar un proyecto cultural y } \\
\text { de espacio público en el terreno }\end{array}$ & $\begin{array}{l}\text { Negación por parte del } \\
\text { propietario de la fábrica de } \\
\text { desarrollar un proyecto } \\
\text { cultural. }\end{array}$ \\
\hline $\begin{array}{c}\text { SUB SISTEMA } \\
\text { SOCIO ECONÓMICO }\end{array}$ & $\begin{array}{l}\text { El perfil socio-económico de la } \\
\text { población de la zona presenta } \\
\text { un NSE medio-bajo }\end{array}$ & $\begin{array}{l}\text { Ubicación del terreno dentro } \\
\text { de un área con } \\
\text { predominancia de pueblos } \\
\text { jóvenes }\end{array}$ & $\begin{array}{l}\text { Propiciar escenarios de } \\
\text { desarrollo económico en la zona }\end{array}$ & $\begin{array}{l}\text { Falta de indentificación de la } \\
\text { población chimbotana con la } \\
\text { zona }\end{array}$ \\
\hline
\end{tabular}




\begin{tabular}{|c|c|c|c|c|}
\hline & FORTALEZAS & DEBILIDADES & OPORTUNIDADES & AMENAZAS \\
\hline \multirow[b]{2}{*}{$\begin{array}{l}\text { ASPECTO } \\
\text { CULTURAL }\end{array}$} & $\begin{array}{l}\text { El proyecto cuenta con espacios } \\
\text { de difusión cultural y artísticas }\end{array}$ & -- & -- & -- \\
\hline & $\begin{array}{l}\text { Reciclaje de elementos } \\
\text { industriales para revalorar y } \\
\text { enfatizar la identidad industrial } \\
\text { chimbotana. }\end{array}$ & $\begin{array}{l}\text { Costo elevado de } \\
\text { mantenimiento de las } \\
\text { estructuras }\end{array}$ & $\begin{array}{l}\text { Según el sistema de inversión } \\
\text { costera del PDU Chimbote } \\
\text { 2012-2022, la MPS propone el } \\
\text { financiamiento de la } \\
\text { "Construcción del centro de } \\
\text { fortalecimiento de la identidad } \\
\text { y valores culturales de la } \\
\text { provincia en la zona costera." y } \\
\text { la "Construcción e } \\
\text { implementación del centro } \\
\text { cultural en la ciudad de } \\
\text { Chimbote. }\end{array}$ & $\begin{array}{l}\text { Corrosión de las estructuras por } \\
\text { efecto del clima }\end{array}$ \\
\hline \multirow[b]{2}{*}{$\begin{array}{l}\text { ASPECTO SOCIO } \\
\text { ECONÓMICO }\end{array}$} & $\begin{array}{l}\text { Contar con programa como } \\
\text { talleres que generen } \\
\text { emprendimientos e industrias } \\
\text { creativas }\end{array}$ & -- & $\begin{array}{l}\text { Nuevos puestos de trabajo y } \\
\text { destinados a distintos rubros }\end{array}$ & -- \\
\hline & $\begin{array}{l}\text { Proyecto orientado } \\
\text { principalmente a un público } \\
\text { objetivo joven }\end{array}$ & -- & $\begin{array}{l}\text { El } 20.09 \% \text { de la población total } \\
\text { de Chimbote se encuentra en } \\
\text { el rango de edad de 10-19 años } \\
\text { (población joven) }\end{array}$ & -- \\
\hline \multirow{2}{*}{$\begin{array}{l}\text { ASPECTO MEDIO } \\
\text { AMBIENTAL }\end{array}$} & $\begin{array}{l}\text { Liberar la fábrica hacia el frente } \\
\text { costero }\end{array}$ & $\begin{array}{l}\text { Una de las estructuras } \\
\text { existentes ocupa el área } \\
\text { destinada para el desarrollo del } \\
\text { futuro malecón }\end{array}$ & $\begin{array}{l}\text { Creación del malecón y } \\
\text { dotación de un espacio público } \\
\text { inexistente a la población. }\end{array}$ & Riesgo de Tsunami \\
\hline & $\begin{array}{l}\text { Creación de un borde de } \\
\text { interacción y actividad }\end{array}$ & -- & $\begin{array}{l}\text { Reducción de la percepción de } \\
\text { inseguridad en el borde costero } \\
\text { y volcar la mirada de la ciudad } \\
\text { a la bahía }\end{array}$ & 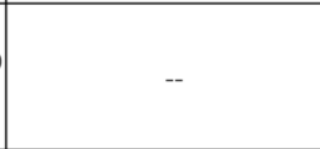 \\
\hline \multirow{2}{*}{ ASPECTO URBANO } & $\begin{array}{l}\text { Proyecto como regenerador del } \\
\text { paso del tejido industrial al } \\
\text { residencial }\end{array}$ & -- & $\begin{array}{l}\text { Dotación de un nuevo uso a un } \\
\text { espacio inactivo }\end{array}$ & -- \\
\hline & $\begin{array}{l}\text { Proyecto que cuenta con plazas } \\
\text { con capacidad de albergar a } \\
\text { grandes masas }\end{array}$ & -- & $\begin{array}{l}\text { Generar escenarios de difusión } \\
\text { cultural como la "Fiesta de San } \\
\text { Pedrito" }\end{array}$ & $\begin{array}{l}\text { Oposición por parte de los } \\
\text { vecinos al no querer una } \\
\text { aglomeración de usuarios en el } \\
\text { terreno }\end{array}$ \\
\hline
\end{tabular}

\subsubsection{Stakeholders}

Para el desarrollo del proyecto, será necesaria la participación de entidades públicas y privadas, que tengan interés y jurisdicción en la zona. El proyecto presenta un alcance distrital por lo que a nivel local, intervendrían entidades como la Municipalidad Provincial del Santa y el Colegio de Arquitectos región Ancash; a nivel nacional, la Fábrica Cultural se convertiría en punto de cultura, despertando así el interés del Ministerio de Cultura; así también al haber integrado como parte del proyecto el desarrollo del malecón en el borde costero, el Ministerio del Ambiente y la Marina de Guerra tendrá actuación en el proceso. 
Ilustración 8.129 Matriz de intersados

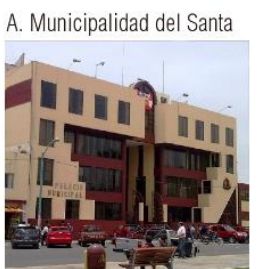

F. Inversionista

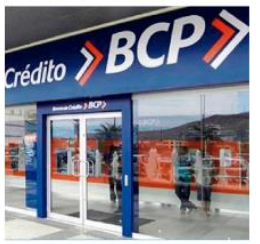

MINAM

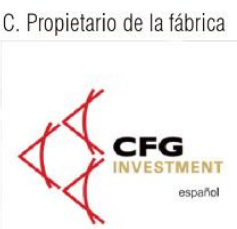

G. Ministerio del Ambiente

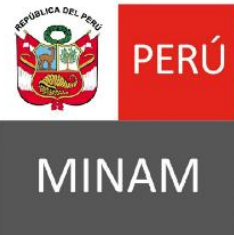

H. Colectivos Ambientalistas

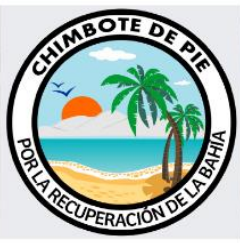

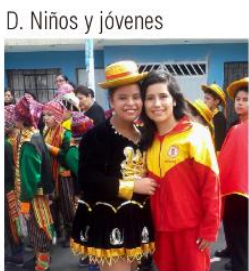

E. Ministerio de Cultura

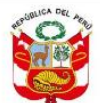

PERÚ

Ministerio

de Cultura

I. Medios de difusión

J. Colegio de Arquitectos

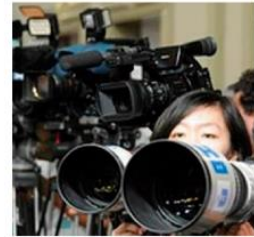

Matriz de los stakeholders

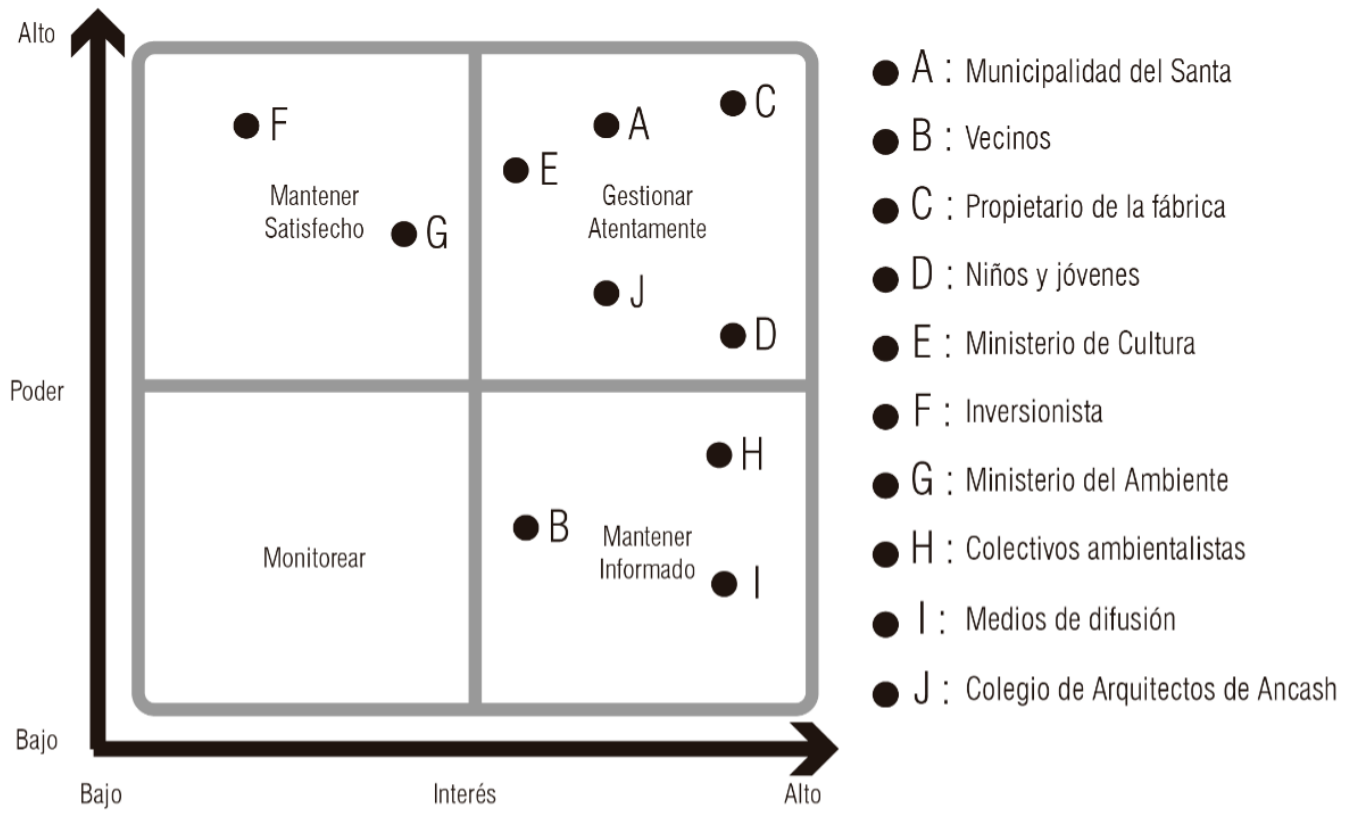

Fuente: Elaboración propia 


\subsubsection{Gestión del tiempo del proyecto}

8.27.4.1 Cronograma genérico del proyecto

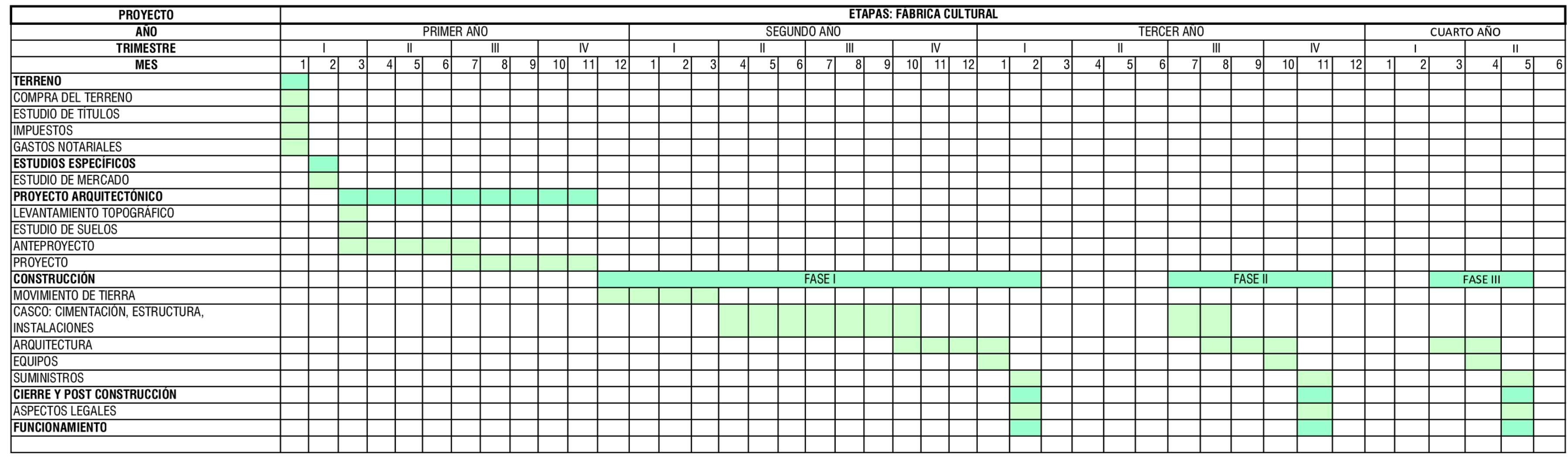




\subsubsection{Gestión económica - financiero}

\subsubsection{Construcción por etapas}

La construcción del proyecto ha sido organizada por etapas para una mejor gestión y viabilidad del mismo. Por tal motivo, el proyecto se estructura en tres etapas. La primera consta de la construcción de los espacios más cercanos a la bahía, con la finalidad de activar este borde y recuperar los galpones en donde se desarrollará una muestra del pasado de Chimbote y de la fábrica para fortalecer la identidad chimbotana. Seguido de ello, en la segunda etapa se plantea construir los galpones intermedios acompañados de los tanques servidores que complementan el programa. Finalmente, en la tercera etapa se construirá los dos galpones restantes con sus respectivos tanques y la rejilla medianera.

\section{Ilustración 8.130 Etapa 1 de la construcción del proyecto}

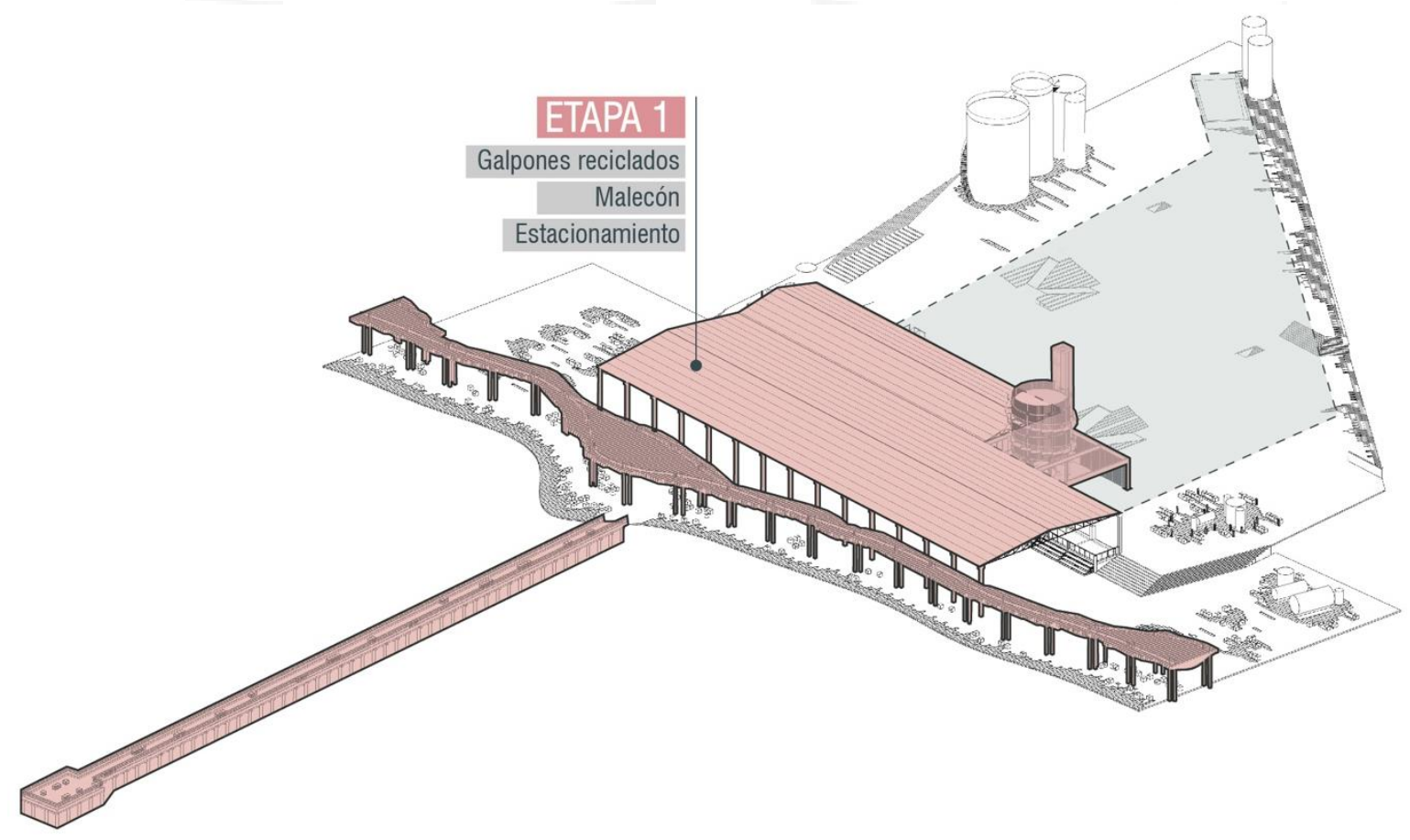

Fuente: Elaboración propia 


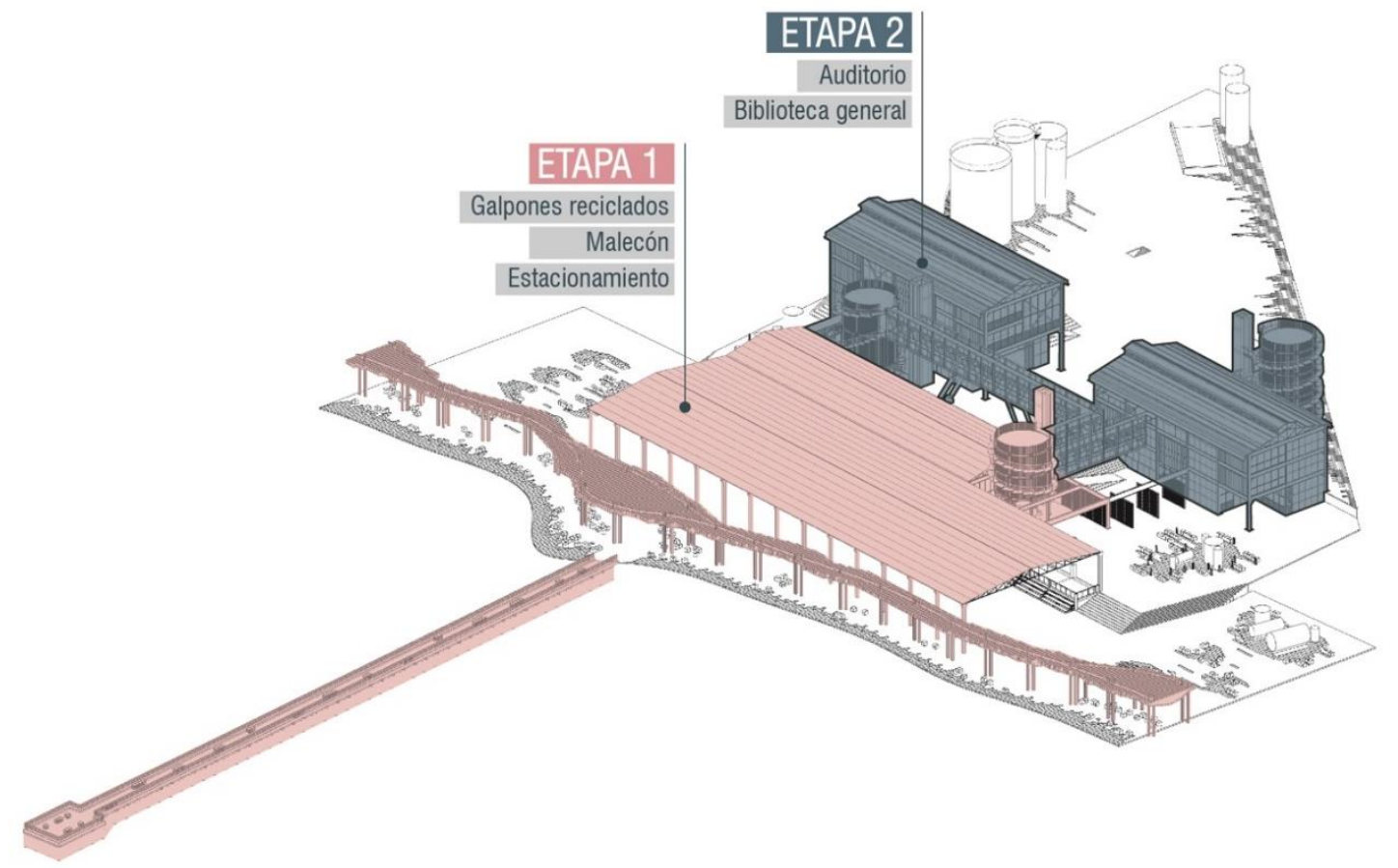

Fuente: Elaboración propia

Ilustración 8.132 Etapas de construcción del proyecto

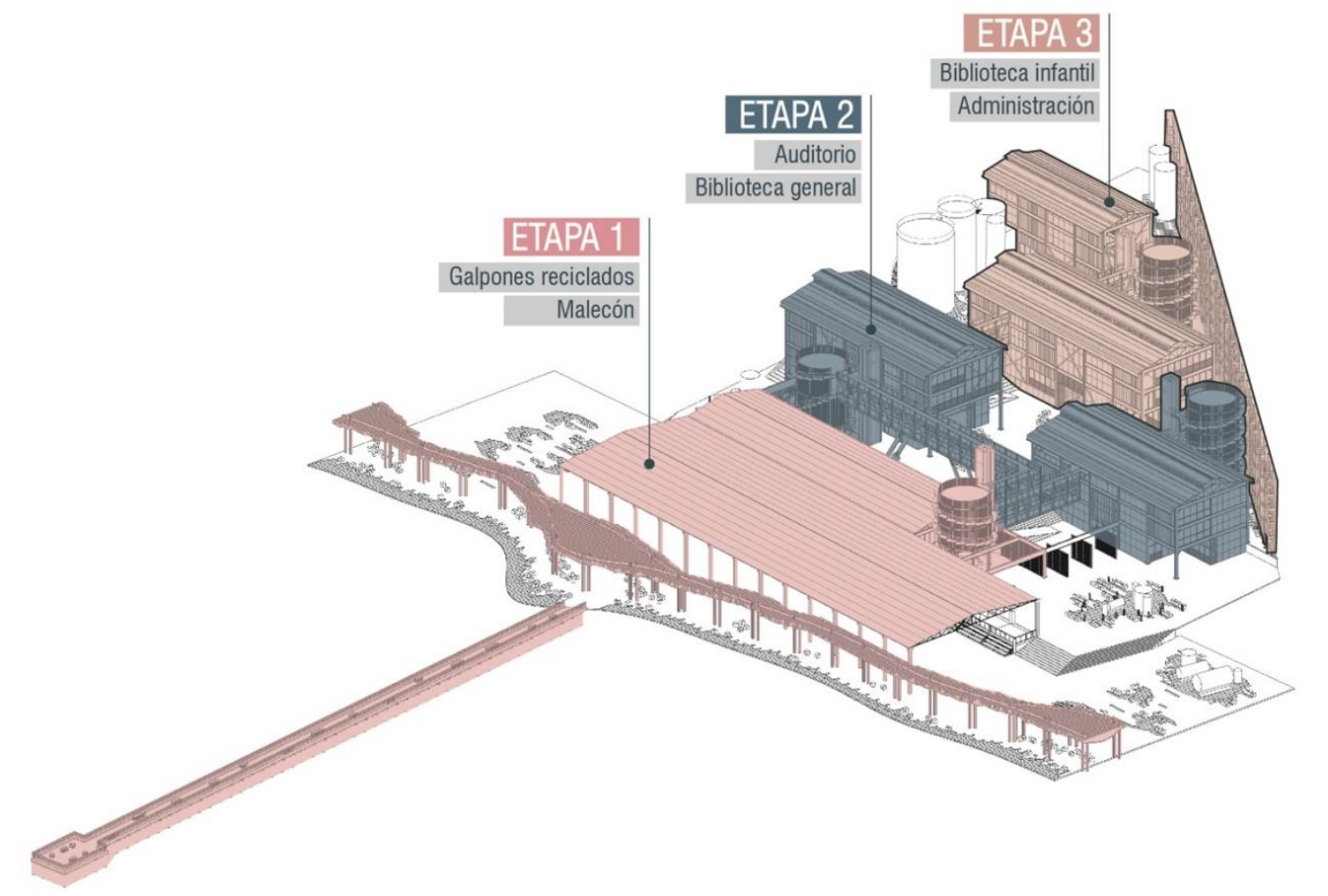

Fuente: Elaboración propia 
8.27.5.2 Presupuesto referencial del proyecto

Tabla 8.4 Presupuesto referencial del proyecto

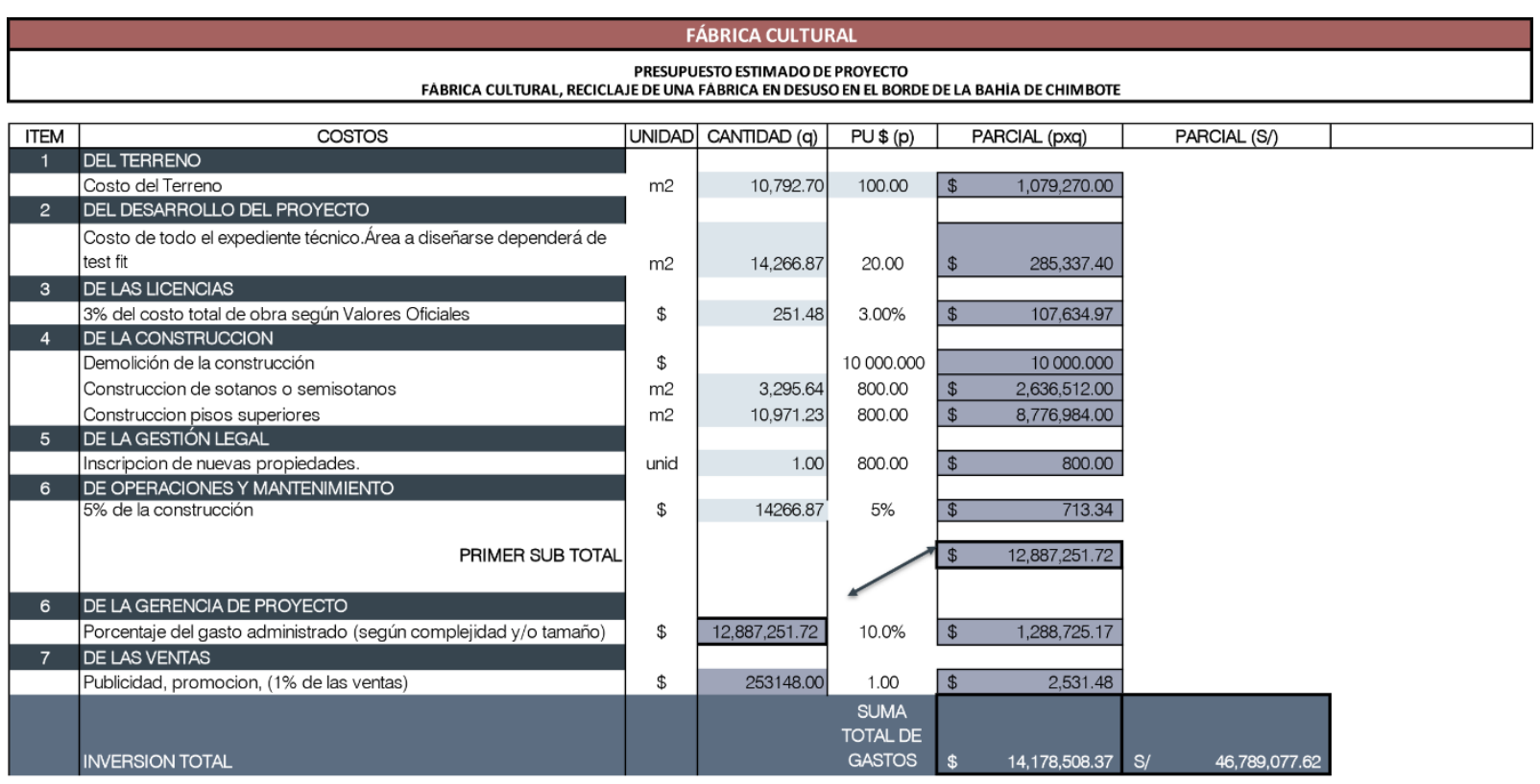

Fuente: Elaboración propia

La inversión total del proyecto es de aproximadamente cuarenta y seis millones setecientos ochenta y nueve mil soles, que será recuperada a partir del sétimo año después de haberse construido la primera etapa del proyecto. Si bien, el proyecto ha sido concebido como un proyecto social, al diseñar se ha planteado espacios que pueden alquilarse o concesionarse para que a través de este ingreso se pueda recuperar la inversión y se continúe beneficiando la población chimbotana haciendo uso de los espacios de la fábrica cultural.

Tabla 8.5 Recuperación de la inversión

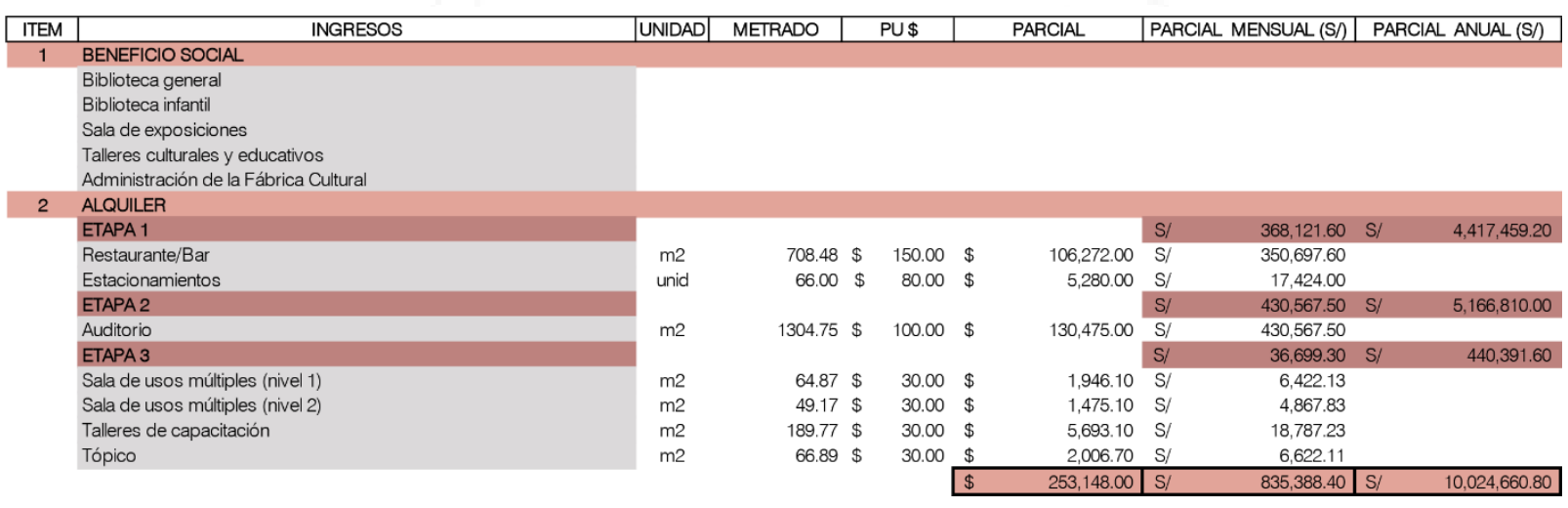

Fuente: Elaboración propia 
Tabla 8.6 Monto recuperado por año

\begin{tabular}{|l|ll|ll|}
\hline RECUPERACIÓN DE LA INVERSIÓN & & & \\
\hline AÑO1 (después de construida la etapa 1) & S/ & $4,417,459.20$ & & \\
\hline AÑO2 (después de construida la etapa 2) & S/ & $9,584,269.20$ & S/ & $14,001,728.40$ \\
\hline & & & & \\
AÑO 3 (después de construida la etapa 3) & S/ & $14,442,120.00$ & S/ & $28,443,848.40$ \\
\hline AÑO 4 & S/ & $14,442,120.00$ & S/ & $42,885,968.40$ \\
\hline AÑO 5 & S/ & $14,442,120.00$ & S/ & $57,328,088.40$ \\
\hline AÑO 6 & S/ & $14,442,120.00$ & S/ & $71,770,208.40$ \\
\hline
\end{tabular}

Fuente: Elaboración propia

Ilustración 8.133 Cronograma de recuperación de la inversión

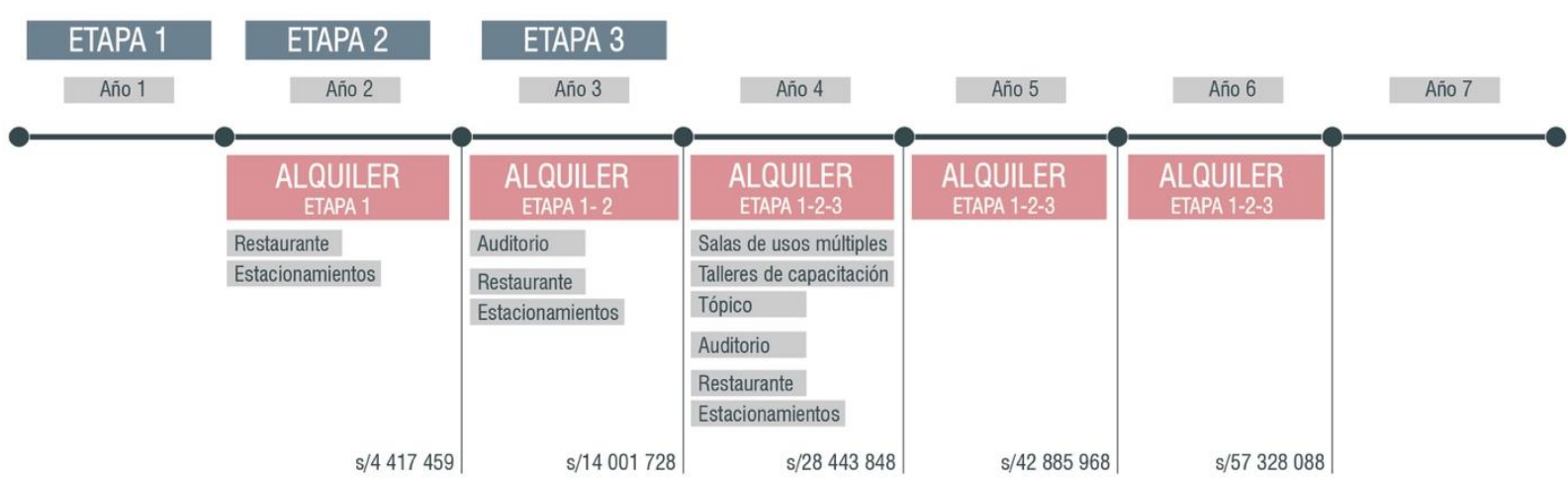

Fuente: Elaboración propia

\subsubsection{Beneficio del proyecto}

El carácter del proyecto es cultural, no obstante, los beneficios que este aportaría para la ciudad de Chimbote y la población son de distintos ámbitos. A nivel urbano, por ser un proyecto que parte de una red de activación de las fábricas en desuso, regeneraría y activaría la zona reduciendo la percepción de inseguridad, activaría comercialmente las calles y aumentaría el valor del suelo de una zona considerada poco atractiva para la inversión pública y privada, lo que conllevaría a atraer el turismo y contar con una oferta turística variada. El proyecto urbanamente a escala humana también contribuiría a dotarle de espacios públicos a los habitantes de la zona, al mismo tiempo que les ofrecería un nuevo paisaje urbano con vegetación y recuperación de las piezas industriales de la antigua fábrica.

A nivel socio cultural, la fábrica sería un importante punto de cultura que mejoraría el nivel de educación de los niños y jóvenes, quienes complementarían lo aprendido en el colegio, a las mujeres fileteras y pescadores les proporcionaría un mayor grado de instrucción, 
abriéndoles una importante puerta para insertarse en la oferta laboral del mercado. Además, la fábrica generaría nuevos puestos de trabajo en la zona, otorgándole a los vecinos la posibilidad de tener un empleo cerca de sus viviendas. Puesto que el proyecto se encuentra inserto en una fábrica en desuso y recicla elementos característicos de la actividad industrial en Chimbote, contribuiría a repotenciar y fortalecer los lazos identitarios y la memoria colectiva de la población que se encuentra estrechamente ligada al mar y a la pesca.

A nivel ambiental, el proyecto aportará en volcar la mirada de la ciudad a la bahía teniendo interés en recuperar ambientalmente este paisaje a través de desarrollar un malecón que una los 11 kilómetros de la bahía y reduzca la contaminación de residuos sólidos acumulada en el borde, convertida en una barrera física, visual y en una atmosfera insalubre hacia el mar con la que diariamente los habitantes tienen que lidiar, exponiendo su salud.

Finalmente, la fábrica cultural se convertiría en un referente urbano, social, cultural y ambiental a nivel local, nacional e internacional, pues Chimbote además de ser conocido por ser puerto y producir conservas y harina de pescado, también sería reconocido por contar con un equipamiento urbano, hito de la arquitectura chimbotana situado en una fábrica, espacio importante dentro del pasado histórico y la dinámica social de la ciudad.

\subsubsection{Fuentes de financiamiento}

El financiamiento del proyecto se realizaría a través de inversión pública por parte de la Municipalidad Provincial del Santa, quien para obtener la propiedad legal de la fábrica realizaría una permuta con la compañía pesquera CFG Investment, otorgándole un terreno en la zona industrial del 27 de octubre a cambio de obtener la propiedad de la actual fábrica inoperativa en la zona de la Florida Baja. Lugar donde la fábrica ya no puede operar debido a lo establecido en la ordenanza Nº01-2009-MPS y por la zonificación actual con la que cuenta.

La permuta se daría en el marco de que el proyecto a realizarse es de índole importante por encontrarse dentro del PDU y PAT, cubre la demanda social insatisfecha de equipamientos culturales en la ciudad, al mismo tiempo que le otorgaría al terreno un mejor y mayor uso, principio que actualmente no está cumpliendo, y representaría una oportunidad para el propietario actual de contar con un terreno en una zona donde pueda ejercer sus actividades industriales.

De esta forma, el proyecto sería de propiedad pública, donde la MPS tendría la administración total del equipamiento. 
Ilustración 8.134 Vista aérea del proyecto Fábrica Cultural

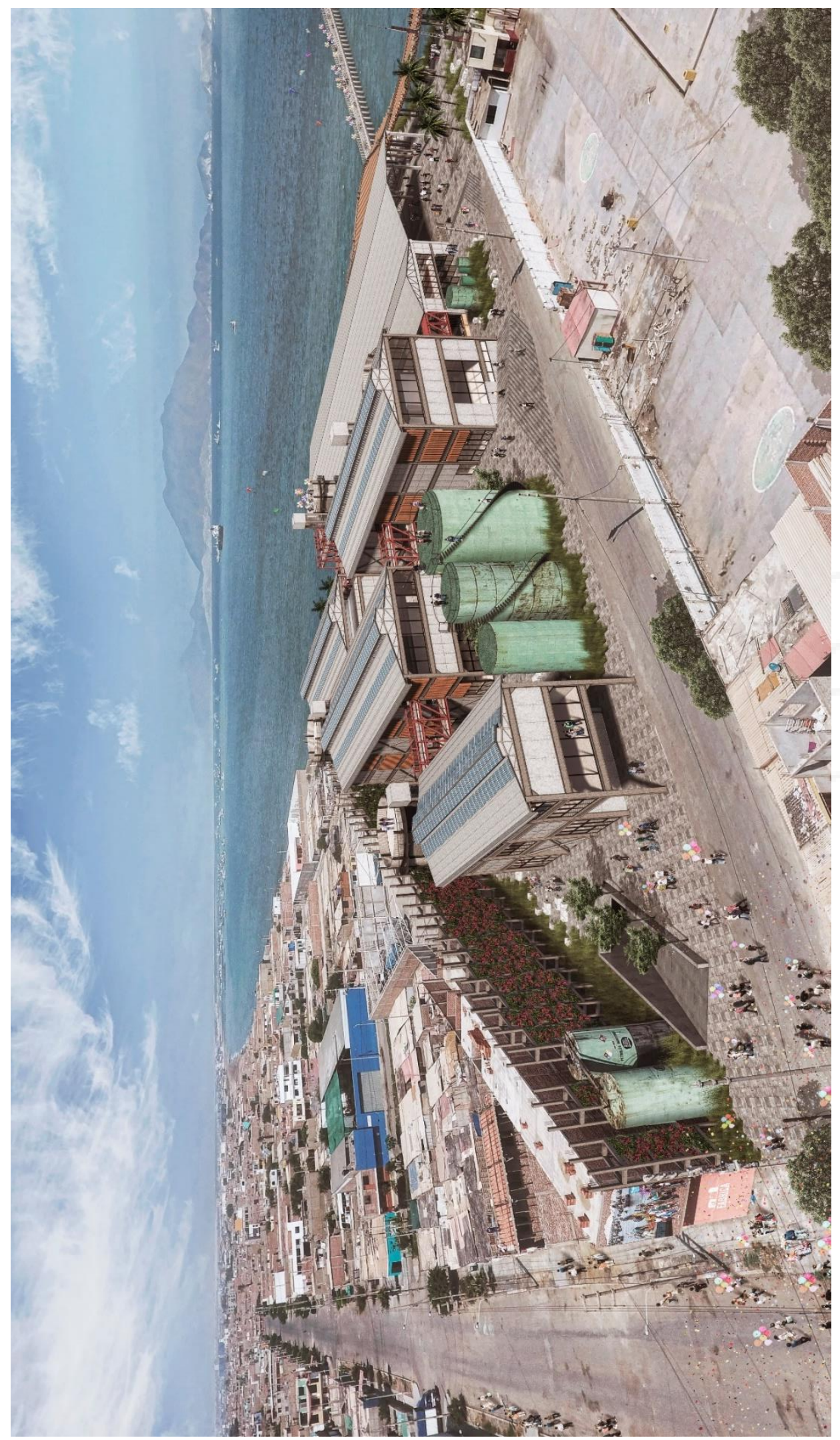

Fuente: Elaboración propia 


\subsubsection{Gestión social del proyecto}

\subsubsection{La Fábrica}

El proyecto fábrica cultural ha sido desarrollada como marca La Fábrica. Nombre que se le ha otorgado como estrategia de marketing social y urbano para vincular a la población con el proyecto y hacer énfasis en la relación que tiene el proyecto cultural con el pasado industrial que ha marcado la historia de Chimbote, haciendo conocida la ciudad por ser el primer puerto productor y exportador de harina de pescado, y representando hoy un espacio donde confluyen el valor histórico del pasado y la actividad cultural del presente.

\section{Ilustración 8.135 Marca La Fábrica}

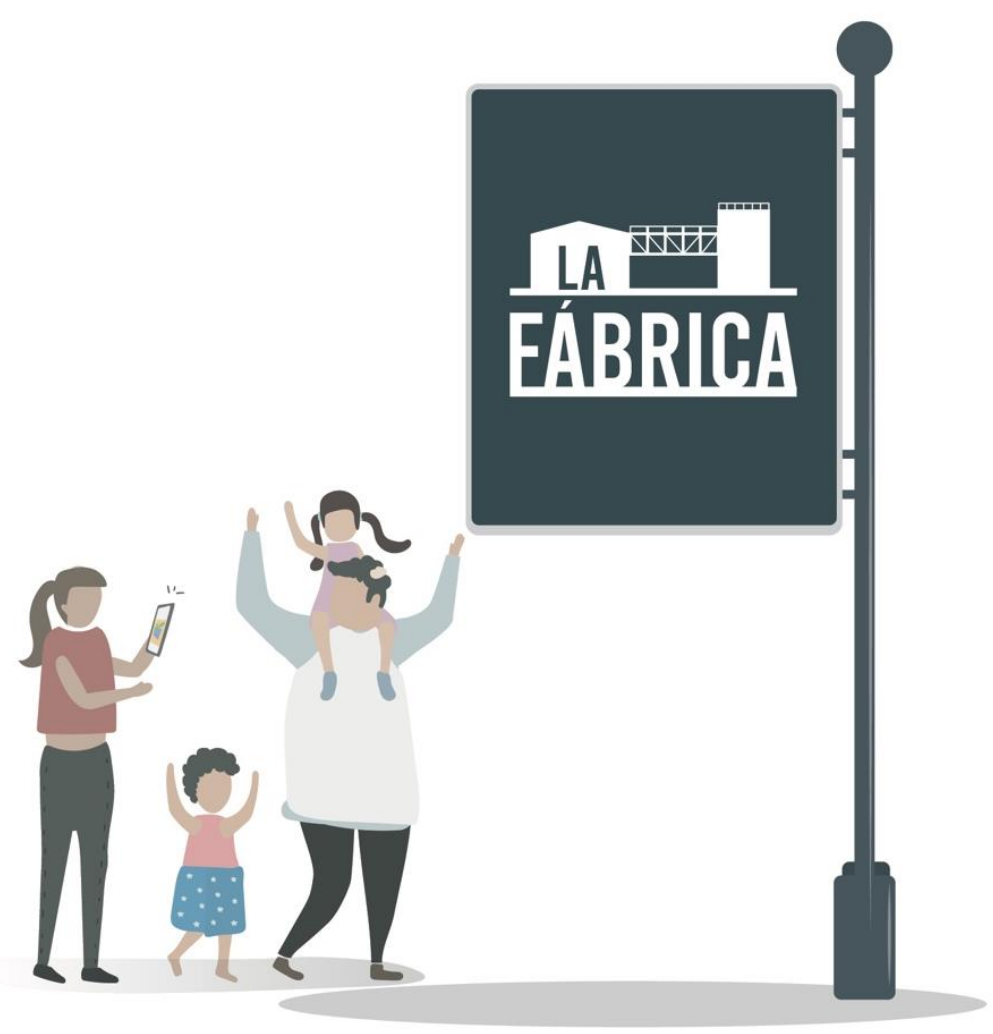

Fuente: Elaboración propia

\subsubsection{Estudio de mercado del proyecto}

En la actualidad Chimbote cuenta con un centro cultural. El Centro Cultural Centenario se encuentra ubicado en la Av. Prolongación Alfonso Ugarte. Este equipamiento funciona desde el año 2006 y comprende un área de 400 m2. 
Ilustración 8.136 Competencia de equipamiento cultural en Chimbote

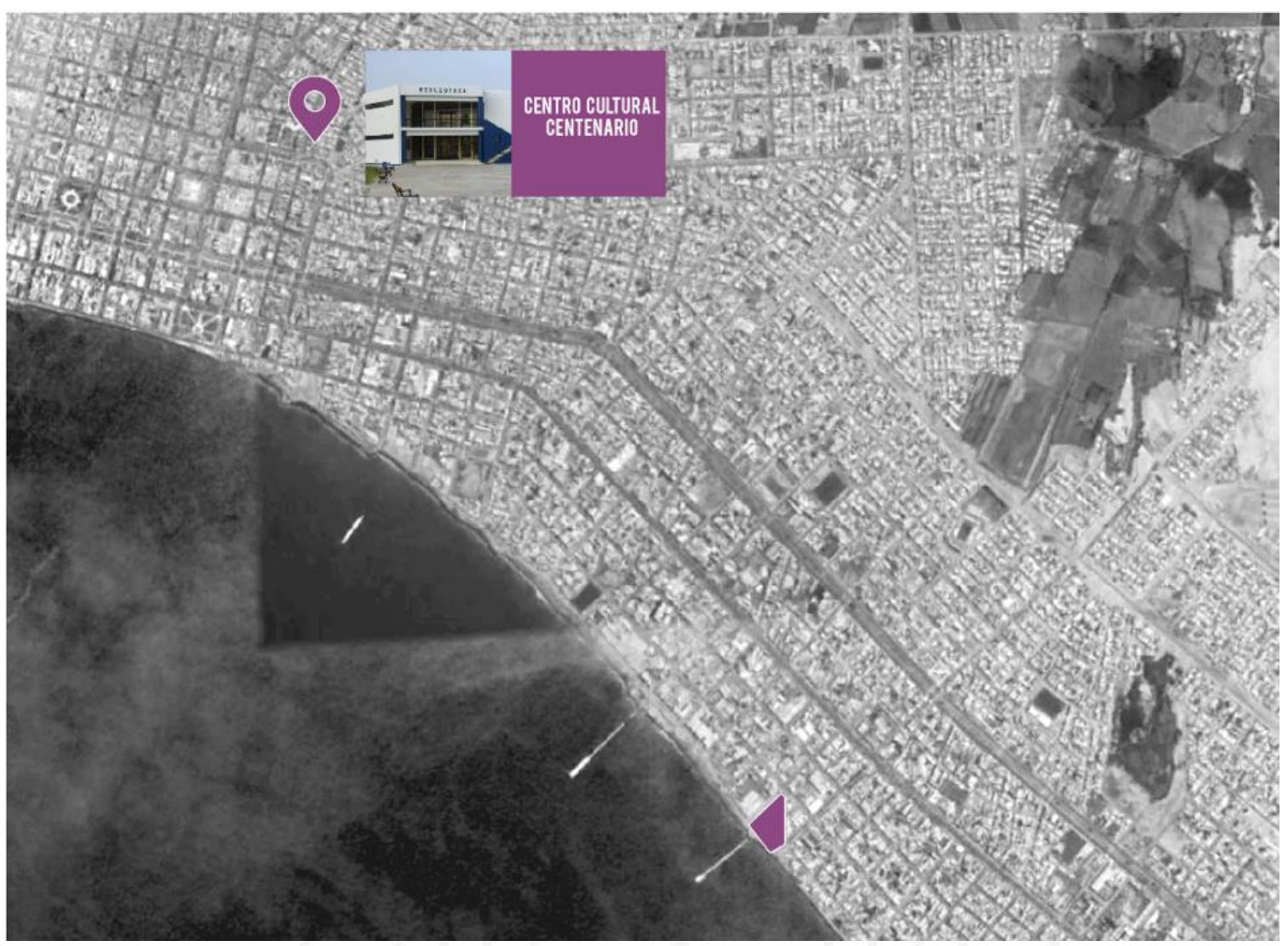

Fuente: Elaboración propia

Este equipamiento está orientado principalmente a niños y jóvenes. La oferta de talleres es variada, siendo el de mayor acogida el de dibujo y pintura. La cantidad de alumnos que recibe por mes por medio de los talleres es de 500 alumnos.

El cuadro a continuación presenta la relación de alumnos inscritos para los meses de enero y febrero del año 2017. Como se puede apreciar la relación de alumnos fluctúa entre los 400 y 500 alumnos, siendo el taller con mayor demanda el de dibujo y pintura y el de menor demanda el de flauta dulce. 
Tabla 8.7 Cantidad de alumnos inscritos por talleres

\begin{tabular}{|c|c|c|c|c|c|}
\hline \multicolumn{6}{|c|}{ Centro Cultural Centenario } \\
\hline \multicolumn{6}{|c|}{ TALLERES DE VERANO 2017} \\
\hline \multicolumn{6}{|c|}{ NÚMERO DE PARTICIPANTES POR TALLER } \\
\hline $\mathrm{N}^{\circ}$ & TAU IFR & ENERO & FERPCRO & TOTA & \\
\hline 1 & BALLET & 89 & 62 & & 99 \\
\hline 2 & DANZA CONTEMPORANEA & 18 & 13 & & 20 \\
\hline 3 & MARINERA & 37 & 28 & & 49 \\
\hline 4 & BAILE MODERNO & 27 & 9 & & 30 \\
\hline 5 & DIB Y PINTURA & 78 & 83 & & 134 \\
\hline 6 & DIB A CARBONCILLO & 27 & 27 & & 38 \\
\hline 7 & MANUALIDADES & 9 & 13 & & 18 \\
\hline 8 & EST TEMPRANA & 8 & 0 & & 9 \\
\hline 9 & LECTURA & 10 & 3 & & 12 \\
\hline 10 & INGLES & 23 & 18 & & 33 \\
\hline 11 & ORATORIA & 28 & 21 & & 40 \\
\hline 12 & TEATRO & 19 & 18 & & 31 \\
\hline 13 & AJEDREZ & 9 & 18 & & 25 \\
\hline 14 & FLAUTA DULCE & 4 & 5 & & 6 \\
\hline 15 & GUITARRA & 45 & 32 & & 62 \\
\hline 16 & PIANO & 22 & 21 & & 29 \\
\hline 17 & CANTO & 22 & 21 & & 36 \\
\hline 18 & TECLADO & 10 & 8 & & 14 \\
\hline 19 & PERCUSION & 12 & 7 & & 13 \\
\hline & & 497 & 407 & & \\
\hline
\end{tabular}

Fuente: Elaboración propia

Ilustración 8.137 Participantes de los talleres por sexo

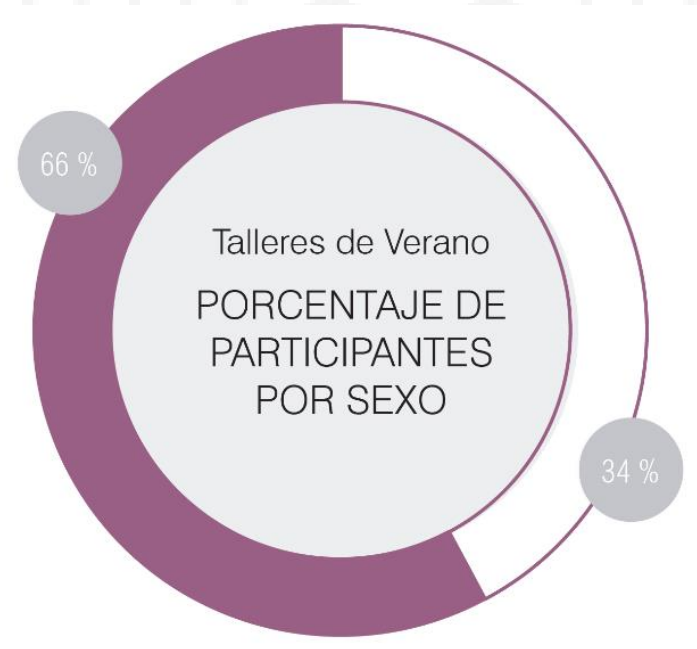

Femenino

Masculino

Fuente: Elaboración propia 
En relación con los alumnos inscritos por taller el $66 \%$ de ellos es del sexo femenino, mientras que el $34 \%$ restante es del sexo femenino.

\section{Ilustración 8.138 Alumnos inscritos por edades}

\begin{tabular}{|c|c|c|c|c|c|c|c|c|c|}
\hline TALLER & & & & & ENERO & & & & \\
\hline & $1 \mathrm{A3}$ & $4 \mathrm{A6}$ & $7 \mathrm{A9}$ & $10 \mathrm{~A} 12$ & $13 \mathrm{~A} 15$ & $16 \mathrm{~A} 18$ & $19 \mathrm{~A} 21$ & 22 A MÁS & \\
\hline BALLET & 6 & 33 & 25 & 7 & 16 & 1 & & 1 & 13 \\
\hline DANZA CONTEMPORANEA & & & 3 & 5 & 7 & 3 & & & 28 \\
\hline MARINERA & & 15 & 9 & 5 & & & & 8 & 9 \\
\hline BAILE MODERNO & & 3 & 16 & 5 & 3 & & & & 83 \\
\hline DIB Y PINTURA & 1 & 32 & 27 & 12 & 4 & 1 & 1 & & 27 \\
\hline DIB A CARBONCILLO & & & 5 & 9 & 11 & 2 & & & 13 \\
\hline MANUALIDADES & & & 3 & 6 & & & & & 0 \\
\hline EST TEMPRANA & 3 & & & & & & & & 3 \\
\hline LECTURA & & & 2 & 5 & 3 & & & & 18 \\
\hline INGLES & & & 5 & 11 & 7 & & & & 21 \\
\hline ORATORIA & & & 8 & 4 & 5 & 8 & 2 & 1 & 18 \\
\hline TEATRO & & 3 & 7 & 3 & 6 & & & & 18 \\
\hline AJEDREZ & & 2 & 4 & 3 & & & & & 5 \\
\hline FLAUTA DULCE & & & 2 & 2 & & & & & 32 \\
\hline GUITARRA & & & 9 & 14 & 14 & 6 & & 2 & 21 \\
\hline PIANO & & 1 & 2 & 8 & 9 & 2 & & & 21 \\
\hline CANTO & & 2 & 3 & 4 & 10 & 2 & & 1 & 8 \\
\hline TECLADO & & & 2 & 3 & 5 & & & & 7 \\
\hline PERCUSION & & 1 & 2 & 3 & 6 & & & & 407 \\
\hline TOTAL & 10 & 92 & 134 & 109 & 106 & 25 & 3 & 13 & 752 \\
\hline
\end{tabular}

Fuente: Elaboración propia

La tabla anterior representa la cantidad de alumnos por edades inscritos en los distintos talleres en el mes de enero del 2017. Como se puede apreciar el rango de edades que más asiste a talleres es entre 7 y 9 años, mientras que el rango de edad que menos acude a talleres se encuentra entre los 19 y 21 años.

Además, el centro cultural alberga la Orquesta Sinfónica de Chimbote, formada por los alumnos que asisten a los talleres que aquí se brindan. Sin embargo, el espacio actual con el que cuentan no satisface la demanda, haciendo necesario la adquisición de un espacio más amplio, donde se pueden ofrecer espectáculos musicales como también de otra índole. 


\section{REFERENCIAS}

Ministerio de Ambiente. (2012). Plan de Recuperación Ambiental de la Bahía "El Ferrol". El Peruano.

Aguero, A. V. (2014). Plan de Regeneración Urbana-Patrimonial para el Centro Histórico de Tomé. Santiago, Chile: Universidad de Chile.

Aldo Facho, R. A. (8 de Junio de 2016). Habitar: Arquitectura + Ambiente + Ciudad . Obtenido de https://habitar-arq.blogspot.pe/search?updated-max=2016-0612T20:12:00-05:00\&max-results $=10 \&$ start $=2 \&$ by-date $=$ false

Alicante, U. d. (s.f.). Universidad de Alicante. Obtenido de https://web.ua.es/es/labclima/diccionario-y-glosario-en-ordenacion-delterritorio.html\#letraU

Antoine, C. (31 de diciembre de 2011). Políticas Culturales en Francia. Obtenido de http://cristian-antoine.blogspot.pe/2011/12/las-politicas-culturales-en-francia.html

Arantes, A. (1993). Horas furtadas dois ensaios sobre consumo e entretenimento. São Paulo, Brasil: Instituto de Filosofia e Ciencias Humanas, UNICAMP.

Arroyo Icochea, T. (2007). 250 Años de historias y leyendas de Chimbote. Chimbote: Río Santa Editores.

Barletta, F., Pereira, M., Robert, V., \& Yoguel, G. (2013). Argentina: dinámica reciente del sector de software y servicios informáticos. Revista de la CEPAL(110), 137-155. Obtenido de http://www.cepal.org/publicaciones/xml/1/50511/RVE110Yoqueletal.pdf

Berruete Martínez, F. (2017). Los vacíos urbanos, una nueva deficinición. Revista Urbano $N^{o} 35,114-122$.

Bierre, R., \& García-Almirall, P. (2011). Beneficios potenciales de los procesos d reconversión portuaria. Proceedings of 7VCT, 639-644.

Blass, F. B. (2003). Historia de Chimbote. Lima: San Marcos E.I.R.L.

Borga, F. F. (26 de Mayo de 2009). La forma Moderna en Latinoamérica. Obtenido de http://laformamodernaenlatinoamerica.blogspot.pe/2013/06/plan-regulador-dechimbote.html

Calderón Calderón, B., \& Ruiz-Valdepeñas, H. (2007). El lugar del patrimonio industrial en los procesos de transformación urbana: de la ruina a la explotación de las reliquias fabriles en Valladolid. Ería 72, 55-73.

Calleja Molina, M. (2013). Reciclaje arquitectónico: definición, historia y capacidad. Universidad Politécnica de Valencia, 1-130. 
Campos, L. (2004). Identidad y memoria urbana. Recuerdo y olvido, coninuidades y discontinuidades en la ciudad. Revista de Urbanismo, 25-32.

Careri, F. (2013). Walkscapes, el andar como práctica estética. Barcelona: Gustavo Gili.

Centro del Patrimonio Mundial de la UNESCO. (2005). Directrices prácticas para la aplicacion de la Convención del Patrimonio Mundial. Comité Intergubernamental de protección del Patrimnio mundial cultural y natural. París: Centro del Patrimonio Mundial de la UNESCO.

CEPAL. (2016). Agenda 2030 y los Objetivos de Desarrollo Sostenible. Santiago.

Certas, M. N. (1998). Una reflexión sobre la reciente transformación de Barcelona. Revista de Facultad de Letras y Geografía I, Volumen XIV, 61-75.

Ching, F. D. (1998). Arquitectura Forma, Espacio y Orden. Barcelona: Gustavo Gili.

Choy, M., \& Chang, G. (2014). Medidas macroprudenciales aplicadas en el Perú. Lima: Banco Central de Reserva del Perú. Obtenido de http://www.bcrp.gob.pe/docs/Publicaciones/Documentos-deTrabajo/2014/documento-de-trabajo-07-2014.pdf

Congreso de la República. (2016). Proyecto de Ley 197/2016-CR. Ley que declara de interés nacional la problemática de la erosión costera en las playas del litoral peruano. Lima, Perú.

Congreso de la República del Perú. (2016). Proyecto de Ley 678/2016-CR. Ley de gestión sostenible e integrada de la zona marino costera del Perú. Lima, Perú.

Consejo Nacional de la Cultura y las Artes. (2011). Guía Introducción a la gestión e infraestrucrura de un Centro Cultural Comunal. Valparaíso.

Consejo Nacional del Ambiente del Perú. (2000). Diágnostico ambiental y propuestas técnicas para la recuperación de la Bahía El Ferrol. Lima: CONAM.

Cultura, M. d. (s.f.). Puntos de Cultura. Obtenido de http://puntosdecultura.pe/puntoscultura/centro-cultural-centenario

Díaz Sánchez, N. (s.f.). Biblioteca Virtual Miguel De Cervantes. Obtenido de http://www.cervantesvirtual.com/portales/biblioteca_nacional_del_peru/historia/

Diccionario de arquitectura y construcción. (8 de Noviembre de 2012). Obtenido de http://www.parro.com.ar/definicion-de-ambiente

Diego Sánchez Gonzalez, L. Á. (2014). Identidad y Espacio Público, ampliando ámbitos y prácticas. Barcelona: Gedisa S.A.

Educación, M. d. (2013). Patrimonio Cultural y Memoria Colectiva. Córdoba.

Estudio de regeneración urbana. (1976). México D.F: COPEVI.

ETSA Sevilla. (junio de 2014). Proyectos 7/Proyecos 8. Obtenido de Proyectos 7/Proyecos 8: https://proyectos4etsa.wordpress.com 
Fernardi, R. B. (2009). La ciudad y la urbanización. Estudios Históricos, 3.

García Nieto, J. P. (2013). Consturye tu Web comercial: de la idea al negocio. Madrid: RAMA.

García Page, C. (2003). Arquitectura: Lareconversión más chic. Grandes del diseño internacional se apuntan al reciclaje transformando viejas fábricas en museos y galerías de arte. Suplemento dominical del Heraldo de Aragón.

Gausa, M. (2001). Diccionario metápolis de Arquitectura. Barcelona.

Gehl, J. (2004). La humanización del espacio urbano. Barcelona: Reverté.

Gehl, J. (2010). Ciudades para la gente. Barcelona: El Equilibrista Otra Vez.

Genovés, E. (1 de Abril de 2014). Gernovés Arquitectura. Obtenido de http://m2earquitectura.blogspot.pe/2013/01/i-n-v-e-s-t-g-c-i-o-n-reciclaje.html

Gilles, C. C. (2013). Los riesgos por el "abandono cultural" del patrimonio industrial: maestranzas ferroviarias en Chile. Bogotá.

Glosario de términos urbanísicos. (s.f.). Normas urbanísticas, Abdaes. Obtenido de http://www.abades.es/normas_urbanisticas/normativa/glosario.pdf

Grindlay Moreno, A. (2008). Ciudades y puertos. Ciudades 11, 53-80.

Gutiérrez, A., \& Talesnik, D. (2002). Transformaciones de frentes de agua: la forma urbana como producto estándar. Eure, 1-17.

Habitat, O. (2016). Regeneración urbana, Jornadas de trabajo. Madrid.

Hernández Martínez, A. (2008). El reciclaje de la arquitectura industrial. Departamento de historia del arte, 29-51.

Holl, S. (1991). Edge of a city. En S. Holl, Edge of the city. New York: Pamphlet Architecture.

Icochea, T. A. (2007). 250 Años de historias y leyendas de Chimbote. Chimbote: Rio Santa Editores.

Iraegui Cuentas, E. (2014). Conceptos de Rehabilitación Urbana. El caso de Per del caso viejo de Bilbao. País Vasco.

Izazaga, H. R. (1 de Abril de 2014). Universidad de Guanajuato. Obtenido de http://www.interiorgrafico.com/edicion/decima-tercera-edicion-abril-2013/elconcepto-de-reciclaje-en-el-contexto-del-patrimonio-cultural-edificado

Jacobs, J. (2011). Muerte y vida de las grandes ciudades. Madrid: Capitán Swing Libros.

Kuramoto, J. (2005). El clúster pesquero de Chimbote: acción conjunta limitada y la tragedia de los recursos colectivos. Lima.

le Duc, V. (1997). Dictionnaire de l'architecture médievale Viollet-le-Duc. Francia: Edición facsímil del original. 
Loures, L. (2008). Post-Industrial Landscapes: dereliction or heritage? Department of Landscape Architecture; Faculty of Natural Resources,University of Algarve, 23-28.

Ludeña Urquizo, W. (1998). Patrimonio industrialen el Perú del siglo xx: ¿exotismo cultural o memoria. Apuntes vol.21 $N^{\circ} 01,92-113$.

Lynch, K. (2008). La imagen de la ciudad (Gustavo Gill ed.). Barcelona.

Maderuelo, J. (2006). El paisaje, génesis de un concepto. (A. editores, Ed.) Madrid.

Maderuelo, J., Arribas, D., Cancer, L., Driedich, L., Gómez Aguilera, F., Mata Olmo, R., . . . Zoido, F. (2010). Paisaje y Patrimonio. Madrid: ABADA Editores.

Martínez Monedero, M. (2012). Reciclaje de arquitectura vs restauración arquitectónica, ¿herramientaas contrapuestas? Hábitat y Sociedad $N^{\circ}$ 5, 23-33.

Martínez, J. I. (2007). Del Patrimonio Cultural al Industrial: Una Mirada Socioantropológica. Patrimonios Culturales: Educación e Interpretación. Cruzando límites y produciendo alternativas., 57-72.

Ministerio de Ambiente. (4 de Agosto de 2015). Resolución Ministerial N¹89-2015MINAM. Lima, Perú.

Ministerio de Cultura, B. I. (2011). Atlas de Infraestructura y Patrimonio Cultural de las Américas, Perú. México: Ministerio de Cultura.

Ministerio de Vivienda, C. y. (2013). Plan de desarrollo urbano de Nuevo Chimbote 2011 2013. Chimbote, Perú.

Ministerio del Ambiente. (15 de Setiembre de 2005). Ley N²8611. Ley General del Ambiente. Lima, Perú.

Molina, M. C. (s.f.). Universidad de Valencia. Obtenido de http://docplayer.es/12251901Reciclaje-arquitectonico-definicion-historia-y-capacidad.html

Municipalidad de la Habana. (1994). Plan Maestro para la Revitalización. Obtenido de http://www.planmaestro.ohc.cu/index.php/informacion-general/5-contactos

Nogué, J. (2007-2009). La construcción social del paisaje . Madrid: Biblioteca Nueva.

OEFA, O. d. (2016). Situación actual de las empresas ubicadas en la bahía El Ferrol. Lima.

ONU, H. (2016). Regeneración Urbana. Jornadas de trabajo, regeneración urbana, (págs. 535). Madrid.

(2012). PAT Santa. Municipalidad Provincial del Santa, Chimbote.

(2012). PDU de la ciudad de Chimbote . Municipalidad Provincial del Santa.

Péres Porto, J., \& Merino, M. (2010). Definicion.de. Obtenido de jttps://deficinion.de/veda/

Pozo, G. S. (22 de Diciembre de 2012). Urbanismo. Com. Obtenido de http://www.urbanismo.com/el-paisaje-urbano/ 
Raymundo, J. (5 de Diciembre de 2014). Identidades Peruanas. Obtenido de http://identidadesperuanas.com/2014/12/identidad-cultural-de-chimbote/

Rish Lerner, E. M. (2005). El Valor de la Cultura en los Procesos de Desarrollo Urbano Sustentable. Catalunya: Departamento de Cultura de Catalunya.

Sabaté Bel, J. (2005). De la preservación del patrimonio a la ordenación del paisaje. Catalunya.

Sabaté Bel, J. (s.f.). Paisajes culturales. El patrimonio como recurso básico para un nuevo modelo de desarrollo. Urban 9, 8-27.

Sánchez Mustieles, D. (marzo de 2014). Patrimonio Industrial. Obtenido de Patrimonio Industrial: http://patrindustrialquitectonico.blogspot.com

Schubert, D. (2004). Transformación de zonas portuarias y costeras en desuso: experiencias, posibilidades y problemas. Ciudades $8,15-36$.

Sennett, R. (2013). La ciudad abierta. Barcelona.

Sennett, R. (s.f.). La ciudad abierta. Barcelona.

Solà-Morales, I. (2009). Terrain vague. En S. Landrove, M. Puente, M. J. Rivas, H. Smith, \& S. Suzuki, Colección de Compendio de Arquitectura Contemporánea. Barcelona, España.

Taracena, E. (16 de Agosto de 2013). Arquitectura, Literatura. Obtenido de https://conarqket.wordpress.com/2013/08/16/la-revitalizacion-urbana-un-procesonecesario/

Texeira Coelho. (1986). Usos da Cultura, Políticas de Ação Cultural. São Paulo, Brasil: Paz e terra.

TICCIH. (2003). Carta Nizhny Tagil sobre el patrimonio industrial. Rusia.

Trachana, A. (2000). Paisajes culturales. Caso de los paisajes industriales. Universidad Politécnica de Madrid, 1-16.

Trachana, A. (2011). La recuperación de los paisajes industriales como paisajes culturales. Ciudades, Universidad de Valladolid, 189-212.

Turrado, I. A. (s.f.). TEORÍA, HISTORIA Y PROYECTO . Obtenido de https://upcommons.upc.edu/bitstream/handle/2099/14876/60_65_ISabell_Aparici_.pd $\mathrm{f}$

UNAM. (s.f.). Espacio Público. Obtenido de http://www.ub.edu/multigen/donapla/espacio1.pdf

University of Ferrara, \& UNESCO's World Hetritage Centre. (2002). Cultural Landscapes: the Challenge of Conservation. Ferrara, Italy: World Heritage Papers.

Unyén Velezmoro, V. (2016). Chimbote, un viaje por la historia. Chimbote, Perú: Editorial Super Gráfica E.I.R Ltda. 
Valero Ramos, E. (2010). Reciclaje de polígonos residenciales, una alternativa sostenible. SB10mad. Sustainable building conference. Sevilla: inédito.

Valero Ramos, E., \& Chacón Linares, E. (2009). Crecer por dentro, estrategias del reciclaje urbano para el tecer milenio . Índice, 529-536.

Velezmoro, V. N. (25 de Junio de 2012). Chimbote e Identidad Cultural. Obtenido de http://victorunyenvelezmoro.blogspot.com/2012/06/chimbote-e-identidadcultural.html

Wittmann, R. (2006). ¿Hubo una revolución en la lectura a finales del siglo XVIII? En G. Cavallo, \& R. Chartier, Historia de la lectura en el mundo occidental (págs. 435-472). México D.F.: Santillana.

Zarza, D. (2001). Desbordes urbanos. Circo. 


\section{BIBLIOGRAFÍA}

Ministerio de Ambiente. (2012). Plan de Recuperación Ambiental de la Bahía "El Ferrol". El Peruano.

Aguero, A. V. (2014). Plan de Regeneración Urbana-Patrimonial para el Centro Histórico de Tomé. Santiago, Chile: Universidad de Chile.

Aldo Facho, R. A. (8 de Junio de 2016). Habitar: Arquitectura + Ambiente + Ciudad. Obtenido de https://habitar-arq.blogspot.pe/search?updated-max=2016-0612T20:12:00-05:00\&max-results $=10 \&$ start $=2 \&$ by-date $=$ false

Alicante, U. d. (s.f.). Universidad de Alicante. Obtenido de https://web.ua.es/es/labclima/diccionario-y-glosario-en-ordenacion-delterritorio.html\#letraU

Antoine, C. (31 de diciembre de 2011). Políticas Culturales en Francia. Obtenido de http://cristian-antoine.blogspot.pe/2011/12/las-politicas-culturales-en-francia.html

Arantes, A. (1993). Horas furtadas dois ensaios sobre consumo e entretenimento. São Paulo, Brasil: Instituto de Filosofia e Ciencias Humanas, UNICAMP.

Arroyo Icochea, T. (2007). 250 Años de historias y leyendas de Chimbote. Chimbote: Río Santa Editores.

Barletta, F., Pereira, M., Robert, V., \& Yoguel, G. (2013). Argentina: dinámica reciente del sector de software y servicios informáticos. Revista de la CEPAL(110), 137-155. Obtenido de http://www.cepal.org/publicaciones/xml/1/50511/RVE110Yoqueletal.pdf

Berruete Martínez, F. (2017). Los vacíos urbanos, una nueva deficinición. Revista Urbano $N^{o} 35,114-122$.

Bierre, R., \& García-Almirall, P. (2011). Beneficios potenciales de los procesos d reconversión portuaria. Proceedings of 7VCT, 639-644.

Blass, F. B. (2003). Historia de Chimbote. Lima: San Marcos E.I.R.L.

Borga, F. F. (26 de Mayo de 2009). La forma Moderna en Latinoamérica. Obtenido de http://laformamodernaenlatinoamerica.blogspot.pe/2013/06/plan-regulador-dechimbote.html

Calderón Calderón, B., \& Ruiz-Valdepeñas, H. (2007). El lugar del patrimonio industrial en los procesos de transformación urbana: de la ruina a la explotación de las reliquias fabriles en Valladolid. Ería 72, 55-73.

Calleja Molina, M. (2013). Reciclaje arquitectónico: definición, historia y capacidad. Universidad Politécnica de Valencia, 1-130. 
Campos, L. (2004). Identidad y memoria urbana. Recuerdo y olvido, coninuidades y discontinuidades en la ciudad. Revista de Urbanismo, 25-32.

Careri, F. (2013). Walkscapes, el andar como práctica estética. Barcelona: Gustavo Gili.

Centro del Patrimonio Mundial de la UNESCO. (2005). Directrices prácticas para la aplicacion de la Convención del Patrimonio Mundial. Comité Intergubernamental de protección del Patrimnio mundial cultural y natural. París: Centro del Patrimonio Mundial de la UNESCO.

CEPAL. (2016). Agenda 2030 y los Objetivos de Desarrollo Sostenible. Santiago.

Certas, M. N. (1998). Una reflexión sobre la reciente transformación de Barcelona. Revista de Facultad de Letras y Geografía I, Volumen XIV, 61-75.

Ching, F. D. (1998). Arquitectura Forma, Espacio y Orden. Barcelona: Gustavo Gili.

Choy, M., \& Chang, G. (2014). Medidas macroprudenciales aplicadas en el Perú. Lima: Banco Central de Reserva del Perú. Obtenido de http://www.bcrp.gob.pe/docs/Publicaciones/Documentos-deTrabajo/2014/documento-de-trabajo-07-2014.pdf

Congreso de la República. (2016). Proyecto de Ley 197/2016-CR. Ley que declara de interés nacional la problemática de la erosión costera en las playas del litoral peruano. Lima, Perú.

Congreso de la República del Perú. (2016). Proyecto de Ley 678/2016-CR. Ley de gestión sostenible e integrada de la zona marino costera del Perú. Lima, Perú.

Consejo Nacional de la Cultura y las Artes. (2011). Guía Introducción a la gestión e infraestrucrura de un Centro Cultural Comunal. Valparaíso.

Consejo Nacional del Ambiente del Perú. (2000). Diágnostico ambiental y propuestas técnicas para la recuperación de la Bahía El Ferrol. Lima: CONAM.

Cultura, M. d. (s.f.). Puntos de Cultura. Obtenido de http://puntosdecultura.pe/puntoscultura/centro-cultural-centenario

Díaz Sánchez, N. (s.f.). Biblioteca Virtual Miguel De Cervantes. Obtenido de http://www.cervantesvirtual.com/portales/biblioteca_nacional_del_peru/historia/

Diccionario de arquitectura y construcción. (8 de Noviembre de 2012). Obtenido de http://www.parro.com.ar/definicion-de-ambiente

Diego Sánchez Gonzalez, L. Á. (2014). Identidad y Espacio Público, ampliando ámbitos y prácticas. Barcelona: Gedisa S.A.

Educación, M. d. (2013). Patrimonio Cultural y Memoria Colectiva. Córdoba.

Estudio de regeneración urbana. (1976). México D.F: COPEVI.

ETSA Sevilla. (junio de 2014). Proyectos 7/Proyecos 8. Obtenido de Proyectos 7/Proyecos 8: https://proyectos4etsa.wordpress.com 
Fernardi, R. B. (2009). La ciudad y la urbanización. Estudios Históricos, 3.

García Nieto, J. P. (2013). Consturye tu Web comercial: de la idea al negocio. Madrid: RAMA.

García Page, C. (2003). Arquitectura: Lareconversión más chic. Grandes del diseño internacional se apuntan al reciclaje transformando viejas fábricas en museos y galerías de arte. Suplemento dominical del Heraldo de Aragón.

Gausa, M. (2001). Diccionario metápolis de Arquitectura. Barcelona.

Gehl, J. (2004). La humanización del espacio urbano. Barcelona: Reverté.

Gehl, J. (2010). Ciudades para la gente. Barcelona: El Equilibrista Otra Vez.

Genovés, E. (1 de Abril de 2014). Gernovés Arquitectura. Obtenido de http://m2earquitectura.blogspot.pe/2013/01/i-n-v-e-s-t-g-c-i-o-n-reciclaje.html

Gilles, C. C. (2013). Los riesgos por el "abandono cultural" del patrimonio industrial: maestranzas ferroviarias en Chile. Bogotá.

Glosario de términos urbanísicos. (s.f.). Normas urbanísticas, Abdaes. Obtenido de http://www.abades.es/normas_urbanisticas/normativa/glosario.pdf

Grindlay Moreno, A. (2008). Ciudades y puertos. Ciudades 11, 53-80.

Gutiérrez, A., \& Talesnik, D. (2002). Transformaciones de frentes de agua: la forma urbana como producto estándar. Eure, 1-17.

Habitat, O. (2016). Regeneración urbana, Jornadas de trabajo. Madrid.

Hernández Martínez, A. (2008). El reciclaje de la arquitectura industrial. Departamento de historia del arte, 29-51.

Holl, S. (1991). Edge of a city. En S. Holl, Edge of the city. New York: Pamphlet Architecture.

Icochea, T. A. (2007). 250 Años de historias y leyendas de Chimbote. Chimbote: Rio Santa Editores.

Iraegui Cuentas, E. (2014). Conceptos de Rehabilitación Urbana. El caso de Per del caso viejo de Bilbao. País Vasco.

Izazaga, H. R. (1 de Abril de 2014). Universidad de Guanajuato. Obtenido de http://www.interiorgrafico.com/edicion/decima-tercera-edicion-abril-2013/elconcepto-de-reciclaje-en-el-contexto-del-patrimonio-cultural-edificado

Jacobs, J. (2011). Muerte y vida de las grandes ciudades. Madrid: Capitán Swing Libros.

Kuramoto, J. (2005). El clúster pesquero de Chimbote: acción conjunta limitada y la tragedia de los recursos colectivos. Lima.

le Duc, V. (1997). Dictionnaire de l'architecture médievale Viollet-le-Duc. Francia: Edición facsímil del original. 
Loures, L. (2008). Post-Industrial Landscapes: dereliction or heritage? Department of Landscape Architecture; Faculty of Natural Resources, University of Algarve, 23-28.

Ludeña Urquizo, W. (1998). Patrimonio industrialen el Perú del siglo xx: ¿exotismo cultural o memoria. Apuntes vol.21 $N^{\circ} 01,92-113$.

Lynch, K. (2008). La imagen de la ciudad (Gustavo Gill ed.). Barcelona.

Maderuelo, J. (2006). El paisaje, génesis de un concepto. (A. editores, Ed.) Madrid.

Maderuelo, J., Arribas, D., Cancer, L., Driedich, L., Gómez Aguilera, F., Mata Olmo, R., . . . Zoido, F. (2010). Paisaje y Patrimonio. Madrid: ABADA Editores.

Martínez Monedero, M. (2012). Reciclaje de arquitectura vs restauración arquitectónica, ¿herramientaas contrapuestas? Hábitat y Sociedad $N^{\circ}$ 5, 23-33.

Martínez, J. I. (2007). Del Patrimonio Cultural al Industrial: Una Mirada Socioantropológica. Patrimonios Culturales: Educación e Interpretación. Cruzando límites y produciendo alternativas., 57-72.

Ministerio de Ambiente. (4 de Agosto de 2015). Resolución Ministerial N¹89-2015MINAM. Lima, Perú.

Ministerio de Cultura, B. I. (2011). Atlas de Infraestructura y Patrimonio Cultural de las Américas, Perú. México: Ministerio de Cultura.

Ministerio de Vivienda, C. y. (2013). Plan de desarrollo urbano de Nuevo Chimbote 2011 2013. Chimbote, Perú.

Ministerio del Ambiente. (15 de Setiembre de 2005). Ley N²8611. Ley General del Ambiente. Lima, Perú.

Molina, M. C. (s.f.). Universidad de Valencia. Obtenido de http://docplayer.es/12251901Reciclaje-arquitectonico-definicion-historia-y-capacidad.html

Municipalidad de la Habana. (1994). Plan Maestro para la Revitalización. Obtenido de http://www.planmaestro.ohc.cu/index.php/informacion-general/5-contactos

Nogué, J. (2007-2009). La construcción social del paisaje . Madrid: Biblioteca Nueva.

OEFA, O. d. (2016). Situación actual de las empresas ubicadas en la bahía El Ferrol. Lima.

ONU, H. (2016). Regeneración Urbana. Jornadas de trabajo, regeneración urbana, (págs. 535). Madrid.

(2012). PAT Santa. Municipalidad Provincial del Santa, Chimbote.

(2012). PDU de la ciudad de Chimbote . Municipalidad Provincial del Santa.

Péres Porto, J., \& Merino, M. (2010). Definicion.de. Obtenido de jttps://deficinion.de/veda/

Pozo, G. S. (22 de Diciembre de 2012). Urbanismo. Com. Obtenido de http://www.urbanismo.com/el-paisaje-urbano/ 
Raymundo, J. (5 de Diciembre de 2014). Identidades Peruanas. Obtenido de http://identidadesperuanas.com/2014/12/identidad-cultural-de-chimbote/

Rish Lerner, E. M. (2005). El Valor de la Cultura en los Procesos de Desarrollo Urbano Sustentable. Catalunya: Departamento de Cultura de Catalunya.

Sabaté Bel, J. (2005). De la preservación del patrimonio a la ordenación del paisaje. Catalunya.

Sabaté Bel, J. (s.f.). Paisajes culturales. El patrimonio como recurso básico para un nuevo modelo de desarrollo. Urban 9, 8-27.

Sánchez Mustieles, D. (marzo de 2014). Patrimonio Industrial. Obtenido de Patrimonio Industrial: http://patrindustrialquitectonico.blogspot.com

Schubert, D. (2004). Transformación de zonas portuarias y costeras en desuso: experiencias, posibilidades y problemas. Ciudades $8,15-36$.

Sennett, R. (2013). La ciudad abierta. Barcelona.

Sennett, R. (s.f.). La ciudad abierta. Barcelona.

Solà-Morales, I. (2009). Terrain vague. En S. Landrove, M. Puente, M. J. Rivas, H. Smith, \& S. Suzuki, Colección de Compendio de Arquitectura Contemporánea. Barcelona, España.

Taracena, E. (16 de Agosto de 2013). Arquitectura, Literatura. Obtenido de https://conarqket.wordpress.com/2013/08/16/la-revitalizacion-urbana-un-procesonecesario/

Texeira Coelho. (1986). Usos da Cultura, Políticas de Ação Cultural. São Paulo, Brasil: Paz e terra.

TICCIH. (2003). Carta Nizhny Tagil sobre el patrimonio industrial. Rusia.

Trachana, A. (2000). Paisajes culturales. Caso de los paisajes industriales. Universidad Politécnica de Madrid, 1-16.

Trachana, A. (2011). La recuperación de los paisajes industriales como paisajes culturales. Ciudades, Universidad de Valladolid, 189-212.

Turrado, I. A. (s.f.). TEORÍA, HISTORIA Y PROYECTO . Obtenido de https://upcommons.upc.edu/bitstream/handle/2099/14876/60_65_ISabell_Aparici_.pd $\mathrm{f}$

UNAM. (s.f.). Espacio Público. Obtenido de http://www.ub.edu/multigen/donapla/espacio1.pdf

University of Ferrara, \& UNESCO's World Hetritage Centre. (2002). Cultural Landscapes: the Challenge of Conservation. Ferrara, Italy: World Heritage Papers.

Unyén Velezmoro, V. (2016). Chimbote, un viaje por la historia. Chimbote, Perú: Editorial Super Gráfica E.I.R Ltda. 
Valero Ramos, E. (2010). Reciclaje de polígonos residenciales, una alternativa sostenible. SB10mad. Sustainable building conference. Sevilla: inédito.

Valero Ramos, E., \& Chacón Linares, E. (2009). Crecer por dentro, estrategias del reciclaje urbano para el tecer milenio . Índice, 529-536.

Velezmoro, V. N. (25 de Junio de 2012). Chimbote e Identidad Cultural. Obtenido de http://victorunyenvelezmoro.blogspot.com/2012/06/chimbote-e-identidadcultural.html

Wittmann, R. (2006). ¿Hubo una revolución en la lectura a finales del siglo XVIII? En G. Cavallo, \& R. Chartier, Historia de la lectura en el mundo occidental (págs. 435-472). México D.F.: Santillana.

Zarza, D. (2001). Desbordes urbanos. Circo. 
ANEXOS 


\section{ANEXO 1: FÁBRICAS EN LA BAHÍA EL FERROL}

"Año de la consolidación del Mar de Grau"

"Decenio de las personas con Discapacidad en el Perú"

\section{ANEXO $N^{\circ} 1$}

Cuadro $N^{\circ}$ 1: Supervisiones a los EIP de la bahía EI Ferrol

\begin{tabular}{|c|c|c|c|c|c|c|c|}
\hline \multirow{2}{*}{$\mathbf{N}^{\circ}$} & \multirow{2}{*}{ EMPRESA } & \multirow{2}{*}{ ACTIVIDAD } & \multicolumn{5}{|c|}{ FECHA DE SUPERVISIÓN } \\
\hline & & & 2012 & 2013 & 2014 & 2015 & 2016 \\
\hline 1 & $\begin{array}{c}\text { ACTIVIDADES PESQUERAS } \\
\text { S.A. }\end{array}$ & Enlatado & $6 / 12$ & - & $18 / 2$ & $26-27 / 10$ & -- \\
\hline 2 & $\begin{array}{l}\text { CONSORCIO PESQUERO EL } \\
\text { FERROL S.A.C. }\end{array}$ & Enlatado & $6 / 12$ & - & $19 / 2$ & $\begin{array}{c}16-18 / 2 \\
19-22 / 5^{*} \\
23-28 / 10 \\
6 / 11 \\
23-26 / 11 \\
16 / 12\end{array}$ & $\begin{array}{c}18-19 / 2 \\
20 / 6\end{array}$ \\
\hline 3 & $\begin{array}{l}\text { CORPORACIÓN PESQUERA } \\
\text { HILLARY S.A.C. }\end{array}$ & $\begin{array}{l}\text { Enlatado / } \\
\text { Harina } \\
\text { residual } \\
\end{array}$ & - & $17 / 4$ & $\begin{array}{c}20-21 / 3 \\
23 / 10\end{array}$ & $\begin{array}{c}19-21 / 2 \\
19-22 / 5^{*} \\
22 / 10 \\
\end{array}$ & $15-18 / 2$ \\
\hline 4 & DON FERNANDO S.A.C. & $\begin{array}{l}\text { Enlatado / } \\
\text { Harina } \\
\text { residual }\end{array}$ & $5 / 7$ & $26 / 11$ & $18-19 / 3$ & $\begin{array}{c}17-20 / 2 \\
19-22 / 5^{\star}\end{array}$ & $15-17 / 2$ \\
\hline 5 & OLDIM S.A. & Enlatado & $10 / 10$ & -- & $18 / 3$ & $\begin{array}{c}16-21 / 2 \\
17 / 7 \\
19-22 / 5^{\star} \\
23-25 / 11 \\
\end{array}$ & $\begin{array}{l}15-18 / 2 \\
22-26 / 6\end{array}$ \\
\hline 6 & $\begin{array}{l}\text { INVERSIONES FARALLÓN } \\
\text { S.A.C. }\end{array}$ & $\begin{array}{l}\text { Enlatado / } \\
\text { Harina } \\
\text { residual }\end{array}$ & $29 / 11$ & $8-9 / 7$ & $19-20 / 3$ & $\begin{array}{c}18-21 / 2 \\
19-22 / 5^{\star}\end{array}$ & $16-19 / 3$ \\
\hline 7 & $\begin{array}{l}\text { CORPORACIÓN PESQUERA } \\
\text { APOLO S.A.C. }\end{array}$ & Enlatado & -- & $21 / 8$ & $21 / 3$ & $\begin{array}{c}17-19 / 2 \\
29 / 9 \\
\end{array}$ & $15-19 / 2$ \\
\hline 8 & $\begin{array}{l}\text { COMPAN̂IA PESQUERA DEL } \\
\text { PACIFICO CENTRO S.A. }\end{array}$ & Harina & $29 / 11$ & $19 / 4$ & $19-20 / 5$ & $18-25 / 5$ & $23-27 / 6$ \\
\hline 9 & $\begin{array}{l}\text { INVERSIONES OSLO S.A.C. } \\
\text { (EX.CORPORACIÓN PFG - } \\
\text { CENTINELA S.A.C) }\end{array}$ & Harina & $5 / 7$ & $\begin{array}{c}24 / 4 \\
19- \\
20 / 12\end{array}$ & $21-22 / 5$ & $\begin{array}{l}23-26 / 5 \\
19-22 / 5^{\star}\end{array}$ & $\begin{array}{l}16-17 / 2 \\
24-28 / 6\end{array}$ \\
\hline 10 & PESQUERA EXALMAR S.A.A. & Harina & $\begin{array}{c}6 / 7 \\
29 / 11\end{array}$ & $9 / 7$ & $20-23 / 5$ & $08-15 / 6$ & $20-25 / 6$ \\
\hline 11 & $\begin{array}{c}\text { PROCESADORA DE } \\
\text { PRODUCTOS MARINOS S.A. }\end{array}$ & Harina & -- & $25 / 4$ & $19-23 / 5$ & $\begin{array}{l}12-14 / 6 \\
19-22 / 5^{*}\end{array}$ & $\begin{array}{l}16-17 / 2 \\
23-25 / 6\end{array}$ \\
\hline 12 & $\begin{array}{c}\text { PESQUERA CONSERVAS } \\
\text { DE CHIMBOTE LA } \\
\text { CHIMBOTANA S.A.C. }\end{array}$ & $\begin{array}{l}\text { Enlatado / } \\
\text { Harina } \\
\text { residual }\end{array}$ & $23 / 10$ & $23 / 11$ & $22-23 / 5$ & $\begin{array}{c}18-19 / 4 \\
18-19 / 2 \\
2-4 / 9 \\
27-29 / 10 \\
\end{array}$ & $15-20 / 2$ \\
\hline 13 & $\begin{array}{l}\text { INVERSIONES QUIAZA } \\
\text { S.A.C. }\end{array}$ & $\begin{array}{c}\text { Enlatado / } \\
\text { Harina } \\
\text { residual } \\
\end{array}$ & -- & $28 / 10$ & $19-20 / 5$ & $\begin{array}{c}17-21 / 2 \\
19-22 / 5^{\star} \\
18 / 9 \\
\end{array}$ & $\begin{array}{c}17-19 / 2 \\
23 / 6\end{array}$ \\
\hline-14 & $\begin{array}{l}\text { CORPORACION PESQUERA } \\
1313 \text { S.A. }\end{array}$ & Harina & $\begin{array}{c}4 / 4 \\
5 / 12 \\
\end{array}$ & $28 / 10$ & $20-21 / 6$ & $21-22 / 5$ & $16-18 / 8$ \\
\hline 15 & $\begin{array}{l}\text { PESQUERA CENTINELA } \\
\text { S.A.C. }\end{array}$ & Harina & - & $\begin{array}{c}4 / 3 \\
27 / 11 \\
\end{array}$ & $17-18 / 6$ & $10-12 / 6$ & $\begin{array}{l}07-08 / 1 \\
19-20 / 5 \\
\end{array}$ \\
\hline 16 & $\begin{array}{l}\text { PESQUERA CENTINELA } \\
\text { S.A.C. }\end{array}$ & Enlatado & - & $20 / 4$ & $18-19 / 8$ & $\begin{array}{c}16 / 2 \\
19-22 / 5^{\star}\end{array}$ & $18-19 / 2$ \\
\hline 17 & $\begin{array}{l}\text { PESQUERA CENTINELA } \\
\text { S.A.C. }\end{array}$ & Congelado & - & $4 / 3$ & $17-18 / 9$ & $\begin{array}{c}17 / 2 \\
19-22 / 5^{\star} \\
2-3 / 9 \\
\end{array}$ & $17-19 / 2$ \\
\hline 18 & CFG INVESTMENT S.A.C. & Harina & $4 / 12$ & $\begin{array}{c}21-23 / 5 \\
25- \\
27 / 11 \\
\end{array}$ & $19-20 / 6$ & $17-20 / 05$ & $22-23 / 6$ \\
\hline 19 & CFG INVESTMENT S.A.C. & Enlatado & -- & $22-24 / 5$ & $20-21 / 8$ & $\begin{array}{c}17-18 / 2 \\
19-22 / 5^{\star} \\
\end{array}$ & $17-19 / 2$ \\
\hline
\end{tabular}


"Año de la consolidación del Mar de Grau"

"Decenio de las personas con Discapacidad en el Perú"

\begin{tabular}{|c|c|c|c|c|c|c|c|}
\hline \multirow{2}{*}{$\mathbf{N}^{\circ}$} & \multirow{2}{*}{ EMPRESA } & \multirow{2}{*}{ ACTIVIDAD } & \multicolumn{5}{|c|}{ FECHA DE SUPERVISIÓN } \\
\hline & & & 2012 & 2013 & 2014 & 2015 & 2016 \\
\hline 20 & $\begin{array}{l}\text { TECNOLÓGICA DE } \\
\text { ALIMENTOS S.A. }\end{array}$ & Harina & - & $24 / 4$ & $16-18 / 6$ & $\begin{array}{c}11 / 3 \\
12-14 / 6\end{array}$ & $20-24 / 6$ \\
\hline 21 & PESQUERA JADA S.A. & $\begin{array}{l}\text { Harina / } \\
\text { Enlatado }\end{array}$ & $25 / 10$ & $10-11 / 7$ & $16-17 / 6$ & $\begin{array}{c}18-21 / 2 \\
19-22 / 5^{\star}\end{array}$ & $17-19 / 2$ \\
\hline 22 & $\begin{array}{l}\text { EMP. DE CONSERVAS DE } \\
\text { PESCADO BELTRAN EIRL }\end{array}$ & Enlatado & - & $28 / 8$ & $24-25 / 7$ & $\begin{array}{c}17-21 / 2 \\
19-22 / 5^{\star}\end{array}$ & $17-19 / 2$ \\
\hline 23 & VLACAR S.A.C. & $\begin{array}{l}\text { Harina I } \\
\text { Enlatado }\end{array}$ & $05 / 12$ & $25 / 10$ & $21-22 / 7$ & $\begin{array}{l}15-16 / 7 \\
19-22 / 5^{*}\end{array}$ & $15-17 / 2$ \\
\hline 24 & CRIDANI S.A.C. & Enlatado & $23 / 10$ & $\begin{array}{c}25- \\
26 / 10\end{array}$ & $18-19 / 8$ & $\begin{array}{c}16 / 21 / 2 \\
24 / 11\end{array}$ & $\begin{array}{c}15-19 / 2 \\
12 / 7\end{array}$ \\
\hline 25 & $\begin{array}{l}\text { INVERSIONES GENERALES } \\
\text { DEL MAR S.A.C. }\end{array}$ & Enlatado & -- & $7 / 3$ & $20-21 / 8$ & $\begin{array}{c}18-20 / 2 \\
17 / 07 \\
19-22 / 5^{\star}\end{array}$ & $\begin{array}{l}15-19 / 2 \\
9-11 / 6 \\
23-24 / 6 \\
\end{array}$ \\
\hline 26 & $\begin{array}{l}\text { GRUPO EMPRESARIAL } \\
\text { ORTIZ S.A.C. }{ }^{35}\end{array}$ & Enlatado & $24 / 10$ & - & $15-16 / 9$ & $\begin{array}{c}16,17 / 2 \\
19-22 / 5^{\star} \\
21-23 / 10 \\
6-12 / 11^{\star 36} \\
16 / 12 \\
\end{array}$ & $\begin{array}{c}7-8 / 1 \\
15 / 1 \\
15-16 / 2 \\
12-13 / 4 \\
20-22 / 6\end{array}$ \\
\hline 27 & $\begin{array}{c}\text { MAR PERUANO EMPRESA } \\
\text { PESQUERA S.A. }\end{array}$ & Congelado & -- & $28 / 10$ & $15-16 / 9$ & $17-20 / 2$ & $18-19 / 3$ \\
\hline 28 & PROTEFISH S.A.C. & Harina & -- & $7 / 3$ & $20-24 / 10$ & $\begin{array}{l}20-21 / 2 \\
19-22 / 5^{*}\end{array}$ & $15-16 / 2$ \\
\hline 29 & $\begin{array}{l}\text { PROTEINAS DEL PERÚ } \\
\text { S.A.C. }\end{array}$ & $\begin{array}{l}\text { Harina } \\
\text { residual }\end{array}$ & -- & $6 / 3$ & $20-21 / 10$ & $\begin{array}{l}21-23 / 2 \\
19-22 / 5^{\star}\end{array}$ & $19-20 / 2$ \\
\hline 30 & $\begin{array}{l}\text { CONCENTRADOS DE } \\
\text { PROTEINAS S.A.C. }\end{array}$ & $\begin{array}{l}\text { Harina } \\
\text { residual }\end{array}$ & -- & $5 / 3$ & $10 / 12$ & $\begin{array}{l}18-20 / 2 \\
19-22 / 5^{\star}\end{array}$ & $14-18 / 3$ \\
\hline 31 & $\begin{array}{l}\text { CONSERVERA SAN LUCAS } \\
\text { S.A.C (EX COMPANEX PERU } \\
\text { S.A.) }\end{array}$ & Enlatado & $24 / 10$ & $8 / 7$ & $20-21 / 8$ & $\begin{array}{c}19-20 / 2 \\
19-22 / 5^{\star}\end{array}$ & $14-18 / 3$ \\
\hline 32 & GÉNESIS E.I.R.L. & Enlatado & $24 / 11$ & $10 / 7$ & $18-19 / 8$ & $\begin{array}{l}16-17 / 2 \\
19-22 / 5^{\star} \\
21-23 / 10\end{array}$ & $16-19 / 3$ \\
\hline 33 & INVERSIONES REGAL S.A. & Enlatado & -- & $16 / 4$ & $20-21 / 8$ & $\begin{array}{l}16-19 / 2 \\
19-22 / 5^{\star}\end{array}$ & $\begin{array}{l}28-29 / 2 \\
14-16 / 3 \\
\end{array}$ \\
\hline 34 & PESQUERA FLORES S.A. & $\begin{array}{l}\text { Enlatado / } \\
\text { Harina } \\
\text { residual }\end{array}$ & -- & $\begin{array}{c}5 / 3 \\
24 / 10\end{array}$ & $18-19 / 8$ & $\begin{array}{c}18-19 / 2 \\
19-22 / 5^{\star}\end{array}$ & $15-17 / 3$ \\
\hline 35 & $\begin{array}{l}\text { EMPRESA PESQUERA } \\
\text { GAMMA S.A. }\end{array}$ & $\begin{array}{l}\text { Enlatado / } \\
\text { Harina } \\
\text { residual }\end{array}$ & $23 / 10$ & $25 / 11$ & $20-21 / 11$ & $\begin{array}{l}19-22 / 5^{\star} \\
20-21 / 10\end{array}$ & $17-20 / 2$ \\
\hline 36 & $\begin{array}{l}\text { CORPORACIÓN PESQUERA } \\
\text { INCA S.A.C. }\end{array}$ & Harina & $4 / 12$ & $\begin{array}{l}23 / 4 \\
27 / 5\end{array}$ & $\begin{array}{c}5-6 / 2 \\
21-22 / 5\end{array}$ & $08-10 / 6$ & $20-22 / 6$ \\
\hline 37 & $\begin{array}{c}\text { PROCESOS } \\
\text { HIDROBIOLOGICOS } \\
\text { KREVOIMAR NORTE S.A.C. }\end{array}$ & Enlatado & -- & $29 / 10$ & $20-24 / 10$ & $\begin{array}{c}19-21 / 2 \\
13 / 8 \\
25 / 11\end{array}$ & $15-19 / 2$ \\
\hline 38 & A.P. PESCA S.R.L & Curado & -- & -- & -- & -- & $17-19 / 3$ \\
\hline 39 & $\begin{array}{l}\text { CORPORACIÓN PESQUERA } \\
\text { INCA S.A.C. }\end{array}$ & Harina & -- & $11 / 7$ & $\begin{array}{l}\text { No opera } \\
\text { actualmente }\end{array}$ & $\begin{array}{c}\text { No opera } \\
\text { actualmente }\end{array}$ & $\begin{array}{l}\text { No opera } \\
\text { actualme } \\
\text { nte }\end{array}$ \\
\hline
\end{tabular}

35 Mediante Resolución Directoral № 552-2014-PRODUCE/DGCHD, emitida el 31 de octubre del 2014, PRODUCE aprobó a favor de Grupo Empresarial Ortiz S.A.C., el cambio de titularidad de licencia de operación, dejando sin efecto la Resolución Directoral № 266-2005-PRODUCE/DGCHD, con la que se otorgó licencia de operación a la empresa Santa Cruz Inversiones S.A.C.

36 Dicha supervisión documental comprende cuatro (4) verificaciones realizadas por la Oficina de Enlace del OEFA en Chimbote. 
"Año de la consolidación del Mar de Grau"

"Decenio de las personas con Discapacidad en el Perú"

\begin{tabular}{|c|c|c|c|c|c|c|c|}
\hline \multirow{2}{*}{$\mathbf{N}^{\circ}$} & \multirow{2}{*}{ EMPRESA } & \multirow{2}{*}{ ACTIVIDAD } & \multicolumn{5}{|c|}{ FECHA DE SUPERVISIÓN } \\
\hline & & & 2012 & 2013 & 2014 & 2015 & 2016 \\
\hline 40 & CFG INVESTMENT S.A.C. & Harina & -- & $23-24 / 5$ & $\begin{array}{c}\text { No opera } \\
\text { actualmente }\end{array}$ & $\begin{array}{c}\text { No opera } \\
\text { actualmente }\end{array}$ & $\begin{array}{l}\text { No opera } \\
\text { actualme } \\
\text { nte }\end{array}$ \\
\hline 41 & CRIDANI S.A.C. & Harina & -- & $28 / 10$ & $\begin{array}{c}\text { No opera } \\
\text { actualmente }\end{array}$ & $\begin{array}{c}\text { No opera } \\
\text { actualmente }\end{array}$ & $\begin{array}{l}\text { No opera } \\
\text { actualme } \\
\text { nte }\end{array}$ \\
\hline 42 & SEAFROST S.A.C. & Enlatado & -- & $8 / 3$ & $17,18 / 9$ & $\begin{array}{c}\text { No opera } \\
\text { actualmente }\end{array}$ & $\begin{array}{c}\text { No opera } \\
\text { actualme } \\
\text { nte }\end{array}$ \\
\hline 43 & $\begin{array}{c}\text { CONSERVAS SANTA ADELA } \\
\text { S.A. }\end{array}$ & Harina & -- & $23 / 5$ & $\begin{array}{c}\text { No opera } \\
\text { actualmente }\end{array}$ & $\begin{array}{c}\text { No opera } \\
\text { actualmente }\end{array}$ & $\begin{array}{c}\text { No opera } \\
\text { actualme } \\
\text { nte }\end{array}$ \\
\hline 44 & $\begin{array}{c}\text { CORPORACION } \\
\text { INDUSTRIAL MILAGROS DEL } \\
\text { MAR S.A. }\end{array}$ & Harina & $24 / 10$ & $24 / 5$ & $\begin{array}{c}\text { No opera } \\
\text { actualmente }\end{array}$ & $\begin{array}{c}\text { No opera } \\
\text { actualmente }\end{array}$ & $\begin{array}{c}\text { No opera } \\
\text { actualme } \\
\text { nte }\end{array}$ \\
\hline 45 & INVERSIONES RIGEL S.A. & Harina & $25 / 10$ & $24-25 / 5$ & $\begin{array}{c}\text { No opera } \\
\text { actualmente }\end{array}$ & $\begin{array}{c}\text { No opera } \\
\text { actualmente }\end{array}$ & $\begin{array}{c}\text { No opera } \\
\text { actualme } \\
\text { nte }\end{array}$ \\
\hline 46 & $\begin{array}{c}\text { FÁBRICA DE CONSERVAS } \\
\text { URANO S.A. }\end{array}$ & Harina & - & $11 / 7$ & $\begin{array}{l}\text { No opera } \\
\text { actualmente }\end{array}$ & $\begin{array}{l}\text { No opera } \\
\text { actualmente }\end{array}$ & $\begin{array}{c}\text { No opera } \\
\text { actualme } \\
\text { nte }\end{array}$ \\
\hline 47 & DON RAÚL S.A.C. & Harina & -- & $22 / 5$ & $\begin{array}{c}\text { No opera } \\
\text { actualmente }\end{array}$ & $\begin{array}{c}\text { No opera } \\
\text { actualmente }\end{array}$ & $\begin{array}{l}\text { No opera } \\
\text { actualme } \\
\text { nte }\end{array}$ \\
\hline
\end{tabular}

Cuadro $\mathrm{N}^{\circ}$ 2: Supervisiones realizadas a APROCHIMBOTE

\begin{tabular}{|c|c|c|c|c|c|c|}
\hline \multirow{2}{*}{ EIP } & \multicolumn{7}{|c|}{ FECHA DE SUPERVISIÓN } \\
\cline { 2 - 7 } & ACTIVIDAD & 2012 & 2013 & 2014 & 2015 & 2016 \\
\hline \multirow{2}{*}{ APROCHIMBOTE } & Estación de & & $28 / 2$ & $8 / 7$ & \multirow{2}{*}{$19-22 / 05$} & $17-20 / 2$ \\
\hline & Bombeo & -- & $6 / 3$ & $17 / 9$ & $19-22$ & \\
\hline
\end{tabular}

Supervisión documental. 


\section{ANEXO 2: ORDENANZA Nº 001-2009-MPS}

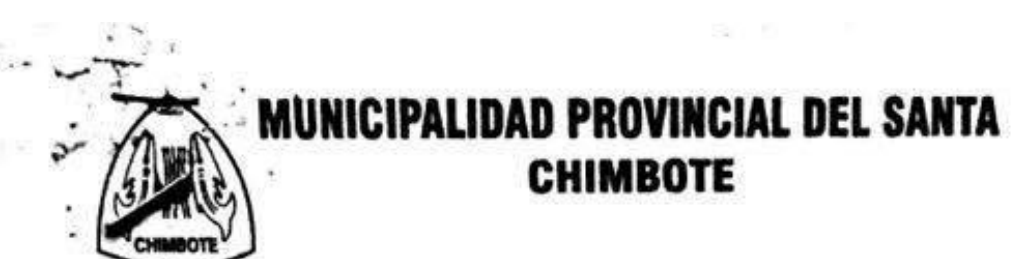

Ordenanza Municipal N001-2009-MPS

Chimbote. 27 de Enero del 2009

LA SEÑORA ALCALDESA DE LA MUNICIPALIDAD

PROVINCLAL DEL SANTA:

POR CUANTO:

En Sesión Ordinaria del 26 de Enero del 2009, el Concejo Provincial del Santa, trato el Dictamen No 002-2008/MPS.CSyGA, sobre el Proyecto de Ordenamzo que establece el plazo maximo para que las plantas dedicadas a las actividades de producción de harina de pescodo, extracción de aceite de pescado, neutralizadoras de aceite de pescado y otras animales marinos y toda actividad industrial considerado dentro del Cuadro de Zonificación 1-3e I-4, ubicadas en Zonas Residenciales se trasladen a Zonas de Uso Industrial. y:

\section{CONSIDERANDO:}

Que, el articulo $194^{\circ}$ de la Constitución Politica del Estado. modificada or Ley $N^{\circ} 27680$ - Ley de Reforma Constitucional del Capitulo XIV del Título IV. sobre Descentralización. reconoce a los gobiernos locales autonomia politica. económica y administrativa en asuntos de su competencia; siendo astomto de su competencia emitir las norma. idenicas generales en materia de organización del espacio fisico y uso del suelo asi como sobre prolección y conservación del ambiente, conforme al Art. 73 de la Ley Orgánica de Municipalidades $N^{\circ} 27972$.

Que, el Articulo $2^{\circ}$ inciso I) de la Constitución Politica del Estado. establece que toda persona tiene derecho a la vida, a su identidad, a su integridad moral, psiguica y fisica y a su libre desarrollo y bienestar; siendo ast, recogiendo el mandato constitucional, la Ley Orgánica de Municipalidades $N^{\circ}$ 27972. en el Articulo X del Titulo Preliminar encarga a los Orgánica de Municipalidades $N^{2}$ del desarrollo local, siendo ésta permanente e integral. teniendo como objeto el facilitar la competitividad local y propiciar mejores condiciones de vida de su población:

Que. en cumplimiento de las competencias asignadas a esto

Qul, determina conforme al Reglamento de Acondicionamiento Territorial y Municipalidad Provincial, determina conforme al Reglamento de AcondicionamienIo Territial Desarrollo Urbano, aprobado mediante Decreto SUpremo
modificatoria el Decreto Supremo $N^{\circ}$ 012-2004-VIVIENDA, que el uso de suelos y la compatibilidad con las distintas zonas urbanas se da de acuerdo a las zonificaciones siguientes. Residencial, Comercial, Industrial y de Usos Especiales; especificando que dentro de la Zono Industrial, se dan las calificaciones de suelo, siguientes: I-1 Zana de Industria Elemental y Complementaria, con actividad no molesta ni peligrasa: I-2. Zona de Industria Liviana, con actividad no molesta ni peligrasa; 1-3. Zona de Gran Industria, con actividad Molesta y Peligrosa, - I-4. Zona de Industria Pesada Básica, con actividad Molesta y Peligrosa; consecuentemente, por el tipo de actividad, las plantas dedicadas a la producción de harina y extracción de aceite $y / 0$ neutralizadoras de aceite de pescado y otros amimales marinos y toda actividad industrial considerado dentro del Cuadro de Zonificación $1-3$ e $\mathrm{l-4}$, no pueden permanecer en Zonas Residenciales por incompatibilidad en la calificación del uso de suele:

Que. el Concejo Provincial del Santa. assmiendo responsablemente su competencia de propiciar mejores condiciones de vida en la población. considera prudente conceder como plazo máximo hasta el 31 de Diciembre del 2009, para el traslado de las plantas dedicadas a la producción de harina de pescado. extracción de aceite de pescado. neutralizadoras de aceile de pescado y otros animales marinos y toda actividad industrial considerado dentro del Cuadro de Zanificación 1.3 e 1.4 . del Reglamento Nacional de Edificaciones, aprobudo por Decreto Supremo $N^{\circ}$ 011-2006-VIVIENDA, que se encuentren ubicadas en Zonas Residenciales hacia Zonas Industriales (1-3 e (-4): 


\section{ANEXO 3: SISTEMA DE INVERSIÓN PROVINCIAL EN LA ZONA COSTERA}

\begin{tabular}{|c|c|c|c|c|c|c|c|}
\hline 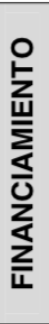 & 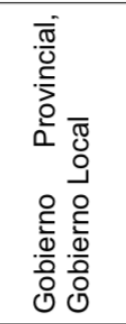 & 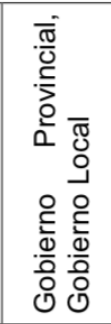 & 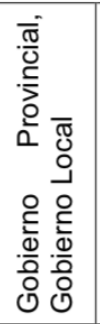 & 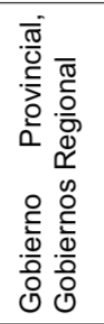 & 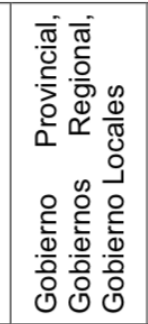 & 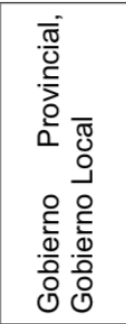 & 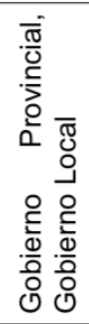 \\
\hline 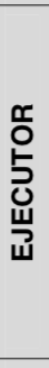 & 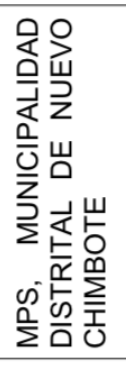 & 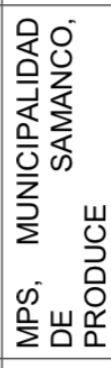 & 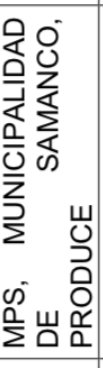 & 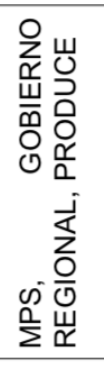 & 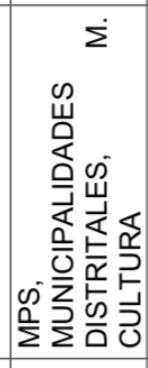 & 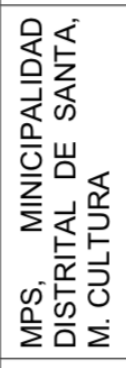 & 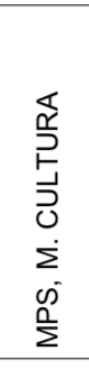 \\
\hline $\begin{array}{l}\text { 온 } \\
\text { 일 }\end{array}$ & 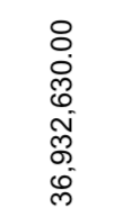 & $\begin{array}{l}\text {. } \\
0 \\
0 \\
\infty \\
0 \\
0 \\
0 \\
0\end{array}$ & 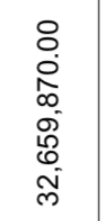 & 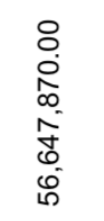 & 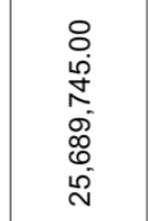 & 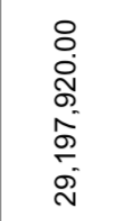 & 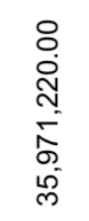 \\
\hline 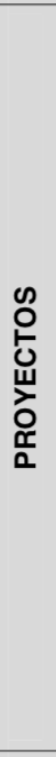 & 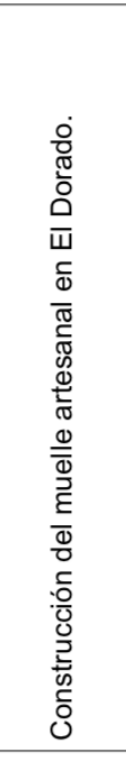 & 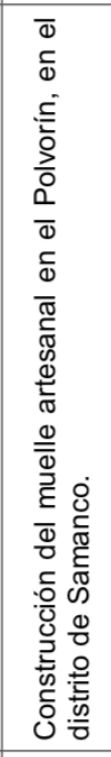 & 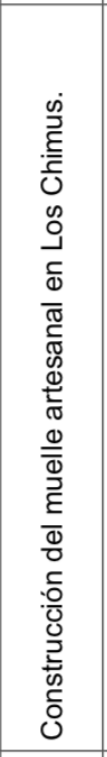 & 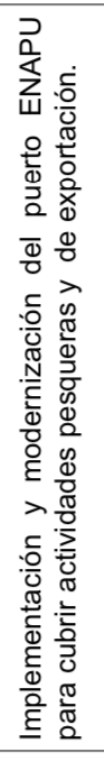 & 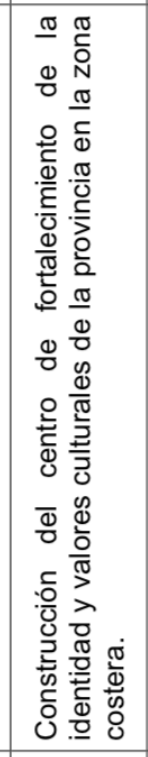 & 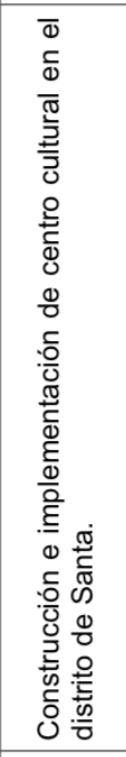 & 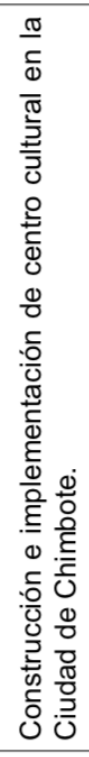 \\
\hline$\stackrel{\circ}{\mathbf{z}}$ & $\mathscr{q}$ & $\mathcal{f}$ & $\stackrel{\infty}{+}$ & $\vec{\sigma}$ & ద & in & ธิ \\
\hline & & & & & & & \\
\hline
\end{tabular}


ANEXO 4: SISTEMA DE INVERSIÓN URBANA PDU 2012-2022

\begin{tabular}{|c|c|c|c|c|}
\hline $\mathrm{N}^{\circ}$ & PROYECTO & MONTO & EJECUTOR & FINANCIAMIENTO \\
\hline 51 & $\begin{array}{l}\text { Habilitación de Zona Turística Industrial } 2 \\
\text { (TASA Y Rigel). }\end{array}$ & $56,352,760.00$ & $\begin{array}{l}\text { MPS, } \\
\text { SEDACHIMBOTE, } \\
\text { HIDRANDINA }\end{array}$ & $\begin{array}{l}\text { Gobierno Provincial, } \\
\text { Inversión Privada }\end{array}$ \\
\hline 52 & $\begin{array}{l}\text { Habilitación de Zona Turística Industrial } 3 \\
\text { (27 DE OCTUBRE). }\end{array}$ & $58,235,855.00$ & $\begin{array}{l}\text { MPS, } \\
\text { SEDACHIMBOTE, } \\
\text { HIDRANDINA }\end{array}$ & $\begin{array}{l}\text { Gobierno Provincial, } \\
\text { Inversión Privada }\end{array}$ \\
\hline 53 & $\begin{array}{l}\text { Habilitación del Parque Industrial San } \\
\text { Antonio. }\end{array}$ & $62,253,580.00$ & $\begin{array}{l}\text { MPS, } \\
\text { SEDACHIMBOTE, } \\
\text { HIDRANDINA }\end{array}$ & $\begin{array}{l}\text { Gobierno Provincial, } \\
\text { Inversión Privada }\end{array}$ \\
\hline 54 & $\begin{array}{l}\text { Reconversión del Coliseo Paul Harris a } \\
\text { Zona de Recreación. }\end{array}$ & $61,778,695.00$ & MPS & $\begin{array}{l}\text { Gobierno Provincial, } \\
\text { Inversión Privada }\end{array}$ \\
\hline 55 & Renovación urbana del sector San Pedro. & $59,752,855.00$ & MPS & $\begin{array}{l}\text { Gobierno Provincial, } \\
\text { Inversión Privada }\end{array}$ \\
\hline 56 & $\begin{array}{l}\text { Reconversión Urbana para la construcción } \\
\text { del Centro Cívico Comercial. }\end{array}$ & $60,878,570.00$ & MPS & $\begin{array}{l}\text { Gobierno Provincial, } \\
\text { Inversión Privada }\end{array}$ \\
\hline 57 & $\begin{array}{l}\text { Intervención Urbana del Centro Cívico de } \\
\text { Nuevo Chimbote. }\end{array}$ & $61,854,355.00$ & MPS & $\begin{array}{l}\text { Gobierno Provincial, } \\
\text { Inversión Privada }\end{array}$ \\
\hline 58 & $\begin{array}{l}\text { Apertura de calle desde el Jr. Cahuide del } \\
\text { P.J. El Progreso hacia Psje. Elías Aguirre } \\
\text { del P.J. Bolívar Alto. }\end{array}$ & $35,713,495.00$ & MPS, MTC & Gobierno Provincial \\
\hline 59 & $\begin{array}{l}\text { Mejoramiento y construcción del sistema } \\
\text { de recolección, tratamiento y disposición } \\
\text { final de las aguas servidas de Chimbote }\end{array}$ & $4,000,000.00$ & $\begin{array}{l}\text { MPS. } \\
\text { SEDACHIMBOTE, } \\
\text { Gobierno Regional } \\
\text { de Ancash }\end{array}$ & $\begin{array}{l}\text { Gobierno Provincial, } \\
\text { Gobierno Regional }\end{array}$ \\
\hline 60 & $\begin{array}{l}\text { Construcción del sistema de recolección, } \\
\text { tratamiento y disposición final de las aguas } \\
\text { servidas en Nuevo Chimbote }\end{array}$ & $265,983,670.00$ & $\begin{array}{l}\text { MPS, } \\
\text { Municipalidad } \\
\text { Distrital de Nuevo } \\
\text { Chimbote, } \\
\text { SEDACHIMBOTE, } \\
\text { Gobierno Regional } \\
\text { de Ancash }\end{array}$ & $\begin{array}{l}\text { Cooperación } \\
\text { Internacional }\end{array}$ \\
\hline 61 & $\begin{array}{l}\text { Rehabilitación de las lagunas secundarias } \\
\text { y efluentes Las Gaviotas en el P.J. Villa } \\
\text { maría del distrito de Nuevo Chimbote }\end{array}$ & $277,570.00$ & $\begin{array}{l}\text { MPS, } \\
\text { Municipalidad } \\
\text { Distrital de Nuevo } \\
\text { Chimbote, } \\
\text { SEDACHIMBOTE, } \\
\text { Gobierno Regional } \\
\text { de Ancash }\end{array}$ & $\begin{array}{l}\text { Gobierno Provincial, } \\
\text { Gobierno Regional, } \\
\text { Gobierno Local }\end{array}$ \\
\hline 62 & $\begin{array}{l}\text { Ampliación y Mejoramiento de PTAR "Las } \\
\text { Gaviotas y Centro Sur" en Nuevo Chimbote }\end{array}$ & $1,200,000.00$ & $\begin{array}{l}\text { MPS, } \\
\text { Municipalidad } \\
\text { Distrital de Nuevo } \\
\text { Chimbote, } \\
\text { SEDACHIMBOTE, } \\
\text { Gobierno Regional } \\
\text { de Ancash } \\
\end{array}$ & $\begin{array}{l}\text { Gobierno Provincial, } \\
\text { Gobierno Regional, } \\
\text { Gobierno Local }\end{array}$ \\
\hline 63 & $\begin{array}{l}\text { Implementación y mejoramiento del } \\
\text { sistema integral de agua potable en } \\
\text { Chimbote }\end{array}$ & $8,000,000.00$ & $\begin{array}{l}\text { MPS, } \\
\text { SEDACHIMBOTE, } \\
\text { Gobierno Regional } \\
\text { de Ancash }\end{array}$ & $\begin{array}{l}\text { Gobierno Provincial, } \\
\text { Gobierno Regional }\end{array}$ \\
\hline
\end{tabular}

Fuente y elaboración: Equipo técnico PDU 


\section{ANEXO 5: ENCUESTA REALIZADA A ALUMNOS DE PRIMARIA DE LA I.E Nº88008}

1. ¿En qué piensas cuando escuchas CHIMBOTE?

2. ¿Te acercas seguido a ver el mar en la ciudad?

$\mathrm{Si}$

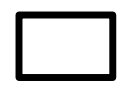

No

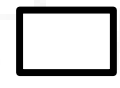

¿Por qué?

3. ¿Qué significa el malecón para ti?
a. Basura
b. Peligro
c. Contaminación
d. Paseo
e. Diversión

4. Las fábricas para Chimbote son:

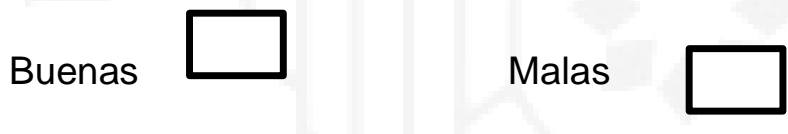

¿Por qué?

5. ¿Te gustaría tener una plaza frente al mar para pasear y desarrollar actividades después del colegio?

$\mathrm{Si}$

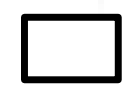

No

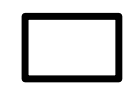

6. ¿Qué actividades quisieras realizar?
a. Baile
f. Manualidades
b. Canto
g. pintura
c. Teatro
h. deportes
d. Música
i. Leer
e. Computación
j. Otro

7. ¿Vas al centro cultural centenario?

$\mathrm{Si}$

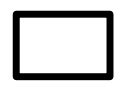

No

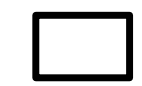

¿Por qué? 


\section{ANEXO 6: ENCUESTA REALIZADA A ALUMNOS DE SECUNDARIA DE LA I.E Nº88008}

¿En qué piensas cuando escuchas CHIMBOTE?

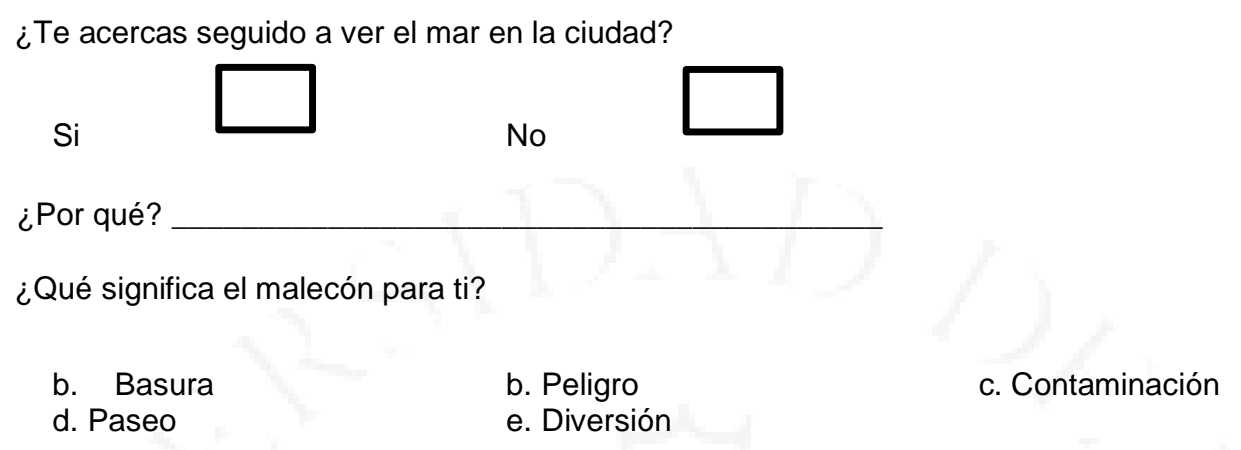

Las fábricas para Chimbote son:

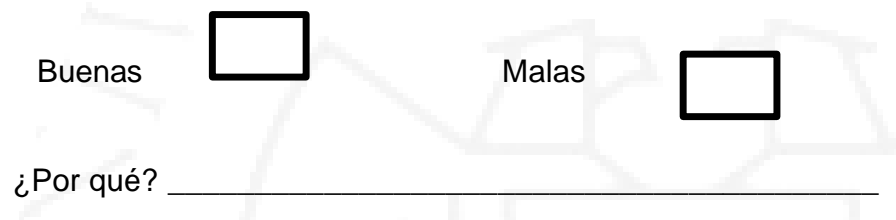

¿Te gustan que las fábricas estén cerca a tu casa?

$\mathrm{Si}$

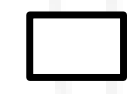

No

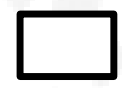

Del 1 al 10, que tanto considerarías que las fábricas son parte de la historia de Chimbote, donde 1 es poco y 10 mucho

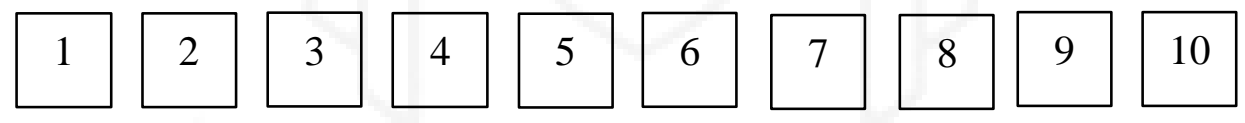

¿Te gustaría tener una plaza frente al mar para pasear y desarrollar actividades después del colegio?

Si $\quad$ No $\square$

¿Qué actividades quisieras realizar?
f. Baile
b. Manualidades
d. Pintura
e. Teatro
c. Canto
g. Música
h. Leer
f. deporte
i. Computación

j. Otro

¿Vas al centro cultural centenario?

Si

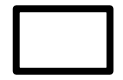

No

¿Por qué? 